\title{
DEVELOPMENT OF INNOVATIVE DESIGNS OF BRIDGE BARRIER SYSTEM INCORPORATING REINFORCING STEEL OR GFRP BARS
}

By

\section{Hamidreza Khederzadeh}

Master of Applied Science, Ryerson University, Canada, 2010

Bachelor of Science, Yasouj Azad University, Iran, 1999

A dissertation

Presented to Ryerson University

In partial fulfillment of the requirements for the degree of

Doctor of Philosophy

In the Program of

Civil Engineering

Toronto, Ontario, Canada, 2014

(C) Hamidreza Khederzadeh 2014 


\section{Author's Declaration}

I hereby declare that I am the sole author of this thesis. This is a true copy of the dissertation, including any required final revisions, as accepted by my examiners.

I authorize Ryerson University to lend this thesis to other institutions or individuals for the purpose of scholarly research.

I further authorize Ryerson University to reproduce this thesis by photocopying or by other means, in total or in part, at the request of other institutions or individuals for the purpose of scholarly research.

I understand that my dissertation may be made electronically available to the public. 


\title{
Abstract \\ DEVELOPMENT OF INNOVATIVE DESIGNS OF BRIDGE BARRIER SYSTEM INCORPORATING REINFORCING STEEL OR GFRP BARS
}

\author{
By \\ Hamidreza Khederzadeh \\ Doctor of Philosophy in Civil Engineering \\ Department of Civil Engineering, Ryerson University \\ Toronto, Ontario, Canada
}

2014

In harsh environment, corrosion of steel reinforcement causes durability problems. Glass Fiber Reinforced Polymer (GFRP) has emerged as an alternative to corrosion-related problem of steel bars in development of sustainable bridge deck and barrier walls. The current research program has been divided into five phases. In phase I, an extensive study has been conducted on pullout strength and bond behavior of pre-installed GFRP bars into concrete slabs and concrete cubes. In phase II, based on the Canadian Highway Bridge Design Code (CHBDC) factored applied moment at deck-wall junction, three configurations of GFRP-reinforced barrier detailing, using High-Modulus (HM) and Standard-Modulus (SM) GFRP bars, were proposed. The proposed barriers were tested by constructing five actual-size, 1.0-m long, PL-3 barrier models to determine their ultimate load carrying capacities and failure modes. In phase III, a full-scale PL3 barrier made of GFRP-HM bars, with headed-end anchors as connecting bars to the deck slab, was constructed and tested under transverse static loading at both interior and exterior locations to-collapse to determine its crack pattern, failure mode and static ultimate load carrying capacity. In phase IV, from the trapezoidal failure pattern observed during testing the GFRP-reinforced PL-3 barriers, the research program was extended to revisit the triangular yield-line failure 
patterns in steel-reinforced PL-2 and PL-3 barriers specified in AASHTO-LRFD specifications. Experimental static tests to-collapse were conducted on constructed actual-size PL-2 and PL-3 steel-reinforced barriers, leading to more accurate expressions for their transverse load capacities developed based on the yield-line theory. In phase V, non-linear finite element analysis was conducted on GFRP-reinforced bridge barriers tested in phase III. The finite-element modeling was conducted to solely simulate the experimental test results for future research. A good agreement between experimental observations and numerical finite-element modeling was observed. Finallly, this research led to (i) a more accurate design procedure for the GFRP- and steel-reinforced barrier wall and the barrier-deck joint, and (ii) design tables for the applied moment and tensile forces to be used to design the deck slab and the barrier deck-junction to resist transverse loading resulting from vehicle impact. 


\section{Acknowledgements}

The author would like to express deep thanks to his supervisor, Dr. K. Sennah, whose constant support, excellent guidance, supervision and scholarly counsel allowed this project to carry forward and fulfill my expectations. Sincere thanks to you. The author wishes to thank Dr. Clifford Lam from Ministry of Transportation of Ontario for his valuable suggestions, assistance and enthusiasm that were essential pieces of this research.

Special thanks for the financial support to this research project from the Ontario Ministry of Transportation, MTO, Highway Infrastructure Innovation Funding Program, HIIFP. A great thank you goes out to Trancel-Pultrall Inc. for their financial and in-kind contribution, cooperation and ongoing effort became a corner stone of this project. The financial support of Ontario Centre of Excellence (OCE) to this research program is very much appricated.

The author would like to thank Mr. Nidal Jaalouk for his continuous support, commitment and dedication, which was greatly appreciated.

There are not enough words to express my gratitude to my family especially my parents, who have always supported and encouraged my studies, and who have always been and remain my inspiration. I dedicate this to you. 


\section{Dedication}

\section{TO MY FAMILY}

for their endless love and support in every step of my life 


\section{Table of Contents}

Author's Declaration......................................................................................................... ii

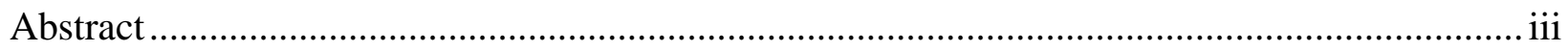

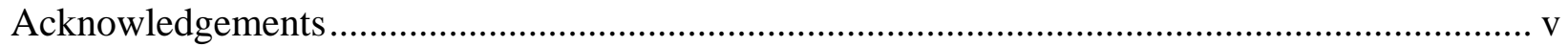

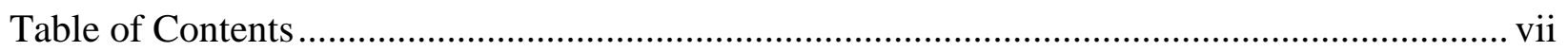

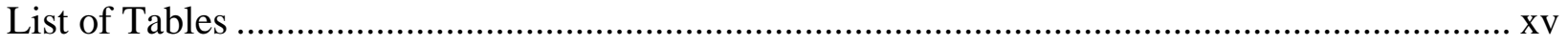

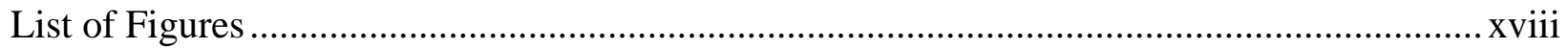

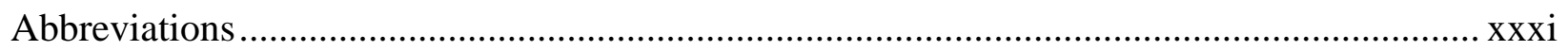

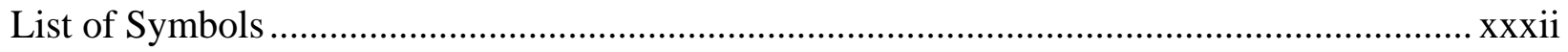

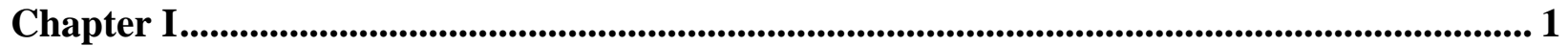

Introduction ................................................................................................................................ 1

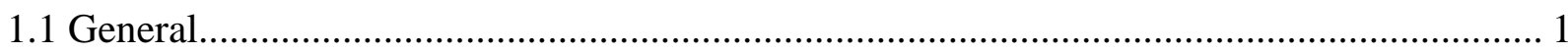

1.2 The Dilemma and Need for the Research................................................................... 1

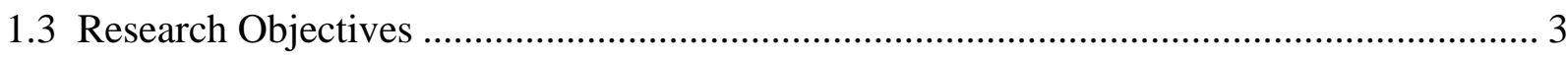

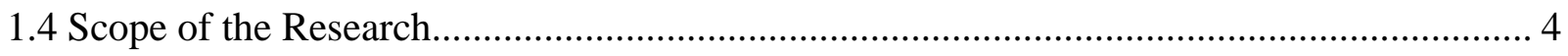

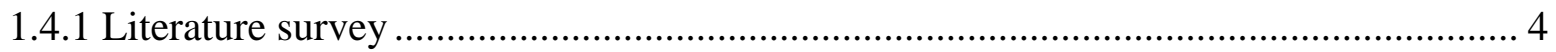

1.4.2 Pull-out tests on GFRP bars anchored to concrete...................................................... 4

1.4.3 Testing to complete collapse of the proposed barrier system .................................. 6

1.4.4 Static Load Testing on GFRP-Reinforced Concrete Barrier wall ............................. 9

1.4.5 Finite-Element Computer Simulation ................................................................. 10

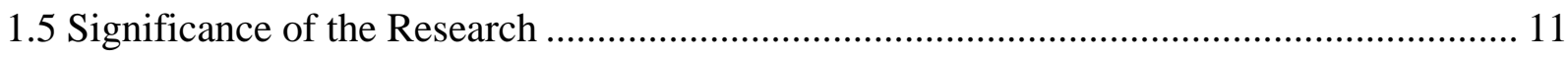

1.6 Content and Arrangement of the Thesis ...................................................................... 11

Chapter II ................................................................................................................................................... 13

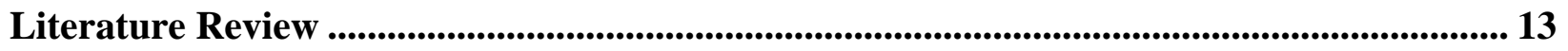

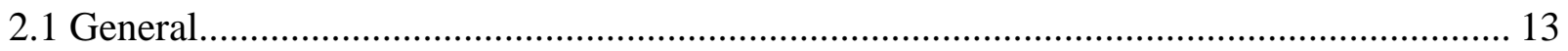

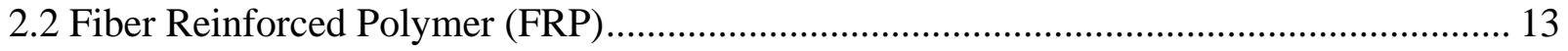

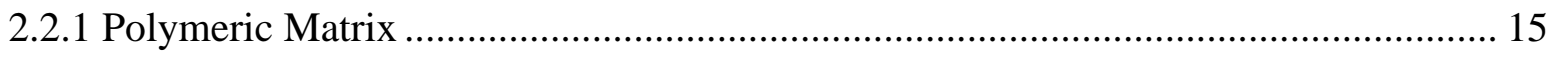

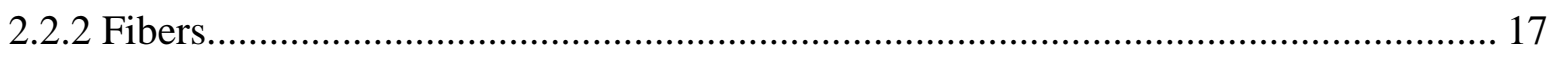

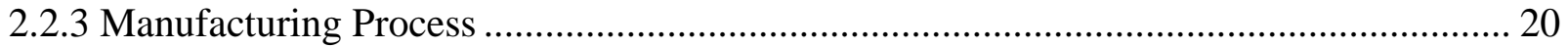

2.2.4 Mechanical Properties and Behavior of FRPs ...................................................... 21 
2.3 Bond Mechanism of Reinforcing Bars .................................................................... 27

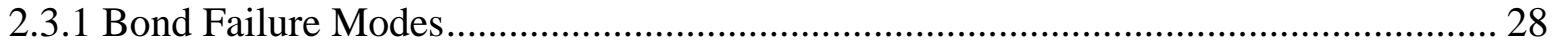

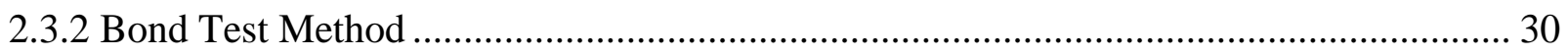

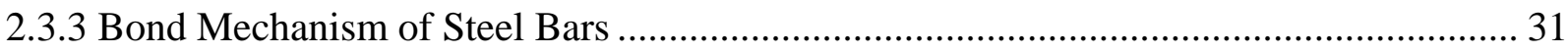

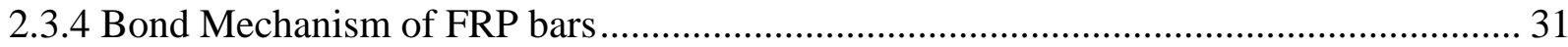

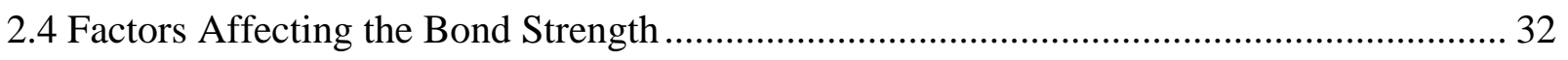

2.4.1 Influence of Concrete Compressive Strength ..................................................... 32

2.4.2 Influence of Concrete Cover, Bar Spacing and Confinement.................................. 33

2.4.3 Influence of Embedment Length ..................................................................... 34

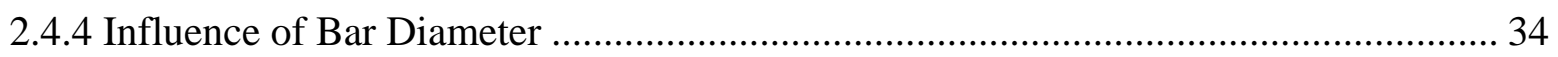

2.4.5 Influence of Bar Modulus of Elasticity.............................................................. 35

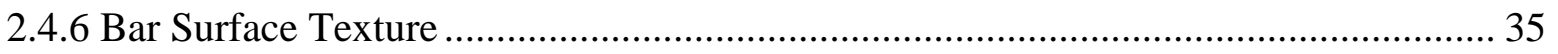

2.5 Evaluation of Bond Strength of Bars in Concrete ................................................... 36

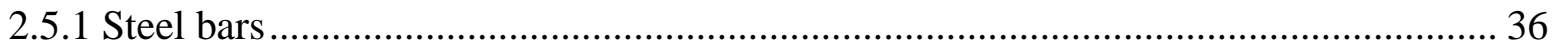

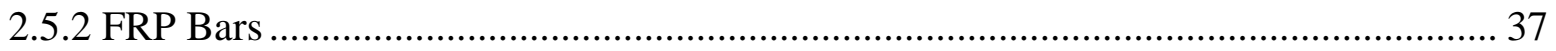

2.6 Bond Strength and Development Length of FRP Bars by Design Codes ........................ 39

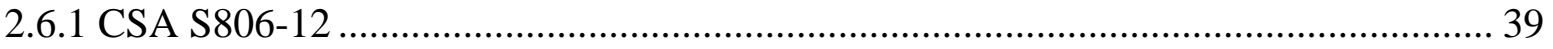

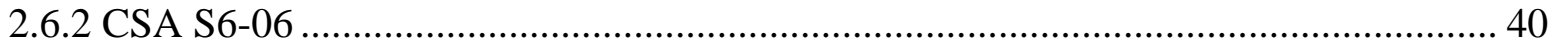

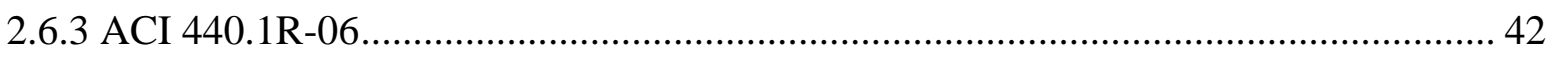

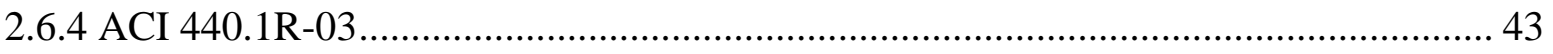

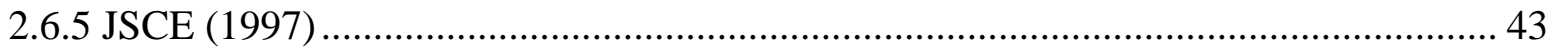

2.7 Development Length of Steel Anchor Head in Concrete .............................................. 45

2.7.1 Tensile Resistance of Steel Anchor ................................................................ 45

2.7.2 Tensile Concrete Breakout Capacity ................................................................. 45

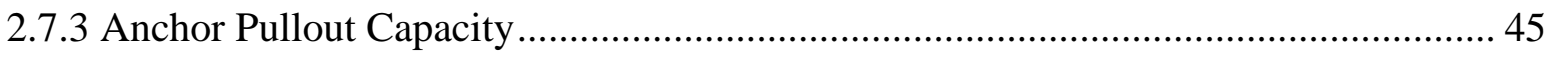

2.7.4 Concrete Side Face Blowout.......................................................................... 46

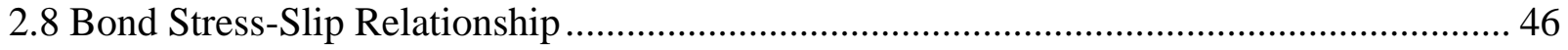

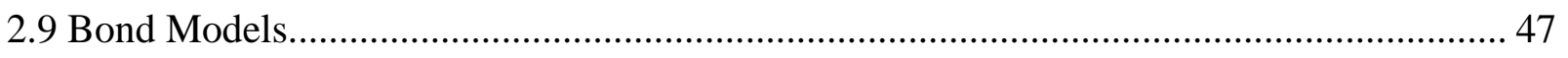

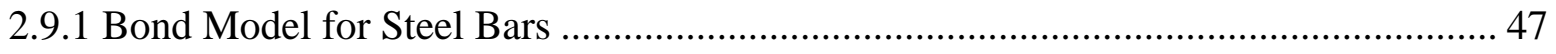

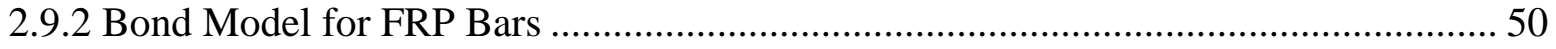

2.10 Bond Properties of FRP Bars in Literatures ........................................................ 52 


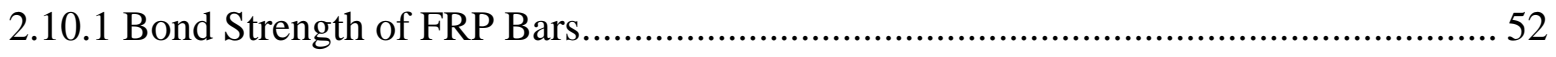

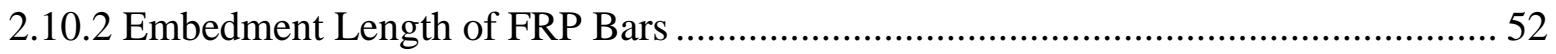

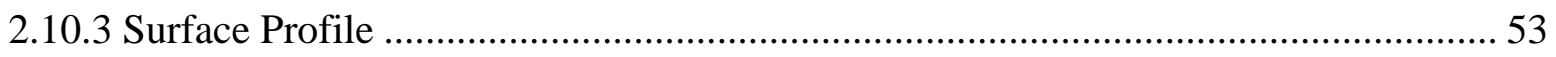

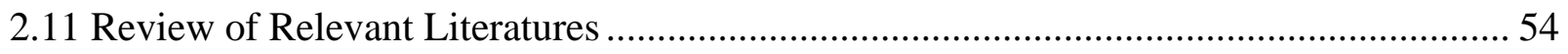

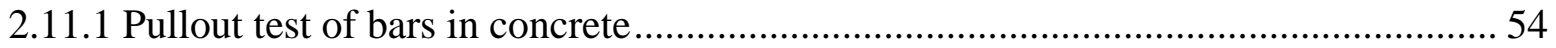

2.11.2 Effect of concrete and GFRP properties on bond behavior .................................... 55

2.11.3 Pullout tests of GFRP bars by beam test............................................................... 57

2.11.4 Miscellaneous literature on bond behavior of GRFP bars ........................................ 58

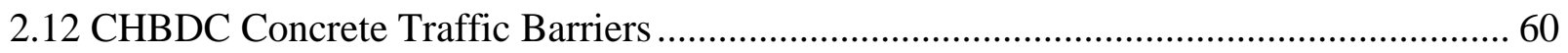

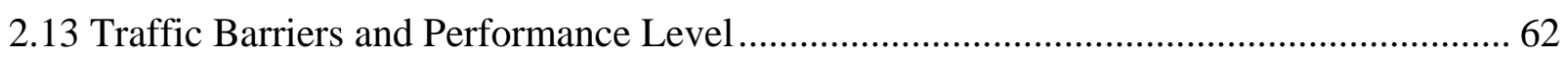

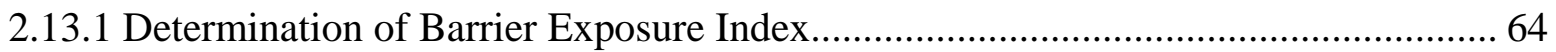

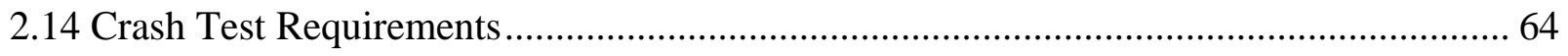

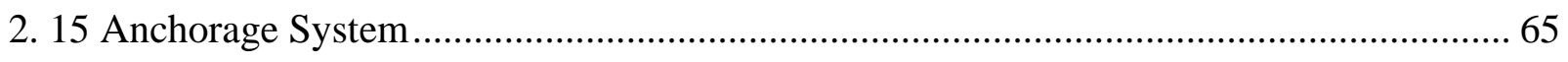

2.16 Transverse Moment and Tensile Force in Traffic Barriers ………………….................. 65

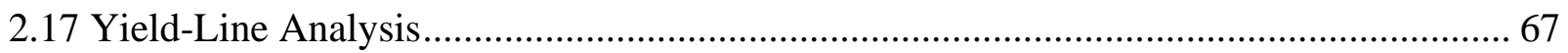

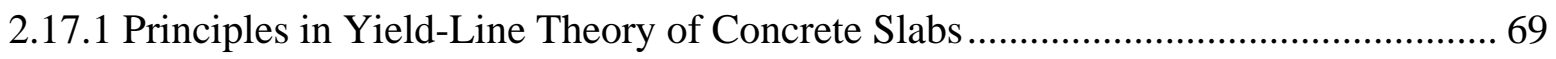

2.17.2 The Virtual Work Method of Analysis ..................................................................... 70

2.17.3 Yield-Line Theory in Bridge Barrier Walls .............................................................. 72

2.18 Verification of AASHTO-LRFD Yield-Line at Interior Location .................................... 76

2.19 Verification of AASHTO- LRFD Yield-Line at Exterior Location ................................... 80

2.20 Investigation of Punching Shear Strength of GFRP Bars in Concrete Slab ...................... 83

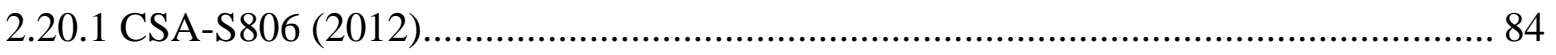

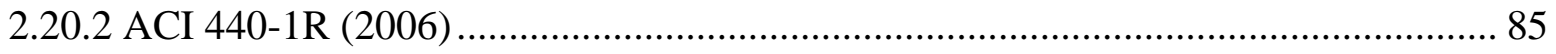

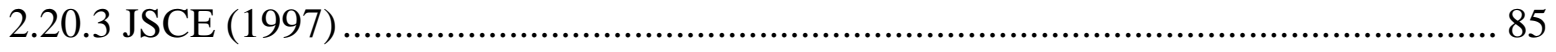

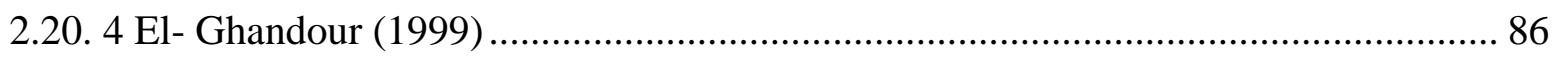

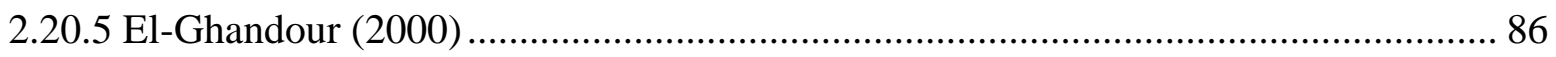

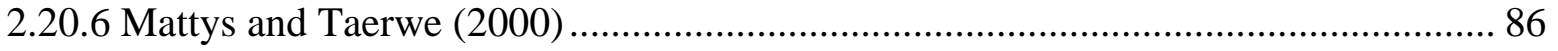

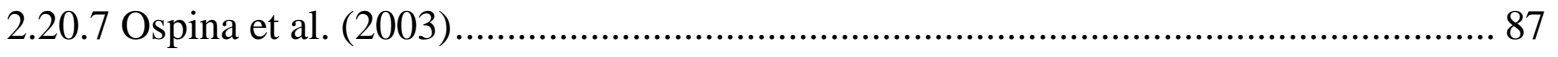

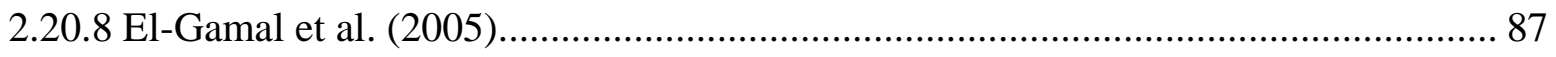

2.21 Punching Shear Strength of Steel-Reinforced Concrete Slab .......................................... 87

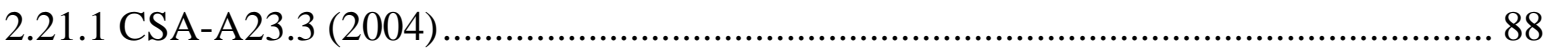




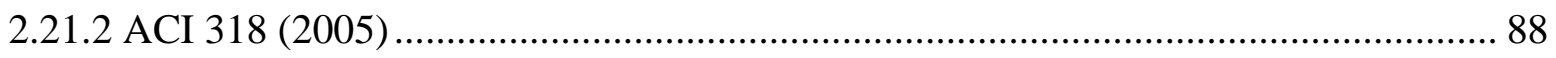

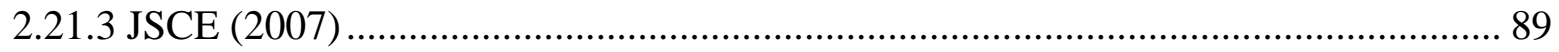

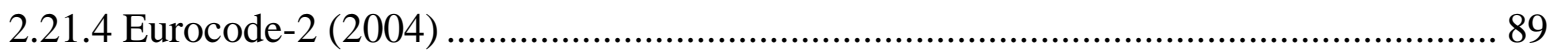

2.21.5 British Code-1997 (BS 8110) ………………................................................... 90

2.21.6 CEB-FIP Model Code 1990 (MC90) ………...................................................... 90

2.22 Current Literature Review on Concrete Barriers......................................................... 90

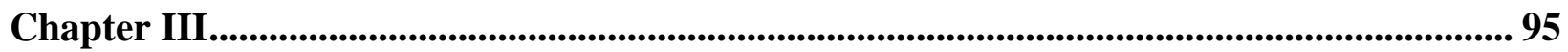

Pullout Strength of GFRP Bars in Concrete ...................................................................................... 95

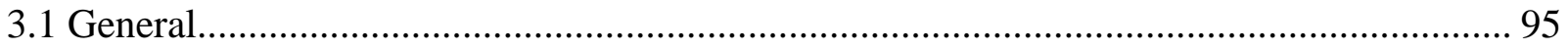

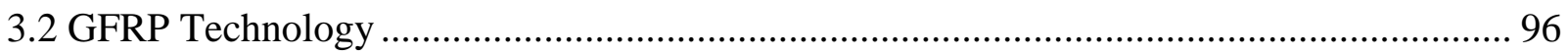

3.3 Experimental Study on Pullout Specimens in Concrete slab ............................................. 98

3.4 Experimental Study on Pullout Specimens in Concrete Cubes ......................................... 105

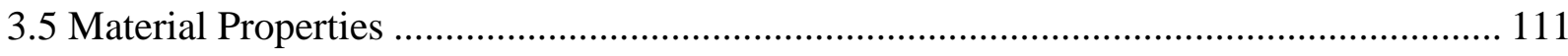

3.5.1 Concrete Slab Pullout Specimens …………………............................................. 111

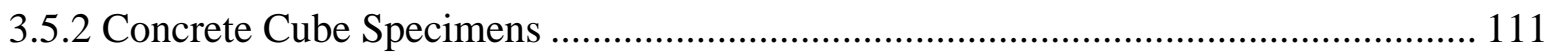

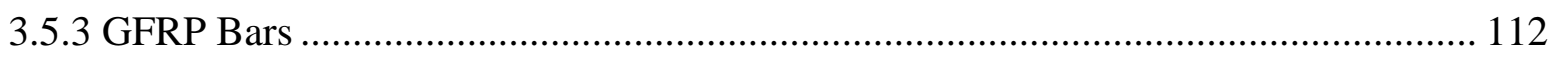

3.6 Test Setup and Procedures...................................................................................... 113

3.6.1 Test Setup for Concrete Slabs ................................................................................ 113

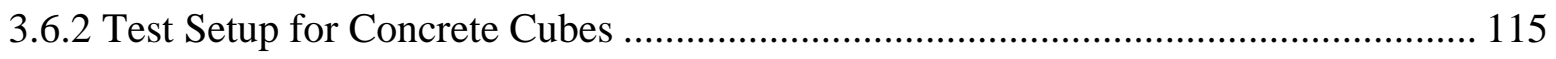

3.7 Experimental results of pullout specimens in concrete slabs ........................................... 115

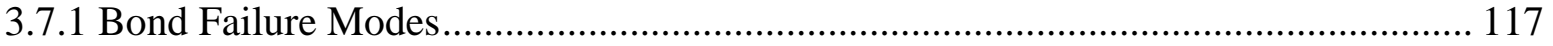

3.7.2 Factors Affecting Bond Strength ...................................................................... 123

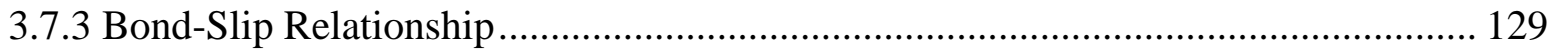

3.8 Experimental Results of Pullout Specimens in Concrete Cubes ........................................ 144

3.8.1 Bond Failure Modes............................................................................................. 149

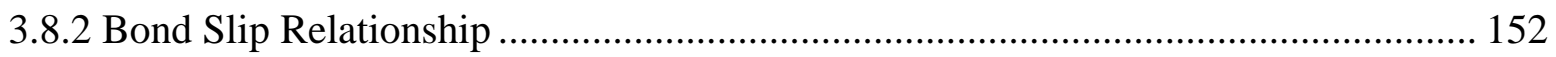

3.9 Analytical Investigation of Bond - Slip Relationship...................................................... 157

3.10 Basic Development Length of GFRP Bars in Concrete ……........................................... 162

3.11 Development Length Equations for Headed Bars ....................................................... 168

3.11.1 Effective Depth of Concrete Cone Breakout for Headed Bars .................................. 171

3.12 Development Length of GFRP Hook Bars - Comparison to Code Predictions .............. 174 
3.12.1 ACI 440.1R (2006) and CSA-S806 (2012)……….......................................... 175

3.12.2 Proposed Equation for Hook Bars ……………............................................... 175

3.13 Development Length of GFRP Straight End Bars - Comparison to Code Predictions ... 177

3.13.1 Analytical Calculation of Development Length ................................................... 177

3.13.2 Comparison to Code Predictions ............................................................................ 178

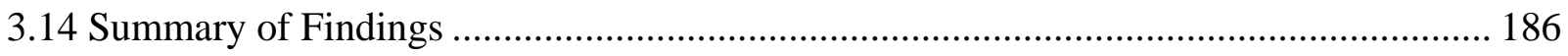

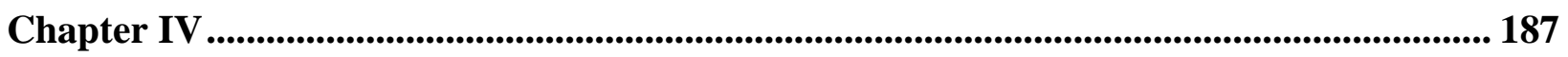

Development of GFRP-Reinforced Concrete Bridge Barrier-Deck Slab Interface............. 187

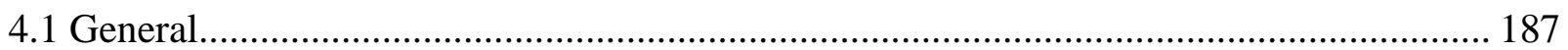

4.2 Background of the Developed GFRP-Reinforced Barriers …………………….............. 189

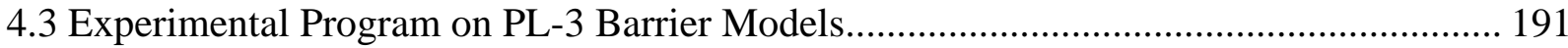

4.4 Experimental Results for the Tested PL-3 Barrier Models ……………………….......... 199

4.5 Cross-Sectional Analysis of Barrier Models ………........................................................ 217

4.6 Investigation of Diagonal Tension Failure ……………........................................... 218

4.6.1 Cracking Moment in the Deck due to Diagonal Tension Crack ................................ 222

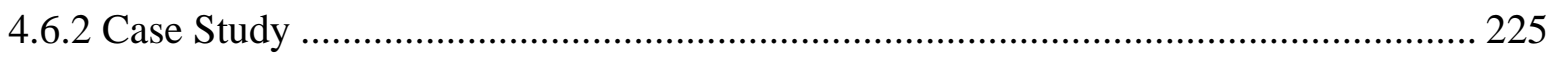

4.6.3 Minimum Reinforcement Ratio for Diagonal Tension Crack .................................. 225

4.7 Analytical Modeling of Deck-Wall Connection.............................................................. 227

4.8 Analysis of Developed PL-3 Barriers by Strut and Tie Model ........................................ 230

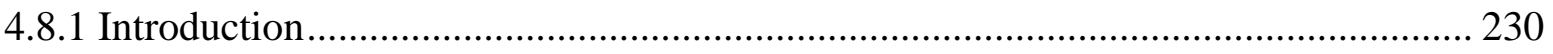

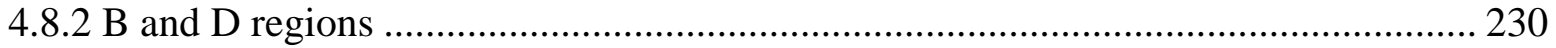

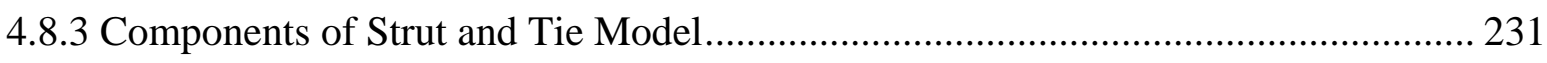

4.8.4 Development of Truss Model ............................................................................ 232

4.8.5 Application of Strut and Tie Mode (STM) on Tested Barriers.................................. 233

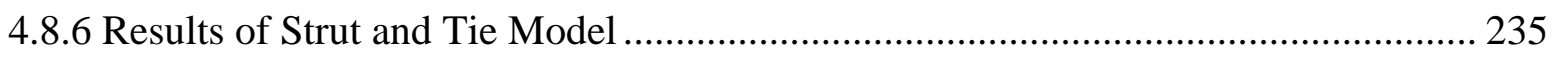

4.9 Empirical Expressions for Transverse Moments and Tensile Forces in Bridge Barriers.. 243

4.9.1 Parametric Study ............................................................................................. 244

4.9.2 Finite Element Modeling Using SAP 2000 ........................................................ 246

4.9.3 Finite Element Results and Discussions .............................................................. 247

4.9.4 Developed Equations ……………................................................................ 259

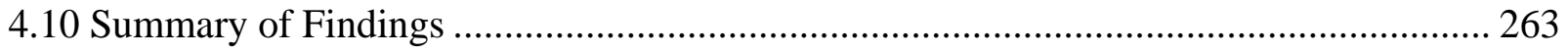


Chapter V

Static Load Testing on Full-Scale GFRP-Reinforced Barriers

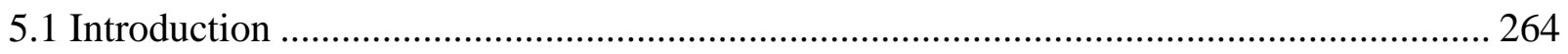

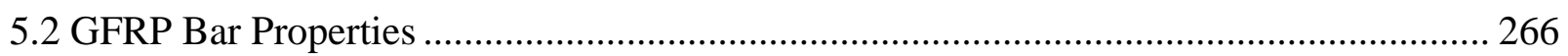

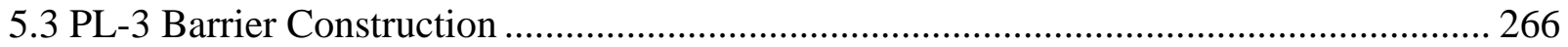

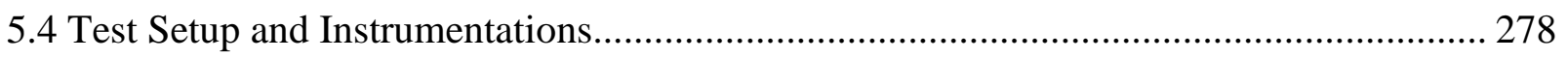

5.5 Experimental Test Results over 2400-mm at Interior Location .................................. 281

5.6 Experimental Test Results over 2400-mm at Exterior Location ................................... 285

5.7 Experiment Test Results over 1000-mm Length at Interior Region ............................. 291

5.8 Experiment Test Results over 1000-mm Length at Exterior Region ............................. 296

5.9 Deformability of 1-m Long Tested Barriers........................................................... 300

5.10 Analytical Investigation of Punching Shear Strength of PL-3 Barriers Reinforced with

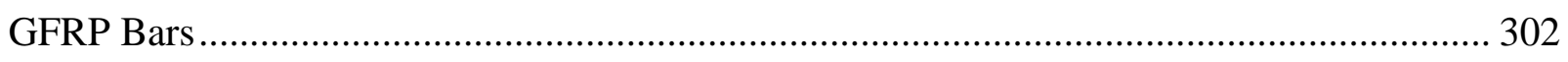

5.10.1 Proposed Punching Shear Equation for PL-3 GFRP Barriers ............................. 306

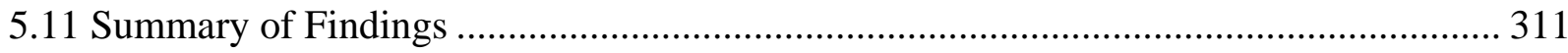

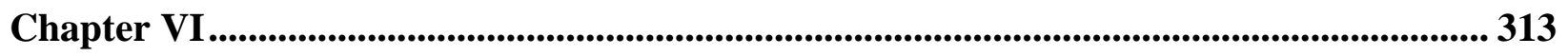

Static Load Testing on Full-Scale Steel-Reinforced Barriers .................................................. 313

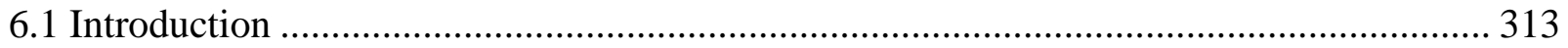

6.2 AASHTO-LRFD Yield-Line Failure Pattern .......................................................... 315

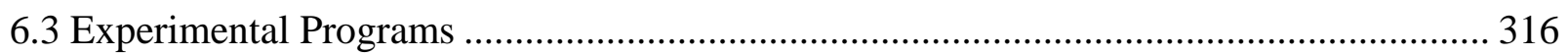

6.3.1 PL-3 Steel-Reinforced Barrier Configuration .................................................. 316

6.3.2 PL-2 Steel-Reinforced Barrier Configuration ................................................... 318

6.4 Test Setup, Instrumentations and Test Procedure ..................................................... 321

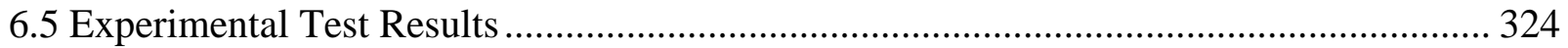

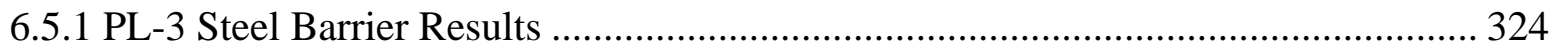

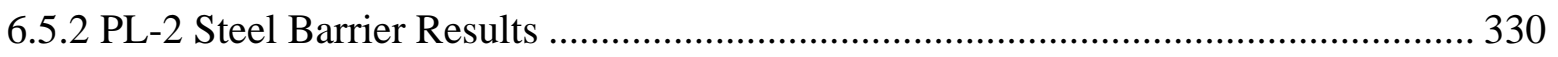

6.6 Development of Yield-Line Failure Pattern ............................................................. 336

6.6.1 Developed Yield-Line Failure Pattern at Interior Location .................................. 336

6.6.2 Developed Yield-Line Failure Pattern at Exterior Location .................................. 345

6.7 Considerations of Possible Yield-Line Failure Patterns .............................................. 352

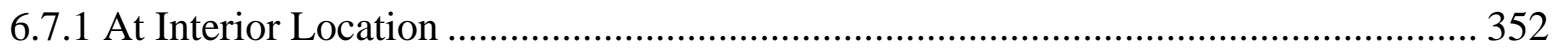


6.7.2 At Exterior Location 355

6.8 Critical Yield-Line Length and Wall Resistance of CHBDC Barriers.............................. 360

6.9 Longitudinal Length of Barrier Wall ............................................................................ 360

6.10 Bending and Twisting Moments Along or Normal to the Yield-Lines........................... 365

6.11 Analytical Investigation of Punching Shear Strength in Steel-Reinforced Barriers ....... 368

6.11.1 Proposed Punching Shear Prediction Models for PL-3 and PL-2 Steel-Reinforced

Bridger Barriers .......................................................................................................... 369

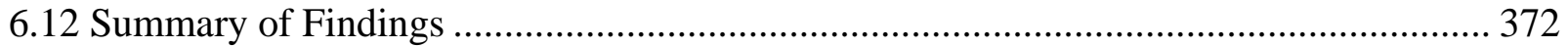

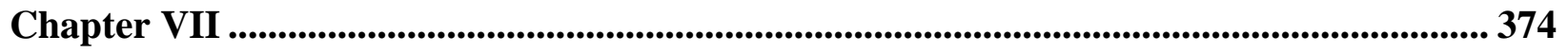

Finite-Element Modeling of PL-3 Traffic Barriers........................................................................... 374

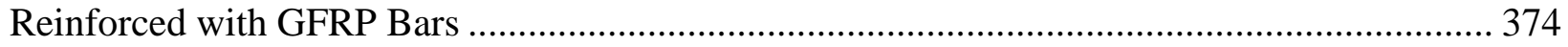

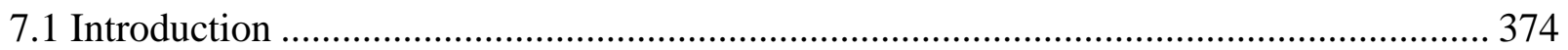

7.2 Details of Concrete Barriers …………....................................................................... 375

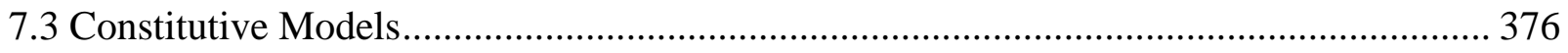

7.3.1 Concrete Damaged Plasticity (CDP) Model .............................................................. 376

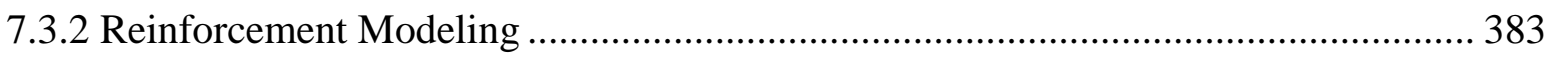

7.3.3 Dynamic Explicit Analysis versus Implicit/Standard Analysis ................................ 386

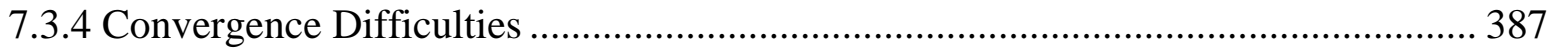

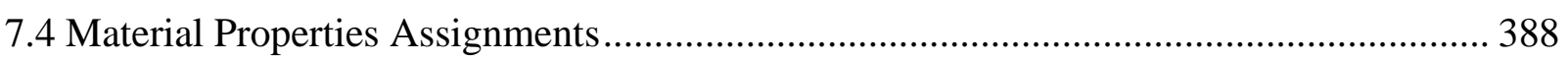

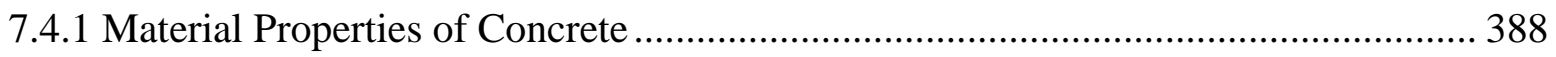

7.4.2 Material Properties of Reinforcement ..................................................................... 394

7.5 Defining contact interface between reinforcing bars and concrete ................................. 396

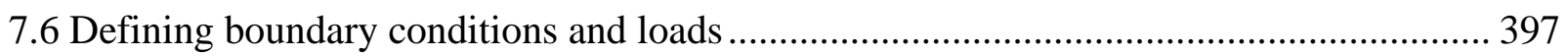

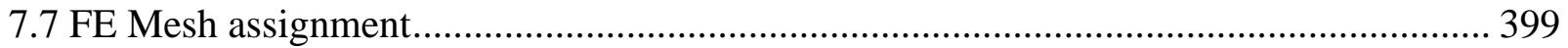

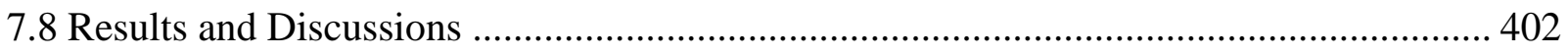

7.8.1 Finite-Element Results of Barrier Model (1) ............................................................. 402

7.8.2 Finite-Element Results of TTI Barrier at Interior Location....................................... 414

7.8.3 Finite-Element Results of TTI Barrier at Exterior Location....................................... 425

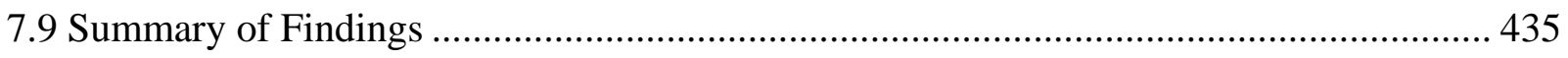

Chapter VIII.............................................................................................................................. 437

Conclusions and Recommendations for Future Study ................................................................ 437 
8.1 Summary.

8.2 Pullout of GFRP Bars in Concrete Cubes and Concrete Slabs...................................... 438

8.3 Development of Deck-Wall Joint Detail Using GFRP Bars ........................................ 440

8.4 Static Tests on Full-Scale GFRP-Reinforced Bridge Barriers ..................................... 442

8.5 Static Tests on Full-Scale Steel-Reinforced Bridge Barriers ........................................ 444

8.6 Finite-Element Modeling of GFRP-Reinforced Bridge Barriers ................................. 445

8.7 Recommendations for Future Research.............................................................. 445

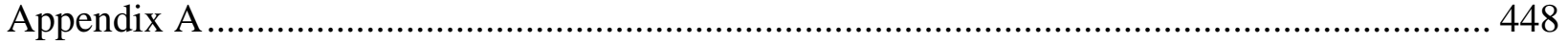

Experimental Results of Pullout of GFRP bars in Concrete ............................................... 448

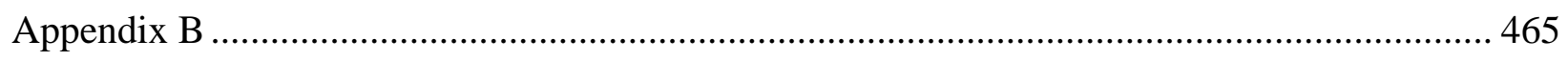

Results from Concrete Core Sampling ........................................................................ 465

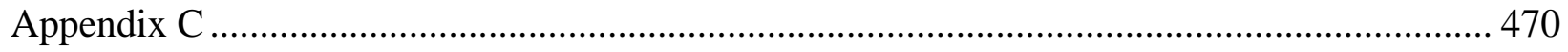

Results of Strut and Tie Model in Barrier Models 1 to 5.................................................. 470

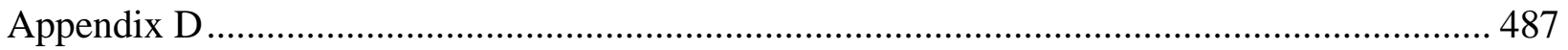

Moment and Tensile Force Intensity Factors in Traffic Barriers ........................................ 487

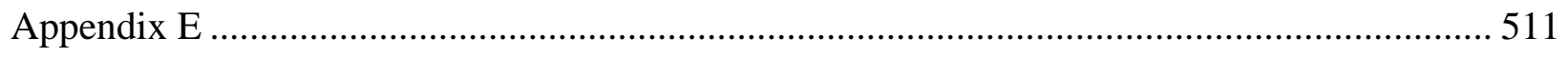

Punching Shear Resistance of GFRP-Reinforced PL-3 Barriers .......................................... 511

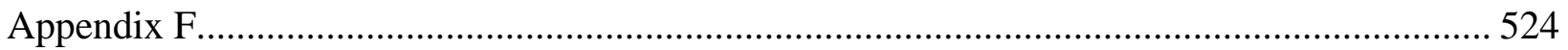

Calculations of Critical Wall Resistance, $\mathrm{R}_{\mathrm{w}}$, and Critical Yield-Line Length, $\mathrm{L}_{\mathrm{c}}$, for Standard

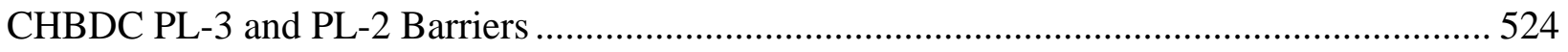

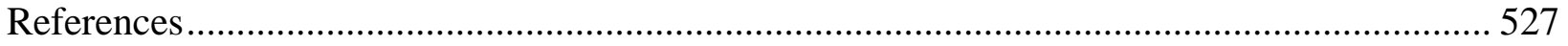




\section{List of Tables}

Table 2. 1 Typical properties of thermosetting resins (Source: ISIS Manual 3, 2007) .............. 16

Table 2. 2 Quantitative comparison of the properties of glass, carbon and aramid fibers........... 18

Table 2. 3 Typical mechanical properties of various fibers (Source: ISIS Manual 3, 2007)....... 19

Table 2. 4 Selected properties of currently available FRP bars ........................................... 23

Table 2. 5 Selected properties of currently available FRP strengthening systems .................... 24

Table 2. 6 Typical tensile properties of reinforcing bars (Source: ACI 440.1R-03) ................. 26

Table 2. 7 Pullout and beam test results in the literature ..................................................... 53

Table 2. 8 Effect of embedment length on bond strength of FRP bars.................................. 54

Table 2. 9 Effect of surface profile on bond strength of FRP bars .......................................... 55

Table 2. 10 Transverse, Longitudinal and Vertical Loads on the Traffic Barriers ..................... 67

Table 2. 11 Design Transverse Moments and Tensile Forces in Cantilever decks due to

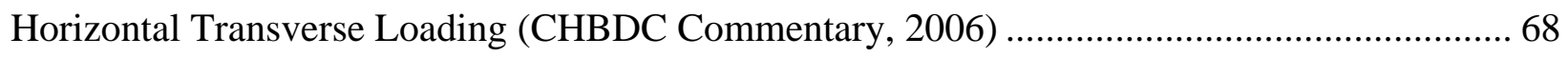

Table 2. 12 Factored Design Forces for Traffic Railings (AASHTO-LRFD, 2012).................. 68

Table 3. 1 GFRP Material properties (From manufacturer data sheet) .................................. 97

Table 3. 2 Pullout strength increase for concrete slab models............................................... 129

Table 3. 3 Summary of the average experimental test results for straight end bars in slab model 1

Table 3. 4 Summary of averaged experimental test results for headed-end bars in slab model 1

Table 3. 5 Summary of averaged experimental test results for hook bars in slab model 1 ....... 142

Table 3. 6 Summary of experimental test results of pullout cube specimens .......................... 146

Table 3. 7 Summary of mBPE and CMR bond parameters ................................................ 159

Table 3.8 bond factor parameter, $\mathrm{C}_{2}$, and measured development length of GFRP bars ......... 164

Table 3. 9 Modified bond factors used in Eq. 3.13 ............................................................. 164

Table 3. 10 Basic development length comparison of different codes .................................. 168

Table 3. 11 Development length calculations for GFRP headed end bars in concrete.............. 172

Table 3. 12 Value of parameters for CSA S806-12 and ACI 440.1R 6 development length

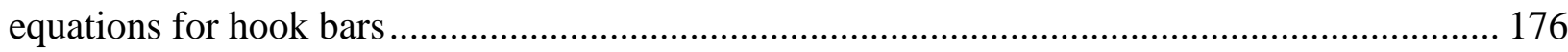


Table 3. 13 CSA S806-12 and ACI 440.1R 006 development length requirement and computed bond stress compared with proposed equations .......................................................... 176

Table 3. 14 Value of parameters used to determine the required development length............. 178

Table 3. 15 Analytically calculated development length of GFRP bars in concrete ................. 178

Table 3. 16 Value of parameters for CSA S806-12 development length equation................... 179

Table 3. 17 CSA S806-12 development length requirements and computed bond stress......... 179

Table 3. 18 Value of parameters for CSA S6-06 development length equation....................... 181

Table 3. 19 CSA S6- 06 development length requirements and computed bond stress............ 181

Table 3. 20 Parameters used for ACI 440.1R-06 development length equation ...................... 182

Table 3. 21 ACI 440.1R - 06 development length requirement and computed bond stress ....... 182

Table 3. 22 Parameters for ACI 440.1R-03 development length equation............................. 183

Table 3. 23 ACI 440.1R - 03 development length requirement and computed bond stress ....... 183

Table 3. 24 Parameters for JSCE-1997 development length equation .................................... 184

Table 3. 25 JSCE - 1997 development length requirement and computed bond stress............. 184

Table 3. 26 Development Length comparisons between codes and the proposed equation for straight bars 185

Table 3. 27 Bond strength comparison between codes and the proposed equation for straight bars 185

Table 4. 1 Barrier Designations used in current study for each model................................. 196

Table 4. 2 Sumarry of experimental findings of the tested barrier models.............................. 216 Table 4. 3 Comparison between analytical and experimental results by diagonal tension cracks 224

Table 4. 4 Comparison of the Work by Matta et al. (2008) with Current Study ...................... 225

Table 4. 5 Design strength of struts, tension ties and nodal zone by various codes ................. 236

Table 4. 6 Barrier designations used in the current study for each barrier model ................... 237

Table 4. 7 Resulting forces $(\mathrm{F})$ in struts, ties and reactions in each barrier model $(\mathrm{kN})$.......... 238

Table 4. 8 Compressive strut loads and comparison with design strength of compressive........ 238

Table 4. 9 Tension tie load (T1) and comparison with design strength of reinforcing tie at barrierdeck joint 241 
Table 4. 10 Truss element loads and comparison with design strength of Nodes P3 and P5 at barrier-deck joint for barrier Model 4 (GS4-HM) ............................................................... 242

Table 4. 11 Flexural and tension tie desing strength ratio at barrier-deck joint ......................... 242

Table 4. 12 Predicted design force equations at barrier- deck interface ................................... 260

Table 4. 13 Predicted design force equations at barrier- deck interface ...................................... 261

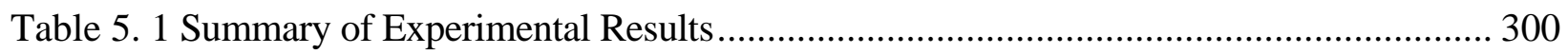

Table 5. 2 Deformability of tested $1 \mathrm{~m}$ long barrier walls.......................................................... 301

Table 5. 3 Punching shear capacities from various codes and provisions for PL-3 GFRP-

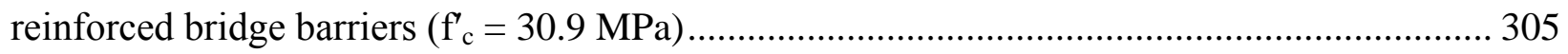

Table 5. 4 Tested-to-Predicated punching shear capacity of PL-3 GFRP barrier wall............... 305

Table 5. 5 Barrier designations considered for the proposed punching shear equation .............. 306

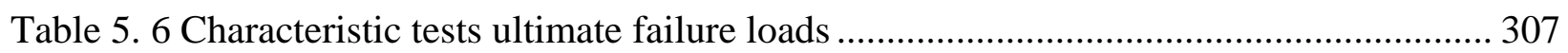

Table 5. 7 Ratio of experimental-to-proposed punching shear capacity of PL-3 GFRP barriers311

Table 6. 1 Characteristic concrete compressive strength of PL-3 and PL2 steel barriers .......... 318

Table 6. 2 Summary of Experimental Results of the test steel barriers ......................................... 334

Table 6. 3 Comparison of ultimate wall resistance for various yield-line patterns at interior location

Table 6. 4 Comparison of ultimate wall resistance for possible yield-line patterns at exterior location

Table 6. 5 Punching shear capacities from various codes for PL-3 and PL-2 steel bars ............ 369

Table 6. 6 Experimental and proposed punching shear capacities of the tested barriers

Table 7. 1 Elastic material properties of GFRP reinforcing bars................................................ 385

Table 7. 2 Experimental concrete compressive strengths ....................................................... 389 


\section{List of Figures}

Figure 1. 1 PL-3 GFRP-reinforced bridge barrier detailing for new constructions..................... 3

Figure 1. 2 Pullout test setup for specimens placed into concrete slab..................................... 6

Figure 1. 3 View of proposed barrier walls; (a) with headed-end GFP HM bars and $300 \& 150$ mm bar spacing, (b) with $90^{\circ}$ bent V-Rod bars, (c) with $180^{\circ}$ hook V-Rod bars and (d) reference

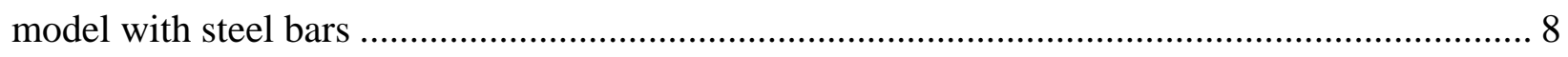

Figure 1. 4 Schematic diagram of static test setup of the traffic barriers .................................. 8

Figure 1. 5 View of barrier wall built at Texas Transportation Institution site ......................... 9

Figure 1. 6 Views of the proposed test specimens for monotonic tests ................................ 10

Figure 2. 1 Various types of FRPs for reinforcement and rehabilitating the concrete structures (Adopted: ISIS Canada Module 3, 2006) ....................................................................... 14

Figure 2. 2 Basic material components of FRP composite ................................................. 15

Figure 2. 3 View of concrete slab strengthened with CFRP sheets .......................................... 21

Figure 2. 4 Typical stress-strain curve of various FRP (Adopted: ACI 440R-96) ..................... 22

Figure 2. 5 Stress- strain relationship of fibers, matrix and FRP (Adpoted: ISIS Canada Module

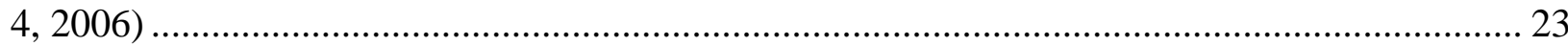

Figure 2. 6 Stress- strain relationships for various FRP strengthening systems ....................... 25

Figure 2. 7 Bond force transfer mechanism (Adopted: ACI 408.2R-92) ................................ 28

Figure 2. 8 Pullout resistance mechanism for a deformed bar, (a) anchored bar under tension b) forces on reinforcing bar, and (c) forces on concrete (Adopted: Chaallal and Lachemi, 2010)... 29 Figure 2. 9 Bond failure mechanism; (a) splitting cracks between bars and concrete, and (b) pullout failure mode along the bar surface (Adopted: ACI 408R-03) .................................... 30 Figure 2. 10 Schematic diagram of pullout test specimen ................................................. 31 Figure 2. 11 Variation of bond and tensile stresses along the length of the steel bar in reinforced concrete structure subjected to pullout force; (a) concrete block subjected to tensile force, (b) bond stress distribution along the bar length, and (c) tensile stress distribution along the bar

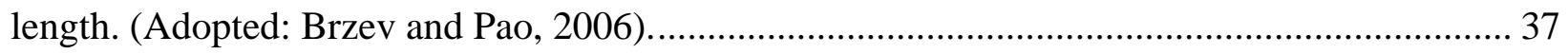

Figure 2. 12 Variation of slip, bond stress, bond force and strain along the bonded length of FRP

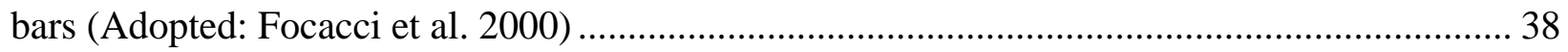

Figure 2. 13 Typical bond stress-slip relationship for GFRP bars ....................................... 47 
Figure 2. 14 BPE Model (Adopted: Eligehausen et al. 1983). ............................................ 48

Figure 2. 15 Marti's bond-slip model (Adopted: Marti, 1999) ............................................ 49

Figure 2. 16 Modified BPE model (Adopted: Cosenza et al. 1997) ........................................ 51

Figure 2. 17 Principle of external work done on a slab section (Adopted; Caprani, 2006)......... 71

Figure 2. 18 Yield-Line pattern for interior region of barrier wall ......................................... 74

Figure 2. 19 Yield-Line pattern for end region of barrier wall ............................................ 74

Figure 2. 20 AASHTO-LRFD yield-line pattern at interior location ...................................... 76

Figure 2. 21 Original and deformed shape of top portion of barrier wall at interior location

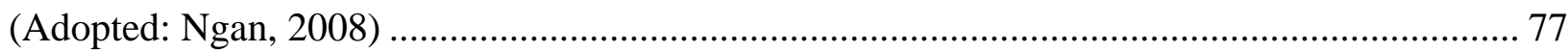

Figure 2. 22 Original and deformed shape of barrier wall at exterior location ........................ 80

Figure 3. 1 Views of V-ROD bars; straight (left), bend (middle) and headed (right) bars.......... 96

Figure 3. 2 Views of GFRP sand-coated HM \& SM bars Figure 3. 3 View of headed end bar 98

Figure 3. 4 Concrete slab models $1 \& 2$ with single GFRP bars ........................................... 99

Figure 3. 5 View of formwork of slab models $1 \& 2$ prior to installation of GFRP bars .......... 100

Figure 3. 6 Placement of GFRP hook bars in the formwork ........................................... 100

Figure 3. 7 Installation of GFRP headed end bars in the formwork ................................... 101

Figure 3.8 Placement of GFRP straight end bars in the formwork................................... 101

Figure 3.9 View of GFRP bars in the formwork prior to concrete casting ........................... 101

Figure 3. 10 Marked GFRP bars with $200 \mathrm{~mm}$ embedment length; (a) straigth bar, (b) headed-

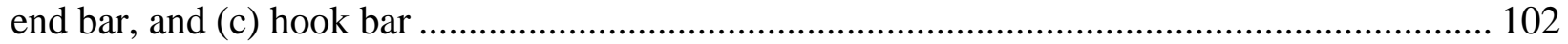

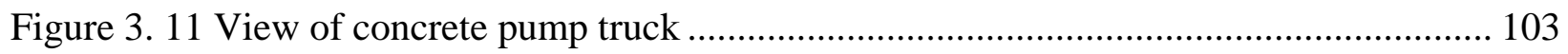

Figure 3.12 View of concrete casting of the slab Model 1 ............................................... 103

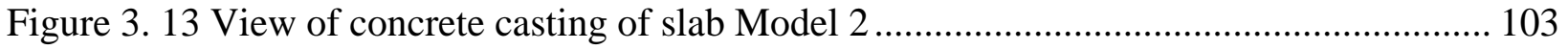

Figure 3.14 Vibrating concrete during casting to remove entrapped-air .............................. 104

Figure 3.15 View of taking concrete cylinder specimens from compressive strength test........ 104

Figure 3. 16 Leveling out GFRP bars after concrete casting to make them vertical in the slab. 104

Figure 3. 17 Concrete curing using plastic sheets...................................................... 105

Figure 3. 18 Schematic view of $150 \mathrm{~mm}$ concrete cubes with single GFRP straight end bars .. 106

Figure 3. 19 Schematic view of $200 \mathrm{~mm}$ concrete cubes with single GFRP straight end bars .. 106

Figure 3. 20 Schematic view of $300 \mathrm{~mm}$ concrete cubes with single GFRP headed end bars ... 107 
Figure 3.21 Schematic view of $300 \mathrm{~mm}$ x $500 \mathrm{~mm}$ concrete cubes with single GFRP hook bars 107

Figure 3. 22 Placement of GFRP straight and headed - end bars in $150 \mathrm{~mm}$ cubes................. 109

Figure 3.23 Placement of GFRP straight - end bars in $200 \mathrm{~mm}$ cubes ................................. 109

Figure 3. 24 View of GFRP headed - end bars embedded in $300 \mathrm{~mm}$ cubes .......................... 109

Figure 3. 25 Placement of GFRP hook bars in $300 \mathrm{~mm}$ x $500 \mathrm{~mm}$ concrete cubes ................. 110

Figure 3.26 View of concrete casting of the pullout cubes using plastic pipe........................ 110

Figure 3. 27 Photo of cast concrete in $150 \mathrm{~mm}$ cubes with cylinder test cured next to the

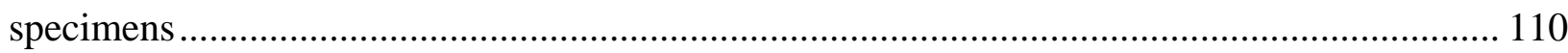

Figure 3.28 View of concrete blocks after removal of formworks .................................... 111

Figure 3. 29 Concrete compressive strength developments for slab models 1 and 2 .............. 112

Figure 3. 30 Concrete compressive strength developments for concrete cube specimens ......... 112

Figure 3. 31 Schematic diagram of pullout test setup of single GFRP bars in concrete slab .... 114

Figure 3. 32 View of single GFRP bar test setup for concrete slab specimens ...................... 114

Figure 3. 33 Photo of pullout test setup of single GFRP bars in concrete cubes..................... 115

Figure 3. 34 Pullout failure mode in slab model 2 with $100 \mathrm{~mm}$ embedment length and straight

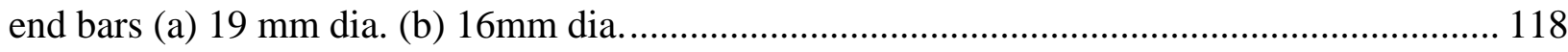
Figure 3. 35 Pullout failure mode in slab model 1 with $150 \mathrm{~mm}$ embedment length and straight end bars (a) $19 \mathrm{~mm}$ dia. (b) $16 \mathrm{~mm}$ dia.

Figure 3. 36 Pullout failure mode in slab model 2 with $200 \mathrm{~mm}$ embedment length and straight

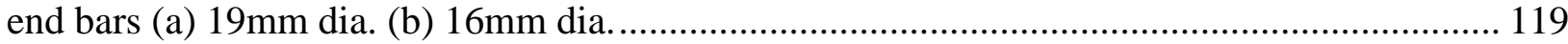
Figure 3. 37 Concrete cone breakout failure in $100 \mathrm{~mm}$ embedment length and Headed- end bars (a) $16 \mathrm{~mm}$ dia. (b) $19 \mathrm{~mm}$ dia. 120 Figure 3. 38 Pullout with head broken failure mode in slab model 2 with $150 \mathrm{~mm}$ embedment length (a) $16 \mathrm{~mm}$ bar dia. (b) $19 \mathrm{~mm}$ bar dia. 121

Figure 3. 39 Pullout with headed broken failure mode in slab model 1 with $150 \mathrm{~mm}$ embedment length (a) $16 \mathrm{~mm}$ bar dia. (b) $19 \mathrm{~mm}$ bar dia. 121 Figure 3. 40 Rebar slippage failure mode in slab model 1 with straight end bars (a) $16 \mathrm{~mm}$ bar dia. (b) $19 \mathrm{~mm}$ bar dia. 122 Figure 3. 41 Rebar slippage failure mode in slab model 2 with straight end bars (a) $16 \mathrm{~mm}$ bar dia. (b) $19 \mathrm{~mm}$ bar dia. 122 
Figure 3. 42 Rebar rupture failure mode in slab model 1 with $16 \mathrm{~mm}$ bar diameter (a) with 200 mm embedment length (b) with $150 \mathrm{~mm}$ embedment length 123

Figure 3. 43 Rebar rupture failure mode in slab model 2 with $16 \mathrm{~mm}$ bar diameter (a) with 200 mm embedment length (b) with 150 mm embedment length..... 123 Figure 3. 44 Effect of bar diameter on average bond stress for different bars in slab model 1.. 124 Figure 3. 45 Effect of bar diameter on average bond stress for different bars in slab model 2.. 125 Figure 3. 46 Effect of concrete strength on the average bond stress for different bars in slab models 1 and 2 ..... 126

Figure 3. 47 Effect of embedment length on the applied pullut load for various bars in slab models 1 and 2 . 128

Figure 3. 48 Effect of embedment length on bond stress for various bars in slab models 1 and 2

Figure 3. 49 Typical bond stress- loaded end slip for straight end bars 130

Figure 3. 50 Average bond stress versus loaded-end slip for GFRP 19M bar in slab model 1.. 131 Figure 3. 51 Average peak bond stress versus embedment length for straight end bars in slab model 1 133

Figure 3. 52 Average bond stress versus loaded-end slip for straight-end bars \#5 and \#6..... 134

Figure 3.53 Typical bond stress-loaded end slip for headed end bars 135

Figure 3. 54 Average bond stress versus loaded-end slip for M19 GFRP Bars in slab model 1136 Figure 3. 55 Average peak bond stress versus embedment length for headed end bars in slab model 1 . 138

Figure 3. 56 Average bond stress versus loaded-end slip for headed-end bars for different bar size and embedment lengths in slab model $1 . .$. 138

Figure 3. 57 GFRP headed bar failed by head broken showing removal of disk shape head.... 139

Figure 3.58 Typical bond stress - loaded end slip for hook bars ...................................... 140

Figure 3. 59 GFRP hook rupturing locations (a) at bent portion (b) in straight portion............ 140 Figure 3. 60 Average pre-peak bond stress versus loaded-end slip for hook bars in slab model 1

Figure 3. 61 Loaded-end slip versus embedment length for various bars in slab model 1 142

Figure 3. 62 Peak bond stress comparison for straight, headed and hook bars for slab model 1143 Figure 3. 63 Average bond stress versus loaded-end slip GFRP hook bars in slab model 1..... 144 
Figure 3. 64 Comparison of pullout load (a) and the average bond stress (b) with the increase in embedment length of the tested bars. 147

Figure 3. 65 Effect of bar size on bond strength with the increase in embedment length ......... 148

Figure 3. 66 Effect of bar end geometry on bond strength with embedment length increase .... 149 Figure 3.67 Failure mode of tested concrete cubes; (a) pullout, (b) concrete splitting, (c) concrete splitting followed by bar pulled out from broken head and (d) rebar rupture

Figure 3. 68 Pullout failure modes with; (a) failure at bar concrete interface, and (b) failure at bar-core interface by shearing off the surface texture

Figure 3. 69 Average bond stress - loaded end slip relationships with bars with different end anchorage system. 154

Figure 3. 70 Typical average bond stress - free end relationship of GFRP bars in concrete..... 155 Figure 3. 71 Average bond stress free-end slip relationships with bars with different end anchorage system . 156

Figure 3. 72 Comparison of experimental and analytical bond stress-slip relationships 161 Figure 3. 73 Linear regression analysis for bond factors; (a) for straight bars, (b) for headed bars, and (c) for hook bars 165

Figure 3. 74 FRP modification factor, $\mathrm{K}_{\mathrm{F}}$ for concrete breakout capacity of GFRP headed bars in concrete 170

Figure 3. 75 Schematic view of effective concrete cone breakout failure 173

Figure 3. 76 Views of experimentally tested GFRP headed anchors showing depth of concrete cone breakout failure for variable embedment lengths 173

Figure 3. 77 Trace effective concrete cone breakout as a function of bar embedment length ... 174

Figure 4. 1 Corrosion-induced degradation of steel-reinforced bridge barrier wall 188

Figure 4. 2 Traditional PL-3 steel-reinforced barrier detailing with bent bars ....................... 188

Figure 4. 3 Proposed Ryerson University Barrier Details ...................................................... 192

Figure 4. 4 GFRP-reinforced Barrier detailing from MTO Standard Drawing SS110-92......... 193

Figure 4. 5 Views of GFRP bars in barrier Model 1 ....................................................... 194

Figure 4. 6 Views of GFRP bars in barrier Model 2 ...................................................... 195

Figure 4. 7 Views of GFRP bar arrangement in barrier Model 3 ......................................... 196

Figure 4. 8 Views of GFRP bars in barrier Model 4 ......................................................... 196 
Figure 4. 9 View of steel bars arrangement in barrier Model 5

Figure 4. 10 Photo of casting of the barrier models.

Figure 4. 11 Test setup and sensor locations for the barrier models...................................... 198

Figure 4. 12 View of the crack pattern in barrier Model 1 with HM-GFRP bars..... 202

Figure 4. 13 Load-deflection curves for the barrier wall, deck horizontal movement and deck uplift in barrier Model 1 202

Figure 4. 14 View of the crack pattern in barrier Model 2 with SM-GFRP bent bars 205

Figure 4. 15 Load-deflection curves for barrier wall, deck horizontal movement and deck uplift in barrier Model 2 205

Figure 4. 16 View of the crack pattern in barrier Model 3 with SM-GFRP bars with $180^{\circ}$ hooks 208

Figure 4. 17 Load-deformation curves for barrier wall, deck horizontal movement and deck uplift in barrier Model 3 209

Figure 4. 18 View of the crack pattern in barrier Model 4 with HM-GFRP bars

Figure 4. 19 Load-deformation curves for barrier wall, deck horizontal movement and deck uplift in barrier Model 4 212

Figure 4. 20 View of the crack pattern in barrier Model 5 with steel reinforcing bars 215

Figure 4. 21 Load-deformation curves for barrier wall, deck horizontal movement and deck uplift in barrier Model 5 215

Figure 4. 22 Barrier wall subjected to transverse load due to diagonal tension cracks 220 Figure 4. 23 Stress distribution at deck-wall joint indicating tensile stresses (positive sign) and compressive stresses (negative sign) 220

Figure 4. 24 Free body diagram and internal forces at corner joint of barrier wall.................. 221 Figure 4. 25 Resultant compressive and tensile forces in the deck slab and barrier wall.......... 223 Figure 4. 26 Analytical modeling of deck-wall response; barrier wall subjected to transverse load (top) and rotations of the deck and wall under the applied load (bottom). 228 Figure 4. 27 Comparison of load-deformation response of experiment and analytical modeling in (a) barrier Model 1, and (b) barrier Model 3 229

Figure 4. 28 Assumed D-region in the Barrier Models 234 Figure 4. 29 (a) Stress trajectories and assumed truss model, and (b) truss model in analysis proposed by Aminmansour et al. (2004). 235 
Figure 4. 30 Typical FE modeling of traffic barriers.

Figure 4. 31 Contour of moment dispersion in PL-3 barrier walls with $8 \mathrm{~m}$ length; (a) at exterior location and (b) at interior location 248

Figure 4. 32 Moment intensity factor in the deck of the PL-3 barrier wall versus barrier length as a function of cantilever deck slab length and deck slab thickness at interior location. 249

Figure 4. 33 Moment intensity factor at base of the PL-3 barrier wall versus cantilever deck length as a function of barrier length and deck slab thickness at interior location..... 250 Figure 4. 34 Extrapolation of moment intensity versus barrier longitudinal length for PL-3 barrier at interior location 251

Figure 4. 35 Comparison of moment intensity factors for PL-3 and TL-5 barriers at interior location as a function of barrier length 251

Figure 4. 36 Comparison of moment intensity factors for PL-3 and TL-5 barriers at exterior location as a function of barrier length

Figure 4. 37 Comparison of tensile force intensity factor for PL-3 and TL-5 barriers at interior location as a function of barrier length 254 Figure 4. 38 Comparison of tensile force intensity factors for PL-3 and TL-5 barriers at exterior location as a function of barrier length 255 Figure 4. 39 Extrapolation of moment intensity factor versus barrier longitudinal length for PL-2 barrier at interior location 257

Figure 4. 40 Comparison of FE modeling with the developed equations for PL-3 and PL-2 traffic barriers 262 Figure 4. 41 Comparison of FE modeling with the developed equations for Tl-5 and Tl-4 traffic barriers 262

Figure 5. 1 Prototype barrier elevation built at TTI.......................................................... 267

Figure 5. 2 Cross-section of existing concrete slab foundation and the proposed barrier .......... 268

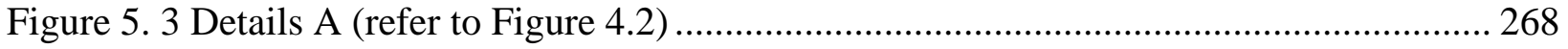

Figure 5. 4 Reinforcing details at deck slab-barrier wall interface ....................................... 269

Figure 5. 5 Connecting M16 bars TYPE 100 (top) and TYPE 101 (bottom) .......................... 269

Figure 5. 6 Detail of the control joint (right) and cross-section at the control joint (left) ......... 270 
Figure 5. 7 Schematic diagram of the barrier wall showing the difference between the MTO barrier and the constructed barrier configurations ..... 270

Figure 5. 8 Layout of the GFRP bars in the barrier wall and the steel bars in the deck cantilever 271

Figure 5. 9 Horizontal and vertical GFRP bars arrangement............................................ 271

Figure 5. 10 Saw-cut the barrier and deck slab for static testing 273

Figure 5. 11 View of the existing concrete foundation with projecting steel dowels at deck level

Figure 5. 12 View of steel reinforcement in the deck slab 274

Figure 5. 13 View of GFRP bars installation. 274

Figure 5. 14 View of the GFRP reinforcement 274

Figure 5. 15 View of welding reinforing steel in the deck to the longitudinal steel strap......... 275

Figure 5. 16 Close-up view of barrier anchorage to deck slab ........................................... 275

Figure 5. 17 Views of the formwork for concrete casting .............................................. 276

Figure 5. 18 Views of the barrier during casting (a) the deck cantilever and (b) the barrier wall

Figure 5. 19 Views of (a) Front and (b) back face of the barrier wall after removing the formwork. 278

Figure 5. 20 View of the barrier wall and the paved area in front of the barrier wall 278

Figure 5. 21 Views of test setup for static testing of the barrier wall at interior and exterior locations over $2.4 \mathrm{~m}$ length and cantilever test over $1 \mathrm{~m}$ length..... 280

Figure 5.22 Views of sensor attachments over 2.4 and $1 \mathrm{~m}$ lengths of the wall locations ........ 281

Figure 5.23 Crack pattern of barrier wall at interior location .......................................... 283

Figure 5. 24 Load-deformation relationships of barrier wall at interior location (see Figure 5.22

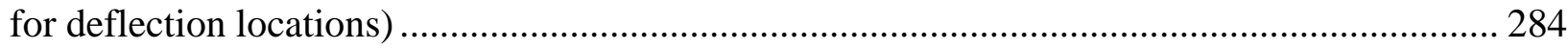

Figure 5. 25 AASHTO-LRFD yield line crack failure patter at interior location..................... 285

Figure 5. 26 Crack pattern of barrier wall at exterior location (a) ........................................ 286

Figure 5. 27 Load-deformation relationships of barrier wall at exterior location (a) -(see Figure

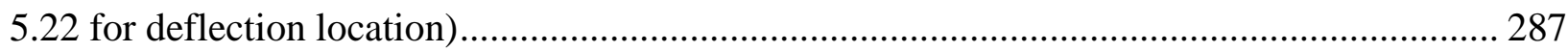

Figure 5.28 Shematic diagrams of sensor locations in the new exterior location (b) .............. 288

Figure 5. 29 Crack pattern of barrier wall at exterior location ........................................... 289 
Figure 5. 30 Load-deformation relationships of the barrier wall at exterior location (b) - (see

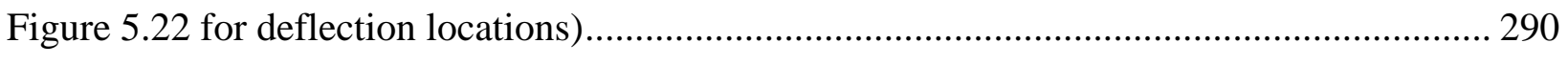

Figure 5.31 AASHTO-LRFD yield line crack failure patter at exterior location ....................... 290

Figure 5. 32 Load- horizontal concrete strain curves at back face of the barrier wall............... 291

Figure 5. 33 Marked barrier wall prior saw-cutting ................................................................ 293

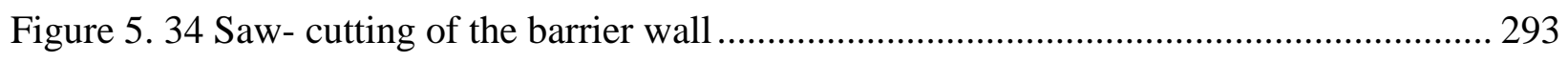

Figure 5. 35 Barrier and reinforcement removal over $500 \mathrm{~mm}$ on each side of test barrier....... 293

Figure 5. 36 Crack pattern over $1 \mathrm{~m}$ length of the barrier at interior region .............................. 294

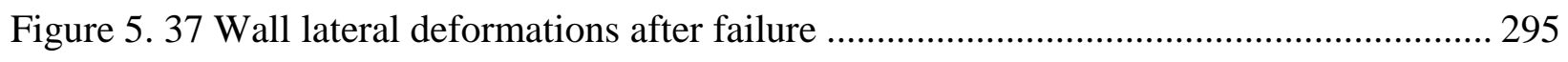

Figure 5. 38 Load- deformation curve of barrier wall and deck slab over $1000 \mathrm{~mm}$ long barrier at

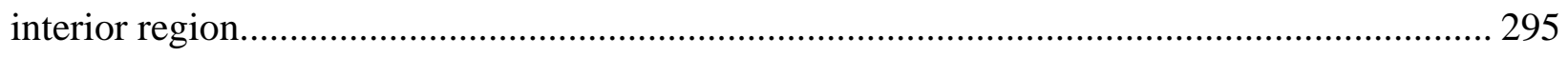

Figure 5. 39 Marked location of barrier end location prior saw-cutting................................... 297

Figure 5. 40 Crack pattern over $1 \mathrm{~m}$ length at exterior region................................................... 298

Figure 5. 41 Lateral deformation of wall under the applied load ........................................... 298

Figure 5. 42 Load- deformation curve of barrier wall and deck slab at end location over $1 \mathrm{~m}$ long

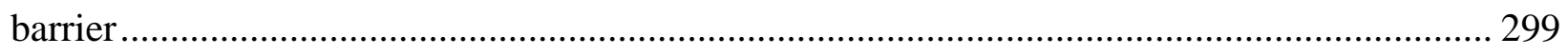

Figure 5. 43 Determination average critical punching shear perimeter .................................... 303

Figure 5. 44 Critical perimeter for punching shear at interior and exterior locations. ................. 310

Figure 6. 1 Geometry and reinforcement arrangements in PL-3 barriers reinforced with

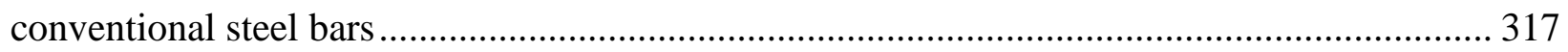

Figure 6. 2 View of the PL-3 steel barrier during construction ................................................ 317

Figure 6. 3 Views of the PL-3 steel barrier after placement of CFRP sheets on the deck slab .. 318

Figure 6. 4 Core sample testing of the PL-3 steel barrier ........................................................... 319

Figure 6. 55 Geometry and reinforcement arrangements in PL-2 barriers reinforced with

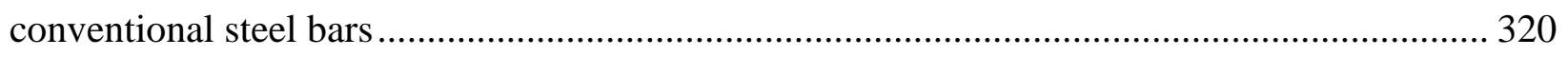

Figure 6. 6 Views of the PL-2 steel barrier after placement of CFRP sheets on the deck slab .. 321

Figure 6. 7 Views of the test setups for static testing of the steel-reinforced barriers ................ 322

Figure 6. 8 Designated sensor locations in PL-3 traffic barrier .............................................. 323

Figure 6. 9 Designated sensor locations in PL-2 traffic barrier ................................................ 324

Figure 6. 10 Crack pattern at front and back faces of PL-3 steel traffic barrier .......................... 326 
Figure 6. 11 Load-deformation curves of the tested PL-3 steel barrier at interior location 327

Figure 6. 12 Crack patterns at front and back faces of the PL-3 traffic barrier at exterior location

Figure 6. 13 trace of load-wall deformation and load-strain curves in PL-3 barrier at exterior location.

Figure 6. 14 Crack pattern at front and back face of PL-2 steel traffic barrier at interior location

Figure 6. 15 trace of load-wall deformation and load-strain curves in PL-2 barrier at interior location.

Figure 6. 16 Crack patterns at front and back faces of the PL-2 traffic barrier at exterior location

Figure 6. 17 Trace of load-wall deformation and load-strain curves in PL-2 barrier at exterior location 335

Figure 6. 18 Trapezoidal yield-line failure pattern at interior location showing deformed shape of top of the wall with $X \geq \mathrm{L}_{\mathrm{t}}$ 338

Figure 6. 19 Proposed trapezoidal yield-line failure at interior location showing deformation of top of the wall with $\mathrm{X}<\mathrm{L}_{\mathrm{t}}$..... 342

Figure 6. 20 Proposed trapezoidal yield-line failure pattern at exterior location $\left(\mathrm{X} \geq \mathrm{L}_{\mathrm{t}}\right)$....... 346

Figure 6. 21 Proposed trapezoidal yield-line failure pattern at exterior location $\left(\mathrm{X}<\mathrm{L}_{\mathrm{t}}\right) \ldots \ldots \ldots 350$

Figure 6. 22 Possible yield-line failure patterns at interior location of the barriers 354

Figure 6. 23 Determination of critical wall resistance for YL-3 and YL-4 failure modes as a

function of parameter $(\mathrm{n})$ 356

Figure 6. 24 Possible yield-line patterns at exterior location 358

Figure 6. 25 Ultimate resistance of barrier wall by trapezoidal failure pattern for YL-2 and YL-3

Figure 6. 26 View of Standard CHBDC PL-3 and PL-2 traffic barriers 361

Figure 6. 27 Graphs of critical wall lateral resistance, $R_{w}$, as a function of bar vertical and horizontal spacing in PL-3 and PL-2 barriers at interior location 361

Figure 6. 28 Graphs of critical wall lateral resistance, $R_{w}$, as a function of bar vertical and horizontal spacing in PL-3 and PL-2 barriers at exterior locations 
Figure 6. 29 Graphs of critical yield line length, $L_{c}$, as a function of bar vertical and horizontal spacing in PL-3 and PL-2 barriers at interior locations 362

Figure 6. 30 Graphs of critical yield line length, $L_{c}$, as a function of bar vertical and horizontal spacing in PL-3 and PL-2 barriers at exterior locations 363

Figure 6. 31 Bending moment resistant of barrier wall along the diagonal yield-line at exterior location 366

Figure 6. 32 Bending and twisting moment resistances across a diagonal yield-line................ 366

Figure 6. 33 Critical perimeter of punching shear zone in steel-reinforced barriers . 371

Figure 7. 1 Selected barrier models for numerical analysis 376

Figure 7. 2 The Drucker-Prager hyperbolic plastic flow function (Adopted; Hibbitt et al. 2011) 382

Figure 7. 3 Truss bar element 384

Figure 7. 4 Typical stress-strain curve of concrete in tension and compression 389

Figure 7. 5 Graphs of tension stiffening response of concrete 393

Figure 7. 6 Hognestad parabolic pre- and post-peak concrete compression response. 394

Figure 7. 7 Graphs of concrete response in compression 395

Figure 7.8 Graph of true stress vs. plastic strain for steel reinforcement 396

Figure 7. 9 Barrier Model 1 showing boundary conditions and the applied pressure load 397

Figure 7.10 View of TTI barrier model at interior location showing boundary conditions and transverse applied pressure load 398

Figure 7. 11 View of TTI barrier model at exterior location showing boundary conditions and transverse applied pressure load 399

Figure 7. 12 Barrier models with finite element meshing 401

Figure 7. 13 Geometry of modelled barriers with rebar arrangements in the deck and the wall 403 Figure 7. 14 FE modeling of load-deformation response of barrier Model 1 by linear analysis and comparison with experimental results and manual calculations. 405

Figure 7. 15 Load-displacement response of the barrier model with variable concrete tensile cracking strength..... 406

Figure 7. 16 Geometric variation of the headed-end anchor 407

Figure 7. 17 Variation of head anchor diameter on FE modeling results 407 
Figure 7. 18 Stresses and strains developed in the reinforcing bars 408

Figure 7. 19 Influence of dilation angle on the load-displacement response of tested barrier Model 1 and comparison with the experiment. 409

Figure 7. 20 Induced crack patterns in the modeling compared with experimental cracks........ 412

Figure 7.21 Cracking surface range in the wall and deck portions of the barrier model.......... 412

Figure 7.22 Mesh refinement study on the barrier Model 1 ............................................. 413

Figure 7. 23 Influence of concrete tensile cracking on the barrier response .......................... 416

Figure 7. 24 Influence of dilation on the barrier response at TTI interior location .................. 417

Figure 7.25 Lateral deformation of the TTI barrier model at interior location....................... 418

Figure 7.26 Maximum principal strains in reinforcing bars at interior location..................... 419

Figure 7.27 Concrete compressive strains at back of the barrier model at interior location ..... 419

Figure 7.28 Barrier overall failure criterion compared with the experiment at interior location

Figure 7.29 Flexural, diagonal and punching shear crack mappings of the barrier model at interior location 422

Figure 7. 30 Punching shear failure pattern of the barrier wall at back face 422

Figure 7. 31 Induced cracked surface in the barrier model at interior location 423

Figure 7. 32 Mesh refinement study on the TTI barrier at interior location 424

Figure 7. 33 Influence of mesh element size on the barrier response at interior location 424

Figure 7. 34 Influence concrete cracking strength on the barrier model at exterior location ..... 426

Figure 7. 35 Influence of dilation angle on the barrier response at exterior location 427

Figure 7.36 Lateral deformation of barrier model at exterior location 428

Figure 7. 37 Stresses and strains in the reinforcement at exterior location of the barrier model 429 Figure 7. 38 Concrete compressive strains at back of the barrier model at exterior location..... 429 Figure 7.39 Barrier overall failure criterion compared with the experiment at exterior location

Figure 7. 40 Flexural, diagonal and punching shear crack mappings of the barrier model at exterior location 432

Figure 7. 41 Punching shear failure pattern of the barrier at back face 432

Figure 7. 42 Crack patterns at corner joint of the exterior location of the barrier model 433 Figure 7. 43 Mesh refinement study on the TTI barrier at exterior location ..... 434 
Figure 7. 44 Influence of mesh element size on the barrier response at exterior location......... 434

Figure 7. 45 Induced cracked surface in the barrier model at exterior location ...................... 435 


\begin{tabular}{ll} 
& \multicolumn{1}{c}{ Abbreviations } \\
AASHTO & American Association of State Highway and Transportation Officials \\
AFRP & Aramid Friber Reinforced Polymer \\
ACI & American Concrete Institute \\
AS-3600 & Austrailian Code \\
ASTM & American Society of Testing and Materials \\
CHBDC & Canadian Highway Bridge Design Code \\
CDP & Concrete Damaged Plasticity \\
CSA & Canadian Standards Association \\
CSC & Concrete Smeared Crackig \\
FDOT & Florida Department of Transportation \\
FRP & Fiber Reinforced Polymer \\
GFRP & Glass Fiber Reinforced Polymer \\
HIIFP & Highway Infrastructure Innovation Funding Program \\
HM & High Modulus \\
JSCE & Japanese Society of Civil Engineering \\
LRFD & Load and Resistance Factor Design \\
LVDT & Linear Variation Displacement Transducer \\
MASH & Manual for Assessing Safety Hardware \\
MTO & Ministry of Transportation of Ontario \\
NCHRP & National Cooperative Highway Research Program \\
OCE & Ontario Centre of Excellence \\
PL-2 & Performance Level 2 \\
PL-3 & Performance Level 2 \\
POT & Potentiometer \\
RCCAO & Residential and Civil Construction Alliance of Ontario \\
SM & Standard Modulus \\
STM & Strut and Tie Model \\
TL-4 & Test Level 4 \\
TL-5 & Test Level 5 \\
TTI & Texas Transportation Institution \\
&
\end{tabular}




\section{List of Symbols}

$\mathrm{AADT}_{1}$ Average annual daily traffic for the first year after the construction

$\mathrm{A}_{\mathrm{F}} \quad$ Area of FRP bar

$\mathrm{A}_{t} \quad$ Area of transverse reinforcement which is vertically arranged to the assumed splitting failure surface

$\mathrm{A}_{\mathrm{tr}} \quad$ Area of transverse reinforcement normal to the plane through the anchored bars

$\mathrm{B}_{\mathrm{e}} \quad$ Barrier exposure index

b The width of barrier wall over which diagonal tension crack

$b_{o}, 0.5 \mathrm{~d}$ The critical perimeter length measured at $0.5 \mathrm{~d}$ from the loading patch

d Effective slab depth

$\mathrm{d}_{\mathrm{F}} \quad$ FRP bar diameter

C The lesser of the cover to the center of the bar or (1/2) of the center-to-center spacing of the bars being developed

$\mathrm{C}_{\mathrm{d}} \quad$ Compression force in the deck

$\mathrm{C}_{\mathrm{w}} \quad$ Compression force in the wall

$\mathrm{E}_{\mathrm{F}} \quad$ Modulus of elasticity of FRP bars

$\mathrm{E}_{\mathrm{S}} \quad$ Modulus of elasticity of steel bars

$\mathrm{E}_{\mathrm{t}} \quad$ Modulus of elasticity of transverse reinforcement

$\mathrm{E}_{\mathrm{o}} \quad$ Standard modulus of elasticity

F Constant value determined by curve fitting for Malvar model

$f_{\text {bod }}$ Desing bond strength of concrete

$f_{c r} \quad$ Flexural cracking strength of concrete

$f_{c t} \quad$ The tensile cracking strength of concrete

$\mathrm{f}_{\mathrm{cu}} \quad$ The concrete cube strength

$\mathrm{F}_{\text {diag. }}$. The transverse load applied to the wall due to diagonal tension cracks

$\mathrm{F}_{\mathrm{F}} \quad$ Stress in the FRP bar

$f_{f u} \quad$ Design strength of FRP bars at ultimate

$\mathrm{f}_{\mathrm{r}} \quad$ Concrete modulus of rupture

$f t \quad$ Tensile concrete strength

$\mathrm{F}_{\mathrm{t}} \quad$ Nominal transverse wall resistance 
$f_{\mathrm{y}} \quad$ Yield stress of steel bars

$\mathrm{f}_{\mathrm{c}}^{\prime} \quad$ Concrete compressive strength

$\mathrm{f}_{\mathrm{ck}}^{\prime} \quad$ Concrete compressive strength

G Constant value determined by curve fitting for Malvar model

$\mathrm{H} \quad$ Height of barrier wall

$\mathrm{I}_{\mathrm{cr}} \quad$ Cracking moment of inertia

$\mathrm{I}_{\mathrm{e}, \mathrm{d}} \quad$ Effective moment of inertia in the deck

$\mathrm{I}_{\mathrm{g}} \quad$ Goss moment of inertia

J Deformability Factor

$\mathrm{K}$ The calibration factor given 10 for cast-in place steel headed anchors

$\mathrm{K}_{1} \quad$ Bar location factor

$\mathrm{K}_{2} \quad$ Concrete density factor

$\mathrm{K}_{3} \quad$ Bar size factor

$\mathrm{K}_{4} \quad$ Bar fiber factor

$\mathrm{K}_{5} \quad$ Bar surface profile factor

$\mathrm{K}_{\mathrm{tr}} \quad$ Transverse reinforcement index

L The length of yield-line or its projected length onto the axis of rotation for that region

$\mathrm{L}_{\mathrm{c}} \quad$ Critical length of yield-line failure pattern

$\mathrm{L}_{\mathrm{d}} \quad$ Embedment length of the bar in concrete

$\mathrm{L}_{\mathrm{dc}} \quad$ The length of diagonal tension crack in the corner joint

$\mathrm{L}_{\mathrm{db}} \quad$ Basic development length of bar in concrete

$\mathrm{L}_{\mathrm{t}} \quad$ Longitudinal length of distribution of impact force

$\mathrm{M}_{\mathrm{b}} \quad$ Flexural resistance of the cap beam

$\mathrm{M}_{\mathrm{c}} \quad$ Flexural resistance of the wall about itd horizontal axis

$\mathrm{M}_{\mathrm{d}} \quad$ Flexural moment in the deck

$\mathrm{M}_{\mathrm{d}, \mathrm{cr}} \quad$ Cracking moment in the deck

$\mathrm{M}_{\mathrm{IF}} \quad$ Moment intensity factor

$\mathrm{M}_{\mathrm{s}} \quad$ the moment capacity at service load

$\mathrm{M}_{\mathrm{t}} \quad$ The ultimate torsional resisting moment normal to the direction of the diagonal yield-line

$\mathrm{M}_{\mathrm{u}} \quad$ The ultimate moment capacity of the section

$\mathrm{M}_{\mathrm{w}} \quad$ Flexural resistance of the wall about its vertical axis 
$\mathrm{M}_{\alpha} \quad$ The ultimate resisting moment per length along the diagonal yield-line

$\mathrm{m}$ Moment of resistance of slab per meter run represented by the reinforcement crossing the yield-line

$\mathrm{N} \quad$ External load acting within particular region

$\mathrm{N}_{\mathrm{br}} \quad$ Tensile Concrete Breakout Capacity

$\mathrm{N}_{\mathrm{pr}} \quad$ Anchor Pullout Capacity

$\mathrm{N}_{\mathrm{sbr}} \quad$ Concrete Side Face Blowout

$\mathrm{N}_{\mathrm{sr}} \quad$ Tensile Resistance of Steel Anchor

$\mathrm{n} \quad$ Number of bars being developed or spliced

$\mathrm{p} \quad$ Curve fitting parameter for mBPE model (Eq. 2.28)

$\mathrm{R}_{\mathrm{w}} \quad$ Total transverse resistance of the barrier wall

$\mathrm{s} \quad$ Spacing of transverse reinforcement

S slip of bar in concrete (Eq. 2.19)

$\mathrm{S}_{\mathrm{le}} \quad$ The actual loaded-end slip of the bar

$\mathrm{S}_{\mathrm{m}} \quad$ The measured slip captured by LVDTs

$\mathrm{S}_{\mathrm{r}} \quad$ Curve fitting parameter for CMR model

$\mathrm{S}_{1} \quad$ The slip corresponding to the maximum bond stress

$\mathrm{T}$ The tensile force acting perpendicular to the diagonal crack

$\mathrm{T}_{\mathrm{IF}} \quad$ Tensile force intensity factor

$\mathrm{U}_{\mathrm{b}} \quad$ The internal work done by the cap beam

$\mathrm{U}_{\mathrm{c}} \quad$ The internal work done by vertical reinforcement

$\mathrm{U}_{\mathrm{i}} \quad$ The total internal work by rotating yield-lines

$\mathrm{U}_{\mathrm{w}} \quad$ The internal work done by horizontal reinforcement

$\mathrm{V}$ The coefficient of variation

$\mathrm{V}_{\mathrm{c}} \quad$ Punching shear strength

$\mathrm{W}_{\mathrm{cr}} \quad$ Crack width of FRP reinforced structure

$\mathrm{W}_{\mathrm{E}} \quad$ External work done

$\alpha \quad$ Bar location factor (Eq. 2.8)

$\alpha \quad$ Curve fitting for BPE model (Eq. 2.19)

$\alpha_{2}$ Modification factor for bond strength of FRP

$\beta \quad$ Curve fitting parameter for CMR model 
$\beta_{\mathrm{c}} \quad$ The ratio of long side to short side of the concentrated load or loading patch

$\theta \quad$ The rotation of the region about its axis of rotation

$\gamma_{c} \quad$ Characteristic value for the concrete compressive strength

$\lambda \quad$ Concrete density factor

$v \quad$ Efficiency factor (Eq. 4.28)

$\Delta_{\text {elong }}$ Elongation of the bars between concrete surface and point of attachment of the LVDT

$\delta \quad$ The vertical displacement of applying external load

$\sigma \quad$ The confining axisymmetric radial pressure

$\tau \quad$ Average bond stress

$\tau_{1} \quad$ The maximum bond stress

$\tau_{\text {avg }}$ The average bond strength

$\tau_{\mathrm{chr}}$. Characteristic bond stress

$\varphi_{c} \quad$ The concrete resistance factor

$\rho_{\mathrm{f}} \quad$ The FRP tensile reinforcement ratio

$\varepsilon_{\mathrm{s}} \quad$ The tensile strain in the tension tie

$\varepsilon_{s h} \quad$ The strain at strain hardening

$\varepsilon_{u} \quad$ The ultimate strain

$\varepsilon_{y} \quad$ Yield strain of the reinforcement

$\varepsilon_{t}^{c k} \quad$ Cracking strain in concrete in tension

$\varepsilon_{\mathrm{t}} \quad$ Total concrete strain in tension

$\varepsilon_{0 t}^{e l} \quad$ Elastic strain of the undamaged materials in tension

$\varepsilon_{t}^{p l} \quad$ Plastic strain of concrete in tension

$\varepsilon_{c}^{i n} \quad$ Inelastic strain of concrete in compression

$\varepsilon_{\mathrm{c}} \quad$ Total strain of concrete in compression

$\varepsilon_{0 c}^{e l} \quad$ Elastic strain of concrete in compression

$\varepsilon_{c}^{p l} \quad$ Plastic strain of concrete in compression

$\psi_{\mathrm{u}} \quad$ The ultimate curvature

$\psi_{\mathrm{s}} \quad$ The curvature at service load 


\section{Chapter I}

\section{Introduction}

\subsection{General}

The Residential and Civil Construction Alliance of Ontario, Canada, (RCCAO, 2007) announced a report on Ontario bridges in November 2007 called "Ontario's Bridges: Bridging the Gap". It was stated that the Ontario bridges are delayed over the years for regular maintenance, inspections and lack of government oversight. Also, the report on the bridge failures in Laval, Quebec and Minneapolis, Minnesota, has underlined the deferred maintenance of such bridges in rehabilitating or reconstructing of the deteriorated bridges and the necessities to take timely actions to protect the public safety. The investigations on Ontario bridges have also shown that they were built in 1950 s and 1960s so that most of them will require costly rehabilitations and maintenance after 50 years of service life. Most bridges built prior to 1970s, did not include airentrained concrete or use coated bars to maintain reinforcement from corrosion due to freeze and thaw effects or deterioration by de-icing salt. Such deficiencies caused degradation in bridge decks and bridge barriers due to corrosion of steel reinforcement. Therefore, the main candidates for the costly replacement are bridge decks, railings and barrier walls. Based on RCCAO report, it was recommended that to develop the public safety and sustainability of bridges in Ontario, bridge engineering designs should be extended to promote the life expectancy and reduce the maintenance costs of bridges. This can be achieved by using non-corrosive Glass Fiber Reinforced Polymer (GFRP) bars. The use of GFRP bars with its corrosion resistant nature in lieu of steel bars will eliminate corrosion related problems resulting from the use of deicing salt in winter times and increase the service life of the structure.

\subsection{The Dilemma and Need for the Research}

Bridge barriers made of steel reinforced concrete normally suffer from corrosion of steel bars by de-icing salt. As a result, constant repair and maintenance is needed to enhance the life cycle of 
these barrier walls. An alternative approach is to replace the steel bars with non-corrodible glass fiber reinforcing bars known as GFRP. For construction of new barriers, their reinforcing steel bars need to be anchored to the deck slabs. Anchorage system for concrete are comprised of preinstalled or cast-in-place anchors. A cast-in-place anchor, as shown in Figure 1.1a for new construction, is typically composed of GFRP bars with straight ends, $\mathrm{J}$ bents or headed ends. The behavior of pre-installed GFRP anchors in concrete barriers has been extensively investigated as shown in the following chapters. However, very few investigations studied the behavior of preinstalled anchors using GFRP bars, especially with the presence of headed ends shown in Figure 1.1b. The sand-coated GFRP bars provide means to increase the bond behavior between concrete and the bars. This bond behavior expects to increase with the presence of headed-ends compared to the conventionally straight end bars. However, in accordance with Canadian Highway Bridge Design Code (CHBDC) clause 12.4.3.5 (CSA, 2006a), the appropriateness of anchorage system in bridge barrier wall should be based on its performance under vehicular crash testing. The suitability of anchorage system should be such that significant damage shall not occur both in anchorage system or deck during crash testing. Thus, CHBDC requires the performance of crash testing on prototype bridge barrier wall segments using GFRP bars to examine its suitability in resisting shear force and flexural moment. If crash testing results for anchorage systems are not available, the adequacy of a barrier that has the same details as those of an existing barrier may be determined by evaluating the existing barrier's performance when struck by vehicle (CHBDC clause 12.4.3.1). In addition, CHBDC clause 12.4.3.4.4 requires the crash test for longitudinal barrier test levels 2, 4 and 5 of National Cooperative Highway Research Program (NCHRP) report 350 shall be that to meet the crash test requirements for performance levels 1,2 and 3 , respectively. However, CHBDC requires that if crash testing of barriers and anchorage system are not available, the design of anchorage and deck system shall be such that to resist the maximum bending moment and shear force transfer to them at the barrier-deck interface. Thus, the current research investigates the ultimate load carrying capacities of bridge barriers reinforced with sand-coated GFRP bars with headed-end anchorage system under static load testing till complete collapse of the barriers.

The American Associsation of State Highway Officials (AASHTO, 2004) specified a triangular yield-line pattern on the barrier wall to determine its resisting transverse force to the equivalent 
impact force. Literature review showed no experimental basis for this triangular yield-line pattern. Therefore, experimental testing on actual scale PL-3 and PL-2 barriers was conducted to determine the actual crack pattern at failure under static transverse load. Then, modification calculations will be performed to determine more accurate resisting force to the equivalent vehicle impact force.

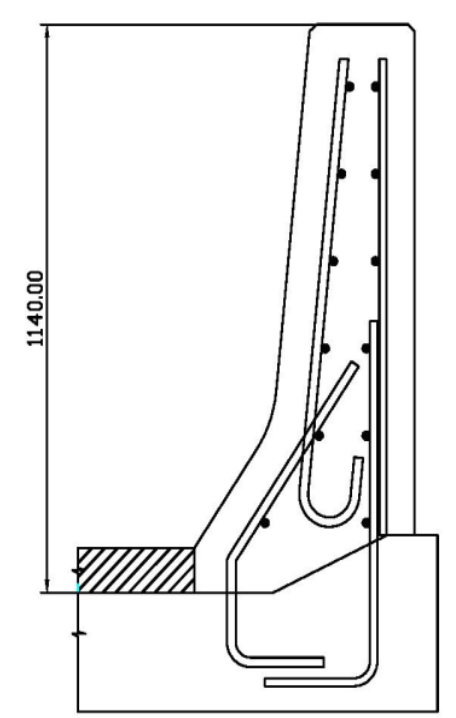

a) Anchorage with $\mathrm{J}$ bents

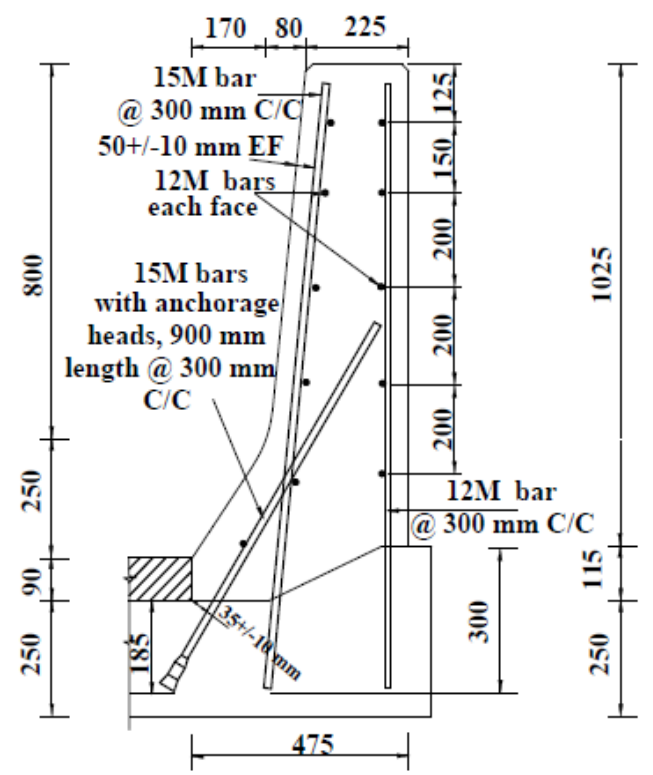

b) Proposed anchorage with straight bars and bars With headed-ends

Figure 1. 1 PL-3 GFRP-reinforced bridge barrier detailing for new constructions

\subsection{Research Objectives}

The objective of the proposed research project is to develop an accurate design procedure for PL3 and PL-2 barrier walls reinforced with steel or GFRP bars. Specific objectives of this research are:

1. To investigate experimentally mechanical properties of GFRP bars under direct monotonic pullout testing. The purpose of this phase of research is to examine bond behavior of GFRP bars embedded into concrete deck slabs and concrete cubes. The ultimate goal is to determine the anchorage length requirements to sustain pullout load resulting from vehicle impact to bridge barriers.

2. To conduct experimental testing to-complete-collapse on the developed PL-3 barrier walls reinforced with GFRP bars to correlate their static ultimate load carrying capacities 
with the factored design loads specified in the CHBDC and to examine crack and failure patterns and load-deformation behavior.

3. To perform experimental testing to-complete-collapse on PL-2 and PL-3 barrier walls reinforced with steel reinforcement and investigate their static ultimate load carrying capacities, crack pattern and failure modes with those specified in AASHTO-LRFD specifications.

4. To conduct linear elastic finite-element analysis on PL-2 and PL-3 bridge barriers to investigate the effect of geometrical variations on factored transverse moment developed at base of the wall as well as factored tensile force developed in the deck slab.

5. To conduct non-linear explicit finite-element (FE) modeling on the experimentally tested PL-3 bridge barrier reinforced with GFRP bars at interior and exterior locations by using ABAQUS software (Hibbitt et al., 2011) to validate FE modeling with experimental test results.

\subsection{Scope of the Research}

The proposed research will include the tasks described in the following subsections.

\subsubsection{Literature survey}

The first step in developing a new barrier system would be to review and document foreign and domestic information on the state-of-the-art in pullout development of FRP bars in concrete, barrier structural design, rebar detailing, static testing of bridge barriers, and computer simulation.

\subsubsection{Pull-out tests on GFRP bars anchored to concrete}

This task deals with testing to-collapse different scenarios of anchorage of GFRP bars into concrete blocks. These scenarios include the following parameters:

- Embedment length;

- Bar size;

- Concrete strength; and

- Headed end versus no heads and bend bars. 
Concrete slabs containing single GFRP bars with variable bar size, embedment depth and concrete strength have been built at Ministry of Transportation of Ontario (MTO) site. In addition, concrete cubes have been constructed at Ryerson University structural laboratory with the same test variables as the concrete slabs. Pullout tests have been conducted on each bar and results were analyzed. The objective of these tests was to investigate all possible types of anchorage failure modes, including pullout, bar slippage from concrete, and concrete or bar breakage. In this phase, concrete slabs were cast with a thickness of $300 \mathrm{~mm}$. Steel reinforcement were laid down in the slab and GFRP bars were placed vertically prior to casting concrete. In accordance with the ASTM E-488-96 (ASTM, 1996) requirements, a test setup was proposed as shown in Figure 1.2 to test the pre-installed GFRP anchors. It should be mentioned that all pullout slab tests have been conducted on the MTO site in actual atmospheric conditions. For specimens failing by concrete breakout, the experimental results were compared to the steel bar pullout capacity specified in ACI-349-01 (ACI, 2001) and CSA A23.04 (CSA, 2004) and the concrete capacity design (CCD) predication equations that are being used for steel anchors (Fuchs et al., 1995). It should also be noted that bar sizes considered in this study are 16 and 19 $\mathrm{mm}$, representing GFRP bars typically used in PL-2 and PL-3 barriers, respectively. The embedment lengths were taken as 100, 150 and 200-mm with concrete strength of 30 and 35 MPa representing the commonly used concrete for reinforced concrete and precast concrete deck slabs in Ontario, respectively. To reach more reliable and realistic data, five identical specimens were tested for each parameter, and probability analysis has been performed on the experimental findings to determine the characteristic bond strength based on the variation of the number of tested specimens and the change in strength values as compared to the mean bond strength. The testing machine for pullout tests were capable of applying tensile force to GFRP bars at a rate not greater than 22,000 N/min. Additionally, in accordance with Annex D and H of CSA-S806 (2012), the bond behavior and development length of GFRP bars were further examined using concrete cubes in order to compare the test results with those obtained from bond strength testing on concrete slabs. The concrete cubes of 150, 200 and 300-mm widths have been built at Ryerson University structural laboratory with GFRP bars placed vertically at center of the cubes. The cubes were then tested under increasing monotonic loading until failure. Various test failure modes have been investigated and the ultimate loads and bond-slip relationship have been compared with those of GFRP bars embedded into concrete slab. 


\subsubsection{Testing to complete collapse of the proposed barrier system}

The primary objective of this static testing was to correlate the ultimate load carrying capacity of the proposed GFRP barrier walls with the CHBDC factored design loads and investigate the failure pattern and load-deformation behavior. Five barrier walls (Figure 1.3) were erected at Ryerson University structural laboratory and tested under increasing monotonic loading up tocomplete-collapse. Five full-scale tests were conducted as follows:

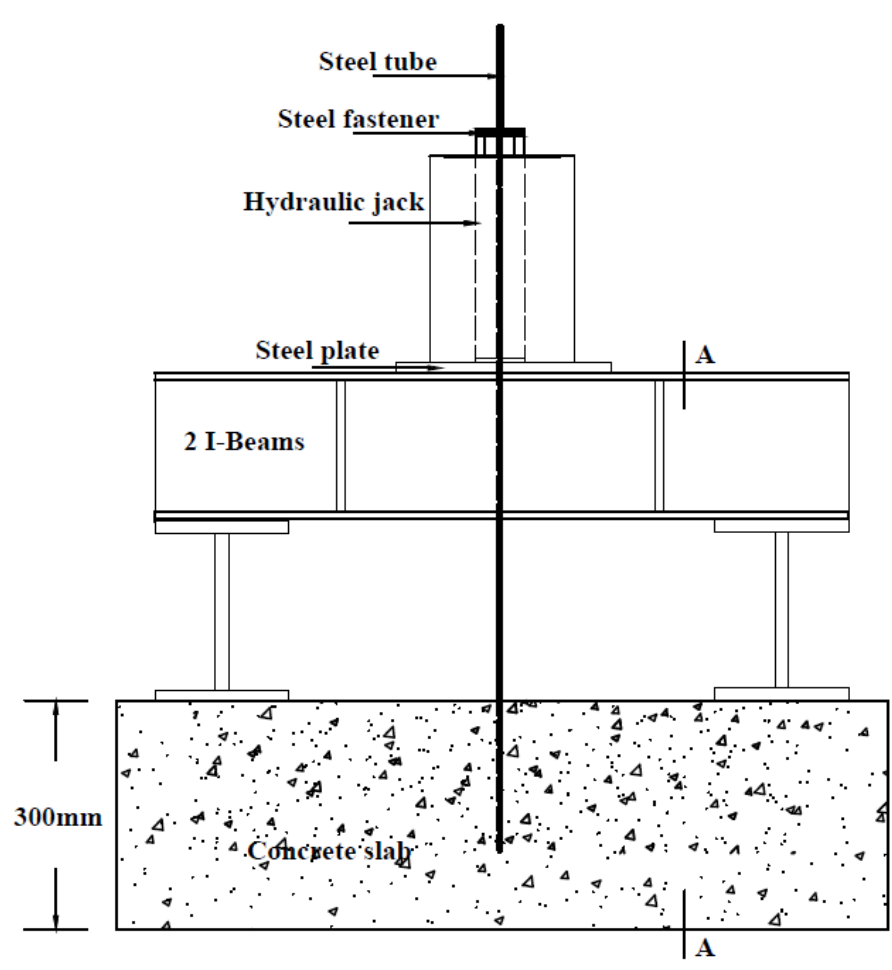

Elevation

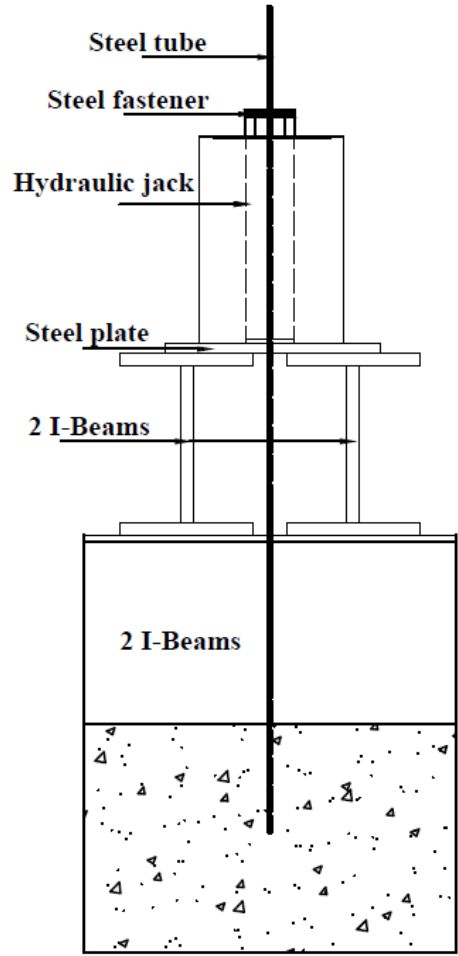

Section A-A

Figure 1. 2 Pullout test setup for specimens placed into concrete slab

1- The first and fourth specimens represent PL-3 barrier wall in which a 1.0-m lateral line load was applied horizontally near the top of the barrier wall. This failure test was intended to examine the flexural capacity of the junction between barrier wall and the deck slab. The use of High-Modulus (HM) GFRP bars with headed-end anchors was investigated (Figure 1.3a).

2- The second specimen represents a PL-3 barrier wall and a line load of 1.0-m applied near the top of the barrier wall. In this series, the use of Standard Modulus (SM) GFRP bars with bent was investigated (Figure 1.3b). 
3- The third specimen represents a PL-3 barrier wall and a line load over a length of 1.0-m applied at top of the barrier wall to examine its load carrying capacity, while the use of lowmodulus GFRP bars with 180'-hook was investigated (Figure 1.3c).

4- The fifth specimen represents a PL-3 barrier reinforced with conventional steel bars on which a line load of 1.0-m applied near the top of the barrier. This series of barrier represents a reference barrier to compare the results with those of GFRP-reinforced barriers (Figure $1.3 \mathrm{~d})$.

Figure 1.4 shows schematic diagram of the proposed laboratory test setup. Each barrier specimen was supported over the structureal laboratory floor, then, tied down to the floor using 50-mm diameter threaded rods. SYSTEM 6000 data acquisition unit was used to record readings from all sensors.

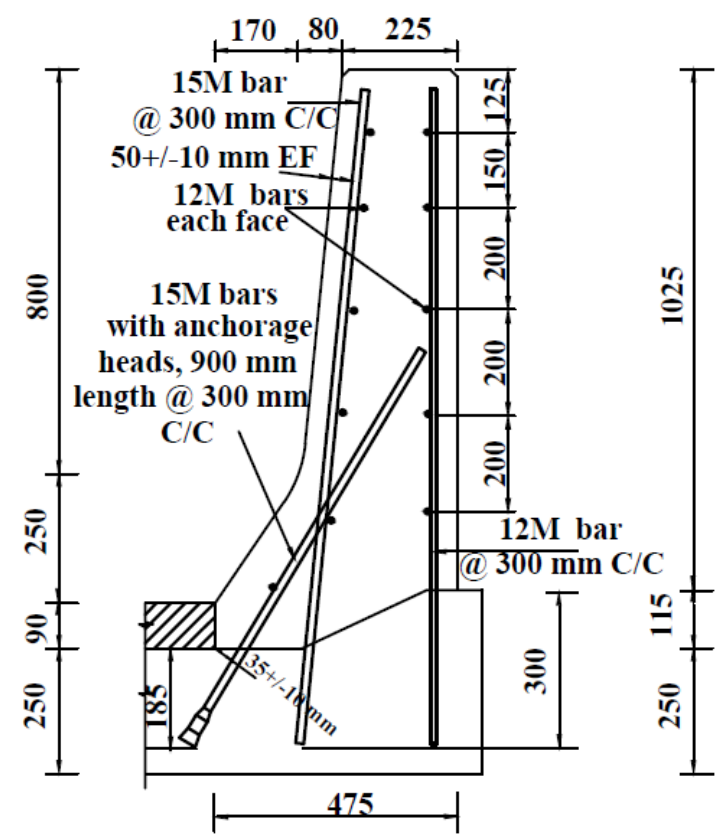

(a) Barrier model 1and 4

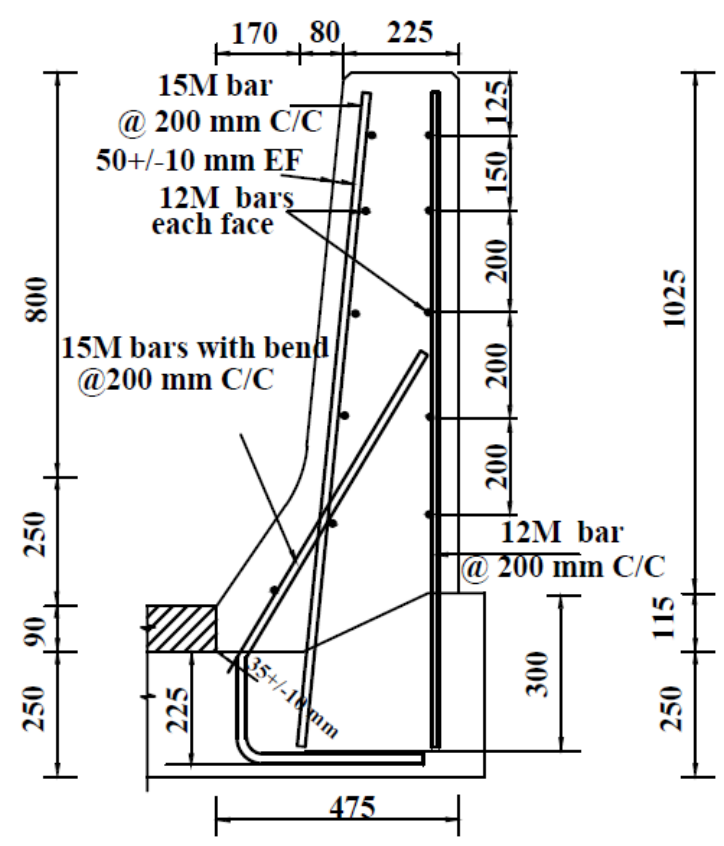

(b) Barrier model 2 


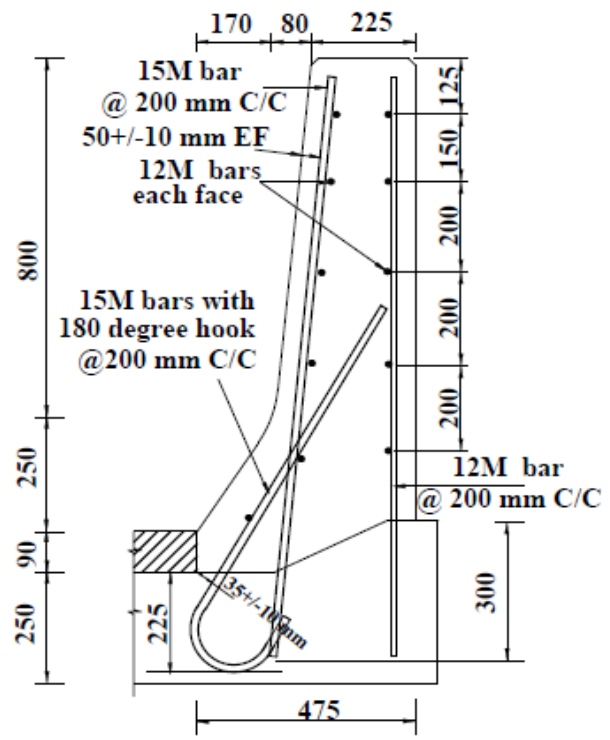

(c) Barrier model 3

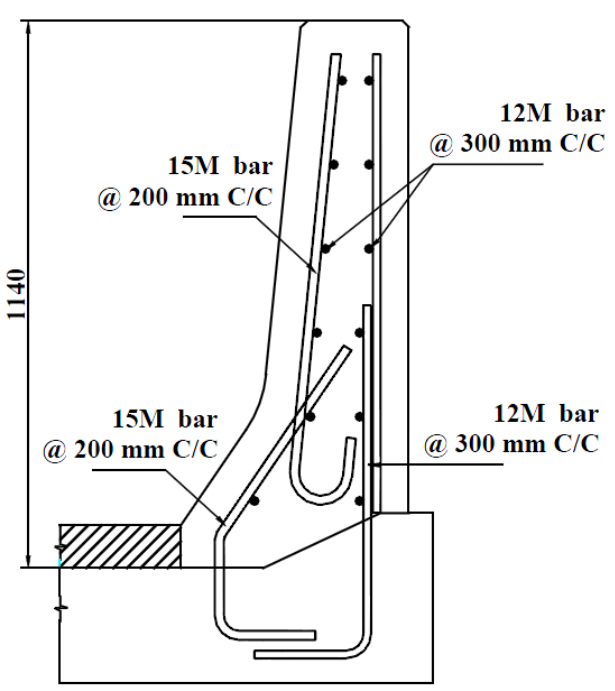

(d) Barrier model 5

Figure 1. 3 View of proposed barrier walls (a) with headed-end GFRP HM bars, (b) with PL-3 bent GFRP bars, (c) with $180^{\circ}$ hook GFRP bars and (d) reference model with steel bars

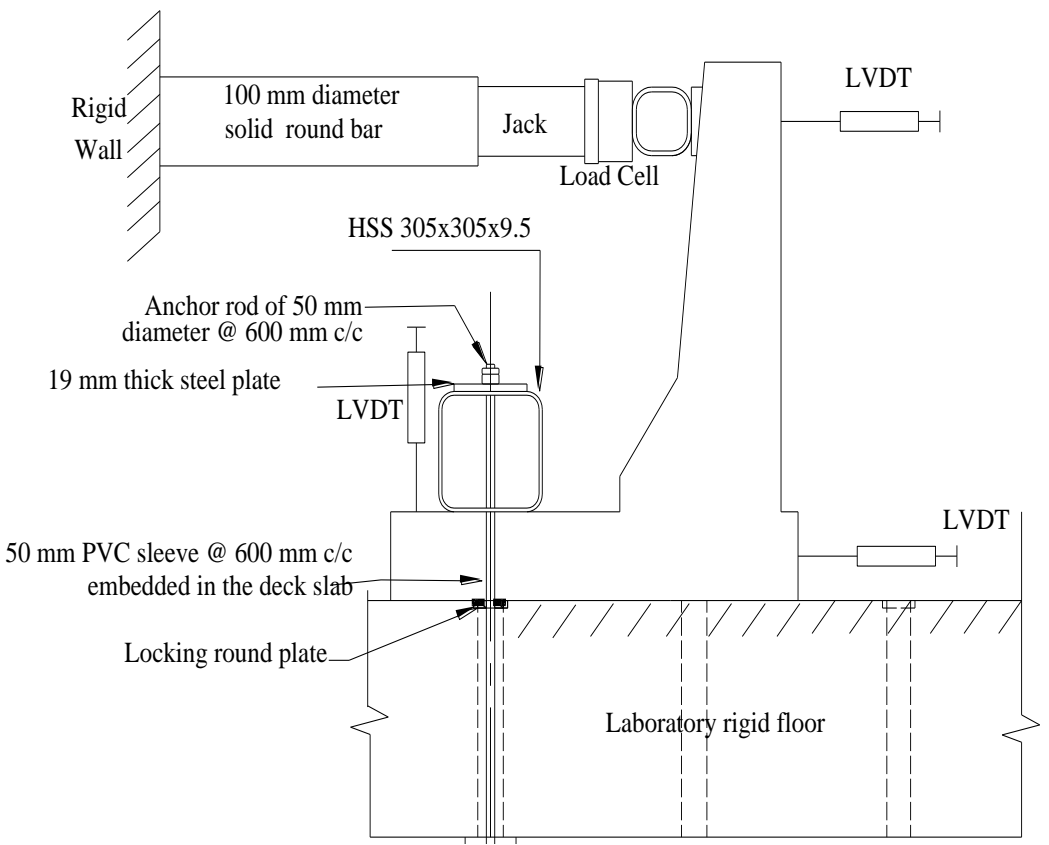

Figure 1. 4 Schematic diagram of static test setup of the traffic barriers 


\subsubsection{Static Load Testing on GFRP-Reinforced Concrete Barrier wall}

The 27.6-m long barrier wall built at Texas Transportation Institution (TTI) was tested monotonically up-to-failure under static load. The primary objective of the static testing was to examine the validity and application of the connection between barrier and the concrete deck slab to resist the CHBDC design loads and to observe the difference in crack patterns and structural behavior of the proposed barriers system with those specified in the AASHTO-LRFD spercifications. The barrier wall shown in Figure 1.5 was tested statically at interior and exterior locations. In addition, the constructed barrier wall at the TTI was saw-cut to experimentally test the one-way action of the barrier wall through 1.0-m length of the barrier. The high-tech data acquisition system was used to capture data during testing. Patch loads representing vehicle impact with the barrier face was applied using a small-length steel beam with rubber pad to evenly distribute the horizontal concentrated jacking load over a limited wall length to avoid any localized premature failure. Crack patterns and ultimate load carrying capacity were recorded. Three different monotonic load scenarios, as shown in Figure 1.6, were considered as follows:

a. The first test series represents a PL-3 barrier wall that a 1.0-m lateral line load applied horizontally near the top of the barrier wall. This failure test was intended to examine the flexural capacity of the junction between barrier wall and deck slab.

b. The second test series represents a PL-3 barrier wall and a line load over a length of 2.4$m$ applied at the end of the barrier wall to examine its load carrying capacity, which the vehicle impacts the barrier at its end.

c. The third test series represents a PL-3 barrier wall and a line load of 2.4-m applied at the mid-length of the barrier wall.

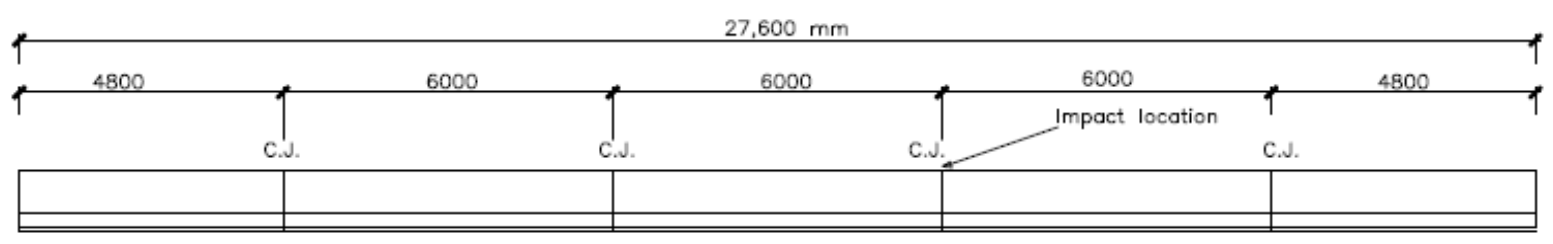

Figure 1. 5 View of barrier wall built at Texas Transportation Institution site 


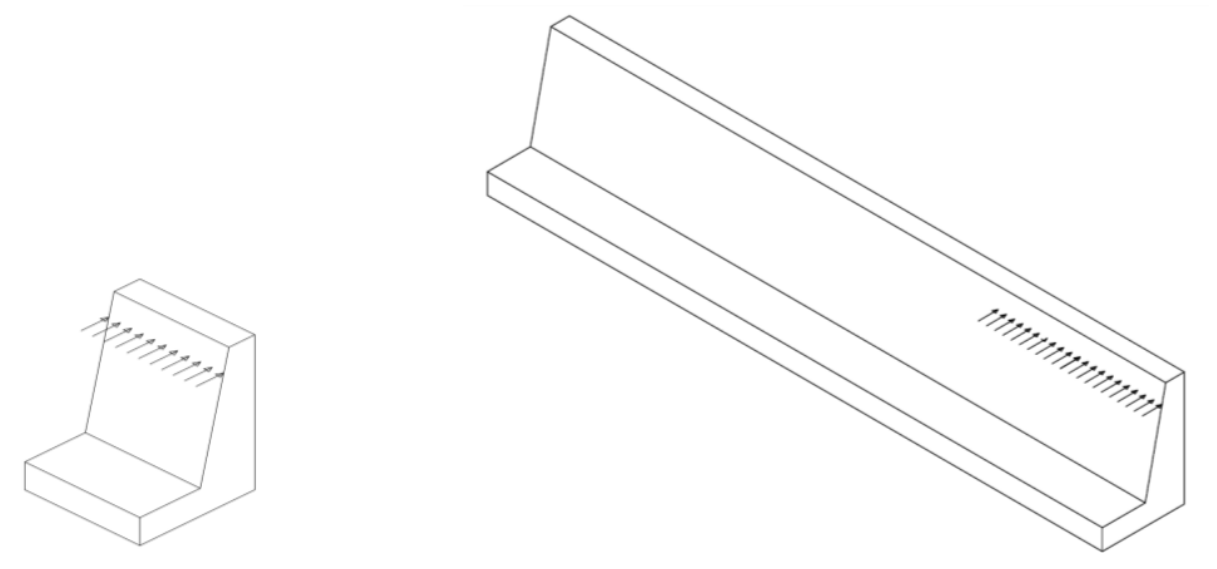

(a) Test 1: PL-3 barrier with 1.0-m line loading

(b) Test 2: PL-3 barrier with 2.4-m end loading

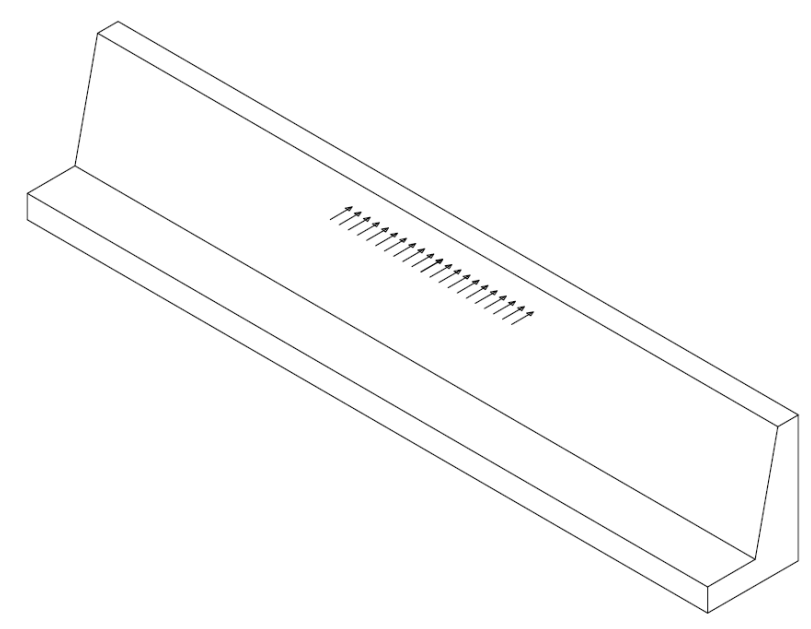

(c) Test 3: PL-3 barrier with 2.4-m central loading

Figure 1. 6 Views of the proposed test specimens for monotonic tests

\subsubsection{Finite-Element Computer Simulation}

CHBDC requires that traffic barrier details conform to those of a traffic barrier that has been successfully crash tested. Traffic barrier crash testing is considered to be successful if the traffic barrier provides adequate protection to the occupants of the vehicle striking the barrier, to other nearby vehicles on the roadway and to people and property beneath the bridge. However, if crash testing of the traffic barriers is not available, the suitability of the traffic barrier can be examined by static test to-complete-collapse. As an alternative, computer simulation tools are increasingly being used for the assessment of overall strength and structural capacity of traffic barriers. Therefore, the author performed finite-element modeling of the tested GFRP barrier wall to validate the experimental test results with computer simulations using ABAQUS software. The 
simulations were first examined on 1.0-m long barrier reinforced with headed-end GFRP bars. The results of FE modeling for this barrier were then used to simulate the actual barrier tested experimentally at TTI site.

\subsection{Significance of the Research}

The candidate has recently initiated a comprehensive research project on static tests of PL-3 bridge barriers reinforced with GFRP bars. The static tests were conducted on a 27.6-m long barrier wall built at TTI site. Given the successful static load tests, MTO has produced standard drawings for the PL-3 barrier with the proposed GFRP bar detailing. In spite of the successful design of the PL-3 barrier, the outcome of this research can be applied only to new construction. The applicant has conducted pullout testing of pre-installed GFRP bars with (i) straight ends, (ii) headed ends and (iii) J-bents. The results of the proposed research would be employed in the development of barrier wall-deck slab anchorage length and its applicability to new bridge construction.

\subsection{Content and Arrangement of the Thesis}

Followed by the introduction chapter, chapter II provides most recent literature reviews on pullout strength of GFRP bars in concrete as well as experimental test programs conducted on FRP-reinforced bridge barriers. Chapter III explains the experimental program conducted on single GFRP bars into concrete slabs and concrete cubes and corresponding experimental outcomes. Chapter IV describes experimental program and the results on the proposed smallscale barrier detailing using GFRP bars with headed-end, $180^{\circ}$ hook and bent bars. Also, the analysis results of PL-3 bridge barriers by strut and tie model were presented. The linear-elastic finite-element analysis on selected PL-2 and PL-3 was investigated for the effects of variable geometry on tensile and moment capacities in the deck slab. Chapter V presents results of the experimentally tested full-scale PL-3 barrier reinforced with GFRP-HM bars under static load testing. Chapter VI presents extended research programs and the results on steel-reinforced PL-2 and PL-3 bridge barriers subjected to static load testing. Chapter VII provides non-linear finiteelement modelling of GFRP-reinforced bridge barrier to correlate its results with experimental test results for future research. Chapter VIII presents conclusions of the current research 
programs and recommendations for future research studies. Appendices at the end of the thesis include relevant figures and graphs for experimental results and images. 


\section{Chapter II}

\section{Literature Review}

\subsection{General}

Steel and concrete have been widely used in civil engineering structures worldwide and served civil engineering community well, contributed to the safety and success of the developed world over the years. The use of steel-reinforcing bars in reinforced concrete applications is due to its cost-effective, strength and ductility that are known as the well suited materials in civil engineering structures. However, in certain aggressive environment, steel reinforced concrete normally suffers from corrosion of the steel by de-icing salt. As a result, constant repair and maintenance is required to improve the service life of such reinforcing bars. To prevent such deteriorations in reinforced concrete structures, it is presumed the need for new materials that can prolong the life cycle of the structures, while still the design requirements and durability of structures are maintained. More recently, fiber reinforced polymer (FRP) bars have been of significant attention for new structures and being investigated as a suitable alternative to reinforcing steel bars. Over past 20 years, FRPs have emerged as practical materials in many civil engineering structures. FRPs have also been in used over 50 years in automotive and aerospace industries where high tensile strength and lightweight materials are of concern. The more application of FRP materials in civil engineering structures can be attributed to the reduction in overall cost of the structures in addition to other numerous advantages over conventional steel reinforcement. Some of these advantages include: high strength-to-weight ratios, durability in harsh environment, ease of handling and installations, electromagnetic neutrality and low thermal conductivity.

\subsection{Fiber Reinforced Polymer (FRP)}

Fiber-reinforced polymers (FRPs) known as corrosion-related resistant, are assumed to be an alternative to reinforcing steel bars in civil engineering structures to prevent corrosion of steel bars when exposed to harsh environment. Over past decades, various types and configuration of 
FRP materials have been produced and used in many structural applications around the world. The high-tensile strength and light weight applications have made FRPs as attractive materials in building structures or rehabilitation of the existing structures. FRP materials can be manufactured as reinforcing bars, sheets, plates and wraps for constructions of new structures or strengthening and rehabilitation purposes. Figure 2.1 shows view of currently used FRP bars and sheet for reinforcement or rehabilitation of concrete structures. FRPs are known as composite materials that are made of high-strength fibers placed in a polymeric matrix (Figure 2.2). Fibers are extremely strong and stiff that are bonded by matrix enabling to work together as a composite materials. In FRP composite materials, fiber must be a continuous reinforcement which is usually stiffer than the matrix. However, if fibers are not continuous, the volume fraction of fibers should be at least more than 10 percent to provide significant reinforcement function (ACI 440R-96). The most important factors affecting FRP composites may include: fiber mechanical properties, fiber orientations, length, shape and composition of fibers, mechanical properties of resin matrix, and adhesion of the bond between fibers and the matrix. In FRP composites, fibers mostly take most of the applied load, while the matrix acts to bind the fibers and transfer the loads between them. Therefore, since the FRPs are composed of two different materials, their properties tend to be dependent on each of the individual constituent. The role and properties of the matrix and fiber component materials are discussed in the following sections.

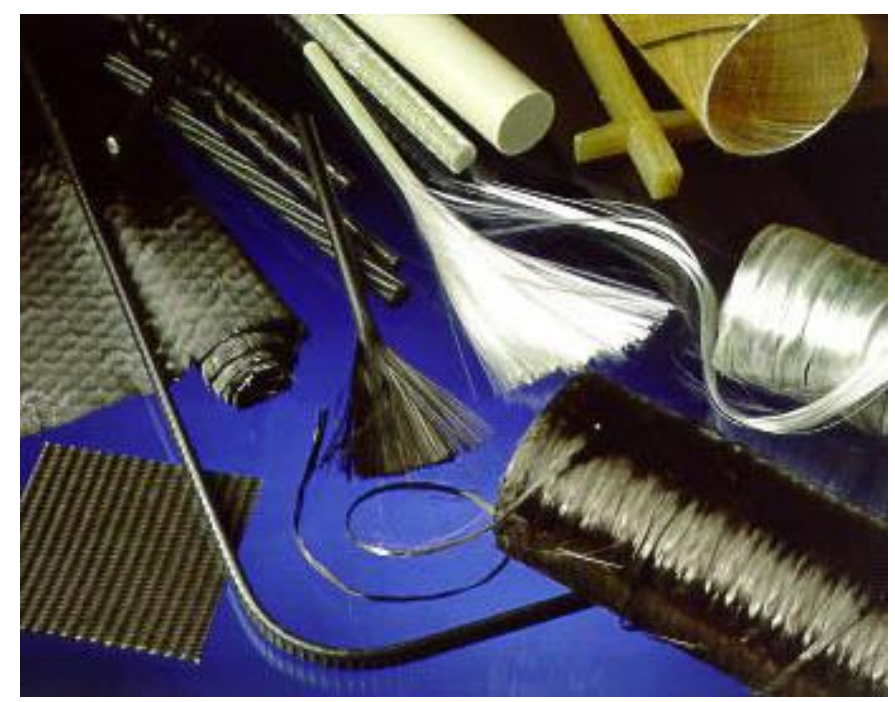

Figure 2. 1 Various types of FRPs for reinforcement and rehabilitating concrete structures (Adopted: ISIS Canada Module 3, 2006) 


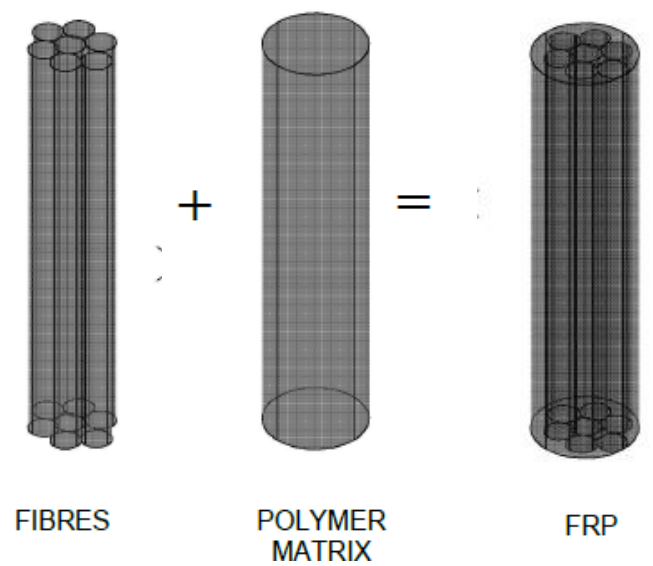

Figure 2. 2 Basic material components of FRP composite

\subsubsection{Polymeric Matrix}

The matrix materials protect and bind the fibers in FRP in such a way that: to keep abrasional and environmental degradation of fibers, to scatter the fibers within the composite, to transfer the load between the fibers, and to be compatible with the fibers under chemical and thermal effects. As such, selection of matrix materials is very important due to the fact that the final mechanical properties and manufacturing process of FRP composites are affected by the physical and thermal properties of matrix. In order to be able to reach full strength of the fibers, the matrix should be able to develop a higher ultimate strain than the fibers (Phillips, 1989). The matrix not only coat the fibers and transfer the loads between them, but also transfer the inter-laminar and in-plane shear in the composite and provide lateral support to fibers against buckling when subjected to compressive forces (ISIS Manual 3, 2007). There are two matrix properties that are widely used in FRP materials namely as: thermoplastic and thermosetting resins. Thermoplastic resins include various polymeric compounds such as polyethylene, nylon and polyamides, while thermosetting resins may include polyesters, vinylesters and epoxies. Brief descriptions of these matrix properties are provided below;

Thermoplastics: are composed from long-chain molecules that are linked together by weak secondary bonds, but maintain extremely strong bonds within individual molecules. In thermoplastics, the molecules are free to slide relative to one another at high temperature, so that they can be reshaped by heating and cooling repeatedly without changing their molecular 
structure. Thermoplastic resins are not often used in civil engineering structures due to inferior thermal and physical properties when compared to thermosetting resins.

Thermosetting: thermosetting polymers are used more often in civil engineering structures. They are composed of long-chain low molecular-weight liquids with very low viscosity that are made from monomers. However, for these polymers the molecular chains are crossed-link through primary chemical bonds. Thermosetting matteirals shape a rigid three-dimensional structure and prevent reshaping by heat or pressure. Therefore, thermosetting polymers cannot be softened and will weaken at high temperatures. However, thermosetting polymers maintain suffcient thermal resistance at service temperatures, adequate chemical resistance and exhibit reduced creep and relaxation properties compared to thermoplastic polymers. As such, due to difficulty to reversibly soften the thermosetting polymers, the bent FRPs must be form during manufacturing process. Some commonly used thermosetting materials in the manufacture of infrastructure composites include: polyesters, vinylesters and epoxies. Due to low cost and ease of processing, polyesters are the mostly used polymers in manufacturing of FRP infrastructure applications. Vinylesters are categorized as a class of polyesters due to their similar processing procedures. Also, due to strong acid and alkalis resistance, they are commonly used for manufacturing of FRP bars for concrete structures. However, vinylesters cost slightly more than polyesters. Epoxies are widely used in wet lay-up applications of FRP sheets and plates. Some of the superior characteristics of epoxies include; high strength, good dimensional stability, relatively good high-temperature properties, strong resistance to chemicals (except acids) and superior toughness. The cost of epoxy resins are significantly more than polyesters and vinylesters. Some of the mechanical properties of these thermosetting resins are provided in Table 2.1.

Table 2. 1 Typical properties of thermosetting resins (Source: ISIS Manual 3, 2006)

\begin{tabular}{|c|c|c|c|c|}
\hline Resin Type & Specific gravity & $\begin{array}{c}\text { Tensile strength } \\
(\mathrm{MPa})\end{array}$ & $\begin{array}{c}\text { Tensile modulus } \\
(\mathrm{GPa})\end{array}$ & $\begin{array}{c}\text { Cure shrinkage } \\
(\%)\end{array}$ \\
\hline Polyester & $1.10-1.40$ & $34.5-103.5$ & $2.1-3.45$ & $5-12$ \\
\hline Vinylester & $1.12-1.32$ & $73-81$ & $3-3.35$ & $5.4-10.30$ \\
\hline Epoxy & $1.20-1.30$ & $55-130$ & $2.75-4.10$ & $1-5$ \\
\hline
\end{tabular}




\subsubsection{Fibers}

Fibers used in the composition of FRP materials must possess high strength, high stiffness and relatively high toughness, durability and preferably low cost. FRPs are known as orthotropic materials due to the fact that fibers used in the construction of FRP applications are continuous and oriented in specific directions in which they are stronger and stiffer in fiber directions. The fibers should generally possess high stiffness, high ultimate strength and low variation of strength between individual fibers and uniform cross-sections. In civil engineering structures, the most commonly used fibers are: glass, carbon and aramid fibers. The suitability of fibers in different applications depends on several factors such as: required strength, stiffness, durability, cost constraint and the availability of component materials.

Glass Fibers: Glass fibers are the most inexpensive fibers used in civil engineering applications that are produced by a process called direct melt, where 3 to 25 micron fibers are formed and drawn from glass melt. There are two types of glass fibers namely as: E-glass as the most common grade and R-glass as the more expensive but stronger fibers. Notable characteristics of glass fibers include: high strength, moderate elastic modulus and density and low thermal conductivity. Since glass fibers are heavier than carbon and aramid fibers, they are used in the structures where weight is not critical so that larger deformation of the structure due to lower modulus of elasticity is not a concern. Glass fibers are ususally used in manufacturing of FRP reinforcing bars, pultruded FRP structural sections, FRP wraps for seismic upgrades and filament wound FRP tubes.

Carbon Fibers: carbon filaments with a diameter ranging between 5 to 8 microns are produced in a process called controlled pyrolysis. There are three sources for carbon fibers: pitch, a byproduct of petroleum distillations, PAN (polyacrylonitrile), and rayon (ACI 440R-96). Formation of carbon fibers requires a processing temperature greater than $1000^{\circ} \mathrm{C}$. At this temperature most synthetic fibers will melt and vaporize except the acrylic fibers that the molecular structures retained under high-temperature carbonization. Carbon fibers are of two types namely: the high modulus Type I and the high strength Type II with a difference in their fiber microstructure. Although carbon fibers are deemed more expensive than glass fibers, their use in civil engineering applications are growing. Some of the physical characteristics of carbon fibers 
includes: high strength, high modulus of elasticity, low density and their outstanding resistance to thermal, chemical and environmental effects. Carbon fibers may be used in some structural engineering applications such as: pre-stressing tendons for concrete, structural FRP wraps for repair and strengthening of reinforced concrete beams, columns and slabs. Due to light weight of carbon fibers compared to glass fibers, they are an ideal choice in the structures where weight or deflections is sensitive.

Aramid Fibers: Aramid fibers with stiffness grades of 60 and $120 \mathrm{GPa}$ can be manufactured from aromatic polyamide by a process known as extrusion and spinning. The notable characteristics of these fibers are: high strength, moderate modulus of elasticity and low density. In addition, FRPs made of aramid fibers have low compressive and shear strengths and are more susceptible to degradation from exposure to ultraviolet radiations and moisture. Thus, the higher cost and durability factors may restrict the use of these fibers in specific applications.

In FRP reinforcing materials, although the strength and stiffness of the FRPs are governed by fibers, the overall mechanical properties depend on several other factors namely as: material properties of polymeric matrix, fiber volume fraction, fiber orientation, fiber cross-sectional area and manufacturing process. Glass and Carbon fibers are the most commonly used fibers in North America. Matrix materials are generally epoxies or vinylesters. Tables 2.2 and 2.3 provide a quantitative comparison of mechanical properties of current available types of fibers.

Table 2. 2 Quantitative comparison of the properties of glass, carbon and aramid fibers (Source: Newhook and Svecova, 2006)

\begin{tabular}{|c|c|c|c|}
\hline \multirow{2}{*}{ Properties } & \multicolumn{3}{|c|}{ Fiber type } \\
\cline { 2 - 4 } & Glass & Carbon & Aramid \\
\hline Tensile strength & Very good & Very good & Very good \\
\hline Modulus of elasticity & Adequate & Very good & Good \\
\hline Long-Term behavior & Adequate & Very good & Good \\
\hline Fatigue behavior & Adequate & Excellent & Good \\
\hline Alkaline resistance & Adequate & Very good & Good \\
\hline Cost & Very good & Adequate & Adequate \\
\hline
\end{tabular}


Table 2. 3 Typical mechanical properties of various fibers (Source: ISIS Manual 3, 2006)

\begin{tabular}{|c|c|c|c|c|c|c|}
\hline & er type & $\begin{array}{c}\text { Tensile } \\
\text { strength } \\
(\mathrm{MPa})\end{array}$ & $\begin{array}{l}\text { Elastic } \\
\text { modulus } \\
(\mathrm{GPa})\end{array}$ & $\begin{array}{c}\text { Elongation } \\
(\%)\end{array}$ & $\begin{array}{l}\text { Coefficient of } \\
\text { thermal expansion } \\
\left(\times 10^{-6}\right)\end{array}$ & $\begin{array}{c}\text { Poisson's } \\
\text { ratio }\end{array}$ \\
\hline & & & & & & \\
\hline & $\begin{array}{l}\text { High } \\
\text { strength }\end{array}$ & 3500 & $200-240$ & $1.3-1.8$ & $(-1.2$ to -0.1$) \alpha_{L^{*}}$ & \\
\hline 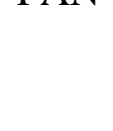 & $\begin{array}{c}\text { High } \\
\text { modulus }\end{array}$ & $2500-4000$ & $350-650$ & $0.4-0.8$ & (7 to 12$) \alpha_{T^{*}}$ & -0.2 \\
\hline & Ordinary & $780-1000$ & $38-40$ & $2.1-2.5$ & & \\
\hline Pitch & $\begin{array}{c}\text { High } \\
\text { modulus }\end{array}$ & $3000-3500$ & $400-800$ & $0.4-1.5$ & $(-1.6$ to -0.9$) \alpha_{\mathrm{L}}$ & N/A \\
\hline & & & & & & \\
\hline & $\operatorname{lar} 29$ & 3620 & 82.7 & 4.4 & N/A & \\
\hline & $\operatorname{lar} 49$ & 2800 & 130 & 2.3 & $\begin{array}{l}-2 \alpha_{\mathrm{L}} \\
59 \alpha_{\mathrm{T}}\end{array}$ & \\
\hline & $\operatorname{ar} 129$ & 4210 (est.) & 110 (est.) & - & N/A & 025 \\
\hline & lar 149 & 3450 & $172-179$ & 1.9 & N/A & \\
\hline & jaron & 2800 & 130 & 2.3 & $\begin{array}{l}-2 \alpha_{\mathrm{L}} \\
59 \alpha_{\mathrm{T}}\end{array}$ & \\
\hline & hnora & 3500 & 74 & 4.6 & N/A & \\
\hline & & & & & & \\
\hline & Glass & $3500-3600$ & $74-75$ & 4.8 & 5 & 0.2 \\
\hline & Glass & 4900 & 87 & 5.6 & 2.9 & 0.22 \\
\hline Alkal & $\begin{array}{l}\text { resistance } \\
\text { lass }\end{array}$ & $1800-3500$ & $70-76$ & $2-3$ & N/A & N/A \\
\hline
\end{tabular}

$* \alpha_{\mathrm{L}}$ and $\alpha_{\mathrm{T}}$ denote the coefficient of thermal expansion in longitudinal and radial directions, respectively. 


\subsubsection{Manufacturing Process}

There are varieties of manufacturing process that FRP components by which can be produced. However, the most commonly used procedures for manufacturing of FRP materials are: pultrusion, wet lay-up and filament winding.

Pultrusion: is a technique of producing continuous FRP component of any length with constant or nearly constant profile. Pultrusion process is commonly used to produce FRP bars, rods, tendons, plates and structural sections. In this method, continuous strands of FRP materials are drawn from creels, through a resin tank that is saturated with resin. The resin-impregnated fiber glass then passes through a heated die where the polymeric matrix hardens into the shape of the die to produce a structural component. The surface profile of the FRP bars is usually braided or sand-coated to ensure a good bond between the bars and concrete

Wet Lay-up: This technique is also known as the hand lay-up or contact molding. This method is used often for rehabilitation applications to manufacture FRP sheets or fabrics that are bonded to structural components such as beam, columns or slabs. In this method, a roller is used to press the fiber into a rigid mould covered with resin. Additional fibers may also be added to outer surface of the fibers to ensure full impregnation of the fibers. Also, extera layers of FRP can be placed on top of each other to ensure adequate thickness of FRP is achieved. In strengthening applications, once the resins have been cured, FRP sheets remain bonded to the structural members. This method can be easily and rapidly performed in the field. Figure 2.3 shows view of the concrete slab strengthened with CFRP sheets performed by the authors to conduct static testing of steel-reinforced PL-3 barrier wall. 


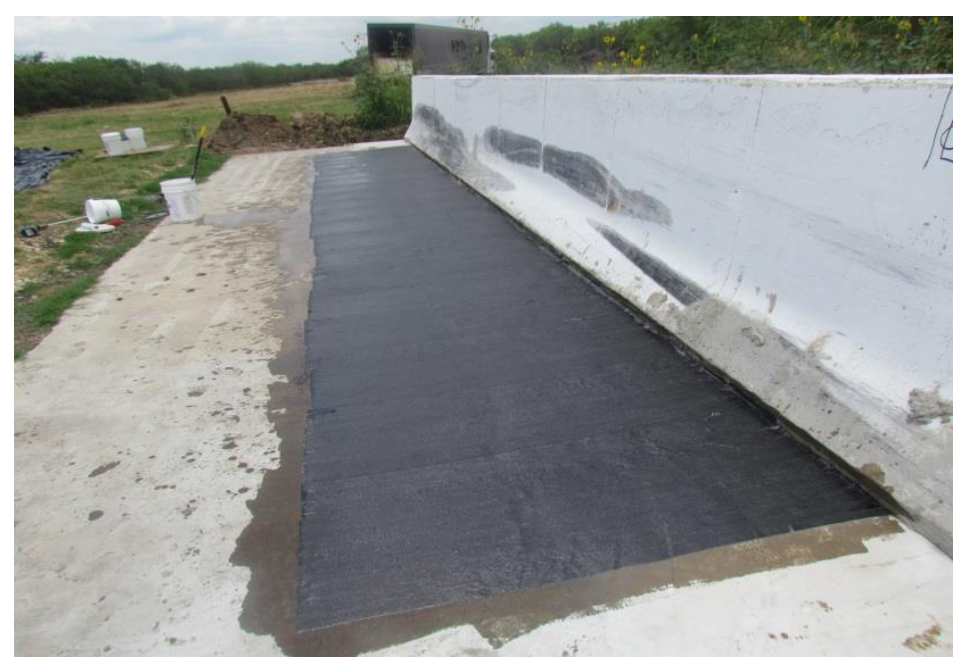

Figure 2. 3 View of concrete slab strengthened with CFRP sheets

Filament Winding: This manufacturing technique is used for members that utilize hollow FRP poles, pipes and tubes such as stay-in-place formwork for concrete piles. In this method, fibers are drawn off spools, through a mobile resin path, which are then wounded on a rotating mandrel. The placement of fiber onto the mandrel can be controlled by a computer program. This manufacturing technique allows variations in the fiber orientations so that filament wound member can be produced with different mechanical properties as needed.

\subsubsection{Mechanical Properties and Behavior of FRPs}

Mechanical properties of FRPs are significantly dependent on relative proportion of fiber and matrix, mechanical properties of the fibers and matrix, orientation of the fibers within the matrix and the manufacturing process. Mechanical properties are highly directional dependent, which is stronger in the direction of the fibers. Based on experimental program conducted on existing FRP materials, it was observed that all FRPs exhibited linear elastic stress-strain behavior until failure with no yielding point. Failure at ultimate was followed by rupturing of FRP materials. Figure 2.4 compares the stress-strain relationships of various FRP bars compared to steel bars. 


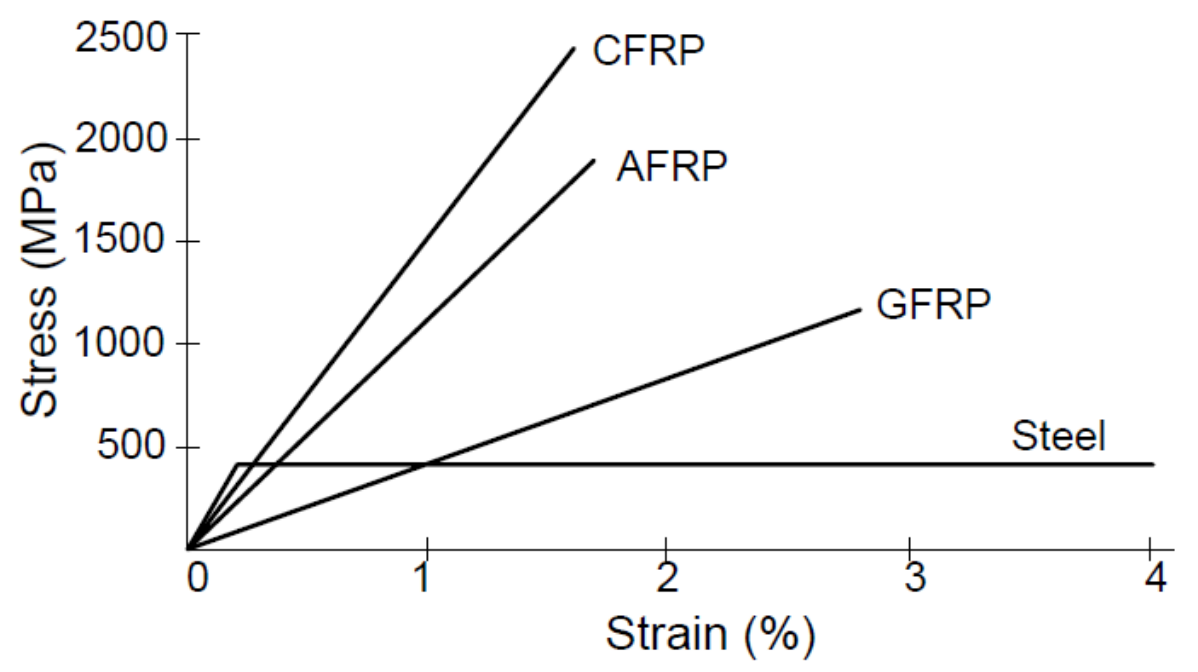

Figure 2. 4 Typical stress-strain curve of various FRP types (Adopted: ACI 440R, 1996)

From experimental programs performed on FRP bars, it has been observed that FRPs are usually weak under compression forces; however, they have relatively high strength under the applied tensile forces. Therefore, FRPs are more effective under tensile forces and used as tensile reinforcement. The overall response of FRP materials depends significantly on the failure strain of the fiber or the matrix as well as volume fraction of the fibers. In most civil engineering structures, fiber volume fraction of FRPs is larger than 0.1 that is considered large. Thus, if failure strain of matrix is greater than the failure strain of fibers, and fiber volume fraction is large, then the load transfer from the fibers to the matrix at initial fiber fracture is large and therefore the FRP fails. Figure 2.5 compares stress-strain relationship of fibers, matrix and FRP in the case when matrix failure strain is greater than the fibers. Table 2.4 and Table 2.5 show typical properties of the available FRP reinforcing bars and FRP strengthening products, respectively. 


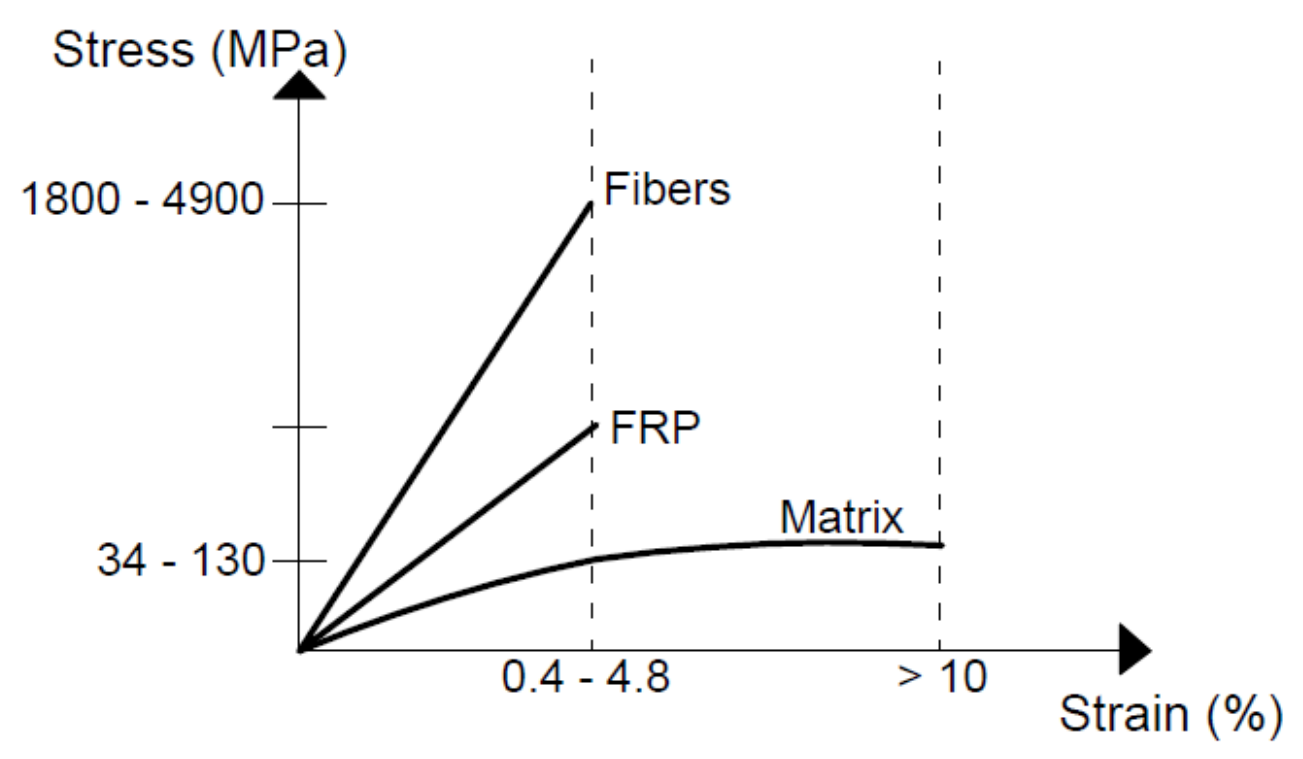

Figure 2. 5 Stress-strain relationship of fibers, matrix and FRP (Adpoted: ISIS Canada Module 4, 2006)

Table 2. 4 Selected properties of currently available FRP bars (Source: ISIS Canada Module 2, 2006)

\begin{tabular}{|c|c|c|c|c|c|}
\hline Bar Type & Designation & $\begin{array}{c}\text { Diameter } \\
(\mathrm{mm})\end{array}$ & $\begin{array}{c}\text { Area } \\
\left(\mathrm{mm}_{2}\right)\end{array}$ & $\begin{array}{c}\text { Tensile } \\
\text { strength } \\
(\mathrm{MPa})\end{array}$ & $\begin{array}{c}\text { Elastic } \\
\text { modulus } \\
(\mathrm{GPa})\end{array}$ \\
\hline Deformed steel & $\# 10$ & 11.3 & 100 & $400 *$ & 200 \\
\hline V-ROD CFRP Rod & $3 / 8$ & 9.5 & 71 & 1431 & 120 \\
\hline V-ROD GFRP Rod & $3 / 8$ & 9.5 & 71 & 765 & 43 \\
\hline NEFMAC GFRP Grid & $\mathrm{G} 10$ & N/A & 79 & 600 & 30 \\
\hline NEFMAC CFRP Grid & $\mathrm{C} 16$ & N/A & 100 & 1200 & 100 \\
\hline NEFMAC AFRP Grid & A16 & N/A & 92 & 1300 & 54 \\
\hline LEADLINE CFRP Rod & Round & 12 & 113 & 2255 & 147 \\
\hline
\end{tabular}

*Specified yield strength of steel

In external strengthening applications, unidirectional FRP materials are used that exhibit typically a linear elastic response till failure, while do not perform yielding behavior as shown by conventional steel reinforcement. Figure 2.6 demonstrates typical stress-strain relationship of 
FRP strengthening materials compared to steel reinforcement. FRP materials generally have higher strengths than the yielding strength of steel bars, although they do not yield; however, they have strain at failure considerably less than steel.

Table 2. 5 Selected properties of currently available FRP strengthening systems (Source: ISIS Canada Module 2, 2006)

\begin{tabular}{|c|c|c|c|c|c|c|}
\hline FRP Type & Fiber type & $\begin{array}{c}\text { Weight } \\
\left(\mathrm{g} / \mathrm{m}^{2}\right)\end{array}$ & $\begin{array}{c}\text { Thickness } \\
(\mathrm{mm})\end{array}$ & $\begin{array}{c}\text { Tensile } \\
\text { strength } \\
(\mathrm{MPa})\end{array}$ & $\begin{array}{c}\text { Elastic } \\
\text { modulus } \\
(\mathrm{GPa})\end{array}$ & $\begin{array}{c}\text { Strain at } \\
\text { failure } \\
(\%)\end{array}$ \\
\hline \multicolumn{7}{|c|}{ Fyfe Co. LLC } \\
\hline Tyfo SHE-51 & Glass & 930 & 1.3 & 575 & 26.1 & 2.2 \\
\hline Tyfo SCH-35 & Carbon & - & 0.89 & 991 & 78.6 & 1.3 \\
\hline \multicolumn{7}{|c|}{ Mitsubishi } \\
\hline Replark 20 & Carbon & 200 & 0.11 & 3400 & 230 & 1.5 \\
\hline Replark 30 & Carbon & 300 & 0.17 & 3400 & 230 & 1.5 \\
\hline Replark MM & Carbon & - & 0.17 & 2900 & 390 & 0.70 \\
\hline Replark HM & Carbon & 200 & 0.14 & 1900 & 640 & 0.30 \\
\hline \multicolumn{7}{|c|}{ Sika } \\
\hline Hex 100G & Glass & 913 & 1 & 600 & 26.1 & 2.2 \\
\hline Hex 103C & Carbon & 618 & 1 & 960 & 73.1 & 1.3 \\
\hline CarboDur S & Carbon & 2240 & $1.2-1.4$ & 2800 & 165 & 1.7 \\
\hline CarboDur M & Carbon & 2240 & 1.2 & 2400 & 210 & 1.2 \\
\hline CarboDur H & Carbon & 2240 & 1.2 & 1300 & 300 & 0.5 \\
\hline \multicolumn{7}{|c|}{ Catson Bowman Acme } \\
\hline MBrace EG 900 & Glass & 900 & 0.35 & 1517 & 72.4 & 2.1 \\
\hline MBrace CF 530 & Carbon & 300 & 0.17 & 3500 & 373 & 0.94 \\
\hline MBrace AK 60 & Aramid & 600 & 0.28 & 2000 & 120 & 1.6 \\
\hline
\end{tabular}




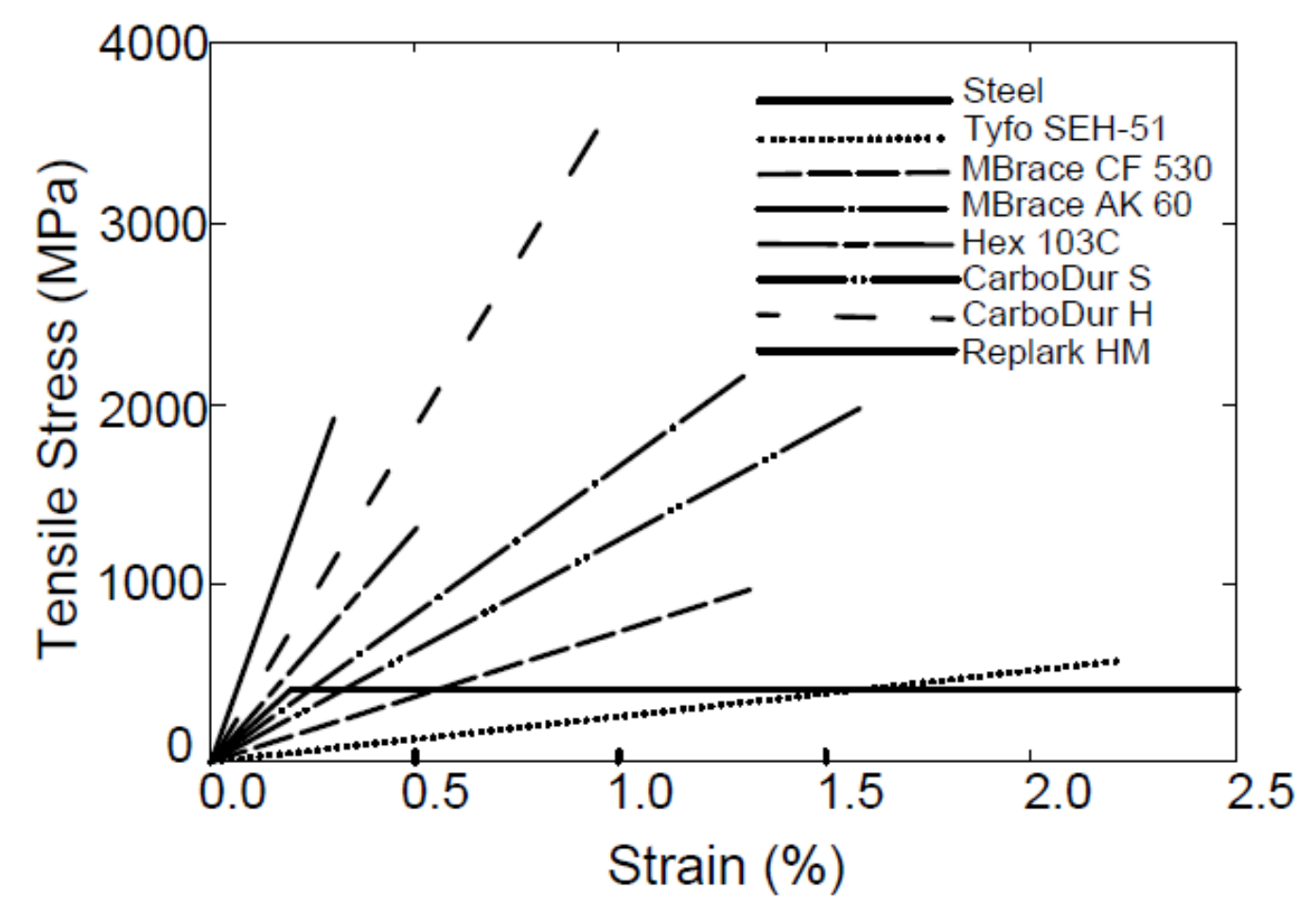

Figure 2. 6 Stress-strain relationships for various FRP strengthening systems (Adopted: ISIS Canada Module 6, 2006)

Tensile Behavior: FRP bars do not display yielding (plastic behavior) before rupturing when subjected to tensile loading. As noted earlier, tensile behavior of FRP bars is considered by types of fibers and is linear elastic till failure. The tensile properties of some commonly used FRP bars are provided in Table 2.6. Generally, tensile strength and stiffness of FRP bars can be affected by some factors namely as: the ratio of fiber-volume fraction, rate of curing, manufacturing process and manufacturing quality control (Wu, 1990). In addition, the study performed by Faza and GangaRao (1993b) revealed that some FRP bars exhibited substantial effect of cross-sectional area on tensile strength of FRP bars. The study showed, for instance, a reduction in tensile strength up to $40 \%$ was observed as bar diameter was increased from $9.5-\mathrm{mm}$ to $22.2-\mathrm{mm}$. Also, FRP bars cannot be bent in the field once it is manufactured with exception to this is an FRP bar with thermoplastic resin in which it can be reshaped under pressure and heat. FRP bent bars must be produced by the manufacturers, however, a strength reduction of $40 \%$ to $50 \%$ may occur in the bent portion compared to the tensile strength of straight portion due to fiber bending and stress concentrations (Nanni et al. 1998). 
Table 2. 6 Typical tensile properties of reinforcing bars (Source: ACI 440.1R, 2003)

\begin{tabular}{|c|c|c|c|c|}
\hline & Steel & GFRP & CFRP & AFRP \\
\hline Nominal yield stress $(\mathrm{MPa})$ & $276-517$ & N/A & N/A & N/A \\
\hline Tensile strength $(\mathrm{MPa})$ & $483-690$ & $483-1600$ & $600-3690$ & $1720-2540$ \\
\hline Elastic modulus $\times 10^{3}(\mathrm{GPa})$ & 200 & $35-51$ & $120-580$ & $41-125$ \\
\hline Yield strain $(\%)$ & $1.4-2.5$ & N/A & N/A & N/A \\
\hline Rupture strain $(\%)$ & $6-12$ & $1.2-3.1$ & $0.5-1.7$ & $1.9-4.4$ \\
\hline
\end{tabular}

Typical values for fiber volume fractions ranging from 0.5 to 0.7 .

Compressive Behavior: Wu (1990) performed experimental tests on FRP bars with length to diameter ratio of 1:1 and 1:2 and have shown lower compressive strength than tensile strength. The failure mode for FRP bars subjected to compressive force may include to: transverse tensile failure, fiber microbuckling, or shear failure. These failure modes are usually depend on: type of fiber, fiber volume fraction and the type of resin. Compressive strength of GFRP, CFRP and AFRP bars are reported to be 55\%,78\% and $20 \%$ of the tensile strength, respectively (Mallick 1988, Wu 1990). In addition, compressive modulus of elasticity of GFRP, CFRP and AFRP bars are reported as $80 \%, 85 \%$ and $100 \%$ of the tensile elastic modulus for the same product, respectively (Mallick 1988, Ehsani 1993).

Shear Behavior: FRP bar composites have found to be usually weak in interlaminar shear due to the fact that layers or unreinforced resin lie between layers of fibers. Since there is no reinforcing materials between the layers, shear strength of FRP bars are governed by strength of polymeric matrix. A solution to this is to orient the fibers in off-axis direction across the layers in which it will increase the shear strength depending on the degree of offset.

Bond Behavior: The experimental tests on FRP bars revealed that bond performance of FRPs dependent on: the design, manufacturing process, bars mechanical properties and the environmental conditions (Al-Dulaijan et al. 1996, Nanni et al. 1997, Bakis et al. 1998, Bank et al. 1998 and Freimanis et al. 1998). The bond force transmitted between the FRP bars and concrete can be due to: (i) adhesion resistance of the interface known as chemical bond, (ii) frictional resistance of the interface against slip, and (iii) mechanical interlock due to irregularity 
of the interface. In FRP bars, the bond force is transferred to the fibers through resin; however, bond shear failure in the resin may also be possible (ACI 440.1R-03). When a bonded FRP bar is subjected to increasing tensile load, adhesion resistance between bar and the concrete breaks down, and deformations on the bar surface cause inclined contact force between bar and the concrete. Therefore, the stress at bar surface due to the applied tensile force in the direction of the bar can be regarded as bond stress between the bar and the concrete. Unlike steel bars, the bond of FRP bars into concrete appeared not to be significantly dependent on concrete compressive strength providing that sufficient concrete cover is provided to prevent longitudinal splitting failure (Nanni et al. 1995, Benmokrane et al. 1996, Kachlakev and Lundy 1998).

\subsection{Bond Mechanism of Reinforcing Bars}

Steel reinforcement is embedded into concrete to increase the structural capacity of the structural members under flexure, shear, compression or torsion. The reinforcing bars usually acts either under tension or compression. For a reinforcing bar to develop the required tension or compression forces, a perfect bond mechanism is required between the bar and the concrete. A prefect bond is representation of no slippage at bar-concrete interface. The strength and stability of a reinforced concrete significantly depends on the bond behavior developed between the bar and the concrete. If there is no bond, for example the reinforcing bars are extremely smooth that there is no bond at bar-concrete interface, the concrete and the bar will move independently of each other, thus, the bar can freely slide inside the concrete. In a reinforced concrete structure for an optimal design, an efficient and reliable load transfer should be developed between concrete and the bars. The transfer of load between the reinforcing bars and surrounding concrete, as shown in Figure 2.7 will occur by three mechanisms: (i) chemical adhesion between the bar and the concrete, (ii) frictional forces, and (iii) mechanical anchorage or bearing stress. Chemical adhesion is the primary failure to break down the chemical bond between concrete and the bar. Chemical adhesion usually provides the least contribution to the bond mechanism between concrete and the bar, thus, the deformed bar, ribbed or sand-coated GFRP bars are mostly used in practice to increase the chemical adhesion. Friction forces mostly develop at the surface between the deformed bar or sand-coatings and the concrete. Bearing or mechanical interlock is developed by the bearing of the bar ribs against the concrete. In conventional steel reinforcement, bond failure is a result of the bearing caused by side splitting or shearing of 
concrete surface due to pullout forces. However, in case of sand-coated GFRP bars, bond failure may also develop when the bearing stress exceed the strength between sand-coated surface and the bars core.

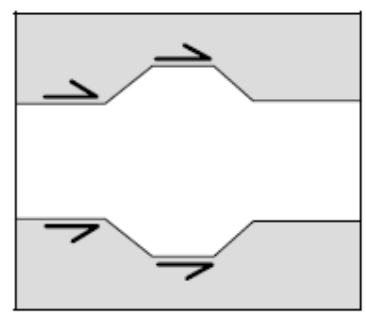

(a) Adhesion

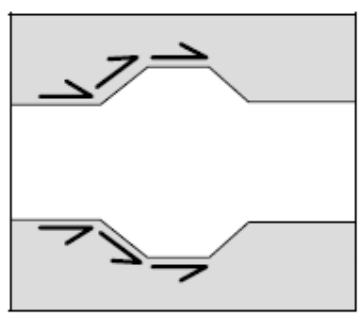

(b) Friction

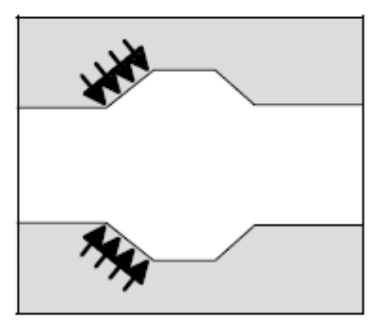

(c) Bearing

Figure 2. 7 Bond force transfer mechanism (Adopted: ACI 408.2R, 1992)

To achieve adequate bond strength, the bar must be embedded into concrete or anchored in concrete over certain length called development length, and should have sufficient confinement by surrounding concrete (concrete cover) or transverse reinforcement. If sufficient development length of the bar into concrete is provided, the shear and radial stresses developed along the bar will be less than concrete capacity; therefore, the bar can reach its desired design strength. However, if inadequate development length of the bar or confinement is provided, shear or radial stresses may exceed the concrete strength and the bar pull out of the concrete.

\subsubsection{Bond Failure Modes}

Figure 2.8 shows a deformed reinforcing bar embedded into concrete. The bond between the steel reinforcing bar and the concrete is initially achieved by adhesion and friction. However, once the bar slip inside the concrete due to applied tensile force, the load transfer is developed by bearing on the bar deformations. These bearing forces are then balanced by equivalent forces but in opposite directions acting on the concrete that can be divided into longitudinal and radial components parallel and perpendicular to the bar. Further increase in the applied tensile force causes bond deterioration and cracking of concrete that induce two failure modes as follows: 


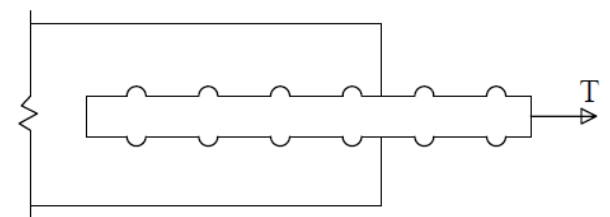

(a)

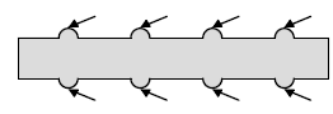

(b)

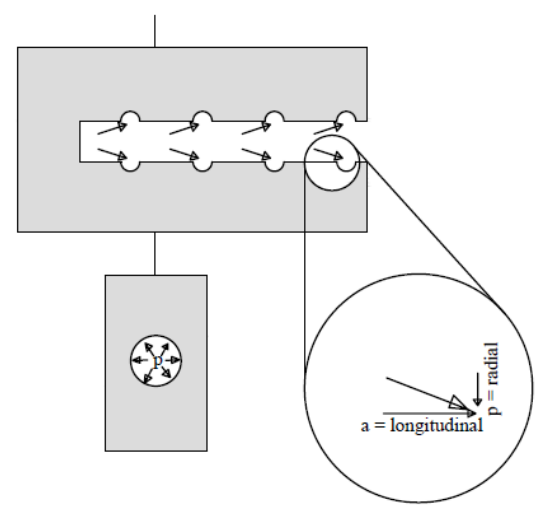

(c)

Figure 2. 8 Pullout resistance mechanism for a deformed bar: (a) anchored bar under tension (b) forces on reinforcing bar, and (c) forces on concrete (Adopted: Chaallal and Lachemi, 2010)

Pullout Failure: pullout failure usually occurs if bar spacing or concrete cover is sufficient or happens in case of smaller bar diameters. As a result the entire bar pulls out of the concrete. Once the adhesion bond and friction resistance of the bar is reached, the concrete member fails by shearing along a cylindrical failure surface around the bar as shown in Figure 2.9 (b). Pullout failure usually occurs when radial forces acting on the bar is lower than the surrounding concrete capacity and the longitudinal shear components are greater than the concrete capacity.

Splitting Failure: splitting failure occurs if concrete cover, confinement or bar spacing are not sufficient to resist the tensile strength of the surrounding concrete resulting from wedging effect of the bar deformations. Splitting failure mode is characterized by concrete splitting along the reinforcing bar and also tends to occur along the shortest distance between the bar and the nearest edge distance or between the two adjacent bars (Figure 2.9a). Splitting failure can be attributed to the diagonal shear failure when radial pressure by the deformed bar is greater than the surrounding concrete strength.

It is generally understood that both failure modes are related to slippage of the bars relative to the concrete. Splitting failure occurs if all bonds fail. In other words, if radial cracks reach outer surface of the concrete all bond capacity will vanish and a brittle bond failure occurs. In pullout failure, the bond strength is greater due to higher confinement provided to the bars. However, in 
real practice, a pure bond failure rarely occurs rather the failure may be accompanied by pull through-splitting failure by crushing the concrete surrounding the bars.

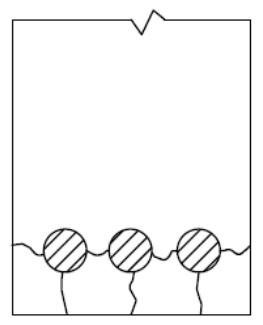

(a)

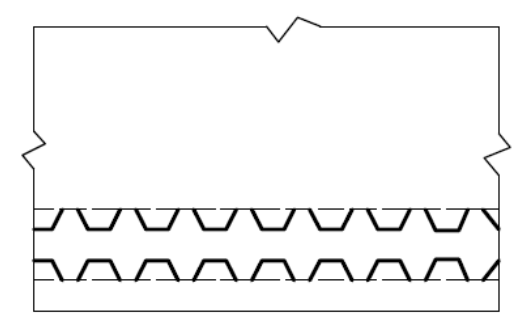

(b)

Figure 2. 9 Bond failure mechanism: (a) splitting cracks between bars and concrete, and (b) pullout failure mode along the bar surface (Adopted: ACI 408R, 2003)

\subsubsection{Bond Test Method}

Pullout testing method has been used to determine bond strength of FRP bars. This test method is the most common method used by researchers to estimate the bond behavior of bars in concrete. In this method, a single bar is embedded into a central axis of a concrete block or concrete cylinder as shown in Figure 2.10. The bar should be extended outward sufficient enough through the bearing blocks and provide adequate length to be gripped for pullout testing. For larger bar diameters, larger concrete blocks may be used to maintain the minimum side cover to the bar at least five to six times the bar diameter in order to prevent splitting failure. If a specimen is failed in the grip, the test should be disregarded and additional tests may be conducted (CSA S806, 2012). To prevent stress concentration at loaded end and equalize the stresses due to the applied load on the loaded end, a bond breaker with PVC or other suitable material may be used. The testing machine should be capable of applying adequate loading at a rate neither greater than $22000 \mathrm{~N} / \mathrm{mm}$ nor greater than $1.27 \mathrm{~mm} / \mathrm{min}$. The loaded end of the bar should be sufficiently anchored to transfer load to the bar until pullout or splitting failure modes are reached. The load transferring device should only apply the axial load to the bar not flexural or torsional forces. The displacement should be measured at both free and loaded ends using appropriate displacement measuring devices. The loading and reading of the pullout test should be continued until: (i) FRP bar rupture occurs, (ii) concrete splitting occurs, or (iii) at least the bar pull out of the concrete at loaded end region with a minimum slippage of $2.5-\mathrm{mm}$. 


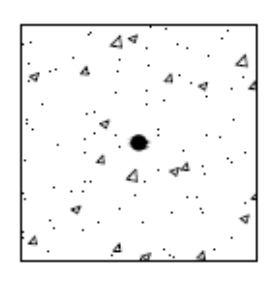

Plan View

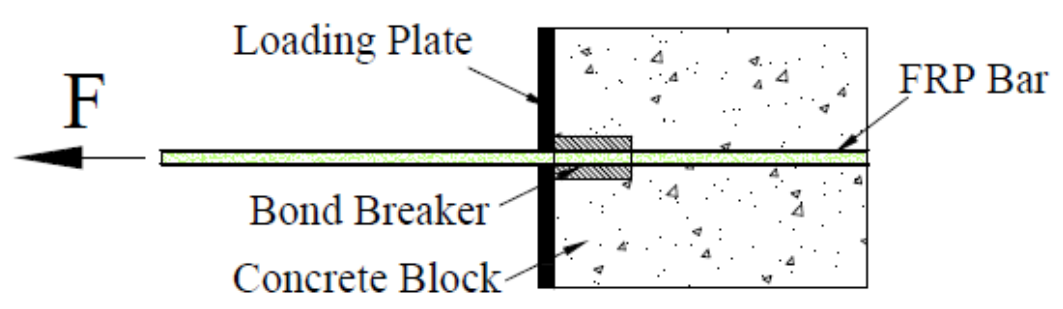

Elevation View

Figure 2. 10 Schematic diagram of pullout test specimen

\subsubsection{Bond Mechanism of Steel Bars}

Bond of deformed steel bars in concrete takes place due to surface deformation of the bar or loss of surface adhesion. This is due to the fact that bearing forces on the ribs will increases resulting in an increase in frictional force on the ribs and barrel of the bar. As the bearing forces increase, the frictional forces will also increase; thus, the force-transfer mechanism between the bar and the concrete occurs. As the bar start to slip, the frictional forces on the barrel reduce, and the bar pulls out by shearing off the concrete surrounding the bar.

\subsubsection{Bond Mechanism of FRP bars}

Due to differences in mechanical properties and force transfer of steel and FRP bars, bond mechanism in FRP-reinforced structures is not analogous to that of steel bars. Steel-reinforced concrete are usually known as isotropic, homogenous and elasto-plastic materials due to their behavior in the orthogonal directions. However, FRP bars are made of fibers and resins that make them in a FRP-reinforced structure as anisotropic, non-homogenous and linear-elastic material. This is due to the fact that FRP material behavior is different in the two orthogonal directions in that the longitudinal properties are affected by fibers, while the transverse properties are affected by resins. The material anisotropy behavior of FRP bars leads to different mechanical properties compared to steel bars; thus, the bond mechanism and development of internal forces may varies comparably to steel bars. Variations in surface texture of FRP bars; sand-coated, braided, spiral, ribbed and indented surfaces that are created by the fibers and epoxies cause non-homogenous bars resulting in the reduction of their bond strengths. Therefore, unlike the steel bars, bearing stresses may not be significant in FRP-reinforced structures, and the bond mechanism will be through adhesion and friction. In GFRP bars with sand-coated surface, 
bearing stresses may exceed the shearing strength of bar-core interface and failure occurs at these locations.

\subsection{Factors Affecting the Bond Strength}

Bond strength of FRP bars in concrete may be affected by several factors namely as: bar diameter, fibers strength, bar modulus of elasticity, concrete cover, embedment depth, bar surface texture, bars spacing, confinement, bar end conditions and concrete compressive strength. A brief discussion of some of the factors affecting the bond strength of FRP-reinforced concrete structures is presented in the following sections.

\subsubsection{Influence of Concrete Compressive Strength}

The effect of concrete compressive strength on bond strength is considered to be a significant factor due to the fact that the load transfer between concrete and FRP bars are mainly by bearing, and bond failure by splitting or shearing of the concrete. The development of bond stress is also influenced by tensile and compressive strengths of the concrete. The tensile micro-cracks, for instance, depend on the tensile strength of concrete, while the bearing stresses apply high compressive stresses to the surrounding bar. From experimental studies conducted by Martin (1982) on pullout of steel bars in concrete, it was observed that the bond stress is proportional to the concrete compressive strength of $16-50 \mathrm{MPa}$ when the slip range is between 0.1 to $1 \mathrm{~mm}$. It was also observed that for slip less than $0.1 \mathrm{~mm}$ or greater $1 \mathrm{~mm}$, the concrete compressive strength is less effective and proportional to the $2 / 3$ power of concrete compressive strength. In FRP-reinforced concrete, the studies conducted by Achillides (1998), Achillidies and Pilakoutas (2004) and Baena et al. (2009) on the concrete strength showed that the bond strength of FRP bars is not significantly affected by concrete compressive strengths greater than $30 \mathrm{MPa}$ due the fact that failure occurs at FRP-concrete interface. However, the bond strength is significantly affected by concrete compressive strengths less than $15 \mathrm{MPa}$ since the failure occurs in the concrete matrix rather than the FRP bars. In addition, the experimental studies carried out by Cosenza et al. (2002) revealed that pullout failure occurs in concrete compressive strengths less than $30 \mathrm{MPa}$ due to breaking of the surrounding concrete, while the bars are still undamaged. For concrete compressive strengths greater than 55-60 MPa, the failure is mainly due to the damage

of FRP bars rather than the surrounding concrete. For concrete compressive strengths between 30 
to $55 \mathrm{MPa}$, failure accompanied by the damage on FRP bars and the surrounding concrete. Also, experimental programs performed by other researchers, which are also dictated in most design practice codes showed that bond strength of FRP bars was related to the square root of the concrete compressive strength (ACI 40-03, Makitani et al. 1993, Benmokrane et al. 1996, Ehsani et al. 1996, and Tighiouart et al. 1998).

\subsubsection{Influence of Concrete Cover, Bar Spacing and Confinement}

Concrete cover to the reinforcing bars protects the transverse concrete cracking, which significantly influences the bond behavior. Similar behavior was also observed for the cases of reinforcement spacing and confinement provided to the reinforcement. The studies conducted by Tepfers (1973), Orangun et al. (1977) and Eligehausen (1979) showed that pullout and splitting failures depend on the concrete cover thickness, in which splitting failure occurs in small concrete cover or bar spacing and pullout failure takes place in larger concrete cover or bar spacing. The experimentally study conducted by Ehsani et al. (1996) on 102 pullout specimens showed that the bond failure of GFRP bars in concrete is influenced by concrete cover. The study revealed that splitting failure occurs for concrete cover less than or equal to the bar diameter, while pullout failure occurs for concrete cover greater than two times the bar diameter. Also, it was observed that increasing the concrete cover thickness will increase the bond strength. Most practical codes (CSA S806, 2012, CSA S6, 2006, ACI 440.1R, 2006 and JSCE, 2007) consider effects of concrete over and bar spacing on the bond strength of FRP bars. The confinement provided by reinforcement also increases the bond force required to cause failure and limit the progression of the splitting cracks (Tepfers, 1973, Orangun et al. 1977). The research study performed by Darwin et al. (1996) on the increased confinement to the steel bars by providing high relative rib area ( 0.10 to 0.14 rib area) showed an increase to the bond strength. However, since generally FRP bars do not provide sufficient relative rib area, the increase in confinement by the transverse reinforcement may not increase the bond strength (Wambeke and Sheild, 2006). Thus, more experimental programs may be required to examine effect of confinement on the bond strength. The CSA S6 (2006) and JSCE (2007) are the only design practice codes that consider effects of transverse reinforcement in estimation of bond of FRP bars in concrete. 


\subsubsection{Influence of Embedment Length}

The effect of embedment length on the average bond strength of FRP bars in concrete was studied by many researchers, among them; Ehsani et al. (1995), Benmokrane et al. (1996), Cosenza et al. (1997), Sheild et al. (1997), Tigiouart et al. (1998) amd Achillides and Pilakouta (2004). The studies showed that the average bond strength along the bar decreases by increasing the embedment length of FRP bars in concrete. This result was similar to the case in steelreinforced concrete. Generally, the increase in embedment length of a bar will increase the bond capacity; however, this increase is not proportional to the increase in the embedment length. This can be attributed to non-uniform stress distributions along the length of the bar. The studies showed a high stress concentration at loaded-end region of the bars at the beginning of the pullout test, which non-uniformly reduces the stresses to zero at free-end of the bar. Thus, the increase in the embedment length will increase the force required to pull the bar out of the concrete so that the failure to occur. Ehsani et al. (1995) showed that an increase in the embedment length will increase the initial pullout load as well as the initial stiffness of bond-slip curve. Chaalla et al. (1993) also characterized the bond behavior of GFRP bars by pullout. Their results indicated that concrete splitting failure may occur in longer embedment length, while pullout failure occurs at shorter embedment length. In the study, it was also observed that beyond the peak load, the applied pullout load reduces immediately with a slip in descending phase representing that with increase in slip, the bond decreases suddenly due to the shearing of surface deformation of GFRP reinforcing bars.

\subsubsection{Influence of Bar Diameter}

The experimental studies on the effect of bar diameter on bond strength showed that bond strength decreases with increase in the bar diameter. The study has been investigated by many researchers namely as: Larralde and Silva (1993), Benmokrane et al. (1996), Tighiouart et al. (1998 and 1999), Achillides and Pilakoutas (2004), Baena et al. (2009) and Hao et al. (2009). The decrease in the bond strength due to the increase in the bar size was explained as follow by the researches. Tigiouart et al. (1998) attributed the decrease in bond strength to the increased amount of bleed water trapped beneath the bar with larger bar diameters creating more voids than the smaller bar diameters. Thus, more voids decrease the contact surface between the bar and the concrete. Achillides and Pilakouts (2004) attributed this effect due to less adhesion 
provided by larger bar size than smaller bar size. Baena et al. (2009) explained that the decrease in the bond strength of larger bar size may be due to the poisson's effect developed during pullout testing. It is explained that the bar diameter reduces when it is under tension. The reduction in bar diameter increases with the bar size: thus, the poisson's effect has greater influence on the bars with larger diameters resulting in the decrease in contact surface between the bar and the concrete. The decrease in bond strength of FRP bars with larger bar size was also attributed to the shear lag effect (Kadam, 2006). The shear lag effect occurs when the normal stress in the bar varies along the cross-section due to lower shear stiffness in longitudinal direction of the bar. In GFRP bars, resins usually are used to bind the longitudinal fibers and control the shear stiffness, so that it causes differential displacements to occur along the crosssectional area of the bar when a tensile force is applied. This variation is greater in larger bar diameter; thus, the bond strength decreases more in the larger bar diameters.

\subsubsection{Influence of Bar Modulus of Elasticity}

Limited research programs have studied the effect of bars modulus of elasticity on bond behavior of FRP bars. However, the Canadian Highway Bridge Design Code (CSA-S6-06) considers the required development length of FRP bars in concrete as a function of modular ratio of FRP to steel bars. The equation showed that the greater the modulus of elasticity of FRP bars results in a smaller development length required, consequently, the bond strength of FRP bars increases. Bar modulus effect was also investigated by Aly and Benmokrane (2005) and found that the bond strength of FRP bars are related to the square root of longitudinal modulus of elasticity of FRP bars.

\subsubsection{Bar Surface Texture}

FRP reinforcing bars in the market have been manufactured with various surface textures such as: braided, sand-coated, ribbed, spiral and indented. CSA S806 (2012) provides modification factors to account for these surface textures. A modification factor of 1 was attributed to sandcoated and braided FRP bars representing highest bond strength developed by these bars. The highest modification factor was assigned to the indented bars (modification factor of 1.8) providing the least bond strength of the bars. Hao et al. (2009) also investigated the effect of FRP surface conditions with varying the rib height and rib spacing. The study showed that a rib 
spacing equal to the bar diameter and rib height equal to $6 \%$ of the bar diameter developed the increased bond strength. Baena et al. (2009) also suggested that surface conditions of FRP bars have greater influence when the bond failure occurs at concrete-bar interface. Consenza et al. (1997) investigated the effect of various surface profiles on the bond strength of FRP bars and derived the bond-slip experimental law for bars with ribbed, sand-coated and braided and sanded FRP bars. It was observed that the braided and sanded surface profile provided the highest bond strength, while sand-coated FRP bars developed the least free-end slip.

\subsection{Evaluation of Bond Strength of Bars in Concrete}

\subsubsection{Steel bars}

The bond strength of steel bars in concrete is represented in terms of shear stresses developed at bar-concrete interface, which is deemed as structural properties that are dependent on materials and geometry of the reinforcing bars (ACI 408R, 2003). The bond between steel bar and the surrounding concrete can be explained by pullout testing of bars embedded in a concrete block (Figure 2.11). When a bar is subjected to increasing tensile force, $\mathrm{T}$, the bond stress, $\mathrm{u}$, develops at outside surface of the reinforcing bar, that $(u)$ is defined as the shearing stress transferred from concrete to the bar. The distribution of bond stress along the embedded length of the bar in concrete is not uniform as shown in Figure 2.11b. As the test starts, the bond stress reaches its maximum value at near the loaded-end region and zero at the embedded end. At the end of the test, the bond stress develops a more uniform behavior, in which the bond stress is zero at both ends of the embedment length. The tensile stress developed in the bar reaches its maximum value at the loaded end region and zero at its embedment end (Figure 2.11c). It should be noted that the distribution of tensile stress in the diagram is shown as linear stress variations representing a conservative assumption, however, the actual behavior is not uniform. 
(a)

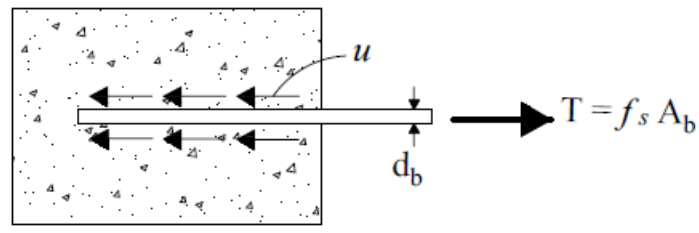

(b)

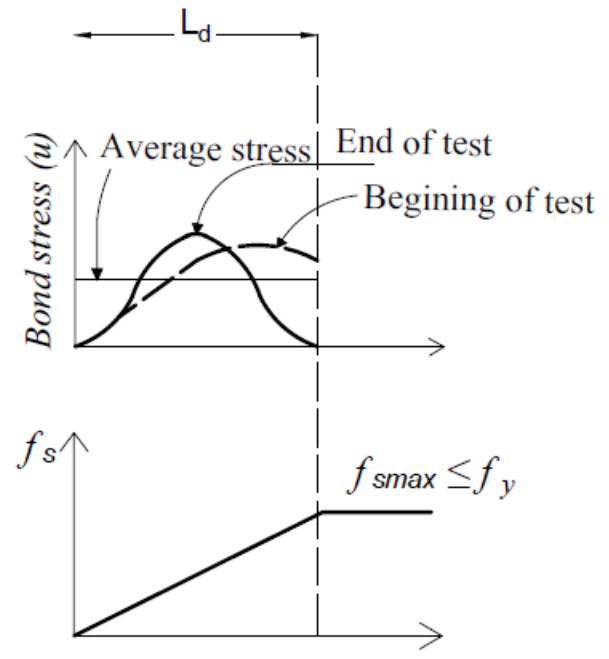

Figure 2. 11 Variation of bond and tensile stresses along the length of the steel bar in reinforced concrete structure subjected to pullout force; (a) concrete block subjected to tensile force, (b) bond stress distribution along the bar length, and (c) tensile stress distribution along the bar length. (Adopted: Brzev and Pao, 2006)

\subsubsection{FRP Bars}

It is common to assume a constant bond stress along the bonded length of steel bars. However, in case of FRP bars, this assumption is less valid due to relatively lower stiffness. Figure 2.12 shows variations of bond stress, slip, bar load and strain along the bonded length of FRP bars in concrete. As shown in the figure, the bond stress, bar load and strain reduce along the bonded length resulting in greater slip at loaded-end than the free-end (Pecce at al. 2001). The bond stress reaches its maximum value at the load-end region and reaches to its minimum value at embedment end in a non-uniform shape. The bar load and strain along the length of the bar also changes non-uniformly with its maximum values at loaded-end region and zero at embedment end of the bar. The highest slip occurs at the loaded-end region that will be reduced to almost zero once the embedment length is greater than the development length of the bar. 


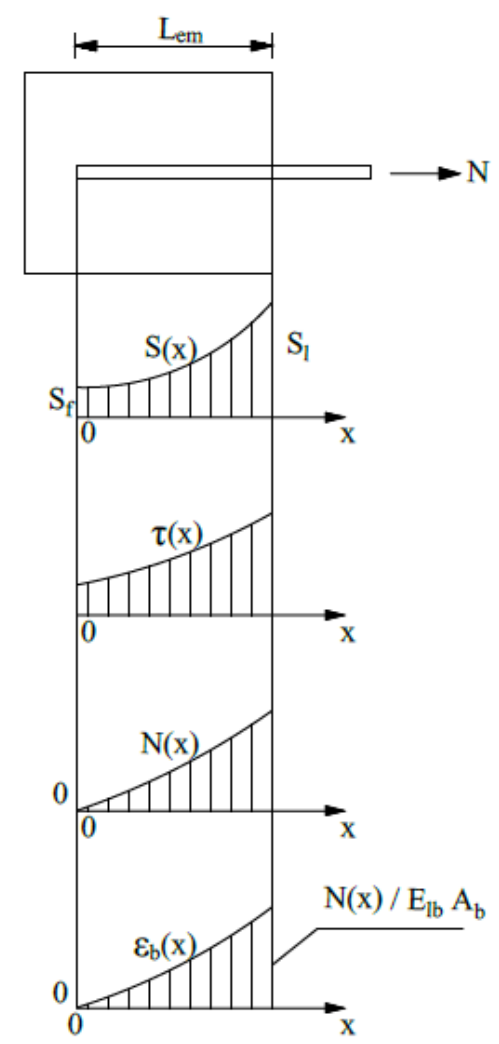

Figure 2. 12 Variation of slip, bond stress, bond force and strain along the bonded length of FRP bars (Adopted: Focacci et al. 2000)

However, in design practice, a uniform distribution of stress is assumed providing that the tensile force on the bar can be resisted by an average bond stress $(u=\tau)$ acting on the surface of the bar. In order to satisfy equilibrium conditions, the resultant bond stress must be equal to the tensile force developed in the bar within the embedded length of, $\mathrm{L}_{\mathrm{d}}$, that is:

$\left(\pi \cdot \mathrm{d}_{\mathrm{F}} \cdot \mathrm{L}_{\mathrm{d}}\right) \tau=\mathrm{T}=\mathrm{A}_{\mathrm{F}} \cdot f_{F}$

Where $d_{F}$ is FRP bar diameter $(\mathrm{mm}), L_{d}$ is embedment length of the bar $(\mathrm{mm}), \tau$ is the average bond stress (MPa), $A_{F}$ is the area of FRP bar, and $F_{F}$ is the stress in the FRP bar. Rearranging the Eq. 2.1, the average bond strength of bars in concrete can be written as:

$\tau=\frac{T}{\pi \cdot d_{F} L_{d}}=\frac{f_{F} A_{F}}{\pi \cdot d_{F} L_{d}}=\frac{f_{F} d_{F}}{4 L_{d}}$ 


\subsection{Bond Strength and Development Length of FRP Bars by Design Codes}

In design practice, the term development length is used representing the length of embedded bar necessary to develop the design strength of reinforcement at critical sections (CSA A23.3, 2004). At this point, the bar cannot be pulled out rather the bar reaches its rupture stress. Thus, the bar has developed its full tensile strength. The development length of bar in concrete, $\mathrm{L}_{\mathrm{d}}$, can be related to the bond strength using Eq. 2.2 above. The development length of FRP bars in concrete by design codes practice is discussed in the following sections.

\subsubsection{CSA S806-12}

Canadian Standard Association (CSA S806, 2012) specifies the following equation to determine development length of FRP bars in concrete.

$\mathrm{L}_{\mathrm{d}}=1.15 \frac{\mathrm{K}_{1} \mathrm{~K}_{2} \mathrm{~K}_{3} \mathrm{~K}_{4} \mathrm{~K}_{5}}{d_{c s}} \frac{f_{F}}{\sqrt{f^{\prime}{ }_{c}}} \mathrm{~A}_{\mathrm{F}}$

Where,

$\mathrm{L}_{\mathrm{d}}=$ Development length of FRP bars in tension (mm).

$\mathrm{K}_{1}=$ Bar location factor: 1.3 for horizontal reinforcement placed so that more than $300 \mathrm{~mm}$ of fresh concrete is cast in the member below the development length or splice; 1.0 for all other cases.

$\mathrm{K}_{2}=$ Concrete density factor: 1.3 for structural low-density concrete; 1.2 for structural semi-low -density factor concrete; and 1.0 for normal density concrete.

$K_{3}=$ Bar size factor: 0.8 for $A_{F} \leq 300 \mathrm{~mm}^{2}$; and 1.0 for $A_{F}>300 \mathrm{~mm}^{2}$

$\mathrm{K}_{4}=$ Bar fiber factor: 1.0 for CFRP and GFRP; 1.25 for AFRP

$\mathrm{K}_{5}=$ Bar surface profile factor: can be taken as less than 1 but not less than 0.5. However, in absence of experimental results the following values can be used: 1.0 for surfaceroughened or sand-coated surfaces; 1.05 for spiral pattern surfaces; 1.0 for braided surfaces; 1.05 for ribbed surfaces; and 1.80 for indented surfaces.

$\mathrm{d}_{\mathrm{cs}}=$ The lesser of: (a) the distance from the closest concrete surface to the center of the bar being developed; or (b) two-thirds of the center-to-center spacing of the bar being developed. But, the value shall not be taken greater than $2.5 \mathrm{~d}_{\mathrm{F}}(\mathrm{mm})$.

$f_{F}=$ Ultimate design stress in FRP tension reinforcements (MPa) 
$\mathrm{f}_{\mathrm{c}}^{\prime}=$ Concrete compressive strength $(\mathrm{MPa})$. The square root of concrete compressive strength shall not exceed $8 \mathrm{MPa}$.

$\mathrm{A}_{\mathrm{F}}=$ Area of one FRP bar $\left(\mathrm{mm}^{2}\right)$.

The development length calculated from Eq. 2.3 can be used to determine the required average bond strength using Eq. 2.2. Thus, Eq. 2.3 can be rearranged as follow:

$\tau=\frac{\mathrm{d}_{\mathrm{cs}} \sqrt{f^{\prime}{ }_{c}}}{1.15 K_{1} \mathrm{~K}_{2} \mathrm{~K}_{3} \mathrm{~K}_{4} \mathrm{~K}_{5} \pi \cdot d_{F}}$

Eq.2.4 shows that the bond strength of FRP bar in concrete is a function of concrete compressive strength, concrete cover, bar diameter and bar modification factors.

\subsubsection{CSA S6-06}

The Canadian Highway Bridge Design Code (CHBDC) specified modification to the development length of steel bars in concrete by multiplying the modular ratio of FRP to steel bars to determine development length of FRP bars in concrete. Therefore, the following equation was adopted:

$\mathrm{L}_{\mathrm{d}}=0.45 \frac{\mathrm{K}_{1} \mathrm{~K}_{4}}{\left(d_{c s}+K_{t r} \frac{E_{F}}{E_{S}}\right)}\left(\frac{f_{F}}{f_{c r}}\right) \mathrm{A}_{\mathrm{F}}$

Where,

$\mathrm{L}_{\mathrm{d}}=$ Development length of FRP bars in tension (mm).

$\mathrm{K}_{1}=$ Bar location factor: 1.3 for horizontal reinforcement placed so that more than $300 \mathrm{~mm}$ of fresh concrete is cast in the member below the development length or splice; 1.0 for all other cases.

$\mathrm{K}_{4}=\mathrm{Bar}$ surface factor representing the ratio of bond strength of FRP to that of steel bar having the same cross-sectional area, but not greater than 1.0. In absence of experimental data shall be taken as 0.8 . 
$\mathrm{d}_{\mathrm{cs}}=$ The lesser of: (a) the distance from the closest concrete surface to the center of the bar being developed; or (b) two-thirds of the center-to-center spacing of the bar being developed.

$f_{F}=$ Ultimate design stress in FRP tension reinforcements (MPa)

$\mathrm{f}_{\mathrm{c}}^{\prime}=$ Concrete compressive strength $(\mathrm{MPa})$. The square root of concrete compressive strength shall not exceed $8 \mathrm{MPa}$.

$\mathrm{A}_{\mathrm{F}}=$ Area of one FRP bar $\left(\mathrm{mm}^{2}\right)$.

$\mathrm{E}_{\mathrm{F}}=$ Modulus of elasticity of FRP bars $(\mathrm{MPa})$

$E_{S}=$ Modulus of elasticity of steel bars $=200,000(\mathrm{MPa})$

$f_{c r}=$ Flexural cracking strength of concrete (MPa) equal to: (a) $0.4 \sqrt{f^{\prime}{ }_{c}}$ for normal-density concrete; (b) $0.34 \sqrt{f^{\prime}}$ for semi-low density concrete; and (c) $0.3 \sqrt{f^{\prime}}$ for low-density concrete.

$\mathrm{K}_{\mathrm{tr}}=$ Transverse reinforcement index (mm). It can be calculated as $\mathrm{K}_{\mathrm{tr}}=\frac{A_{t r} f_{y}}{10.5 . S . n}$; however, the $\left(d_{c s}+K_{t r} \frac{E_{F}}{E_{S}}\right)$ shall be taken less than or equal to $2.5 \mathrm{~d}_{\mathrm{F}}$.

$A_{t r}=$ Area of transverse reinforcement normal to the plane through the anchored bars $\left(\mathrm{mm}^{2}\right)$

$f_{\mathrm{y}}=$ Yield stress of steel bars (MPa)

$\mathrm{S}=$ Spacing of transverse reinforcement $(\mathrm{mm})$

$\mathrm{n}=$ Number of bars being developed or spliced

Similarly, employing Eq. 2.2, the required average bond strength of FRP bars in concrete can be expressed as follow:

$\tau=\frac{\left(\mathrm{d}_{\mathrm{cs}}+K_{t r} \frac{E_{F}}{E_{S}}\right) \cdot f_{c r}}{0.45 K_{1} \mathrm{~K}_{4} \pi \cdot d_{F}}$

It can be understood that the CHBDC development length equation is a function of concrete cover, concrete cracking strength, modular ratio of FRP to steel, bar diameter and the modification factors. 


\subsubsection{ACI 440.1R-06}

The American Concrete Institute, Committee 440 (ACI 440.1R-06) presents the following equation based on the work by Wambeke and Sheild (2006) to predict the developable bar stress for a given concrete cover and embedment length. The equation is developed based on assumption of $\mathrm{C} / \mathrm{d}_{\mathrm{F}}$ greater than 3.5 and embedment length greater than $19 \mathrm{~d}_{\mathrm{F}}$ so that the pullout failure mode to occur.

$f_{f e}=\frac{0.083 \sqrt{f_{c}^{\prime}}}{\alpha}\left(13.6 \frac{L_{d}}{d_{F}}+\frac{C}{d_{F}} \frac{L_{d}}{d_{F}}+340\right) \leq f_{f u}$

knowing the fact that the stress in FRP reaches its design strength at ultimate, $f_{f u}$, the development length of FRP bars in concrete can be estimated by solving for $\mathrm{L}_{\mathrm{d}}$ in Eq. 2.7 providing that:

$\mathrm{L}_{\mathrm{d}}=\frac{f_{f u} d_{F} \alpha-28.22 d_{F} \sqrt{f^{\prime}{ }_{c}}}{1.1288 \sqrt{f^{\prime}{ }^{\prime}}+0.083 \sqrt{f^{\prime}{ }_{c}\left(\frac{C}{d_{F}}\right)}}$

The American Concrete Institute ACI 440.1R (2006) also specified the following equation based on the work done by Wambeke and Sheild (2006) to determine the average bond stress of FRP bars in concrete:

$\tau=\left(0.33+0.025 \frac{C}{d_{F}}+8.3 \frac{d_{F}}{L_{d}}\right) \sqrt{f^{\prime}{ }_{c}}$

Where,

$\mathrm{C}=$ The lesser of the cover to the center of the bar or $(1 / 2)$ of the center-to-center spacing of the bars being developed.

$\mathrm{d}_{\mathrm{F}}=$ Diameter of FRP bar $(\mathrm{mm})$

$\mathrm{L}_{\mathrm{d}}=$ Embedment length of FRP bar in concrete $(\mathrm{mm})$

$\mathrm{f}_{\mathrm{c}}^{\prime}=$ Concrete compressive strength

$\mathrm{C} / \mathrm{d}_{\mathrm{F}}=$ Cover-to-diameter ratio. The ratio should not be taken greater than 3.5. 
$\alpha=$ Bar location factor: 1.5 for horizontal reinforcement place above $300 \mathrm{~mm}$ of concrete; 1.0 for bars with less than $300 \mathrm{~mm}$ of concrete below.

$f_{f u}=$ Design tensile strength of FRP bars $(\mathrm{MPa})$

The ACI 440.1R-06 development length equation is a function of bar diameter, bar strength, concrete cover, and concrete compressive strength and bar location factors.

\subsubsection{ACI 440.1R-03}

The American Concrete Institute, Committee 440 (ACI 440.1R, 2003) specified the development length of FRP bars in concrete based on the experimental programs conducted by Ehsani et al. (1996a) and Gao et al. (1998b) when the failure of FRP bar was controlled by pullout rather than concrete splitting. The ACI suggested the following expression:

$\mathrm{L}_{\mathrm{d}}=\frac{d_{F} f_{f u}}{18.5}$

The Eq. 2.2 can be used to determine the required average bond strength of the FRP bars. Substituting Eq. 2.10 into Eq. 2.2, the following bond stress value can be obtained:

$\tau=4.63$

The ACI 440. 1R (2003) development length equation takes into account only the bar diameter and bar ultimate strength.

\subsubsection{JSCE (1997)}

The Japanese Society of Civil Engineering (1997) applied modifications to the development equation for steel bars. The basic development length of FRP tensile reinforcement that undergoes bond splitting failure can be determined as follow:

$\mathrm{L}_{\mathrm{d}}=\alpha_{1} \frac{f_{F}}{4 f_{\text {bod }}} d_{F} \quad$ Where $\mathrm{L}_{\mathrm{d}}>20 \mathrm{~d}_{\mathrm{F}}$ 
Using Eq. 2.2, the average bond strength of FRP bars in concrete can be determined as follow:

$\tau=\frac{f_{b o d}}{\alpha_{1}}$

Where,

$f_{F}=$ Design tensile strength of FRP $(\mathrm{MPa})$

$\alpha_{1}=1.0$ for $\mathrm{K}_{\mathrm{c}} \leq 1.0$

0.9 for $1.0<\mathrm{K}_{\mathrm{c}} \leq 1.5$

0.8 for $1.5<\mathrm{K}_{\mathrm{c}} \leq 2$

0.7 for $2<\mathrm{K}_{\mathrm{c}} \leq 2.5$

0.6 for $K_{c}>2.5$

$\mathrm{K}_{\mathrm{c}}=\frac{C}{d_{F}}+\frac{15 A_{t}}{S \cdot d_{F}} \cdot \frac{E_{t}}{E_{0}}$

Where,

$\mathrm{C}=$ the lesser of: downward cover from main reinforcements or half of the distance between the anchored reinforcement $(\mathrm{mm})$

$A_{t}=$ area of transverse reinforcement which is vertically arranged to the assumed splitting failure surface $\left(\mathrm{mm}^{2}\right)$

$\mathrm{S}=$ Distance between centers of the transverse reinforcement $(\mathrm{mm})$

$\mathrm{E}_{\mathrm{t}}=$ Modulus of elasticity of transverse reinforcement $(\mathrm{MPa})$

$\mathrm{E}_{\mathrm{o}}=$ Standard modulus of elasticity, 200,000 (MPa)

$f_{b o d}=$ Desing bond strength of concrete $(\mathrm{MPa})=0.28 \alpha_{2} \mathrm{f}_{\mathrm{ck}}^{\prime 2 / 3} / \gamma_{\mathrm{c}} \leq 3.2$

$\alpha_{2}=$ Modification factor for bond strength of FRP: 1.0 where bond strength is equal to or greater than that of deformed steel bars; otherwise, value should be reduced according to test results.

$\mathrm{f}_{\mathrm{ck}}^{\prime}=$ Concrete compressive strength $(\mathrm{MPa})$

$\gamma_{c}=$ Characteristic value for the concrete compressive strength taken as 1.3 
From Eq. 2.12, it can be followed that the development length of FRP bars in concrete is a function of concrete compressive strength, bar diameter, bar location factor, concrete cover and confinement provided by the transverse reinforcement.

\subsection{Development Length of Steel Anchor Head in Concrete}

The Canadian Standard CSA A23.3 (2004) specifies resistance of a steel anchor head in concrete as least value of the following possible failure modes:

\subsubsection{Tensile Resistance of Steel Anchor}

The factored resistance of a steel anchor in concrete shall be determined based on the properties of anchor materials and physical dimensions of the anchor head provided that:

$\mathrm{N}_{\mathrm{sr}}=\varphi_{\mathrm{s}} \cdot \mathrm{n} \cdot \mathrm{A}_{\mathrm{se}} \cdot \mathrm{F}_{\mathrm{ut}} \cdot \mathrm{R}$

\subsubsection{Tensile Concrete Breakout Capacity}

The factored concrete breakout capacity of an anchor in tension shall not exceed the following:

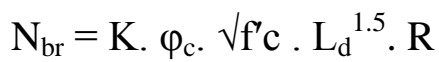

Where $\mathrm{K}$ is the calibration factor given 10 for cast-in place steel headed anchors and 7 for postinstalled anchors based on CSA A23.3 (2004). The modification factor, R, is given in Clause D5.4 in CSA A23.3 (2004).

\subsubsection{Anchor Pullout Capacity}

The pullout resistance of a single anchor in concrete under tensile load shall not exceed the following equation:

$N_{p r}=8 \varphi_{c} \cdot f_{c}^{\prime} \cdot A_{b h} \cdot R$ 


\subsubsection{Concrete Side Face Blowout}

The CSA A23.3 (2004) specifies concrete side face blowout capacity if the edge distance to the anchor head is less than 0.4 times the development length $\left(C \leq 0.4 \mathrm{~L}_{\mathrm{d}}\right)$. If such condition applies, the concrete side face blowout capacity can be determined from the following equation:

$\mathrm{N}_{\mathrm{sbr}}=13 \cdot 3 \mathrm{c} \cdot \sqrt{ } \mathrm{A}_{\mathrm{bh}} \cdot \varphi_{\mathrm{c}} \cdot \sqrt{ } \mathrm{f}_{\mathrm{c}}^{\prime} \cdot \mathrm{R}$

\subsection{Bond Stress-Slip Relationship}

When a bar is subjected to increasing tensile force, it pulls out of the concrete if the embedment length of the bar is less than the required development length. Thus, the bond stress which is the shearing stress acting along the surface area of the reinforcing bar is developed and the bar slippage or relative displacement of bar with respect to undisturbed concrete takes place. The typical bond stress-slip relationship of GFRP bars in concrete for slip at free-end is shown in Figure 2.13. As the failure occurs, the bar reaches its ultimate bond stress, $\tau_{\max .}$, and the corresponding slip, $S_{\max }$, due to the failure load. The curve is typically divide into two phases namely as: pre-peak and post-peak phases. In pre-peak phase, chemical adhesion between the bar and concrete is lost, internal micro-cracks are formed and the bearing of bar surface deformations on the surrounding concrete cause splitting cracks by hoop stresses. Due to increasing applied load, the ultimate bond failure occurs when either the splitting cracks reach the concrete surface or pullout of the bar occurs due to shearing of the concrete. In post-peak phase, residual stresses exist due to remaining friction by mechanical interlocking; thus, a smooth descending branch can be observed.

It is common to analytically establish bond-slip constitutive relationship for the bond between reinforcing bars and the concrete. The relationship can be introduced in the solution problems such as the calculations of the development length (Consenza et al. 1996). Several models have been established for bond-slip law of FRP bars that are modified from steel bars. However, there still require an extensive research program to determine an analytical model for bond-slip constitutive law of FRP bars in concrete. The existing formulas that are established for bond-slip law of FRP bars in concrete are regarded as general laws that are validated by determining the 
curve fitting. The following sections describe the available constitutive law for steel and FRP bars in concrete.

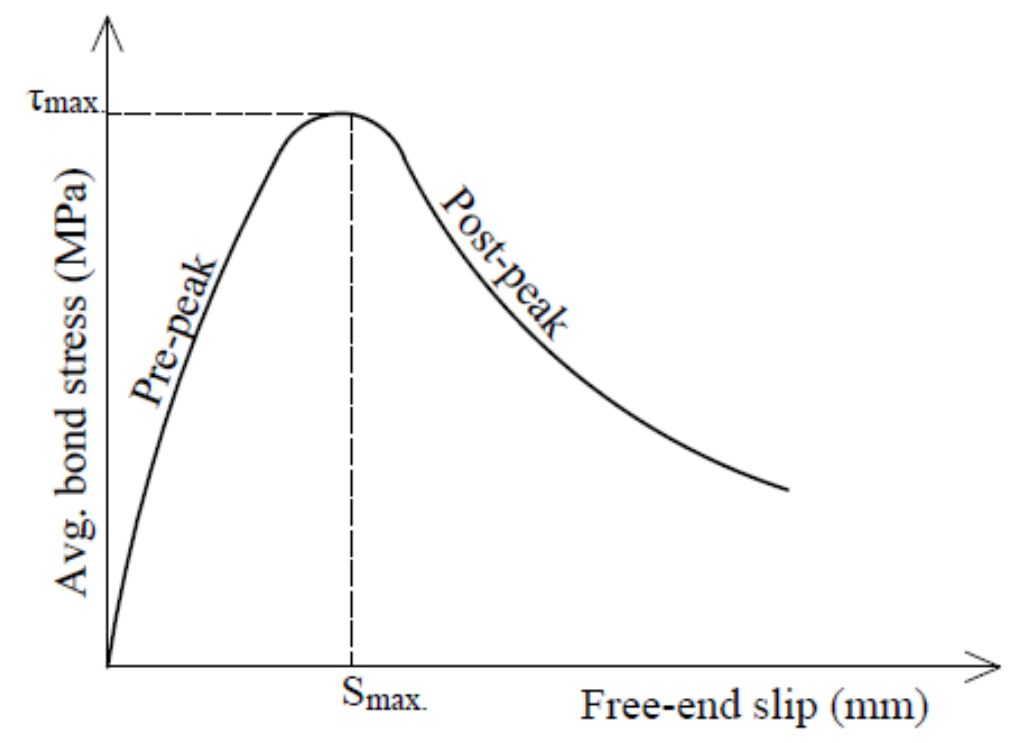

Figure 2. 13 Typical bond stress-slip relationship for GFRP bars

\subsection{Bond Models}

\subsubsection{Bond Model for Steel Bars}

The following sections describe some models on bond stress-slip constitutive laws for steel reinforcing bars in concrete.

\subsubsection{Mirza-Houde Model (1978)}

Mirza and Houde (1978) performed experimental testing on 62 tension specimens and measured the end slip and elongation of embedded bar. On the basis of their work, the following expression was derived based on the experimental data:

$\tau=539.8 S-25610 S^{2}+592200 S^{3}-5574000 S^{4}$

Where, $\tau$ is the bond stress and $\mathrm{S}$ is the relative slip. 


\subsubsection{Bertero, Popov, and Eligehausen Model (BPE Model, 1983)}

Eligehausen et al. (1983) developed the well-known bond-slip law for deformed steel bars that failed through pullout mode of failure. Figure 2.14 shows the constitutive model representing four distinct branches. The following expressions were derived to represent the ascending and descending branches of the model:

$\tau=\tau_{1} \cdot\left(\frac{S}{S_{1}}\right)^{\alpha} \quad$ for $0 \leq \mathrm{S} \leq \mathrm{S}_{1}$

$\tau=\tau_{1} \quad$ for $S_{1} \leq S \leq S_{2}$

$\tau=\tau_{1}-\left(\tau_{1}-\tau_{3}\right) \cdot\left(\frac{S-S_{2}}{S_{3}-S_{2}}\right) \quad$ for $\mathrm{S}_{2} \leq \mathrm{S} \leq \mathrm{S}_{3}$

$\tau=\tau_{3} \quad$ for $S<S_{3}$

Where $\tau_{1}$ is the maximum bond stress, $S_{1}$ is the slip corresponding to the maximum bond stress. $\tau_{3}$ is the residual stress that can be determined from experimental test results along with values for $S_{2}$ and $S_{3}$. The curve fitting parameter, $\alpha$, should be between zero to 1 to be physically meaningful. Eligehausen et al. (1983) suggested a value of $\alpha=0.40$ for deformed steel bars.

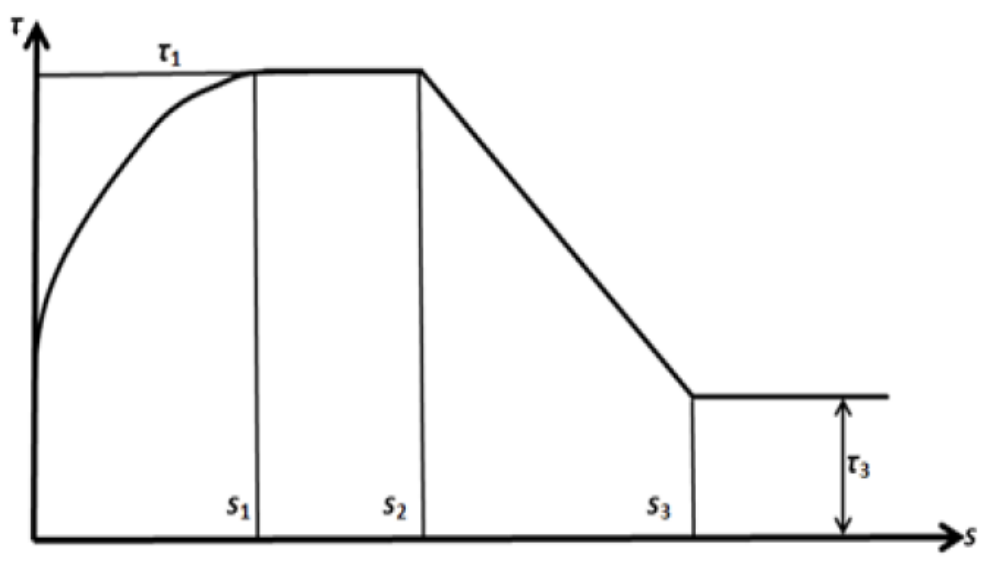

Figure 2. 14 BPE Model (Adopted: Eligehausen et al. 1983)

In this model, the ascending branch represents the stage where the ribs on the reinforcing bars develop adhesion to the concrete, so that local crushing and micro-cracking take place. Thus, in 
this branch, the bond-slip curve nonlinearly increases up to failure point, S1. The horizontal line in this model between $S_{1}$ and $S_{2}$ occurs only for confined concrete, where the advanced crushing and shearing of the concrete between the ribs occur. The descending branch refers to reduced bond stress caused by splitting cracks along the bars. The last horizontal line refers to the residual stress developed by the minimum transverse reinforcement.

\subsubsection{Marti's Model (1999)}

Marti proposed a simplified approach for bond-slip law of steel bars. It was assumed a rigid plastic model that bond stress is constant with respect to variation of the slip. The assumption was made on the basis that the Young's modulus of elasticity of steel varies between elastic and non-elastic region. Therefore, the proposed model for bond stress was composed of two constant values before and after yielding of steel reinforcement. Figure 2.15 shows the rigid plastic model developed for bond-slip relationship before and after yielding of the reinforcement. Thus, the following equations were adopted:
$\tau_{\mathrm{b} 0}=2.0 f_{c t}$
(before yielding)
$\tau_{\mathrm{b} 1}=f_{c t}$
(after yielding)

(Eq. 2.23)

(Eq. 2.24)

Where $f_{c t}$ is the tensile cracking strength of concrete.

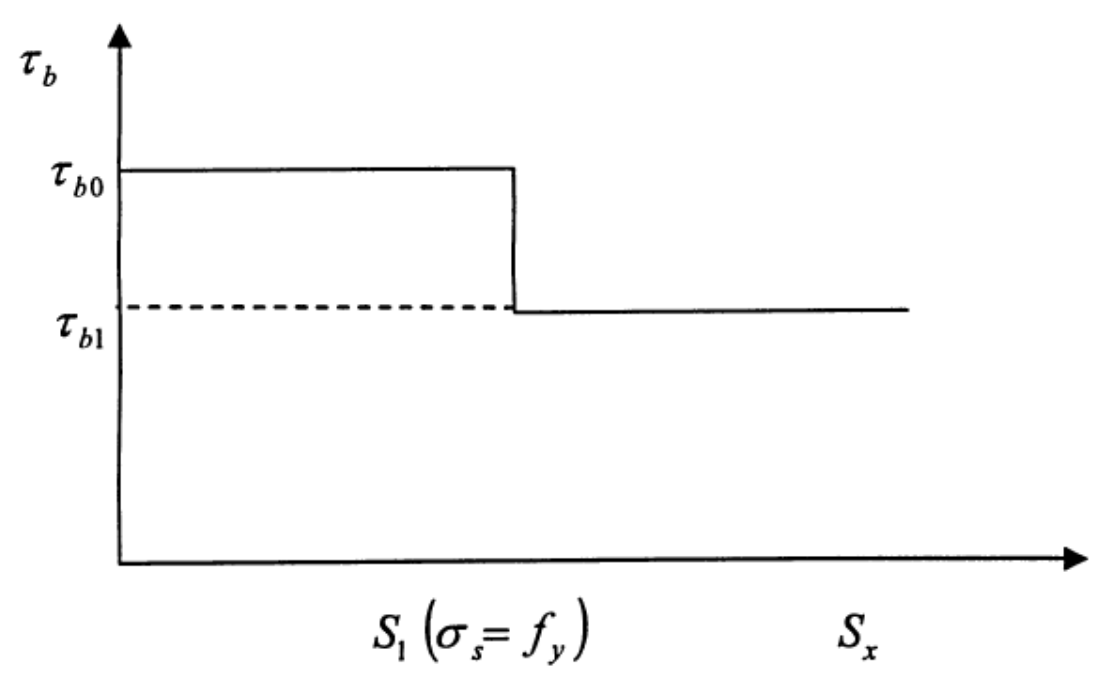

Figure 2. 15 Marti’s bond-slip model (Adopted: Marti, 1999) 


\subsubsection{Bond Model for FRP Bars}

An analytical model of the bond-slip constitutive law for FRP reinforced concrete members is required to carry out numerical analysis of reinforced concrete response and the interaction between concrete and the FRP reinforcement. The following sections briefly explain some of the available bond-slip law for FRP bars in concrete.

\subsubsection{Malvar Model (1994)}

Malvar (1994) proposed the first bond stress-slip law for FRP rods in concrete. The model was proposed on GFRP bars with various outer surface textures. The experimental programs conducted with different level of confinement pressure and a constant value of tensile strength of concrete. From experimental test results, Malvar proposed an overall bond model based on the two constants $F$ and $G$ that can be determined by curve-fitting of experimental bond-slip curves. Therefore, the following bond model was derived:

$\frac{\tau}{\tau_{m}}=\frac{F\left(\frac{S}{s_{m}}\right)+(G-1) \cdot\left(\frac{S}{s_{m}}\right)^{2}}{1+(F-2) \cdot\left(\frac{S}{s_{m}}\right)+G\left(\frac{S}{s_{m}}\right)^{2}}$

Where $\tau_{m}$ and $S_{m}$ are peak bond stress and slip at peak bond stress. F and G are the constant values determined by curve fitting. In addition, Malvar also proposed the following equations to determine peak bond stress and slip at peak bond stress for a given value of confinement pressure;

$\frac{\tau_{m}}{f_{t}}=\mathrm{A}+\mathrm{B}\left(1-\mathrm{e}^{-\mathrm{C} \sigma / f t}\right)$

$\mathrm{S}_{\mathrm{m}}=\mathrm{D}+\mathrm{E} \sigma$

Where $\sigma$ is the confining axisymmetric radial pressure, $f t$ is tensile concrete strength, $\tau_{m}$ is peak bond stress, $\mathrm{S}_{\mathrm{m}}$ is the slip at peak bond stress and A,B,C and D are empirical constants determined for each bar type. 


\subsubsection{Modified BPE Model}

The application of BPE model was successfully applied to bond behavior of FRP bars in concrete by researchers: Faoro (1992), Aluno Rossetti et al. (1995), Cosenza et al. (1995), Focacci et al. (2000) and Pecce et al. (2001). Cosenza et al. (1996) proposed modification to the BPE mode in that the bond-slip curve of experimental FRP bars has shown lack of the second branch. The modified BPE model shown in Figure 2.16 represents the same ascending branch as BPE model, with the second horizontal branch is neglected, and a softening branch having a slope of p. $\tau_{1} / S_{1}$ from $\left(S_{1}, \tau_{1}\right)$ to $\left(S_{3}, \tau_{3}\right)$. Thus, the following equation was adopted for the descending branch;

$\frac{\tau}{\tau_{1}}=1-\mathrm{p}\left(\frac{S}{S_{1}}-1\right)$

The last branch is a horizontal branch at $\mathrm{S}>\mathrm{S}_{3}$ represents the friction component of reinforcement $\left(\tau_{3}\right)$. The modified BPE model is more appropriate for FRP bond model than the original BPE model and the parameters $\mathrm{p}$ and $\alpha$ must be determined by curve fitting of experimental results.

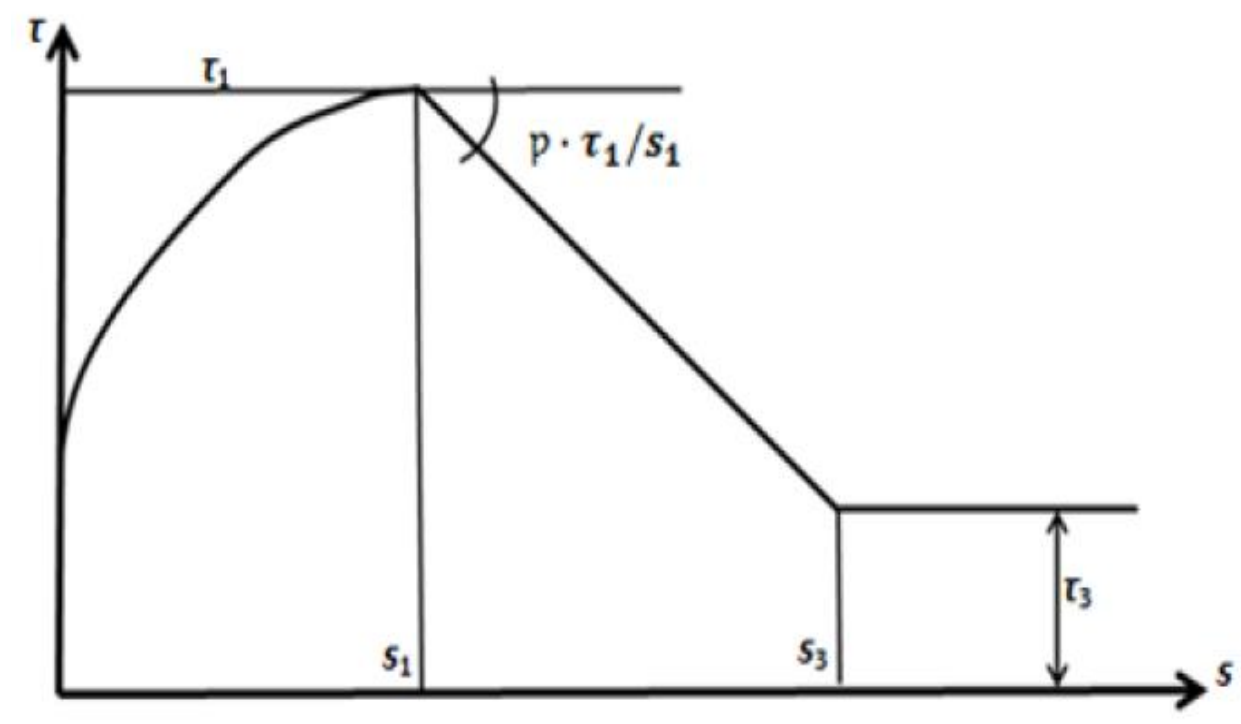

Figure 2. 16 Modified BPE model (Adopted: Cosenza et al. 1997) 


\subsubsection{Cosenza, Manfred, and Realfonzo Model (CMR Model, 1995)}

A more refined method is needed for the ascending branch of bond-slip curve due to the fact the most structural problems are to be dealt with at serviceability limit state level (Cosenza et al. 1997). For such a reason, a new model was proposed by Cosenza et al. (1995) to represent the ascending branch of bond stress-slip curve. The model was regarded as an alternative to the BPE model and defined as follow:

$\frac{\tau}{\tau_{m}}=\left(1-\mathrm{e}^{\mathrm{S} / \mathrm{Sr}}\right)^{\beta}$

Where $\tau_{m}$ is the peak bond stress, $S_{\mathrm{r}}$ and $\beta$ are to be determined based on the curve fitting of experimental test data.

\subsection{Bond Properties of FRP Bars in Literatures}

\subsubsection{Bond Strength of FRP Bars}

The trend in the literature have shown that the average bond strength of concrete structures reinforced with GFRP bars are found to be approximately $60 \%$ to $90 \%$ to that of conventional steel reinforcement, depending on the bar diameter and the embedment depth (Nanni et al. 1995). This trend was observed by experimental tests conducted in both pullout and beam tests. Table 2.7 summarizes results of the experimental tests in the literatures that have been conducted on GFRP bars by either pullout or beam tests.

\subsubsection{Embedment Length of FRP Bars}

The effect of embedment length of FRP bars on bond properties have been investigated by several authors namely as: Makitani et al. (1993), Tighiouart et al. (1998), Consenza et al. (1999) and Achillides and Pilakoutas (2004). Based on experimental programs conducted by pullout or beam testing of FRP bars in concrete, it was observed that as the embedment length increases the average ultimate bond stress decreases due to the fact that the increase in the pullout load is not proportional to the increase in the embedment length. Achillides and Pilakoutas (2004) explained this phenomenon due to non-linear distribution of bond stress along the embedded length of the 
bar in longer embedment lengths. However, in short embedment lengths the effect of nonlinearity may be solved, but more experimental tests may be required.

Table 2. 7 Pullout and beam test results in the literature

\begin{tabular}{|c|c|c|c|c|c|c|}
\hline Authors & $\begin{array}{c}\text { Test } \\
\text { method }\end{array}$ & $\begin{array}{c}\mathrm{d}_{\mathrm{F}}{ }^{*} \\
(\mathrm{~mm})\end{array}$ & $\begin{array}{c}\mathrm{L}_{\mathrm{d}}{ }^{*} \\
\left(\text { No. of } \mathrm{d}_{\mathrm{F}}\right)\end{array}$ & Bar type & $\begin{array}{c}\mathrm{f}_{\mathrm{c}}{ }^{*} \\
(\mathrm{MPa})\end{array}$ & $\begin{array}{c}\tau_{\text {avg }}{ }^{*} \\
(\mathrm{MPa})\end{array}$ \\
\hline Rossetti et al. 1995 & Pullout & 12 & 5 & GFRP & 54 & 0.95 \\
\hline Benmokrane et al. 1996 & Beam & 16 & 10 & GFRP & 31 & 7.3 \\
\hline \multirow{2}{*}{ Ehsani et al. 1996 } & Beam & \multirow{2}{*}{19.05} & 8 & GFRP & 27.5 & 7.6 \\
\cline { 2 - 4 } & Pullout & & & & 32.1 & 10.10 \\
\hline \multirow{2}{*}{ Tighiourat et al. 1998 } & Pullout & 16 & 10 & GFRP & 37 & 10.8 \\
\cline { 2 - 3 } & Beam & 19.05 & & & 31 & 6.6 \\
\hline Pecce et al. 2001 & Beam & 12.7 & 5 & GFRP & 39 & 13.9 \\
\hline Harajili et al. 2004 & Beam & 16 & 5 & GFRP & 41 & 8.5 \\
\hline Mosley et al. 2008 & Beam & 16 & 19 & GFRP & 41 & 2.95 \\
\hline
\end{tabular}

$* \mathrm{~d}_{\mathrm{F}}=$ FRP bars diameter, $\mathrm{L}_{\mathrm{d}}=$ embedment length, $\mathrm{f}_{\mathrm{c}}^{\prime}=$ concrete compressive strength and $\tau_{\text {avg }}=$ average bond strength

It is also stated by some authors that if the embedment length is greater than the development length of the bar in concrete, the bar slippage at free-end will not occur; thus the bar develops its full strength. According to Pecce et al. (2001) at embedment lengths greater than $20 \mathrm{~d}_{\mathrm{F}}$ and according to Ehsani et al. (1996) at embedment lengths greater than $16 \mathrm{~d}_{\mathrm{F}}$, the rebar rupture took place prior to failures by pullout or side splitting. Table 2.8 below summarizes some of the experimental study conducted on the effect of embedment length of FRP bars on bond strength.

\subsubsection{Surface Profile}

Similar to steel bars, it is recommended that not to use smooth GFRP bars in concrete due to the loss of friction and mechanical interlock between the bar and the concrete. Various FRP manufacturing companies use different surface profile to improve the bond interaction between FRP bars and the concrete. Some of the surface profile approved by the design code may include; sand-coated, helical or braided wrapping, spiral, ribbed and indented. 
Table 2. 8 Effect of embedment length on bond strength of FRP bars

\begin{tabular}{|c|c|c|c|c|}
\hline Authors & $\begin{array}{c}\mathrm{d}_{\mathrm{F}} \\
(\mathrm{mm})\end{array}$ & $\begin{array}{c}\mathrm{L}_{\mathrm{d}} \\
\text { (No. of } \mathrm{d}_{\mathrm{F}} \text { ) }\end{array}$ & $\begin{array}{c}\mathrm{f}^{\prime} \mathrm{c} \\
(\mathrm{MPa})\end{array}$ & $\begin{array}{c}\tau_{\mathrm{avg}} \\
(\mathrm{MPa})\end{array}$ \\
\hline \multirow{2}{*}{ Makitani et al. 1993} & \multirow{2}{*}{12} & 10 & 30 & 15 \\
\hline & & 20 & 26 & 11.4 \\
\hline \multirow{2}{*}{ Tighiourat et al. 1998} & \multirow{2}{*}{12.7} & 6 & 30 & 11.3 \\
\hline & & 16 & 31 & 8.7 \\
\hline \multirow{2}{*}{ Cosenza et al. 1999} & \multirow{2}{*}{12.7} & 5 & \multirow{2}{*}{39} & 16.5 \\
\hline & & 10 & & 14.5 \\
\hline \multirow{2}{*}{ Achillides and Pilakoutas, 2004} & \multirow{2}{*}{13} & 6 & \multirow{2}{*}{46} & 11.9 \\
\hline & & 10 & & 9.1 \\
\hline
\end{tabular}

Due to the differences in the surface profile of FRP bars, many experimental programs have been conducted by the authors to study this effect (Makitani et al. 1993, Rossetti et al. 1995 and Malvar et al. 2003). Most experimental program showed better performance of FRP bars with roughened or sand-coated surface profile when compared to other surface profiles such as braided wrapping. In addition, the bars with sand-coated surface showed smaller free-end slip at failure load compared to the bars with indented or ribbed bars. Table 2.9 summarizes some of the experimental programs comparing the effect of surface profile on bond strength of FRP bars. The variety of test results in Table 2.9 may be attributed to the lack of standard manufacturing process of FRP bars, since the bond mechanism of FRP bars in concrete depend on surface geometry, type of resin and bars mechanical properties (Cosenza et al. 1997).

\subsection{Review of Relevant Literatures}

\subsubsection{Pullout test of bars in concrete}

Few authors dealt with pullout failure of reinforcing steel bars in concrete. Among them, Harajli et al. (2004) studied the effect of confinement on bond strength between steel bars and concrete and produced a splitting and pullout failure bond-slip relationship for steel bars in confined and plain concrete. The relationship between bar size and bond strength of FRP bars in concrete has been investigated by few researchers (among them, Hao et al., 2009; Baena, et al., 2009; 
Achillides and Pilakoutas, 2004; Tighiouart et al., 1998; Benmokrane et al., 1996). Similar to steel bars, it is evident that deformed bars produce a significantly higher bond than plain bars due to the mechanical interlocking between the surface of the bar and the surrounding concrete (Cosenza et al., 1997).

Table 2. 9 Effect of surface profile on bond strength of FRP bars

\begin{tabular}{|c|c|c|c|c|c|c|}
\hline Authors & Surface profile & $\begin{array}{c}\mathrm{d}_{\mathrm{F}} \\
(\mathrm{mm})\end{array}$ & $\begin{array}{c}\mathrm{L}_{\mathrm{d}} \\
\left(\text { No. of } \mathrm{d}_{\mathrm{F}}\right)\end{array}$ & $\begin{array}{l}\text { Bar } \\
\text { Type }\end{array}$ & $\begin{array}{c}\mathrm{f}^{\prime} \mathrm{c} \\
(\mathrm{MPa})\end{array}$ & $\begin{array}{c}\tau_{\text {avg }} \\
(\mathrm{MPa})\end{array}$ \\
\hline \multirow{3}{*}{ Makitani et al. 1993} & Sand-coated & \multirow{3}{*}{12} & \multirow{3}{*}{10} & \multirow{3}{*}{ CFRP } & 27 & 13.6 \\
\hline & Helical strands & & & & 29 & 13.4 \\
\hline & $\begin{array}{l}\text { Sand-coated and } \\
\text { braided strands }\end{array}$ & & & & 30 & 15.9 \\
\hline \multirow{4}{*}{ Rossetti et al. 1995} & Smooth & \multirow{2}{*}{8} & \multirow{4}{*}{5} & \multirow{4}{*}{ GFRP } & \multirow{4}{*}{54} & 1.36 \\
\hline & Rough & & & & & 1.79 \\
\hline & Smooth & \multirow{2}{*}{12} & & & & 0.94 \\
\hline & Rough & & & & & 2.86 \\
\hline \multirow{2}{*}{ Malval et al. 2003} & Sand-coated & 8.2 & 9.3 & \multirow{2}{*}{ CFRP } & 51 & 2.20 \\
\hline & Ribbed & 10.2 & 10.2 & & 34 & 4.20 \\
\hline
\end{tabular}

\subsubsection{Effect of concrete and GFRP properties on bond behavior}

Other research conducted by Hao et al. (2009) on 90 pullout specimens of GFRP bars with different rib spacing showed that the bond strength is affected by the rib spacing. Ehsani et al. (1996) conducted tests on 102 specimens with GFRP bars to investigate the effect of concrete cover on bond strength. The study showed that the concrete cover had a significant effect on the type of bond failure. The effect of concrete strength on the bond behavior was studied by Makitani et al. (1993), Benmokrane et al. (1996) and Tighiouart et al. (1998). It was concluded that the bond strength increases is proportional to the square root of the compressive strength of concrete. Hao et al. (2008) studied bond strength of glass fiber reinforced polymer ribbed bars in normal strength concrete. Pullout test has been performed on 30 specially designed GFRP ribbed bars with test variables of; bar diameter, rib spacing, and rib height. Bond failure mode, the average bond strength, slip at the loaded end, the initial bond stiffness and bond-slip relationship curves were analyzed for each test specimens. In experimental study, pullout specimens with centric loading have been carried out to determine the bond-slip relationship between GFRP bars 
and concrete. It was found that bond strength and bond-slip performance of the bars varied with relative rib area which is the ratio of projected rib area normal to the direction of bar axis to the normal bar perimeter and center-to-center rib spacing. In pullout test of the specimens, most specimens failed by pull-through mode of failure. However, there were cases that bond failure took place by peeling of the surface layer of the bars. Also, design recommendations for bond between GFRP/Steel wires composite bars and concrete were studied by Hao et al. (2008). GFRP/ Steel composite inherit several advantages over GFRP or ordinary steel bars due to its high tensile strength, high elastic modulus and good ductility behavior. The research was aimed to study the bond characteristics between GFRP/Steel composites and concrete. Thus, a total of 180 pullout specimens were examined under monotonic static loading based on ACI code specifications. The test variables included; rib spacing, bar diameter, embedded length, concrete compressive strength, concrete cover thickness and concrete cast depth. Due to relatively low elastic modulus and absence of a well-defined yield plateau of GFRP bars, non-corrosion GFRP/Steel composite provides high ductility and elastic modulus with tensile strength of larger than ordinary steel bars. Stress-strain relationship of GFRP/Steel composite bars is similar to yielding characteristics of ordinary steel bars making these composite bars a superior alternative to ordinary steel bars in concrete structures. The test results revealed that concrete cover has a significant effect on bond failure mode of GFRP/Steel composite bars. If the concrete cover ranges from 1-3 times the rebar diameter, splitting failure will occur, while for concrete covers equal or greater than three times the bar diameter, pullout failure or rupture of bars will happen. Chaallal et al. (1993) conducted experimental study of pullout behavior and bond characteristics of glass fiber reinforced polymer embedded in normal and high strength concrete and cement grout. A total of 18 series of test (four identical tests for each test) have been carried out. Twelve series were conducted to evaluate the optimal anchorage length and six series were prepared to examine the effect of top cast rods. The 18 series where designed to investigate the effect of GFP rod diameter, concrete strength and embedment depth. Concrete compressive strength of $30 \mathrm{MPa}$ as normal strength and $80 \mathrm{MPa}$ as high-strength concrete were used to study the effect of concrete strength on bond behavior of GFP rods, development length and the modification factor for the use of top reinforcement. Cement grout also has been used as an embedment medium to simulate anchoring systems. The GFP bars used in the study had diameter of 12.7, 15.9 and $19.1 \mathrm{~mm}$ possessing surface deformation and sand-coating for higher performance. The 
embedment lengths of 5or 10 times bar diameter were considered. The experimental results showed that bond strength of GFP bars is about $12 \mathrm{MPa}$ in concrete and about $4 \mathrm{MPa}$ in cement grout with an optimal anchorage length of 10 times the bar diameter. In addition, an average modification factor of 1.23 for effect of top reinforcement in normal strength concrete and 1.18 in high-strength concrete has been introduced.

\subsubsection{Pullout tests of GFRP bars by beam test}

Ehsani, et al. (1997) studied bond behavior of FRP bars by direct pullout test using beam test reinforced with FRP bars. The test variables comprised of testing 18 pullout specimens with varying bar size, embedment length and comparing the results with 48 beam tests. In this study, Ehsani, et al. (1997) concluded that the development length measured using direct pullout method is found to be rather un-conservative. Precise analysis of the test data for the pullout test showed that the ultimate bond stresses increased by an average of $13 \%$. The results of pullout test method were compared with beam tests and Ehsani, et al. (1997) concluded that beam tests provide more accurate evaluation of bond behavior of reinforcement in concrete.

Bond strength of Glass Fiber Reinforce Polymer (GFRP) in concrete beam members were tested experimentally by Tighiouart et al. (1998) and the results were compared with that of steel reinforcement. The test variables of the study include; FRP bar types, FRP and steel bar size, embedment length and concrete depth. A total of 64 concrete beams including two types of FRP bars were tested. Bar diameters considered in the study were 12.7, 15.9, 19.1 and $25.4 \mathrm{~mm}$ for both FRP and steel bars. The embedment length was chosen as 6,10 and 16 times the bar diameter, while the concrete depths of 200, 600 and $1000 \mathrm{~mm}$ were investigated in 18 pullout test specimens. Bond tests using beams were investigated in accordance with RILEM specifications. The beam test specimens consisted of two concrete blocks joined at the top by a

steel ball and at the bottom with FRP or steel bars for the aim of bond strength evaluations. In addition, the direct pullout test was performed for the effect of top bar reinforcement. Comparison of the test results showed that the average bond strength between GFRP bars and concrete decrease with the increase of bar diameters. They also found that by increasing the embedment depth, the applied tensile load of the bars approach the tensile capacity of the bars. In FRP bars, the adhesion and friction controls the bond behavior of the bars. In addition, they 
concluded that bond strength developed in FRP bars was found to be lower than that of steel reinforcements. For the effect of top reinforcements, they recommended a factor of 1.30 to be employed to account for the effect of top reinforcement.

\subsubsection{Miscellaneous literature on bond behavior of GRFP bars}

Benmokrane et al. (1996) studied the bond behavior of GFRP bars in concrete structures using pullout test. The results stated that the deformed GFRP bars failed in pullout due to low bearing stresses produced in the concrete/ deformed bar interface. The use of transverse reinforcement in the slabs provides confinement to anchored bars to limit splitting cracks and therefore increases bond strength (Darwin and Graham, 1993). Few authors performed pullout and bond tests on FRP bars (Ahmed et al., 2008; Cosenza et al., 1997; Chaallal and Benmokrane, 1993). While others developed analytical models for the bond between FRP bars and concrete (Cosenza et al., 1997, 1996 and 1995; Malvar, 1994; Eligehausen et al., 1983; Faoro 1992; Rossetti et al., 1995; Focacci et al., 2000; Pecce et al., 2001). Other researchers (Alunno et al. 1995) studied the local bond stress-slip relationships of glass fiber reinforced plastic (GRP) bars embedded in concrete. The bond relationships between glass fiber reinforced bars and concrete has been studied to investigate the use of these bars as reinforcement of concrete constructions when ordinary steel bars are matter of concern in corrosive environments. The tests were conducted on 13 specimens with diameters of 8 and $12 \mathrm{~mm}$ and smooth or rough surfaces. The tests were performed on 200 $\mathrm{mm}$ cubic concrete specimens with embedded length of $5 \mathrm{~d}_{\mathrm{b}}$ for each specimen. The following experimental results were observed; (1) Mechanical properties of GFRP bars such as mean tensile strength $\mathrm{f}_{\mathrm{t}}$, relative strain, $\epsilon_{\mathrm{u}}$, and elastic modulus, $\mathrm{E}$, are not dependent on diameter and surface types of the bars; (ii) there was comparable results between tensile strength of GFRP bars and plain steel bars; (iii) The stress-strain curve did not show any plastic behavior and Hook's law observed until failure; (iv) The maximum allowable stress of GFRP bars are limited to onehalf of the characteristic tensile strength, $\mathrm{f}_{\mathrm{t}}$, due to the absence of plastic behavior in the bars; (v) The elastic modulus is approximately $1 / 5$ to $1 / 7$ of that plain steel bars. GFRP bars with smooth and rough surfaces showed high tensile strength, which was comparable to that plain steel bar; however, due to the ductility of GFRP bars, the stress-strain diagram remained linear until failure. It is not advisable to use GFRP bars with smooth surface as reinforcement in concrete structures since they revealed low bond strength with concrete compared to that of rough surface. 
Also, a safety factor of equal or greater than 2 has been suggested due to the absence of plastic behavior in the bars. The experimental and analytical model of rough GFRP bars showed that rough GFRP bars are beneficial for following applications; relatively lightly stressed concrete structures exposed to particularly aggressive environments; longitudinal and transverse joints of concrete pavements, consolidation of historical buildings and monuments through injected bar reinforcements especially if large quantity of chloride ions are present.

Experimental study of bond behavior between concrete and FRP bars using pullout test was performed by Baena et al. (2009). The study presents experimental results of pullout test on 88 concrete specimens based on ACI 440-3R-04 and CSA S806-02. Carbon-fiber, Glass-fiber and steel bars with constant embedment depth of five times the rebar diameter have been investigated. The test variables include; bar surface, rebar diameter, fiber type and concrete strength. The global behavior of bond stress-slip relationship is presented by an initial increase in the bond stress at little slippage, followed by softening of the curve when the maximum bond stress is reached. Bond of the bars prior to failure can be attributed to the bearing of deformed bars, adhesion and friction between the bar and concrete. Once this contact (adhesion) is failed, different failure behavior can be proposed for different surface treatment. For non-deformed bars, the bar surface played an important role in the bond strength, increasing the importance with increase in concrete strength. Thus, it is observed that failure mode of the bars is located at the interface between concrete and the bars or by internal debonding of the bar itself. The effect of concrete strength on bond was also investigated in this study. The strength of concrete affects the bond failure mode of bars during pullout test. As indicated by other literatures, for concrete with compressive strength greater than $30 \mathrm{MPa}$, the bond failure takes place at the surface of FRP bars presenting that bond failure mode is not dependent significantly on the compressive strength of concrete. However, for concrete with lower compressive strengths (around 15MPa), the bond failure mode alters and failure occurs at concrete interface matrix. The mean bond strengths obtained for different bars showed that higher concrete strength provides higher bond strength. Generally, bond behavior between FRP bars and concrete found to be dependent on many factors including; concrete compressive strength, bar diameter and surface treatment. It was also observed that the effect of bar surface treatment is less important in concretes with lower compressive strength compared to that of higher concrete compressive strength. 
The bond behavior of Eurocrete fiber reinforced polymer (FRP) bars made of glass, carbon, aramid and hybrid in concrete using direct pullout test was investigated by Achillides et al. (2004). In this study, over 130 concrete cube specimens were tested in direct pullout test preventing the cubes from splitting. Achillides et al. (2004) investigated the influence of different parameters on bond strength such as embedment length, type, shape, surface characteristics, bar size and concrete strength. The embedment depth of the bars were designed as multipliers of the bar diameter to facilitate the comparison of different bar diameters. Pullout test was performed as a commonly used test method for the assessment of bond behavior of reinforced concrete members. In this study the RILEM/CEB/FIP pullout arrangement has been further investigated for the aim of bond test to obtain bond-slip relationship at the loaded and free ends of FRP bars subjected to a pullout load. The specially designed pullout arrangement provided an adequate confinement to the bars so that all specimens were failed in pull-through mode of failure; therefore, the maximum bond strength has been reached in the bars. Also, it was observed that for concrete strength greater than $30 \mathrm{MPa}$, failure occur either in concrete or by peeling of the surface layer of the bars rather than in concrete only as is the case for deformed steel bars. Thus, the mode of failure of FRP bars in normal concrete was found to be different from that of deformed steel reinforcement due to damage of resin rich surface occurred when pullout load occurred. In addition, they found that the inter-laminar shear strength just below the resin rich surface layer of the bars is controlled mainly by bond strength of FRP bars, however for concrete strength less the $15 \mathrm{MPa}$, concrete crushed at concrete-FRP bar interface and the shear strength of concrete controlled the bond strength. Compared to hybrid and aramid bars,

carbon fiber polymer and glass fiber polymer developed very similar bond strength characteristic; just below what was expected for deformed steel bars under similar experimental conditions. Achillides et al. (2004) also found that bond strength decreases with the increase in the embedment depth of the bars. In addition, smaller diameter bars produced higher bond strength than larger bar size, while, the square shape bars developed up to $25 \%$ higher bond strength than round shape bars.

\subsection{CHBDC Concrete Traffic Barriers}

Steel-reinforcement is commonly being used in reinforced concrete structures, such as bridge barrier walls. In cold regions, however, when steel-reinforcement is used, they can be exposed to 
harsh environmental conditions, which result in corrosion of steel reinforcement and consequent deterioration. The use of glass fiber-reinforced polymer (GFRP) bars with its corrosion resistant nature in lieu of steel bars will eliminate corrosion related problems resulting from the use of deicing salt in winter time and increase the service life of the structure. However, design of traffic barriers reinforced with GFRP bars should meet requirements of the CHBDC. Bridge barriers and bridge rails designed to date were required to meet the requirement for crash and safety in accordance with National Cooperative Highway Research Program (NCHRP) Report 350. The design forces for bridge rails specified in Canadian Highway Bridge Design Code (CSA, 2006a and CSA 2006b) is based on the AASHTO-LRFD Guide Specification for Bridge Rails (AASHTO, 1989) that corresponds to the test levels stipulated in NCHRP Report 350, "Recommended Procedures for the Safety Performance Evaluation of Highway Features" (Ross et al., 1993). This report contains six test levels for longitudinal barriers. Test levels 1 through 3 (TL-1 to TL-3) relate to the passenger vehicles (820 to $2000 \mathrm{~kg}$ ) and vary by impact speed and impact angle. Test levels 4 through 6 retain consideration of passenger cars, but also incorporate consideration of heavy trucks $(8,000$ to $36,000 \mathrm{~kg})$. Accordingly, Canadian Highway Bridge Design Code (CHBDC) requires that the appropriateness of bridge barrier anchorage system to the deck should be based on its performance during crash testing of the traffic barriers. The crash testing of the bridge barriers is carried out to investigate suitability of traffic barriers against structural adequacy, occupant risk and vehicle trajectory after the collision. The purpose of the concrete traffic barriers is to redirect an errant vehicle in a controlled manner in the event of a collision. The vehicle shall not penetrate, over-turn or roll-over the traffic barriers. It should not also cause a secondary accident with vehicles in other lanes. In addition, the traffic barriers should have sufficient strengths to endure the primary impact caused by the collision and remain effective in redirecting the vehicles after the impact. The evaluation of vehicle crashworthiness has involved numerous full-scale crash tests of the vehicle and highway hardware to verify the compliance with regulatory requirements (Alberson et al., 2005; Reid et al. 2001; Plaxico et al. 2000; Pfeifer and Sicking, 1997).

The CHBDC specifies requirements for the design of traffic barriers in Section 12, in which the barrier are divided into four different types based on their functions, namely as: traffic barrier, pedestrian barrier, bicycle barrier and combination barrier. For evaluation of a barrier, general 
factors shall be considered in addition to the basic strength requirements such as: durability, ease of repair, visibility through or over barrier, deck drainage, snow accumulation on and snow removal from the deck, future wearing surfaces and aesthetics. For a damaged barrier, the damage should be repaired quickly with minimum disruption caused to traffic. In addition, the CHDBC allows examining the suitability of the traffic barriers based on the static test tocomplete-collapse of the traffic barriers in lieu of vehicle crash test. However, the ultimate strength of traffic barriers tested under static load should be greater than the maximum transverse load limits specified in the CHDBD, that is $357 \mathrm{kN}$ and $170 \mathrm{kN}$ for Performance Level 3 (PL-3) and Performance Level 2 (PL-2) traffic barriers, respectively. The corresponding values in AASHTO-LRFD are $550 \mathrm{kN}$ (124 kips) and $240 \mathrm{kN}$ (54 kips) for Test Level 5 (TL-5) and (TL4), respectively.

\subsection{Traffic Barriers and Performance Level}

In accordance with the CHBDC, traffic barriers should be provided on both sides of the highway bridges to define the superstructure edges in reducing the consequences of vehicle leaving the roadways during the event of an accident. To reduce these consequences, crash tests are to be used to examine adequacy of the traffic barriers. The adequacy of a traffic barrier in reducing the occurrence of an accident is based on the level of the protection provided to: occupants in the vehicle, vehicles in other lanes, and people, workers and properties in the area. These levels of protection are provided if: vehicles do not over-turn the traffic barriers, redirect and travel along the barrier in the same lane without penetration to the other lanes. The requirement for the traffic barriers is also categorized based on their performance levels that are dependent on site conditions, expected frequency and consequences of vehicle accidents on the site. These performance levels depend on traffic volume, percentage of trucks in traffic mix, highway type, barrier clearance, highway curvature, highway design speed, superstructure height above the ground level, number of people at risk beneath the bridge and hazards existing beneath the bridge. Based on the specified levels, CHBDC classifies three performance levels for traffic barriers in reducing the consequences of vehicles leaving the roadways. These performance levels follow that: 
Performance Level 1 (PL-1): The expected frequency and the consequence of vehicle leaving the roadway for this performance level is similar to those expected on low-traffic volume roads. This performance level requires crash testing with a small automobile or a pickup truck as specified in the CHBDC with appropriate impact angle and speed.

Performance Level 2 (PL-2): The expected frequency and the consequence of vehicle leaving the roadway for this performance level is similar to those expected on high- to- moderate traffic volume highways. This performance level requires crash testing with a small automobile, a pickup truck and a single unit truck as specified in the CHBDC with appropriate impact angle and speed.

Performance Level 3 (PL-3): The expected frequency and the consequence of vehicle leaving the roadway for this performance level is similar to those expected on high-traffic volume highways with high percentage of truck. This performance level requires crash testing with a small automobile, a pickup truck and a tractor-trailer as specified in the CHBDC with appropriate impact angle and speed.

Under section 12.4.3.2.2, the CHBDC also specifies that alternative performance levels should be approved by the Regulatory Authority and should meet the requirement of crash testing. These performance levels may be considered along with performance levels 1, 2 and 3 when defining the optimum performance level. Also, the CHBDC clause 12.4.3.3 (Table 12.8 in the CHBDC) requires barrier height for the PL-1, PL-2 and PL-3 traffic barriers to be 680, 800 and 1050-mm, respectively. The barrier heights specified above, are meant to be the minimum heights required for each of the performance level, and generally are adequate for containing the vehicles. The traffic barrier height requirements anticipate preventing vehicles from vaulting or rolling over a traffic barrier. As the center of gravity of the impacting vehicle increases, the required traffic barrier height will also be increased to contain the vehicle. In case, when a traffic barrier is located between the roadway and a sidewalk or bikeway, the sidewalk or bikeway shall have a smooth surface without snag points with a minimum height of $600-\mathrm{mm}$ measured from the surface of the sidewalk or bikeway. 


\subsubsection{Determination of Barrier Exposure Index}

The barrier exposure index, $\mathrm{B}_{\mathrm{e}}$, is used to determine the barrier performance level. With this approach, the performance level can be evaluated based on the estimated average annual daily traffic for the first year after the construction, $\mathrm{AADT}_{1}$, which is limited to a maximum of 10,000 vehicles per day per traffic lane and vehicle speed of $80 \mathrm{~km} / \mathrm{h}$ or greater. To calculate the barrier exposure index, the $\mathrm{AADT}_{1}$ should be multiplied by highway type $\left(\mathrm{k}_{\mathrm{h}}\right)$, highway curvature $\left(\mathrm{k}_{\mathrm{c}}\right)$, highway grade $\left(\mathrm{k}_{\mathrm{g}}\right)$ and superstructure height factors $\left(\mathrm{k}_{\mathrm{s}}\right)$ as follows:

$\mathrm{B}_{\mathrm{e}}=\left(\mathrm{AADT}_{1} \cdot \mathrm{K}_{\mathrm{h}} \cdot \mathrm{K}_{\mathrm{c}} \cdot \mathrm{K}_{\mathrm{g}} \cdot \mathrm{K}_{\mathrm{s}}\right) / 1000$

Where the values of $\mathrm{k}_{\mathrm{h}}$, $\mathrm{kc}, \mathrm{kg}$, and $\mathrm{k}_{\mathrm{s}}$ are specified in Tables 12.1 to 12.4 of the CHBDC. Based on the estimated barrier exposure index, vehicle speed and the percentage of vehicle in the mix, the optimum performance level can be determined from Tables 12.5 to 12.7 of the CHBDC.

\subsection{Crash Test Requirements}

In accordance with CHBDC clause 12.4.3.4, traffic barriers shall meet the crash test requirements based on the optimum performance level mentioned above. The crash test requirements for performance levels 1,2 and 3 shall be determined based on the AASHTO Guide Specifications for Bridge Railings (AASHTO-1989), unless otherwise, the crash test requirements shall be approved based on alternative performance levels specified in clause 12.4.3.2.2. However, crash test requirements shall be satisfied along entire length of a traffic barrier, when considering changes in barrier type, shape, alignment, or strength that affect the barrier performance. The crash test requirements for longitudinal barrier specified in the AASHTO-LRFD as Test Levels 2, 4 and 5 of NCHRP Report 350 shall meet the crash test requirements for Performance Levels 1, 2 and 3, respectively. The traffic barrier transitions also shall meet the crash test requirements used for appraising the approach roadway traffic barrier. In case, when the traffic barrier is located on a bridge sidewalk or curb, the crash test requirements shall be satisfied with the barrier placed on a similar curb or sidewalk. 


\section{15 Anchorage System}

Traffic barriers should be designed with anchorage systems so that the damage shall not occur to them or cause damage to the bridge deck during a collision event. The capability of the traffic barrier during crash testing can be evaluated primarily based on the performance of its anchorage system. The CHBDC requires that suitability of an anchorage system in a traffic barrier should be based on its performance during crash test. However, it is also stated that if crash testing of barrier for the anchorage is not available, the anchorage and deck shall be designed to resist the maximum bending and shear force transmitted to them at the barrier-deck interface. These forces can be estimated based on the maximum transverse load limits specified in the CHBDC that can be transferred to the base of the wall as well as the deck slab.

\subsection{Transverse Moment and Tensile Force in Traffic Barriers}

The specified traffic loads are based on the performance levels during vehicular impact that are determined by the applicable crash test requirements. CHBDC specifies transverse, longitudinal and vertical service loads on the traffic barriers shown in Table 2.10 that shall be applied simultaneously on the traffic barriers. These load effects are generated during a crash test when an errant vehicle impacting the traffic barriers. These loads should be used in the design of traffic barrier anchorage system and deck only for each of PL-1, PL-2 and PL-3 traffic barriers when subjected to specified line load at specific height of load application (see Table 2.10). Transverse loads provide the dominate loading on the base of traffic barriers and deck slab compared to the longitudinal and vertical loads. The transverse loads create bending moment and shear force at base of the traffic barriers, while it produces bending moment and tensile forces in the deck slab. Due to applied transverse loads, the loads distribute in the barrier wall and deck slab with dispersal angles shown in Table C5.4 of CHBDC Comentary (CSA-S6.1, 2006). The specified loads provided in Table 2.10 incorporate a live load factor of 1.7 to obtain the associated design load of the traffic barriers. The resulting force effects due to horizontal loads alone in the deck slab can be determined and superimposed on the analysis results along with vertical loads applied to the traffic barriers. To determine the transverse load effects, CHBDC presents simplified methods of analysis. It should be noted that in determination of moment and tensile

force intensities, a constant cantilever deck slab length at the exterior edge or face of the barrier wall equal to $1.5 \mathrm{~m}$ was considered. This cantilever length can be increased by linear dispersion 
equal to 0.8 times the distance between the longitudinal length of the deck slab being analyzed and the face of the barrier, providing a dispersion angle of $21^{\circ}$ at inner portion of the deck slab. In previous codes (OHBDC and CAN/CSA-S6-88) a dispersion angle of $21^{\circ}$ was assumed to be conservative in most cases that underestimate the magnitude of design loads. Thus, a refined method of analysis using linear elastic finite element modeling was implemented to determine dispersal of combined transverse and vertical loads that are applied over certain lengths of PL-3 and PL-2 barriers. Table 2.11 summarizes the factored design transverse moments and tensile forces in the deck slab due to horizontal transverse loading at interior and exterior locations of PL-3 and PL-2 traffic barriers (CHBDC Commentary, 2006), which are obtained from finite element linear analysis. In addition, the height of load application above the deck slab considering an asphalt thickness of $90-\mathrm{mm}$ is presented in Table 2.11. Also, the factored moment intensity at base of barrier wall and tensile force intensity in the deck slab specified in the CHBDC were provided per meter length at deck-wall junction at interior or exterior locations. In FE modeling, CHBDC assumed linear dispersion lines of moment and tensile forces into barrier wall and deck slab, although the actual lines of dispersions are not linear and vary from element to element. The classic concept used for load dispersion is to indicate the approximate nature of moment and tensile force dispersal. The CHBDC also indicated that the actual dispersal lines depend on the stiffness and geometry of the barrier and deck elements and location of loads relative to the supporting elements. The results of these analyses by linear dispersion loads will be implemented in a separate analysis for the effects of vertical loading on the barrier. The combined effect would be used to determine the length and size of the cantilever deck reinforcement that is required to resist traffic barrier loads. These requirements are considered separately for the design of cantilever deck slab to resist vertical axle loads by vehicles. The highest load effect providing the maximum amount of reinforcement will then govern. The design transverse factored loads in CHBDC are compared with their counterparts in AASHTOLRFD. Table 2.12 provides summary of design forces for traffic railings in Test Level 4 (TL-4) and Test Level 5 (TL-5) as per AASHTO- LRFD (2012). 
Table 2. 10 Transverse, longitudinal and vertical loads on the traffic barriers (CSA, 2006b)

\begin{tabular}{|c|c|c|c|c|c|c|c|c|c|}
\hline \multirow{2}{*}{$\begin{array}{c}\text { Load } \\
\text { direction }\end{array}$} & \multicolumn{3}{|c|}{ PL - 1} & \multicolumn{3}{|c|}{ PL - 2} & \multicolumn{3}{|c|}{ PL - 3} \\
\hline & $\begin{array}{l}\text { Load } \\
(\mathrm{kN})\end{array}$ & $\begin{array}{l}\text { Length } \\
(\mathrm{mm})\end{array}$ & $\begin{array}{l}\text { Height } \\
(\mathrm{mm})\end{array}$ & $\begin{array}{l}\text { Load } \\
(\mathrm{kN})\end{array}$ & $\begin{array}{l}\text { Length } \\
(\mathrm{mm})\end{array}$ & $\begin{array}{l}\text { Height } \\
(\mathrm{mm})\end{array}$ & $\begin{array}{l}\text { Load } \\
(\mathrm{kN})\end{array}$ & $\begin{array}{l}\text { Length } \\
(\mathrm{mm})\end{array}$ & $\begin{array}{l}\text { Height } \\
(\mathrm{mm})\end{array}$ \\
\hline $\begin{array}{c}\text { Transverse } \\
\text { load, kN }\end{array}$ & 50 & 1200 & & 100 & 1050 & & 210 & 2400 & \\
\hline $\begin{array}{c}\text { Longitudinal } \\
\text { load, } \mathrm{kN}\end{array}$ & 20 & 1200 & 600 & 30 & 1050 & 700 & 70 & 2400 & 900 \\
\hline $\begin{array}{l}\text { Vertical } \\
\text { load, kN }\end{array}$ & 10 & 5500 & & 30 & 5500 & & 90 & 12000 & \\
\hline
\end{tabular}

\subsection{Yield-Line Analysis}

An elastic analysis of reinforced concrete slab provides no information on its ultimate load carrying capacity. An exact solution to the ultimate flexural strength of reinforced concrete slabs can be found, but it is possible to determine lower and upper bounds to the true collapse load. The yield-line theory of analysis gives an upper bound limitation to the ultimate flexural capacity of a reinforced concrete slab. This method is a powerful method to determine the required bending moment resistance and therefore the necessary reinforcement, especially for slabs of non-regular geometry or loading. Yield-line theory is a well-known design method of reinforced concrete slab, and similar structural elements. It is an analysis approach that determines the ultimate load capacity of reinforced concrete slabs, which was pioneered by Danish engineer and K. W. Johansen in 1940s. The theory investigates failure mechanism at the ultimate limit state. It closely considers the plastic collapse or limit analysis of reinforced concrete structures, which is deemed as an upper bound or mechanism approach. The theory is only applicable to ductile or under-reinforced concrete slabs that meet the following assumptions: (a) yield-line of reinforced concrete structures takes place when moment capacity of the section has been reached, (b) additional moment cannot be taken by the section after yielding and (c) the section can endure any amount of rotation. From the assumption made above, the theory is based on the principle that the internal work done in yield-line rotating is equal to the external work done by the applied loads. 
Table 2. 11 Design transverse moments and tensile forces in cantilever decks due to horizontal transverse loading (CSA, 2006b)

\begin{tabular}{|c|c|c|}
\hline Load Description & PL-3 Barriers & PL-2 Barriers \\
\hline Factored transverse load, $\mathrm{F}_{\mathrm{t}}(\mathrm{kN})$ & 357 & 170 \\
\hline Length of load application, $(\mathrm{mm})$ & 2400 & 1050 \\
\hline Traffic barrier total height, $(\mathrm{mm})$ & 1140 & 915 \\
\hline Height of load application above the deck, $(\mathrm{mm})$ & 990 & 790 \\
\hline Moment in inner portion of deck, $(\mathrm{kN} . \mathrm{m} / \mathrm{m})$ & 83 & 38 \\
\hline Tensile force in inner portions of deck, $(\mathrm{kN} / \mathrm{m})$ & 144 & 100 \\
\hline Moment in end portion of deck, $(\mathrm{kN} . \mathrm{m} / \mathrm{m})$ & 102 & 52 \\
\hline Tensile force in end portion of deck, $(\mathrm{kN} / \mathrm{m})$ & 161 & 142 \\
\hline
\end{tabular}

Table 2. 12 Factored design forces for traffic railings (AASHTO-LRFD, 2012)

\begin{tabular}{|c|c|c|c|c|c|c|c|c|c|}
\hline \multirow{2}{*}{$\begin{array}{c}\text { Load } \\
\text { direction }\end{array}$} & \multicolumn{3}{|c|}{ TL-2 or (PL-1) } & \multicolumn{3}{|c|}{ TL-4 or (PL-2) } & \multicolumn{3}{|c|}{ TL-5 or (PL-3) } \\
\hline & $\begin{array}{r}\text { Load } \\
(\mathrm{kN})\end{array}$ & $\begin{array}{c}\text { Length } \\
(\mathrm{mm})\end{array}$ & $\begin{array}{l}\text { Height } \\
(\mathrm{mm})\end{array}$ & $\begin{array}{l}\text { Load } \\
(\mathrm{kN})\end{array}$ & $\begin{array}{l}\text { Length } \\
(\mathrm{mm})\end{array}$ & $\begin{array}{l}\text { Height } \\
(\mathrm{mm})\end{array}$ & $\begin{array}{l}\text { Load } \\
(\mathrm{kN})\end{array}$ & $\begin{array}{l}\text { Length } \\
(\mathrm{mm})\end{array}$ & $\begin{array}{l}\text { Height } \\
(\mathrm{mm})\end{array}$ \\
\hline $\begin{array}{c}\text { Transverse } \\
\text { load, kN }\end{array}$ & 120 & 1220 & \multirow{3}{*}{510} & 240 & 1070 & \multirow{3}{*}{812} & 550 & 2440 & \multirow{3}{*}{1065} \\
\hline $\begin{array}{l}\text { Longitudinal } \\
\text { load, } \mathrm{kN}\end{array}$ & 40 & 1220 & & 80 & 1070 & & 182 & 2440 & \\
\hline $\begin{array}{l}\text { Vertical } \\
\text { load, kN }\end{array}$ & 20 & 5500 & & 80 & 5500 & & 356 & 12200 & \\
\hline
\end{tabular}

Yield-line theory of analysis is determined based on the two most popular applications namely as: Virtual Work Method and Standard Formulae (or Equilibrium) Method. Virtual work method is the most popular and easy way of applying yield-line theory of analysis that is more attractive to engineers for the design by yield-line theory. The method is assumed that at failure: the energy induced by the applied load is equal to the internal energy dissipated within the yield-lines. However, the standard formulae method is regarded as a quick approach for common solutions that covers varying support conditions and loading arrangements on the basis of method given by 
Johansen (1968). Yield-line theory of analysis possess some advantages over linear-elastic analysis as follows: (a) simplicity of the method avoid the use of complicated computer programs, (b) helps to understand the ultimate behavior of a structure (c) linear-elastic analysis is based on the assumption that the first yield occurs, while the yield-line analysis assumes the ultimate capacity of the slab so that it causes the collapse of the structure. (d) Versatility of the method especially for awkward shapes, and (e) yield-line analysis provides an economic concrete slab designs since it considers the ultimate limit state design. On the other hand, the yield-line theory of design has also some disadvantages such as; (a) a deep understanding of the method is required so that an appropriate failure mechanism is selected, (b) the design method could be dangerous if it is not properly checked or failure mechanism selected, and (c) it does not provide information of slab behavior in service.

\subsubsection{Principles in Yield-Line Theory of Concrete Slabs}

Yield-line design is a simple method to comprehend; however, there are numerous essential principles that require to be considered. A yield-line is represented by cracks in a reinforced concrete slab across which the reinforcing steel is yielded and along which the plastic rotation of slab section takes place. When a reinforced concrete slab is loaded to failure, yield-lines develop in highly stressed areas of slab causing to develop into continuous plastic hinges. These plastic hinges progress into a mechanism to form yield-line pattern. Yield-lines divide slab into individual regions in which each individual region pivot about its axes of rotation. Yield-line pattern and axes of rotation should conform to the yield-line rules and meet the fundamental and main assumptions on yield-line theory as follow:

1. At fracture, the bending moment per unit length is constant along the fracture line and is equal to yielding moment of steel reinforcement. The fracture is assumed to occur once steel reinforcement is yielded.

2. Individual region of yield-line pattern rotates along line of supported edges. In slabs supported directly by columns, axes of rotation pass through the columns.

3. The elastic deformation is small compared to the plastic deformation at fracture so that it can be ignored. Therefore, it follows that the fractured slab parts remain plane through the collapse so that they intersect in straight lines. So, the yield-lines are straight. 
4. The lines of fracture on the sides of two adjacent slab parts must pass through the point of intersection of the axes of rotation of those regions.

5. Yield lines must end at slab end boundaries.

6. Continuous supports repel and a simple support attracts the yield-lines.

In addition to above rules and assumptions, the following limitation on yield-line theory should also be taken into account:

1. Analysis is based on the rotational capacity at the yield-line, for instance, lightly reinforced slabs.

2. The theory assumed moment capacity of the slab at ultimate limit state. It is the therefore assumed an earlier failure would not occur due to shear or bonding.

3. The theory does not give any information on stresses, deflections or service load conditions of slabs.

In yield-line theory of analysis, practically there might be several yield-line patterns that could be applied to particular slab configurations and loadings. However, the aim is to investigate the yield-line pattern that gives the critical moment (the highest moment or the least load capacity). It should be noted that the yield-line method is an upper bound solution that gives the results either correct or theoretically unsafe. This upper-bound solution may discourage some designers; however, this can be overcome by assuming that the result of yield-line analysis will be well within $10 \%$ of the correct value. It is therefore to increase moments or reinforcement determined from calculations by $10 \%$ (The $10 \%$ rule). As mentioned previously, there are two approaches in determining the critical pattern and ensuring a safe design, namely as: the virtual work method and standard formulae method. The principles of virtual work method will be discussed herein.

\subsubsection{The Virtual Work Method of Analysis}

Virtual Work Method of analysis is one the most popular and easy way to apply yield-line analysis of slabs. The fundamental principle of virtual work method is that the external work must be equal to the internal work. In other word, the external work applied due to the applied load on the slab must be equal to the internal energy dissipated within the rotating yield-lines providing that: 


\section{External Work done $=$ Internal Energy dissipated}

A general slab region with elemental loading is shown in Figure 2.17. The external work done by elemental load can be written as:

$\mathrm{W}_{\mathrm{E}}=(\mathrm{w} \cdot \mathrm{dA}) \cdot \delta=(\mathrm{w} \cdot \mathrm{dA}) \cdot \mathrm{r} \cdot \theta$

The total external work done is:

$\mathrm{W}_{\mathrm{E}}=\int(\mathrm{w} \cdot \mathrm{dA}) \cdot \mathrm{r} \cdot \theta=\mathrm{w} \cdot \theta \cdot \int \mathrm{r} \cdot \mathrm{dA}$

But, $\int \mathrm{r} . \mathrm{dA}$ is the first moment of area, so the total external work done can be expressed as:

$\mathrm{W}_{\mathrm{E}}=\mathrm{w}$. Area. $\delta_{\text {Centroid }}$

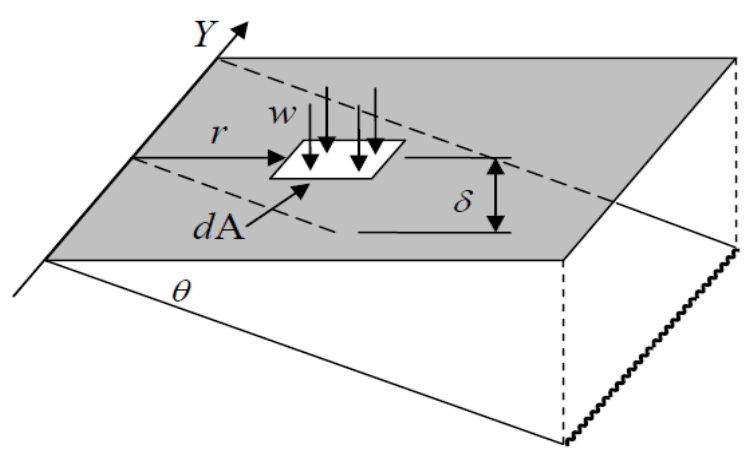

Figure 2. 17 Principle of external work done on a slab section (Adopted; Caprani, 2006)

For an orthotropic slab, the internal work done can be determined by taking a section perpendicular to the yield-line and finding its rotation. Then, the internal work is calculated by multiplying the moment capacity at that angle times the length of the yield-line and the corresponding rotation. Thus, the principle of virtual work method can generally be expressed as follow;

$\sum(\mathrm{N} . \delta)_{\text {for all region }}=\sum\left(\mathrm{m} . \mathrm{L} . \theta_{)}\right.$for all region 
Where,

$\mathrm{N}=$ external load acting within particular region $(\mathrm{kN})$

$\delta=$ the vertical displacement of applying external load, $\mathrm{N}(\mathrm{m})$

$\mathrm{m}=$ moment of resistance of slab per meter run represented by the reinforcement crossing the yield-line $(\mathrm{kN} . \mathrm{m} / \mathrm{m})$

$\mathrm{L}=$ the length of yield-line or its projected length onto the axis of rotation for that region $(\mathrm{m})$

$\theta=$ the rotation of the region about its axis of rotation $(\mathrm{m} / \mathrm{m})$

It should be noted that rotation of the regions about the yield-line can be resolved by rotation of that region about principal axes of rotation and can be calculated as a function of length and size of the maximum deflection of the regions. From Eq. 2.33 it can be noticed that the external work done can be calculated by taking the sum of the resultant force for each type of external load (i.e uniformly distributed load, line load or point load) acting on each region and multiplying it by its vertical deflection measured as a proportion of the maximum deflection in the proposed yieldline pattern. The internal energy dissipated can also by calculated by taking the sum of projected length of each yield-line around a region onto the axis of the rotation of that region and multiplying by the resistance moment on it and angle of the rotation of that region. Diagonal yield-lines are assumed to be resolved into the small horizontal and vertical steps at right angle to the reinforcement and parallel to the axes of the rotation of the two regions it divides. The length of a diagonal yield-line is taken as the summation of the each individual projected length steps onto the relevant axes of rotation.

In physics, a fundamental principle is assumed that energy cannot be created or destroyed. Thus, in the yield-line mechanism by equating external work to the internal energy, the values of unknowns (i.e. maximum moment or minimum value of load capacity) can be determined. If deemed compulsory, several iterative may be required to determine maximum value of moment or least value of load capacity from each chosen yield line pattern.

\subsubsection{Yield-Line Theory in Bridge Barrier Walls}

The yield-line analysis is based on the ultimate flexural capacity of the concrete components as specified in the AASHTO-LRFD Bridge Design Specifications (AASHTO 2004). In the 
analysis, it is assumed that the yield-line failure pattern occurs within the barrier wall only and does not extend into the deck slab. This means that the deck slab must have sufficient resistance to force the yield-line failure pattern to remain within the barrier wall. If the failure pattern extends into the deck, the equations for resistance of the barrier wall will not be valid. The AASHTO-LRFD yield-line analysis is also based on the assumption that sufficient longitudinal length of barrier wall exists to result in the desired yield-line failure pattern. For short lengths of barrier walls, a single yield line may form along the juncture of the barrier wall and the deck slab. Such a failure pattern is permissible, and the barrier wall resistance should be computed using appropriate analysis. Moreover, the AASHTO-LRFD yield-line analysis is based on the assumption that the negative and positive wall resisting moments are equal and that the negative and positive beam resisting moments are also equal. AASHTO-LRFD assumes two yield-line failure patterns based on the location of the truck collision with the barrier wall, as shown in Figures 2.18 and 2.19. A force $F_{t}$ distributed over a length $L_{t}$, shown in the figure, produces the first yield-line failure pattern caused by a truck collision within a wall segment. This interior yield-line pattern is assumed to have three yield-lines. Two of the yield-lines have tension on the inside face of the barrier wall and one yield-line has tension on the outside face of the barrier wall. The latter is a vertical crack along the height of the barrier wall at the location of vehicle impact. The second yield-line failure pattern occurs at end of the barrier wall as produced by a force $F_{t}$ distributed over a length $L_{t}$ shown in Figure 2.19. In this case, there is only one diagonal yield-line that produces tension on the inside face of the barrier. This type of yield-line pattern is assumed to occur at bridge barrier ends and at locations of deflection joints and expansion joints. A solution is obtained for the barrier wall load carrying capacity (i.e. nominal barrier wall resistance) by equating the external work due to the applied loads to the internal work delivered by the resisting plastic moments along the yield-lines. The resisting moment along the yield-line is a resultant of the moment about the vertical axis from the longitudinal reinforcement (Mw) and the moment about the horizontal axis from the transverse reinforcement (Mc). The angle of the inclined yield-lines can be expressed in terms of the critical length $\mathrm{L}_{c}$ as shown in Figure 2.18. The applied force $F_{t}$ is then minimized with respect to the length $L_{c}$ to get the least value of this upper bound solution. As such, the following equations are introduced in AASHTO-LRFD Specifications. 


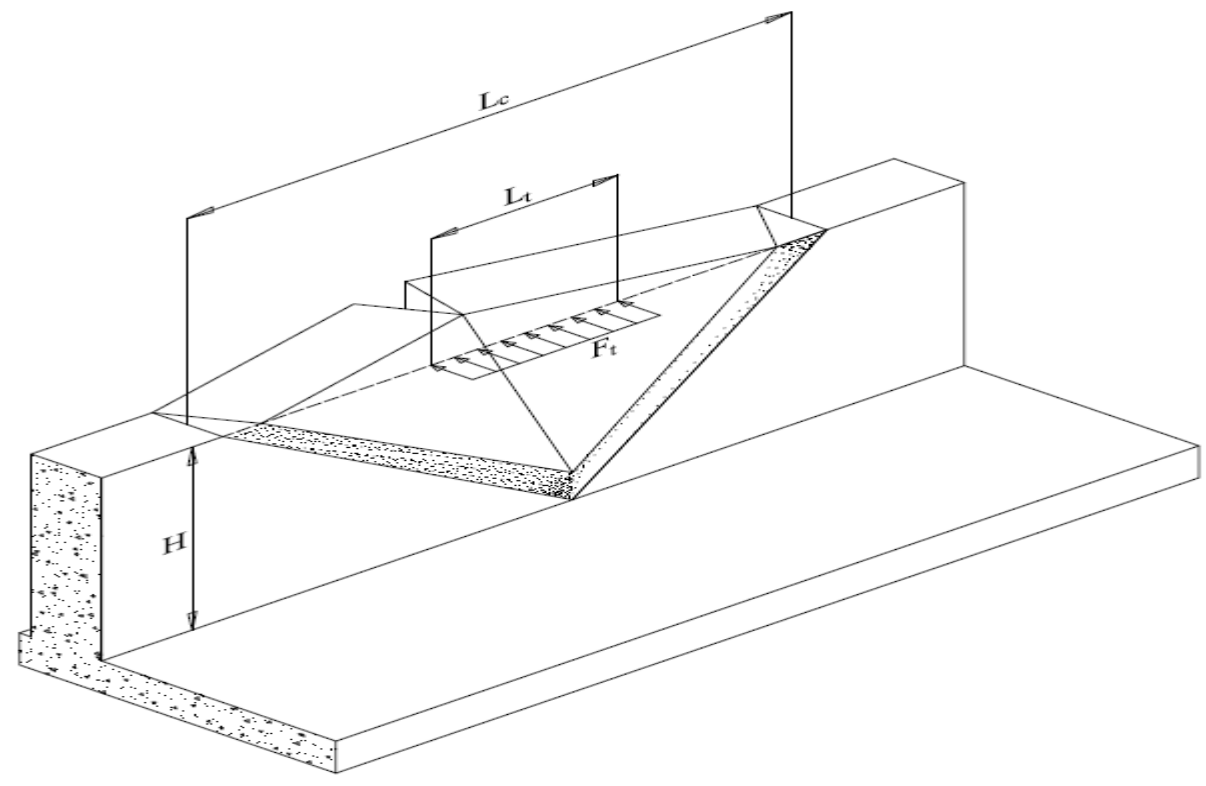

Figure 2. 18 Yield-Line pattern for interior region of barrier wall

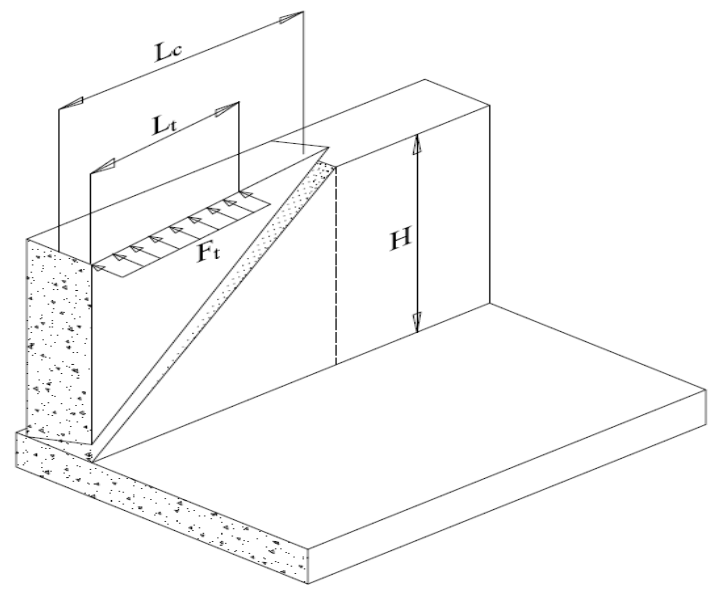

Figure 2. 19 Yield-Line pattern for end region of barrier wall

\section{For interior region of barrier walls}

The critical barrier wall length over which the yield-line mechanism occurs can be taken as:

$\mathrm{L}_{\mathrm{ci}}=\frac{\mathrm{L}_{\mathrm{t}}}{2}+\sqrt{\left(\frac{\mathrm{L}_{\mathrm{t}}}{2}\right)^{2}+\left(\frac{\left.8 \mathrm{HM}_{\mathrm{bint}}+\mathrm{M}_{\mathrm{wint}} \mathrm{H}\right)}{\mathrm{M}_{\mathrm{cint}}}\right)}$ 
The nominal barrier wall resistance to transverse load may be determined as:

$$
\mathrm{R}_{\mathrm{wi}}=\left(\frac{2}{2 \mathrm{~L}_{\mathrm{ci}}-\mathrm{L}_{\mathrm{t}}}\right)\left(8 \mathrm{M}_{\mathrm{bint}}+8 \mathrm{M}_{\mathrm{wint}} \mathrm{H}+\frac{\mathrm{M}_{\mathrm{cint}} \mathrm{L}_{\mathrm{ci}}{ }^{2}}{\mathrm{H}}\right)
$$

\section{For end region of barrier walls}

The critical barrier wall length over which the yield line mechanism occurs can be taken as:

$$
\mathrm{L}_{\mathrm{ce}}=\frac{\mathrm{L}_{\mathrm{t}}}{2}+\sqrt{\left(\frac{\mathrm{L}_{\mathrm{t}}}{2}\right)^{2}+\mathrm{H}\left(\frac{\left.\mathrm{M}_{\text {bend }}+\mathrm{M}_{\mathrm{wend}} \mathrm{H}\right)}{\mathrm{M}_{\text {cend }}}\right)}
$$

The nominal barrier wall resistance to transverse load may be determined as:

$$
\mathrm{R}_{\mathrm{we}}=\left(\frac{2}{2 \mathrm{~L}_{\mathrm{ce}}-\mathrm{L}_{\mathrm{t}}}\right)\left(\mathrm{M}_{\text {bend }}+\mathrm{M}_{\text {wend }} \mathrm{H}+\frac{\mathrm{M}_{\mathrm{cend}} \mathrm{L}_{\mathrm{ce}}{ }^{2}}{\mathrm{H}}\right)
$$

Where $\mathrm{L}_{\mathrm{ci}}$ is critical length of interior yield-line failure pattern; $\mathrm{L}_{\mathrm{ce}}$ is critical length of exterior yield-line failure pattern; $L_{t}$ is longitudinal length of distribution of impact force, $\mathrm{F}_{t} ; \mathrm{H}$ is height of barrier wall; $M_{b}$ is flexural resistance of the cap beam; $M_{w}$ is flexural resistance of the wall about its vertical axis; $M_{c}$ is flexural resistance of the wall about itd horizontal axis; and $R_{w}$ is total transverse resistance of the barrier wall. For use of the above equations, $\mathbf{M}_{\mathrm{c}}$ and $\mathrm{M}_{\mathrm{w}}$ should not vary significantly over the height of the wall. Where the width of the concrete wall varies along the height, $\mathbf{M}_{\mathrm{c}}$ should be calculated as the average of its value along the height. The nominal resistance equations include flexural resistance, $\mathrm{M}_{\mathrm{b}}$, when a top beam or beam cap is present at the top of the wall. The terminology of AASHTO-LRFD specifications, $\mathrm{R}_{\mathrm{w}}$ is the nominal resistance of the barrier and it is compared to the CHBDC nominal transverse load mentioned earlier for structural adequacy. Resistance factors to both concrete and reinforcing steel were applied to obtain the factored transverse resistance of the barrier wall. The ultimate 
load capacity of the wall is a function of the moment capacity of the beam at the top of the wall $(\mathrm{Mb})$, the moment capacity of the wall $\left(\mathrm{M}_{\mathrm{w}}\right)$ and the cantilever moment capacity of the wall $\left(\mathrm{M}_{\mathrm{c}}\right)$. If the bridge deck is weak, it may control or limit the cantilever moment capacity $\left(\mathrm{Mc}_{\mathrm{c}}\right)$. However, those equations indicate that the total load capacity of the wall can be increased by strengthening the wall by adding more horizontal reinforcement.

\subsection{Verification of AASHTO-LRFD Yield-Line at Interior Location}

For an assumed yield-line pattern in a barrier wall with consistent geometry and boundary conditions, the solution to yield line pattern can be obtained by equating the work done due to applied external load to the internal energy dissipated within the yield-line by formation of resisting plastic moments. The applied load determined by this method, $\mathrm{F}_{\mathrm{t}}$, is either less than or greater than the actual load, that is either correct or unsafe. The applied force, $F_{t}$, is then minimized with respect to the critical yield-line length, $\mathrm{L}_{c}$, to find least value of this upper bound solution. Thus, the yield-line equation stated above at interior location with the yield-line pattern shown in Figure 2.20 is derived as follow:

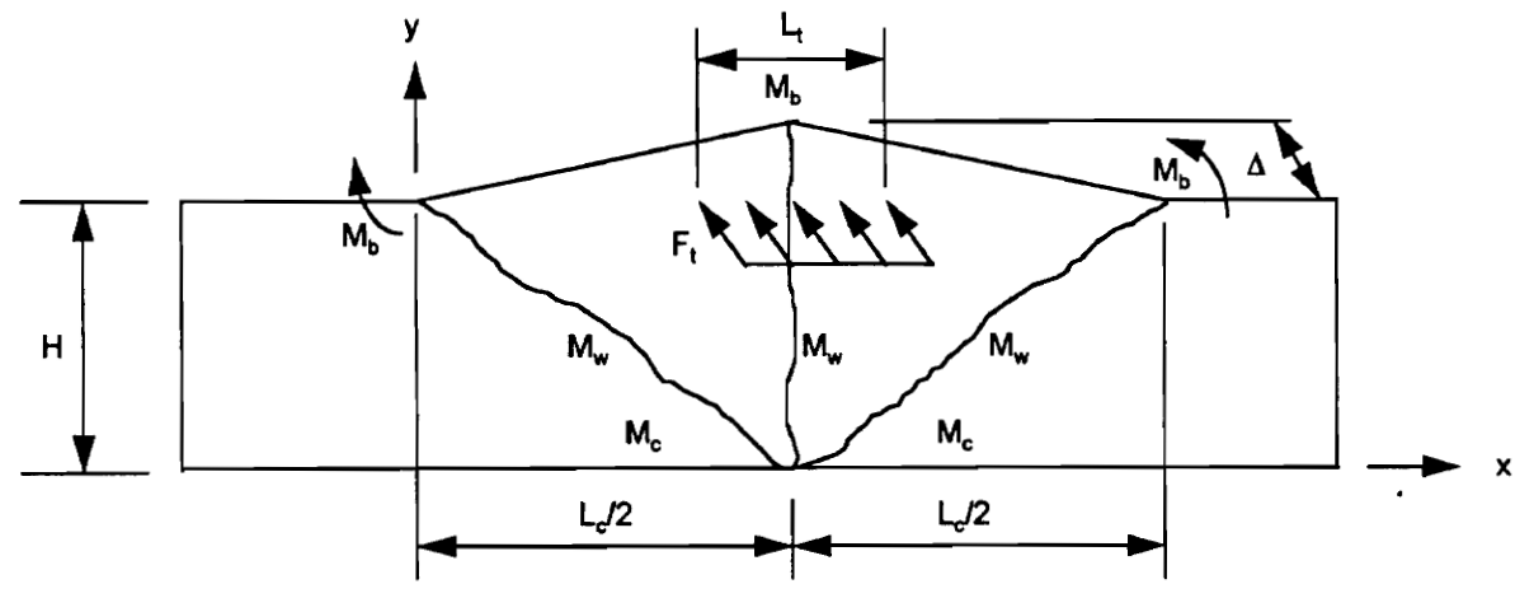

Figure 2. 20 AASHTO-LRFD yield-line pattern at interior location (Adopted from AASHTO, 2004)

\section{1- Calculate External Work}

The original and deformed shape of barrier wall after the application of the external load is shown in Figure 2.21. The shaded area represents the total work done due to applied external line 
load of $w_{t}=F_{t} / L_{t}$ that causes deformation of wall system to occur. If assumed the maximum deformation of wall system equal to $\delta$, the virtual displacement, $\mathrm{x}$, can be calculated as follow;

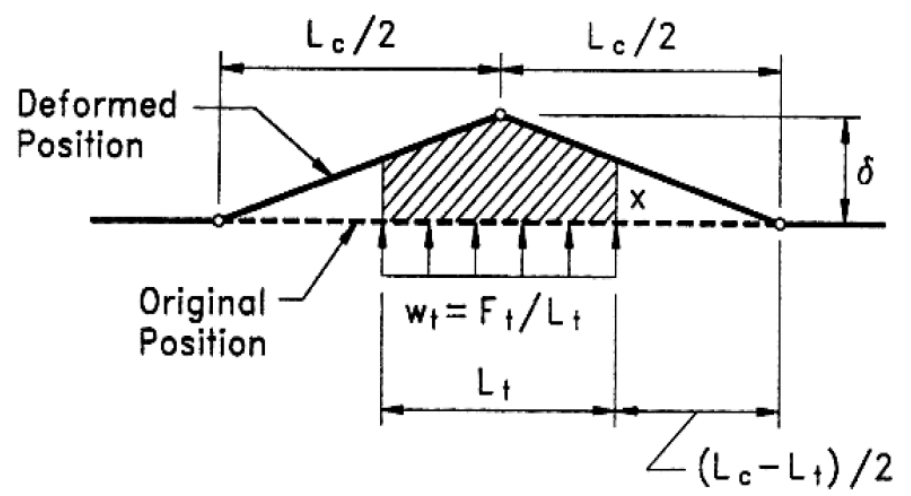

Figure 2. 21 Original and deformed shape of top portion of barrier wall at interior location (Adopted: Ngan, 2008)

$\mathrm{x}=\frac{\delta \cdot\left(L_{c-} L_{t}\right)}{L_{c}}$

And, the deformed area under the applied external line load can be estimated as:

Deformed area $=\frac{\delta . L_{t}\left(L_{c}-\frac{L_{t}}{2}\right)}{L_{c}}$

Therefore, the total external work done by the line load, $\mathrm{w}_{\mathrm{t}}$, is calculated as:

$\mathrm{W}_{\mathrm{E}}=\mathrm{w}_{\mathrm{t} \cdot}($ area $)=\frac{\delta \cdot F_{t} \cdot\left(L_{c}-\frac{L_{t}}{2}\right)}{L_{c}}$

\section{2- Calculate Internal Work}

The internal work is assumed to be as the product of yielding moment of the reinforcement crossing the yield-lines and the rotation of the wall regions through which yield-lines act. It is therefore assumed that all segments of the wall to be rigid so that all rotations are concentrated at 
the yield-lines. Thus, the total internal work is the summation of each individual internal work by cap beam, horizontal and vertical reinforcement that can be calculated as follow:

At the top of the wall, it is assumed that the wall and the cap beam experienced rotation, $\theta$, due to the small deformation by the applied load. It is therefore deformation, $\delta$ over the length $\mathrm{L}_{\mathrm{c}}$ can be determined as:

$\delta=\theta \cdot \frac{L_{C}}{2}$

At the limit state, it is assumed that the cap beam develop plastic moment, $\mathbf{M}_{\mathrm{b}}$, equal to its bending moment resistance, $\mathbf{M}_{\mathrm{n}}$. Assuming that the positive and negative plastic moment strengths are equal, the internal work done by the cap beam, $\mathrm{U}_{\mathrm{b}}$, can be written as:

$\mathrm{U}_{\mathrm{b}}=4 \cdot \mathrm{M}_{\mathrm{b}} \cdot \theta=\frac{8 M_{b .} \delta}{L_{c}}$

The barrier wall is usually reinforced in both vertical and horizontal directions. The horizontal reinforcement develops wall flexural resistance, $\mathrm{M}_{\mathrm{w}}$, about vertical axis, while the vertical reinforcement develops cantilever flexural resistance of the wall system, $\mathbf{M}_{\mathrm{c}}$, about the horizontal axis. It is also assumed that the positive and negative moment resistances, $\mathbf{M}_{\mathrm{w}}$, are equal and that the rotation of the wall about the horizontal plane is $\theta$. The internal work done by horizontal reinforcement, $\mathrm{U}_{\mathrm{w}}$, by the wall moment of $\mathrm{M}_{\mathrm{w}} \cdot \mathrm{H}$ is:

$\mathrm{U}_{\mathrm{w}}=4 \cdot \mathrm{M}_{\mathrm{w}} \cdot \mathrm{H} \cdot \theta=\frac{8 M_{w} \cdot H \cdot \delta}{L_{C}}$

The rotation of the wall about vertical plane of rotation is equal to $\beta=\delta / \mathrm{H}$. The internal work done by vertical reinforcement, $\mathrm{U}_{\mathrm{c}}$, due to cantilever wall moment of $\mathrm{M}_{\mathrm{c}} \mathrm{L}_{\mathrm{c}}$ is:

$\mathrm{U}_{\mathrm{c}}=\frac{M_{C} \cdot L_{c} \cdot \delta}{H}$ 
The total internal work is summation of work done by cap beam, horizontal and vertical reinforcement providing that:

$\mathrm{U}_{\mathrm{i}}=\mathrm{U}_{\mathrm{b}}+\mathrm{U}_{\mathrm{w}}+\mathrm{U}_{\mathrm{c}}=\frac{8 M_{b} \cdot \delta}{L_{C}}+\frac{8 M_{w} \cdot H \cdot \delta}{L_{C}}+\frac{M_{C} \cdot L_{c} \cdot \delta}{H}$

Given the fact that external work is equal to internal work $\left(\mathrm{W}_{\mathrm{E}}=\mathrm{U}_{\mathrm{i}}\right)$, we obtain:

$\mathrm{F}_{\mathrm{t}}=\left(\frac{2}{2 L_{C-} L_{t}}\right)\left(8 \mathrm{M}_{\mathrm{b}}+8 \mathrm{M}_{\mathrm{w}} \cdot \mathrm{H}+\frac{M_{C} \cdot L_{C}{ }^{2}}{H}\right)$

The value for $L_{c}$ can be then minimized by differentiating the equation for $F_{t}$ with respect to $L_{c}$ providing that:

$\frac{d\left(F_{t}\right)}{d\left(L_{c}\right)}=0$

This minimization provides a quadratic equation that can be solved to find $\mathrm{L}_{\mathrm{c}}$ as follow:

$\mathrm{L}_{\mathrm{c}}=\frac{L_{t}}{2}+\sqrt{\left(\frac{L_{t}}{2}\right)^{2}+\frac{8 M_{b} H+8 M_{w} H^{2}}{M_{c}}}$

When the $L_{c}$ value is used in the equation for $F_{t}$, the minimum value of transverse force, $F_{t}$, is obtained. This minimum transverse force represents the barrier wall nominal transverse resistance, $\mathrm{R}_{\mathrm{w}}$ so that:

$\min F_{t}=R_{w}$

Thus, the minimum nominal resistance of the barrier wall system at interior location can be written as: 


$$
\mathrm{R}_{\mathrm{w}}=\left(\frac{2}{2 L_{c-} L_{t}}\right)\left(8 \mathrm{M}_{\mathrm{b}}+8 \mathrm{M}_{\mathrm{w}} \cdot \mathrm{H}+\frac{M_{C} \cdot L_{c}{ }^{2}}{H}\right)
$$

\subsection{Verification of AASHTO- LRFD Yield-Line at Exterior Location}

Similar to interior location, for an assumed yield-line pattern with consistent geometry and boundary conditions, the solution for yield-line pattern can be obtained by equating the external work to the internal work. The sections below summarize the calculation of external and internal works followed by derivation of the yield-line equations at exterior location:

\section{1- Calculate External Work}

At exterior location, the barrier wall deformed as shown in Figure 2.22 with the formation of one plastic hinge moment through the yield-line. The shaded area represents the total external work done by the line load of $\mathrm{w}_{\mathrm{t}}=\mathrm{F}_{\mathrm{t}} / \mathrm{L}_{\mathrm{t}}$ that causes deformation of wall system to occur. If assumed the maximum deformation of wall system equal to $\delta$, the virtual displacement, $\mathrm{x}$, can be calculated as follow:

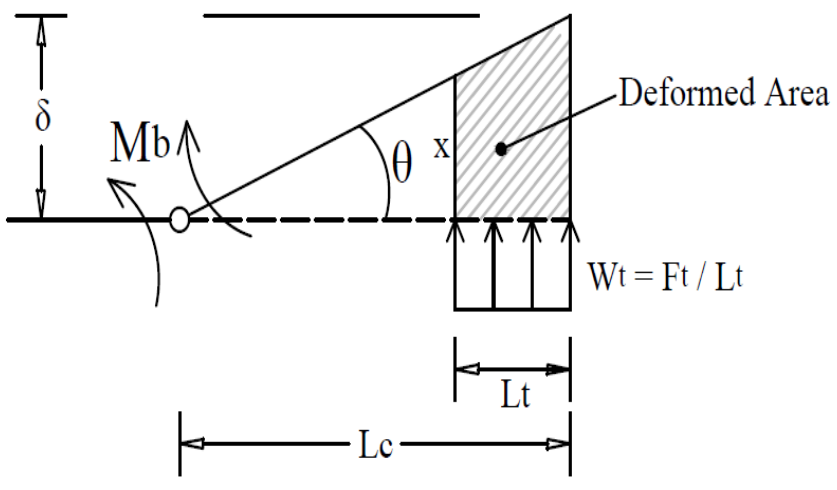

Figure 2. 22 Original and deformed shape of barrier wall at exterior location

$\mathrm{x}=\frac{\delta \cdot\left(L_{c-}-L_{t}\right)}{L_{C}}$

Then, the deformed area under the applied load can be determined as: 
Deformed area $=\frac{\delta \cdot L_{t}\left(2 L_{c}-L_{t}\right)}{2 L_{c}}$

The total external work done by the line load, $\mathrm{w}_{\mathrm{t}}$, is calculated as:

$\mathrm{W}_{\mathrm{E}}=\mathrm{w}_{\mathrm{t}} \cdot($ deformed area $)=\frac{\delta \cdot F_{t} \cdot\left(2 L_{c}-L_{t}\right)}{2 L_{c}}$

\section{2- Calculate Internal Work}

Due to the applied external load, the wall and cap beam has a rotation, $\theta$, about the yield-line in a horizontal plane producing a small deformation. The small deformation $\delta$ can be determined as:

$\delta=\theta . L_{c}$

The internal work done by the cap beam, $\mathrm{U}_{\mathrm{b}}$, can be written as:

$\mathrm{U}_{\mathrm{b}}=\mathrm{M}_{\mathrm{b}} \cdot \theta=\frac{M_{b} \cdot \delta}{L_{C}}$

The internal work done by horizontal reinforcement, $\mathrm{U}_{\mathrm{w}}$, by the wall moment of $\mathrm{M}_{\mathrm{w}} \cdot \mathrm{H}$ is:

$\mathrm{U}_{\mathrm{w}}=\mathrm{M}_{\mathrm{w}} \cdot \mathrm{H} \cdot \theta=\frac{M_{W} \cdot H \cdot \delta}{L_{C}}$

The internal work done by vertical reinforcement, $U_{c}$, due to cantilever wall moment of $M_{c} L_{c}$ is:

$\mathrm{U}_{\mathrm{c}}=\frac{M_{C} \cdot L_{C} \cdot \delta}{H}$

The total internal work is equal to: 
$\mathrm{U}_{\mathrm{i}}=\mathrm{U}_{\mathrm{b}}+\mathrm{U}_{\mathrm{w}}+\mathrm{U}_{\mathrm{c}}=\frac{M_{b} \cdot \delta}{L_{C}}+\frac{M_{w} \cdot H \cdot \delta}{L_{C}}+\frac{M_{C} \cdot L_{C} \cdot \delta}{H}$

Since external work is equal to internal work $\left(\mathrm{W}_{\mathrm{E}}=\mathrm{U}_{\mathrm{i}}\right)$, we obtain:

$\mathrm{F}_{\mathrm{t}}=\left(\frac{2}{2 L_{c-} L_{t}}\right)\left(\mathrm{M}_{\mathrm{b}}+\mathrm{M}_{\mathrm{w}} \cdot \mathrm{H}+\frac{M_{C} \cdot L_{c}{ }^{2}}{H}\right)$

The value for $L_{c}$ can be then minimized by differentiating the equation for $F_{t}$ with respect to $L_{c}$ providing that:

$\frac{d\left(F_{t}\right)}{d\left(L_{c}\right)}=0$

The critical length, $\mathrm{L}_{\mathrm{c}}$, can be calculated as:

$\mathrm{L}_{\mathrm{c}}=\frac{L_{t}}{2}+\sqrt{\left(\frac{L_{t}}{2}\right)^{2}+\frac{M_{b} H+M_{w} H^{2}}{M_{c}}}$

Knowing that:

$\min F_{t}=R_{w}$

Thus, the minimum nominal resistance of the barrier wall system at exterior location can be written as:

$\mathrm{R}_{\mathrm{w}}=\left(\frac{2}{2 L_{c-} L_{t}}\right)\left(\mathrm{M}_{\mathrm{b}}+\mathrm{M}_{\mathrm{w}} \cdot \mathrm{H}+\frac{M_{C} \cdot L_{c}{ }^{2}}{H}\right)$ 


\subsection{Investigation of Punching Shear Strength of GFRP Bars in Concrete Slab}

Steel reinforcement is a common structural system being used in reinforced concrete bridge barriers. The long-term durability of such structures has become a major concern in the construction industry. One of the main factor concerning durability and service life of steelreinforced structures is the corrosion of steel bars especially when the structures are exposed to harsh environment. Steel-reinforced bridge decks and barriers that are exposed to de-icing salt during cold weather require extensive and expensive maintenance during their service life. The use of Glass Fiber Reinforcing Polymer (GFRP) bars as non-corrodible has emerged an innovative solution to corrosion related problems, reduce the maintenance cost and increase the service life of bridge structures.

Extensive research programs have been conducted to investigate the shear behavior of concrete structures in general and especially punching shear of two-way slab reinforced with FRP bars. In addition, since early 1960s, most research programs have been conducted on punching shear behavior of steel-reinforced slabs and several design models were developed. However, these models cannot be applied directly to FRP reinforced concrete slabs. Experimental tests have shown that FRP-reinforced concrete member experienced reduced shear strength compared to steel-reinforced structures due to lower modulus of elasticity of FRP bars. The lower modulus of elasticity in turn results in larger deformation and developing wider and deeper cracks.

According to ACI 440.1R (2006), punching shear design of FRP reinforced concrete is similar to that of steel reinforcement. However, the differences in mechanical properties of FRP bars affect shear strength that must be taken into account. Some of these differences may include: lower modulus of elasticity of FRP bars, lower transverse shear strength of FRP bars and high tensile strength of FRP bars with no yielding point. ACI 318(2005) and CSA A23.3 (2004) do not consider the steel reinforcement ratio in determining punching shear strength of steel-reinforced concrete slabs. This is due to the fact that steel bars possess relatively high modulus of elasticity as such the depth to the neutral axis dose not vary significantly after cracking when compared to a FRP-reinforced concrete section with equal area of longitudinal reinforcement. The shear resistance will be then area of concrete compression zone after cracking. On the other hand, due to lower axial stiffness of FRP bars which is a product of reinforcement area and modulus of 
elasticity, the depth to the neutral axis reduces in FRP-reinforced concrete members after cracking. Therefore, the depth of the compression zone is reduced and crack widths are wider. Wider cracks in turn decrease the contribution of aggregate interlock and as a result the shear resistance of the concrete is reduced.

Previous research performed on shear capacity of FRP-reinforced flexural concrete members without shear reinforcement proved that slab shear strength is affected by stiffness of tensile (flexural) reinforcement (Nagasaka et al. 1993; Zhao et al. 1995; JSCE 1997; Sonobe et al. 1997; Michaluk et al. 1998; Tureyen and Frosch 2002\& 2003). Consequently, the FRP design codes ,CSA-S806-12 (CSA, 2012), ACI 440-1R-06 (ACI, 2006) and JSCE Guidelines (1997) and other empirical punching shear equations developed by researchers (El-Ghandour et al. 1999, and 2000, Mattys and Taerwe, 2000, Ospina et al., 2003, El-Gamal et al., 2005 and Jacobson el al., 2005) considered the FRP flexural reinforcement ratio in calculating punching shear strength of FRP-reinforced concrete slabs. The following punching shear models for FRPreinforced members have been selected to predict the punching shear capacities of barrier wall, which can be then compared to the test ultimate punching shear loads.

\subsubsection{CSA-S806 (2012)}

The Canadian Standard "Design and construction of building structures with fibre reinforced polymers," CSA-S806 (2012), specifies the punching shear strength of FRP-reinforced concrete as the smallest of the following three equations. It can be noticed that these equations are the modified forms of those specified in the Canadian Standard "Design of Concrete Structures," CSA-A23.3 (2004), to account for the FRP-reinforcing bar ratio.

$$
\begin{aligned}
& V_{c}=\left(1+2 / \beta_{c}\right) \cdot 0.028 \lambda \varphi_{c}\left(E_{f} \cdot \rho_{f .} f_{c}^{\prime}\right)^{1 / 3} \cdot b_{o}, 0.5 d \cdot d \\
& V_{c}=\left[\left(\alpha_{s} \cdot d / b_{o}, 0.5 d\right)+0.19\right] \cdot 0.147 \lambda \varphi_{c}\left(E_{f} \cdot \rho_{f .} f_{c}^{\prime}\right)^{1 / 3} \cdot b_{o, 0.5 d} \cdot d \\
& V_{c}=0.056 \lambda \varphi_{c}\left(E_{f} . \rho_{f} f_{c}^{\prime}\right)^{1 / 3} \cdot b_{o}, 0.5 d \cdot d
\end{aligned}
$$


Where $\beta_{\mathrm{c}}$ is the ratio of long side to short side of the concentrated load or loading patch, $\lambda$ is a density factor (i.e for normal density concrete is equal to 1), $\varphi_{\mathrm{c}}$ is the concrete resistance factor, $E_{\mathrm{f}}$ is modulus of elasticity of FRP bars, $\rho_{\mathrm{f}}$ is the FRP tensile reinforcement ratio, $\mathrm{f}_{\mathrm{c}}$ is the concrete compressive strength in $\mathrm{MPa}, \mathrm{b}_{\mathrm{o}}, 0.5 \mathrm{~d}$ is the critical perimeter length measured at $0.5 \mathrm{~d}$ from the loading patch, $d$ is effective slab depth in $(\mathrm{mm})$ and $\alpha_{\mathrm{s}}$ is a factor to adjust $\mathrm{V}_{\mathrm{c}}$ for support dimensions that is equal to 4 for interior columns, 3 for edge columns and 2 for corner columns.

\subsubsection{ACI 440-1R (2006)}

The American Standard "Guide for the design and construction of structural concrete reinforced with FRP bars," ACI 440-1R (2006), specified the equation below for calculating punching shear capacity of FRP-reinforced concrete slab:

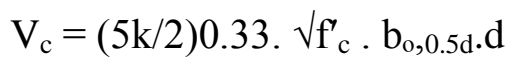

Where $\mathrm{k}=\left[\sqrt{2 \rho_{f} n_{f}+\left(\rho_{f} n_{f}\right)^{2}}-\rho_{f} \cdot n_{f}\right]$ and $n_{f}$ is modular ratio equal to $\left(\mathrm{E}_{\mathrm{f}} / \mathrm{E}_{\mathrm{c}}\right)$

\subsubsection{JSCE (1997)}

The Japanese Standard "Recommendation for Design and Construction of Concrete Structures Using Continuous Fiber Reinforcing Materials," (JSCE, 1997) specifies that the punching shear strength can be determined from the following equation:

$V_{c}=\beta_{d} \cdot \beta_{p} \cdot \beta_{r} \cdot\left(f_{p c d} / \gamma_{b}\right) \cdot b_{o}, 0.5 d \cdot d$

Where $\beta_{\mathrm{d}}=\sqrt[4]{\frac{1000}{d}} \leq 1.5(\mathrm{~d}$ in $\mathrm{mm}), \beta_{\mathrm{p}}=\left(100 \rho_{\mathrm{f}} \mathrm{E}_{\mathrm{f}} / \mathrm{E}_{\mathrm{s}}\right)^{1 / 3} \leq 1.5, \beta_{\mathrm{r}}=1+\frac{1}{\left[1+0.25\left(\frac{u_{\mathrm{o}}}{d}\right)\right]} ; \mathrm{u}_{\mathrm{o}}$ is the perimeter of concentrated load area, $\mathrm{f}_{\mathrm{pcd}}=0.2 \sqrt{ } \mathrm{f}_{\mathrm{c}}^{\prime} \leq 1.2$ in MPa and $\gamma_{\mathrm{b}}$ is a partial safety factor to account for concrete compressive strengths below $50 \mathrm{MPa}$ (1.3) and above $50 \mathrm{MPa}$ (1.5). However, $\gamma_{\mathrm{b}}$ was set equal to 1 to determine an un-factored prediction capacity to be compared with experimental ultimate strength. 


\subsection{El- Ghandour (1999)}

From the experimental tests performed on FRP-reinforced flat slabs, El-Ghandour et al. (1999) proposed a modification to the punching shear strength specified in the ACI code "Building Code Requirements for Structural Concrete," ACI- 318-05, (ACI, 2005) by applying the term $\left(\mathrm{E}_{\mathrm{f}} / \mathrm{E}_{\mathrm{s}}\right)^{1 / 3}$ to the predicted punching shear strength as follow:

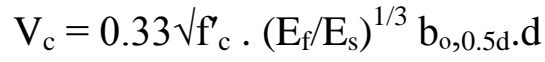

\subsubsection{El-Ghandour (2000)}

El-Ghandour et al. (2000) proposed a modification to the British Code "Structural use of concrete," BS 8110-1 (British, 2002) by applying strain correction factor $\left(0.0045 / \varepsilon_{\mathrm{y}}\right)$ to the equivalent reinforcement ratio $\left(\rho_{\mathrm{s}}=\rho_{\mathrm{f}} \mathrm{E}_{\mathrm{f}} / \mathrm{E}_{\mathrm{s}}\right)$ so that a strain limit of 0.0045 is assumed for FRP reinforcements. $\varepsilon_{\mathrm{y}}$ is the yield strain of steel reinforcement typically equal 0.002 . Therefore, ElGhandour et al. proposed the following equation to determine the punching shear strength of FRP-reinforced concrete slabs.

$V_{c}=0.79\left[100 \rho_{f}\left(E_{f} / E_{s}\right) \cdot\left(0.0045 / \varepsilon_{y}\right)\right]^{1 / 3} \cdot\left(f_{c u} / 25\right)^{1 / 3}(400 / d)^{1 / 4} b_{o}, 1.5 d \cdot d$

Where $f_{c u}$ is the concrete cube strength equal to $\left(f_{c u}=f_{c}^{\prime} / 0.8 \mathrm{MPa}\right)$ and $b_{o}, 1.5 d$ is the critical perimeter length measured at a distance $1.5 \mathrm{~d}$ away from the loading patch.

\subsubsection{Mattys and Taerwe (2000)}

Mattys and Taerwe (2000) conducted experimental study on punching shear strength of concrete slabs reinforced with FRP grids. From the experimental investigations, they proposed the following modification to the provisions of BS-8110-1 92002) Standard to account for the use of FRP bars.

$V_{c}=1.36\left[100 \rho_{f}\left(E_{f} / E_{s}\right)\right]^{1 / 3}\left(f_{c}^{\prime}\right)^{1 / 3}(1 / d)^{1 / 4} \cdot b_{o}, 1.5 d \cdot d$ 


\subsubsection{Ospina et al. (2003)}

Ospina et al. performed experimental tests on flat slabs reinforced with FRP bars and grids and proposed a modification to the punching shear strength suggested by Mattys and Taerwer (2000) as follow:

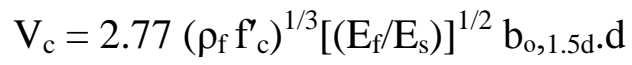

\subsubsection{El-Gamal et al. (2005)}

El-Gamal et al. (2005) proposed modification to the ACI 318-05 punching shear equation by applying a new parameter $(\alpha)$ as follows:

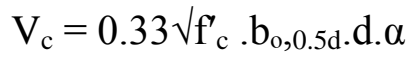

Where $\alpha=0.5\left(\rho_{\mathrm{f}} \mathrm{E}_{\mathrm{f}}\right)^{1 / 3} \cdot\left(1+8 \mathrm{~d} / \mathrm{b}_{\mathrm{o}, 0.5 \mathrm{~d}}\right)$ and $\mathrm{E}_{\mathrm{f}}$ is in GPa.

\subsubsection{Jacobson et al. (2005)}

Jaconson el al. (2005) conducted experimental investigation on punching shear capacity of double layer FRP grid-reinforced slabs and proposed a new model which is a modification of the empirical approach suggested by Mattys andTaerwe (2000) as follows:

$V_{c}=4.5\left(\rho_{f} f_{c}^{\prime}\right)^{1 / 3} \cdot(1 / d)^{1 / 4} \cdot b_{o}, 1.5 d \cdot d$

Where $\rho_{\mathrm{f}}$ is to be calculated as the average of the two reinforcement ratios in both longitudinal and transverse directions.

\subsection{Punching Shear Strength of Steel-Reinforced Concrete Slab}

Nemours research programs have been conducted on the punching shear strength of concrete slabs reinforced with conventional steel bars. The following code specifications provide the most commonly used punching shear strength predictions in steel reinforced concrete slabs: 


\subsubsection{CSA-A23.3 (2004)}

The Canadian Standard "Design of Concrete Structures" specifies the punching shear capacity of a steel-reinforced concrete slab without shear reinforcement as the smallest of:

$V_{c}=\left(1+2 / \beta_{c}\right) \cdot 0 \cdot 19 \lambda \varphi_{c} \cdot \sqrt{ } f_{c}^{\prime} \cdot b_{o, 0.5 d} \cdot d$

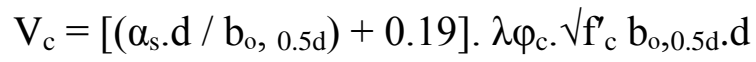

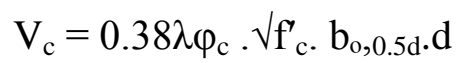

Where $\beta_{\mathrm{c}}$ is the ratio of long side to short side of column, concentrated load or reaction area, $\lambda$ is concrete density ( $\lambda=1$ for normal density concrete), $\varphi_{\mathrm{c}}$ is concrete resistant factor equal to 0.75according to CHBDC code and 0.65 according to CSA-A23.3 (2004). $\mathrm{f}_{\mathrm{c}}{ }_{\mathrm{c}}$ is the 28-days concrete compressive strength, $b_{0,0.5 \mathrm{~d}}$ is the critical perimeter at a distance $0.5 \mathrm{~d}$ to the loading patch area, $d$ is effective depth of concrete section and $\alpha_{s}$ is a factor to adjust $V_{c}$ for support dimensions that is 4 for interior columns, 3 for edge columns and 2 for corner columns.

\subsubsection{ACI 318 (2005)}

The American Standard "Building Code Requirements for Structural Concrete and Commentary" specifies the punching shear capacity of a non-prestressed steel-reinforced concrete slab as the least of the following equations:

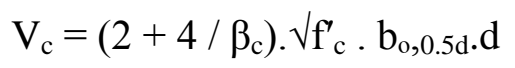

$V_{c}=\left[\left(\alpha_{s} \cdot d / b_{o}, 0.5 d\right)+2\right] \cdot V f_{c}^{\prime} b_{o}, 0.5 d \cdot d$

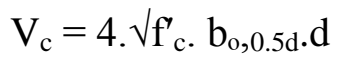

Where all parameters are similar to those specified for CSA-A23.3 (2004) except that $\alpha_{\mathrm{s}}$ is 40 for interior columns, 30 for edge columns and 20 for corner columns. 


\subsubsection{JSCE (2007)}

The Japanese Standard "Standard Specifications for Concrete Structures" provides an empiricalbased equation for punching shear capacity of planar members. JSCE (2007) accounts for reinforcement ratio $(\rho)$ that is the average values for the reinforcement in the two directions. The punching shear equation is provided as:

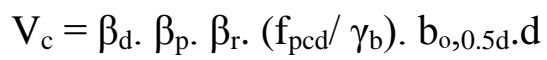

Where $\beta_{\mathrm{d}}=\sqrt[4]{\frac{1000}{d}} \leq 1.5\left(\mathrm{~d}\right.$ in mm), $\beta_{\mathrm{p}}=(100 \rho)^{1 / 3} \leq 1.5, \beta_{\mathrm{r}}=1+\frac{1}{\left[1+0.25\left(\frac{u_{\mathrm{o}}}{d}\right)\right]} ; \mathrm{u}_{\mathrm{o}}$ is the perimeter of concentrated load area, $\mathrm{f}_{\mathrm{pcd}}=0.2 \sqrt{ } \mathrm{f}_{\mathrm{c}}^{\prime} \leq 1.2 \mathrm{in} \mathrm{\textrm {MPa }}$ and $\gamma_{\mathrm{b}}$ is a partial safety factor to account for concrete compressive strengths below 50MPa (1.3) and above 50MPa (1.5). However, $\gamma_{\mathrm{b}}$ was set equal to 1 to determine an un-factored prediction capacity to be compared with experimental ultimate strength.

\subsubsection{Eurocode-2 (2004)}

The European Standard "Design of Concrete Structures" provides an empirical-based equation to define punching shear resistance of concrete slab reinforced with steel. Similar to JSCE (2007), Eurocode-2 (2004) considers a bi-directional reinforcement ratio, $\rho$, as the average reinforcement ratio in longitudinal (x) and transverse (y) directions. The following equation has adopted:

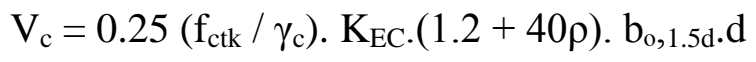

Where $\mathrm{f}_{\mathrm{ctk}}=0.7 \mathrm{f}_{\mathrm{ctm}}$, and $\mathrm{f}_{\mathrm{ctm}}=0.3\left(\mathrm{f}_{\mathrm{ck}}\right)^{2 / 3}\left(\mathrm{f}_{\mathrm{ck}}\right.$ in MPa), $\mathrm{K}_{\mathrm{EC}}=(1.6-\mathrm{d}) \geq 1(\mathrm{~d}$ in meters $)$ and $\rho=$ $\sqrt{\rho x \rho y} \leq 0.15 . \rho_{\mathrm{x}}$ and $\rho_{\mathrm{y}}$ are reinforcement ratios in longitudinal and transverse directions, respectively. The partial safety factor, $\gamma_{\mathrm{c}}$, was set equal to 1 to get an unfactored prediction of punching shear capacity. The characteristic concrete compressive strength, $f_{c k}$, was used. The characteristic tensile strength, $\mathrm{f}_{\mathrm{ctk}}$, was determined from the mean value of the tensile strength, $\mathrm{f}_{\mathrm{ctm}}$. 


\subsubsection{British Code-1997 (BS 8110)}

The British Standard 8110 "Structural Use of Concrete-Code of Practice for Design and Construction" provides the punching shear capacity of steel reinforced concrete slabs as follows:

$\mathrm{V}_{\mathrm{c}}=0.79 \mathrm{~K}_{1}\left(\mathrm{~K}_{2} / \gamma_{\mathrm{m}}\right) \cdot(100 \rho)^{1 / 3} \cdot(400 / \mathrm{d})^{1 / 4} \cdot \mathrm{b}_{\mathrm{o}, 1.5 \mathrm{~d} \cdot \mathrm{d}}$

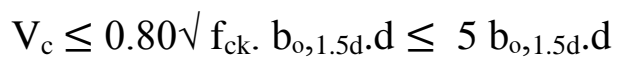

Where $K_{2}=\left(f_{c k} / 25\right)^{1 / 3} \geq 1\left(f_{c k}\right.$ in MPa), $(400 / d) \geq 1(d$ in mm), and $0.0015 \leq \rho \leq 0.03$. Similar to Eurocode 2, the partial safety factor, $\gamma_{\mathrm{m}}$, was set to $1 . \mathrm{K}_{1}$ is a variable enhancement factor for support compression and is set conservatively to 1 .

\subsubsection{CEB-FIP Model Code 1990 (MC90)}

The European Code (MC90) "Design Code for Concrete" specifies punching shear resistance of concrete slabs reinforcement with steel bars as follow:

$\mathrm{V}_{\mathrm{c}}=0.12 \cdot \xi \cdot\left(100 \rho \mathrm{f}_{\mathrm{ck}}\right)^{1 / 3} \cdot \mathrm{b}_{\mathrm{o}, 2 \mathrm{~d} \cdot \mathrm{d}}$

Where $\xi=1+(0.2 / \mathrm{d})^{1 / 2}$ and $\mathrm{d}$ in meters and $\mathrm{f}_{\mathrm{ck}}$ in MPa. A partial safety factor is likely included as a part of the constant 0.12 (Mattys and Taewre, 2000). As such, the 0.12 constant was divided by partial safety factor of 1.5 to get an un-factored prediction of punching shear capacity. Thus, a constant factor of 0.18 was used in Eq. 28 instead of 0.12 .

\subsection{Current Literature Review on Concrete Barriers}

A Few authors dealt with the use of Fiber Reinforced Polymers (FRPs), in concrete barriers. Maheu and Bakht (1994) developed a new barrier wall using FRP (GFRP) NEFMAC grids, with connection to the deck slab by means of double-headed tension bars of steel spaced at $300 \mathrm{~mm}$. The new barrier wall system was adopted in the CHBDC (2000). El-Gamal et al. (2007) conducted pendulum impact testing on PL-2 and PL-3 barrier walls reinforced with new GFRP bars produced by Pultrall Inc. of Quebec, with lower tensile strength and higher modulus of 
elasticity than those used in the earlier pendulum impact testing conducted by them in 2001. Using the new type of GFRP bars was expected to lead to considerable savings in the cost of bridge barriers reinforced with FRP bars. As comparison, the test was conducted on barriers similar to the ones tested by the authors in 2001 with old GFRP bars. The difference between current barriers in the study with those in 2001 was manufacturing process and the differences in mechanical properties of the new GFRP bent bars. Two full scale $10 \mathrm{~m}$ long bridge barrier types PL-2 and PL-3 were constructed and tested. Pendulum crash test of 3 tons pear-shaped iron ball were carried out for the two barriers. In the study by El-Gamal et al. (2007) crack pattern, crack width and strains developed in the reinforcing bars were investigated. Form the test results, the behavior of new GFRP bent bars used in PL-2 and PL-3 barriers under impact load was similar or even better than those tested in 2001 with the same conditions. The crack patterns was similar to those tested in 2001 but the number of crack observed was less with a crack density of $20 \%$ $30 \%$ of those tested in 2001. Similarly, the average crack width observed was $20 \%$ of the average crack width seen in 2001 tested barriers. The same criterion was observed for the reinforcing strains showing less strain in current study than those in 2001.

An extensive research program investigating the use of glass fiber reinforced polymer (GFRP) in concrete bridge deck barrier was carried out by El-Salakawy et al. (2003). In their study, PL - 2 and PL - 3 bridge barriers were tested with geometry and reinforcement details similar to the Canadian Highway Bridge Design Code. Conventional steel reinforced barrier was used as comparison to its counterpart with sand-coated GFRP bars. In addition, a new bridge barrierdeck slab detailing was proposed by extending the main reinforcement of the wall through the slab. The study included two parts; Part (I) static test carried out on laboratory built barrier walls namely as; two PL-2 and two PL-3 barriers with $2 \mathrm{~m}$ long, and Part (II) impact loading by the use of pendulum crash test using 3 tons pear-shaped iron balls. The test conducted on eight fullscale PL-2 and PL-3 barriers with $10 \mathrm{~m}$ longitudinal dimension. The results of the study focused on comparing the overall behavior and cracking pattern of barrier walls reinforced with GFRP with that of conventional steel reinforcement under both static and impact loadings. It was found that the overall behavior of GFRP bars was similar to that of steel bars under both static and impact loads. El-Salakawy et al. (2003) observed that the laboratory tests performed on PL-2 and PL-3 barriers were failed by shear in all cases. However, the failure load in concrete made of 
GFRP was $13 \%$ for PL-2 and $14 \%$ for PL-3 less than that of concrete made with steel reinforcement. This was attributed to lower stiffness of the GFRP bars resulting in wider cracks. Also, El-Salakawy et al. (2005) conducted pendulum impact tests on GFRP reinforced barriers to examine the crack pattern, stresses and deflection under impact loading.

The study on connection of concrete railing post and bridge deck with FRP bars was conducted by Matta et al. (2009). From experimental tests and analytical models performed, a rational design for the connection joints has been validated to meet the requirements specified at component (connection) level prescribed by AASHTO (2012). In addition, the structural response of the connection until failure was accurately modeled so that to well-establish design principles of FRP reinforced concrete.

Sennah et al. (2010) conducted experimental study on the use of GFRP ribbed bars in bridge barrier under vehicle impact load. GFRP ribbed bars $12 \mathrm{~mm}$ and $16 \mathrm{~mm}$ were used as vertical bars in back and front faces of barrier walls. The headed end GFRP ribbed bars were utilized as connecting bars between deck slab and barrier wall with proper anchorages. In accordance with Test Level 5 (TL-5) of MASH (2009), vehicle crash test were conducted using 36000V van-type tractor trailer (cab-behind-engine model of $36000 \mathrm{~kg}$ gross weight) to impact the barrier wall at a nominal speed and angle of $80 \mathrm{~km} / \mathrm{h}$ and $15^{\circ}$, respectively. The test was conducted to evaluate the strength of the barrier in containing and redirecting heavy vehicles. According to Sennah et al. (2010), crash test results showed that the barrier contained and redirected the $36000 \mathrm{~V}$ vehicle. The vehicle did not penetrate, underride or override the parapet. No detached elements, fragments, or other debris from the barrier were present to penetrate or show potential for penetrating the occupant compartment, or to present undue hazard to others in the area. No occupant compartment deformation occurred. The $36000 \mathrm{~V}$ test vehicle remained upright during and after the collision event.

Static test and failure mode of precast concrete barriers were experimentally and analytically investigated by Jeon et al. (2008). Five series of precast barriers with variable joint connection between the barriers were tested on Test Level 4 (TL-4) and Test Level 5 (TL - 5) barriers adopted from AASHTO-LRFD at interior location. It was observed that failure mainly occurred 
above the tapered portion of the wall in a trapezoidal failure shape rather than the AASHTOLRFD triangular failure shape extended to the base of the wall. Jeon et al. (2008) proposed a revised failure mode and predictive equation of the strength based on the actual yield-line. In addition, analysis and design of concrete traffic railing was investigated by Alberson et al. (2011). From the full scale static and dynamic testing of the concrete traffic railings, it was observed that failure mode of the traffic barrier followed by two-way punching shear when the capacity of the railing exceeded at interior regions for some concrete traffic barriers. A proposed punching shear prediction model was presented. It was also recommended that the traffic barriers should be checked and evaluated to resist both moment load conditions (yield-line analysis) and two-way punching shear. Ngan (2008) conducted an experimental program on Performance Level 2 (PL-2) Precast Concrete Bridge Barriers reinforced with steel bars for the aim of investigating its structural behavior and anchorage capacity in accordance with CHDBC. The test results proved that the precast concrete bridge barrier complied with the current code specifications in terms of strength and overall structural behavior. The anchorage system of the tested barrier was sufficient as the failure occurred within the body of the barrier. It was also observed a trapezoidal failure mode of the precast concrete barrier at interior location.

A few investigators conducted vehicle crash tests on selected TL-5 concrete bridge barrier to resist vehicle impact (Hirsch and Arnold, 1981; Buth and Campise, 1982; Hirsch and Fairbanks, 1984a and 1984b; Campise and Buth, 1986; Hirsch et al., 1986; Beason and Hirsch, 1989; Buth et al., 1993a and 1993b; Alberson et al., 1997; Polivka et al., 2005; Rosenbaugh et al., 2007; Lechtenberg et al., 2009). Buth et al. (2003) conducted vehicle crash test on a $685 \mathrm{~mm}$ height bridge open-rail reinforced with glass fibre reinforced polymer bars. The test was performed using Test Level 3 of NCHRP Report 350, using pickup truck. Results showed that the railing demonstrated adequate structural capacity by containing and redirecting the vehicle with no structural distress. However, the vehicle rolled onto its side and did not pass the performance requirements of NCHRP Report 350. Sheikh et al. (2012) conducted experimental and finiteelement analysis on minimum railing height and design impact load of longitudinal barriers based on Manual for Assessing Safety Hardware (MASH) for TL-4 rails, similar to PL-2 barrier type in Canada. From their study, the minimum recommended barrier height of $813 \mathrm{~mm}$ by 
MASH has been increased to $915 \mathrm{~mm}$. Also, they recommended a design impact load of $356 \mathrm{kN}$ for MASH TL-4 rails.

Ngan (2008) conducted finite element investigation of anchorage capacity of PL-2 precast concrete bridge barrier. The precast barrier was loaded at interior and exterior location with a load of $100 \mathrm{kN}$ over a length of $1050 \mathrm{~mm}$ as per CHBDC code. It was observed when barrier is loaded at end location, the maximum stresses and displacements were about double compared to the interior location. Similar to experimental testing, stress concentrations was observed in the vicinity of anchorages. A finite element model of a steel-reinforced concrete safety-shape bridge rail with New Jersey shape was developed by Murray et al. (2007). The numerical model was conformed to the stand details and specifications of a rail as per Florida Department of Transportation (FDOT). An impactor was modelled to transfer the load to the barrier wall through a wood block. The FE results showed damage concentrations in the concrete at the location of wood block that was not the case in the experimental testing. This was found due to the fact that timber block was not in complete contact with the concrete. However, proper contact between the barrier and timber block showed stresses (erosion) at the tapered portion of the wall in addition to inclined shear cracks as agreed with experimental testing. 


\section{Chapter III}

\section{Pullout Strength of GFRP Bars in Concrete}

\subsection{General}

Steel reinforcing bars have been widely used in reinforced concrete applications due to its costeffective, strength and ductility that are known as the well suited materials in civil engineering structures. However, steel reinforced concrete normally suffers from corrosion of the steel by deicing salt in certain aggressive environment. As a result, constant repair and maintenance is needed to enhance the life cycle of such reinforcing bars. More recently, fiber reinforced polymer (FRP) bars have been of significant attention for new structures and being investigated as a suitable alternative to reinforcing steel bars. A cast-in-place anchor, for new constructions, is typically composed of GFRP bars with straight ends, $\mathrm{J}$ bends or headed ends as depicted in Figure 3.1. The behavior of pre-installed anchors in concrete has been extensively investigated as shown in previous chapter. However, very few investigations studied the behavior of preinstalled anchors using GFRP bars, especially the presence of headed-ends. The sand-coated GFRP bars provide means to increase the bond behavior between concrete and the bars. The bond behavior will increase with the presence of headed-end compared to the conventionally straight end bars. The load transfer mechanism of GFRP bars placed in concrete is due the bond behavior between sand-coated FRP bar and surrounding concrete. The load transfer significantly depends on the material properties at sand coated-bar interface or sand coated-concrete interface. The high strength and low modulus of elasticity as well as the differences in the properties of the fiber materials compared to those of the matrix may lead to bond characteristics difference from those for steel bars (Wang et al., 1999). Pullout resistance of FRP anchors in concrete is influenced by: 1) the surrounding concrete strength; 2) the concrete crack pattern at failure; 3) the connective bond strength between concrete and the sand-coated (i.e. the irregular and rough surfaces of GFRP bars are expected to provide mechanical resistance and increase the connective bond strength; 4) the connective bond strength between the coating layer provided on the GFRP bar surface to enhance its bond performance and the core of the GFRP bar (i.e. in some cases, it 
may limit the capacity if it is expected to peel off at a corresponding low bond stress; 5) the shear strength of the resin used within the GFRP bar itself; 6) the interaction between anchors for shorter spacing that promotes anchor group failure rather than single anchor failure; 7) bar edge distance to the concrete vertical surface; 8) pullout of anchor in uncracked or cracked concrete. The latter is very important since at positive moment region (i.e. within bridge span), concrete slab will be in compression and it will be fully effective in resisting pullout force. However, at negative moment region (i.e. over the piers or at the interior supports or continuous bridge girders or continuous voided slab bridges), the top surface of concrete deck slab is expected to have flexural cracks normal to the direction of the barrier wall. These cracks, even if they meet the minimum crack width requirements specified in the CHBDC for top slabs in continuous bridges, they will affect the ultimate pullout capacity of the GFRP anchors. Like steel anchors, if embedment length of GFRP bars is small, the concrete cone breakout failure would occur. However, if embedment length of GFRP bars is large, combined concrete/bond failure would occur. The combined failure includes a shallow concrete cone with bond failure below the cone. In some cases, radial cracks may occur dividing the cone into pieces instead of one piece cone. The bond failure may occur at concrete-bar surface interface, or by peeling off the coating layer of the GFRP bar (i.e. surface layer-bar core interface).
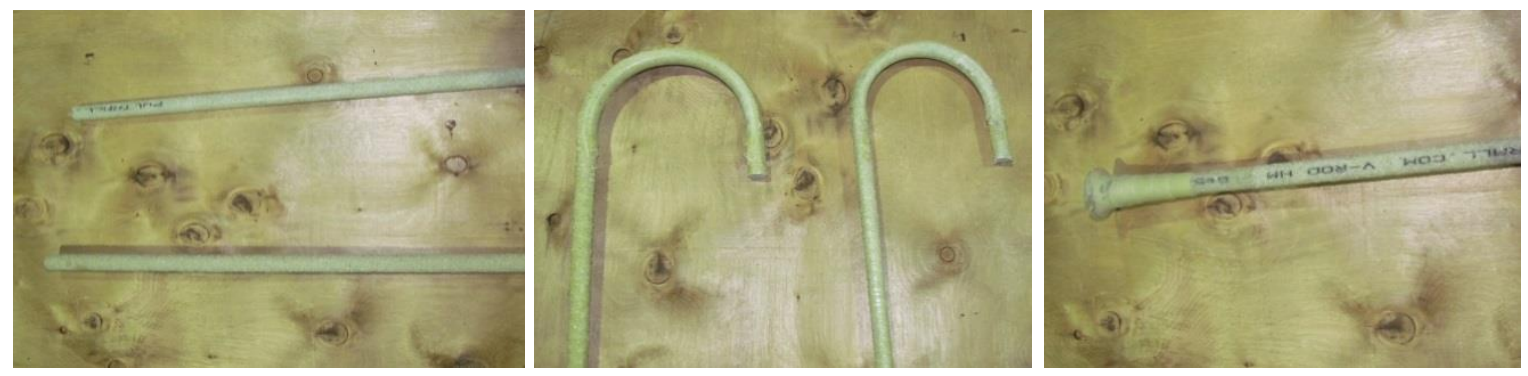

Figure 3. 1 Views of sand-coated GFRP bars; straight (left), 180'-hook (middle) and headed (right) bars

\subsection{GFRP Technology}

Fiber Reinforced Polymers (FRPs) are persumed as an excellent alternative to corrosion-related problems of reinforcing steel bars in bridge decks. GFRP bars are considered less expensive than carbon and aramid FRPs; thus, they are more attractive to bridge deck and barrier applications. Two types of GFRP bars were used in current study, namely: (i) GFRP bars with high modulus 
(HM) and (ii) GFRP bars with standard modulus (SM). The sand-coated surface profile of these bars, shown in Figure 3.2, ensure optimal bond between concrete and the bar. Table 3.1 summarizes material properties of the bars considered in the study herein. It should be noted that the $180^{\circ}$ hook bars are manufactured using standard modulus material. The modulus of elasticity of M15 hook bars used in the current research program is $50 \mathrm{MPa}$ with a tensile strength at bent portion equal to $473 \mathrm{MPa}$. It should be noted that the hook or bent bars cannot be reshapped on the site, and must be produced by the manufacturer. Due to redirection of fibers during bending process, the tensile strength of hook and bent portion are much less than the straight portion. Therefore, the design of the structures with hook or bent bars, the number of GFRP bars may be increased or even doubled.

Table 3. 1 GFRP Material properties (Pultrall, 2011)

\begin{tabular}{|c|c|c|c|c|c|}
\hline $\begin{array}{l}\text { Product } \\
\text { type }\end{array}$ & Bar Size & $\begin{array}{c}\text { Guaranteed tensile } \\
\text { strength }(\mathrm{MPa})\end{array}$ & $\begin{array}{c}\text { Modulus of } \\
\text { elasticity (GPa) }\end{array}$ & $\begin{array}{l}\text { Strain } \\
\text { at } \\
\text { failure }\end{array}$ & $\begin{array}{c}\text { Cross- } \\
\text { sectional } \\
\text { area }\left(\mathrm{mm}^{2}\right)\end{array}$ \\
\hline \multirow{3}{*}{$\mathrm{HM}^{*}$} & \#4 (M12) & 1312 & $65.6 \pm 2.5$ & $2.0 \%$ & 126.7 \\
\hline & \#5 (M15) & 1184 & $62.5 \pm 2.5$ & $1.89 \%$ & 197.9 \\
\hline & \#6 (M19) & 1105 & $64.7 \pm 2.5$ & $1.70 \%$ & 285 \\
\hline \multirow{3}{*}{$\mathrm{SM}^{* *}$} & \#4 (M12) & 941 & 53.6 & $1.76 \%$ & 126.7 \\
\hline & \#5 (M15) & 934 & 55.4 & $1.69 \%$ & 197.9 \\
\hline & \#6 (M19) & 807 & 56.6 & $1.43 \%$ & 285 \\
\hline \multirow{2}{*}{ SM-Bent } & \multirow{2}{*}{ \#5 (M15) } & 473 (bent portion) & \multirow{2}{*}{50} & \multirow{2}{*}{$1 \%$} & \multirow{2}{*}{197.9} \\
\hline & & 1051(straight portion) & & & \\
\hline \multirow{2}{*}{$\begin{array}{c}\text { SM-180 } \\
\text { hook }\end{array}$} & \multirow{2}{*}{ \#5 (M15) } & 473 (bent portion) & \multirow{2}{*}{50} & \multirow{2}{*}{$1 \%$} & \multirow{2}{*}{197.9} \\
\hline & & 1051(straight portion) & & & \\
\hline
\end{tabular}

In the current study, GFRP bars with straight-end, headed-end and bent bars were used for the aim of investigating the bond characteristics of the bars in concrete that can be then used as reinforcing bars in bridge barrier walls. The material properties of headed part is composed of a thermo-setting polymeric that is placed at the end of the straight bar, as shown in Figure 3.3 and 
hardened at high temperatures. The polymeric mix is composed of an alkali resistant Vinyl Ester resin, with a similar propoerties used in the straight bars. The outer diameter of the head has a maximum diameter of 2.5 times bar size. This geometry ensures optimal anchorage forces and minimal transverse splitting action in the vicinity of the head.
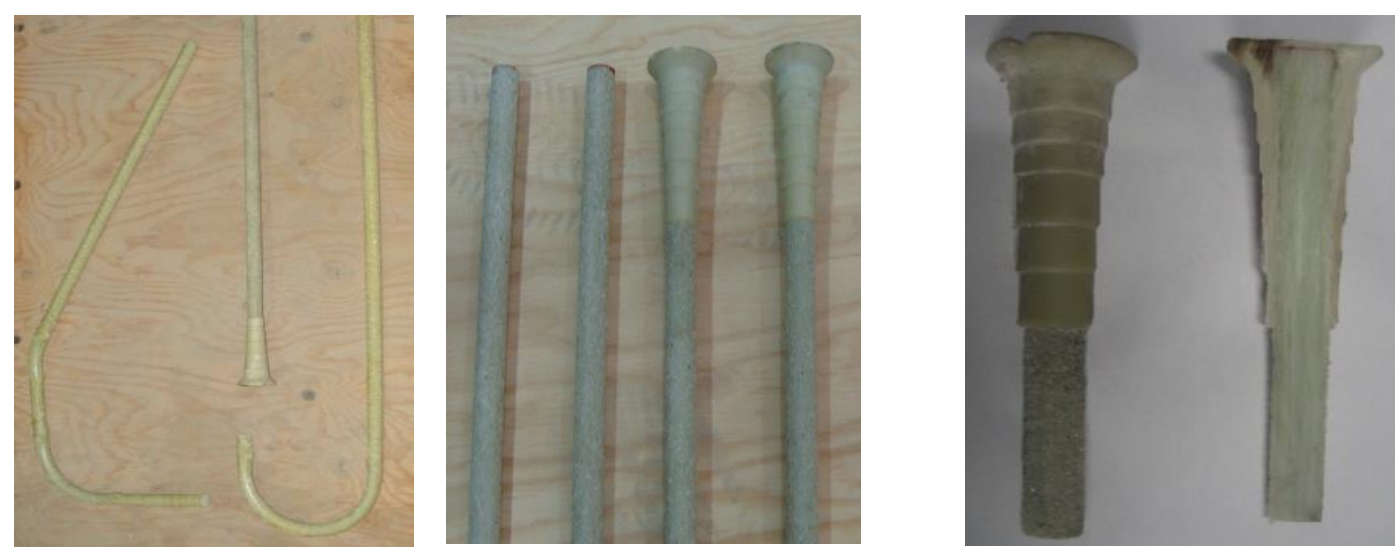

Figure 3. 2 Views of GFRP sand-coated HM and SM bars Figure 3. 3 View of headed-end bar

\subsection{Experimental Study on Pullout Specimens in Concrete slab}

To conduct pullout validation testing, two actual size concrete slabs were constructed. The concrete slabs contained single GFRP bars that were built at Ministry of Transportation of Ontario (MTO) site. This experimental program was undertaken to investigate bond strength of GFRP bars in concrete by direct pullout test incorporating different scenarios such as variable embedment depth, bar size, concrete strength and GFRP bars with straight, headed ends, and $180^{\circ}$ hook bars. The concrete slabs had a length of 33.30-m including five joints dividing the slab into six panels. Each panel was separated by $1.30 \times 0.30-\mathrm{m}$ plywood at the joint connections. Five panels had dimensions of 5.7-m length, 1.30-m width and 0.30-m thickness, while the last panel had a dimension of 4.8-m length, 1.30-m width, and 0.30-m thickness as shown Figure 3.4. Steel mesh reinforcement was placed in the concrete slabs at the top and bottom at a spacing of 300$\mathrm{mm}$ center-to-center. Concrete cover from edges to the steel mesh reinforcement was arranged so that each vertical GFRP bars is placed in center of steel reinforcement mesh grid. Concrete cover to steel mesh reinforcement from top and bottom was considered as $70-\mathrm{mm}$. Once steel mesh reinforcement is placed into the formwork, the longitudinal and transverse $2 \times 4$ plywoods were mounted on the top of the formwork, as depicted in Figure 3.5, so that the GFRP bars could be placed vertically in the slab. 

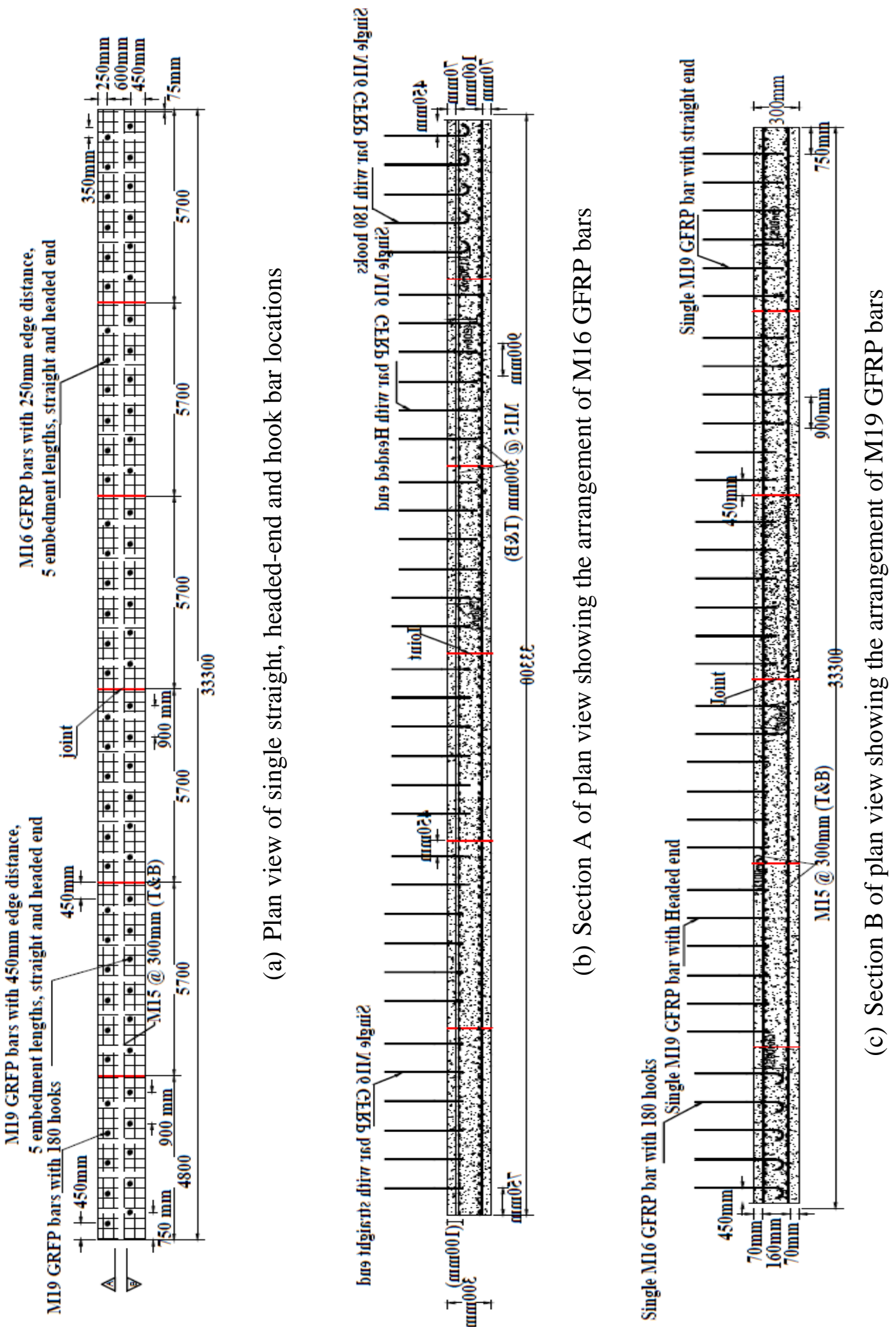

Figure 3. 4 Concrete slab models 1 and 2 with single GFRP bars 
GFRP bars were placed in staggered arrangement with center to center spacing of GFRP bars equal to $900-\mathrm{mm}$. This arrangement was selected in order to prevent overlapping the failure mode of two adjacent bars. Figure 3.5 shows image of the formwork with top and bottom mesh reinforcement as well as the installed $2 \times 4$ lumber. GFRP bars were then attached to the lumber using clamps that were screwed to the lumber (Figures 3.6 to 3.8). Figure 3.9 shows image of the final placement of GFRP bars in the formwork and Figure 3.10 shows marked GFRP bars with 200-mm embedment length in the formwork. In accordance with CSA-S806 (2012), five identical bars were cast for pullout testing. Each identical group bars differed from other group in the form of embedment length, bar size and anchorage type.

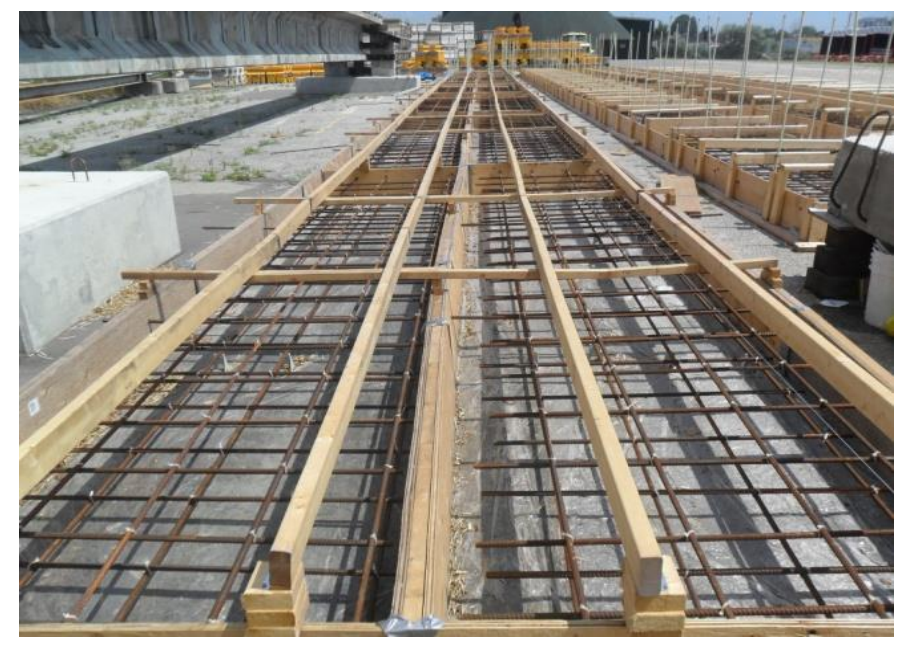

Figure 3. 5 View of formwork of slab models 1 and 2 prior to installation of GFRP bars

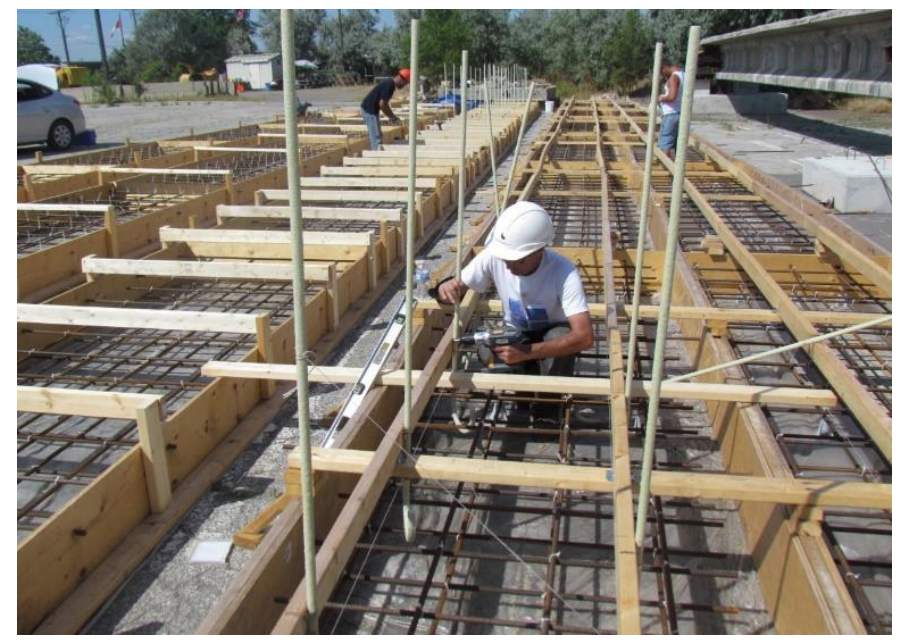

Figure 3. 6 Placement of GFRP hook bars in the formwork 


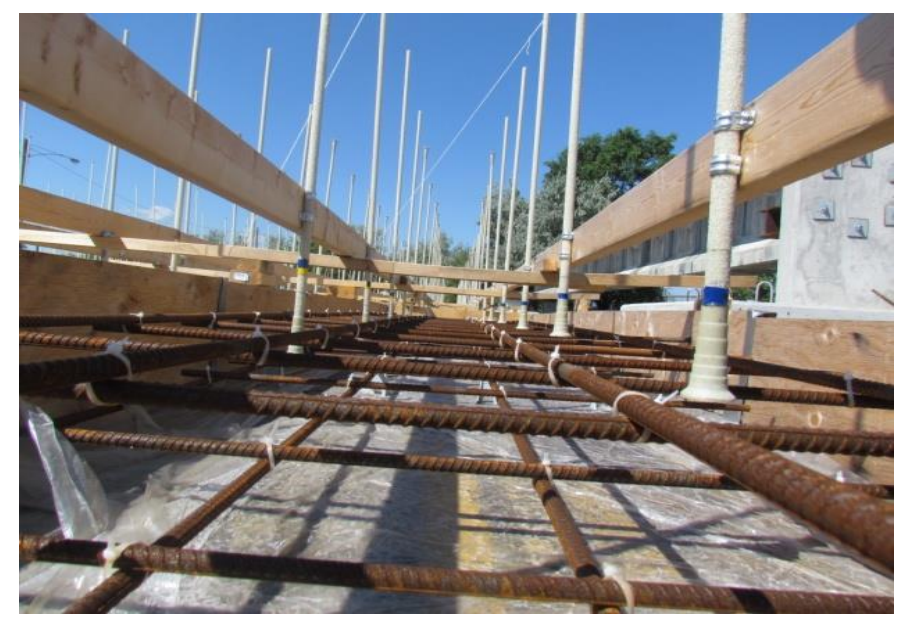

Figure 3. 7 Installation of GFRP headed-end bars in the formwork

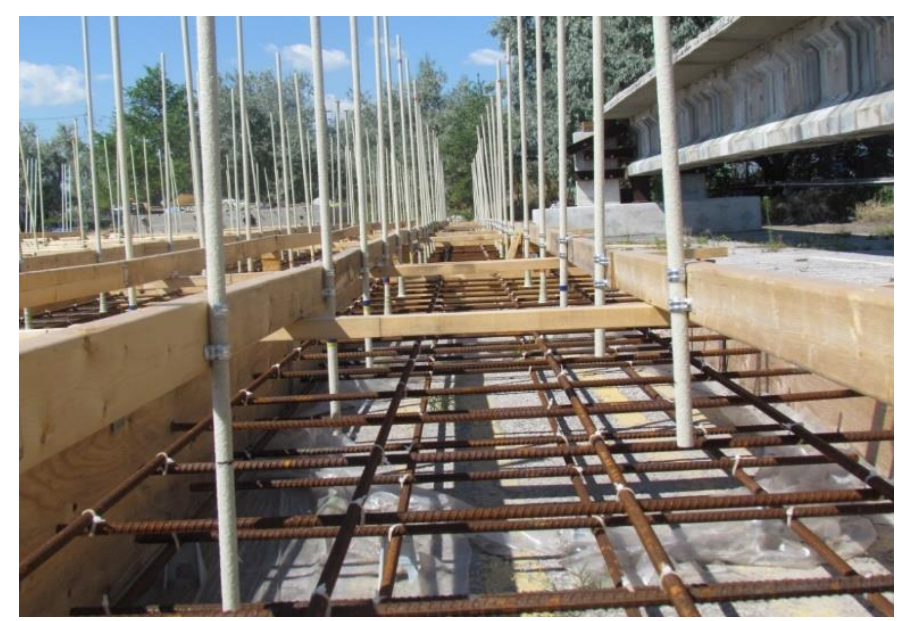

Figure 3. 8 Placement of GFRP straight-end bars in the formwork

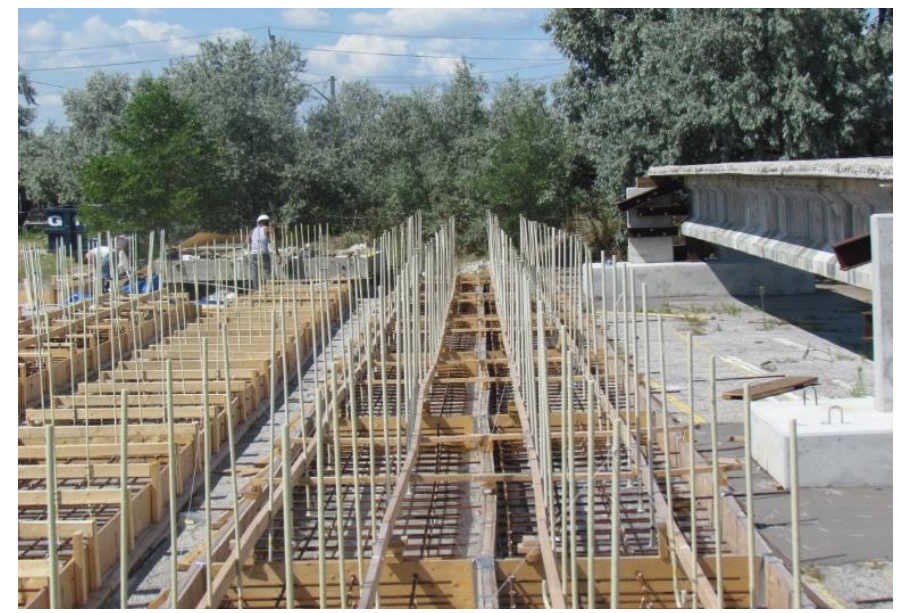

Figure 3. 9 View of GFRP bars in the formwork prior to concrete casting 

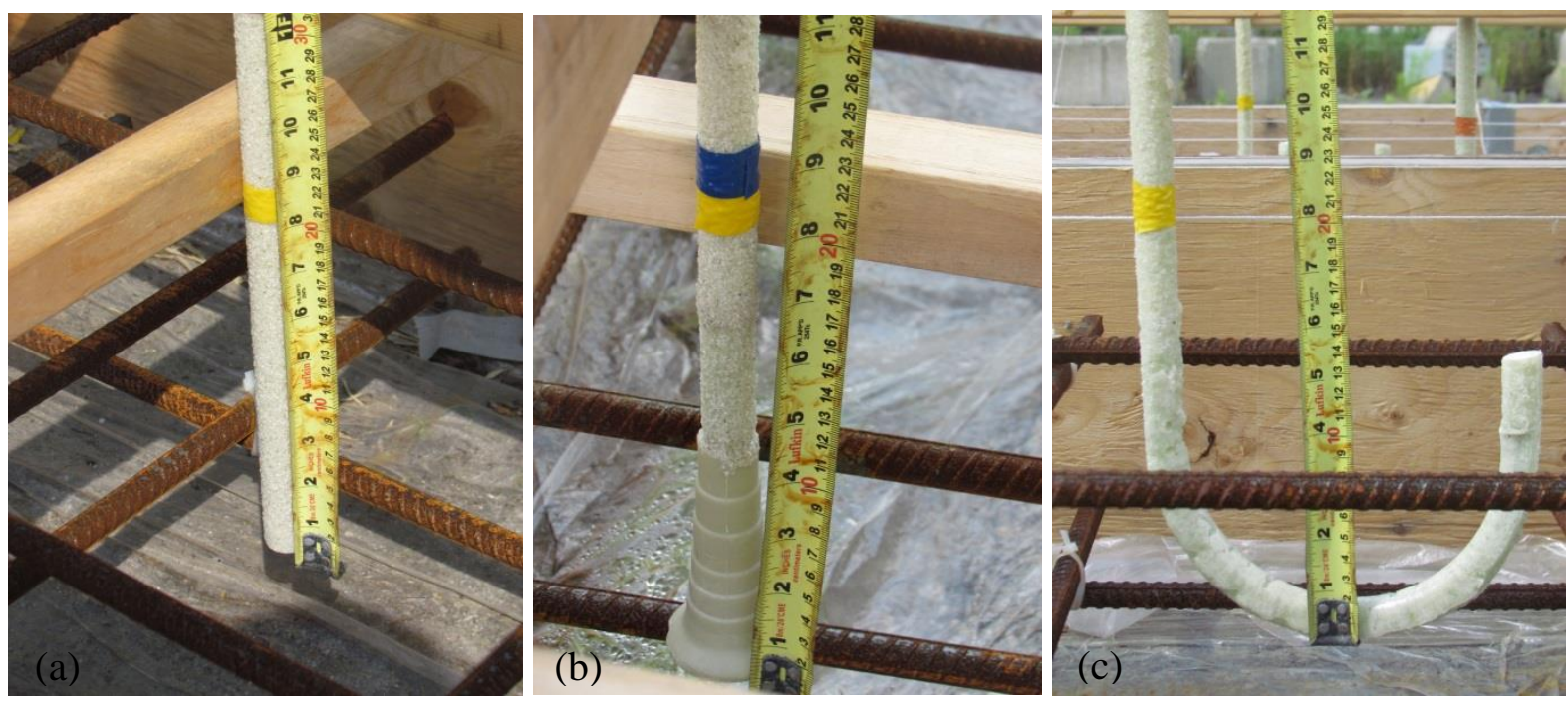

Figure 3. 10 Marked GFRP bars with 200-mm embedment length; (a) straigth bar, (b) headedend bar, and (c) $180^{\circ}$-hook bar

After placement of GFRP bars in the formwork, concrete casting of the slab Models 1 and 2 were performed using concrete pump truck shown in Figures 3.11. Figures 3.12 and 3.13 show images of the slabs during concrete casting. It should be noted that concrete slab Model 2 was cast a day after the casting of slab Model 1. During concrete casting, concrete was vibrated in order to remove entrapped air from concrete and avoiding concrete from honeycombing on the sides and surface (Figure 3.14). In addition, concrete cylinders of 100-mm diameter and 150-mm length were cast in the same conditions as the concrete slabs to ensure the compressive strength of the samples as expected. Figure 3.15 shows photo of concrete cylinders taken from different batches. After casting, all GFRP bars were leveled and placed vertically in the slab due to misalignment of some of the GFRP bars during casting (Figure 3.16). The concrete slabs were then watered for seven days, and two times per day, and cured using plastic sheets shown in Figure 3.17 to prevent evaporation of hydrated cement from surface. 


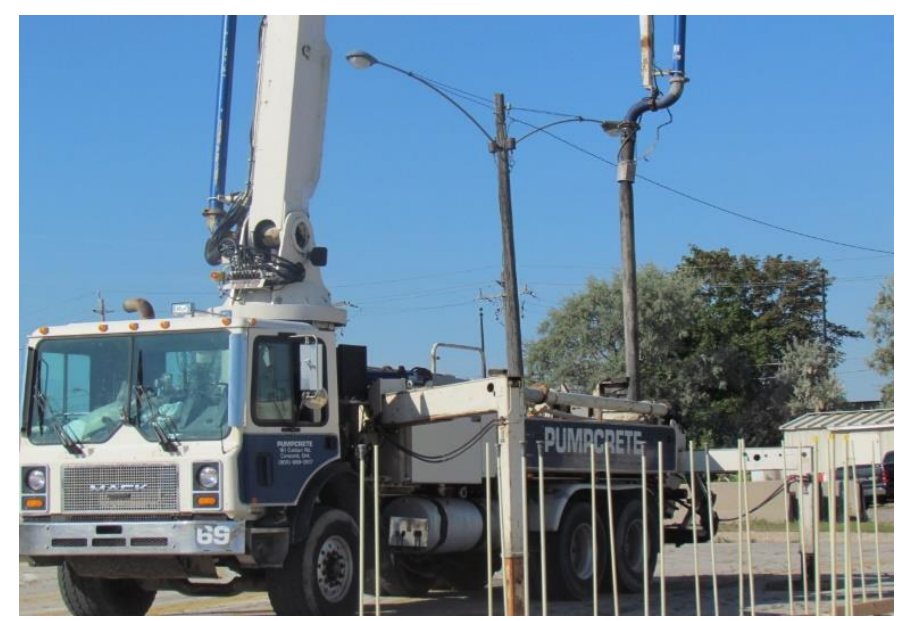

Figure 3.11 View of concrete pump truck

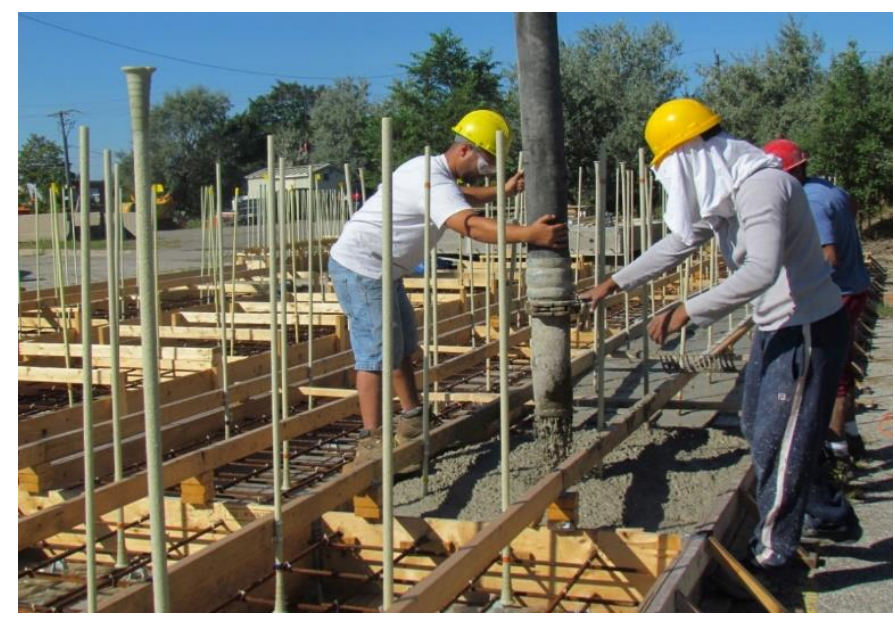

Figure 3. 12 View of concrete casting of slab Model 1

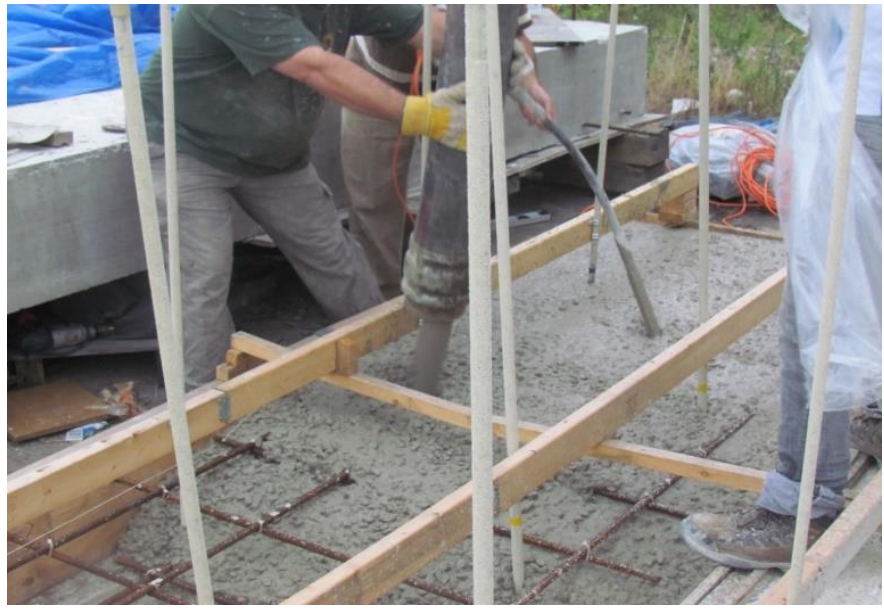

Figure 3. 13 View of concrete casting of slab Model 2 


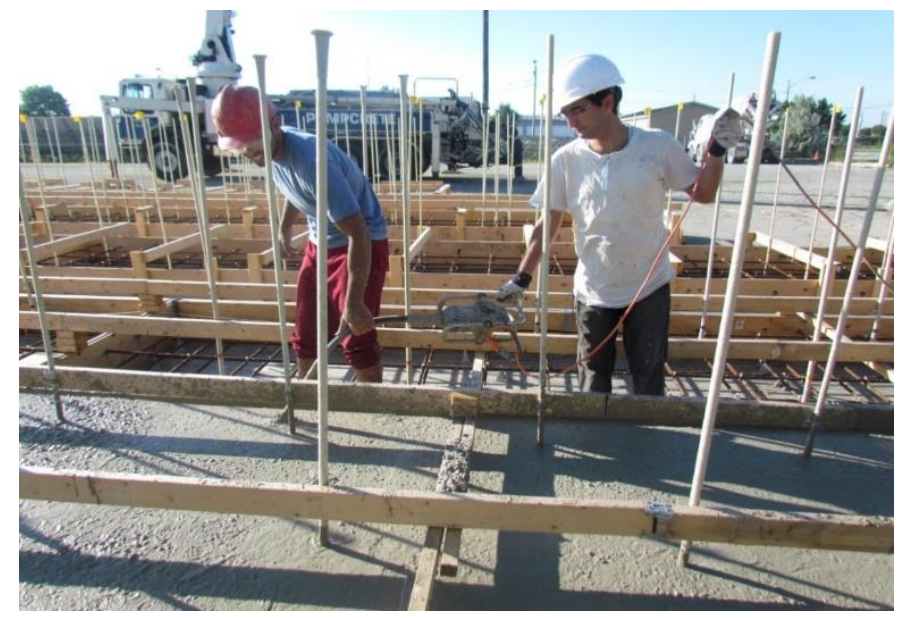

Figure 3. 14 Vibrating concrete during casting to remove entrapped-air

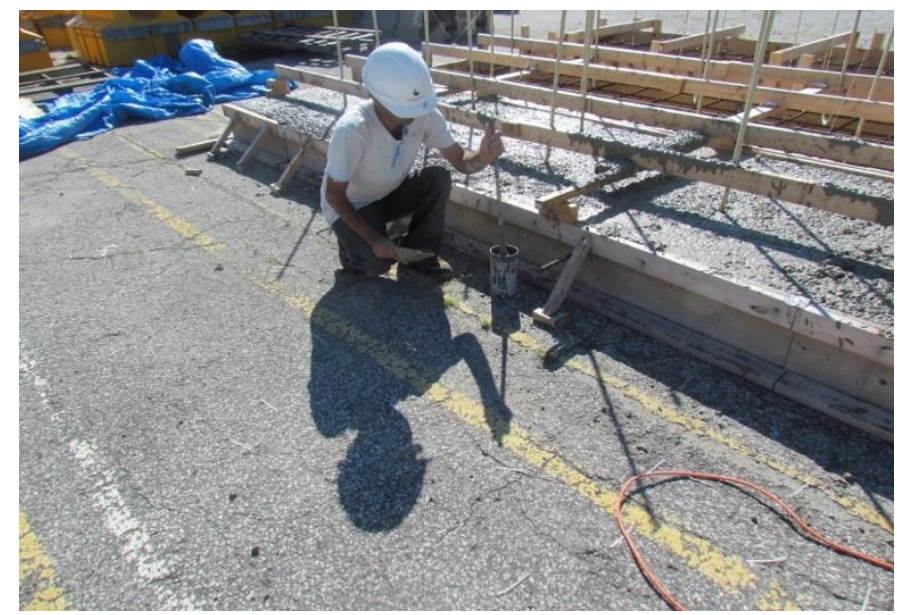

Figure 3. 15 View of taking concrete cylinder specimens from compressive strength test

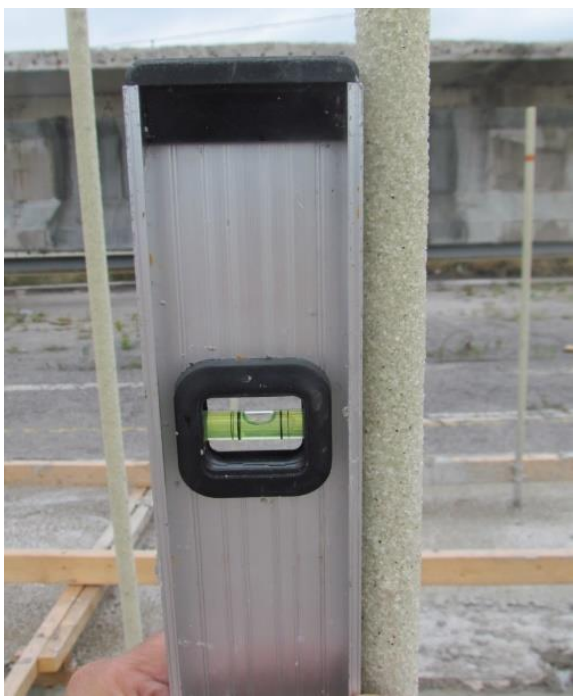

Figure 3. 16 Leveling out GFRP bars after concrete casting to make them vertical in the slab 


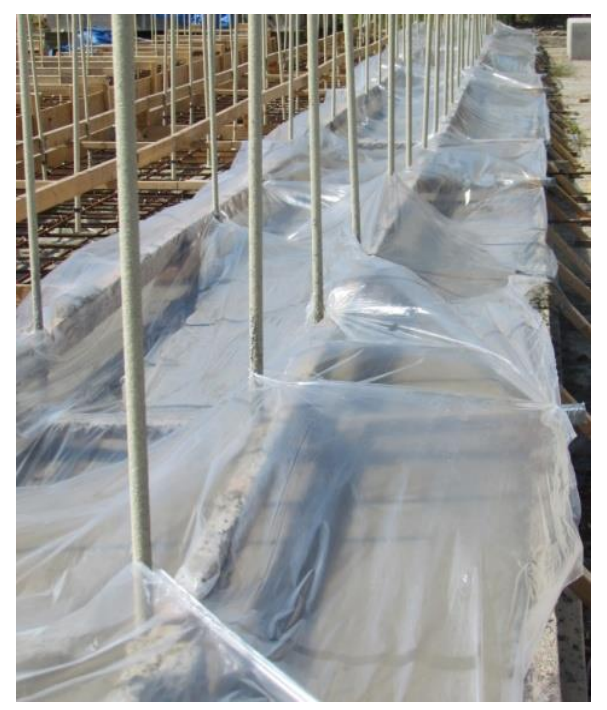

Figure 3.17 Concrete curing using plastic sheets

\subsection{Experimental Study on Pullout Specimens in Concrete Cubes}

Pullout testing of GFRP bars in concrete was also investigated on 114 concrete cube specimens with variable sizes. The concrete specimens contained single GFRP bars placed vertically in the center of each cube. The experimental program was carried out to investigate ultimate pullout capacity of GFRP bars in concrete cubes with variable parameters such as embedment length, bar size and GFRP bars with straight- and headed-ends versus hook bars. The size of concrete cubes was selected in accordance with CSA-S806 (2012) and ACI 440.3R (2004) incorporating the use of concrete cubes with 150-mm and 200-mm widths, respectively. However, the size of concrete cubes was changed based on the different GFRP-end anchorage system. Of the 114 concrete cubes, 48 were constructed with 150 -mm cubes containing both straight- and headedend bars of 15- and 19-mm diameters. In addition, 24 concrete cubes of 200-mm size were constructed that contained only straight end bars to account for larger concrete cover to the bars. Since GFRP headed-end bars tend to have a larger effect on the concrete surrounding the bars, 24 concrete cubes of 300-mm dimension were constructed in which only GFRP headed-end bars were placed. GFRP hook bars were placed into $300-\mathrm{mm}$ by $50-\mathrm{mm}$ concrete forms with variable embedment depths. A total of 18 GFRP hook bars of 15- and 19-mm diameters were constructed. Each single GFRP pullout cube contained three identical test specimens. Figures 3.18 to 3.21 schematically illustrate the arrangement of GFRP bars into the concrete cube specimens. 


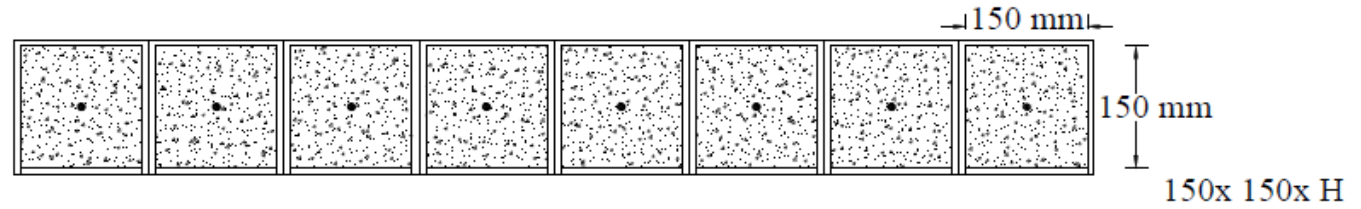

Embedment length $=\mathrm{H}-50 \mathrm{~mm}$

M19-GFRP, 3 identical bars each M15-GFRP, 3 identical bars each

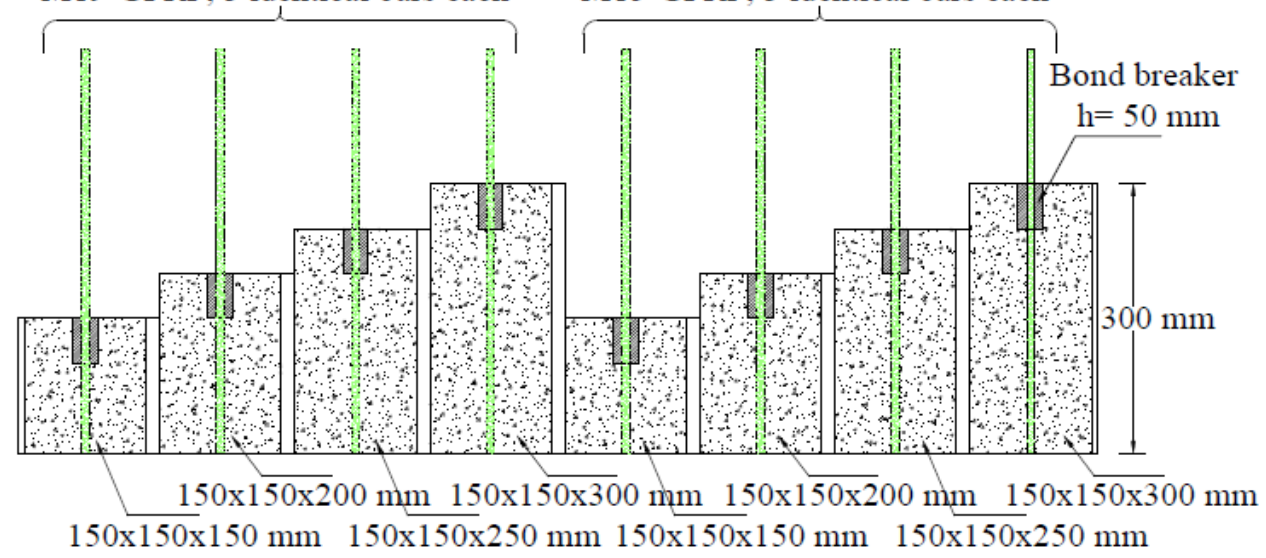

Figure 3. 18 Schematic view of 150-mm width concrete cubes with single GFRP straight-end bars
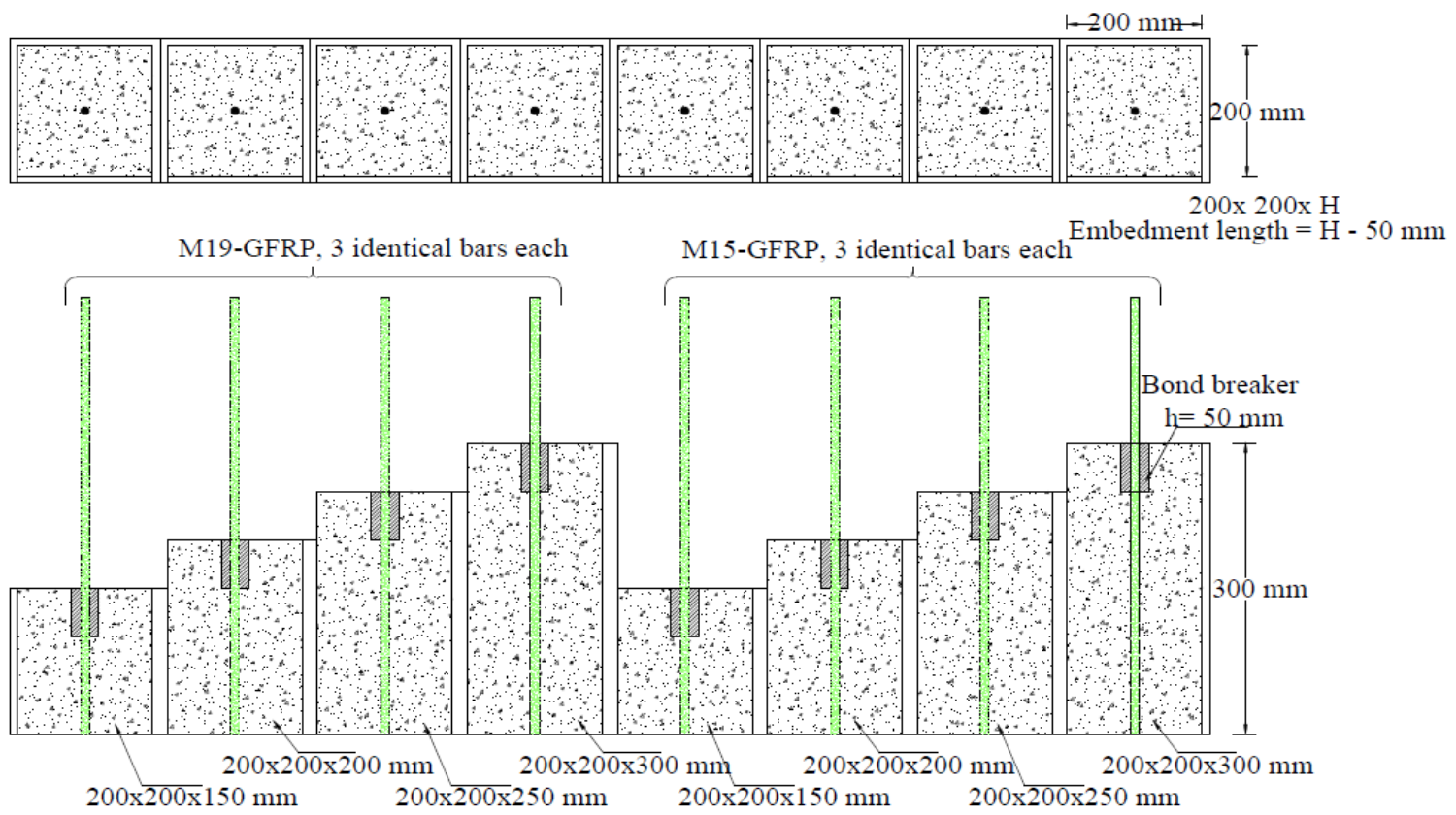

Figure 3. 19 Schematic view of 200-mm width concrete cubes with single GFRP straight- end bars 


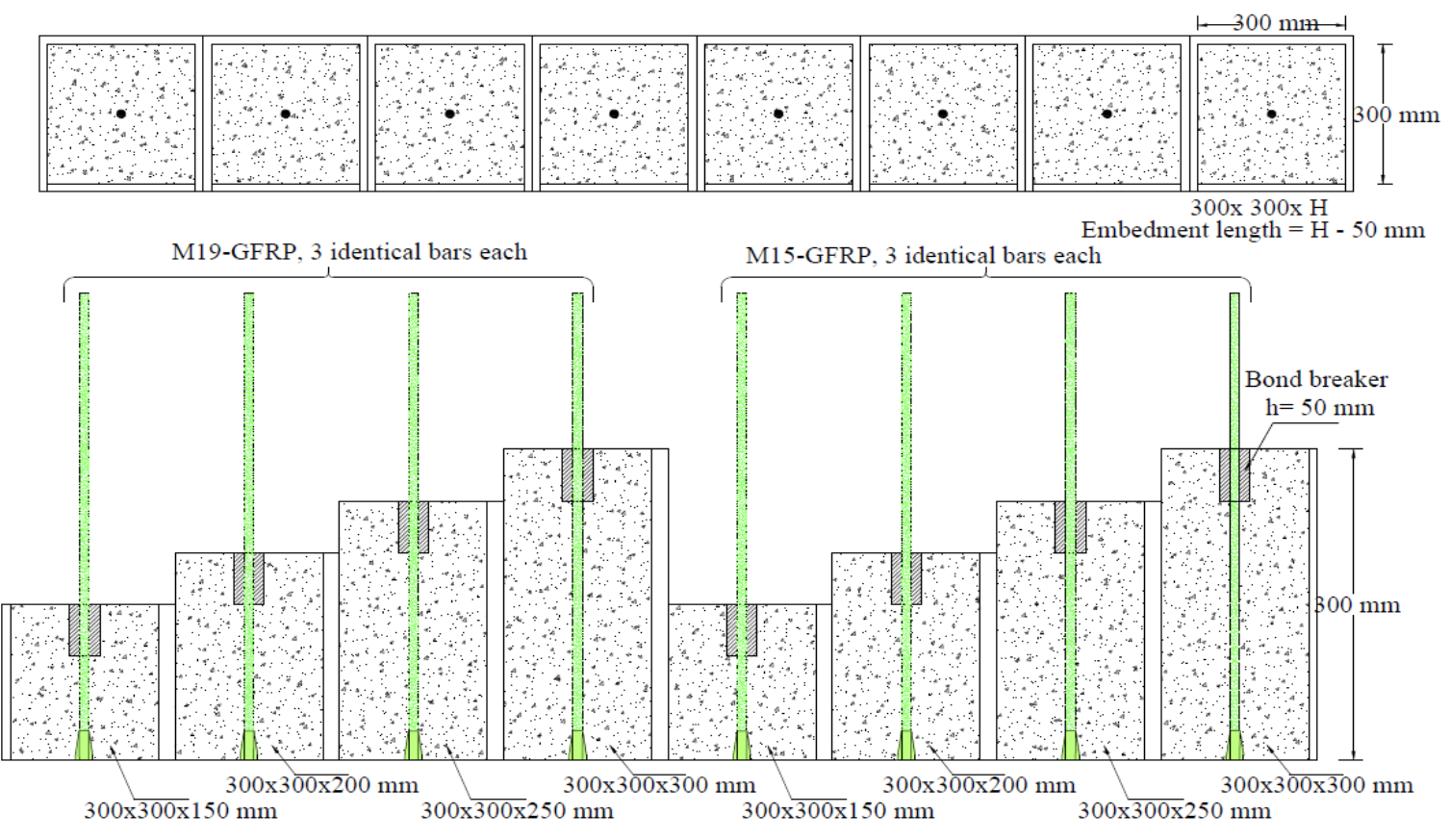

Figure 3. 20 Schematic view of 300-mm width concrete cubes with single GFRP headed-end bars

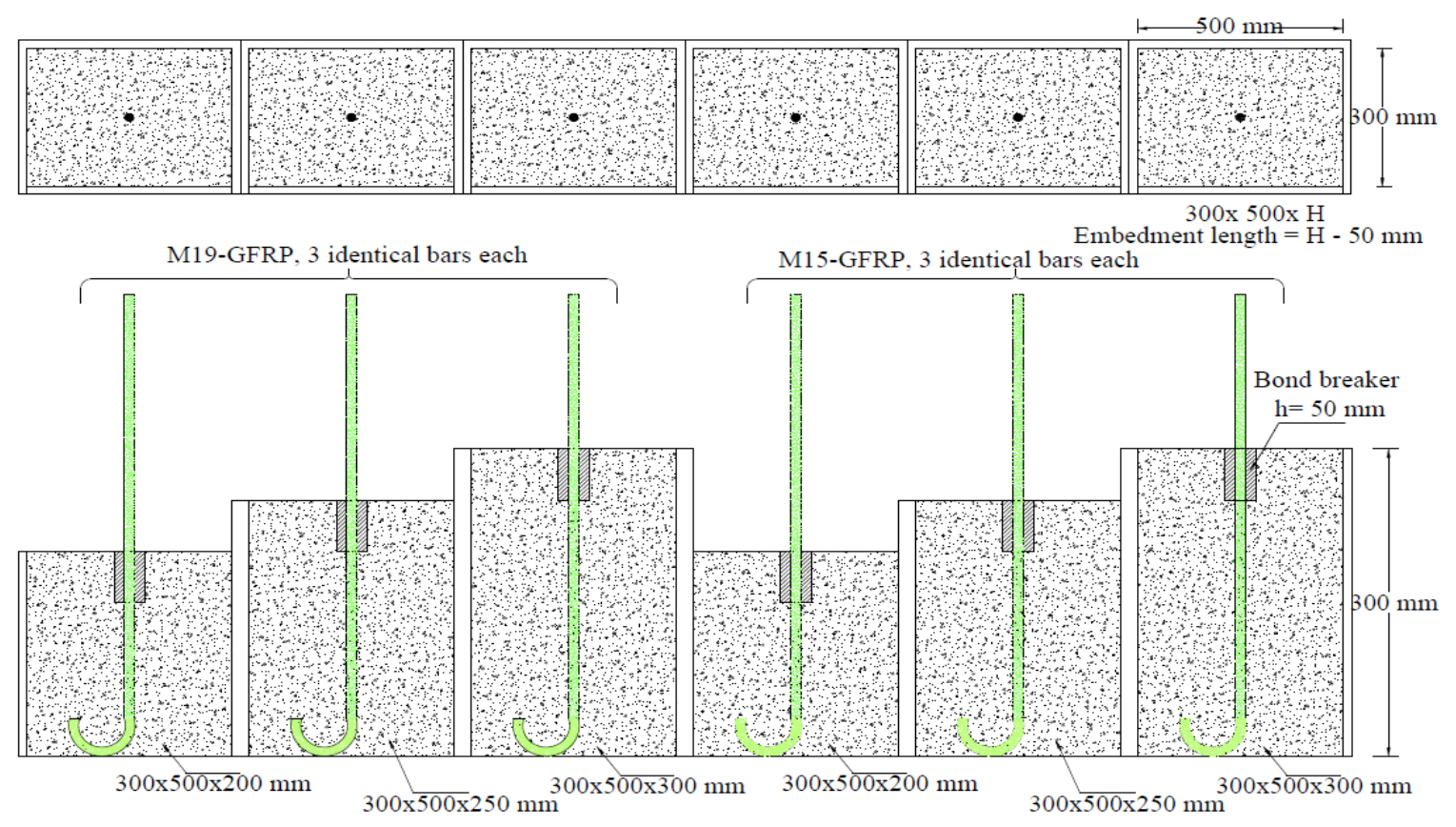

Figure 3. 21 Schematic view of 300-mm x 500-mm concrete cubes with single GFRP hook bars 
Figures 3.22 to 3.25 depict views of the constructed pullout cube specimens prior to concrete casting. As shown in the figures, each set of the concrete cubes were placed side by side in such a way that the three identical samples are placed next to each other. Each GFRP bar is placed concentrically into the concrete cubes using 2 x 4 lumber by means of steel clamps. Small drilling hole was made at bottom of the formwork to ensure that the GFRP bars are placed in the center of each cube. Also, the holes are meant for the projection of GFRP bars at bottom of the cubes so that free end slip could be measured. Four different embedment lengths were investigated in this study for each of the 15- and 19-mm diameter GFRP bars, namely 100, 150, 200 and 250-mm. The embedment length was within 5 to 16 times the bar diameters. Variable embedment lengths are meant to investigate bond behavior, loaded-end slip variations, development length and failure modes of the bars under increasing the embedment length. However, it is understood from literature that shorter embedment lengths result in more uniform bond stress distribution along the bar, while it tends to amplify local irregularities and variations in the test results. On the other hand, increasing embedment length reduces these irregularities and magnifies the non-linearity of bond mechanism between the bar and the surrounding concrete. As such, it is expected that the bond stress distribution to be non-uniform along the embedded length of the bars. Due to the applied tensile load, stress concentration is expected to produce at loaded-end location of the bars. To alleviate the effect of high stress concentration, a $50-\mathrm{mm}$ bond breaker was placed in each of the specimen. All cubes were then cast on the same day and a total of 10 concrete cylinders were cast simultaneously and cured in the same conditions as the concrete cubes. It should also be noted that concrete was cast in three layers and each layer was vibrated to avoid air-entrapping especially around the bars. Figures 3.26 and 3.27 show photos of concrete cubes during and after casting of the concrete with the concrete cylinders taken for compressive strength test, which are cured in the same environment next to the concrete cube specimens. Figure 3.28 shows view of concrete cubes after removal of the formworks. 


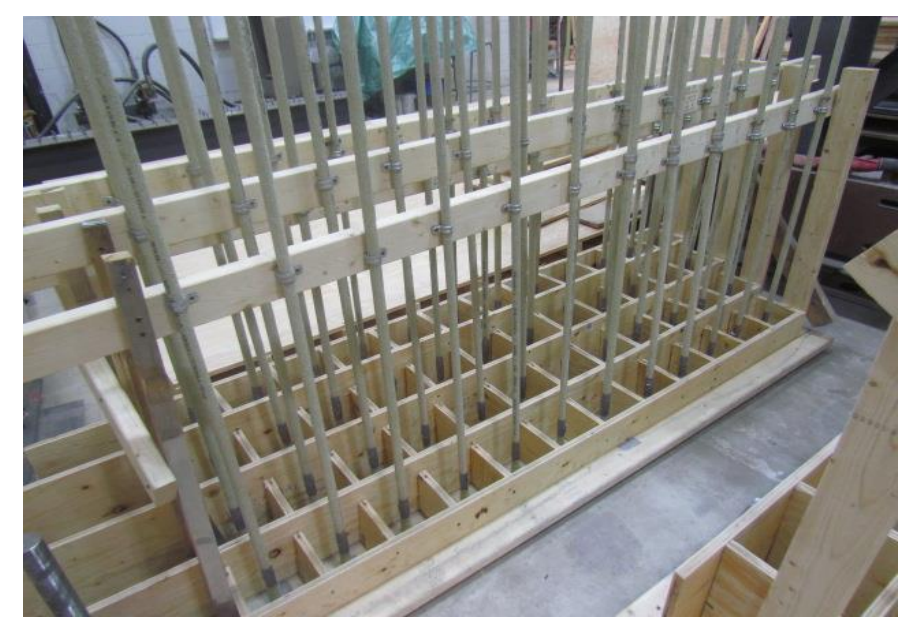

Figure 3. 22 Placement of GFRP straight and headed-end bars in 150-mm width cubes

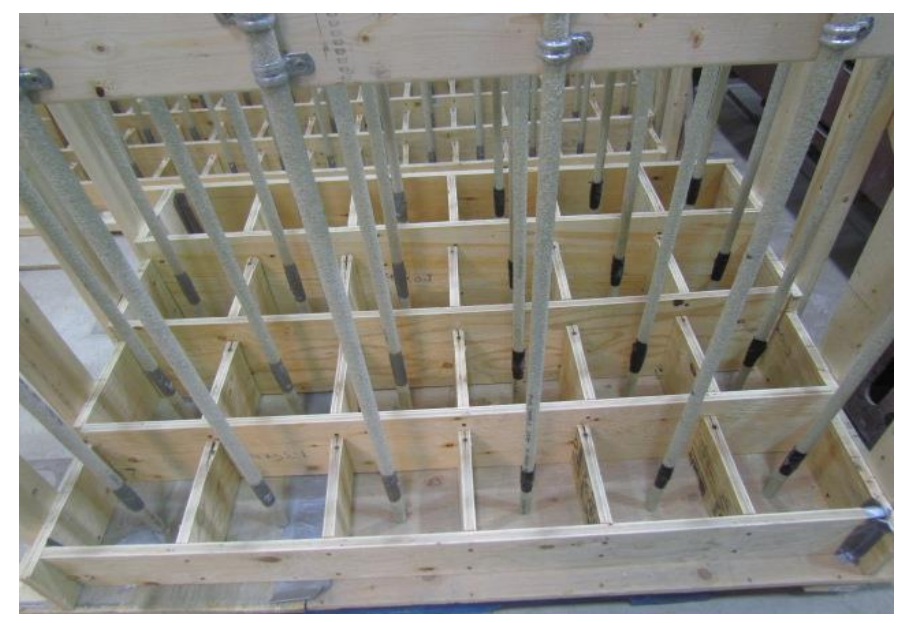

Figure 3. 23 Placement of GFRP straight-end bars in 200-mm width cubes

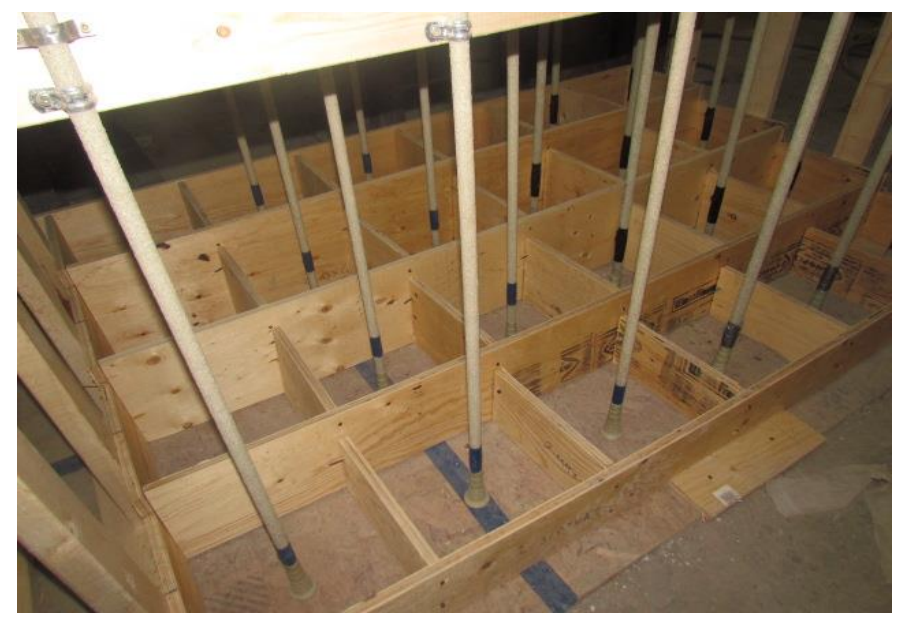

Figure 3. 24 View of GFRP headed-end bars embedded in 300-mm width cubes 


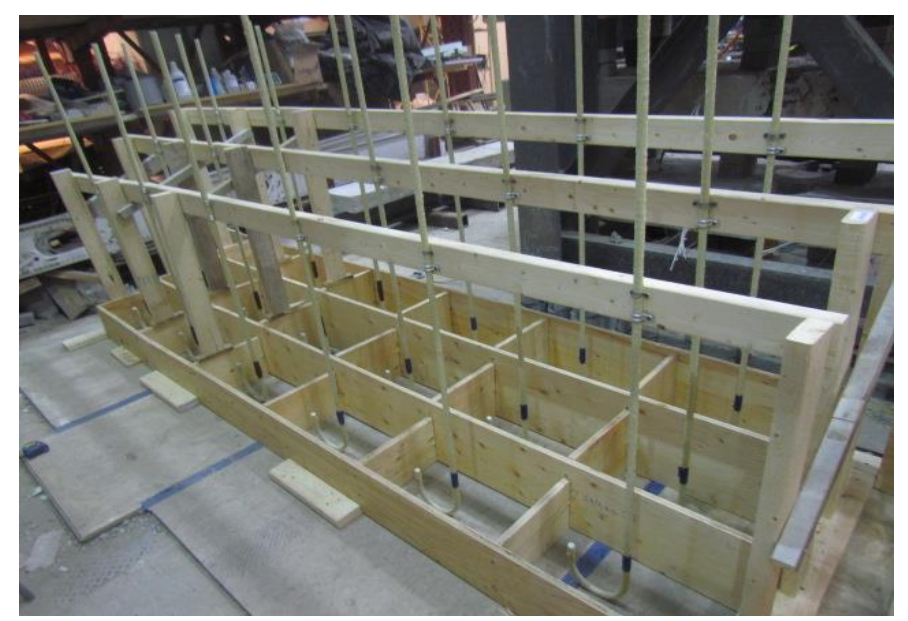

Figure 3. 25 Placement of GFRP hook bars in 300-mm x 500-mm concrete cubes

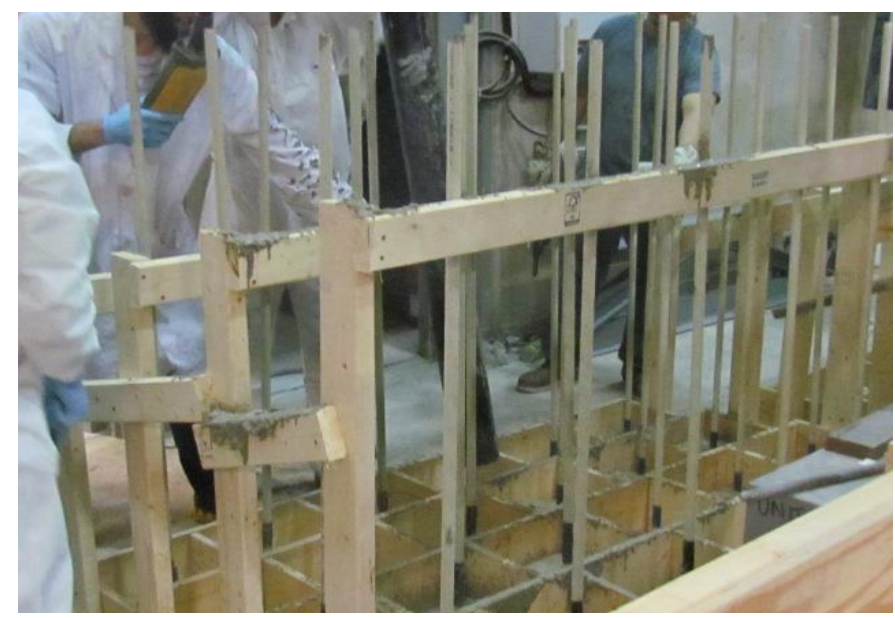

Figure 3.26 View of concrete casting of the pullout cubes using plastic pipe

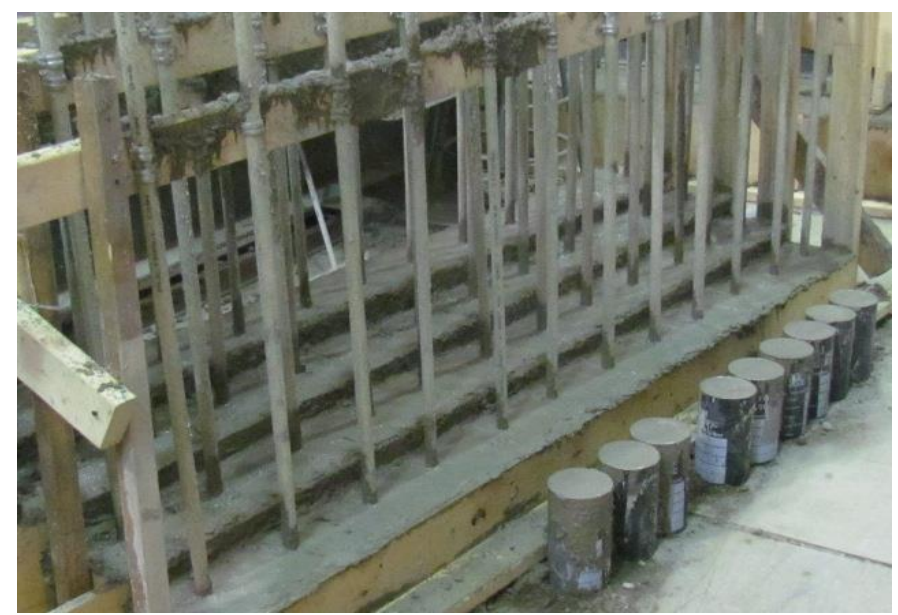

Figure 3. 27 Photo of cast concrete in 150-mm width cubes with cylinders cured next to the specimens 


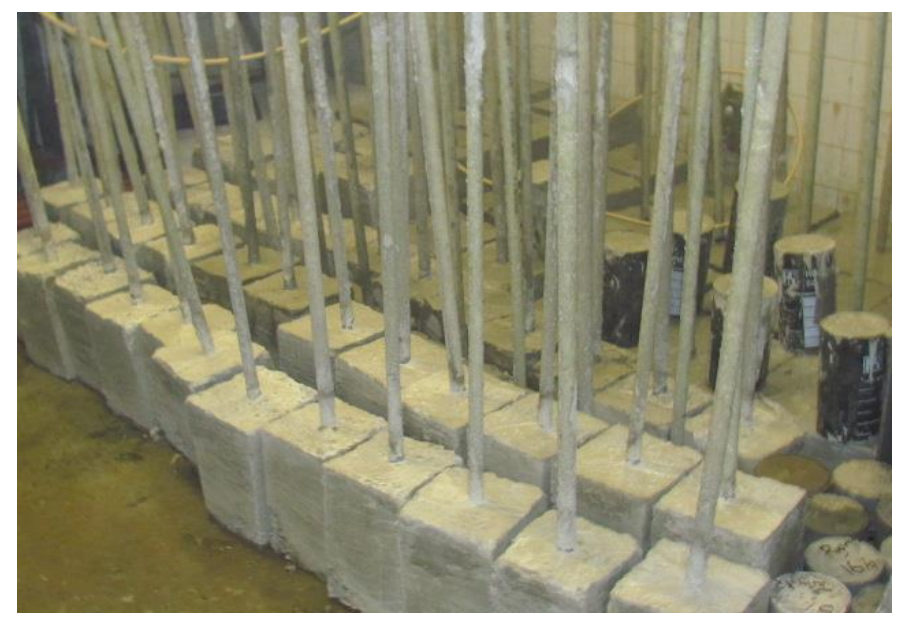

Figure 3. 28 View of concrete blocks after removal of formworks

\subsection{Material Properties}

\subsubsection{Concrete Slab Pullout Specimens}

As mentioned earlier, concrete cylinders of standard size of 150x100-mm were taken on the day of casting and cured in the same conditions as the test specimens. The concrete cylinders were tested at 3,7 and 28 days of casting. A total of 20 concrete cylinders were prepared and results of compressive strength tests from each batch were presented in the Tables A.1 and A.2 in Appendix A. However, the average of each batch was selected and the test result is shown in Figure 3.29 for slab models 1 and 2. Average concrete compressive strengths of 30.6 and 36.17 $\mathrm{MPa}$ were taken for barrier models 1 and 2, respectively. These values are considered in bond strength and development length equations of GFRP bars in the concrete slabs.

\subsubsection{Concrete Cube Specimens}

Concrete compressive cylinder tests were also performed on the pullout cube specimens. A total of 10 concrete cylinders were cast at the same time of casting the pullout cubes. The concrete cylinders were cured beside the cube specimens and tested at 3, 7 and 28 days. Figure 3.30 shows the concrete compressive improvement over time. An average 28 days concrete strength of 34.9 MPa was determined and considered in the calculation for all samples. 


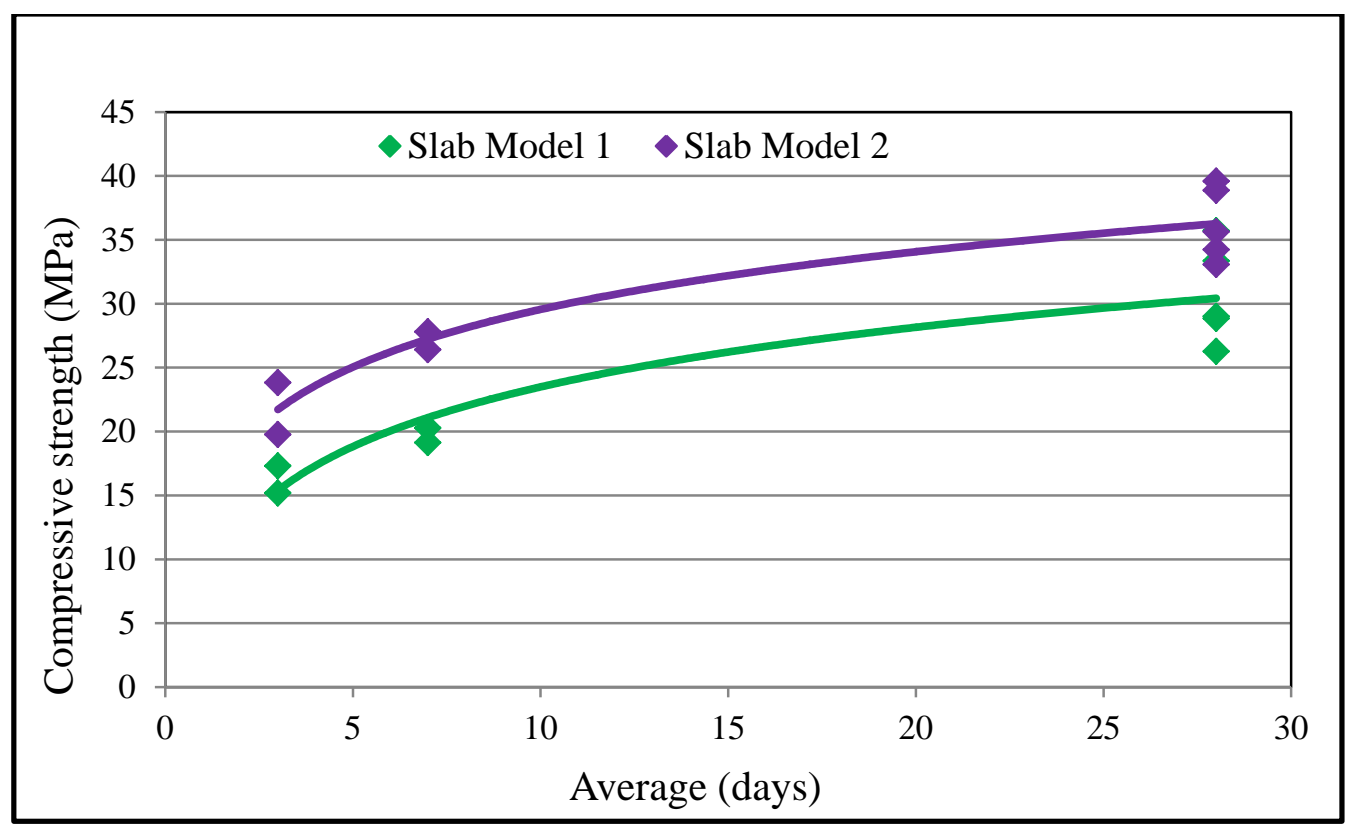

Figure 3. 29 Concrete compressive strength developments for slab models 1 and 2

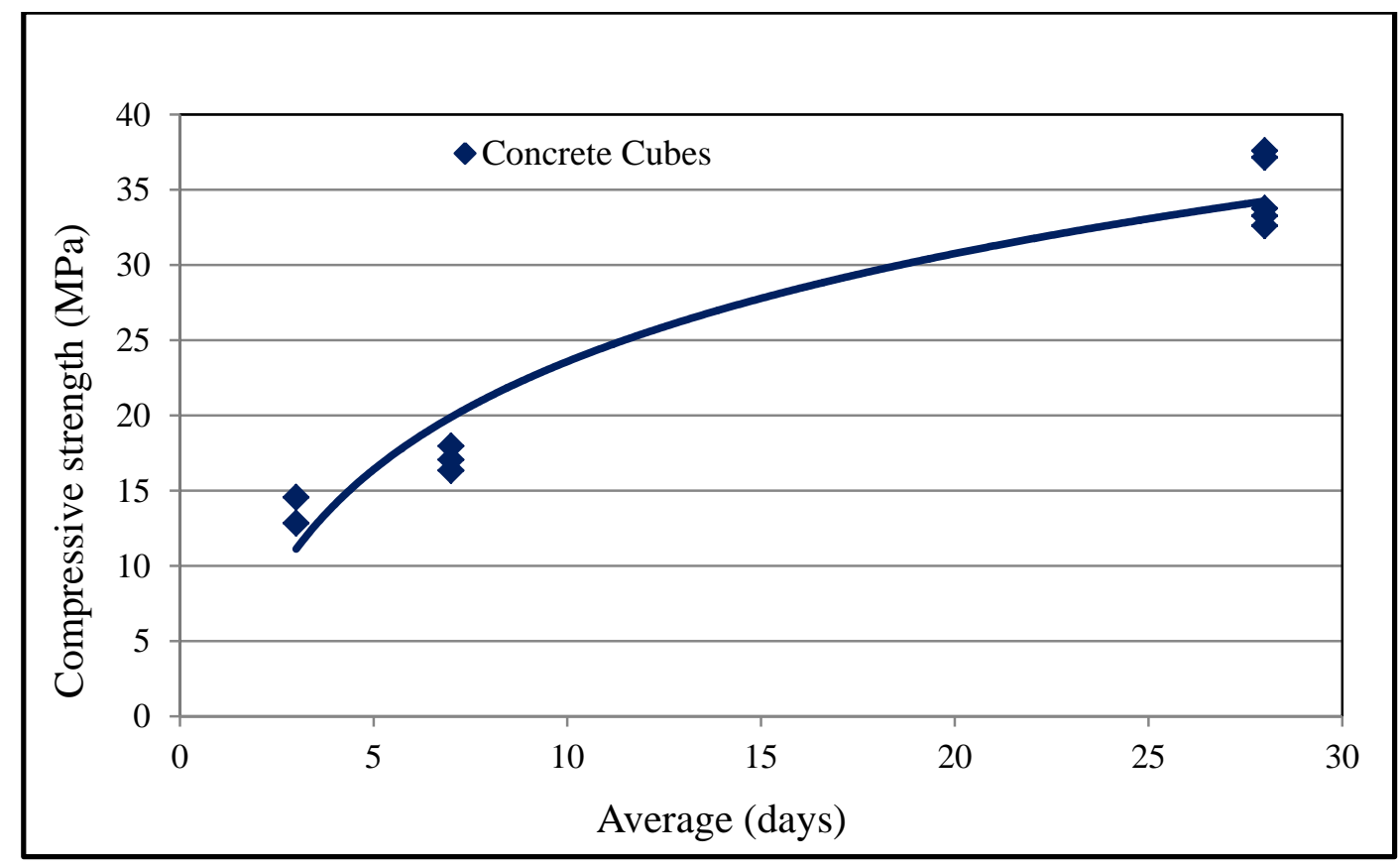

Figure 3. 30 Concrete compressive strength developments for concrete cube specimens

\subsubsection{GFRP Bars}

GFRP bars manufactured by Pultrall Inc. (Pultrall, 2011) were used in this study. Two types of bars, namely: Hig-Modulus (HM) and Standard-Modulus (SM) bars have been investigated. The 
GFRP bar sizes of $15 \mathrm{M}$ and $19 \mathrm{M}$ that have mostly been used in bridge construction were employed to study their bond behavior under variable bar size. The surface profile of the GFRP bars was sand-coated to increase the bond between concrete and the bars. The matrix resins of the GFRP bars were composed of vinyl-ester resins with a maximum of $35 \%$ volume fraction, while fiber reinforcement were composed of continuous E-glass fibers with a minimum of $65 \%$ volume fraction. GFRP material properties provided in Table 3.1 were used in all calculations.

\subsection{Test Setup and Procedures}

The pullout test specimens were tested once the desired concrete compressive strength was reached. The pullout tests started at minimum of 28 days after the casting. The following sections explain the test setup, equipment and the methodology used to perform pullout testing of the GFRP bars in concrete.

\subsubsection{Test Setup for Concrete Slabs}

Figure 3.31 shows schematic diagram of pullout specimens in concrete slabs. The test setup composed of three HSS 100x100x6.4 beams placed on each side of the GFRP bars with two additional HSS beams mounted on the top of the three HSS, on the sides of the GFRP bars (See Figure 3.32). The GFRP bars passed centrically through a hollow cylindrical jack with capacity of $500 \mathrm{kN}$ and stroke of $150-\mathrm{mm}$. The cylindrical jack was connected to the hydraulic pumping machine to apply the tensile load. A load-cell with capacity of $222 \mathrm{kN}$ was placed on the top of cylindrical jack with GFRP bar passing through the center of the load-cell. Two heavy capacity steel grips were placed on the top of the load-cell to hold the GFRP bars in place under the direct pullout load applied by hydraulic jack. Additional bearing steel plates and rubber pads were placed in between cylindrical jack and the load-cell and between load-cell and the grips as damper in order to prevent damaging the equipment under high applied load. This was also necessary to secure the contact between the load-cell and the jack as well as the jack and the grip for small irregularities which might introduce accidental bending of bar during loading or

movement caused by local crushing. The displacement sensor (LVDT) was clamped to the GFRP bars and placed on top surface of concrete in order to record the linear displacement change (slip) under the pullout load. 


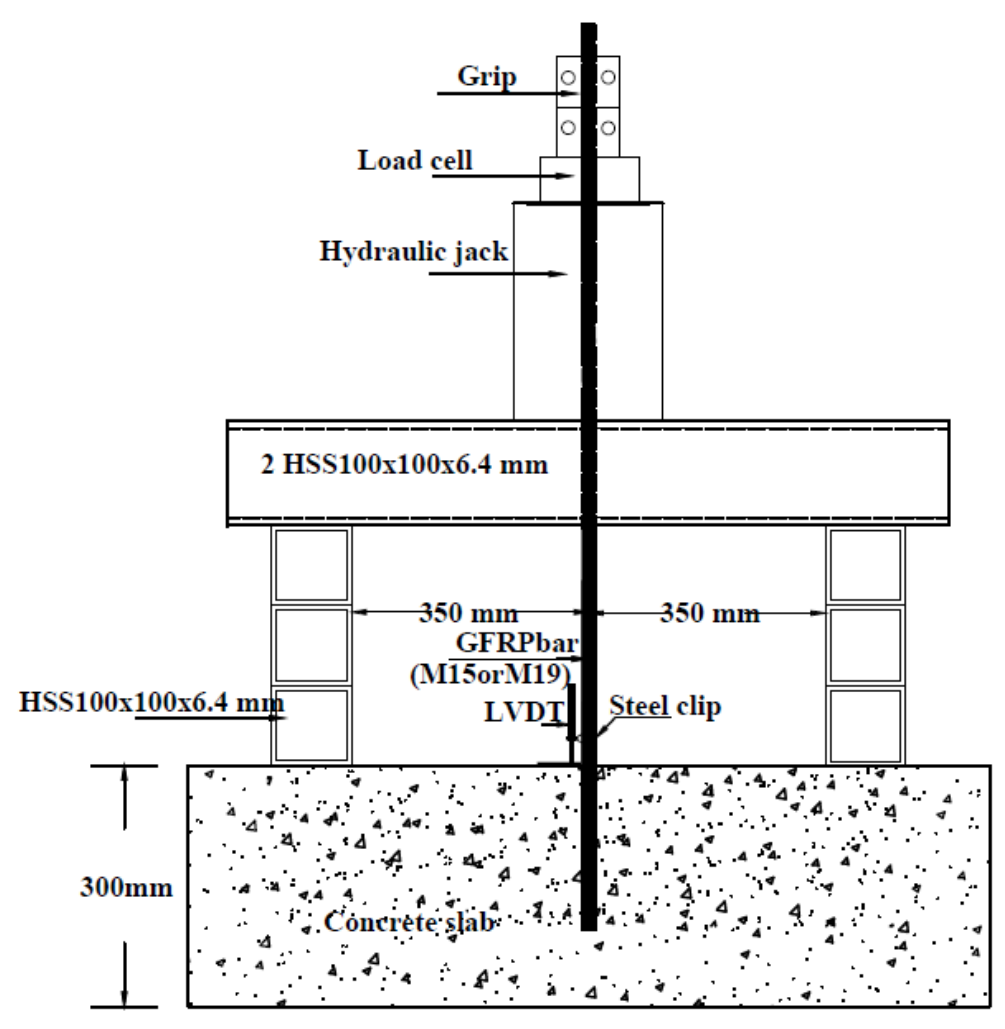

Figure 3. 31 Schematic diagram of pullout test setup of single GFRP bars in concrete slab

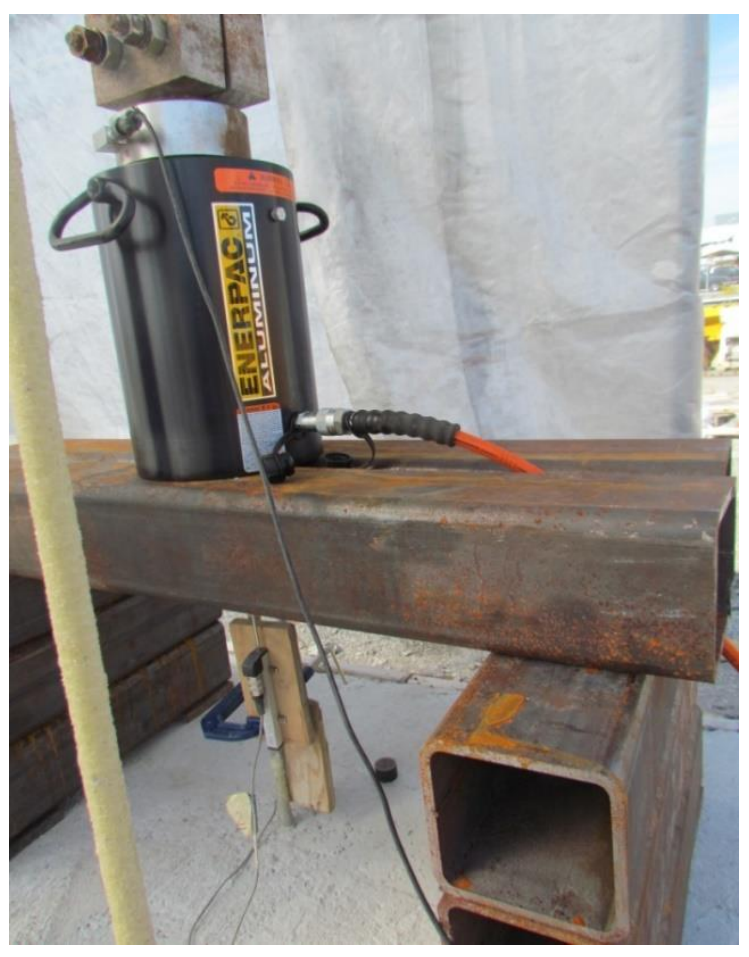

Figure 3. 32 View of single GFRP bar test setup for concrete slab specimens 


\subsubsection{Test Setup for Concrete Cubes}

The test setup, shown in Figure 3.33, was composed of hydraulic jack, load-cell, grips, adjusting plates and rubber pads. The cylindrical jack was connected to hydraulic pumping machine to apply the tensile load. A load-cell with capacity of $440 \mathrm{kN}$ was placed in front of the hydraulic jack and utilized to capture the applied load. Steel grips were placed at the end of the test setup to maintain GFRP bars in place under direct pullout load applied by hydraulic jack. Additional bearing steel plates and rubber pads were placed in between cylindrical jack and the load-cell as well as between the load-cell and the grips as damper in order to prevent damaging of the equipment under high applied load. The displacement sensors (POTs) were clamped to the GFRP bars at both free-end loaded-end locations in order to record slips of the bar relative to the concrete specimen under the pullout load.

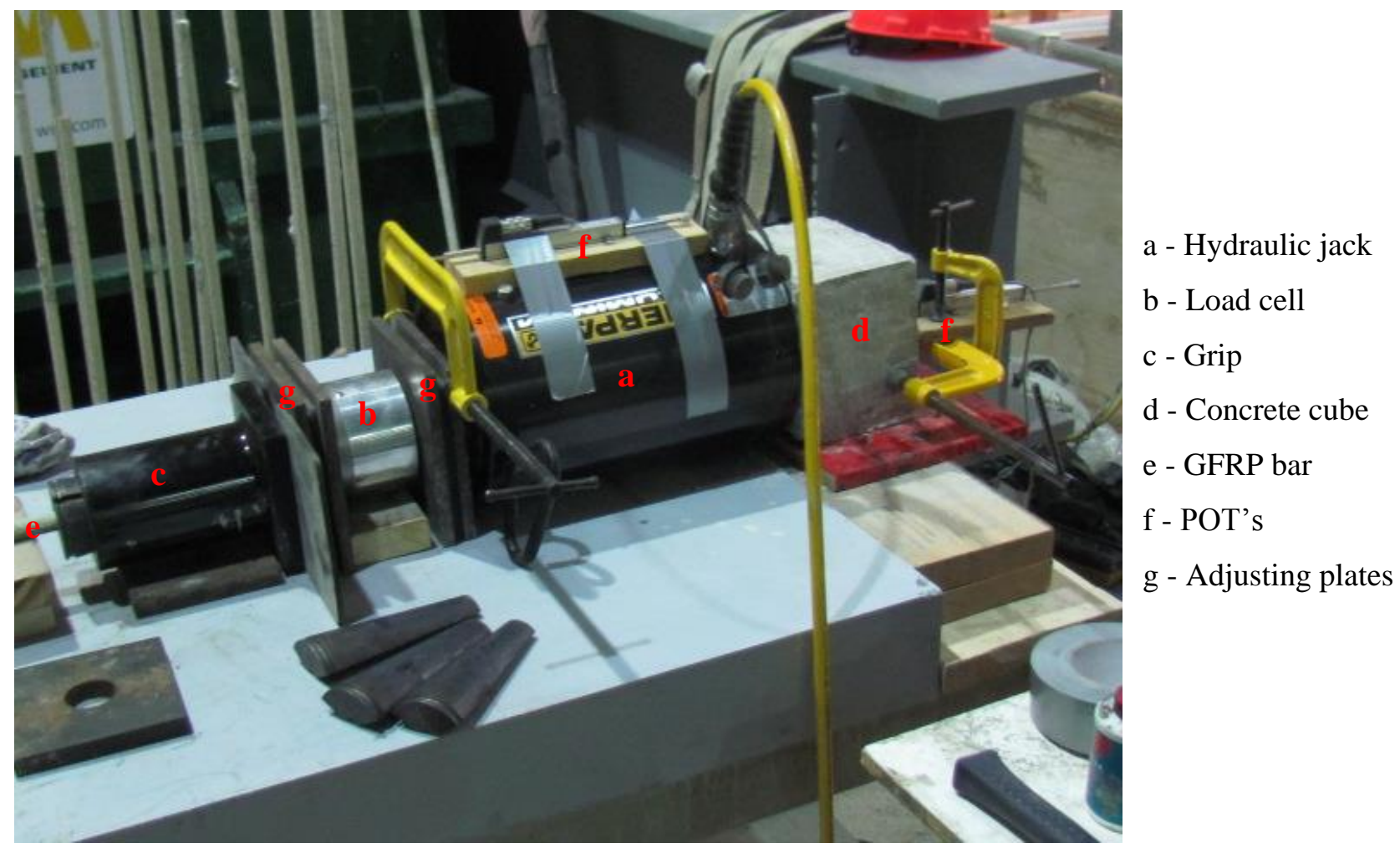

Figure 3. 33 Photo of pullout test setup of single GFRP bars in concrete cubes

\subsection{Experimental results of pullout specimens in concrete slabs}

Pullout tests were conducted on GFRP bars to investigate the effect of bar size, embedment length, bar end geometry and concrete strength on bond behavior of GFRP bars in concrete. The 
test was performed using the Vishay System 6000 data-acquisition machine running strain smart software. The machine has a scanning rate of 10,000 scans per second per channel. However, for the proposed study, the scan rate of only 10 scans per second has been used. The GFRP bar positioned in the testing machine was undertaken direct tension force in a deflection-controlled mode at a rate of about $0.2 \mathrm{kN} / \mathrm{s}$. The test stopped if the bars failed in pull through, bar rupture or pullout with head-broken modes of failure. The bond performance of concrete reinforced with GFRP bars can be characterized by mode of failure, bond strength and bond-slip relationship. Tables A.1 and A.2 in Appendix A summarize the pullout test results for single GFRP bars in concrete slab including failure modes, bond strength and the corresponding loaded-end slip due to the applied load. Although a non-uniform stress distribution is proposed in the literature along the bonded length of the bars, the bond strength was calculated by assuming a uniform stress distribution along the bars to simplify the analysis. Thus, the bond strength was found to be as a function of the applied tensile load and the perimeter area of the bar providing that:

$\tau=\mathrm{P} /\left(\pi \mathrm{dL}_{\mathrm{d}}\right)$

Where $\tau$ is the bond strength, $\mathrm{P}$ is the applied tensile load, $\mathrm{d}$ is the nominal bar diameter, and $\mathrm{L}_{\mathrm{d}}$ is the bond or embedment length of the bars. However, the CSA-S807 (2010) specifies that the minimum specified tensile strength and the corresponding bond strength shall be taken as the mean value of the test results multiplied by the factor, $F_{t}$, provided that;

$\tau_{\mathrm{chr} .}=\tau_{\mathrm{avg}} \cdot \mathrm{F}_{\mathrm{t}}$

$\mathrm{F}_{\mathrm{t}}=\frac{1-1.645 \mathrm{~V}}{1+\frac{1.645 \mathrm{~V}}{\sqrt{n}}}$

Where $\tau_{\mathrm{avg}}$ is the average bond strength obtained from experimental test data for identical samples, $\tau_{\mathrm{chr}}$. is the characteristic bond strength, $\mathrm{V}$ is the coefficient of variation of the bond strength obtained from qualifications tests, and $\mathrm{n}$ is the number of identical test samples. For 
each identical test samples, the characteristic bond strength is determined and provided in the tables in Appendix A.

Slip at the loaded-end was measured by the LVDT attached to the concrete surface. However, the actual loaded-end slip was calculated by subtracting the bar elongation from the measured loaded-end slip provided that:

$\Delta_{\text {elong }}=(\mathrm{P} . \mathrm{L}) /\left(\mathrm{A}_{\mathrm{f}} . \mathrm{E}_{\mathrm{f}}\right)$

$\mathrm{S}_{\mathrm{le}}=\mathrm{S}_{\mathrm{m}}-\Delta_{\mathrm{elong}}$

Where $\Delta_{\text {elong }}$ is elongation of the bars between concrete surface and point of attachment of the LVDT, $\mathrm{P}$ is the applied jacking load, $\mathrm{L}$ is the length of elongated bar equal to $180 \mathrm{~mm}, \mathrm{~A}_{\mathrm{f}}$ and $\mathrm{E}_{\mathrm{f}}$ are bar cross-sectional area and modulus of elasticity, respectively, $S_{\mathrm{le}}$ is the actual loaded-end slip of the bars, and $\mathrm{S}_{\mathrm{m}}$ is the measured slip captured by LVDTs.

\subsubsection{Bond Failure Modes}

The average bond strength was calculated as the average of the five identical test specimens. The modes of failure for the GFRP bars are provided in the following sections. Tables A.1 and A.2 provides failure modes of each tested GFRP bar. The specimens were generally showed pullout (PO), concrete cone breakout (CCB), pullout with head broken (POHB), bar slippage (RS) and bar rupture (RR) modes of failure. As a general case, the bond failure occurred partly on the surface of the bar by separating bond between concrete and the bar and partly occurred in the concrete by peeling off the surface layer of the GFRP bar.

\subsubsection{Pullout Failure Mode (PO)}

Most specimens with straight-end failed in pull-through mode. This was due to the fact that concrete provided adequate confinement to GFRP bar so that the bar enabled to reach its maximum bond strength. The concrete composed with GFRP generally failed when the bar was pulled out from concrete with no visible or sign of cracks surrounding the concrete; however, the conically-shaped concrete breakout was observed on top surface of concrete slab as depicted in 
Figure 3.35. This type of failure mode occurred in GFRP bars with straight-end mostly for embedment length greater than 150-mm. The failure mode may indicate the presence of low bearing stresses produced by GFRP bar interface. And, as long as the stress at bar-concrete interface exceeds the adhesion resistance of the GFRP surface texture, the whole bar moved out as a rigid body. Figures 3.34 to 3.36 compare pullout failure mode in slab models 1 and 2 with 15- and 19-mm bar diameters. In all cases, pullout occurred by surface conically-shaped failure, while the embedded bar pulled out of concrete. As a result, it can be concluded that ultimate bond strength of specimens is characterized by shearing strength of concrete surrounding the bars which failed when the tensile load in the bar exceeded the ultimate tensile strength in the concrete. In most cases, the surface conically shape area in the $15 \mathrm{M}$ GFRP bars was observed greater than the $19 \mathrm{M}$ bars. This may be attributed to the higher bond strength developed by the $15 \mathrm{M}$ bars compared to the $19 \mathrm{M}$ bars.
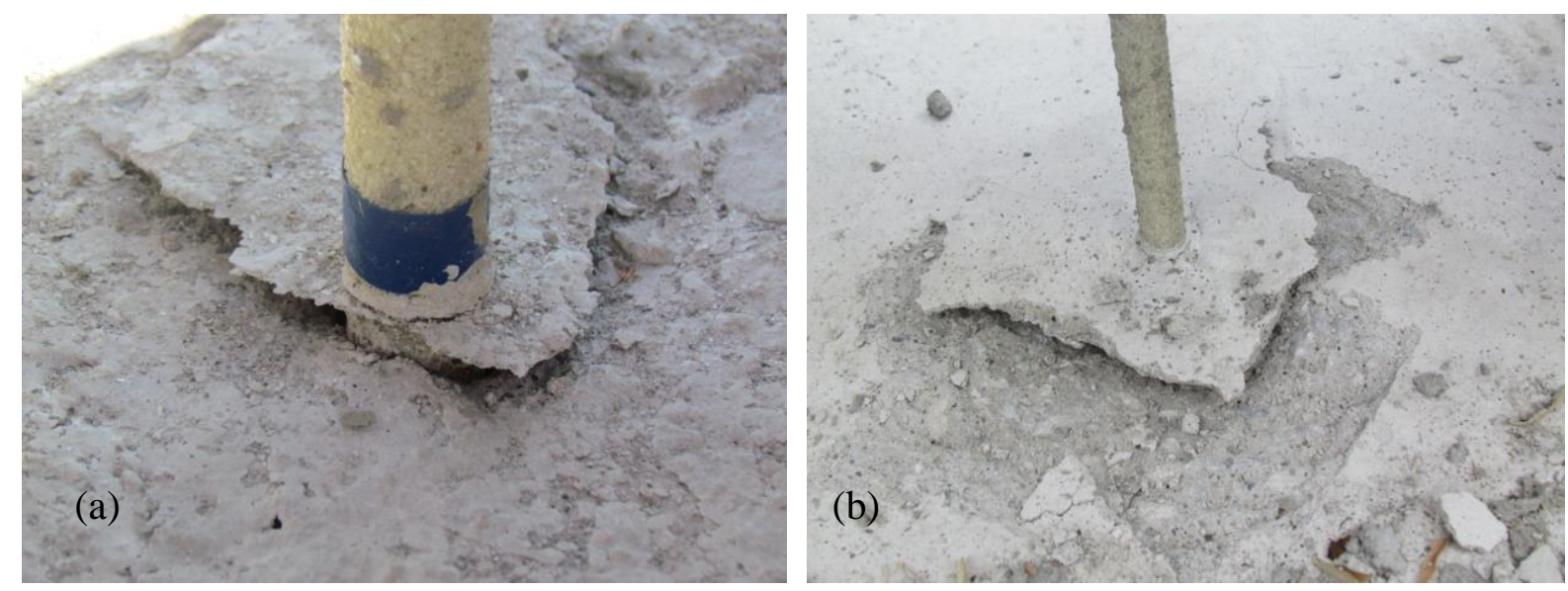

Figure 3. 34 Pullout failure mode in slab model 2 with 100-mm embedment length for straightend bars (a) M19 bar (b) M15 bar

\subsubsection{Concrete Cone Breakout (CCB)}

This type failure mode occurred only in head-end bars mostly with 100-mm embedment length. The failure accompanied by a huge explosion with a large concrete conically shape breakout, while the GFRP headed ends were intact. Damage did not observe in the head portion of the bars indicating sufficient strength of headed bars, while the tensile strength of surrounding concrete was reached. 

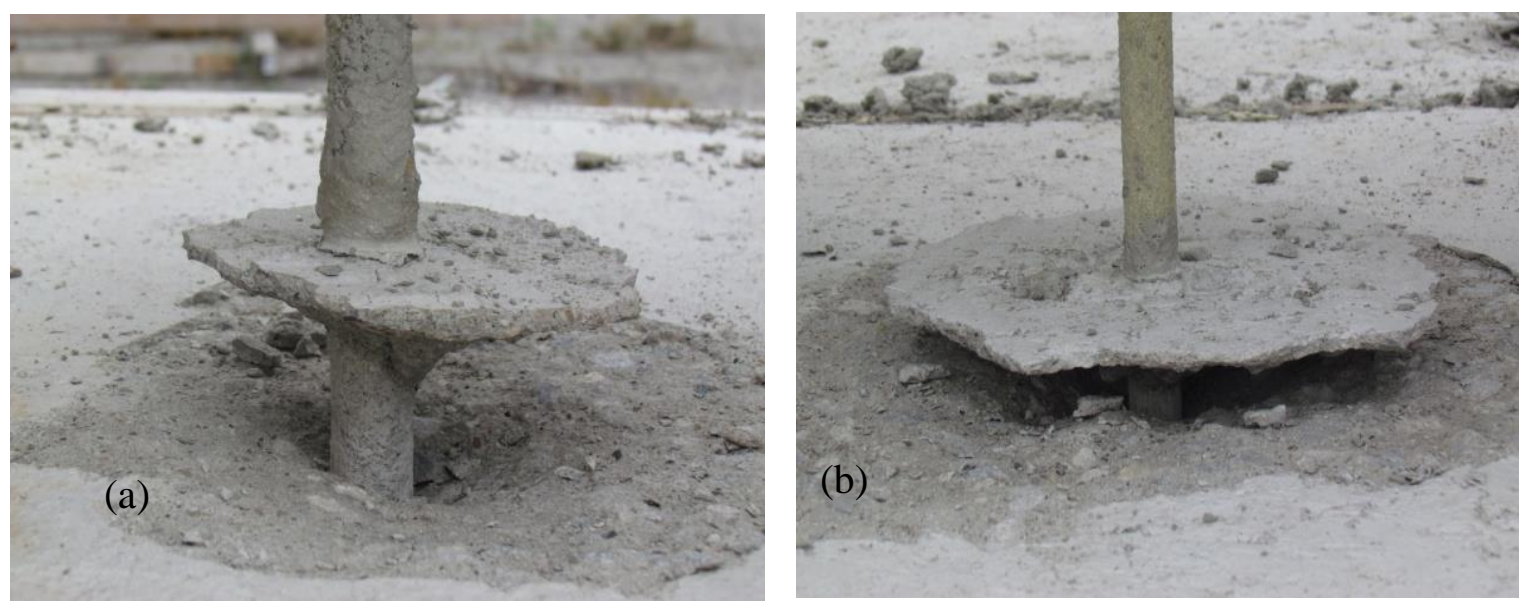

Figure 3. 35 Pullout failure mode in slab model 1 with 150 -mm embedment length for straightend bars (a) M19 bar (b) M15 bar
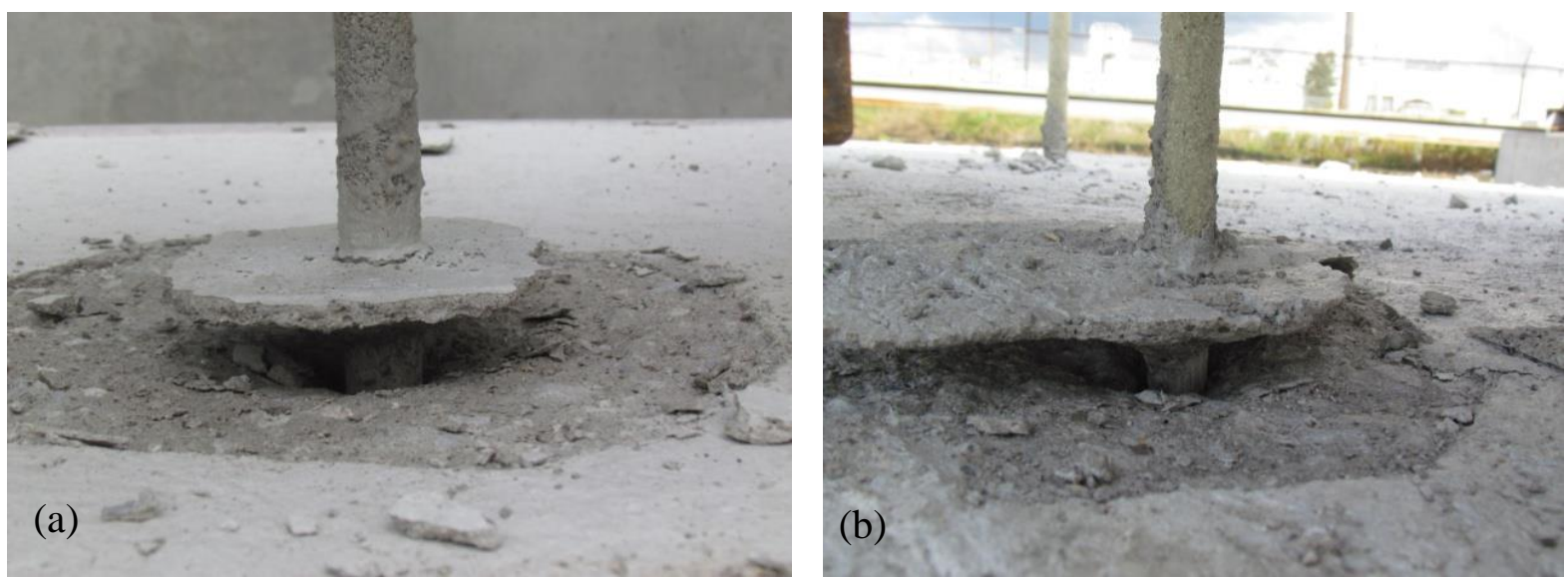

Figure 3. 36 Pullout failure mode in slab model 2 with 200-mm embedment length for straightend bars (a) M19 bar (b) M15 bar

In CCB failure of headed-end GFRP bars, visible signs of radial and circumferential cracks have been observed on top surface of concrete. The failure mode is regarded as a brittle failure since the whole bar and the surrounding concrete came out showing frictional resistance between the bars and the concrete. Due to anchorage resistance of the heads, the failure load was higher than that for straight-end bars with similar embedment length resulting in higher bond strength of headed bars. Comparing the average bond strength given in Table A.1 and Table A.2 confirms this observation. Figure 3.37 shows view of the headed-end bar failed by concrete cone breakout in a $100-\mathrm{mm}$ embedment length. 

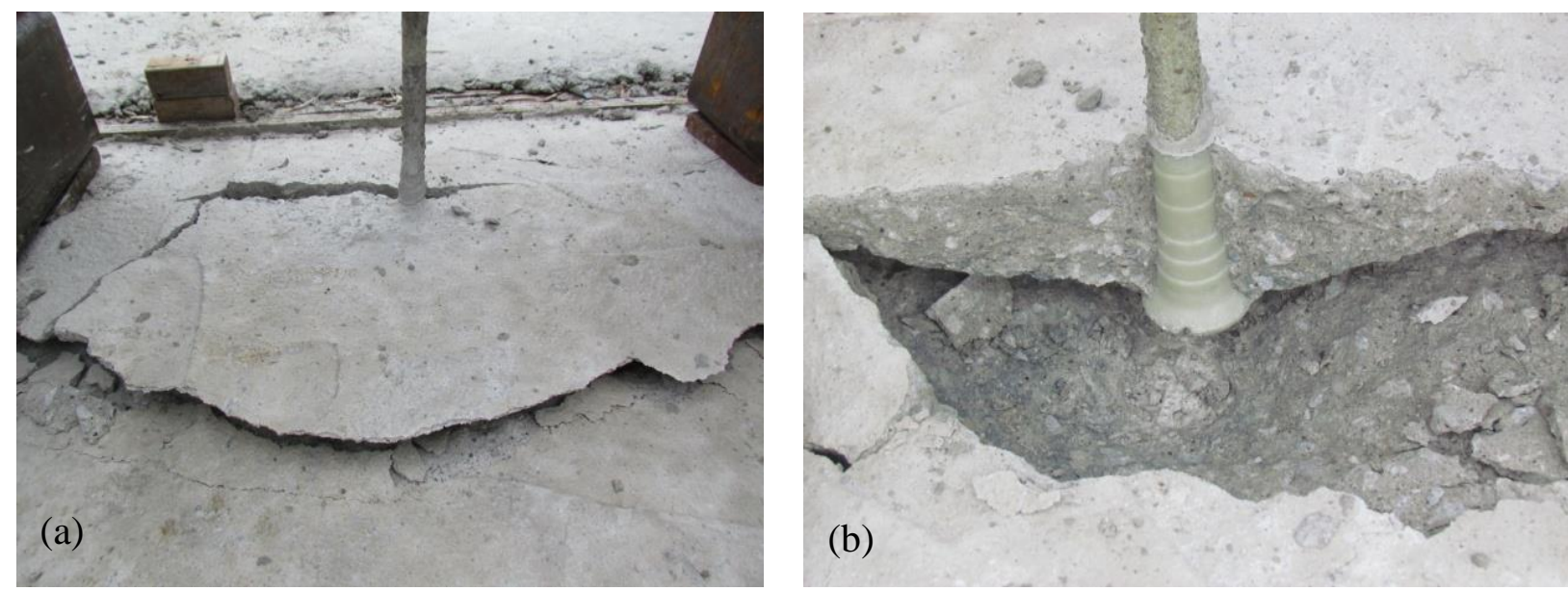

Figure 3. 37 Concrete cone breakout failure in 100-mm embedment length for headed-end bars (a) M15 bar (b) M19 bar

\subsubsection{Pullout Failure Mode with Head-Broken (POHB)}

In some test specimens with headed-end bars, the failure was accompanied by a huge noise separating the headed-end from GFRP bars. The failure modes provided in Tables A.1 and A.2 show that this type of failure occurred mostly in bars with embedment lengths of 150- and 200$\mathrm{mm}$. This may indicate that due to increased confinement provided between the bar and surrounding concrete by the head in larger embedment lengths, it increases the applied tensile load. Therefore, the local stresses developed at bar-head interface reach the ultimate capacity leading to breaking the head from the bars. Figures 3.38 and 3.39 depict this type of failure mode in slab models 1 and 2 with 150-mm embedment length. As shown in the figures, the large conically-shaped concrete breakout was accompanied by a huge explosion due to the fact that GFRP headed bars with larger embedment lengths required larger load to reach its ultimate bond strength. This can be attributed to the expanded conically shaped concrete by increasing the embedment length of the headed bars.

\subsubsection{Rebar Slippage Failure Mode (RS)}

Slippage of bars from concrete was observed in some of the tested specimens. This failure mode occurred in only straight end bars with mainly 100- and 150-mm embedment lengths. Comparing this failure mode with respect to bar diameter, the failure was more pronounced in bars with 16mm diameter than 19-mm diameter. The failure mode observed when the interface contact between sand-coated and the bar core was sheared. 

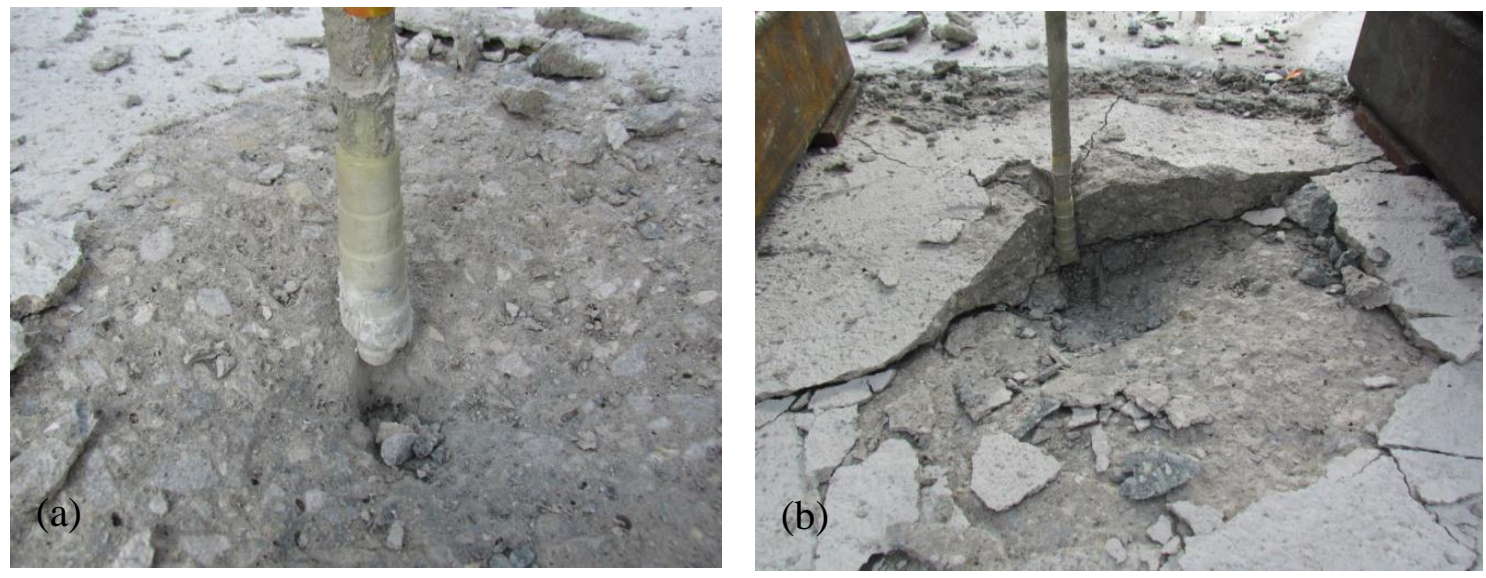

Figure 3. 38 Pullout with head broken failure mode in slab model 2 with 150-mm embedment length (a) M15 bar (b) M19 bar
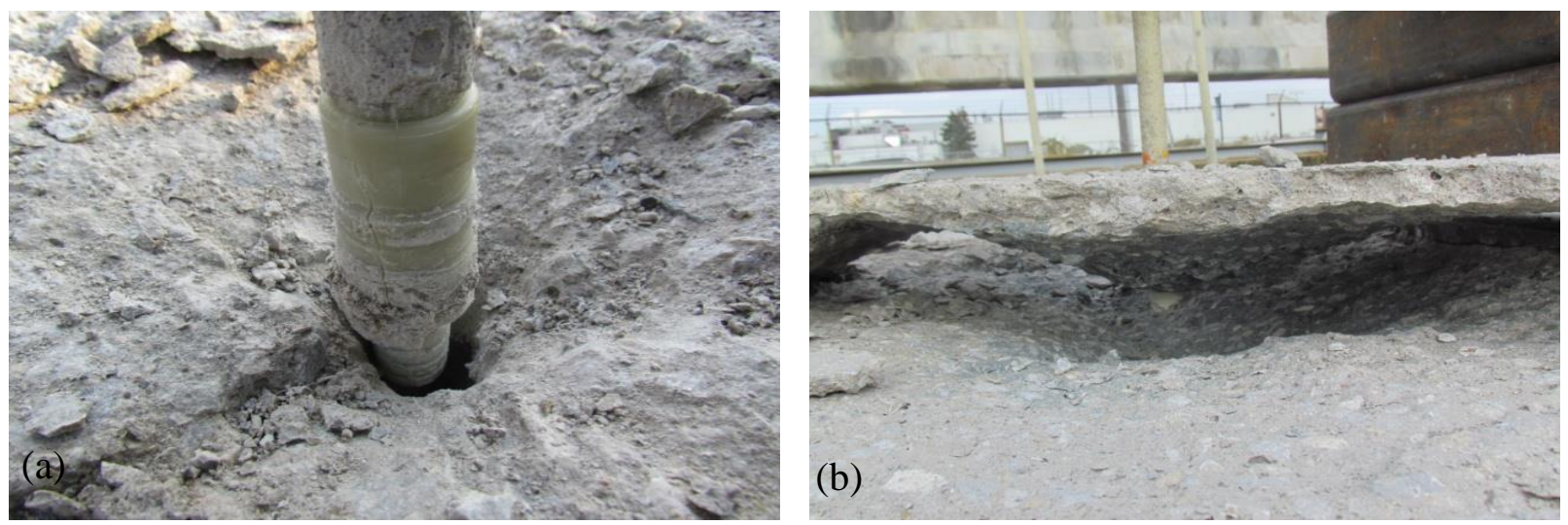

Figure 3. 39 Pullout with headed broken failure mode in slab model 1 with $150-\mathrm{mm}$ embedment length (a) M15 bar (b) M19 bar

This may be due to high confinement developed between concrete and the bars with straight-end exceeding the shearing strength at sand coated-bar core interface. Therefore, in case when the tensile strength of bars exceeds the local stresses at the interface, it causes to overcome the adhesion at sandcoated-bar core interface. As a result, the whole bar sliped out of concrete without any sign of cracking on the surrounding concrete. If the bond strength at interface increases, this type of failure is more probable to occur which was the case in the 16-mm bars developing higher bond strength compared to the 19-mm diameter bars. Figures 3.40 and 3.41 show typical failure mode of bar slippage in slab models 1 and 2, respectively, with 16- and 19$\mathrm{mm}$ diameters. The photos clearly show bond failure at interfaces with white powder sticking to the bars. 

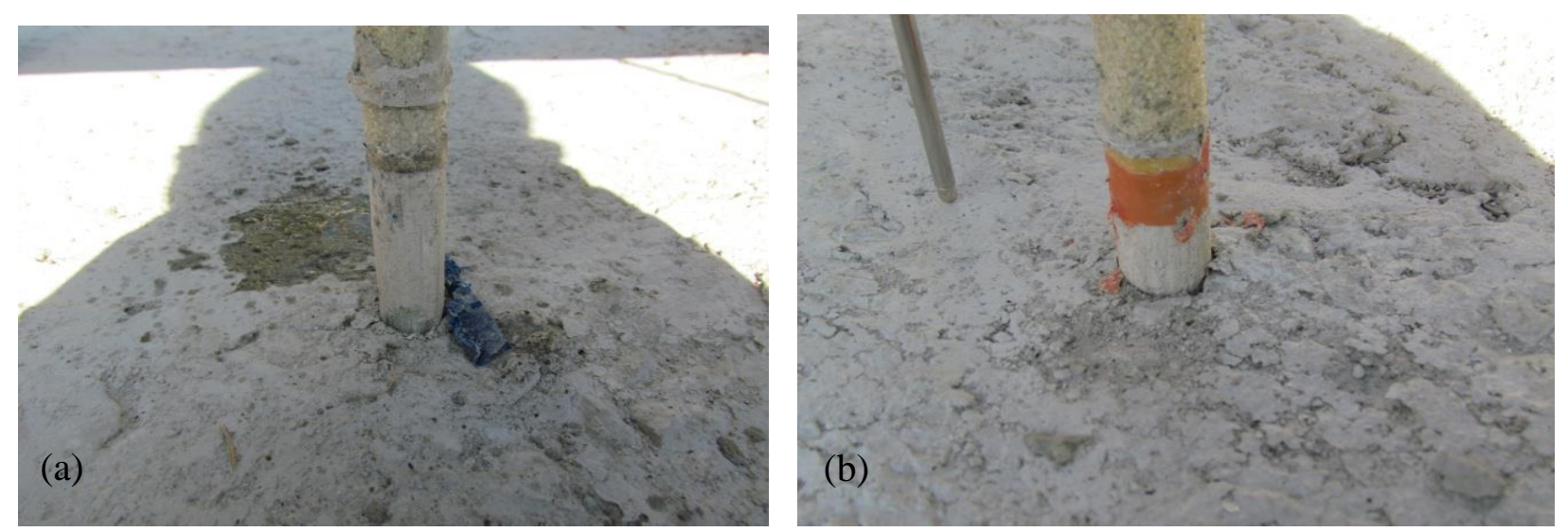

Figure 3. 40 Rebar slippage failure mode in slab model 1 with straight-end bars (a) M15 bar (b) M19 bar
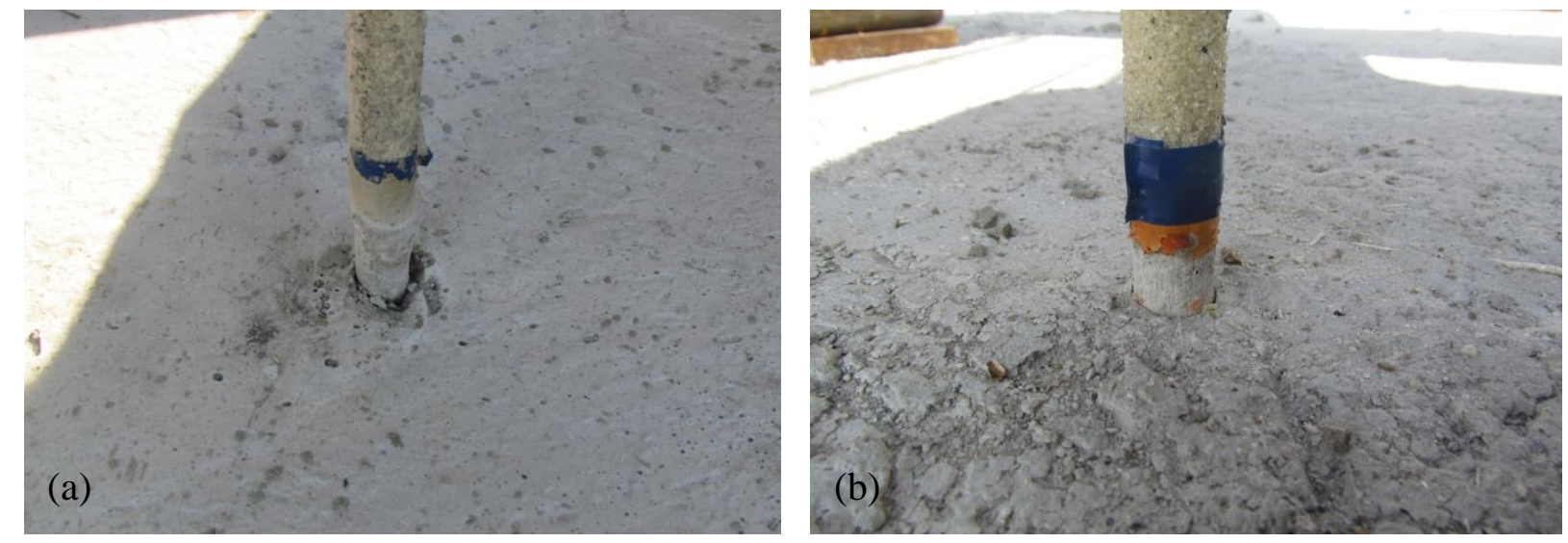

Figure 3. 41 Rebar slippage failure mode in slab model 2 with straight-end bars (a) M15 bar (b) M19 bar

\subsubsection{Rebar Rupture Failure Mode (RR)}

This type of failure mode occurred in all GFRP hooked bars. Generally, straight- and headed-end bars used in this study were all made of high-modulus (HM) bars, while GFRP hook bars were made of standard modulus (SM). Due to heat transfer during the bending process of GFRP bars, the bent portion of hook bars experiences lower ultimate tensile strength compared to the straight portion. The guaranteed tensile strength for straight portion of the GFRP bent bars were given as 1051 and $953 \mathrm{MPa}$ by the manufacturer for \#5 (15M) and \#6 (19M) bars, respectively. While, the average tensile strength for bent portion of GFRP-bent bars were given as $473 \mathrm{MPa}$ for \#5 and $429 \mathrm{MPa}$ for \# 6 bars which are less than $50 \%$ of tensile strength of the straight portion. Due to such tensile strength characteristics of the bent portion, all hooked bars failed in bar rupture mode of failure. Due to such failure mode, one may conclude that GFRP hook bars developed 
their ultimate bond strength. When the bond stress exceeded the ultimate tensile strength of the bent portion, rupture of the bars occurred. As such, the hook bars reached their ultimate tensile strength once the failure occurred. Figures 3.42 and 3.43 show images of this type of failure mode in slab models 1 and 2 with variable embedment lengths.
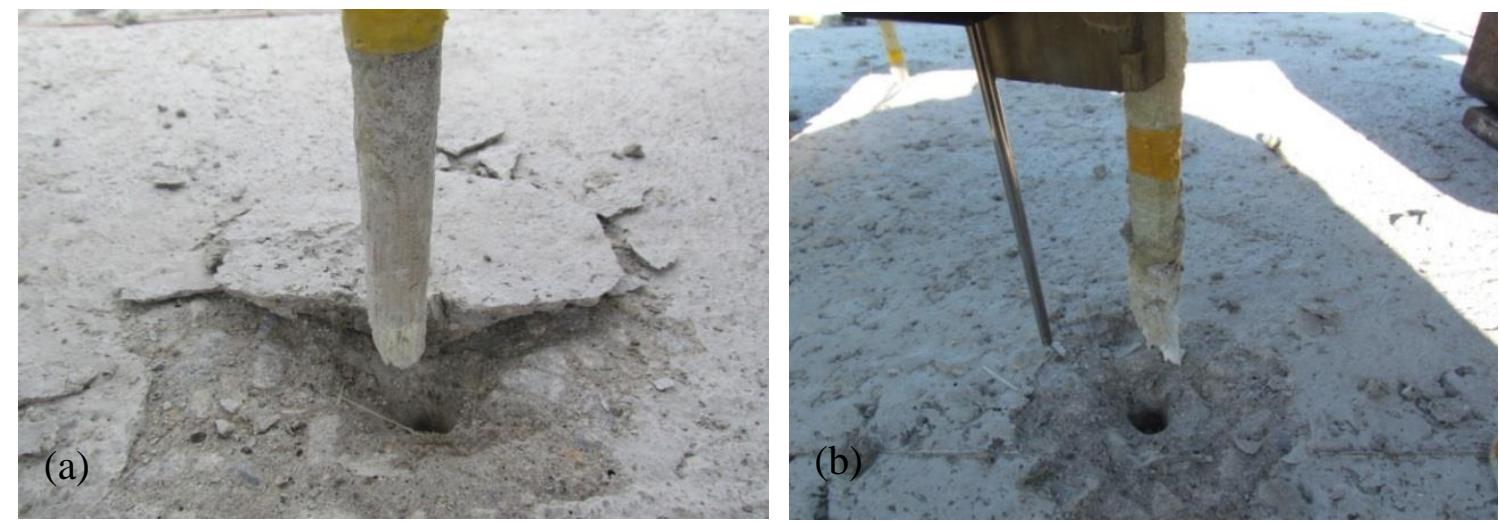

Figure 3. 42 Rebar rupture failure mode in slab model 1 with 16-mm bar diameter (a) with 200mm embedment length (b) with 150-mm embedment length
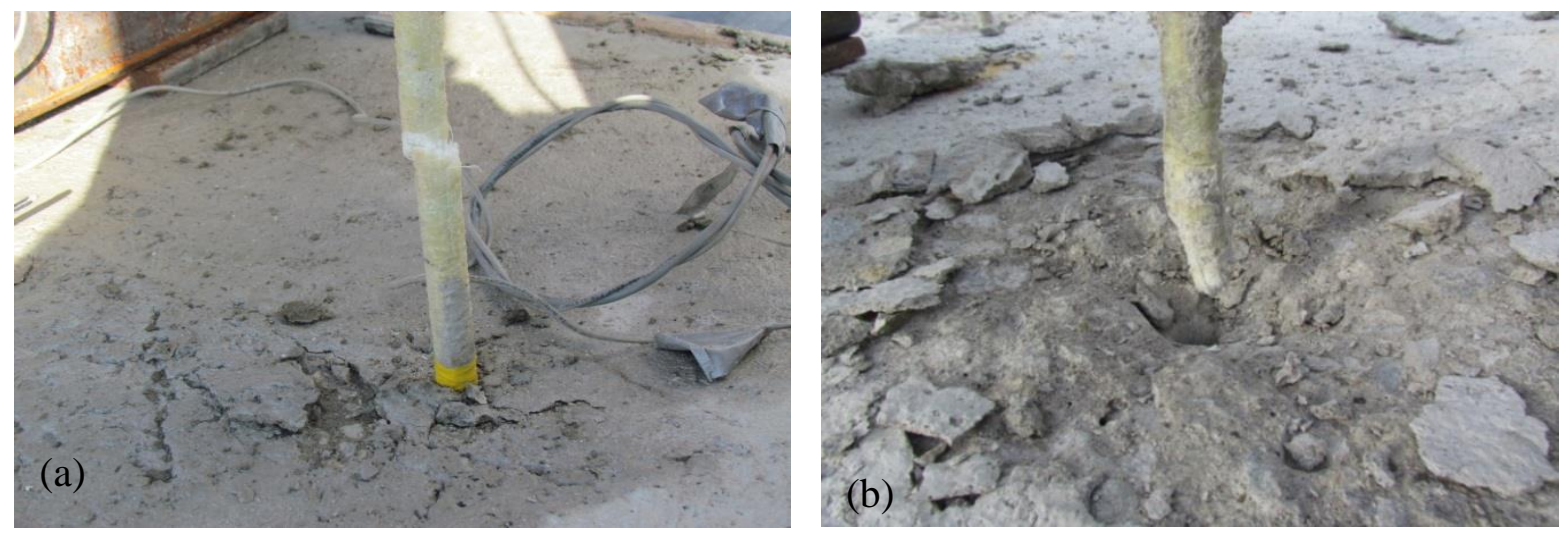

Figure 3. 43 Rebar rupture failure mode in slab model 2 with 16-mm bar diameter (a) with 200mm embedment length (b) with 150-mm embedment length

\subsubsection{Factors Affecting Bond Strength}

\subsubsection{Effect of Bar Diameter}

Tables A.1 and A.2 compared the average bond strength obtained for GFRP bars of 16-mm (\# 5) and 19-mm (\#6) diameters. Comparing results in all cases revealed that increasing bar diameter lowers the bond strength of the GFRP bars. This may attributed to the several reasons: the first reason is that load-slip curves in larger size bars may have more brittle failure than the bars with smaller size; the second reason is that the Poisson's effect develops in the bars as a result of 
longitudinal stresses caused by the applied tensile loads. As the bar size increases, this Poisson's effect is more severe resulting in more reduction in the lateral bar diameter on which it reduces the mechanical interlocking between the bars and concrete, the third reason is that bleeding water trapped beneath the bar creating larger size voids between the bars and concrete. As a result, the contact surface between the bars and the surrounding concrete may reduce in larger size bars. By comparing test results, an average reduction in bond strength of $11.7 \%, 9.26 \%$, and $8.76 \%$ was found for bars with 100, 150 and 200-mm embedment lengths, respectively, when the bar size increases from 16- to 19-mm. This trend was approximately similar in both concrete slab models. Figures 3.44 and 3.45 show the effect of bar diameter on bond strength of GFRP bars with an increase in embedment length in slab models 1 and 2.

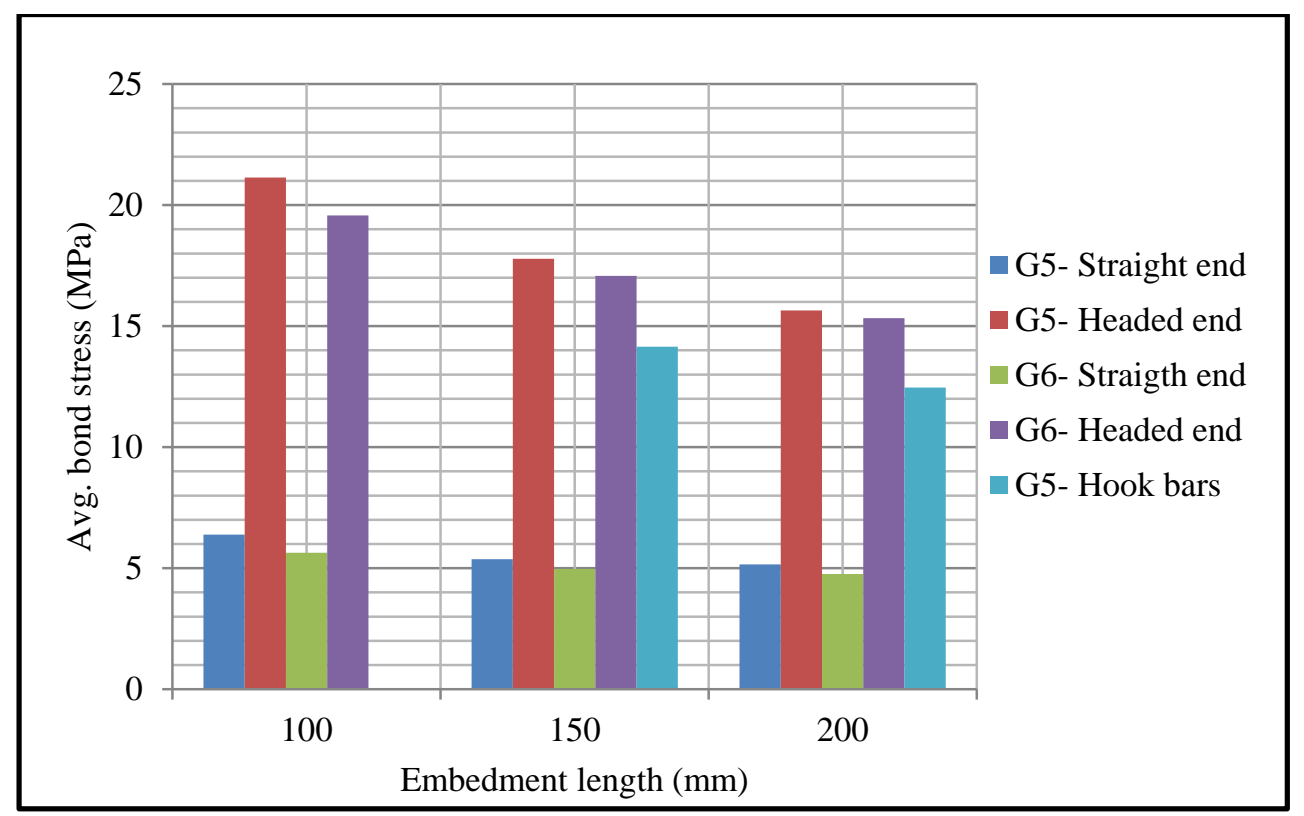

Figure 3. 44 Effect of bar diameter on average bond stress for different bars in slab model 1 


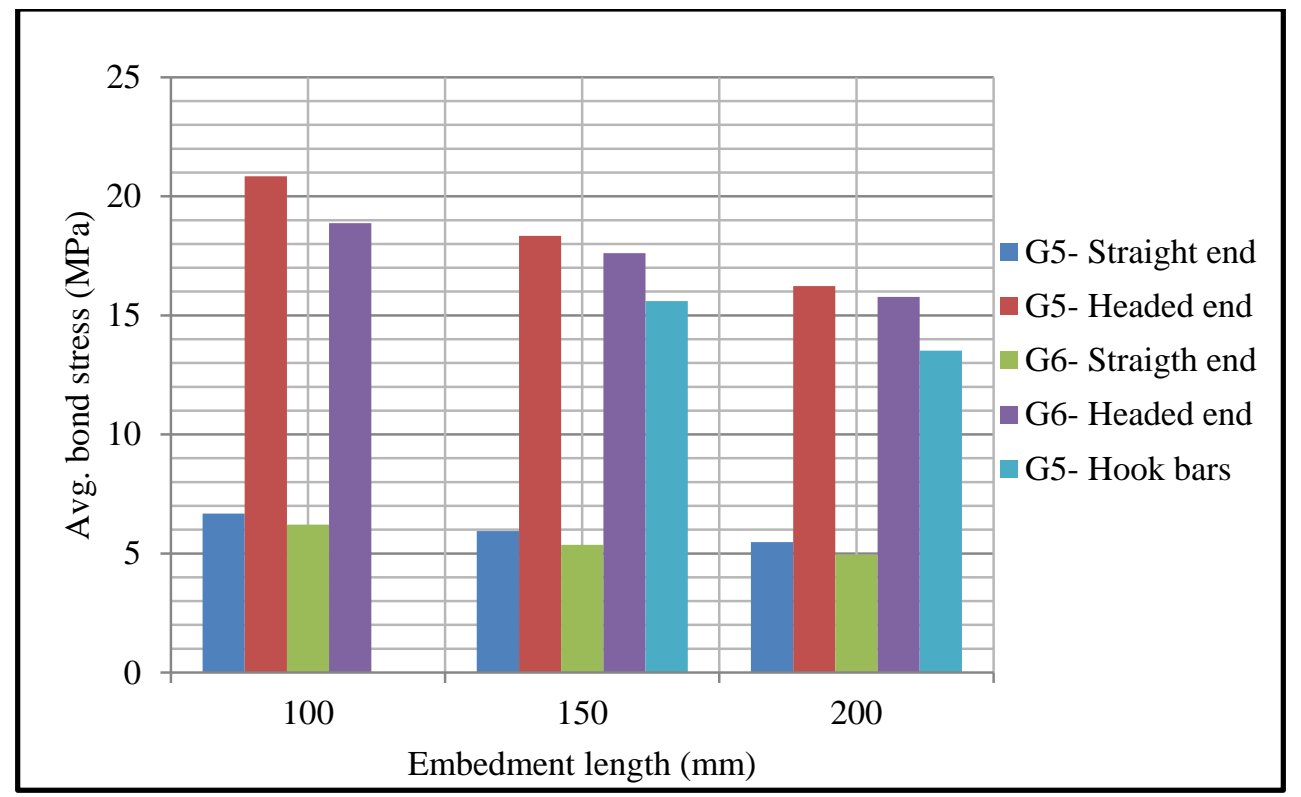

Figure 3. 45 Effect of bar diameter on average bond stress for different bars in slab model 2

\subsubsection{Effect of Concrete Compressive Strength}

From test results obtained in slab models 1 and 2 with average concrete strengths of 30.6 and 36.17 MPa, respectively, it could be observed that the increase in bond strength was not very significant which was found to be within $3 \%$ to a maximum of $8 \%$. This was due to the fact that bond failure occurred at surface of the GFRP bars in case of straight-end bars, rupture of the bars in case of GFRP hook bars and pullout with head broken in case of headed-end bars. Figure 3.46 compares the effect of bond strength on concrete compressive strength in slab models 1 and 2. It can be seen from graphs that there is insignificant difference in bond strength values in both slab models. The trend was similar to the findings by other researchers that concrete compressive strength greater than $30 \mathrm{MPa}$ would not significantly increase the bond strength.

\subsubsection{Effect of Bar-End Geometry}

Bars with different end anchorages have been investigated in this study, namely: straight-end, headed-end and bars with $180^{\circ}$ hook. From test results, it was observed that GFRP bars with headed-end developed the most promising bond strength characteristics possessing the highest value of the average bond strength. 


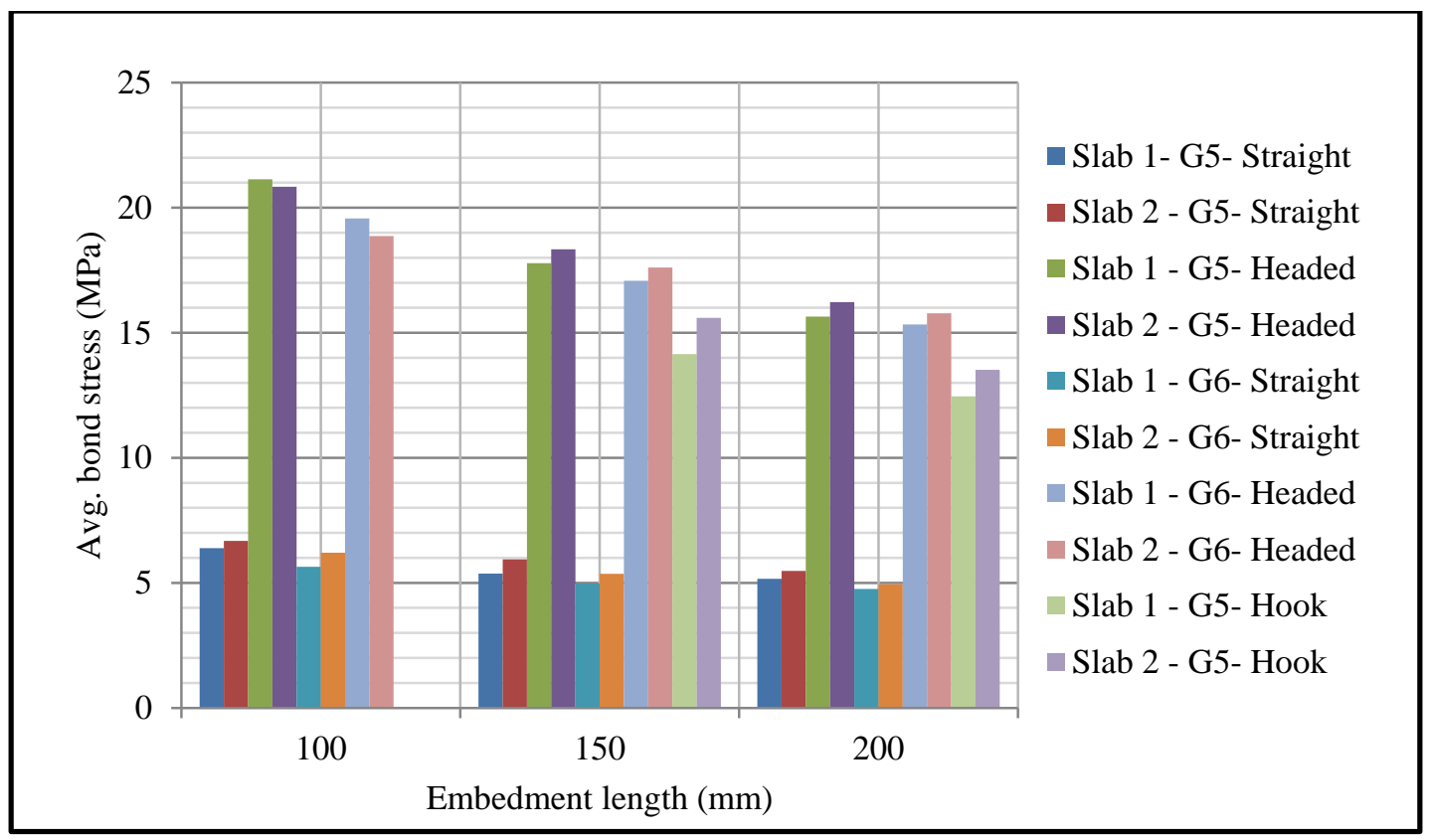

Figure 3. 46 Effect of concrete strength on the average bond stress for different bars in slab models 1 and 2

Hook bars also developed relatively high values of bond strength, however, the maximum bond strength followed by rupturing the bars causing a brittle failure of the bars. This indicates that GFRP hook bars developed their ultimate bond strengths resulting in rupturing the bars at bent portion. The least bond strength development was attributed to GFRP bars with straight ends. Figures 3.44 and 3.45 compare the effect of different bar end geometry on bond strength in slab models 1 and 2. As shown in the figures, headed-end bars produced comparablely high values of bond strength in contrast to straight-end bars for a bar of the same size and same concrete strength. The GFRP bars with $180^{\circ}$ hooked-end showed an intermediate value of bond strength for a bar size and strength similar to headed-end and straight bars. Thus, it can be concluded that the presence of disc-shaped head increases the effect of confinement by the surrounding concrete. This in turn would increase the load required to cause failure when it is compared with GFRP bars with straight-end or hook geometries and in similar conditions.

\subsubsection{Effect of Embedment Length}

From experimental test results, it can be observed that increasing embedment length of GFRP bars decreases the maximum average bond strength. This might be due to non-linear distribution of the stresses along the embedded length of the bars in case of larger embedment length. It is 
also observed that larger bar diameter required larger embedment length to develop the same bond strength, while for bars with the same diameter, increasing embedment length reduces the bond strength of the GFRP bars. In addition, the tests have shown that the pullout force depends on the embedment length; the longer the embedment length, the larger force required to pull the bar out of the concrete. Figure 3.47 shows the effect of embedment length on the applied jacking load. It can be seen from the figure that by increasing embedment length, the load required to develop the pullout strength of the bars are also increased accordingly. Figure 3.48 depicts the effect of embedment length on bond strength of GFRP bars in concrete. It can be clearly observed that as the embedment length increases the bond strength between concrete and the bars decreases in all tested specimens. For instance, the average bond strengths of GFRP straight-end bars with 150 - and $200-\mathrm{mm}$ embedment lengths were found $84 \%$ and $71 \%$ to that of $100-\mathrm{mm}$, respectively, for the $16 \mathrm{~mm}$ bar diameter. Similarly, the average bond strengths of headed-end bars with 150- and 200-mm embedment lengths were observed $83 \%$ and $74 \%$ to that of bar with 100-mm, while for the case of hook bars, the average bond strength of GFRP bars with 200-mm embedment was found equal to $88 \%$ that of the bar with $150-\mathrm{mm}$ embedment length. The increase in the average bond strength for the tested GFRP bars in concrete slab models 1 and 2 was calculated and provided in Table 3.2. The bond strength of GFRP bars with 200-mm embedment length was considered as the reference values. The increase in bond strength for 150and 100-mm embedment lengths were then determined based on the reference values. The increase in bond strength for the two concrete slab models was found to be insignificant. However, by decreasing the embedment length from 200-mm to $100-\mathrm{mm}$, the bond strength increases to a maximum of $23.8 \%, 30.71 \%$ and $14.91 \%$ for GFRP bars with straight-end, headed-end and hook bars, respectively. It should also be noted that the bond strength increase for hook bars was determined by comparing only 150-mm embedment length to the reference value. This was due to the fact that the tail length of hook bars is 150-mm which was fully embedded into concrete. 


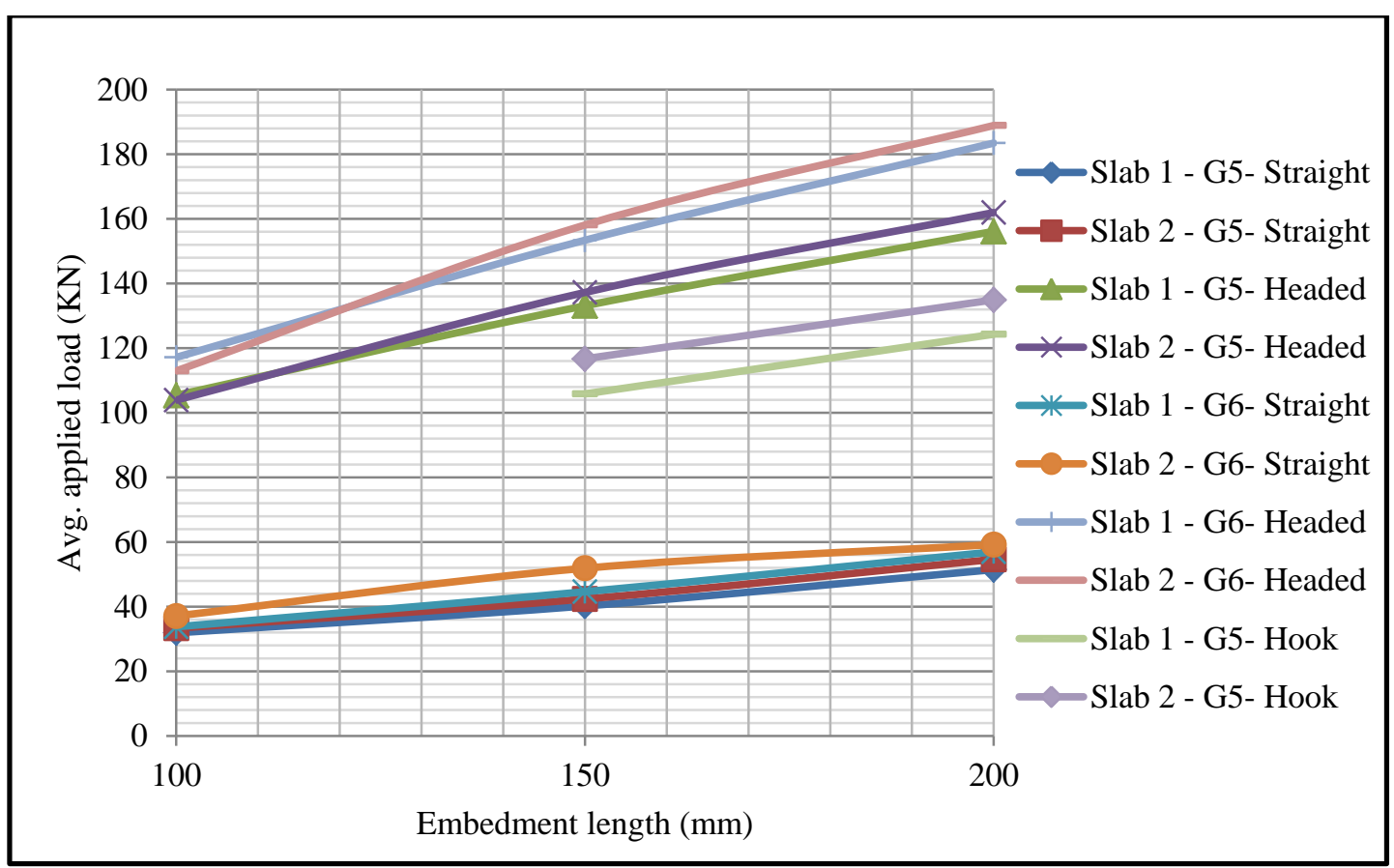

Figure 3. 47 Effect of embedment length on the applied pullut load for various bars in slab models 1 and 2

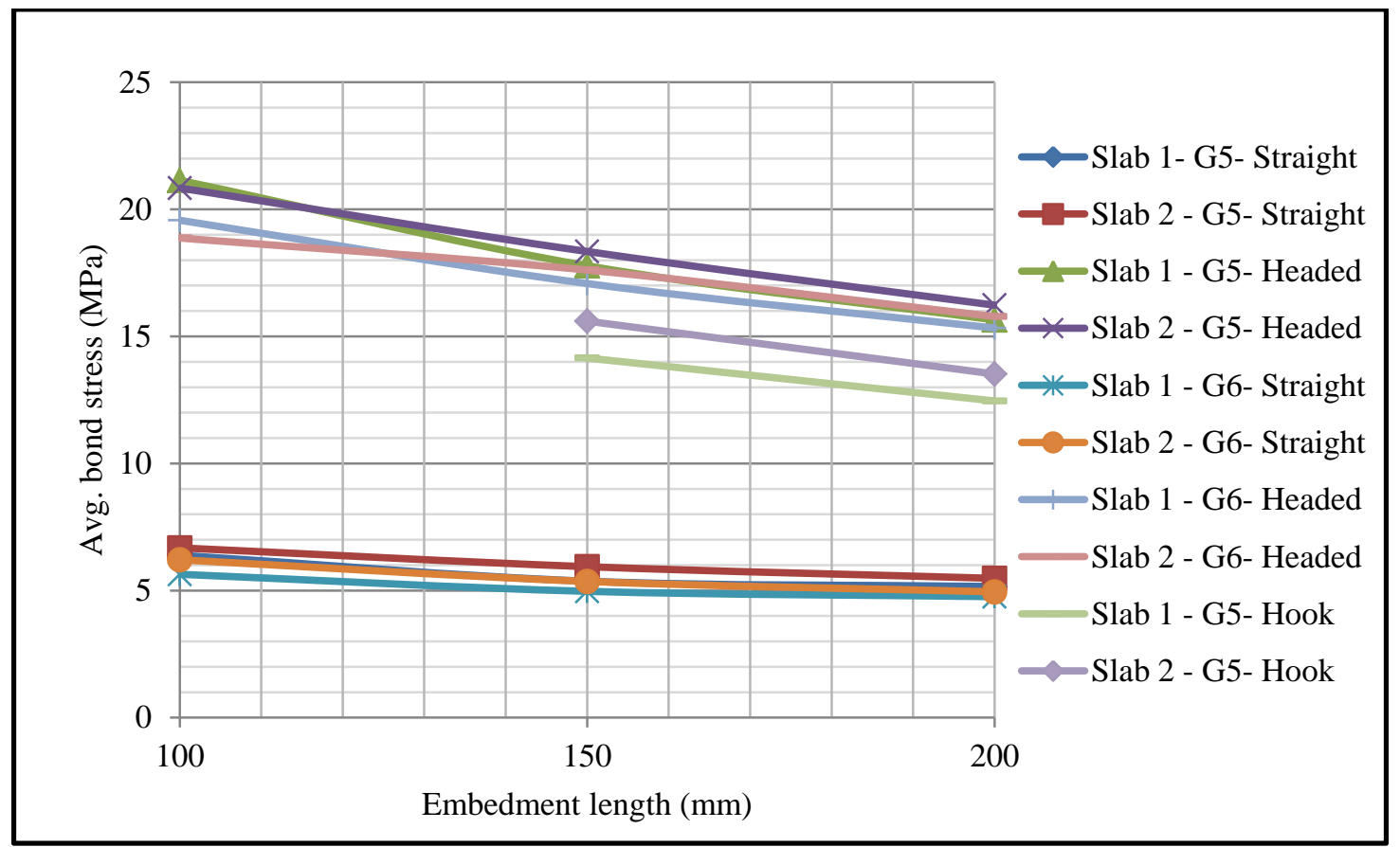

Figure 3. 48 Effect of embedment length on bond stress for various bars in slab models 1 and 2 
Table 3. 2 Pullout strength increase for concrete slab models

\begin{tabular}{|c|c|c|c|c|}
\hline \multirow{2}{*}{$\begin{array}{l}\text { Embedment } \\
\text { length (mm) }\end{array}$} & \multirow{2}{*}{ Bar size } & \multicolumn{3}{|c|}{ Slab model $1\left(\mathrm{f}_{\mathrm{c} \text {, avg. }}=30.6 \mathrm{MPa}\right)$} \\
\hline & & Straight-end & Headed-end & hook \\
\hline 200 & \multirow{3}{*}{ \#5 (M15) } & - & - & - \\
\hline 150 & & $14.6 \%$ & $15.73 \%$ & $13.6 \%$ \\
\hline 100 & & $21.9 \%$ & $28.4 \%$ & - \\
\hline 200 & \multirow{3}{*}{ \#6 (M19) } & - & - & - \\
\hline 150 & & $11.89 \%$ & $12.63 \%$ & - \\
\hline \multirow[t]{2}{*}{100} & & $17.43 \%$ & $19.6 \%$ & - \\
\hline & & \multicolumn{3}{|c|}{ Slab model $2\left(\mathrm{f}_{\mathrm{c}, \text { avg. }}^{\prime}=36.17 \mathrm{MPa}\right)$} \\
\hline 200 & \multirow{3}{*}{ \#5 (M15) } & - & - & - \\
\hline 150 & & $15.62 \%$ & $16.81 \%$ & $14.91 \%$ \\
\hline 100 & & $23.8 \%$ & $30.71 \%$ & - \\
\hline 200 & \multirow{3}{*}{ \#6 (M19) } & - & - & - \\
\hline 150 & & $13.48 \%$ & $13.58 \%$ & - \\
\hline 100 & & $18.63 \%$ & $21.65 \%$ & - \\
\hline
\end{tabular}

\subsubsection{Bond-Slip Relationship}

\subsubsection{Straight-End Bars}

The bond stress-slip curve was determined for specimens failed in pullout mode of failure. From experimental test results, it was observed that bond strength increases until it reaches its maximum strength followed by a sudden loss of bond after the peak shown by decreasing branch of the bond stress-slip curves. Figure 3.49 shows a typical bond stress-loaded end slip relationship for straight bars. The curve is typically divided into two phases, namely: pre-peak and post-peak phases. The pre-peak phase is also subdivided into two phases based on the bond stiffness of GFRP bars, defined as the slope of the bond-slip curve. In phase I with $0 \leq \tau<\tau_{1}$, linear-elastic behavior can be observed with approximately large bond stiffness $E_{1}$ due to slip corresponding to bar elongation. Thus, all bond mechanisms (adhesion, mechanical interlock and friction) are assumed to be intact. In this phase, it was assumed that free-end slip was 
approximately zero. In phase II with $\tau_{1} \leq \tau \leq \tau_{\max }$, bond stiffness softening, $\mathrm{E}_{2}$, is observed till the maximum bond strength was reached representing that the chemical adhesion was broken and mechanical interlock has begun to deteriorate. Thus, the free-end can be assumed to begin slipping. In phase III with $\tau_{\max } \leq \tau<\tau_{2}$, the bond stress loss occurs and the bond mechanism was represented only by friction between GFRP bars and the concrete till it reached the residual stress, $\tau_{2}$. The residual stress represented the amount of bond strength created by frictional resistance between the bar and the concrete once the bond failure was occurred and the bar continued to pull out of concrete by increasing the slip.

\subsection{Pre-Peak Behavior}

Figure 3.50 shows pre-peak graphs of bond stress versus loaded-end slip for GFRP 19M bars in concrete slab model 1 for 100, 150 and 200-mm embedment lengths. It can be seen that the bars experienced quite large slip corresponding to bar elongation at approximately $75 \%$ to $85 \%$ of the peak bond stress. This is due to the fact that all the three bond mechanism (adhesion, mechanical interlock and friction) are engaged. At this point, by visual inspection of bond stress-slip curve of the GFRP bars, it was observed that the initial bond stress, $\tau_{1}$, was $80.13 \%$ and $82.16 \%$ to that of $\tau_{\max }$ on average for M15 (\#5) and the M19 (\#6) bars, respectively.

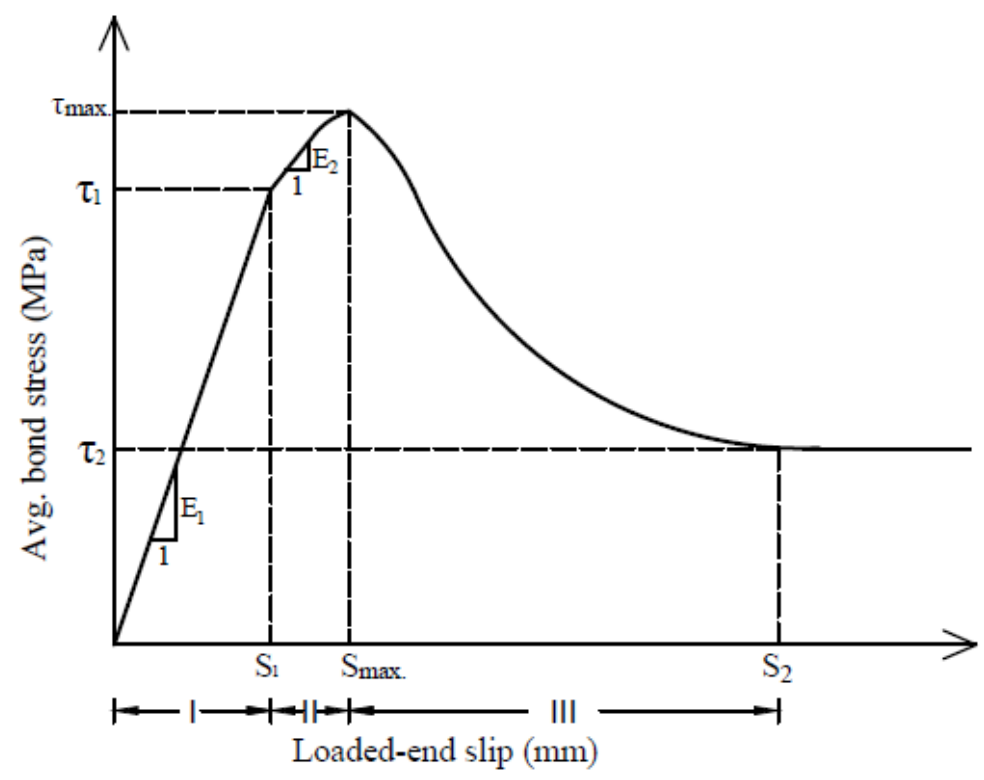

Figure 3. 49 Typical bond stress-loaded end slip relationship for straight end bars 


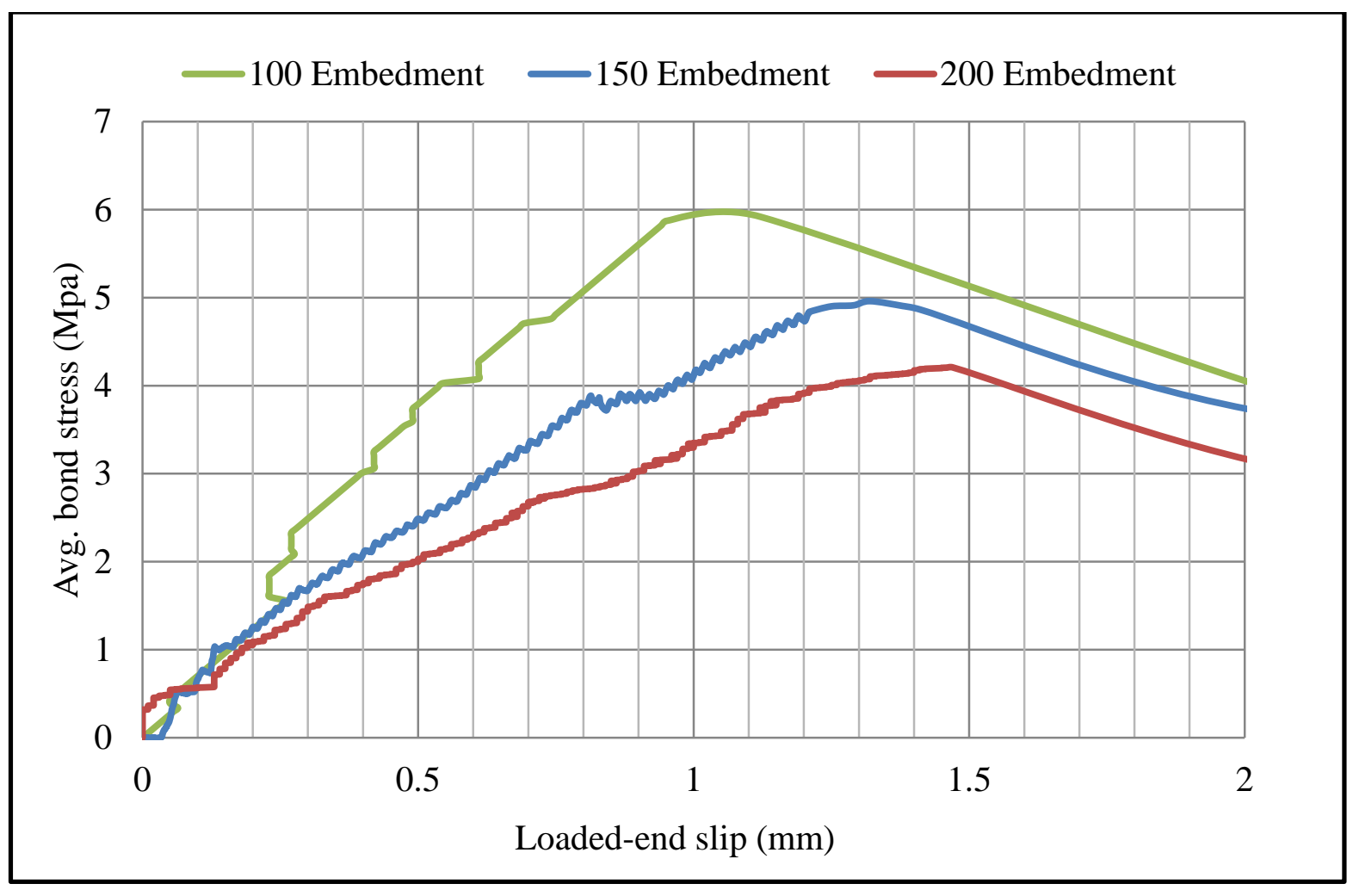

Figure 3. 50 Average bond stress versus loaded-end slip for 19M GFRP bar in slab model 1

Table 3. 3 Summary of the average experimental test results for straight end bars in slab model 1

\begin{tabular}{|c|c|c|c|c|c|c|c|}
\hline $\begin{array}{c}\text { Specimen } \\
\text { notation }\end{array}$ & $\mathrm{d}_{\mathrm{b}}(\mathrm{mm})$ & $\begin{array}{c}\mathrm{P}_{\text {max.** }} \\
(\mathrm{kN})\end{array}$ & $\begin{array}{c}\tau_{1^{* *}} \\
(\mathrm{MPa})\end{array}$ & $\begin{array}{c}\tau_{\max } * * \\
(\mathrm{MPa})\end{array}$ & $\begin{array}{c}\mathrm{S}_{\max .} \\
(\mathrm{mm})\end{array}$ & $\mathrm{f}_{\mathrm{b}}(\mathrm{MPa})$ & $\mathrm{f}_{\mathrm{b}} / \mathrm{f}_{\mathrm{u}}$ \\
\hline G5-100EM-S* & 15.88 & 25.6 & 4.03 & 5.12 & 1.07 & 161.2 & 0.140 \\
\hline G5-150EM-S & 15.88 & 34.12 & 3.72 & 4.56 & 1.23 & 203.2 & 0.172 \\
\hline G5-200EM-S & 15.88 & 43.6 & 3.52 & 4.25 & 1.51 & 260.2 & 0.220 \\
\hline G6-100EM-S & 19.05 & 29.70 & 4.01 & 4.96 & 1.12 & 118.5 & 0.110 \\
\hline G6-150EM-S & 19.05 & 40.5 & 3.77 & 4.51 & 1.34 & 156.6 & 0.142 \\
\hline G6-200EM-S & 19.05 & 49.6 & 3.40 & 4.14 & 1.67 & 199.9 & 0.181 \\
\hline
\end{tabular}

*Specimen notation: GFRP bar \#5 (15.88mm) diameter with 100mm embedment and straight-end bar

** $\tau_{\max }, \tau_{1}$ and $\mathrm{P} * *$ are the characteristic bond strength and tensile strength (Eq. 3.1a) obtained from peak bond strength and peak tensile load of 5 identical samples

$\mathrm{fu}=1184 \mathrm{Mpa}$ for bar \#5 and $1105 \mathrm{MPa}$ for \#6 
The summary of experimental test results for straight-end bars in concrete slab model 1 is presented in Table 3.3. A reduction in bond stiffness of GFRP straight-end bars was observed beyond the initial bond stress, $\tau_{1}$, which can be understood by the decrease in the slope of bond stress-slip curves. Therefore, it can be proposed that the adhesion and mechanical interlock between the bars and concrete have begun to deteriorate causing slippage of the bar relative to concrete. At loaded-end location, it was expected that the bars experience larger slip due to nonlinear distribution of stresses along the embedded length of the bars.

\subsection{Peak Bond Stress}

From Table 3.3 (also shown in Figure 3.51) the average peak bond stress, $\tau_{\max }$, decreases as the embedment length increases from $100-\mathrm{mm}$ to $200-\mathrm{mm}$. This can be due to the fact that the peak bond stress dose not proportionally increases with the increase in the embedment length. Also, as shown in Table 3.3, larger loaded-end slip was observed at peak bond stress for bars with longer embedment lengths because of the increase in the applied pullout load causing a larger bar elongation. In the current research, it was found that as the embedment length increased from 100 to $200-\mathrm{mm}$, there were $71 \%$ and $67 \%$ increase in the load-end slip for M15 and the M19 bars, respectively. In addition, the observation was made for the increase in the loaded-end slip of the M19 GFRP bars compared to M15 bars with similar embedment length. The bar stresses at peak load, $\mathrm{f}_{\mathrm{b}}$, were also determined and presented in Table 3.3. It can be seen that the bars did not reach their ultimate strength in all embedment lengths. However, the stress in the bars increases as the embedment length increases. Comparison between stress in the bars and their ultimate strength showed a maximum of $22 \%$ and $18.1 \%$ of the ultimate bar strength for M15 and M19 bars (see Table 3.3). However, it can be seen that for a bar with similar embedment length, the M15 (\#5) bars experiences a larger bar stress than that for the M19 (\#6) bars.

\subsection{Post-Peak Behavior}

In post-peak behavior of GFRP straight-end bars in concrete, the bar slippage occurred rapidly by increasing the applied pullout load since the only bond mechanism was provided by frictional resistance between the bar and concrete. Figure 3.52 shows graphs of bond stress-loaded end slip of the M15 (\#5) and the M19 (\#6) bars in concrete slab model 1. 


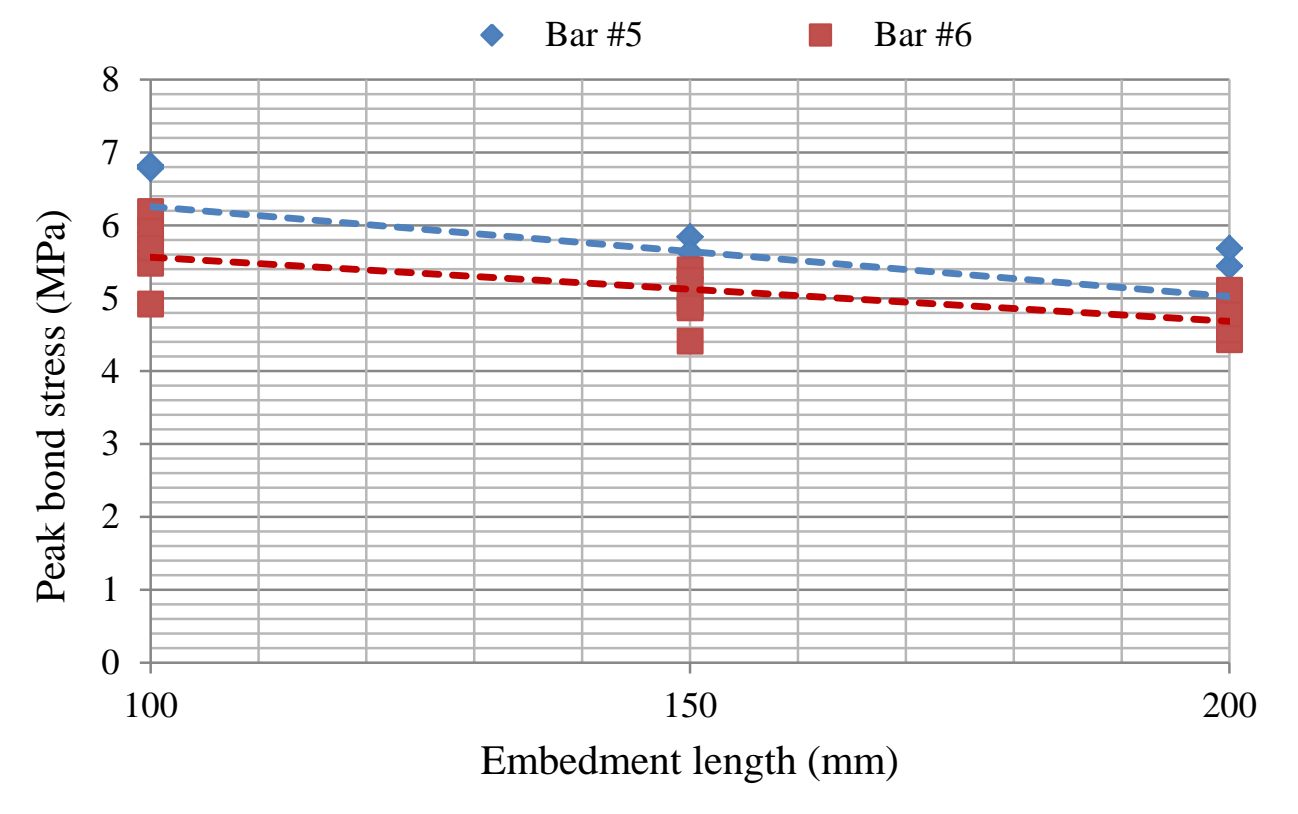

Figure 3. 51 Average peak bond stress versus embedment length for straight end bars in slab model 1

It can be seen from the graphs that the descending branch of bond stress-slip gradually decreased as the slip of the bar increased and fictional forces stabilized until it reached the residual stress, $\tau_{2}$. The average residual stresses for M15 (\#5) bars were found to be $35.4 \%, 39.2 \%$ and $46.4 \%$ to that of maximum bond stress for bars with 100, 150 and 200-mm embedment length, respectively, with an average value equal to $40.2 \%$ for all embedment lengths. Similarly, the average residual stresses for M19 (\#6) bars were found to be $34.13 \%, 36.7 \%$ and $41.3 \%$ to that of the ultimate bond stress for bars with 100, 150 and 200-mm embedment lengths, respectively, with an average value of $37.4 \%$. It can also be observed from the graphs that the bars maintained a more consistent residual stresses, while in most cases M15 bars reached greater residual stresses than those for M19 bars for a bar with similar embedment length. This can be attributed to the poisson's effect and bleeding water that has greater influence on M19 bars than M15. The residual stresses were calculated by visual inspection of bond-slip curves where the slope of the descending branch started to flatten and become nearly zero. 


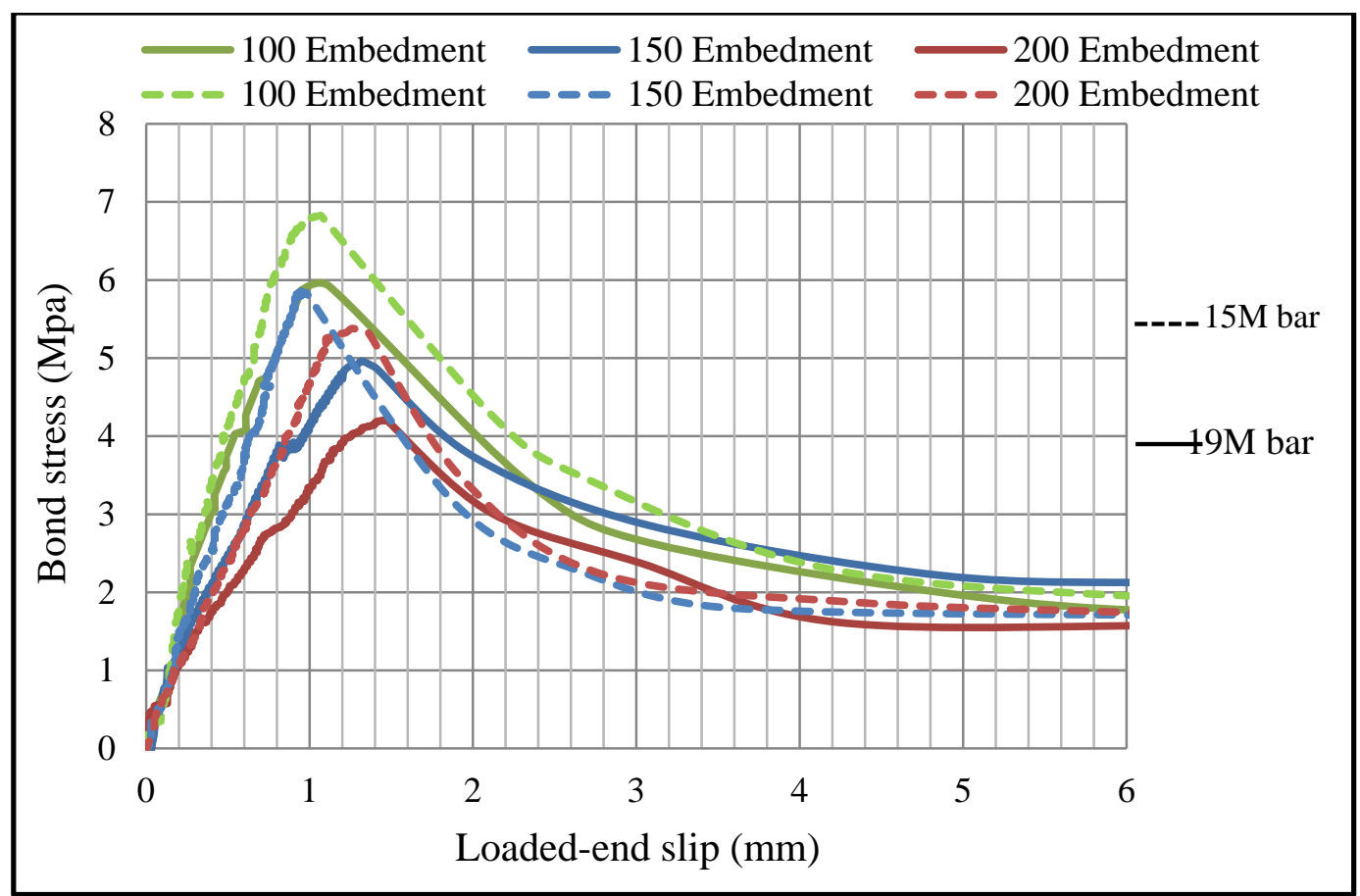

Figure 3. 52 Average bond stress versus loaded-end slip for straight-end M15 and M19 GFRP bars

\subsubsection{Headed-End Bars}

The bond stress-loaded end slip relationship for headed-end bars generally exhibited similar trends as straight-end bars except with the difference in post-peak residual stresses. Figure 3.53 shows typical bond stress-loaded end slip for GFRP headed bars. As mentioned earlier, the GFRP headed bars experienced two types of failure modes, namely: concrete cone breakout (CCB) and pullout with head broken (POHB). If the failure is accompanied with concrete cone breakout, the entire bar with the surrounding conically-shaped concrete will be pulled out. Thus, after failure, the descending branch of the bond stress-slip would rapidly decrease to zero (shown as dash line in Figure 3.53). However, for the pullout with head broken, the failure is reached when the bar stress reaches the strength of the head portion. This means that by increasing the applied load, the head portion would be broken and therefore a rapid decrease in the descending branch of bond-stress curve can be observed to nearly zero stress. However, due to addition frictional resistance between the bar and the concrete, the bar would experience a small residual stress which is shown in Figure 3.53 as $\tau_{2}$. Based on the test results, it can be assumed that post failure behavior of head-end bars is mainly brittle. 


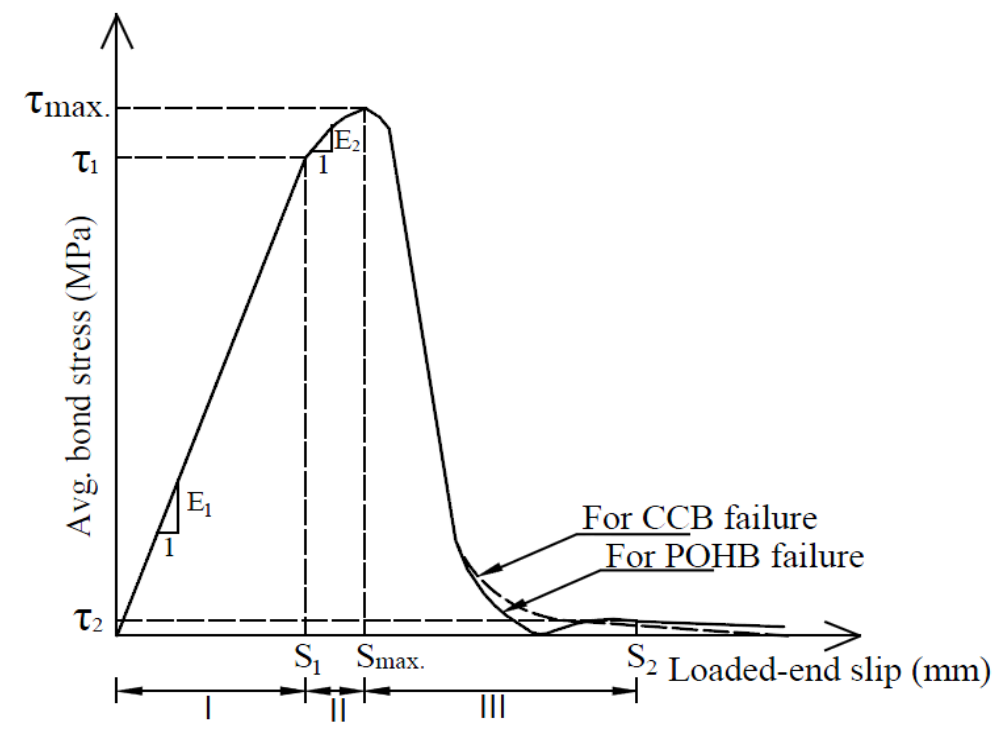

Figure 3. 53 Typical bond stress-loaded end slip for headed end bars

\subsection{Pre-Peak Behavior}

Figure 3.54 shows graphs of average bond stress-loaded end slip of GFRP headed bars for bars with 19-mm diameters. It can be observed that as the embedment length increases, the average bond stress decreases, resulting in much lower initial bond stiffness, $\mathrm{E}_{1}$. By visual inspection of the experimental graphs, it was observed that the bond stiffness $E_{2}$ for headed bars is softer than that for straight end bars due to larger loaded-end slip developed by headed-end bars. The larger loaded-end slip can be attributed to the fact that pullout load in headed-end bars increased, resulting in larger bar elongation. In addition, the initial bond stress, $\tau_{1}$, was found to be $86.5 \%$ and $89.5 \%$ on average to that of peak bond stress for M15 (\#5) and M19 (\#6) GFRP bars, respectively. The initial bond stress of headed bars were found to be somewhat greater than that for the straight end bars, which can be related to the presence of anchorage head increasing the mechanical interlock and adhesion resistance between bars and the concrete. In addition, the results shown in Table 3.4 explain that as the embedment length increases from 100-mm to 200$\mathrm{mm}$, the initial bond stress, $\tau_{1}$, decreases. On the other hand, for a bar with similar embedment length, the initial bond stress of M15 bars was larger than that for M19 bars. 


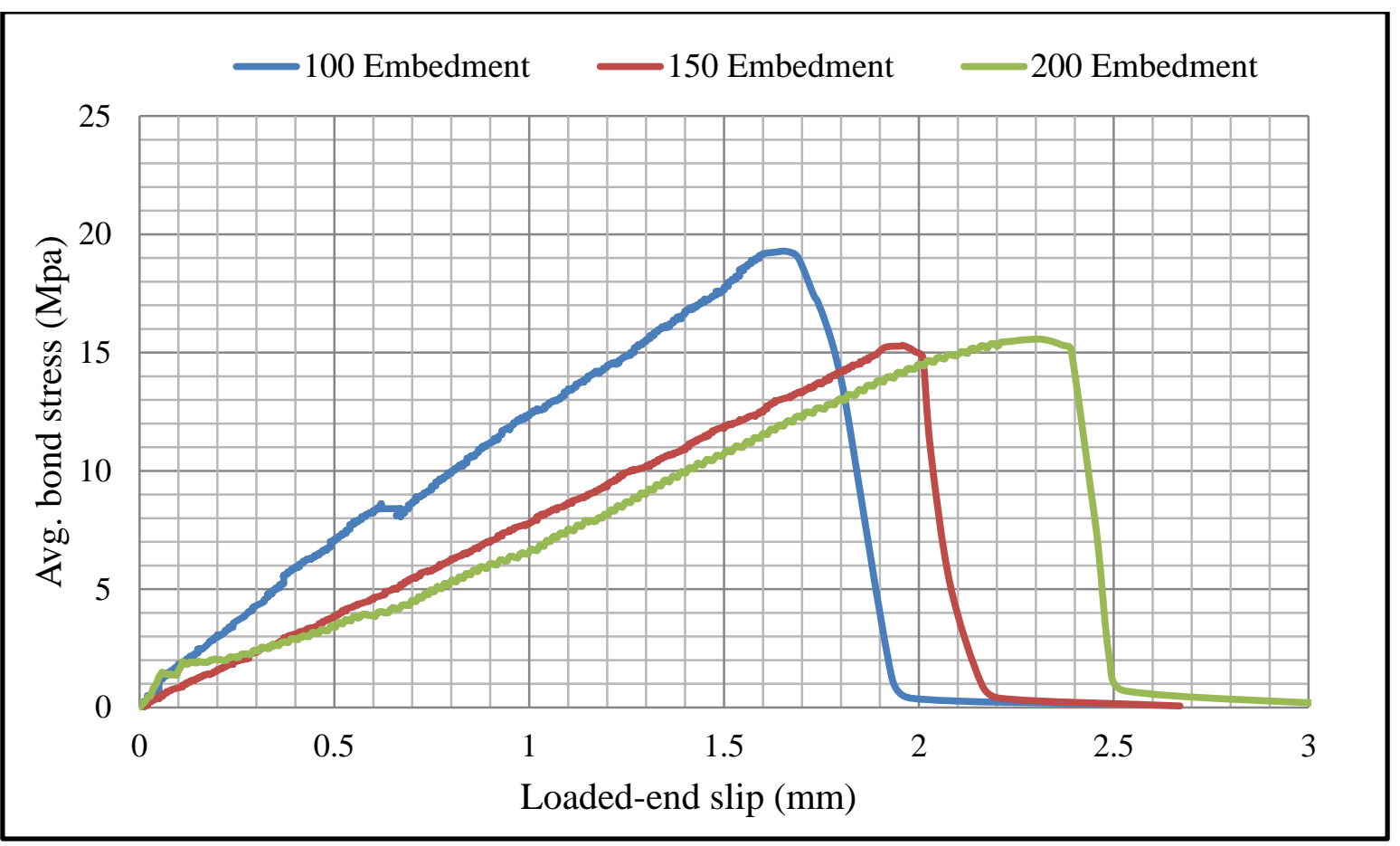

Figure 3. 54 Average bond stress versus loaded-end slip for M19 GFRP bars in slab model 1

Table 3. 4 Summary of averaged experimental test results for headed-end bars in slab model 1

\begin{tabular}{|c|c|c|c|c|c|c|c|}
\hline $\begin{array}{c}\text { Specimen } \\
\text { notation }\end{array}$ & $\begin{array}{c}\mathrm{d}_{\mathrm{b}} \\
(\mathrm{mm})\end{array}$ & $\begin{array}{c}\mathrm{P}_{\max *} \\
(\mathrm{kN})\end{array}$ & $\begin{array}{c}\tau_{1^{* *}} \\
(\mathrm{MPa})\end{array}$ & $\begin{array}{c}\tau_{\max * *} \\
(\mathrm{MPa})\end{array}$ & $\begin{array}{c}\mathrm{S}_{\max } \\
(\mathrm{mm})\end{array}$ & $\mathrm{f}_{\mathrm{b}}(\mathrm{MPa})$ & $\mathrm{f}_{\mathrm{b}} / \mathrm{f}_{\mathrm{u}}$ \\
\hline G5-100EM-H* & 15.88 & 93.3 & 15.73 & 18.70 & 1.21 & 532.70 & 0.450 \\
\hline G5-150EM-H & 15.88 & 118.98 & 13.82 & 15.90 & 1.65 & 672.60 & 0.570 \\
\hline G5-200EM-H & 15.88 & 134.3 & 11.76 & 13.46 & 2.08 & 788.91 & 0.667 \\
\hline G6-100EM-H & 19.05 & 100.96 & 14.76 & 16.87 & 1.46 & 411.05 & 0.372 \\
\hline G6-150EM-H & 19.05 & 121.13 & 11.53 & 13.27 & 1.83 & 538.21 & 0.487 \\
\hline G6-200EM-H & 19.05 & 138.7 & 9.52 & 11.17 & 2.05 & 643.70 & 0.583 \\
\hline
\end{tabular}

*Specimen notation: GFRP bar \#5 (15.88mm) diameter with $100 \mathrm{~mm}$ embedment and headed-end bar

** $\tau_{\max }, \tau_{1}$ and $\mathrm{P} * *$ are the characteristic bond strength and tensile strength (Eq. 3.1a) obtained from peak bond strength and peak tensile load of 5 identical samples

$\mathrm{fu}=1184 \mathrm{MPa}$ for M15 (\#5) bars and 1105MPa for M19 (\#6) bars 


\subsection{Peak Bond Stress}

The maximum loaded-end slip corresponding to the peak bond stress in headed-end bars were found to be greater than that for straight-end bars by an average ratio of $141 \%$. This can be attributed to the higher pullout load and consequently higher bar stress achieved with the presence of head anchors. Figure 3.55 shows the trend of peak bond stress versus embedment length of headed-end bars in concrete. Similar to straight-end bars, as the embedment length increases, the peak bond stress of GFRP bars in concrete decreases. However, unlike straight-end bars, there is not much difference in peak bond stress of M15 (\#5) and M19 (\#6) bars for a bar with similar embedment length. The trend shown in Figure 3.55 also shows that this difference is gradually vanished when embedment length increases from 100-mm to 200-mm. This phenomenon can be attributed to the fact that as the embedment length increases, bar stress reaches the strength of the head portion causing break down of the headed part regardless of bar diameter. Thus, the bar will be pulled out of the concrete. From Table 3.4, it can also be observed that the bar stress dramatically increases with the increase in the embedment length compared to the straight-end bars with similar conditions. The increase in bar stress for $15-\mathrm{mm}$ bar diameter is higher than that observed for the 19-mm bar diameter. Also, comparison between bar stress and the bars ultimate strength showed that the headed-end bars reached approximately $66.7 \%$ and $58.3 \%$ of their ultimate bar strength for M15 and the M19 bars, respectively. In addition, Table 3.4 shows the increase in the maximum loaded-end slip corresponding to peak bond stress with the increase in the embedment length. It was observed that the increase in loaded-end slip for headed-end bars was greater than that for straight-end bars due the higher stresses achieved by the head anchors.

\subsection{Post-Peak Behavior}

Figure 3.56 shows trace of bond stress-loaded end slip for variable bar size and bar embedment length in slab model 1. Unlike straight-end bars, it can be seen from the graphs that the descending branch of headed bars rapidly decreases to nearly zero stress since the failure of the headed-end bars followed by concrete cone breakout (CCB) or pullout with head broken (POHB). The traces shown in Figure 3.56 show the cases with concrete cone breakout failure. For a headed-end bar embedded into concrete, when the bar reaches the peak stress, it begins to pull out from the anchor head developing a high stress concentration in the head portion until it 
breaks at bar-head connection. As the bar pulls out, the bar deformation occurs against the anchor head leading to the development of frictional stresses. In most cases, the bar was sheared off during the initial rupturing as shown in Figure 3.57 in which the disk shape of the head has been broken out and the remaining part along with GFRP bar-core has been pulled out of the concrete. Visual inspection of experimental test results failed by pullout head broken showed an average residual bond stress ranging from $4.8 \%$ to $21.3 \%$ of the peak bond stress.

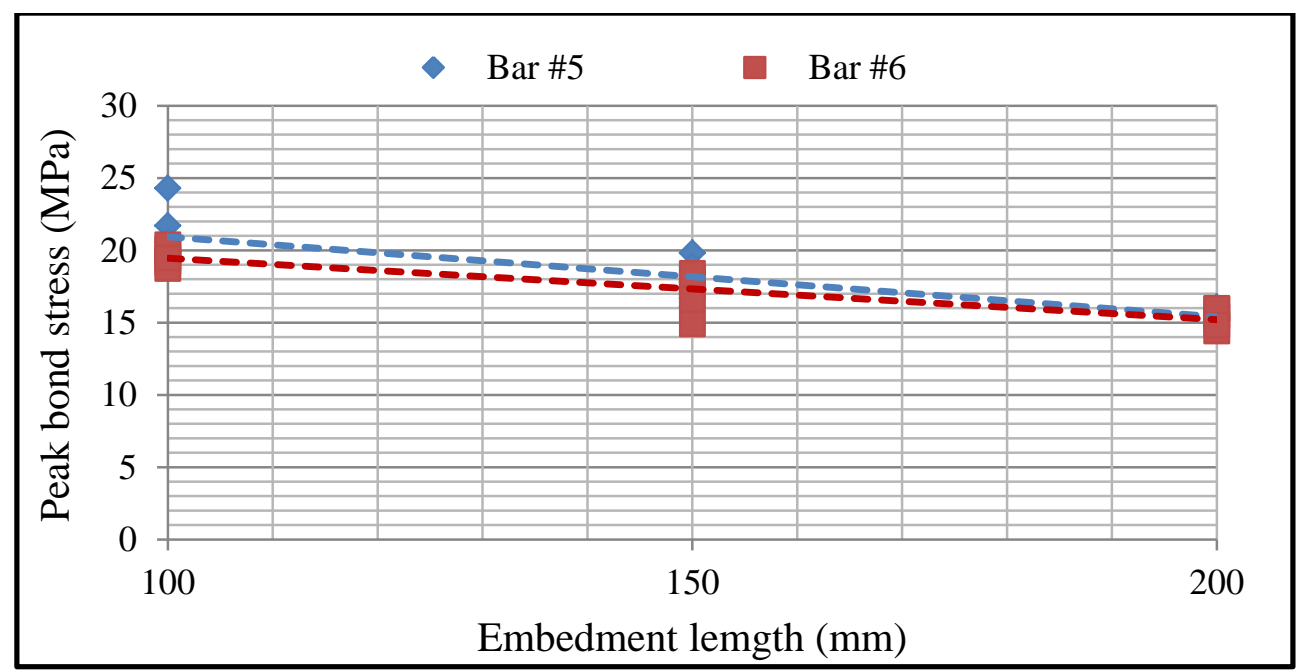

Figure 3. 55 Average peak bond stress versus embedment length for headed-end bars in slab model 1

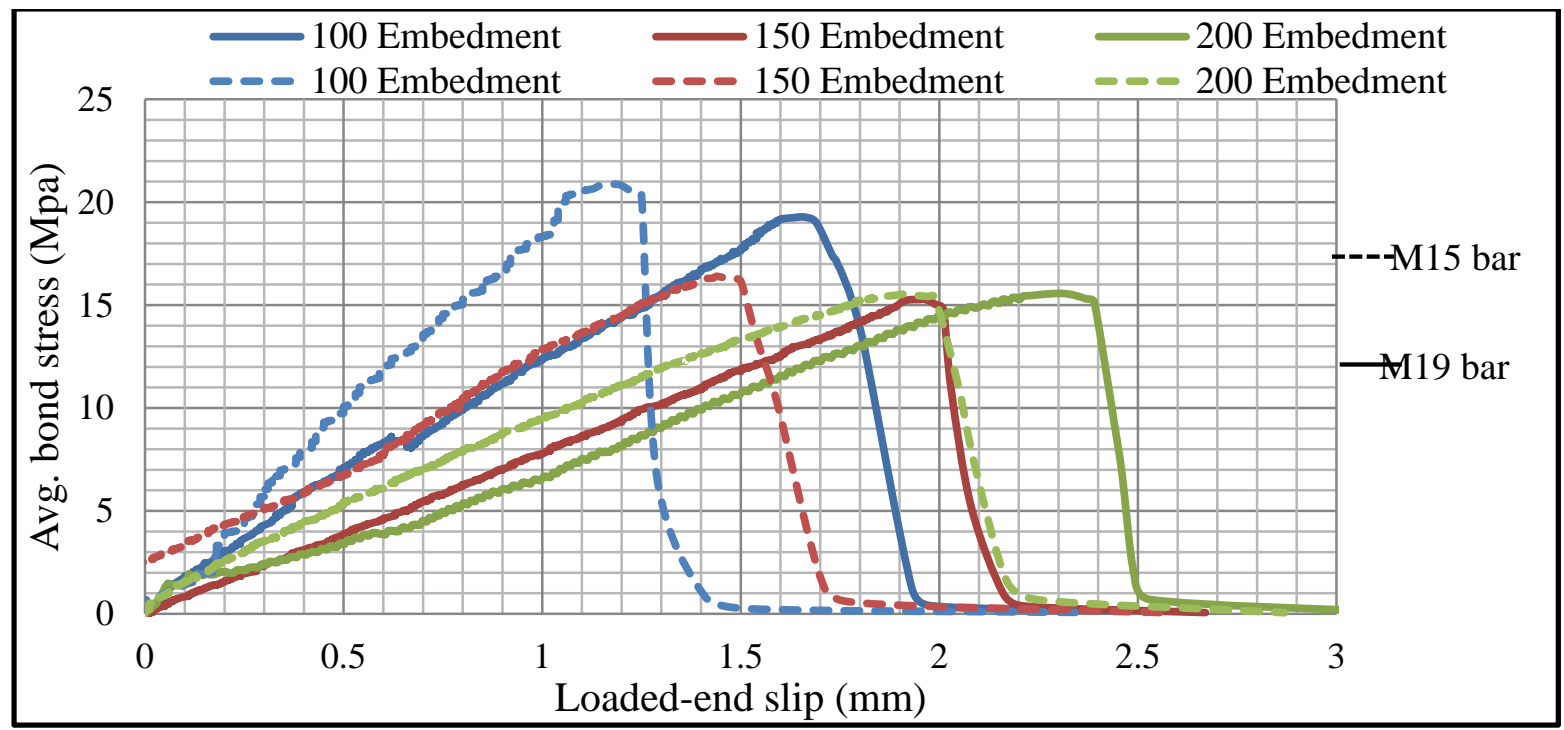

Figure 3. 56 Average bond stress versus loaded-end slip for headed-end bars for different bar size and embedment lengths in slab model 1 


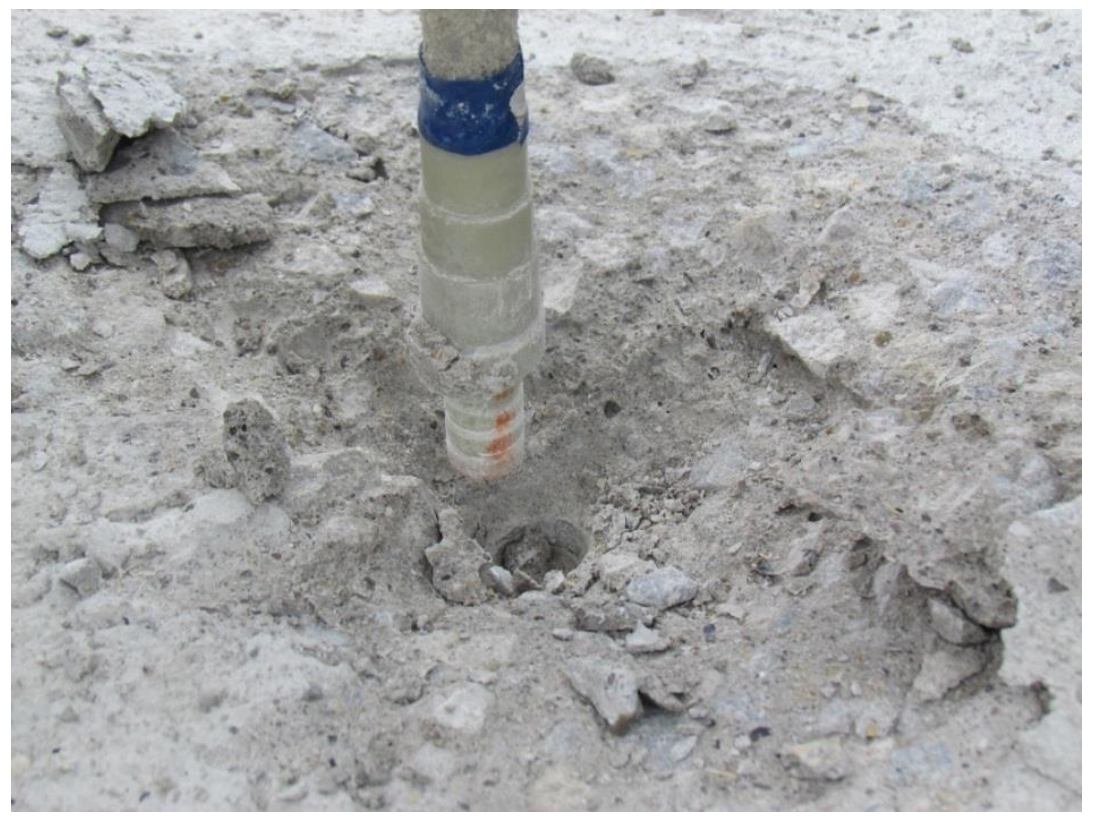

Figure 3. 57 Failure of GFRP headed-end showing broken head with end portion left in concrete

\subsubsection{Hook Bars}

The bond stress-loaded end slip relationship for hook bars exhibited similar behavior as the headed-end bars in which after the failure by bar rupture, the bond stress rapidly dropped to nearly zero stress as shown in Figure 3.58. The overall trend depends on the location of bar rupture, which has been observed either at bent portion inside the concrete slab or in the straight portion outside of the concrete slab (see Figure 3.59). In either case, the bars experienced some residual stresses due to frictional resistance or due to remaining strength of intact fibers until the bar entirely pulled out of concrete or all fibers were ruptured. From experimental observations, the post-peak behavior of hook bars in concrete was brittle with a sudden drop of stress in the bar.

\subsection{Pre-Peak Behavior}

The average bond stress-loaded end slip curves of GFRP hook bars in concrete slab model 1 is shown in Figure 3.60. Due to the failure type by bar rupture, GFRP bars exhibited quite a large initial bond stress, $\tau_{1}$, reaching up to $93 \%$ of the peak bond stress, $\tau_{\max }$. This can be due to the fact that GFRP hook bars developed their ultimate strength and bar stress-slip curves linearly increased till close to the failure point. The initial bond stress with respect to the peak bond stress 
in hook bars were found to be $115 \%$ and $106 \%$ greater than those for straight and headed-end bars, respectively. This can be attributed to the fact that hook bars are made of standard modulus (SM) bars, while straight and headed-end bars are made of high modulus (HM) bars. Due to lower modulus of elasticity of the hook bars, it was also observed that the bars experienced larger slip and consequently much lower initial stiffness, $\mathrm{E}_{1}$, compared to headed and straightend bars. In addition, due to larger slip associated with these bars, the bond stiffness, $\mathrm{E}_{2}$, was found to soften much more than headed-end and straight-end bars.

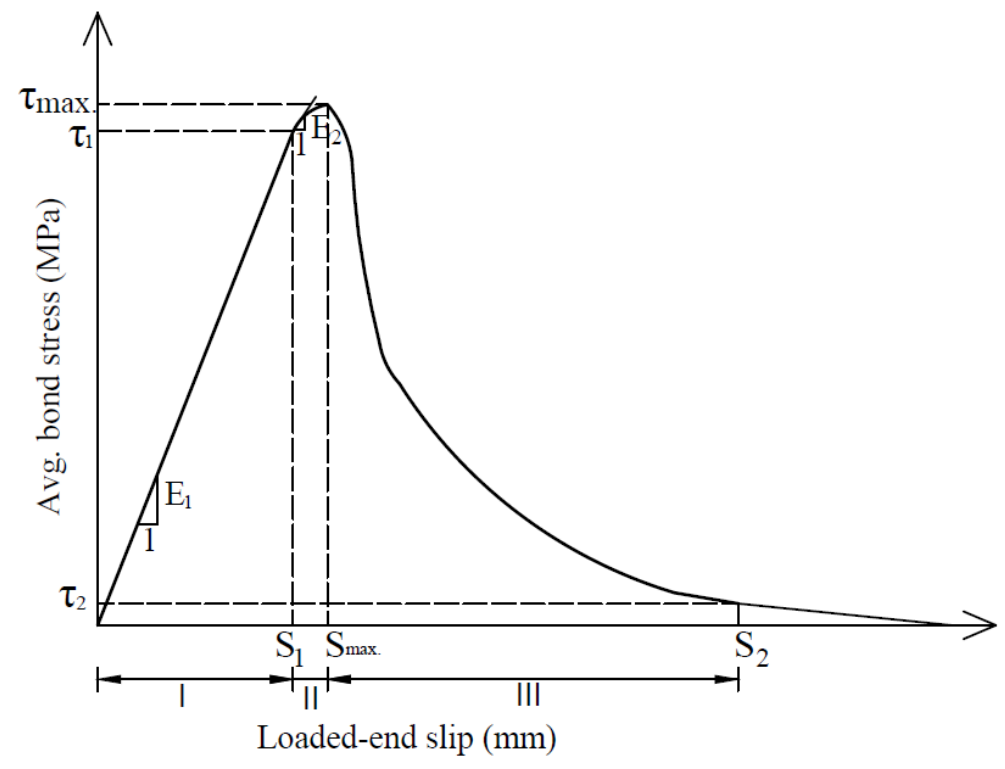

Figure 3. 58 Typical bond stress-loaded end slip for hook bars
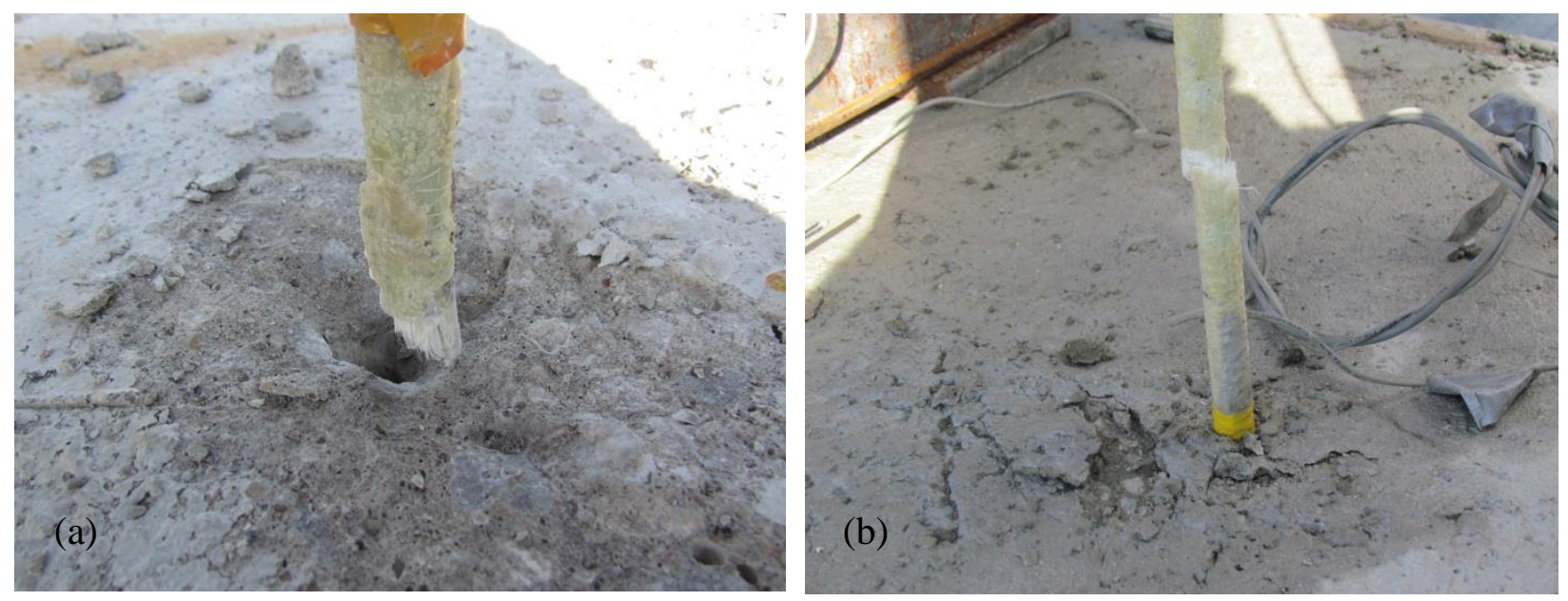

Figure 3. 59 GFRP hook rupture locations (a) at bent portion (b) at straight portion 


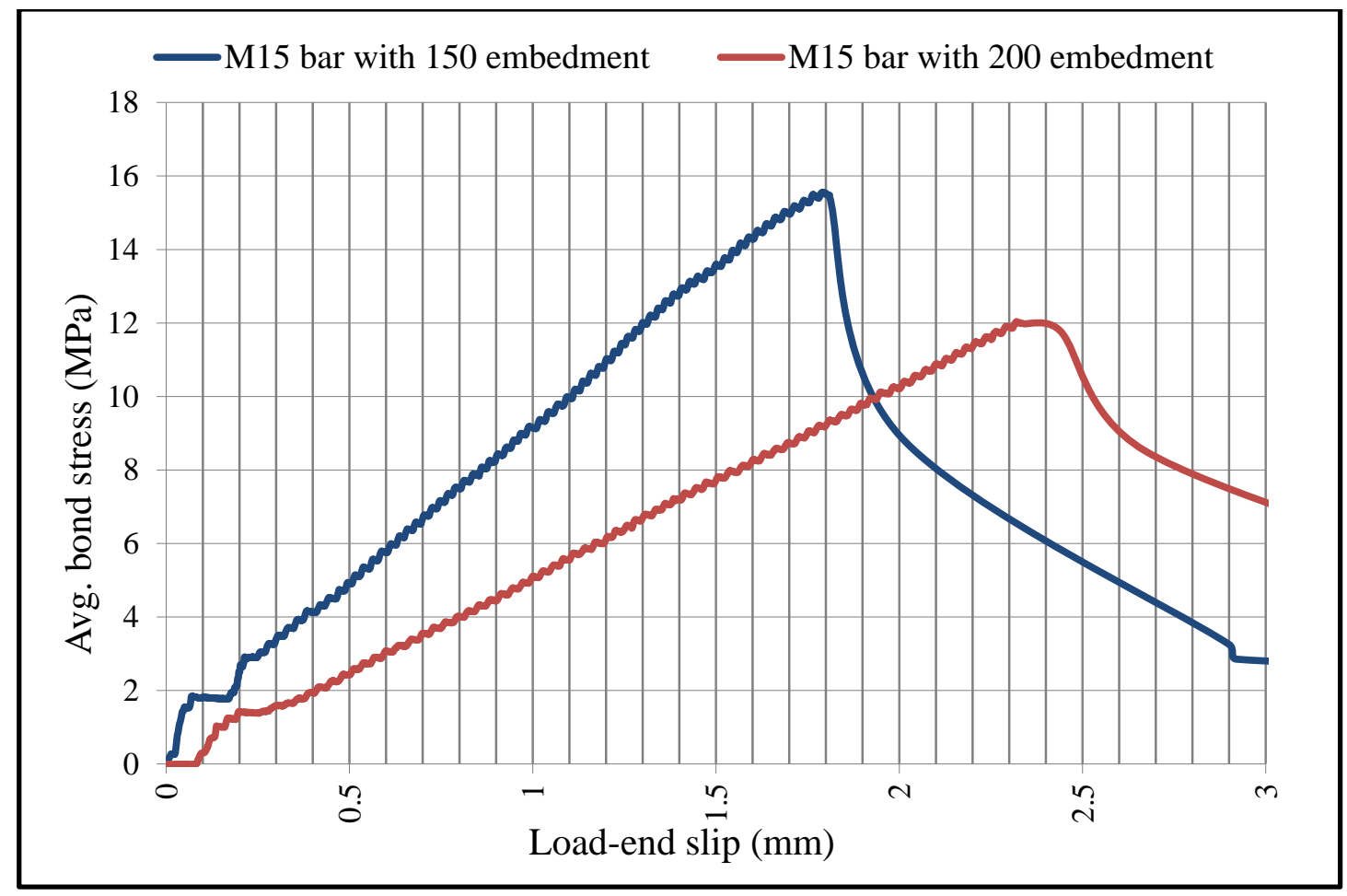

Figure 3. 60 Average pre-peak bond stress versus loaded-end slip for hook bars in slab model 1

\subsection{Peak Bond Stress}

Table 3.5 gives a summary of experimental test results for GFRP hook bars in concrete slab model 1. It can be seen that the peak bond stress decreases as the embedment length increases from 150 to $200-\mathrm{mm}$. The initial bond stress, $\tau_{1}$, was found to be close to the peak bond stress (up to $93 \%$ of peak bond stress), while the residual stress, $\tau_{2}$, was within $10 \%$ to $15 \%$ of the peak bond stress. The ultimate tensile strength of the bent portion for M15 (\#5) GFRP hook bars used in this research was found $473 \mathrm{MPa}$ from manufacturer data sheets. Comparison made between the stresses developed in the bars with the tensile strength of the bent portion showed that the bar stress increased by $13 \%$ and $33 \%$ for 150 and $200-\mathrm{mm}$ embedment length to that of ultimate tensile strength causing the bars to rupture. The maximum loaded-end slip at peak bond stress in hook bars were found to be $114 \%$ and $157 \%$ greater than that for headed-end and straight-end bars, respectively (see Figure 3.61). It can also be observed that by increasing the embedment length for all bar end anchorage system, the loaded-end slip also increases. However, the maximum loaded-end slip was attributed to the hook bars due lower elastic modulus of the bars. The trend of peak bond stress versus embedment length of bars in concrete for the hook, straight- 
and headed-end bars are compared in Figure 3.62. It can be observed that increasing the embedment length lowers the average peak bond stress. However, it can be understood that headed-end bars developed the largest peak bond stress, which hook bars developed an intermediate margin with the straight-end bars developing the least peak bond stress.

Table 3. 5 Summary of averaged experimental test results for hook bars in slab model 1

\begin{tabular}{|c|c|c|c|c|c|c|c|c|c|}
\hline $\begin{array}{c}\text { Specimen } \\
\text { notation }\end{array}$ & $\begin{array}{c}\mathrm{d}_{\mathrm{b}} \\
(\mathrm{mm})\end{array}$ & $\begin{array}{c}\mathrm{P}_{\text {max.** }} \\
(\mathrm{kN})\end{array}$ & $\begin{array}{c}\tau_{\max *} \\
(\mathrm{MPa})\end{array}$ & $\begin{array}{c}\tau_{1^{* *}} \\
(\mathrm{MPa})\end{array}$ & $\begin{array}{c}\tau_{2^{* *}} \\
(\mathrm{MPa})\end{array}$ & $\begin{array}{c}\mathrm{f}_{\mathrm{b}} \\
(\mathrm{MPa})\end{array}$ & $\mathrm{f}_{\mathrm{b}} / \mathrm{F}_{\mathrm{u}}$ & $\begin{array}{c}\mathrm{S}_{\max .} \\
(\mathrm{mm})\end{array}$ & Failure \\
\hline $\begin{array}{c}\text { G5-150EM- } \\
\text { HO* }\end{array}$ & 15.88 & 93.91 & 12.55 & 11.65 & 1.89 & 534.8 & 1.13 & 1.93 & Rupture \\
\hline $\begin{array}{c}\text { G5-200EM- } \\
\text { HO }\end{array}$ & 15.88 & 106.9 & 10.71 & 9.68 & 1.44 & 628.2 & 1.33 & 2.30 & Rupture \\
\hline
\end{tabular}

*Specimen notation: GFRP bar \#5 (15.88mm) diameter with 150mm embedment and hook bar

$* * \tau_{\max }, \tau_{1}, \tau_{2}$ and $\mathrm{P} * *$ are the characteristic bond strength and tensile strength (Eq. 3.1a) obtained from peak bond strength and peak tensile load of 5 identical samples

$\mathrm{Fu}=473 \mathrm{MPa}$ for bent portion of bar \#5 (from manufacturer data sheet)

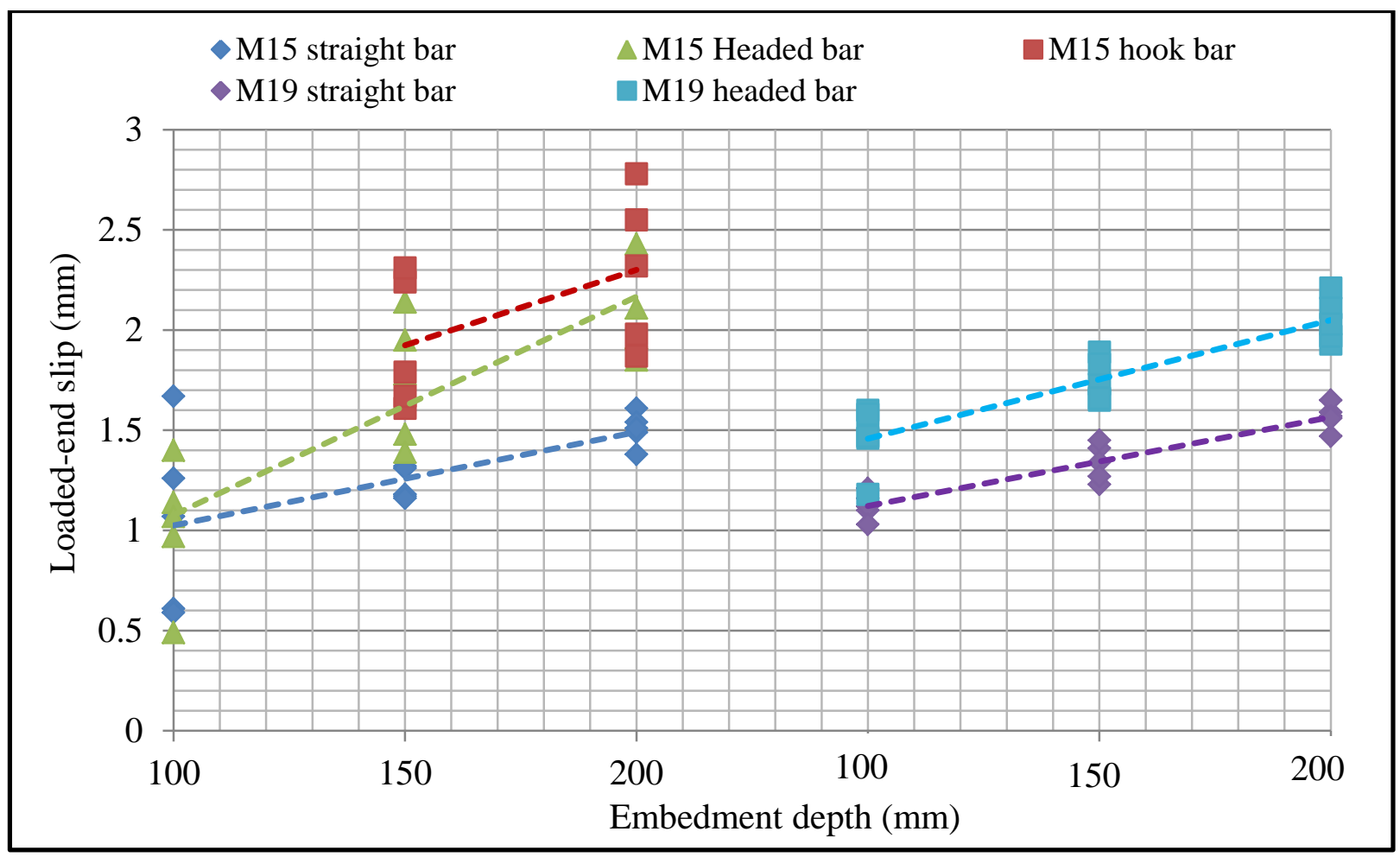

Figure 3. 61 Loaded-end slip versus embedment length for various bars in slab model 1 


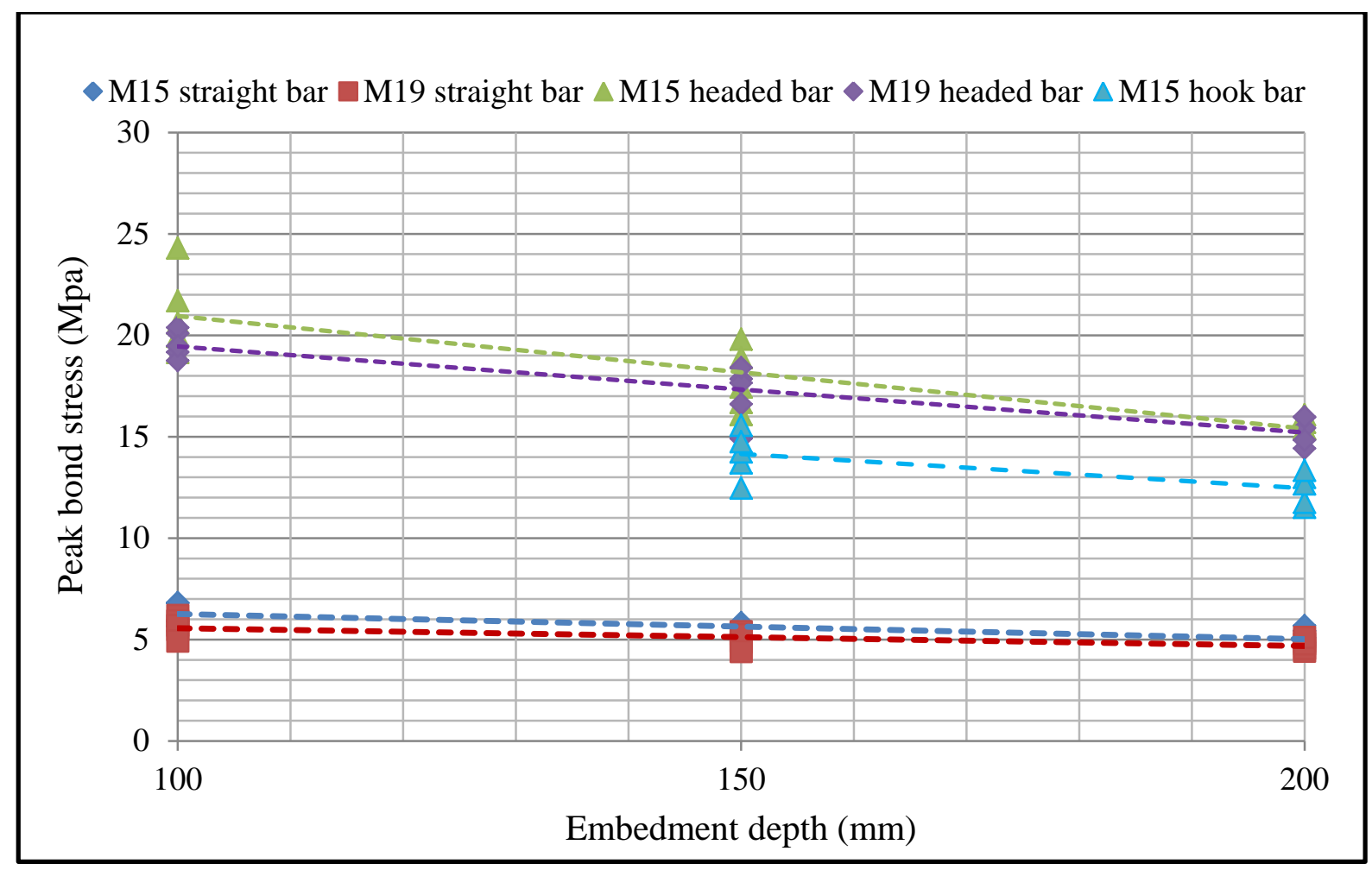

Figure 3. 62 Peak bond stress comparison for straight, headed and hook bars for slab model 1

\subsection{Post-Peak Behavior}

The relationship between bond stress and load-end slip of GFRP hook bars in concrete slab model 1 is shown in Figure 3.63. It can be seen from the graphs that the descending branch of bond-slip curve shows a rapid loss of bond stress up to some point, gaining strength and again decreasing the bond stress by increase in the slip. The jump in post-peak response of GFRP hook bars in concrete can be attributed to gradually rupturing the fibers in the bar itself. Once the failure occurs, some of the fibers start to rupture while still the remaining fibers carry the pullout load. By increasing the applied load, the fiber strength diminishes until all the fibers are ruptured. If the failure occurs inside the concrete or at the bent portion, the frictional resistance between the bar and the concrete delays the loss of bond stress until the fictional resistance is removed. At this point, the bar experiences some residual stresses which found to be very small compared to the peak bond stress. 


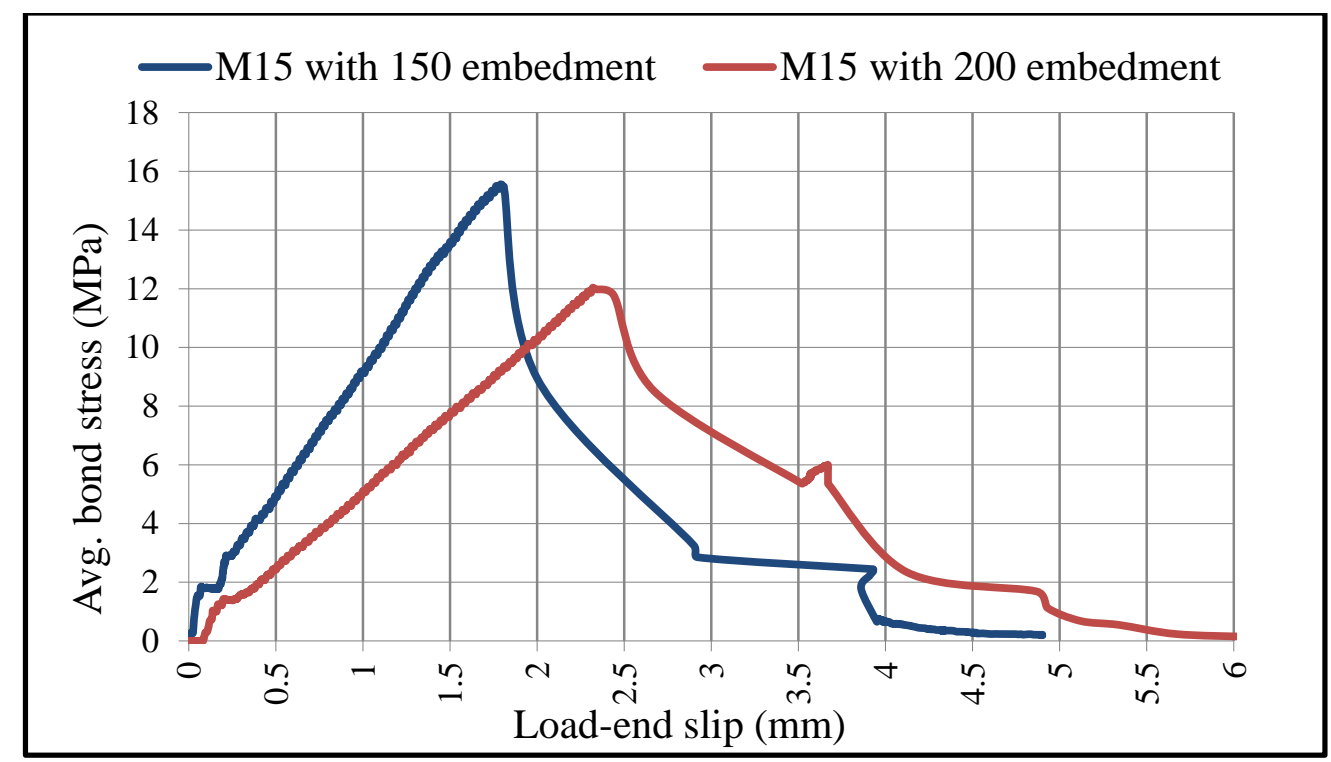

Figure 3. 63 Average bond stress versus loaded-end slip GFRP hook bars in slab model 1

\subsection{Experimental Results of Pullout Specimens in Concrete Cubes}

Pullout test on concrete cube specimens was also performed using Vishay System 6000 dataacquisition machine running strain smart software. The scan rate of 10 scans per second has been used to capture the data. The displacement sensors (POTs) were clamped to the GFRP bars at both free-end and loaded-end locations in order to record the linear displacement change (slip) under the pullout load. The GFRP test specimen positioned in the testing machine was undertaken direct tension force in a deflection controlled mode to the specimen at a rate of about $0.2 \mathrm{kN} / \mathrm{s}$. The test stopped when bar pullout, concrete splitting or bar rupture occured. Bond performance of GFRP bars in concrete are usually evaluated based on bond failure modes, bond strength and bond-slip relationship. Although a non-linear distribution of stress is reported in the literatures along the embedded length of the bars, a uniform distribution of stresse can be assumed along the embedment length. Thus, Eq. 3.1a can be utilized to determine the characteristic bond strength of the bars which is a function of applied pullout load and perimeter surface area of the embedded bar. As mentioned earlier, displacement sensors (POTs) have been utilized to capture both free-end and loaded-end slips. At free-end, the bar shows very small slip oscillating between zero to $0.01-\mathrm{mm}$. At the time of failure, the free-end slip suddenly increased. At loaded-end, the elongation of the bar between concrete surface and point of the attachment of the POT has been taken into account and calculated using Eq. 3.2. It should be noted that the 
length of elongated bar, L, was considered as 210-mm. Thus, slip at loaded-end was calculated by subtracting the bar elongation from measured slip using Eq. 3.3. The characteristic bond strength was calculated as the average bond strength of the three identical test specimens multiplied by the factor, $F_{t}$, (Eq. 3.1b).

The experimental test results and modes of failure for each GFRP bars are provided in Table A.3 in Appendix A. The specimens generally failed in pullout (PO), concrete splitting (CS), concrete splitting accompanied with bar pulled out from head broken (CS-POHB) and bar rupture (RR) modes of failure. As general case, the pullout failure occurred partly in surface of the bar by separating bond between concrete and the bars and partly occurred in the concrete by peeling off the surface layer of the GFRP bars. A summary of experimental test results and modes of failure for GFRP bars in 150-mm cubes for straight and headed-end bars as well as the 300x500-mm blocks for hook bars are provided in Table 3.6. Comparison of the test results with pullout specimens in concrete slabs showed similar behavior for factors affecting the bond strength. From Table 3.6, it can be observed that pullout force depends on the embedment length: the longer the embedment length, the larger force required to pull the bar out of the concrete. However, by increasing the embedment length, the maximum average bond stress reduces. This might be due to non-linear distribution of the stresses along the length of the bars in case of larger embedment length. Figure 3.64 graphically compares the effect of the increase in the embedment length on the applied tensile load and bond strength of the GFRP bars in each set of concrete cubes. It can be seen that as the embedment length increases, the applied tensile load required for pullout to occur also increases, while the bond strength between the bars and concrete decreases.

The stresses in GFRP bars at failure are also provided in Table 3.6. From experimental test results, it was observed that by increasing the embedment length, bar stresses approach to their ultimate tensile strengths. However, the increase in bar stress for headed bars was found to be higher than that for hook and straight-end bars. It should also be noted that the stress in the hook bars were compared to the ultimate tensile strength of the bent portion as bar rupture mainly occurred in this location. From experimental observations, it was noticed that the bar stresses in the hook bars exceeded the ultimate tensile strength of bent portion causing bar rupture failure 
mode, except for one specimen with M19 (\#6) hook bar and 150-mm embedment length on which concrete side splitting occured. In addition, it was observed that the larger bar diameter required, larger embedment length to develop the same bond strength. On the other hand, for the bars with the same diameter, increasing the embedment length reduces the bond strength of the GFRP bars. Figure 3.65 compares the effect of bar size on the average bond strength with the increase in development length of GFRP bars.

Table 3. 6 Summary of experimental test results of pullout cube specimens

\begin{tabular}{|c|c|c|c|c|c|c|c|c|c|}
\hline \multirow{2}{*}{$\begin{array}{c}\text { Specimen } \\
\text { notation }\end{array}$} & \multirow{2}{*}{$\begin{array}{c}\mathrm{L}_{\mathrm{d}} \\
(\mathrm{mm})\end{array}$} & \multicolumn{2}{|c|}{ Slip (mm) } & \multirow{2}{*}{$\begin{array}{c}\mathrm{f}_{\mathrm{c}}^{\prime} \\
(\mathrm{MPa})\end{array}$} & \multirow{2}{*}{$\begin{array}{l}\mathrm{P}_{\text {chr. }}{ }^{\mathrm{c}} \\
(\mathrm{KN})\end{array}$} & \multirow{2}{*}{$\begin{array}{c}\tau_{\text {chr. }}{ }^{\mathrm{c}} \\
(\mathrm{MPa})\end{array}$} & \multirow{2}{*}{ SD } & \multirow{2}{*}{$\begin{array}{c}\text { Bar } \\
\text { stress } \\
(\mathrm{MPa})\end{array}$} & \multirow{2}{*}{$\begin{array}{l}\text { Failure } \\
\text { mode }^{b}\end{array}$} \\
\hline & & $\mathrm{S}_{\mathrm{fe}}$ & $\mathrm{S}_{\mathrm{le}}$ & & & & & & \\
\hline \multirow{4}{*}{$\begin{array}{c}\text { G5-C150- } \\
S^{a}\end{array}$} & 100 & 0.01 & 12.81 & \multirow{4}{*}{34.9} & 55.9 & 11.2 & 1.86 & 282.2 & CS \\
\hline & 150 & 0.16 & 25.8 & & 80.43 & 10.7 & 1.20 & 406.11 & $\mathrm{PO}$ \\
\hline & 200 & 0.01 & 23.8 & & 91.51 & 9.17 & 0.60 & 462.03 & $\mathrm{CS}$ \\
\hline & 250 & 0.05 & 24.02 & & 113.3 & 9.06 & 0.21 & 572.21 & $\mathrm{PO}$ \\
\hline \multirow{4}{*}{$\begin{array}{c}\text { G5-C150- } \\
\mathrm{H}^{\mathrm{a}}\end{array}$} & 100 & 0.01 & 12.92 & \multirow{4}{*}{34.9} & 70.85 & 14.2 & 1.67 & 357.7 & $\mathrm{CS}$ \\
\hline & 150 & 0.24 & 31.3 & & 96.03 & 12.8 & 1.43 & 484.9 & CS-OHB \\
\hline & 200 & 0.01 & 27.8 & & 115.4 & 11.85 & 1.69 & 582.7 & CS-OHB \\
\hline & 250 & 0.18 & 27.2 & & 124.73 & 9.97 & 0.68 & 629.7 & $\begin{array}{c}\text { CS- } \\
\mathrm{OHB}\end{array}$ \\
\hline \multirow{4}{*}{$\begin{array}{c}\text { G6-C150- } \\
\mathrm{S}^{\mathrm{a}}\end{array}$} & 100 & 0.04 & 23.8 & \multirow{4}{*}{34.9} & 62.7 & 10.51 & 1.03 & 220.1 & PO \\
\hline & 150 & 0.02 & 24.51 & & 90.04 & 10.03 & 0.51 & 315.91 & $\mathrm{PO}$ \\
\hline & 200 & 0.01 & 25.79 & & 114.94 & 9.57 & 1.16 & 403.81 & CS \\
\hline & 250 & 0.05 & 23.71 & & 126.4 & 8.44 & 1.44 & 443.31 & $\mathrm{PO}$ \\
\hline \multirow{4}{*}{$\begin{array}{c}\text { G6-C150- } \\
\mathrm{H}^{\mathrm{a}}\end{array}$} & 100 & 0.02 & 20.9 & \multirow{4}{*}{34.9} & 72.14 & 12.05 & 0.97 & 253.1 & $\mathrm{CS}$ \\
\hline & 150 & 0.07 & 22.7 & & 96.11 & 10.71 & 2.22 & 337.2 & CS-OHB \\
\hline & 200 & 0.05 & 24.41 & & 112.4 & 9.4 & 1.31 & 394.4 & CS-OHB \\
\hline & 250 & 0.21 & 21.9 & & 128.66 & 8.6 & 0.92 & 451.4 & $\mathrm{CS}-\mathrm{OHB}$ \\
\hline \multirow{3}{*}{$\begin{array}{c}\mathrm{G} 5-\mathrm{C} 300 \mathrm{x} \\
500-\mathrm{HO}^{\mathrm{a}}\end{array}$} & 150 & 0.25 & 24.2 & \multirow{3}{*}{34.9} & 105.01 & 14.03 & 2.34 & 530.2 & $\mathrm{RR}$ \\
\hline & 200 & 0.21 & 29.9 & & 122.54 & 12.3 & 1.43 & 618.7 & $\mathrm{RR}$ \\
\hline & 250 & 0.19 & 31.6 & & 144.5 & 11.58 & 1.24 & 729.8 & $\mathrm{RR}$ \\
\hline \multirow{3}{*}{$\begin{array}{c}\text { G6-C300x } \\
500-\mathrm{HO}^{\mathrm{a}}\end{array}$} & 150 & 0.05 & 21.6 & \multirow{3}{*}{34.9} & 119.63 & 13.33 & 2.63 & 419.73 & CS \\
\hline & 200 & 0.11 & 28.3 & & 140.95 & 11.77 & 1.14 & 494.5 & RR \\
\hline & 250 & 0.08 & 26.3 & & 164.95 & 11.03 & 0.097 & 578.9 & $\mathrm{RR}$ \\
\hline
\end{tabular}

a- Average of three test specimens

b- $\mathrm{PO}=$ pull-out; $\mathrm{RR}=$ rebar rupture; $\mathrm{CS}=$ concrete splitting; $\mathrm{CS}-\mathrm{POHB}=$ concrete splitting with bar pulled-out from head broken

$\mathrm{c}=$ characteristic peak tensile load and characteristic peak bond strength (Eq. 3.1a) obtained from testing of 3 identical samples. 


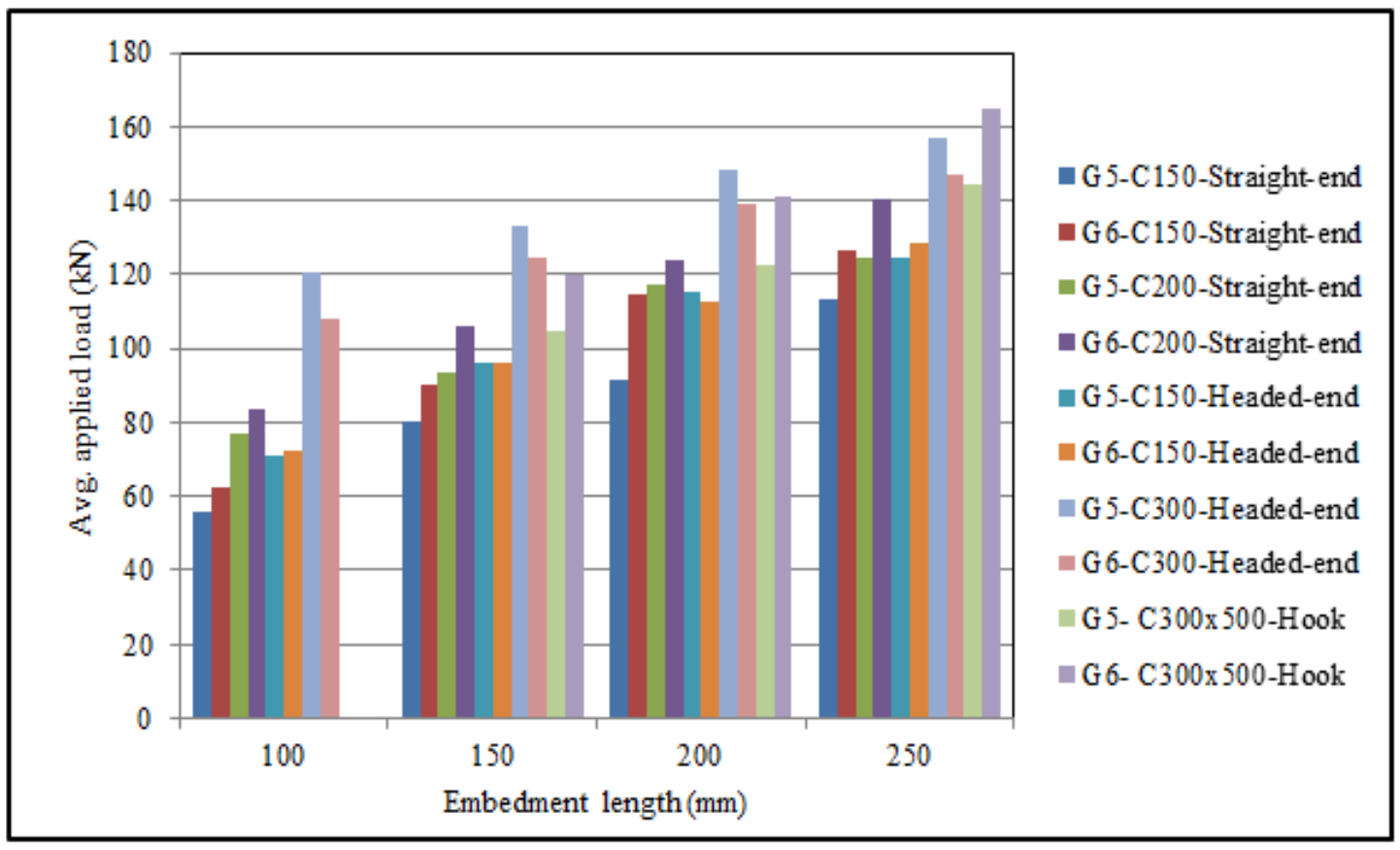

(a) Pullout load vs. embedment length relationship

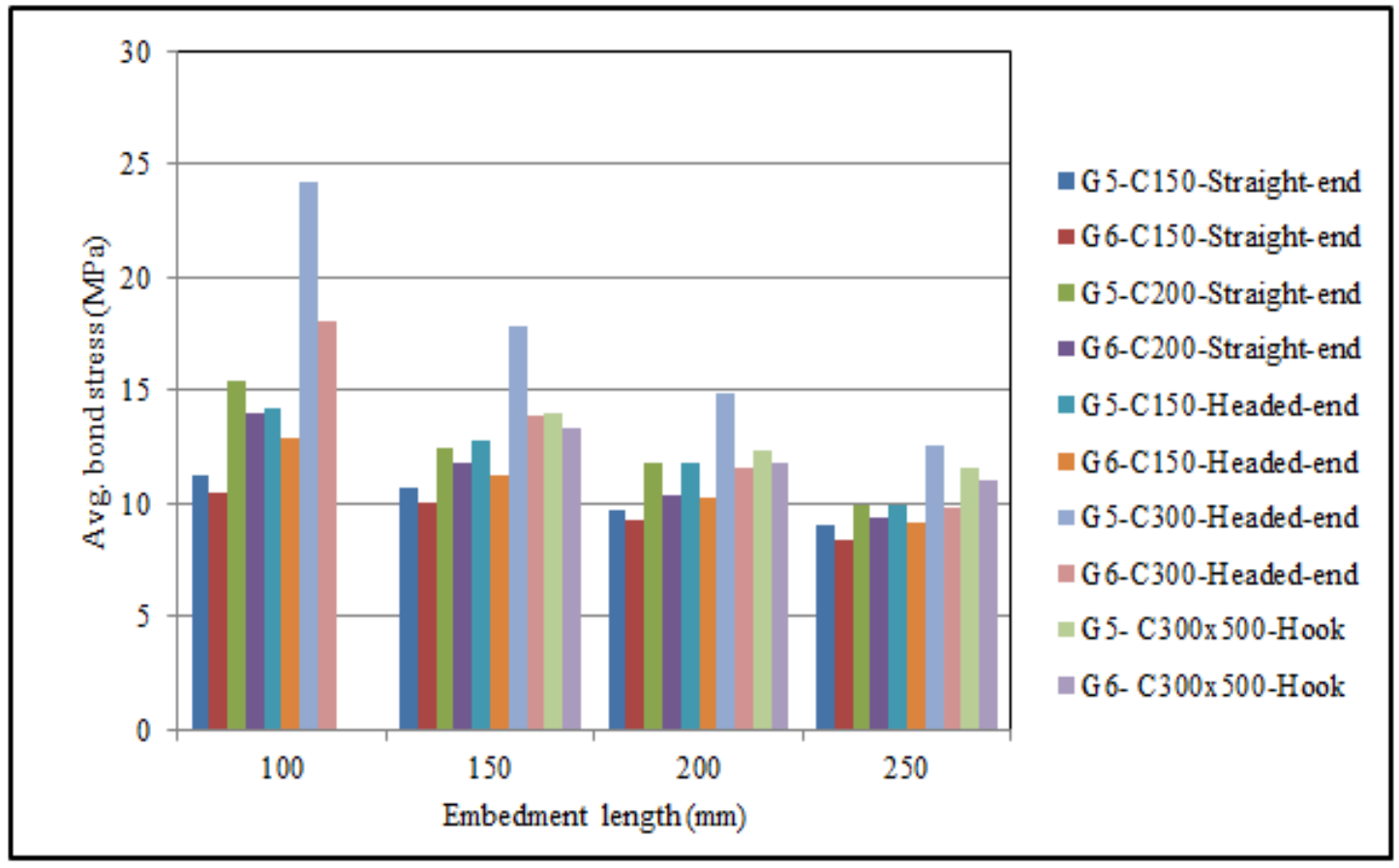

(b) Bond stress vs. embedment length relationship

Figure 3. 64 Effect of embedment length on (a) pullout load, and (b) bond stress 


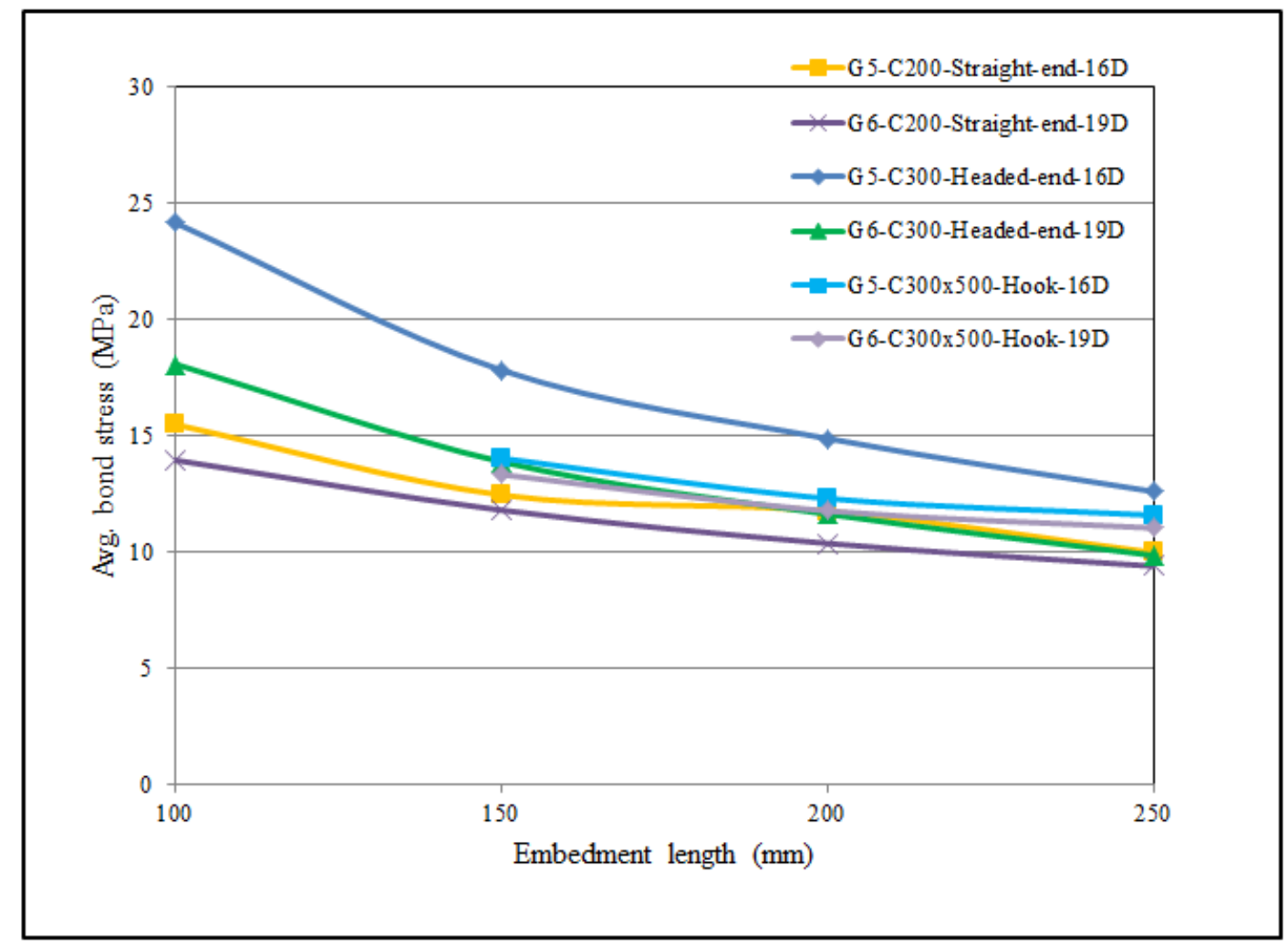

Figure 3. 65 Effect of bar size on bond strength with the increase in embedment length

Similar to the experimental testing on concrete slab specimens, bars with different end anchorages such as straight-end, headed-end and $180^{\circ}$ hook bars have been investigated. Similar behavior as the concrete slab models were observed with variable end-anchorage systems. From the test results, it has been observed that GFRP bars with headed-ends developed the most promising bond strength characteristics possessing the highest value of the average bond strength. The hooked bars also developed relatively high values of bond strength, however, the maximum bond strength followed by rupturing causing a brittle failure of the bars. The least bond strength development was attributed to GFRP bars with straight ends. Figure 3.66 compares the bond strength variations for GFRP bars with straight-ends and headed-ends in the 150-mm concrete cubes. It can be noticed that there is a comparable difference for bond stress of M15 (\#5) bars between the headed-end and the straight-end bars for all embedment lengths, while the difference in bond stress of M19 (\#6) was less comparable due to the fact that as the embedment length increases in larger bar size due to poisson's effects and bleeding water, the contact surface between the bars and concrete diminishes causing reduction in the bond stress of 
the bars. The slip at free-end and loaded-end of the tested cube specimens is also presented in Table A.3 in Appendix A. It can be observed that GFRP bars experienced very small slip values at free-end location. However, the slip at loaded-end location was relatively high. This is due to low modulus of elasticity of GFRP bars producing larger deformation of the bars at loaded-end locations. As such, due to these comparable differences in slip at free-end and loaded-end, it can be concluded that bond stress distribution is non-uniform along the embedded length of the bars. This non-uniformity of bond stress would be elevated by increasing embedment length of GFRP bars into concrete.

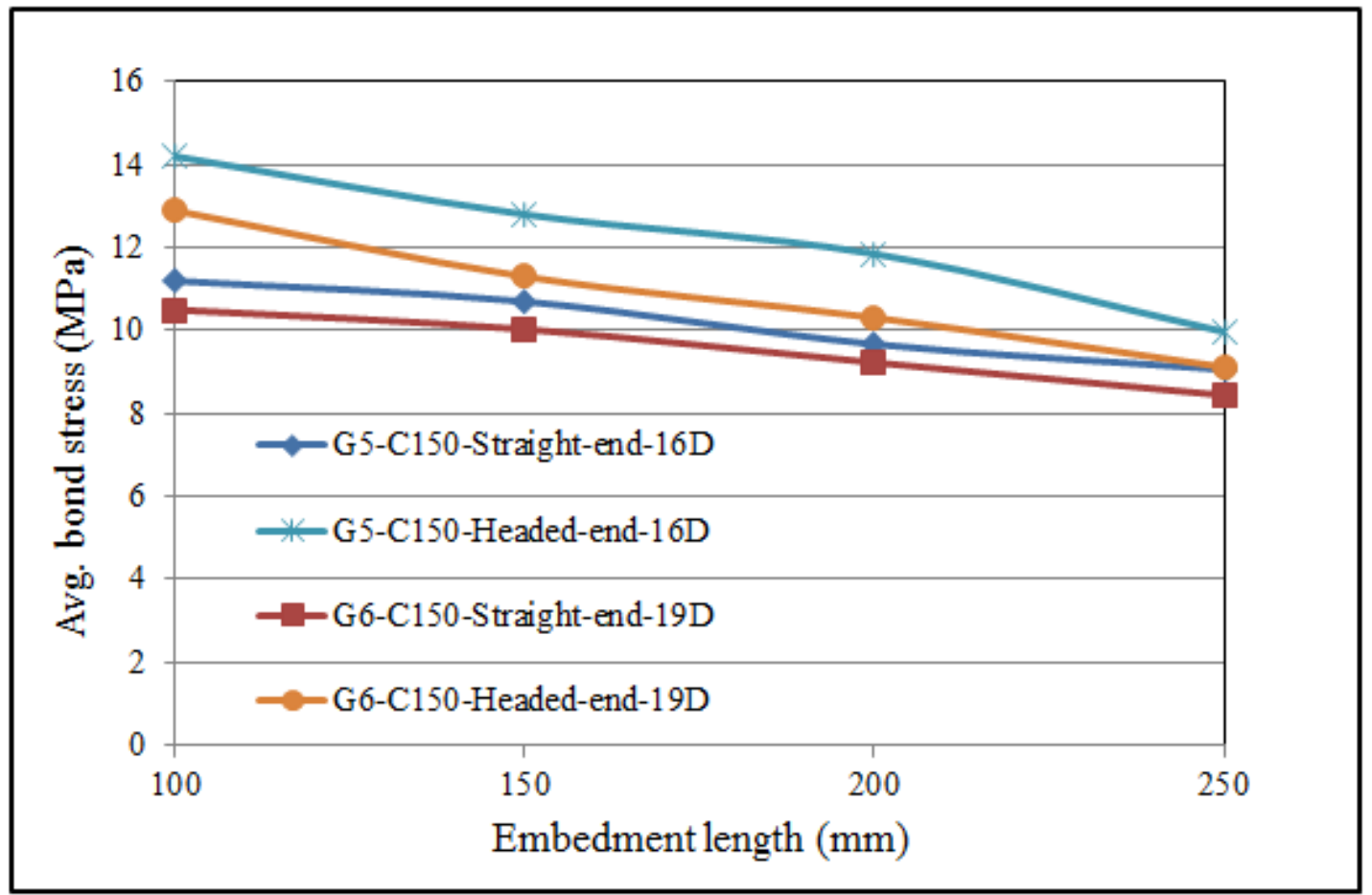

Figure 3. 66 Effect of bar end geometry on bond strength with increase in embedment length

\subsubsection{Bond Failure Modes}

The bond failure of GFRP pullout cube specimens followed four different types of failure modes depending on the bar type, embedment length, concrete cover and cube size. The following sections briefly explain the failure modes associated with testing of GFRP pullout cube specimens: 
Pullout (PO) Failure: pullout failure mostly appeared in the concrete cube specimens of 200$\mathrm{mm}$ width and in some cases in concrete cubes of $150-\mathrm{mm}$ width. The failure was more probable to occur for specimens with M15 (\#5) GFRP bars and larger embedment lengths. Thus, it can concluded that this failure mode occurs if sufficient concrete cover or confinement are provided for the GFRP bars as were the case for 200-mm concrete cube specimens. In pullout failure, the entire bars pulled out of concrete without any sign of cracks on the surrounding concrete. The failure may be due to the loss of all the three bond mechanism (adhesion, mechanical interlock and friction), upon which the interface contact was removed and the bar was sheared off along a cylindrical failure surface. Figure 3.67a shows view of a $200-\mathrm{mm}$ concrete cube failed by pullout of bar in concrete. The experimental pullout specimens also show that the pullout failure happened either at concrete-bar or bar-core interfaces (See Figure 3.68).

Concrete Splitting (CS) Failure: Concrete side splitting occurred mainly in 150-mm concrete cubes for straight-end bars with 100 and 150-mm embedment lengths. In few cases this failure mode has been observed in greater embedment lengths if it were found that concrete cover to the GFRP bars was reduced during casting. Also, concrete splitting failure was observed in some headed-end bar specimens with embedment length of 100-mm due to the fact that the bars did not reach the strength of head portion and due to wedging effect by the anchor heads. However, as the concrete cube size increased from $150-\mathrm{mm}$ cubes to $200-\mathrm{mm}$, concrete splitting failure rarely occurred in the specimens except in a few specimens with 100 -mm embedment lengths. Generally, the splitting failure occurs if cover to the reinforcement is not adequate to resist the tensile strength of the surrounding concrete. Therefore, it can be concluded that to prevent splitting failure, sufficient confinement should be provided to the reinforcement. From specimens failed by splitting, it was noticed that the splitting failure occurred along the length of GFRP bars with radial cracks at the surface of the concrete cubes. The radial crack tends to reach the concrete edges with the shortest distance. An image of this type of failure with three radial cracks at concrete surface is shown in Figure 3.67b.

Concrete Splitting and Pullout with Head Broken (CS-POHB) Failure: This failure mode took place only in GFRP head-end bars with both 150 and 300-mm concrete cubes. However, in some cases the failure was only accompanied with pullout with head broken without the concrete side 
splitting. In the 300-mm concrete cubes with headed bars, due to higher confinement provided by surrounding concrete, the bond strength was higher than that for the $150-\mathrm{mm}$ concrete cubes. In addition, as the bar embedment length increased, the failure was only pullout with head broken without side splitting of the concrete cubes. Thus, it can be concluded that if adequate concrete cover is not provided to the GFRP headed bars, concrete splitting will occur. However, if sufficient concrete cover and confinement is provided, the failure would be followed by only pullout with head broken. It was found that if the ratio of concrete cover to bar embedment length $\left(c / L_{d}\right)$ is greater than 0.75 , the failure of headed bars will be accompanied only by pullout with head broken provided that the minimum concrete cover is 10 times the bar diameter. The ratio can be regarded as the minimum size effect for headed anchor bars. The side concrete splitting occur if the tensile strength of surrounding concrete is less than the wedging effect of headed anchor bars. A photo of the 300-mm concrete cube failed by side splitting and pullout with head broken is shown in Figure 3.67c.
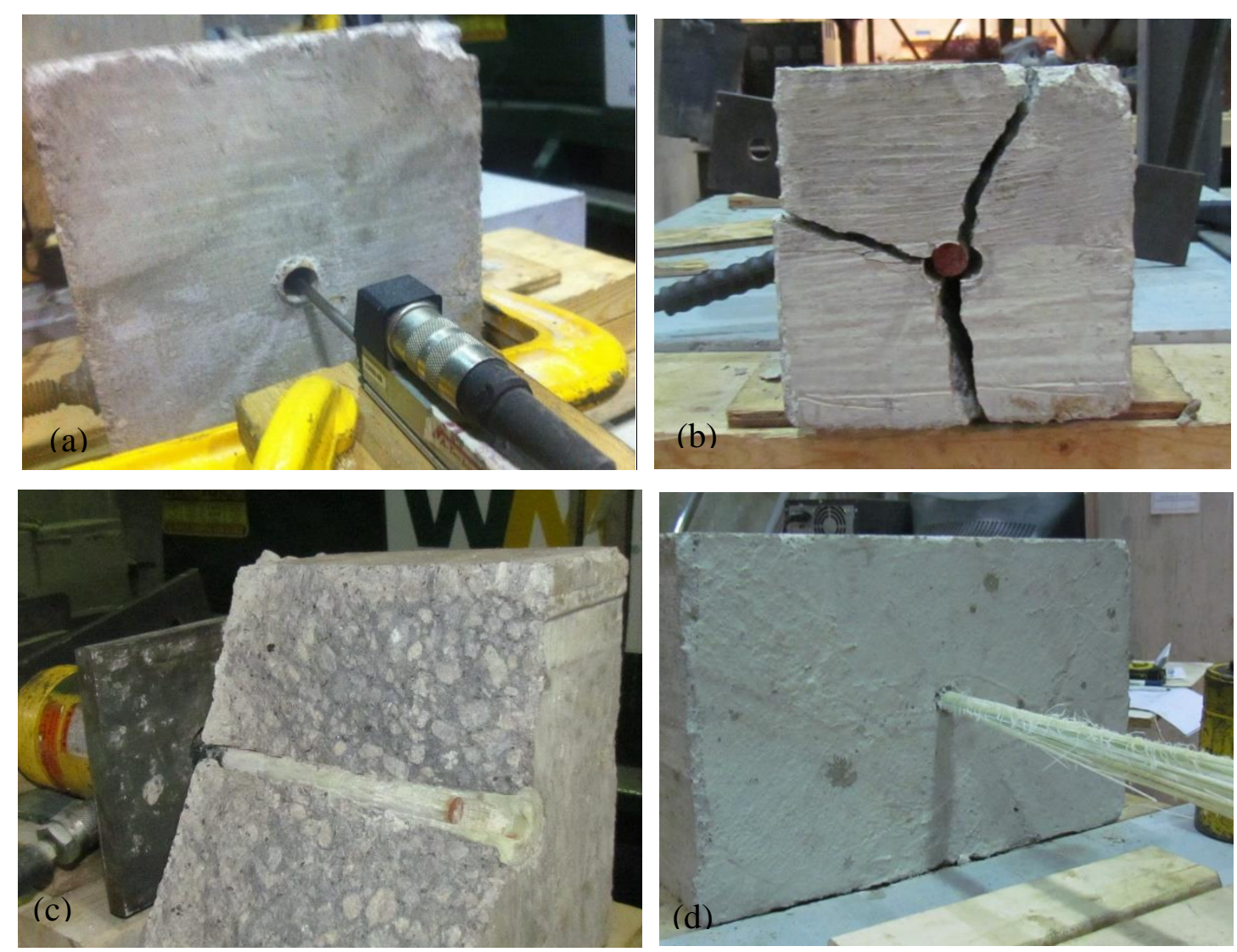

Figure 3. 67 Failure mode of tested concrete cubes; (a) pullout, (b) concrete splitting, (c) concrete splitting followed by bar pulled out from broken head and (d) bar rupture 

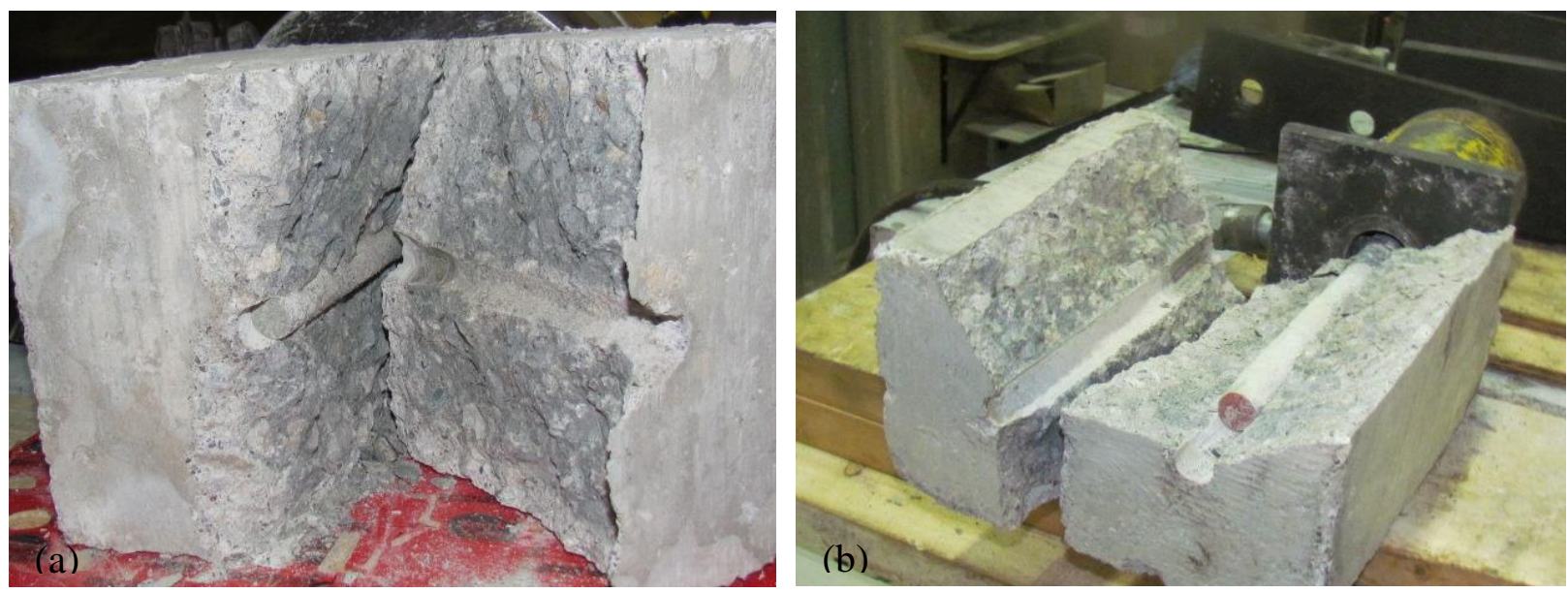

Figure 3. 68 Pullout failure modes with; (a) failure at bar concrete interface, and (b) failure at bar-core interface by shearing off the surface texture

Rebar Rupture Failure: Similar to the case in concrete slab models, this failure occurred only in GFRP hook bars with embedment length mainly greater than 200-mm. For bars with 150-mm embedment length, concrete splitting failure occurred prior to bar rupture. This was dissimilar to the case in concrete slab models since the GFRP bars did not reach their ultimate tensile strength at bent portion. And, due to insufficient confinement provided by the surrounding concrete, the concrete splitting to the shortest edge distance occurred. However, in concrete slab models, the edge distance was sufficient to provide adequate confinement. Therefore, as the embedment length increased in concrete cube specimens, the failure was accompanied with bar rupture due to the fact that bar stresses reached the tensile strength of the bent portion. Figure 3.67d illustrates view of such failure mode showing rupturing of the fibers after the failure.

\subsubsection{Bond Slip Relationship}

The average bond stress-slip relationship for GFRP bars in concrete cube specimens were investigated at both free-end and loaded-end locations. The loaded-end slip was measured by one potentiometer (POT) attached to the bearing plates at loaded-end region. The elongation of the bar between the bearing plates and the concrete surface was subtracted from the measured slip. At free-end, one POT was attached to the GFRP bars where the bar was projected out from bottom surface. The following sections briefly explain the bond-slip behavior at loaded-end and free- end locations. 
Bond Stress - Loaded End Relationship: Similar to pullout tests in concrete slab models, the bond stress versus loaded-end relationships depend on the bar-end geometry and types of failure modes. For GFRP bars with straight-end: if the failure is followed by pullout of bars in concrete, the post-peak phase showed smooth decaying branch after the peak bond stress until the friction between the bar and concrete is removed, following by some residual stresses due to increase in the slip. However, if the failure is concrete side splitting, the post-peak phase showed a sudden and brittle loss of stress after the peak bond stress. Figure 3.69a shows the average bond stressloaded end relationship for M15 (\#5) bars in 200-mm concrete cubes with variable embedment lengths. It should be noted the bond stress-loaded end relationship for 100-mm embedment length shown in the Figure 3.69a was followed by concrete side splitting, while other graphs show pullout failure mode. In GFRP bars with headed-end, a sudden decaying branch was also observed if the failure was accompanied by concrete side splitting (Figure 3.69b with 100-mm embedment length). However, for the case where pullout occurred from broken head, the decaying branch showed smoother loss of stress with residual stresses at $10 \%-15 \%$ of the peak bond stress. Figure 3.69b shows graphs of average bond stress versus loaded-end slip for 300mm concrete cubes for M15 (\#5) bars. In GFRP hook bars, a brittle post-peak behavior was observed whether the failure occurred by splitting or bar rupture. In these bars, sudden loss of bond stress was noticed in which the stress decreased linearly to nearly zero value.

In addition, similar to concrete slab models, the peak bond stresses decreased once the embedment lengths of the bars increased from 100 to $250-\mathrm{mm}$. Also, it was observed that the bar loaded-end slip increased proportional to the increase in the embedment lengths of bars in the concrete. 


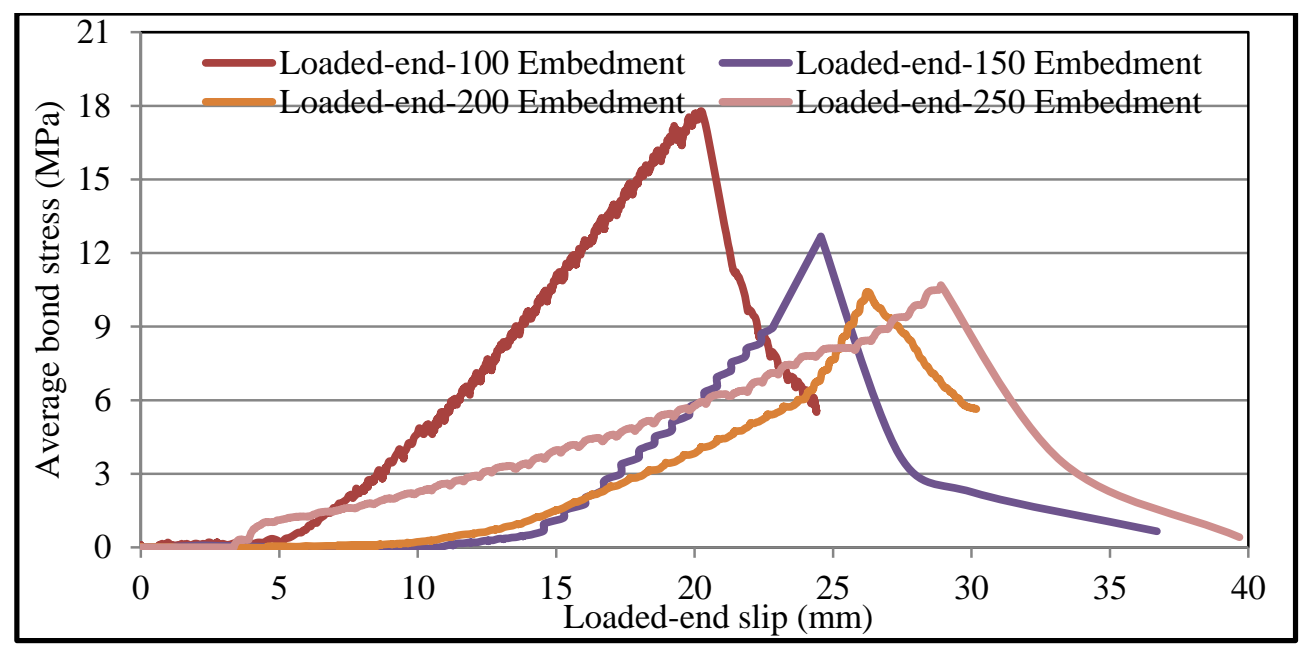

(a) Straight-end bars

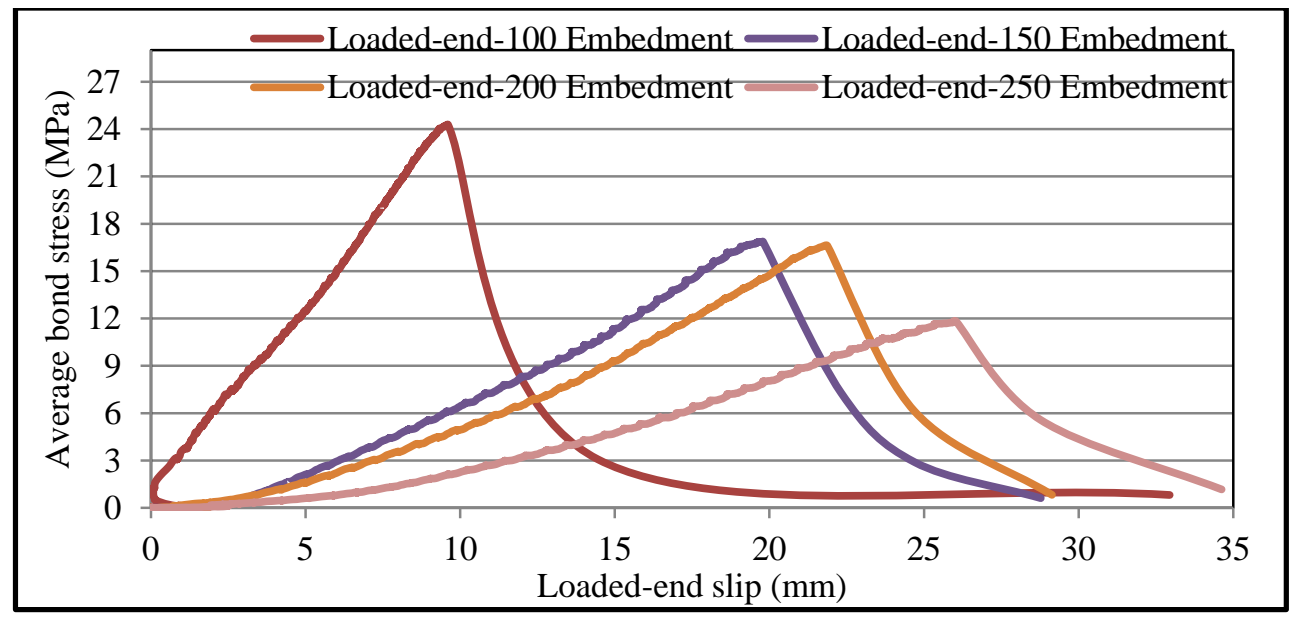

(b) Headed-end bars

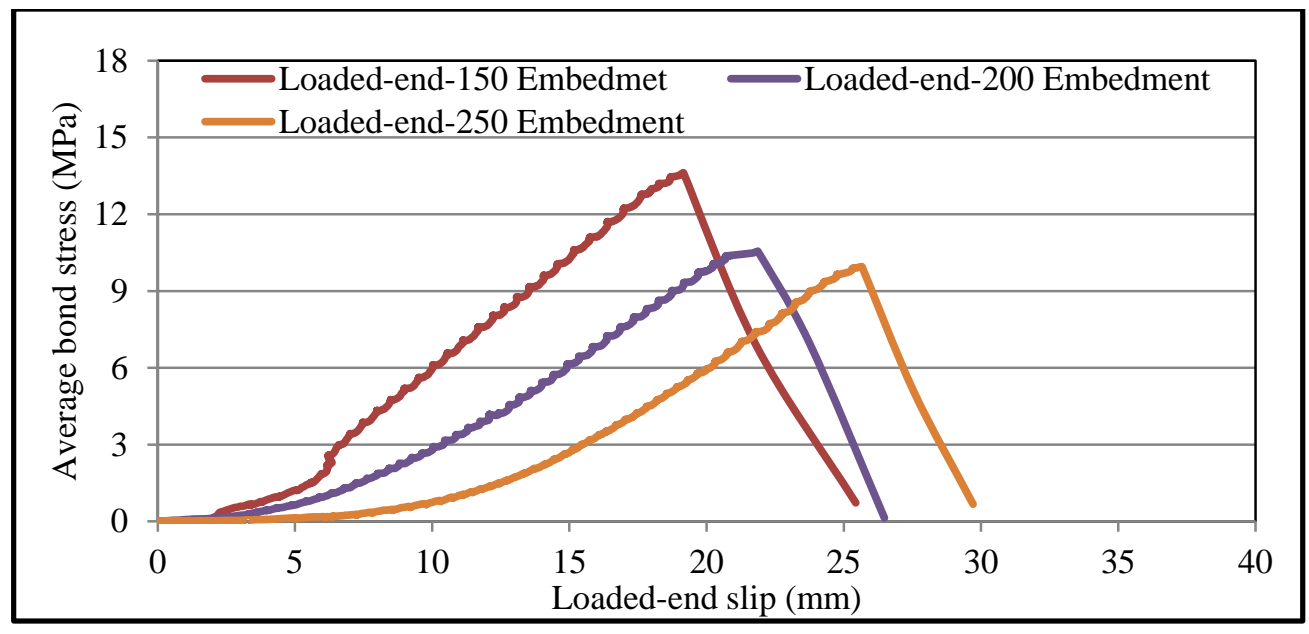

(c) Hook bars

Figure 3. 69 Average bond stress-loaded end slip relationships with bars with different embedment lengths 
Bond Stress-Free End Relationship: The bond stress-slip relationship at free-end locations confirmed to the modified BPE model stated in chapter 2, which is also typically shown in Figure 3.70. The experimental test results showed that at free-end location the bars experienced a very small slip value oscillating between 0 and $0.01-\mathrm{mm}$. However, if failure of the bars followed by pullout, the bars began to slip at a bond stress equal to $70 \%-80 \%$ of the peak bond stress. Thus, the pre-peak behavior composed of two phases. The first phase showed bond stiffness of nearly infinity due to the small slip values. In this stage, it was assumed that all three bond mechanism (adhesion, mechanical interlock and friction) are intact. The second phase in pre-peak response corresponds to the free-end slippage as the bar starts to pull out from concrete. In this stage, the adhesion resistance was assumed to be damaged and mechanical interlock between the bar and the concrete begins to deteriorate. As the free-end slip continued to increase, the bond stiffness started to reduce that is shown by the smoothened ascending branch in Figure 3.70. However, after the peak bond stress, the post-peak behavior showed a linear decrease in the bond stress due to frictional resistance between the bar and the concrete until it reaches some value of residual stress. In case the failure was accompanied with concrete side splitting, the post-peak response showed a sudden decrease in the bond stress to nearly zero stress. Figure 3.71 shows typical examples of bond stress versus free-end slip relationship for M15 (\#5) GFRP for each of straight-end, headed-end and hook bars in the concrete cube specimens.

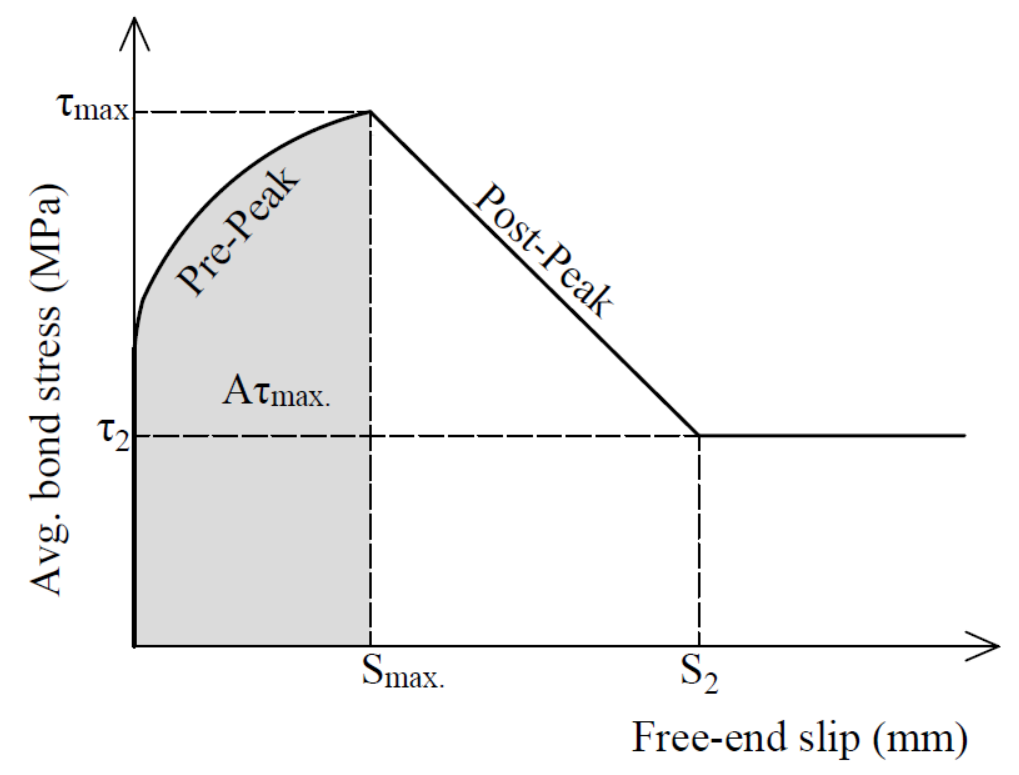

Figure 3. 70 Typical average bond stress-free end relationship of GFRP bars in concrete 


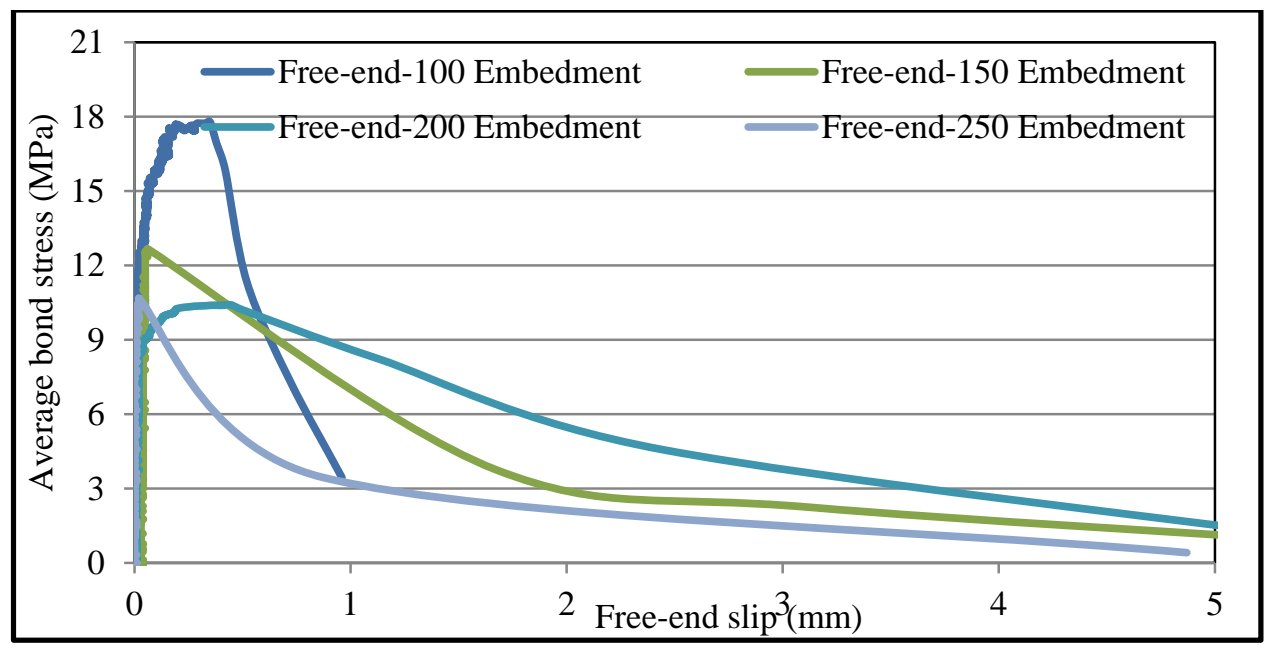

(a) Straight-end bars

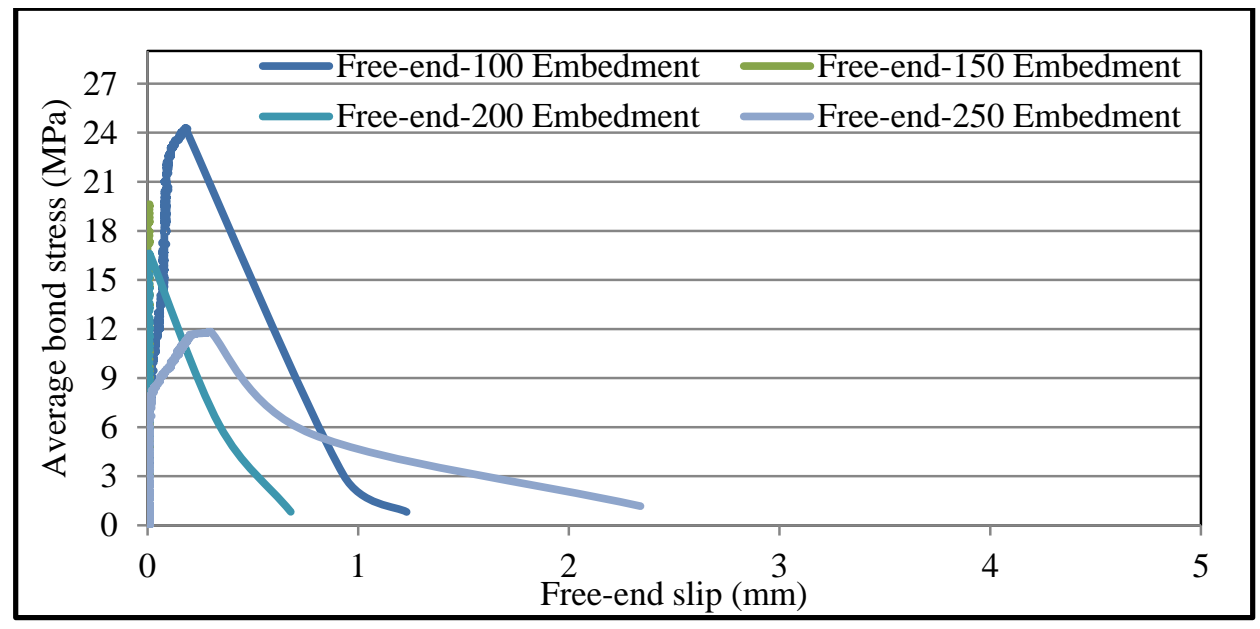

(b) Headed-end bars

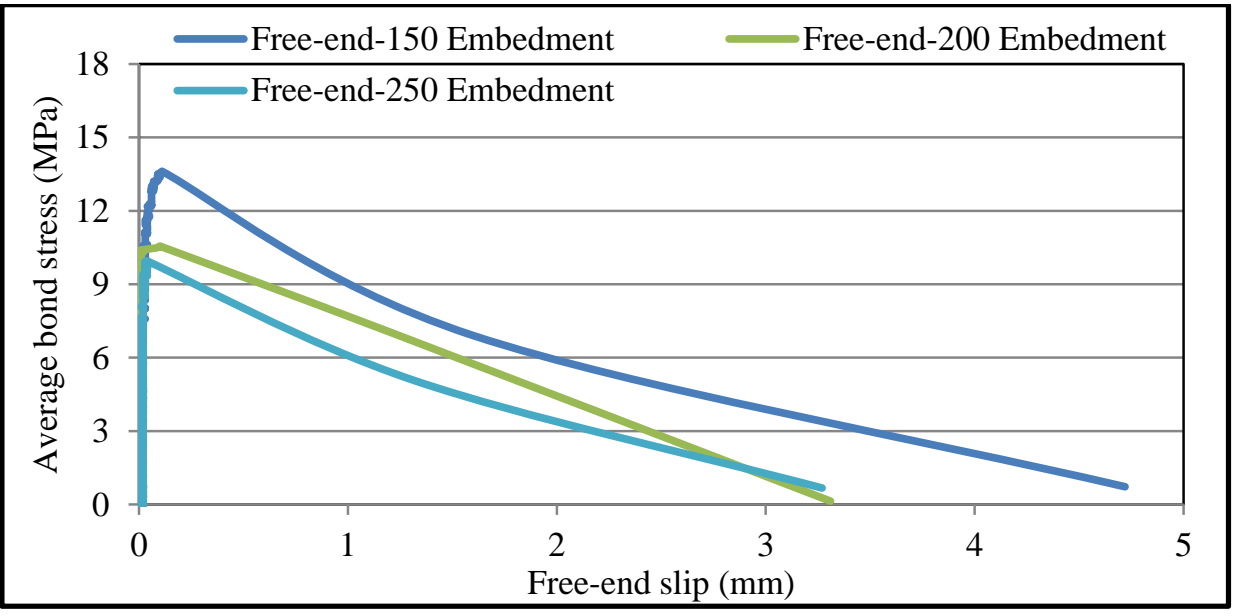

(c) Hook bars

Figure 3. 71 Average bond stress vs. free-end slip relationships with bars of different embedment lengths 


\subsection{Analytical Investigation of Bond - Slip Relationship}

Bond between concrete and GFRP reinforcement can be described by means of constitutive relationships such as $\tau$-s relationship which is available for steel reinforcement. However, due to non-linearity and larger deformation associated with GFRP bars under tensile load, an extensive research effort is still required to represent analytical modelling of bond-slip constitutive law for GFRP bars. Although, there have been few formulations for FRP bars that intended to establish a general law, the validation has to be investigated by comparison with experimental results by means of determining its parameters such as curve fitting. Thus, no specific formulations for different types of bars have been developed so far (Cosenza et al. 1997). Experimental test programs on pullout and beam specimens have been carried out to evaluate the constitutive laws. Consenza et al. (1997) performed experimental tests by means of pullout and beam tests on specimens with embedment lengths of five times the bar diameter or less and proposed the modified BPE model stated in chapter 2. In the constitutive models, it was assumed a constant stress distribution along the embedded length of the bar, while slip was measured at free-end location. In FRP reinforcing bars, due to lower modulus of elasticity, the bars experience higher deformation. As such the slip at loaded-end is significantly different from that at the free-end. Therefore, the assumption of uniform stress distribution along embedded length is not valid. The experimental test performed on very short embedment lengths ( 2 - 3 times the bar diameter) showed more uniform stress distribution. However, shorter embedment length amplifies the local irregularities causing variations in the test results. So, more experimental testing may be required. On the other hand, the experimental tests performed on longer embedment lengths (5 times the bar diameter and more) showed less local irregularities and test results variations but the stress distributions along the embedded length were rather non-uniform.

The bond stress versus slip at free-end location is utilized to investigate the bond stress-slip constitutive models. The experimental pullout tests on concrete cube specimens showed that the bond stress-free end slip are composed of two branches, namely: (i), the ascending branch for the slip between zero to the slip corresponding to peak bond stress $\left(0 \leq \mathrm{s} \leq \mathrm{S}_{\max }\right.$ ), and (ii), the descending branch for the slip between slip at peak bond stress and slip corresponding to the residual stress $\left(\mathrm{S}_{\max } \leq \mathrm{s} \leq \mathrm{S}_{2}\right.$ ). The modified BPE (mBPE) model was used to represent the bond-slip relationship for the ascending branch provided that: 
$\tau=\tau_{\max } \cdot\left(\frac{S}{S_{\max }}\right)^{\alpha}$

for $0 \leq \mathrm{S} \leq \mathrm{S}_{\max }$

Where $\tau_{\max }$ and $S_{\max }$ are the maximum bond stress and corresponding free-end slip obtained from experimental test results, $\alpha$ is a curve fitting parameter that can be calibrated from experimental tests using the least square method. Alternatively, it can be estimated by equating the area under the ascending branch of bond stress-free end slip obtained from experimental test results and the constitutive model provided that (see Figure 3.70):

$\mathrm{A}_{\tau \max }=\int_{0}^{S \max } \tau_{\max }\left(\frac{S}{S_{\max }}\right)^{\alpha} \mathrm{ds}=\frac{\tau_{\max S_{\max }}}{1+\alpha}$

Where $\mathrm{A} \tau_{\max }$ is the area under the bond stress-free end slip obtained from experimental test results. Thus, the curve fitting parameter, $\alpha$, can be determined as a function of peak bond stress and slip as well as the area under the experimental test results, $\mathrm{A} \tau_{\max }$, using the following equation (Cosenza et al. 1997):

$\alpha=\frac{\tau_{\max } S_{\max }}{A_{\tau_{\max }}}-1$

In the current study, the curve fitting parameter, $\alpha$, calibrated using the least square method by comparing the analytical model with experimental test results. In addition, the ascending branch of experimental test results were compared with the bond-slip constitutive law proposed by Cosenza et al. (1995) known as CMR model as follow:

$\frac{\tau}{\tau_{\max }}=\left(1-\mathrm{e}^{\mathrm{S} / \mathrm{Sr}}\right)^{\beta}$

Where $\tau_{\text {max }}$ is the peak bond stress, and $S_{\mathrm{r}}$ and $\beta$ are to be determined based on the curve fitting of experimental test data. Table 3.7 provides summary of the bond parameters $\left(\tau_{\max }, S_{\max }, \alpha, S_{r}\right.$ and $\beta$ ) obtained from experimental data and the curve fitting parameters. 
Table 3. 7 Summary of mBPE and CMR bond parameters

\begin{tabular}{|c|c|c|c|c|c|}
\hline & \multirow{2}{*}{$\tau_{\max }(\mathrm{MPa})$} & \multirow{2}{*}{$\mathrm{S}_{\mathrm{m}, \mathrm{fe}}(\mathrm{mm})$} & mBPE Model & \multicolumn{2}{|c|}{ CMR Model } \\
\cline { 4 - 6 } & & & $\alpha$ & $\mathrm{S}_{\mathrm{r}}$ & $\beta$ \\
\hline G5/ C200- 100EM & 14.97 & 0.49 & 0.277 & -0.093 & 0.212 \\
\hline G6/ C200- 100EM & 12.66 & 0.07 & 0.087 & -0.012 & 0.39 \\
\hline G5/ C200- 150EM & 13.19 & 0.10 & 0.229 & -0.066 & 0.282 \\
\hline G6/ C200- 150EM & 12.23 & 0.07 & 0.134 & -0.031 & 0.157 \\
\hline G5/ C200- 200EM & 14.91 & 0.11 & 0.338 & -0.032 & 0.63 \\
\hline G6/ C200- 200EM & 11.09 & 0.29 & 0.091 & -0.09 & 0.485 \\
\hline G5/ C200- 250EM & 8.97 & 0.18 & 0.108 & -0.095 & 0.48 \\
\hline G6/ C200- 250EM & 10.33 & 0.18 & 0.164 & -0.055 & 0.274 \\
\hline
\end{tabular}

From experimental tests conducted on GFRP concrete cubes, curve-fitting parameters of mBPE and CMR models were determined and summarized in Table 3.7. The parameters presented herein are only for test specimens failed by pullout in 200-mm concrete cubes. The parameter were determined for M15 (\#5) and M19 (\#6) bars. To construct ascending branch of mBPE and CMR models, bond stress versus free-end slip determined from experimental test results was considered. Figure 3.72 compares experimental test results with analytical models showing good correlations between them. It can be understood from the graphs that both analytical models well represent the bond stress-slip constitutive law compared to the experimental test data. It is also possible to observed that both CMR and $\mathrm{mBPE}$ models provided an initial slope at very small slip (i.e. $s=0$ ) equal to infinity so that the adhesion phenomena between concrete and the bar could be reproduced quite well. In some of the experimental test results, there existed relatively small debonding of bar from concrete at slip range between 0.01 and $0.03 \mathrm{~mm}$ which was considered quite small slip. When comparing the two bond stress-slip constitutive models, the mBPE model was quite in more agreement with the experimental test results than the other model. This can be understood from the initial bond stiffness of mBPE model representing the adhesion and mechanical interlock between concrete and the bar before the bar slippage begins. The current study gives an average curve fitting parameters of $0.18,-0.06$ and 0.364 for $\alpha, S_{\mathrm{r}}$ and $\beta$, respectively, for GFRP bars with sand-coated surface profile. 

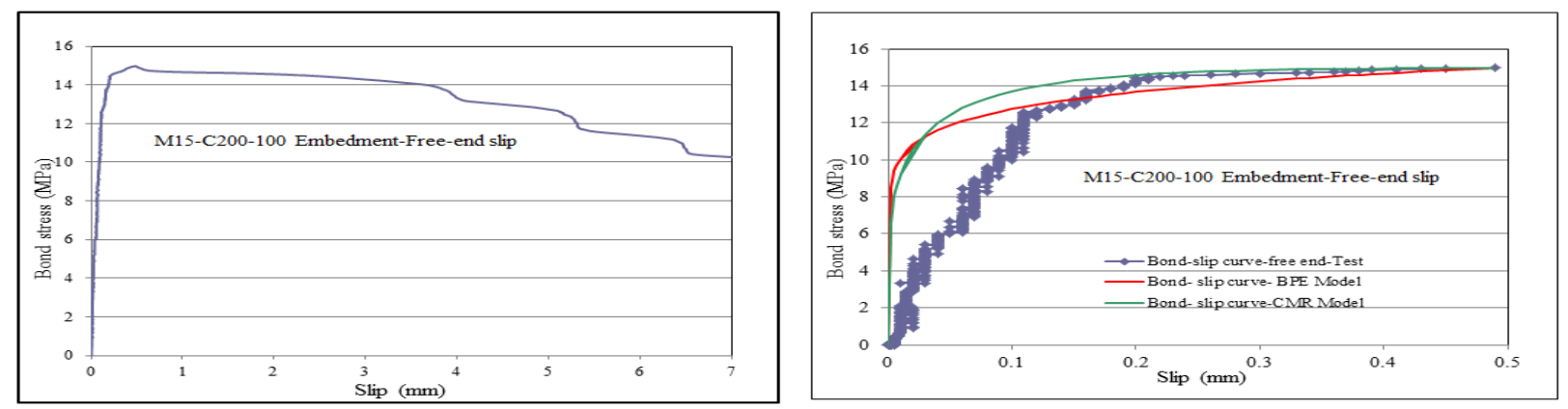

(a) M15-200x200x100-free-end slip
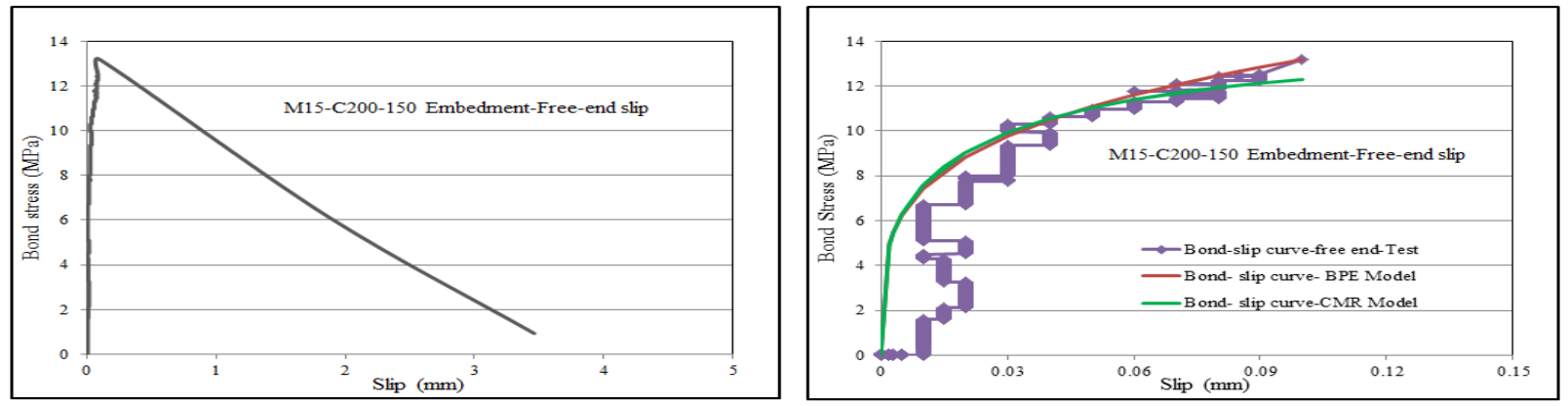

(b) M15-200x200x150-free-end slip
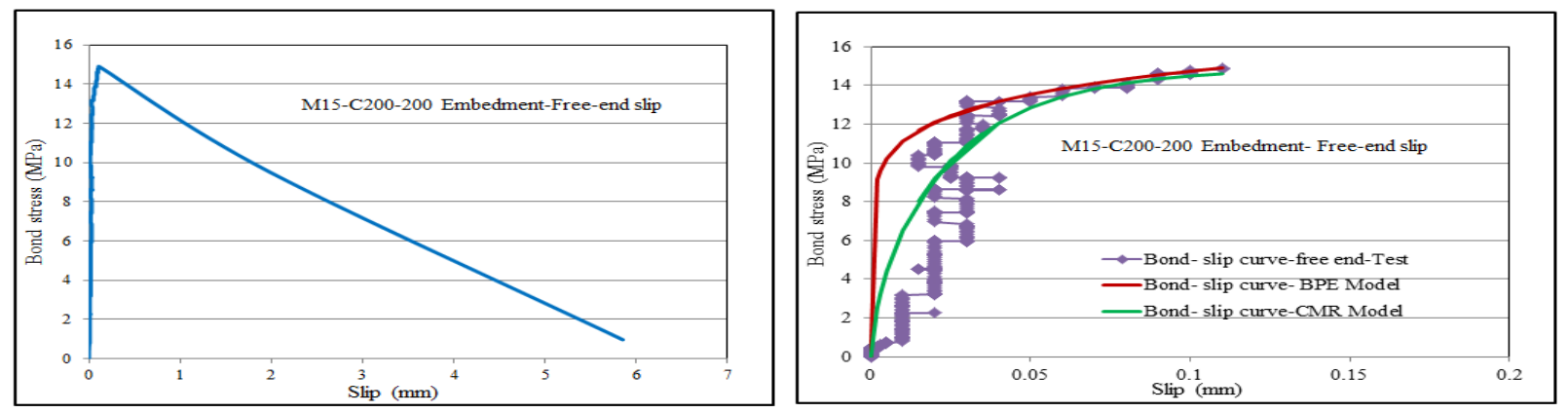

(c) M15-200x200x200-free-end slip
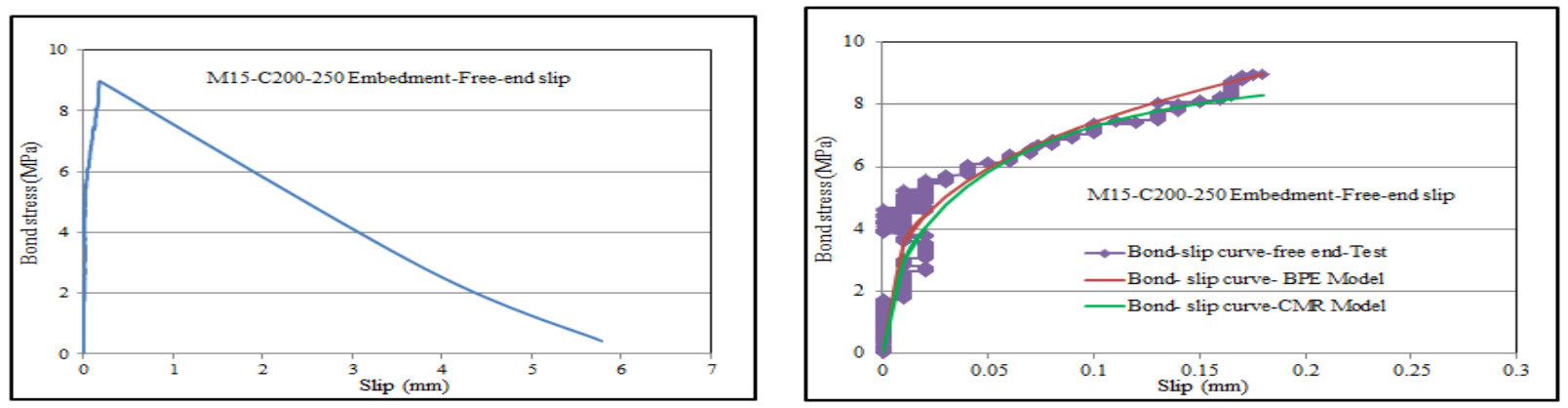

(d) M15-200x200x250-free-end slip 

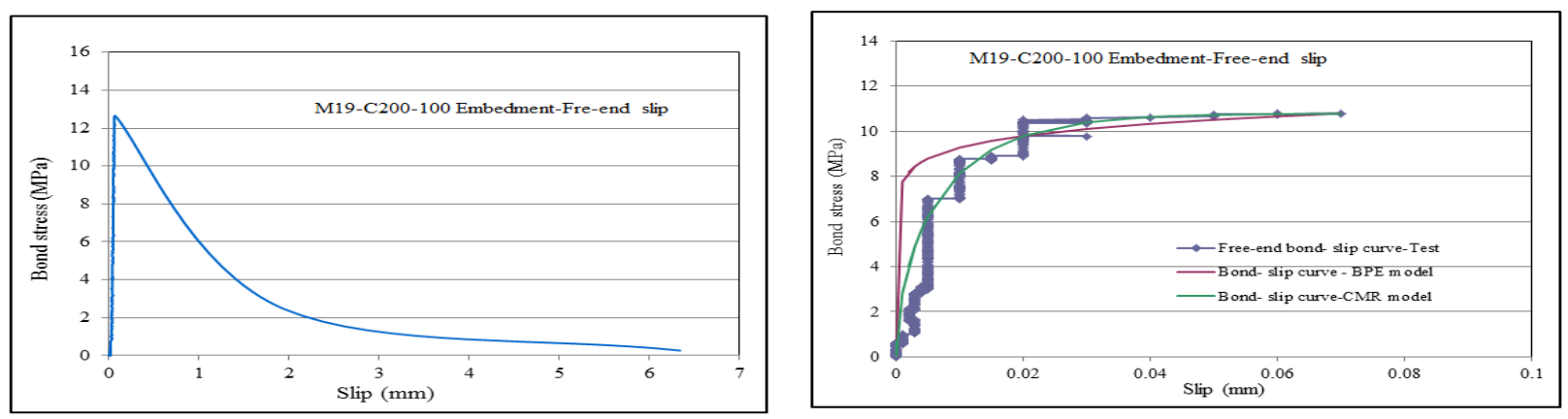

(e) M19-200x200x100-free-end slip
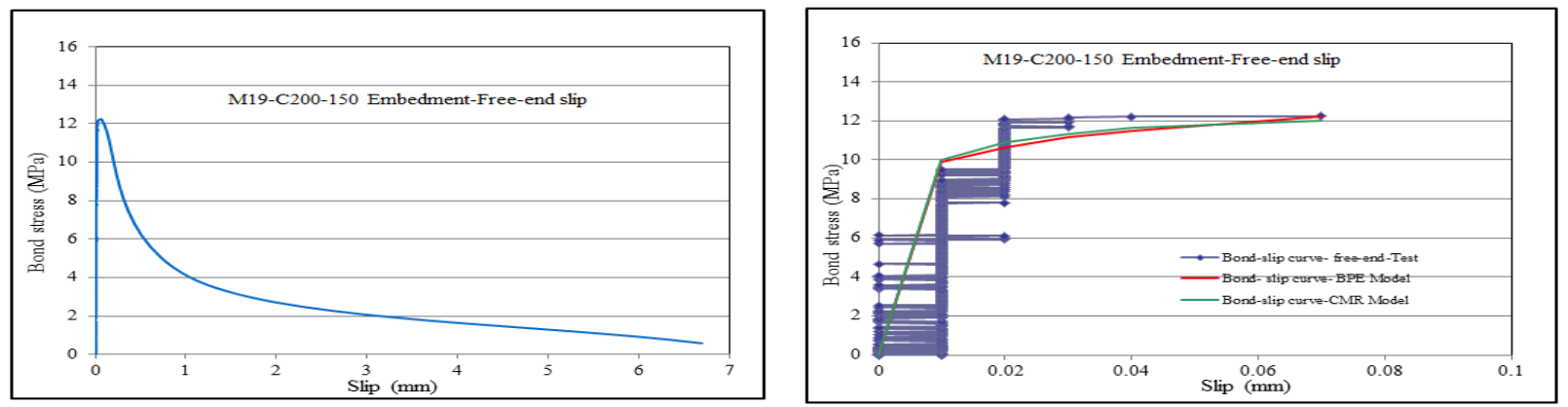

(f) M19-200x200x150-free-end slip
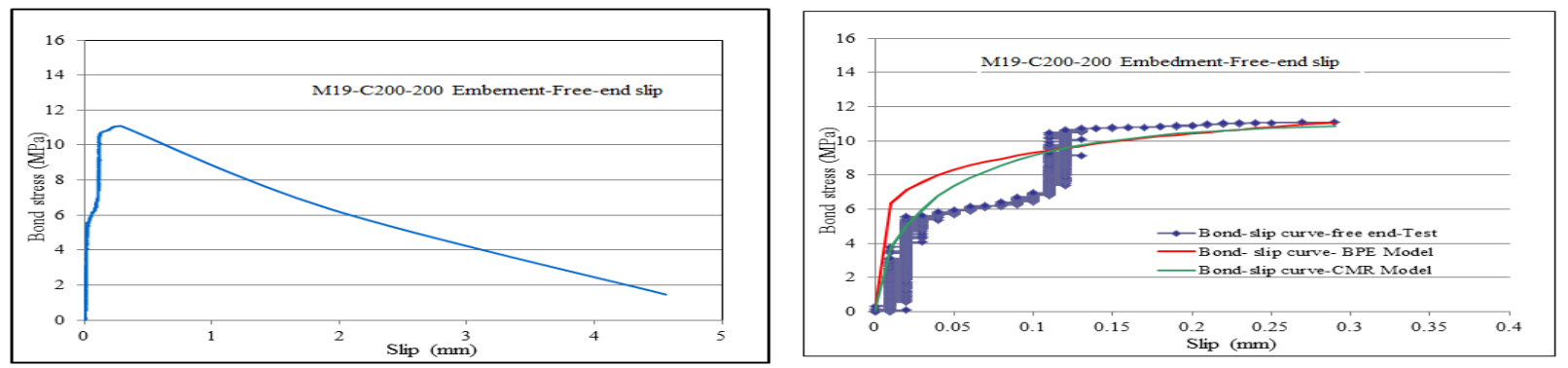

(g) M19-200x200x200-free-end slip
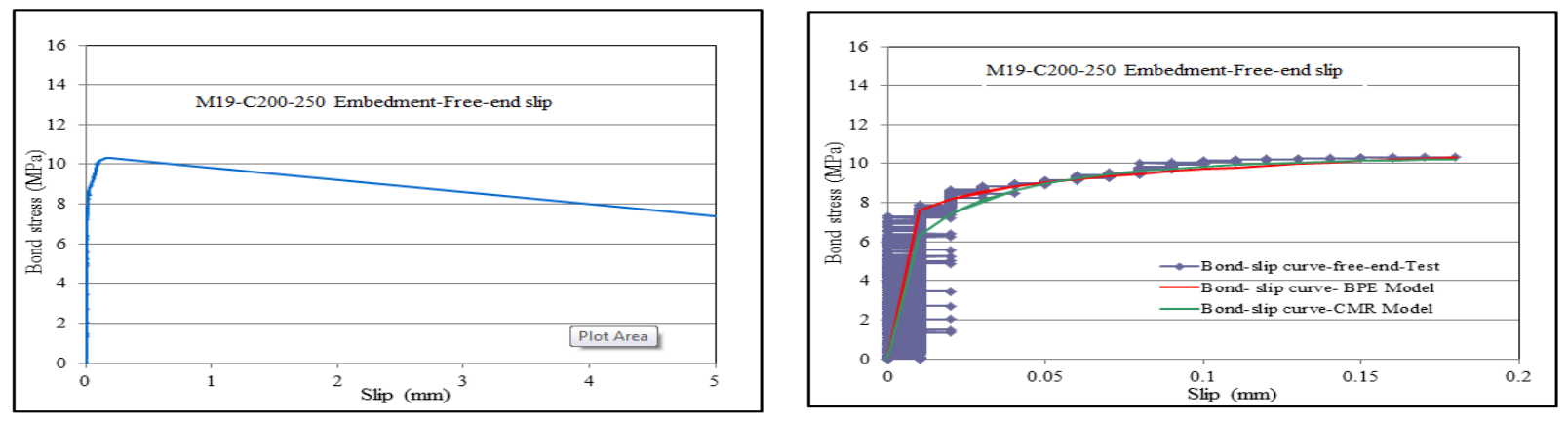

(h) M19-200x200x250-free-end slip

Figure 3. 72 Comparison of experimental and analytical bond stress-slip relationship 


\subsection{Basic Development Length of GFRP Bars in Concrete}

Development length for GFRP bars with straight-end, headed-end and hook bars were determined based on experimental tests conducted on the pullout specimens in the concrete slab models and concrete cubes. The development length for straight end bars was determined according to specimens failed by pullout. The development length for the headed-end and hook bars were determined based on the specimens failed by pullout with head broken and bar rupture failures modes, respectively. During experimental tests, the applied loads and corresponding slips at loaded- and free-ends were measured at each monotonic static load level. The transfer of stress between GFRP bars and concrete is characterized by bond strength between them. Under the assumption of constant bond stress along the length $\mathrm{L}_{\mathrm{db}}$ embedded in concrete and subjected to a pullout force, the following equilibrium equation may be derived:

$\pi \cdot \mathrm{d}_{\mathrm{b}} \cdot \mathrm{L}_{\mathrm{db}} \cdot \tau=\mathrm{A}_{\mathrm{b}} \cdot \mathrm{F}_{\mathrm{f}}$

From Eq. 3.6, the basic development length follows:

$\mathrm{L}_{\mathrm{db}}=\left(\mathrm{A}_{\mathrm{b}} \cdot \mathrm{F}_{\mathrm{f}}\right) /\left(\pi \cdot \mathrm{d}_{\mathrm{b}} \cdot \tau\right)=\left(\mathrm{d}_{\mathrm{b}} \cdot \mathrm{F}_{\mathrm{f}}\right) / 4 \tau$

Where $d_{b}$ is the bar diameter in $\mathrm{mm}, \mathrm{F}_{\mathrm{f}}$ is the ultimate tensile strength of bars in $\mathrm{MPa}$, and $\mathrm{L}_{\mathrm{db}}$ is the basic development length of the GFRP bars. For GFRP bars, it was found that the average bond strength, $\tau$, is a linear function of the square root of the concrete compressive strength and bar diameter provided that:

$\tau=\left(\mathrm{C}_{1} \cdot \sqrt{ } \mathrm{f}_{\mathrm{c}}^{\prime}\right) / \mathrm{d}_{\mathrm{b}}$

Where, $\mathrm{C}_{1}$ is a constant parameter. Therefore, Eq. 3.7 can be rearranged as follow:

$\mathrm{L}_{\mathrm{db}}=\left(\mathrm{A}_{\mathrm{b}} \cdot \mathrm{F}_{\mathrm{f}}\right) /\left(\pi \cdot \mathrm{C}_{1} \cdot \sqrt{\mathrm{f}}_{\mathrm{c}}^{\prime}\right)=\left(\mathrm{d}_{\mathrm{b}}^{2} \cdot \mathrm{F}_{\mathrm{f}}\right) /\left(4 \cdot \mathrm{C}_{1} \cdot{\sqrt{\mathrm{f}^{\prime}}}_{\mathrm{c}}\right)$

So that a second constant $\mathrm{C}_{2}$ could be set in any of the following forms: 
$\mathrm{C}_{2-1}=1 /\left(\pi \cdot \mathrm{C}_{1}\right)$

$\mathrm{C}_{2-2}=\mathrm{d}_{\mathrm{b}} /\left(4 \cdot \mathrm{C}_{1}\right)$

$\mathrm{C}_{2-3}=\mathrm{d}_{\mathrm{b}} /\left(4 \cdot \mathrm{C}_{1} \cdot V_{\mathrm{f}_{\mathrm{c}}^{\prime}}\right)$

Where $\mathrm{C}_{2}$ is the bond factor reflecting the effect of bar diameter and concrete compressive strength. Thus, Eq. 3.9 can be written as:

$\left.L_{d b}=\left(C_{2-1} \cdot A_{b} \cdot F_{f}\right) / \sqrt{ } f_{c}^{\prime}\right)=\left(C_{2-2} \cdot d_{b} \cdot F_{f}\right) /\left(\sqrt{ } f_{c}^{\prime}\right)=\left(C_{2-3} \cdot d_{b} \cdot F_{f}\right)$

From Eqs. 3.7 and 3.13, the bond factor, $\mathrm{C}_{2}$, can be determined as follows:

$\mathrm{C}_{2-1}=\left(\sqrt{ } \mathrm{f}_{\mathrm{c}}^{\prime}\right) /\left(\pi \cdot \mathrm{d}_{\mathrm{b}} \cdot \tau\right)$

$\mathrm{C}_{2-2}=\left(\sqrt{\mathrm{f}_{\mathrm{c}}^{\prime}}\right) /(4 \tau)$

$\mathrm{C}_{2-3}=1 /(4 \tau)$

Where $\tau$ is the average peak bond stress calculated from experimental tests and reported in Tables A.1 to A.3 in Appendix A. From experimental test results, the bond factors, $\mathrm{C}_{2-1}, \mathrm{C}_{2-2}, \mathrm{C}_{2-}$ 3, were calculated for each GFRP bars and reported in Table 3.8. It should be noted that Table 3.8 provides the bond factors obtained from the experimental test conducted on concrete cube specimens with concrete compressive strength of $34.9 \mathrm{MPa}$. The measured basic development length for each set of concrete cubes was also determined using Eq. 3.13 and provided in Table 3.8. According to the calculated values, the bond factor parameters should be selected in such a way that the resulting equation yields a conservative value of basic development length. As such, the bond factors, $\mathrm{C}_{2}$, used in Eq. 3.13 were modified for each of the GFRP end anchorage system and reported in Table 3.9. 
Table 3. 8 Bond factor parameter, $\mathrm{C}_{2}$, and measured development length of GFRP bars

\begin{tabular}{|c|c|c|c|c|c|c|c|}
\hline \multirow{2}{*}{$\begin{array}{l}\text { Specimen } \\
\text { notation }\end{array}$} & \multirow{2}{*}{$\begin{array}{c}\mathrm{L}_{\mathrm{d}} \\
(\mathrm{mm})\end{array}$} & \multicolumn{3}{|c|}{$\mathrm{C}_{2}$} & \multirow{2}{*}{$\begin{array}{l}\mathrm{P}_{\max } \\
(\mathrm{kN})\end{array}$} & \multirow{2}{*}{$\begin{array}{c}\text { Stress in the } \\
\text { bars at Failure } \\
(\mathrm{MPa})\end{array}$} & \multirow{2}{*}{$\begin{array}{l}\mathrm{L}_{\mathrm{db}}(\mathrm{mm}) \\
\text { Eq. } 3.13\end{array}$} \\
\hline & & $\mathrm{C}_{2-1}$ & $\mathrm{C}_{2-2}$ & $\mathrm{C}_{2-3}$ & & & \\
\hline \multirow{4}{*}{ G5-C150-S ${ }^{\mathrm{a}}$} & 100 & 0.010 & 0.134 & 0.023 & 55.9 & 282.2 & 426.5 \\
\hline & 150 & 0.011 & 0.140 & 0.024 & 80.43 & 406.11 & 445.6 \\
\hline & 200 & 0.0136 & 0.173 & 0.029 & 91.51 & 462.03 & 550.6 \\
\hline & 250 & 0.0131 & 0.163 & 0.028 & 113.3 & 572.21 & 518.8 \\
\hline \multirow{4}{*}{$\mathrm{G} 5-\mathrm{C} 150-\mathrm{H}^{\mathrm{a}}$} & 100 & 0.0084 & 0.11 & 0.018 & 70.85 & 357.7 & 350.1 \\
\hline & 150 & 0.0093 & 0.116 & 0.021 & 96.03 & 484.9 & 369.2 \\
\hline & 200 & 0.011 & 0.131 & 0.022 & 115.4 & 582.7 & 416.93 \\
\hline & 250 & 0.0119 & 0.149 & 0.025 & 124.73 & 629.7 & 474.2 \\
\hline \multirow{4}{*}{ G6-C150-S ${ }^{\mathrm{a}}$} & 100 & 0.0095 & 0.142 & 0.024 & 62.7 & 220.1 & 505.98 \\
\hline & 150 & 0.0099 & 0.148 & 0.025 & 90.04 & 315.91 & 527.36 \\
\hline & 200 & 0.0104 & 0.156 & 0.026 & 114.94 & 403.81 & 555.86 \\
\hline & 250 & 0.0120 & 0.181 & 0.031 & 126.4 & 443.31 & 644.95 \\
\hline \multirow{4}{*}{$\mathrm{G} 6-\mathrm{C} 150-\mathrm{H}^{\mathrm{a}}$} & 100 & 0.0082 & 0.123 & 0.021 & 72.14 & 253.1 & 456.13 \\
\hline & 150 & 0.0095 & 0.142 & 0.024 & 96.11 & 337.2 & 526.6 \\
\hline & 200 & 0.011 & 0.159 & 0.027 & 112.4 & 394.4 & 589.6 \\
\hline & 250 & 0.012 & 0.163 & 0.029 & 128.66 & 451.4 & 604.5 \\
\hline \multirow{3}{*}{$\mathrm{G} 5-\mathrm{C} 150-\mathrm{HO}^{\mathrm{a}}$} & 150 & 0.0096 & 0.12 & 0.018 & 105.01 & 530.2 & 381.9 \\
\hline & 200 & 0.0117 & 0.131 & 0.021 & 122.54 & 618.7 & 416.93 \\
\hline & 250 & 0.0123 & 0.147 & 0.0253 & 144.5 & 729.8 & 467.85 \\
\hline \multirow{3}{*}{$\mathrm{G} 6-\mathrm{C} 150-\mathrm{HO}^{\mathrm{a}}$} & 150 & 0.0083 & 0.114 & 0.021 & 119.63 & 419.73 & 406.21 \\
\hline & 200 & 0.0098 & 0.126 & 0.231 & 140.95 & 494.5 & 448.97 \\
\hline & 250 & 0.0112 & 0.137 & 0.223 & 164.95 & 578.9 & 488.16 \\
\hline
\end{tabular}

The $\mathrm{C}_{2}$ coefficients ensure that all calculated basic development length from Eq. 3.13 is greater than the measured ones. To validate the modified bond factors, $\mathrm{C}_{2}$, of the Table 3.9, linear regression analysis of the test data was also conducted for $\mathrm{C}_{2-2}$ values and shown in Figure 3.73. The linear regression analysis showed good correlation with the modified $\mathrm{C}_{2-2}$ values.

Table 3. 9 Modified bond factors used in Eq. 3.13

\begin{tabular}{|c|c|c|c|}
\hline \multirow{2}{*}{ Bar end anchorage } & \multicolumn{3}{|c|}{$\mathrm{C}_{2}$} \\
\cline { 2 - 4 } & $\mathrm{C}_{2-1}$ & $\mathrm{C}_{2-2}$ & $\mathrm{C}_{2-3}$ \\
\hline Straight & 0.014 & 0.175 & 0.03 \\
\hline Headed & 0.013 & 0.161 & 0.027 \\
\hline Hook & 0.012 & 0.145 & 0.025 \\
\hline
\end{tabular}



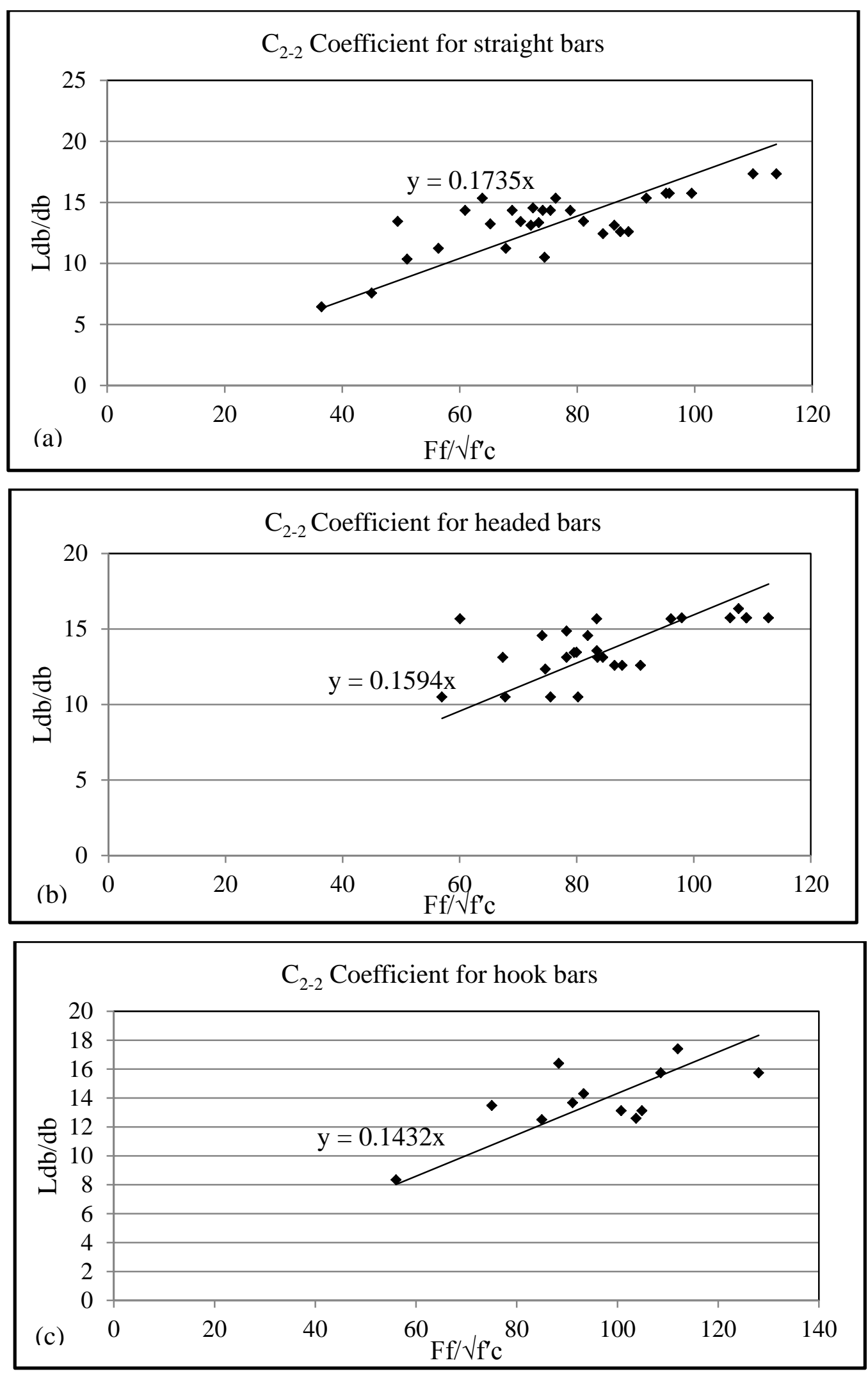

Figure 3. 73 Linear regression analysis for bond factors; (a) for straight bars, (b) for headed bars, and (c) for hook bars 
Since the basic development of Eq. 3.13 with bond factor $\mathrm{C}_{2-2}$ (Eq. 3.15) account for different GFRP bar diameters and concrete compressive strength, the following equations were adopted for basic development length of GFRP straight end, headed end and hook bars, respectively:

$\mathrm{L}_{\mathrm{db}}=\left(0.175 . \mathrm{d}_{\mathrm{b}} \cdot \mathrm{F}_{\mathrm{f}}\right) /\left(\sqrt{ } \mathrm{f}_{\mathrm{c}}^{\prime}\right) \quad$ For straight end bars

$\mathrm{L}_{\mathrm{db}}=\left(0.161 \cdot \mathrm{d}_{\mathrm{b}} \cdot \mathrm{F}_{\mathrm{f}}\right) /\left({\sqrt{\mathrm{f}_{\mathrm{c}}^{\prime}}}_{\mathrm{c}}\right) \quad$ For headed end bars

$\mathrm{L}_{\mathrm{db}}=\left(0.145 \cdot \mathrm{d}_{\mathrm{b}} \cdot \mathrm{F}_{\mathrm{f}}\right) /\left({ }^{\prime} \mathrm{f}_{\mathrm{c}}^{\prime}\right) \quad$ For hook bars

As such, from Eq.s 3.7, and 3.13 considering $\mathrm{C}_{2-1}$ values, the bond strength of GFRP bars with straight-end, headed-end and hook bars can be estimated as follows:

$\tau=\left(22.75 . \vee \mathrm{f}_{\mathrm{c}}^{\prime}\right) / \mathrm{d}_{\mathrm{b}} \quad$ For straight-end bars

(Eq. 3.20)

$\tau=\left(24.5 . \vee \mathrm{f}_{\mathrm{c}}^{\prime}\right) / \mathrm{d}_{\mathrm{b}} \quad$ For headed-end bars

$\tau=\left(26.6 . V \mathrm{f}_{\mathrm{c}}^{\prime}\right) / \mathrm{d}_{\mathrm{b}} \quad$ For hook bars

(Eq. 3.22)

The modified bond factor parameters and resulting basic development lengths were compared with bond factors and basic development lengths prescribed in CSA-S806 (2012), CSA-S6 (2006), ACI 440-1R (20060 and JSCE (1997) in which the following equations were adopted. It should be noted that in calculating the first term equations of CSA S806 (2012) and CSA-S6 (2006) below, concrete compressive strength of $34.9 \mathrm{MPa}$ for the concrete cube specimens investigated herein was considered.

$\mathrm{L}_{\mathrm{db}}=\left(0.361 \cdot \mathrm{d}_{\mathrm{b}} \cdot \mathrm{F}_{\mathrm{f}}\right) /\left({ }^{\mathrm{f}_{\mathrm{c}}^{\prime}}\right)=0.0611 \cdot \mathrm{d}_{\mathrm{b}} \cdot \mathrm{F}_{\mathrm{f}} \quad(\mathrm{CSA}-\mathrm{S} 806-12)-$ straight end bars

(Eq. 3.23a)

$\mathrm{L}_{\mathrm{dh}}=\left(165 \mathrm{~K}_{2} \mathrm{~d}_{\mathrm{b}}\right) /\left(\sqrt{ } \mathrm{f}_{\mathrm{c}}^{\prime}\right) \quad$ for $\mathrm{F}_{\mathrm{f}} \leq 520 \mathrm{MPa} \quad$ (CSA-S806-12) - hook bars (Eq. 3.23b)

$\mathrm{L}_{\mathrm{dh}}=\left(\mathrm{F}_{\mathrm{f}} \cdot \mathrm{K}_{2} \mathrm{~d}_{\mathrm{b}}\right) /\left(3.1 \mathrm{~V}_{\mathrm{c}}^{\prime}\right)$ for $520<\mathrm{F}_{\mathrm{f}}<1040 \mathrm{MPa}(\mathrm{CSA}-\mathrm{S} 806-12)-$ hook bars $\quad$ (Eq. 3.23c) 
$\mathrm{L}_{\mathrm{dh}}=\left(330 \mathrm{~K}_{2} \mathrm{~d}_{\mathrm{b}}\right) /\left({ }^{\prime} \mathrm{f}_{\mathrm{c}}^{\prime}\right) \quad$ for $\mathrm{F}_{\mathrm{f}} \geq 1040 \mathrm{MPa} \quad(\mathrm{CSA}-\mathrm{S} 806-12)-$ hook bars $\quad$ (Eq. 3.23d)

$\mathrm{L}_{\mathrm{db}}=\left(0.353 \cdot \mathrm{d}_{\mathrm{b}} \cdot \mathrm{F}_{\mathrm{f}}\right) /\left({ }^{\mathrm{f}_{\mathrm{c}}^{\prime}}\right)=0.05975 \cdot \mathrm{d}_{\mathrm{b}} \cdot \mathrm{F}_{\mathrm{f}} \quad(\mathrm{CSA}-\mathrm{S6} 6-06)-$ straight end bars $\quad$ (Eq. 3.24)

$\mathrm{L}_{\mathrm{db}}=0.0541 \mathrm{~d}_{\mathrm{b}}\left(\mathrm{C}_{\mathrm{E}}\right) \mathrm{F}_{\mathrm{f}}=0.038 . \mathrm{d}_{\mathrm{b}} \cdot \mathrm{F}_{\mathrm{f}}, \mathrm{C}_{\mathrm{E}}=0.7(\mathrm{ACI} 440.1 \mathrm{R}-06)-$ straight end bars (Eq. 3.25a)

$\mathrm{L}_{\mathrm{dh}}=\left(165 \mathrm{~d}_{\mathrm{b}}\right) /\left(\sqrt{ } \mathrm{f}_{\mathrm{c}}^{\prime}\right)$ for $\mathrm{F}_{\mathrm{f}} \leq 520 \mathrm{MPa} \quad(\mathrm{ACI} 440.1 \mathrm{R}-06)-$ hook bars

(Eq. 3.25b)

$\mathrm{L}_{\mathrm{dh}}=\left(\mathrm{F}_{\mathrm{f} .} \mathrm{d}_{\mathrm{b}}\right) /\left(3.1 \mathrm{~V}_{\mathrm{c}}^{\prime}\right)$ for $520<\mathrm{F}_{\mathrm{f}}<1040 \mathrm{MPa}(\mathrm{ACI} 440.1 \mathrm{R}-06)-$ hook bars

(Eq. 3.25c)

$\mathrm{L}_{\mathrm{dh}}=\left(330 \mathrm{~d}_{\mathrm{b}}\right) /\left({ }^{\mathrm{f}_{\mathrm{c}}^{\prime}}\right)$ for $\mathrm{F}_{\mathrm{f}} \geq 1040 \mathrm{MPa} \quad$ (ACI440.1R-06) - hook bars

(Eq. 3.25d)

$\mathrm{L}_{\mathrm{db}}=0.0781 \cdot \mathrm{d}_{\mathrm{b}} \cdot \mathrm{F}_{\mathrm{f}} \quad($ JSCE-97) - Straight end bars

Table 3.10 compares basic development lengths calculated from Eqs 3.17 to 3.19 with those of codes specifications stated above. It can be observed from the table that CSA-S806 (2012) and CSA-S06 (2006) provided basic development length for straight-end bars more than 206\% and 202\% greater than the required basic development length calculated from Eqs 3.17 to 3.19 in which a minimum factor of safety of 2.06 and 2.02 could be assumed, respectively. This factor of safety was assumed to be 1.28 and 2.63 for ACI- 1R (2006) and JSCE (1997). In case of hook bars, both the CSA-806 (2012) and ACI440.1R (2006) presented a factor of safety of 1.34 and 1.44 for M15 (\#5) and M19 (\#6) bars, respectively. 
Table 3. 10 Basic development length comparison of different codes

\begin{tabular}{|c|c|c|c|c|c|c|c|c|c|c|c|}
\hline & \multirow{2}{*}{$\begin{array}{c}\text { GFRP } \\
\text { bar }\end{array}$} & \multicolumn{2}{|c|}{ Experiment } & \multicolumn{2}{|c|}{$\begin{array}{c}\text { CSA-S806-12 } \\
\text { Eq. } 3.23 \\
\end{array}$} & \multicolumn{2}{|c|}{$\begin{array}{l}\text { CSA-S6-06 } \\
\text { Eq. 3.24 }\end{array}$} & \multicolumn{2}{|c|}{$\begin{array}{l}\text { ACI-1R-06 } \\
\text { Eq. } 3.25\end{array}$} & \multicolumn{2}{|c|}{$\begin{array}{c}\text { JSCE } \\
\text { Eq. } 3.26\end{array}$} \\
\hline & & $\# 5$ & \#6 & $\# 5$ & \#6 & $\# 5$ & \#6 & $\# 5$ & \#6 & $\# 5$ & \#6 \\
\hline \multirow{3}{*}{$\begin{array}{c}\text { Basic } \\
\text { development } \\
\text { length, } \\
\mathrm{L}_{\mathrm{db}}(\mathrm{mm})\end{array}$} & $\begin{array}{l}\text { Straight } \\
\text { end } \\
\text { Eq. } 3.17\end{array}$ & 557 & 624 & 1149 & 1286 & 1124 & 1258 & 715 & 800 & 1468 & 1644 \\
\hline & $\begin{array}{c}\text { Headed } \\
\text { end } \\
\text { Eq.3.18 }\end{array}$ & 512 & 574 & - & - & - & - & - & - & - & - \\
\hline & $\begin{array}{c}\text { Hook } \\
\text { Eq.3.19 }\end{array}$ & 462 & 517 & 620 & 745 & - & - & 620 & 745 & - & - \\
\hline
\end{tabular}

\subsection{Development Length Equations for Headed Bars}

As mentioned in Chapter 2, the Canadian Standard CSA A23.3 (2004) specifies the least of the following equations to determine resistance of a steel anchor head in concrete:

- Tensile Resistance of Steel Anchor

$\mathrm{N}_{\mathrm{sr}}=\varphi_{\mathrm{s}} \cdot \mathrm{n} \cdot \mathrm{A}_{\mathrm{se}} \cdot \mathrm{F}_{\mathrm{ut}} \cdot \mathrm{R}$

\section{- Tensile Concrete Breakout Capacity}

$\mathrm{N}_{\mathrm{br}}=\mathrm{K} \cdot \varphi_{\mathrm{c}} \cdot \sqrt{\mathrm{f}}^{\prime} \mathrm{c} \cdot \mathrm{L}_{\mathrm{d}}{ }^{1.5} \cdot \mathrm{R}$

Where, $\mathrm{K}$ is the calibration factor given as 10 for cast-in steel headed anchors and 7 for postinstalled anchors based on CSA A23.3 (2004). The modification factor, R, is taken equal to 1 for cast-in headed studs subjected to tension loads.

- Anchor Pullout Capacity

$N_{p r}=8 \varphi_{c} \cdot f_{c}^{\prime} \cdot A_{b h} \cdot R$

(Eq. 2.16)

- Concrete Side Face Blowout 
$\mathrm{N}_{\mathrm{sbr}}=13.3 \mathrm{c} \cdot \sqrt{ } \mathrm{A}_{\mathrm{bh}} \cdot \varphi_{\mathrm{c}} \cdot \sqrt{ } \mathrm{f}_{\mathrm{c}}^{\prime} \cdot \mathrm{R}$

On the basis of experimental programs conducted on 54 GFRP headed anchors in concrete slabs and concrete cubes, the author recommend the required development length of GFRP headedend bars in concrete based on Eq. 3.18. On the basis of this finding, the following equations have been adopted to determine the required development length of GFRP headed anchors in concrete in accordance with the CSA-A23.3 (2004) recommendations for steel anchors. It should be noted that the author did not perform the effect of concrete side face blowout failure since the edge distance for the tested headed anchor bars were greater than $0.4 \mathrm{~L}_{\mathrm{d}}$.

Tensile Resistance of GFRP Headed Anchor: on the basis of ultimate tensile resistance of GFRP headed bars in concrete, the following equation has been adopted to determine the required development length of headed anchor bars into concrete:

$\mathrm{L}_{\mathrm{db}}=\left(0.161 \cdot \mathrm{d}_{\mathrm{b}} \cdot \mathrm{F}_{\mathrm{f}}\right) /\left({ }^{\prime} \mathrm{f}_{\mathrm{c}}^{\prime}\right)$

Tensile Concrete Breakout Capacity: similar equation to that specified in CSA A23.3 (2004) was considered to determine the required development length of GFRP bars in concrete due to tensile concrete breakout capacity:

$\mathrm{L}_{\mathrm{db}}=\sqrt[1.5]{\frac{N_{b r}}{K_{F} \varphi_{c} \sqrt{f^{\prime} c}}}$

Where $\mathrm{K}_{\mathrm{F}}$ is the modification factor calibrated to $5 \%$ fractile of the test results for the headedend anchors in concrete, which can be determined as follow:

$\mathrm{K}_{\mathrm{F}}=\frac{P_{\max }}{\sqrt{f^{\prime}{ }^{\prime}} L_{d}^{1.5}}$

The $\mathrm{K}_{\mathrm{F}}$ was modified based on Eq. 3.28 from experimental test results for GFRP headed-end specimens failed by pullout with head broken. The $\mathrm{K}_{\mathrm{F}}$ was found as a function of peak tensile 
load obtained from experimental tests, embedment length and concrete compressive strength. Figure 3.74 shows graph of calibrated modification factor, $\mathrm{K}_{\mathrm{F}}$, versus embedment length of bar in concrete. In accordance with CSA-A23.3 (2004), the $\mathrm{K}_{\mathrm{F}}$ should be calibrated to $5 \%$ fractile of the test results. As such, a modification factor, $\mathrm{K}_{\mathrm{F}}$, of 9.75 can be obtained for sand-coated GFRP bars with headed end anchorage system.

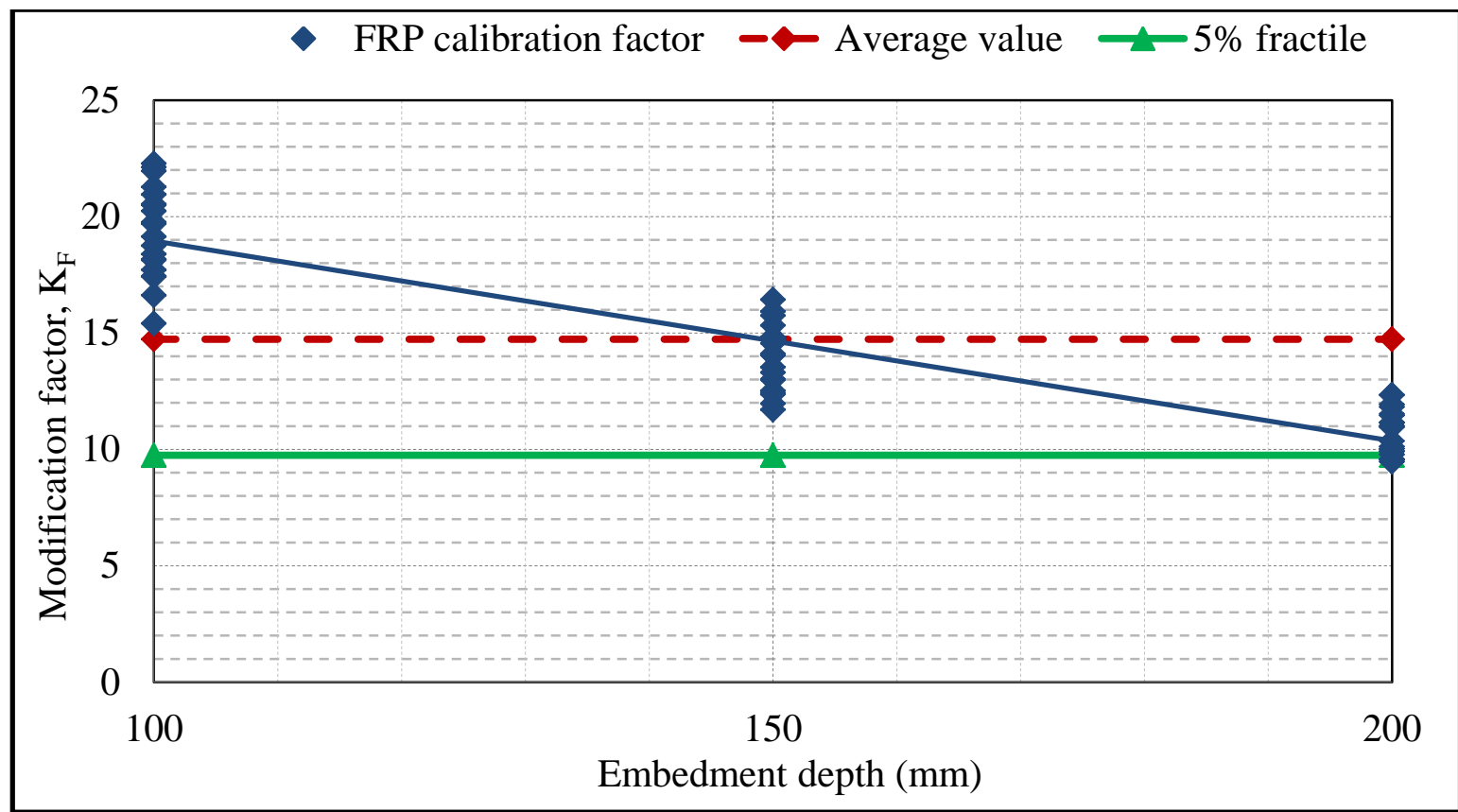

Figure 3. 74 FRP modification factor, $\mathrm{K}_{\mathrm{F}}$, for concrete breakout capacity of GFRP headed bars in concrete

Anchor Pullout Capacity: From the experimental test results on GFRP headed anchors and the developed equation for GFRP headed bars in concrete (Eq. 3.18), the following equation was adopted to evaluate the required development length of GFRP headed anchors in concrete due to anchor pullout capacity:

$\mathrm{L}_{\mathrm{db}}=\frac{N_{p r}}{4.87 d_{F} \sqrt{f^{\prime} c}}$

Where $\mathrm{N}_{\mathrm{br}}$ and $\mathrm{N}_{\text {pr }}$ in the above equations are the pullout force obtained from experimental test results. Based on the three equations proposed above, the development length of GFRP headedend bars in concrete were determined and provided in Table 3.11. The calculations were made 
for both concrete cube and concrete slab specimens for M15 (\#5) and M19 (\#6) GFRP headed bars. The results showed that the tensile concrete breakout capacity (Eq. 3.27) yielded the most critical development length of GFRP headed bars in concrete for all test specimens. This may be due to high tensile strength of the GFRP headed bars that exceeded the tensile capacity of the surrounding concrete.

\subsubsection{Effective Depth of Concrete Cone Breakout for Headed Bars}

Pullout tests have been conducted on GFRP headed-end bars in concrete slab models with embedment lengths of 100, 150 and 200-mm. From experimental observation, it was noticed that as the embedment length $\left(\mathrm{L}_{\mathrm{db}}\right)$ increases, the effective depth of concrete cone breakout, $\left(\mathrm{h}_{\mathrm{ef}}\right)$, shown in Figure 3.75 decreases. Figure 3.76 shows views of concrete cone breakout failure in GFRP headed anchors with variable embedment lengths. It was observed that for the test specimens with 100-mm embedment length, the entire bar was pulled out with the embedment length equal to the effective concrete cone depth. Thus, a ratio of effective concrete cone depth to the bar embedment length $\left(\mathrm{h}_{\mathrm{ef}} / \mathrm{L}_{\mathrm{db}}\right)$ of equal to 1 was taken as the reference value for bars with 100-mm embedment length. However, for bars with larger embedment lengths, the experimental results showed an average $h_{\mathrm{ef}} / \mathrm{L}_{\mathrm{db}}$ ratio of 0.71 and 0.53 for bars with 150 and 200-mm embedment lengths, respectively. The graph of $h_{e f} / L_{d b}$ ratio versus the increase in the embedment length was developed and is shown in Figure 3.77. A non-linear regression analysis using exponential function yielded the following equation to determine the effective depth of concrete cone failure as a function of bar embedment length.

$\left.\mathrm{h}_{\mathrm{ef}}=2 \mathrm{~L}_{\mathrm{db}} \cdot \mathrm{e}_{\mathrm{db}}^{-(0.007 \mathrm{~L}}\right) \quad$ (in $\left.\mathrm{mm}\right)$

(Eq. 3.30) 
Table 3. 11 Development length calculations for GFRP headed end bars in concrete

\begin{tabular}{|c|c|c|c|c|c|c|c|}
\hline $\begin{array}{c}\text { Specimen } \\
\text { Designation }\end{array}$ & $\begin{array}{c}\mathrm{f}_{\mathrm{c}}^{\prime} \\
(\mathrm{MPa})\end{array}$ & $\begin{array}{c}\mathrm{d}_{\mathrm{F}} \\
(\mathrm{mm})\end{array}$ & $\begin{array}{c}\text { Failure } \\
\text { load } \\
(\mathrm{kN})\end{array}$ & $\begin{array}{c}\mathrm{F}_{\mathrm{F}} \\
(\mathrm{MPa})\end{array}$ & $\begin{array}{c}\mathrm{L}_{\mathrm{db}}(\mathrm{mm}) \\
\text { Eq. 3.18 }\end{array}$ & $\begin{array}{c}\mathrm{L}_{\mathrm{db}}(\mathrm{mm}) \\
\text { Eq. 3.27 }\end{array}$ & $\begin{array}{c}\mathrm{L}_{\mathrm{db}}(\mathrm{mm}) \\
\text { Eq. 3.29 }\end{array}$ \\
\hline G5-100EM/H1 & 30 & 15.88 & 108.2 & 1184 & 552.3 & 213.4 & 255.4 \\
\hline G5-150EM/H3 & 30 & 15.88 & 130.58 & 1184 & 552.3 & 241.9 & 308.3 \\
\hline G5-200EM/H1 & 30 & 15.88 & 156.75 & 1184 & 552.3 & 273.2 & 370.1 \\
\hline G6-100EM/H1 & 30 & 19.05 & 114.75 & 1105 & 618.8 & 221.9 & 225.8 \\
\hline G6-150EM/H4 & 30 & 19.05 & 149.13 & 1105 & 618.8 & 264.3 & 293.5 \\
\hline G6-200EM/H5 & 30 & 19.05 & 177.5 & 1105 & 618.8 & 296.8 & 349.3 \\
\hline G5-100EM/H2 & 35 & 15.88 & 107.28 & 1184 & 511.7 & 201.5 & 234.5 \\
\hline G5-150EM/H3 & 35 & 15.88 & 134.41 & 1184 & 511.7 & 234.2 & 293.8 \\
\hline G5-200EM/H3 & 35 & 15.88 & 160.32 & 1184 & 511.7 & 263.4 & 350.4 \\
\hline G6-100EM/H1 & 35 & 19.05 & 113.24 & 1105 & 572.9 & 208.9 & 214.3 \\
\hline G6-150EM/H3 & 35 & 19.05 & 158.16 & 1105 & 572.9 & 261.1 & 288.2 \\
\hline G6-200EM/H5 & 35 & 19.05 & 186.5 & 1105 & 572.9 & 291.4 & 339.8 \\
\hline Concrete Slab 1 ${ }^{1}$ & 30.6 & 15.88 & 156.13 & 1184 & 547.2 & 270.7 & 364.9 \\
\hline Concrete Slab 1 & 30.6 & 19.05 & 183.45 & 1105 & 612.7 & 301.4 & 357.5 \\
\hline Concrete Slab 2 & 36.17 & 15.88 & 162 & 1184 & 503.3 & 262.4 & 348.3 \\
\hline Concrete Slab 2 & 36.17 & 19.05 & 188.9 & 1105 & 563.5 & 290.7 & 338.6 \\
\hline
\end{tabular}

\footnotetext{
${ }^{1}$ Average of five identical pullout test specimens for 200-mm embedment depth
} 


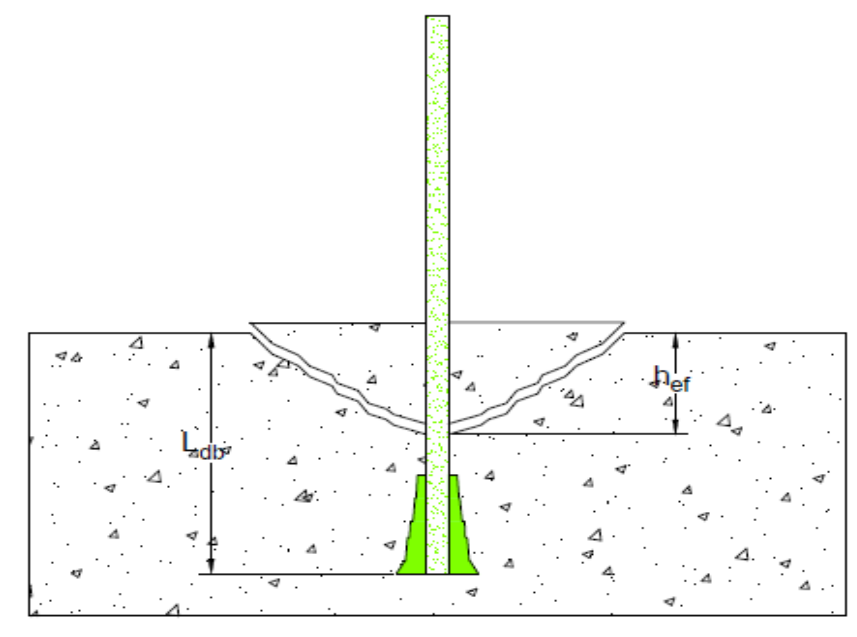

Figure 3. 75 Schematic view of effective concrete cone breakout failure

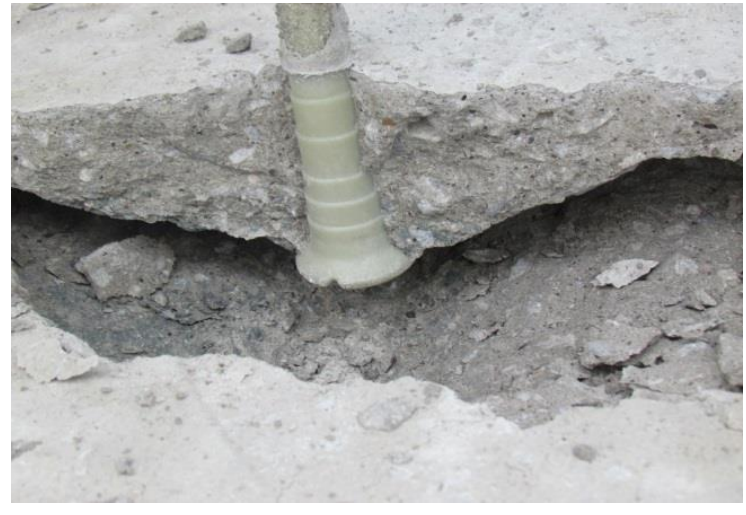

(a)100-mm embedment length

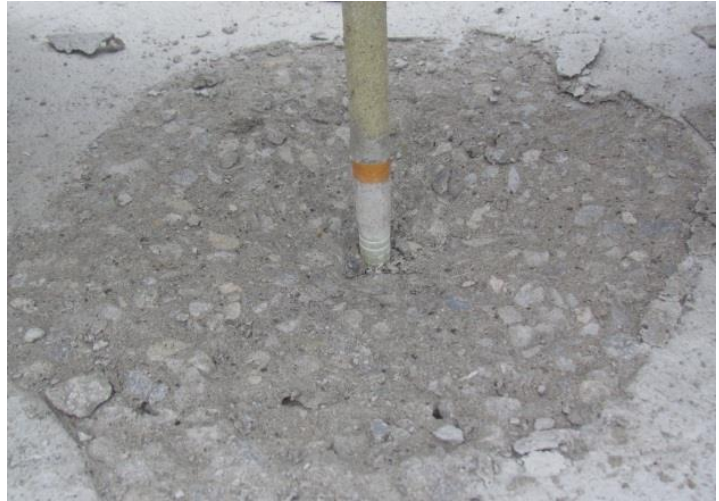

(b)150-mm embedment length

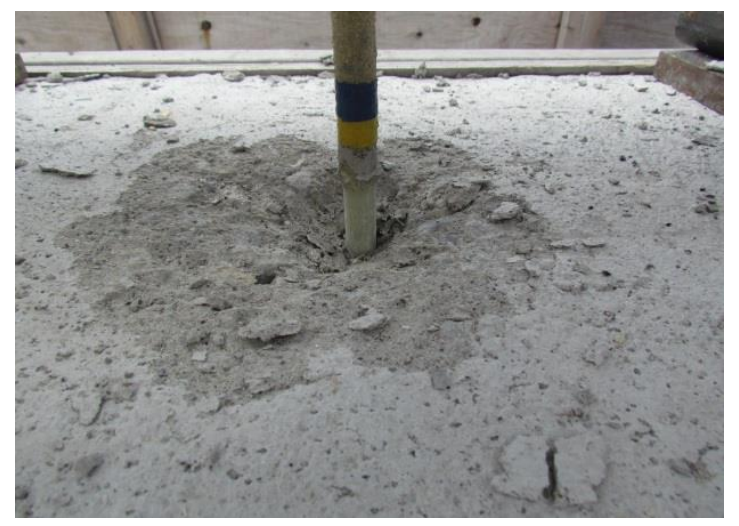

(c) 200-mm embedment length

Figure 3. 76 Views of experimentally tested GFRP headed anchors showing depth of concrete cone breakout failure for variable embedment lengths 


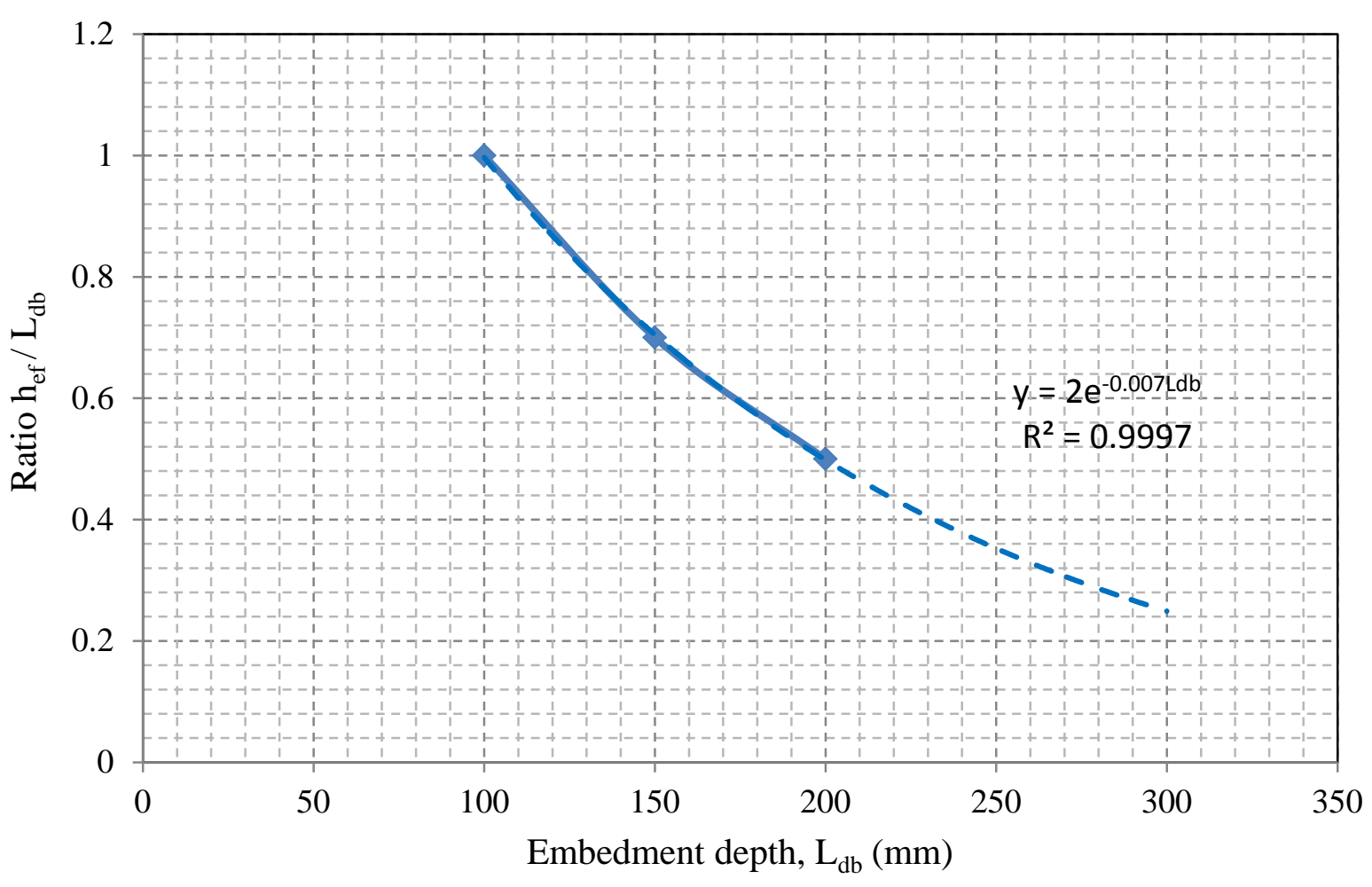

Figure 3.77 Trace effective concrete cone breakout as a function of bar embedment length

\subsection{Development Length of GFRP Hook Bars - Comparison to Code Predictions}

From experimental data available, the basic development length of GFRP bars in concrete were compared with the available development length equations in the codes as well as the proposed equations suggested by the author (Eq. 3.19). It must be noted that the development lengths determined by the author does not apply any factor of safety associated with them. Thus, this will be taken into account when comparing the results with code provisions and recommendations. The average bond strength along the development lengths provided in the following sections can be determined using Eq. 3.31 below:

$\tau=\frac{d_{f} F_{u}}{4 L_{d}}$

For compassion, the development lengths provided from the following codes will be determined based on the bar size, concrete strength, concrete cover and GFRP reinforcement properties. The 
value of the parameters in the following sections can be found in the specified codes and provisions.

\subsubsection{ACI 440.1R (2006) and CSA-S806 (2012)}

The ACI 440.1R (2006) and CSA-S806 (2012) recommended the following equations for the development length of bent bars in concrete. It should be noted that CSA-S806 (2012) multiplies the following equations by $\mathrm{K}_{2}$ factor to account for concrete density.

$$
\begin{array}{ll}
\mathrm{L}_{\mathrm{d}}=165 \frac{d_{F}}{\sqrt{f^{\prime}{ }_{c}}} & \text { For } f_{F} \leq 520 \mathrm{MPa} \\
\mathrm{L}_{\mathrm{d}}=\frac{f_{F}}{3.1} \frac{d_{F}}{\sqrt{f^{\prime}{ }_{c}}} & \text { For } 520<f_{F} \leq 1040 \mathrm{MPa} \\
\mathrm{L}_{\mathrm{d}}=330 \frac{d_{F}}{\sqrt{f^{\prime}{ }_{c}}} & \text { For } f_{F}>1040 \mathrm{MPa}
\end{array}
$$

Where $L_{d}$ should be greater than $12 d_{F}$ or $230-m m$. Substituting Eq. 3.32 into Eq. 3.31, the required bond stress of GFRP hook bars in concrete can be determined as follow:

$$
\tau=\frac{f_{F} \sqrt{f_{c}^{\prime}}}{1320}
$$

It can be noticed that the development length of GFRP bent bars in concrete is a function of bar

diameter, bar tensile strength and concrete compressive strength. However, the bond stress of GFRP bent bars is proportional to the bar ultimate tensile strength and square root of concrete compressive strength.

\subsubsection{Proposed Equation for Hook Bars}

From experimental testing of GFRP bars into concrete slabs and concrete pullout cubes, the author proposed the Eq. 3.19 for the required development length of bent bars into concrete.

Table 3.12 shows the values of parameter used in Eq. 3.32 for each bar size and concrete compressive strength used in the current study. On the basis of above codes and 
recommendations, the development length and bond strength of GFRP bars in concrete have also been determined and summarized in Tables 3.13. From the results provided in Table 3.13, it can be observed that the ACI 440.1R (2006) and CSA-S806 (2012) overestimated the required development length by a minimum safety factor of 1.92. Since the experimental test results showed that all GFRP bars failed by rupturing the bars at bent portion, therefore, one may conclude that the proposed equation is a better indication of the required development length of GFRP hook bars in concrete or a maximum reduction of 50\% to the ACI 440.1R (2012) and CSA S806 (2012) equations is recommended.

Table 3. 12 Value of parameters for CSA S806-12 and ACI 440.1R-06 development length equations for hook bars per current test results

\begin{tabular}{|c|c|c|}
\hline Parameters & M16 (\#5) GFRP bar & M19 (\#6) GFRP bar \\
\hline $\mathrm{K}_{2}$ & 1 & 1 \\
\hline$f_{F}$ & 1184 & 1105 \\
\hline $\mathrm{A}_{\mathrm{F}}$ & 197.9 & 285 \\
\hline $\mathrm{d}_{\mathrm{F}}$ & 15.88 & 34.05 \\
\hline$f^{\prime}{ }^{\prime}$ (concrete cube test) & 34.9 & $30.6^{*}$ \\
\hline$f^{\prime}{ }_{c}$ (concrete slab test) & $30.6^{*}$ & $36.17^{* *}$ \\
\hline$f^{\prime}{ }^{\prime}$ (concrete slab test) & $36.17^{* *}$ & \\
\hline
\end{tabular}

*Average concrete compressive strength was considered for the slab 1 pullout tests.

**Average concrete compressive strength was considered for the slab 2 pullout tests.

Table 3. 13 CSA S806-12 and ACI 440.1R-06 development length requirement and computed bond stress compared with proposed equations

\begin{tabular}{|c|c|c|c|c|c|c|c|c|}
\hline \multirow{3}{*}{$\begin{array}{c}\text { Concrete } \\
\text { specimens }\end{array}$} & \multicolumn{3}{|c|}{ ACI 440 and CSA S806 } & \multicolumn{4}{c|}{ Proposed Eq. 3.19 } \\
\cline { 2 - 9 } & M16 (\#5) bars & \multicolumn{2}{c|}{ M19 (\#6) bars } & \multicolumn{2}{c|}{ M16 (\#5) bars } & \multicolumn{2}{c|}{ M19 (\#6) bars } \\
\cline { 2 - 9 } & $\begin{array}{c}\mathrm{L}_{\mathrm{d}} \\
(\mathrm{mm})\end{array}$ & $\begin{array}{c}\tau \\
(\mathrm{MPa})\end{array}$ & $\begin{array}{c}\mathrm{L}_{\mathrm{d}} \\
(\mathrm{mm})\end{array}$ & $\begin{array}{c}\tau \\
(\mathrm{MPa})\end{array}$ & $\mathrm{L}_{\mathrm{d}}(\mathrm{mm})$ & $\begin{array}{c}\tau \\
(\mathrm{MPa})\end{array}$ & $\mathrm{L}_{\mathrm{d}}(\mathrm{mm})$ & $\begin{array}{c}\tau \\
(\mathrm{MPa})\end{array}$ \\
\hline Concrete cubes & 887.1 & 5.3 & 1064.1 & 4.95 & 461.5 & 10.18 & 516.7 & 10.18 \\
\hline Concrete slab 1 & 947.3 & 4.96 & 1136.4 & 4.63 & 492.8 & 9.54 & 551.8 & 9.54 \\
\hline Concrete slab 2 & 871.3 & 5.4 & 1045.3 & 5.03 & 453.3 & 10.37 & 507.5 & 10.37 \\
\hline
\end{tabular}




\subsection{Development Length of GFRP Straight End Bars - Comparison to Code Predictions 3.13.1 Analytical Calculation of Development Length}

It is possible to analytically determine the development length of GFRP bars in concrete based on the value of the curve fitting parameters $(\alpha)$ provided in Table 3.7. Foccaci et al. (2000) proposed the following equation in which the load in FRP bar is related to the required development length of the bar in concrete so that the slip at the free-end is equal zero. The proposed method involves finding parameters of a given bond stress-slip relationship so that the results of an experimental bond test can be predicted in terms of maximum applied pullout force and the corresponding peak bond stress.

$\mathrm{N}\left(\mathrm{L}_{\mathrm{d}}\right)=\frac{2 E_{l b} A_{b}}{1-\alpha} \cdot\left[\frac{2 \tau_{\max }(1-\alpha)^{2}}{E_{l b} d_{b}(1+\alpha)}\right]^{1 /(1-\alpha)} \cdot \mathrm{L}_{\mathrm{d}}{ }^{(1+\alpha) /(1-\alpha)}$

Where,

$\mathrm{N}\left(\mathrm{L}_{\mathrm{d}}\right)=$ load in the bar at a development length greater or equal to the embedment length $(\mathrm{N})$

$\mathrm{L}_{\mathrm{d}}=$ the required development length $(\mathrm{mm})$

$\mathrm{E}_{\mathrm{lb}}=$ modulus of Elasticity of FRP bars (MPa)

$A_{b}=$ cross-sectional area of FRP bars $\left(\mathrm{mm}^{2}\right)$

$\mathrm{d}_{\mathrm{b}}=$ FRP bar diameter $(\mathrm{mm})$

$\alpha=$ curve fitting parameter from mBPE model

$\tau_{\max }=$ peak bond stress from experiments $(\mathrm{MPa})$

From Eq. 3.34, the required development length of the GFRP bars in concrete can be determined. Table 3.14 summarizes the value of the parameters used in the current study. Based on the value of parameters and solving for $\mathrm{L}_{\mathrm{d}}$ in Eq. 3.34, the required development length of GFRP bars in concrete were determined and provided in Table 3.15. Using Eq. 3.31, the average bond stress was then calculated for each test specimen. The required development length of the GFRP determined by this method was then compared to the code predictions as well as the proposed equation for straight-end bars (Eq. 3.17). 
Table 3. 14 Value of parameters used to determine the required development length

\begin{tabular}{|c|c|c|}
\hline Parameters & M16 (\#5) GFRP bar & M19 (\#6) GFRP bar \\
\hline$\alpha$ & See Table 3.7 & See Table 3.7 \\
\hline $\mathrm{C}=\tau_{\max }(\mathrm{MPa})$ & See Table 3.7 & See Table 3.7 \\
\hline$f_{f u}(\mathrm{MPa})$ & 1184 & 1105 \\
\hline $\mathrm{A}_{\mathrm{F}}\left(\mathrm{mm}^{2}\right)$ & 197.9 & 285 \\
\hline $\mathrm{d}_{\mathrm{F}}(\mathrm{mm})$ & 15.88 & 19.05 \\
\hline $\mathrm{E}_{\mathrm{F}}(\mathrm{MPa})$ & 62600 & 64700 \\
\hline $\mathrm{N}=f_{f u} \cdot \mathrm{A}_{\mathrm{F}}(\mathrm{N})$ & 234,314 & 314,925 \\
\hline
\end{tabular}

Table 3.15 Analytically calculated development length of GFRP bars in concrete

\begin{tabular}{|c|c|c|}
\hline Concrete Specimens & $\mathrm{L}_{\mathrm{d}}(\mathrm{mm})$ & $\tau$ (MPa) \\
\hline G5/ C200- 100EM & 415.3 & 11.32 \\
\hline G6/ C200- 100EM & 444.2 & 11.85 \\
\hline G5/ C200- 150EM & 435.9 & 10.8 \\
\hline G6/ C200- 150EM & 476 & 11.05 \\
\hline G5/ C200- 200EM & 449.2 & 10.46 \\
\hline G6/ C200- 200EM & 503.1 & 10.46 \\
\hline G5/ C200- 250EM & 551.3 & 8.53 \\
\hline G6/ C200- 250EM & 564.4 & 9.32 \\
\hline
\end{tabular}

\subsubsection{Comparison to Code Predictions}

\section{- CSA- S806-12}

The required development length provided by CSA-S806 (2012) can be determined from Eq. 2.3. For the calculated development length from Eq. 2.3, the bond strength can be determined using Eq. 3.31 above.

$$
\mathrm{L}_{\mathrm{d}}=1.15 \frac{\mathrm{K}_{1} \mathrm{~K}_{2} \mathrm{~K}_{3} \mathrm{~K}_{4} \mathrm{~K}_{5}}{d_{c s}} \frac{f_{F}}{\sqrt{f^{\prime} c}} \mathrm{~A}_{\mathrm{F}}
$$


$\tau=\frac{\mathrm{d}_{\mathrm{cs}} \sqrt{f^{\prime}}{ }_{c}}{1.15 K_{1} \mathrm{~K}_{2} \mathrm{~K}_{3} \mathrm{~K}_{4} \mathrm{~K}_{5} \pi \cdot d_{F}}$

Table 3.16 shows value of parameters used in Eq.s 2.3 and 2.4 for each bar size and concrete strength. While, Table 3.17 shows the corresponding development length and bond strength calculated from Eqs. 2.3 and 2.4.

Table 3. 16 Value of parameters for CSA S806-12 development length equation

\begin{tabular}{|c|c|c|}
\hline Parameters & M16 (\#5) GFRP bar & M19 (\#6) GFRP bar \\
\hline $\mathrm{K}_{1}$ & 1 & 1 \\
\hline $\mathrm{K}_{2}$ & 1 & 1 \\
\hline $\mathrm{K}_{3}$ & 1 & 1 \\
\hline $\mathrm{K}_{4}$ & 1 & 1 \\
\hline $\mathrm{K}_{5}$ & 1 & 1 \\
\hline $\mathrm{d}_{\mathrm{cs}}$ & 39.7 & 47.63 \\
\hline$f_{F}$ & 1184 & 1105 \\
\hline $\mathrm{A}_{\mathrm{F}}$ & 197.9 & 285 \\
\hline $\mathrm{d}_{\mathrm{F}}$ & 34.88 & 19.05 \\
\hline$f_{c}$ (concrete cube test) & $30.6^{*}$ & 34.9 \\
\hline$f_{{ }^{\prime}}$ (concrete slab test) & $36.17^{* *}$ & $30.6^{*}$ \\
\hline$f^{\prime}$ (concrete slab test) & $36.17^{* *}$ \\
\hline
\end{tabular}

*Average concrete compressive strength was considered for the slab 1 pullout tests.

**Average concrete compressive strength was considered for the slab 2 pullout tests.

Table 3. 17 CSA S806-12 development length requirements and computed bond stress.

\begin{tabular}{|c|c|c|c|c|}
\hline \multirow{2}{*}{ Concrete specimens } & \multicolumn{2}{|c|}{ M16 (\#5) GFRP bars } & \multicolumn{2}{c|}{ M19 (\#6) GFRP bars } \\
\cline { 2 - 5 } & $\mathrm{L}_{\mathrm{d}}(\mathrm{mm})$ & $\tau(\mathrm{MPa})$ & $\mathrm{L}_{\mathrm{d}}(\mathrm{mm})$ & $\tau(\mathrm{MPa})$ \\
\hline Concrete cubes & 1149 & 4.09 & 1287 & 4.09 \\
\hline Concrete slab 1 & 1227 & 3.83 & 1374.6 & 3.83 \\
\hline Concrete slab 2 & 1128.6 & 4.16 & 1264.3 & 4.16 \\
\hline
\end{tabular}


It be seen from Table 3.17 that the bar size does not influence the bond strength of GFRP bars in concrete. However, the concrete compressive strength influenced the bond strength for a GFRP with similar bar size.

\section{- CSA-S6-06}

The Canadian Highway Bridge Design Code (CHBDC, 2006) specifies the following equations for the development of FRP bars into concrete. Using the Eq. 3.31, the bond strength of FRP bars can be then determined.

$\mathrm{L}_{\mathrm{d}}=0.45 \frac{\mathrm{K}_{1} \mathrm{~K}_{4}}{\left(d_{c s}+K_{t r} \frac{E_{F}}{E_{S}}\right)}\left(\frac{f_{F}}{f_{c r}}\right) \mathrm{A}_{\mathrm{F}}$

$\tau=\frac{\left(\mathrm{d}_{\mathrm{cs}}+K_{t r} \frac{E_{F}}{E_{S}}\right) \cdot f_{c r}}{0.45 K_{1} \mathrm{~K}_{4} \pi \cdot d_{F}}$

The value of parameters used in the above two equations are provided in Table 3.18 for each bar size and concrete strength. The calculated values of development length and the corresponding bond strength are presented in Table 3.19. Similar to the CSA-S806 (2012), bar size does not influence the bond strength of FRP bars in concrete, while the concrete strength dose. It can be also noticed that as the bar size increases, the required development length of FRP bars in concrete proportionally increases.

\section{- ACI 440.1R - 06}

The development length required for FRP reinforced structures by ACI 440.1R (2006) is determined from Eq. 2.8. ACI 440.1R (2006) recommended Eq. 2.9 in calculating bond stress of FRP bars in concrete. ACI 440.1R (2006) considers bond strength as a function of bar diameter, concrete cover, development length and concrete compressive strength. 
Table 3. 18 Value of parameters for CSA S6-06 development length equation

\begin{tabular}{|c|c|c|}
\hline Parameters & M16 (\#5) GFRP bar & M19 (\#6) GFRP bar \\
\hline $\mathrm{K}_{1}$ & 1 & 1 \\
\hline $\mathrm{K}_{4}$ & 1 & 47.63 \\
\hline $\mathrm{d}_{\mathrm{cs}}+\mathrm{K}_{\mathrm{tr}}\left(\mathrm{E}_{\mathrm{f}} / \mathrm{E}_{\mathrm{s}}\right)$ & 1184 & 1105 \\
\hline$f_{F}$ & 197.9 & 285 \\
\hline $\mathrm{A}_{\mathrm{F}}$ & 15.88 & 19.05 \\
\hline $\mathrm{d}_{\mathrm{F}}$ & 34.9 & 34.9 \\
\hline$f^{\prime}{ }^{\prime}$ (concrete cube test) & $30.6 *$ & $30.6^{*}$ \\
\hline$f^{\prime}{ }^{\prime}$ (concrete slab 1 test) & $36.17^{* *}$ & $36.17^{* *}$ \\
\hline$f^{\prime}{ }^{\prime}$ (concrete slab 2 test) & 2.36 & 2.36 \\
\hline $\mathrm{f}_{\mathrm{cr}}($ cube test) & 2.21 & 2.21 \\
\hline $\mathrm{f}_{\mathrm{cr}}$ (concrete slab 1 test) & 2.41 & 2.41 \\
\hline $\mathrm{f}_{\mathrm{cr}}$ (concrete slab 2 test) & & 16 \\
\hline
\end{tabular}

*Average concrete compressive strength was considered for the slab 1 pullout tests.

**Average concrete compressive strength was considered for the slab 2 pullout tests.

Table 3. 19 CSA-S6-06 development length requirements and computed bond stress.

\begin{tabular}{|c|c|c|c|c|}
\hline \multirow{2}{*}{ Concrete specimens } & \multicolumn{2}{|c|}{ M16 (\#5) GFRP bars } & \multicolumn{2}{c|}{ M19 (\#6) GFRP bars } \\
\cline { 2 - 5 } & $\mathrm{L}_{\mathrm{d}}(\mathrm{mm})$ & $\tau(\mathrm{MPa})$ & $\mathrm{L}_{\mathrm{d}}(\mathrm{mm})$ & $\tau(\mathrm{MPa})$ \\
\hline Concrete cubes & 1125.4 & 4.17 & 1260.7 & 4.17 \\
\hline Concrete slab 1 & 1201.8 & 3.91 & 1346.3 & 3.91 \\
\hline Concrete slab 2 & 1102.1 & 4.26 & 1234.6 & 4.26 \\
\hline
\end{tabular}

$\mathrm{L}_{\mathrm{d}}=\frac{f_{f u} d_{F} \alpha-28.22 d_{F} \sqrt{f^{\prime}{ }_{c}}}{1.1288 \sqrt{f^{\prime}{ }_{c}}+0.083 \sqrt{f^{\prime}{ }_{c}}\left(\frac{C}{d_{F}}\right)}$

$\tau=\left(0.33+0.025 \frac{C}{d_{F}}+8.3 \frac{d_{F}}{L_{d}}\right) \sqrt{f^{\prime}{ }_{c}}$ 
The values of parameter used in the calculation of development length and bond stress are provided in Table 3.20. The resulting development length and bond stress were then determined and are presented in Table 3.21. From the calculation results, it can be observed that bond strength of FRP bars in concrete is affected neither by bar size nor by concrete compressive strength.

Table 3. 20 Parameters used for ACI 440.1R-06 development length equation

\begin{tabular}{|c|c|c|}
\hline Parameters & M16 (\#5) GFRP bar & M19 (\#6) GFRP bar \\
\hline$\alpha$ & 1 & 1 \\
\hline$\left(\mathrm{C} / \mathrm{d}_{\mathrm{F}}\right)$ & 3.5 & 3.5 \\
\hline$f_{f u}$ & 1184 & 1105 \\
\hline $\mathrm{A}_{\mathrm{F}}$ & 197.9 & 285 \\
\hline $\mathrm{d}_{\mathrm{F}}$ & 15.88 & 19.05 \\
\hline$f^{\prime}$ (concrete cube test) & 34.9 & 34.9 \\
\hline$f^{\prime}$ (concrete slab test) & $30.6^{*}$ & $30.6^{*}$ \\
\hline$f^{\prime}{ }_{c}$ (concrete slab test) & $36.17^{* *}$ & $36.17^{* *}$ \\
\hline
\end{tabular}

*Average concrete compressive strength was considered for the slab 1 pullout tests.

**Average concrete compressive strength was considered for the slab 2 pullout tests.

Table 3. 21 ACI 440.1R - 06 development length requirement and computed bond stress

\begin{tabular}{|c|c|c|c|c|}
\hline \multirow{2}{*}{ Concrete specimens } & \multicolumn{2}{|c|}{ M16 (\#5) GFRP bars } & \multicolumn{2}{c|}{ M19 (\#6) GFRP bars } \\
\cline { 2 - 5 } & $\mathrm{L}_{\mathrm{d}}(\mathrm{mm})$ & $\tau(\mathrm{MPa})$ & $\mathrm{L}_{\mathrm{d}}(\mathrm{mm})$ & $\tau(\mathrm{MPa})$ \\
\hline Concrete cubes & 1926.7 & 2.87 & 2131.8 & 2.91 \\
\hline Concrete slab 1 & 2079 & 2.66 & 2302.4 & 2.69 \\
\hline Concrete slab 2 & 1886.9 & 2.93 & 2087.3 & 2.97 \\
\hline
\end{tabular}


- ACI 440.1R -03

The ACI 440.1R (2003) specifies the following equation (Eq. 2.10) to determine the required development length of FRP bars in concrete. Substituting Eq. 2.10 into Eq. 3.31 yields bond strength of 4.63. Thus, it can be understood that the bond stress obtained from Eq. 2.10 is not affected by bar size and concrete compressive strength. Tables 3.22 and 3.23 provide the value of parameters used and the corresponding development length calculations.

$\mathrm{L}_{\mathrm{d}}=\frac{d_{F} f_{f u}}{18.5}$

Table 3. 22 Parameters for ACI 440.1R-03 development length equation

\begin{tabular}{|c|c|c|}
\hline Parameters & M16 (\#5) GFRP bar & M19 (\#6) GFRP bar \\
\hline$f_{f u}$ & 1184 & 1105 \\
\hline $\mathrm{A}_{\mathrm{F}}$ & 197.9 & 285 \\
\hline $\mathrm{d}_{\mathrm{F}}$ & 15.88 & 19.05 \\
\hline
\end{tabular}

Table 3.23 ACI 440.1R - 03 development length requirement and computed bond stress

\begin{tabular}{|c|c|c|c|c|}
\hline \multirow{2}{*}{ Concrete specimens } & \multicolumn{2}{|c|}{ M16 (\#5) GFRP bars } & \multicolumn{2}{c|}{ M19 (\#6) GFRP bars } \\
\cline { 2 - 5 } & $\mathrm{L}_{\mathrm{d}}(\mathrm{mm})$ & $\tau(\mathrm{MPa})$ & $\mathrm{L}_{\mathrm{d}}(\mathrm{mm})$ & $\tau(\mathrm{MPa})$ \\
\hline Concrete cubes & 1016.3 & 4.63 & 1137.9 & 4.63 \\
\hline Concrete slab 1 & 1016.3 & 4.63 & 1137.9 & 4.63 \\
\hline Concrete slab 2 & 1016.3 & 4.63 & 1137.9 & 4.63 \\
\hline
\end{tabular}

\section{- JSCE (1997)}

Japanese Society of Civil Engineering (JSCE, 1997) specifies the following equations in determination of development length and bond stress for structures reinforced with FRP bars.

$\mathrm{L}_{\mathrm{d}}=\alpha_{1} \frac{f_{F}}{4 f_{\text {bod }}} d_{F} \quad$ Where $\mathrm{L}_{\mathrm{d}}>20 \mathrm{~d}_{\mathrm{F}}$

(Eq. 2.12) 
$\tau=\frac{f_{b o d}}{\alpha_{1}}$

The value of parameter used to calculate the required development and the corresponding bond stress is presented in Table 3.24. Based on these values, the development length and the bond stress were calculated and provided in Table 3.25. Similar to the ACI 440.1R (2003), the bond stress of FRP bars in concrete is affected by niether bar size nor concrete compressive strength.

Table 3. 24 Parameters for JSCE-1997 development length equation

\begin{tabular}{|c|c|c|}
\hline Parameters & M16 (\#5) GFRP bar & M19 (\#6) GFRP bar \\
\hline$\alpha_{1}$ & 0.6 & 0.6 \\
\hline$f_{F}$ & 1184 & 1105 \\
\hline $\mathrm{A}_{\mathrm{F}}$ & 197.9 & 285 \\
\hline $\mathrm{d}_{\mathrm{F}}$ & 15.88 & 19.05 \\
\hline$F_{\text {bod }}$ & 3.2 & 3.2 \\
\hline
\end{tabular}

Table 3. 25 JSCE - 1997 development length requirement and computed bond stress

\begin{tabular}{|c|c|c|c|c|}
\hline \multirow{2}{*}{ Concrete specimens } & \multicolumn{2}{|c|}{ M16 (\#5) GFRP bars } & \multicolumn{2}{c|}{ M19 (\#6) GFRP bars } \\
\cline { 2 - 5 } & $\mathrm{L}_{\mathrm{d}}(\mathrm{mm})$ & $\tau(\mathrm{MPa})$ & $\mathrm{L}_{\mathrm{d}}(\mathrm{mm})$ & $\tau(\mathrm{MPa})$ \\
\hline Concrete cubes & 881.3 & 5.33 & 986.7 & 5.33 \\
\hline Concrete slab 1 & 881.3 & 5.33 & 986.7 & 5.33 \\
\hline Concrete slab 2 & 881.3 & 5.33 & 986.7 & 5.33 \\
\hline
\end{tabular}

\section{- Proposed Development Length Equation for Straight Bars}

Based on the experimental pullout tests conducted by the author on GFRP bars embedded into concrete slabs and concrete cubes, the author proposed the following equation to determine the basic development of GFRP straight-end bars into concrete. The bond stress can be then calculated by substituting the following equation into Eq. 3.31.

$L_{d}=\left(0.175 \cdot d_{b} \cdot F_{f}\right) /\left(\sqrt{ } f_{c}^{\prime}\right)$ 
The required development lengths and corresponding bond stresses from prediction codes are summarized in Table 3.26 and 3.27. The code prediction values are compared with the proposed equation by the author as well as the development length and bond stress calculations by analytical investigations. By comparing the results, it can be observed that the proposed equation for straight-end bars is in good agreement with the required development lengths obtained by analytical model (Table 3.15), while still maintaining a margin of safety factor with minimum value of 1.18. However, comparing the proposed equation with the code predictions revealed a factor of safety of 2.06, 2.02, 3.46, and 1.48 for the CSA-S806 (2012), CSA-S6 (2006), ACI 440.1R (2006), and JSCE (1997), respectively. Thus, it can be concluded that the code equations significantly overestimates the development length of FRP bars in concrete and can be reduced by up to 50\% for the CSA-S806 (2012) and CSA-S6 (2006). The results of this chapter are limited to bars confined in concrete. As such, bars with small concrete cover is outside the scope of this research.

Table 3. 26 Development Length comparisons between codes and the proposed equation for straight bars

\begin{tabular}{|c|c|c|c|c|c|c|c|c|c|c|}
\hline \multirow{2}{*}{$\begin{array}{c}\text { Concrete } \\
\text { specimens }\end{array}$} & \multicolumn{2}{|c|}{ CSA S806-12 } & \multicolumn{2}{|c|}{ CSA S6-06 } & \multicolumn{2}{c|}{ ACI 440.1R-06 } & \multicolumn{2}{|c|}{ JSCE- 1997 } & \multicolumn{2}{c|}{$\begin{array}{c}\text { Proposed } \\
\text { Eq. 3.17 }\end{array}$} \\
\cline { 2 - 11 } & M16 & M19 & M16 & M19 & M16 & M19 & M16 & M19 & M16 & M19 \\
\hline $\begin{array}{c}\text { Concrete } \\
\text { cubes }\end{array}$ & 1149 & 1287 & 1125.4 & 1260.7 & 1926.7 & 2131.8 & 881.3 & 986.7 & 557 & 624 \\
\hline $\begin{array}{c}\text { Concrete } \\
\text { slab 1 }\end{array}$ & 1227 & 1374.6 & 1201.8 & 1346.3 & 2079 & 2302.4 & 881.3 & 986.7 & 595 & 666 \\
\hline $\begin{array}{c}\text { Concrete } \\
\text { slab 2 }\end{array}$ & 1128.6 & 1264.3 & 1102.1 & 1234.6 & 1886.9 & 2087.3 & 881.3 & 986.7 & 547 & 613 \\
\hline
\end{tabular}

Table 3.27 Bond strength comparison between codes and the proposed equation for straight bars

\begin{tabular}{|c|c|c|c|c|c|c|c|c|c|c|}
\hline \multirow{2}{*}{$\begin{array}{c}\text { Concrete } \\
\text { specimens }\end{array}$} & \multicolumn{2}{|c|}{ CSA S806-12 } & \multicolumn{2}{|c|}{ CSA S6-06 } & \multicolumn{2}{|c|}{ ACI 440.1R-06 } & \multicolumn{2}{|c|}{ JSCE- 1997 } & \multicolumn{2}{c|}{$\begin{array}{c}\text { Proposed } \\
\text { Eq. }\end{array}$} \\
\cline { 2 - 12 } & M16 & M19 & M16 & M19 & M16 & M19 & M16 & M19 & M16 & M19 \\
\hline $\begin{array}{c}\text { Concrete } \\
\text { cubes }\end{array}$ & 4.09 & 4.09 & 4.17 & 4.17 & 2.87 & 2.91 & 5.33 & 5.33 & 8.5 & 7.05 \\
\hline $\begin{array}{c}\text { Concrete } \\
\text { slab 1 }\end{array}$ & 3.83 & 3.83 & 3.91 & 3.91 & 2.66 & 2.69 & 5.33 & 5.33 & 7.92 & 6.61 \\
\hline $\begin{array}{c}\text { Concrete } \\
\text { slab 2 }\end{array}$ & 4.16 & 4.16 & 4.26 & 4.26 & 2.93 & 2.97 & 5.33 & 5.33 & 8.62 & 7.18 \\
\hline
\end{tabular}




\subsection{Summary of Findings}

Bond strength and the required development length of GFRP bars in concrete were investigated on 114 concrete cubes and 140 pullout slab specimens. The experimental test variables include: fiber content (i.e. HM versus SM bars), bar end anchorage condition and bar diameter. Based on the experimental test results, general conclusions have been made, namely: (i) Increasing bar diameter lowered the bond strength, (ii) The bar approached its ultimate tensile strength with increase in the embedment depth, (iii) The increase in embedment depth also led to reduction in bond strength between concrete and GFRP bars and increase in the required applied load to pull the bar out of concrete, (iv) An increase in embedment depth for the same load decreased the average value of bond strength. This might be due to non-linear distribution of the stresses along the length of the bars in case of larger embedment depth, and (v) The larger bar diameter required larger embedment depth to develop the same bond strength, while for bars with the same diameter, increasing the embedment depth reduces the bond strength of the GFRP bars. In addition, the main findings of this research include: (i) GFRP bars with head anchors provided the most promising candidate in developing bond behavior between concrete and the bars, (ii) New equations for basic development lengths of GFRP bars in tension with straight-ends, headed-ends and $180^{\circ}$-hook bars were proposed, (iii) The existing equations in the code for the required development length of FRP bars in concrete overestimated the results by a minimum safety factor of 2 for straight-end bars and 1.92 for hook bars. In case of hook bars, the experimental test results showed failure of all bars by rupturing at the bend portion. Thus, a maximum of $50 \%$ reduction to the ACI 440.1R (2006) or CSA-S806 (2012) equations is recommended. In case of headed-end bars, the failure of the bars in concrete was governed by concrete breakout capacity given in CSA-A23.3 (2004) provision. Based on such failure mode, a new equation was proposed for the development length of headed-end bars in concrete on the basis of concrete breakout capacity, and (iv) From the test results obtained in both 30.6 and 36.17 MPa concretes, it was observed that the value of average bond strength is slightly increased in the 36.17-MPa concrete. However, the increase in bond strength was not very significant in all types of GFRP bars with a difference of $3 \%$ to maximum of $8 \%$. 


\section{Chapter IV}

\section{Development of GFRP-Reinforced Concrete Bridge Barrier-Deck Slab Interface}

\subsection{General}

Corrosion of steel reinforcement due to environmental effects is a major cause of deterioration problem in bridge barriers. Glass Fiber Reinforced Polymers (GFRP) not only addresses this durability problem, but also provides exceptionally high tensile strength. The use of glass fiber polymer bars in bridge constructions is rapidly increasing due to their corrosion resistance that lead to less environmental effects. GFRP bars may be an alternative to conventional steel reinforcement in bridge structures especially when they are in direct contact with harsh environment. During winter time, de-icing salt is a serious threat to the exposed bridge components. Barrier walls made of steel are assumed to be affected by such environmental condition in such a way that presence of cracks on barrier surface cause the salt solution to penetrate into the barrier wall. Upon reaching the reinforcing steel bars, it causes corrosion of the bars, and consequently the overall strength of the barrier will be reduced. Such reduction in barrier strength may cause to reduce the structural adequacy of the barrier during vehicle collisions, and therefore failure of the barrier to occur. Figure 4.1 shows photo of a degraded barrier wall that was induced by corrosion of steel-reinforcing bars.

Numerous researches conducted on environmental behavior of GFRP bars have shown that these bars are remarkably resistant to corrosion when compared to steel bars. Additionally, researches on mechanical properties of GFRP bars have shown significantly higher tensile strength compared to the yielding point of steel bars. Due to cantilever action of barrier walls under vehicle impact load, high tensile strength GFRP bars may be a suitable alternative to the conventional steel reinforcement when used in the barrier wall. As such, it was decided to revise the available standard PL-3 barrier detailing with steel reinforcement (shown in Figure 4.2) and develop a new barrier detailing with GFRP bars as reinforcement. As the design procedure for 
GFRP barrier walls is not yet established, an equivalent area of reinforcement with some modification in bar arrangement have been made. The following sections examine various bar type and bar spacing for the development of the barrier wall.

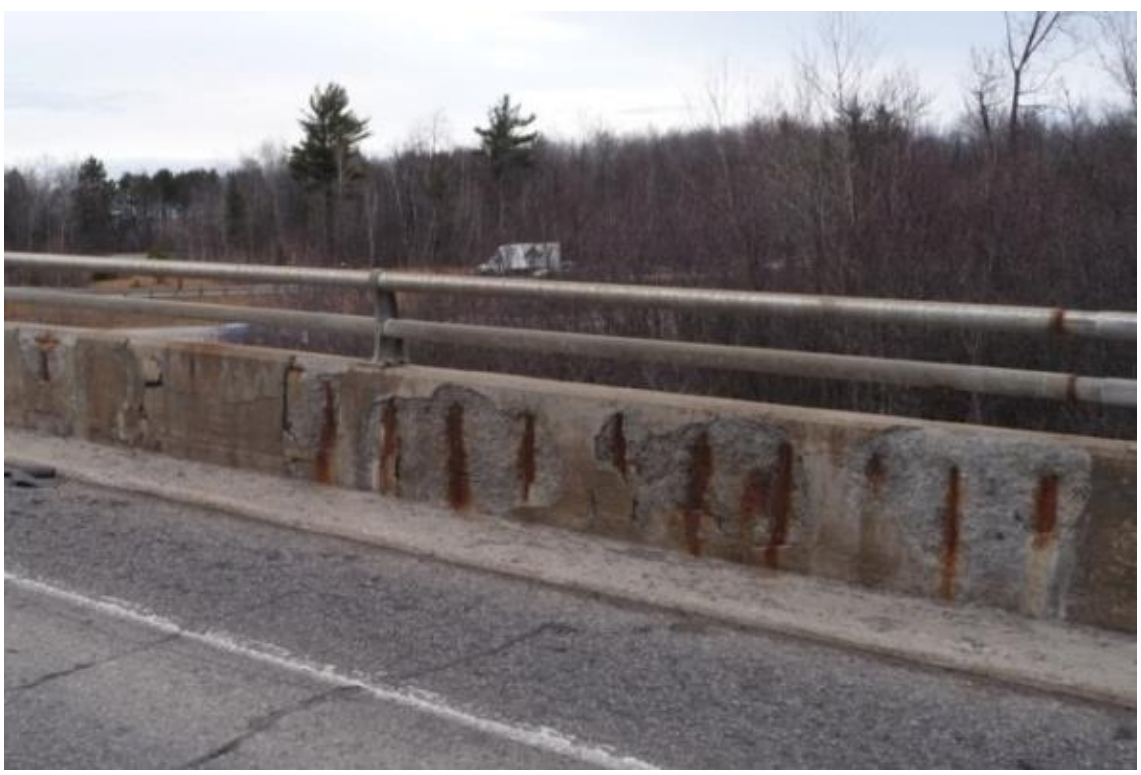

Figure 4. 1 Corrosion-induced degradation of steel-reinforced bridge barrier wall

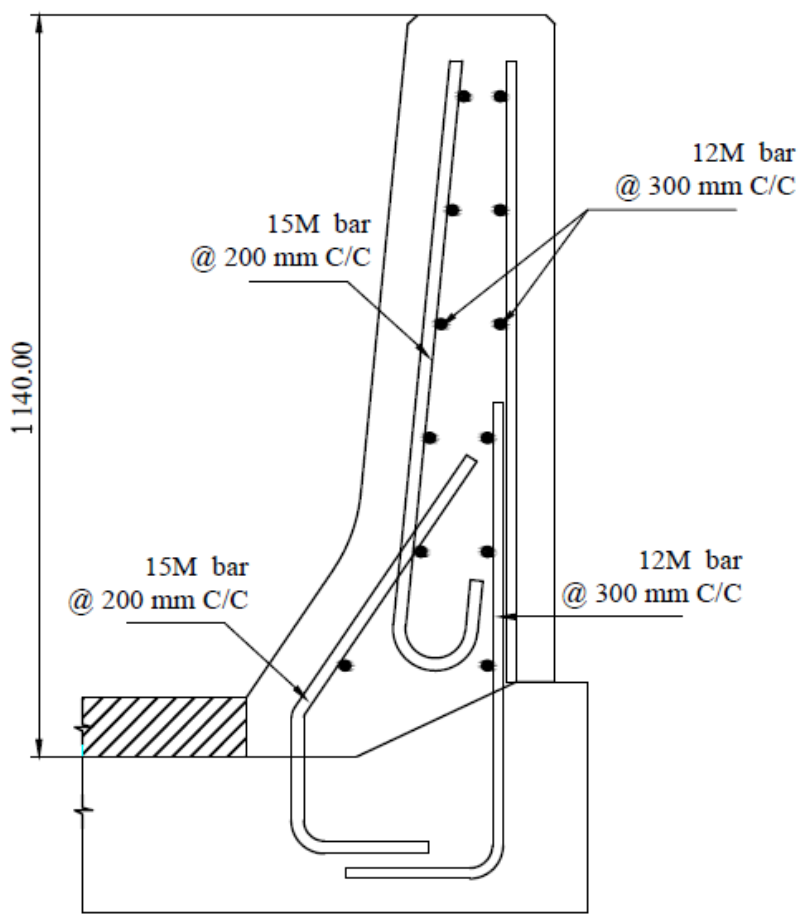

Figure 4. 2 Traditional PL-3 steel-reinforced barrier detailing with bent bars 


\subsection{Background of the Developed GFRP-Reinforced Barriers}

The design process of bridge barrier walls specified in the Canadian Highway Bridge Design Code (CSA, 2006a and CSA, 2006b) is based on the AASHTO guide specification for bridge railings (AASHTO, 1989) and the AASHTO guide for selecting, locating and designing traffic barriers (AASHTO, 1977). The initial design of the proposed PL-3 precast bridge barrier (Sennah et al., 2010) was carried out to meet the CHBDC design criteria specified for static loading at the anchorage between deck slab and the barrier wall. CHBDC specifies transverse, longitudinal and vertical loads of 210,70 and $90 \mathrm{kN}$, respectively, that can be applied simultaneously over a certain barrier length. CHBDC specifies that transverse load shall be applied over a barrier length of 2400-mm for PL-3 barriers. Since transverse loading creates the critical load carrying capacity, both the longitudinal and vertical loads were not considered in the design of barrier wall reinforcement and anchorage between the deck slab and the barrier wall. It should be noted that CHDBC specifies a live load factor of 1.7. Thus, the design impact load on PL-3 barrier wall over 2400-mm length is $357 \mathrm{kN}$ as for the design of vertical and horizontal reinforcement in the barrier wall. An AASHTO-LRFD bridge design specification (AASHTO, 2012) specifies yield-line analysis for the ultimate flexural capacity of the steel-reinforced barrier walls under vehicle impact. In the analysis, it was assumed that the yield-line failure pattern occurs within the barrier wall only and does not extend into the deck slab. This means that the deck slab must have sufficient resistance to force the yield-line failure pattern to remain within the barrier wall. The AASHTO-LRFD yield-line analysis is also based on the assumption that sufficient longitudinal length of barrier wall exists to result in the desired yield-line failure pattern. It should be noted that the yield-line analysis is typically invoked to evaluate the nominal strength of concrete bridge barriers with steel reinforcement. Due to the linear elastic behavior of GFRP reinforcing bars up to failure, the ASSHTO-LRFD yield-line equations cannot be used in the design of GFRP reinforcement in the barrier wall. However, both equilibrium of forces and compatibility of deformation conditions should be explicitly accounted for by implementing suitable analytical or numerical methods. Since such analytical or numerical modeling is as yet unavailable, evaluation of a full-scale structure or a prototype by load testing is the only means to qualify the proposed barrier detailing for use in Canada bridges. 
CHBDC prescribes guidelines for railing loads to be considered for the design of barrier anchorage and the edge of the deck slab in bridge cantilever barriers. According to the maximum lateral loads and dispersion angle of the load effect along the height of the barrier (see Table 2.10 and Figure 2.20), factored applied moments at barrier-deck junction given in CHBDC were derived from finite-element (FE) modeling. These are the resulting moments at the face of the barrier-to-deck joint used in the design of the barrier anchorage. Lateral load also exerts shear at the barrier anchorage which usually does not govern. CHBDC specifies that design of the barrier-deck anchorage capacity can be achieved by code-approved manual calculations or experimental testing under static loads to failure in lieu of conducting vehicle crash testing.

A recent design work conducted at Ryerson University on PL-3 bridge barrier has led to an economical glass fiber reinforced polymer (GFRP) bar detailing for sustainable construction. Such design incorporated the use of special sand-coated GFRP bars and end anchorage heads to ensure the optimal bond between concrete deck slab and the barrier wall. The design work conducted on PL-3 bridge barriers proposed the use of M15 (\#5) and M12 (\#4) GFRP bars as vertical reinforcement in the barrier front and back faces, respectively, with M12 (\#4) GFRP bars as horizontal reinforcement in both front and back faces of the barriers. Given the fact that the material cost of the GFRP bar differs based on the type of the bar (i.e. high-modulus versus standard modulus, straight-end bar versus bent bar, headed-end bar and bar with $180^{\circ}$-hook), three different GFRP bar proposals for barrier wall reinforcement and barrier wall-deck slab interface have been developed as shown in Figure 4.3. Proposal No.1 incorporated the use of high-modulus (HM) bars with headed-ends embedded in the deck slab. Proposal No.2 incorporated the use of standard-modulus (SM) bars with bent bars, while proposal No.3 incorporated SM bars with $180^{\circ}$ hooks embedded in the deck slab. Since established design criteria for GFRP-reinforced barriers is as yet unavailable, it was decided to build and test-tocollapse few barrier models to qualify the proposed barrier details for ultimate strength. Five full-scale barrier models of 1000-mm length, representing PL-3 barriers were erected and tested to-collapse to determine their ultimate load carrying capacities and failure modes. Four barriers were erected using GFRP bars. Two of these barrier models were built using high modulus (HM) GFRP bars with end anchorage heads, while the other two models were built using GFRP bent and $180^{\circ}$-hook, respectively, with standard modulus (SM) GFRP bars. The fifth barrier model 
was made of conventional steel reinforcement as per Ministry of Transportation of Ontario (MTO) barrier drawings that was used as reference sample. This chapter presents results from ultimate load tests in the form of crack pattern, deflection history, and ultimate load carrying capacity as compared to the design values specified in the Canadian Highway Bridge Design Code for barrier anchorage into the deck slabs. Results from ultimate load carrying capacities of the tested barriers would be taken to test the actual size bridge barriers at interior and exterior locations under the static load test, which would be presented in the next chapter.

It is worth to mention that a preliminary design work conducted at Ryerson University on PL-3 bridge barrier with GFRP ribbed bars led to the first world-wide vehicle crash test (Sennah et al, 2011). The crash test resulted in a MTO standard drawing SS110-92 released by the Ontario Ministry of Transportation in May 2011 (Figure 4.4). It should also be noted that Ryerson University research team conducted a second world-wide vehicle crash testing on PL-3 barrier using GFRP-HM bars with headed-end anchorage system (proposal No.1) in December 2011 (Sennah and Khederzadeh, 2012). As shown in Figure 4.4, the new arrangement of GFRP barrier system would significantly reduce the cost, given the increased spacing of vertical bars reduced to 300-mm. Also, the traditional lap splice of the vertical bars at back face of the barrier wall as well as the bents of these bars in the bridge deck slab, shown in Figure 4.2, were eliminated to reduce the material and labor cost. This decision was reached due to the fact that vertical bars at back face of the barrier walls are always in compression when the barrier is subjected to vehicle impact.

\subsection{Experimental Program on PL-3 Barrier Models}

Five full-scale PL-3 barrier models were erected and tested to-collapse to determine their ultimate load carrying capacities and failure modes. The length of the barriers was taken 900-mm for barrier models 1 and 2 and 1000-mm for barrier models of 3, 4 and 5 to investigate the barrier-deck anchorage strength. Concrete cover to front and back GFRP bars in the barrier walls and top layer of the bars in the deck slab was taken as 50-mm. The PL-3 barrier walls had a thickness of 225-mm from top surface, which was proportionally increased to 305-mm at a depth of $800-\mathrm{mm}$ and further increased to $475-\mathrm{mm}$ at depth of $1025-\mathrm{mm}$ to the deck slab-barrier joint. 


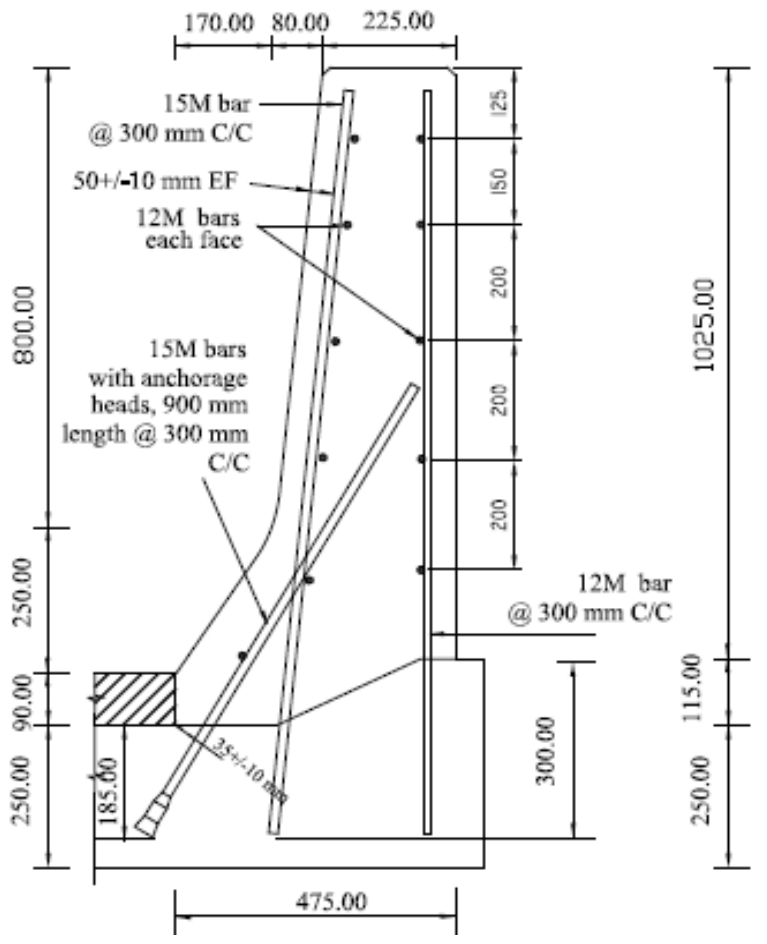

a) Proposal No. 1

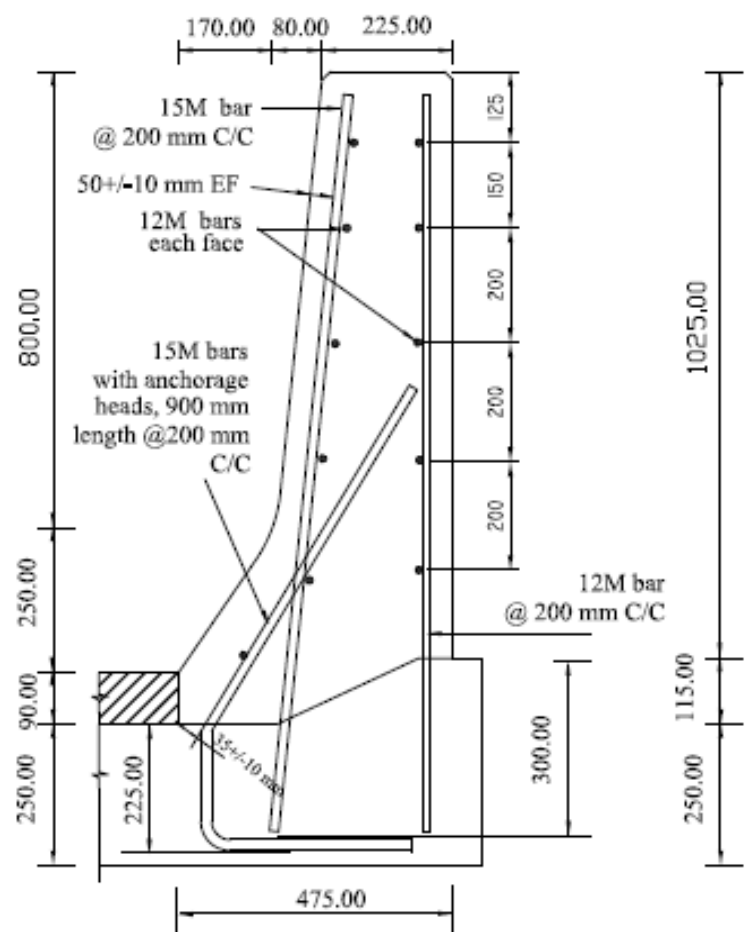

(b) Proposal No. 2

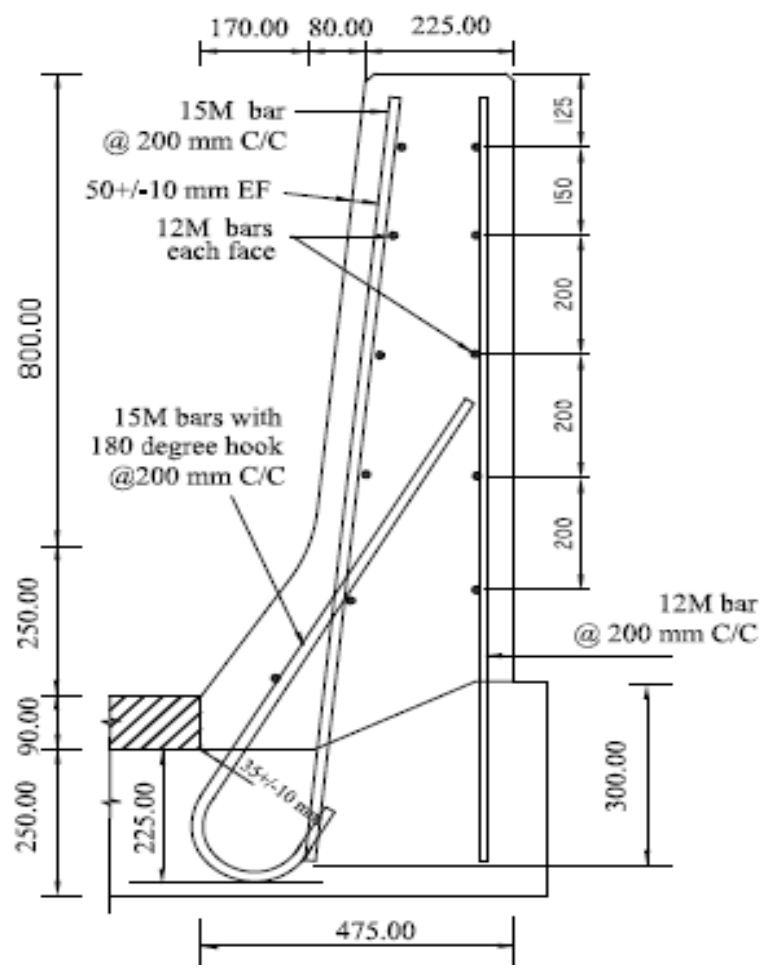

c) Proposal No. 3

Figure 4. 3 Proposed Ryerson University barrier detail 


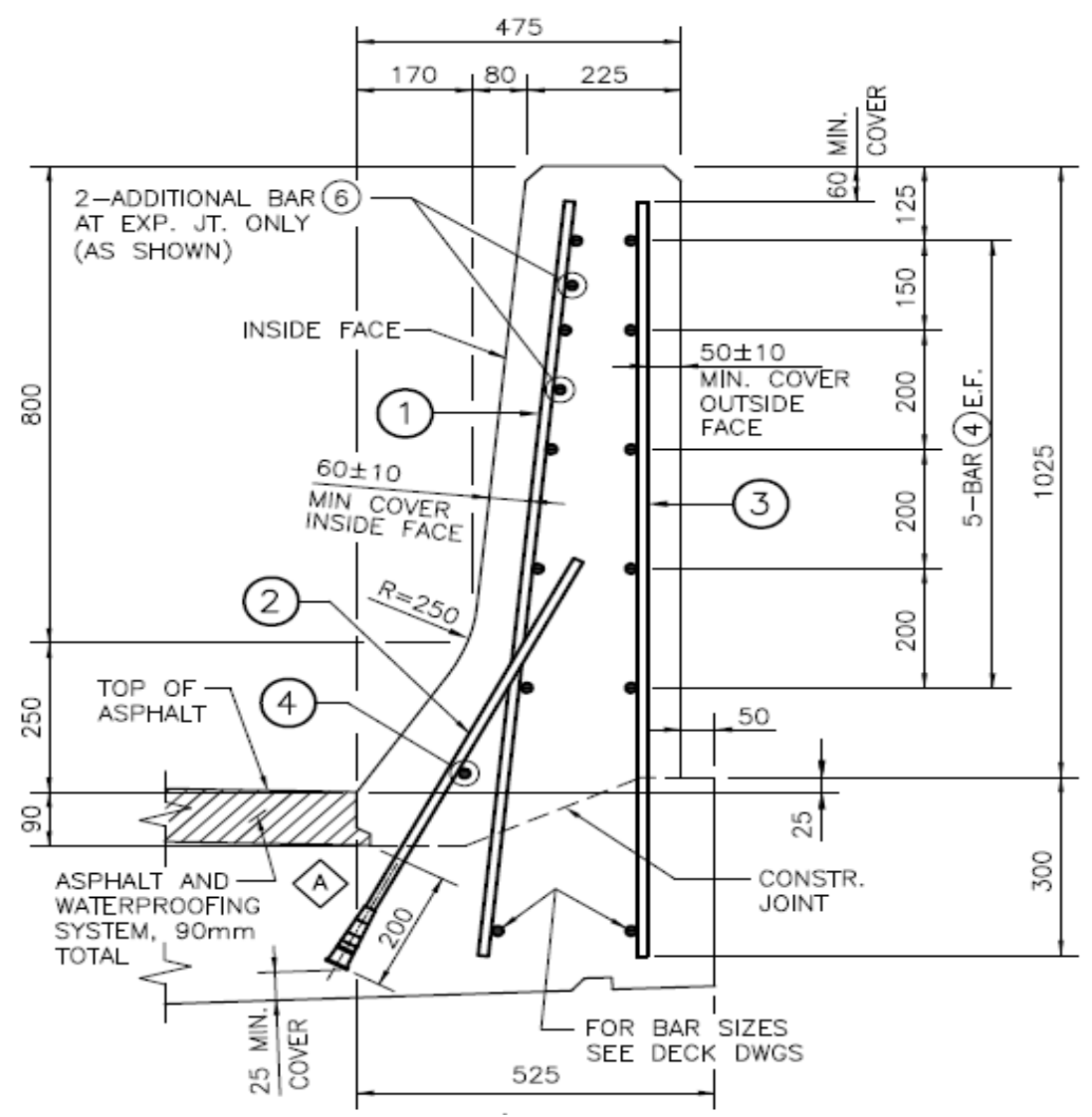

Figure 4. 4 GFRP-reinforced barrier detailing from MTO standard drawing SS110-92 (Adopted: MTO, May 2011)

The concrete deck slab had an average thickness of 300-mm under the barrier wall which was reduced to 250-mm in the slab portion, and reinforced with M20 steel bars as top reinforcement layer with 100-mm spacing and M15 steel bars at 300-mm spacing as bottom reinforcement layer in the direction normal and parallel to the wall, respectively. In barrier models 1 to 4 , sandcoated GFRP bars were used as vertical and horizontal reinforcement in front and back faces of the barrier, while the fifth barrier was constructed using reinforcing steel bars only as a reference specimen. The characteristic compressive strength of the concrete forming the barrier models was obtained from core sampling as $25.4 \mathrm{MPa}$. More details regarding core sampling of the barrier wall and calculations on characteristic compressive strength can be found in Appendix B.

Barrier Model 1 was constructed using high-modulus (HM) GFRP bars with bar detailing shown in Figure 4.3(a). 15M-GFRP bars with headed-end were placed at 300-mm center-to-center spacing in front face of the barrier at deck-barrier joint. In addition, 15M-GFRP bars were placed 
at front face of the barrier wall extending into the deck slab at 300-mm spacing. 12M-GFRP bars were placed as horizontal reinforcement as well as vertical reinforcement in back face of the wall at 300-mm spacing. Figure 4.5 shows view of GFRP bar arrangement in Model 1.
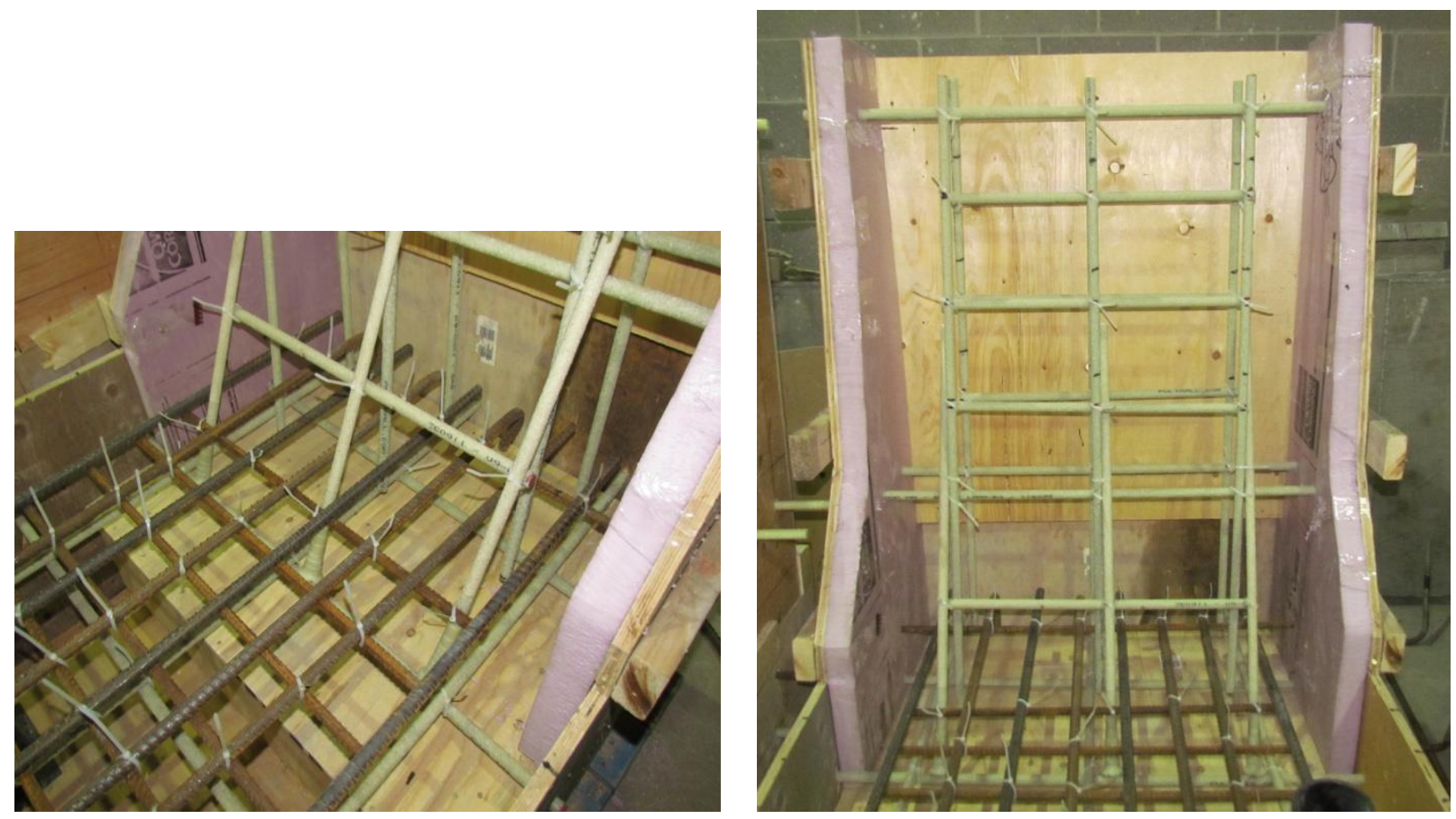

Figure 4. 5 Views of GFRP bars in barrier Model 1

Model 2 barrier incorporated the use of standard modulus (SM) GFRP bars in the barrier wall. At the junction of barrier to the deck slab, M15 GFRP bent bars were placed at 200-mm spacing in barrier front face. In addition, M15-GFRP bars were placed at 200-mm spacing at the tapered portion in the front face of the barrier, with the bars extended into the deck slab as shown in Figure 4.3(b). M12-GFRP bars at 200-mm spacing were used as horizontal bars as well as vertical bars in back face of the barrier wall. Figure 4.6 shows view of GFRP bars in barrier Model 2 before concrete casting. 

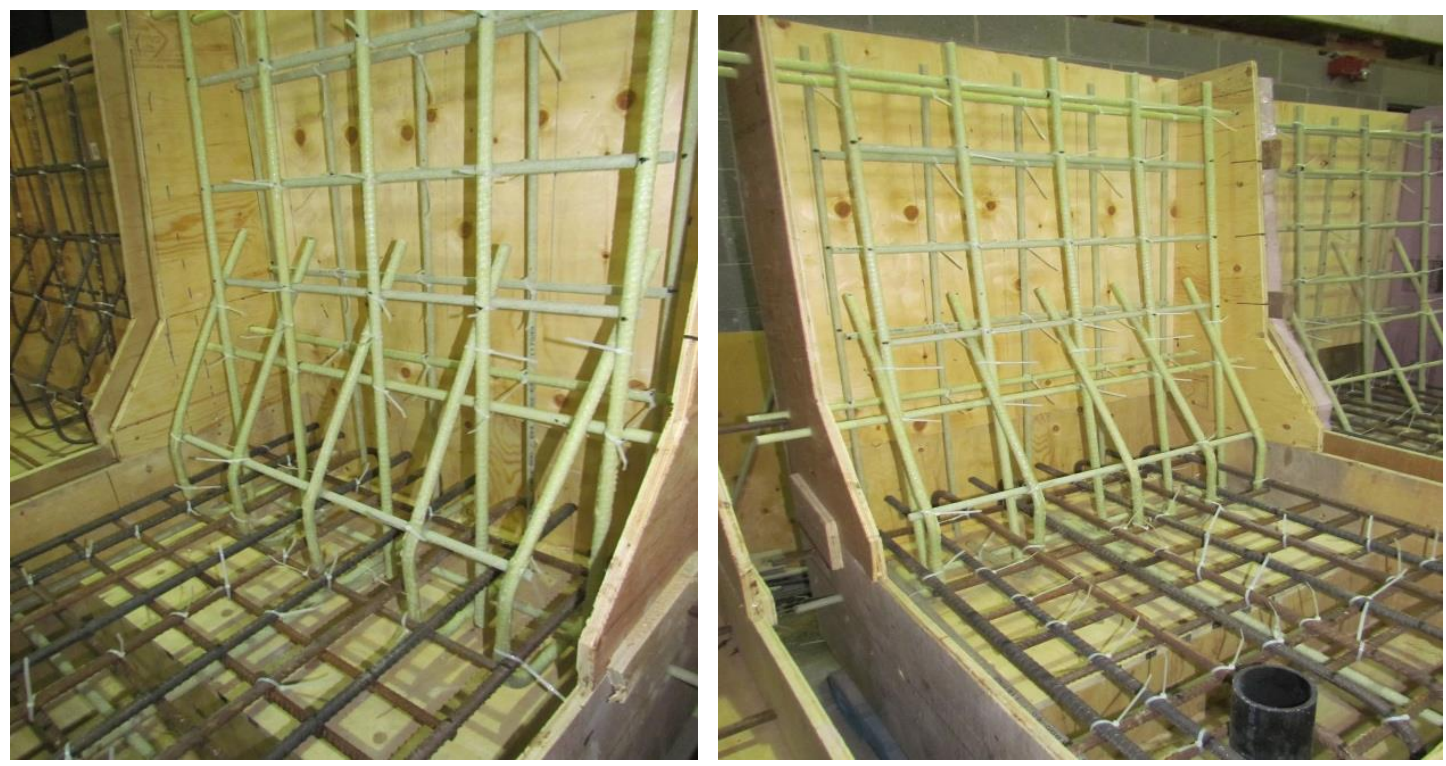

Figure 4. 6 Views of GFRP bars in barrier Model 2

Similar to barrier Model 2, barrier Model 3 was built using SM-GFRP bars but with $180^{\circ}$-hook at the junction of deck slab to the barrier wall. The arrangement of GFRP reinforcing bars in the wall portion was taken similar to the barrier Model 2. Figure 4.7 shows views of the placement of GFRP bars in the formwork before concrete casting. Barrier Model 4 was constructed similar to Model 1 except that the HM-GFRP vertical bars were placed at 150-mm center-to-center spacing representing the barrier wall at its ends or at the construction joint locations. However, the spacing for GFRP horizontal bars as well as vertical bars in the back face of the wall was kept as 300-mm. Figure 4.8 shows views of formwork with GFRP installation prior to concrete casting. Barrier Model 5 was constructed as reference sample using conventional steel reinforcement, as per MTO standard drawing for reinforced steel bridge barriers. Figure 4.9 shows a photo of this barrier model with steel reinforcement at front and back faces of the wall as vertical and horizontal reinforcement. The M15 steel bars with $180^{\circ}$-hook were placed to reinforce the top tapered portion of the barrier front face, while M15 bent bars were placed in bottom tapered portion extending into the deck slab, all bars placed at 200-mm center-to-center spacing. M12 steel bars were placed in the model as horizontal bars as well as vertical bars in back face of the wall at 300-mm spacing. Table 4.1 summarizes description of the tested barrier models. 

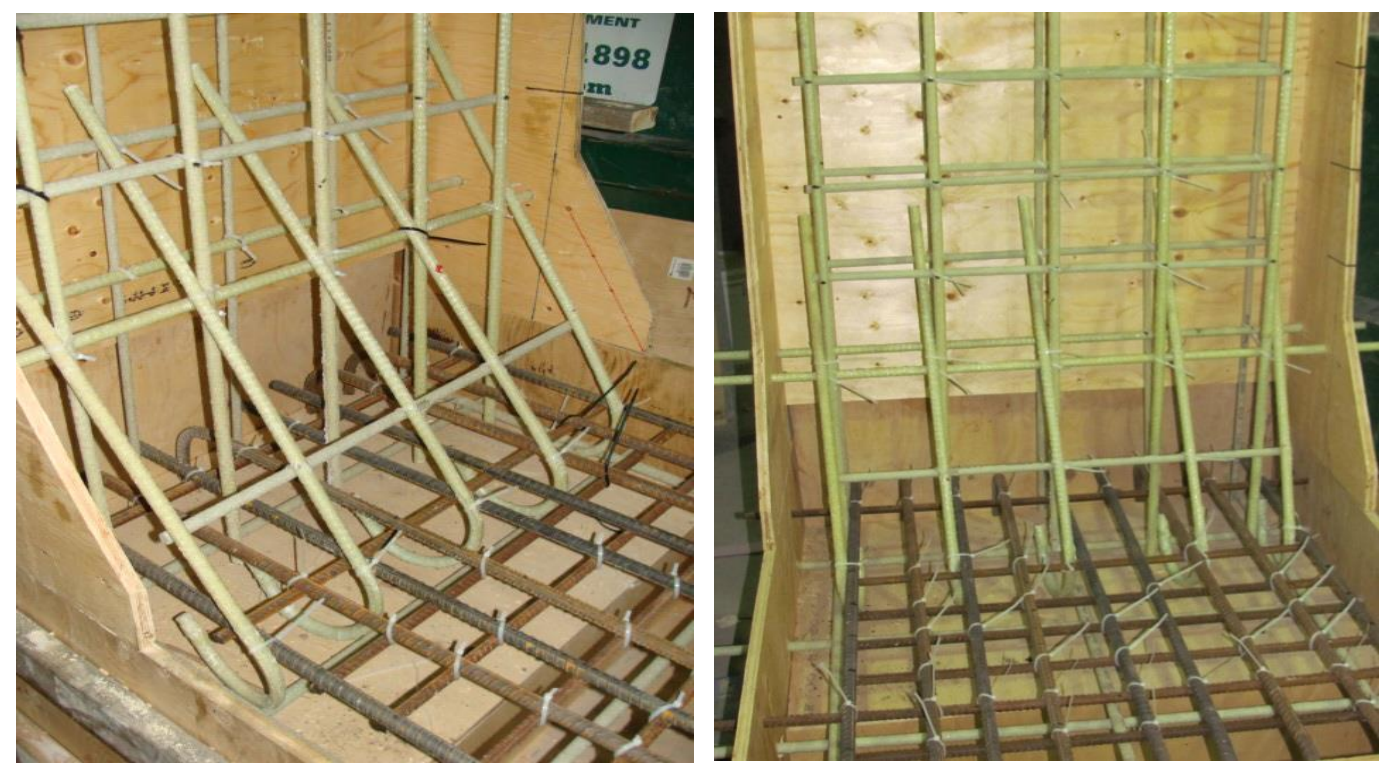

Figure 4. 7 Views of GFRP bar arrangement in barrier Model 3
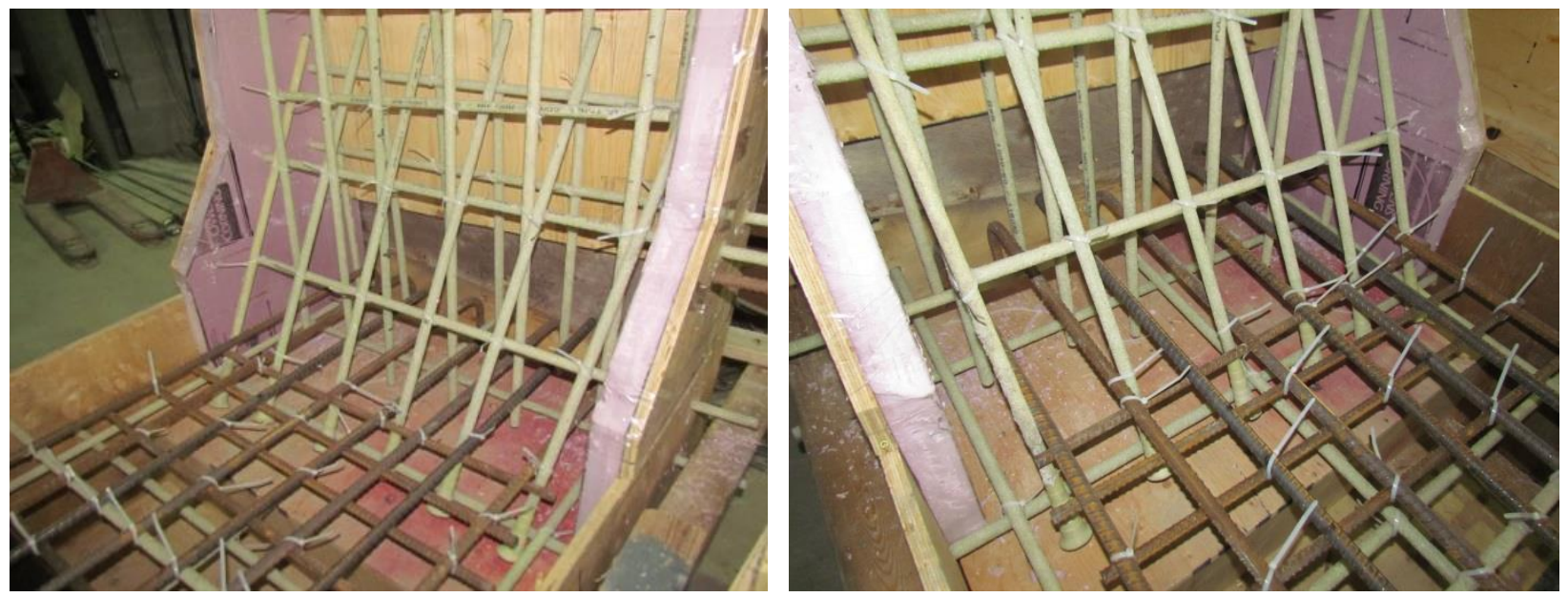

Figure 4. 8 Views of GFRP bars in barrier Model 4

Table 4. 1 Barrier Designations used in current study for each model

\begin{tabular}{|c|l|}
\hline Model No. & \multicolumn{1}{|c|}{ Description of Models } \\
\hline 1 & Specimen No. 1 with GFRP-HM and headed-end bars at 300-mm spacing \\
\hline 2 & Specimen No. 2 with GFRP-SM and bent bars at 200-mm spacing \\
\hline 3 & Specimen No. 3 with GFRP-SM and $180^{\circ}$ hook bars at 200-mm spacing \\
\hline 4 & Specimen No. 4 with GFRP-HM and headed-end bars at 150-mm spacing \\
\hline 5 & Specimen No. 5 with conventional steel reinforcement at 200-mm bar spacing \\
\hline
\end{tabular}




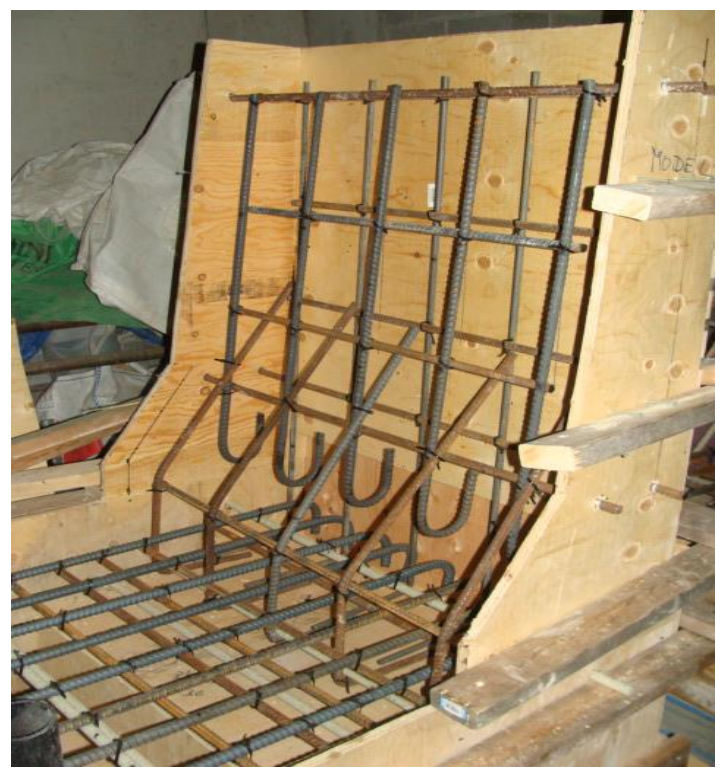

Figure 4. 9 View of steel bars arrangement in barrier Model 5

All barrier models were cast in the same day using the same concrete batch. The casting was scheduled so that the deck portion was cast first, followed by casting the wall portion of the barrier walls. At each time step during casting, concrete was vibrated uniformly. To prevent the presence of void at deck-wall junction or wall tapered portion joint, the wall and the deck at these locations were hammered for the ease of movement of concrete in the joints. Figure 4.10 illustrates images of barrier wall during casting.

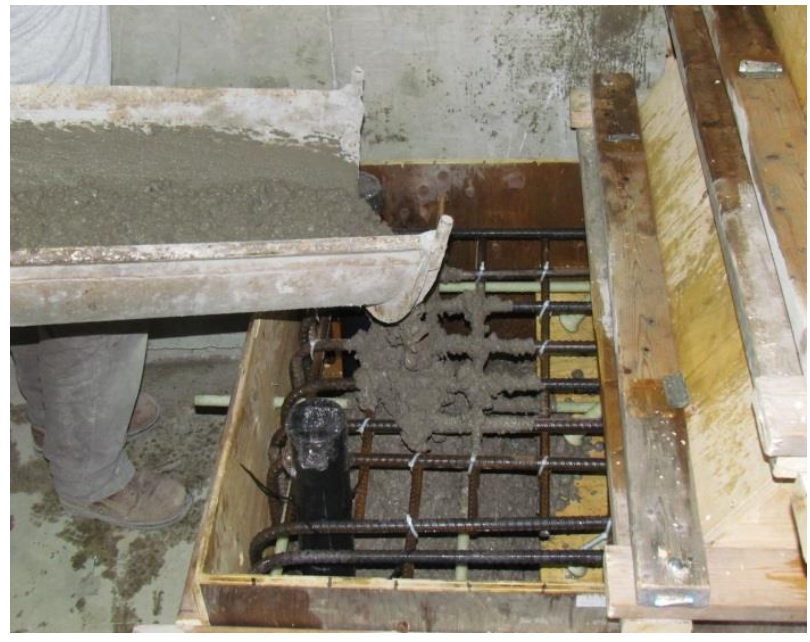

a) Deck casting

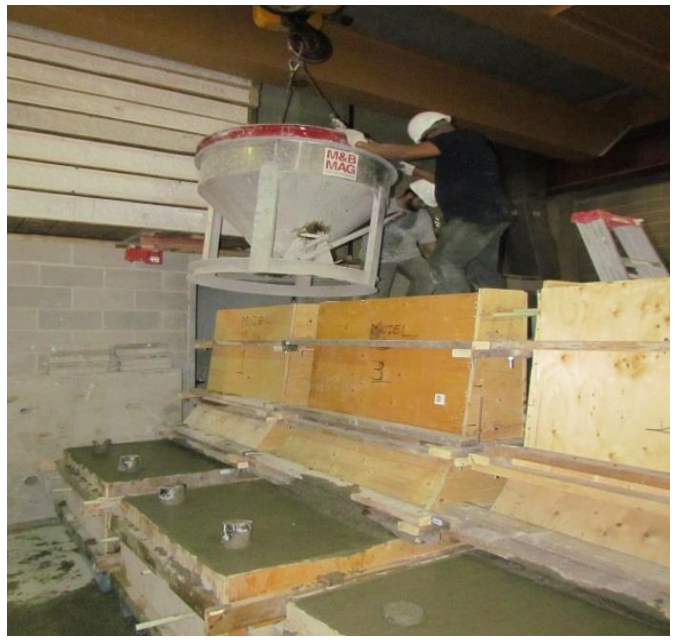

b) Deck after casting and wall during casting

Figure 4. 10 Photo of casting of the barrier models 
It should be noted that the cast barrier models had the barrier wall connected to the projecting cantilever deck slab to allow for rotation at the barrier-deck junction. The cantilever deck slab was fixed to an end concrete block that was anchored to the laboratory concrete floor using tiedown anchoring system.

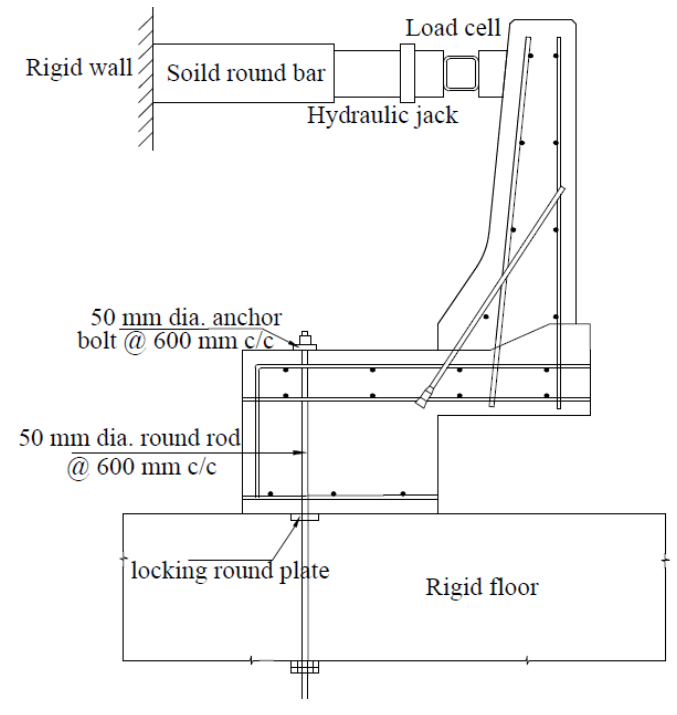

a) Schematics diagram of the test setup

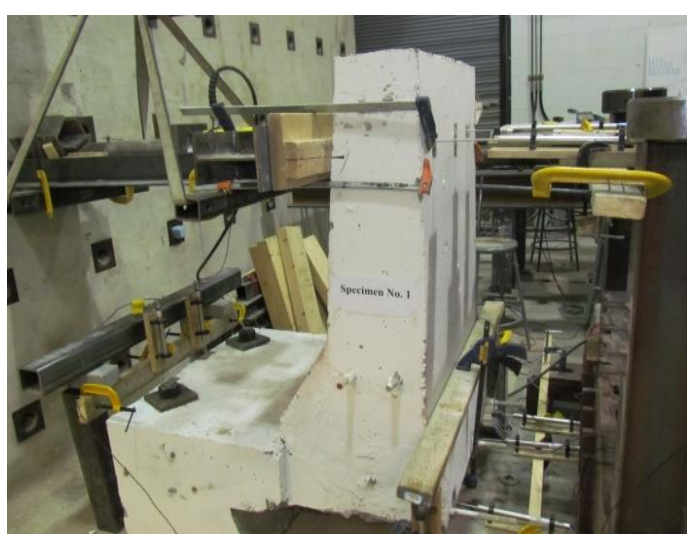

b) View of the test setup for Model No. 1

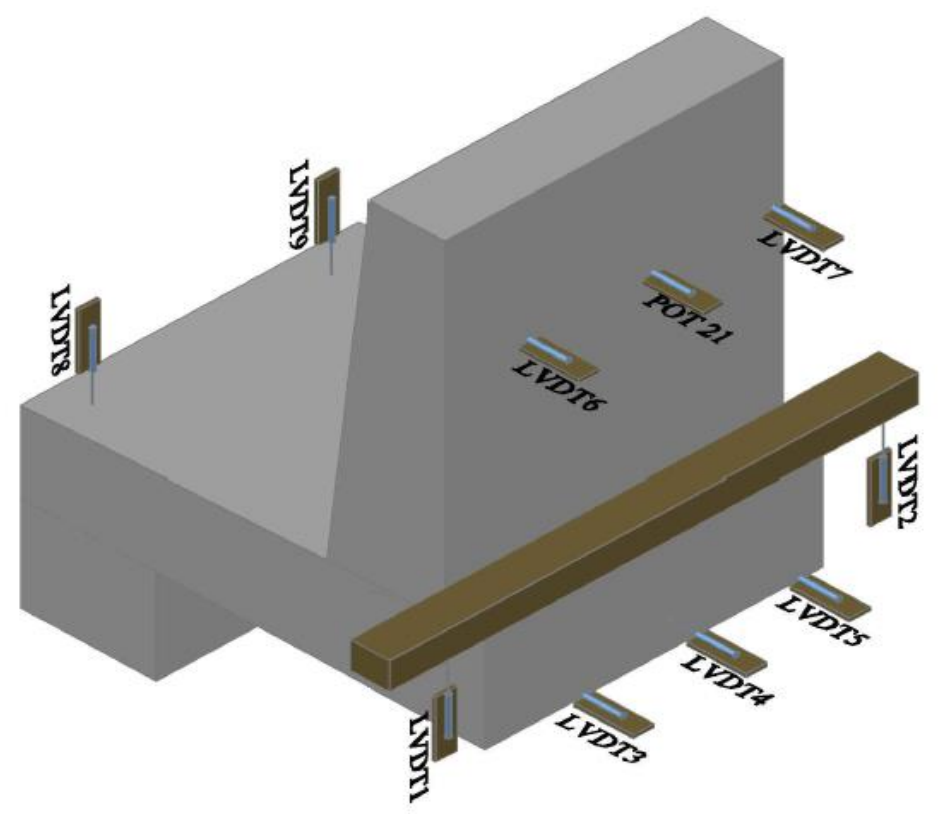

c) Schemactic diamgram showing LVDT locations

Figure 4. 11 Test setup and sensor locations for the barrier models 
Figure 4.11 shows schematic diagrams and view of the test setup with the location of LVDTs. Each barrier specimen was supported over the structural laboratory floor, then, tied down to the floor using 50-mm diameter threaded rods. Each rod was placed at 600-mm center-to-center and tightened by applying a specified torque to control the slab uplift during testing. A $900 \mathrm{kN}$ hydraulic jack was used to apply horizontal load to the barrier wall. A universal flat load-cell of $900 \mathrm{kN}$ capacity was used to measure the applied loads on barrier models. SYSTEM 6000 data acquisition unit was used to record readings from all sensors.

Each specimen was tested under increasing monotonic load up to collapse. During the test, jacking load was applied in increment of $10 \mathrm{kN}$. At each load increment, the load was maintained for few minutes to observe crack initiation and propagation as well as changes in barrier geometry as depicted from LVDT readings. Failure of the barrier model was attained when the readings from sensors were increasing while the model did not take any further increase in load. Figure 4.11c shows LVDT locations, which were (i) at the top of the back side of the barrier wall oriented in the direction of the applied load; (ii) at the bottom of the deck slab to measure slab movement under transverse load; (iii) at the top of the back side of the deck slab to measure any possible uplift under load; and (iv) at back side of the wall to capture the possible vertical displacement of the barrier wall.

\subsection{Experimental Results for the Tested PL-3 Barrier Models}

Barrier model 1 with HM-GFRP bars and headed-end anchors was tested to-complete-collapse. The length of this barrier was 900-mm in longitudinal direction. The load was applied at 990-mm above the deck slab per CHBDC for PL-3 barriers tested under static test. The load was applied manually using hydraulic jack and load increments were captured by the load-cell attached to the system. The load was applied in increment of $10 \mathrm{kN}$ to observe the crack initiation in the barrier wall and the slab. First visible flexural crack appeared at the junction of barrier wall-to-deck slab at load of $20 \mathrm{kN}$ as depicted in Figure 4.12. With increase in load, cracks were further developed at the corner of deck-to-slab junction down into the deck slab. Similarly, cracks were initiated in the deck slab at 25 to $30 \mathrm{kN}$ due to combined flexure and tension. 
At load of $40 \mathrm{kN}$, flexural crack was observed at junction of the upper and lower portions of the tapered wall. At this loading stage, cracks started to propagate horizontally through the thickness at the intersection of deck-to-barrier in addition to the cracks observed earlier in the slab. Cracks propagated significantly untill barrier reached the failure load of $95.49 \mathrm{kN}$. The barrier primary failure took place at corner of deck-to-slab interface due to diagonal tension crack failure. As such, the ultimate moment resisted per meter length of the barrier wall was $95.49 \mathrm{kN}$ x $0.990-\mathrm{m}$ height / 0.90-m width equal to $105.04 \mathrm{kN} . \mathrm{m} / \mathrm{m}$, which was greater than the CHBDC factored design moment of $83 \mathrm{kN} . \mathrm{m} / \mathrm{m}$ shown in Table 2.11 for interior locations of the barrier wall. At failure stage, the ultimate net lateral deflection of barrier wall was recorded as $24.45-\mathrm{mm}$, while the deck slab showed an average horizontal displacement of 1.63-mm. At failure, an average deck uplift of 2.87-mm was observed. The net barrier lateral deflection in all barrier models was determined by subtracting the deck horizontal displacement and the proportional ratio for deck uplift. Figure 4.13 shows load-deformation curves recorded for the barrier Model 1.

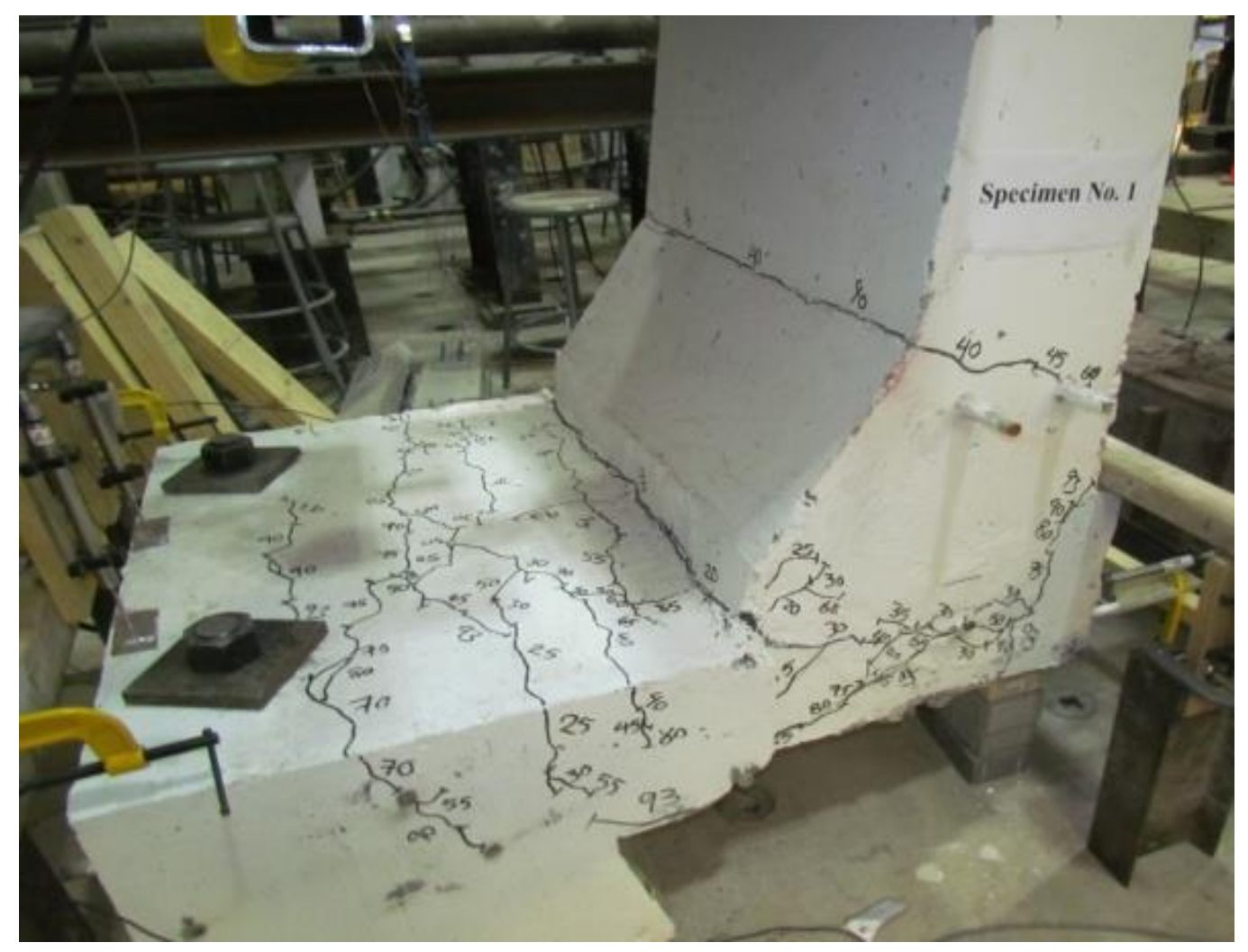

a) General view of cracks in the deck and barrier wall 


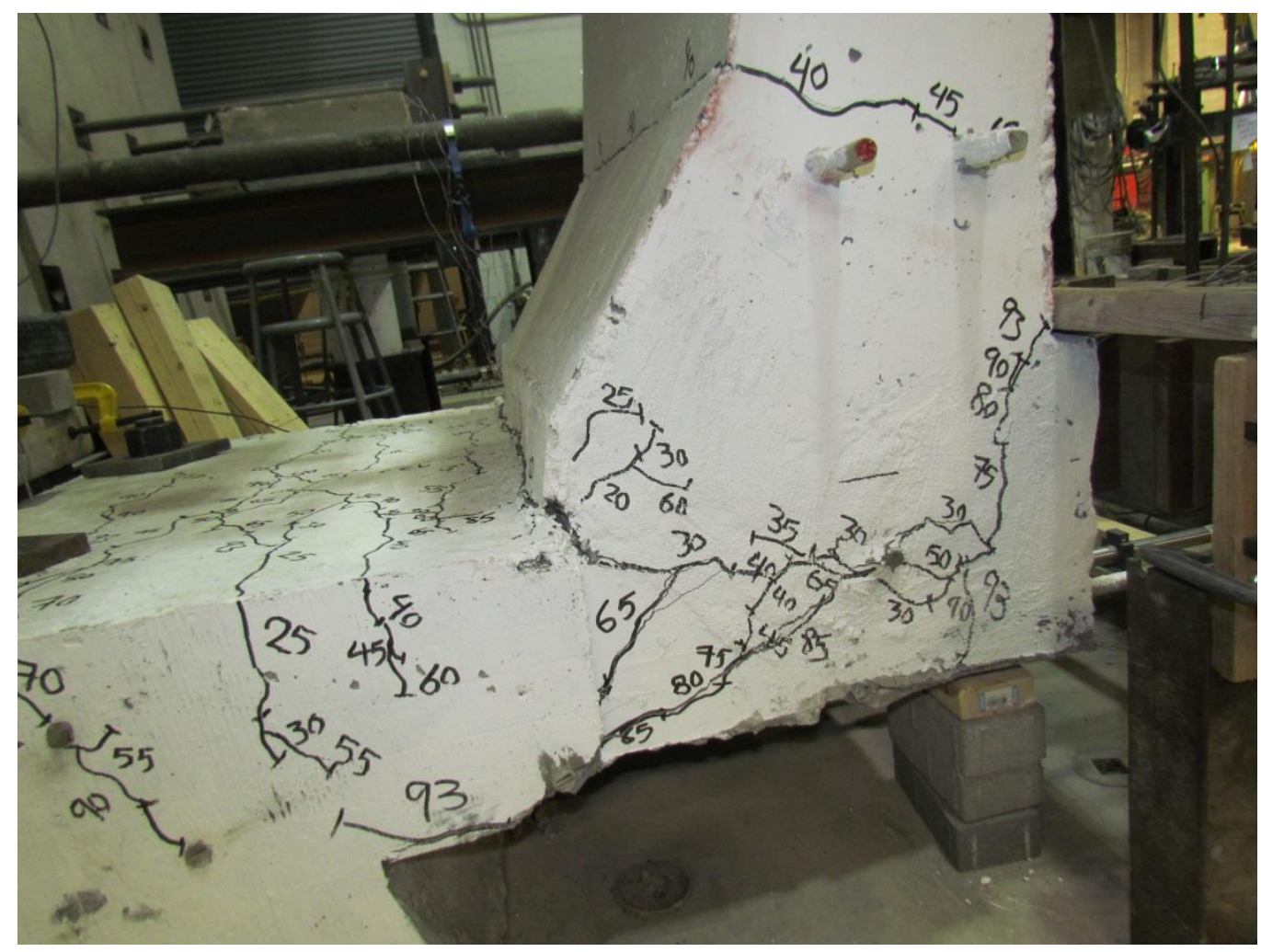

b) Close-up view of crack pattern at barrier-deck junction (right view)

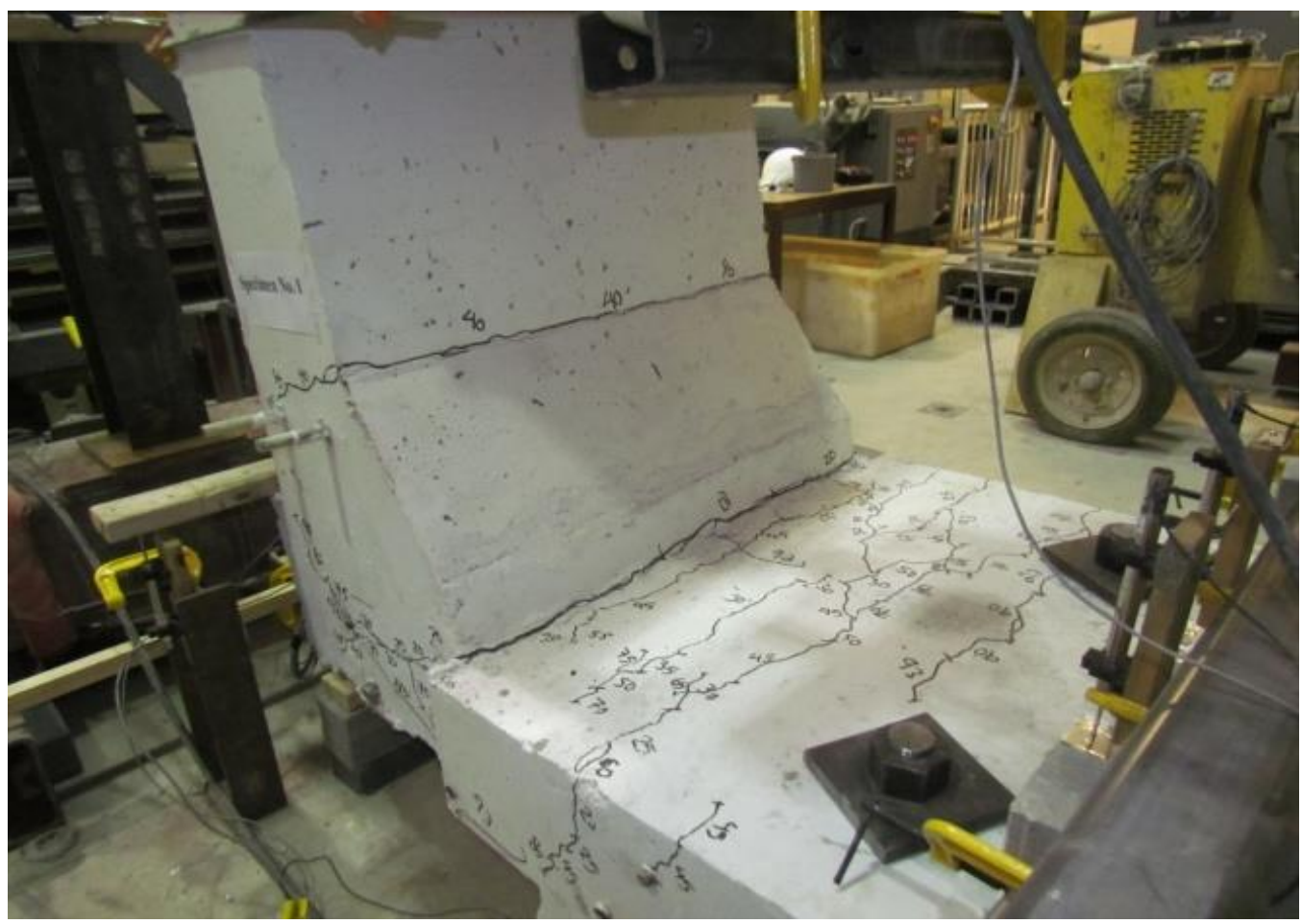

(c) View of cracks in the barrier and deck from the left side 


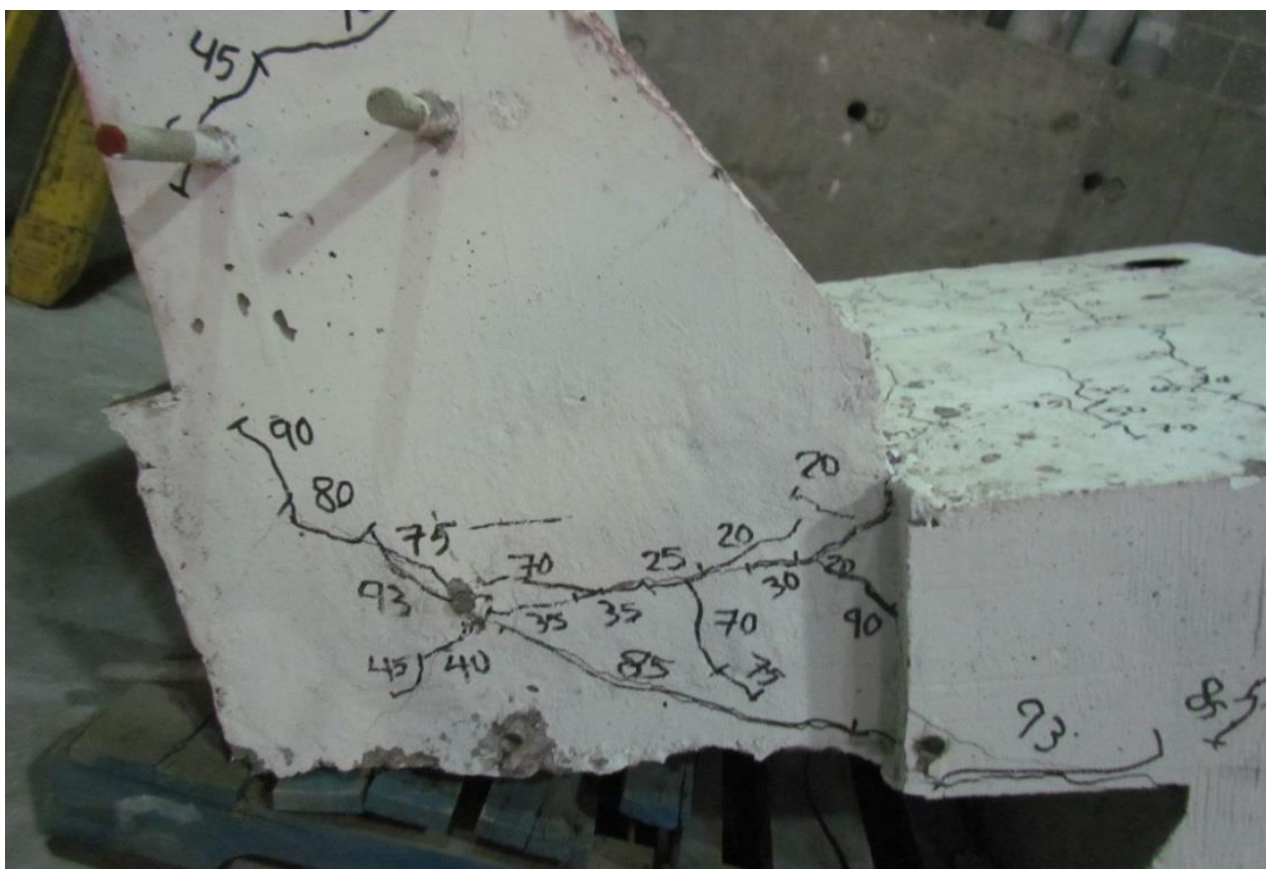

(d) Close-up view of crack pattern at the barrier-deck junction (left view)

Figure 4. 12 View of the crack pattern in barrier Model 1 with HM-GFRP bars

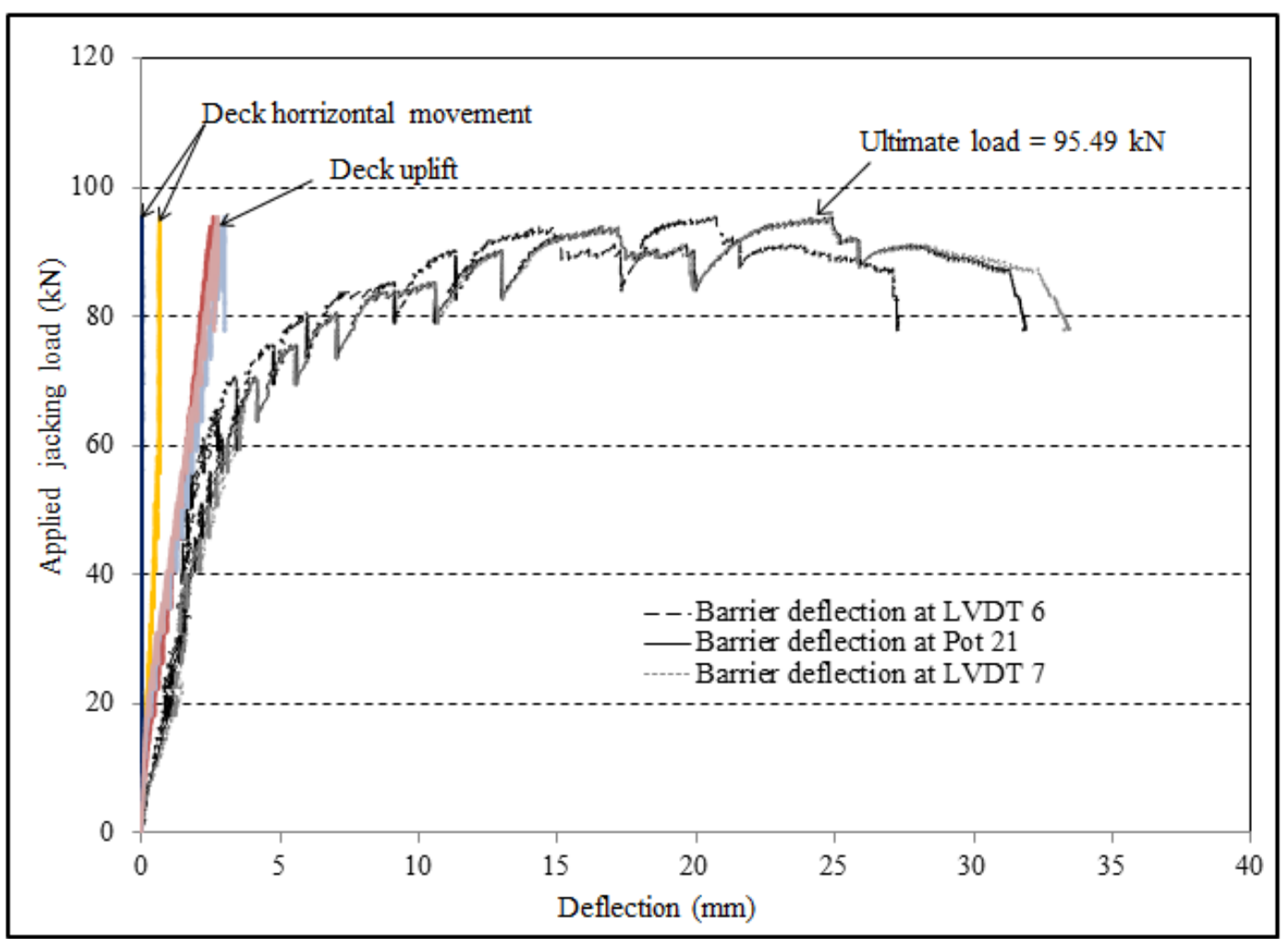

Figure 4. 13 Load-deflection curves for the barrier wall, deck horizontal movement and deck uplift in barrier Model 1 
In barrier Model 2, standard modulus GFRP bent bars were placed vertically in front face of the barrier wall at 200-mm spacing. The barrier had a length of 1000-mm in longitudinal direction. The load was applied at 990-mm above the deck slab similar to barrier Model 1. Figure 4.14 shows view of the crack pattern at failure. In this barrier model, the first flexural crack was observed at fixed end of the deck slab at load of $40 \mathrm{kN}$. By increasing the load to $50 \mathrm{kN}$, cracks were further developed in the deck slab and vertical cracks appeared on each side of the deck slab due to combined tension and flexural loadings. At $60 \mathrm{kN}$ load, a horizontal flexural crack was observed at the deck-to-barrier junction. A similar flexural crack was initiated at junction of the upper and lower portion of the tapered wall at load increment of $65 \mathrm{kN}$, which was further developed into the wall thickness at higher load. At load range of 70 to $100 \mathrm{kN}$, cracks propagated further into the slab and barrier thicknesses. At $100 \mathrm{kN}$ load, a flexural crack was observed at top tapered portion of the barrier wall. With increase in the applied load, cracks propagated further into the deck thickness at barrier-deck junction that led to failure at $116.32 \mathrm{kN}$ primarily due to diagonal tension crack at barrier-deck corner joint. As such, the maximum moment reached at failure of deck-to-barrier junction was $116.32 \mathrm{kN}$ x $0.990-\mathrm{m}$ height equal to $115.2 \mathrm{kN} . \mathrm{m} / \mathrm{m}$. This ultimate load carrying capacity was greater than the factored design moment of $83 \mathrm{kN} . \mathrm{m} / \mathrm{m}$ specified in CHBDC at interior location shown in Table 2.11. The barrier wall exhibited a net lateral deflection of 31.25-mm with deck horizontal displacement of 4.37-mm and deck uplift of 5.3-mm at failure. The load-deflection curves captured by LVDTs are displayed in Figure 4.15.

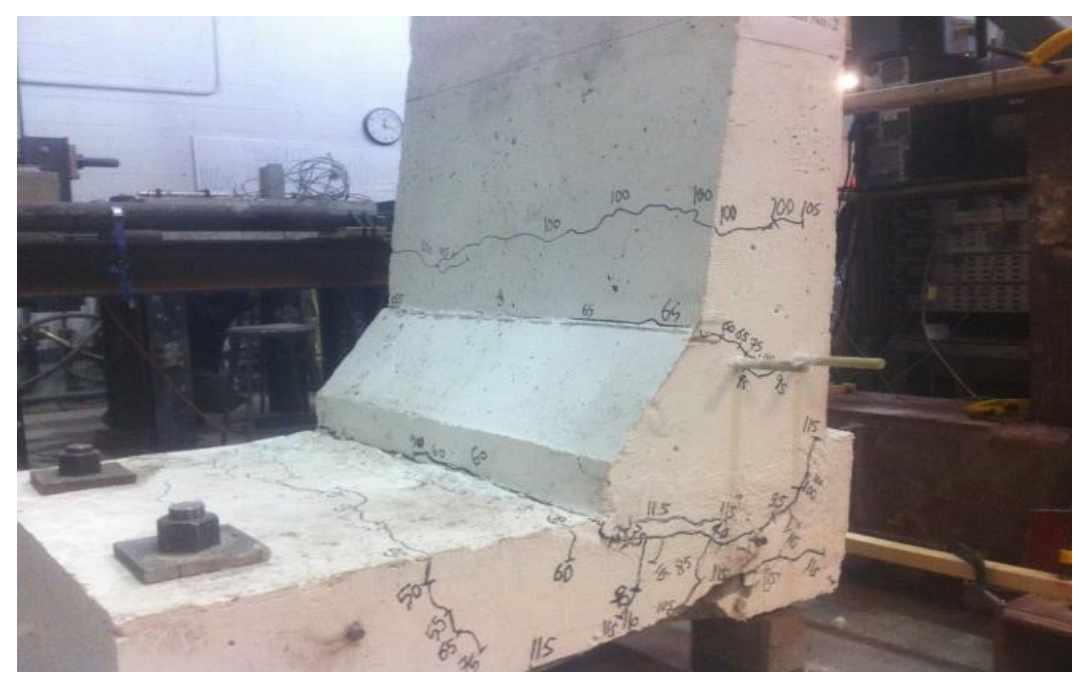

a) View of cracks in the barrier and deck from right side 


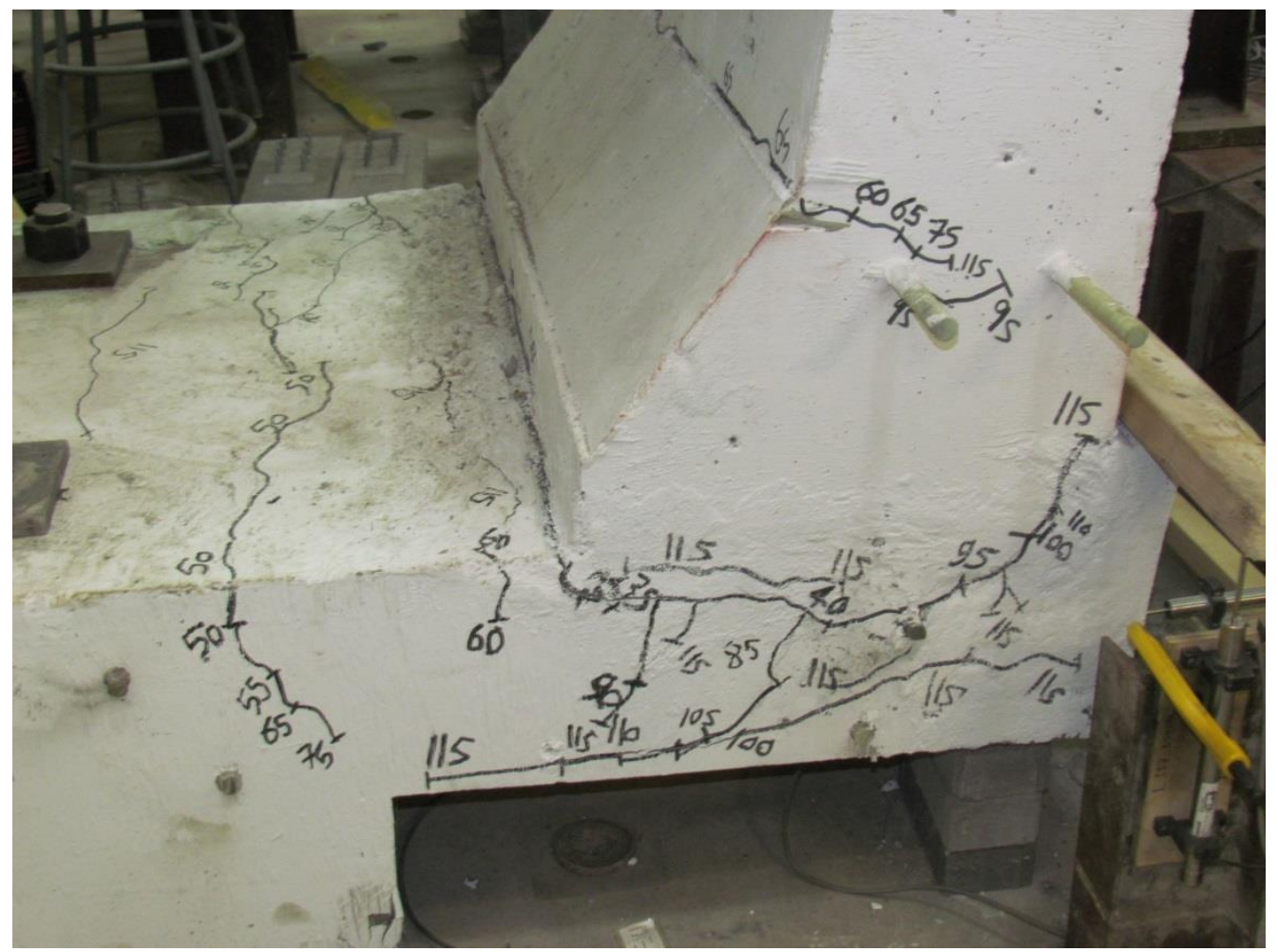

b) Close-up view of crack pattern at barrier-deck junction from the right side

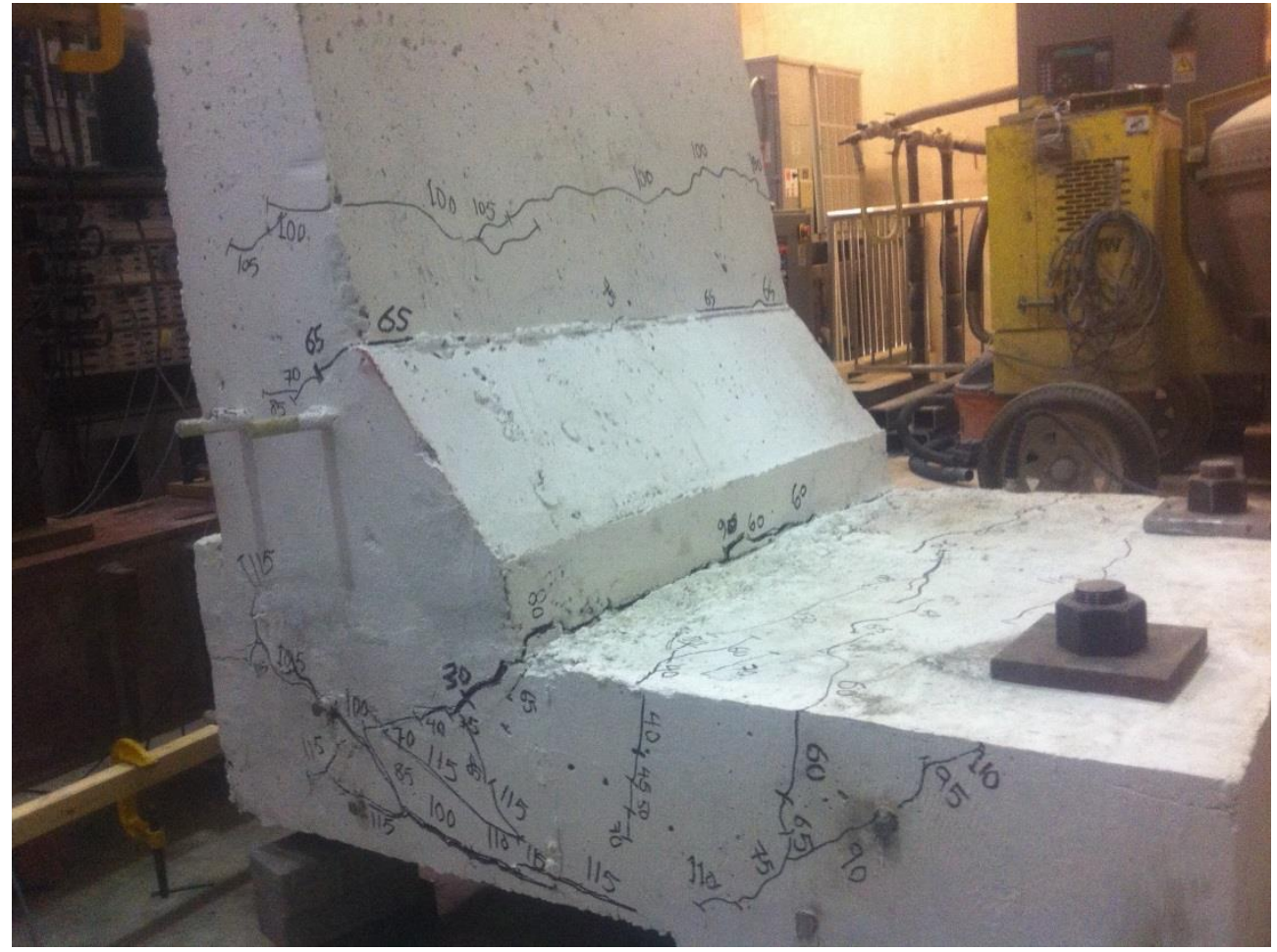

c) View of cracks in the deck and barrier wall from the left side 


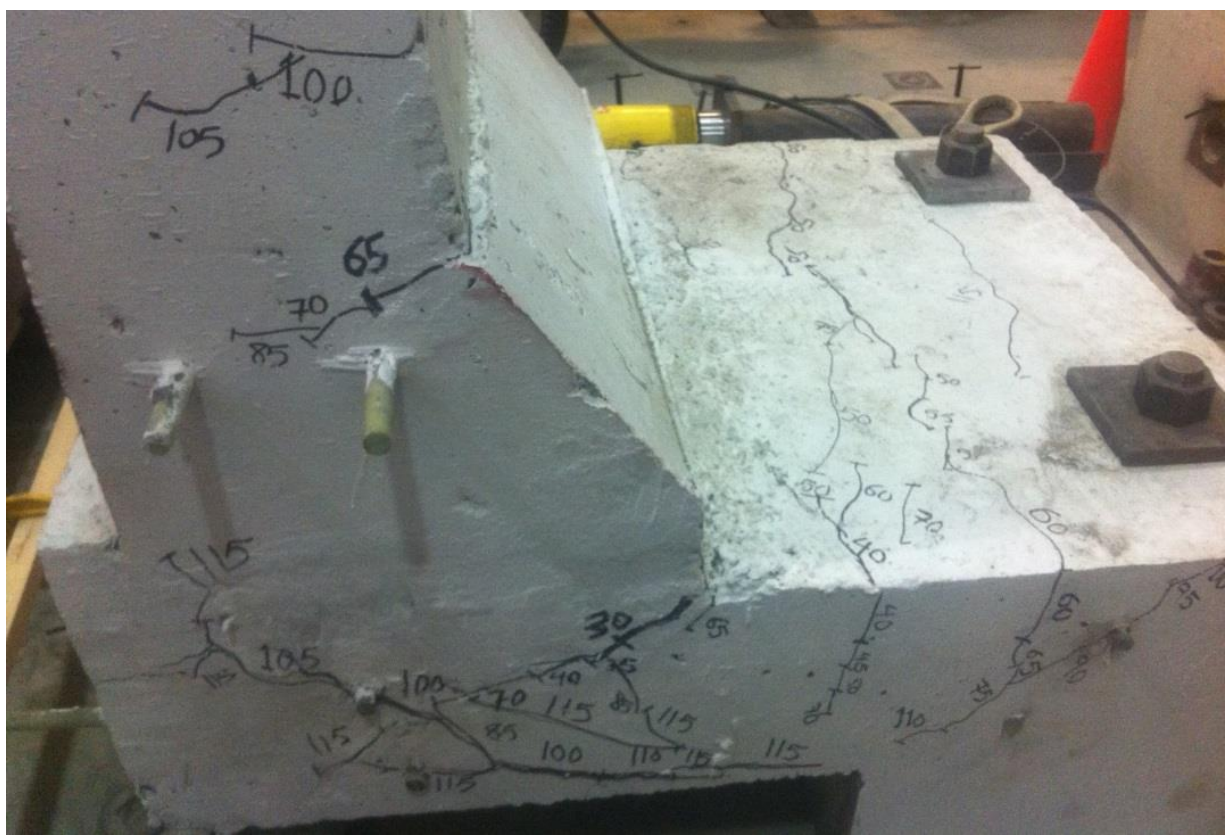

d) Close-up view of crack pattern at barrier-deck junction from left side

Figure 4. 14 View of the crack pattern in barrier Model 2 with SM-GFRP bent bars

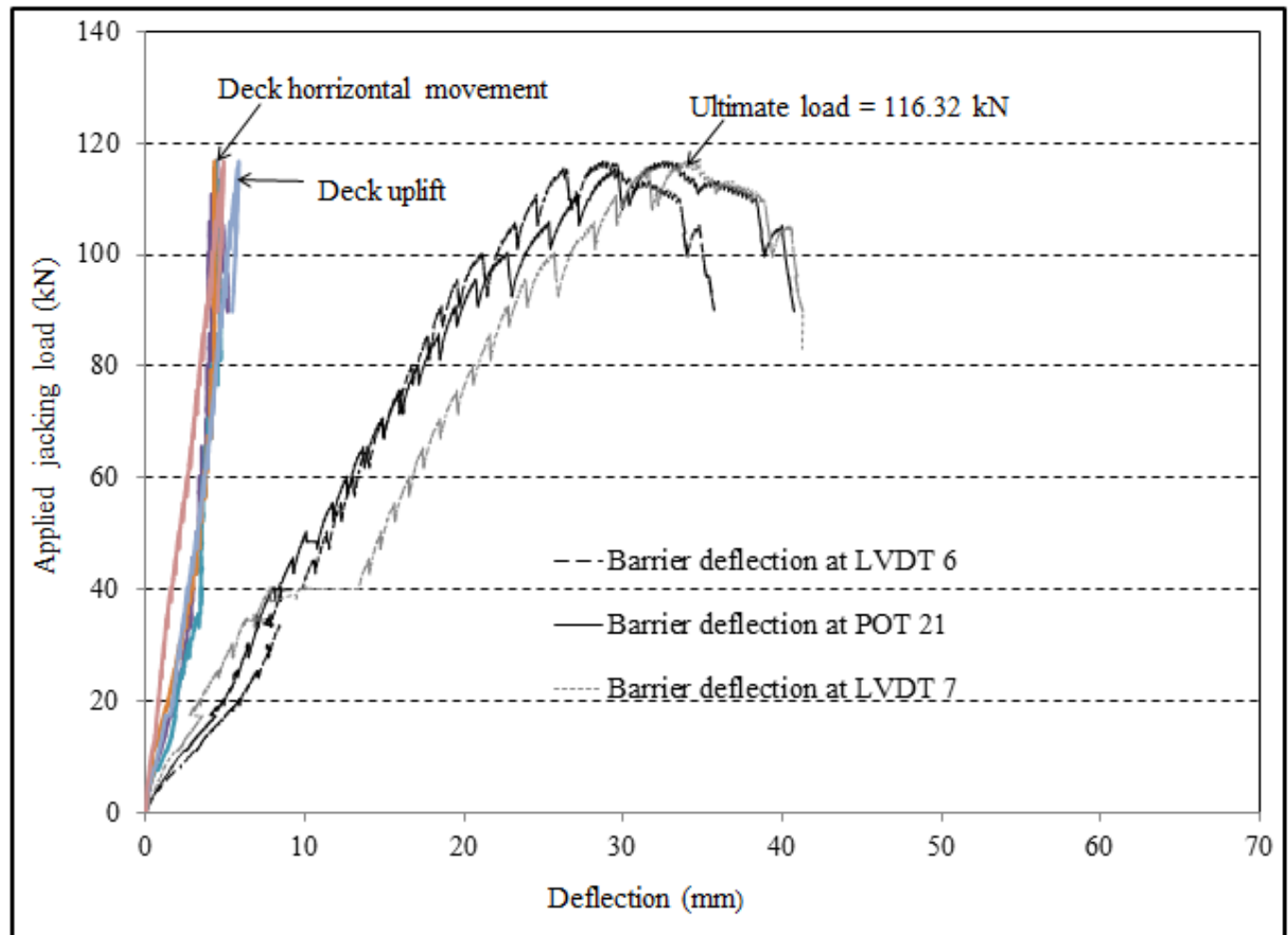

Figure 4. 15 Load-deflection curves for barrier wall, deck horizontal movement and deck uplift in barrier Model 2 
Barrier Model 3 was constructed using standard modulus GFRP bars by placing GFRP bars with $180^{\circ}$-hooks at 200-mm spacing as vertical bars at front face of the barrier wall. The barrier had a length of 1000-mm in longitudinal direction. Similar to barrier Models 1 and 2, the load was applied 990-mm above the deck slab. Figure 4.16 shows view of the crack pattern at failure in barrier Model 3. The first visible flexural crack was observed at deck-barrier junction at an applied load of $30 \mathrm{kN}$. At this load, other flexural crack was observed at junction of the top and bottom tapered portions of the barrier wall as well as in the deck slab. With increase in the applied load to $45 \mathrm{kN}$, cracks started to propagate into the barrier-deck corner down into the slab thickness. Also, vertical cracks were detected in the deck slab when the load increased from 50 to $70 \mathrm{kN}$ due combined tension and flexural loading on the deck slab. At this loading stage, cracks were further developed in corner junction of barrier-to-deck as well as through the thickness in both the barrier wall and the deck slab. At $100 \mathrm{kN}$, a second flexural crack was observed in the top tapered portion of the barrier wall, extending significantly through thickness at the same load increment. Moreover, several flexural cracks were formed on the top surface of the deck slab at load ranging from 50 to $100 \mathrm{kN}$. Consequently, the barrier failed at load of $107.13 \mathrm{kN}$ at the corner of barrier-to-deck junction due to diagonal tension crack failure. The resulting maximum moment at barrier-deck junction was calculated as $107.13 \mathrm{kN}$ x $0.990-\mathrm{m}$ hieght equal to $106.06 \mathrm{kN} . \mathrm{m} / \mathrm{m}$, which was also greater that the CHBDC factored design moment of $83 \mathrm{kN} . \mathrm{m} / \mathrm{m}$ for barrier tested at interior location. It should be noted that the barrier had a net deflection of 23.26-mm at failure with deck slab displacement of 1.57-mm in horizontal direction and deck slab uplift of 4.24-mm. Figure 4.17 shows load-deflection curves of the barrier and the deck slab under the applied load. 


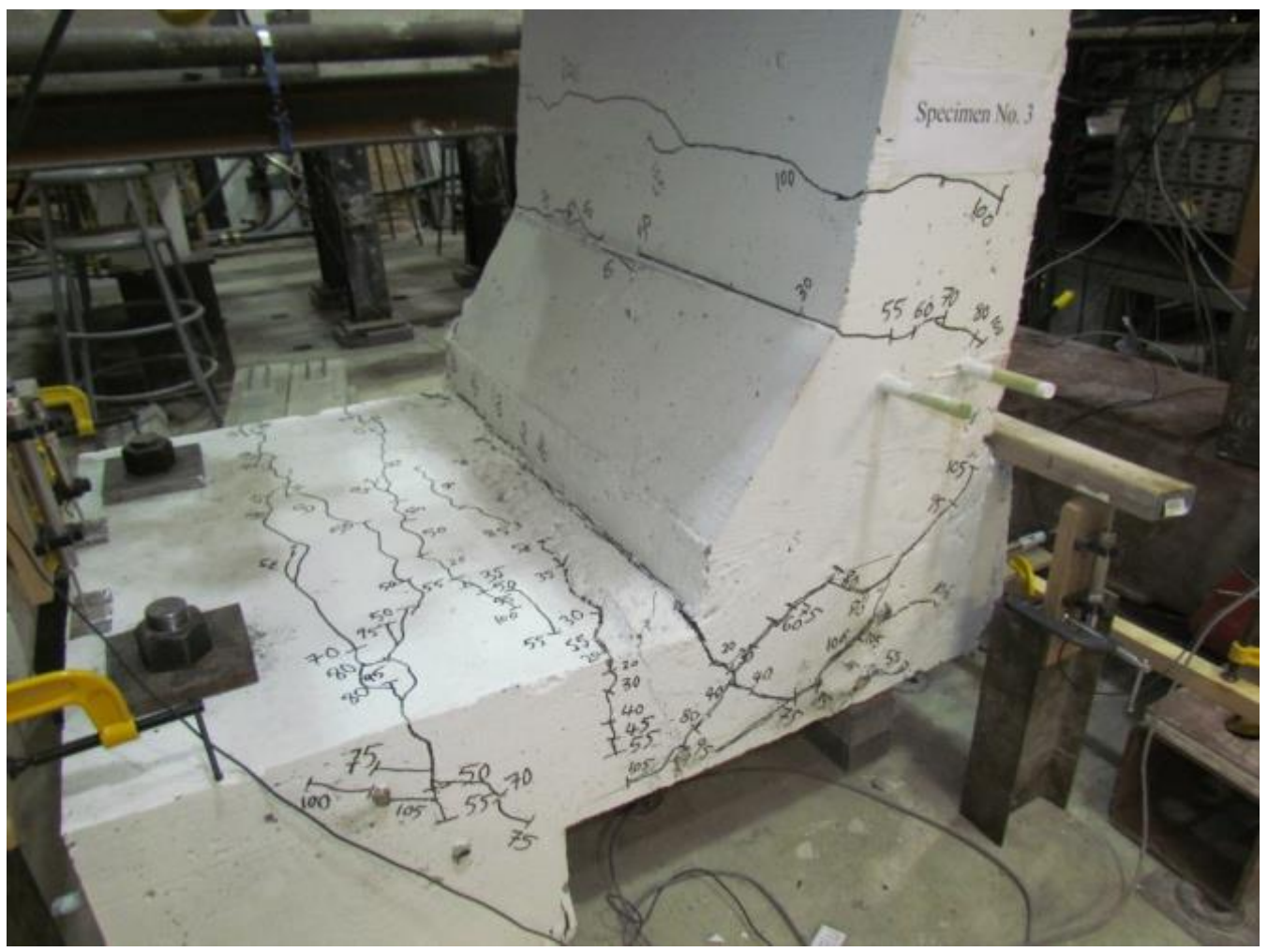

a) View of cracks in the deck and barrier wall from the right side

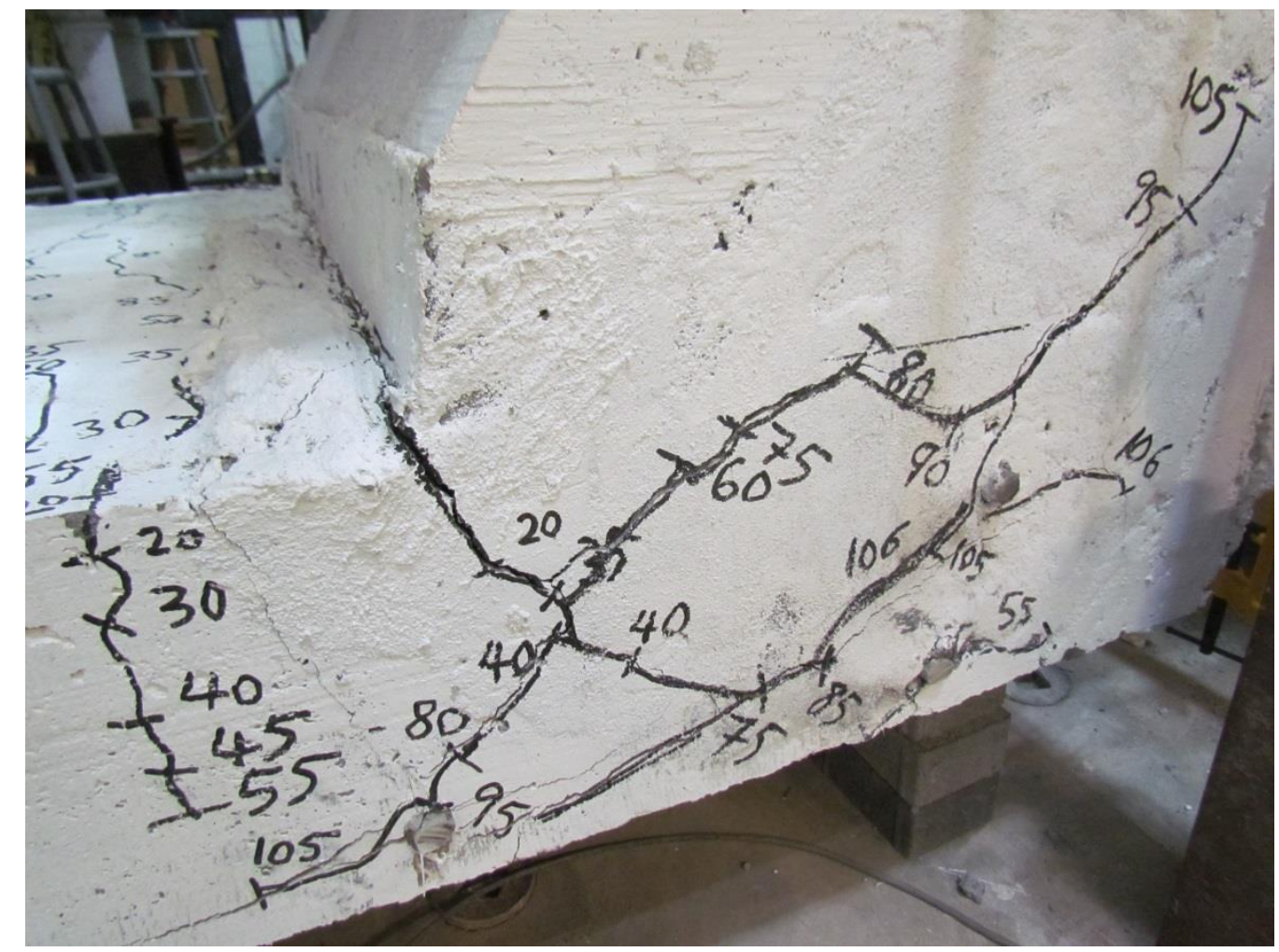

b) Close-up view of the crack pattern at the barrier-deck junction from the right side 


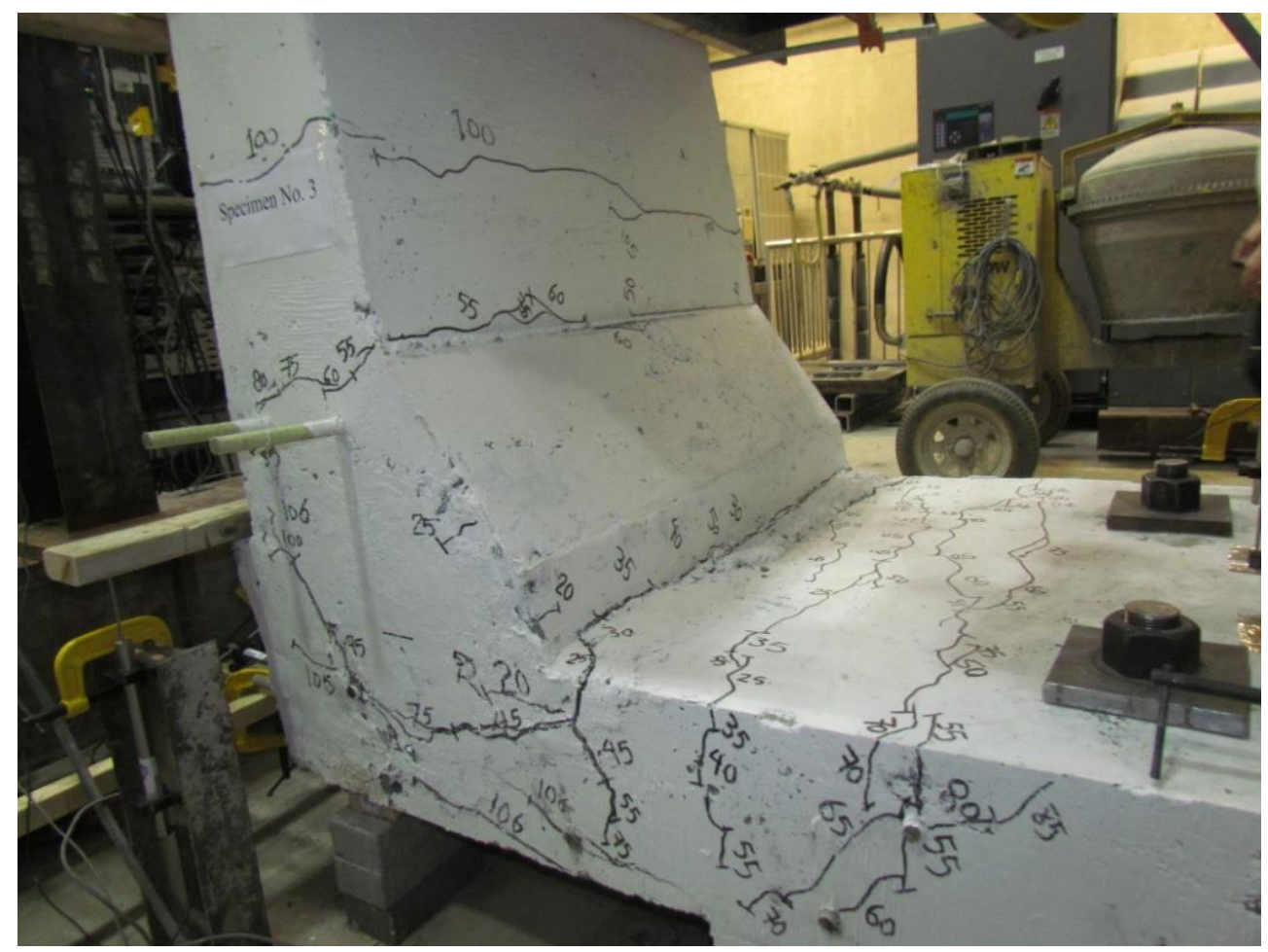

c) View of cracks at the deck and barrier wall from the left side

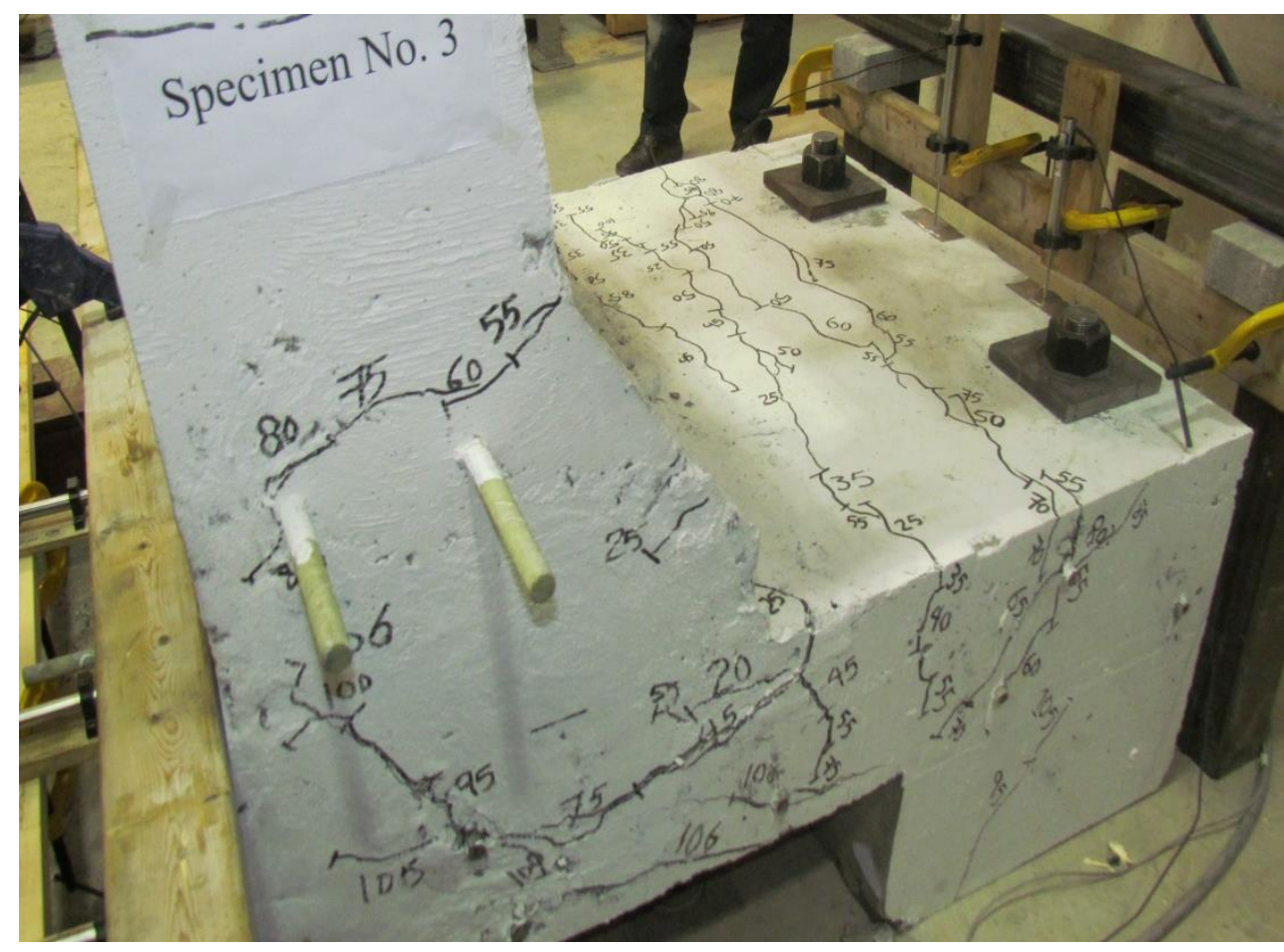

d) Close-up view of crack pattern at the barrier-deck junction from the left side

Figure 4. 16 View of the crack pattern in barrier Model 3 with SM-GFRP bars with $180^{\circ}$ hooks 


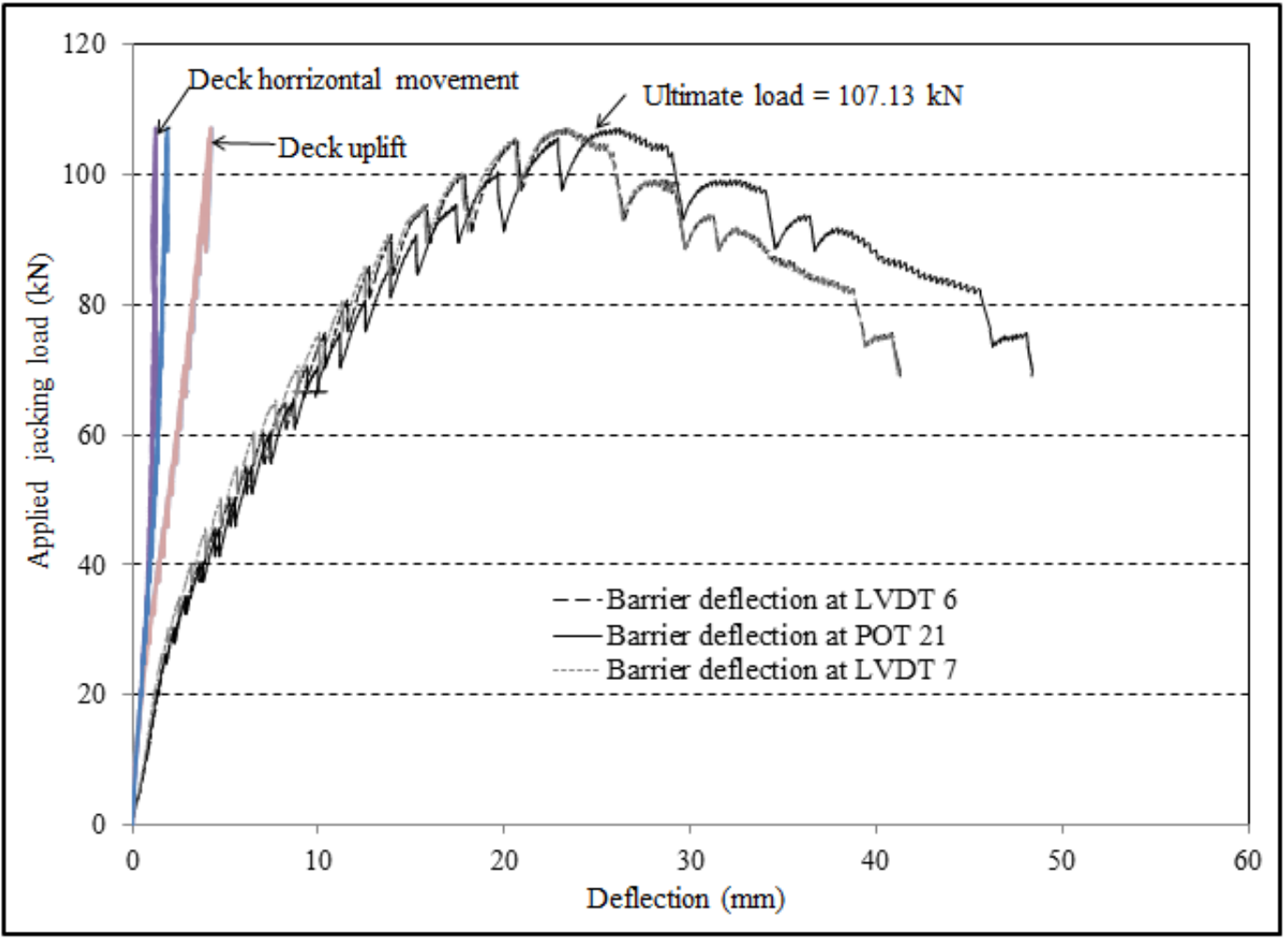

Figure 4. 17 Load-deformation curves for barrier wall, deck horizontal movement and deck uplift in barrier Model 3

In barrier Model 4, vertical high-modulus GFRP bars were placed at 150-mm spacing in front face of the barrier wall. Similar to other barrier models, the load was applied 990-mm above the deck. Figure 4.18 shows view of the crack pattern in barrier Model 4 at failure. The first visible flexural crack was observed at the barrier-deck joint at a load of $25 \mathrm{kN}$. Further cracks due to combined flexural moment and tension load appeared in the deck slab with the increase in the applied load. At $60 \mathrm{kN}$, a flexural crack was observed at the junction of the top and bottom tapered portion of the barrier wall. At $70 \mathrm{kN}$ load, a similar flexural crack was observed right above the junction between the top and bottom tapered portion of the wall and propagated significantly through the thickness at the same load increment. At this load increment, cracks were also propagated through the thickness at corner of the barrier-to-deck junction. At $95 \mathrm{kN}$ load, a second flexural crack was observed at top tapered portion of the barrier wall. The load continued to increase until the barrier failed at $153.3 \mathrm{kN}$ in the deck slab. The failure of the barrier occurred at lower portion of the deck slab due to concrete splitting at the compression side of the slab under the barrier wall. The experimental results led to a maximum applied 
moment at the barrier-deck junction of $153.32 \mathrm{kN} \times 0.990-\mathrm{m}$ hieght / $0.90 \mathrm{~m}$ width equal to $168.6 \mathrm{kN} . \mathrm{m} / \mathrm{m}$, which was far greater that the CHBDC factored design moment of $102 \mathrm{kN} . \mathrm{m} / \mathrm{m}$ at barrier end location as shown in Table 2.11. It should be noted that the net lateral deflection of the barrier wall was $43.2-\mathrm{mm}$, with an average deck horizontal displacement of 5.53-mm. and an average deck uplift of 2.47-mm at failure. Figure 4.19 shows load-deflection curves in barrier Model 4.

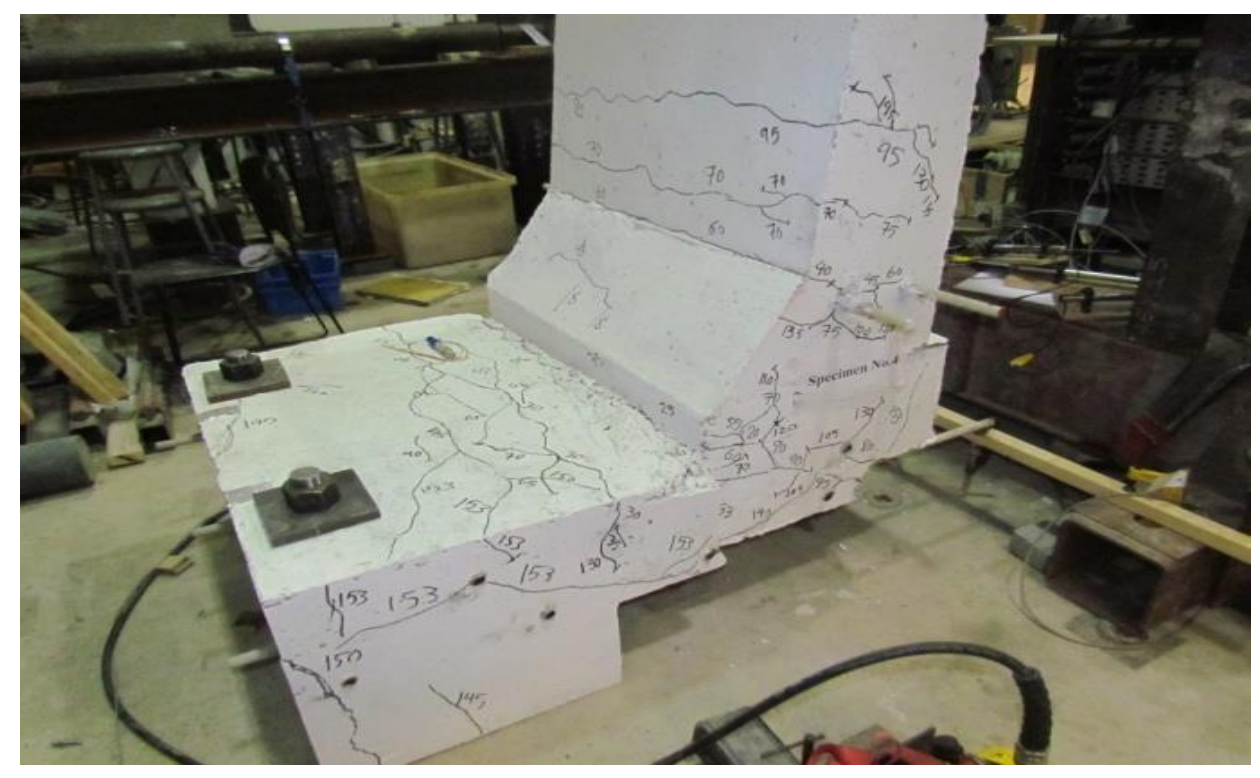

a) View of crack in the barrier and deck from right side

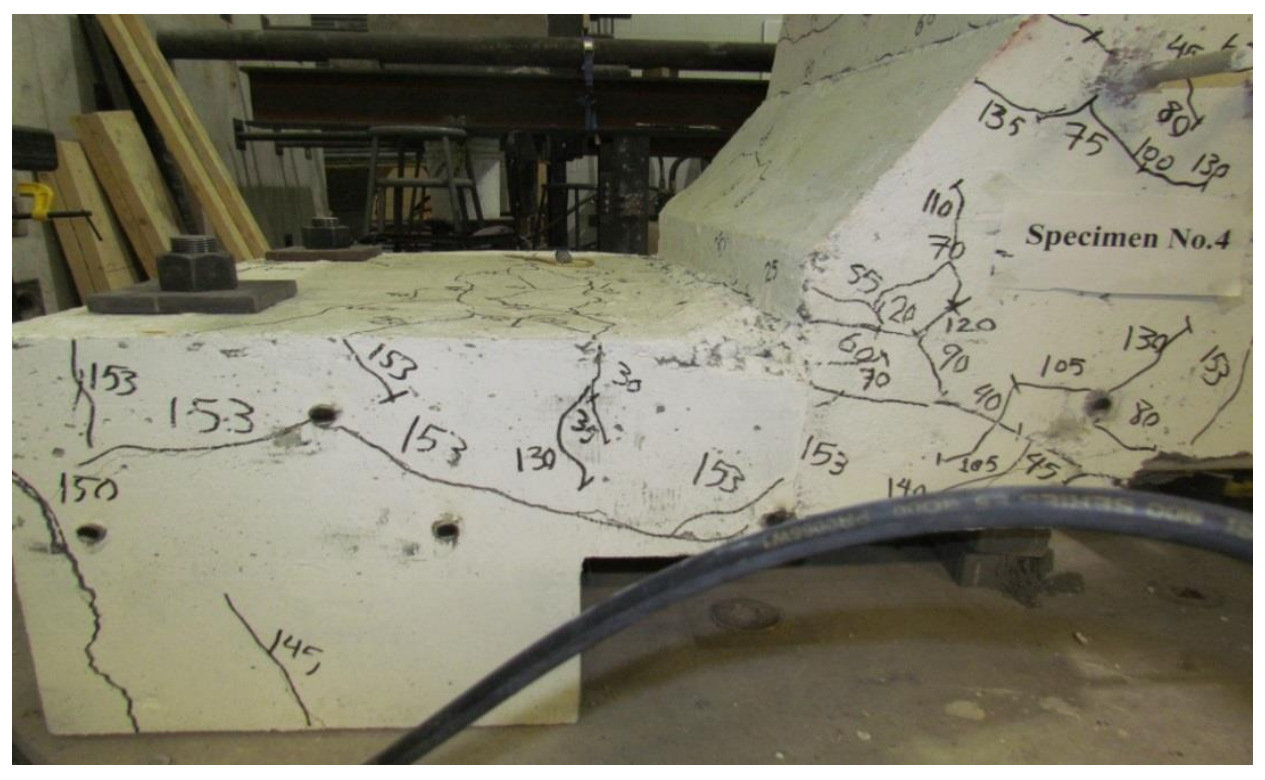

b) Close-up view of crack pattern at barrier-deck junction from right side 


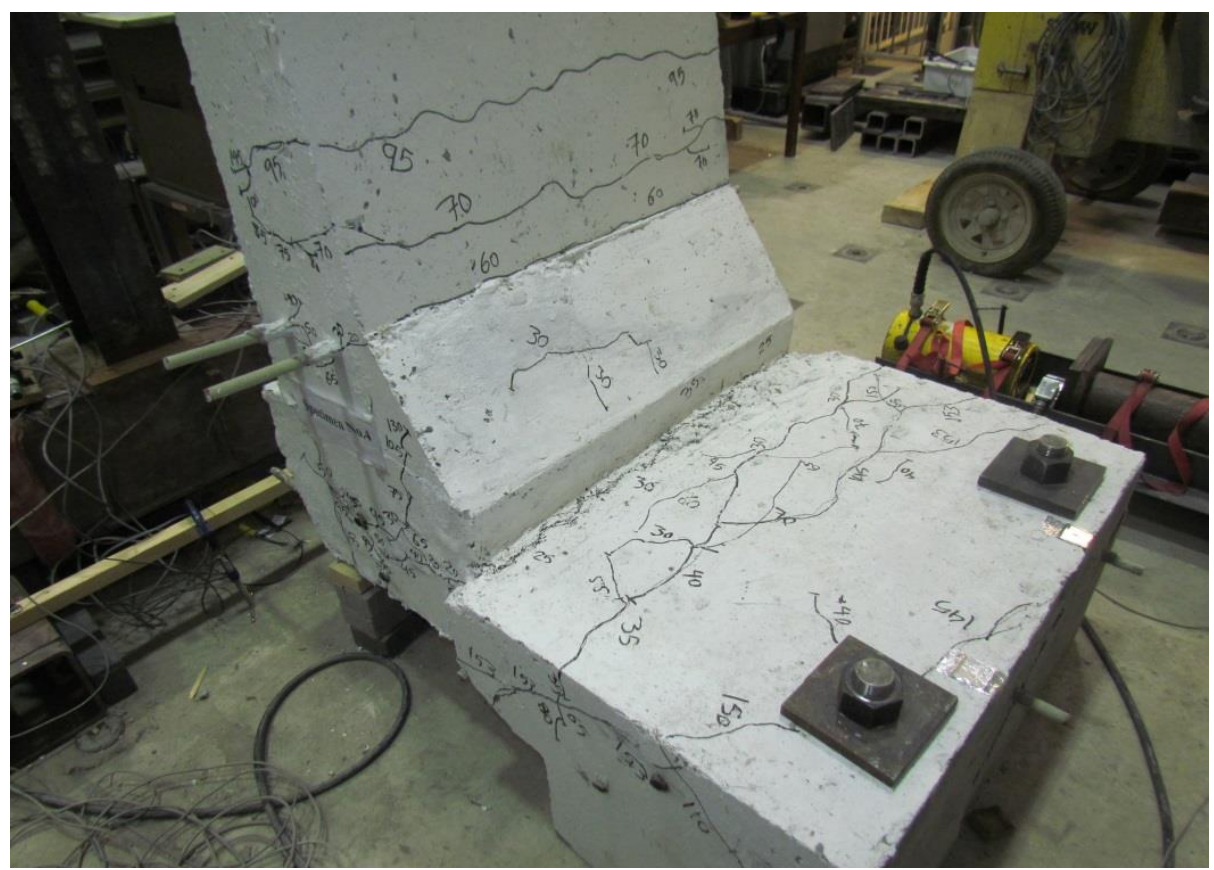

c) View of cracks at the barrier and deck from left side

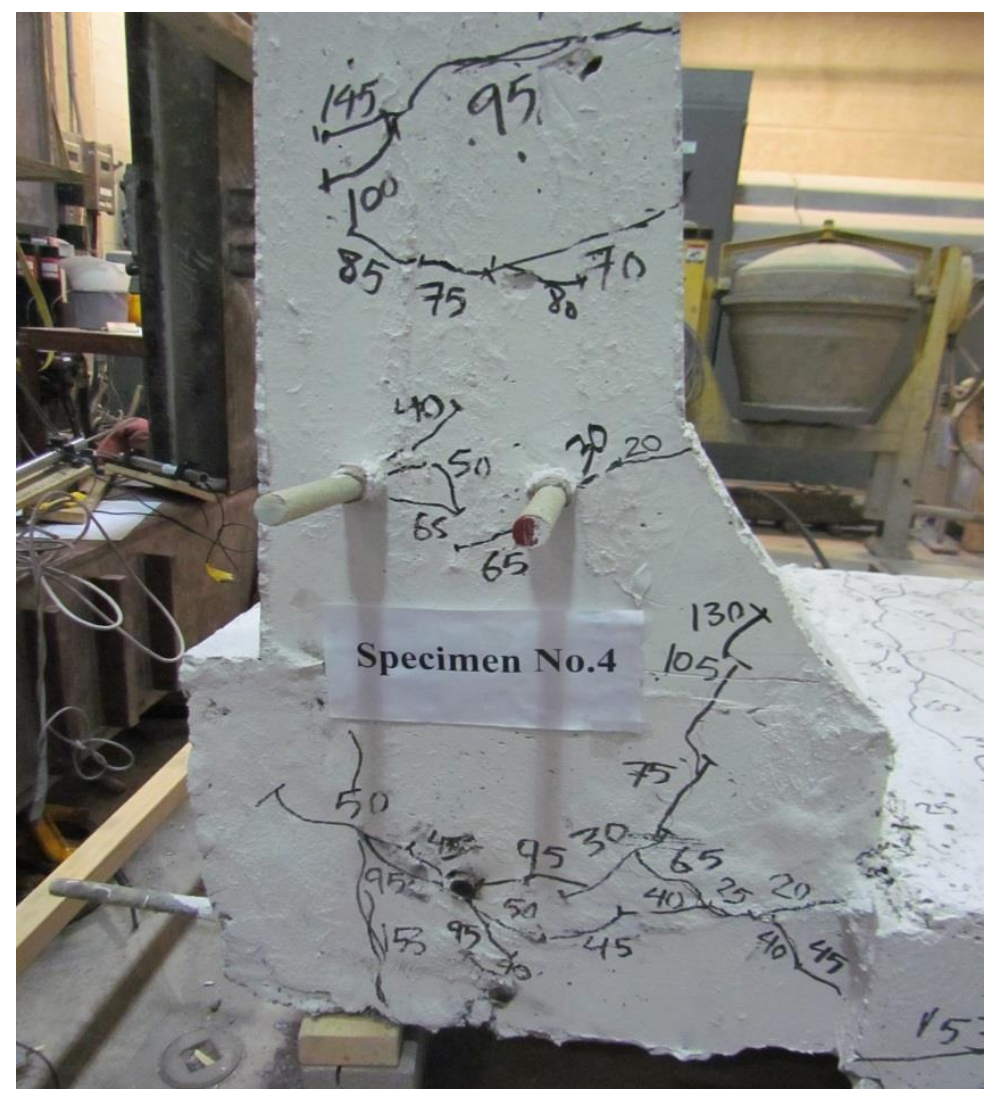

d) Close-up view of crack pattern at barrier-deck junction from left side

Figure 4. 18 View of the crack pattern in barrier Model 4 with HM-GFRP bars 


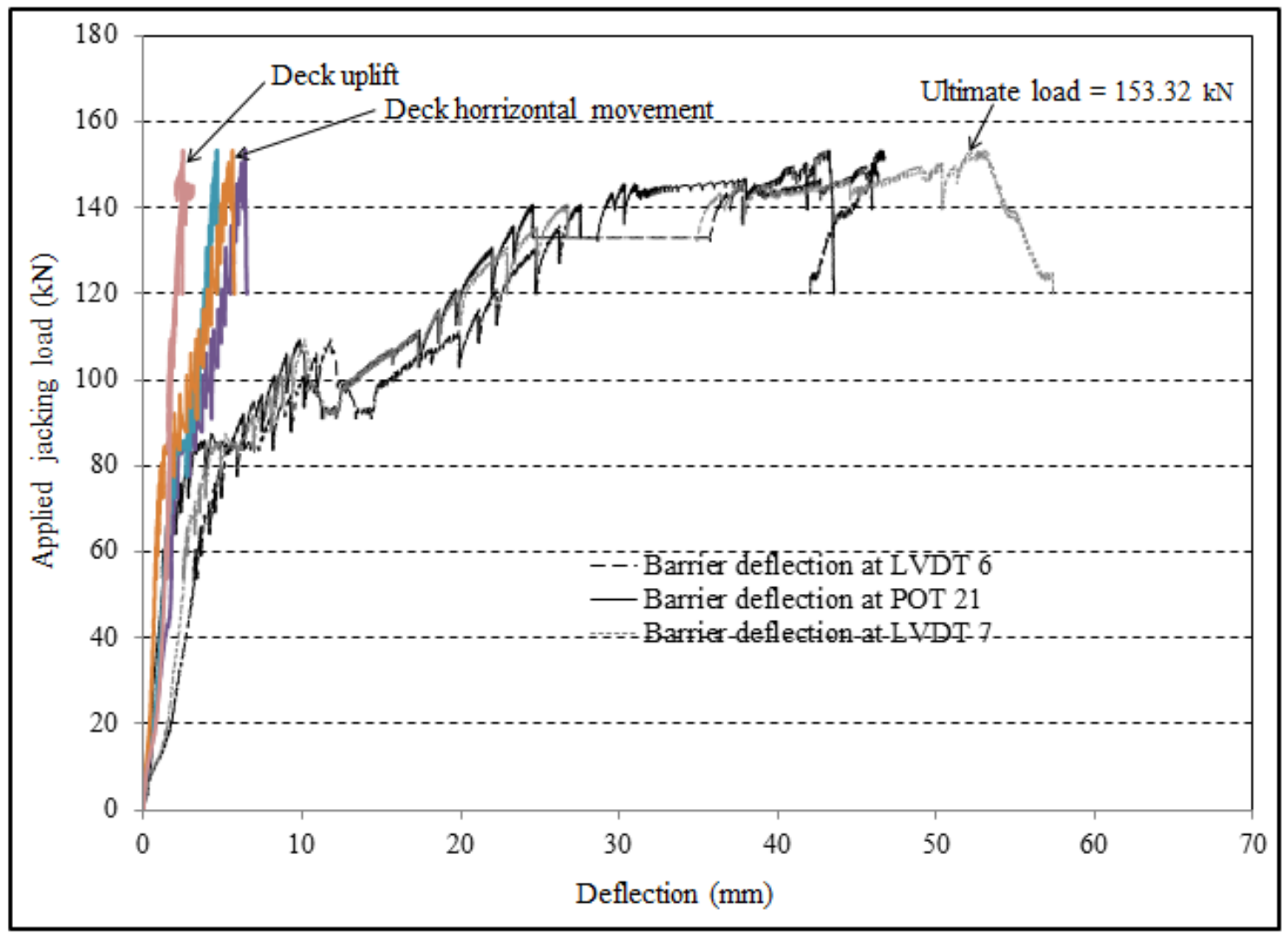

Figure 4. 19 Load-deformation curves for barrier wall, deck horizontal movement and deck uplift in barrier Model 4

Barrier Model 5 was constructed as reference model to compare the results with barrier models reinforced with GFRP bars. In this barrier model, M15 steel bars were placed vertically in front face of the barrier wall at 200-mm spacing. Similar to GFRP-reinforced barrier models, the load was applied at $990-\mathrm{mm}$ above the deck slab. Figure 4.20 shows view of the crack pattern observed in barrier Model 5 at failure. At load step of $20 \mathrm{kN}$, the first visible flexural crack was observed at the barrier-to-deck junction, which was extended down into the slab at the corner of deck-barrier joint. With load increase to $50 \mathrm{kN}$, few flexural cracks were observed in the deck slab extending through the deck thickness. In addition, at load step of $50 \mathrm{kN}$, a flexural crack was developed at junction of the top and bottom tapered portion of the wall, which was extended into the wall thickness with increase in the load. At load of $85 \mathrm{kN}$, few cracks were developed horizontally at the corner of the deck-barrier wall. With increase in the load to $105 \mathrm{kN}$, other flexural crack was observed at top portion of the tapered wall and propagated through the wall thickness. In addition, more flexural cracks appeared at the top surface of the deck slab. With 
further increase in load, cracks widened, leading to barrier failure at $128.92 \mathrm{kN}$ at corner junction of deck-to-barrier wall under combined tension and flexure. Results led to a maximum moment at the barrier-deck junction of $128.92 \mathrm{kN}$ x $0.990-\mathrm{m}$ heigth equal to $127.63 \mathrm{kN} . \mathrm{m} / \mathrm{m}$, which was far greater that the CHBDC factored design moment of $83 \mathrm{kN} . \mathrm{m} / \mathrm{m}$ at interior location. The barrier wall displayed a net lateral deflection of 17.76-mm, with deck slab horizontal displacement of 5.03-mm and deck uplift of 2.67-mm at failure. Figure 4.21 depicts the loaddeflection curves in the barrier Model 5. Table 4.2 summarizes the experimental findings for the tested models.

Based on the data generated from the experimental study, it can be concluded that the proposed barrier reinforcement detail incorporating GFRP bars with head anchorage, GFRP bars with bent and $180^{\circ}$-hook for PL-3 barrier configuration can be safely used in bridge barrier walls to resist the applied vehicle impact load specified in the CHBDC at the barrier wall-deck slab anchorage.

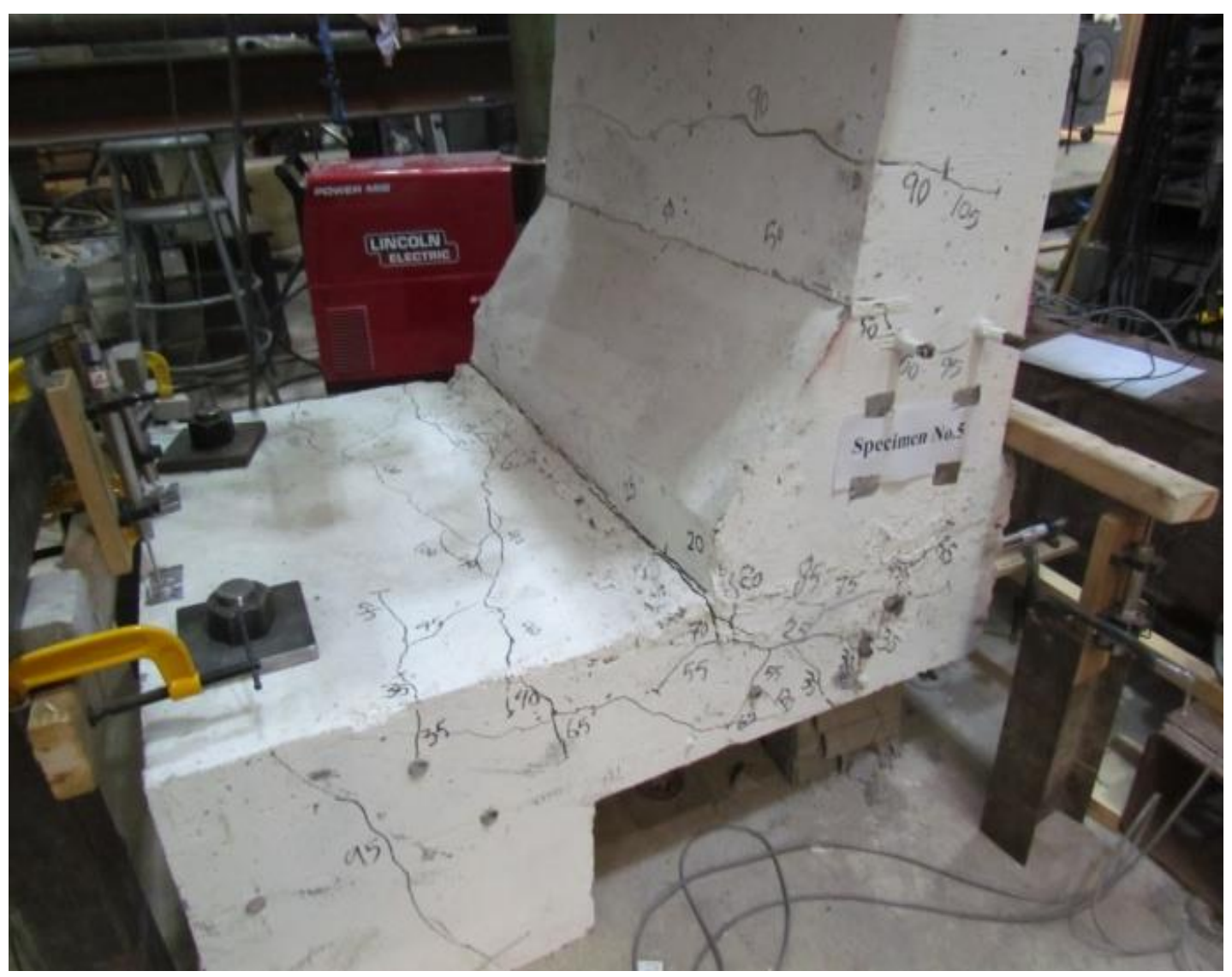

a) View of cracks in the barrier and deck slab from the right side 


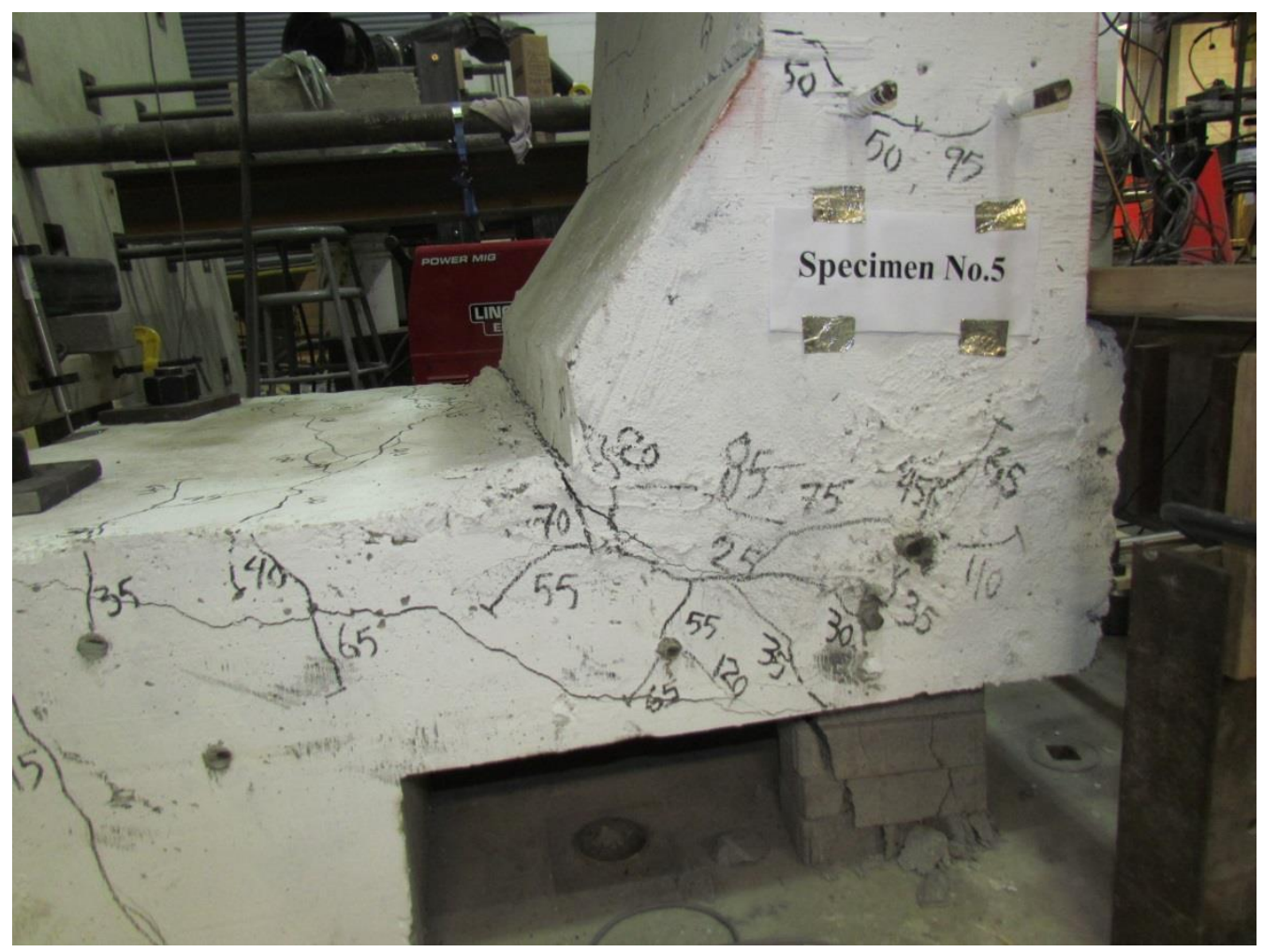

b) View of crack pattern at the barrier-deck junction from the left side

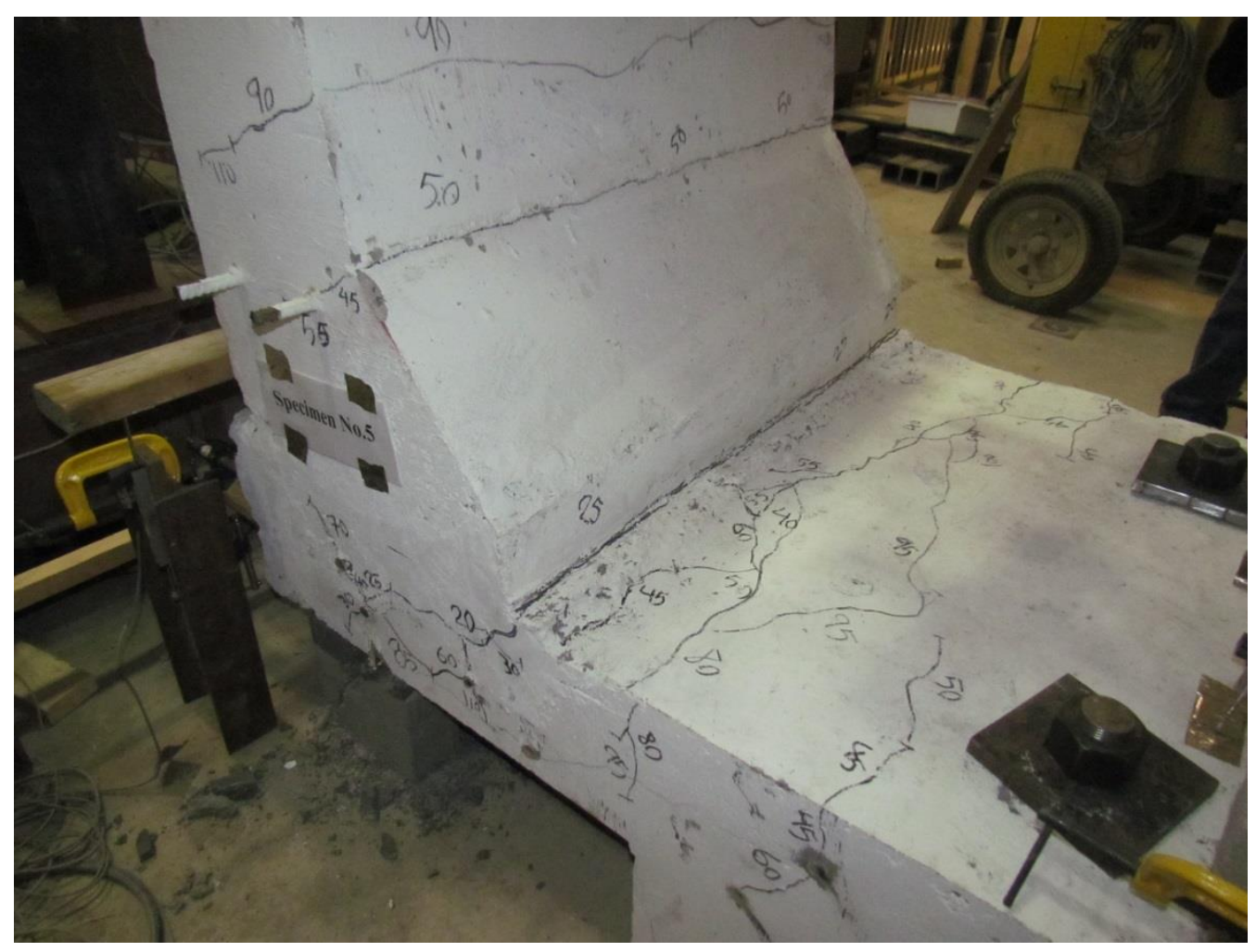

c) View of cracks in the deck and barrier from left side 


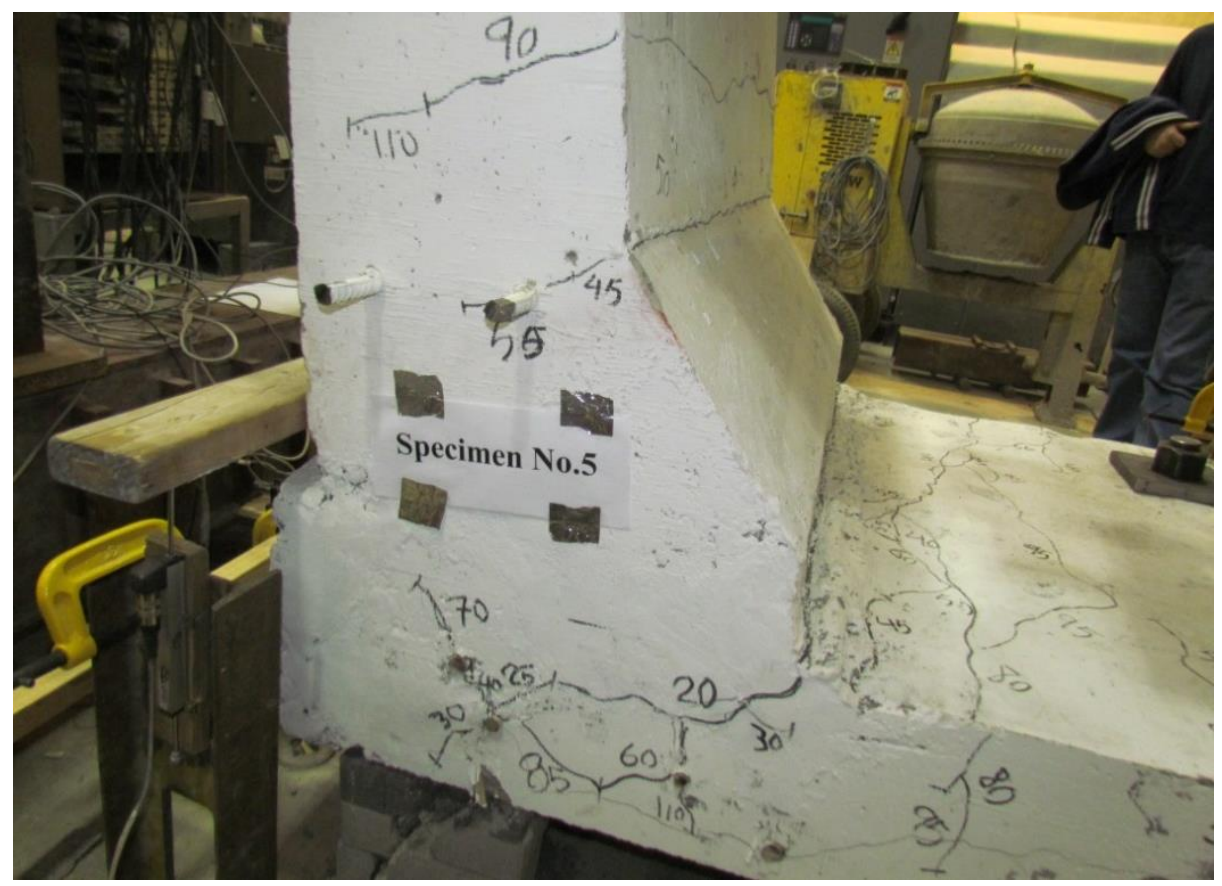

d) Close-up view of crack pattern at the barrier-deck junction from the left

Figure 4. 20 View of the crack pattern in barrier Model 5 with steel reinforcing bars

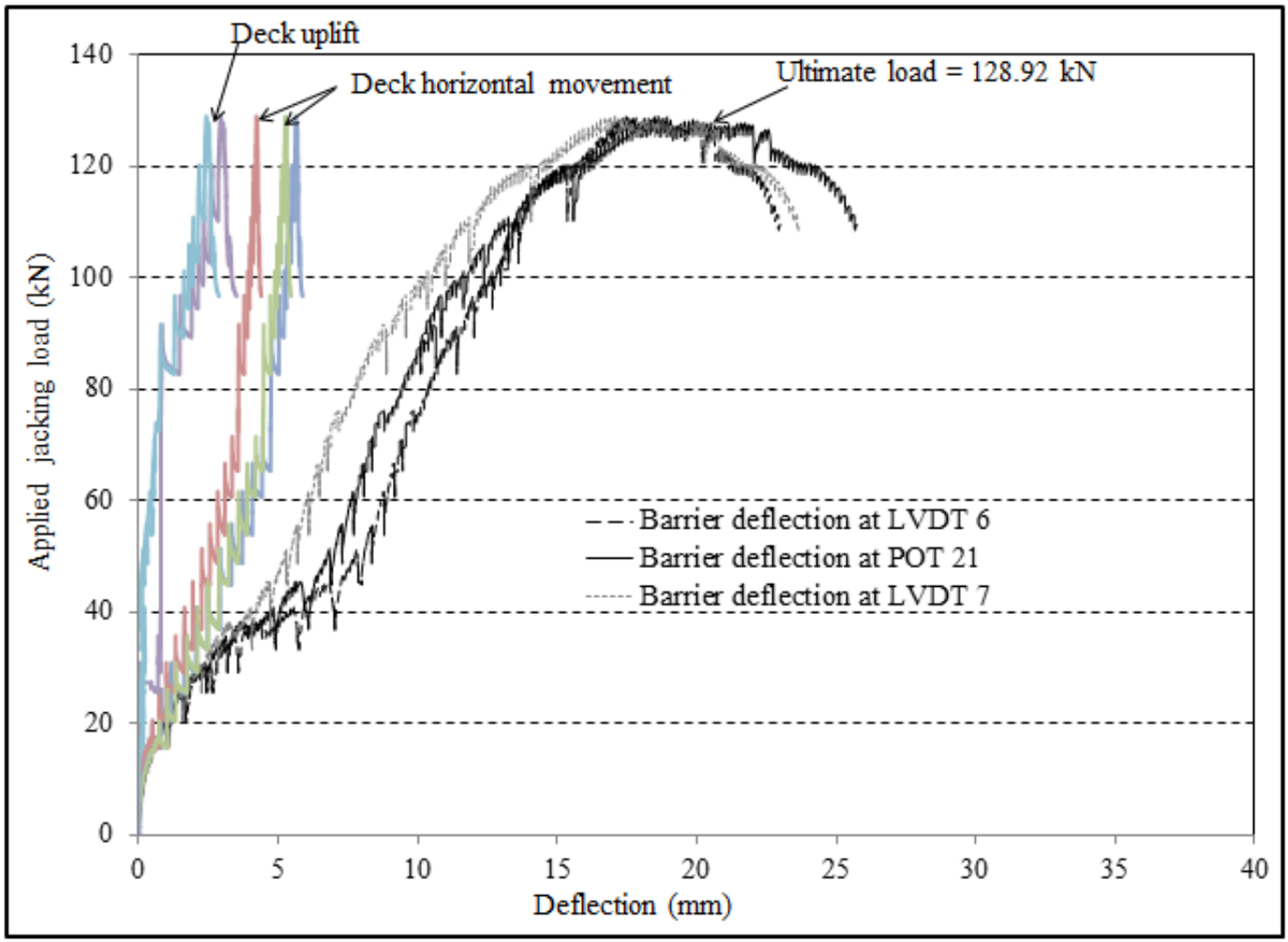

Figure 4. 21 Load-deformation curves for barrier wall, deck horizontal movement and deck uplift in barrier Model 5 
Table 4. 2 Summary of experimental findings of the tested barrier models

\begin{tabular}{|c|c|c|c|c|c|c|}
\hline \multicolumn{2}{|c|}{ Barrier model } & Model 1 & Model 2 & Model 3 & Model 4 & Model 5 \\
\hline \multicolumn{2}{|c|}{ Failure load $(\mathrm{kN} / \mathrm{m})$} & 106.1 & 116.3 & 107.2 & 170.3 & 128.9 \\
\hline \multicolumn{2}{|c|}{ Height of load application (m) } & 0.99 & 0.99 & 0.99 & 0.99 & 0.99 \\
\hline \multicolumn{2}{|c|}{$\begin{array}{l}\text { Experimental moment in the } \\
\text { wall at the base } M_{\text {exp }, w}=F_{\text {exp. }} H_{e} \\
\qquad(\mathrm{kN} . \mathrm{m} / \mathrm{m})\end{array}$} & 105.0 & 115.1 & 106.06 & 168.6 & 127.3 \\
\hline \multicolumn{2}{|c|}{$\begin{array}{c}\text { Experimental moment in the } \\
\text { deck at the joint } \\
\mathrm{M}_{\text {exp } \mathrm{d}=}=\mathrm{F}_{\text {exp }}\left(\mathrm{H}_{\mathrm{e}}+0.5 \mathrm{t}_{\mathrm{d}}\right),(\mathrm{kN} \cdot \mathrm{m} / \mathrm{m})\end{array}$} & 118.3 & 129.7 & 119.5 & 189.9 & 143.7 \\
\hline \multicolumn{2}{|c|}{$\begin{array}{l}\text { Resistance moment in the wall at } \\
\text { the base- cross sectional analysis } \\
\qquad \mathrm{M}_{\mathrm{r}, \mathrm{w}}(\mathrm{kN} \cdot \mathrm{m} / \mathrm{m})\end{array}$} & $243.56^{1}$ & $145.4^{2}$ & $145.4^{2}$ & $323.74^{3}$ & $150.8^{4}$ \\
\hline \multicolumn{2}{|c|}{$\begin{array}{l}\text { Resistance moment in the deck } \\
\text { at the joint- cross sectional } \\
\text { analysis } \mathrm{M}_{\mathrm{r}, \mathrm{d}}(\mathrm{KN} \cdot \mathrm{m} / \mathrm{m})\end{array}$} & $154^{5}$ & $154^{5}$ & $154^{5}$ & $154^{5}$ & $154^{5}$ \\
\hline \multirow{2}{*}{$\begin{array}{c}\text { CHBDC } \\
\text { Moments - } \\
\mathrm{M}_{\text {design }} \\
(\mathrm{kN} \cdot \mathrm{m} / \mathrm{m})\end{array}$} & $\begin{array}{l}\text { Interior } \\
\text { location }\end{array}$ & 83 & 83 & 83 & - & 83 \\
\hline & Exterior location & - & - & - & 102 & - \\
\hline \multicolumn{2}{|c|}{ Safety factor $=M_{\text {exp,w }} / M_{\text {design }}$} & 1.27 & 1.39 & 1.28 & 1.65 & 1.53 \\
\hline \multicolumn{2}{|c|}{$\mathrm{M}_{\mathrm{r}, \mathrm{w}} / \mathrm{M}_{\mathrm{exp}, \mathrm{w}}$} & 2.32 & 1.26 & 1.37 & 1.92 & 1.18 \\
\hline \multicolumn{2}{|c|}{$\mathrm{M}_{\mathrm{r}, \mathrm{d} /} \mathrm{M}_{\mathrm{exp}, \mathrm{d}}$} & 1.30 & 1.19 & 1.29 & 0.81 & 1.02 \\
\hline \multicolumn{2}{|c|}{$\begin{array}{l}\text { Net Deflection of barrier wall } \\
\qquad(\mathrm{mm})\end{array}$} & 24.45 & 31.25 & 23.26 & 43.2 & 17.76 \\
\hline \multicolumn{2}{|c|}{ Deck movement (mm) } & 1.63 & 4.37 & 1.57 & 5.53 & 5.03 \\
\hline \multicolumn{2}{|c|}{ Deck uplift (mm) } & 2.87 & 5.30 & 4.24 & 2.47 & 2.67 \\
\hline
\end{tabular}

(1) 8 -15M $(\rho=0.447 \%)$ GFRP with high modulus (HM) was considered in flexural resistance of wall at the joint (2) $10-15 \mathrm{M}(\rho=0.559 \%)$ GFRP with standard modulus (SM) and strength of bent portion was considered in flexural resistance of wall at the joint

(3) 14-15M $(\rho=0.78 \%)$ GFRP with high modulus (HM) was considered in flexural resistance of wall at the joint

(4) $5-15 \mathrm{M}(\rho=0.24 \%)$ steel bars was considered in flexural resistance of wall at the joint

(5) $9-20 \mathrm{M}(\rho=1.42 \%)$ steel bars was considered in flexural resistance of deck portion at the joint 
As shown in Table 4.2, comparison of test results with the CHBDC design limits showed a minimum of $27 \%$ increase in barrier design strength. It ccould also be observed that barrier Models 1, 2 and 3 showed relatively similar ultimate flexural strengths. Barrier Model 4 which was similar to barrier Model 1 represented the case at exterior location due to the reduced bar spacing to $150-\mathrm{mm}$. The experimental test results showed $65 \%$ increase in overall strength of the barrier Model 4 compared to CHBDC limit at exterior location. Thus, it can be concluded that barrier Models 1 with HM-GFRP bars provided the most cost-effective barrier configuration due to increased bar spacing of 300-mm when compared to barrier Models 2 and 3 with 200-mm bar spacing. As a result, based on the experimental test results observed on the proposed barrier models, proposal No.1 (barrier Models 1 and 4 configurations) was selected to conduct full-scale crash and static tests at interior and exterior locations. It should be noted that results of the vehicular crash testing of this barrier model is not in the scope of this thesis and can be found elsewhere (Sennah and Khederzadeh, 2014). However, the experimental test programs and the results under static load testing are presented in the next chapter.

In addition, experimental findings showed that the proposed GFRP-reinforced barriers were as good as the steel-reinforced barrier with respect to strength at barrier-deck junction. The increase in ultimate flexural strength of steel-reinforced barrier was 1.204, 1.10 and 1.19 when compared to barrier Models 1, 2 and 3, respectively. Also, maximum barrier deflection exhibited in the proposed GFRP-reinforced barriers was more than that observed for steel-reinforced barrier that was attributed to lower modulus of elasticity of the GFRP bars. Such increase in deflection would have a favorable effect in absorbing energy resulting from vehicle impact.

\subsection{Cross-Sectional Analysis of Barrier Models}

Conventional cross-sectional analysis used in beam design was employed to determine ultimate flexural capacity $\left(\mathrm{M}_{\mathrm{r}}\right)$ of the barrier walls at the junction of barrier-to-deck joint. The method was in accordance with ISIS manual 3 (ISIS- 2006) for the design of beams reinforced with FRP bars. Material resistance factors of 0.5, 0.75 and 0.90 were considered for GFRP, concrete and reinforcing steels, respectively as per the CHBDC. The cross-sections of the wall at the base and deck at the connection joint were selected for flexural strength calculation of the barrier models. As such, a height of $475-\mathrm{mm}$ corresponding to wall thickness and $250-\mathrm{mm}$ corresponding to 
deck thickness at barrier-to-deck joint was considered. The ultimate flexural capacities were determined over 1-m length of the barrier to be comparable with the experimental observations. In calculation of flexural capacity of the barrier wall models, effect associated with the inclination of GFRP bars at barrier-to-deck connection were considered. In addition, the extended tension bars into the deck that were placed at front face of the barrier walls were taken into account. It should be noted that in barrier Models 2 and 3 with GFRP-SM bars, the ultimate tensile strength of bent portion of the GFRP bars was considered in flexural strength calculation rather than tensile strength of straight portion, since the tensile strength of bent portion was found to be about $45 \%$ of straight portion as per manufacturer data sheet. Due to reinforcement ratio provided in barrier Models 1 and 4, flexural capacity of thes barriers were determined on the basis of compression failure, while, flexural capacity of barrier Models 2 and 3 were determined based on tension failure mode. Table 4.2 summarizes results of cross-sectional analysis for calculation of ultimate flexural resistance of the barrier models both in the wall and the deck slab at joint location $\left(\mathrm{M}_{\mathrm{r.w}}\right.$ and $\left.\mathrm{M}_{\mathrm{r} . \mathrm{d}}\right)$. It can be observed from Table 4.2 that the ratio of resistance moment of the wall-to-the experimental moment in the wall $\left(\mathrm{M}_{\mathrm{r}, \mathrm{w}} / \mathrm{M}_{\text {exp,w }}\right)$ were all greater than unity indicating addition capacity of the wall system. In addition, the ratio of moment resistance in the deck slab-to-the experimental moment in the deck $\left(\mathrm{M}_{\mathrm{r}, \mathrm{d}} / \mathrm{M}_{\mathrm{exp}, \mathrm{d}}\right)$ were all greater than unity except for barrier Model 4, which the value was 0.81 . This indicated that the deck slab strength was not sufficient to carry the load; therefore, the slab portion has been failed. The finding was confirmed from experimental observations that barrier Model 4 was failed in the deck slab portion.

\subsection{Investigation of Diagonal Tension Failure}

The state of stress in corners and joints as calculated by theory of elasticity is valid in case of reinforced concrete only before cracking occurs (Stage I), After cracking and at the ultimate stage (Stages II and III), the joint acts as a composite structure made by concrete and reinforcement, analysis of which is far more complicated than homogenous bodies (Nilson et al. 1976). Although results by theory of elasticity is valid only prior to concrete cracking, the stress distributions indicates where tensile stresses occur. This in turn is an indication of cause of failure and provides guidance for reinforcement layouts in the corner joints. Failure can be caused by diagonal tension crack owing to the fact that tensile stresses due to external flexural 
moment have not been resisted by reinforcement or proper reinforcement layouts have not been provided. Figure 4.22 shows barrier wall subjected to the transverse load, F, due to diagonal tension crack. Stress distribution at the corner joint of the barrier wall due to the applied moments in the wall and the deck slab is shown in Figure 4.23. The bending stress, $\sigma_{\mathrm{x}}$, shows a high tensile stress at inside corner of the joint indicating crack initiation at inside corner joint under small load. However, stresses at right angle to the bending stresses, $\sigma_{\mathrm{y}}$, provide tensile stresses which cause diagonal crack across the corner joint. Diagonal tension crack results in a sudden failure unless proper reinforcement layouts are provided in these regions (Nilson et al. 1976).

As shown in Figure 4.22, the applied transverse load, $F_{\text {diag. }}$, produces moment in the wall at deck-wall junction $\left(M_{w}=F_{\text {diag }} . H_{e}\right)$. The transverse load exerts shear force, $F_{\text {diag., }}$ at deck-wall junction which causes an axial force, $F_{\text {diag }}$, and a secondary moment equal to $0.5 F_{\text {diag. }} \cdot t_{d}$ in the deck so that the total applied moment in the deck is $M_{d}=F_{\text {diag. }}\left(H_{e}+0.5 t_{d}\right)$. The axial force and the applied moment in the deck produce force couple $\left(\mathrm{C}_{d}-\mathrm{F}_{\text {diag }} / 2\right)$ and $\left(\mathrm{F}_{\mathrm{f}}+\mathrm{F}_{\text {diag. }} / 2\right)$ in the deck portion. The transverse load, $\mathrm{F}_{\text {diag. }}$, also produces compression force in the wall, $\mathrm{C}_{\mathrm{w}}$, which would be transferred to deck by formation of diagonal compression strut of length, $\mathrm{L}_{\mathrm{dc}}$, shown in Figure 4.24. Diagonal tension crack is a sudden and brittle failure and may occur prior to flexural failure in the wall or deck slab when concrete modulus of rupture, $f_{r}$, is reached along the diagonal strut. The analytical procedure of diagonal tension crack failure was carried out using equilibrium equations based on the free body diagram of forces shown in Figure 4.24. The equilibrium equations along $\mathrm{x}^{\prime}$ axis yield the following:

$\mathrm{C}_{\mathrm{d}}=\mathrm{C}_{\mathrm{w}} \cdot \operatorname{Tan} \alpha+\mathrm{F}_{\text {diag. }} . / 2$

Where $\mathrm{C}_{\mathrm{d}}$ is compression force in the deck, $\mathrm{C}_{\mathrm{w}}$ is compression force in the wall and $\mathrm{F}_{\text {diag. }}$ is the transverse load applied to the wall due to diagonal tension cracks. 


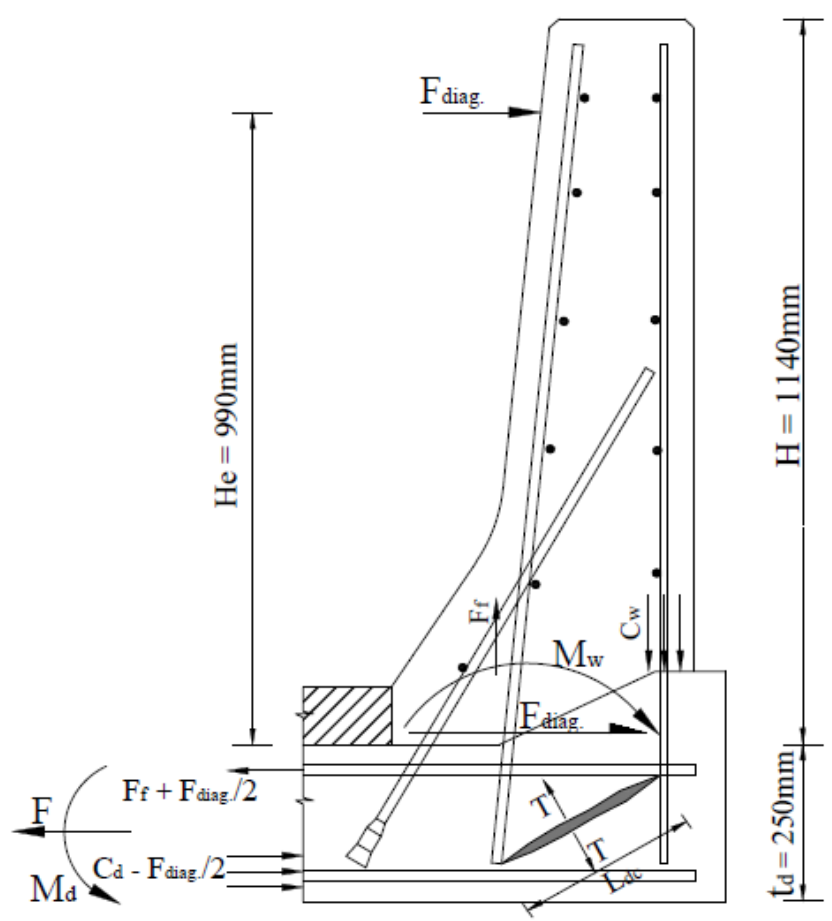

Figure 4. 22 Barrier wall subjected to transverse load due to diagonal tension cracks

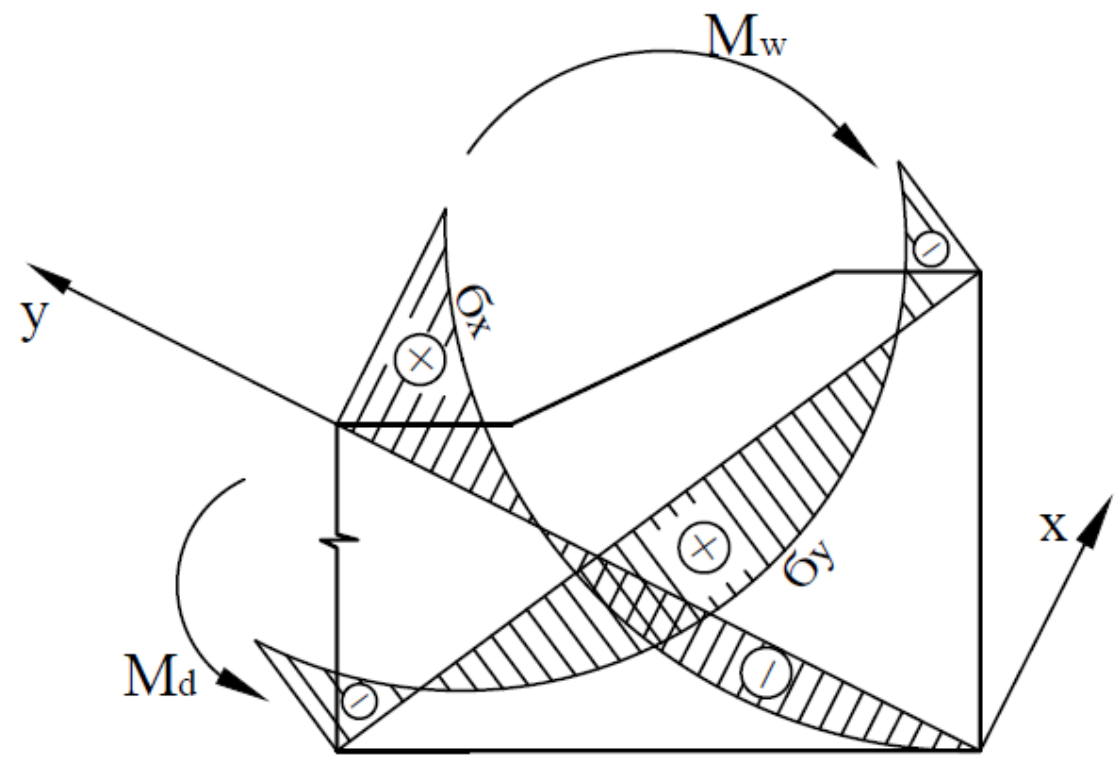

Figure 4. 23 Stress distribution at deck-wall joint indicating tensile stresses (positive sign) and compressive stresses (negative sign) 


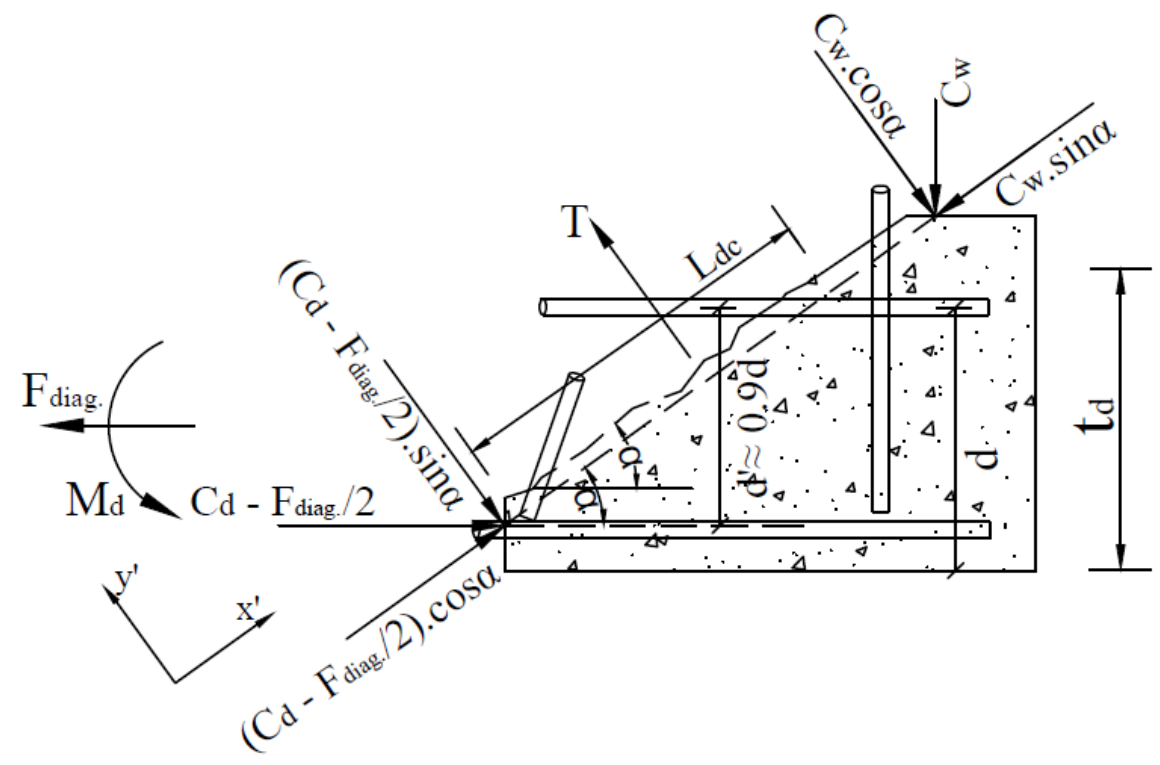

Figure 4. 24 Free body diagram and internal forces at corner joint of barrier wall

$(\alpha)$ is the inclination of diagonal tension crack with respect to horizontal axis. From the experimentally tested barrier walls $(\alpha)$ varied between $37^{\circ}$ to $43^{\circ}$. A crack inclination angle, $(\alpha)$, equal to $40^{\circ}$ is recommended. The equation of equilibrium along $\mathrm{y}^{\prime}$ axis yields:

$\mathrm{C}_{\mathrm{w}}=(\mathrm{T} / \operatorname{Cos} \alpha)-\left(\mathrm{C}_{\mathrm{d}}-\mathrm{F}_{\text {diag. }} . / 2\right) . \operatorname{Tan} \alpha$

Where $\mathrm{T}$ is the tensile force acting perpendicular to the diagonal crack shown in Figure 4.24. The tensile force, $\mathrm{T}$, is calculated by ignoring any strength contribution of the adjacent slab and presuming $\mathrm{f}_{\mathrm{r}}=0.6 \lambda \mathrm{f}_{\mathrm{c}_{\mathrm{c}}}(\mathrm{CSA}$ A23.3-04). The tensile force, T, was given in AASHTO-LRFD (2009) as follow:

$\mathrm{T}=2 / 3 \mathrm{f} . \mathrm{b} . \mathrm{L}_{\mathrm{dc}}$

Where $b$ is the width of barrier wall over which diagonal tension crack is calculated, $L_{d c}$ is the length of diagonal tension crack in the corner joint. The equilibrium equation of internal and external applied moments in the deck yields:

$M_{d}=F_{\text {diag. }} \cdot\left(H_{e}+0.5 t_{d}\right)=\left(C_{d}-F_{\text {diag }} \cdot / 2\right) \cdot d_{d}^{\prime}$ 
Where, $\mathrm{d}_{\mathrm{d}}{ }_{\mathrm{d}}$ is the distance between tension and compression reinforcement in the deck slab. As a reasonable approximation $\mathrm{d}^{\prime}{ }_{\mathrm{d}}$ can be assumed equal to $\left(\mathrm{d}_{\mathrm{d}}{ }_{\mathrm{d}} \cong 0.9 \mathrm{~d}_{\mathrm{d}}\right)$ in which $\mathrm{d}_{\mathrm{d}}$ is the effective depth of concrete from tension reinforcement in the deck to the extreme compression fiber of the deck. Further simplifying of Eq. 4.4 yields the compression force in the deck slab as follow:

$\mathrm{C}_{\mathrm{d}}=\mathrm{F}_{\text {diag. }} \cdot(\mathrm{A})$

Where $\mathrm{A}$ is a constant value and can be determined from equation below:

$\mathrm{A}=\left(\mathrm{H}_{\mathrm{e}}+0.5 \mathrm{t}_{\mathrm{d}}+0.5 \mathrm{~d}_{\mathrm{d}}^{\prime}\right) / \mathrm{d}_{\mathrm{d}}^{\prime}$

$\mathrm{H}_{\mathrm{e}}$ is height of the applied transverse load, $\mathrm{F}_{\text {diag. }}$, above the deck slab, and $\mathrm{t}_{\mathrm{d}}$ is the thickness of deck slab. Substituting Eq. 4.5 into Eq. 4.1 yields the compression force in the wall due to diagonal tension crack as follow:

$\mathrm{C}_{\mathrm{w}}=\mathrm{F}_{\text {diag }} \cdot(\mathrm{A}-0.5) / \mathrm{Tan} \alpha$

Substituting Eqs. 4.5 and 4.7 into Eq. 4.2 and further simplifying estimate the transverse load required to cause diagonal tension crack in the corner joint of barrier walls provided that:

$\mathrm{F}_{\text {diag. }}=(\mathrm{T} . \mathrm{Sin} \alpha) /(\mathrm{A}-0.5)$

\subsubsection{Cracking Moment in the Deck due to Diagonal Tension Crack}

Stresses in deck-wall corner joint may arise in plane of the joint due the applied bending moments in the wall and the deck and also to right angle to the bending stresses due to contact pressure of the GFRP reinforcing bars. The flexural stresses can be approximately determined on the basis of plane stress. The compressive stresses can be resisted by concrete, while the tensile stresses can easily exceed the ultimate tensile strength of concrete. Thus, cracking can be expected to start at corner of the joints at small loads. Due to resulting tensile forces at the joint, diagonal tension crack occurs which tend to be a brittle and sudden failure. 
The transverse load, $F_{\text {diag. }}$, applied to the barrier wall produces cracking moment in the corner joint once the concrete modulus of rupture is reached. The resultant tensile and compressive forces from main reinforcement and concrete in the wall and deck can be determined across the diagonal (Figure 4.25).

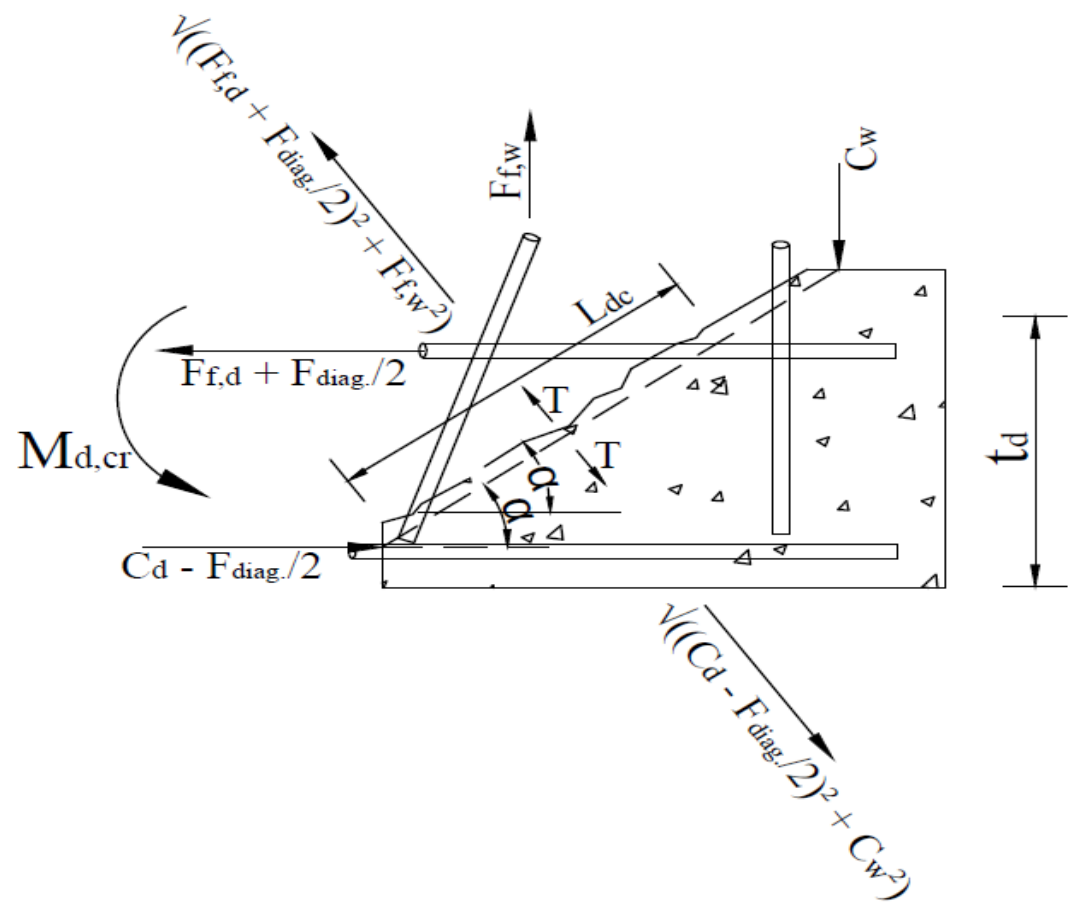

Figure 4. 25 Resultant compressive and tensile forces in the deck slab and barrier wall

On the basis of distribution of stresses across the diagonal tension crack, it is possible to predict cracking moment in the deck, $\mathrm{M}_{\mathrm{d}, \mathrm{cr}}$, which causes the first diagonal tension crack to form. As such, cracking moment in the deck can be derived using resultant forces produced at the joint. From the equilibrium of forces in Figure 4.25 it can be shown that:

$\sqrt{ }\left(C_{w}{ }^{2}+\left(C_{d}-F_{\text {diag }} / 2\right)^{2}\right)=T=2 / 3 f_{r}$ b. $\cdot L_{d c}$

Substituting Eqs. 4.7 and 4.8 into Eq. 4.9 yields:

$\left(\mathrm{C}_{\mathrm{d}}-\mathrm{F}_{\text {diag }} / 2\right)=\mathrm{T}$. Sin $\alpha$

(Eq. 4.10) 
Thus, cracking moment due to flexural resistance of the deck can be estimated by assuming $\mathrm{d}_{\mathrm{d}} \cong$ $0.9 \mathrm{~d}_{\mathrm{d}}$ and can be calculated using equation below:

$M_{d, c r}=\left(C_{d}-F_{d i a g} / 2\right) \cdot d_{d}^{\prime}=0.6 f_{r} \cdot b \cdot L_{d c} \cdot d_{d} \cdot \operatorname{Sin} \alpha$

Eq. 4.11 yields similar moment resistance in the deck due to diagonal tension crack as Eq. 4.4. As stated earlier, experimental tests performed on barrier Models 1, 2 and 3 showed failure of these barriers by diagonal tension crack at the corner joint. Diagonal tension cracks occurred at the corner joint at failure load of $95.49 \mathrm{kN}, 116.3 \mathrm{kN}$ and $107.2 \mathrm{kN}$ in barrier Models 1, 2 and 3, respectively. These failure loads produced experimental cracking moment in the deck equal to 106.5, 129.7 and 119.53 kN.m in barrier Models 1, 2 and 3, respectively. Table 4.3 compares the results obtained from analytical equations (Eqs. 4.5 to 4.8 and Eq. 4.11) to the above experimental test results. From Eq. 4.8, lateral load due to diagonal tension failure, $\mathrm{F}_{\text {diag., was }}$ calculated as $89.3 \mathrm{kN}, 99.1 \mathrm{kN}$ and $92.43 \mathrm{kN}$ in barrier Models 1, 2 and 3, respectively, which were comparable to the experimental results. Such analytical diagonal tension failure loads yielded cracking moment of 99.6, 110.5 and 103.06 kN.m in the deck slab in each of the barrier Models 1, 2 and 3, respectively. Comparison of analytical and experimental results clearly confirmed the failure of the tested barrier due to the development of diagonal tension cracks at the corner joint. The ratio of experimental to analytical cracking moment was within 1.07 to 1.17 confirming the precision of the analytical equations. Such failure mode is expected due to short longitudinal length of the barrier wall causing one-way action failure to occur. Since, the concrete tensile strength at the corner joint is small due to the developed tensile stresses at this region, diagonal tension cracks occur if the concrete modulus of rupture is reached.

Table 4. 3 Comparison between analytical and experimental results by diagonal tension cracks

\begin{tabular}{|c|c|c|c|c|c|c|c|c|c|c|}
\hline $\begin{array}{c}\text { Barrier } \\
\text { model }\end{array}$ & $\begin{array}{c}\alpha \\
\left({ }^{\circ}\right)\end{array}$ & $\begin{array}{c}\mathrm{L}_{\mathrm{dc}} \\
(\mathrm{mm})\end{array}$ & $\begin{array}{c}\mathrm{T} \\
(\mathrm{kN})\end{array}$ & $\begin{array}{c}\mathrm{F}_{\text {diag. }} \\
(\mathrm{kN})\end{array}$ & $\begin{array}{c}\mathrm{C}_{\mathrm{d}} \\
(\mathrm{kN})\end{array}$ & $\begin{array}{c}\mathrm{C}_{\mathrm{w}} \\
(\mathrm{kN})\end{array}$ & $\begin{array}{c}\mathrm{M}_{\mathrm{d}, \mathrm{cr}} \\
(\mathrm{kN} . \mathrm{m})\end{array}$ & $\begin{array}{c}\mathrm{F}_{\text {Exp. }} \\
(\mathrm{kN})\end{array}$ & $\begin{array}{c}\mathrm{M}_{\mathrm{d}, \text { Exp. }} \\
(\mathrm{kN} . \mathrm{m})\end{array}$ & $\begin{array}{c}\mathrm{M}_{\mathrm{d}, \text { Exp.. }} \\
\mathrm{M}_{\mathrm{d}, \mathrm{cr}}\end{array}$ \\
\hline 1 & 41 & 440 & 887 & 89.3 & 626.9 & 669.8 & 99.6 & 95.49 & 106.5 & 1.07 \\
\hline 2 & 43 & 470 & 947.5 & 99.1 & 695.7 & 692.9 & 110.5 & 116.3 & 129.7 & 1.17 \\
\hline 3 & 39 & 475 & 957.6 & 92.4 & 648.8 & 744.2 & 103.06 & 107.2 & 119.53 & 1.16 \\
\hline
\end{tabular}




\subsubsection{Case Study}

The effect of diagonal tension cracks in bridge at post-deck connection was investigated experimentally and analytically by Matta et al. (2008). One full scale post-overhang subassembly was tested under quasi-static loading under the effect of diagonal tension crack. The geometry and reinforcement layout of the post-deck connection can be found elsewhere (Matta et al. 2008). A closed-form procedure was employed in an iterative fashion to explicitly account for the effect of the shear force, $\mathrm{F}_{\text {diag. }}$, and bending moment $\mathrm{M}_{\mathrm{d}, \mathrm{cr}}$ at corner joint due to diagonal tension failure. The result from Matta et al. (2008) study was compared with the developed equations in the current study (Eqs. 4.5 to 4.8 and Eq. 4.11) and summarized in Table 4.4. The developed equations yielded similar agreement with those of Matta et al. (2008) investigations.

Table 4. 4 Comparison of the work by Matta et al. (2008) with current study

\begin{tabular}{|c|c|c|c|c|c|c|c|c|c|c|c|}
\hline & $\begin{array}{c}\mathrm{H}_{\mathrm{e}} \\
(\mathrm{mm})\end{array}$ & $\begin{array}{c}\mathrm{t}_{\mathrm{d}} \\
(\mathrm{mm})\end{array}$ & $\begin{array}{c}\mathrm{f}_{\mathrm{c}} \\
(\mathrm{MPa})\end{array}$ & $\begin{array}{c}\mathrm{b} \\
(\mathrm{mm})\end{array}$ & $\begin{array}{c}\mathrm{L}_{\mathrm{dc}} \\
(\mathrm{mm})\end{array}$ & $\begin{array}{c}\mathrm{T} \\
(\mathrm{kN})\end{array}$ & A & $\begin{array}{l}F_{\text {diag. }} \\
(\mathrm{kN})\end{array}$ & $\begin{array}{c}\mathrm{C}_{\mathrm{d}} \\
(\mathrm{kN})\end{array}$ & $\begin{array}{c}\mathrm{C}_{\mathrm{w}} \\
(\mathrm{kN})\end{array}$ & $\begin{array}{c}\mathrm{M}_{\mathrm{d}, \mathrm{cr}} \\
(\mathrm{kN} . \mathrm{m})\end{array}$ \\
\hline $\begin{array}{l}\text { Matta } \\
\text { et al. } \\
2008\end{array}$ & \multirow{2}{*}{546} & \multirow{2}{*}{178} & \multirow{2}{*}{27.6} & \multirow{2}{*}{1220} & \multirow{2}{*}{178} & 473.8 & - & 52.8 & 290.6 & 391.8 & 33.6 \\
\hline $\begin{array}{l}\text { Current } \\
\text { study }\end{array}$ & & & & & & 473.8 & 5.5 & 52.98 & 291.4 & 392.7 & 33.64 \\
\hline
\end{tabular}

\subsubsection{Minimum Reinforcement Ratio for Diagonal Tension Crack}

Cracking moment in the deck, $\mathrm{M}_{\mathrm{d}, \mathrm{cr}}$, depends on the tensile strength of the concrete. Since concrete is brittle under tensile loads, diagonal tension crack failure has a brittle nature. If the corner joint is capable to take linear-elastic deformation until failure, it is required that GFRP tensile reinforcement should reach their rupture stresses before occurrence of the diagonal tension crack. This means that tensile force in GFRP bars, $\mathrm{F}_{\mathrm{f}}$, at which diagonal tension crack occurs, must satisfy the conditions that:

$F_{f, w} \geq\left(A_{f} f_{f u}\right)_{w}$

$\left(\mathrm{F}_{\mathrm{f}, \mathrm{d}}+\mathrm{F}_{\text {diag. }} / 2\right) \geq\left(\mathrm{A}_{\mathrm{f}} \mathrm{f}_{\mathrm{fu}}\right)_{\mathrm{d}}$ 
Where $F_{f, w}$ is the tensile force in GFRP bars in the wall on the onset of diagonal tension crack, and $F_{f, d}$ is the tensile force in GFRP bars in the deck on the onset of diagonal tension crack. $A_{f}$ is the area of GFRP reinforcing bars in the wall or in the deck and $f_{f u}$ is the ultimate tensile strength of GFRP bars. From resultant forces in the corner joint shown in Figure 4.25 and using the above equation for diagonal tension crack, it follows that:

$\sqrt{ }\left(F_{f, w}{ }^{2}+\left(F_{f, d}+F_{\text {diag }} \cdot / 2\right)^{2}\right)=T=2 / 3 f_{r} \cdot b \cdot L_{d c}$

Substituting Eqs. 4.12 and 4.13 into Eq. 4.14 we obtain:

$\left(A_{f} f_{f u}\right)^{2}{ }_{w}+\left(A_{f} f_{f u}\right)^{2}{ }_{d} \leq T^{2}$

The area of GFRP reinforcing bars in the wall or in the deck can be written as a function of minimum reinforcement ratio provided that:

$\mathrm{A}_{\mathrm{f}, \mathrm{w}}=\rho_{\mathrm{f}, \mathrm{w}} \cdot \mathrm{b} \cdot \mathrm{d}_{\mathrm{w}}$

$\mathrm{A}_{\mathrm{f}, \mathrm{d}}=\rho_{\mathrm{f}, \mathrm{d}} \cdot \mathrm{b} \cdot \mathrm{d}_{\mathrm{d}}$

Also by knowing that $\mathrm{C}_{\mathrm{w}}=\mathrm{T}$. $\operatorname{Cos} \alpha$ and $\mathrm{C}_{\mathrm{d}}=\mathrm{T}$. $\sin \alpha+\mathrm{F}_{\text {dia }}$ / 2 from Figure 4.24 and substituting Eqs. 4.16 and 4.17 into Eq. 4.15, minimum reinforcement ratios in the wall and the deck can be determined so that the diagonal tension crack is prevented. This means if the following conditions are satisfied, failure of barrier wall will be accompanied by flexural mode of failure in the wall or by combined tension-flexural mode of failure in deck.

$\rho_{\mathrm{f}, \mathrm{w}} \leq\left(\mathrm{T} \cdot \operatorname{Cos} \alpha-\mathrm{F}_{\mathrm{dia}} \cdot / 2\right) /\left(\mathrm{b} \cdot \mathrm{d}_{\mathrm{w}} \cdot \mathrm{f}_{\mathrm{fu}}\right)$

$\rho_{\mathrm{f}, \mathrm{d}} \leq\left(\mathrm{T} . \operatorname{Sin} \alpha-\mathrm{F}_{\mathrm{dia}} \cdot / 2\right) /\left(\mathrm{b} . \mathrm{d}_{\mathrm{d}} \cdot \mathrm{f}_{\mathrm{fu}}\right)$

Minimum reinforcement ratio in the wall section of barrier Model 1 was calculated using Eq. 4.18 equal to $0.149 \%$. As such, maximum area of reinforcement required so that diagonal tension 
crack is prevented was found to be $528 \mathrm{~mm}^{2}$. Cross-sectional analysis has been performed using this reinforcement ratio yielding flexural moment resistance in the wall equal to $94.72 \mathrm{kN} . \mathrm{m} / \mathrm{m}$, which was found to be less than cracking moment in the deck due to diagonal tension crack $\left(M_{d, c r}=99.6 \mathrm{kN} \cdot \mathrm{m} / \mathrm{m}\right)$. This indicated that the wall was failed by flexural mode of failure prior to occurrence of diagonal tension crack failure.

\subsection{Analytical Modeling of Deck-Wall Connection}

The analytical modeling was conducted to evaluate load-displacement response of the barrier walls under the applied load, F. The maximum transverse displacement at top of the wall, $\mathrm{U}_{\mathrm{w}}$, can be attributed to the rotation, $\theta_{\mathrm{d}}$, of the deck overhang due to the applied moment in the deck, $\mathrm{M}_{\mathrm{d}}$, and barrier wall self-weight, $\mathrm{W}$, per unit width as well as the displacement of the wall due to the applied transverse load, F, per unit width of the wall. Figure 4.26 shows lateral deformation of the barrier wall under the applied transverse load and the deck slab rotation. Thus, displacement function of the barrier wall can be written as:

$\mathrm{U}_{\mathrm{w}}=\mathrm{U} 1+\mathrm{U} 2=\mathrm{H} \cdot \operatorname{Sin} \theta_{\mathrm{d}}+\mathrm{u}_{\mathrm{w}} \cdot \operatorname{Cos} \theta_{\mathrm{d}}$

Where the deck overhang rotation, $\theta_{\mathrm{d}}$, over the cantilever length, $\mathrm{L}$, can be calculated as:

$\theta_{\mathrm{d}}=\mathrm{L} \cdot\left\{\mathrm{F}\left(\mathrm{H}_{\mathrm{e}}+\mathrm{t}_{\mathrm{d}} / 2\right)+\mathrm{W} \cdot \mathrm{L} / 2\right\} /\left(\mathrm{E}_{\mathrm{c}} \cdot \mathrm{I}_{\mathrm{d}}\right)$

Where $E_{c}$ is the concrete modulus of elasticity, $I_{d}$ is the deck moment of inertia, $H_{e}$ is the height of the applied transverse load, $F$, over the deck slab, and $t_{d}$ is the thickness of deck slab. The transverse displacement in the wall, $\mathrm{u}_{\mathrm{w}}$, due to the applied transverse load, $\mathrm{F}$, can be determined as follow;

$\mathrm{u}_{\mathrm{w}}=\left(\mathrm{F} \cdot \mathrm{H}_{\mathrm{e}}^{2}\right) \cdot\left(\mathrm{H}-\mathrm{H}_{\mathrm{e}} / 3\right) /\left(2 \mathrm{E}_{\mathrm{c}} \cdot \mathrm{I}_{\mathrm{w}}\right)$

On the basis of the assumption that bending moment in the deck, $M_{d}$, exceeds the cracking moment, $\mathbf{M}_{\mathrm{cr}}$, and due to non-linear behavior of overhang, the gross moment of inertia in the deck, $I_{d}$, can be replaced by effective moment of inertia, $I_{e}, d$. The following equations were 
adopted from CSA-A23.3-04 and ISIS Manual 3 for deck slab reinforced with steel and GFRP bars, respectively;

$\mathrm{I}_{\mathrm{e}, \mathrm{d}}=\mathrm{I}_{\mathrm{cr}}+\left(\mathrm{I}_{\mathrm{g}}-\mathrm{I}_{\mathrm{cr}}\right) \cdot\left(\mathrm{M}_{\mathrm{cr}} / \mathrm{M}_{\mathrm{d}}\right)^{3} \leq \mathrm{I}_{\mathrm{g}} \quad$ (For Reinforced Steel bars)

(Eq. 4.23)

$\mathrm{I}_{\mathrm{e}, \mathrm{d}}=\left(\mathrm{I}_{\mathrm{t}} \cdot \mathrm{I}_{\mathrm{cr}}\right) /\left\{\mathrm{I}_{\mathrm{cr}}+\left[1-0.5\left(\mathrm{M}_{\mathrm{cr}} / \mathrm{M}_{\mathrm{d}}\right)^{2}\right]\left(\mathrm{I}_{\mathrm{t}}-\mathrm{I}_{\mathrm{cr}}\right)\right\} \quad$ (For Reinforced GFRP bars) $\quad$ (Eq. 4.24)

Where $I_{g}$ is the gross moment of inertia of the deck section, $M_{c r}$ is the cracking moment, $I_{t}$ is the moment of inertia of an un-cracked section transformed to concrete, and $I_{c r}$ is the cracked moment of inertia that for rectangular sections is given by (CSA-A23.3-04):

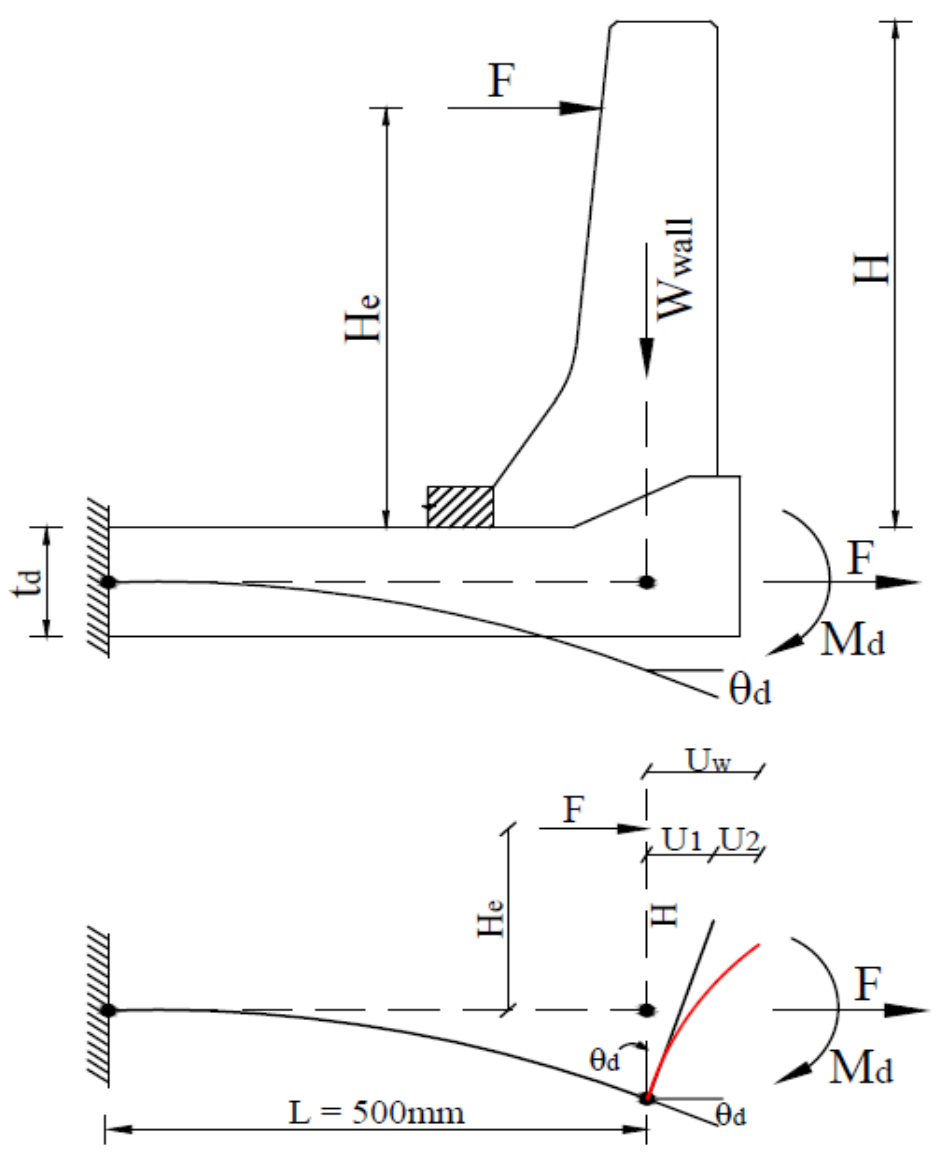

Figure 4. 26 Analytical modeling of deck-wall response; barrier wall subjected to transverse load (top) and rotations of the deck and wall under the applied load (bottom)

$I_{c r}=\left\{b \cdot(k d)^{3}\right\} / 3+n_{s / f} \cdot A_{s / f} \cdot(d-k d)^{2}$ 
Where $b$ is width of cross-section in $\mathrm{mm}, \mathrm{d}$ is the effective depth to GFRP or steel layer in mm, $\mathrm{n}_{\mathrm{s} / \mathrm{f}}$ is the modular ratio of steel or GFRP bars, $\mathrm{A}_{\mathrm{s} / \mathrm{f}}$ is the cross-sectional area of reinforcing steel or GFRP bars, and $\mathrm{k}$ is given by the following equation (CSA-A23.3-04);

$\mathrm{k}=-\mathrm{n}_{\mathrm{s} / \mathrm{f} .} \rho_{\mathrm{s} / \mathrm{f}}+\sqrt{ }\left\{\left(\mathrm{n}_{\mathrm{s} / \mathrm{f}} \cdot \rho_{\mathrm{s} / \mathrm{f}}\right)^{2}+2 \mathrm{n}_{\mathrm{s} / \mathrm{f}} \cdot \rho_{\mathrm{s} / \mathrm{f}}\right\}$

In that $\rho_{\mathrm{s} / \mathrm{f}}$ is the steel or GFRP reinforcement ratio. It is assumed that cracking in the deck slab occurs concurrently with cracking of corner joint between deck-wall junction, which was also observed in the experimental tests. In addition, the gross moment of inertial of the wall section, $I_{w}$, in Eq. 4.22 was replaced by cracked moment of inertia given by Eq. 4.25. The loaddisplacement curves for barrier models 1 and 3 are plotted in Figure 4.27. The load-displacement response of analytical model was performed incorporating the use of Eqs. 4.20 to 4.26. The strength and stiffness were accurately modeled and validated with experimental test results. It is worth mentioning that the discrepancy between the two graphs in Figure 4.27 can be attributed to the non-uniform geometrical shape of the barrier wall, which was approximated in the calculations by analytical modeling.
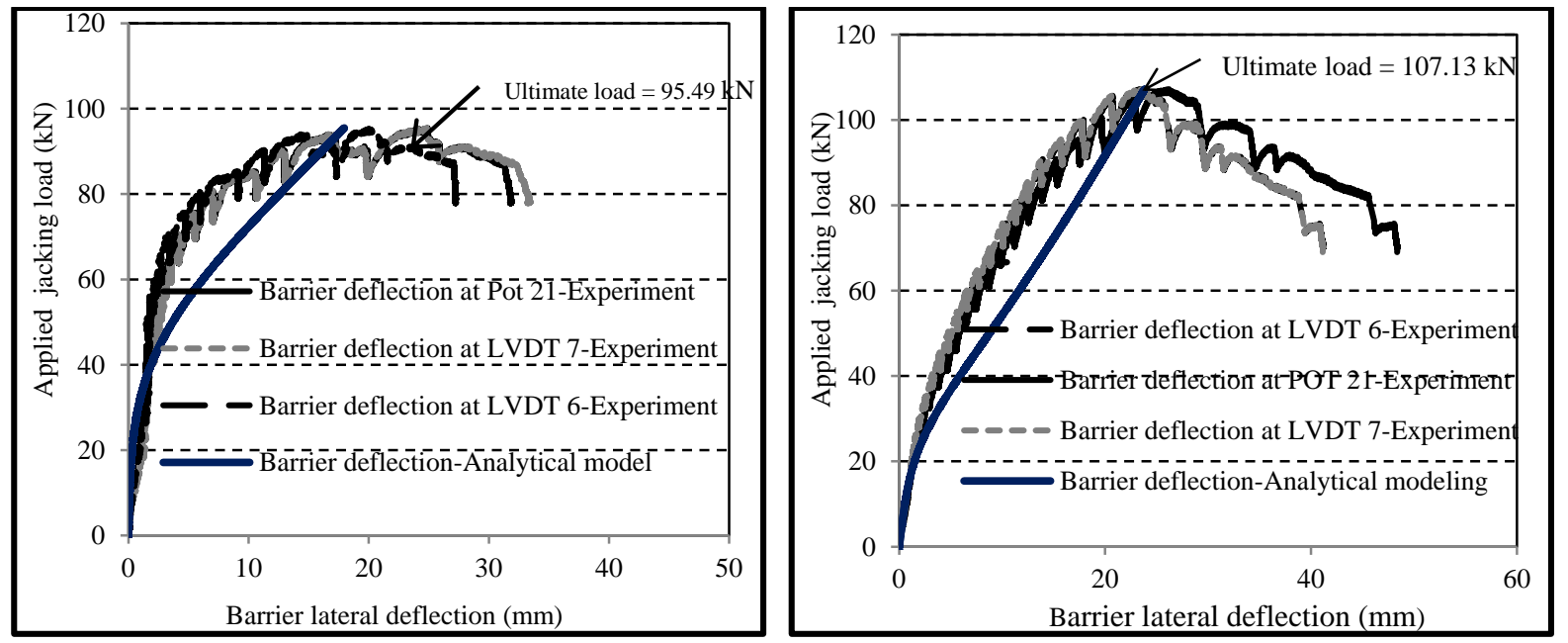

Figure 4. 27 Comparison of load-deformation response of experiment and analytical modeling in (a) barrier Model 1, and (b) barrier Model 3 


\subsection{Analysis of Developed PL-3 Barriers by Strut and Tie Model}

\subsubsection{Introduction}

Strut and tie model comprises a series of tension ties and compression struts that are joined at nodal zone. Such system should be in equilibrium at nodal zone with the applied load. The method utilizes truss model analogy for design of reinforced or prestressed concrete structures that can be used for analysis and design of the structures under both static and dynamic loads. Compression struts and tension ties represent flow of internal stresses in the structures. Strut and Tie model of reinforced concrete structures is useful when the structure does not follow the beam theory of Bernoulli's with linear strain distribution. Bernoulli-Beam theory states that plane sections remain plan after the applied load. Bernoulli's theory facilitates flexural design of reinforced concrete structures by considering linear strain distribution for all loading stage and under ultimate flexural capacity.

The strut and tie model is a unified approach that consider simultaneously the entire load effects (such as shear, bending, axial load, torsion). The method was found to be one of the most suitable methods for shear critical structures as well as design of disturbed regions in concrete structures. It provides a rational approach in which the complex structural members can be simplified to a truss model of analysis. The truss model facilitates to visualize how forces are transferred throughout a structural member. The equivalent truss model is determined on the basis of crack pattern appeared in the structural members under the applied load. As such, crack patterns assist to illustrate the load transfer in the structural members by means of compressive struts or tension ties. Strut and tie model was first presented by Ritter (1899) as a truss analogy model to calculate the internal forces in a cracked members. The method was developed by Schlaich (1987) and Collins and Mitchell (1991) and MacGregor (1997).

\subsection{2 $B$ and $D$ regions}

Structural member may be divided into two regions, namely as: B-region in which the beam theory of linear strain distribution applies, and the region adjacent to discontinuities or disturbances known as D-region where the beam theory is not applied. D-region is portion of the structural members that have complex variations in strain distribution. Regions near the abrupt changes in geometry or concentrated forces are examples of D-region. St. Venant's principle states that D- 
regions span one section depth of the region on either side of discontinuities. As such, D-regions are bounded by cross-section that is a distance (h) from geometric discontinuities or disturb regions, where (h) is the depth of the structural member. Generally, prior to concrete cracking, elastic stress field develops in the structure which can be determined by elastic analysis such as finite element. After cracking, the stress fields will be disturbed causing reorientation of internal forces. Thus, the strut and tie model can be utilized to analysis or design of such structural members. The barrier models under study contain several boundaries and discontinuities along its cross section. As such, the entire cross-section of the barriers could be considered as D-region so that it seems appropriate to use strut and tie model for the analysis and design of such barriers.

\subsubsection{Components of Strut and Tie Model}

Strut and Tie model consists of three main elements including: struts, ties and nodes. Each of these elements is described briefly as follows:

\subsubsection{Compression Struts}

Struts composed of concrete stress fields with compressive stresses in the direction of stresses. The compressive struts represent the resultant of: (i) uniform compressive stress fields or prismatic stress fields; prismatic stress field represents uniform stresses along the length of struts with identical magnitude of the stress, (ii) fan-shaped stress fields; it is an idealization of stress field with minimal curvature of stress flows. This type of stress field does not develop transverse tension stresses as such cracks do not develop along the length of compression struts, and (iii) bottled shaped stress fields that develop bulging stress trajectories. This type of stress field develops transverse tension stresses so that the longitudinal cracks appear along the length of the struts. In fact, the transverse compressive stresses develop in bottleneck location and the transverse tension stresses develop further down the strut. To avoid longitudinal cracks in bottle shaped struts, transverse tension reinforcements may be utilized over certain portions of the struts. Fan-shaped and bottle-shaped struts develop in D-regions where point loads exist. 


\subsubsection{Tension Tie}

Tension ties in strut and tie model are subjected to tensile forces. Tension ties may consist of reinforcing bars or concrete tensile stress fields. In some structural members concrete occasionally might be subjected to tensile stresses with no reinforcement present. In this case, concrete tension ties should resist the tensile stresses; otherwise, the concrete cannot resist any loads. Example of such concrete tension tie is bar anchorage system with no transverse reinforcement.

\subsubsection{Nodal Zone}

Nodal zone consists of zones in which concrete struts and tension ties are joined. Nodal zone are often subjected to complex stress distributions that need specific design considerations.

\subsubsection{Development of Truss Model}

In developing strut and tie model several basic step should be followed, namely: i) B and Dregions and their dimensions and boundaries must be identified. In the barrier under study, the geometric shape of the barriers is non-uniform so that the entire barrier wall and the portion of deck slab under the wall can be considered as D-region, ii) internal stresses and their resultant on the boundaries of D-regions must be determined. In developing strut and tie model, the direction of stress trajectories in finite-element linear-elastic analysis can be utilized, and iii) an internal truss model should be developed to transmit the internal forces from one boundary of D-region to another region so that the equilibrium of internal and external forces is maintained. The truss or strut and tie model should satisfy the following requirements:

a. Loads should be applied on nodes and struts and ties should be only under axial loads

b. The model should be in equilibrium with the applied external loads and the reactions

c. The dimension of struts, ties and nodal zones should be taken into account in determining geometry of the model.

d. Ties shall be permitted to cross struts with sufficient anchorage at support locations

e. Struts shall cross or intersect only at nodes.

f. When two non-collinear forces meet at a node, a third load is required for equilibrium. 
g. It is assumed that no member is loaded beyond its applicable limit states.

h. The angle $\theta$ should be taken as the smallest angle between strut and tie crossing at a node. This angle shall not be taken less than $25^{\circ}$ (According to ACI 318), 30 (According to AS 3600) and 40 (According to Macgregor et al. used in CSAA23.3).

\subsubsection{Application of Strut and Tie Mode (STM) on Tested Barriers}

As pointed earlier, the first step is to determine D-region in the barrier walls. There are several geometric discontinuities in the barrier under study so that the entire barrier wall and the portion of the deck under the barrier could be considered as D-region (shown in Figure 4.28). It should be noted that only the portion of deck directly below the barrier wall is taken into account for analysis. This portion of the deck is subjected to two couple forces resulted from bending moment developed in the barrier and the deck under the applied force. These two forces are not equal to satisfy the external equilibrium forces.

To establish a truss model, direction of stress trajectories in finite-element linear-elastic analysis was utilized. Figure 4.29(a) shows stress trajectories for the entire barrier model in this study and the assumed truss model on the basis of these stress trajectories that was proposed by Aminmansour et al. (2004). Based on the geometric discontinuities and reinforcement arrangement in the barrier models, several truss models were examined. However, the truss model shown in Figure 4.29(b), which was proposed by Aminmansour et al. (2004), was found to be better representation of strut and tie model of the barrier walls in this study, when compared to experimental results. The proposed truss model by Aminmansour et al. (2004) showed that the tension tie (T1) and compressive strut (S2) reinforcement extended into the deck slab, which were similar to the GFRP bar arrangement in the current barrier models. In developing such truss model a number of factors were considered by Aminmansour et al. (2004). First, compressive strength of reinforcing bars and tensile strength of concrete were ignored. As such, it was assumed that concrete cracks under tensile loads. Second, reinforcing ties were designed in such a way that the length and area of the bars to be identical with existing reinforcement in the barrier walls. It should be noted that the reinforcing ties in the deck slab has not been evaluated as it was assumed that failure of the barrier wall occurs in the wall rather than the deck slab. 
Third, additional support and truss members were included in the model for stability of structure. In all tested barriers, the added support and truss members had zero forces.

In strut and tie approach of the barrier models, an external force, F, was applied at a height of 990-mm above the deck slab in accordance with the CHBDC code. The magnitude of the load F was taken as failure load from static load tests performed experimentally on each barrier. The experimental failure load for each barrier model is shown in Table 4.2.

In all barrier models, a bearing plate of $1000 \times 100 \times 20 \mathrm{~mm}$ was assumed at location of load, F, and reaction R2 shown in Figure 4.29 (b). For each barrier model, design strength of concrete struts, tension ties and nodal zone were determined by comparing Canadian code (CSA-A23.3, 2004), American code (ACI-318, 2005), Australian code (AS-3600, 2009) and Japanese code (JSCE, 2007).

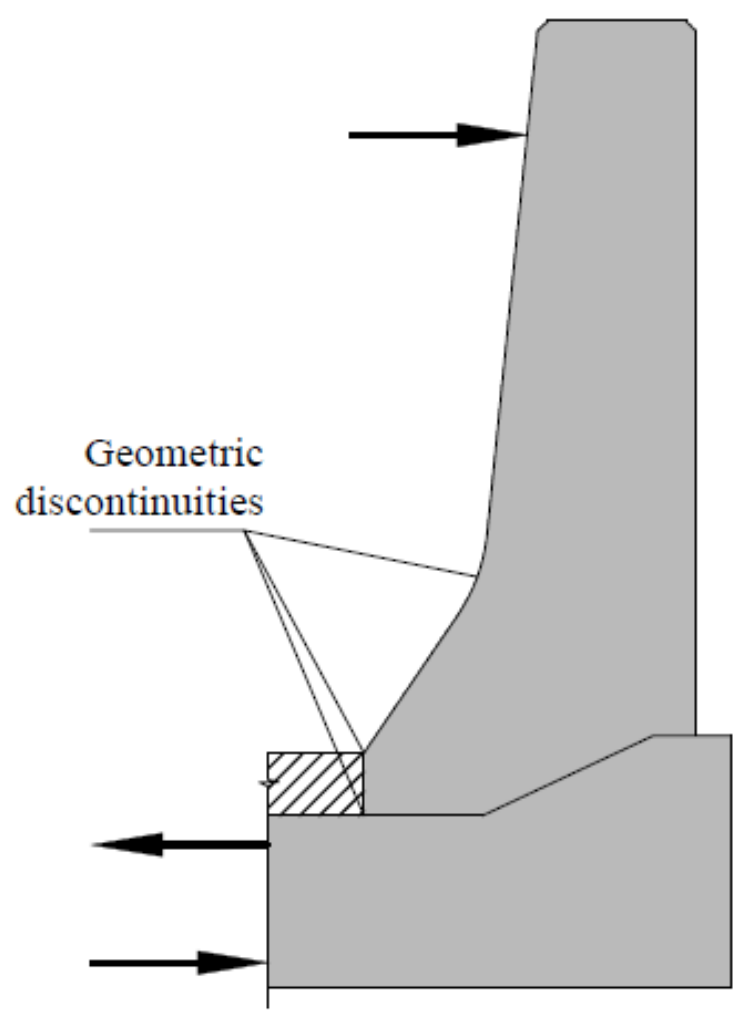

Figure 4. 28 Assumed D-region in the barrier models 


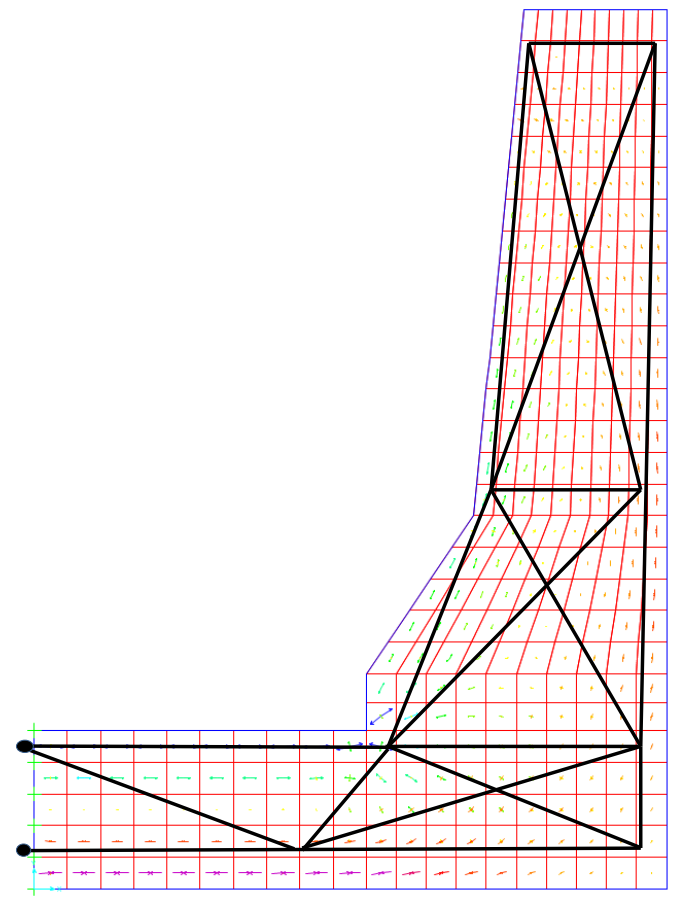

(a)

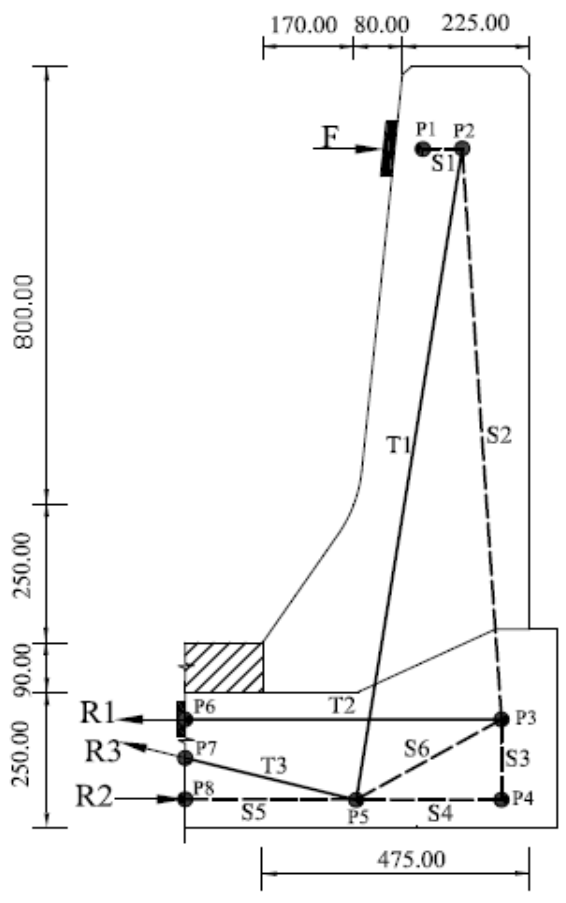

(b)

Figure 4. 29 (a) Stress trajectories and assumed truss model, and (b) truss model in analysis proposed by Aminmansour et al. (2004)

Table 4.5 provides relevant strut and tie design strength equations based on the above mentioned codes. In STM, the area of interest was taken at barrier-to-deck joint as well as the area underneath the wall portion. As such, the strength of tension tie reinforcement at barrier-to-deck joint was examined. In addition, the behavior of compression struts underneath the wall portion was investigated.

\subsubsection{Results of Strut and Tie Model}

Truss model shown in Figure 4.29b was used in the analysis considering solid lines (T1 and T2) as tension tie reinforcement in the barrier wall and the deck slab, respectively. Struts S1, S2 and S6 were assumed as bottle shaped struts with no reinforcement, while struts S3, S4 and S5 were assumed as prismatic struts. The provided width of tension ties was assumed as two times the distance from concrete edge to the center of the reinforcement in the existing barrier models tested experimentally. The length of tension ties and struts were assumed as 1-m equal to the length of the barrier models considered for the analysis. 
Table 4. 5 Design strength of struts, tension ties and nodal zone by various codes

\begin{tabular}{|c|c|c|c|}
\hline \multirow{2}{*}{ Designated code } & \multicolumn{3}{|c|}{ Strut and Tie design equations } \\
\hline & Design of concrete struts & Design of tension ties & Design of nodal zone \\
\hline ACI-318-05 & $\begin{array}{l}\varphi_{\mathrm{c}} \mathrm{F}_{\mathrm{ns}}=\varphi_{\mathrm{c}} f_{\mathrm{ce}} \mathrm{A}_{\mathrm{cs}} \\
f_{\mathrm{ce}}=0.85 \beta_{\mathrm{s}} f_{\text {'c }}=v f_{\text {' }^{\prime}} \\
\beta_{\mathrm{s}}=\text { From ACI } 318-05 \\
\quad \text { Appendix A }\end{array}$ & $\begin{array}{c}\Phi_{\mathrm{frp}} \mathrm{F}_{\mathrm{nt}}=0.5 f_{f \mathrm{u}} \mathrm{A}_{\mathrm{st}} \\
f_{f \mathrm{u}}=\mathrm{C}_{\mathrm{E}} \cdot f_{f \mathrm{u}^{*}}=0.7 f_{f \mathrm{u}^{*}}\end{array}$ & $\begin{array}{l}\varphi_{\mathrm{c}} \mathrm{F}_{\mathrm{nn}}=\varphi_{\mathrm{c}} f_{\mathrm{cu}} \mathrm{A}_{\mathrm{n}} \\
f_{\mathrm{cu}}=0.85 \beta_{\mathrm{n}} f_{\mathrm{c}} \\
\beta_{\mathrm{n}}=\text { From ACI } 318-05 \\
\quad \text { Appendix A }\end{array}$ \\
\hline CSA-A23.3 & $\begin{array}{l}\varphi_{\mathrm{c}} \mathrm{F}_{\mathrm{ns}}=\varphi_{\mathrm{c}} f_{\mathrm{ce}} \mathrm{A}_{\mathrm{cs}} \\
f_{\mathrm{ce}}=\alpha_{1} \beta_{\mathrm{s}} f_{\mathrm{c}}=v f_{\mathrm{c}_{\mathrm{c}}} \\
f_{\mathrm{ce}}=\frac{1}{0.8+170 \varepsilon 1} \cdot f_{\mathrm{c}}=v f_{{ }_{\mathrm{c}}} \\
\beta_{\mathrm{s}}=v / \alpha_{1}=\frac{1}{(0.8+170 \varepsilon 1) \alpha 1} \\
\alpha_{1}=0.85-0.0015 f_{\mathrm{c}}\end{array}$ & $\Phi_{\mathrm{frp}} \mathrm{F}_{\mathrm{nt}}=0.5 f_{f \mathrm{u}} \mathrm{A}_{\mathrm{st}}$ & $\begin{array}{l}\varphi_{\mathrm{c}} \mathrm{F}_{\mathrm{nn}}=\varphi_{\mathrm{c}} f_{\mathrm{ce}} \mathrm{A}_{\mathrm{n}} \\
f_{\mathrm{ce}}=\alpha_{1} \beta_{\mathrm{n}} f_{\mathrm{c}} . \\
\beta_{\mathrm{n}}=0.867 \text { for CCC node } \\
\beta_{\mathrm{n}}=0.765 \text { for CCT node } \\
\beta_{\mathrm{n}}=0.663 \text { for CTT or } \\
\quad \text { TTT node }\end{array}$ \\
\hline AS-3600 & $\begin{array}{l}\varphi_{\mathrm{st}} \mathrm{F}_{\mathrm{ns}}=\varphi_{\mathrm{st}} f_{\mathrm{ce}} \mathrm{A}_{\mathrm{cs}} \\
f_{\mathrm{ce}}=0.9 \beta_{\mathrm{s}} f_{\mathrm{c}} \\
\beta_{\mathrm{s}}=1 \text { for prismatic struts } \\
\beta_{\mathrm{s}}=\frac{1}{1+0.66 \cot ^{2} \theta} \text { for fan- } \\
\text { shaped struts } \\
\quad 0.3 \leq \beta_{\mathrm{s}} \leq 1.0\end{array}$ & $\Phi_{\mathrm{frp}} \mathrm{F}_{\mathrm{nt}}=0.5 f_{f \mathrm{u}} \mathrm{A}_{\mathrm{st}}$ & $\begin{array}{c}\varphi_{\mathrm{st}} \mathrm{F}_{\mathrm{nn}}=\varphi_{\mathrm{st}} f_{\mathrm{cu}} \mathrm{A}_{\mathrm{n}} \\
f_{\mathrm{cu}}=0.90 \beta_{\mathrm{n}} f_{\mathrm{c}} \\
\beta_{\mathrm{n}}=1 \text { for CCC node } \\
\beta_{\mathrm{n}}=0.8 \text { for CCT node } \\
\beta_{\mathrm{n}}=0.6 \text { for CTT or } \\
\quad \text { TTT node }\end{array}$ \\
\hline JSCE-2007 & $\begin{array}{l}\mathrm{F}_{\mathrm{Rcd}}=f_{\text {'cd.eff }} \mathrm{A}_{\mathrm{cs}} / \gamma_{\mathrm{b}} \\
f_{\text {'cd.eff }}=v_{1} v_{2} f^{\prime} c d \\
\gamma_{\mathrm{b}}=1.3 \\
v=0.85 . \beta_{\mathrm{s}} \\
\beta_{\mathrm{s}}=\left(v_{1} v_{2}\right) / 0.85\end{array}$ & $\Phi_{\mathrm{frp}} \mathrm{F}_{\mathrm{nt}}=0.77 f_{f \mathrm{u}} \mathrm{A}_{\mathrm{st}}$ & - \\
\hline
\end{tabular}

Note: $\varphi_{\mathrm{st}}=\varphi_{\mathrm{c}}$ in AS-3600 code

$f^{\prime} c_{d}=f_{\text {c }}$ in JSCE-2007 code

$\varphi_{c}=1 / \gamma_{b}$ in JSCE- 2007 code

Table 4.6 provides barrier designation for each of the barrier under study. GFRP material properties provided in Table 3.1 was considered for calculation of tension tie design strength. Truss element forces and reactions from analysis of the truss model in Figure 4.29b are shown in Table 4.7 for all barrier models. It should be noted that the force in $\mathrm{T} 3$ member was zero due to the fact that this member is a dummy member added for stability of the truss model, also there is no shear in the deck. In addition, the strut forces S3 and S4 were zero since these struts are orthogonal members connected at node P4. The experimental results were consistent with these findings. 
Table 4. 6 Barrier designations used in the current study for each barrier model

\begin{tabular}{|c|c|}
\hline $\begin{array}{c}\text { PL-3 Barrier } \\
\text { designation }\end{array}$ & Description of Models \\
\hline GS1- HM & $\begin{array}{r}\text { Specimen No. 1 with GFRP bars, high modulus of elasticity and } \\
\text { headed-end bars with 300-mm spacing }\end{array}$ \\
\hline GS2-ST & $\begin{array}{r}\text { Specimen No. 2 with GFRP bars, standard modulus of elasticity and } \\
\text { bent bars with 200-mm spacing }\end{array}$ \\
\hline GS3-ST & $\begin{array}{r}\text { Specimen No. 3 with GFRP bars, standard modulus of elasticity } \\
\text { and180 - hook bars with 200-mm spacing }\end{array}$ \\
\hline GS4- HM & $\begin{array}{r}\text { Specimen No. 4 with GFRP bars, high-modulus of elasticity and } \\
\text { headed-end bars with 150-mm spacing }\end{array}$ \\
\hline SS5- CS & $\begin{array}{r}\text { Specimen No. 2 with conventional steel reinforcement and 200-mm } \\
\text { bar spacing }\end{array}$ \\
\hline
\end{tabular}

ACI-318 specifies that design strength of tension tie, compressive struts and nodal zone $\left(\varphi F_{n}\right)$ should be greater than the factored applied loads in struts, ties or nodal zones $(F)$ such that;

$\mathrm{F}^{*}=\varphi \mathrm{F}_{\mathrm{n}} \geq \mathrm{F}$

Where $\varphi$ is the material resistance factor, $F_{n}$ is nominal resistance of the strut, tie or nodal zone. Values of applied load $(\mathrm{F})$, design strength $\left(\varphi \mathrm{F}_{\mathrm{n})}\right.$ and the ratio of the applied load-to-design strength $\left(\mathrm{F} / \mathrm{F}^{*}\right)$ of struts, ties and nodal zones are calculated and provided in Appendix $\mathrm{C}$. The ratio of applied compressive forces to the design strength of concrete struts for each barrier model is compared in Table 4.8 from various codes. From the table, CSA-A23.3 (2004) shows failure of struts S5 and S6 in barrier Models 1 to 4 in which the ratio of applied compressive struts to design strength of struts $\left(\mathrm{F} / \mathrm{F}^{*}\right)$ is well greater than one. The CSA-A23.3 (2004) code was found to be very conservative compared to other codes in predicting design strength of compressive struts. 
Table 4. 7 Resulting forces $(\mathrm{F})$ in struts, ties and reactions in each barrier model $(\mathrm{kN})$

\begin{tabular}{|c|c|c|c|c|c|c|c|c|c|}
\hline \multicolumn{2}{|c|}{} & T1 & T2 & S1 & S2 & S5 & S6 & R1 & R2 \\
\hline GS1- HM & F & 302.8 & 841.7 & -106.1 & -290.8 & -735.6 & -871.9 & 841.7 & -735.6 \\
\hline GS2- ST & F & 331.9 & 922.6 & -116.3 & -318.8 & -806.3 & -955.7 & 922.6 & -806.3 \\
\hline GS3- ST & F & 305.9 & 805.4 & -107.2 & -293.8 & -743.3 & -880.9 & 805.4 & -743.3 \\
\hline GS4- HM & F & 486.1 & 1351 & -170.3 & -486.3 & -1181 & -1399 & 1351 & -1181 \\
\hline SS5- CS & F & 367.9 & 1022 & -128.9 & -353.3 & -893.7 & -1059 & 1022 & -893.7 \\
\hline
\end{tabular}

CSA-A23.3 (2004) recommended compressive strength of struts equal to $f_{\text {ce }}=v f_{{ }^{\prime} \mathrm{c}} \leq 0.85 f^{\prime} \mathrm{c}$ in which the efficiency factor, $v$, can be computed using equations below:

$v=\frac{1}{0.8+170 \varepsilon 1} \leq 0.85$

$\varepsilon_{1}=\varepsilon_{\mathrm{s}}+\left(\varepsilon_{\mathrm{s}}+0.002\right) \cot ^{2} \theta$

Where $\varepsilon_{\mathrm{s}}$ is the tensile strain in the tension tie assuming a strain of 0.002 to determine efficiency factor. The strain 0.002 is intended to represent the strain in reinforcing steels at yielding. However, since there is no yielding of FRP bars and due to lower values of modulus of elasticity of FRP bars, the strain in FRP bars reach much higher values than strain in steel bars at yielding. As such, Eq. 4.28 provides conservative values of efficiency factors so that the reduction factor $\beta_{\mathrm{s}}=v / \alpha_{1}$ is much smaller in CSA-A23.3 (2004) compared to the $\beta_{\mathrm{s}}$ provided in other codes. Thus, the CSA-A23.3 (2004) model seems to overestimate the design strength of concrete struts and therefore not valid for FRP-reinforced concrete. ACI-318 (2005) results showed much more reliable strength ratios that were consistent with the experimental observations. According to ACI 318 (2005), barrier Model 4 made of GFRP-HM bars spaced at 150-mm were failed at S5 and S6 strut locations. Experimental observations showed failure of struts at these locations at failure load. 
Table 4. 8 Compressive strut loads and comparison with design strength of compressive

\begin{tabular}{|c|c|c|c|c|c|c|c|c|c|c|}
\hline \multirow{2}{*}{\multicolumn{2}{|c|}{$\begin{array}{c}\text { Specimen } \\
\text { designation }\end{array}$}} & \multirow{3}{*}{$\begin{array}{c}\mathrm{F}(\mathrm{kN}) \\
106.1 \\
\end{array}$} & \multicolumn{2}{|c|}{ CSA-A23.3 } & \multicolumn{2}{|c|}{ ACI-318 } & \multicolumn{2}{|c|}{ AS-3600 } & \multicolumn{2}{|c|}{ JSCE-2007 } \\
\hline & & & $\beta_{\mathrm{s}}$ & $\mathrm{F} / \mathrm{F}^{*}$ & $\beta_{\mathrm{s}}$ & $\mathrm{F} / \mathrm{F}^{*}$ & $\beta_{\mathrm{s}}$ & $\mathrm{F} / \mathrm{F}^{*}$ & $\beta_{\mathrm{s}}$ & $\mathrm{F} / \mathrm{F}^{*}$ \\
\hline \multirow{6}{*}{ GS1- HM } & $\mathrm{S} 1$ & & 1 & 0.076 & 1 & 0.065 & 1 & 0.077 & 1 & 0.064 \\
\hline & S2 & 290.8 & 0.31 & 0.702 & 0.6 & 0.29 & 0.34 & 0.59 & 0.8 & 0.21 \\
\hline & S3 & 0 & 0.31 & 0 & 0.6 & 0 & 1 & 0 & 0.8 & 0 \\
\hline & S4 & 0 & 1 & 0 & 1 & 0 & 1 & 0 & 0.8 & 0 \\
\hline & S5 & 735.6 & 0.285 & 1.92 & 0.6 & 0.76 & 0.94 & 0.57 & 0.8 & 0.55 \\
\hline & S6 & 871.9 & 0.21 & 2.96 & 0.6 & 0.85 & 0.74 & 0.82 & 0.6 & 0.83 \\
\hline \multirow{6}{*}{ GS2- ST } & S1 & 116.3 & 1 & 0.087 & 1 & 0.072 & 1 & 0.085 & 1 & 0.07 \\
\hline & S2 & 318.8 & 0.492 & 0.46 & 0.6 & 0.32 & 0.34 & 0.65 & 0.8 & 0.23 \\
\hline & S3 & 0 & 0.494 & 0 & 0.6 & 0 & 1 & 0 & 0.8 & 0 \\
\hline & S4 & 0 & 1 & 0 & 1 & 0 & 1 & 0 & 0.8 & 0 \\
\hline & S5 & 806.4 & 0.46 & 1.31 & 0.6 & 0.83 & 0.94 & 0.63 & 0.8 & 0.61 \\
\hline & S6 & 922.65 & 0.34 & 1.93 & 0.6 & 0.91 & 0.74 & 0.86 & 0.6 & 0.88 \\
\hline \multirow{6}{*}{ GS3-ST } & S1 & 107.2 & 1 & 0.080 & 1 & 0.066 & 1 & 0.078 & 1 & 0.065 \\
\hline & S2 & 293.86 & 0.492 & 0.43 & 0.6 & 0.29 & 0.34 & 0.60 & 0.8 & 0.21 \\
\hline & S3 & 0 & 0.494 & 0 & 0.6 & 0 & 1 & 0 & 0.8 & 0 \\
\hline & S4 & 0 & 1 & 0 & 1 & 0 & 1 & 0 & 0.8 & 0 \\
\hline & S5 & 743.3 & 0.46 & 1.21 & 0.6 & 0.76 & 0.94 & 0.57 & 0.8 & 0.56 \\
\hline & S6 & 880.9 & 0.34 & 1.84 & 0.6 & 0.86 & 0.74 & 0.83 & 0.6 & 0.84 \\
\hline \multirow{6}{*}{ GS4- HM } & S1 & 170.3 & 1 & 0.12 & 1 & 0.11 & 1 & 0.12 & 1 & 0.102 \\
\hline & S2 & 486.3 & 0.31 & 1.17 & 0.6 & 0.48 & 0.34 & 0.99 & 0.8 & 0.35 \\
\hline & S3 & 0 & 0.31 & 0 & 0.6 & 0 & 1 & 0 & 0.8 & 0 \\
\hline & S4 & 0 & 1 & 0 & 1 & 0 & 1 & 0 & 0.8 & 0 \\
\hline & S5 & 1180.7 & 0.285 & 3.1 & 0.6 & 1.21 & 0.94 & 0.92 & 0.8 & 0.89 \\
\hline & S6 & 1399.5 & 0.21 & 4.74 & 0.6 & 1.37 & 0.74 & 1.31 & 0.6 & 1.34 \\
\hline \multirow{4}{*}{ SS5- CS } & S1 & 128.9 & 1 & 0.096 & 1 & 0.08 & 1 & 0.094 & 1 & 0.077 \\
\hline & S2 & 353.3 & 0.586 & 0.43 & 0.6 & 0.35 & 0.34 & 0.72 & 0.8 & 0.25 \\
\hline & S5 & 893.7 & 1 & 0.67 & 0.6 & 0.92 & 0.94 & 0.69 & 0.8 & 0.67 \\
\hline & S6 & 1059.3 & 0.823 & 0.92 & 0.6 & 1.04 & 0.74 & 0.994 & 0.6 & 1.01 \\
\hline
\end{tabular}

$\mathrm{F}$ is the load in compressive truss elements due to experimental failure loads.

$\mathrm{F}^{*}$ is the design strength of compressive struts

AS-3600 (2009) and JSCE (2007) strength ratios showed approximately similar results, showing failure of S6 strut in barrier model 4. According to ACI-318 (2005), AS-3600 (2009) and JSCE (2007), struts in barrier Models 1, 2 and 3 did not fail under the applied loads that were consistent with experimental findings. In barrier Model 5 made of conventional steel reinforcement, strength ratio in all code specifications showed critical values (close to one) at strut S6 location. This is an indication of failure of barrier at S6 strut location under the applied load that was observed in experimental testing of barrier Model 5. Generally, ACI-318 (2005) 
presented the most suitable design strength of concrete struts for FRP and steel-reinforced concrete barriers compared with other code specifications. Table 4.9 compares the strength ratio of applied tension tie at barrier-to-deck joint (T1) to the design strength of reinforcing tension tie $\left(\mathrm{T}^{*}\right)$. In barrier Models 1 to 4 made of GFRP bars, the strength ratios were less than unity indicating the remaining capacities of the barrier walls so that sufficient amount of reinforcement were provided. In barrier Model 5 with steel reinforcement as tension ties, the steel ties went somewhat beyond their design strength. Development of flexural cracks at barrier-to-deck joint in experimental testing of barrier Model 5 confirmed this outcome. Although the strength ratio in barrier Model 5 is close to unity, it is recommended to increase the size of tension reinforcing bars at front face of the barrier from $15 \mathrm{M}$ to $20 \mathrm{M}$. Increasing the tension reinforcing bar size reduces strength ratios $\left(\mathrm{T}_{\left.1 / \mathrm{T}^{*}\right)}\right.$ ) to $0.9,0.85,0.96$ and 0.81 in the CSA A.23.3 (2004), ACI 318 (2005), AS-3600 (2009) and JSCE (2007) codes, respectively. The reduction in strength ratio was found to be $17 \%$ if the bar size increases to $20 \mathrm{M}$ bar. In this observation, AS-3600 (2009) was found to overestimate design strength of tension ties in steel-reinforced barrier walls compared to other code specifications.

As mentioned earlier, struts S5 and S6 were failed in barrier Model 4 under the applied compressive forces. Thus, the strength ratio of the nodal zones P3 and P5 in Figure 4.31b were investigated in this barrier model. Table 4.10 provides the strength ratio of applied truss element loads to the design strength of nodal zone. CSA-A23.3 (2004) and AS-3600 (2009) showed failure of node P3 at strut faces of T2 and S6 with the strength ratio greater than unity. The two codes, also, presented failure of node P5 at strut faces of S5 and S6. The two observations were consistent with experimental testing of barrier Model 4 showing cracks of struts at node faces of S5 and S6 at failure load. ACI-318 (2005) showed the strength ratio close to unity for both P3 and P5 nodes. It should be noted that the strength ratio of nodal zone for JSCE (2007) were not available. The strength ratio of nodal zone at all other nodes as well as all nodes in barrier Models 1, 2, 3 and 5 were found to be less than unity indicating that loads applied at nodal faces were well below their design strengths. These observations concurred with experimental findings and are provided in Appendix C. 
Table 4.11 summarizes flexural strength ratio of experimental tests to the cross-sectional analysis as well as the design strength ratio of tension tie reinforcement based on CSA-A23.3 (2004) code. Comparing the results explained that barrier Models 1 to 4 made of GFRP bars with sandcoated surface show both flexural strength ratio and tension tie design strength ratio well less than unity indicating additional capacity of these barrier models. However, barrier Model 5 with conventional steel reinforcement shows both flexural strength ratio and tension tie design strength ratio exceeding the unity indicating the needs for additional steel reinforcement in tension face of the barrier. As mentioned earlier, an increasing the bar size from $15 \mathrm{M}$ to $20 \mathrm{M}$ will overcome this need.

Table 4. 9 Tension tie load (T1) and comparison with design strength of reinforcing tie at barrierdeck joint

\begin{tabular}{|c|c|c|c|c|}
\hline \multirow{4}{*}{ Code } & $\begin{array}{c}\text { Specimen } \\
\text { designation }\end{array}$ & $\mathrm{T} 1$ & $\mathrm{~T}^{*}$ & $\mathrm{~T} 1 / \mathrm{T}^{*}$ \\
\hline \multirow{4}{*}{ CSA- A23.3 } & GS1- HM & 302.8 & 702.9 & 0.32 \\
\cline { 2 - 5 } & GS2-ST & 331.9 & 494.7 & 0.67 \\
\cline { 2 - 5 } & GS3- ST & 306 & 494.7 & 0.62 \\
\cline { 2 - 5 } & GS4- HM & 486.06 & 1405.9 & 0.35 \\
\cline { 2 - 5 } & SS5- CS & 367.9 & 340 & 1.08 \\
\hline \multirow{5}{*}{ ACI-318 } & GS1- HM & 302.8 & 492 & 0.46 \\
\cline { 2 - 5 } & GS2- ST & 331.9 & 346.3 & 0.96 \\
\cline { 2 - 5 } & GS3- ST & 306 & 346.3 & 0.88 \\
\cline { 2 - 5 } & GS4- HM & 486.06 & 984 & 0.42 \\
\cline { 2 - 5 } & SS5- CS & 367.9 & 360 & 1.02 \\
\hline & GS1- HM & 302.8 & 702.9 & 0.32 \\
\cline { 2 - 5 } & GS2- ST & 331.9 & 494.7 & 0.67 \\
\cline { 2 - 5 } & GS3- ST & 306 & 494.7 & 0.62 \\
\cline { 2 - 5 } & GS4- HM & 486.06 & 1405.9 & 0.30 \\
\cline { 2 - 5 } & SS5- CS & 367.9 & 320 & 1.15 \\
\hline & GS1- HM & 302.8 & 1083 & 0.21 \\
\cline { 2 - 5 } & GS2- ST & 331.9 & 762 & 0.435 \\
\cline { 2 - 5 } & GS3- ST & 306 & 762 & 0.401 \\
\cline { 2 - 5 } & GS4- HM & 486.06 & 2165 & 0.19 \\
\cline { 2 - 5 } & SS5- CS & 367.9 & 380 & 0.97 \\
\hline
\end{tabular}

$\mathrm{T} 1$ is the applied tensile load in tension tie 1

$\mathrm{T}^{*}$ is the design strength of tension tie reinforcements 
Table 4. 10 Truss element loads and comparison with design strength of Nodes P3 and P5 at barrier-deck joint for barrier Model 4 (GS4-HM)

\begin{tabular}{|c|c|c|c|c|c|c|c|}
\hline Code & $\begin{array}{l}\text { Specimen } \\
\text { designation }\end{array}$ & Node ID & Node face & $\mathrm{F}$ & $\beta_{\mathrm{n}}$ & $\mathrm{F}^{*}$ & $\mathrm{~F} / \mathrm{F}^{*}$ \\
\hline \multirow{8}{*}{ CSA-A23.3 } & \multirow{8}{*}{ GS4-HM } & \multirow{4}{*}{ P3 } & S2 & 486.3 & 0.765 & 1125 & 0.432 \\
\hline & & & $\mathrm{T} 2$ & 1351.05 & 0.765 & 1023 & 1.32 \\
\hline & & & S3 & 0 & 0.765 & 1125 & 0 \\
\hline & & & S6 & 1399.5 & 0.765 & 1125 & 1.24 \\
\hline & & \multirow{4}{*}{ P5 } & $\mathrm{S} 4$ & 0 & 0.765 & 1074 & 0 \\
\hline & & & S6 & 1399.5 & 0.765 & 1074 & 1.30 \\
\hline & & & $\mathrm{T} 1$ & 486.06 & 0.765 & 1176 & 0.413 \\
\hline & & & S5 & 1180.7 & 0.765 & 1023 & 1.15 \\
\hline \multirow{8}{*}{ ACI-318 } & \multirow{8}{*}{ GS4-HM } & \multirow{4}{*}{ P3 } & $\mathrm{S} 2$ & 486.3 & 0.8 & 1425 & 0.34 \\
\hline & & & $\mathrm{T} 2$ & 1351.05 & 0.8 & 1295 & 1.04 \\
\hline & & & S3 & 0 & 0.8 & 1425 & 0 \\
\hline & & & S6 & 1399.5 & 0.8 & 1425 & 0.98 \\
\hline & & \multirow{4}{*}{ P5 } & $\mathrm{S} 4$ & 0 & 0.8 & 1360 & 0 \\
\hline & & & S6 & 1399.5 & 0.8 & 1360 & 1.03 \\
\hline & & & $\mathrm{T} 1$ & 486.06 & 0.8 & 1490 & 0.33 \\
\hline & & & S5 & 1180.7 & 0.8 & 1295 & 0.91 \\
\hline \multirow{8}{*}{ AS-3600 } & \multirow{8}{*}{ GS4-HM } & \multirow{4}{*}{ P3 } & $\mathrm{S} 2$ & 486.3 & 0.8 & 1207 & 0.402 \\
\hline & & & $\mathrm{T} 2$ & 1351.05 & 0.8 & 1097 & 1.23 \\
\hline & & & S3 & 0 & 0.8 & 1207 & 0 \\
\hline & & & S6 & 1399.5 & 0.8 & 1207 & 1.16 \\
\hline & & \multirow{4}{*}{ P5 } & $\mathrm{S} 4$ & 0 & 0.8 & 1152 & 0 \\
\hline & & & S6 & 1399.5 & 0.8 & 1152 & 1.21 \\
\hline & & & $\mathrm{T} 1$ & 486.06 & 0.8 & 1262 & 0.385 \\
\hline & & & S5 & 1180.7 & 0.8 & 1097 & 1.07 \\
\hline
\end{tabular}

Table 4. 11 Flexural and tension tie desgin strength ratio at barrier-deck joint

\begin{tabular}{|c|c|c|c|c|c|c|}
\hline & GS1-HM & GS2-ST & GS3-ST & GS4-HM & SS5-CS & SS5-CS \\
\hline $\mathrm{M}_{\mathrm{exp}, \mathrm{w}} / \mathrm{M}_{\mathrm{r}, \mathrm{w}}$ & 0.43 & 0.79 & 0.73 & 0.52 & 0.85 & 1.05 \\
\hline $\begin{array}{c}\mathrm{T} 1 / \mathrm{T}^{*} \\
(\mathrm{CSA}-\mathrm{A} 23.3)\end{array}$ & 0.32 & 0.67 & 0.62 & 0.35 & - & 1.08 \\
\hline
\end{tabular}

SS5-CS ${ }^{1}-\mathrm{M}_{\text {exp,w }}$ is calculated considering both tension and compression reinforcements SS5-CS $-\mathrm{M}_{\text {exp,w }}$ is calculated considering tension reinforcement only 


\subsection{Empirical Expressions for Transverse Moments and Tensile Forces in Bridge Barriers}

Traffic loads on barriers can be determined based on their performance levels when subjected to vehicular impact loads. The impact load creates vertical, transverse and longitudinal loads on the barriers, while the transverse load is considered as critical load exerting bending moment and shear force at the base of the wall, and bending moment and tensile force in the deck slab. The specified traffic loads on each traffic barrier was provided in Table 2.10. Based on the dispersal angles of load distribution, moments and tensile forces are transferred to the deck slab, which were provided in Table 2.11 for PL-2 and PL-3 barriers. The CHBDC specifies that these moments and tensile forces are obtained from linear elastic finite element analysis, while a constant cantilever deck slab length at the exterior edge or face of the barrier equal to $1.5-\mathrm{m}$ was assumed. The CHBDC code also requires that the maximum transverse load obtained by linear FE modeling to be superimposed on a separate analysis for the effect of vertical loading on the barrier. The magnitude and distribution of load effects due to vertical loading significantly depends on the location of beam lines in the deck cross-section. While, the magnitude of moment intensity due to the transverse loading is not sensitive to this geometrical feature, rather the variation has an influence on the dispersal of moment intensity in the deck slab. However, CHBDC did not provide any further information regarding geometric variation of cantilever deck slab and traffic barriers. While, it is assumed that the magnitude of moments and tensile forces will be affected by such geometrical variations due to the changes in dispersion of forces in barrier walls and deck slabs. As such, linear elastic FE modeling was further investigated on PL3 and PL-2 barriers as well as their AASHTO-LRFD counterparts, TL-5 and TL-4 barriers as comparison. Table 2.12 provides summary of design forces for traffic railings in TL-4 and TL-5 as per AASHTO-LRFD (2012). It can be clearly seen from Table 2.11 and Table 2.12 that PL-3 and PL-2 barriers have an overall height of 1140- and 915-mm compared to 1066- and 812-mm height of TL-5 and Tl-4 traffic barriers. However, the height of load applications for TL-5 and TL-4 above the deck is 1066- and 812-mm compared to 990- and 790-mm height of load applications in PL-3 and PL-2, respectively. Due to such differences in overall height and location of load application, it was presumed that TL-5 and TL-4 barriers should carry higher moment and tensile force intensities compared to PL-3 and PL-2 traffic barriers. The height of load application has a significant effect, as the load applied at exterior location creates higher 
moment intensity at base of the wall compared to the interior location when subjected to similar force.

In designing decks supporting concrete parapet railings, AASHTO- LRFD (2012) stated that the deck overhang should be designed to resist a flexural moment per unit length of the deck, $\mathrm{M}_{\mathrm{s}}$ that acts simultaneously with tensile force, $T$, exceeding $M_{c}$ of the parapet at its base where $M_{c}$ is the cantilevered moment action of concrete parapet railing. The axial tensile force per unit length in the deck, T, may be calculated from the following:

$\mathrm{T}=\frac{R_{W}}{L_{C}+2 H}$

Where $R_{w}$ is parapet transverse resistance, $L_{c}$ is critical length of yield line failure pattern, and $H$ is the overall height of the wall. It can be observed that AASHTO-LRFD in designing cantilever deck slabs does not consider geometric variations in cantilever deck slabs and traffic barriers rather take into account the transverse wall resistance by yield line theory that accounts for the

amount of reinforcing bars in traffic barrier walls in addition to critical failure lengths and overall height of the wall. Therefore, the objective of this study was to undertake a parametric study using linear elastic FE modeling on few influencing factors such as barrier length $\left(\mathrm{L}_{\mathrm{b}}\right)$, cantilever deck length $\left(\mathrm{L}_{\mathrm{d}}\right)$, cantilever deck thickness $\left(\mathrm{t}_{\mathrm{d}}\right)$ and barrier types (PL-3 and PL-2 versus TL-5 and TL-4).

\subsubsection{Parametric Study}

As mentioned earlier, variable geometric conditions were taken into account to investigate dispersal of moment and tensile force intensities into the deck slab. The following provides key parameters considered herein:

Barrier Length: In order to promote moment intensities to longitudinal length of the traffic barriers, four different lengths in PL-3 and TL-5 barriers (6, 8, 10 and $12 \mathrm{~m}$ ) and four variable lengths in PL-2 and TL-4 barriers (4, 6, 8, and 10) have been considered. The minimum lengths ( 4- and 6-m) in those barriers have been considered as critical lengths required during crash 
testing of such barriers at interior or exterior locations. The maximum barrier lengths were assumed as 12-m in PL-3 and TL-5 barriers and 10-m in PL-2 and TL-4 barriers since analysis showed that the larger barrier length had minimal effects on dispersal of moment and tensile forces at interior locations and no effects at exterior locations.

Cantilever Deck Length: In designing cantilever deck slab using GFRP bars, the cantilever decks should be checked against serviceability limit states for deflection rather than flexural strength of the deck portion. This is due to the fact that GFRP bars maintain lower modulus of elasticity that cause more deflection compared to traditional deck slab reinforced with steel bars. In cases, where longer cantilever deck slab is required, the deflection becomes more critical that results in designing heavier GFRP reinforced decks. This may not be an economical use of GFRP bars since the design will be costly due to the use of congested reinforcement in the deck slab. In practice, the cantilever deck slabs reinforced with GFRP bars have lengths between 1 to 1.5-m. Therefore, in this study various cantilever deck lengths of $0,0.5,1,1.5$ and 2-m were considered to investigate the effects of such variables on dispersal of the forces. The cantilever deck length of zero represents a barrier wall that is fixed at its base. In practice, this case may be encountered when the barrier wall is connected to a stiff slab such as solid or voided slab bridges with a total thickness more than 1-m.

Cantilever Deck Thickness: The conventional traffic barriers studied herein may be connected to the deck slab projecting from slab-on-girder or box-girder bridges with variable deck slab thickness between 200 to 300-mm. In current study, deck slab thickness of 225, 250, 300 and 350-mm were considered for PL-3 and TL-5 barriers and deck slab thickness of 180, 200, 250 and 300-mm were assumed for PL-2 and TL-4 barriers. Increasing deck slab thickness enhances stiffness of the deck resulting in higher moment intensity in the wall, to the extent that it may be considered as fixed base barrier.

Barrier Types: the parametric studies were carried out on selected PL-3 and PL-2 barriers with tapered face. PL-3 barrier had a thickness of 475-mm at its base, tapering to 225-mm at top of the wall, while PL-2 barriers had a thickness of 450-mm at the base, tapered to $225-\mathrm{mm}$ at its top. The parametric studies were also performed on F-shape concrete parapets (TL-5) and New- 
Jersey shape concrete parapets (TL-4) with tapered face in AASHTO-LRFD (2012). The barrier wall thickness varied from $439-\mathrm{mm}$ to $228-\mathrm{mm}$ in TL-5 barriers, while it varied from $379-\mathrm{mm}$ to $152-\mathrm{mm}$ in TL-4 barriers.

\subsubsection{Finite Element Modeling Using SAP 2000}

The General SAP2000 package (Computers and Structures, 2010) was employed to conduct linear elastic 3D modeling of the traffic barriers. The barrier walls and cantilever deck slab portions were modelled by shell elements with five degrees of freedom at each node. The maximum mesh size of 50x50-mm was considered with aspect ratio not greater than 1.3 in some cases. Figure 4.30 illustrates view of FE modeling of the traffic barriers showing mesh elements provided in the wall and the deck portions. Thickness of shell elements in the deck slab was considered similar to the thickness of the cantilever deck portion, while in the traffic barrier wall, the thickness of shell elements varied along the height of the wall to best-fit the cross-sectional variations of the tapered wall. Thus, for each $50-\mathrm{mm}$ segment of the wall along the height, an average wall thickness was assumed as the thickness of shell elements in the wall. The end conditions of the cantilever deck slab induced fixed supports by restraining all degrees of freedom at nodes along the line of supports. All traffic barriers were modelled with similar material properties, namely as: Concrete compressive strength of $30 \mathrm{MPa}$, modulus of elasticity of 24.6 GPa and poisson's ratio of 0.2. In addition, mesh reinforcement were not considered in the modeling. For each traffic barrier model, a unit load of 1-kN was applied in transverse direction over specified length and height mentioned in Tables 2.11 and 2.12. The load was applied both at interior and exterior locations of the traffic barriers. The resultant moments and tensile forces were obtained in the deck over one meter length, within centerline of the applied load at interior location and end of traffic barrier at exterior location. The unit load of $1-\mathrm{kN}$ was selected so that to obtain moment and tensile force intensity factors $\left(M_{I F}\right.$ and $\left.T_{I F}\right)$ in deck slab, respectively. Then, the factored design moments and tensile forces per meter of the wall would be equal to the moment or tensile force intensity factors multiplied by the applicable factored transverse load, $F_{t}$ (given in Tables 2.11 and 2.12) providing that: 
Factored Moment per meter of the deck $=\mathrm{M}_{\mathrm{IF}} . \mathrm{F}_{\mathrm{t}}$

Factored Tensile Force per meter of the deck $=\mathrm{T}_{\mathrm{IF}} . \mathrm{F}_{\mathrm{t}}$

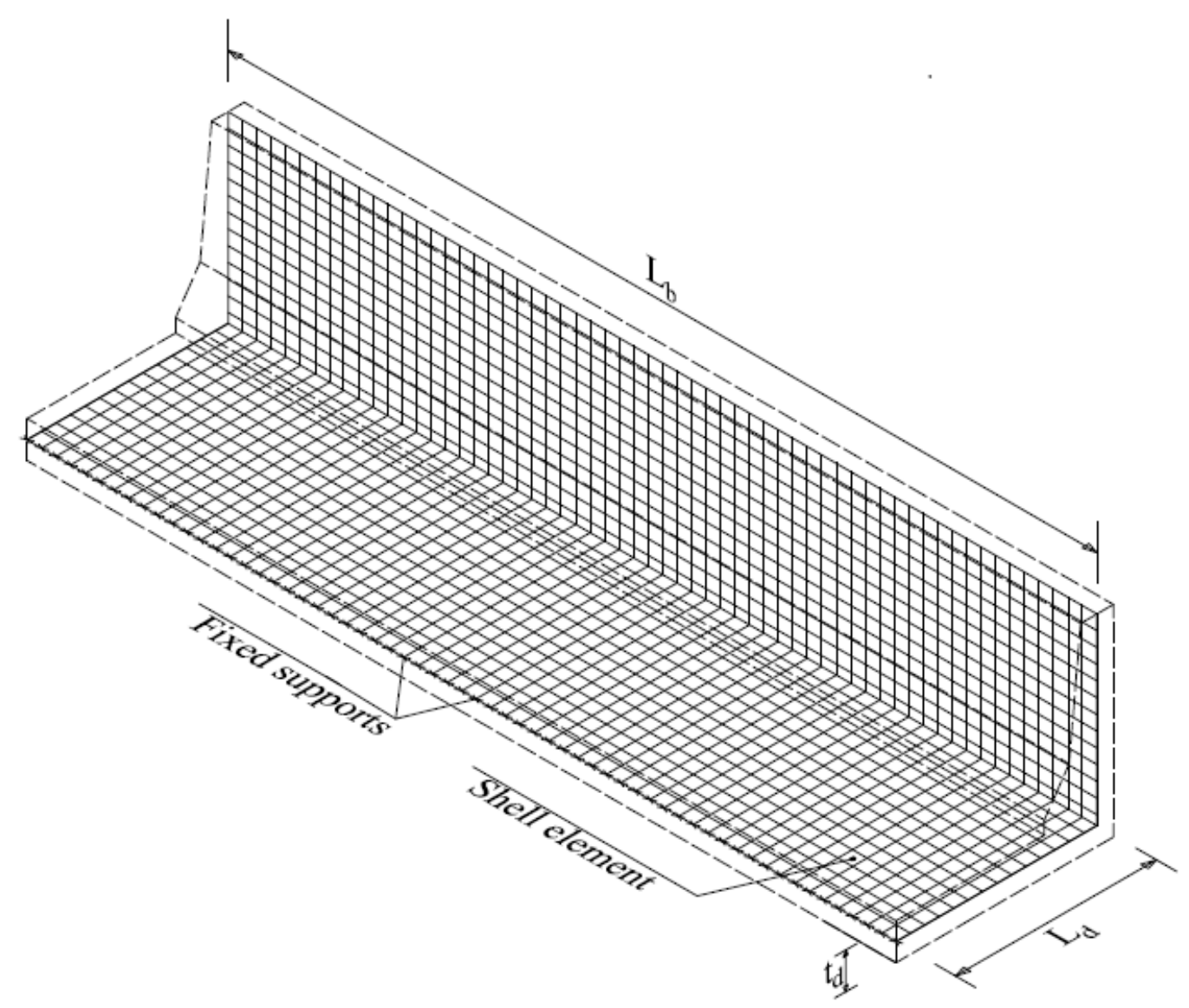

Figure 4. 30 Typical FE modeling of traffic barriers

\subsubsection{Finite Element Results and Discussions}

As mentioned earlier, CHBDC specifies that the transverse, longitudinal and vertical loads shall be applied simultaneously to the barrier wall. However, since the transverse loads simulating vehicular impact loads create the critical load carrying capacity of the wall, both longitudinal and vertical loads were ignored in the analysis. Thus, a transverse unit load of 1-kN was applied on each of the traffic barrier. The dispersal of moment intensity in a PL-3 barrier wall of 8-m length is shown in Figure 4.31. At exterior location, the maximum moment intensity occurred at the end of the barrier and diminishing the intensity toward the longitudinal length of the traffic barrier. 
However, at interior location, the maximum moment intensity occurred under the applied transverse load and diminishing the intensity toward both ends of the traffic barriers. Thus, one can conclude that the critical location of the applied factored moment per meter length at base of the wall is under the centerline of the applied load at interior locations and at end-corner of the exterior locations. The following subsections discuss results of FE modeling of the tested traffic barriers.

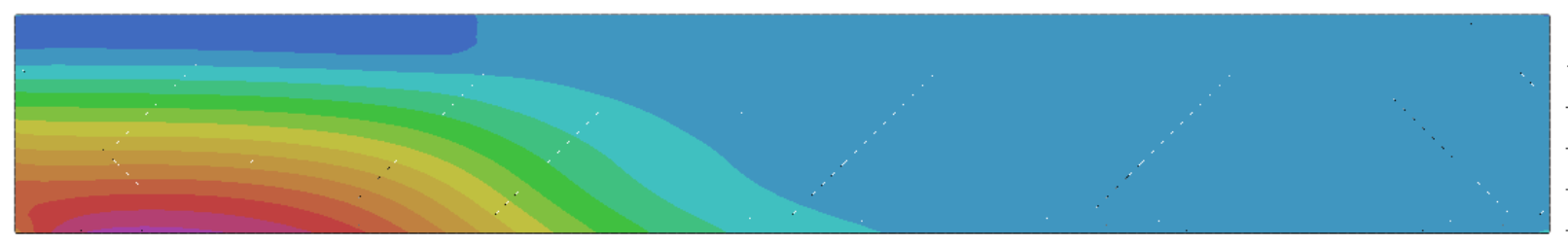

(a)

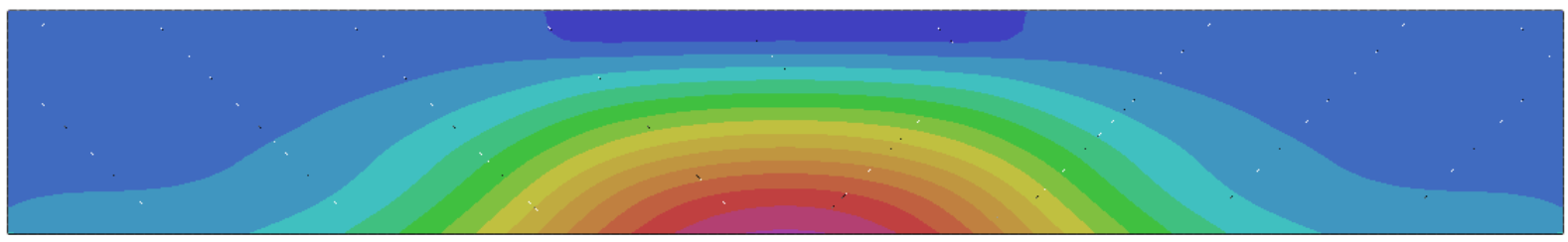

(b)

Figure 4. 31 Contour of moment dispersion in PL-3 barrier walls with 8-m length; (a) at exterior location and (b) at interior location

\subsubsection{PL-3 and TL-5 Traffic Barriers}

Moment Intensity Factor $\left(M_{I F}\right)$ at interior location of the deck per meter at face of the wall: Due to applied transverse load of $357 \mathrm{kN}$, CHBDC Commentary specifies moment per meter of the deck at interior location equal to $83 \mathrm{kN} . \mathrm{m} / \mathrm{m}$, which was estimated for a barrier with cantilever deck length of $1.5-\mathrm{m}$. The moment has an intensity factor $\left(\mathrm{M}_{\mathrm{IF}}\right)$ of $83 / 357$ equal to 0.232 due to a unit transverse load. The intensity factor was compared with results of the study herein on PL-3 traffic barriers. Figure 4.32 shows graph of moment intensity factor $\left(\mathrm{M}_{\mathrm{IF}}\right)$ in the deck slab in PL-3 barriers versus barrier longitudinal length as a function of cantilever deck length and thickness. The graphs were compared with the CHBDC moment intensity factor of 0.232 for PL-3 barriers. Based on the graph representation, general observations were made for all traffic barrier models, namely as: (i) by increasing barrier longitudinal lengths from 6-m to $12-\mathrm{m}$, the moment intensity factor decrease, (ii) increasing the cantilever deck lengths from 0.5 - 
$\mathrm{m}$ to 2-m decreases moment intensity factors, while (iii) increasing cantilever deck thickness from 225-mm to 350-mm significantly increases moment intensity factors. For a barrier considered as fixed base, a moment intensity factor $\left(\mathrm{M}_{\mathrm{IF}}\right)$ of 0.364 was observed for all barrier lengths, which means an increase in $\mathrm{M}_{\mathrm{IF}}$ of $57 \%$ compared to the CHBDC recommendation. In addition, it can be seen from the graphs that CHBDC overestimated the $\mathrm{M}_{\mathrm{IF}}$ for cantilever deck thickness less than 250-mm in most cases; however, it underestimated the $\mathrm{M}_{\mathrm{IF}}$ for deck thickness greater than 300-mm which was observed to be $11.7 \%$ for deck thickness of $300-\mathrm{mm}$ and $18.6 \%$ for deck thickness of 350-mm. It should also be noted that $\mathrm{M}_{\mathrm{IF}}$ had less effect for barrier length greater than $10-\mathrm{m}$ with maximum of $1.67 \%$ differences between 10 - and 12-m long barriers.

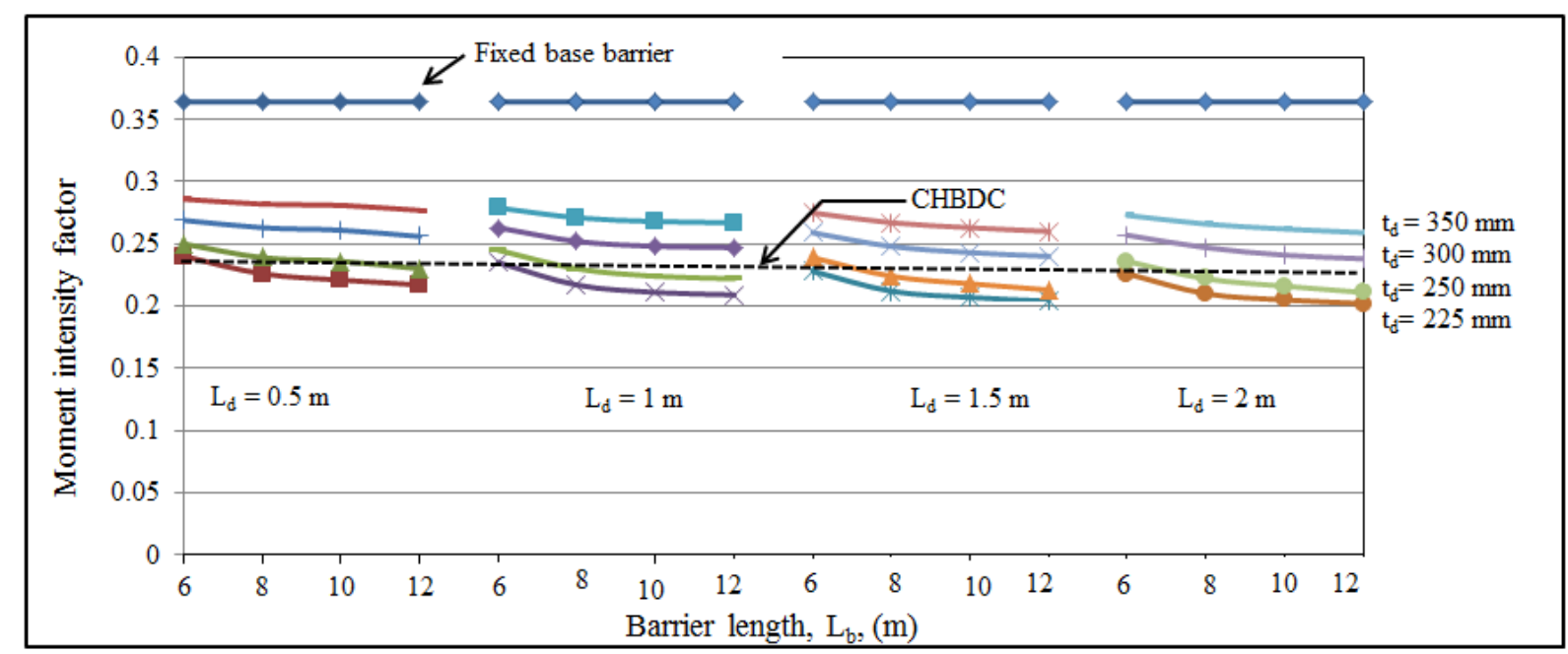

Figure 4. 32 Moment intensity factor in the deck of the PL-3 barrier wall versus barrier length as a function of cantilever deck slab length and deck slab thickness at interior location.

Figure 4.33 shows graph of moment intensity factor versus cantilever deck length as a function of barrier length and deck thickness. It can be observed from the graphs that for cantilever deck lengths greater than 1.5-m and deck thickness less than 250-mm, in all barrier lengths, CHBDC overestimated the $\mathrm{M}_{\mathrm{IF}}$, while it underestimated the $\mathrm{M}_{\mathrm{IF}}$ by increasing the deck thickness to 350mm. Moreover, it can be seen that decreasing cantilever deck length $\left(\mathrm{L}_{\mathrm{d}}\right)$ from 2-m to 0.5-m, $\mathrm{M}_{\mathrm{IF}}$ increases by $6.47 \%$ on average greater than CHBDC limit for barrier lengths less than $8-\mathrm{m}$. 


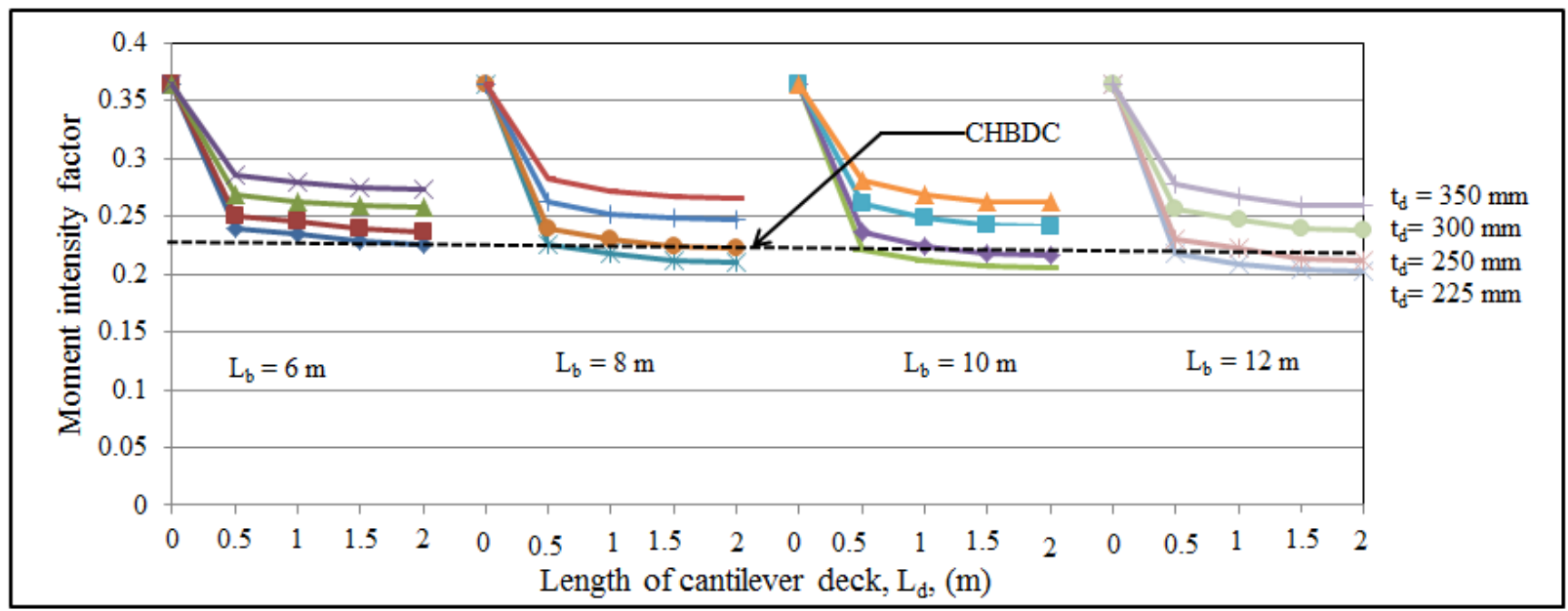

Figure 4. 33 Moment intensity factor at base of the PL-3 barrier wall versus cantilever deck length as a function of barrier length and deck slab thickness at interior location

Moment intensity factors $\left(\mathrm{M}_{\mathrm{IF}}\right)$ for barrier length less than 6-m were extrapolated for deck slab length of $0.5-\mathrm{m}$ with all variable deck slab thickness. Figure 4.34 shows view of extrapolated barrier length up to 1-m long barrier. It can be observed that decreasing barrier length from 6-m to a maximum of 1-m significantly increases moment intensity factors due to decrease in dispersal angle of the transverse load in the wall and deck portions. In the same manner, a transverse unit load of 1-kN was applied on TL-5 traffic barriers and moment intensity factors $\left(\mathrm{M}_{\mathrm{IF}}\right)$ were determined in the deck slab. Due to geometrical variations and height of load application in TL-5 barriers, moment intensity factors $\left(\mathrm{M}_{\mathrm{IF}}\right)$ were found to be greater than PL-3 traffic barriers. Figure 4.35 compares results of FE modeling on TL-5 and PL-3 barriers in terms of moment intensity factor for cantilever deck lengths of 0.5- and 1-m. In case of fixed base barrier, TL-5 barrier exhibited a $\mathrm{M}_{\mathrm{IF}}$ of 0.386 which increased by $6.04 \%$ compared to PL-3 barriers. For barrier length of $0.5-\mathrm{m}, \mathrm{M}_{\mathrm{IF}}$ in TL-5 barrier increased by $9.24 \%$ on average compared to PL-3 barriers, while for barrier length of 1-m, the increase was $7.65 \%$. When comparing TL-5 moment intensity factors with the CHBDC limit, it can be observed that CHBDC underestimates the $\mathrm{M}_{\mathrm{IF}}$ in most cases for all barrier lengths, cantilever deck lengths and cantilever deck thickness greater than 250-mm. Graphs of $\mathrm{M}_{\mathrm{IF}}$ versus barrier lengths and cantilever deck lengths in all traffic barriers at interior and exterior locations can be found in Appendix D. 


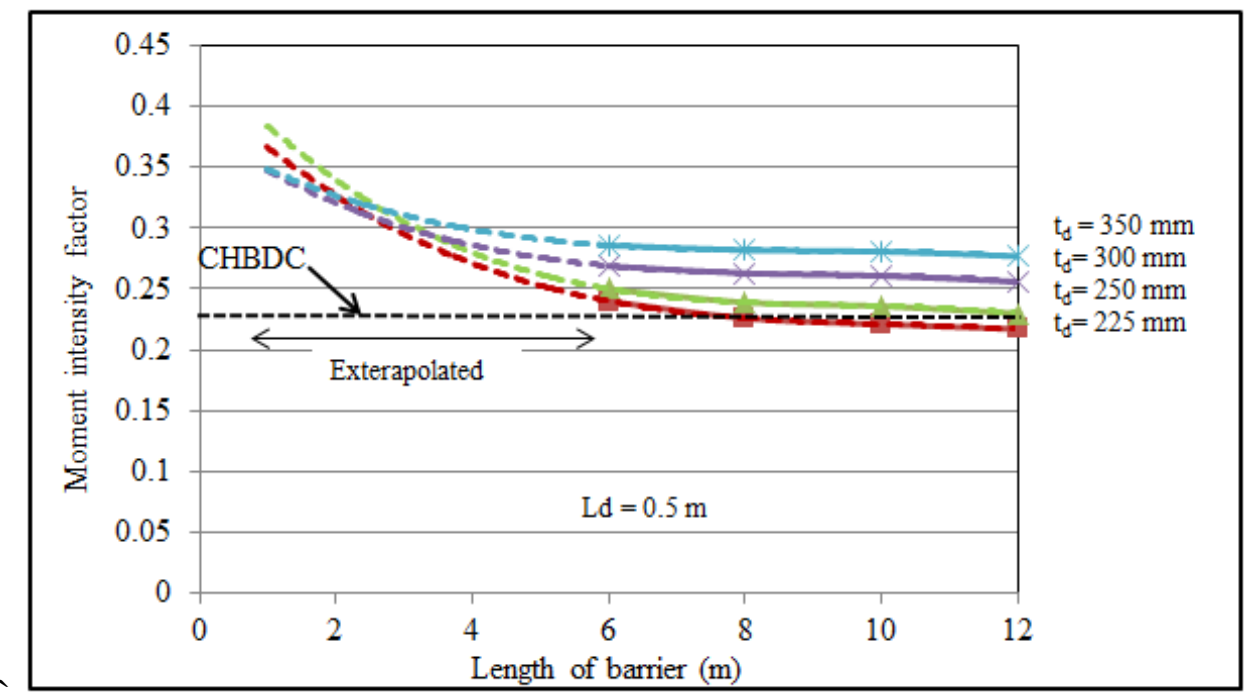

Figure 4. 34 Extrapolation of moment intensity versus barrier longitudinal length for PL-3 barrier at interior location

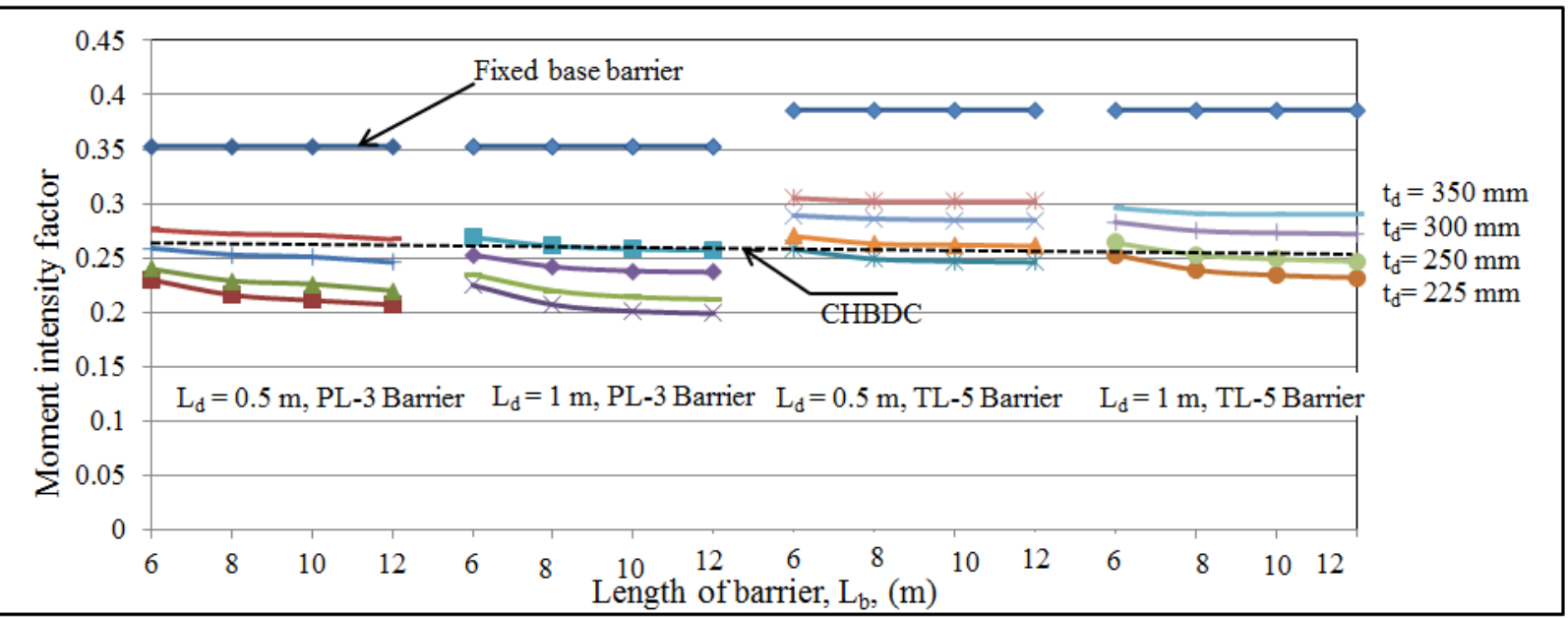

Figure 4. 35 Comparison of moment intensity factors for PL-3 and TL-5 barriers at interior location as a function of barrier length

Moment Intensity Factor $\left(M_{I F}\right)$ at exterior location of the deck per meter at face of the wall:

At exterior location, CHBDC specifies moment per meter length of the deck equal to 102 $\mathrm{kN} . \mathrm{m} / \mathrm{m}$ which results in a moment intensity factor $\left(\mathrm{M}_{\mathrm{IF}}\right)$ of 0.286 in PL-3 traffic barriers. The $\mathrm{M}_{\mathrm{IF}}$ due to a fixed base barrier at exterior location was found to be 0.404 which represents a $41.3 \%$ increase compared to the CHBDC limit. The $\mathrm{M}_{\mathrm{IF}}$ at exterior location for fixed base barriers increased by $11 \%$ when it was compared to interior location. It should be noted that barrier longitudinal length had no effect on moment intensity factors of fixed base barriers at 
both interior and exterior locations. Generally, a similar trend was observed at exterior location compared to interior location of the traffic barriers. However, it was found that barrier length greater than 10-m had insignificant effect on increasing the $\mathrm{M}_{\mathrm{IF}}$. This trend was similar in both PL-3 and TL-5 traffic barriers. For deck slab thickness greater than 300-mm, CHBDC underestimated the $\mathrm{M}_{\mathrm{IF}}$ by $17.6 \%$ on average for cantilever length less than $1-\mathrm{m}$ and $2.7 \%$ on average for cantilever lengths greater than $1.5-\mathrm{m}$. In addition, it was observed that the $\mathrm{M}_{\mathrm{IF}}$ had an average increase of $16.3 \%$ at exterior location when it is compared to interior location.

Moment intensity factor for TL-5 traffic barrier with fixed base was 0.422 which had an increase of $4.5 \%$ compared to PL-3 traffic barriers. Figure 4.36 shows comparison of the $\mathrm{M}_{\mathrm{IF}}$ in PL-3 and TL-5 traffic barriers at exterior location for barrier lengths of 0.5- and 1-m. It can be seen from the graphs that for all barrier lengths and cantilever deck thickness in TL-5 barriers, CHBDC underestimated the moment intensity factors. It was also observed that by increasing the barrier length from 6- to 8-m, the $\mathrm{M}_{\mathrm{IF}}$ comparably decreased, while barrier lengths greater than 10-m had insignificant effect on increasing the $\mathrm{M}_{\mathrm{IF}}$. As such, it can be generally concluded that at exterior location of PL-3 and TL-5 traffic barriers, barrier length less than 8-m, cantilever thickness greater than 250-mm and cantilever deck length less than 1-m had significant effect on the moment intensity factors when they were compared with the CHBDC limit.

\section{Tensile Force Intensity Factors $\left(T_{I F}\right)$ at interior location of the deck per meter at face of the} wall: CHBDC Commentary specifies tensile force per meter length of barrier at interior location equal to $144 \mathrm{kN}$. The tensile force was obtained for a barrier with cantilever deck length of 1.5$\mathrm{m}$. Due to the factored transverse load of $357 \mathrm{kN}$, a tensile force intensity factor $\left(\mathrm{T}_{\mathrm{IF}}\right)$ of 0.403 can be obtained. For a deck thickness of 225-mm and cantilever deck length of $1.5-\mathrm{m}$, the $\mathrm{T}_{\mathrm{IF}}$ was $0.404,0.402,0.400$ and 0.399 for barrier lengths of $6,8,10-$ and $12-\mathrm{m}$. These values were very close to the $\mathrm{T}_{\mathrm{IF}}$ prescribed by the CHBDC. However, as the cantilever deck length was decreased to $0.5-\mathrm{m}$, the $\mathrm{T}_{\mathrm{IF}}$ is increased to 0.423 for a barrier length of $6-\mathrm{m}$ representing an increase of about $5 \%$ in the $\mathrm{T}_{\mathrm{IF}}$ compared to the CHBDC limit. 


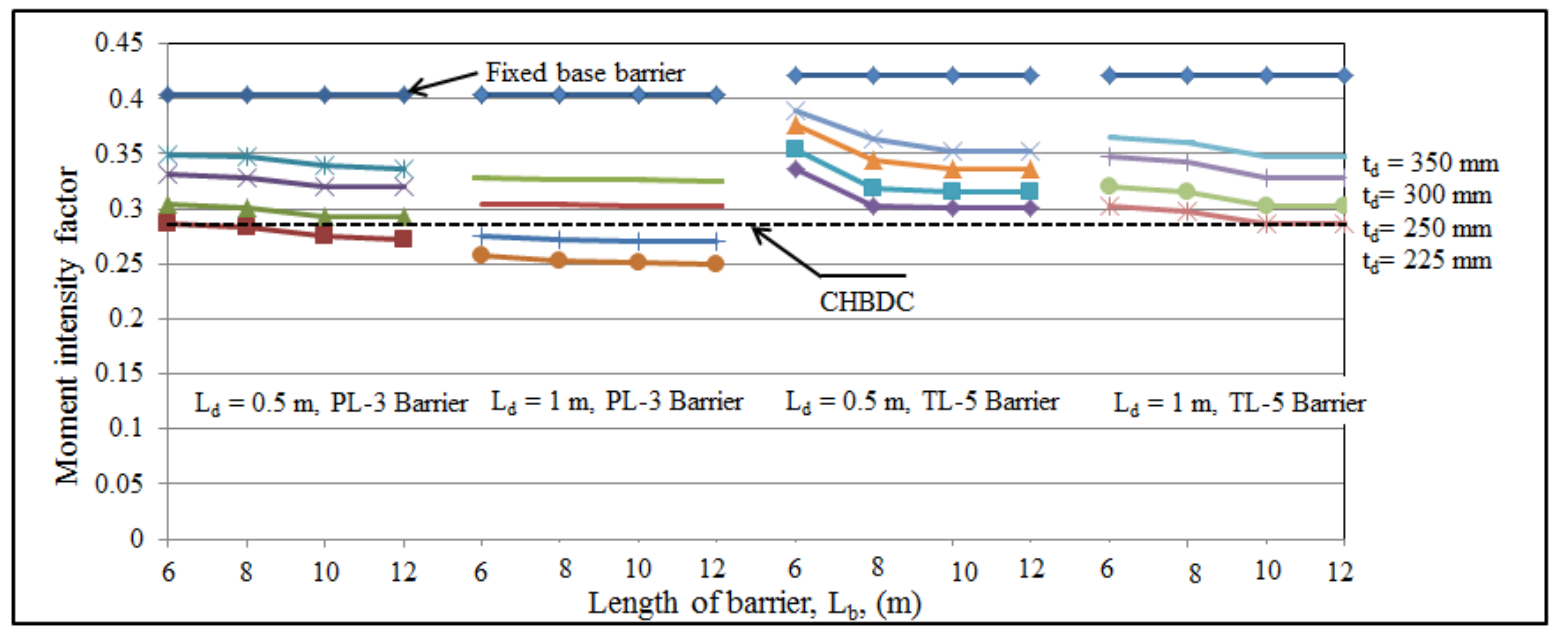

Figure 4. 36 Comparison of moment intensity factors for PL-3 and TL-5 barriers at exterior location as a function of barrier length

In addition, as the cantilever deck thickness was increased from $225-\mathrm{mm}$ to $350-\mathrm{mm}$, the $\mathrm{T}_{\mathrm{IF}}$ becomes 0.435 which increased by $8 \%$ compared to the CHBDC. It was also observed from FE analysis that barrier length greater than 10-m and cantilever deck length greater than 1.5-m does not have significant effect on the $\mathrm{T}_{\mathrm{IF}}$. While, increasing the cantilever deck thickness from 225$\mathrm{mm}$ to $350-\mathrm{mm}$ increased the $\mathrm{T}_{\mathrm{IF}}$ by $5 \%$ on average. For the fixed base barriers, a $\mathrm{T}_{\mathrm{IF}}$ of 0.471 was obtained which was increased by $16.9 \%$ compared with CHBDC limit.

Similar to PL-3 traffic barriers, in TL-5 barriers, decreasing the cantilever deck thickness from 1.5- to $0.5-\mathrm{m}$ increased the $\mathrm{T}_{\mathrm{IF}}$ by $4.2 \%$. For barriers with the length greater than $10-\mathrm{m}$, and cantilever deck length greater than 1.5-m, the $\mathrm{T}_{\mathrm{IF}}$ did not changed comparably. In case of barriers with fixed base, the $\left(\mathrm{T}_{\mathrm{IF}}\right)$ becomes 0.487 which was increased by $3.4 \%$ compared to PL-3 traffic barriers and $20.8 \%$ compared to the CHBDC limit. Figure 4.37 compares the tensile force intensity factors in PL-3 and TL-5 traffic barriers at interior location. It can be observed from the figure that CHBDC limit underestimated the $\mathrm{T}_{\mathrm{IF}}$ most cases in PL-3 barriers by an average of $3.2 \%$ and all cases in TL-5 barriers by an average of $6.1 \%$ for barrier length less than 1-m. In addition, it can be understood that there was an average increase of $2.9 \%$ in the $\mathrm{T}_{\mathrm{IF}}$ in TL-5 traffic barriers compared to PL-3 barriers. 


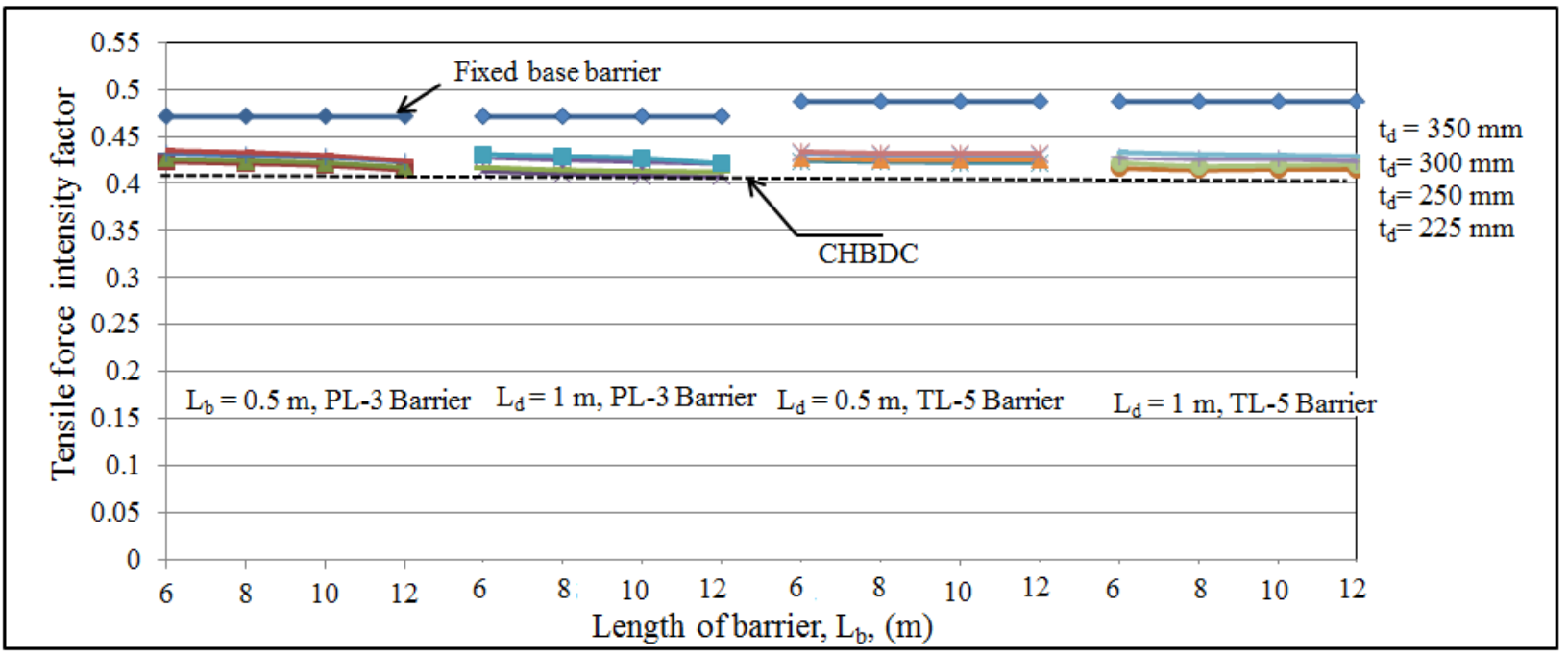

Figure 4. 37 Comparison of tensile force intensity factor for PL-3 and TL-5 barriers at interior location as a function of barrier length

\section{Tensile Force Intensity Factors $\left(T_{I F}\right)$ at exterior location of the deck per meter at face of the} wall: At exterior location of PL-3 traffic barriers, CHBDC specifies a factored tensile force per meter length of barrier equal to $161 \mathrm{kN}$, which yields a tensile force intensity factor of 0.451 . For a barrier with similar cantilever deck length of $1.5-\mathrm{m}$ and deck thickness of 225-mm, FE modeling exhibited the $\mathrm{T}_{\mathrm{IF}}$ of 0.454 which was deemed close to the CHBDC limit. However, decreasing the cantilever deck length to $0.5-\mathrm{m}$, increased the $\mathrm{T}_{\mathrm{IF}}$ to 0.465 with a $3.1 \%$ differences with the CHBDC limit. In addition, by increasing the deck thickness from 225-mm to 350-mm, the $\mathrm{T}_{\mathrm{IF}}$ becomes 0.479 that was increased by $6.2 \%$ compared with CHBDC. Similar to interior location, cantilever deck length greater than 1.5-m and barrier length greater than 10-m did not have substantial effects on tensile force intensity factors. For barriers with fixed base, the $\mathrm{T}_{\mathrm{IF}} \mathrm{was}$ 0.517 which was increased by $14.6 \%$ compared to the CHBDC limit. For a barrier with similar cantilever deck length, thickness and barrier length subjected to the same transverse loading, the $\mathrm{T}_{\mathrm{IF}}$ increased by an average of $10.2 \%$ at exterior location when it was compared with interior location.

In TL-5 traffic barriers subjected to unit transverse loading at exterior location, similar trend to PL-3 traffic barriers was observed. The $\mathrm{T}_{\mathrm{IF}}$ was increased by decreasing cantilever deck length from $2-\mathrm{m}$ to $0.5-\mathrm{m}$, and, by increasing the deck thickness from $225-\mathrm{mm}$ to $350-\mathrm{mm}$. However, the $\mathrm{T}_{\mathrm{IF}}$ was decreased when increasing the barrier length from 6- to 12-m. In case of fixed base 
barriers, a $\mathrm{T}_{\mathrm{IF}}$ value of 0.534 was obtained which means a $3.3 \%$ increase in the $\mathrm{T}_{\mathrm{IF}}$ value compared to PL-3 barriers and $18.4 \%$ increase compared to the CHBDC limit. Figure 4.38 compares tensile force intensity factors between PL-3 and TL-5 traffic barriers for cantilever deck length of 0.5- and 1-m. Comparison of the two traffic barriers showed an average of 3.8\% differences in the $\mathrm{T}_{\mathrm{IF}}$ in TL-5 barriers compared to PL-3 barriers.

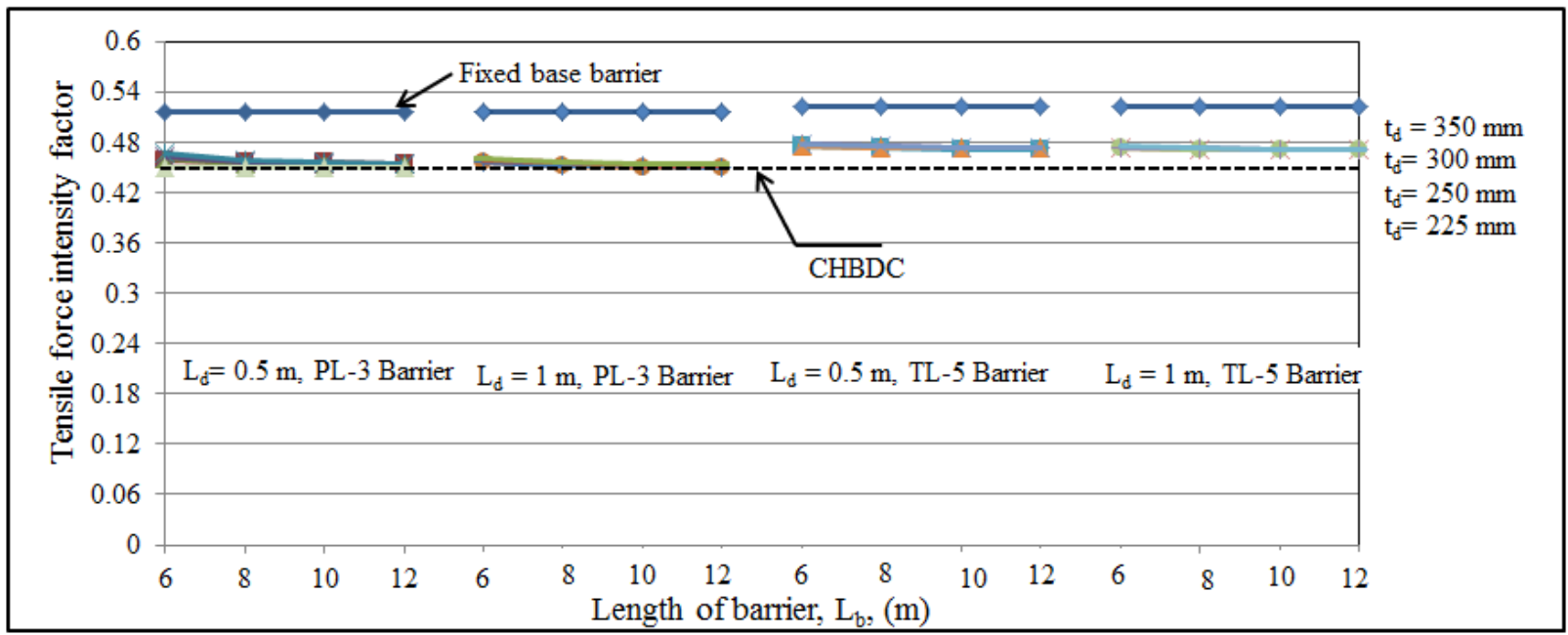

Figure 4. 38 Comparison of tensile force intensity factors for PL-3 and TL-5 barriers at exterior location as a function of barrier length

\subsubsection{PL-2 and TL-4 Traffic Barriers}

Moment Intensity Factor $\left(M_{I F}\right)$ at interior location of the deck per meter at face of the wall: For a cantilever deck length of 1.5-m, CHBDC specifies moment at interior location of PL-2 barriers equal to $38 \mathrm{kN} . \mathrm{m} / \mathrm{m}$. Due to an applied transverse load of $170 \mathrm{kN}$ per CHBDC, a moment intensity factor $\left(\mathrm{M}_{\mathrm{IF}}\right)$ of 0.224 can be obtained. In the current study, the moment intensity factor for a deck thickness of 180-mm and barrier length of 4-m was obtained as 0.229. The FE analysis also showed that by decreasing cantilever deck length to $0.5-\mathrm{m}$ and increasing deck thickness to $300-\mathrm{mm}$, the $\mathrm{M}_{\mathrm{IF}}$ increased by $8.5 \%$ and $32.1 \%$, respectively, when they were compared with the CHBDC limit. Therefore, it can be clearly seen that increasing the deck thickness significantly increased the $\mathrm{M}_{\mathrm{IF}}$ as was the case in PL-3 traffic barriers. However, increasing the barrier length from 4- to $10-\mathrm{m}$ decreased the $\mathrm{M}_{\mathrm{IF}}$ by an average value of $9.8 \%$. It was also observed that there was not a comparable difference in the $\mathrm{M}_{\mathrm{IF}}$ for barrier length greater than $8-\mathrm{m}$ and deck cantilever length greater than $1.5-\mathrm{m}$. Thus, one can conclude that the CHBDC 
limit underestimated the $\mathrm{M}_{\mathrm{IF}}$ for barrier length less than 6-m with cantilever deck length less than 1-m and deck thickness over 200-mm. For a barrier considered as fixed base, the $\mathrm{M}_{\mathrm{IF}}$ became 0.451 which was increased by $101.3 \%$ compared to the CHBDC recommendation. Figure 4.39 shows extrapolation of moment intensity factor for a cantilever deck length of $0.5-\mathrm{m}$ in PL-2 barriers at interior location. By reducing the barrier length to 1-m, it can be observed that the $\mathrm{M}_{\mathrm{IF}}$ significantly increased. This indicates that CHBDC excessively underestimated the $\mathrm{M}_{\mathrm{IF}}$ when the barrier length or cantilever deck length was decreased.

In TL-4 traffic barriers, by decreasing the cantilever deck length to $0.5-\mathrm{m}$ and increasing the deck thickness to $300-\mathrm{mm}$, the $\mathrm{M}_{\mathrm{IF}}$ increased by $17 \%$ and $46.2 \%$ compared to the CHBDC and by $7.8 \%$ and $10.8 \%$ compared to PL-2 barriers. However, increasing the barrier length from 4 - to $10-\mathrm{m}$, decreased the $\mathrm{M}_{\mathrm{IF}}$ by an average value of $11.3 \%$. For fixed base barrier, the $\mathrm{M}_{\mathrm{IF}}$ value was obtained as 0.468 which was increased by $3.8 \%$ compared to PL-2 traffic barriers. From comparison of the $\mathrm{M}_{\mathrm{IF}}$ for both PL-2 and TL-4 barriers at interior location, an average increase of 9.8\% was observed in TL-4 traffic barriers.

\section{Moment Intensity Factor $\left(M_{I F}\right)$ at exterior location of the deck per meter at face of the wall:} CHBDC Commentary specifies moment at exterior location of PL-2 traffic barrier equal to 52 $\mathrm{kN} . \mathrm{m} / \mathrm{m}$, which was obtained for a cantilever deck length of $1.5-\mathrm{m}$. The moment yields a moment intensity factor $\left(\mathrm{M}_{\mathrm{IF}}\right)$ of 0.306 for the specified transverse load of $170 \mathrm{kN}$ in CHBDC. In the current study, for a deck thickness of 200-mm, barrier length of 4-m and cantilever deck length of $1.5-\mathrm{m}$, the $\mathrm{M}_{\mathrm{IF}}$ was found from $\mathrm{FE}$ modeling equal to 0.287 . Thus, it could be concluded that CHBDC overestimated the $\mathrm{M}_{\mathrm{IF}}$ for deck thickness less than 200-mm, barrier length greater than 8-m, and cantilever deck length greater than $1.5-\mathrm{m}$. However, it underestimated the $\mathrm{M}_{\mathrm{IF}}$ 's for deck thickness greater than 250-mm with all barrier and cantilever deck lengths. For instance, for a barrier of 4-m length with cantilever deck length of $0.5-\mathrm{m}$ and deck thickness of $300-\mathrm{mm}$, the $\mathrm{M}_{\mathrm{IF}}$ was 0.436 which was $51.3 \%$ greater than theCHBDC limit. It should also be noted that for a barrier length of 4-m with cantilever deck thickness of 0.5-m and deck thicknesses of 180- and 200-mm, CHBDC underestimated the $\mathrm{M}_{\mathrm{IF}}$ by $4.3 \%$ and $9.2 \%$, respectively. For fixed base barriers, the $\mathrm{M}_{\mathrm{IF}}$ was determined from analysis equal to 0.592 which was increased by $93.5 \%$ compared to the CHBDC limit. Therefore, it could be concluded that by 
decreasing the deck cantilever length, traffic barriers performed more rigidity at the base and the $\mathrm{M}_{\mathrm{IF}}$ significantly increased.

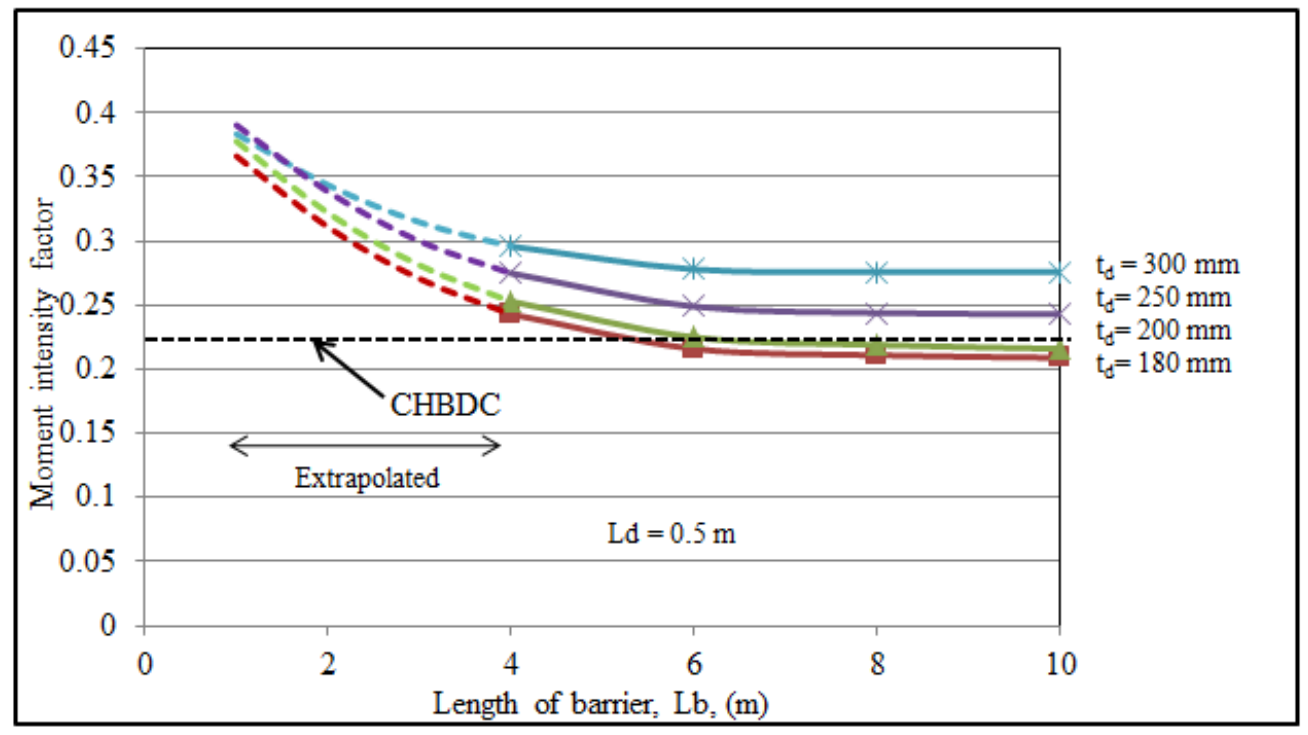

Figure 4. 39 Extrapolation of moment intensity factor versus barrier longitudinal length for PL-2 barrier at interior location

In TL-4 traffic barrier, the $\mathrm{M}_{\mathrm{IF}}$ increased by maximum of $34 \%$ when the deck thickness increased from 180 - to $300-\mathrm{mm}$. In addition, the $\mathrm{M}_{\mathrm{IF}}$ was increased by $14.2 \%$ when the cantilever deck length decreased from 2- to $0.5-\mathrm{m}$. However, the $\mathrm{M}_{\mathrm{IF}}$ was only increased by $2.8 \%$ when the barrier length decreased from 10- to 4-m. This indicated that the barrier longitudinal length was less effective in increasing the $\mathrm{M}_{\mathrm{IF}}$ especially for barrier longer than 8-m. Comparison of the PL2 and TL-4 traffic barriers showed an average difference of $12.8 \%$ between the barriers. For the case of fixed base TL-4 barrier, the $\mathrm{M}_{\mathrm{IF}}$ was obtained as 0.612 which was increased by $3.4 \%$ compared to PL-2 traffic barrier.

\section{Tensile Force Intensity Factor $\left(T_{I F}\right)$ at interior location of the deck per meter at face of the} wall: At exterior location of PL-2 traffic barriers, CHBDC specifies tensile force per meter of the barrier equal to $100 \mathrm{kN}$. This tensile force for a cantilever deck length of $1.5-\mathrm{m}$ revealed a tensile force intensity factor $\left(\mathrm{T}_{\mathrm{IF}}\right)$ of 0.588 . In FE modeling of PL-2 traffic barriers, similar $\mathrm{T}_{\mathrm{IF}}$ was observed for deck thicknesses of 180- and 200-mm with cantilever deck lengths of 1.5- and 2-m. 
However, decreasing the cantilever deck length to $0.5-\mathrm{m}$ with similar deck thickness increased the $\mathrm{T}_{\mathrm{IF}}$ by an average of $8.5 \%$. In cases when the deck thickness increased to $300-\mathrm{mm}$, the $\mathrm{T}_{\mathrm{IF}}$ was increased by maximum of $16.5 \%$. In addition, it was noticed that decreasing the cantilever deck length from 2- to $0.5-\mathrm{m}$, the $\mathrm{T}_{\mathrm{IF}}$ was increased by maximum of $8.1 \%$, while decreasing barrier length from $10-$ to $4-\mathrm{m}$, the $\mathrm{T}_{\mathrm{IF}}$ was only increased by maximum of $2.1 \%$. Therefore, it could be understood that changes in deck thickness and cantilever deck length were more effective in increasing the $\mathrm{T}_{\mathrm{IF}}$ than the barrier longitudinal lengths. Analysis of the data with the limit in CHBDC showed that CHBDC comparably underestimated the $\mathrm{T}_{\mathrm{IF}}$ for barrier length less than 6-m, cantilever deck less than 1-m and deck thickness more than 250-mm. For barriers with the fixed base, the $\mathrm{T}_{\mathrm{IF}}$ was obtained as 0.783 that indicates an increase of $33.2 \%$ compared with the CHBDC limit.

In TL-4 traffic barriers, it was observed that decreasing the cantilever deck length from 2- to 0.5$\mathrm{m}$ increased the $\mathrm{T}_{\mathrm{IF}}$ by maximum of $9.2 \%$; while decreasing the barrier length from 10- to 4-m, increased the $\mathrm{T}_{\mathrm{IF}}$ by only $2.85 \%$. However, increasing the deck thickness from 180 - to $300-\mathrm{mm}$ increased the $\mathrm{T}_{\mathrm{IF}}$ to a maximum of $17.8 \%$. In case of fixed base barriers, the $\mathrm{T}_{\mathrm{IF}}$ of 0.811 was achieved indicating $3.6 \%$ increase compared to PL-2 traffic barriers.

\section{Tensile Force Intensity Factor $\left(T_{I F}\right)$ at exterior location of the deck per meter at face of the} wall: CHBDC requires a tensile force per meter of the deck at exterior location equal to $142 \mathrm{kN}$. This tensile force for a cantilever deck length of $1.5-\mathrm{m}$ yields a tensile force intensity factor $\left(\mathrm{T}_{\mathrm{IF}}\right)$ of 0.835 . In the current study for a similar condition as CHBDC, the $\mathrm{T}_{\mathrm{IF}}$ was obtained as 0.825 which was considered acceptable. Similar to interior location, CHBDC overestimated the $\mathrm{T}_{\mathrm{IF}}$ for barrier deck length over 1.5-m, barrier length over 8-m and deck thickness less than 200-mm. However, it underestimated the $\mathrm{T}_{\mathrm{IF}}$ when the cantilever deck length was reduced to $0.5-\mathrm{m}$ by maximum of $3.2 \%$, the deck thickness increased to $300-\mathrm{mm}$ by $5.8 \%$ and barrier length reduced from $10-$ to $4-\mathrm{m}$ by $1.4 \%$. For fixed base barriers, the $\mathrm{T}_{\mathrm{IF}}$ was obtained equal to 0.887 which was increased by $6.2 \%$ compared to the CHBDC limit.

In TL-4 traffic barriers at exterior location, similar trend as PL-2 barriers at exterior location was observed. However, comparison of the two traffic barriers showed an increase in the $\mathrm{T}_{\mathrm{IF}}$ of TL-4 
barriers by an average of $2.8 \%$. In fixed base barriers, the $\mathrm{T}_{\mathrm{IF}}$ was determined as 0.910 which increased by $2.6 \%$ compared to PL-2 traffic barriers.

\subsubsection{Developed Equations}

Based on data generated from the parametric study, empirical equations were developed to best fit the data by the three variables: barrier length $\left(\mathrm{L}_{\mathrm{b}}\right)$, cantilever deck length $\left(\mathrm{L}_{\mathrm{d}}\right)$ and deck slab thickness $\left(\mathrm{t}_{\mathrm{d}}\right)$. The equations were developed using least square method by best curve fitting statistical option. The proposed equations for the design of deck-barrier wall junction due to simulated vehicle impact load are provided in Tables 4.12 and 4.13. The equations were developed based on the range of the current parametric study and valid for this range. The equations can be used with caution for values outside of those ranges. In order to express confidence in the developed equations with those of FE analysis, Figures 4.40 and 4.41 show closeness of the developed equations with those of FE modeling for all barrier types. It should be noted that some level of conservativeness was maintained in the developed equations due to small differences that may arise by variations in the FE modeling or engineering judgments. 
Table 4. 12 Predicted design force equations at barrier-deck interface

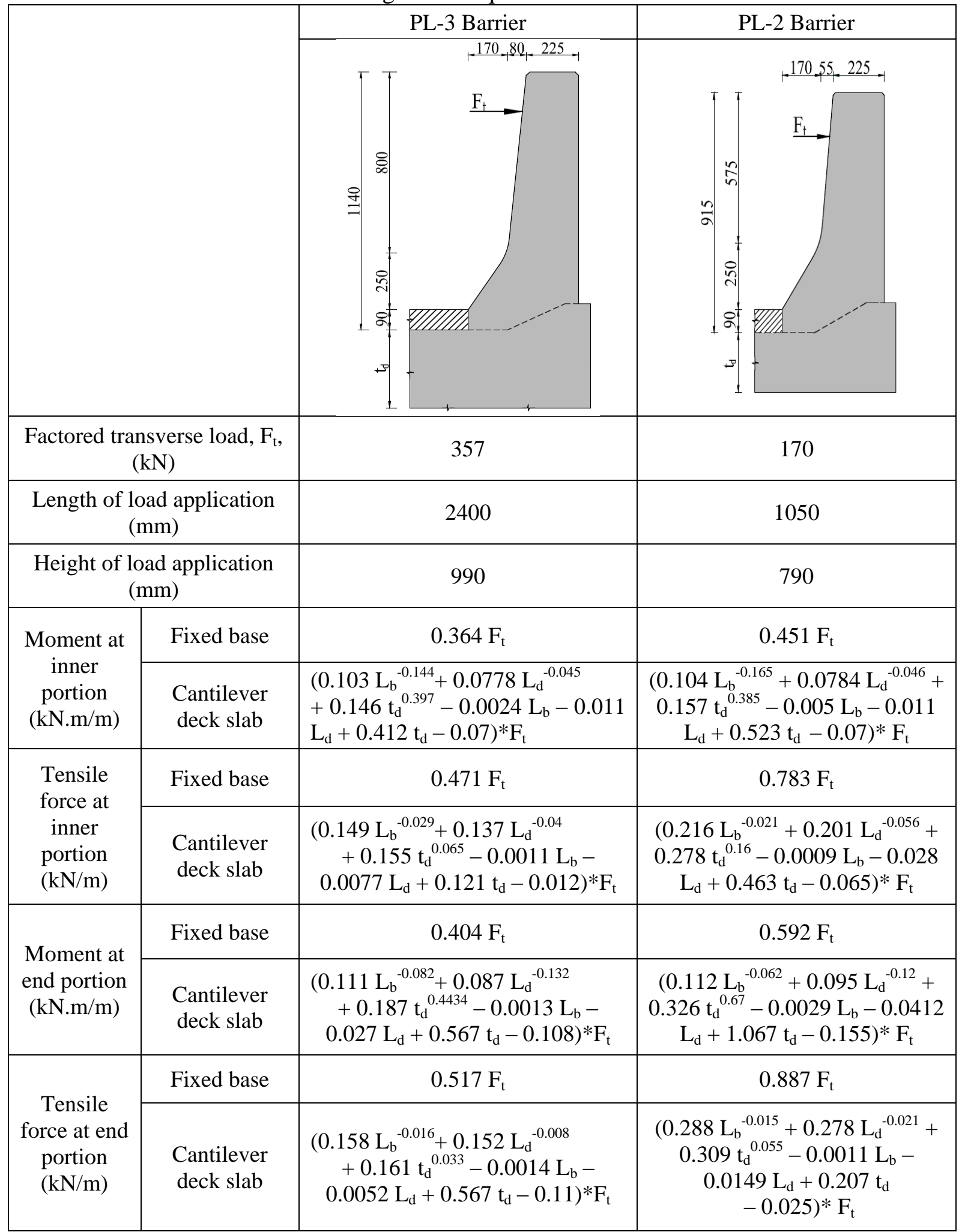


Table 4. 13 Predicted design force equations at barrier-deck interface

\begin{tabular}{|c|c|c|c|}
\hline & & TL-5 Barrier & TL-4 Barrier \\
\hline & & $\mid$ & $\frac{177,50,152}{F_{+}}$ \\
\hline Factored tran & erse load, $F_{t}$, & 550 & 240 \\
\hline $\begin{array}{r}\text { Length of lo } \\
\text { (n }\end{array}$ & application & 2400 & 1050 \\
\hline Height of lo & $\begin{array}{l}\text { application } \\
\text { 1) }\end{array}$ & 1066 & 812 \\
\hline Moment at & Fixed base & $0.386 \mathrm{~F}_{\mathrm{t}}$ & $0.468 \mathrm{~F}_{\mathrm{t}}$ \\
\hline $\begin{array}{c}\text { inner } \\
\text { portion } \\
(\mathrm{kN} \cdot \mathrm{m} / \mathrm{m})\end{array}$ & $\begin{array}{l}\text { Cantilever } \\
\text { deck slab }\end{array}$ & $\begin{array}{l}\left(0.097 \mathrm{~L}_{\mathrm{b}}^{-0.68}+0.084 \mathrm{~L}_{\mathrm{d}}^{-0.049}\right. \\
+0.151 \mathrm{t}_{\mathrm{d}}^{0.377}-0.0018 \mathrm{~L}_{\mathrm{b}}- \\
0.013 \mathrm{~L}_{\mathrm{d}}+0.409 \mathrm{t}_{\mathrm{d}}- \\
0.072) * \mathrm{~F}_{\mathrm{t}}\end{array}$ & $\begin{array}{c}\left(0.108 \mathrm{~L}_{\mathrm{b}}^{-0.16}+0.082 \mathrm{~L}_{\mathrm{d}}^{-0.09}+\right. \\
0.186 \mathrm{t}_{\mathrm{d}}^{0.441}-0.0046 \mathrm{~L}_{\mathrm{b}}- \\
\left.0.017 \mathrm{~L}_{\mathrm{d}}+0.685 \mathrm{t}_{\mathrm{d}}-0.09\right)^{*} \mathrm{~F}_{\mathrm{t}}\end{array}$ \\
\hline Tensile & Fixed base & $0.487 \mathrm{~F}_{\mathrm{t}}$ & $0.811 \mathrm{~F}_{\mathrm{t}}$ \\
\hline $\begin{array}{l}\text { force at } \\
\text { inner } \\
\text { portion } \\
(\mathrm{kN} / \mathrm{m})\end{array}$ & $\begin{array}{l}\text { Cantilever } \\
\text { deck slab }\end{array}$ & $\begin{array}{c}\left(0.143 \mathrm{~L}_{\mathrm{b}}^{-0.007}+0.138 \mathrm{~L}_{\mathrm{d}}^{-0.044}\right. \\
+0.153 \mathrm{t}_{\mathrm{d}}^{0.054}-0.0004 \mathrm{~L}_{\mathrm{b}}- \\
0.0134 \mathrm{~L}_{\mathrm{d}}+0.133 \mathrm{t}_{\mathrm{d}}- \\
0.016)^{*} \mathrm{~F}_{\mathrm{t}} \\
\end{array}$ & $\begin{array}{c}\left(0.233 \mathrm{~L}_{\mathrm{b}}^{-0.012}+0.222 \mathrm{~L}_{\mathrm{d}}^{-0.053}+\right. \\
0.292 \mathrm{t}_{\mathrm{d}}^{0.14}-0.0009 \mathrm{~L}_{\mathrm{b}}- \\
0.0278 \mathrm{~L}_{\mathrm{d}}+0.486 \mathrm{t}_{\mathrm{d}}- \\
0.065)^{*} \mathrm{~F}_{\mathrm{t}} \\
\end{array}$ \\
\hline & Fixed base & $0.422 \mathrm{~F}_{\mathrm{t}}$ & $0.612 \mathrm{~F}_{\mathrm{t}}$ \\
\hline $\begin{array}{l}\text { Moment at } \\
\text { end portion } \\
(\mathrm{kN} \cdot \mathrm{m} / \mathrm{m})\end{array}$ & $\begin{array}{l}\text { Cantilever } \\
\text { deck slab }\end{array}$ & $\begin{array}{c}\left(0.146 \mathrm{~L}_{\mathrm{b}}^{-0.16}+0.102 \mathrm{~L}_{\mathrm{d}}^{-0.14}\right. \\
+0.185 \mathrm{t}_{\mathrm{d}}^{0.33}-0.0041 \mathrm{~L}_{\mathrm{b}}- \\
0.022 \mathrm{~L}_{\mathrm{d}}+0.491 \mathrm{t}_{\mathrm{d}}- \\
0.07) * \mathrm{~F}_{\mathrm{t}} \\
\end{array}$ & $\begin{array}{c}\left(0.122 \mathrm{~L}_{\mathrm{b}}^{-0.016}+0.108 \mathrm{~L}_{\mathrm{d}}^{-0.134}+\right. \\
0.323 \mathrm{t}_{\mathrm{d}}^{0.57}-0.0012 \mathrm{~L}_{\mathrm{b}}- \\
0.042 \mathrm{~L}_{\mathrm{d}}+1.11 \mathrm{t}_{\mathrm{d}} \\
-0.17)^{*} \mathrm{~F}_{\mathrm{t}}\end{array}$ \\
\hline & Fixed base & $0.534 \mathrm{~F}_{\mathrm{t}}$ & $0.910 \mathrm{~F}_{\mathrm{t}}$ \\
\hline $\begin{array}{l}\text { force at end } \\
\text { portion } \\
(\mathrm{kN} / \mathrm{m})\end{array}$ & $\begin{array}{l}\text { Cantilever } \\
\text { deck slab }\end{array}$ & $\begin{array}{c}\left(0.163 \mathrm{~L}_{\mathrm{b}}^{-0.013}+0.159 \mathrm{~L}_{\mathrm{d}}^{-0.006}\right. \\
+0.165 \mathrm{t}_{\mathrm{d}}^{0.024}-0.0011 \mathrm{~L}_{\mathrm{b}}- \\
0.0025 \mathrm{~L}_{\mathrm{d}}+0.1 \mathrm{t}_{\mathrm{d}}- \\
0.009) * \mathrm{~F}_{\mathrm{t}}\end{array}$ & $\begin{array}{c}\left(0.292 \mathrm{~L}_{\mathrm{b}}^{-0.01}+0.282 \mathrm{~L}_{\mathrm{d}}^{-0.033}+\right. \\
0.322 \mathrm{t}_{\mathrm{d}}^{0.066}-0.0015 \mathrm{~L}_{\mathrm{b}}- \\
0.021 \mathrm{~L}_{\mathrm{d}}+0.262 \mathrm{t}_{\mathrm{d}} \\
-0.025)^{*} \mathrm{~F}_{\mathrm{t}}\end{array}$ \\
\hline
\end{tabular}




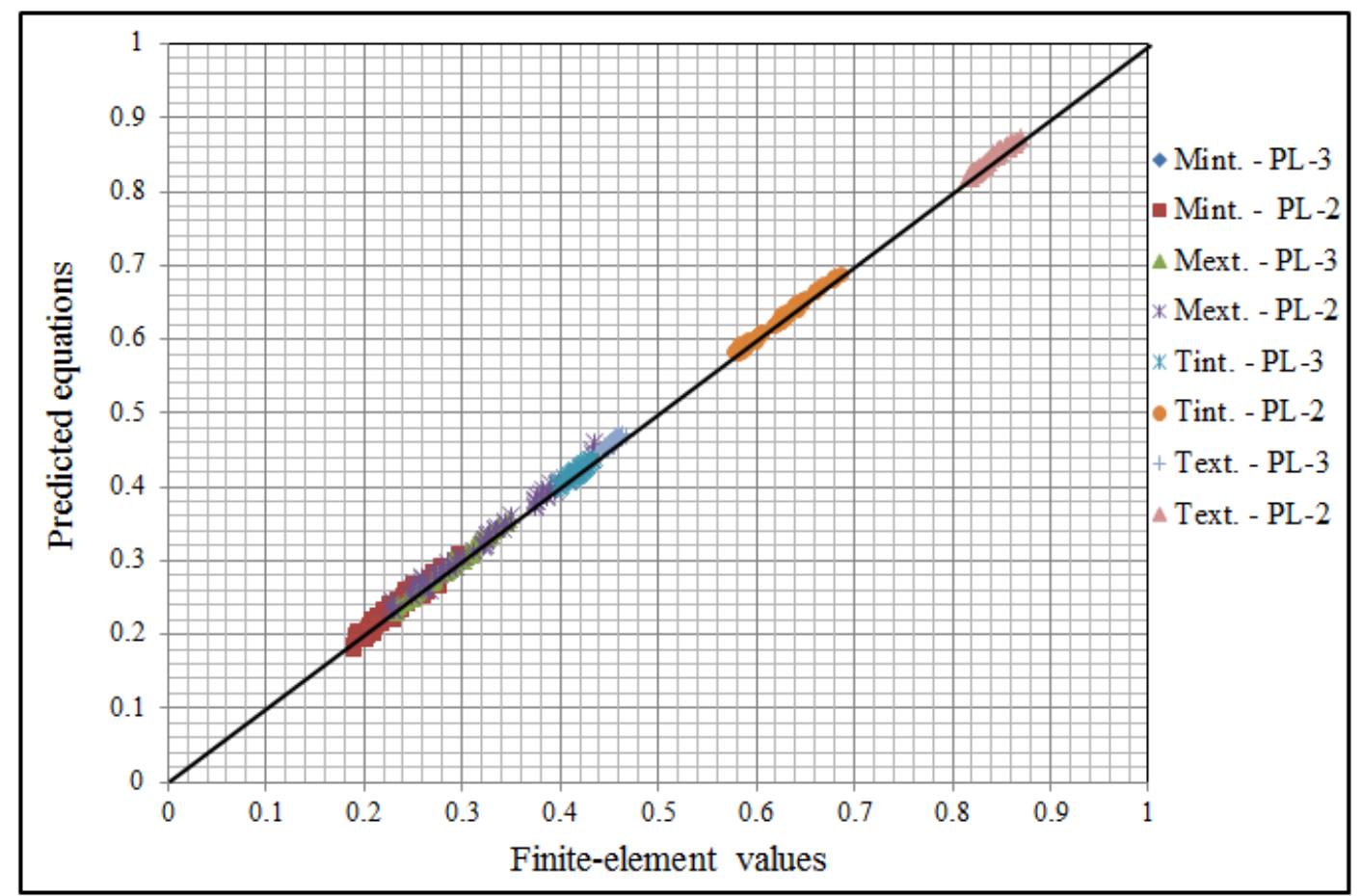

Figure 4. 40 Comparison of FE modeling with the developed equations for PL-3 and PL-2 traffic barriers

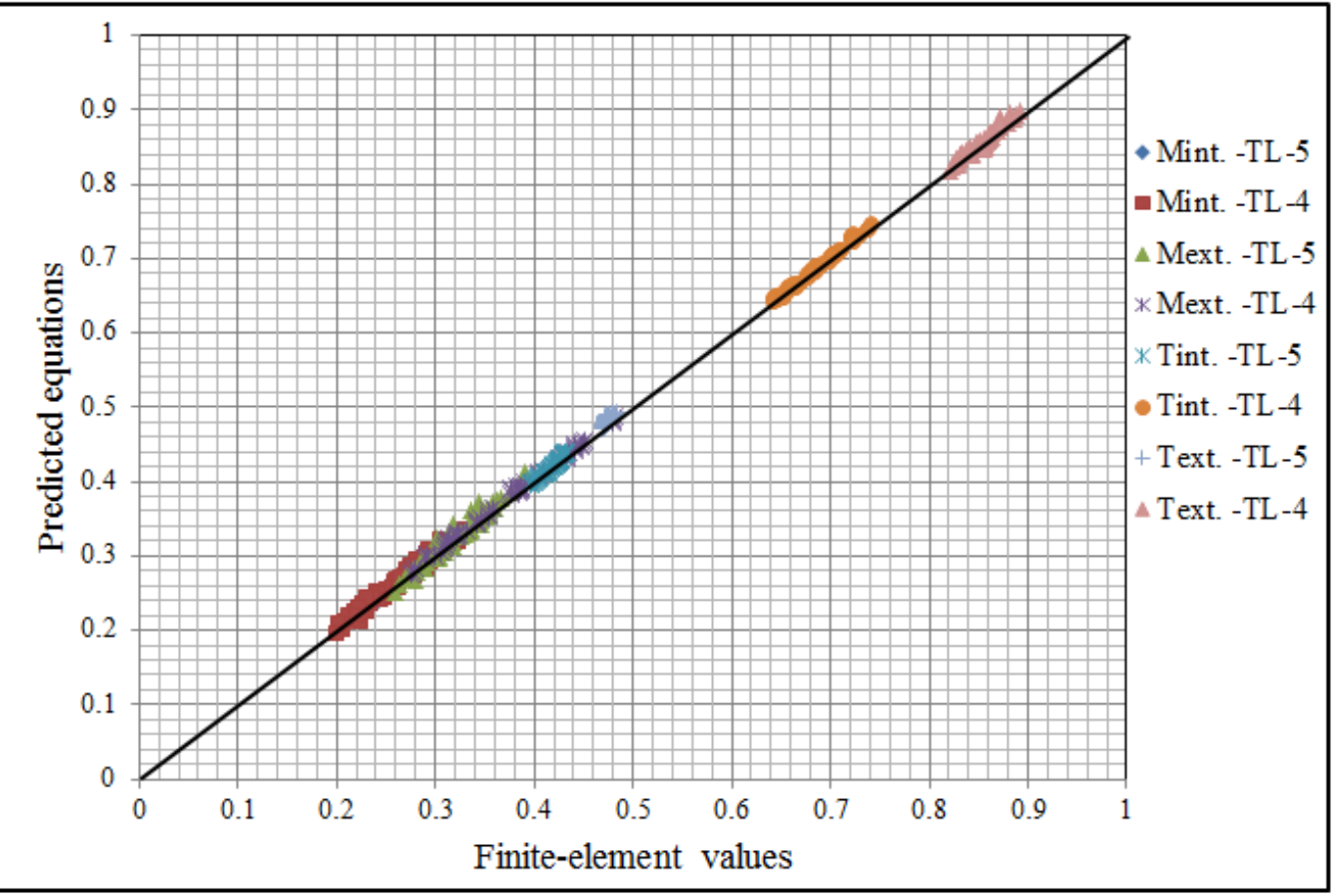

Figure 4. 41 Comparison of FE modeling with the developed equations for Tl-5 and Tl-4 traffic barriers 


\subsection{Summary of Findings}

Experimental program have been conducted on five small-scale PL-3 bridge barriers, in which four barriers were made of GFRP bars and one barrier reinforced with conventional steel reinforcement. From experimental investigations, the connection detail at deck-wall interface using the three proposals was investigated incorporating the use of GFRP headed-end, bend and hook anchor bars as connecting reinforcement. Based on the data generated from the experimental study, the following conclusions are drawn: (i) GFRP bars with head anchors, GFRP bend and $180^{\circ}$ hook bars can be safely used in bridge barrier walls to resist the applied vehicle impact load specified in the Canadian Highway Bridge Design Code (CHBDC) at the barrier wall-deck slab interface. Comparable to steel reinforced barrier wall, GFRP bars developed ultimate load carrying capacity well beyond the design limits prescribed by CHBDC at both interior and exterior locations, (ii) Ultimate flexural capacity of reinforcing bars in tension face of the barrier wall at deck-wall interface can be safely examined by both crosssectional analysis and strut and tie models. The results of flexural capacity of the barrier models by cross-sectional analysis were far beyond the limits prescribed in the CHBDC at interior location $(83 \mathrm{kN} . \mathrm{m} / \mathrm{m})$ and exterior location $(102 \mathrm{kN} . \mathrm{m} / \mathrm{m})$ indicating that sufficient amount of GFRP tension reinforcement are provided. Similar results have been achieved by strut and tie model by calculating design strength of tension tie reinforcement, (iii) Due to the fact that failure of barrier models occurred due to diagonal tension cracks at corner joint, new equations were developed to investigate the effect of diagonal tension failure of the barriers. Accordingly, minimum reinforcement ratio equations were also developed for both the wall and the deck sections so that diagonal tension failure will be prevented, (iv) In addition, analytical modeling was performed to study load-deformation response of barrier wall under the applied transverse load. The structural response developed herein provided relatively good agreements with the experimental investigations and can be incorporated in the design principles of GFRP reinforced concrete structures, and (v) Linear-elastic finite-element analysis was performed on the PL-3 and PL-2 traffic barriers to study the effect of geometrical variations on moment and tensile force intensity factors developed in the deck. Based on this study, empirical equations were developed for design moment and tensile forces per meter at face of the deck slab. 


\section{Chapter V}

\section{Static Load Testing on Full-Scale GFRP-Reinforced Barriers}

\subsection{Introduction}

The design process of bridge barrier walls specified in the Canadian Highway Bridge Design Code (CSA, 2006a and CSA, 2006b) is based on the AASHTO Guide Specification for bridge railings (AASHTO, 1989) and the AASHTO guide for selecting, locating and designing traffic barriers (AASHTO, 1977). The initial design of the proposed PL-3 precast bridge barrier (Sennah et al., 2010) was carried out to meet the CHBDC design criteria specified for static loading at the anchorage between deck slab and the barrier wall. CHBDC specifies transverse, longitudinal and vertical loads of 210, 70 and $90 \mathrm{kN}$, respectively, that can be applied simultaneously over a certain barrier length. CHBDC specifies that transverse load shall be applied over a barrier length of 2400-mm for PL-3 barriers. Since transverse loading creates the critical load carrying capacity, both the longitudinal and vertical loads were not considered in the design of barrier wall reinforcement and anchorages between the deck slab and the barrier wall. It should be noted that CHDBC specifies a live load factor of 1.7. Thus, the design impact load on PL-3 barrier wall over 2400-mm length is $357 \mathrm{kN}$ as for the design of the vertical and horizontal reinforcement in the barrier wall. AASHTO-LRFD bridge design code (AASHTO, 2012) specifies the yield-line analysis for ultimate flexural capacity of the steel-reinforced barrier walls under vehicle impact. In the analysis, it is assumed that the yield-line failure pattern occurs within the barrier wall only and does not extend into the deck slab. In other words, the deck slab must have sufficient resistance to force the yield-line failure pattern to remain within the barrier wall. The AASHTO-LRFD yield-line analysis is also based on the assumption that sufficient longitudinal length of barrier wall exists to result in the desired yield-line failure pattern. It should be noted that the yield-line analysis is typically employed for evaluation of nominal strength of concrete bridge barriers reinforced with steel bars. Since GFRP bars exhibit linear elastic behavior till failure, the ASSHTO-LRFD yield-line equations cannot be used in the design of barriers reinforced with GFRP bars. However, both equilibrium of forces and compatibility of 
deformation conditions should be explicitly accounted for by implementing suitable analytical or numerical methods. Since such analytical or numerical modeling is as yet unavailable, evaluation of a full-scale structure or a prototype by load testing is the only means to qualify the proposed barrier detailing for use in Canada's bridges.

As such, the proposed PL-3 traffic barrier with sand-coated GFRP bars and headed-end anchorage system (Proposal No. 1 in Chapter 4) was further investigated under full-scale static load testing to- complete-collapse. To validate the design strength of the proposed barrier, a PL-3 barrier wall of 27.6-m length was constructed using the proposed GFRP bar configuration, incorporating the use of headed-end bars. The proposed barrier configuration was first crash tested to qualify its use in Canadian bridges (Sennah and Khederzadeh, 2012). The authors conducted the study on the use of sand-coated GFRP bars in bridge barrier under vehicle impact load. GFRP bar sizes of 12- and 16-mm were used as vertical bars in back and front faces of the barrier walls. The headed-end GFRP bars were utilized as connecting bars between deck slab and barrier wall with proper anchorage. In accordance with Test Level 5 (TL-5) of Manual for Assessing Safety Hardwar (MASH, 2009), vehicle crash test were conducted using 36000V vantype tractor trailer (cab-behind-engine model of 36000-kg gross weight) to impact the barrier wall at a nominal speed and angle of $80 \mathrm{~km} / \mathrm{h}$ and $15^{\circ}$, respectively. The test was conducted to evaluate the strength of the barrier in containing and redirecting heavy vehicles. According to Sennah and Khederzadeh (2012), crash test results showed that the barrier contained and redirected the $36000 \mathrm{~V}$ vehicle. The vehicle did not penetrate, underride or override the parapet. No detached elements, fragments, or other debris from the barrier were present to penetrate or show potential for penetrating the occupant compartment, or to present undue hazard to others in the area. No occupant compartment deformation occurred. The $36000 \mathrm{~V}$ test vehicle remained upright during and after the collision event.

However, design procedure under static load equivalent to vehicle impact force is as yet unavailable. The yield-line pattern specified in AASHTO-LRFD specifications for the design of concrete barriers reinforced with steel bars may not be applicable to GFRP-reinforced barrier. This may be attributed to the GFRP bar low stiffness, bond characteristics, and low strength under compression and shear stresses, which leads to linear elastic failure till rupturing of the 
GFRP bars. Thus, plastic deformation of GFRP bars will not occur. Full-scale GFRP-reinforced barrier wall segments were tested to-collapse to determine their structural behavior, crack pattern and ultimate load carrying capacity under simulated vehicle impact load. The results will be then compared to the limits prescribes in the CHBDC for overall adequacy.

\subsection{GFRP Bar Properties}

The sand-coated surface profile of GFRP bars considered in the current study (shown in Figure 3.1), ensures optimal bond between concrete and the bar. High modulus (HM) 12M (\#4) GFRP bars of specified tensile strength of $1312 \mathrm{MPa}$, modulus of elasticity of $65.6 \pm 2.5 \mathrm{GPa}$ and strain at rupture of $2 \%$, as listed in the manufacturers catalogue, were used as barrier reinforcement. Also, 15M (\#5) HM-GFRP bars with specified tensile strength of $1184 \mathrm{MPa}$, modulus of elasticity of $62.5 \pm 2.5 \mathrm{GPa}$ and strain at rupture of $1.89 \%$ were used to reinforce the barrier wall. The $12 \mathrm{M}$ and $15 \mathrm{M}$ bars have cross-sectional areas of 126.7 - and $197.9-\mathrm{mm}^{2}$, respectively. The use of headed-end GFRP bars, shown in Figure 3.1, is proposed in this research to allow for anchorage in concrete at lower cost than bent bars. The bar-head was made of thermo-setting polymeric material cast onto the end of the straight bar and hardened at high temperatures. The wall reinforcing details for the current research is provided in Figure 4.3a.

\subsection{PL-3 Barrier Construction}

A prototype bridge barrier with 27.6-m length was constructed at Texas Transportation Institution (TTI) site in the United States. The barrier wall comprised of four construction joints shown in Figure 5.1 that was crash tested by a remote control $36000 \mathrm{~V}$ tractor trailer at location of the second construction joint. Figures 5.2 and 5.3 illustrate cross-section of the existing concrete slab foundation and the proposed barrier wall. Shown in the image, the existing concrete slab was extended for construction of the new barrier. Figure 5.4 shows reinforcing detail at joint connection of the existing concrete slab to the new barrier. The existing M19 steel bars in the slab were spliced connection to M16 steel bars as well as TYPE 100 and TYPE 101 bars shown in Figure 5.5 by means of welded connection to the longitudinal steel strap. The transverse bars TYPE 100 and TYPE 101 were placed at spacing of 300-mm center-to-center in longitudinal directions that are welded to steel strap and M19 bars in the deck slab. In longitudinal direction of the extended concrete slab, M16 and M25 bars were placed alternatively 
in 300-mm spacing. A uniform slab thickness of 360-mm was constructed for the barrier due to the ease of construction of long barrier size. M15-GFRP bars were placed in front face of the barrier in both horizontal and vertical directions at 300-mm center-to-center spacing. However, M15 bars were placed horizontally in back face of the wall with M12 GFRP bars as vertical reinforcement all at 300-mm center-to-center, since the back face of the wall was in compression and minimum amount of reinforcement would be adequate. Figure 5.6 shows schematic diagram and cross-section of the control joint that was constructed during making the concrete formwork. No saw cutting of the control joint was allowed in the constructed barrier. Figure 5.7 shows layout of the barrier and the deck slab dimension as specified in MTO structural manual. It can be observed that the barrier-deck interface is tapered to avoid water leakage on the traffic underneath the bridge. However, in the constructed barrier shown in Figure 5.8, the tapered portion was eliminated for ease of construction. In such a case, the deck slab was cast while keeping the concrete surface at the interface between the barrier and the slab horizontal with roughed surface. Figure 5.8 presents the layout of GFRP bars in the barrier wall.

The horizontal bars were installed at spacing of 150 -mm for the top two bars and 200-mm for the lower bars to increase barrier resistance to shrinkage cracks. At barrier ends and over a length of 2560-mm, vertical bars at front face of the barrier wall were doubled by reducing bar spacing to $150-\mathrm{mm}$ as depicted in Figure 5.9. Figure 5.9 illustrates arrangement of vertical and horizontal GFRP bars showing the number of bars in each direction as well as the length of splice connections.
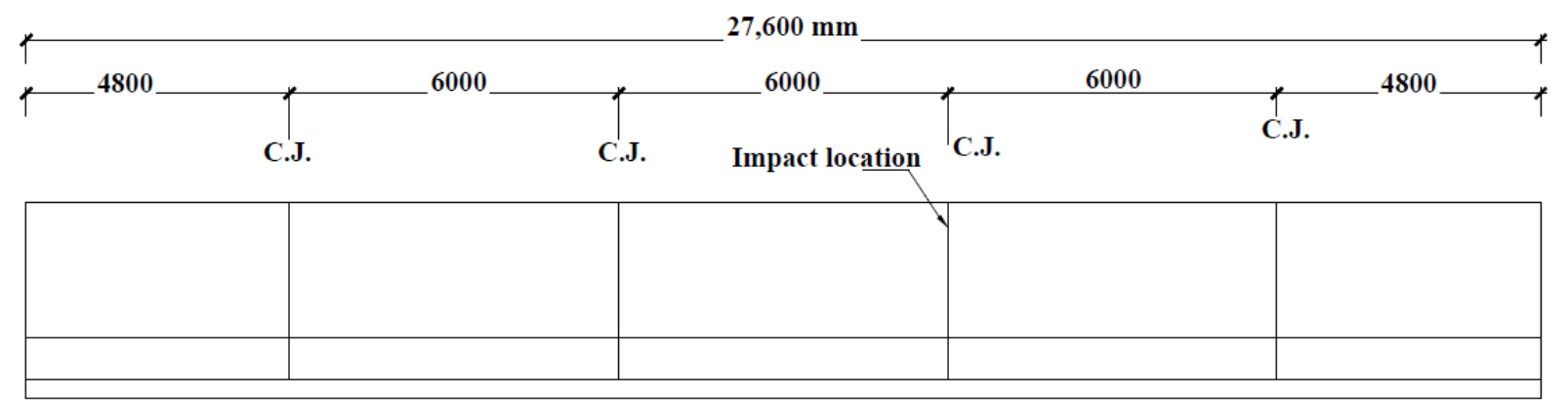

Figure 5. 1 Prototype barrier elevation built at TTI 


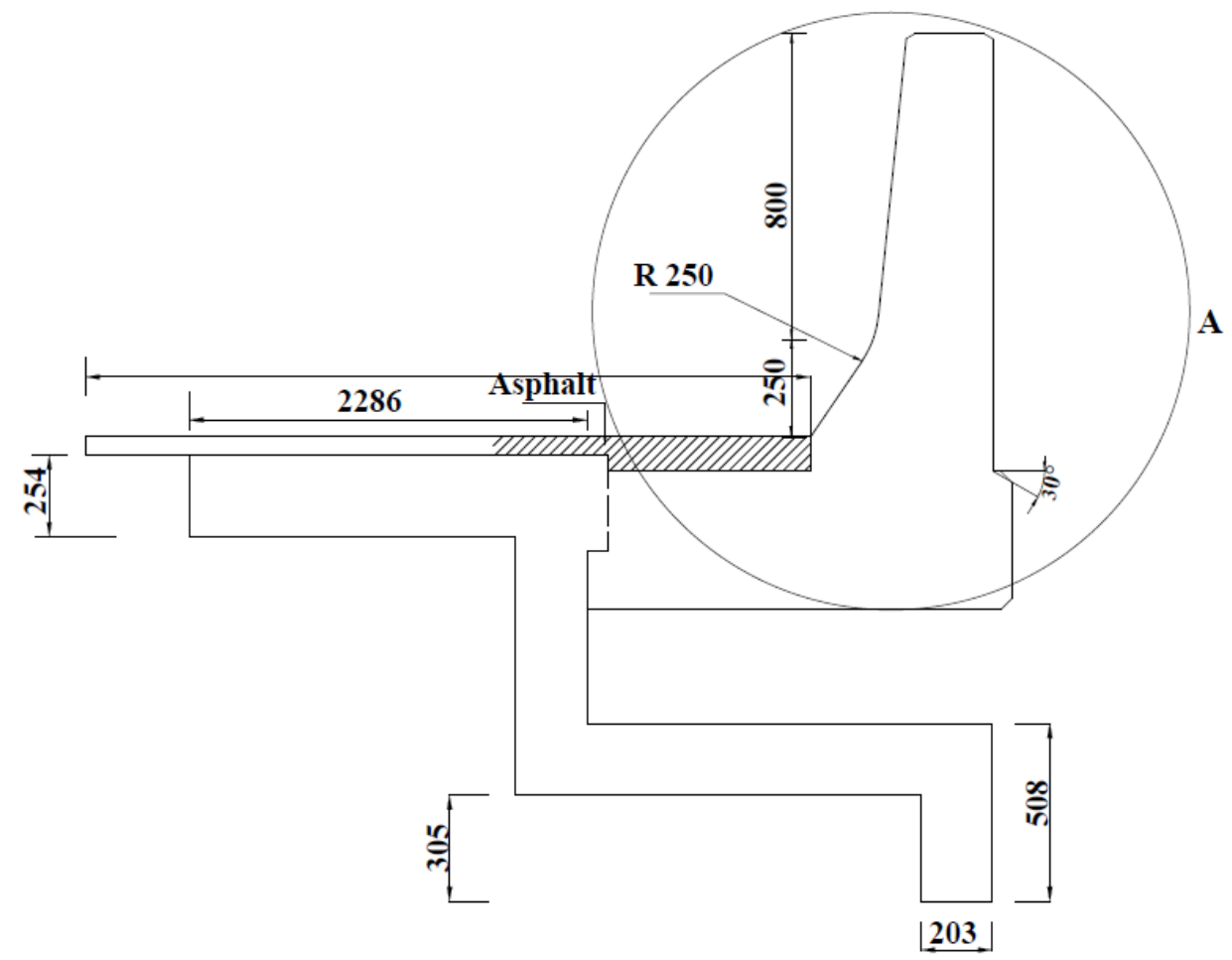

Figure 5. 2 Cross-section of existing concrete slab foundation and the proposed barrier

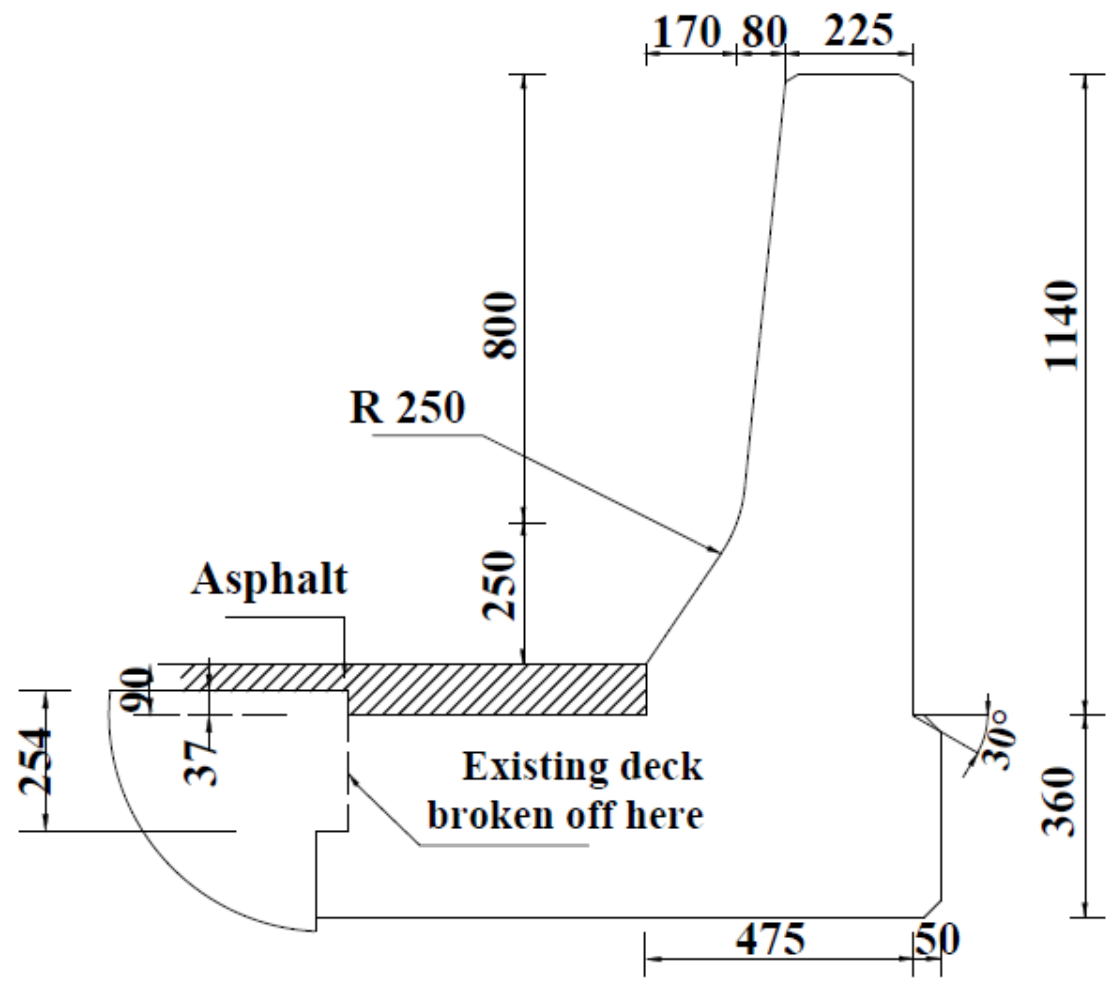

Figure 5. 3 Details A (refer to Figure 4.3a) 


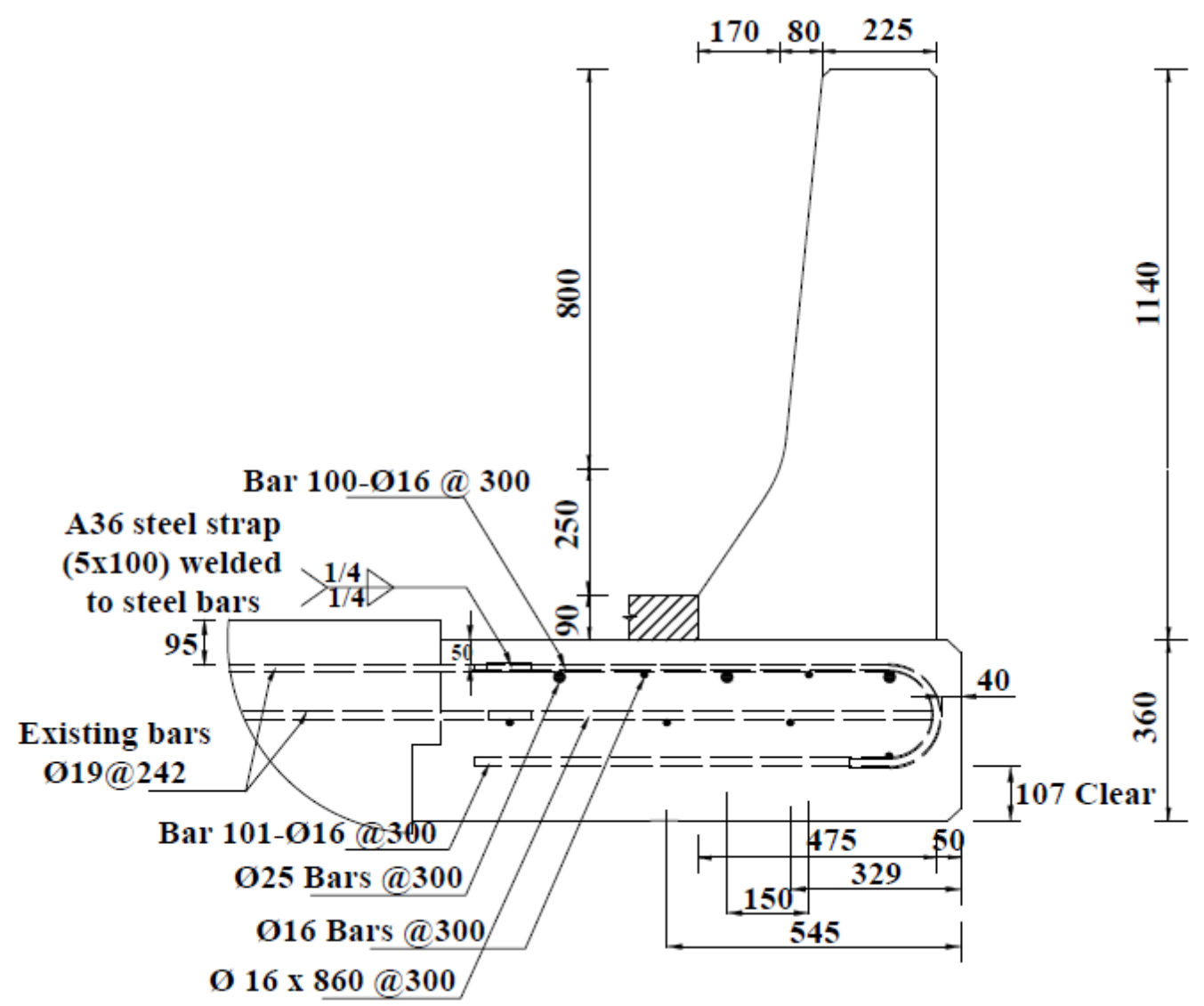

Figure 5. 4 Reinforcing details at deck slab-barrier wall interface
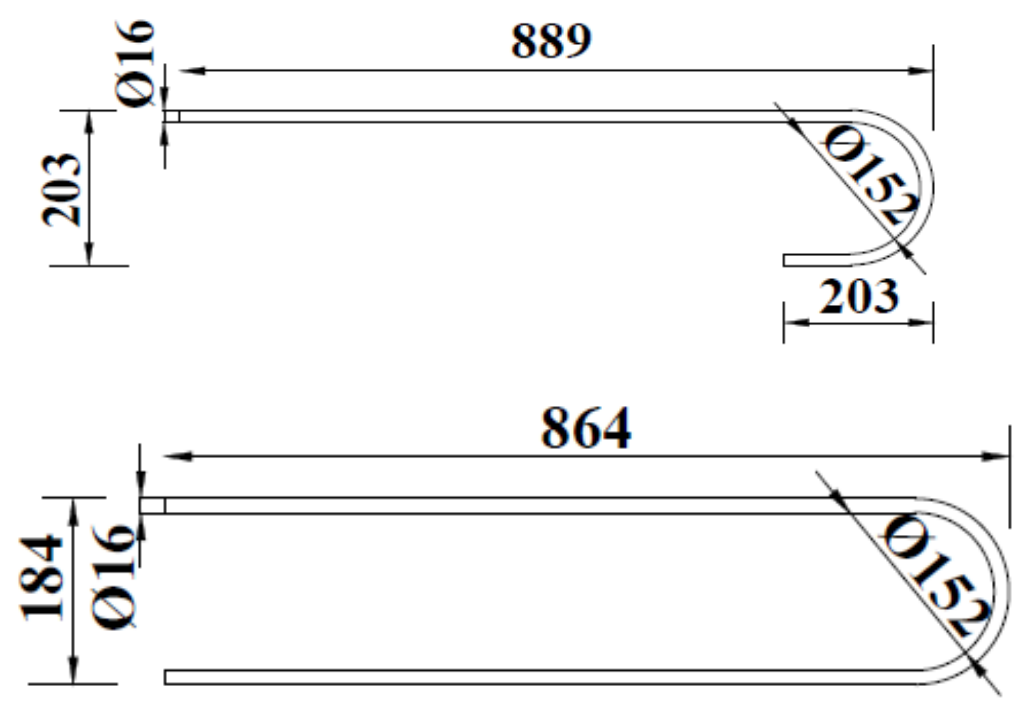

Figure 5. 5 Connecting M16 bars TYPE 100 (top) and TYPE 101 (bottom) 

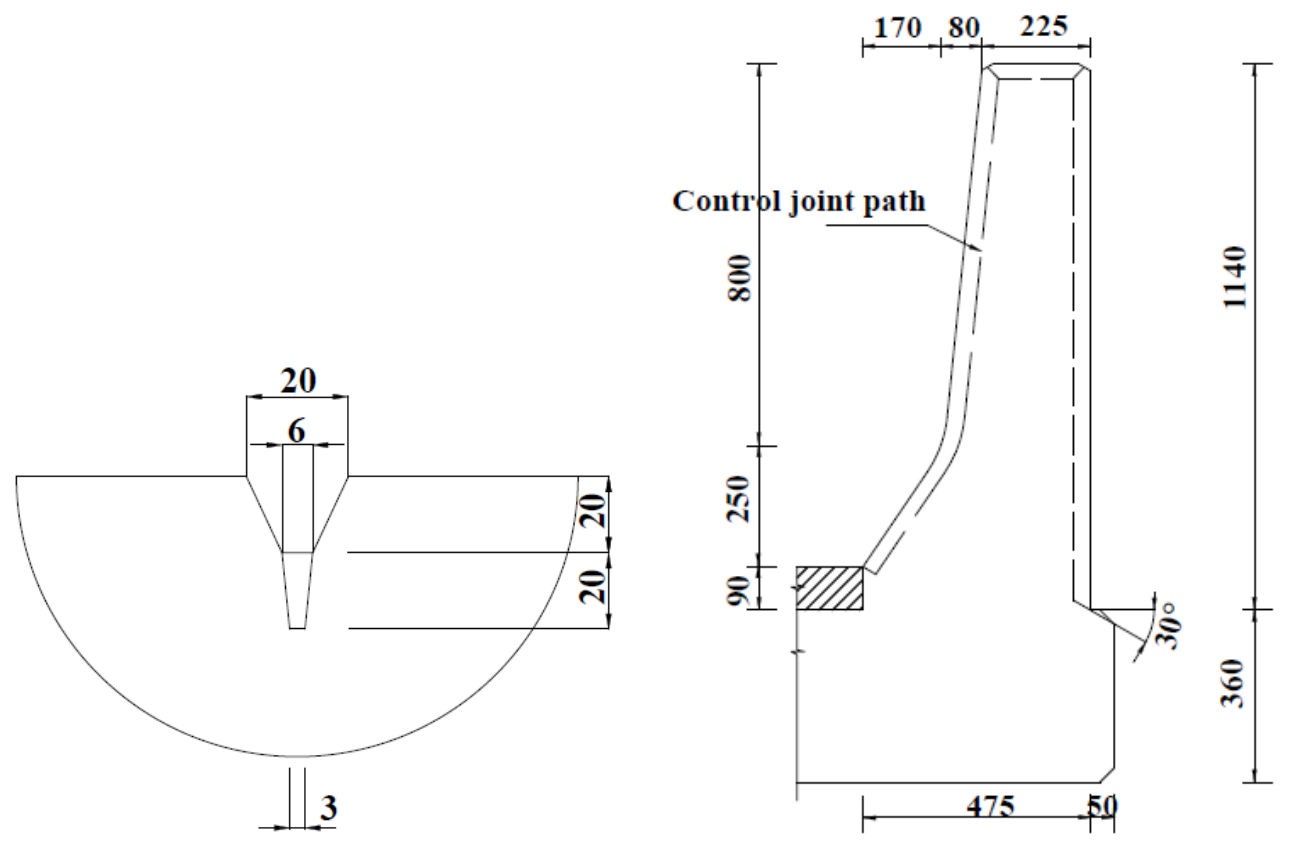

Figure 5. 6 Detail of the control joint (right) and cross-section at the control joint (left)

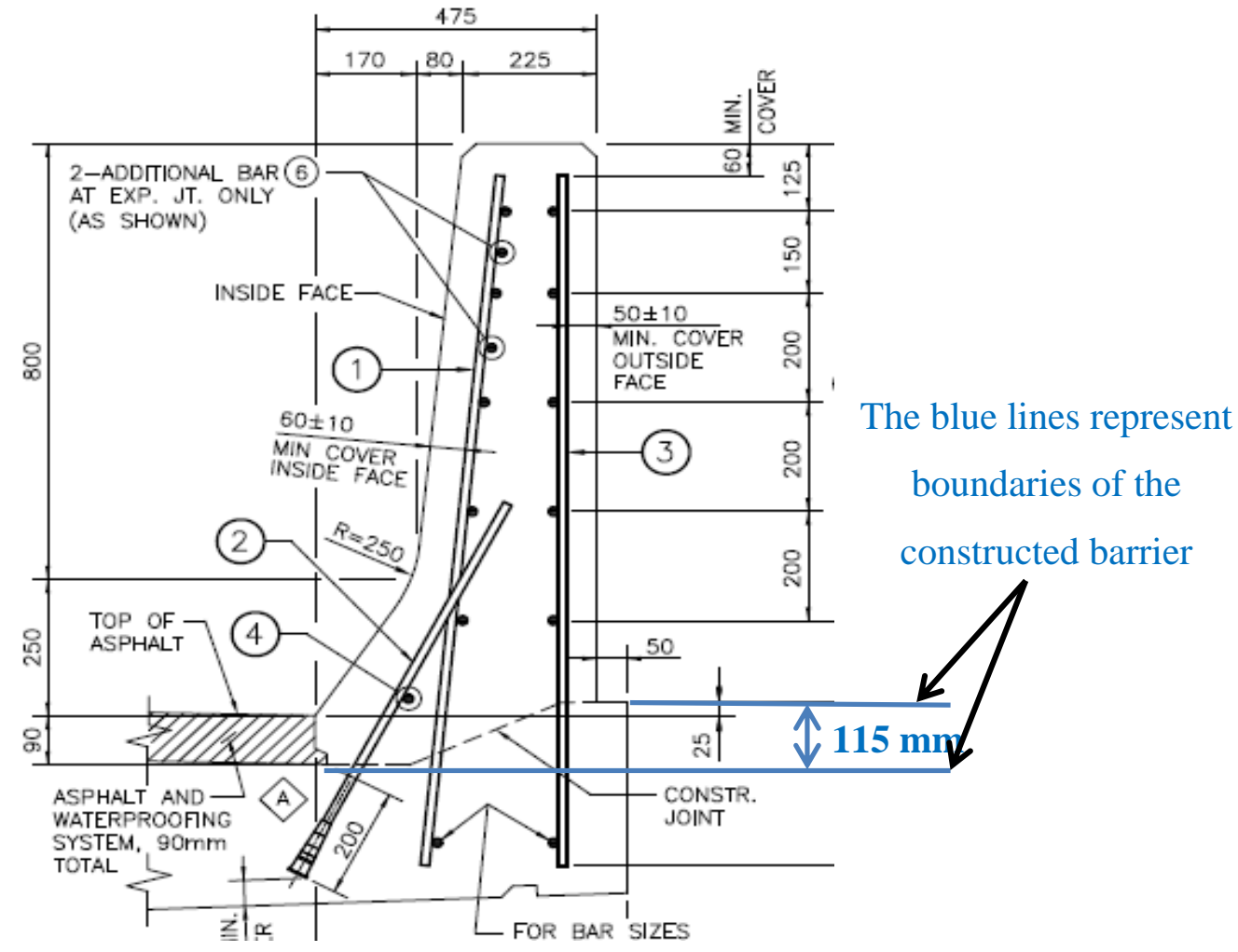

Figure 5. 7 Schematic diagram of the barrier wall showing the difference between the MTO barrier and the constructed barrier configurations 


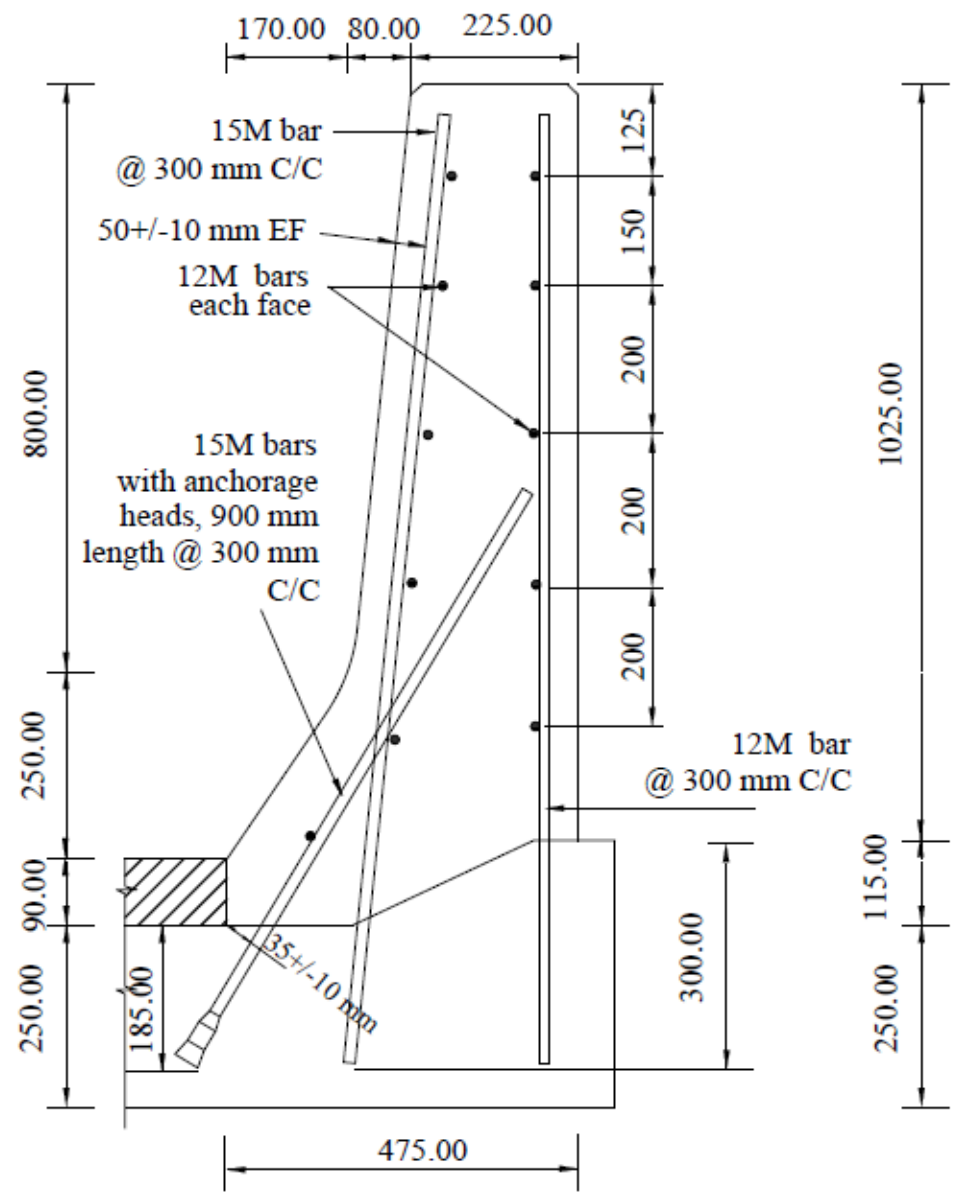

Figure 5. 8 Layout of the GFRP bars in the barrier wall and the steel bars in the deck cantilever

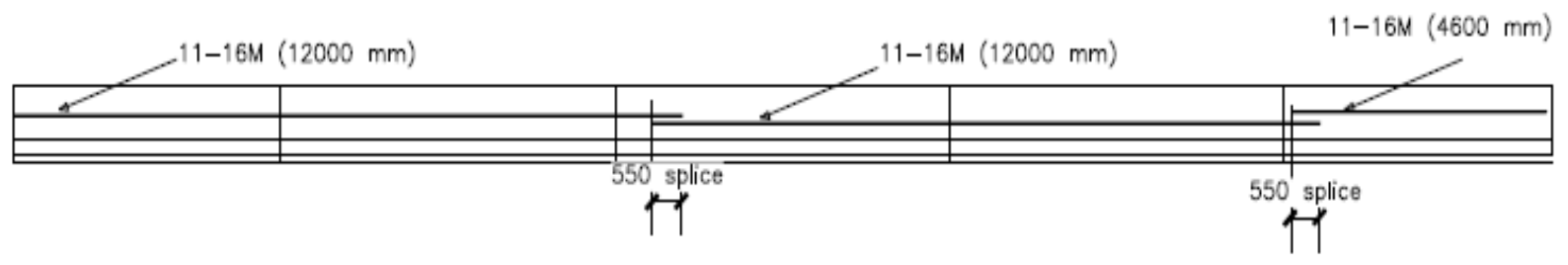

(a) Horizontal bar layout

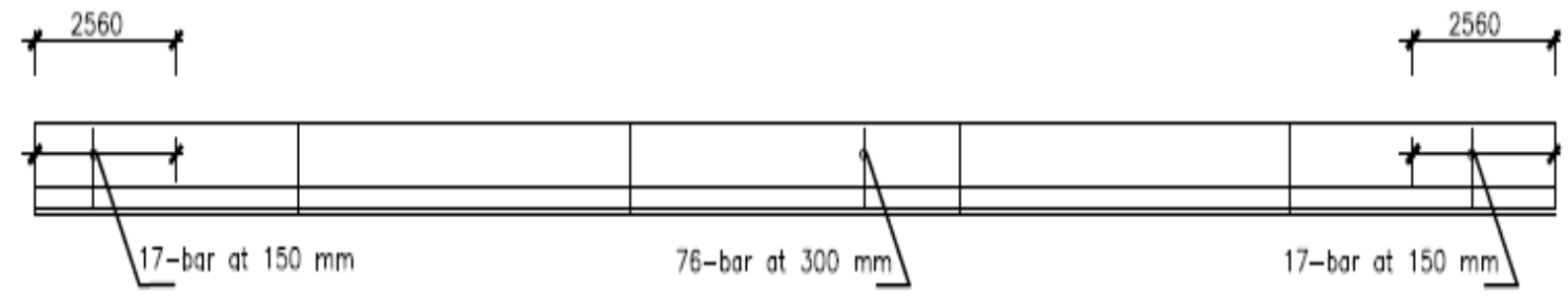

(b) Vertical bar layout

Figure 5. 9 Horizontal and vertical GFRP bars arrangement 
Minimum concrete cover to GFRP bars was considered as $50-\mathrm{m}$ in each face of the barrier. M15 GFRP bars with headed-end were utilized to connect barrier wall to the concrete slab (see Figure 5.8). The GFRP headed-end bars connected the deck slab to the barrier in such a way that the bars were oriented at an angle of about $60^{\circ}$ to the horizontal plane. The minimum concrete cover from GFRP bar to the nearest upper surface of deck slab was $35 \pm 10 \mathrm{~mm}$. The lowest portion of GFRP bars were placed at depth of $185-\mathrm{mm}$ to the top surface of deck slab. The M15 GFRP headed-end bars had a length of 1000-mm and a longitudinal center-to-center spacing of 300$\mathrm{mm}$.

The prototype barrier model has been tested monotonically up to failure under static testing over the lengths of 2.4-m and 1-m (see Figure 5.10). The barrier wall shown in Figure 5.10 has been saw-cut longitudinally so that each 1-m long barrier wall system could be tested separately. Each barrier series has been tested under increasing monotonic loading up to-complete-collapse. Different sensors (concrete and steel strain gauges and LVDTs) have been instrumented at critical locations to capture straining actions with increase in the applied load. The high-tech data acquisition system available at the structural laboratory was used to capture data during testing. Patch loads representing vehicle contact with the barrier face was applied using a small-length steel beam with rubber pad to evenly distribute the horizontal concentrated jacking load over a limited wall length to avoid any localized premature failure. Crack patterns and ultimate load carrying capacity were recorded. Four different monotonic load scenarios, shown in Figure 5.10, were considered;

a) The first specimen represents a PL-3 barrier wall that a 1-m lateral line load was applied horizontally near top of the barrier wall at interior location. This failure test was intended to examine flexural capacity of the junction between barrier wall and the deck slab.

b) The second specimen was the same PL-3 barrier wall as case (a) but the load was applied at edge location of the barrier wall.

c) The third specimen represented a PL-3 barrier wall and a line load of 2.4-m length was applied at interior location of the barrier wall.

d) The fourth specimen represented a PL-3 barrier wall and a line load over a length of 2.4m was applied at end of the barrier wall to examine its load carrying capacity which the vehicle impacts the barrier at its end. 
The failure tests on the 2.4-m central and end barriers are intended to observe the yield-line failure patterns of each barrier type at the central and end locations as compared to those specified in AASHTO-LRFD for steel reinforced concrete barrier walls. These tested for length barrier will examine the contribution of the horizontal reinforcement to load carrying capacity of the barrier wall when impacted by vehicle.

The sequence of the PL-3 barrier constructions is provided in the following figures. Figure 5.11 shows view of the existing concrete foundation with projecting steel dowels at the TTI. Figures 5.12 and 5.13 show photos of steel reinforcement in the deck slab, and installation of GFRP bars in the barrier wall. Figure 5.14 shows view of the GFRP reinforcement before making the timber forms and casting concrete. Figure 5.15 shows welding of the projected steel reinforcement from existing deck slab to the new steel reinforcement in the deck underneath the wall. Figure 5.16 shows close up image of the GFRP anchorage to the deck slab. Figure 5.17 shows views of the formwork of the barrier wall and the cantilever deck slab before finalizing concrete casting that is shown in Figures 5.18(a) and 5.18(b) for the deck slab and the barrier wall, respectively. Figures 5.19 and 5.20 show views of the constructed 27.6-m long barrier after removal of formwork.

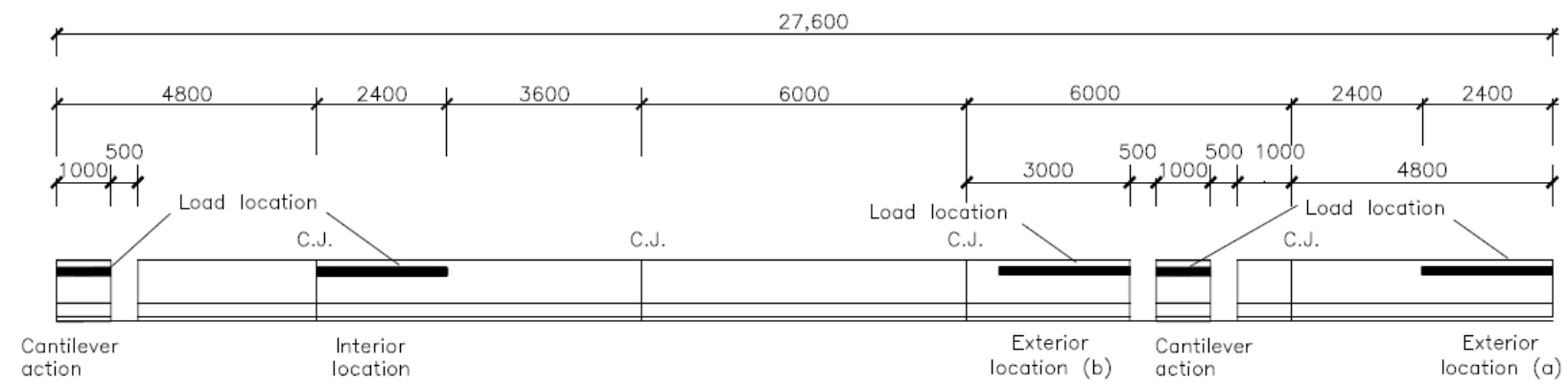

Figure 5. 10 Saw-cut the barrier and deck slab for static testing 


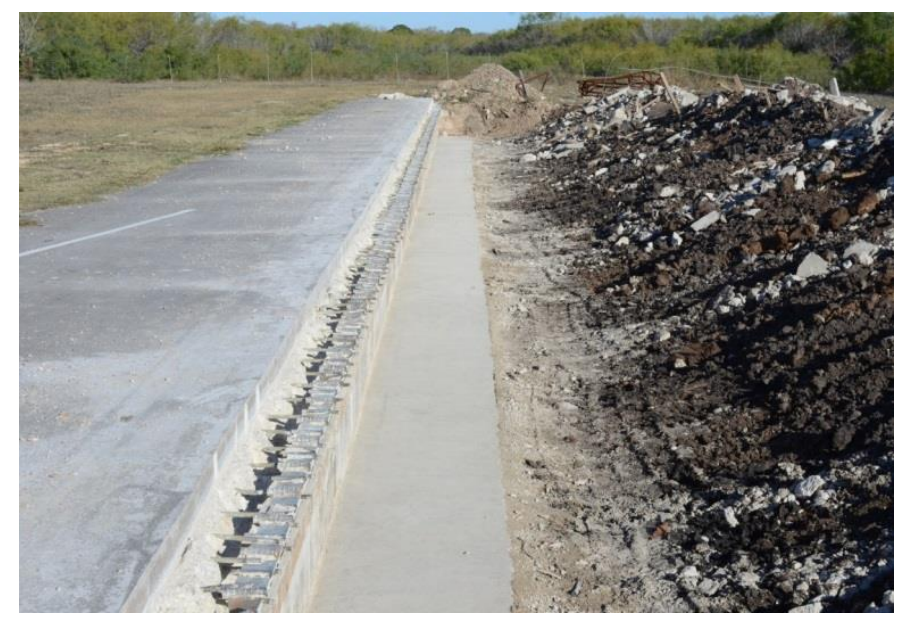

Figure 5. 11 View of the existing concrete foundation with projecting steel dowels at deck level

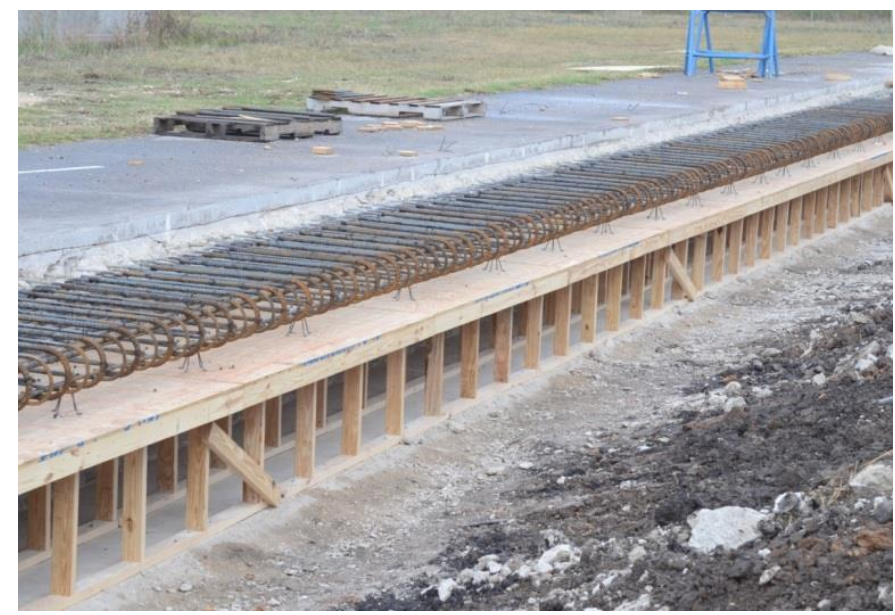

Figure 5. 12 View of steel reinforcement in the deck slab

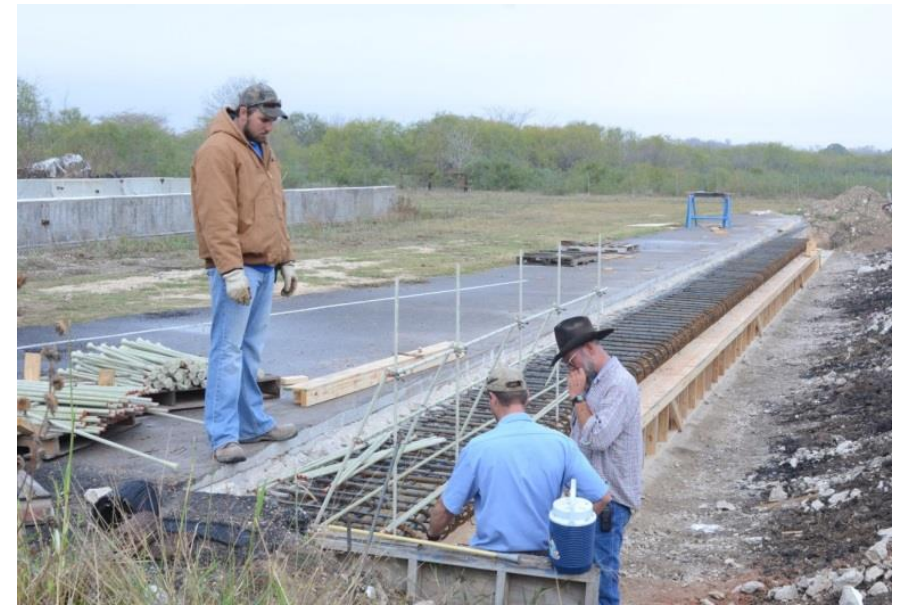

Figure 5. 13 View of GFRP bars installation 


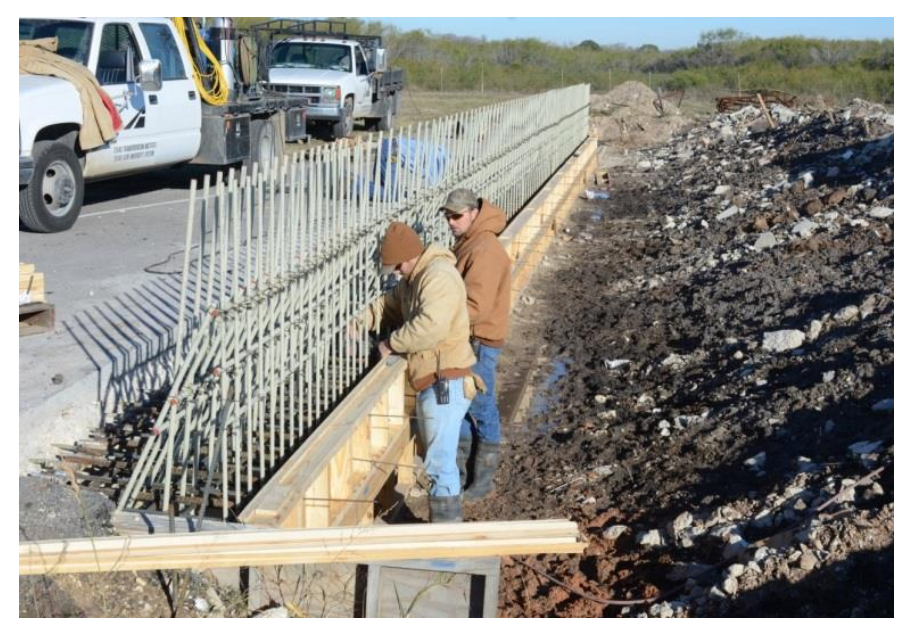

Figure 5. 14 View of the GFRP reinforcement

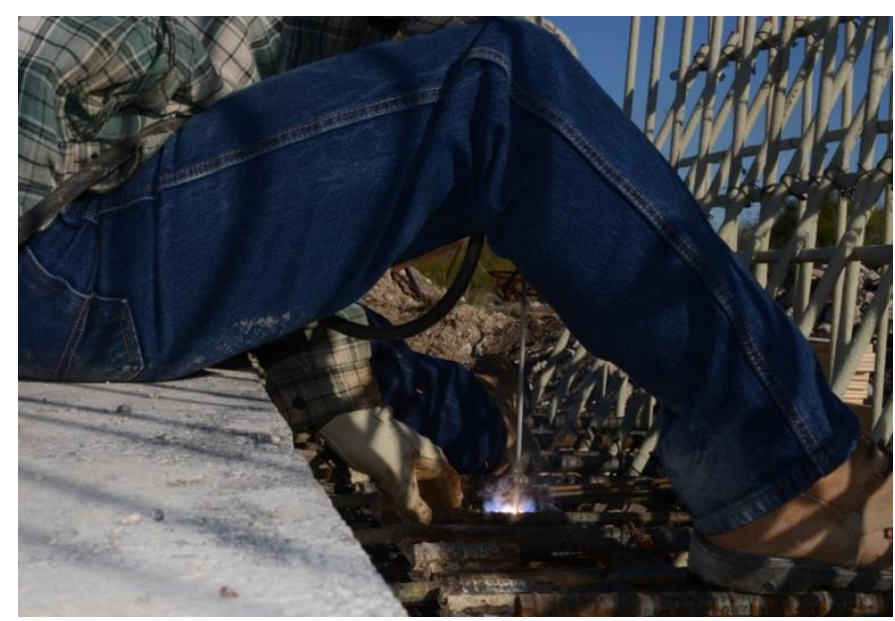

Figure 5. 15 View of welding reinforing steel in the deck to the longitudinal steel strap

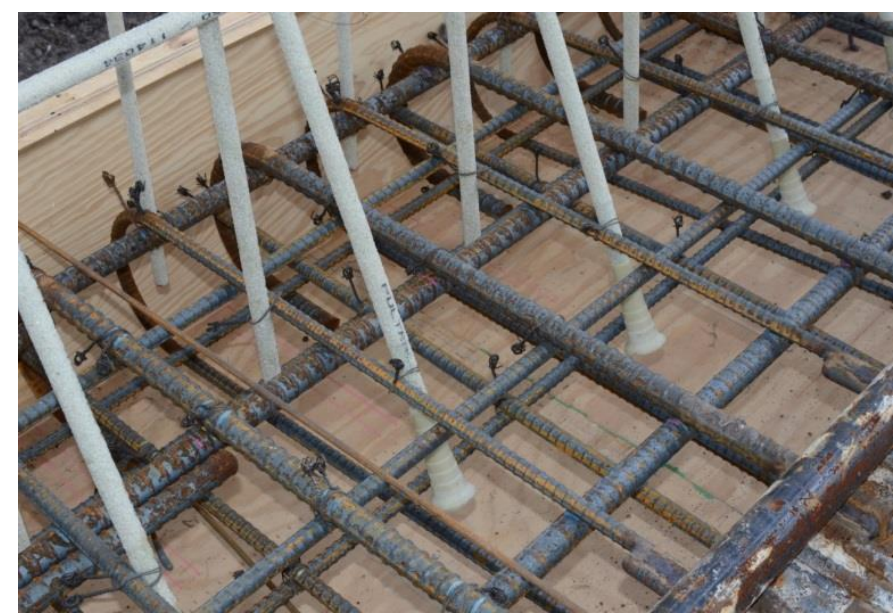

Figure 5. 16 Close-up view of barrier anchorage to deck slab 


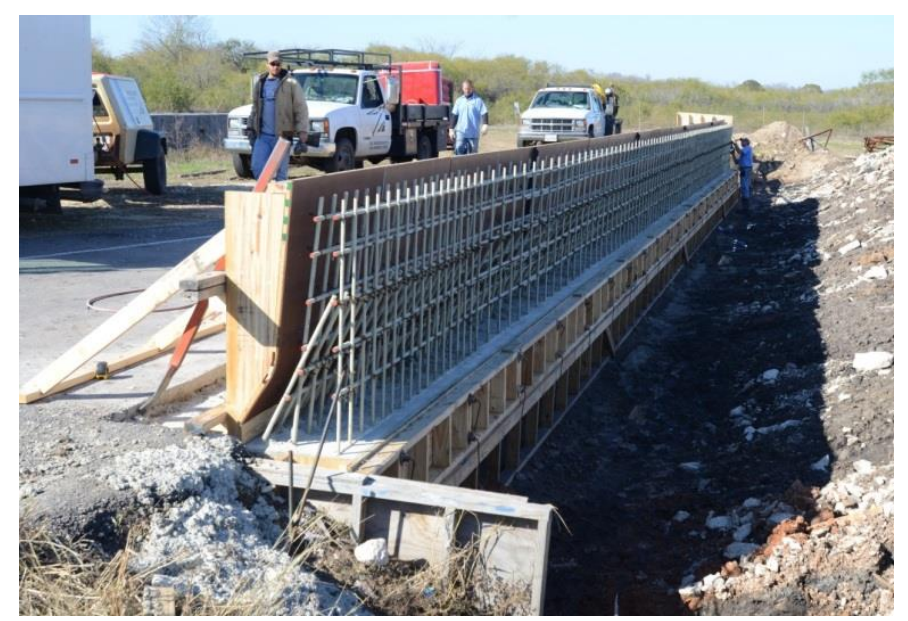

(a)

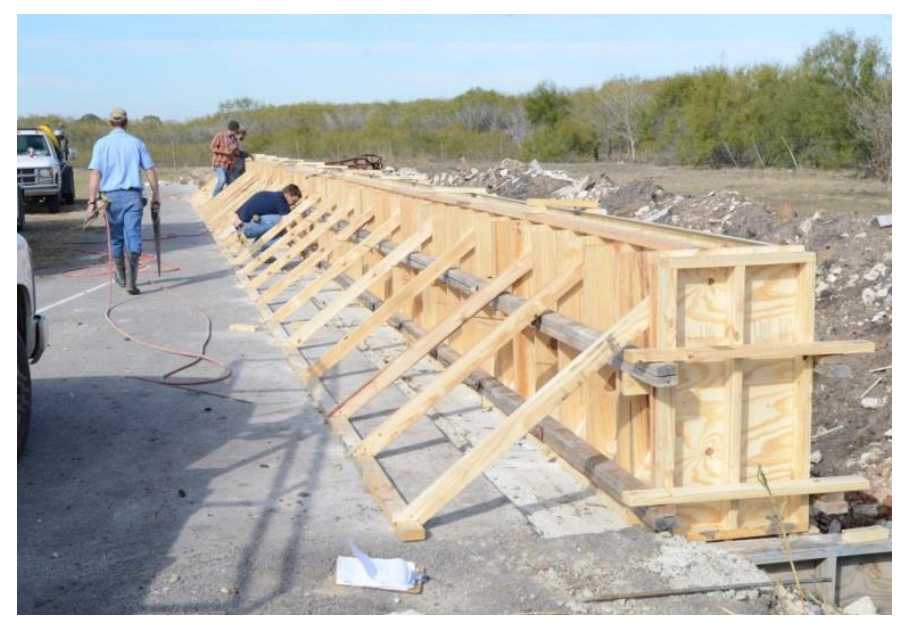

(b)

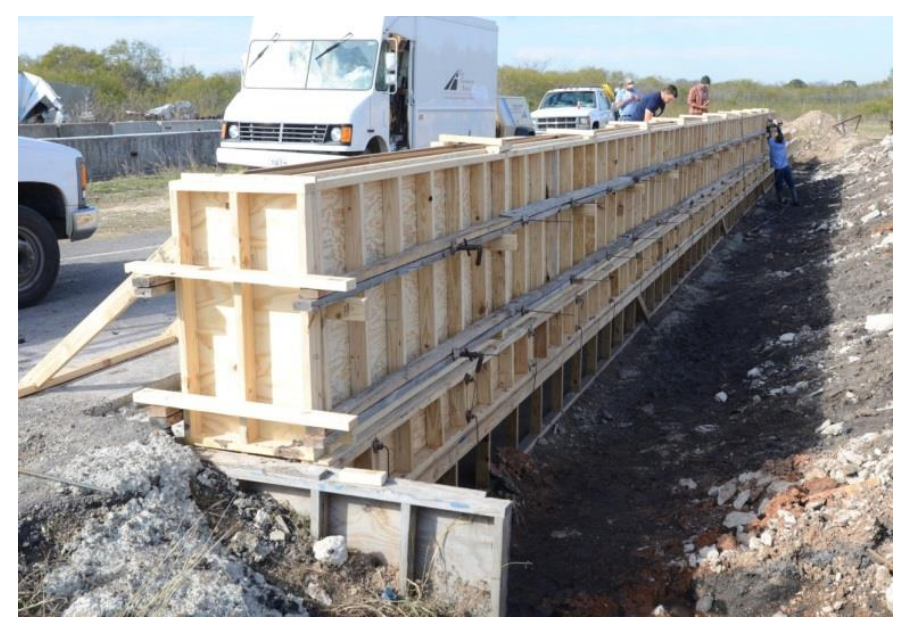

(c)

Figure 5. 17 Views of the formwork for concrete casting 


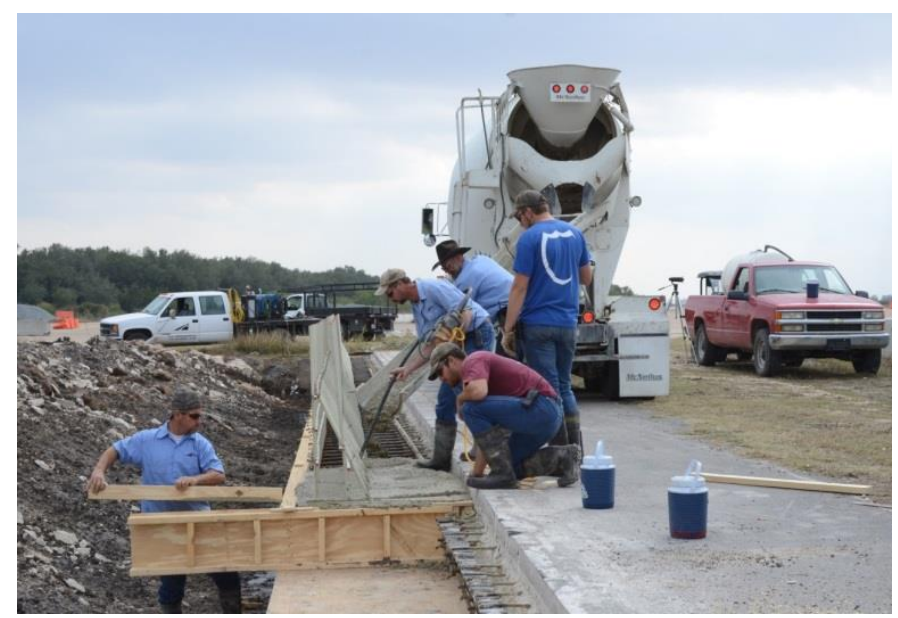

(a)

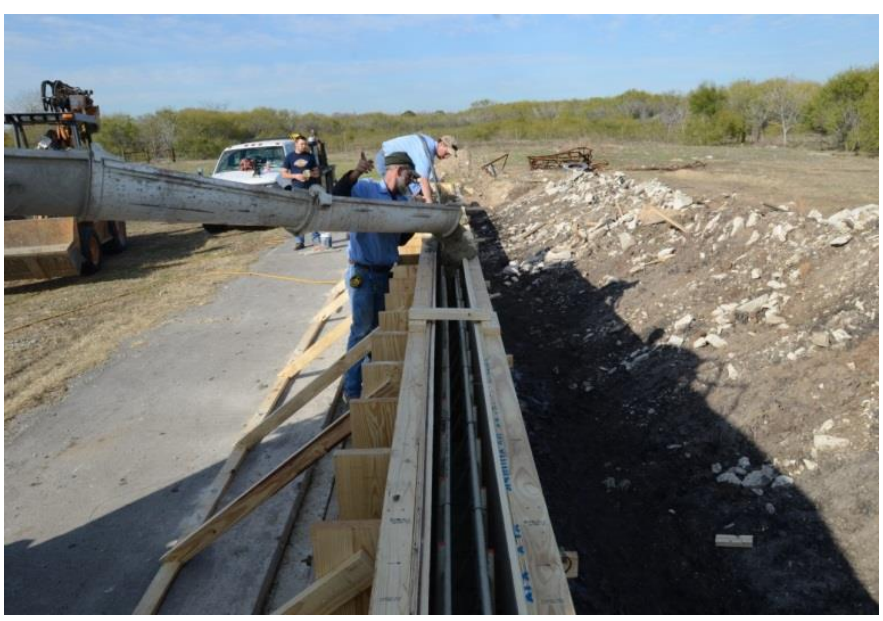

(b)

Figure 5. 18 Views of the barrier during casting (a) the deck cantilever and (b) the barrier wall

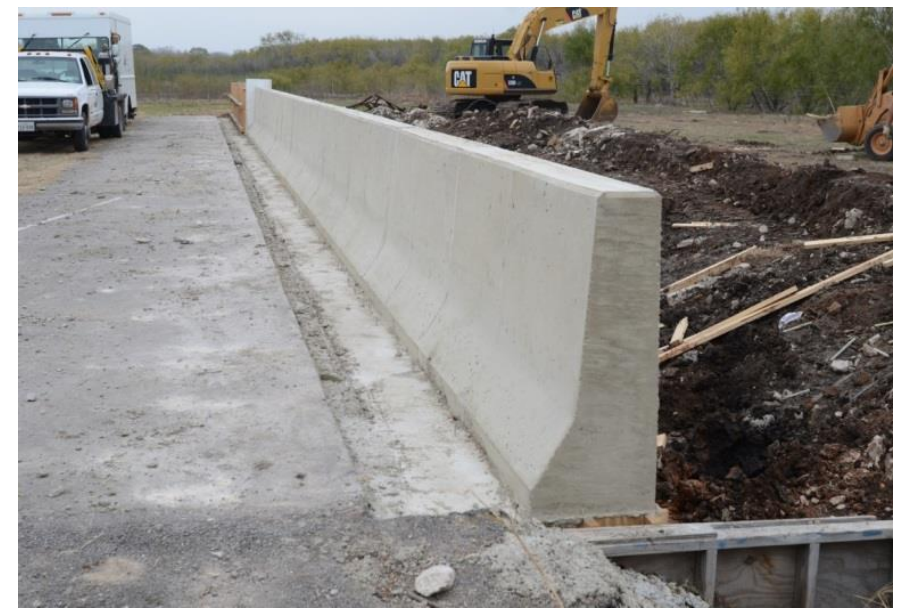

(a) 


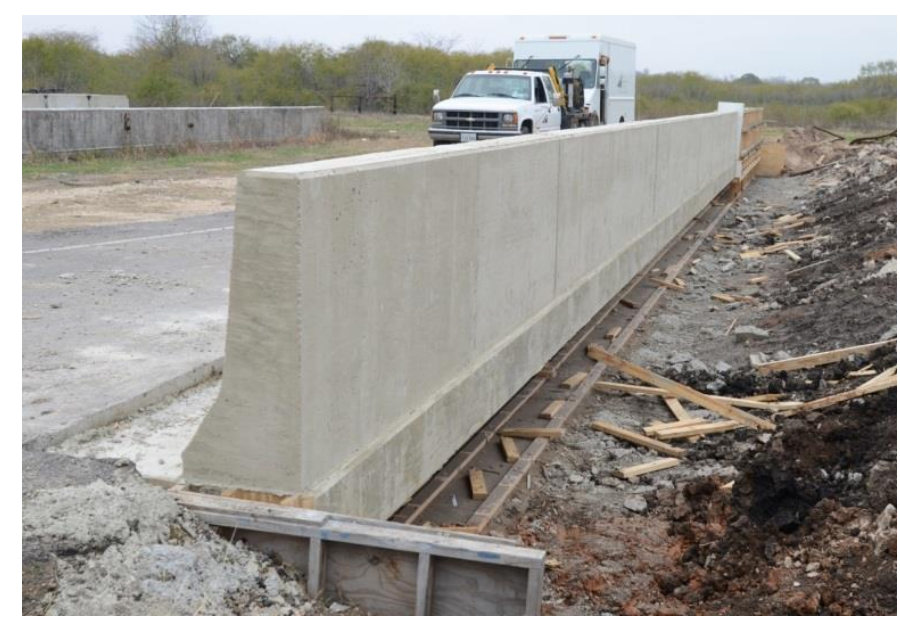

(b)

Figure 5. 19 Views of (a) Front and (b) back face of the barrier wall after removing the formwork

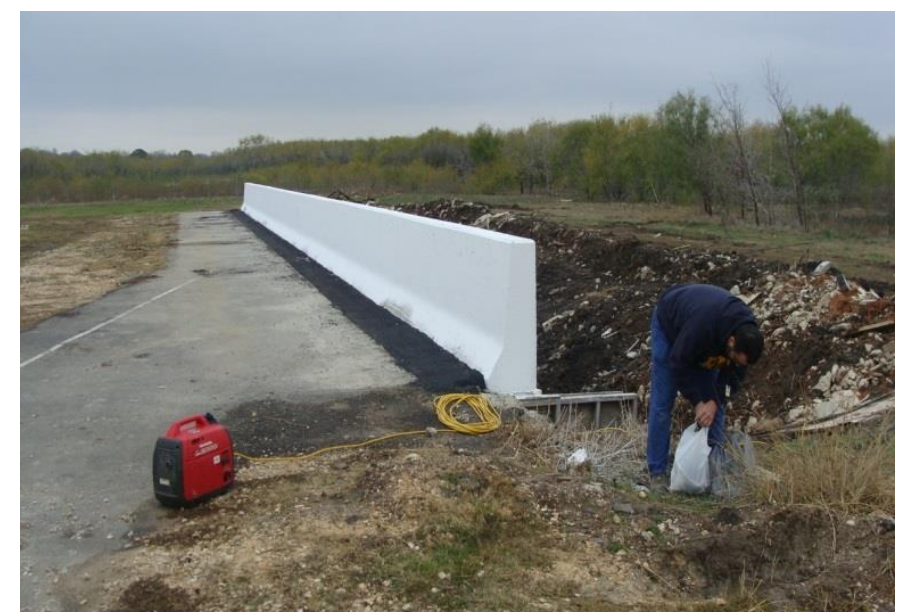

Figure 5. 20 View of the barrier wall and the paved area in front of the barrier wall

\subsection{Test Setup and Instrumentations}

Figure 5.10 showed schematic view of the proposed tests location. The barrier was loaded first at interior location with edge of the loading at the control joint. Then, the barrier was loaded at exterior location marked as (a) in Figure 5.10. However, the test was not successful due to failure in the anchorage between anchor bolts of the loading frame and the deck slab cantilever due to concrete pullout. As such, it was decided to establish other location in the barrier wall so that it could be tested as an exterior location. The barrier was saw-cut between the second and the third control joints to establish exterior location marked as (b) in Figure 5.10. It should be noted that 
the barrier wall was also loaded as cantilever at two locations as depicted in Figure 5.10 to determine the anchorage capacity of the barrier-deck junction. The test setup shown in Figure 5.21 consists of hydraulic jack that applied horizontal load over 2400-mm length of the wall through steel spread beams and 250-mm width trapezoidal timber plank attached to the barrier tapered surface. The applied load was balanced using a steel frame anchored to the concrete foundation on the back side of the hydraulic jack as depicted in Figure 5.21. The jack was connected to hydraulic pump that applied pressure to the system. Load-cell and sensors were attached to the data acquisition system to record readings with increase in the load. Similar test setup was used for testing of the barriers over 1-m length. However, the length of the steel spread beam and the timber plank was 1000-mm to spread the load uniformly at top of the wall.

Before conducting the static test, the constructed barrier was instrumented at loaded regions as shown in Figure 5.22. Linear variable displacement transducers (LVDTs) and potentiometers (POTs) were installed to measure barrier transverse deflection at 990-mm height from the deck slab as well as the vertical deflection of the deck cantilever at equal spacing of $1200-\mathrm{mm}$ in longitudinal direction of the barrier wall. A total of six LVDTs and POTs have been used to capture the lateral deflection of the barrier wall at interior and exterior locations, and other three have been used to capture vertical deflection of the barrier wall. The displacement sensors were attached to the wall in such a way that wall lateral deflection can be captured over 1200-mm on each side of the patch loading at interior location and over 2400-mm to the longitudinal length at exterior location. For barrier length of 1-m, two POTs have been used to determine the wall lateral deflection and other two were used for vertical deflection of the wall.

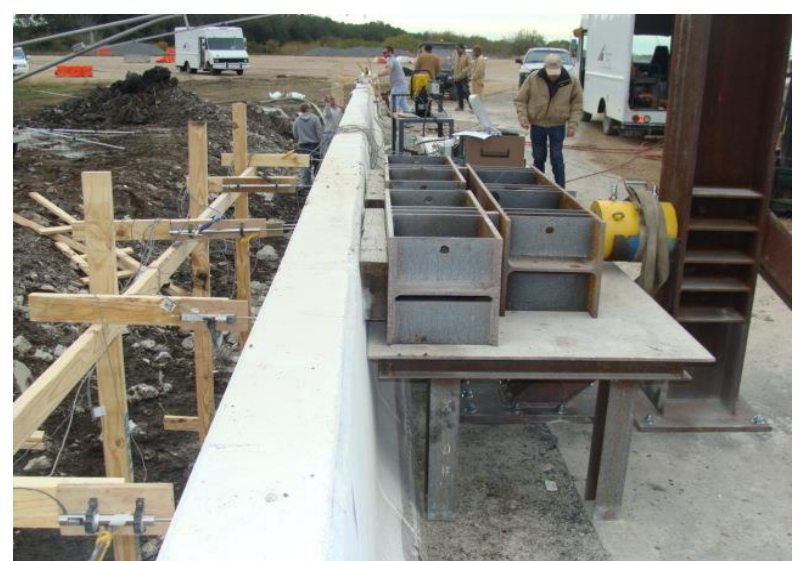

a) Side view at interior location

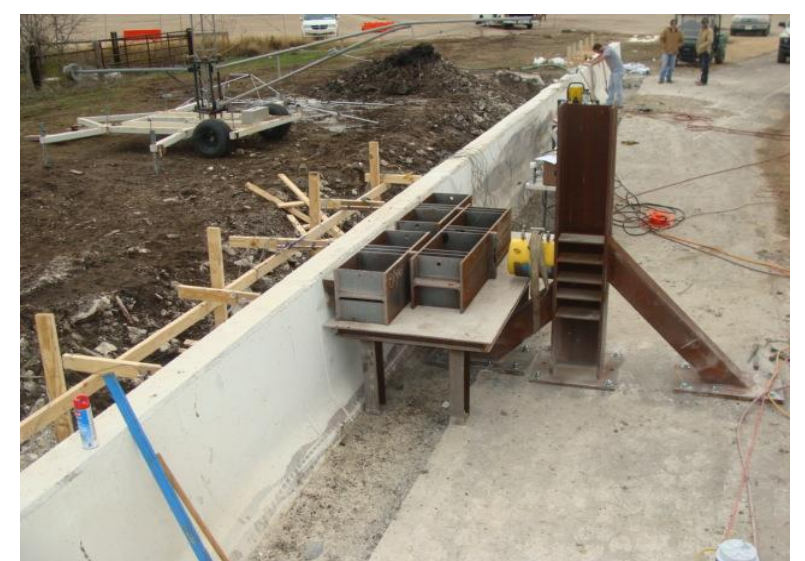

b) Front view at interior location 


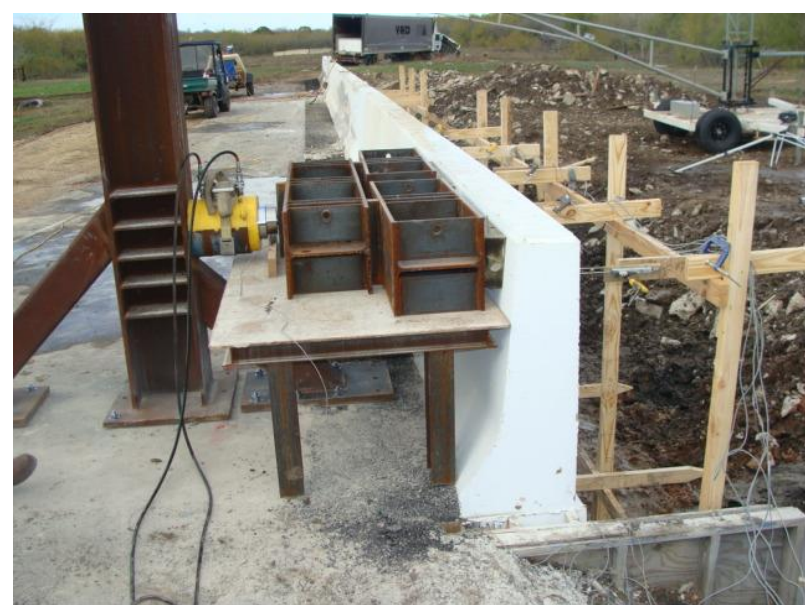

c) Side view at exterior location

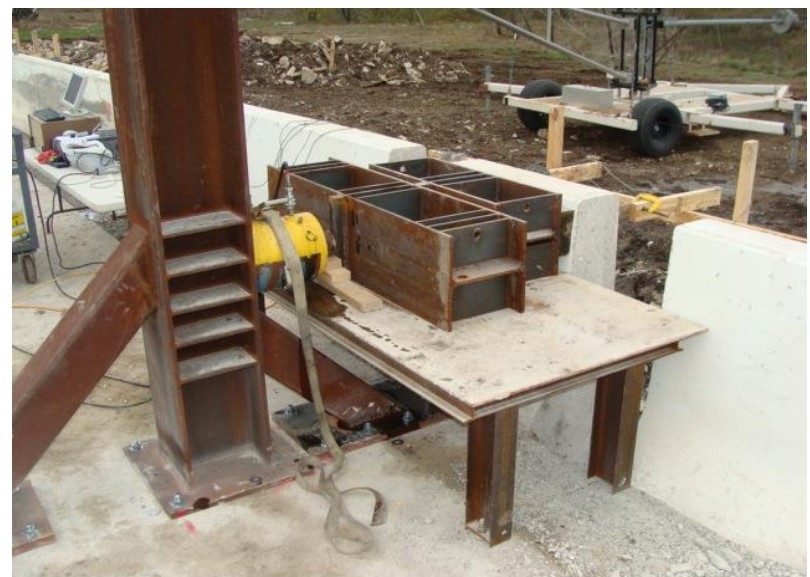

(e) Front view over 1-m loaded length

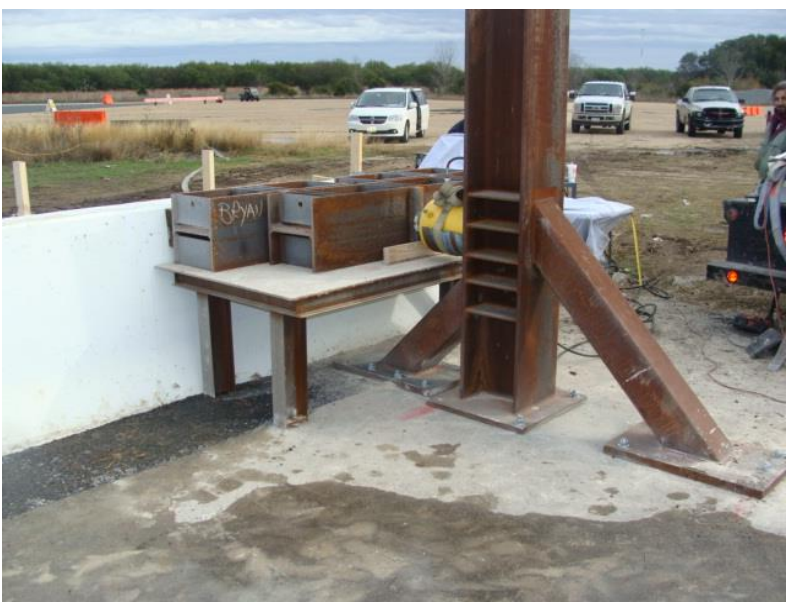

d) Front view at exterior location

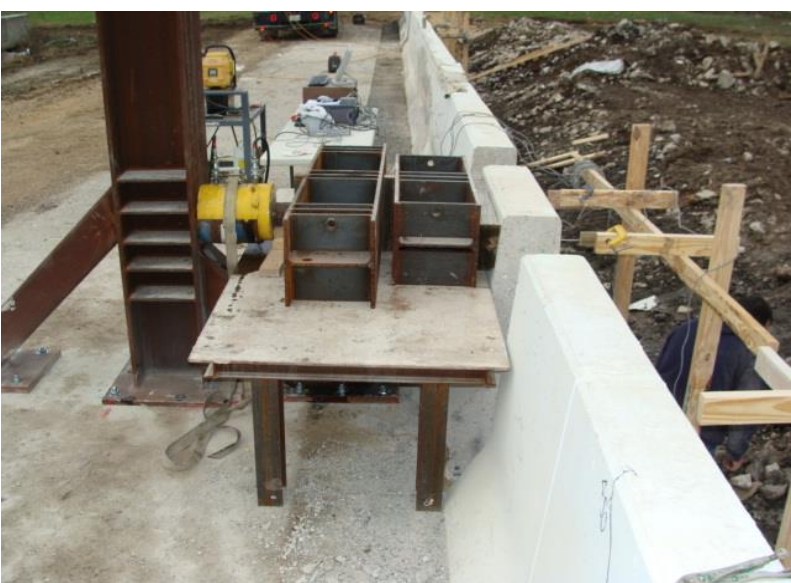

(f) Side view over 1-m loaded length

Figure 5. 21 Views of test setup for static testing of the barrier wall at interior and exterior locations over 2.4-m length and cantilever test over 1-m length
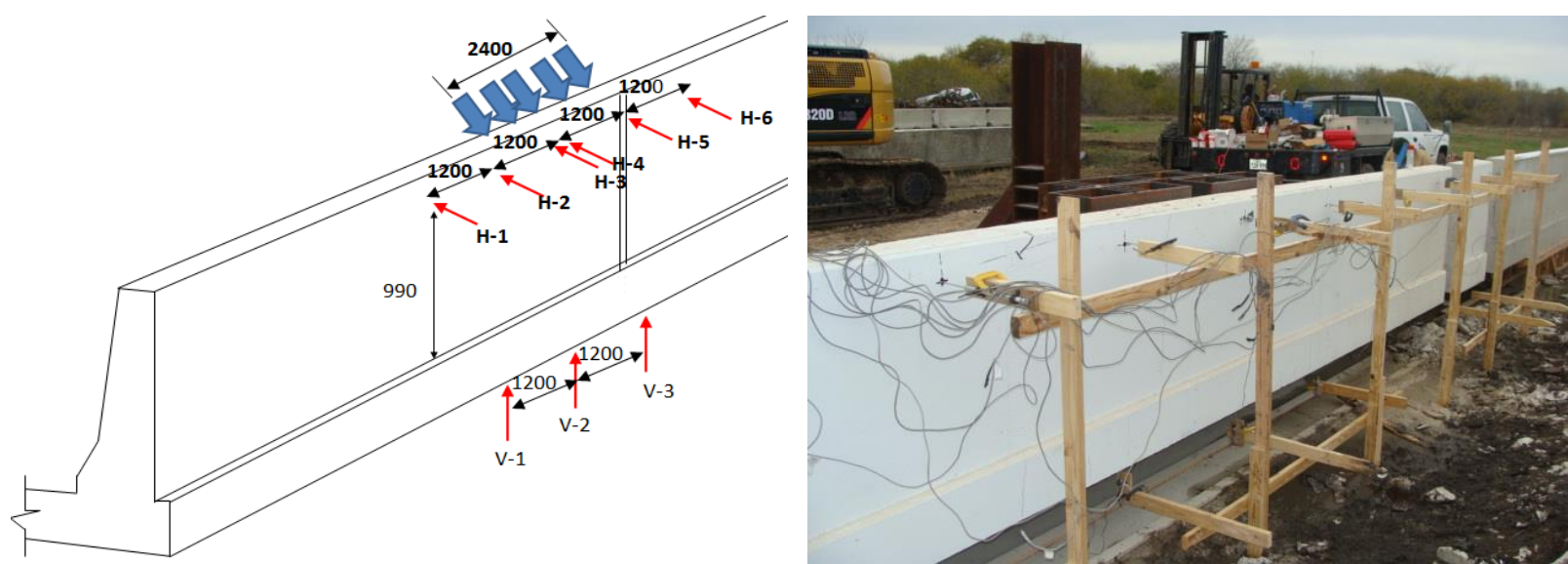

a) Interior location over 2.4-m loaded length 

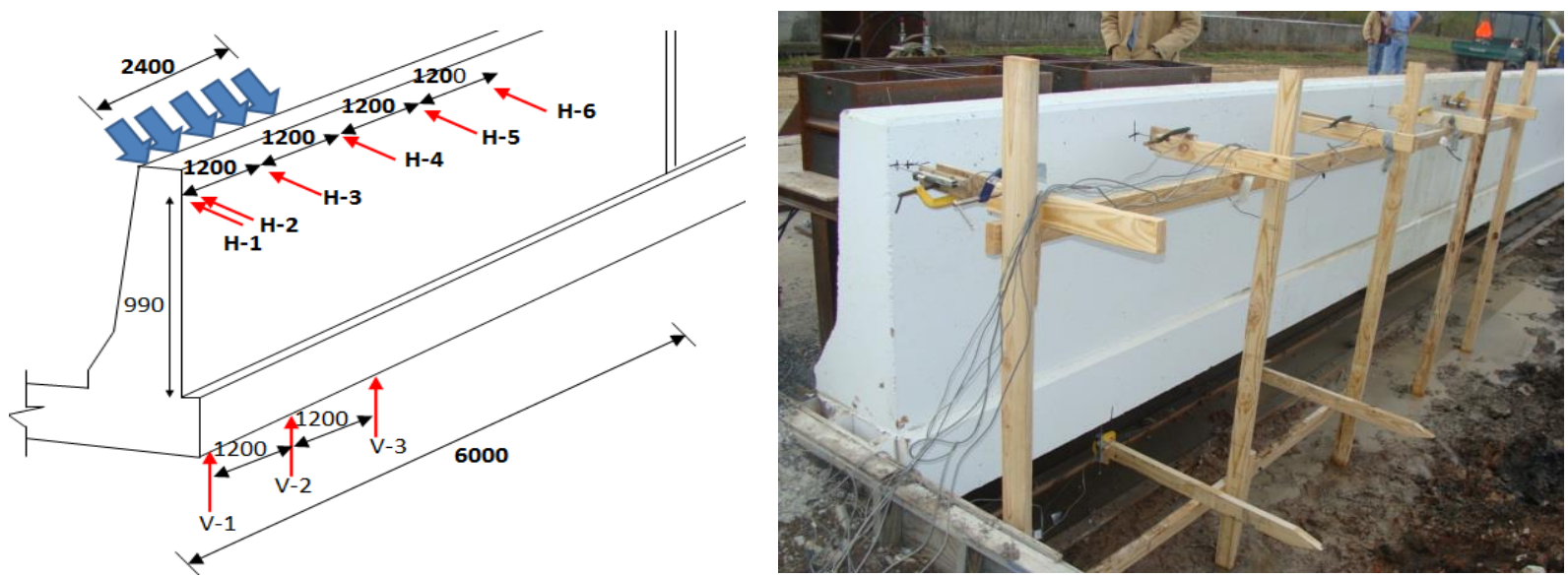

b) Exterior location over 2.4-m loaded length
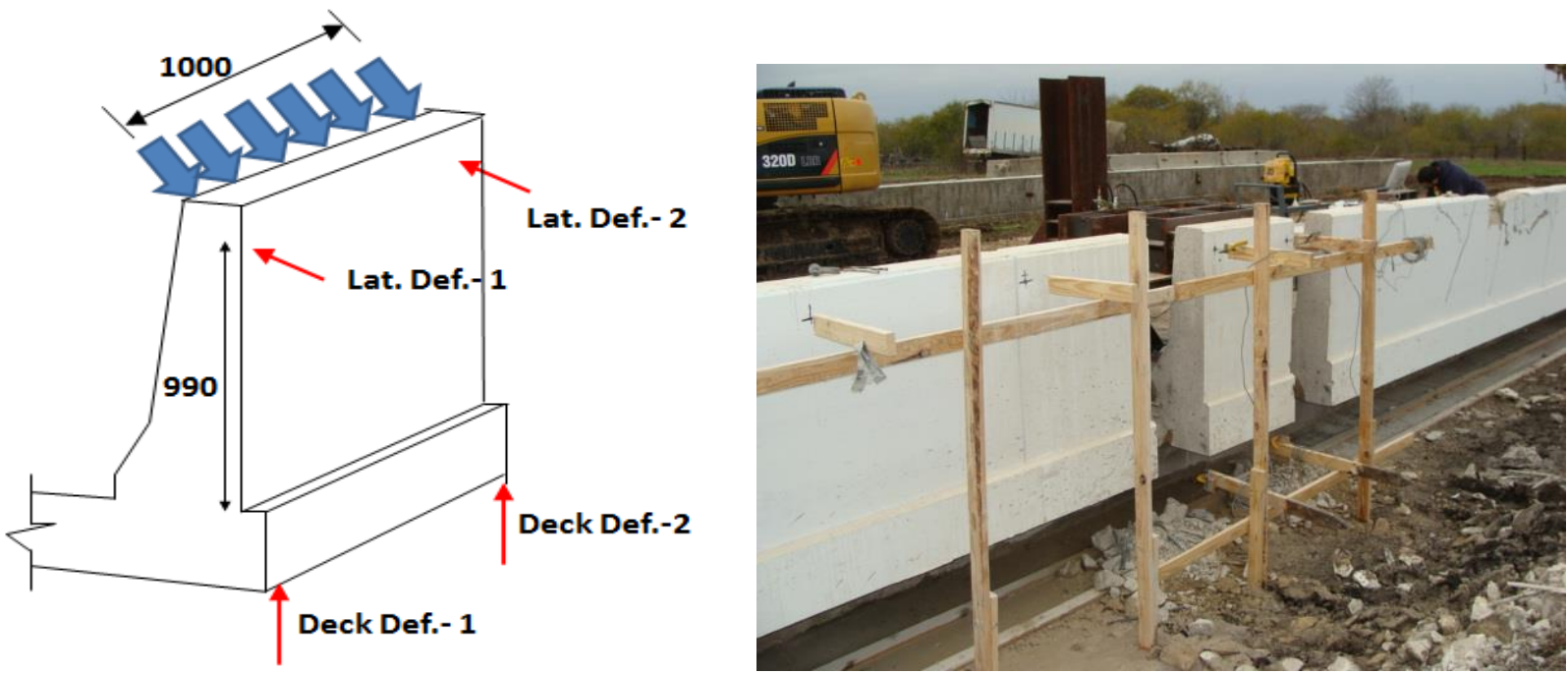

(c) Cantilever test over 1-m over length

Figure 5. 22 Views of sensor attachments over 2.4- and 1-m lengths of the wall locations

\subsection{Experimental Test Results over 2400-mm at Interior Location}

The prototype barrier was subjected to increasing monotonic static load at interior location shown in Figure 5.10. At each $25 \mathrm{kN}$ up to failure, the barrier wall was inspected to mark cracks. The barrier was considered failed when the sensors continued to record increasing deflections with no increase in the applied load. Figure 5.23 shows views of the crack pattern after failure at front and back faces of the barrier wall. It was observed that with increase in the applied load, horizontal crack appeared at front face of the barrier wall-deck slab junction at load of $300 \mathrm{kN}$. Other horizontal cracks were appeared on the tapered portion of the barrier wall at load of 330 
$\mathrm{kN}$. These cracks appeared within the 2400-mm length of the line load, extending diagonally outside the loading region and reaching the top surface of the barrier wall at a load of $425 \mathrm{kN}$. The marked horizontal cracks within the loaded length of the barrier showed that the barrier wall behaved as a cantilever wall within the loaded length, while the two-way slab action appeared outside this region (on the left and right side of the applied line load) in the form of diagonal cracks extending to the top surface of the barrier. However, punching shear crack appeared on each side of the line load at loads greater than $525 \mathrm{kN}$ and propagated through the barrier thickness and to the other side of the line load at ultimate load of $654.9 \mathrm{kN}$. With increasing the applied load, punching shear cracks extended longitudinally at back face of the barrier wall as depicted in Figure 5.23(e). The barrier could not absorb any increase in load beyond $654.9 \mathrm{kN}$. The sudden punching shear failure at the line load location may be attributed to low stiffness of GFRP bars and their linear elastic response till failure.

Figure 5.24 shows load-deflection relationship for the barrier wall at the line load level. It can be observed that barrier wall had a maximum lateral deflection of 15.71-mm. Also, it can be observed that the maximum deflection of the deck slab cantilever at failure was $2.86-\mathrm{mm}$ which was very small, indicating the deck slab cantilever was not affected by the maximum load reached experimentally. The observed crack pattern contradicted with the AASHTO-LRFD crack pattern (Figure 5.25), where the two diagonal yield-lines at front face of the barrier meet at barrier-deck junction located at centerline of the line loading. In addition, few vertical cracks appeared at back face of the barrier wall at load levels equal to and greater than $500 \mathrm{kN}$ as depicted in Figure 5.24(e). These cracks resulted from bending of the barrier wall about a vertical axis due to the two-way action of load transfer in the barrier wall 


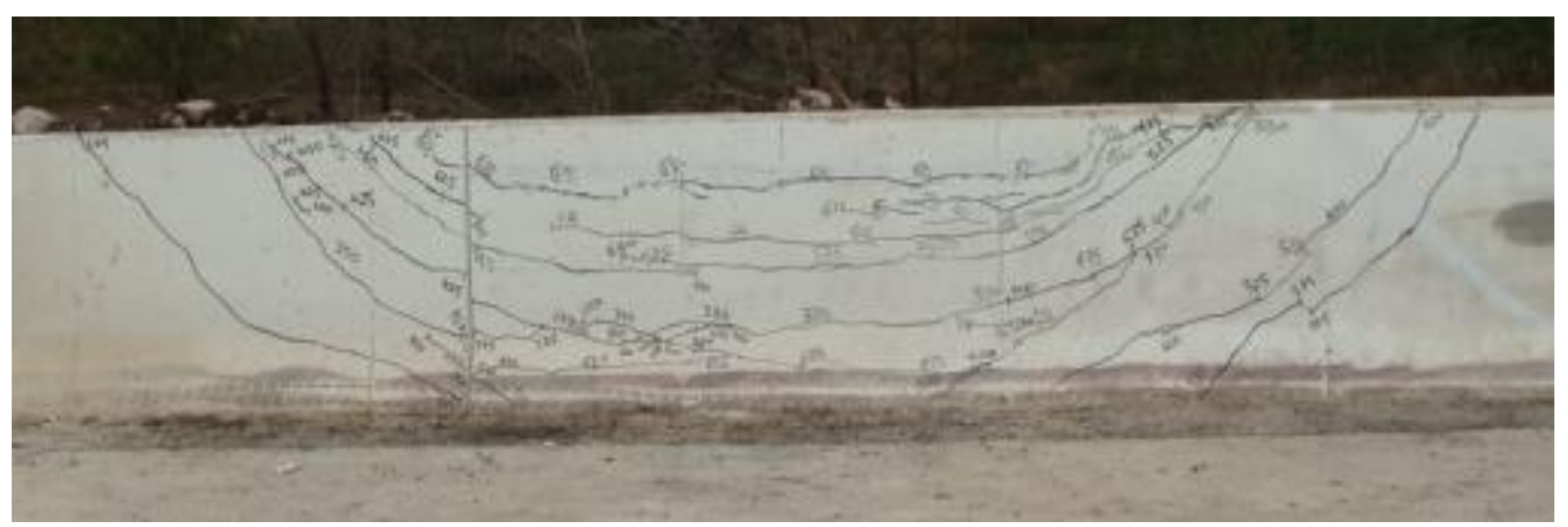

a) Elevation of crack pattern at barrier front face

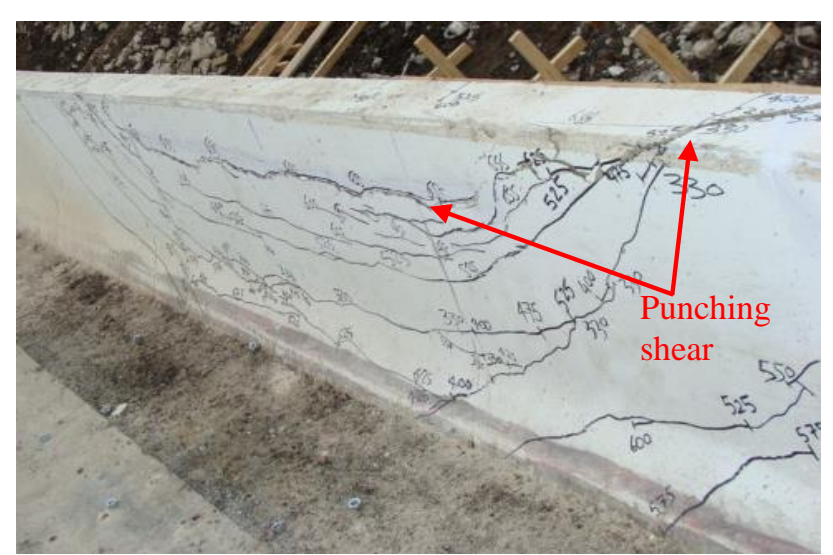

b) Front view of punching shear

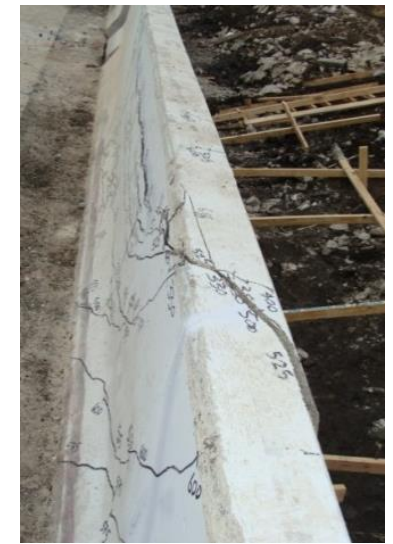

c) Side view of punching shear

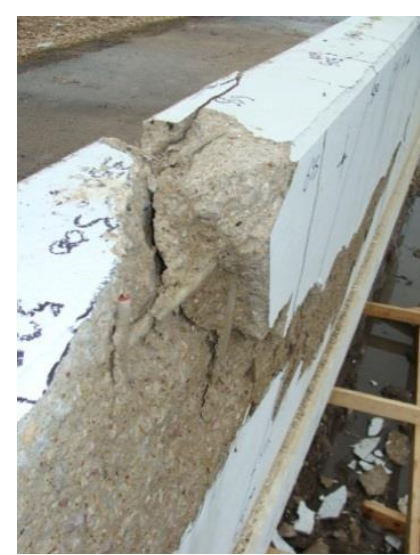

d) Exposed GFRP bars at through crack

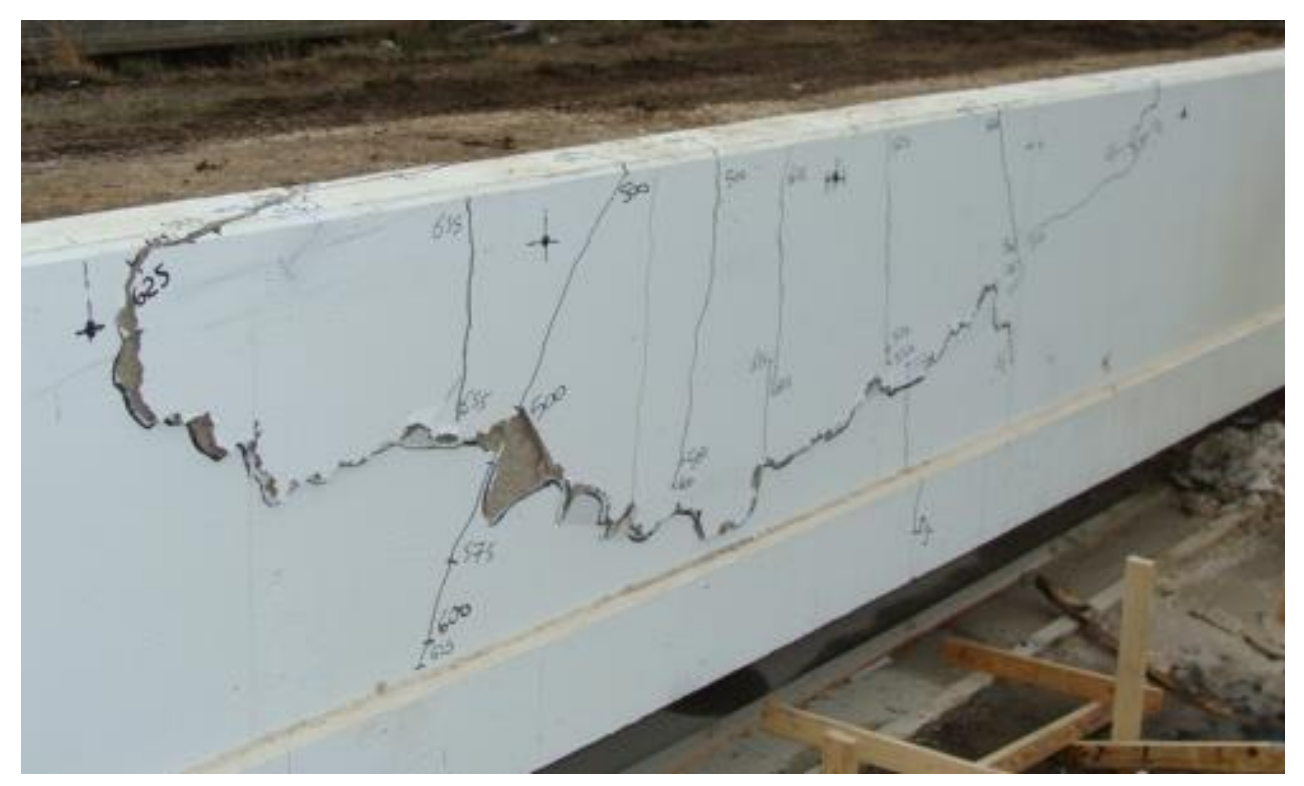

e) Crack pattern at the barrier back face

Figure 5. 23 Crack pattern of barrier wall at interior location 
Inspection of flexural cracks at barrier-deck interface as well as the load-deflection history shown in Figure 5.24 showed that GFRP bar rupture did not occur in the main tension reinforcement at front face of the barrier wall. This was despite the fact that no strain gauges were used to measure strains in GFRP bars. After the test, concrete was removed at the diagonal punching shear crack at back face of the barrier shown in Figure 5.23(d) to expose the GFRP bars at this location. It was observed that the GFRP bars were still intake with no sign of damage. Given the fact that the CHBDC design factored is $357 \mathrm{kN}$, the factor of safety for such loading case is $654.9 / 357=1.83$.

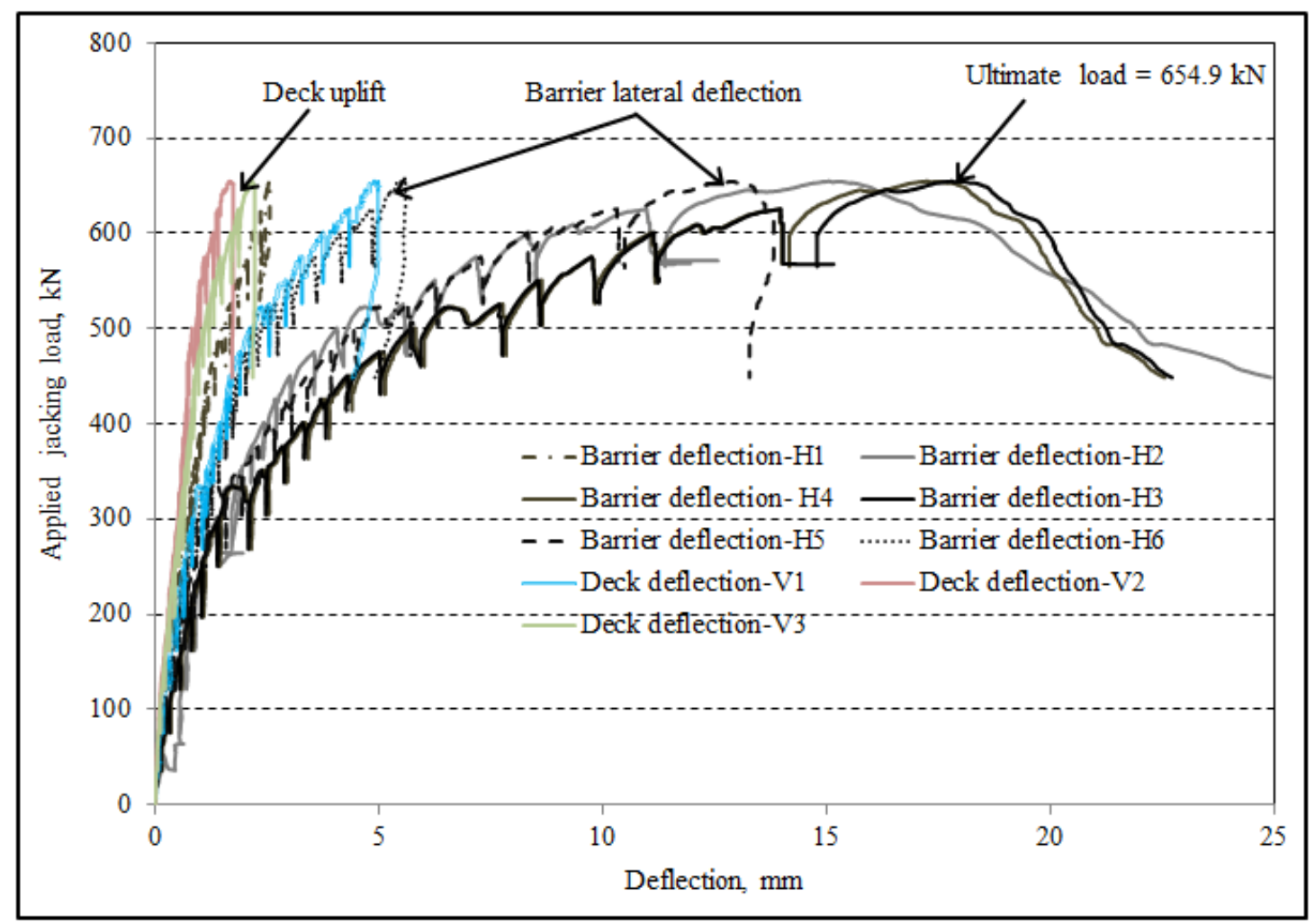

Figure 5. 24 Load-deformation relationships of barrier wall at interior location (see Figure 5.22 for deflection locations) 


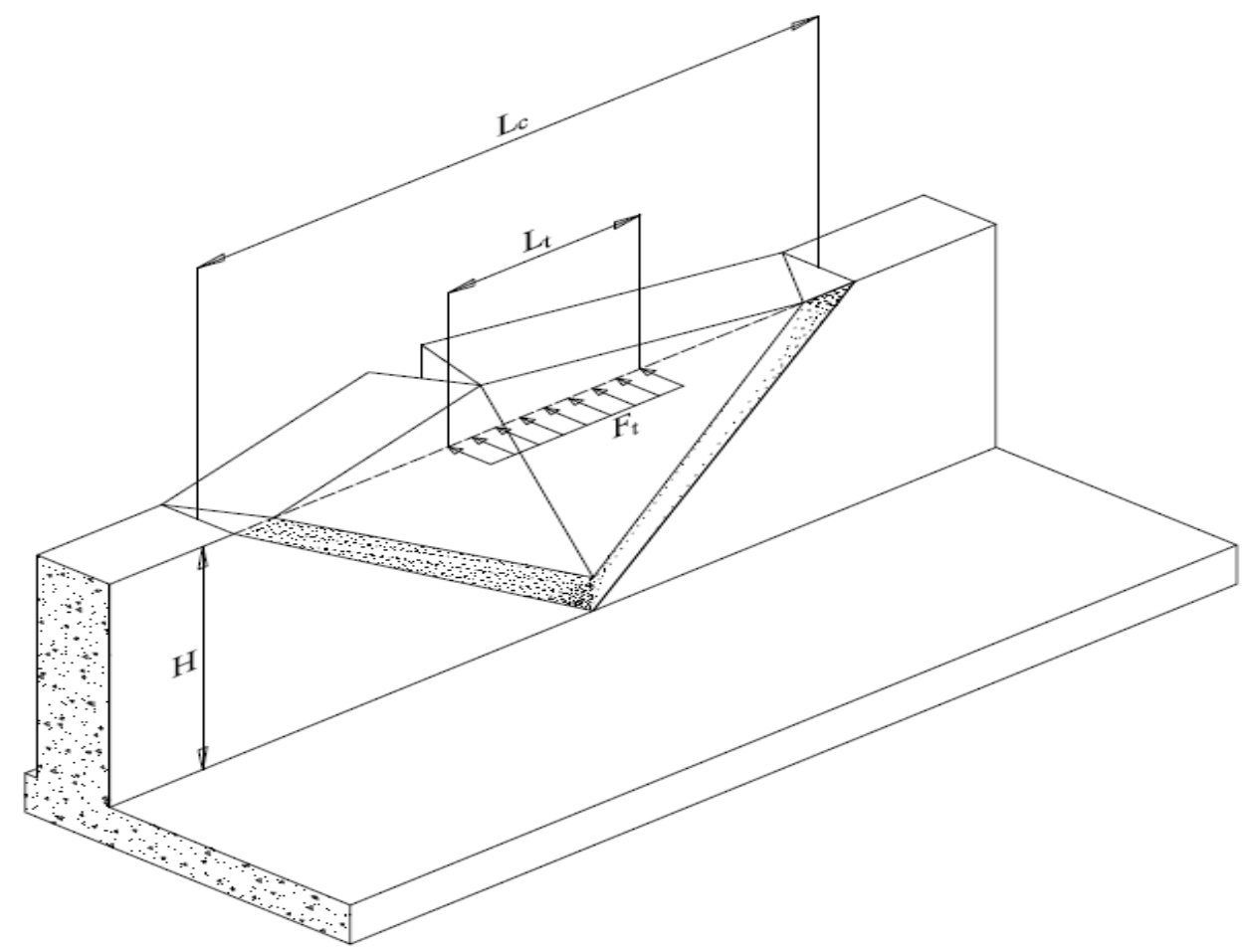

Figure 5. 25 AASHTO-LRFD yield-line failure patter at interior location

\subsection{Experimental Test Results over 2400-mm at Exterior Location}

The barrier wall was loaded at exterior location (a), shown in Figure 5.10, with a line load of 2400-mm length. The load was applied manually and cracks were marked at each $25 \mathrm{kN}$ load step. A first horizontal crack was observed at load of $300 \mathrm{kN}$ at deck-wall junction. At load range of $325 \mathrm{kN}$ to $375 \mathrm{kN}$, other horizontal cracks were observed in the wall portion, which were diagonally extended toward barrier interior location. Cracks were also developed at corner of the barrier at deck-wall interface at this load level. The barrier exhibited flexural cracks within the loaded length and diagonal shear cracks beyond the loaded length. Figure 5.26 shows photos of crack pattern at exterior location (a) at front and back faces of the wall. By increasing the applied load to $450 \mathrm{kN}$, other diagonal cracks were observed outside the line load region that were propagated through the wall thickness at top of the barrier and extended as shear-torsional cracks at back face of the wall. At this load, cracks were also developed at corner of the barrier at deckwall interface. However, sudden pullout failure occurred in the post-installed steel anchors embedded in the deck slab at transverse load of $463.3 \mathrm{kN}$. As such, this failure load was not considered as the failure of the barrier wall at exterior location (a). 


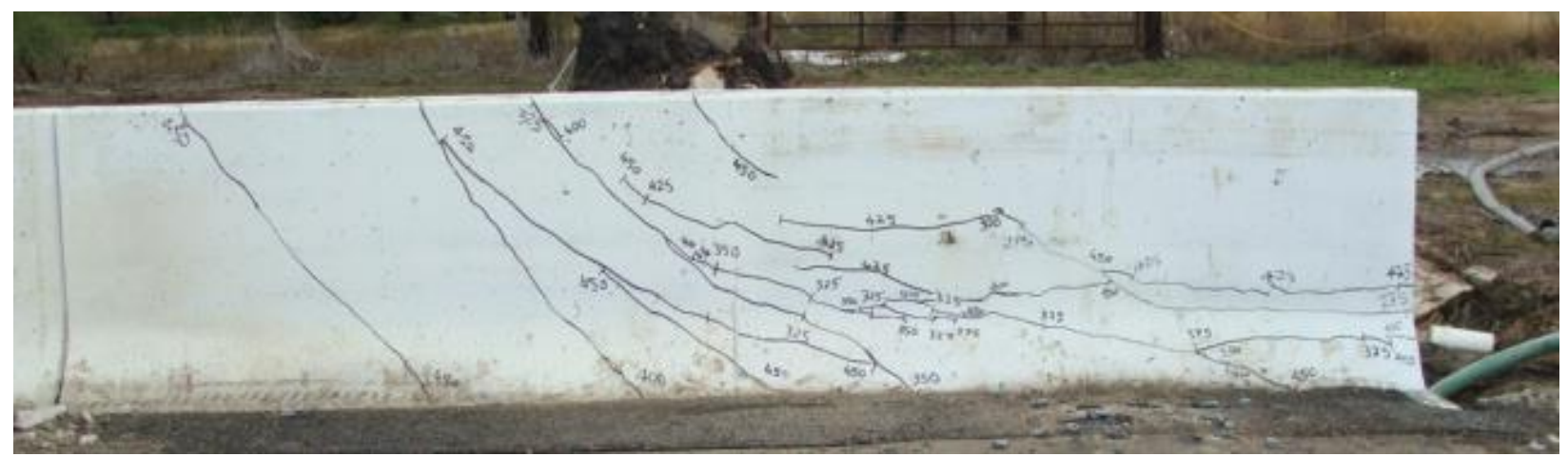

a) Elevation of crack pattern at barrier front face

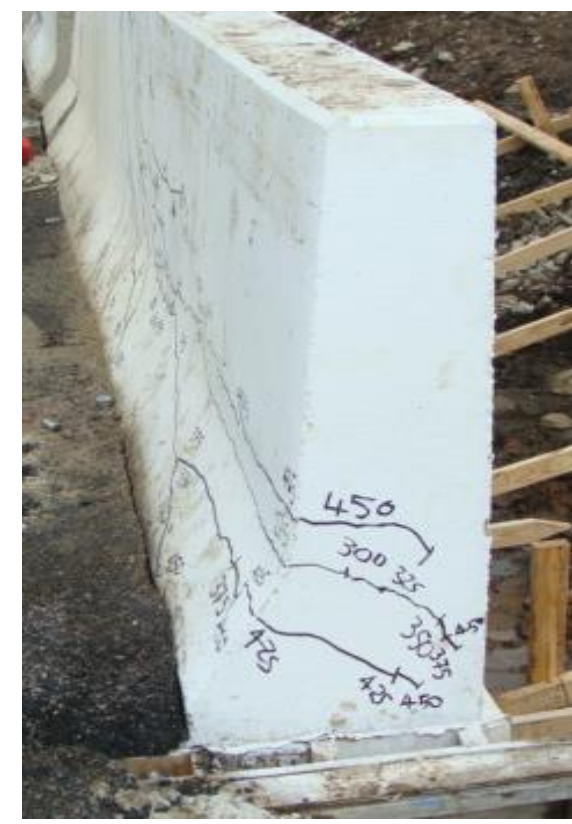

(b) Crack view at barrier corner

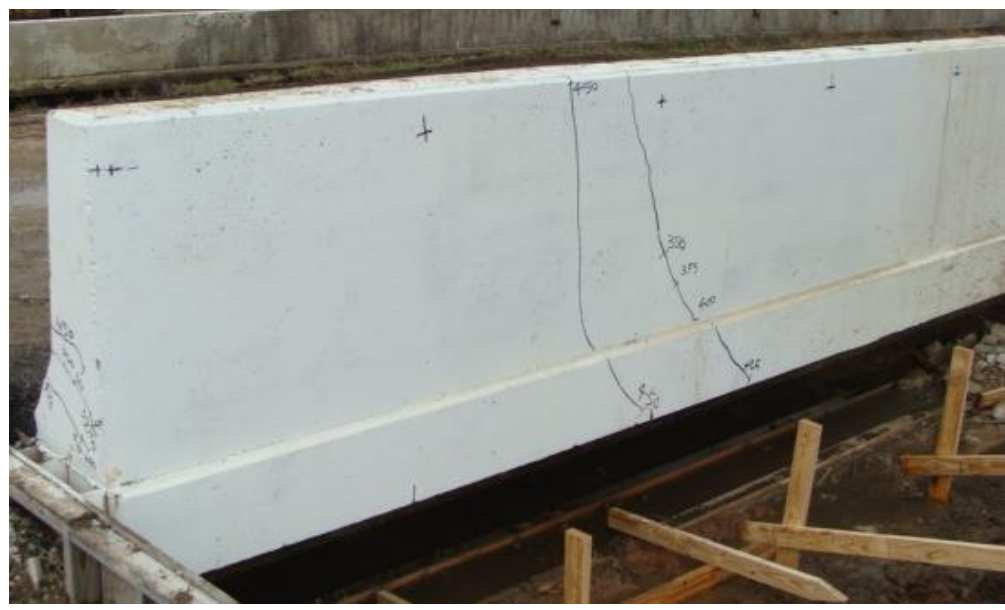

(c) Crack pattern at back face

Figure 5. 26 Crack pattern of barrier wall at exterior location

Figure 5.27 shows graphs of load-deflection curve at exterior location (a). It was observed that barrier exhibited a maximum lateral deflection of 20.46-mm at end location with a deck vertical deflection of 6.43-mm. Since the barrier at exterior location (a) did not fail, it was decided to test the barrier at another exterior location, denoted as exterior location (b) in Figure 5.10. It should be noted that at barrier location (a), spacing of the vertical bars at front face of the barrier was $150-\mathrm{mm}$ within a short length $(2560-\mathrm{mm})$ from end of the barrier. However, all vertical bars at exterior location (b) were at 300-mm spacing. The exterior location (b) was made by performing the barrier saw-cut near the 1-m barrier cantilever action test (Figure 5.10). 


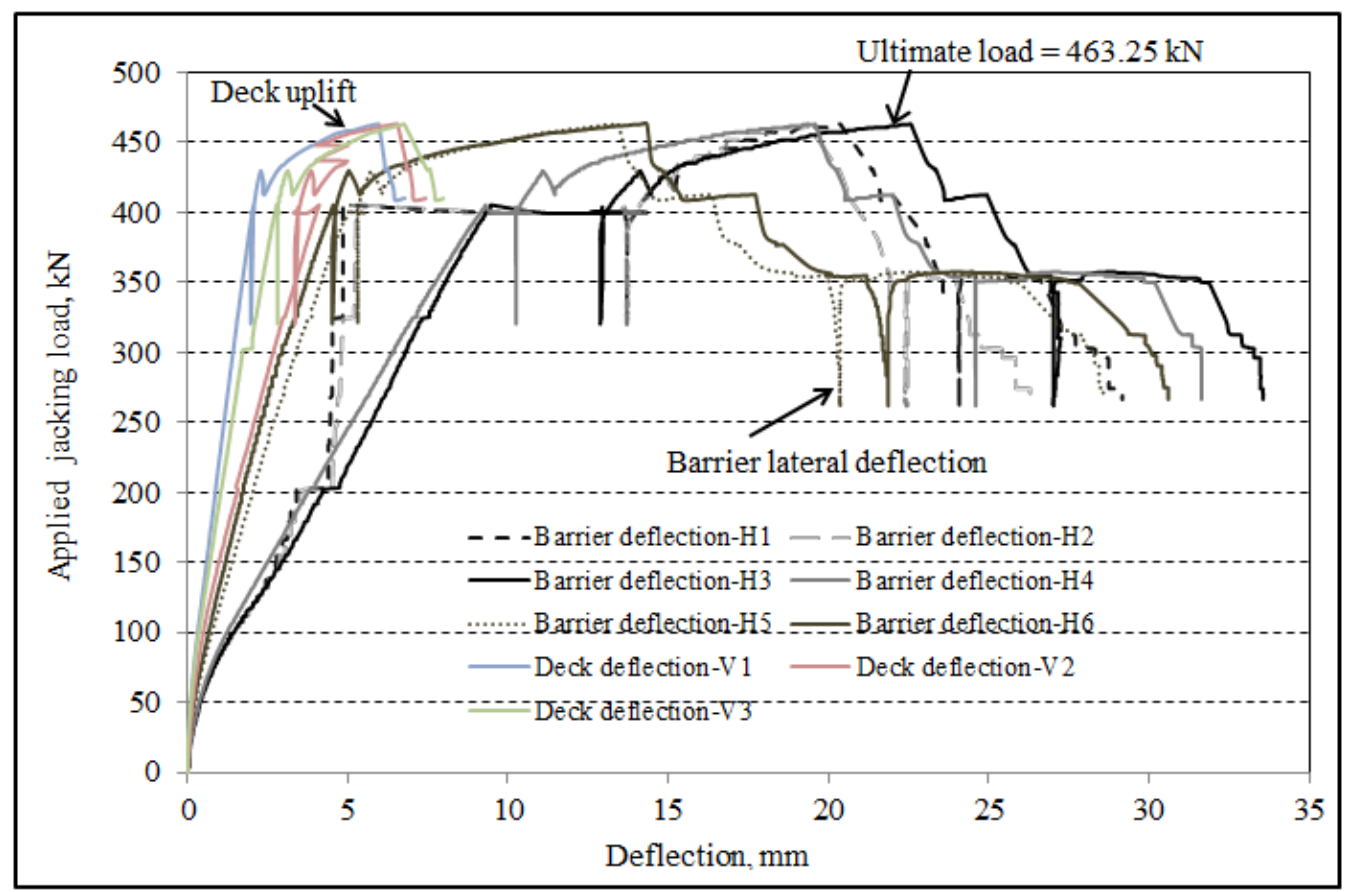

Figure 5. 27 Load-deformation relationships of barrier wall at exterior location (see Figure 5.22 for deflection location)

Figure 5.28 shows view of the sensor location in the new test location at exterior location (b). The piezoelectric strain gauges were also installed at back face of the wall to capture the compressive strains under the applied load. At exterior location (b), the transverse load was applied using an automated hydraulic jack to the barrier wall in $25 \mathrm{kN}$ steps. At each step, the load was maintained for few minutes to mark cracks on each face of the barrier wall. Figure 5.29 shows views of the crack pattern after failure at front and back faces of the barrier wall. It was observed that with increase in the applied load, horizontal flexural crack appeared at front face of the barrier wall-deck slab junction at $325 \mathrm{kN}$ load. Other horizontal cracks appeared at the intersection of the two tapered portions of the barrier wall at a load of $325 \mathrm{kN}$ as depicted in Figure 5.29(a). These cracks appeared within about half of the 2400-mm length of the applied line load, extending diagonally towards the barrier interior location as shown in Figure 5.29(b) and through the barrier thickness at end of the barrier as depicted in Figure 5.29(c). Some of these diagonal cracks reached the top surface of the barrier wall and propagated through the barrier thickness at a load of $450 \mathrm{kN}$ as depicted in Figure 5.29(d). Then, a punching shear crack appeared outside the loaded area and reached the top surface of the barrier wall at a load of 525 $\mathrm{kN}$ shown in Figure 5.29(d). 

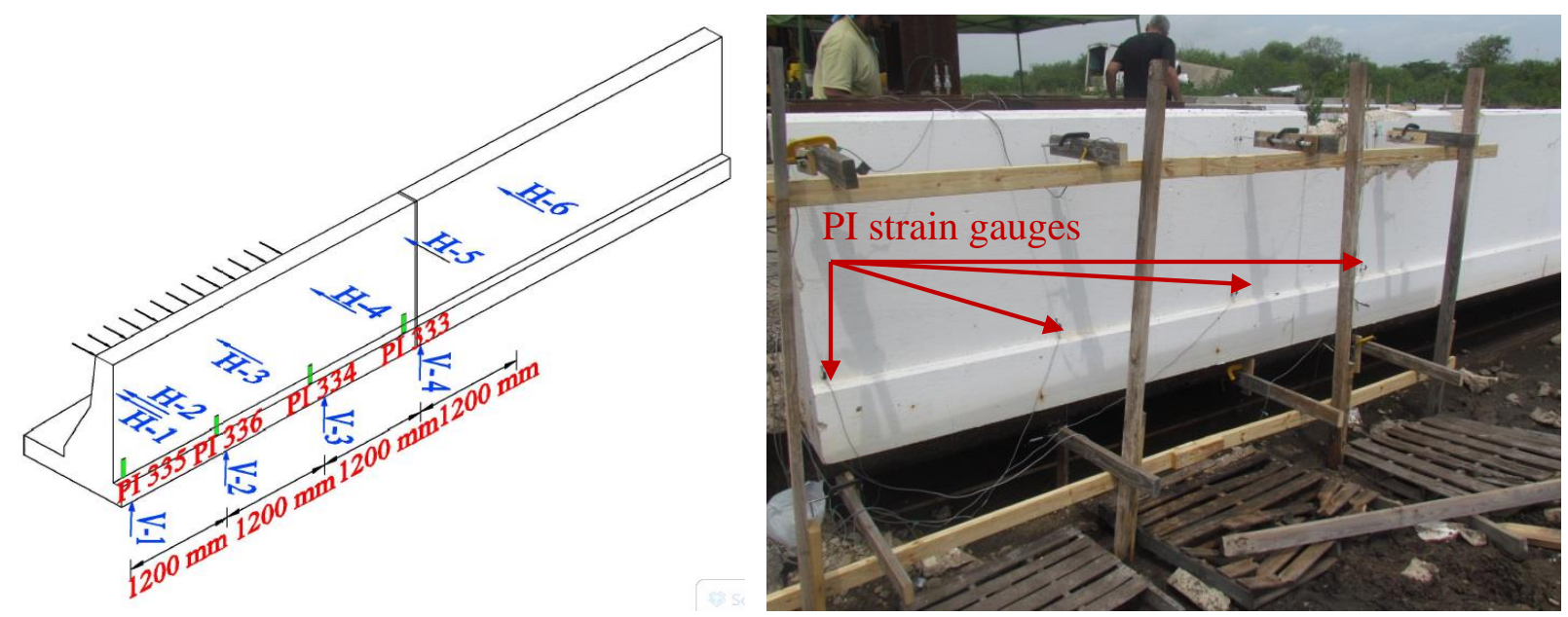

Figure 5. 28 Sensor locations in the new exterior location

With increase in the applied load, punching shear crack continued to appear at back face of the barrier shown in Figure 5.29(e). The test ended when the barrier wall could not absorb load more than $541 \mathrm{kN}$. Figure 5.29(e) shows few diagonal torsional-shear cracks appearing at back face of the barrier wall and extending to the deck slab causing wide torsional-shear crack in the deck slab (appeared at the bottom right corner of Figure 5.29(e). Figure 5.30 shows load-deflection relationship for the barrier wall loaded at its end. It can be observed that barrier wall had a maximum lateral deflection of $26.67-\mathrm{mm}$ at outer point of the line load, decreasing to $15.02-\mathrm{mm}$ at inner side of the line load and to $11.9-\mathrm{mm}$ at a $2400-\mathrm{mm}$ distance from the inner side of the line load. It can also be noticed that the crack pattern contradicted with the AASHTO-LRFD crack pattern (see Figure 5.31), where the exterior portion of the barrier wall, approximately half of the loaded length, acted as a cantilever while the rest of the loaded length acted as two-way slab transferring the load to the deck slab and the unloaded length of the barrier wall. Also, the failure mode was primarily followed by punching shear of the barrier wall. Given the fact that the CHBDC design factored is $357 \mathrm{kN}$, the factor of safety for such loading with ultimate load at failure equal to $541 \mathrm{kN}$ was $541 / 357=1.52$. 


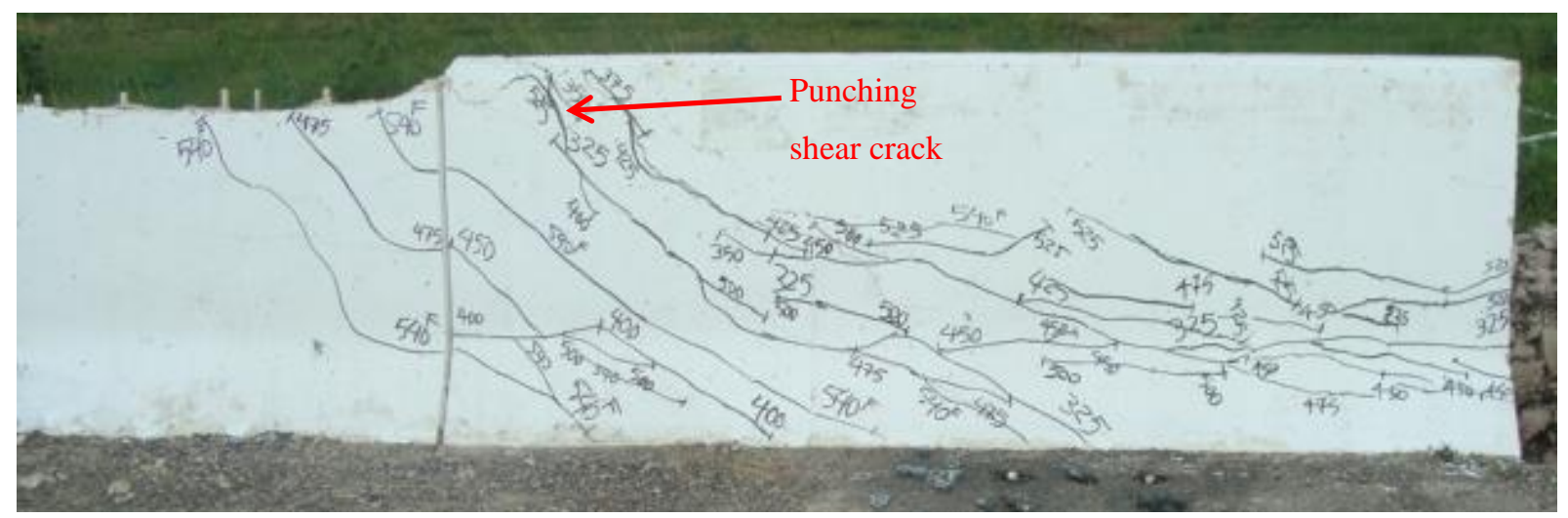

a) Crack pattern at barrier front face
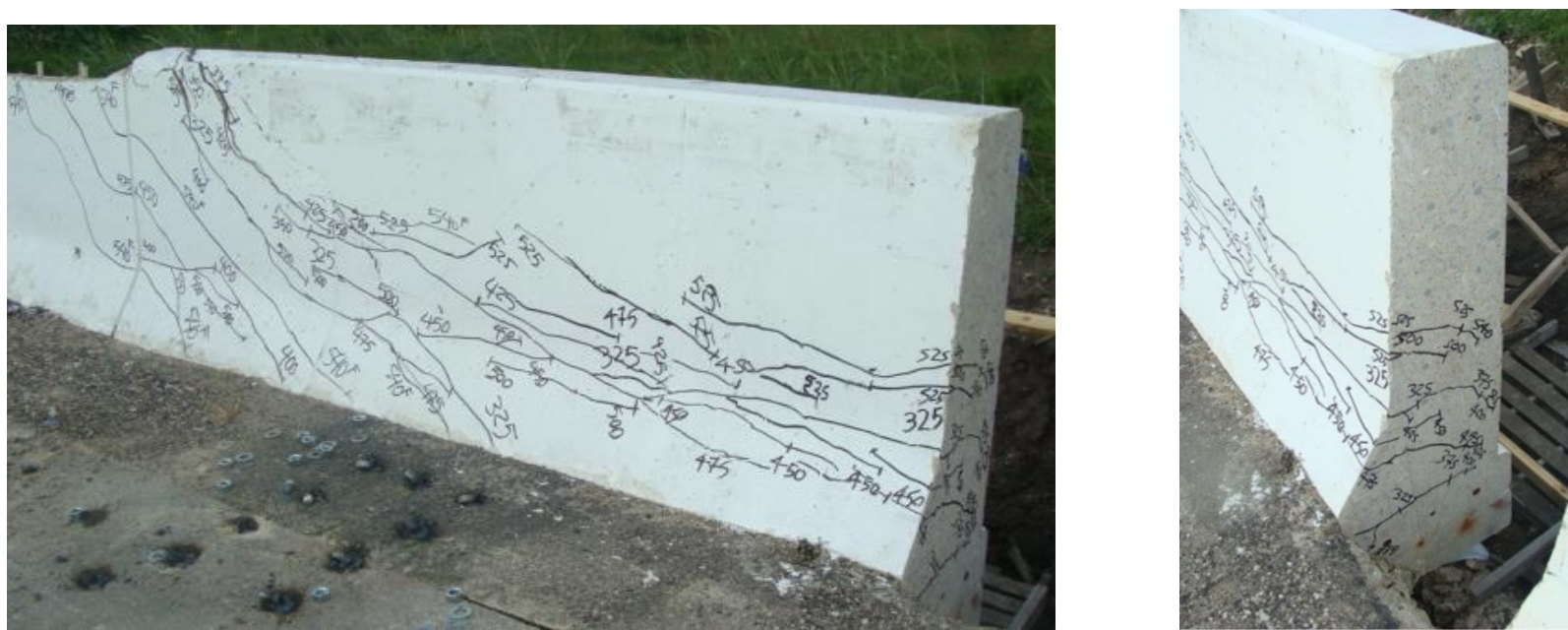

b) Crack pattern showing shear location

c) Cracks at barrier end

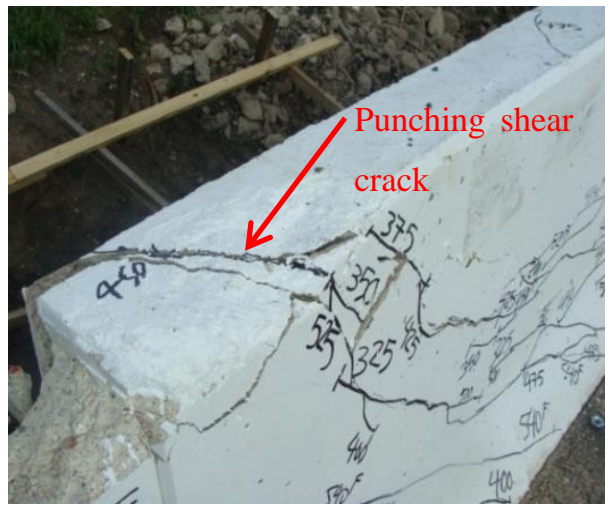

d) Close-up view of punching shear crack

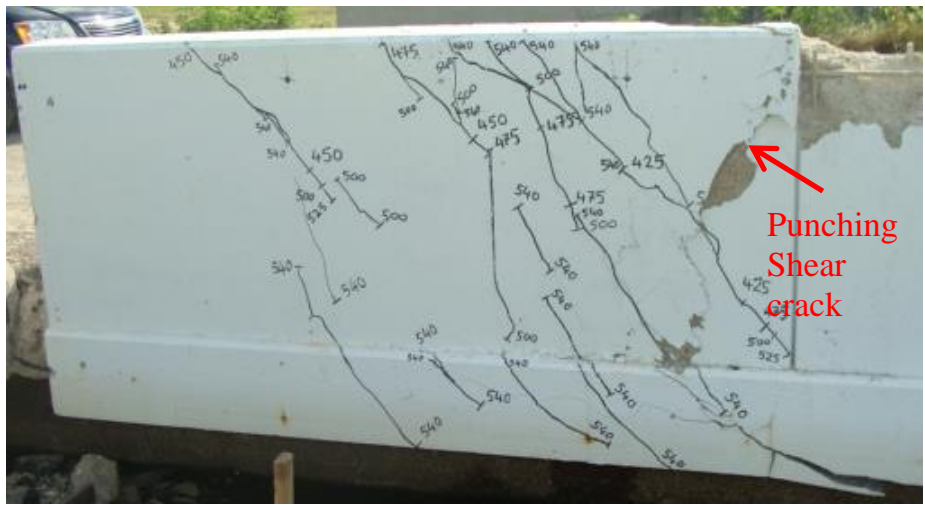

e) Crack pattern at barrier back face

Figure 5. 29 Crack pattern of barrier wall at exterior location 


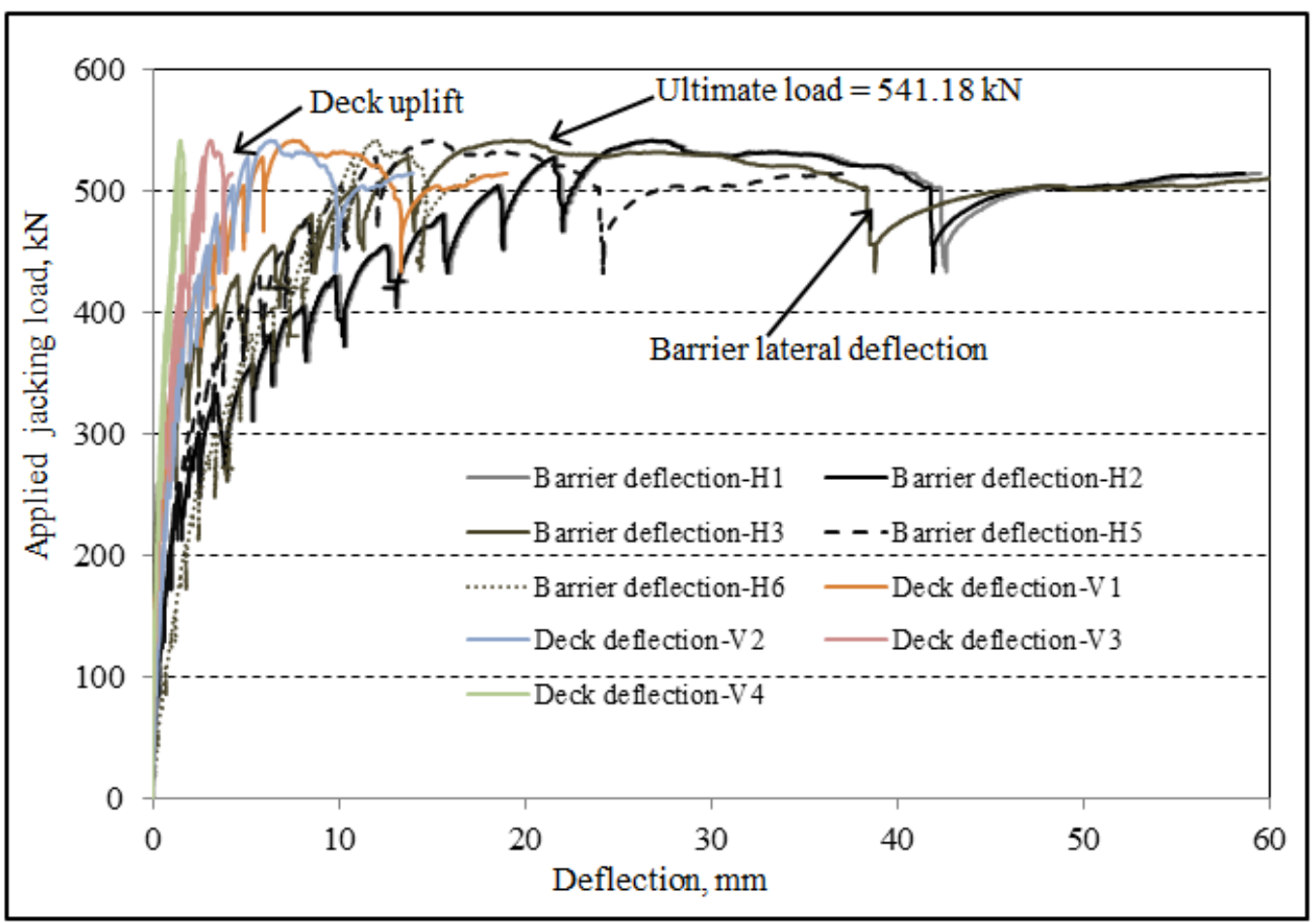

Figure 5. 30 Load-deformation relationships of the barrier wall at exterior location (see Figure 5.22 for deflection locations)

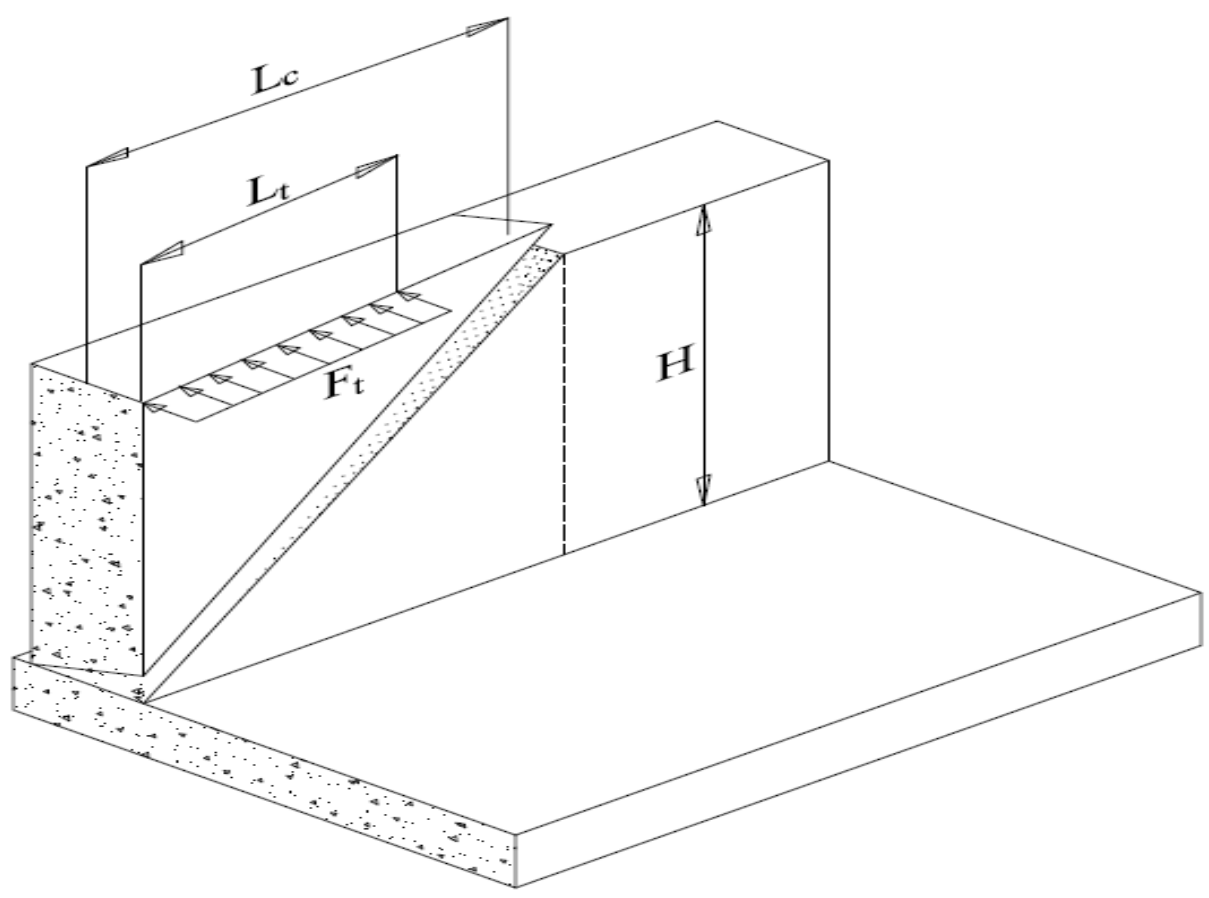

Figure 5. 31 AASHTO-LRFD yield-line failure patter at exterior location 
The strain gauges placed at back face of the barrier wall showed a maximum compressive strain at failure of $-55 \mu \varepsilon$, which was considered significantly smaller than the concrete crushing strain of $-3500 \mu \varepsilon$. As such, it can be concluded that the reinforcement provided sufficient strength to prevent concrete crushing. Figure 5.32 shows graphs of the load-strain curve for the tested barrier at exterior location (b).

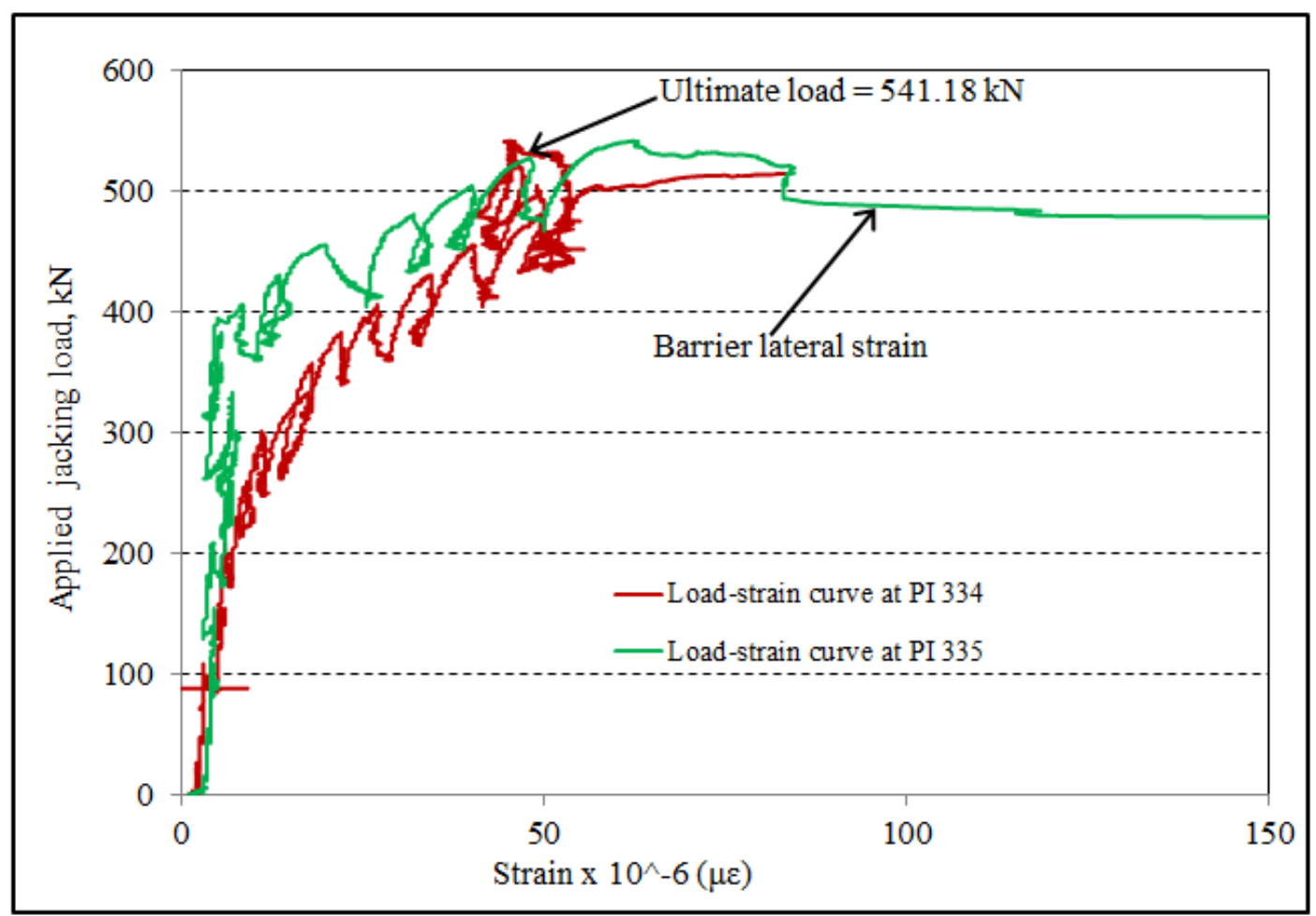

Figure 5. 32 Load-horizontal concrete strain curves at back face of the barrier wall

\subsection{Experiment Test Results over 1000-mm Length at Interior Region}

Experimental tests were also carried out on 1000-mm length of the proposed barrier wall. The test was conducted to investigate one-way action of the barrier under monotonic increasing load. Two scenarios were considered namely as loading the 1-m long barrier at interior region where reinforcement were placed on 300-mm centre-to-centre spacing, and then the same test was performed at end region of the barrier wall with centre-to-centre spacing of the reinforcement equal to $150-\mathrm{mm}$. In case of interior region, the barrier wall shown in Figure 5.10 was saw-cut at location between second and third construction joint. It should be noted that $500-\mathrm{mm}$ of the barrier was saw-cut on each side of 1000-mm long barrier so that the tested barrier wall acted 
independently. Figure 5.33 shows vertical marks inserted on the wall and Figure 5.34 and 5.35 show photos during saw-cutting and removal of concrete and reinforcement in the wall. The barrier specimen was tested under increasing monotonic load up-to-collapse. During the test, jacking load was applied in increment of $20 \mathrm{kN}$ up to the failure. At each load increment, the load was maintained for few minutes to observe crack initiation and propagation as well as displacement recorded by the POTs. Figure 5.36 shows views of the crack pattern of tested barrier wall. The barrier model experienced first horizontal flexural cracks in the barrier-to-deck slab interface. It can also be observed that flexural crack appeared at tapered part of wall at 130 $\mathrm{kN}$ jacking load. Cracks propagated into the wall thickness and deck portion at the same load level. Further increase in the load caused failure of the tested barrier wall at ultimate load of 141 $\mathrm{kN}$. Although flexural cracks appeared in the barrier wall and deck slab, failure of the barrier occurred due to bar anchorage failure. Taking into account the failure load of $83 \mathrm{kN} . \mathrm{m} / \mathrm{m}$ specified in CHBDC (2006) code (see Table 2.11) at interior region of the barrier wall and over 1000-mm long barrier, a factor of safety of $141 * 0.990 / 83$ equal to 1.68 could be achieved.

Under increasing the applied load, the wall experienced lateral movement. Figure 5.37 shows side views of the deformed barrier wall after failure. It can be noticed that maximum lateral deflection of the wall appeared at the tip of the wall. This can be clearly seen in Figure 5.37 from side views. Figure 5.38 shows load-deflection curves of the barrier wall and deck slab uplift. It can be observed from curves that the wall experienced average lateral deflection of $48.7-\mathrm{mm}$ showing large lateral deflection of the wall. This can be attributed to low modulus of elasticity and higher deformability index of GFRP bars compared to its steel reinforcement counterpart. The deck slab was also experienced an average vertical displacement of 23.34-mm. Due to large deflection of the wall, deck slab performed larger rotation resulted in larger vertical displacement of the deck slab. 


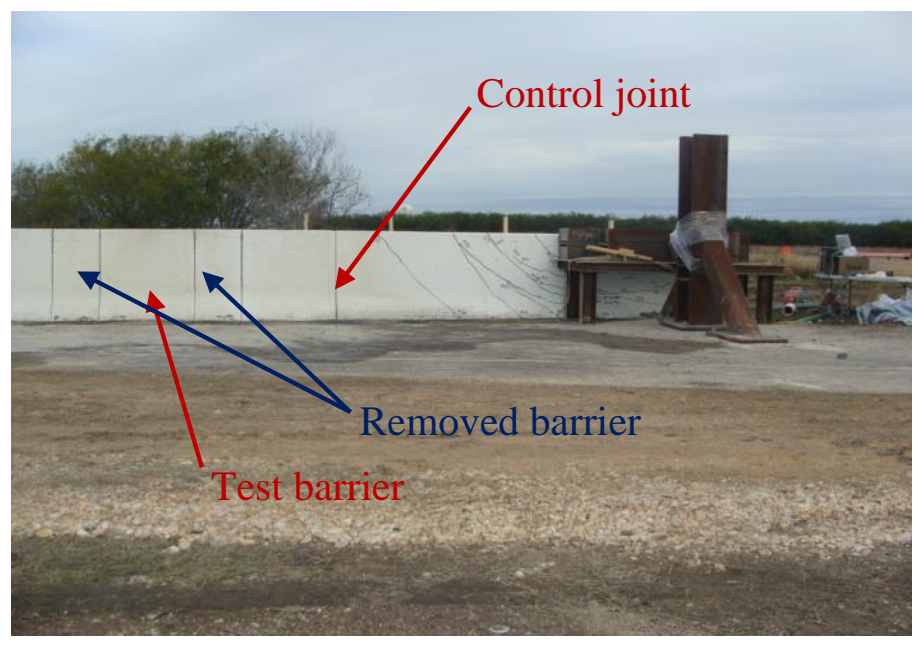

Figure 5. 33 Marked barrier wall prior saw-cutting

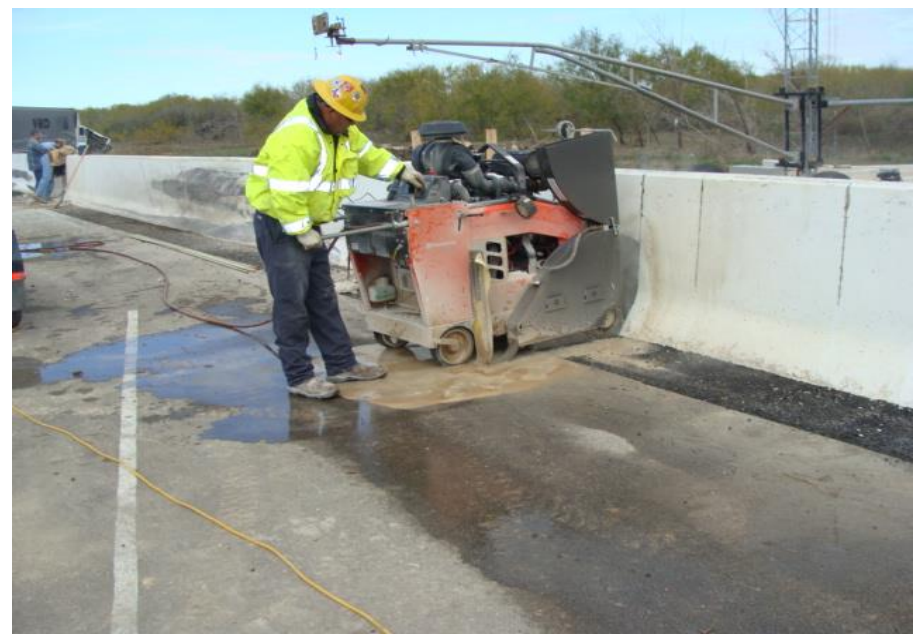

Figure 5. 34 Saw-cutting of the barrier wall

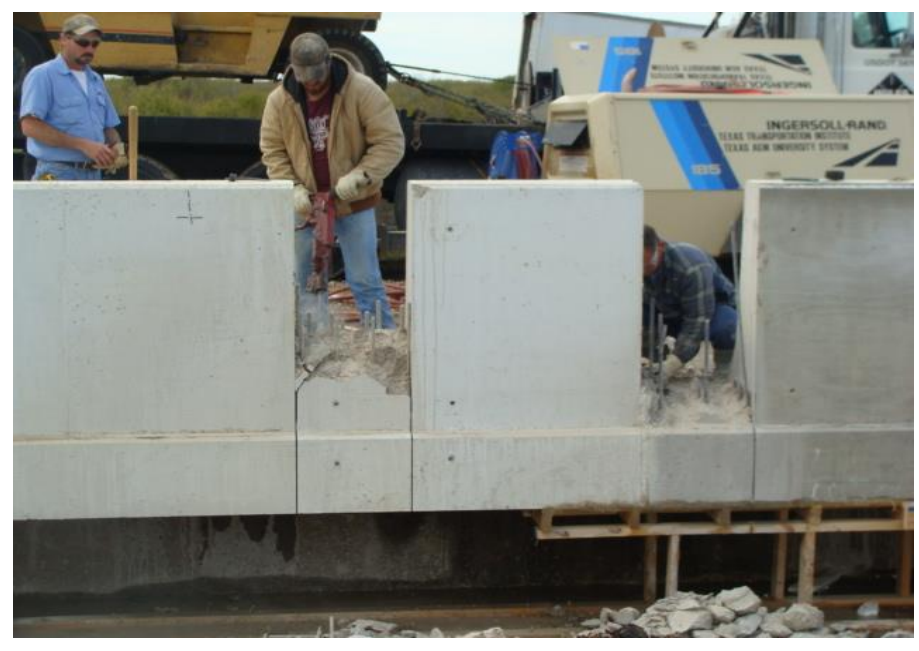

Figure 5. 35 Barrier and reinforcement removal over 500-mm on each side of test barrier 


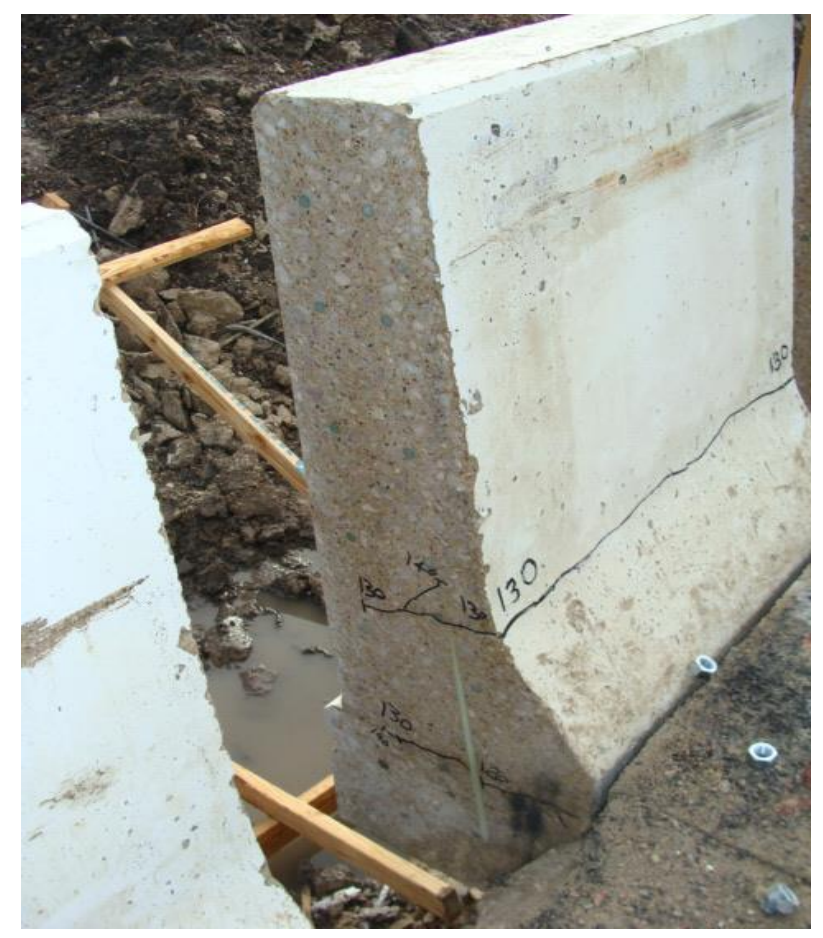

(a) Cracks at front face

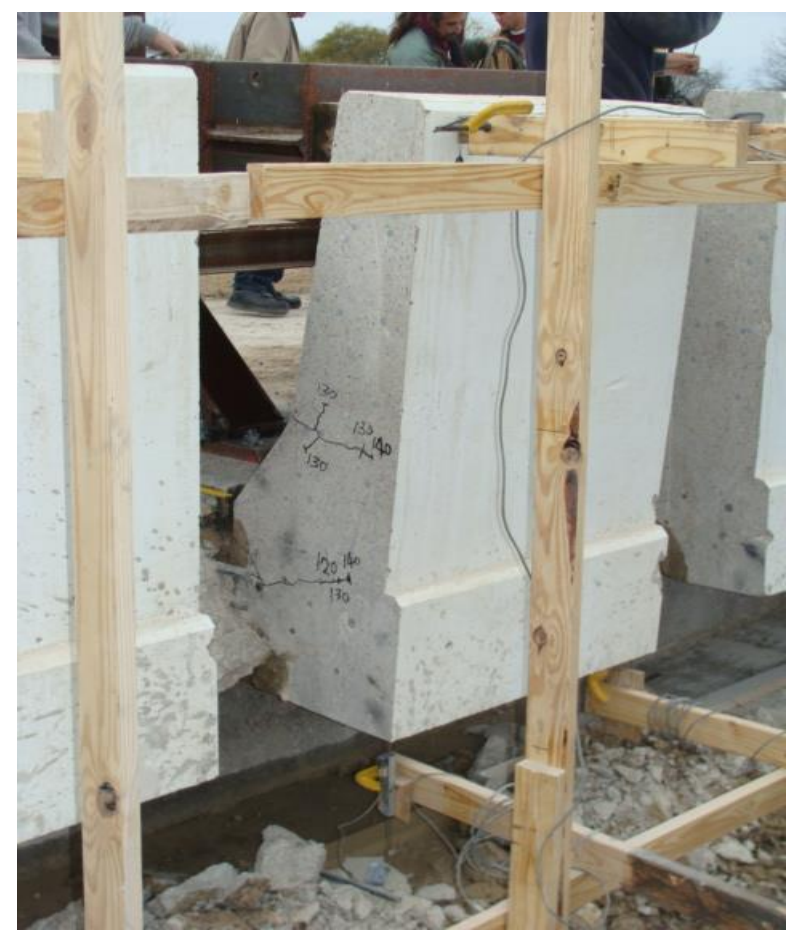

(b) Extended corner cracks

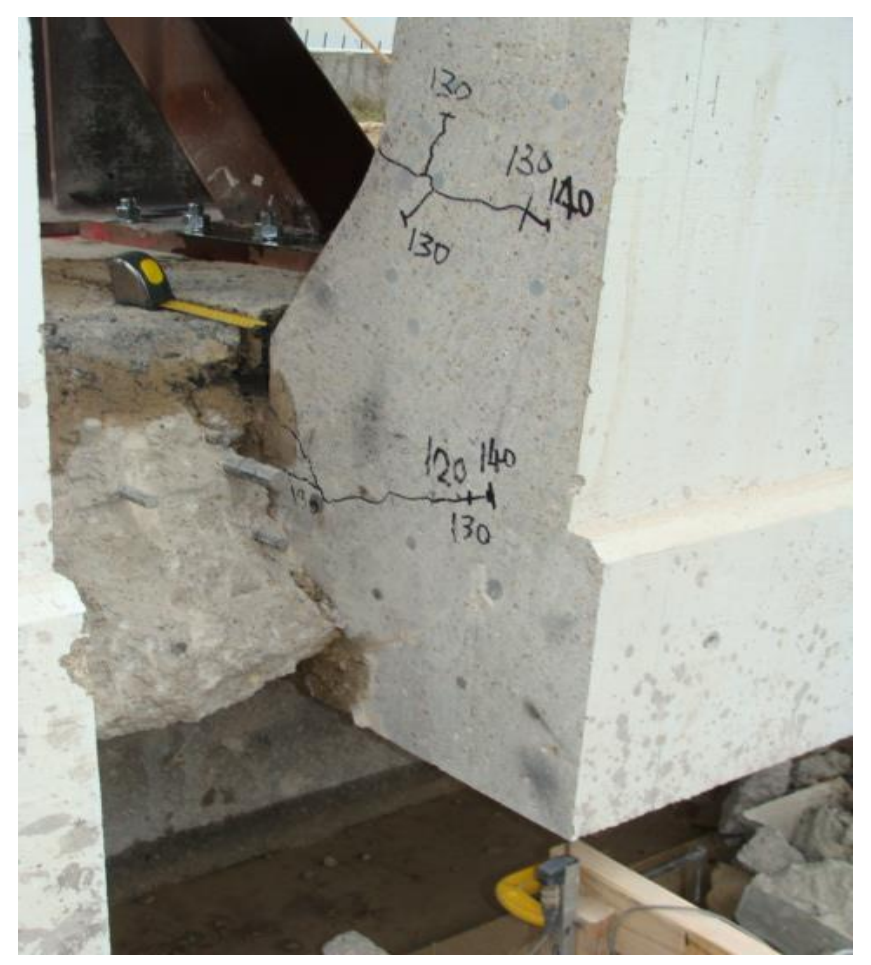

(b) Close up view of corner cracks

Figure 5. 36 Crack pattern over 1-m length of the barrier at interior region 


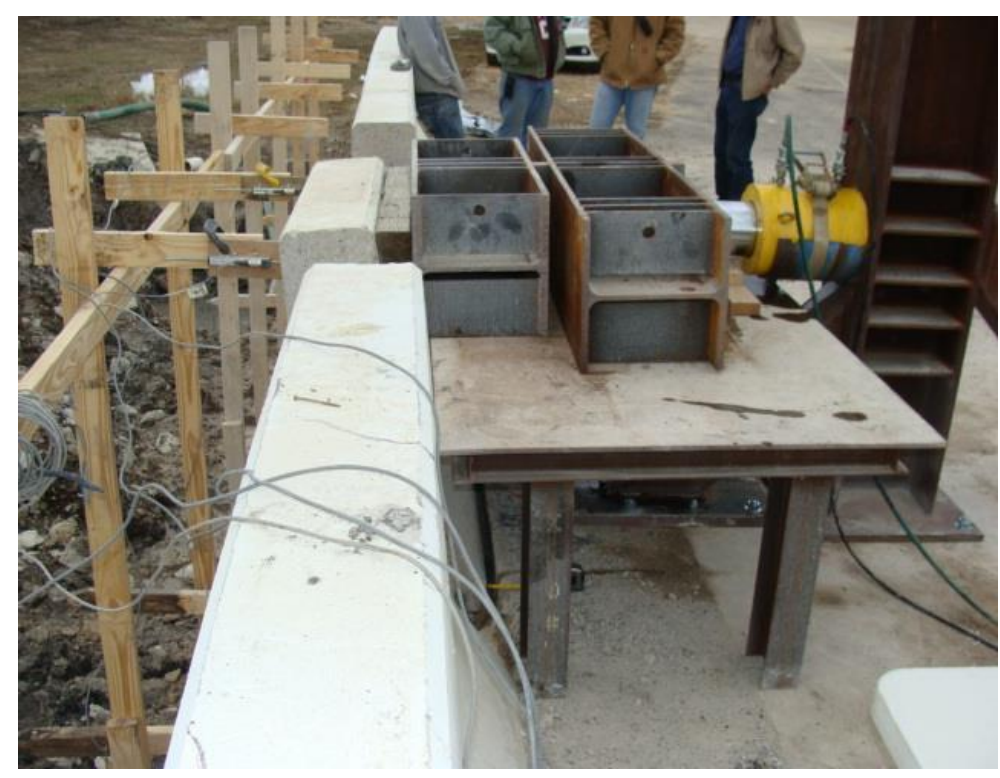

(a) Left view

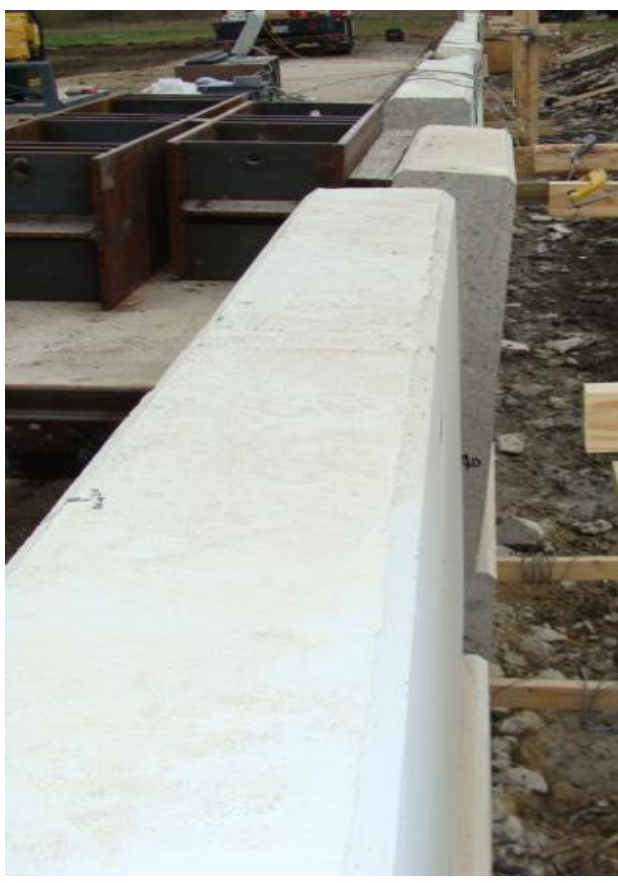

(b) Right view

Figure 5. 37 Wall lateral deformation after failure

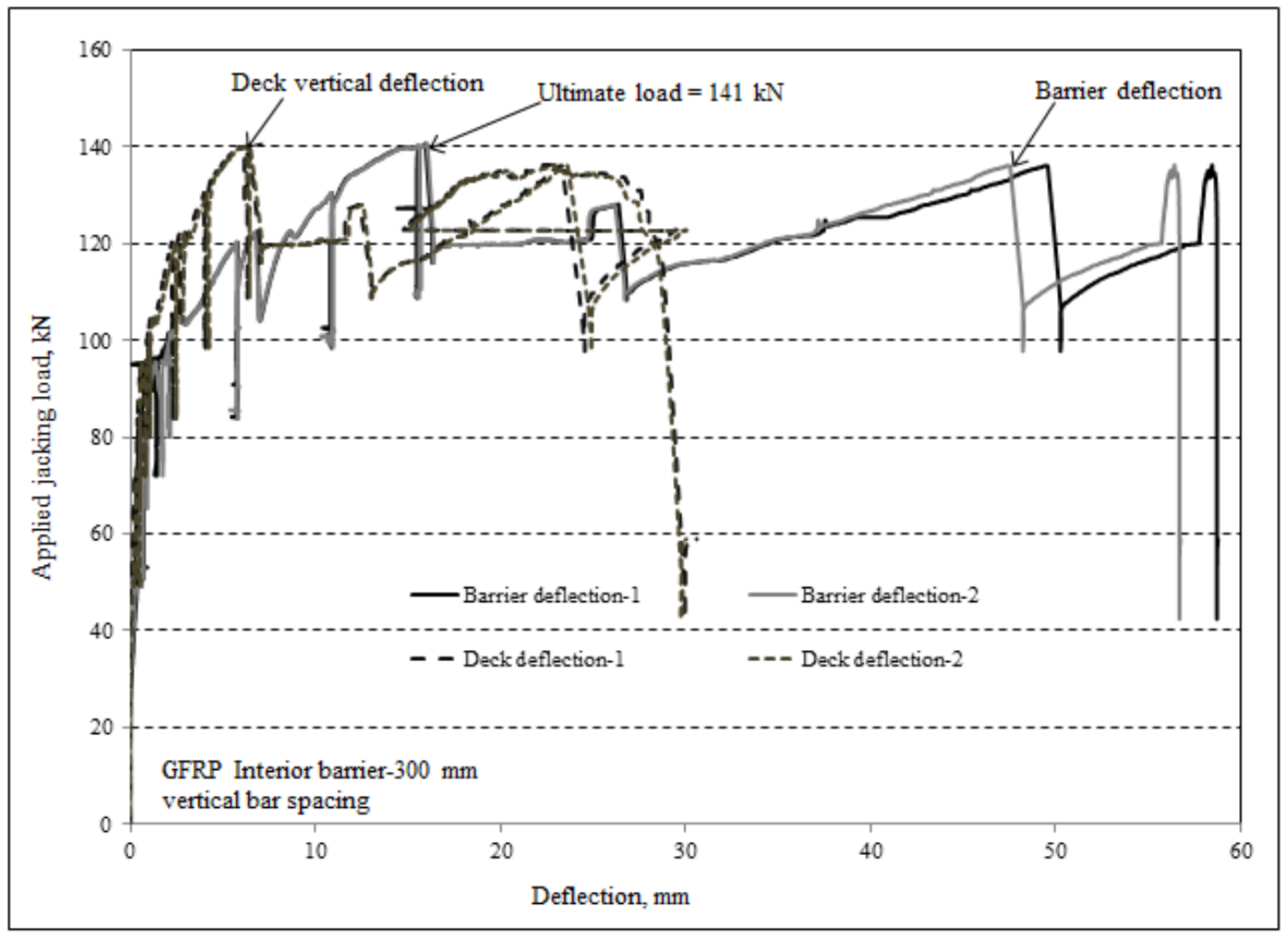

Figure 5. 38 Load- deformation curve of barrier wall and deck slab over 1000-mm long barrier at interior region 


\subsection{Experiment Test Results over 1000-mm Length at Exterior Region}

Experimental test was also performed over 1000-mm length of the barrier at end location where the centre-to-centre spacing of GFRP bars were $150-\mathrm{mm}$. The load was applied at 990-mm above the deck slab per CHBDC for PL-3 barriers tested under static test. The load was applied using automated hydraulic jack and load increments were captured by load-cell attached to the system. The load was applied in the increment of $20 \mathrm{kN}$ to observe crack initiation and crack propagation in the barrier wall and the deck slab. Barrier shown in Figure 5.10 was saw-cut at the left end region. Figure 5.39 shows marked location on the barrier prior to saw-cutting. It should be noted that the construction of 27.6-m long PL-3 barrier built at TTI were continued on the left edge using steel reinforcing bars. Further static test was scheduled to conduct on this PL-3 steel barrier to experimentally investigate and validate bridge barrier failure by yield-line theory. By applying load, the first flexural crack was appeared at tapered portion of the wall at load of $115 \mathrm{kN}$ (Figure 5.40a). By increasing the load, crack was further developed and extended into the wall thickness at load of $130 \mathrm{kN}$. Figures 5.40a and 5.40b illustrate crack initiation at tapered portion of the wall which was developed further at edges of the wall. The load was applied to increase until the failure occurred at load of $152.46 \mathrm{kN}$. At this failure load, a large crack appeared at deck-wall junction that can be seen in Figure 5.40c. This crack can be an indication of anchorage failure of the GFRP bars due to the applied load. Given the fact that the failure load in CHBDC code (Table 2.11) over 1000-mm long barrier at end location is $102 \mathrm{kN}$, the wall experienced a factor of safety against failure of $152.46 * 0.990 / 102$ equal to 1.48 . Testing $1000-\mathrm{mm}$ long barrier wall confirmed one-way action of the wall under the applied load. The term one-way action represents that horizontal cracks appear at either tapered part of the wall or deck-wall junction. However, it has not been observed any diagonal cracks in both 1-m long tested barrier walls. At failure stage, the wall experienced its maximum deflection at the top that can be clearly seen in Figure 5.41. Load-deflection curves of the barrier wall and deck vertical displacement is shown in Figure 5.42. Due to appearance of large crack at deck-wall junction, the wall showed relatively a large deflection of 79.23-mm which confirmed the anchorage failure of the GFRP bars. This can also be attributed to low modulus of elasticity and deformability index of the GFRP bars. As a matter of large deflection of the wall, the deck slab was also subjected to a vertical displacement of 44.12-mm. 


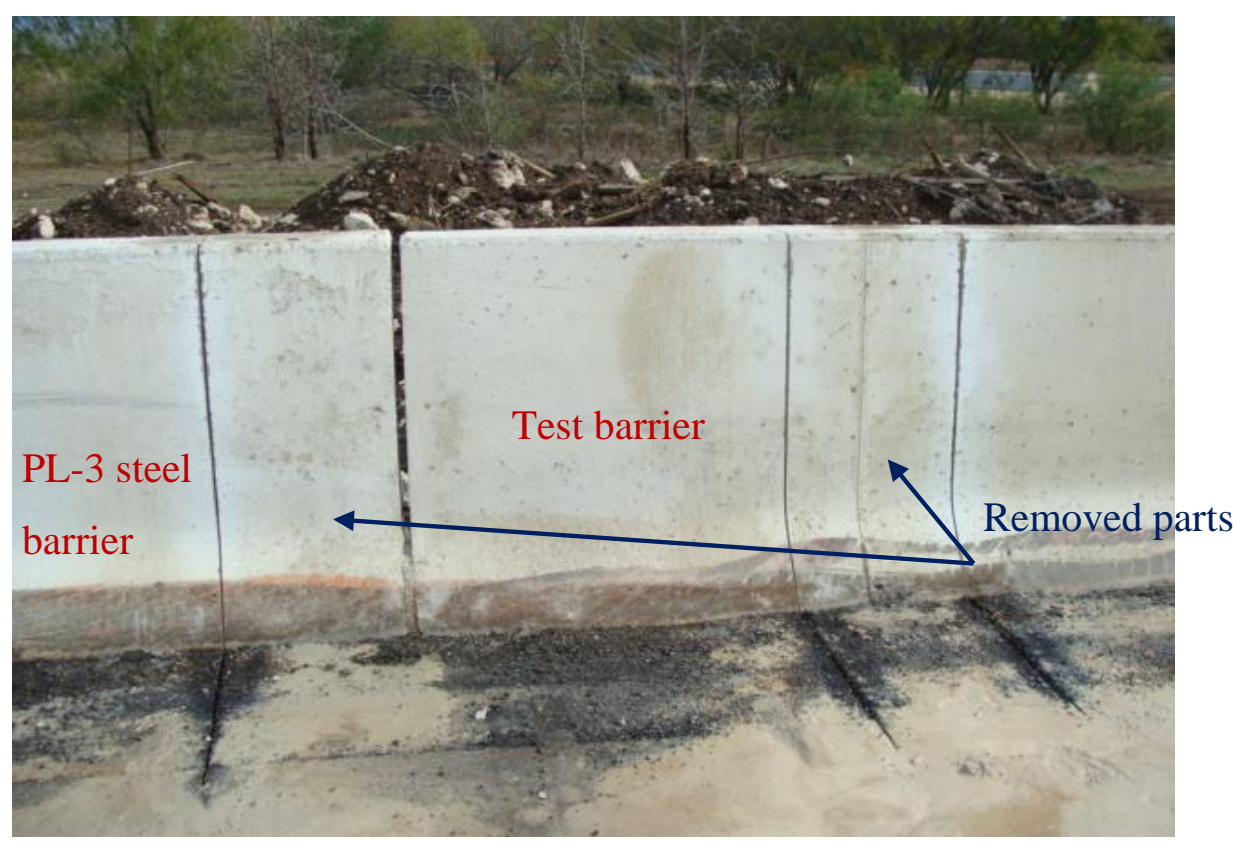

Figure 5. 39 Marked location of barrier end location prior saw-cutting

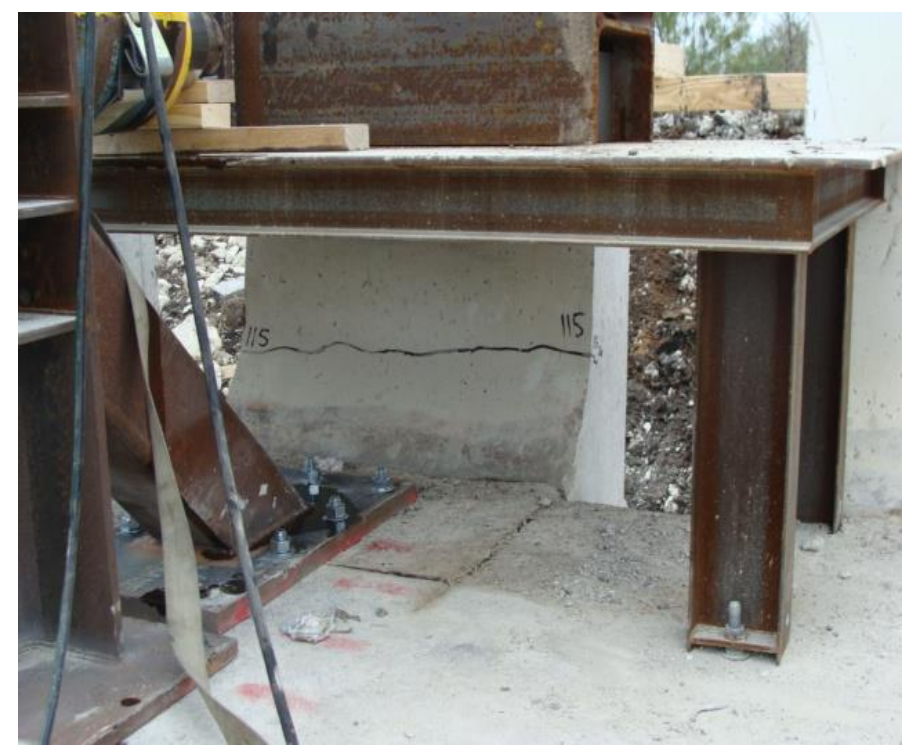

(a) Crack at front face

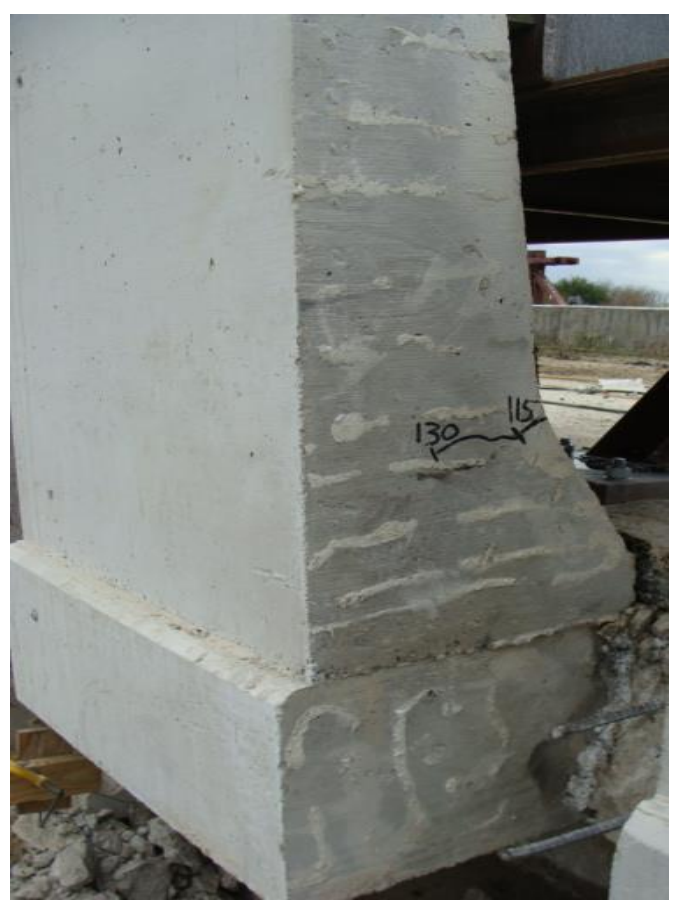

(b) Corner crack 


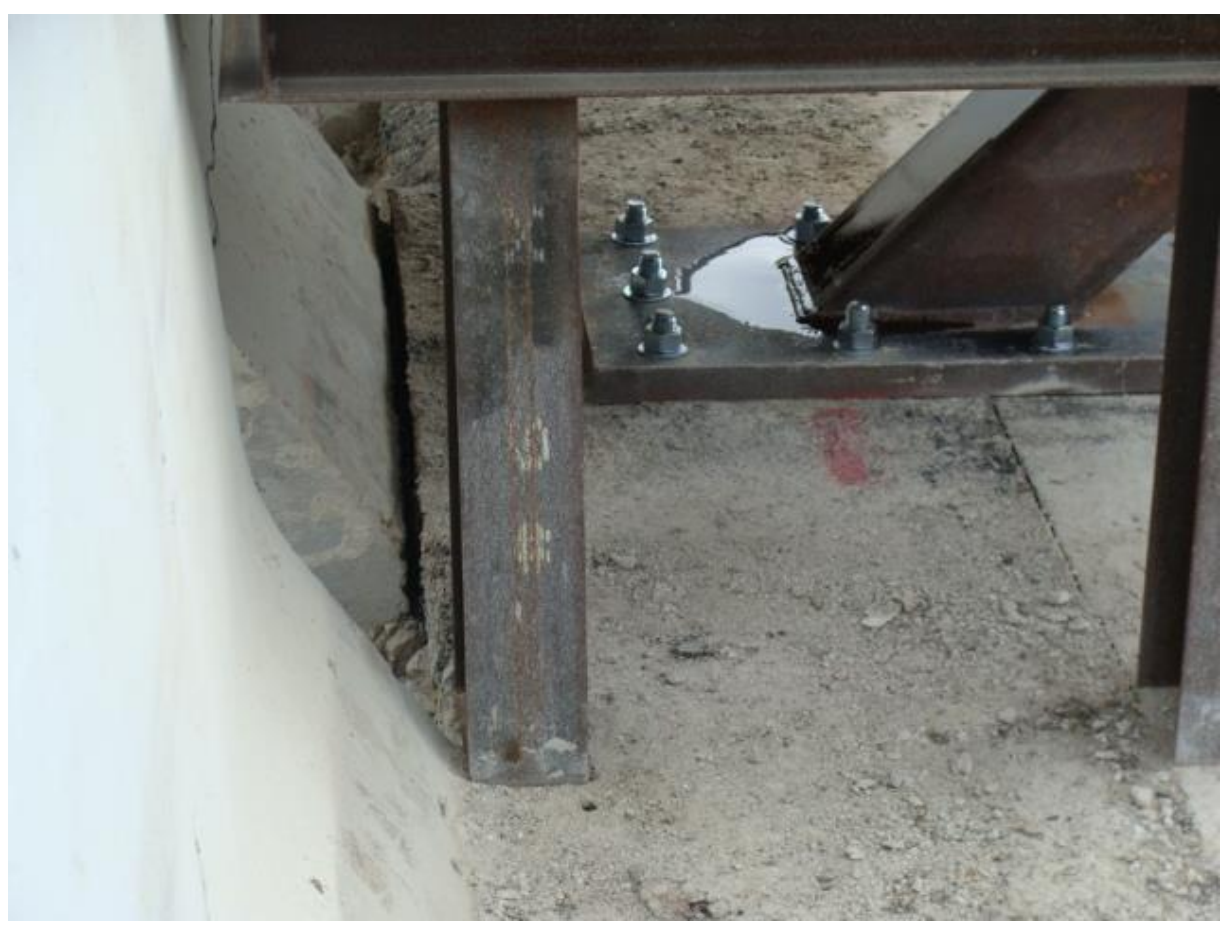

(c) Flexural crack at deck-wall junction

Figure 5. 40 Crack pattern over 1-m length at exterior region
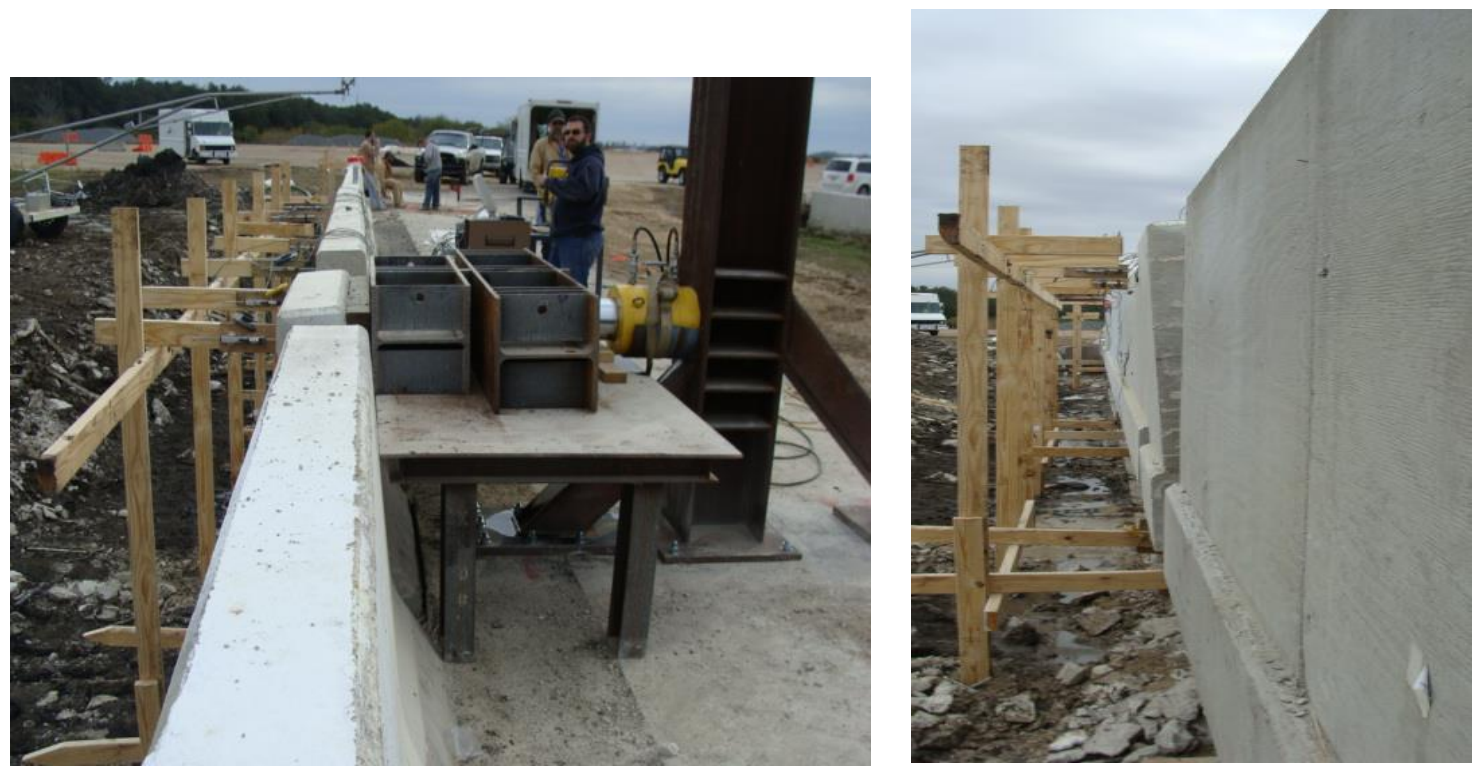

(a) Side view of wall deformation

(b) back face view of wall deformation

Figure 5. 41 Lateral deformation of wall under the applied load 


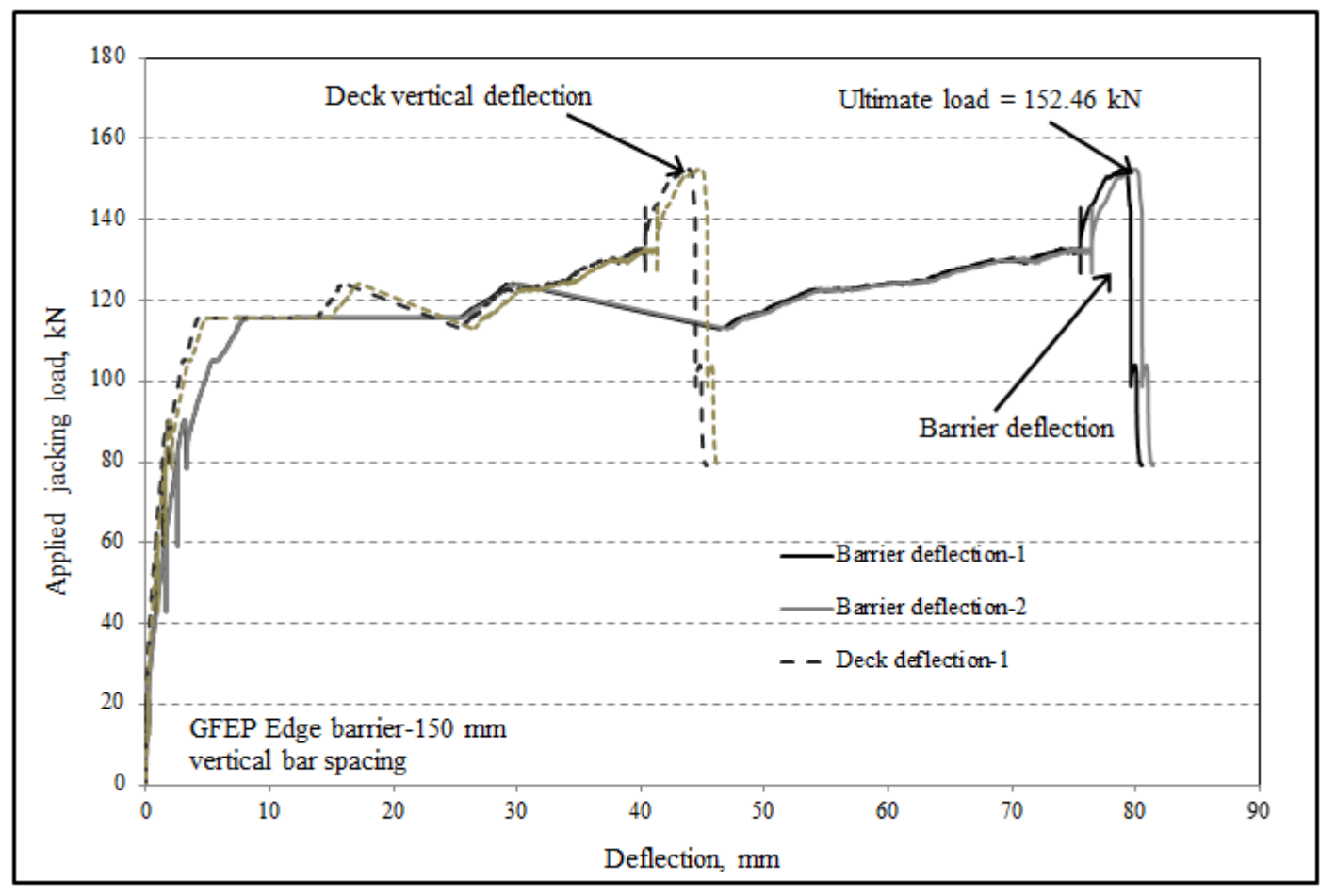

Figure 5. 42 Load- deformation curve of barrier wall and deck slab at end location over $1 \mathrm{~m}$ long barrier

Table 5.1 provides summary of the experimental test results. For barriers tested by cantilever action over 1-m length, the flexural moment at interior and end regions were calculated using the proposed equations provided in Table 4.12. The summary of this finding was also provided in Table 5.1. Moment at interior and end regions were calculated for a cantilever deck length of 700 -mm, deck thickness of 360-mm and barrier length of 1000-mm per experimental tested barriers. The proposed equations yielded moment at base of the wall equal to 124.1 and 141.73 $\mathrm{kN} . \mathrm{m} / \mathrm{m}$ for interior and end regions, respectively. Comparing these results with experimental failure moment, a factor of safety of 1.12 and 1.06 at interior and end regions can be obtained. Thus, it can be observed that the proposed equations provided in Table 4.12 reasonably estimated the ultimate strength of the tested 1-m long PL-3 barriers. When comparing the proposed moments with the CHBDC limits, it can be observed that CHBDC underestimates the ultimate strength of the wall by $49 \%$ and $39 \%$ at interior and end regions, respectively, which can be considered quite large. However, the experimental test results showed a minimum factor of safety of 1.48 based on CHBDC limits confirming sufficient strength of the proposed barrier 
wall shown in Figure 5.8. As mentioned earlier, the proposed barrier was previously crash tested and passed the requirements of CHBDC for overall structural adequacy, occupant risk and vehicle trajectory after a collision. As such, based on static and crash test results, the proposed barrier can be safely used in the construction of PL-3 bridges in Canada.

Table 5. 1 Summary of experimental results

\begin{tabular}{|l|c|c|c|c|}
\hline \multirow{2}{*}{} & \multicolumn{2}{|c|}{ Two-way action test } & \multicolumn{2}{c|}{ One-way action test } \\
\cline { 2 - 5 } & $\begin{array}{c}\text { Interior } \\
\text { location }\end{array}$ & $\begin{array}{c}\text { Exterior } \\
\text { location }\end{array}$ & $\begin{array}{c}\text { Interior } \\
\text { region }\end{array}$ & $\begin{array}{c}\text { Exterior } \\
\text { region }\end{array}$ \\
\hline First crack $(\mathrm{kN})$ & 330 & 325 & 130 & 115 \\
\hline Failure load, $\mathrm{F}_{\text {failure }}(\mathrm{kN})$ & 654.9 & 541.18 & 141 & 152.46 \\
\hline Experimental moment at base of the wall $(\mathrm{kN} . \mathrm{m})$ & - & - & 139.6 & 150.94 \\
\hline Proposed moment at base of the wall $(\mathrm{kN} . \mathrm{m}) *$ & - & - & 124.1 & 141.73 \\
\hline CHDBC factored load, $\mathrm{F}_{\mathrm{CHBDC}}(\mathrm{kN})$ & 357 & 357 & - & - \\
\hline CHBDC moment at inner portion $(\mathrm{kN} . \mathrm{m} / \mathrm{m})$ & - & - & 83 & - \\
\hline CHBDC moment at end portion $(\mathrm{kN} \mathrm{m} / \mathrm{m})$ & - & - & - & 102 \\
\hline Height of load application $(\mathrm{m})$ & 0.99 & 0.99 & 0.99 & 0.99 \\
\hline $\mathrm{F}_{\text {failure }} / \mathrm{F}_{\mathrm{CHBDC}}$ or $\mathrm{M}_{\text {Exp. }} / \mathrm{M}_{\mathrm{CHBDC}}$ & 1.83 & 1.52 & 1.68 & 1.48 \\
\hline $\mathrm{M}_{\text {Exp. }} / \mathrm{M}_{\text {proposed }}$ & - & - & 1.12 & 1.06 \\
\hline $\mathrm{M}_{\text {proposed. }} / \mathrm{M}_{\mathrm{CHBDC}}$ & - & - & 1.49 & 1.39 \\
\hline Max. wall deflection $(\mathrm{mm})$ & 15.71 & 26.67 & 48.7 & 79.23 \\
\hline
\end{tabular}

*Proposed moments at base of the wall at interior and exterior region were calculated using proposed equations in the Table 4.12.

\subsection{Deformability of 1-m Long Tested Barriers}

Ductility of steel reinforced concrete structures is defined as the ratio of the ultimate deflection or curvature of the structure to that of yielding of reinforcing steels. However, as FRP reinforcing bars do not yield at failure, concrete structural members exhibit significant amount of deformation prior to failure. As such, Jaeger et al. (1995) defines the concept of deformability on the basis of deformation characteristics and comparison of the level of safety between ultimate and service states of the structural components. Thus, CHBDC (2006) and Jaeger et al. (1995) describe deformability of sections reinforced with FRP bars by a "deformability factor, J" presented in Eq. 5.1a as follow:

Deformability Factor $(\mathrm{J})=\frac{M u \psi u}{M s \psi s}$ 
Where $M_{u}$ is the ultimate moment capacity of the section, $M_{s}$ is the moment capacity at service load, $\psi_{\mathrm{u}}$ is the ultimate curvature and $\psi_{\mathrm{s}}$ is the curvature at service load. CHBDC requires that deformability factor, J, to be greater than 4 and 6 for rectangular and T-sections, respectively. On the basis of CHBDC, the deformability of 1-m long tested barriers were calculated and summarized in Table 5.2. Shown in the Table, all barrier models presented deformability factor greater than 4 prescribed by CHBDC indicating good ductility of the barrier models. It should be noted that deformability of the barrier was calculated considering an average thickness of barrier wall equal to 370-mm since the thickness of the barriers proportionally increases from cantilever tip to barrier-deck joint. The barrier at interior region showed deformability factor less than the barrier at end region due to the fact that at interior region the bar spacing was $300-\mathrm{mm}$ as such the ultimate moment was less than the barrier at end region with 150-mm bar spacing.

Table 5. 2 Deformability of tested 1-m long barrier walls

\begin{tabular}{|c|c|c|}
\hline & Deformability & CHBDC limit (2006) \\
\hline $\begin{array}{c}\text { Interior region- HM } \\
(300 \text {-mm bar spacing) }\end{array}$ & 4.81 & 4 \\
\hline $\begin{array}{c}\text { End region- HM } \\
(150-\text { mm bar spacing })\end{array}$ & 5.14 & 4 \\
\hline
\end{tabular}

CHBDC clause 16.8.2.3 also requires crack width control for FRP reinforced concrete when maximum tensile strain in FRP under full service loads exceeds 0.0015 . The following equation was adopted in the CHBDC (2006) to determine crack width of FRP reinforced structures:

$\mathrm{W}_{\mathrm{cr}}=2 \cdot \frac{f_{F R P}}{E_{F R P}} \frac{h_{2}}{h_{1}} \mathrm{k}_{\mathrm{b}} \sqrt{d_{c}{ }^{2}+\left(\frac{s}{2}\right)^{2}}$

Where $\mathrm{k}_{\mathrm{b}}$ value should be determined from experimental tests, otherwise, it can be taken as 0.8 for sand-coated FRP bars and 1 for deformed bars, $d_{c}$ is the distance from centroid of the tension reinforcement to the extreme tension surface of concrete, $(\mathrm{mm})$. In calculating $\mathrm{d}_{\mathrm{c}}$, the concrete cover should not be taken greater than $50-\mathrm{mm}$. $h 1$ is the distance from centroid of tension reinforcement to the neutral axis ( $\mathrm{mm})$ and $h 2$ is the distance from the extreme flexural tension surface to the neutral axis ( $\mathrm{mm})$. And, (s) is spacing of shear or tensile reinforcement (mm). The 
crack width at base of the wall was calculated using Eq. 5.1b equal to 0.72. The calculated crack width was found to be relatively equal to the CHBDC limit of 0.70 .

\subsection{Analytical Investigation of Punching Shear Strength of PL-3 Barriers Reinforced with GFRP Bars}

Test results summarized in Table 5.1 showed that the developed GFRP-reinforced PL-3 barriers was qualified to resist the CHDBC factored design load of $357 \mathrm{kN}$, while maintaining factor of safety of 1.83 and 1.52 at interior and exterior locations, respectively. Since the primary failure mode of the tested barrier at interior and exterior locations was due to punching shear, a punching shear strength equation was required to qualify PL-3 barrier wall design, in terms of barrier wall dimension, amount and material characteristics of GFRP bars. This section intends to correlate the experimental findings with the available punching shear strength equations in the literature for FRP-reinforced members.

Due to differences in mechanical properties of steel and GFRP bars, punching shear equations derived for steel-reinforced concrete structures cannot be employed directly to GFRP-reinforced elements. Most of the current code provisions and empirical equations predicting punching shear strength of FRP-reinforced structures are modified forms of those available for steel-reinforced concrete structures to account for lower modulus of elasticity of FRP bars compared to steel bars. Experimental tests have shown that FRP-reinforced concrete member experienced reduced shear strength compared to steel-reinforced structures due to lower modulus of elasticity of FRP bars. The lower modulus of elasticity in turn results in larger deformation and developing wider and deeper cracks. In two-way reinforced concrete slabs, punching shear resistance is provided by shear resistance of concrete in compression zone, $V_{c}$. The shear resistance acts over an area equal to the critical perimeter, $b_{o}$, of punching shear failure plane multiplied by effective depth, $d$, of the concrete section. The critical perimeter, $b_{0}$, is specified in different design codes as either $0.5 \mathrm{~d}$ or $1.5 \mathrm{~d}$ (See section 2.20 in Chapter 2).

An extensive research programs have been conducted on PL-3 GFRP-reinforced bridge barriers that were subjected to static test to-complete-collapse. Experimental studies have shown that the 
barrier walls experienced punching shear mode of failure in addition to cantilever action of the barrier walls. The punching shear cracks developed on the top-front face of the wall and extended diagonally to back face of the wall. It was observed that punching shear cracks appeared at an average distance of $1.5 \mathrm{~d}$ to the patch loading of GFRP-reinforced barrier walls (Figure 5.43). A number of design standards and punching shear models provide design equations applicable to FRP-reinforced concrete slabs. However, punching shear behavior of bridge barrier walls under the applied transverse loads has not yet been studied. As such, an attempt was made in the current research to determine the best punching shear prediction model that can be applicable to PL-3 barriers reinforced with GFRP bars.

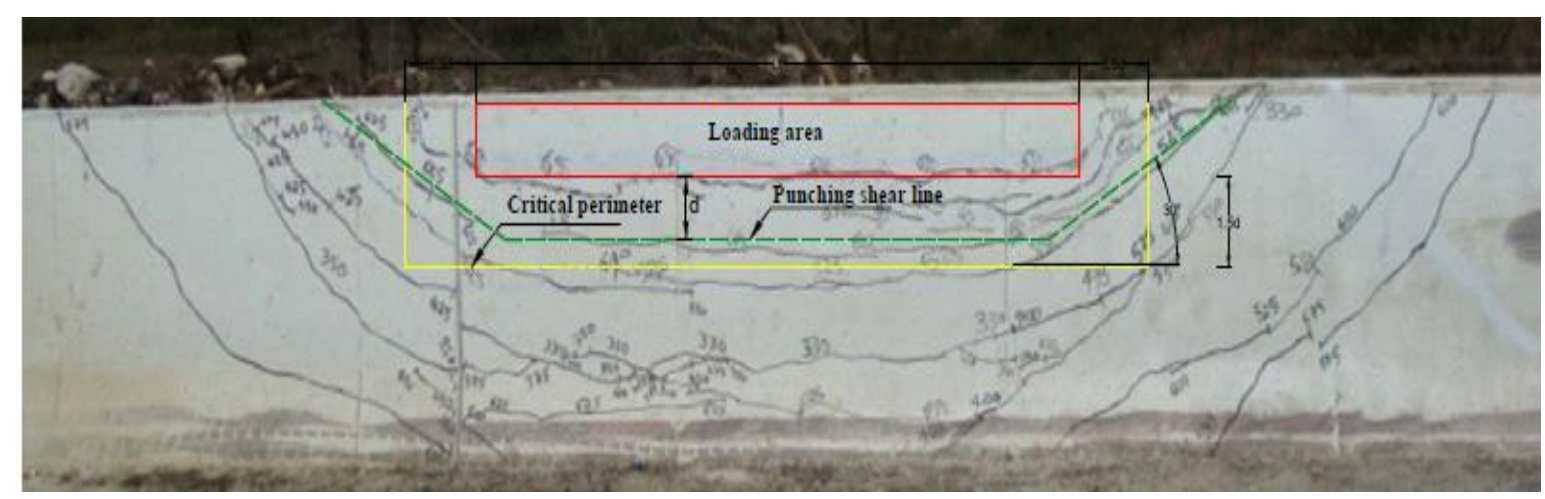

(a) Punching shear region at front face of the barrier

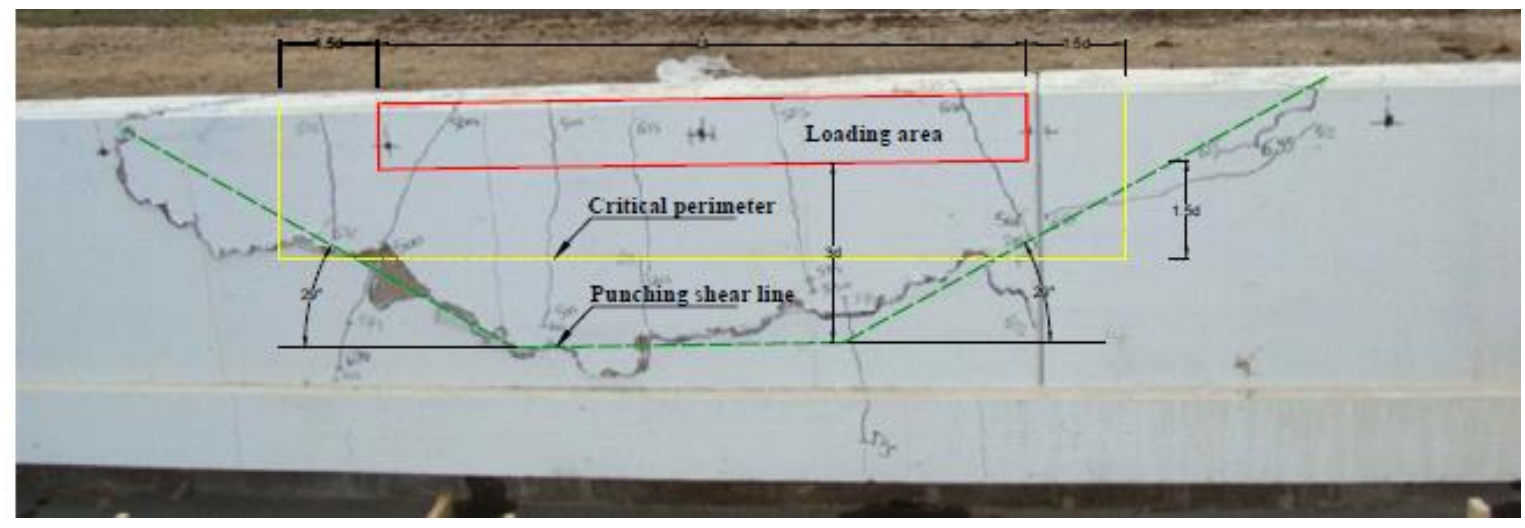

(b) Punching shear region at back face of the wall

Figure 5. 43 Determination of average critical punching shear perimeter 
The punching shear prediction models stated in Chapter 2 (Section 2.20) consider the reinforcement ratio of tension reinforcement in the direction of applied tension force for edge loading, except JSCE (1997) and Jacobson el al. (2005) that considers the average reinforcement ratios in both directions at tension face of slab. The punching shear strength of the developed GFRP-reinforced PL-3 barriers in the current study was calculated using various equations mentioned in Chapter 2 at interior and exterior locations shown in Figure 5.10. It should be noted that the barrier was cast with characteristic concrete compressive strength of $30.9 \mathrm{MPa}$. Table 5.3 provides predicted capacities of the PL-3 barrier in accordance with the available punching shear equations for FRP bars (Chapter 2 section 2.20). Table 5.4 provides the ratio between experimental ultimate load measured and predicted punching shear capacities from equations

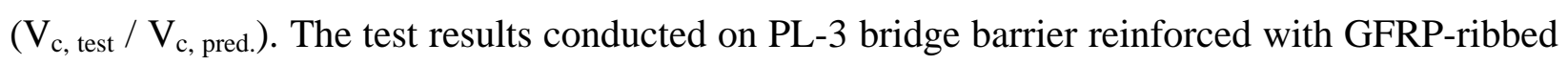
bars with similar configuration and barrier geometry as previously studied by Sennah et al. (2010) are also considered in Table 5.4. The barrier designations in Table 5.4 are defined separately in Table 5.5.

Traditionally, the $\mathrm{V}_{\mathrm{c}, \text { test }} / \mathrm{V}_{\mathrm{c} \text {,pred. }}$. ratio of 1 presents perfectly predicted test capacity, while ratios greater than 1 provide conservatism in designing punching shear capacity of the barrier walls. Ratios less than 1 show that the predicted punching shear models overestimate the experimental shear capacity of the barrier walls making the design unsafe. From punching shear prediction models reported in Table 5.4, the predication by Mattys and Taerwe's (2000) equation yielded reasonable yet conservative punching shear strength for the tested barrier. On the other hand, CSA-S806 (2012) equation yielded the lowest predicted punching shear strength, followed by the ACI 440.1R (2006) equation.

Of the approaches proposed by various codes and researches, the equation by Jacobson et al. (2005) provided the best prediction for punching shear failure of the tested GFRP barrier walls both at interior and exterior locations. It should be noted that this prediction model still maintain some level of conservativeness due to the fact that barrier wall had cantilever action which was assumed fully restrained at the deck slab. Therefore, it can be presumed that punching shear of bridge barriers occurs similar to the edge region of the slab at interior location of the barrier wall and corner region of slab at exterior location of the wall given the fact that the wall is fully 
restrained to the deck slab. Other equations presented in Table 5.4 provided unsafe prediction of the barrier punching strength at least at either the interior or exterior location.

Table 5. 3 Punching shear capacities from various codes and provisions for PL-3 GFRPreinforced bridge barriers $\left(\mathrm{f}_{\mathrm{c}}{ }_{\mathrm{c}}=30.9 \mathrm{MPa}\right)$

\begin{tabular}{|c|c|c|}
\hline \multirow{2}{*}{ Code designation } & \multicolumn{2}{|c|}{$\mathrm{V}_{\mathrm{c}, \text { pred. }}$ for PL-3 FRP bars $(\mathrm{kN})$} \\
\cline { 2 - 3 } & Interior location & Exterior location \\
\hline CSA-S806-12 $\left(\mathrm{V}_{\mathrm{c}, \mathrm{S806}}\right)$ & 319.3 & 346.6 \\
\hline ACI 440.1R-06 $\left(\mathrm{V}_{\mathrm{c}, \mathrm{ACI} 440}\right)$ & 364.9 & 432.8 \\
\hline JSCE $\left(\mathrm{V}_{\mathrm{c}, \mathrm{JSCE}}\right)$ & 637.95 & 702.4 \\
\hline El-Ghandour et al. 1999, $\left(\mathrm{V}_{\mathrm{c}, \text { EGA 1999 }}\right)$ & 854.4 & 736.6 \\
\hline El-Ghandour el al. 2000, $\left(\mathrm{V}_{\mathrm{c}, \mathrm{EGA} \text { 2000 }}\right)$ & 561.3 & 558.15 \\
\hline Mattys and Taerwe, 2000, $\left(\mathrm{V}_{\mathrm{c}, \mathrm{MT}}\right)$ & 447.53 & 445.05 \\
\hline Ospina et al. 2003, $\left(\mathrm{V}_{\mathrm{c}, \mathrm{OSP}}\right)$ & 613.8 & 610.4 \\
\hline El-Gamal et al. 2005 $\left(\mathrm{V}_{\mathrm{c}, \mathrm{EGM}}\right)$ & 551.6 & 630.6 \\
\hline Jacobson et al. 2005 $\left(\mathrm{V}_{\mathrm{c}, \mathrm{JCOB}}\right)$ & 506.05 & 446.96 \\
\hline
\end{tabular}

Table 5. 4 Tested-to-Predicated punching shear capacity of PL-3 GFRP barrier wall

\begin{tabular}{|c|c|c|c|c|c|c|c|c|c|c|}
\hline \multirow{2}{*}{$\begin{array}{c}\text { Barrier } \\
\text { Designation }\end{array}$} & \multirow{2}{*}{$\begin{array}{l}\mathrm{V}_{\mathrm{c}, \text { test }} \\
(\mathrm{kN})\end{array}$} & \multicolumn{9}{|c|}{$\mathrm{V}_{\mathrm{c}, \text { test }} / \mathrm{V}_{\mathrm{c}, \text { pred. }}$} \\
\hline & & $\mathrm{V}_{\mathrm{c}, \mathrm{S} 806}$ & $\begin{array}{c}\mathrm{V}_{\mathrm{c}}, \\
\mathrm{ACI} 440\end{array}$ & $\begin{array}{c}\mathrm{V}_{\mathrm{c}}, \\
\mathrm{JSCE}\end{array}$ & $\begin{array}{c}\mathrm{V}_{\mathrm{c}}, \\
\text { EGA } 1999\end{array}$ & $\begin{array}{c}\mathrm{V}_{\mathrm{c}}, \\
\text { EGA } 2000\end{array}$ & $\begin{array}{l}\mathrm{V}_{\mathrm{c}}, \\
\mathrm{MT}\end{array}$ & $\begin{array}{l}\mathrm{V}_{\mathrm{c}}, \\
\mathrm{OSP}\end{array}$ & $\begin{array}{c}\mathrm{V}_{\mathrm{c}}, \\
\mathrm{EGM}\end{array}$ & $\begin{array}{c}\mathrm{V}_{\mathrm{c}}, \\
\text { JCOB }\end{array}$ \\
\hline P3GFI-PU & 654.9 & 2.05 & 1.79 & 1.03 & 0.77 & 1.17 & 1.46 & 1.07 & 1.19 & 1.29 \\
\hline P3GFI1-SH & 621 & 1.94 & 1.70 & 0.97 & 0.73 & 1.11 & 1.38 & 1.01 & 1.13 & 1.23 \\
\hline \multirow[t]{4}{*}{ P3GFI2- $\mathrm{SH}^{* *}$} & 607 & 1.90 & 1.66 & 0.95 & 0.71 & 1.08 & 1.36 & 0.99 & 1.10 & 1.20 \\
\hline & Mean & 1.96 & 1.71 & 0.983 & 0.74 & 1.12 & 1.4 & 1.02 & 1.14 & 1.24 \\
\hline & SD & 0.078 & 0.07 & 0.042 & 0.031 & 0.046 & 0.053 & 0.042 & 0.05 & 0.05 \\
\hline & COV \% & 3.95 & 3.87 & 4.23 & 4.14 & 4.10 & 3.78 & 4.07 & 4.02 & 3.69 \\
\hline P3GFE1-PU* & 463.3 & 1.34 & 1.07 & 0.66 & 0.63 & 0.83 & 1.04 & 0.76 & 0.73 & 1.04 \\
\hline P3GFE2-PU & 541.2 & 1.56 & 1.25 & 0.77 & 0.73 & 0.97 & 1.22 & 0.88 & 0.86 & 1.21 \\
\hline \multirow[t]{4}{*}{ P3GFE-SH } & 593 & 1.71 & 1.37 & 0.84 & 0.81 & 1.06 & 1.33 & 0.97 & 0.94 & 1.33 \\
\hline & Mean & 1.52 & 1.23 & 0.76 & 0.723 & 0.95 & 1.19 & 0.87 & 0.84 & 1.19 \\
\hline & SD & 0.186 & 0.151 & 0.091 & 0.090 & 0.116 & 0.146 & 0.105 & 0.11 & 0.15 \\
\hline & $\mathrm{COV} \%$ & 12.11 & 12.27 & 11.99 & 12.47 & 12.16 & 12.23 & 12.11 & 12.6 & 12.2 \\
\hline
\end{tabular}

*The test was failed in the deck slab rather than by punching shear failure of the wall

**The test was performed at the location of control joint. 
Table 5. 5 Barrier designations considered for the proposed punching shear equation

\begin{tabular}{|c|c|}
\hline $\begin{array}{c}\text { Barrier } \\
\text { designation }\end{array}$ & Definition \\
\hline P3GFI-PU & PL-3 GFRP barrier tested at interior location-Pultrall bars \\
\hline P3GFI1-SH ${ }^{1}$ & PL-3 GFRP barrier tested at interior location 1-Shoeck bars \\
\hline P3GFI2- $\mathrm{SH}^{1}$ & PL-3 GFRP barrier tested at interior location 2-Sheock bars \\
\hline P3GFE1-PU & PL-3 GFRP barrier tested at exterior location 1-Pultrall bars \\
\hline P3GFE2-PU & PL-3 GFRP barrier tested at exterior location 2-Pultrall bars \\
\hline P3GFE-SH ${ }^{1}$ & PL-3 GFRP barrier tested at exterior location-Shoeck bars \\
\hline
\end{tabular}

1 - The static tests for the shoeck bars were conducted by Sennah et al. (2010)

\subsubsection{Proposed Punching Shear Equation for PL-3 GFRP Barriers}

Each of the punching shear capacity models presented above has been empirically derived for two-way FRP-reinforced concrete slabs with simply-supported or some level of edge restraint. However, none has been specifically derived for punching shear failure of GFRP-reinforced bridge barrier walls under transverse applied load in which some level of restraint is presented due to lateral distribution of load.

Experimental studies conducted on two-way slabs reinforced with GFRPs revealed that due to lower modulus of elasticity of GFRP bars compared to steel reinforcement, punching shear capacity strength increases if the axial or elastic stiffness $\left(\rho_{\mathrm{f}} \mathrm{E}_{\mathrm{f}}\right)$ of tension reinforcement increases (Mattys and Taerwe, 2000). As such, all predicted punching shear equations considered the ratio of main (tension) reinforcement in calculations except JSCE (1997) and Jacobson et al. (2005) prediction models that considered the average tensile reinforcement ratio in both directions. In the current study, the experiment-to-predicted strength ratio on PL-3 GFRPreinforced bridge barrier using Jacobson et al. (2005) equation showed that the average reinforcement ratio should be taken into account, as both transverse and longitudinal reinforcement placed at front face of the wall are subjected to tension force due to the applied transverse load on the wall, which are passing through the punching shear plane. 
Based on a review of the results on previously proposed models, an attempt was made to modify the best proposed prediction models so that a good agreement yet conservative prediction with experimental results of PL-3 GFRP bridge barriers is maintained. Since Jacobson el al. (2005) model provided the best prediction both at interior and exterior locations of the barrier wall, this model along with CSA-S806 (2012) model were empirically modified to account for elastic stiffness of GFRP tension reinforcement and the ratio of long-to-short side of patch loading $\left(\beta_{\mathrm{c}}\right)$. From experimental tests conducted at interior and exterior locations of the barrier wall, the characteristic failure load was obtained in accordance with the CSA-S806 (2010), in which the

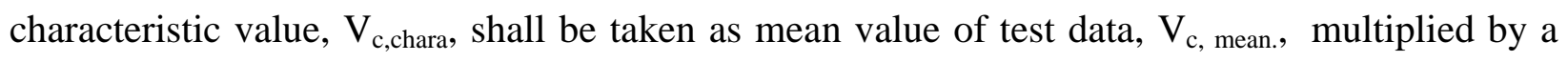
factor, $\mathrm{F}_{\mathrm{t}}$ as follow;

$\mathrm{V}_{\mathrm{c}, \text { chara. }}=\mathrm{V}_{\mathrm{c} \text {, mean. }} \mathrm{F}_{\mathrm{t}}$

$\mathrm{F}_{\mathrm{t}}=\frac{1-1.645 \mathrm{~V}}{1+\frac{1.645 \mathrm{~V}}{\sqrt{n}}}$

Where $\mathrm{V}$ is the coefficient of variation $(\mathrm{COV})$ of the ultimate failure loads from qualification tests and $\mathrm{n}$ is the number of tests performed. Table 5.6 shows the characteristic test failure load at each of interior or exterior location of the barrier walls.

Table 5. 6 Characteristic tests ultimate failure loads

\begin{tabular}{|c|c|c|c|c|c|}
\hline \multicolumn{3}{|c|}{ Interior location } & \multicolumn{3}{|c|}{ Exterior location } \\
\hline & & $\mathrm{V}_{\mathrm{c}, \text { test }}(\mathrm{kN})$ & & & $\mathrm{V}_{\mathrm{c}, \text { test }}(\mathrm{kN})$ \\
\hline \multirow{3}{*}{ Test ID } & P3GFI-PU & 654.9 & \multirow{3}{*}{ Test ID } & P3GFE2-PU & 541.2 \\
\hline & P3GFI1-SH & 621 & & P3GFE-SH & 593 \\
\hline & P3GFI2-SH & 607 & & - & - \\
\hline \multicolumn{2}{|c|}{ Mean $(\mathrm{kN})$} & 627.63 & \multicolumn{2}{|c|}{ Mean $(\mathrm{kN})$} & 567.1 \\
\hline \multicolumn{2}{|c|}{ SD } & 24.63 & \multicolumn{2}{|c|}{ SD } & 36.63 \\
\hline \multicolumn{2}{|c|}{$\operatorname{COV}(\%)$} & 3.92 & \multicolumn{2}{|c|}{$\operatorname{COV}(\%)$} & 6.46 \\
\hline \multicolumn{2}{|c|}{$\mathrm{V}_{\mathrm{c}, \text { chara. }}(\mathrm{kN})$} & 566 & \multicolumn{2}{|c|}{$\mathrm{V}_{\mathrm{c}, \text { chara. }}(\mathrm{kN})$} & 472 \\
\hline
\end{tabular}


The CSA-S806 (2012) and Jacobson et al. (2005) equations were empirically modified to account elastic stiffness and the ratio of long-to-short side of patch loading, $\left(\beta_{\mathrm{c}}\right)$ as follow:

$\mathrm{V}_{\mathrm{c}}=\left(1+2 / \beta_{\mathrm{c}}\right) \cdot \mathrm{X} \cdot \frac{\sqrt[3]{\rho f \cdot E f \cdot f^{\prime} c}}{\sqrt[4]{d}} \cdot \mathrm{b}_{\mathrm{o}, 1.5 \mathrm{~d} \cdot \mathrm{d}}$

Where $\mathrm{X}$ is a factor to account for concrete density and concrete resistance factor equal to $(\mathrm{X}=$

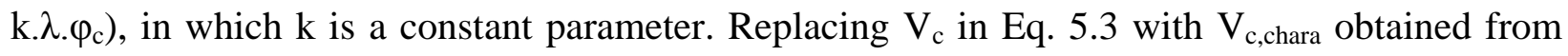
experimental tests and using test data yielded an average $\mathrm{X}$ value at interior and exterior locations of the barrier wall equal to 0.102 . Thus, for a normal density concrete $(\lambda=1)$ with concrete resistance factor of 0.75 , the parameter $\mathrm{k}$ can be determined as 0.136 . It should be noted that the critical perimeter was determined as the average punching shear cracks at front and back face of the wall which was found to be $1.5 \mathrm{~d}\left(\mathrm{~b}_{\circ}, 1.5 \mathrm{~d}\right)$ away from patch loading area (see Figure 5.43). The proposed punching shear equation for PL-3 GFRP bridge barriers, $\mathrm{V}_{\mathrm{c}}$, pro. can be then written as:

$$
\mathrm{V}_{\mathrm{c}, \text { pro. }}=\left(1+2 / \beta_{\mathrm{c}}\right) \cdot 0.136 \cdot \lambda \cdot \varphi_{\mathrm{c}} \cdot \frac{\sqrt[3]{\rho_{f} \cdot E_{f} \cdot f_{c}}}{\sqrt[4]{d}} \cdot \mathrm{b}_{o, 1.5 \mathrm{~d} \cdot \mathrm{d}}
$$

The terms in Eq. 5.4 are defined as follow:

$\beta_{\mathrm{c}}=$ is the ratio of long side to short side of loading patch (see Figure 5.44) equal to $\left(\beta_{\mathrm{c}}=\mathrm{L}_{\mathrm{t}} / \mathrm{W}\right.$ $=9.6$ )

$$
\begin{aligned}
& \rho_{f}=\left(\rho_{f \cdot x} \cdot E_{f \cdot x}+\rho_{f \cdot y} \cdot E_{f \cdot y}\right) /\left(E_{f \cdot x}+E_{f \cdot y}\right) \\
& E_{f}=\left(\rho_{f \cdot x} \cdot E_{f \cdot x}+\rho_{f \cdot y} . E_{f \cdot y}\right) /\left(\rho_{f \cdot x}+\rho_{f \cdot y}\right) \\
& \rho_{f \cdot x}=A_{f . x} /(b \cdot d) \\
& \rho_{f \cdot y}=A_{f . y} /(b . d) \\
& A_{f . x}=A_{b . x .} 1000 / S_{y} \\
& A_{f . y}=A_{\text {b.y. }} 1000 / S_{x}
\end{aligned}
$$

Where,

$\mathrm{L}_{\mathrm{t}}=$ is the length of the loading patch $=2400 \mathrm{~mm}$ for PL-3 bridge barriers

$\mathrm{W}=$ is the width of loading patch $=250 \mathrm{~mm}$ in the current study 
$\rho_{\mathrm{f}}=$ Average reinforcement ratio of transverse and longitudinal GFRP reinforcement at tension face of the barrier wall

$\mathrm{E}_{\mathrm{f}}=$ Average modulus of elasticity of transverse and longitudinal GFRP reinforcement at tension face of the barrier wall $\rho_{\mathrm{f} \cdot \mathrm{x}}=$ GFRP transverse reinforcement ratio along $\mathrm{x}$-axis shown in Figure 5.44(b) $\rho_{\mathrm{f} \cdot \mathrm{y}}=$ GFRP longitudinal reinforcement ratio along $\mathrm{y}$-axis shown in Figure 5.44(b) $\mathrm{E}_{\mathrm{f} \cdot \mathrm{x}}=$ GFRP modulus of elasticity along $\mathrm{x}$-axis $\mathrm{E}_{\mathrm{f} \cdot \mathrm{y}}=$ GFRP modulus of elasticity along $\mathrm{y}$-axis $A_{b . x}=$ Cross-sectional area of one GFRP bar in transverse direction along x-axis $A_{b . y}=$ Cross-sectional area of one GFRP bar in longitudinal direction along y-axis $\mathrm{A}_{\mathrm{f} . \mathrm{x}}=$ Total GFRP reinforcement area in transverse direction per meter of wall $\mathrm{A}_{\text {f.y }}=$ Total GFRP reinforcement area in longitudinal direction per meter of wall $\mathrm{b}=$ Width of wall in transverse or longitudinal direction equal to $1000 \mathrm{~mm}$. $\mathrm{d}=$ Effective wall depth (see Figure 5.44) $\mathrm{S}_{\mathrm{x}}=$ Longitudinal GFRP bar spacing, see Figure 5.44(b) $\mathrm{S}_{\mathrm{y}}=$ Transverse GFRP bar spacing, see Figure 5.44(b) $b_{o, 1.5 d}=$ perimeter of the punching shear plane $=L_{t}+W+4(1.5 d)$ for interior location and $L_{t}+$ $\mathrm{W}+2(1.5 \mathrm{~d})$ at exterior location

Table 5.7 presents the proposed punching shear strength of the barrier wall, denoted as $\mathrm{V}_{\mathrm{c} \text {, pro, }}$ based on the above-mentioned proposed equation. It can be observed that the mean ratio between the experimental and proposed punching shear strength of the barrier wall at interior and exterior locations, $\mathrm{V}_{\mathrm{c} \text {,test }} / \mathrm{V}_{\mathrm{c} \text {,pro, }}$ are 1.14 and 1.09 , respectively. This presented a good agreement between the experimental findings and the theoretical prediction proposed in Eq. 5.4. On the other hand, the ratios between the proposed punching shear strength using Eq. 5.4 and the $357 \mathrm{kN}$ factored design load for PL-3 barrier, $\mathrm{V}_{\mathrm{c} \text {,pro. }} / \mathrm{V}_{\mathrm{CHBDC}}$, was calculated as 1.54 and 1.36 for interior and exterior locations, respectively. Although the ratio between the experimental and design values for punching shear strength should be at least 1 for a safe design in concrete structure, it may be advisable to consider a durability factor for environmental effects that would lead to degradation of GFRP bars. Per CHBDC, this factor would be 0.75 in case of GFRP bars. As such, the ratio between the proposed and the design values for punching shear strength of PL-3 barrier wall 
should be greater than 1.33 in lieu of 1 . Table 5.7 shows that these ratios are 1.54 and 1.36 for interior and exterior locations, respectively. Thus, the proposed Eq. 5.4 for prediction of punching shear resistance of the developed GFRP-reinforced barrier wall shown in Figure 5.8 met both strength and durability requirements. Based on the developed equation above (Eq. 5.4), the punching shear resistance of PL-3 barriers reinforced with GFRP bars for variable horizontal and vertical bar size and bar spacing is provided in Appendix E. It should be noted that the punching shear resistance was calculated for concrete compressive strengths of 25,30 and 35 MPa with high-modulus (HM) and standard-modulus (SM) sand-coated GFRP bars at interior and exterior location of the barriers. Also, the values in red boxes in Appendix E provide unsafe conditions for punching shear resistance of PL-3 barrier with GFRP bar reinforcement.

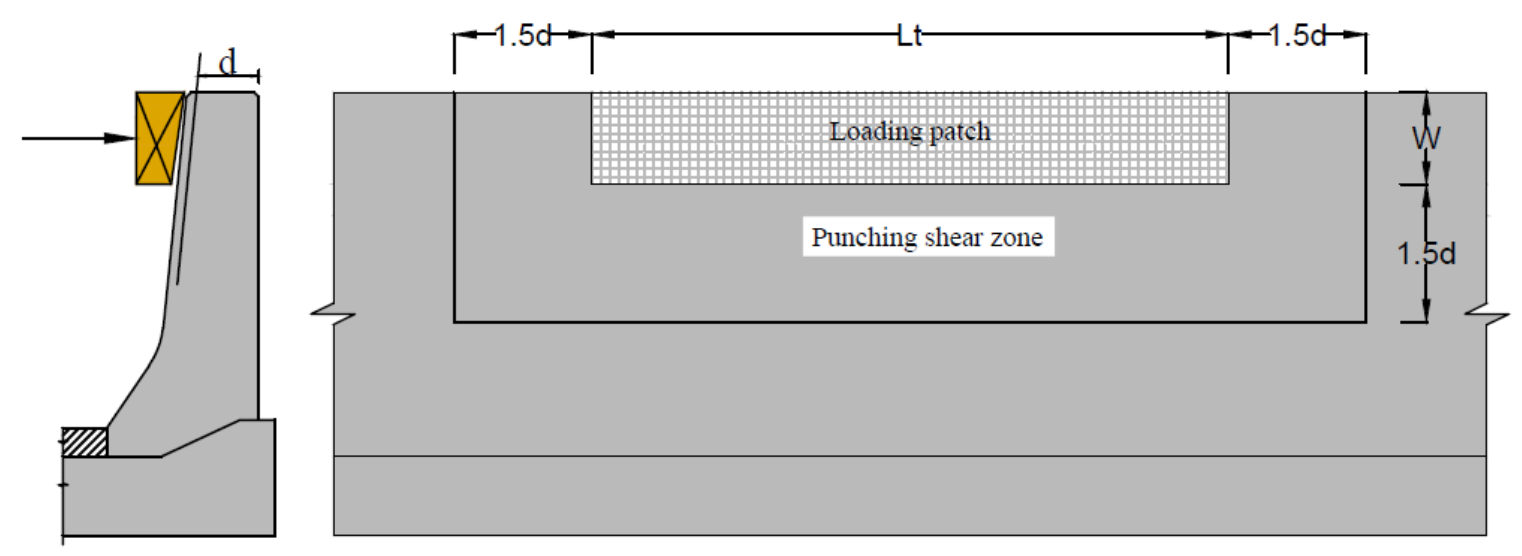

(a) Interior location
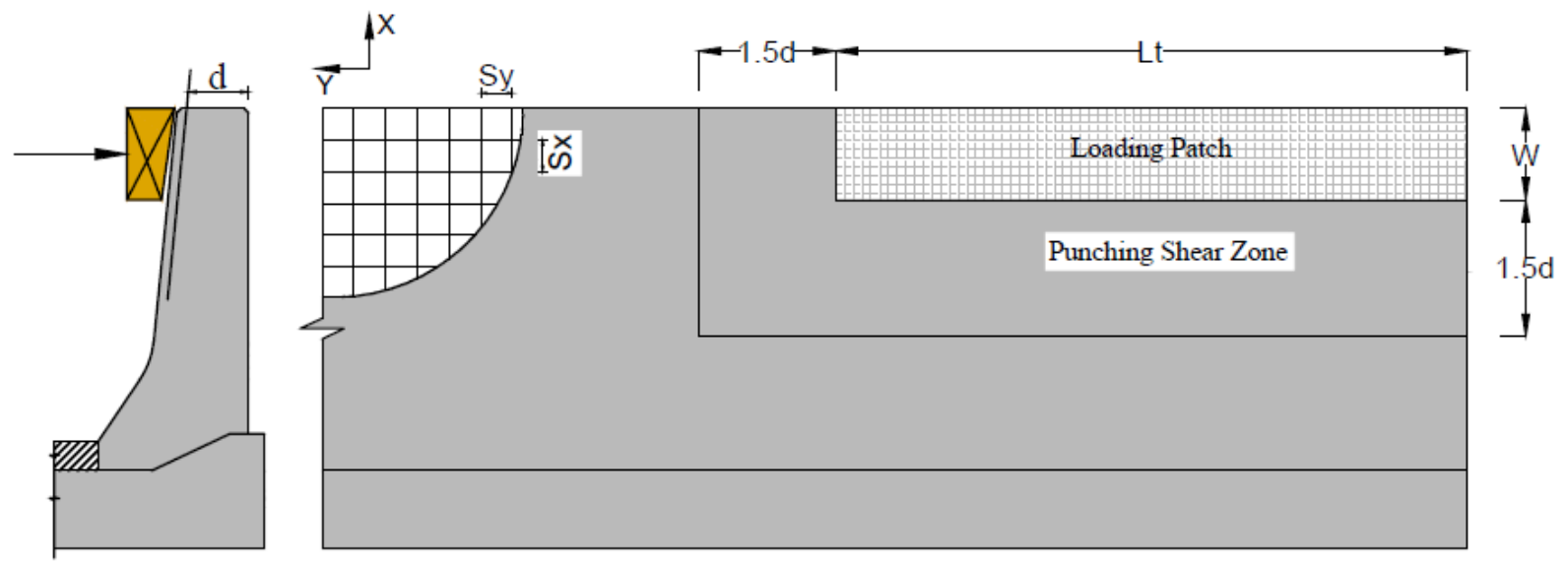

(b) Exterior location

Figure 5. 44 Critical perimeter for punching shear at interior and exterior locations. 
Table 5. 7 Ratio of experimental-to-proposed punching shear capacity of PL-3 GFRP barriers

\begin{tabular}{|c|c|c|c|c|}
\hline Barrier designation & $\mathrm{V}_{\mathrm{c} \text {,test }}(\mathrm{kN})$ & $\mathrm{V}_{\mathrm{c} \text {,pro. }}(\mathrm{kN})$ & $\mathrm{V}_{\mathrm{c}, \text { test }} / \mathrm{V}_{\mathrm{c} \text {, pro. }}$ & $\mathrm{V}_{\mathrm{c}, \text { pro. }} / \mathrm{V}_{\mathrm{c}, \mathrm{CHBDC} * * *}$ \\
\hline P3GFI-PU & 654.9 & 550.4 & 1.19 & 1.54 \\
\hline P3GFI1-SH & 621 & 550.4 & 1.13 & 1.54 \\
\hline \multirow[t]{4}{*}{ P3GFI2- $\mathrm{SH}^{* *}$} & 607 & 550.4 & 1.10 & 1.54 \\
\hline & Mean & - & 1.14 & - \\
\hline & SD & - & 0.046 & - \\
\hline & $\operatorname{COV}(\%)$ & - & 4.01 & - \\
\hline P3GFE1-PU* & 463.3 & 486.1 & 0.95 & 1.36 \\
\hline P3GFE2-PU & 541.2 & 486.1 & 1.11 & 1.36 \\
\hline \multirow[t]{4}{*}{ P3GFE-SH } & 593 & 486.1 & 1.22 & 1.36 \\
\hline & Mean & - & 1.09 & - \\
\hline & SD & - & 0.136 & - \\
\hline & $\operatorname{COV}(\%)$ & - & 12.41 & - \\
\hline
\end{tabular}

*The test was failed in the deck slab rather than by punching shear failure of the wall

**The test was performed at the location of control joint.

$* * * \mathrm{~V}_{\mathrm{CHBDC}}=357 \mathrm{kN}$

\subsection{Summary of Findings}

Experimental programs have been carried on a 27.6-m long PL-3 bridge barrier. The full-scale PL-3 barrier wall reinforced with high-modulus GFRP bars was tested under static loading tocollapse to study its structural behavior, crack pattern and ultimate load carrying capacity. Based on experimental and theoretical investigations, the following conclusions were drawn: (i) In contrast to AASHTO-LRFD yield-line failure pattern specified for steel-reinforced barriers, the developed GFRP-reinforced barrier wall failed due to punching shear around the patch loading location, (ii) The developed GFRP-reinforced barrier exhibited ultimate load carrying capacity far greater than the CHBDC design load with factors of safety of 1.83 and 1.52 for interior and exterior load locations, respectively, and (iii) Based on the test data, an empirical equation was developed for the prediction of punching shear resistance of the developed GFRP-reinforced barrier wall to meet both strength and durability requirements. The equation leads to the factor of safety of 1.54 and 1.36 for interior and exterior load locations, respectively. The equation 
assumes the punching shear plane located at distance $1.5 \mathrm{~d}$ from the loading patch boundaries where $\mathrm{d}$ is the effective depth of the section. 


\section{Chapter VI}

\section{Static Load Testing on Full-Scale Steel-Reinforced Barriers}

\subsection{Introduction}

The design process of traffic barriers specified by the current Canadian Highway Bridge Design Code (CHBDC, 2006), is based on the AASHTO Guide Specifications for Bridge Railings (1989) and the AASHTO Guide for Selecting, Locating, and Designing Traffic Barriers (1977). This includes concrete barriers, Steel W-beam guardrail on timber or steel posts, steel box-beam on steel posts, cable guardrail with steel or timber posts and chain-link fence arresting barrier. The AASHTO guide specification for bridge railings is a major departure from the static load design procedures traditionally used for the design of traffic barriers. It is based on two aspects. The first aspect is that traffic barriers differ from site to site and that the traffic barriers performance should match specific bridge site requirements. This is called multiple performance level concepts. The second aspect is that the traffic barriers should be crash tested to conform the requirements of a specific performance level. Traffic barrier requirements vary from bridge site to bridge site and are based on the expected frequency and consequences of vehicle accidents at a bridge site. CHBDC specifies these requirements in the form of barrier performance levels 1, 2 and 3. These performance levels depend on traffic volume, percentage of trucks in traffic mix, highway type, barrier clearance, highway curvature, highway design speed, superstructure height above the ground level, number of people at risk beneath the bridge and hazards existing beneath the bridge. A traffic barrier serves dual and often conflicting roles. It must be capable of redirecting and/or containing an errant vehicle without imposing un-tolerable conditions on the occupants of the vehicle. It should be able to do this for a range of vehicle sizes and weights, impact speed and impact angles. Compromises are necessary to achieve a balance between the structural and safety requirements. Crashworthiness focuses on the capability of a vehicle to protect its occupants in a collision. Crashworthy barrier is the one that can be impacted by a vehicle at or below the anticipated operating speed of the roadway with low probability of serious injury to the occupants of the vehicle. The evaluation of vehicle crashworthiness has 
involved numerous full-scale crash tests of the vehicle and highway hardware to verify the compliance with regulatory requirements (Alberson et al. 2005; Reid et al. 2001; Plaxico et al. 2000; Pfeifer and Sicking, 1997). CHBDC specifies transverse, longitudinal and vertical loads of 100, 30 and $30 \mathrm{kN}$ and 210, 70 and $90 \mathrm{kN}$ for PL-2 and PL-3, respectively, that can be applied simultaneously over a certain barrier length. CHBDC specifies that transverse load shall be applied over a barrier length of 1050-mm for PL-2 barriers and 2400-mm for PL-3 barriers. Since transverse loading creates the critical load carrying capacity, both the longitudinal and vertical loads were not considered in the design of barrier wall reinforcement and anchorages between the deck slab and the barrier wall. It should be noted that CHDBC specifies a live load factor of 1.7. Thus, the design impact load specified in CHBDC is 170 and $357 \mathrm{kN}$ for PL-2 and PL-3, respectively. As for the design of the vertical and horizontal reinforcement in the barrier wall reinforced with steel bars, the authors utilized yield-line analysis for the ultimate flexural capacity of the barrier wall as specified in the AASHTO-LRFD bridge design specifications (AASHTO, 2012).

The recent static test to complete collapse performed on PL-3 GFRP-reinforced bridge barriers at interior and exterior locations showed development of punching shear through the wall thickness, which was followed by trapezoidal failure shape. This finding was dissimilar to the failure pattern at interior and exterior locations stipulated in AASHTO-LRFD for design of steel reinforced bridge barriers on the basis of yield-line analysis, in which triangular failure shape occurs at interior and exterior locations (See Figures 5.25 and 5.15). The yield-line analysis is based on the ultimate flexural capacity of the concrete members specified in the AASHTOLRFD bridge design specifications (AASHTO, 2012). In the analysis, it was assumed that the yield-lines occur within the barrier wall and do not extend into the deck slab. The experimental test results on GFRP-reinforced bridge barriers showed that diagonal shear cracks develop at barrier front face on both sides of the patch loading. Shear cracks further extended by increasing the load and reached the wall-deck junction forming horizontal flexural cracks at the junction. It was found that the failure was different than the AASHTO-LRFD failure pattern that only shear cracks appear at the barrier front face. Due to such differences, further experimental programs were conducted to investigate the failure mode of performance level 3 (PL-3) and performance level 2 (PL-2) traffic barriers reinforced with conventional steel bars at interior and exterior 
locations. Two constructed full-scale PL-3 and PL-2 steel-reinforced traffic barriers at Texas Transportation Institution (TTI) were tested until complete collapse at interior and exterior locations. Based on the experimental investigation observed on GFRP-reinforced bridge barriers as well as the actual failure of the traffic barriers during vehicle crashes, an extensive study was conducted herein on the failure mode and strength capacity of the traffic barriers on the basis of yield-line theory. The two construced PL-3 and PL-2 traffic barriers at the TTI site were tested under monotonic static test to-complete-collapse and their failure mode and structural behavior were investigated.

\subsection{AASHTO-LRFD Yield-Line Failure Pattern}

In design of barrier wall, it is identified that full scale crash testing program is oriented towards survival of the occupants, however, it does not necessarily consider the ultimate strength of the barrier wall system. The design capacity of the barrier wall system is considered based on the yield-line theory of analysis. The yield-line analysis is a procedure in which the barrier wall system is assumed to behave in-elastically and develop adequate ductility to sustain the applied load until the barrier wall reaches a plastic collapse mechanism. This assumption is realistic when barrier wall is under- reinforced to perform adequate ductility. The barrier wall is assumed to collapse at a certain ultimate load due to development of plastic hinges that is called yieldlines. The AASHTO-LRFD yield-line analysis is also based on the assumption that sufficient longitudinal length of barrier wall exists to result in the desired yield-line failure pattern. For short lengths of barrier walls, a single yield-line may form along the juncture of the barrier wall and the deck slab, which is called one-way action failure mode. Such a failure pattern is permissible, and the barrier wall resistance should be computed using appropriate analysis. Moreover, the AASHTO-LRFD yield-line analysis is based on the assumption that negative and positive wall resisting moments are equal and that negative and positive beam resisting moments are equal. In case, if sufficient longitudinal length of barrier is provided, two-way action failure will develop at interior or exterior locations of the barrier depending at the location of the applied load. AASHTO-LRFD specified that the two-way actions failure follows by formation of diagonal shear cracks at either sides of the patch loading. The design procedure of barrier walls

reinforced with conventional steel bars on the basis of yield-line theory is presented in AASHTO-LRFD codes, which is summarized in Chapter 2. 


\subsection{Experimental Programs}

\subsubsection{PL-3 Steel-Reinforced Barrier Configuration}

The PL-3 traffic barrier at TTI site was tested under quasi-static loading equivalent for vehicle crash testing into the barrier. The constructed PL-3 barrier had a geometry and barrier shape similar to the Standard PL-3 bridge barrier specified in CHDBC which was approved by Ministry of Transportation of Ontario (MTO- SS110-67 drawings) and widely used in Ontario highway bridges. Figure 6.1 depicts geometry and reinforcing details in PL-3 traffic barriers. The minimum height required for PL-3 barrier to prevent vehicle roll-over is specified in CHBDC as $1050-\mathrm{mm}$. The overall height of the barrier above the deck slab is taken as 1140-mm. The traffic barrier had a wall thickness of $225-\mathrm{mm}$ at the top, proportionally increased to $305-\mathrm{mm}$ at the tapered portion of the wall, and further increased to $475-\mathrm{mm}$ at the base of the wall. The wall was reinforced with 19M bars at 200-mm spacing (\#6@8") as vertical reinforcement. The horizontal reinforcement was placed at an average spacing of 250-mm using 19M (\#6@10") steel bars. The deck slab beneath the traffic barrier had a uniform thickness of 360-mm (14") reinforced with 19M bars at 150-mm spacing (\#6@6") as tension reinforcement. It should be noted that the current PL-3 steel barrier was constructed along the previously tested GFRPreinforced PL-3 barrier in Chapter 5. This experimental test aimed to correlate the experimental findings in terms of cracks patterns, failure model and overall strength to be compared with the previously tested GFRP-reinforced PL-3 barriers. Figure 6.2 shows views of the PL-3 steel barrier during construction with placement of connecting steel bars and the barrier after casting. Prior to static testing, the CFRP sheets were placed on the deck slab to further increase the deck slab capacity so that the failure occur within the body of the traffic barrier. Figure 6.3 shows views of the PL-3 barrier with placement of the CFRP sheets on the deck slab prior to testing.

Conventional steel reinforcing bars were used as reinforcement in the wall and the deck slab. The reinforcement bar size of 19M (\#6) with grade 60 steel or specified yield strength of $400 \mathrm{MPa}$ have been utilized. The concrete compressive strength was determined by taking core samples at time of the testing. The concrete core samples were taken along the length of the barrier at different locations. A minimum of three concrete core samples were tested and the characteristic compressive strengths were determined. The characteristic concrete compressive strength of PL3 traffic barrier was found from Eq. $3.1 \mathrm{~b}$ to be as $34.5 \mathrm{MPa}$, which is provided in the Table 6.1. 
Figure 6.4 shows views of core testing of the tested PL-3 steel barrier. In accordance with CHDBC requirements, a resistance factor of 0.9 was taken for steel reinforcing bars, while a resistance factor of 0.75 was considered for concrete.

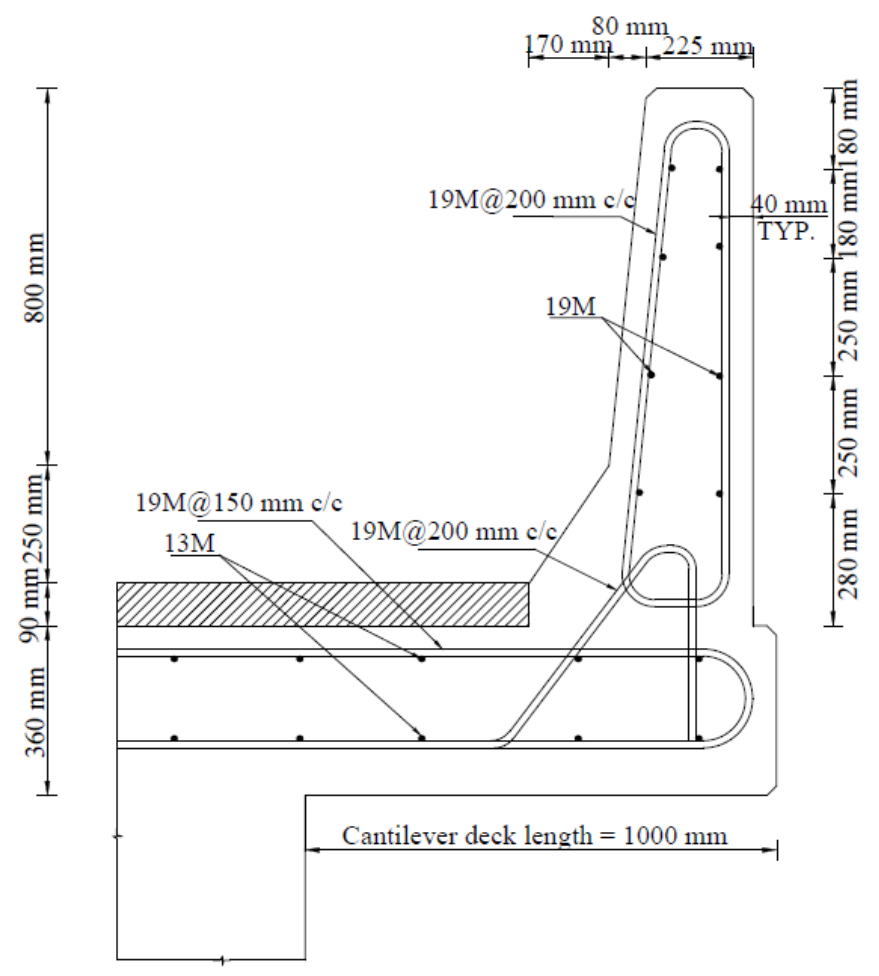

Figure 6. 1 Geometry and reinforcement arrangements in PL-3 barriers reinforced with conventional steel bars

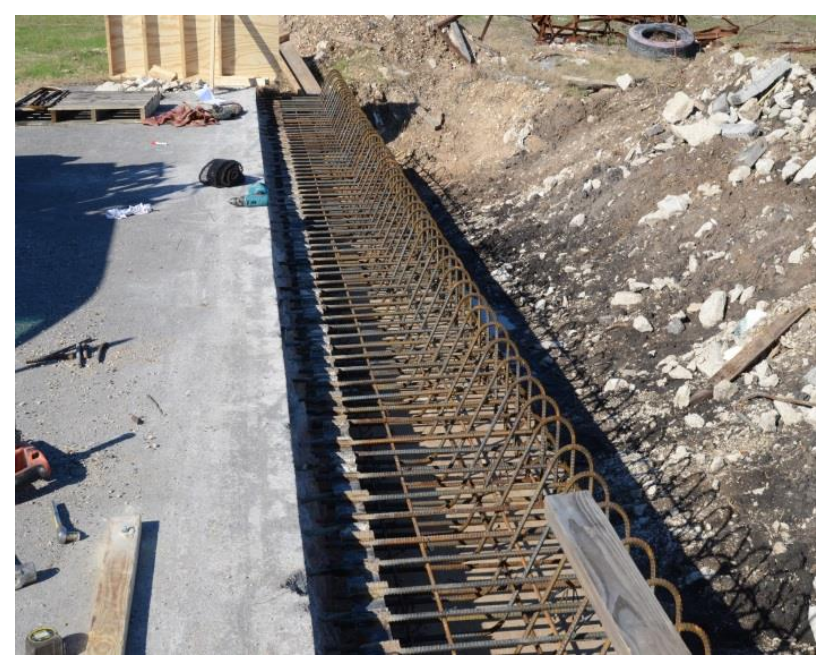

(a) View of connecting bars

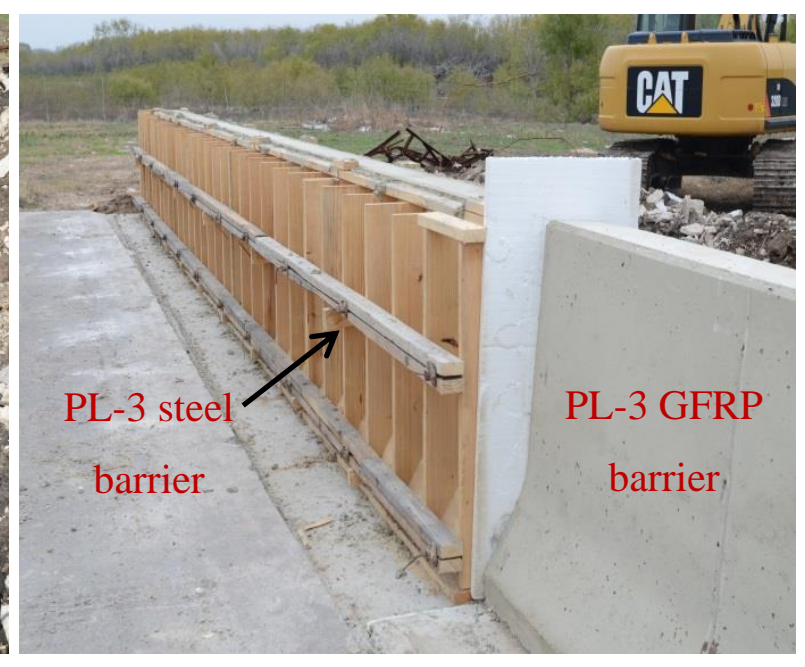

(b) PL-3 steel barrier after casting

Figure 6. 2 View of the PL-3 steel barrier during construction 


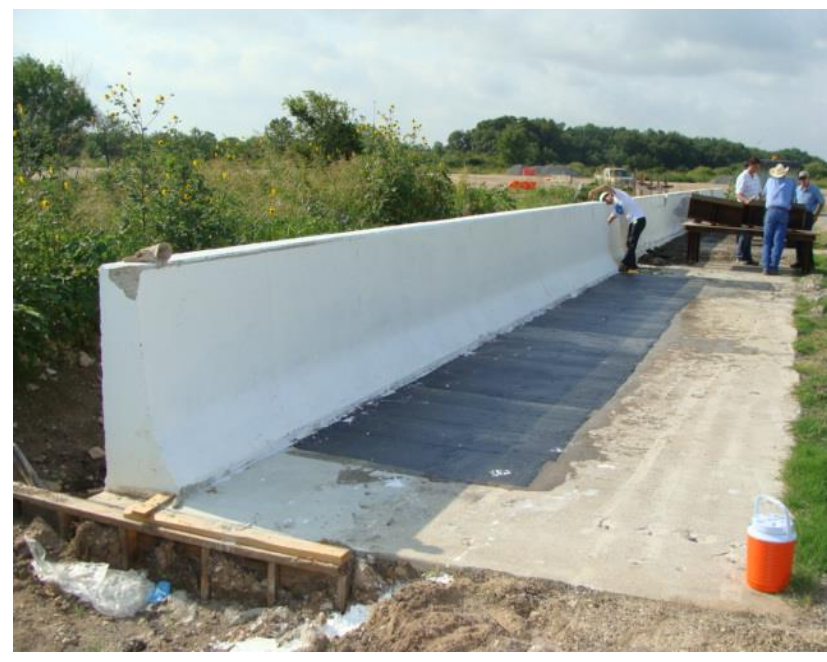

(a) at interior location

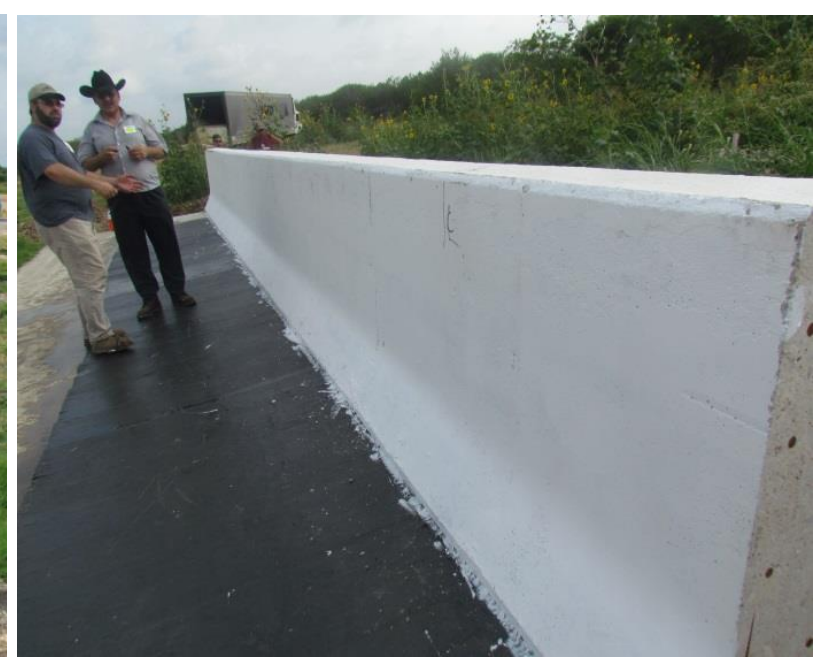

(b) at exterior location

Figure 6. 3 Views of the PL-3 steel barrier after placement of CFRP sheets on the deck slab

Table 6. 1 Characteristic concrete compressive strength of PL-3 and PL2 steel barriers

\begin{tabular}{|c|c|c|c|c|c|c|c|}
\hline $\begin{array}{l}\text { Barrier } \\
\text { type }\end{array}$ & $\begin{array}{c}\text { No. of } \\
\text { test }\end{array}$ & $\begin{array}{c}\text { Data } \\
(\mathrm{MPa})\end{array}$ & $\begin{array}{l}\text { Avg. } \\
\text { value }\end{array}$ & $(\text { Data -Avg. })^{2}$ & $\begin{array}{l}\text { Standard } \\
\text { deviation }\end{array}$ & $\begin{array}{l}\text { Coefficient } \\
\text { of } \\
\text { variation }\end{array}$ & $\begin{array}{c}\text { Characteristic } \\
\text { value } \\
(\mathrm{MPa})\end{array}$ \\
\hline \multirow{3}{*}{ PL-3 } & \multirow{3}{*}{3} & 37.49 & \multirow{3}{*}{39.48} & 3.973 & \multirow{3}{*}{2.01} & \multirow{3}{*}{0.0509} & \multirow{3}{*}{34.51} \\
\hline & & 39.45 & & 0.00111 & & & \\
\hline & & 41.51 & & 4.11 & & & \\
\hline \multirow{4}{*}{ PL-2 } & \multirow{4}{*}{4} & 44.2 & \multirow{4}{*}{44.57} & 0.1387 & \multirow{4}{*}{2.723} & \multirow{4}{*}{0.0611} & \multirow{4}{*}{38.18} \\
\hline & & 41.13 & & 11.85 & & & \\
\hline & & 47.7 & & 9.781 & & & \\
\hline & & 45.26 & & 0.4726 & & & \\
\hline
\end{tabular}

\subsubsection{PL-2 Steel-Reinforced Barrier Configuration}

The TL-4 traffic barrier was constructed in 1997 and was crash tested by Buth et al. (1997) at Texas Transportation Institution site. The constructed TL-4 New Jersey safety shaped barrier was implemented to meet requirements of Performance Level 2 (PL-2) bridge barriers in accordance with AASHTO-LRFD “Guide Specifications for bridge Railings, 1989”. The New Jersey safety shaped barrier was also adopted in CHBDC as requirements of PL-2 barrier in terms of shape, overall height and bar arrangement. Figure 6.5 shows geometry and reinforcing bar arrangement of the New Jersey shaped PL-2 traffic barrier. To prevent vehicle roll-over 
during a collision, CHBDC provides specifications to minimum height of PL-2 traffic barriers as 800-mm.

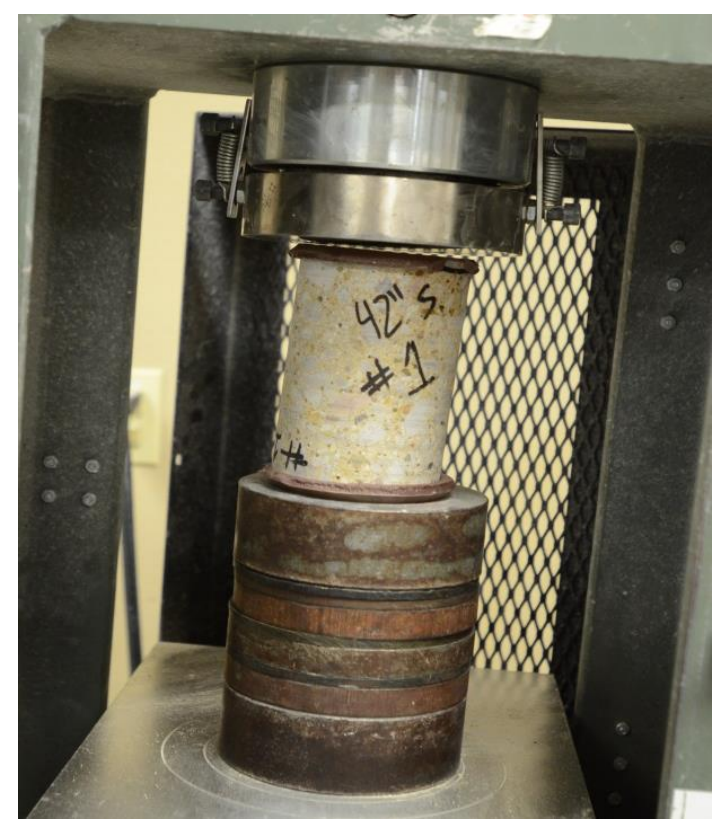

(a) Core sample before testing

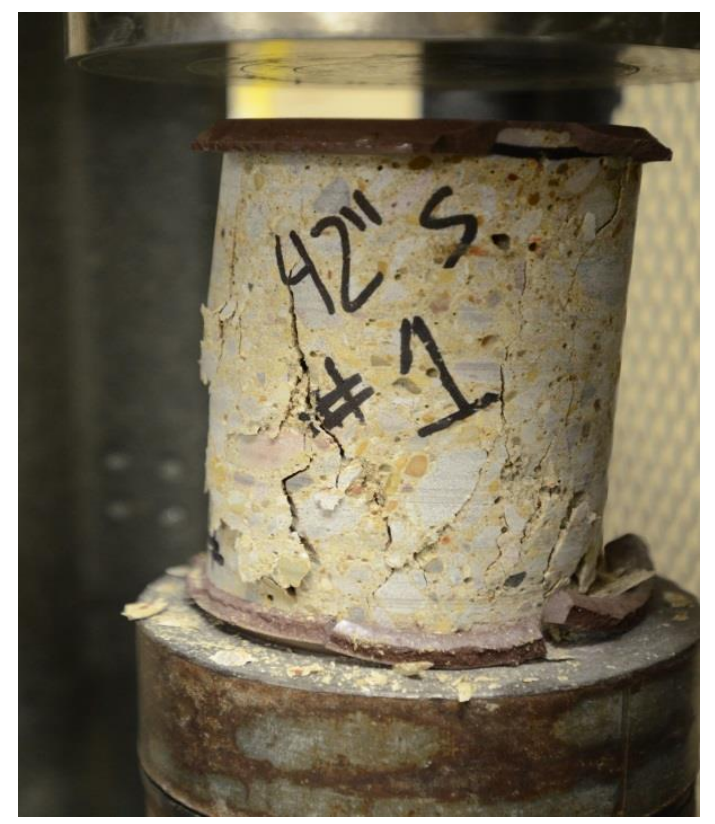

(b) core sample after testing

Figure 6. 4 Core sample testing of the PL-3 steel barrier

The PL-2 New Jersey traffic barrier had also wall thickness of 152-mm at the top that was increased to 203-mm and 381-mm at the tapered portion and base of the wall, respectively. The vertical and horizontal reinforcement at front and back faces of wall were selected as 16M (\#5) and 13M (\#4) bars, respectively, all at 200-mm (8") spacing. The deck underneath the barrier wall had a thickness of 203-mm and heavily reinforced with 16M bars placed at 120-mm bar spacing (\#5@4-3/4") so that to prevent failure in the deck slab. Figure 6.6 illustrates views of the New-Jersey PL-2 traffic barrier before the testing with the placement of CFRP sheets on the deck slab. Conventional steel bars of 13M (\#4) and 16M (\#5) with specified yield strength of $400 \mathrm{MPa}$ and yielding strain of 0.002 have been utilized. The characteristic concrete compressive strength of the PL-2 barrier was determined from four concrete core samples on the day of testing as 38.18 MPa (See Table 6.1).

The New Jersey shape PL-2 traffic barrier under study had been crash tested by Buth et al. (1997). To meet the requirements of Performance Level 2, the barrier was crash tested utilizing 
8.17 tons $(18000 \mathrm{lb})$ truck at the speed limit of $80.5 \mathrm{~km} / \mathrm{h}(50 \mathrm{ml} / \mathrm{h})$ striking the barrier at an angle of 15 degree. The barrier was also tested using a pickup of 2.45 tons $(5400 \mathrm{lb})$ that stroke the barrier at speed limit of $96.6 \mathrm{~km} / \mathrm{h}(60 \mathrm{ml} / \mathrm{h})$ with contact angle of 20 degrees. The 1982 single unit-truck was directed into the New Jersey shaped tested barriers using remote control guidance system. The speed of vehicle at the time of impact was $83.1 \mathrm{~km} / \mathrm{h}(56.1 \mathrm{ml} / \mathrm{h})$ with impact angle of 15.5 degree. From the crash test, it was observed that the New Jersey safety shaped barrier contained and redirect the test vehicle with no significant lateral movement of the barrier wall. It was also observed that there was no damage to the occupant compartment with only small deformation of the compartment. The vehicle trajectory indicated no intrusion into the adjacent traffic lanes.

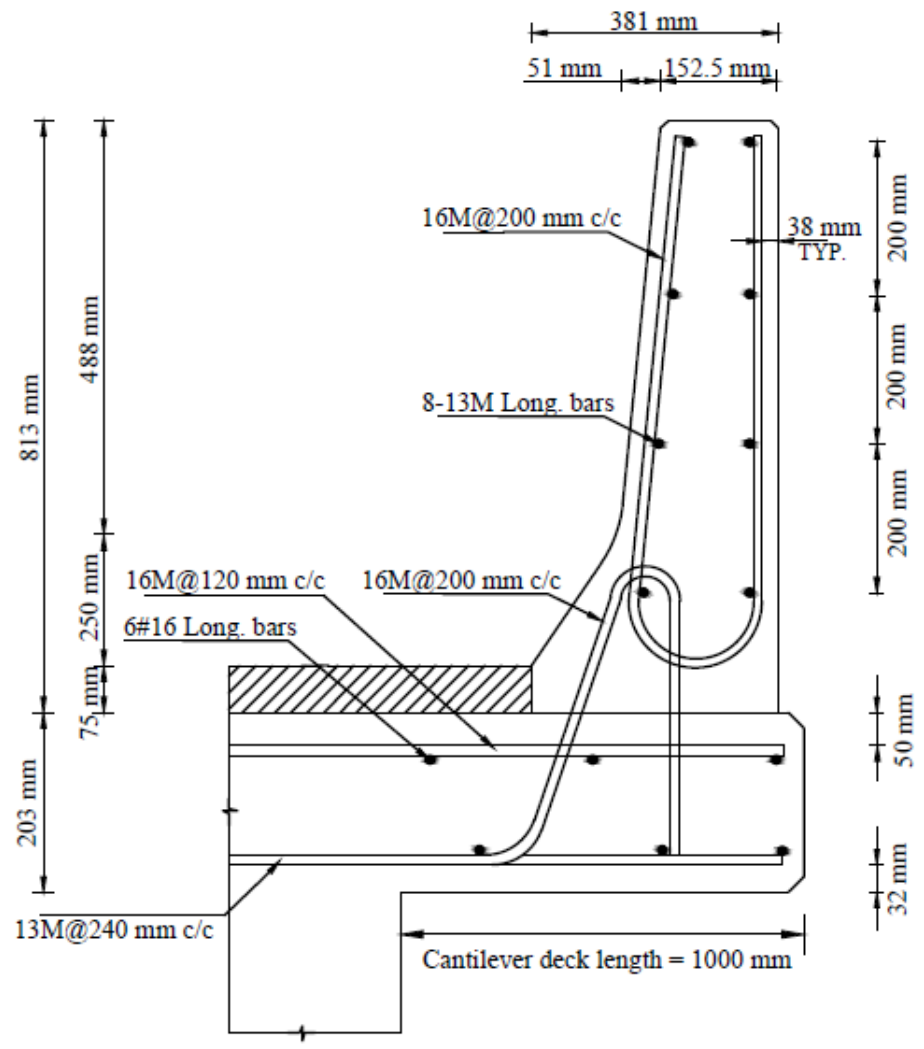

Figure 6. 55 Geometry and reinforcement arrangements in PL-2 barriers reinforced with conventional steel bars 


\subsection{Test Setup, Instrumentations and Test Procedure}

The test setup for static load testing of the traffic barrier is shown in Figure 6.7. It consists of a table with two steel I-beams placed on the top to adjust the distance between load cell and jacking load to the front face of the wall. A wood lumber of 250-mm height and 100-mm thick adjusted the gap between steel I-beam and the wall so that the load could be uniformly distributed to the wall. The equivalent crash load of the vehicle was simulated by a line load $\left(\mathrm{L}_{\mathrm{t}}\right)$ of length 1050-mm and 2400-mm for PL-2 and PL-3 traffic barriers, respectively.

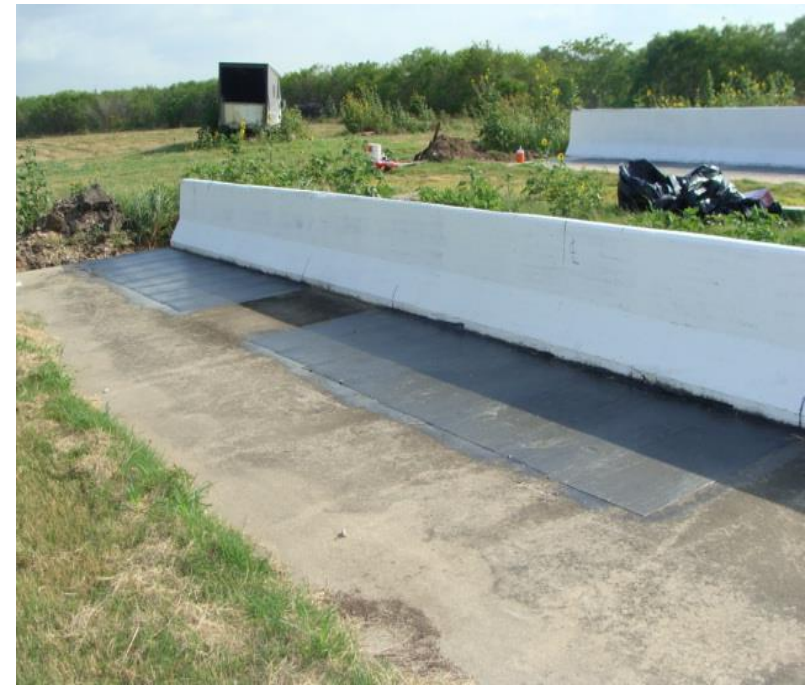

(a) at interior location

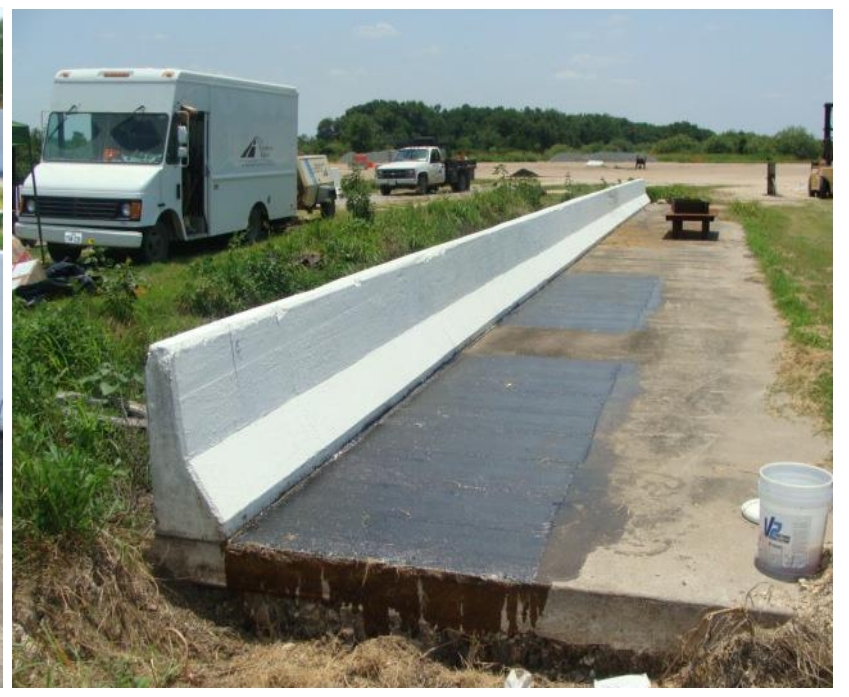

(b) at exterior location

Figure 6. 6 Views of the PL-2 steel barrier after placement of CFRP sheets on the deck slab

The hydraulic jack was supported on a steel column in which the column was tied down to the ground with 19-mm diameter bolts via base plate. The table was also bolted to the ground so that any lateral movement of the table and steel column would be prevented during testing. The jack was connected to the hydraulic pump that applied pressure to the system. Load-cell was also connected to data acquisition system via cable along with other sensors attached to the wall so that the load and displacement could be captured. Before conducting the static test, the constructed barrier was instrumented at the loaded regions. Figures 6.8 and 6.9 show views of sensor designations on the wall and the deck slab over 1050-mm in PL-2 and 2400-mm in PL-3 at interior and exterior locations of the tested barriers. Linear variable displacement transducers (LVDTs) and potentiometers (POTs) were installed to measure barrier transverse deflections at 990-m height from the deck slab and at equal spacing of 1200-mm in the PL-3 barrier and 500- 
$\mathrm{mm}$ in PL-2 barrier in longitudinal direction of the barrier wall. In addition, other displacement sensors were placed at bottom of the deck slab in order to measure vertical deflection of the barrier wall under the applied load. PI stain gauges were also installed at back face of the wall to measure strain changes at compression side of the wall as well as the crack opening at back face of the wall at interior location due to the applied load. The latter strain gauge at interior location (shown in Figures 6.8a and 6.9a as S1) were aimed to observe the vertical crack opening stated in AASHTO-LRFD code in which a vertical crack will appear at back face of the wall (see Figure 5.25). Data acquisition system was used to record data from sensors at a rate of 10,000 scans per second.

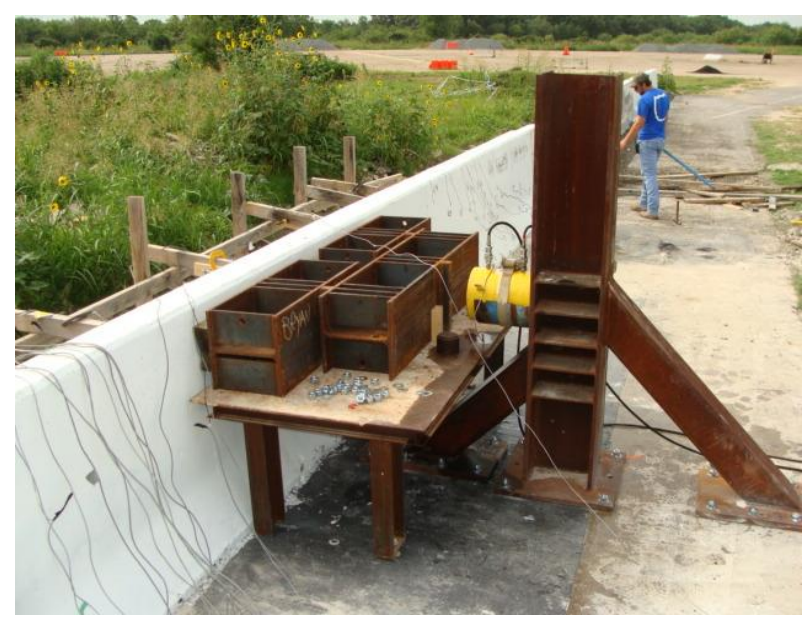

(a) PL-3 barrier at interior location

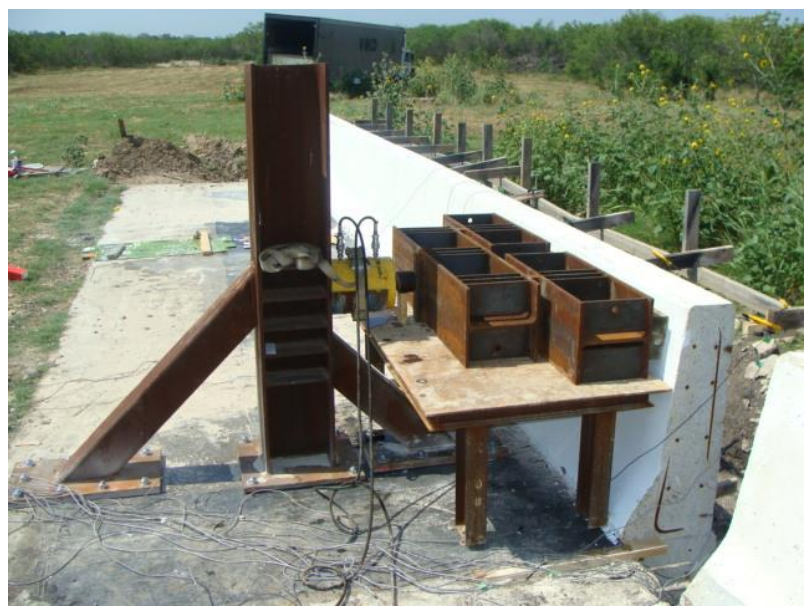

(c)PL-3 barrier at exterior location

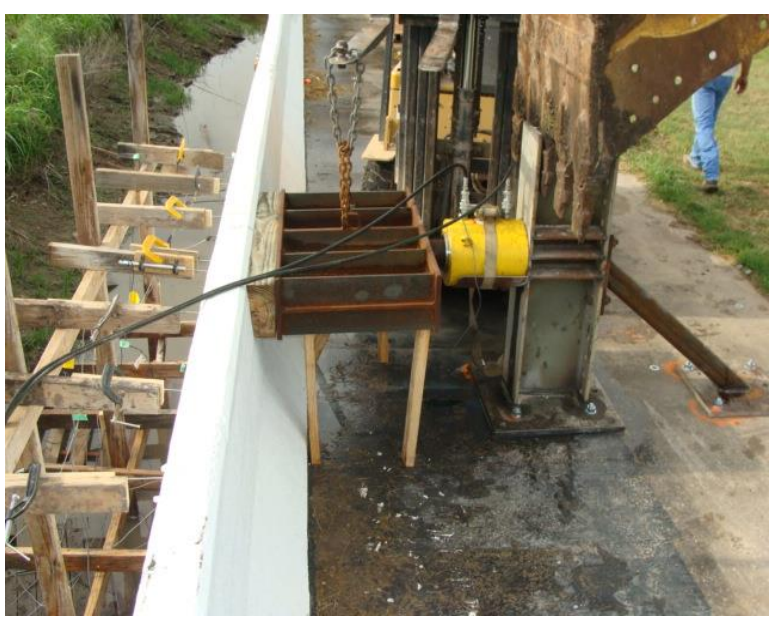

(b) PL-2 barrier at interior location

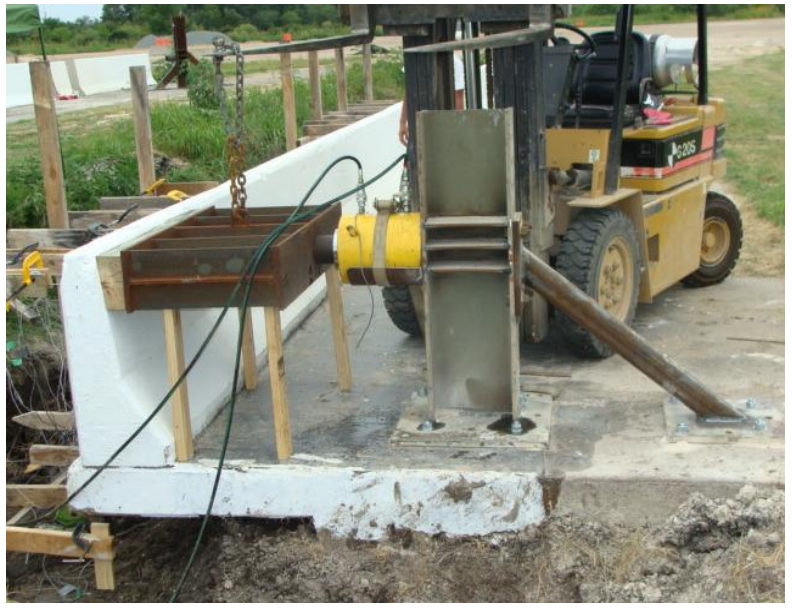

(d) PL-2 barrier at exterior location

Figure 6. 7 Views of the test setup for static testing of the steel-reinforced barrier 

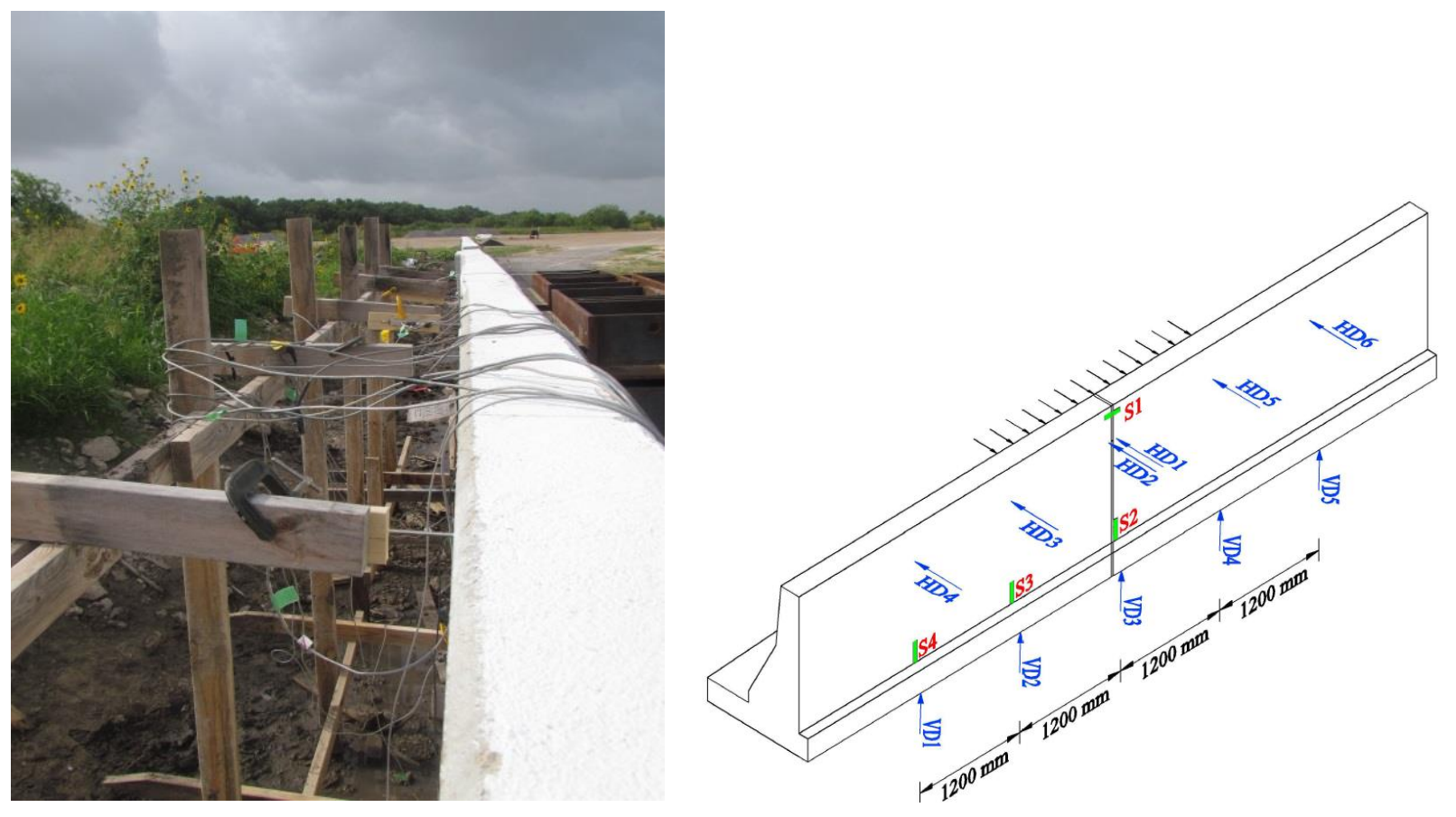

(a) At interior location
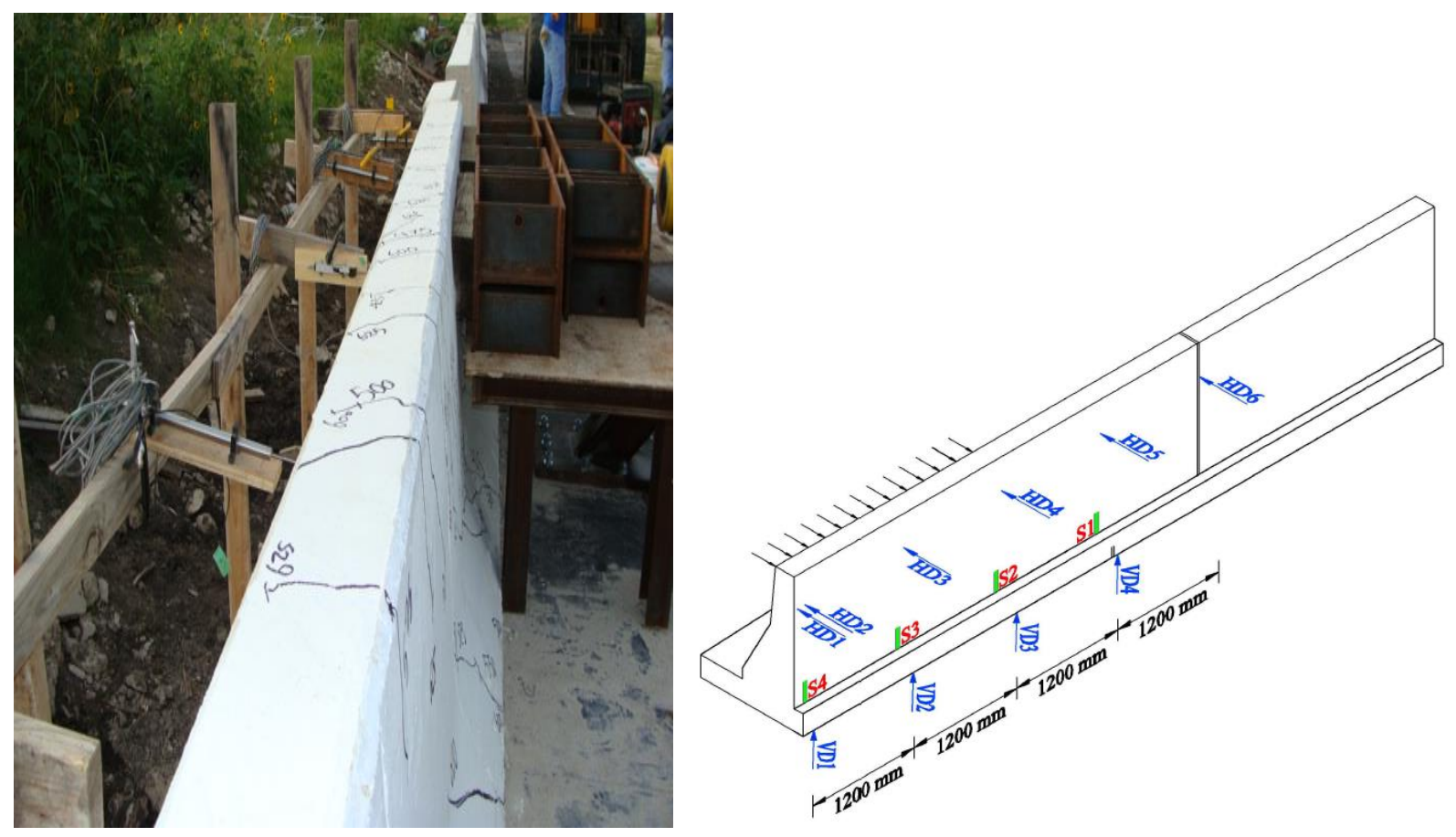

(b) At exterior location

Figure 6. 8 Designated sensor locations in PL-3 traffic barrier 

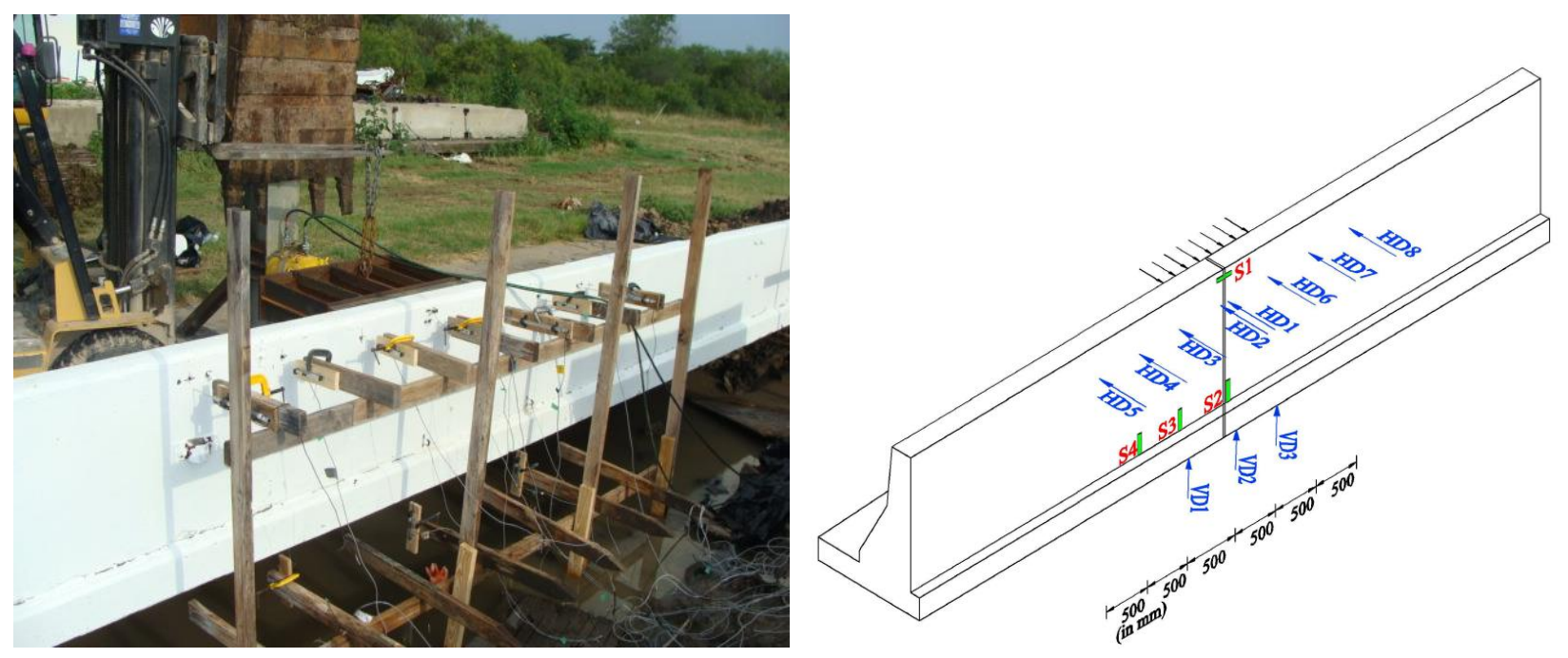

(a) At interior location
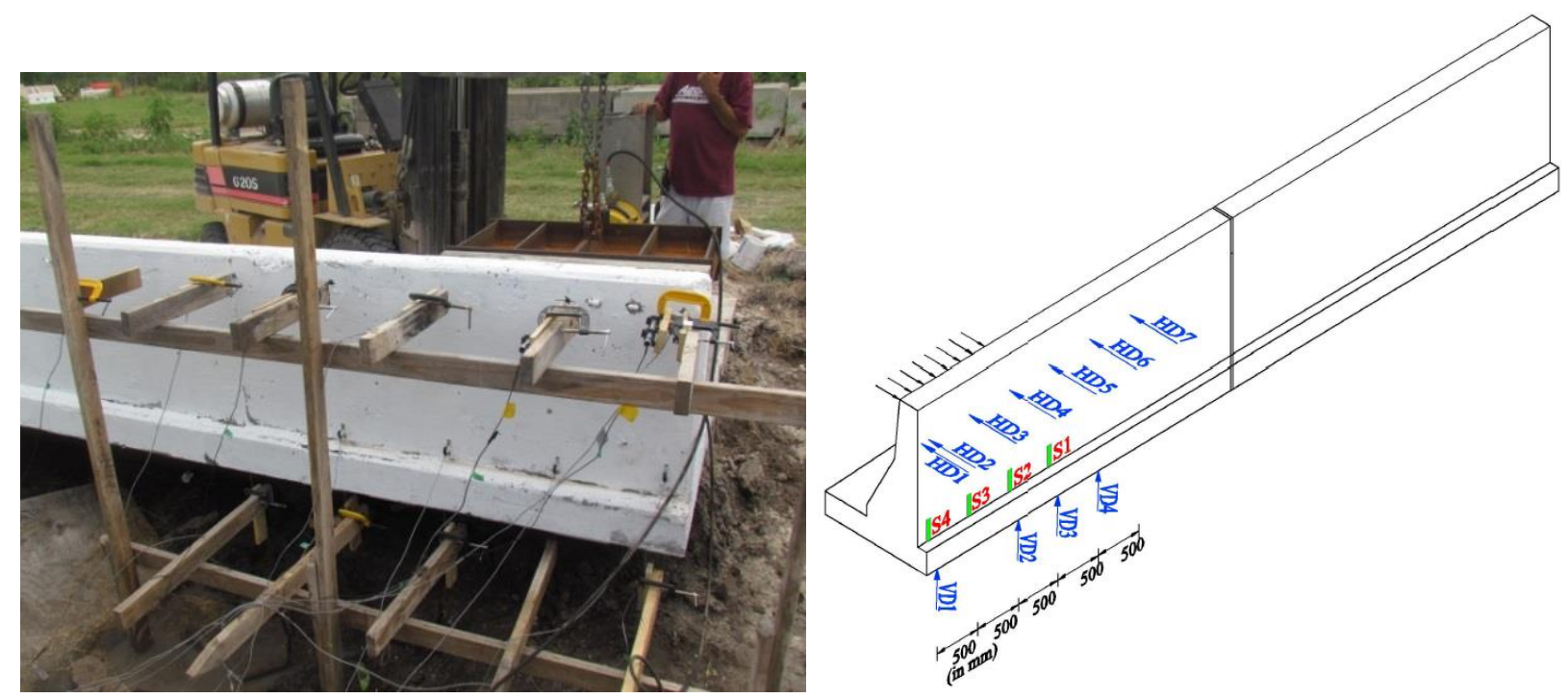

(b) At exterior location

Figure 6. 9 Designated sensor locations in PL-2 traffic barrier

\subsection{Experimental Test Results}

\subsubsection{PL-3 Steel Barrier Results}

\subsubsection{PL-3 Barrier at Interior Location}

The PL-3 traffic barrier was tested to-complete-collapse under increasing monotonic loading at interior location. The load was applied at 990-mm above the deck slab as per CHBDC requirement for static load testing of PL-3 traffic barriers. The load was applied manually using 
hydraulic jack and load increments were captured by the load-cell attached to the system. The load was applied in increment of $50 \mathrm{kN}$ to observe crack initiation in the barrier wall and the deck slab. At each load increment, cracks were marked at front or back faces of the wall. Due to the applied load, initial flexural crack was observed at tapered portion of the wall at $575 \mathrm{kN}$ that was propagated further up into to the wall by increasing the applied load to $725 \mathrm{kN}$. In addition, at load of $575 \mathrm{kN}$, diagonal cracks appeared on each side of the patch loading, which were propagated downward within the wall body and reached the base of the wall at deck-wall junction at higher load levels $(700-800 \mathrm{kN})$. By further increasing the load, cracks did not propagate, rather widened with the increase in the applied load. Furthermore, a horizontal crack was observed at base of the wall under the applied load. This horizontal load was noticed at a load close to the failure load of the wall and within a length about half of the loaded length of 2400-mm. The traffic barrier was loaded until it failed at load of $885.9 \mathrm{kN}$. The ultimate load was far greater than the minimum transverse load limit of $357 \mathrm{kN}$ specified in CHBDC. Given the ultimate load specified in CHBDC code for static testing of PL-3 barrier walls, a factor of safety of 885.9 / 357 equal to 2.48 can be obtained. At back face of the traffic barrier, several vertical cracks were observed that could be attributed to flexural behavior in plane. Figure 6.10 depicts cracks pattern at front and back faces of the wall. From the crack patterns at front face of the wall, it can be noticed that cracks propagated in a trapezoidal failure shape rather than triangular shape stipulated in AASHTO-LRFD on the basis of yield line failure pattern. Thus, it can be concluded that the failure mode of the PL-3 steel barrier was analogous to the failure mode of PL-3 barrier reinforced with GFRP bars. Therefore, the triangular failure pattern stipulated in AASHTO-LRFD is not valid anymore. The maximum wall lateral deflection at failure was $12.91-\mathrm{mm}$. It can be noted that the wall lateral deflection is very small to force the yield-lines into the deck slab and the failure was concentrated in the barrier wall portion. The traces of load-wall lateral deflection and deck vertical displacement for the PL-3 steel barrier at interior location are shown in Figure 6.11. It can be seen from the graphs that the load-deflection curve is linear at initial load followed by plastic deformation of the barrier wall. This can be attributed to plastic behavior of reinforcement at front face of the wall due to the applied load. It should also be mentioned the strain gauges attached to the wall system at interior location were damaged during testing due to high failure load. As such, result from load-strain curve was not available for this barrier at interior location. 


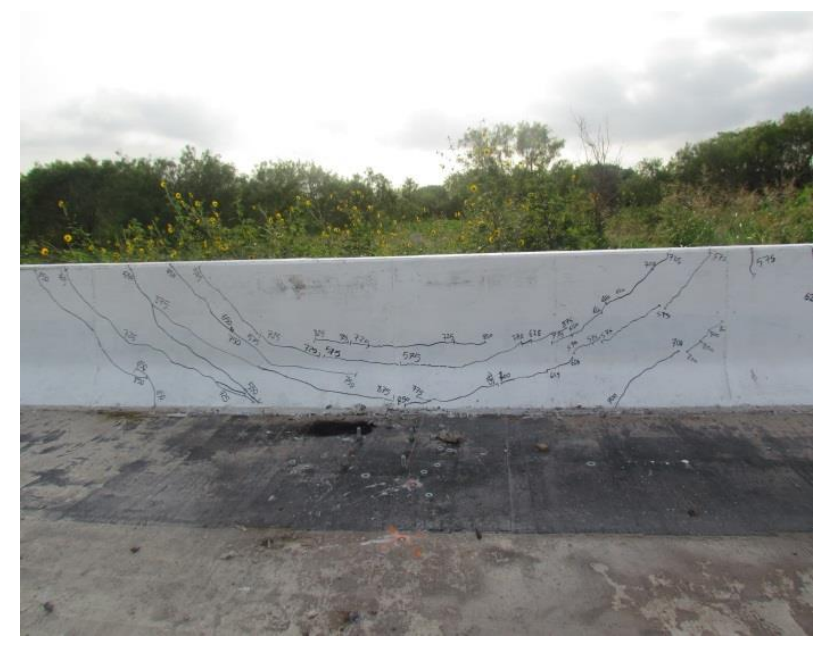

(a) Front face

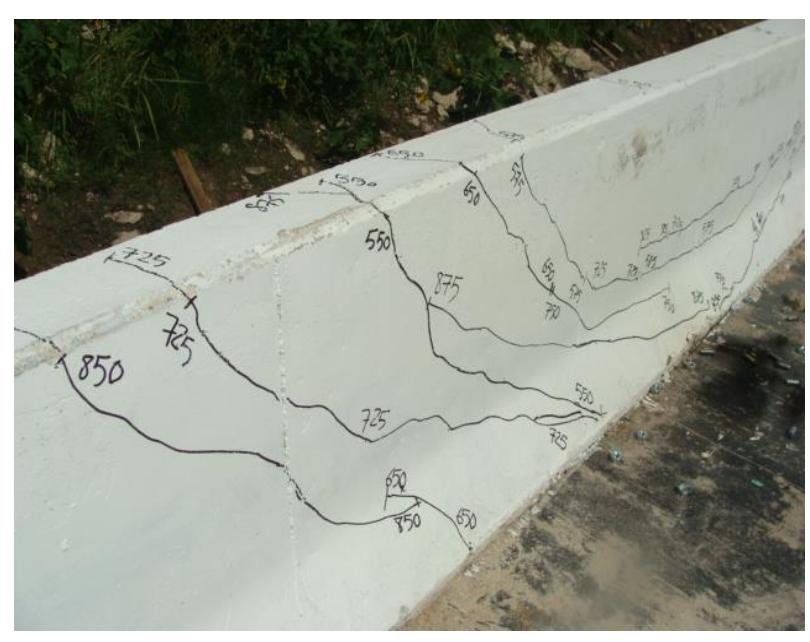

(c) Cracks extending to top of wall thickness

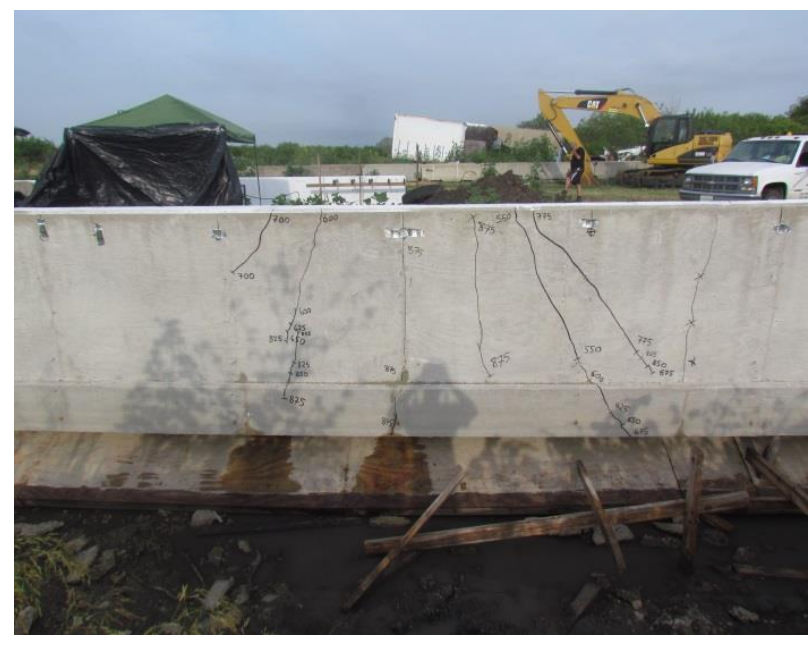

(b) Back face

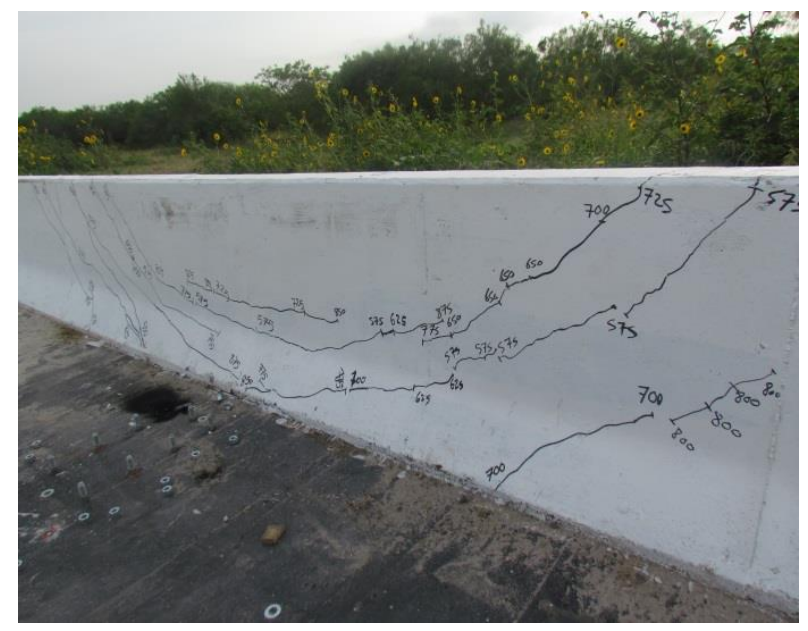

(d) Diagonal cracks in the wall

Figure 6. 10 Crack pattern at front and back faces of PL-3 steel traffic barrier

\subsubsection{PL-3 Barrier at Exterior Location}

The PL-3 traffic barrier was also tested at exterior location under static load testing. In accordance with CHBDC requirements for static testing, the load was applied at 990-mm above the deck slab over a loaded length of $2400-\mathrm{mm}$ for PL-3 barriers. The load was applied in $50 \mathrm{kN}$ increments and maintained for few minutes to mark the crack initiations at front or back faces of the traffic barrier. Due to applied increasing loads, it was observed that the barrier experienced flexural cracks within the loaded region and diagonal-shear cracks beyond the loaded region. 


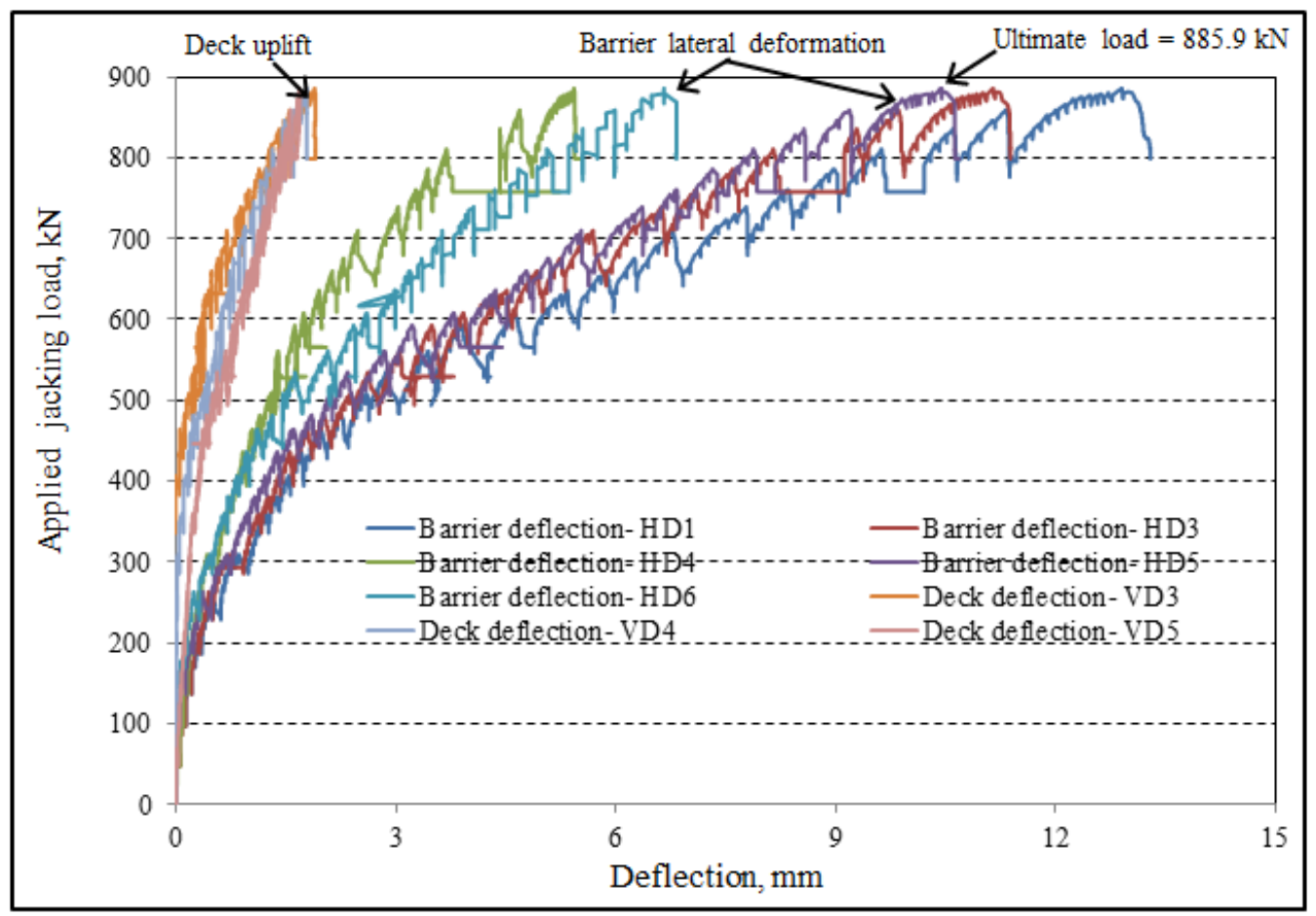

Figure 6. 11 Load-deformation curves of the tested PL-3 steel-reinforced barrier at interior location

Figure 6.12 shows views of crack pattern at front and back faces of the PL-3 traffic barrier at exterior location. The first crack was observed at a load of $425 \mathrm{kN}$ that is diagonally extended toward the top of the traffic barrier by increasing the applied load as shown in Figure 6.12a. At load of $500 \mathrm{kN}$, a horizontal flexural crack appeared at base of the wall. This crack appeared at about two-third of the 2400-mm loaded length, which was diagonally extended into interior region of the barrier wall. By increasing the applied load, other diagonal cracks have been observed at front face of the wall toward the top of the wall extending into the wall thickness as shown in Figure 6.12b. Few cracks also extended into the wall thickness shown in Figure 6.12c at the tapered portion and at the corner base of the wall at loads between 525 to $625 \mathrm{kN}$. The test ended when the barrier could not absorb any further increase in the applied load beyond 627.13 $\mathrm{kN}$. This ultimate load carrying capacity of the wall was greater than the minimum transverse load limit of $357 \mathrm{kN}$ specified in the CHBDC with a factor of safety of 1.76. At back face of the wall, diagonal torsional cracks were observed which were extended down into the deck slab at the failure load (See Figure 6.12d). No sing of vertical cracks due to in plane flexural behaviour were observed at back face of the wall as was the case at interior location. From test 
observations, it can also be noticed a trapezoidal failure pattern at front face of the wall rather than triangular failure pattern caused by only one diagonal tension crack as stipulated in AASHTO-LRFD on the basis of yield-line theory. This failure by trapezoidal shape was also similar to the GFRP-reinforced barriers tested at exterior location.

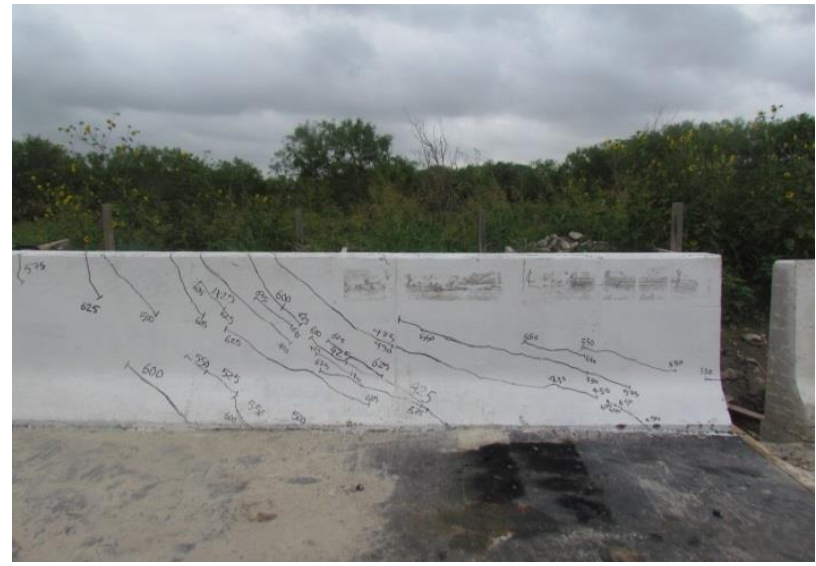

(a) Crack pattern at front face of the wall

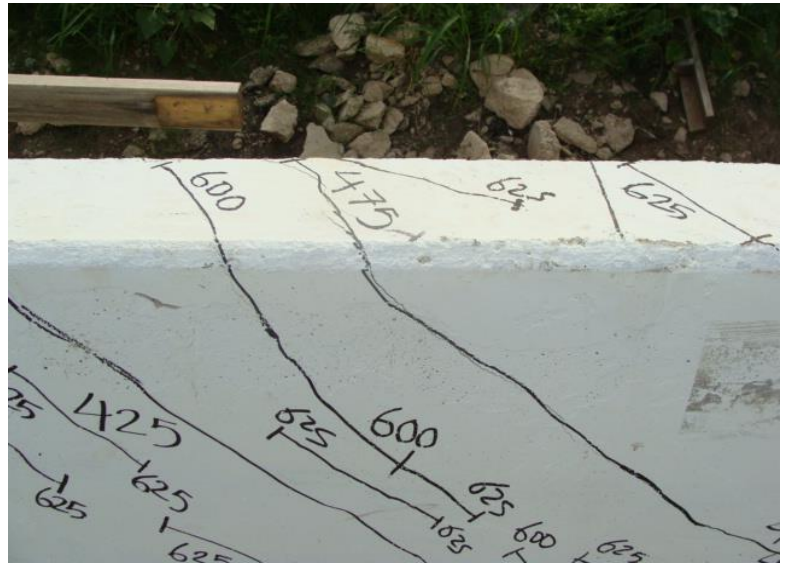

(b) Cracks through the wall thickness

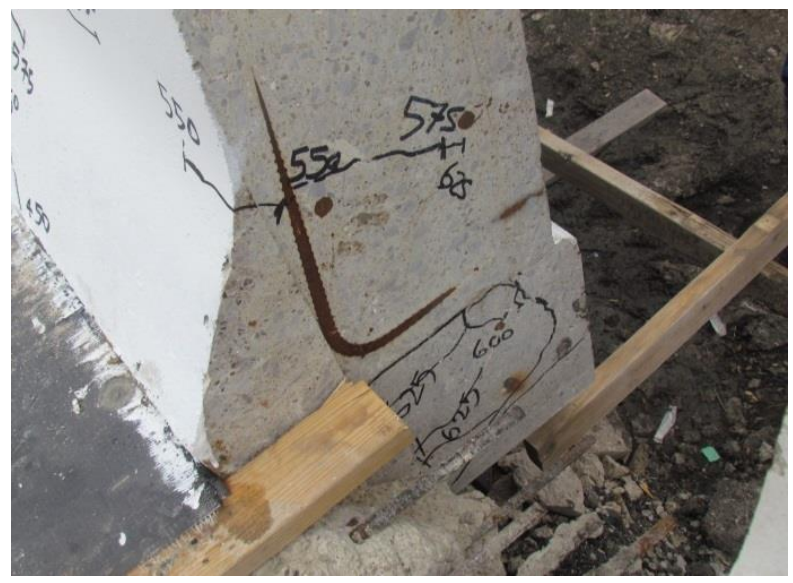

(c) Cracks at the base and tapered portion

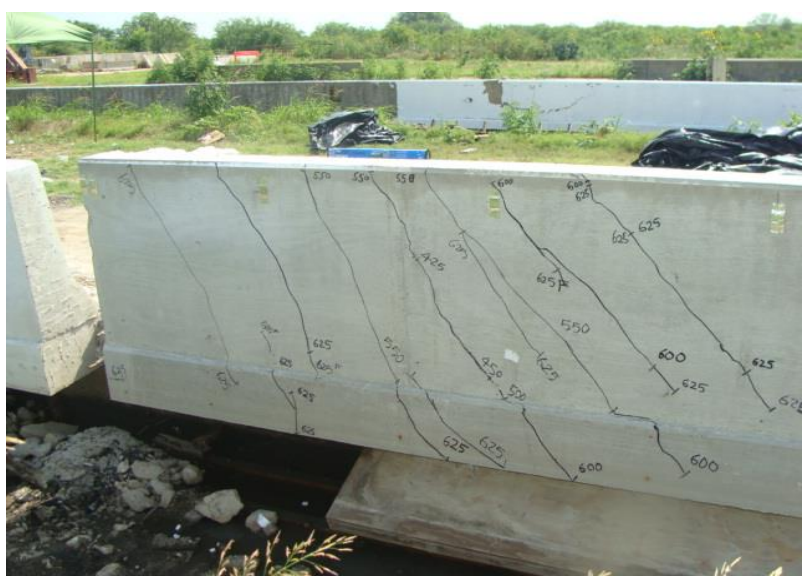

(d) Diagonal torsion cracks at back face

Figure 6. 12 Crack patterns at front and back faces of the PL-3 traffic barrier at exterior location

The traces of load-wall lateral deformation and deck vertical deformation as well as load-strain curve are shown in Figure 6.13. It can be observed that the wall exhibited a maximum lateral deformation of $30.3 \mathrm{~mm}$ that can be regarded as flexural and torsional behavior of the wall at exterior region. 


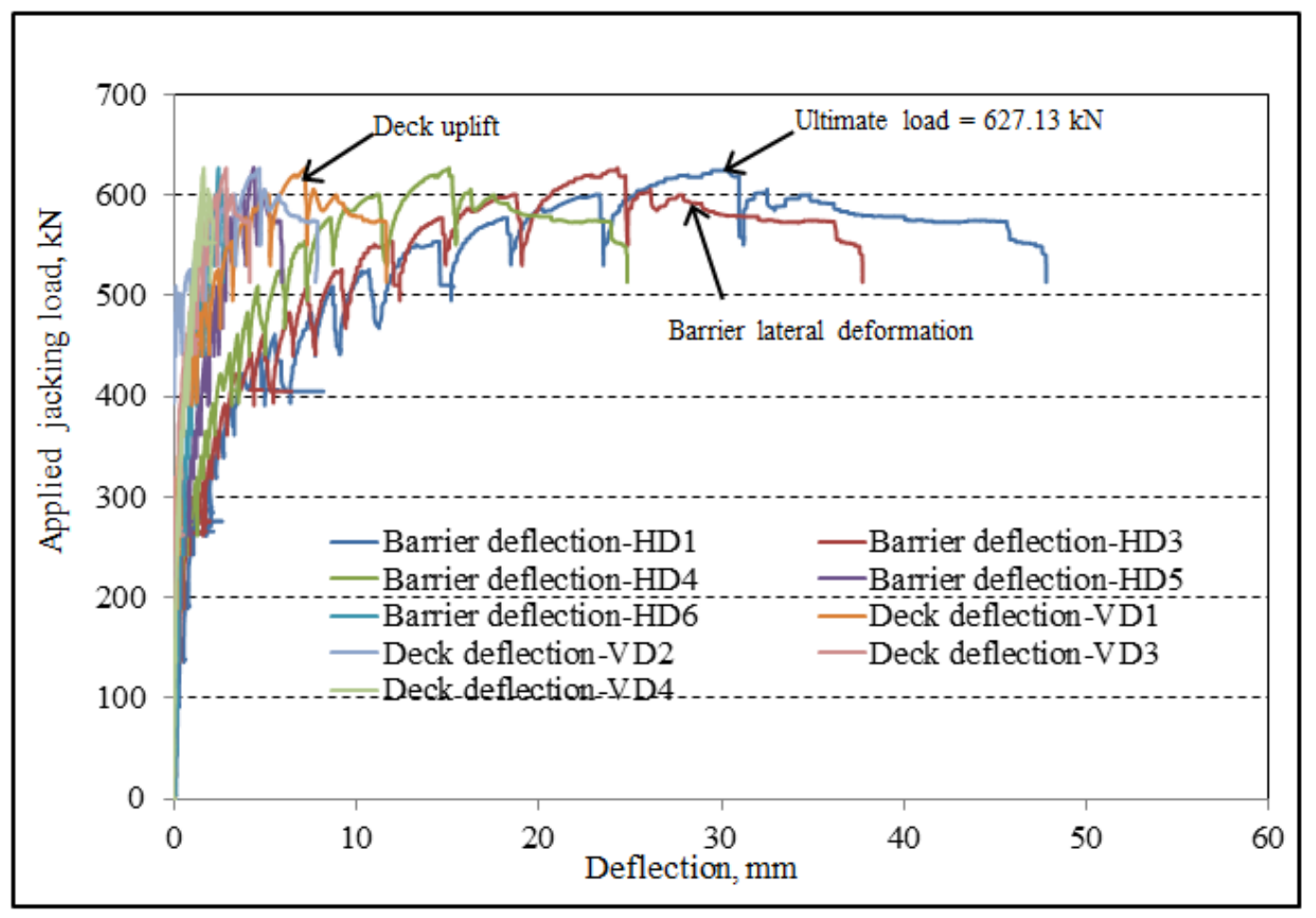

(a) load-deformation curve

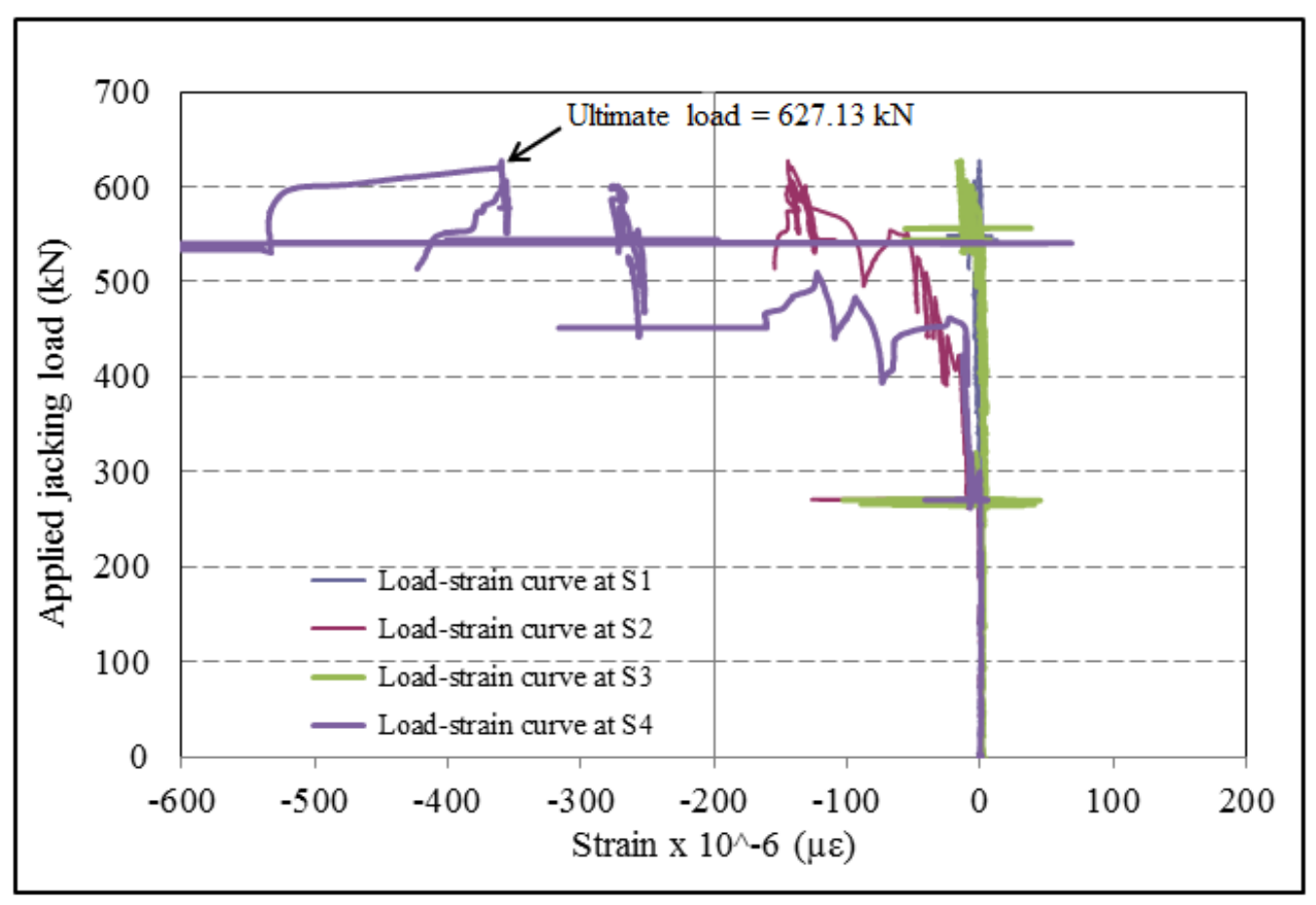

(b) load-strain curve

Figure 6. 13 Trace of load-wall deformation and load-strain curves in PL-3 barrier at exterior location 
It can also be seen that the wall deformation linearly increased at initial load followed by plastic deformation with increase in the applied load. From strain gauges attached to back face of the wall, a maximum compressive strain at failure of $-369.5 \mu \varepsilon$ was observed which was far less than the crushing strain of concrete $(-3500 \mu \varepsilon)$.

\subsubsection{PL-2 Steel Barrier Results}

\subsubsection{PL-2 Barrier at Interior Location}

The constructed PL-2 traffic barrier was tested to-complete-collapse under increasing applied load located 765-mm above the deck slab as per CHBDC requirement. In PL-2 traffic barrier, the first crack was observed at load of $200 \mathrm{kN}$ at tapered portion of the wall. Due to increase in the load, initial crack at the tapered wall was propagated diagonally upward in the wall. At load of $300 \mathrm{kN}$, a second crack appeared above the tapered portion of the wall which was also propagated upward to the top of the wall on each side of the patch loading. Other diagonal cracks were observed in the wall that was extended into the base of the wall at deck-wall junction at load of 340-380 kN. Similar to PL-3 traffic barrier, a horizontal crack was formed at base of the wall once the wall ultimate resistance was reached. The sign of punching shear failure was observed at top of the wall on each side of the patch loading at failure load of $421.9 \mathrm{kN}$. The ultimate failure load was found to be greater than the minimum transverse load limit of $170 \mathrm{kN}$ as specified in CHDBC leading to a factor of safety of 2.48. In addition, the crack pattern was analogous to the case of PL-3 traffic barrier by trapezoidal failure mode. The vertical cracks appeared at back face of the wall confirmed flexural behavior in plane in this region due to the applied load. Figure 6.14 illustrates crack patterns in a trapezoidal failure shape at front face of the wall as well as vertical cracks at back face of the wall. The maximum lateral deformation of the wall was captured by LVDTs attached to the wall equal to 9.42-mm which was deemed small to form yield-line pattern in the deck slab. The graphs of load versus wall and deck deflections as well as load-strain curve for PL-2 barrier are shown in Figure 6.15. Similarly, it can be noticed a linear deformation at initial loading followed by plastic deformation of the wall system at higher load level. It was also observed strain at failure of $-33.5 \mu \varepsilon$ that was comparably small compared to ultimate compressive strain of concrete (-0.0035). 


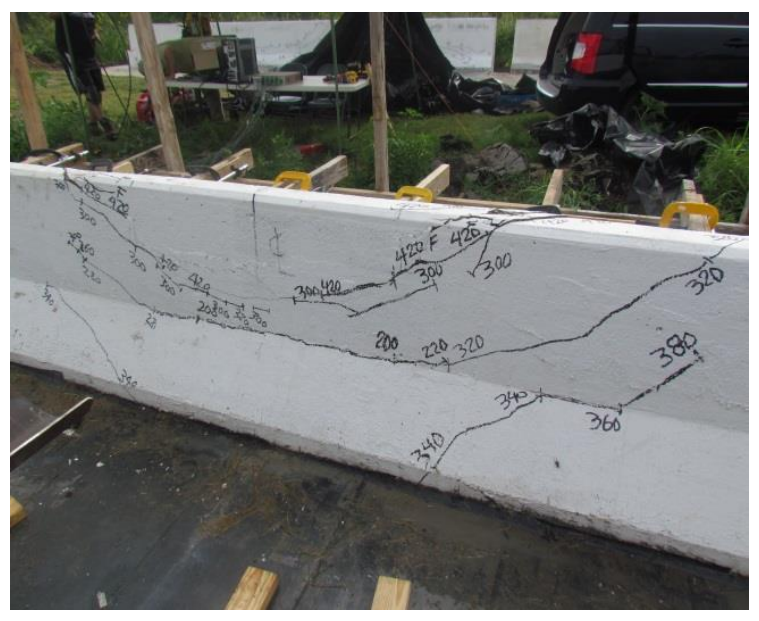

(a) Front face

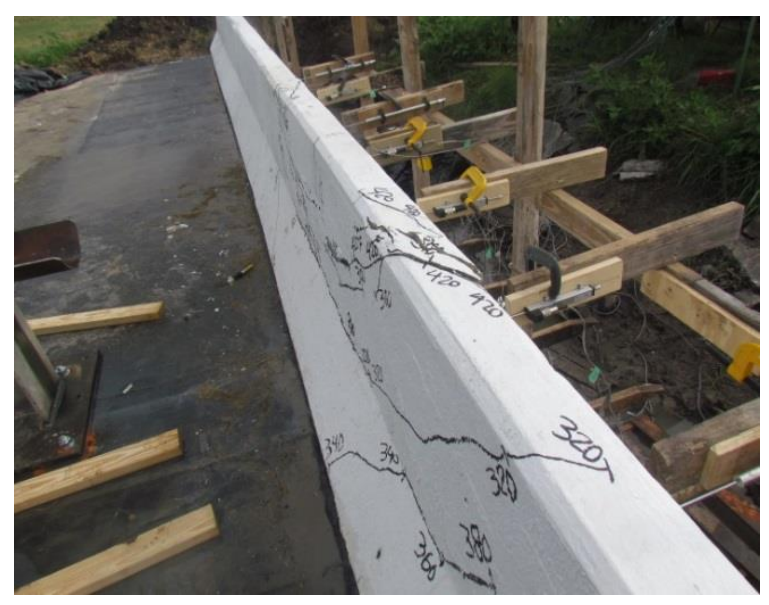

(c) Punching shear failure on top of the wall

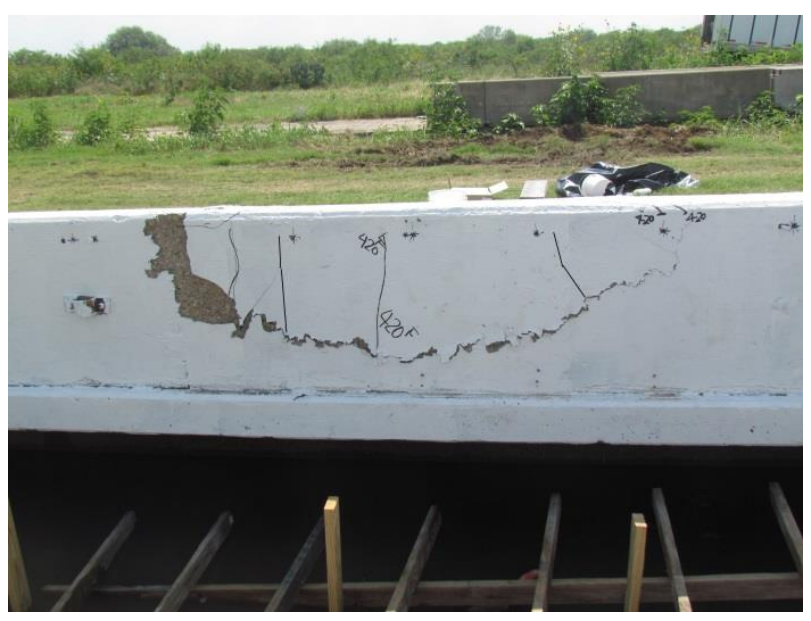

(b) Back face

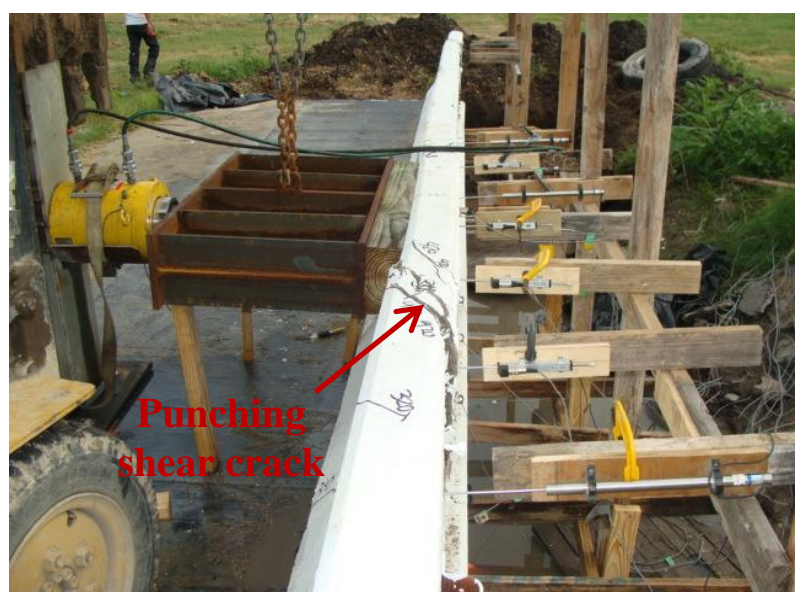

(d) Punching shear through wall thickness

Figure 6. 14 Crack pattern at front and back face of PL-2 steel traffic barrier at interior location

\subsubsection{PL-2 Barrier at Exterior Location}

Static load test was also conducted on the PL-2 traffic barrier at exterior location. The load was applied at $765-\mathrm{mm}$ above the deck slab over a loaded length of 1050-mm. Similar to PL-3 barrier, horizontal flexural cracks were observed within the loaded region of the PL-2 barrier followed by diagonal-flexural cracks beyond the loaded region. Figure 6.16 shows crack patterns in PL-2 traffic barrier at exterior location at front and back faces of the wall. The initial crack occurred at tapered portion of the wall at load of $140 \mathrm{kN}$. Due to increase in the applied load, cracks were propagated diagonally toward the top of the wall and extended into the wall thickness as shown in Figures 6.16a and 6.16b. 


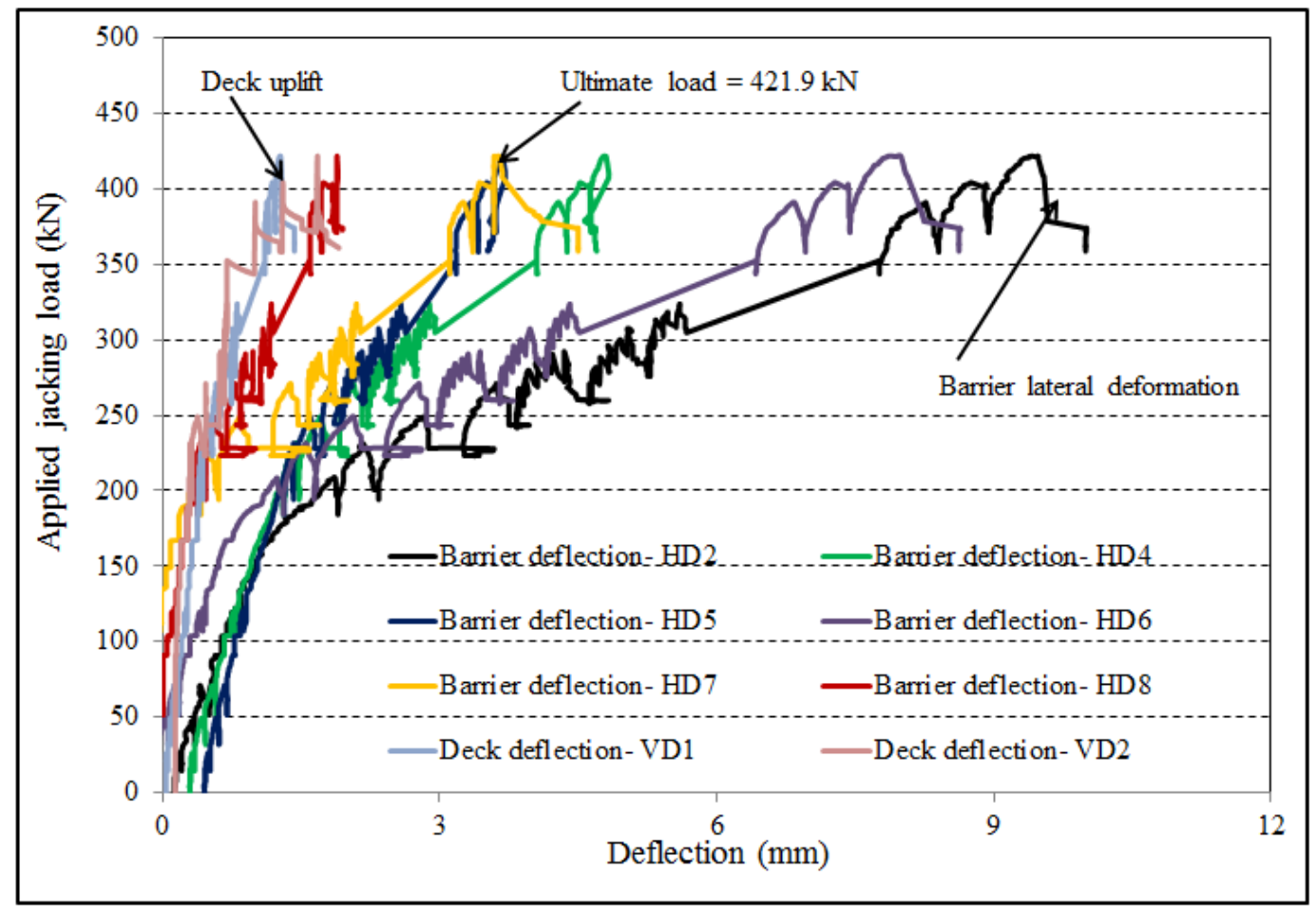

(a) Load-deflection curve

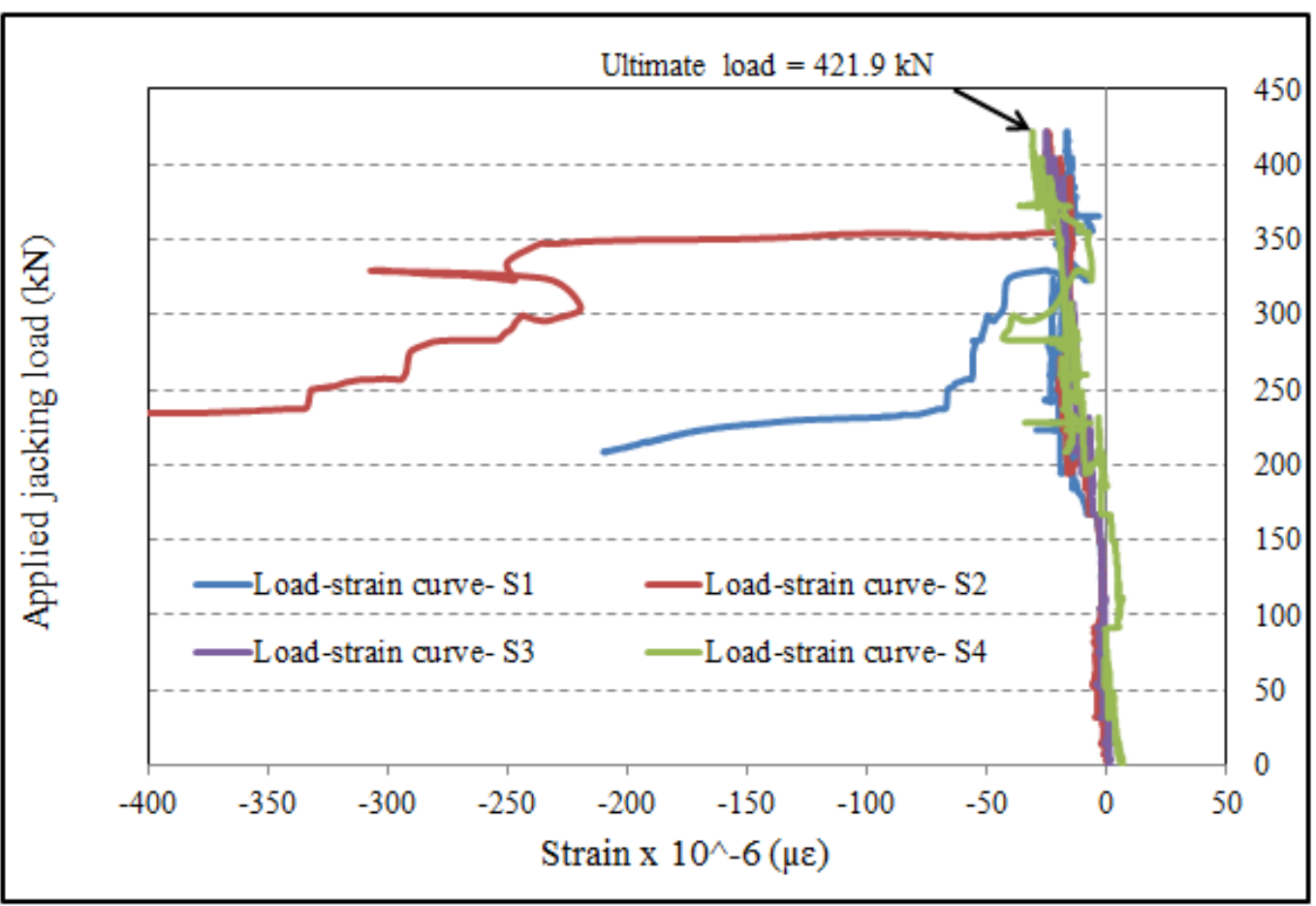

(b) Load-strain curve

Figure 6. 15 Trace of load-wall deformation and load-strain curves in PL-2 barrier at interior location 
In addition, a horizontal flexural crack was observed at base of the wall and within the loaded length of 1050-mm. The load was continued to increase until the wall experienced a punching shear crack at the top and on right side of the loaded region (see Figure 6.16b). At this stage, failure of the wall occurred at load of $243.66 \mathrm{kN}$. The ultimate load was found to be greater than the minimum transverse load limit of $170 \mathrm{kN}$ specified in CHBDC with a factor of safety of 1.43. In addition, a diagonal tension crack was observed at failure load and along the compression strut in the deck portion underneath the wall as shown in Figure 6.16c. The diagonal tension crack can be attributed to the combined shear and flexure that can be developed in the deck slab under the applied load. At back face of the wall, diagonal shear and torsional cracks were observed at failure load that were extended into the deck slab thickness (see Figure 6.16d). Also, no sign of vertical cracks due to in-plane flexural failure was observed at back face of the wall. The failure pattern was also confirmed to the failure patterns in PL-3 steel and GFRP-reinforced barriers at exterior location. Load-deformation curve of the PL-2 traffic barrier and trace of load-strain curve are shown in Figure 6.17. It can be seen that the wall exhibited a maximum deformation of 19.87-mm in a similar trend as PL-3 traffic barrier in which a linear wall deformation followed by plastic deformation took place. In addition, the strain gauges attached to the back face of the wall showed a compressive strain of $-46.5 \mu \varepsilon$ at failure, which is also less than the crushing strain of concrete. This finding was confirmed with the experimental testing as no sign of concrete crushing was observed.

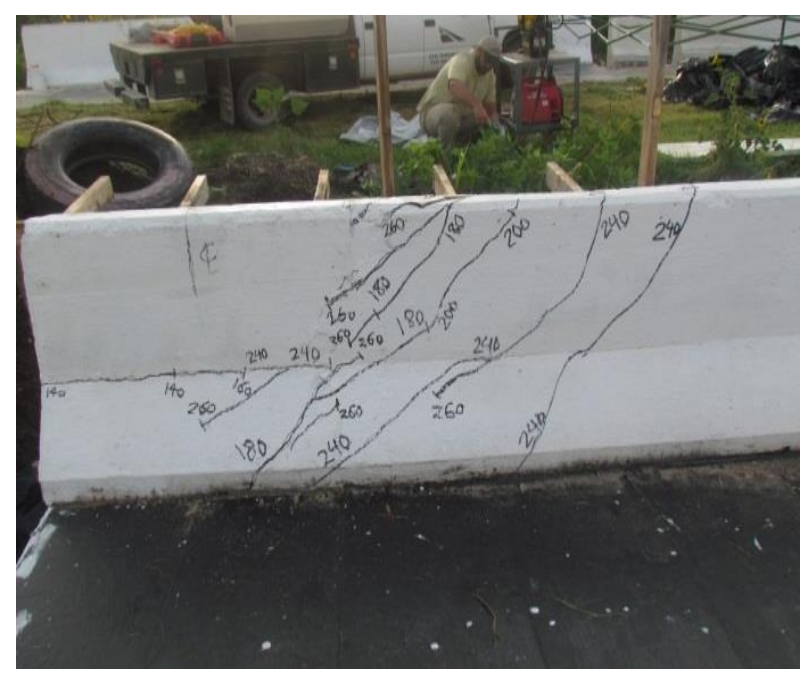

(a) Crack pattern at front face

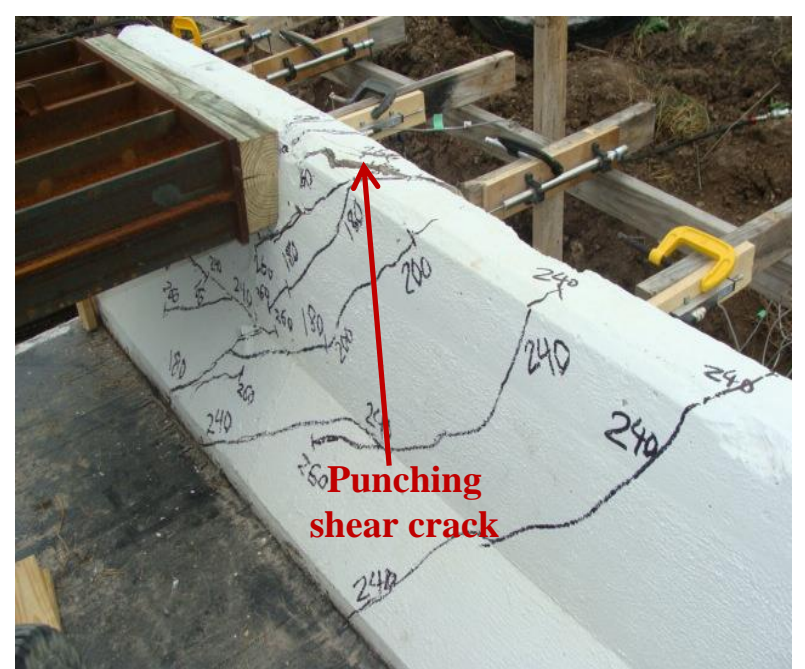

(b) Cracks through the wall thickness 


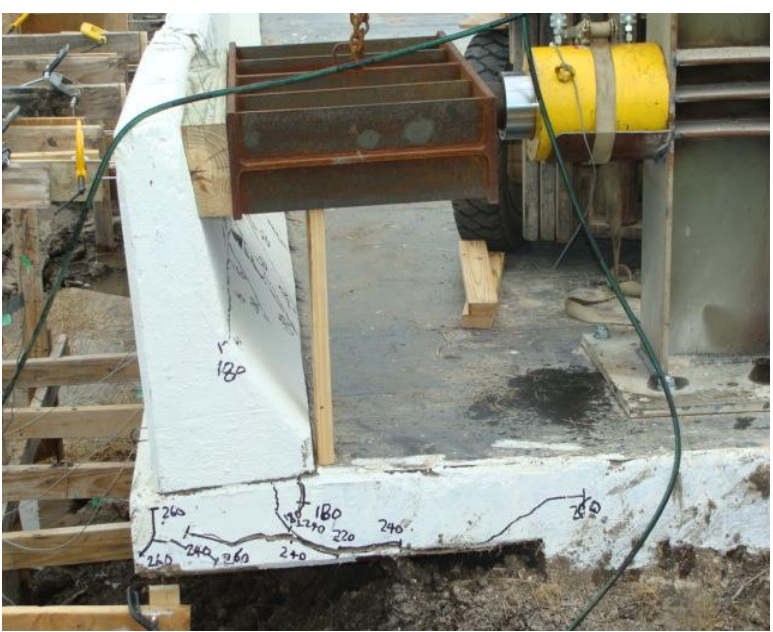

(c) Corner diagonal tension crack

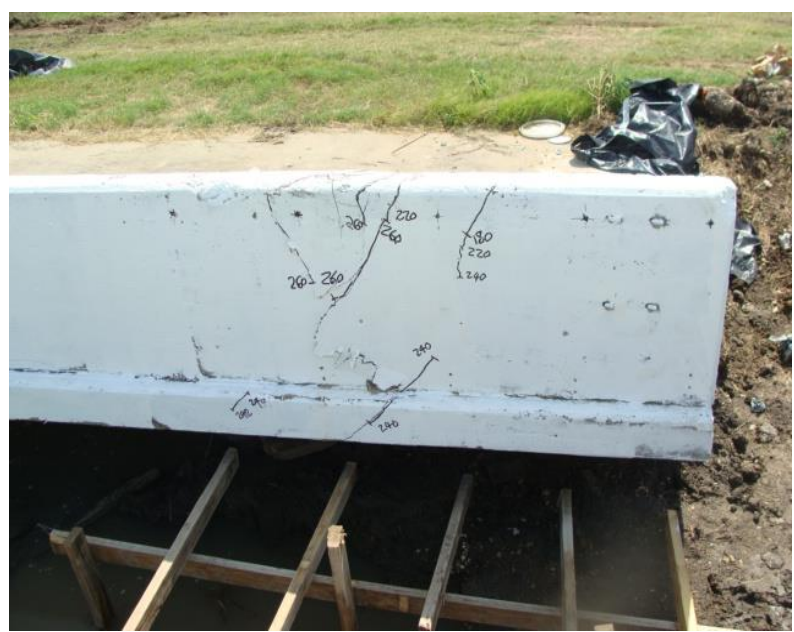

(d) Crack pattern at back face

Figure 6. 16 Crack patterns at front and back faces of the PL-2 traffic barrier at exterior location

A summary of the experimental test results conducted on the PL-3 and PL-2 traffic barriers at interior and exterior locations is provided in Table 6.2. It is generally observed that steelreinforced barriers exhibited similar trend as the GFRP-reinforced barriers in terms of failure mode and crack patterns. Comparison of the test results with the limits provided in the CHBDC revealed that both barriers exhibited additional capacities relatively $248 \%$ at interior location and a minimum of $143 \%$ at exterior location. If considering a durability factor of 0.75 to the experimental failure loads, the ratio of $\mathrm{F}_{\text {failure }} / \mathrm{F}_{\mathrm{CHBDC}}$ should be greater than 1.33, which the values provided in Table 6.2 are all greater than 1.33.

Table 6. 2 Summary of experimental results of the test steel barriers

\begin{tabular}{|l|c|c|c|c|}
\hline \multirow{2}{*}{} & \multicolumn{2}{|c|}{ PL-3 Barrier } & \multicolumn{2}{c|}{ PL-2 Barrier } \\
\cline { 2 - 5 } & $\begin{array}{c}\text { Interior } \\
\text { location }\end{array}$ & $\begin{array}{c}\text { Exterior } \\
\text { location }\end{array}$ & $\begin{array}{c}\text { Interior } \\
\text { location }\end{array}$ & $\begin{array}{c}\text { Exterior } \\
\text { location }\end{array}$ \\
\hline First crack $(\mathrm{kN})$ & 575 & 425 & 200 & 140 \\
\hline Failure load, $\mathrm{F}_{\text {failure }}(\mathrm{kN})$ & 885.9 & 627.13 & 421.9 & 243.66 \\
\hline CHDBC factored load, $\mathrm{F}_{\mathrm{CHBDC}}(\mathrm{kN})$ & 357 & 357 & 170 & 170 \\
\hline Height of load application $(\mathrm{m})$ & 0.99 & 0.99 & 0.765 & 0.765 \\
\hline $\mathrm{F}_{\text {failure }} \mathrm{F}_{\mathrm{CHBDC}}$ & 2.48 & 1.76 & 2.48 & 1.43 \\
\hline Max. wall deflection $(\mathrm{mm})$ & 12.91 & 30.3 & 9.42 & 19.87 \\
\hline Strain at failure $(\mu \varepsilon)$ & - & -369.5 & -33.5 & -46.5 \\
\hline
\end{tabular}




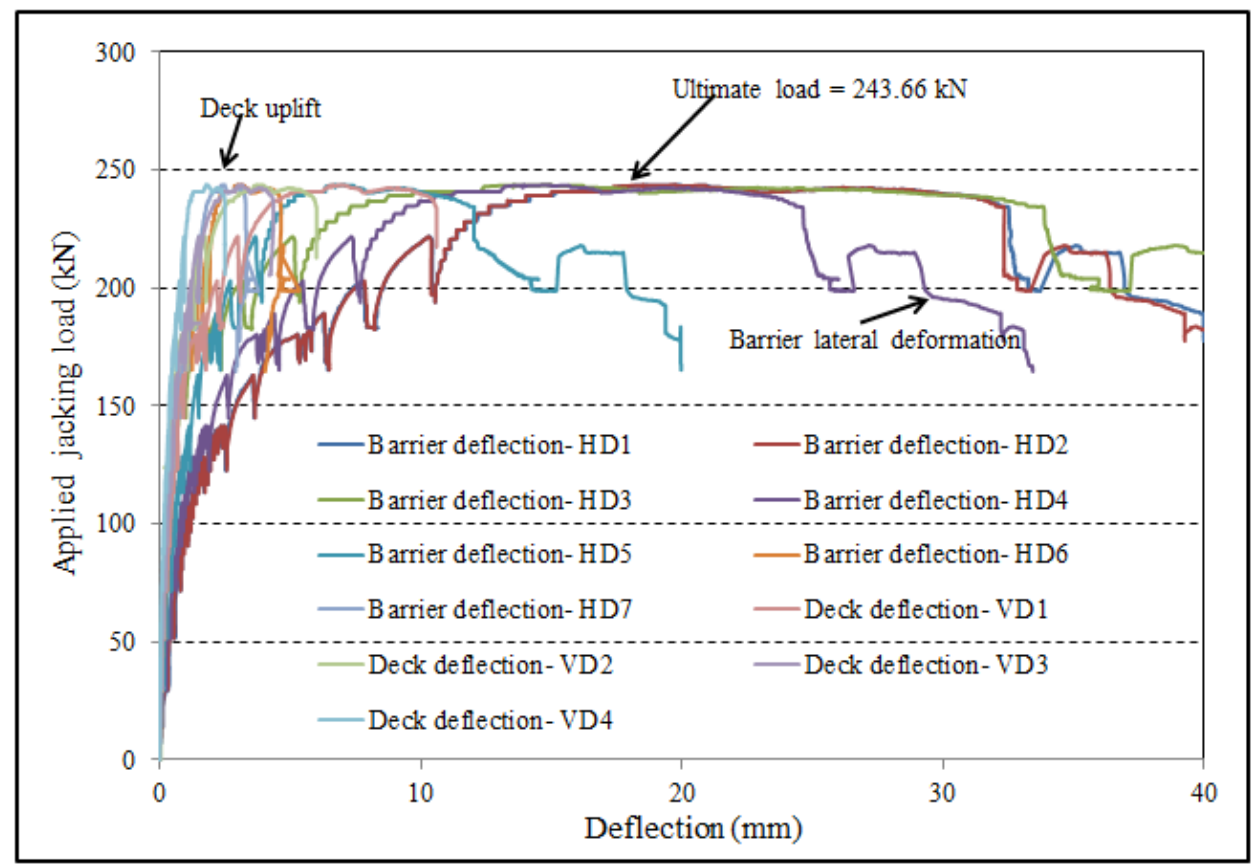

(a) Load-deformation curve

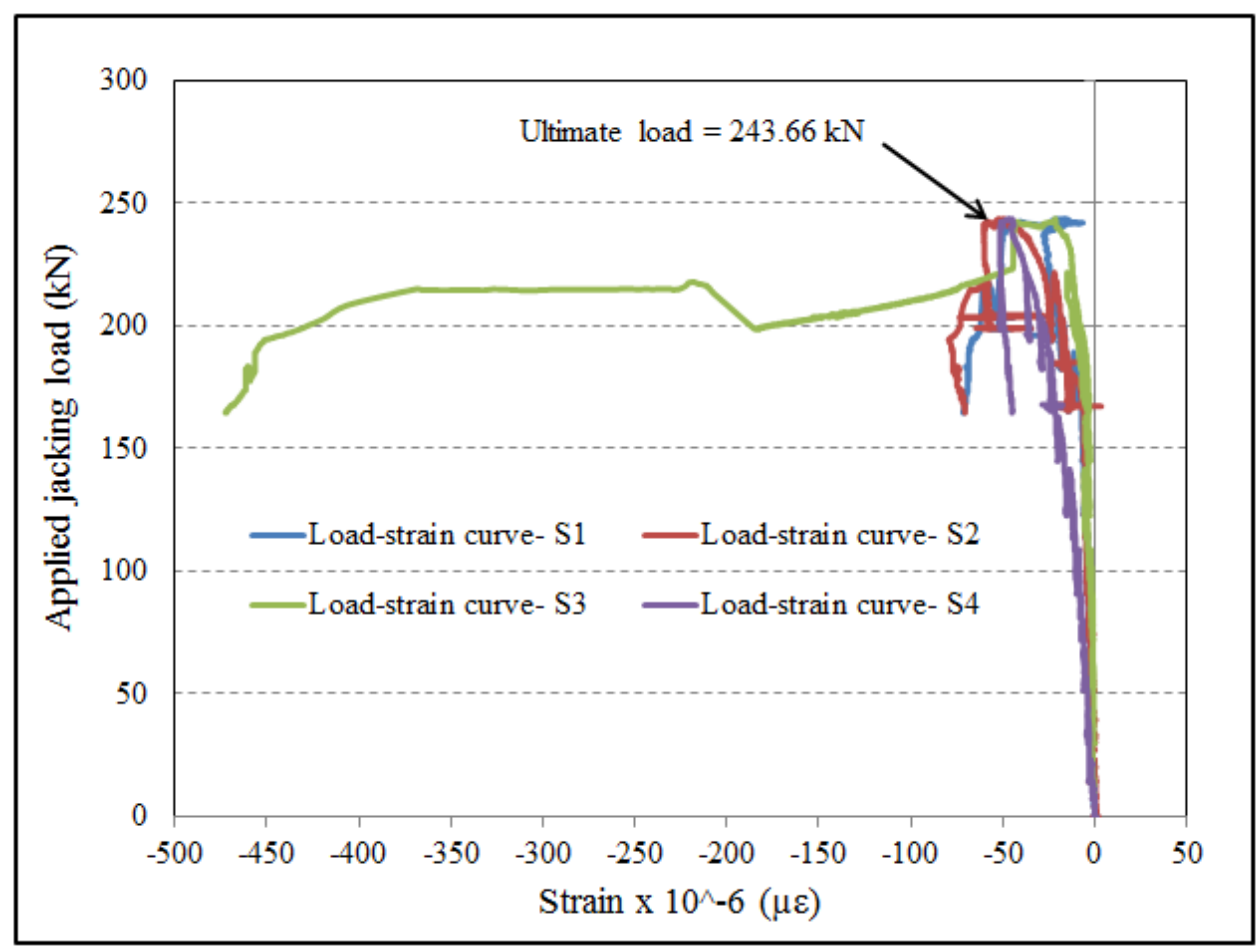

(b) Load-strain curve

Figure 6. 17 Trace of load-wall deformation and load-strain curves in PL-2 barrier at exterior location 


\subsection{Development of Yield-Line Failure Pattern}

From experimental program conducted on PL-3 and PL-2 steel-reinforced as well as the GFRPreinforced bridge barriers, it was observed that the failure pattern by triangular shape stipulated by AASHTO-LRFD is not valid. These findings along with other bridge barriers subjected to actual truck collision confirmed trapezoidal failure pattern of traffic barriers under the equivalent vehicle impact load. As mentioned earlier, design of bridge barriers reinforced by steel bars is based on yield-line theory of analysis. However, the design procedure stated in AASHTO-LRFD considered the failure pattern of the steel barriers by forming two inside and one outside diagonal yield-line patterns at interior location and only one inside diagonal yield-line pattern at exterior location in triangular shapes. The experimental programs herein showed a horizontal yield-line at base of the wall both at interior and exterior locations. The following subsections provide development of the equations on the basis of the current failure pattern in more details.

\subsubsection{Developed Yield-Line Failure Pattern at Interior Location}

The principle of yield-line theory for reinforced concrete bridge barriers and the related equations was originally developed by Hirsch (1978) and reported in AASHTO-LRFD (2012). On the basis of yield-line theory by Hirsch, a triangular failure mode of bridge barriers is proposed. It is assumed that two diagonal yield-lines meet at joint connection between the deck slab and the wall. It was also assumed that yield-lines did not extend into the deck slab. This means that the deck section should provide sufficient strength against the proposed yield-line. However, the experimental test conducted herein on PL-2 and PL-3 steel barriers as well as other experimental programs by researchers (Jeon et al. 2008, El-Salakawy and Islam, 2012) showed that the failure pattern of bridge barrier is accompanied by trapezoidal mode of failure rather that AASHTO-LRFD triangular shape. Thus, an attempt was made to apply modifications to the existing yield-line equations at interior location to represent the failure mode by trapezoidal shape. On the basis of this failure shape at interior location, it wa assumed that two diagonal yield lines are extended from top of the barrier wall down to the deck-wall junction including a horizontal yield-line at the joint connection as shown in Figure 6.18a. At back face of the barrier wall, vertical cracks have been observed that can be regarded as flexural behavior in plane. Thus, it can be assumed that two plastic hinges form at front face of the wall and two plastic hinges develop at back face of the wall. From the proposed yield-line pattern in Figure 6.18a, three 
difference scenarios have been considered in this investigation, namely: (1) The length of horizontal yield-line at the base, $X$, is greater than the loaded length, $L_{t}\left(X>L_{t}\right)$, (2) The length of horizontal yield-line is equal to the loaded length $\left(X=L_{t}\right)$, and (3) The length of horizontal yield-line is less than the loaded length $\left(\mathrm{X}<\mathrm{L}_{\mathrm{t}}\right)$. The following subsections provide derivation of the developed equations at interior location based on the above-mentioned three scenarios.

\subsubsection{PART A- CASES 1 AND 2 WITH $X \geq L t$}

As the first and second scenarios, it was assumed that the line load of length, $\mathrm{L}_{t}$, is applied at top of the wall and within a length equal or less than the horizontal yield-line at base of the wall, X. It was also assumed that the length of horizontal yield-line $\mathrm{X}$ as a function of the loaded length $\mathrm{L}_{\mathrm{t}}$ so that $\left(X=\mathrm{n}_{1} . \mathrm{L}_{\mathrm{t}}\right)$ : where $\mathrm{n}_{1}$ is a magnification factor to $\mathrm{L}_{\mathrm{t}}$ that can be considered any value between 1 and $2\left(1 \leq n_{1} \leq 2\right)$. For an assumed yield-line pattern that is consistent with geometry and boundary conditions of the wall, the wall transverse resistance can be obtained once equality is considered between the external work due to the applied load and internal work caused by the resisting plastic moment along the yield-lines. The angle of rotation of yield-lines at top of the wall can be expressed in terms of maximum wall deflection and critical length, $\mathrm{L}_{\mathrm{c}}$. The partial differentiation for a minimization is then performed with respect to the critical yield length, $\mathrm{L}_{c}$, for an upper bound solution.

\section{External Work:}

The external work is the product of the applied external load and the vertical displacement caused by the applied load. The original and deformed area of top portion of the wall due to the applied external load is shown in Figure 6.18b. The shaded area represents the total external work done due to the applied line load of $\mathrm{w}_{\mathrm{t}}=\mathrm{F}_{\mathrm{t}} / \mathrm{L}_{\mathrm{t}}$. The area of the shaded portion is:

Deformed area $=\mathrm{L}_{\mathrm{t}} . \Delta$

Thus, the external work done due to the line load, $\mathrm{w}_{\mathrm{t}}$, is:

$\mathrm{W}_{\mathrm{E}}=\mathrm{W}_{\mathrm{t}} .($ Deformed area $)=\mathrm{F}_{\mathrm{t}} \cdot \Delta$ 


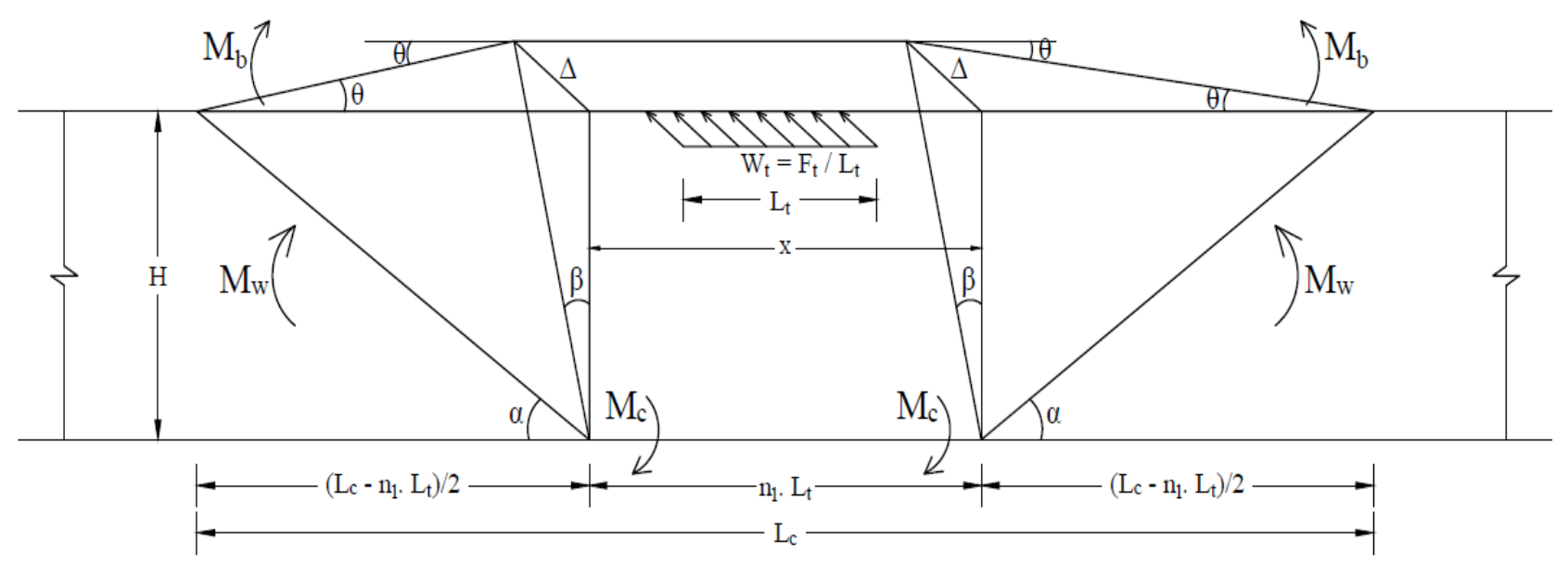

(a) 3D view of wall failure pattern

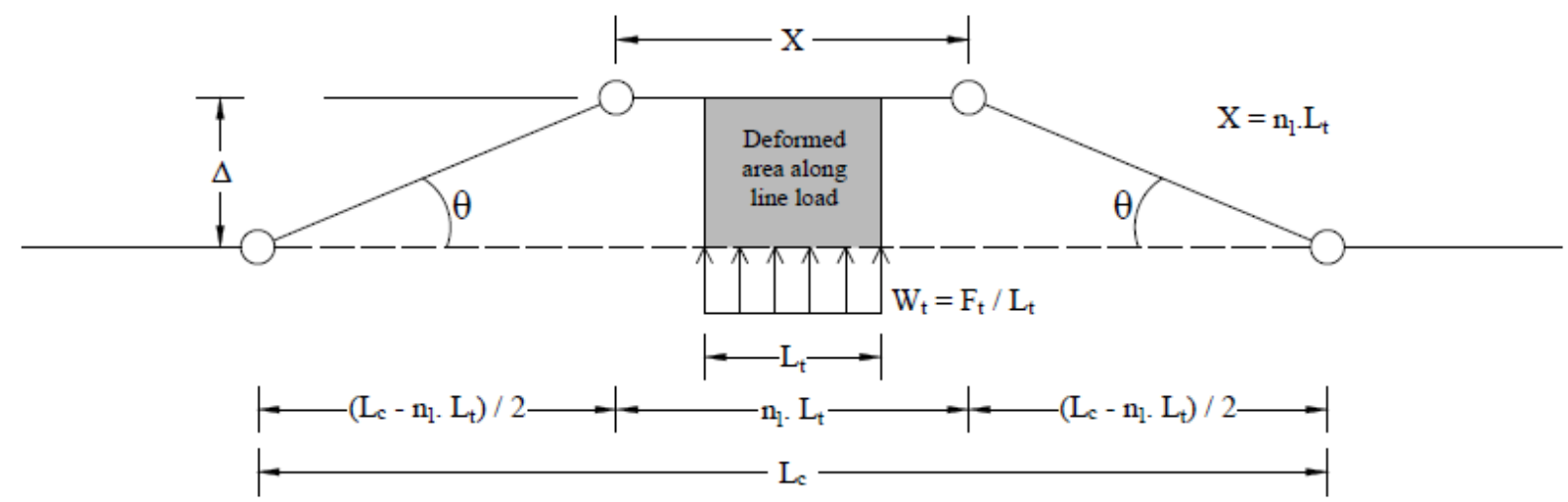

(b) Plan view of the deformed shape of the barrier wall

Figure 6. 18 Trapezoidal yield-line failure pattern at interior location showing deformed shape of top of the wall with $X \geq L_{t}$

\section{Internal Work:}

The internal work done along the yield-lines can be assumed as product of yielding moment of reinforcement crossing the yield-lines and the associated rotation through which they act. It is also presumed that wall segments are perfectly rigid so that the wall rotation is concentrated at the yield-lines. Due to the applied external load, $\mathrm{w}_{\mathrm{t}}$, at top of the wall, rotation $\theta$ of the wall segment shown in Figure $6.18 \mathrm{~b}$ for small deformation $\Delta$ can be written as: 
$\theta=\frac{2 \Delta}{\mathrm{L}_{\mathrm{C}}-\mathrm{n}_{1} \cdot \mathrm{L}_{\mathrm{t}}}$

The barrier wall at the top can be separated into a cap-beam and a uniform thickness wall below that. The cap-beam will develop plastic moment, $\mathrm{M}_{\mathrm{b}}$, at limit state that is assumed to be equal to its nominal bending moment strength, $\mathrm{M}_{\mathrm{n}}$, due to yielding of steel reinforcement. Thus, if assuming positive and negative plastic moment strengths are equal, the internal work done by the cap- beam at the top, $\mathrm{U}_{\mathrm{b}}$, is:

$\mathrm{U}_{\mathrm{b}}=4 \mathrm{M}_{\mathrm{b}} \cdot \theta=\frac{8 \mathrm{M}_{\mathrm{b}} \cdot \Delta}{\mathrm{L}_{\mathrm{c}}-\mathrm{n}_{1} \cdot \mathrm{L}_{\mathrm{t}}}$

In bridge barrier walls, the wall is usually reinforced with steel reinforcement in both horizontal and vertical directions. The horizontal reinforcement develops moment resistance $\mathrm{M}_{\mathrm{w}}$ about vertical axis per unit length of the wall. The vertical reinforcement also develops cantilever moment resistance of the wall system $\mathrm{M}_{\mathrm{c}}$ about horizontal axis per unit length of the wall. It should be noted that it is generally difficult to obtain a flexural resistance along the diagonal yield-line since the barrier wall is reinforced in vertical and horizontal directions. Thus, a simplified method is to separate the flexural resistance along the diagonal yield-line into moment resistance contributions made by vertical and horizontal reinforcement.

If we assumed that positive and negative moment resistance, $\mathrm{M}_{\mathrm{w}}$, about the vertical axis per unit length of the wall are equal and knowing the fact that rotation of the wall in horizontal plane about the inclined yield-line is $\theta$, the work done by horizontal reinforcement, $\mathrm{U}_{\mathrm{w}}$, due to wall moment of $\mathrm{M}_{\mathrm{w}} \cdot \mathrm{H}$ is:

$\mathrm{U}_{\mathrm{w}}=4 \mathrm{M}_{\mathrm{w}} \cdot \mathrm{H} \cdot \theta=\frac{8 \mathrm{M}_{\mathrm{w}} \cdot \mathrm{H} \cdot \Delta}{\mathrm{L}_{\mathrm{c}}-\mathrm{n}_{1} \cdot \mathrm{L}_{\mathrm{t}}}$

If angle of the wall in vertical plane of rotation about the inclined yield-line is $\beta$, and knowing that $\beta$ is equal to $\Delta / \mathrm{H}$, the internal work done by vertical reinforcement, $\mathrm{U}_{\mathrm{c}}$, due to cantilever moment $\mathrm{M}_{\mathrm{c}} \cdot \mathrm{L}_{\mathrm{c}}$ is: 
$\mathrm{U}_{\mathrm{c}}=\mathrm{M}_{\mathrm{c}} \cdot \mathrm{L}_{\mathrm{c}} \cdot \beta=\frac{\mathrm{M}_{\mathrm{c}} \cdot \mathrm{L}_{\mathrm{c}} \cdot \Delta}{\mathrm{H}}$

The total internal work is sum of the work done by cap-beam, horizontal and vertical reinforcement providing that:

$\mathrm{U}_{\mathrm{i}}=\mathrm{U}_{\mathrm{b}}+\mathrm{U}_{\mathrm{w}}+\mathrm{U}_{\mathrm{c}}=\frac{8 \mathrm{M}_{\mathrm{b}} \cdot \Delta}{\mathrm{L}_{\mathrm{c}}-\mathrm{n}_{1} \cdot \mathrm{L}_{\mathrm{t}}}+\frac{8 \mathrm{M}_{\mathrm{w}} \cdot \mathrm{H} \cdot \Delta}{\mathrm{L}_{\mathrm{c}}-\mathrm{n}_{1} \cdot \mathrm{L}_{\mathrm{t}}}+\frac{\mathrm{M}_{\mathrm{c}} \cdot \mathrm{L}_{\mathrm{c}} \cdot \Delta}{\mathrm{H}}$

Given the fact that the external work is equal to the internal work $\left(\mathrm{U}_{\mathrm{i}}=\mathrm{W}_{\mathrm{E}}\right)$, we obtain:

$F_{t}==\frac{8 M_{b}}{L_{c}-n_{1} \cdot L_{t}}+\frac{8 M_{w} \cdot H}{L_{c}-n_{1} \cdot L_{t}}+\frac{M_{c} \cdot L_{c}}{H}$

The maximum value of $F_{t}$ with respect to a change in $L_{c}$ occurs when $\left(\frac{d\left(F_{t}\right)}{d\left(L_{c}\right)}=0\right)$. This minimization gives a quadratic equation that can be solved explicitly to find the critical length, $\mathrm{L}_{\mathrm{c}}$, as:

$\mathrm{L}_{\mathrm{c}}=\mathrm{n}_{1} \cdot \mathrm{L}_{\mathrm{t}}+\sqrt{\left(\mathrm{n}_{1} \cdot \mathrm{L}_{\mathrm{t}}\right)^{2}+\frac{8 M_{b} H+8 M_{w} H^{2}-M_{c} \cdot\left(\mathrm{n}_{1} \cdot \mathrm{L}_{\mathrm{t}}\right)^{2}}{M_{c}}} \quad\left(1 \leq \mathrm{n}_{1} \leq 2\right)$

Knowing that $\mathrm{F}_{\mathrm{t} \text {,min }}=\mathrm{R}_{\mathrm{w}}$, the minimum nominal resistance of the barrier wall system at interior location with $\mathrm{X} \geq \mathrm{L}_{\mathrm{t}}$ can be written as:

$\mathrm{R}_{\mathrm{w}}=\left(\frac{1}{\mathrm{~L}_{\mathrm{c}-} \mathrm{n}_{1} \cdot \mathrm{L}_{\mathrm{t}}}\right)\left(8 \mathrm{M}_{\mathrm{b}}+8 \mathrm{M}_{\mathrm{w}} \cdot \mathrm{H}+\frac{M_{C} \cdot\left(L_{c}{ }^{2}-\mathrm{n}_{1} \cdot \mathrm{L}_{\mathrm{t}} \cdot \mathrm{L}_{\mathrm{c}}\right)}{H}\right) \quad\left(1 \leq \mathrm{n}_{1} \leq 2\right)$

It should be noted that the experimental study conducted by Jeon el. al. (2008) also confirmed trapezoidal mode of failure at interior location. From the investigation, Jeon et al. (2008) observed that cracks mainly occurred above the tapered portion of the wall rather than extending down to the deck-wall junction. Jeon et al. (2008) recommended the following equation for 
trapezoidal mode of failure at interior location considering the height $\mathrm{H}_{1}$ above the tapered portion of the wall:

$\mathrm{R}_{\mathrm{w}}=4 \cdot \sqrt{\frac{2 \mathrm{M}_{\mathrm{c} 1} \mathrm{M}_{\mathrm{w} 1}}{\mathrm{H}_{1}}}+\frac{\mathrm{M}_{\mathrm{c} 1} \mathrm{~L}_{\mathrm{t}}}{\mathrm{H}_{1}}$

Where notations $M_{c 1}$ and $M_{w 1}$ are similar to $M_{c}$ and $M_{w}$ previously defined in Eqs. 6.5 and 6.6 except that the subscript 1 indicates that moment to be determined within the height $\mathrm{H}_{1}$ above the tapered wall. It is also worth mentioning that if considering $\mathrm{n}_{1}$ equal to $1\left(\mathrm{n}_{1}=1\right)$ and taking height above the tapered portion $\left(\mathrm{H}_{1}\right)$ instead of the total barrier height $(\mathrm{H})$, Eq. 6.10 will yield similar result as the equation proposed by Jeon et al. (2008) at interior location (Eq. 6.11).

\subsubsection{PART B-CASE 3 WITH $X<\mathrm{L}_{\mathrm{t}}$}

As the third scenario, it is assumed that the length of the horizontal yield-line at base of the wall (X) is less than the length of the load application, $\mathrm{L}_{\mathrm{t}}$. Therefore, the length of horizontal yieldline at the base can be written as a function of $L_{t}$ providing that $X=n_{2} \cdot L_{t}$, where $n_{2}$ is a reduction factor to $L_{t}$ which can be assumed any value between zero to one $\left(0 \leq n_{2}<1\right)$. The assumed yield-line pattern with a trapezoidal shape and a line load of, $\mathrm{w}_{\mathrm{t}}$ that is distributed over a length, $\mathrm{L}_{\mathrm{t}}$, is shown in Figure 6.19a. The maximum transverse wall resistance can be estimated by equating the external and internal works.

\section{External Work:}

The external work is calculated by multiplying the applied external load to the vertical displacement caused by the applied load. The original and deformed shape of the barrier wall due to the applied external load is shown in Figure 6.19b. The shaded area represents the total external work done due to the applied line load of $\mathrm{w}_{\mathrm{t}}=\mathrm{F}_{\mathrm{t}} / \mathrm{L}_{\mathrm{t}}$. For a maximum wall deflection of $\Delta$, the displacement y can be estimated as:

$\mathrm{y}=\frac{\Delta\left(\mathrm{L}_{\mathrm{c}}-\mathrm{L}_{\mathrm{t}}\right)}{\mathrm{L}_{\mathrm{c}}-\mathrm{n}_{2} \cdot \mathrm{L}_{\mathrm{t}}}$ 
The total area of the shaded portion is:

Deformed area $=\mathrm{A}_{1}+2 \mathrm{~A}_{2}=\frac{\Delta \cdot \mathrm{L}_{\mathrm{t}}\left(2 \mathrm{~L}_{\mathrm{c}}-\mathrm{L}_{\mathrm{t}}-\mathrm{n}_{2}{ }^{2} \cdot \mathrm{L}_{\mathrm{t}}\right)}{2\left(\mathrm{~L}_{\mathrm{c}}-\mathrm{n}_{2} \cdot \mathrm{L}_{\mathrm{t}}\right)}$

The external work done due to the line load, $\mathrm{w}_{\mathrm{t}}$, is:

$\mathrm{W}_{\mathrm{E}}=\mathrm{w}_{\mathrm{t}} \cdot($ Deformed area $)=\mathrm{F}_{\mathrm{t}} \cdot \frac{\Delta\left(2 \mathrm{~L}_{\mathrm{c}}-\mathrm{L}_{\mathrm{t}}-\mathrm{n}_{2}^{2} \cdot \mathrm{L}_{\mathrm{t}}\right)}{2\left(\mathrm{~L}_{\mathrm{c}}-\mathrm{n}_{2} \cdot \mathrm{L}_{\mathrm{t}}\right)}$

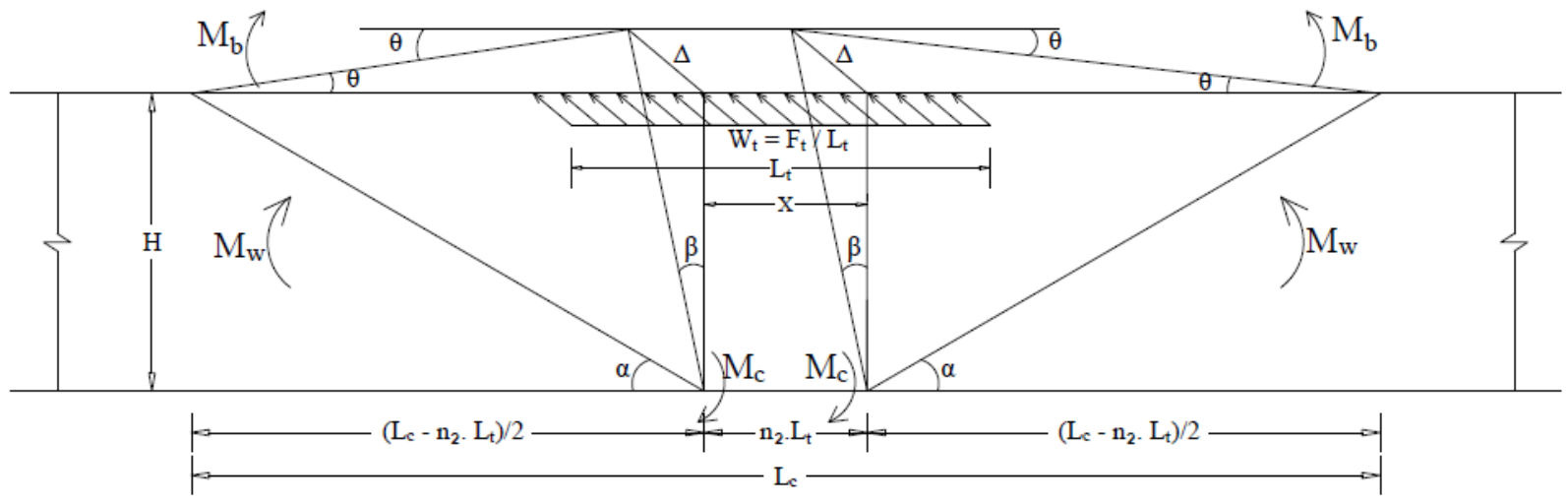

(a) 3D-view of wall failure pattern

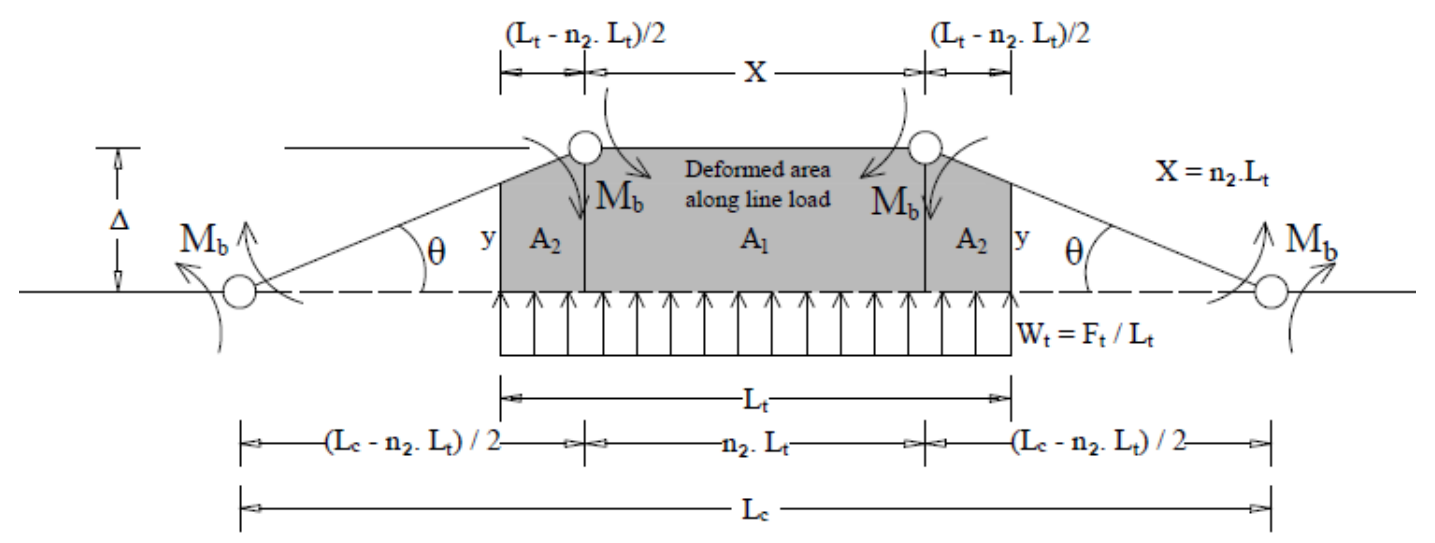

(b) Plan view of deformed shape of the barrier wall

Figure 6. 19 Proposed trapezoidal yield-line failure at interior location showing deformation of top of the wall with $\mathrm{X}<\mathrm{L}_{\mathrm{t}}$ 


\section{Internal Work:}

The internal work done along the yield-lines can be estimated by multiplying the yielding moment of the reinforcement crossing the yield-lines to the rotation caused by them. It is also supposed that wall segments are rigid so that the wall rotation is concentrated at the yield-lines. Due to the applied load, $\mathrm{w}_{\mathrm{t}}$, rotation $\theta$ of the wall shown in Figure $6.19 \mathrm{~b}$ for small deformation $\Delta$ can be written as:

$\theta=\frac{2 \Delta}{\mathrm{L}_{\mathrm{C}}-\mathrm{n}_{2} \cdot \mathrm{L}_{\mathrm{t}}}$

At top of the wall, the barrier wall can be analyzed into a cap-beam and the wall below that. The cap-beam develops plastic moment, $\mathrm{M}_{\mathrm{b}}$, at the limit state. Thus, the internal work done by the cap-beam at the top, $\mathrm{U}_{\mathrm{b}}$, is:

$\mathrm{U}_{\mathrm{b}}=4 \mathrm{M}_{\mathrm{b}} \cdot \theta=\frac{8 \mathrm{M}_{\mathrm{b}} \cdot \Delta}{\mathrm{L}_{\mathrm{c}}-\mathrm{n}_{2} \cdot \mathrm{L}_{\mathrm{t}}}$

Similarly, if assumed that positive and negative moment resistance, $\mathrm{M}_{\mathrm{w}}$, about the vertical axis per unit length of the wall are equal and knowing the fact that projection of the horizontal plane of the rotation about the inclined yield line is $\theta$, the work done by horizontal reinforcement, $\mathrm{U}_{\mathrm{w}}$, due to wall moment of $\mathrm{M}_{\mathrm{w}} \cdot \mathrm{H}$ is:

$\mathrm{U}_{\mathrm{w}}=4 \mathrm{M}_{\mathrm{w}} \cdot \mathrm{H} \cdot \theta=\frac{8 \mathrm{M}_{\mathrm{w}} \cdot \mathrm{H} \cdot \Delta}{\mathrm{L}_{\mathrm{c}}-\mathrm{n}_{2} \cdot \mathrm{L}_{\mathrm{t}}}$

If projection on the vertical plane of the rotation about the inclined yield-line is $\beta$, and, knowing that $\beta$ is equal to $\Delta / \mathrm{H}$, the internal work, $\mathrm{U}_{\mathrm{c}}$, due to cantilever moment $\mathrm{M}_{\mathrm{c}} \cdot \mathrm{L}_{\mathrm{c}}$ is:

$\mathrm{U}_{\mathrm{c}}=\mathrm{M}_{\mathrm{c}} \cdot \mathrm{L}_{\mathrm{c}} \cdot \beta=\frac{\mathrm{M}_{\mathrm{c}} \cdot \mathrm{L}_{\mathrm{C}} \cdot \Delta}{\mathrm{H}}$

The total internal work done by the cap-beam and the reinforcement can be written as: 
$\mathrm{U}_{\mathrm{i}}=\mathrm{U}_{\mathrm{b}}+\mathrm{U}_{\mathrm{w}}+\mathrm{U}_{\mathrm{c}}=\frac{8 \mathrm{M}_{\mathrm{b}} \cdot \Delta}{\mathrm{L}_{\mathrm{c}}-\mathrm{n}_{2} \cdot \mathrm{L}_{\mathrm{t}}}+\frac{8 \mathrm{M}_{\mathrm{w}} \cdot \mathrm{H} \cdot \Delta}{\mathrm{L}_{\mathrm{c}}-\mathrm{n}_{2} \cdot \mathrm{L}_{\mathrm{t}}}+\frac{\mathrm{M}_{\mathrm{c}} \cdot \mathrm{L}_{\mathrm{c}} \cdot \Delta}{\mathrm{H}}$

Given the fact that the external work is equal to the internal work $\left(U_{i}=W_{E}\right)$, we obtain:

$\mathrm{F}_{\mathrm{t}}=\frac{16 \mathrm{M}_{\mathrm{b}}}{2 L_{c}-L_{t}-\mathrm{n}_{2}^{2} \cdot L_{t}}+\frac{16 \mathrm{M}_{\mathrm{w}} \cdot \mathrm{H}}{2 L_{c}-L_{t}-\mathrm{n}_{2}^{2} \cdot L_{t}}+\frac{2 \mathrm{M}_{\mathrm{c}} \cdot\left(L_{c}{ }^{2}-\mathrm{n}_{2} \cdot L_{t} \cdot L_{c}\right)}{\mathrm{H} \cdot\left(2 L_{c}-L_{t}-\mathrm{n}_{2}^{2} \cdot L_{t}\right)}$

The equation above depends on the critical yield-line length, $\mathrm{L}_{\mathrm{c}}$ that determines the angle of yield-line inclination, $\alpha$. The critical value, $L_{c}$ that minimizes $F_{t}$ can be estimated by differentiating of the above equation with respect to $\mathrm{L}_{\mathrm{c}}$. that is; $\frac{d\left(F_{t}\right)}{d\left(L_{c}\right)}=0$. This minimization gives a quadratic equation that can be solved explicitly to find the critical length, $\mathrm{L}_{\mathrm{c}}$, as:

$$
\begin{gathered}
\mathrm{L}_{\mathrm{c}}=0.5 \mathrm{~L}_{\mathrm{t}}\left(1+\mathrm{n}_{2}^{2}\right)+\sqrt{\frac{1}{4} \mathrm{~L}_{\mathrm{t}}^{2}\left(1+\mathrm{n}_{2}^{2}\right)^{2}+\frac{16 M_{b} H+16 M_{w} H^{2}-M_{c \cdot}\left(\mathrm{n}_{2} L_{t}{ }^{2}+\mathrm{n}_{2}{ }^{3} \cdot \mathrm{L}_{\mathrm{t}}{ }^{2}\right)}{2 M_{c}}} \\
\text { for }\left(0 \leq \mathrm{n}_{2}<1\right)
\end{gathered}
$$

Knowing that; $F_{t, \min }=R_{w}$, the minimum nominal resistance of the barrier wall system at interior location with $\mathrm{X}<\mathrm{L}_{\mathrm{t}}$ can be written as:

$\mathrm{R}_{\mathrm{w}}=\left(\frac{1}{2 \mathrm{~L}_{\mathrm{c}-} \mathrm{L}_{\mathrm{t}-} \mathrm{n}_{2}{ }^{2} \cdot \mathrm{L}_{\mathrm{t}}}\right)\left(16 \mathrm{M}_{\mathrm{b}}+16 \mathrm{M}_{\mathrm{w}} \cdot \mathrm{H}+\frac{2 M_{c} \cdot\left(L_{c}{ }^{2}-\mathrm{n}_{2} \cdot \mathrm{L}_{\mathrm{t}} \cdot \mathrm{L}_{\mathrm{c}}\right)}{H}\right) \quad$ for $\left(0 \leq \mathrm{n}_{2}<1\right)(\mathrm{Eq} \cdot 6 \cdot 22)$

It is worth to mention that if $\mathrm{n}_{2}$ is to be taken as zero (considering no horizontal yield-line at the base similar to AASHTO-LRFD), Eqs. 6.21 and 6.22 yield similar equations to AASHTOLRFD's for interior location (Eqs. 2.35 and 2.36). 


\subsubsection{Developed Yield-Line Failure Pattern at Exterior Location}

On the basis of yield-line theory that is originally developed by Hirsch (1978), a triangular failure shape is proposed at exterior location. However, experimental programs conducted herein on PL-3 and PL-2 traffic barriers at exterior location have revealed that the barrier walls failed in a trapezoidal failure mode rather than by triangular failure shape stipulated in AASHTO-LRFD (2012). It is observed that one diagonal yield-line produce tension at inside face of the wall that is diagonally extended from top of the wall down to deck-wall junction followed by a horizontal yield-line at base of the wall. The horizontal yield-line is extended to the end-corner of the barrier wall. Therefore, it can be assumed that the barrier at exterior location develop only one plastic hinge. At the rear of the barrier, torsional cracks have been observed without showing the formation of plastic hinge. From the proposed yield-line pattern shown in Figure 6.20a, three different cases have been investigated, namely as: (1) The length of the horizontal yield-line at the base of the wall, $X$, is greater than the length of the line load, $L_{t}\left(X>L_{t}\right)$, (2) The length of the horizontal yield-line is equal to the length of the line load $\left(X=L_{t}\right)$, and (3) The length of horizontal yield-line is less the length of the line load $\left(\mathrm{X}<\mathrm{L}_{\mathrm{t}}\right)$. The critical yield-line length, $\mathrm{L}_{\mathrm{c}}$, and ultimate wall resistance, $\mathrm{R}_{\mathrm{w}}$, based on the three cases stipulated above are derived as follow:

\subsubsection{PART A-CASES 1 AND 2 WITH $X \geq \mathbf{L}_{t}$}

For cases 1 and 2, It was assumed that a line load of length $L_{t}$ was applied transversely at top of the wall. The line load was applied within a length equal or less than the horizontal yield-line, $\mathrm{X}$. The length of the horizontal yield-line at the base was taken as a factor of the loaded length, $\mathrm{L}_{\mathrm{t}}$ $\left(\mathrm{X}=\mathrm{n}_{1} \cdot \mathrm{L}_{\mathrm{t}}\right)$; where $\mathrm{n}_{1}$ is a magnification factor to $\mathrm{L}_{\mathrm{t}}$ that can be considered any value between 1 and $2\left(1 \leq \mathrm{n}_{1} \leq 2\right)$. For an assumed yield-line pattern that is consistent with geometry and boundary conditions of the wall or deck slab, the ultimate wall resistance can be obtained by equating the external work due to the applied load and internal work caused by resisting plastic moment along the yield-lines. Due to upper bound theorem, the applied transverse load determined by this method is either equal or greater than the actual load which is deemed correct or unsafe. Due to the externally applied load, the wall experienced rotation in horizontal or vertical planes. The wall inclination about the diagonal yield-lines can be determined in terms of maximum wall deflection and length of the deflected wall. A partial differentiation for a minimization with respect to the critical length, $\mathrm{L}_{\mathrm{c}}$, was manipulated for an upper bound solution. 


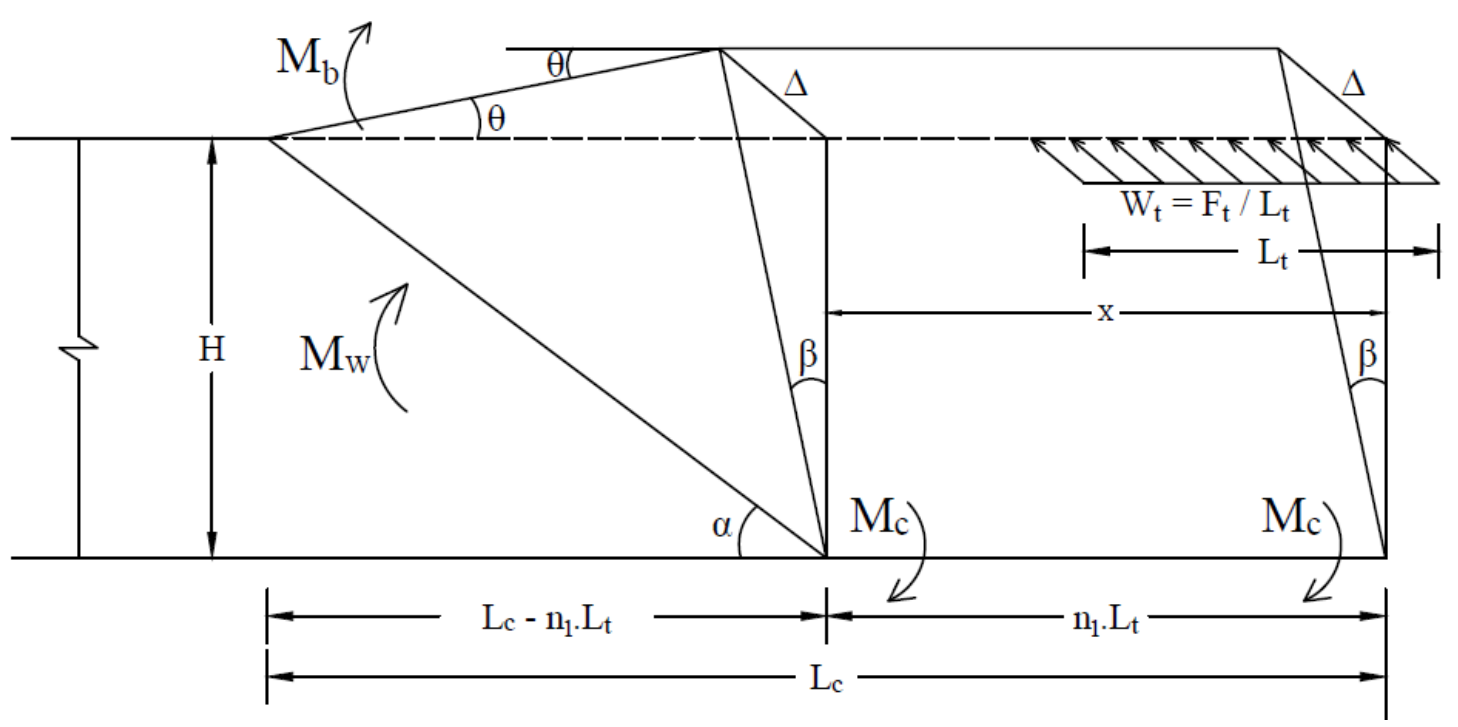

(a) Proposed 3D view of wall failure pattern

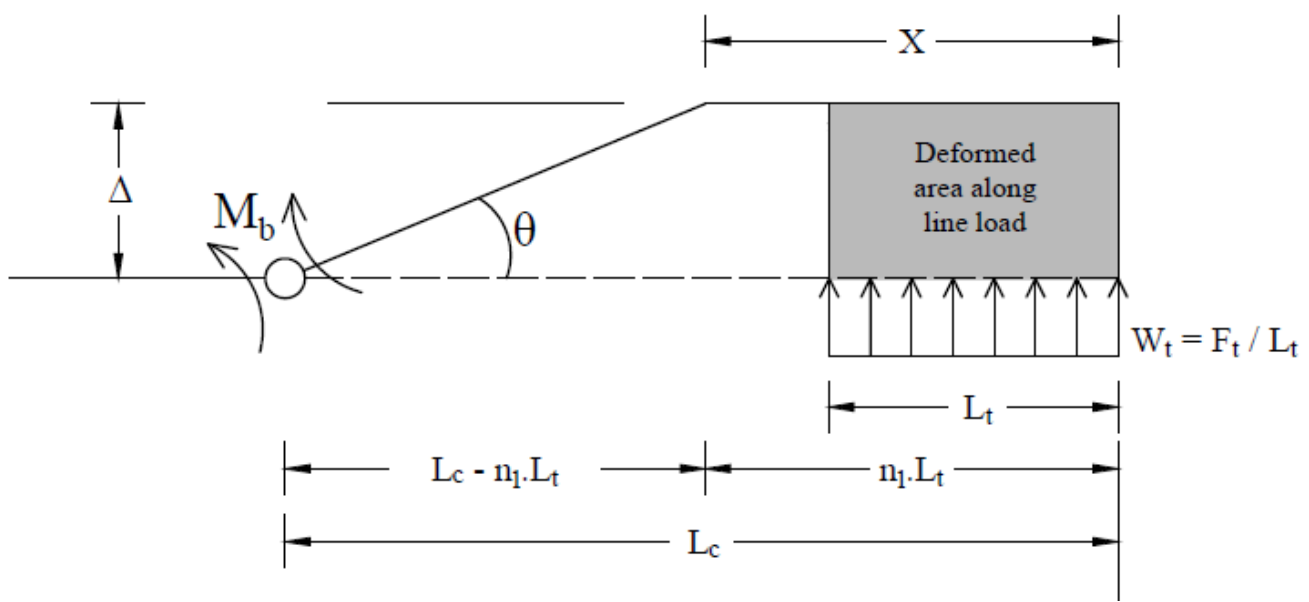

(b) Original and deformed shape of top of the wall

Figure 6. 20 Proposed trapezoidal yield-line failure pattern at exterior location $\left(X \geq L_{t}\right)$

\section{External Work:}

The external work done on the wall can be estimated by multiplying the applied external load to the vertical displacement caused by the applied load. Figure $6.20 \mathrm{~b}$ shows the original and deformed shape of top of the barrier wall after applying the external load. The shaded area represents the total external work done due to the applied line load of $\mathrm{w}_{\mathrm{t}}=\mathrm{F}_{\mathrm{t}} / \mathrm{L}_{\mathrm{t}}$. The area of the shaded portion is: 
Thus, the external work done due to the line load, $\mathrm{w}_{\mathrm{t}}$, is:

$\mathrm{W}_{\mathrm{E}}=\mathrm{W}_{\mathrm{t}} \cdot$ (Deformed area) $=\mathrm{F}_{\mathrm{t}} \cdot \Delta$

\section{Internal Work:}

The internal work done along the yield-lines can be assumed as the product of yielding moment and rotation through which they act. The wall segments should be considered rigid so that rotation of the wall can be assumed only about the yield-lines. The rotation $\theta$ of the wall segment at the top due to external load, $\mathrm{w}_{\mathrm{t}}$, which is shown in Figure 6.20b, can be written as:

$\theta=\frac{\Delta}{\mathrm{L}_{\mathrm{c}}-\mathrm{n}_{1} \cdot \mathrm{L}_{\mathrm{t}}}$

The cap-beam and the barrier wall at the top will act separately. At limit state, the cap-beam develops plastic moment, $\mathrm{M}_{\mathrm{b}}$ that is assumed to be equal to its nominal bending moment strength, $\mathrm{M}_{\mathrm{n}}$. Thus, if assuming positive and negative plastic moment strengths are equal, the internal work done by the cap- beam, $\mathrm{U}_{\mathrm{b}}$, is:

$\mathrm{U}_{\mathrm{b}}=\mathrm{M}_{\mathrm{b}} \cdot \theta=\frac{\mathrm{M}_{\mathrm{b}} \cdot \Delta}{\mathrm{L}_{\mathrm{c}}-\mathrm{n}_{1} \cdot \mathrm{L}_{\mathrm{t}}}$

It should be noticed that barrier wall is usually reinforced in both horizontal and vertical directions. The horizontal reinforcement develops moment resistance $\mathrm{M}_{\mathrm{w}}$ about vertical axis per unit length of the wall. The vertical reinforcement also develops cantilever moment resistance $\mathrm{M}_{\mathrm{c}}$ of the wall system about the horizontal axis per unit length of the wall. If assumed that positive and negative moment resistance, $\mathrm{M}_{\mathrm{w}}$, about the vertical axis per unit length of the wall are equal and knowing the fact that rotation of the wall in horizontal plane about the inclined yield line is $\theta$, the work done by horizontal reinforcement $\mathrm{U}_{\mathrm{w}}$, due to wall moment of $\mathrm{M}_{\mathrm{w}} \cdot \mathrm{H}$ is: 
$\mathrm{U}_{\mathrm{w}}=\mathrm{M}_{\mathrm{w}} \cdot \mathrm{H} \cdot \theta=\frac{\mathrm{M}_{\mathrm{w}} \cdot \mathrm{H} \cdot \Delta}{\mathrm{L}_{\mathrm{c}}-\mathrm{n}_{1} \cdot \mathrm{L}_{\mathrm{t}}}$

If considering rotation of the wall in vertical plane about the inclined yield-line is equal to $\Delta / \mathrm{H}$, the internal work done by the vertical reinforcement, $U_{c}$, due to cantilever moment $M_{c} \cdot L_{c}$ is:

$\mathrm{U}_{\mathrm{c}}=\mathrm{M}_{\mathrm{c}} \cdot \mathrm{L}_{\mathrm{c}} \cdot \beta=\frac{\mathrm{M}_{\mathrm{c}} \cdot \mathrm{L}_{\mathrm{c}} \cdot \Delta}{\mathrm{H}}$

The total internal work done by the cap-beam, horizontal and vertical reinforcement is:

$\mathrm{U}_{\mathrm{i}}=\mathrm{U}_{\mathrm{b}}+\mathrm{U}_{\mathrm{w}}+\mathrm{U}_{\mathrm{c}}=\frac{\mathrm{M}_{\mathrm{b}} \cdot \Delta}{\mathrm{L}_{\mathrm{c}}-\mathrm{n}_{1} \cdot \mathrm{L}_{\mathrm{t}}}+\frac{\mathrm{M}_{\mathrm{w}} \cdot \mathrm{H} \cdot \Delta}{\mathrm{L}_{\mathrm{c}}-\mathrm{n}_{1} \cdot \mathrm{L}_{\mathrm{t}}}+\frac{\mathrm{M}_{\mathrm{c}} \cdot \mathrm{L}_{\mathrm{c}} \cdot \Delta}{\mathrm{H}}$

Since the external work is equal to the internal work $\left(\mathrm{U}_{\mathrm{i}}=\mathrm{W}_{\mathrm{E}}\right)$, we obtain:

$F_{t}==\frac{M_{b}}{L_{c}-n_{1} \cdot L_{t}}+\frac{M_{w} \cdot H}{L_{c}-n_{1} \cdot L_{t}}+\frac{M_{c} \cdot L_{c}}{H}$

The maximum value of $\mathrm{F}_{\mathrm{t}}$ with respect to a change in $\mathrm{L}_{\mathrm{c}}$ occurs when; $\left(\frac{d\left(F_{t}\right)}{d\left(L_{c}\right)}=0\right)$, this minimization gives a quadratic equation that can be solved explicitly to find the critical length, $\mathrm{L}_{\mathrm{c}}$, as:

$\mathrm{L}_{\mathrm{c}}=\mathrm{n}_{1} \cdot \mathrm{L}_{\mathrm{t}}+\sqrt{\left(\mathrm{n}_{1} \cdot \mathrm{L}_{\mathrm{t}}\right)^{2}+\frac{M_{b} H+M_{W} H^{2}-M_{C \cdot} \cdot\left(\mathrm{n}_{1} \cdot \mathrm{L}_{\mathrm{t}}\right)^{2}}{M_{c}}} \quad\left(1 \leq \mathrm{n}_{1} \leq 2\right)$

Knowing that $\mathrm{F}_{\mathrm{t} \text {, min }}=\mathrm{R}_{\mathrm{w}}$, the minimum nominal resistance of the barrier wall system at exterior location with $\mathrm{X} \geq \mathrm{L}_{\mathrm{t}}$ can be written as:

$\mathrm{R}_{\mathrm{w}}=\left(\frac{1}{\mathrm{~L}_{\mathrm{c}-} \mathrm{n}_{1} \cdot \mathrm{L}_{\mathrm{t}}}\right)\left(\mathrm{M}_{\mathrm{b}}+\mathrm{M}_{\mathrm{w}} \cdot \mathrm{H}+\frac{M_{C} \cdot\left(L_{c}{ }^{2}-\mathrm{n}_{1} \cdot \mathrm{L}_{\mathrm{t}} \cdot \mathrm{L}_{\mathrm{c}}\right)}{H}\right) \quad\left(1 \leq \mathrm{n}_{1} \leq 2\right)$ 


\subsubsection{PART B-CASE 3 WITH $X<\mathrm{L}_{t}$}

In the third case, it is presumed that the horizontal yield-line at the wall-deck junction has a length, $\mathrm{X}$, less than the length of the applied external load, $\mathrm{L}_{\mathrm{t}}$. The length of horizontal yield-line at the base is defined as a reduction factor $\left(n_{2}\right)$ to $L_{t}\left(X=n_{2} \cdot L_{t}\right)$, where $n_{2}$ can be assumed any value between zero to one $\left(0 \leq \mathrm{n}_{2}<1\right)$. Figure 6.21a depicts the proposed trapezoidal failure pattern at exterior location with the external applied load of, $\mathrm{w}_{\mathrm{t}}$ that is distributed over a length $\mathrm{L}_{\mathrm{t}}$. The maximum transverse wall resistance can be estimated by equating the external and internal works.

\section{External Work:}

The external work is calculated by multiplying the applied external load to the vertical displacement caused by the applied load. The original and deformed shape of the barrier wall due to the applied external load is shown in Figure 6.21b. The shaded area represents the total external work done due to the applied line load of $\mathrm{w}_{\mathrm{t}}=\mathrm{F}_{\mathrm{t}} / \mathrm{L}_{\mathrm{t}}$. For a maximum wall deflection of $\Delta$, the displacement y can be estimated as:

$\mathrm{y}=\frac{\Delta\left(\mathrm{L}_{\mathrm{c}}-\mathrm{L}_{\mathrm{t}}\right)}{\mathrm{L}_{\mathrm{c}}-\mathrm{n}_{2} \cdot \mathrm{L}_{\mathrm{t}}}$

The total area of the shaded portion is:

Deformed area $=\mathrm{A}_{1}+\mathrm{A}_{2}=\frac{\Delta \cdot \mathrm{L}_{\mathrm{t}}\left(2 \mathrm{~L}_{\mathrm{c}}-\mathrm{L}_{\mathrm{t}}-\mathrm{n}_{2}{ }^{2} \cdot \mathrm{L}_{\mathrm{t}}\right)}{2\left(\mathrm{~L}_{\mathrm{c}}-\mathrm{n}_{2} \cdot \mathrm{L}_{\mathrm{t}}\right)}$

The external work done due to the line load, $\mathrm{w}_{\mathrm{t}}$, is:

$\mathrm{W}_{\mathrm{E}}=\mathrm{w}_{\mathrm{t}} \cdot($ Deformed area $)=\mathrm{F}_{\mathrm{t}} \cdot \frac{\Delta\left(2 \mathrm{~L}_{\mathrm{c}}-\mathrm{L}_{\mathrm{t}}-\mathrm{n}_{2}{ }^{2} \cdot \mathrm{L}_{\mathrm{t}}\right)}{2\left(\mathrm{~L}_{\mathrm{c}}-\mathrm{n}_{2} \cdot \mathrm{L}_{\mathrm{t}}\right)}$ 


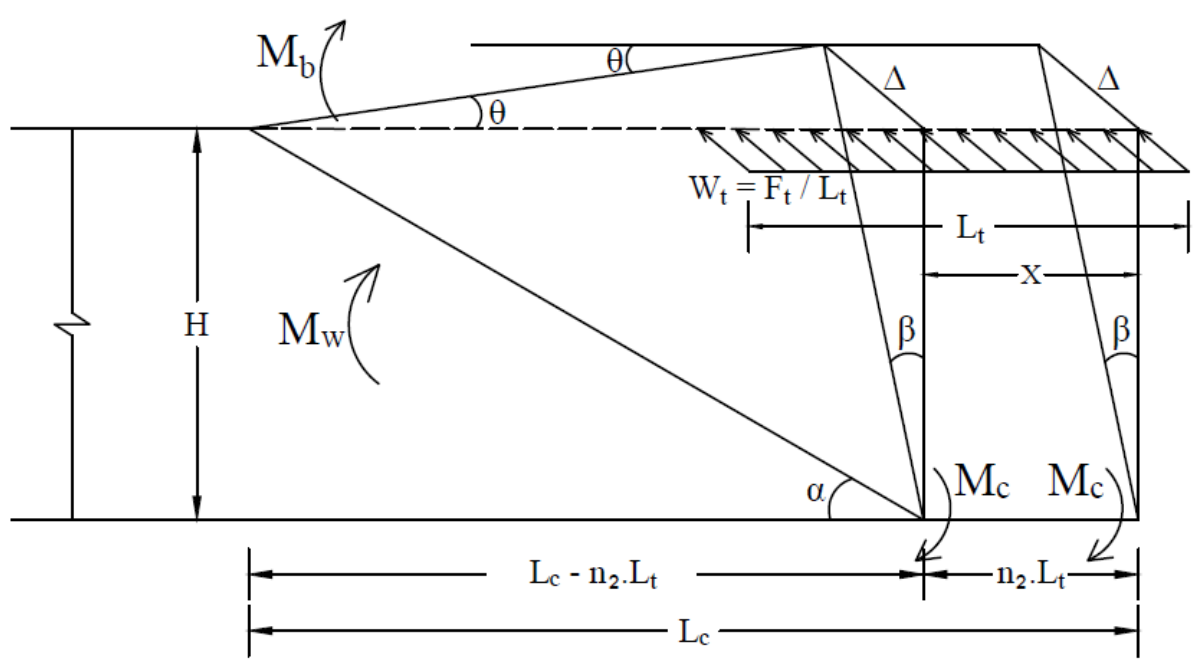

(a) Proposed 3D view of wall failure pattern

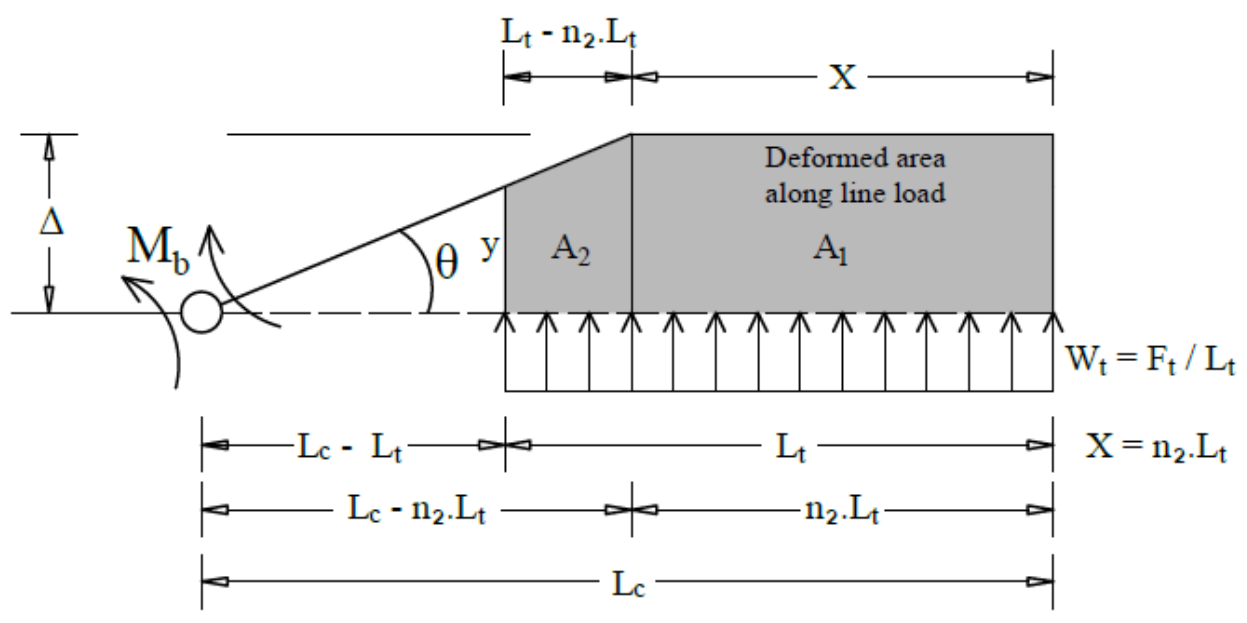

(b) Original and deformed shape of top of the wall

Figure 6. 21 Proposed trapezoidal yield-line failure pattern at exterior location $\left(\mathrm{X}<\mathrm{L}_{\mathrm{t}}\right)$

\section{Internal Work}

The internal work done along the yield-lines can be estimated by multiplying the yielding moment of the reinforcement crossing the yield-lines by the rotation to which they act. It is also supposed that wall segments are rigid so that the wall rotation is concentrated at the yield-lines. The rotation $\theta$ of the wall shown in Figure $6.21 \mathrm{~b}$ for the small deflection $\Delta$ can be written as: 
$\theta=\frac{\Delta}{\mathrm{L}_{\mathrm{C}}-\mathrm{n}_{2} \cdot \mathrm{L}_{\mathrm{t}}}$

The cap-beam develops plastic moment, $\mathbf{M}_{\mathrm{b}}$, at the limit state that is assumed to be equal to its nominal flexural strength, $\mathrm{M}_{\mathrm{n}}$. Thus, the internal work done by the cap-beam at the top, $\mathrm{U}_{\mathrm{b}}$, is:

$\mathrm{U}_{\mathrm{b}}=\mathrm{M}_{\mathrm{b}} \cdot \theta=\frac{\mathrm{M}_{\mathrm{b}} \cdot \Delta}{\mathrm{L}_{\mathrm{c}}-\mathrm{n}_{2} \cdot \mathrm{L}_{\mathrm{t}}}$

If assumed that positive and negative moment resistance, $\mathrm{M}_{\mathrm{w}}$, about the vertical axis per unit length of the wall are equal, the work done by horizontal reinforcement, $\mathrm{U}_{\mathrm{w}}$, due to wall moment of $\mathrm{M}_{\mathrm{w}} \cdot \mathrm{H}$ and wall rotation $\theta$ in horizontal plane is:

$\mathrm{U}_{\mathrm{w}}=\mathrm{M}_{\mathrm{w}} \cdot \mathrm{H} \cdot \theta=\frac{\mathrm{M}_{\mathrm{w}} \cdot \mathrm{H} \cdot \Delta}{\mathrm{L}_{\mathrm{c}}-\mathrm{n}_{2} \cdot \mathrm{L}_{\mathrm{t}}}$

If the wall rotation in vertical plane of the rotation is $\beta$, and knowing that $\beta$ is equal to $\Delta / \mathrm{H}$, the internal work, $\mathrm{U}_{\mathrm{c}}$, due to cantilever moment $\mathrm{M}_{\mathrm{c}} \cdot \mathrm{L}_{\mathrm{c}}$ is:

$\mathrm{U}_{\mathrm{c}}=\mathrm{M}_{\mathrm{c}} \cdot \mathrm{L}_{\mathrm{c}} \cdot \beta=\frac{\mathrm{M}_{\mathrm{c}} \cdot \mathrm{L}_{\mathrm{c}} \cdot \Delta}{\mathrm{H}}$

The total internal work done by the cap-beam and the reinforcement can be written as:

$\mathrm{U}_{\mathrm{i}}=\mathrm{U}_{\mathrm{b}}+\mathrm{U}_{\mathrm{w}}+\mathrm{U}_{\mathrm{c}}=\frac{\mathrm{M}_{\mathrm{b}} \cdot \Delta}{\mathrm{L}_{\mathrm{c}}-\mathrm{n}_{2} \cdot \mathrm{L}_{\mathrm{t}}}+\frac{\mathrm{M}_{\mathrm{w}} \cdot \mathrm{H} \cdot \Delta}{\mathrm{L}_{\mathrm{c}}-\mathrm{n}_{2} \cdot \mathrm{L}_{\mathrm{t}}}+\frac{\mathrm{M}_{\mathrm{c}} \cdot \mathrm{L}_{\mathrm{c}} \cdot \Delta}{\mathrm{H}}$

Given the fact that the external work is equal to the internal work $\left(\mathrm{U}_{\mathrm{i}}=\mathrm{W}_{\mathrm{E}}\right)$, we obtain:

$\mathrm{F}_{\mathrm{t}}=\frac{2 \mathrm{M}_{\mathrm{b}}}{2 L_{c}-L_{t}-\mathrm{n}_{2}^{2} \cdot L_{t}}+\frac{2 \mathrm{M}_{\mathrm{w}} \cdot \mathrm{H}}{2 L_{c}-L_{t}-\mathrm{n}_{2}^{2} \cdot L_{t}}+\frac{2 \mathrm{M}_{\mathrm{c}} \cdot\left(L_{c}{ }^{2}-\mathrm{n}_{2} \cdot L_{t} \cdot L_{c}\right)}{\mathrm{H} \cdot\left(2 L_{c}-L_{t}-\mathrm{n}_{2}{ }^{2} \cdot L_{t}\right)}$ 
The critical value, $\mathrm{L}_{\mathrm{c}}$ that minimizes $\mathrm{F}_{\mathrm{t}}$ can be estimated by defferentiating the above equation

with respect to $\mathrm{L}_{\mathrm{c}}$ that is $\frac{d\left(F_{t}\right)}{d\left(L_{c}\right)}=0$, this minimization gives a quadratic equation that can be solved explicitly to find the critical length, $\mathrm{L}_{\mathrm{c}}$, as:

$$
\begin{gathered}
\mathrm{L}_{\mathrm{c}}=0.5 \mathrm{~L}_{\mathrm{t}}\left(1+\mathrm{n}_{2}^{2}\right)+\sqrt{\frac{1}{4} \mathrm{~L}_{\mathrm{t}}^{2}\left(1+\mathrm{n}_{2}^{2}\right)^{2}+\frac{2 M_{b} H+2 M_{w} H^{2}-M_{c} \cdot\left(\mathrm{n}_{2} L_{t}{ }^{2}+\mathrm{n}_{2}{ }^{3} \cdot \mathrm{L}_{\mathrm{t}}{ }^{2}\right)}{2 M_{c}}} \\
\text { for }\left(0 \leq \mathrm{n}_{2}<1\right)
\end{gathered}
$$

Knowing that $\mathrm{F}_{\mathrm{t} \text {,min }}=\mathrm{R}_{\mathrm{w}}$, the minimum nominal resistance of the barrier wall system at exterior location with $\mathrm{X}<\mathrm{L}_{\mathrm{t}}$ can be written as:

$\mathrm{R}_{\mathrm{w}}=\left(\frac{1}{2 \mathrm{~L}_{\mathrm{c}-} \mathrm{L}_{\mathrm{t}-} \mathrm{n}_{2}{ }^{2} \cdot \mathrm{L}_{\mathrm{t}}}\right)\left(2 \mathrm{M}_{\mathrm{b}}+2 \mathrm{M}_{\mathrm{w}} \cdot \mathrm{H}+\frac{2 M_{c} \cdot\left(L_{c}{ }^{2}-\mathrm{n}_{2} \cdot \mathrm{L}_{\mathrm{t}} \cdot \mathrm{L}_{\mathrm{c}}\right)}{H}\right)$ for $\left(0 \leq \mathrm{n}_{2}<1\right),(\mathrm{Eq} \cdot 6 \cdot 43)$

It is worth to mention that if $\mathrm{n}_{2}$ is to be taken as zero, Eqs. 6.42 and 6.43 yield similar equations specified in AASHTO-LRFD for exterior location (Eqs. 2.37 and 2.38).

\subsection{Considerations of Possible Yield-Line Failure Patterns}

\subsubsection{At Interior Location}

The above developed equations at interior location (Eqs. 6.9, 6.10, 6.21 and 6.22) can be regarded as general case yield-line patterns. In other words, the above equation can be used for both triangular and trapezoidal failure shapes and whether or not the yield-line occurs within the entire height $(\mathrm{H})$ of the barrier or within the height above the tapered portion of the traffic barriers $\left(\mathrm{H}_{1}\right)$. For instance, for a triangular failure shape at interior location, $\mathrm{n}_{2}$ can be taken as zero in Eqs. 6.21 and 6.22; while in the case when yield-line occurred within the tapered portion of the wall the total height of the barrier wall, $\mathrm{H}$, can be replaced by the height of the tapered portion $\mathrm{H}_{1}$ in those equations. Therefore, based on the crack patterns observed from experimental testing of the PL-3 and PL-2 traffic barriers, four possible yield-line failure patterns shown in Figure 6.22 have been examined to investigate the least nominal resistance value of the traffic 
barriers. From the figure, YL-1 and YL-2 represent the AASHTO-LRFD yield line pattern by triangular failure shape. For YL-2 that occurred above the tapered portion of the wall, the height $H$ was replaced by $H_{1}$ in the above developed equations with $n_{1}$ and $n_{2}$ values equal to zero. However, YL-3 and YL-4 were considered similar to this study by trapezoidal failure shape with the assumption that YL-3 occurs within the height $\mathrm{H}_{1}$ of the barrier wall. Results including the critical yield length and the minimum wall resistance for the possible yield-line patterns are shown in Table 6.3. In calculating trapezoidal yield-line patterns with YL-3 and YL-4, using the developed equations, Eqs. 6.21 and 6.22 were used first by considering $\mathrm{n}_{2}$ values between $0 \leq \mathrm{n}_{2}$ $<1$ in 0.01 increments in the excel sheet. Eqs. 6.9 and 6.10 were then used for $\mathrm{n}_{1}$ values between $1 \leq \mathrm{n}_{1} \leq 2$ also in 0.01 increments. The graphs of wall resistance versus (n) values were then plotted and shown in Figure 6.23. From the graphs, the least value of the nominal wall resistance has been taken as the critical value. The corresponding ( $n$ ) value to the least nominal wall resistance can be used to determine the length of horizontal yield-line, $\mathrm{X}$, as a function of loaded length, $\mathrm{L}_{\mathrm{t}}$, at base of the wall $\left(\mathrm{X}=\mathrm{n} \cdot \mathrm{L}_{\mathrm{t}}\right)$. For instance, for YL-4 in PL-3 traffic barrier, the $(n)$ value corresponding to minimum wall resistance of $712.2 \mathrm{kN}$ is taken as 0.60 from Figure 23a. Thus, the length of horizontal yield-line at base of the wall is 0.60 times the loaded length of $2400-\mathrm{mm}$ which is equal to $1440-\mathrm{mm}$. It can also be seen from Figure 6.23 that the critical wall resistance can be obtained for the (n) values between 0.5 to 1. Thus, it can be concluded that Eq.s 6.21 and 6.22 govern and can be regarded to provide the most critical yield-line failure pattern at interior location. It should also be noted that YL-3 denoted by superscript 1 in Table 6.3 is calculated based on Eq. 6.11 developed by Jeon et al. (2008) for the aim of comparison with the current study. However, the value given by the current study for YL-3 provides the exact (n) value, while Jeon et al. (2008) considers the (n) value of 1 in calculating the wall resistance. It can also be observed from Table 6.3 that YL-4 revealed the least value of the wall resistance among all other yield-line patterns with corresponding maximum critical lengths for both PL-3 and PL-2 traffic barriers. Therefore, from experimental and theoretical results stated above, it can generally be concluded that the trapezoidal yield-line pattern with $\mathrm{X}<\mathrm{L}_{\mathrm{t}}$ would govern knowing that Eqs. 6.21 and 6.22 yielded the most critical value of the wall resistance at interior location of the traffic barriers. 

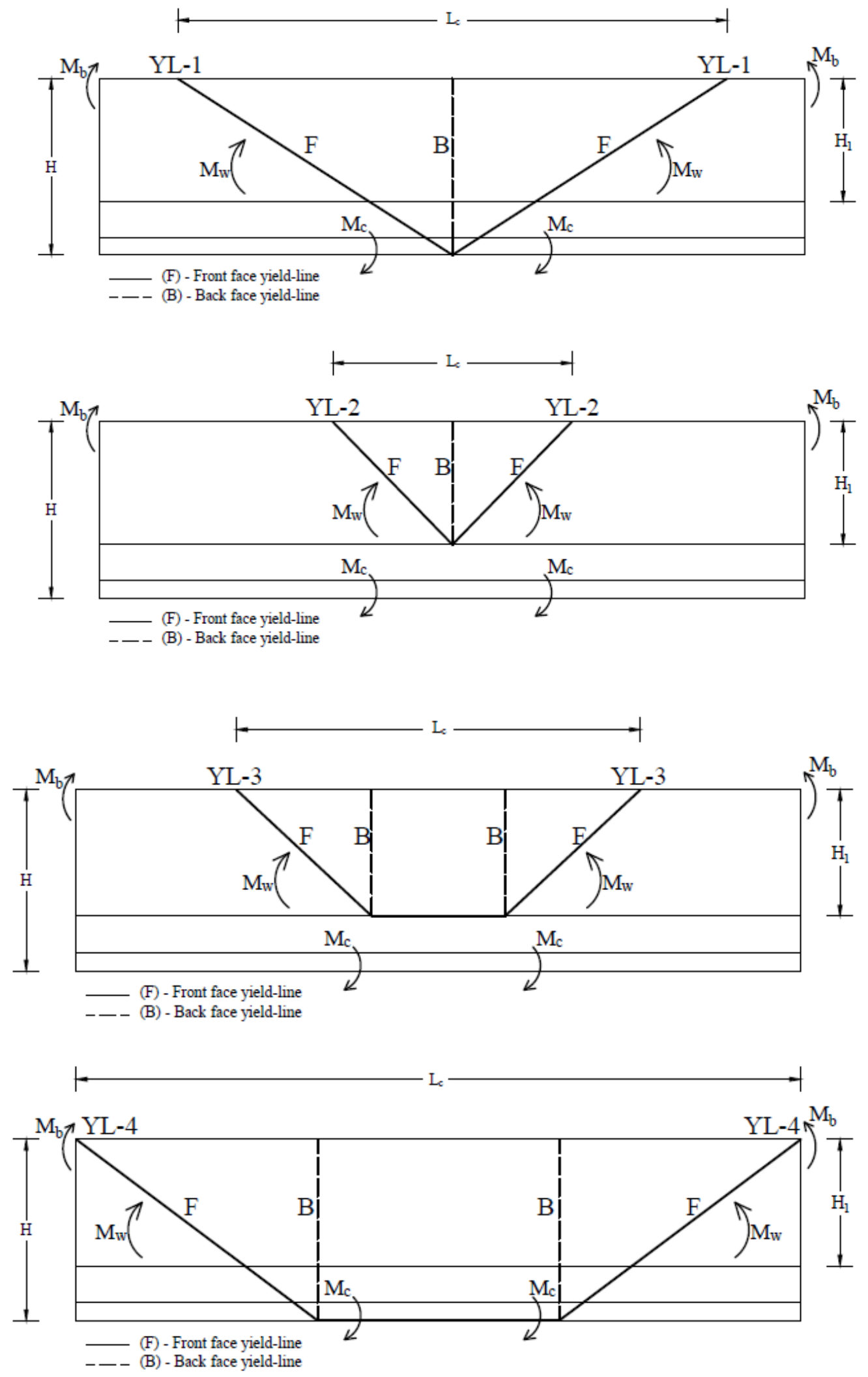

Figure 6. 22 Possible yield-line failure patterns at interior location of the barriers 
Table 6. 3 Comparison of ultimate wall resistance for various yield-line patterns at interior location

\begin{tabular}{|c|c|c|c|c|c|c|c|c|c|c|c|c|}
\hline \multirow{2}{*}{$\begin{array}{c}\text { Barrier } \\
\text { type }\end{array}$} & \multicolumn{5}{|c|}{$\mathrm{L}_{\mathrm{c}}(\mathrm{mm})$} & \multicolumn{6}{|c|}{$\mathrm{R}_{\mathrm{w}}(\mathrm{kN})$} & \multirow{2}{*}{$\begin{array}{c}\text { CHBDC } \\
(\mathrm{kN})\end{array}$} \\
\hline & YL1 & YL2 & $\mathrm{YL}^{1}$ & $\mathrm{YL}^{2}$ & YL4 & YL1 & YL2 & $\mathrm{YL}^{1}$ & $\mathrm{YL}^{2}$ & YL4 & Test & \\
\hline PL-3 & 4016 & 3389 & 4230 & 3580 & 4251 & 810 & 920.9 & 823.5 & 767.6 & 712.2 & 885.9 & 357 \\
\hline PL-2 & 2320 & 1793 & 2204 & 1893 & 2418 & 328.2 & 348.2 & 326 & 311.6 & 304.9 & 421.9 & 170 \\
\hline
\end{tabular}

${ }^{1}$ The critical yield length and wall resistance are calculated based on Jeon et al. 2008 equation

${ }^{2}$ The Critical yield length and wall resistance are calculated based on the current study

\subsubsection{At Exterior Location}

The developed equations at exterior locations (Eq.s 6.31, 6.32, 6.42 and 6.43) can be used for both trapezoidal and triangular yield-line failure patterns. In case of triangular failure pattern, $\mathrm{n}_{2}$ value can be assumed equal to zero in Eqs. 6.42 and 6.43. In calculating trapezoidal yield-line by the developed equations, it can be assumed $\mathrm{n}_{2}$ as any value between zero to one $\left(0 \leq \mathrm{n}_{2}<1\right)$ and $\mathrm{n}_{1}$ as any value between 1 and $2\left(1 \leq \mathrm{n}_{1} \leq 2\right)$ both in very small increments (i.e. 0.01$)$ in the excel sheet. Eqs. 6.42 and 6.43 can be applied to determine the critical length, $\mathrm{L}_{\mathrm{c}}$, and wall resistance, $R_{w}$, for $0 \leq n_{2}<1$ and Eqs. 6.31 and 6.32 can be used to calculate $L_{c}$ and $R_{w}$ for $1 \leq$ $\mathrm{n}_{1} \leq 2$.

From experimental tests performed on PL-3 and PL-2 barriers at exterior location, four possible yield-line patterns were recognized as shown in Figure 6.24. These yield-line patterns have been examined to investigate the ultimate transverse wall resistance that can be understood by least value of the wall resistance through the possible yield-line patterns. YL-1 and YL-4 were selected similar to the AASHTO-LRFD yield-line pattern at exterior location, except that the YL-4 would occur at height of $\mathrm{H}_{1}$ above the tapered portion of the wall. YL-2 and YL-3 represent the trapezoidal failure patterns with the assumption that YL-3 would occur within the height $\mathrm{H}_{1}$. The critical yield length and minimum wall resistance for the possible yield-line patterns were calculated using the above proposed equations at exterior location and the resulting values are summarized in Table 6.4. The graph of wall resistance versus the variable $\mathrm{n}$ values is also shown in Figure 6.25. 


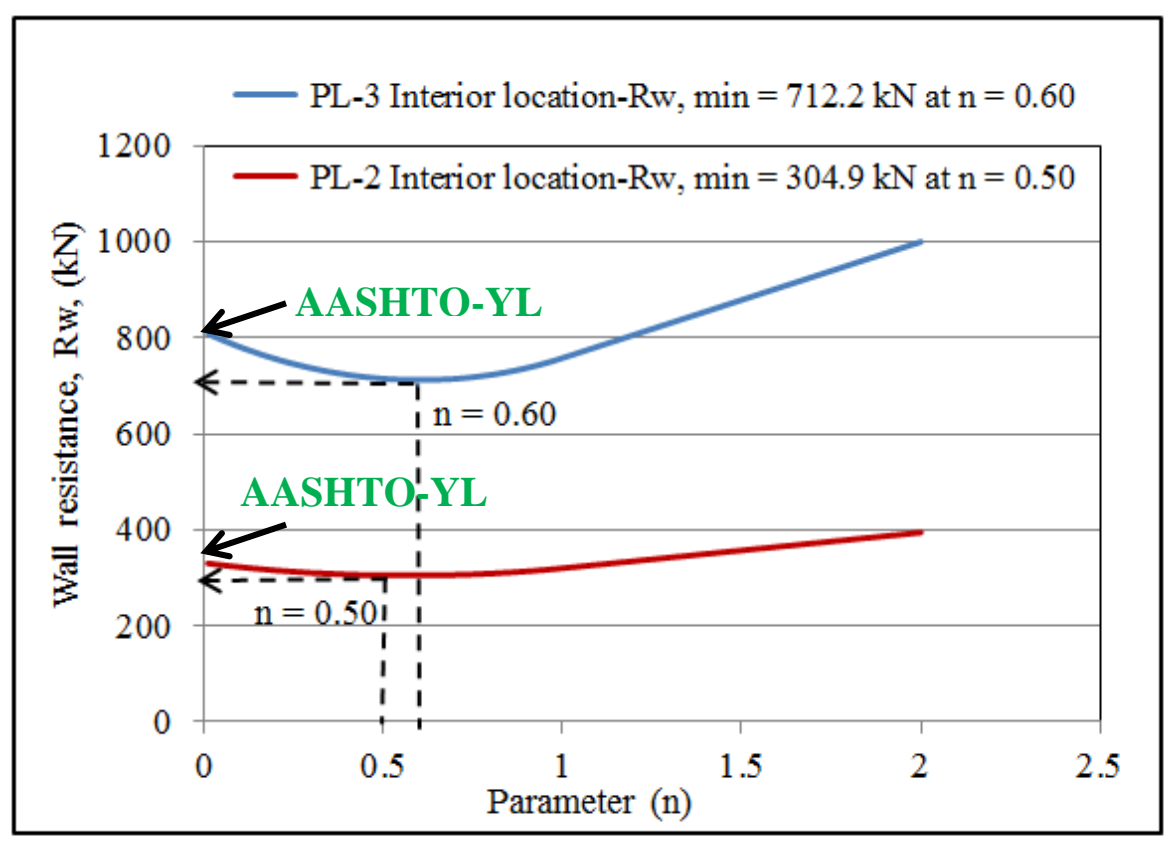

(a) For YL-4

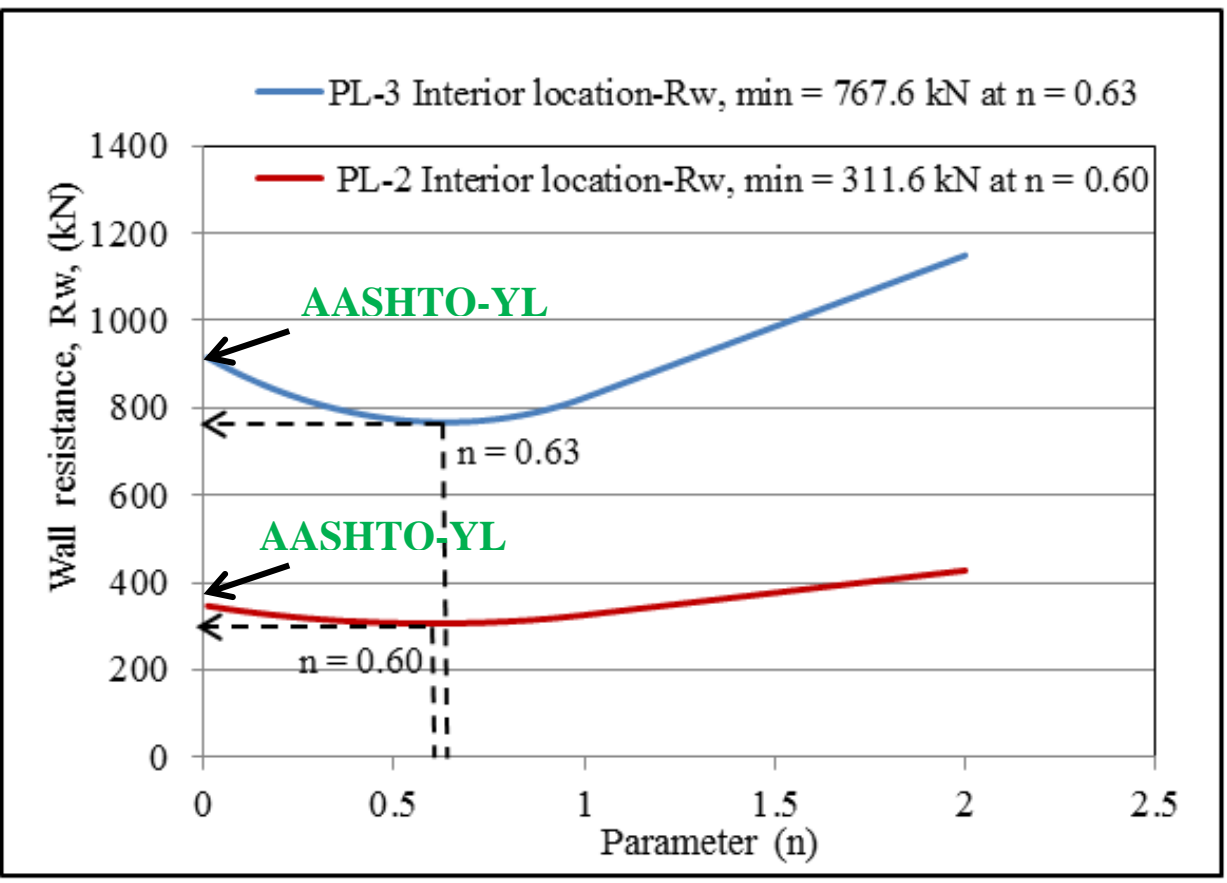

(b) For YL-3

Figure 6. 23 Determination of critical wall resistance for YL-3 and YL-4 failure modes as a function of parameter (n) 
In can be seen from the graphs that minimum value of the wall resistance occurred for (n) values between zero to one. The ultimate wall resistances for YL-2 and YL-3 taken from these graphs are provided in Table 6.4. For YL-2 in PL-3 traffic barrier shown in Figure 6.24, the ultimate wall resistance occurred for (n) value of 0.72 equal to $391.7 \mathrm{kN}$. This means that the length of horizontal yield-line, $\mathrm{X}$, at the base of the wall is 0.72 times the load length $(2400-\mathrm{mm})$ equal to 1728-mm which was in good agreement with the experimental observations. It can also be seen from Table 6.4 that YL-2 with the trapezoidal yield-line failure at the wall base presented the least value of the wall resistance compared to YL-1, YL-3 and YL-4. Thus, from experimental and the theoretical investigations, it can be concluded that trapezoidal yield-line pattern at end regions and over the entire height, $\mathrm{H}$, of the wall will govern and Eqs. 6.42 and 6.43 with $\mathrm{X}<\mathrm{L}_{\mathrm{t}}$ yielded the most critical value of the wall resistance at exterior location of the traffic barriers.

Table 6. 4 Comparison of ultimate wall resistance for possible yield-line patterns at exterior location

\begin{tabular}{|c|c|c|c|c|c|c|c|c|c|c|}
\hline \multirow{2}{*}{$\begin{array}{c}\text { Barrier } \\
\text { type }\end{array}$} & \multicolumn{4}{|c|}{$\mathrm{L}_{\mathrm{c}}(\mathrm{mm})$} & \multicolumn{5}{c|}{$\mathrm{R}_{\mathrm{w}}(\mathrm{kN})$} & CHBDC \\
\cline { 2 - 10 } & YL1 & YL2 & YL3 & YL4 & YL1 & YL2 & YL3 & YL4 & Test & $(\mathrm{kN})$ \\
\hline PL-3 & 2658 & 2806 & 2646 & 2563 & 536.1 & 391.7 & 468.8 & 696.6 & 627.13 & 357 \\
\hline PL-2 & 1180 & 1257 & 1166 & 1129 & 317.9 & 238.3 & 278.7 & 410.2 & 243.66 & 170 \\
\hline
\end{tabular}



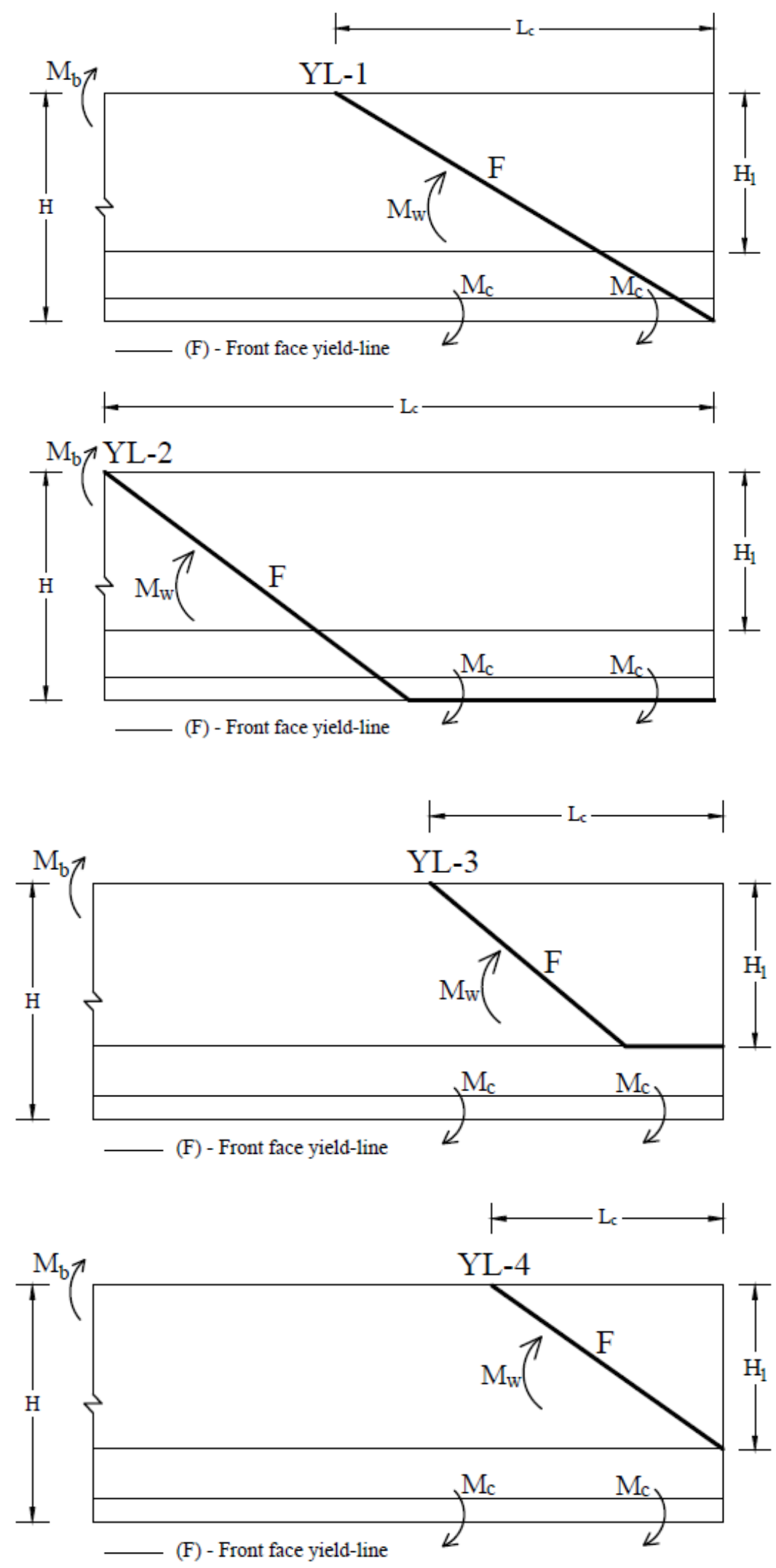

Figure 6. 24 Possible yield-line patterns at exterior location 


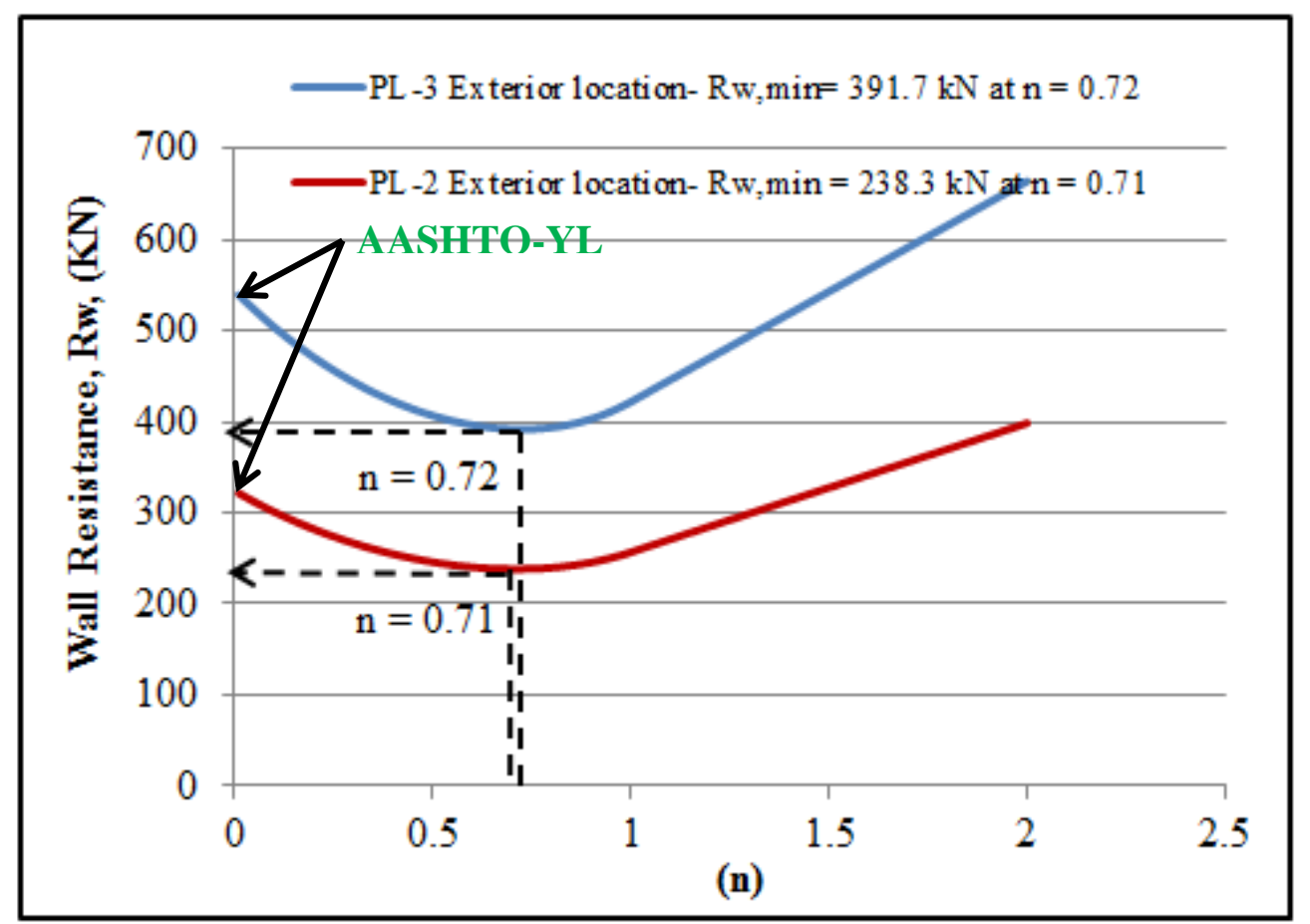

(a) For YL-2

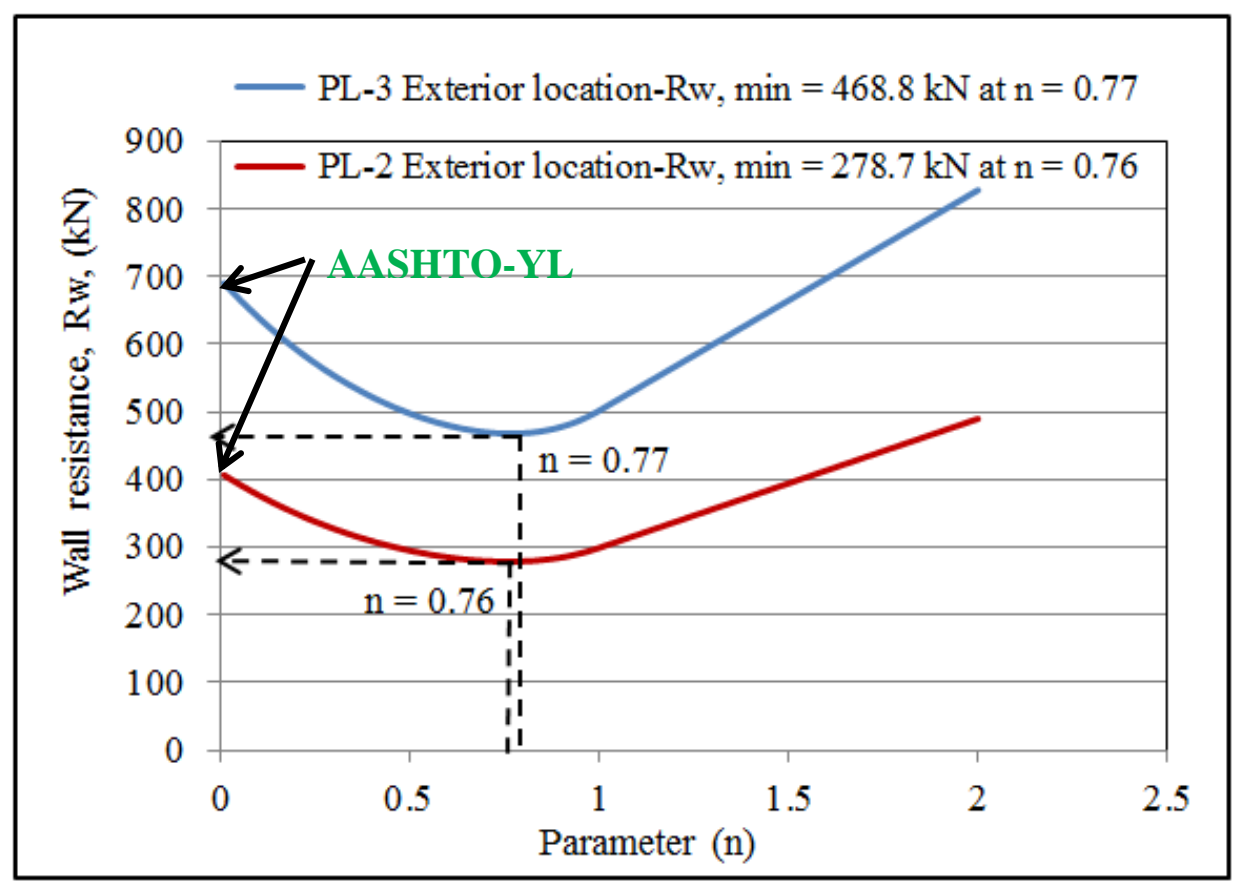

(b) For YL-3

Figure 6. 25 Ultimate resistance of barrier wall by trapezoidal failure pattern for YL-2 and YL-3 


\subsection{Critical Yield-Line Length and Wall Resistance of CHBDC Barriers}

The proposed equations stated above confirmed development of trapezoidal yield-line patterns at exterior and interior locations of the traffic barriers. It was observed that the traffic barriers developed a horizontal yield-line at the base of the wall with a length equal to 0.5 to 1 times the load length, $\mathrm{L}_{\mathrm{t}}$. As such, using the proposed equations at interior and exterior locations (Eq.s $6.21,6.22,6.42$ and 6.43), the critical yield-line lengths and critical wall resistances for the standard PL-2 and PL-3 barriers shown in Figure 6.26 were derived. The calculations were made for barriers with variable horizontal and vertical bar reinforcement. Results of the these calculations are provided in the tables in Appendix F. Figures 6.27 to 6.30 provide graphs of critical wall resistance and critical yield-line length of the PL-3 and PL-2 CHBDC standard barriers as a function of horizontal and vertical bar spacing. The graphs can be utilized to easily determine the wall resistance and the critical yield-line length based on the given bar spacing. As an example, for a PL-3 barrier with horizontal bars spacing of $300 \mathrm{~mm}$ and vertical bars spacing of $225 \mathrm{~mm}, \mathrm{R}_{\mathrm{w}}$ was calculated using the developed equations equal to 584.8 and $381.9 \mathrm{kN}$ at interior and exterior locations, respectively. For the same bars spacing, $\mathrm{L}_{\mathrm{c}}$ was also calculated from the equations equal to 4100- and 3020-mm at interior and exterior locations, respectively. Using the developed graphs for the bar horizontal spacing of 300-mm and vertical spacing of 225 $\mathrm{mm}$ in PL-3 barrier, the same critical lengths and ultimate wall resistances can be determined at interior and exterior locations, respectively.

\subsection{Longitudinal Length of Barrier Wall}

Experimental test results have shown that the longitudinal length of barrier has significant effect on the development of yield-line failure (Kobayashi et al. 1996, Ohta, T 1992). In accordance with CHBDC, if sufficient longitudinal length of barrier wall is not provided, the barrier wall will fail in one-way action by forming a longitudinal crack at the juncture of barrier wall-to-the deck slab. As such, the length of barrier should be sufficient so that the critical length for the yield line, $\mathrm{L}_{\mathfrak{c}}$, lies within the barrier length. The experimental study conducted by Tanaka et al. (1992) has shown dependence of wall resistance with longitudinal length of precast barrier wall. It was shown that shorter length barrier wall results in overall poor resistance due to lack of flexural resistance in plane providing that the barrier length is relatively short. 


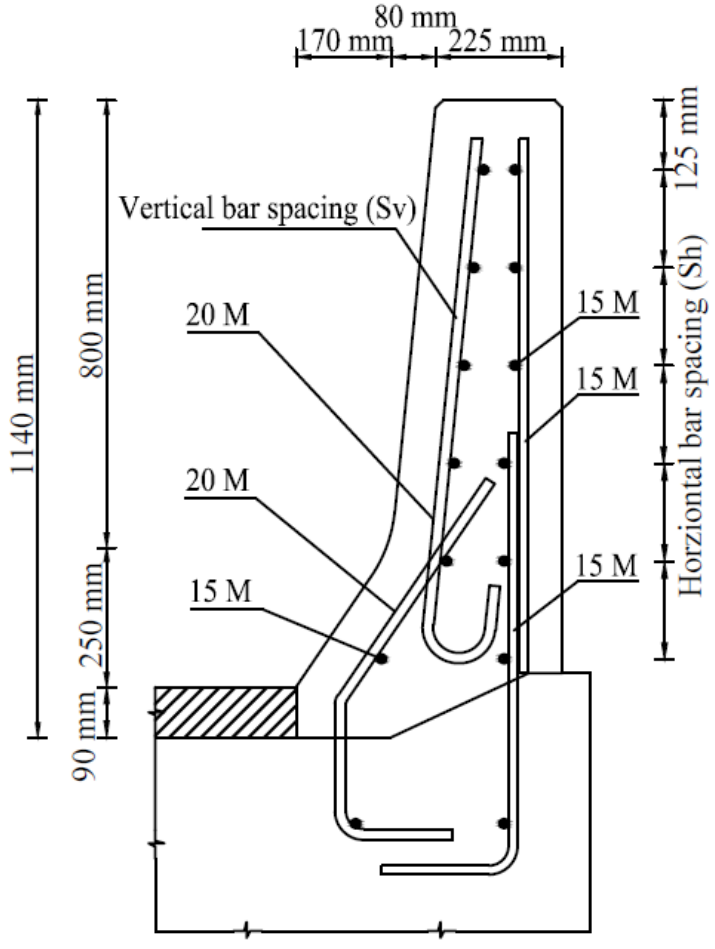

(a) Standard PL-3 barrier

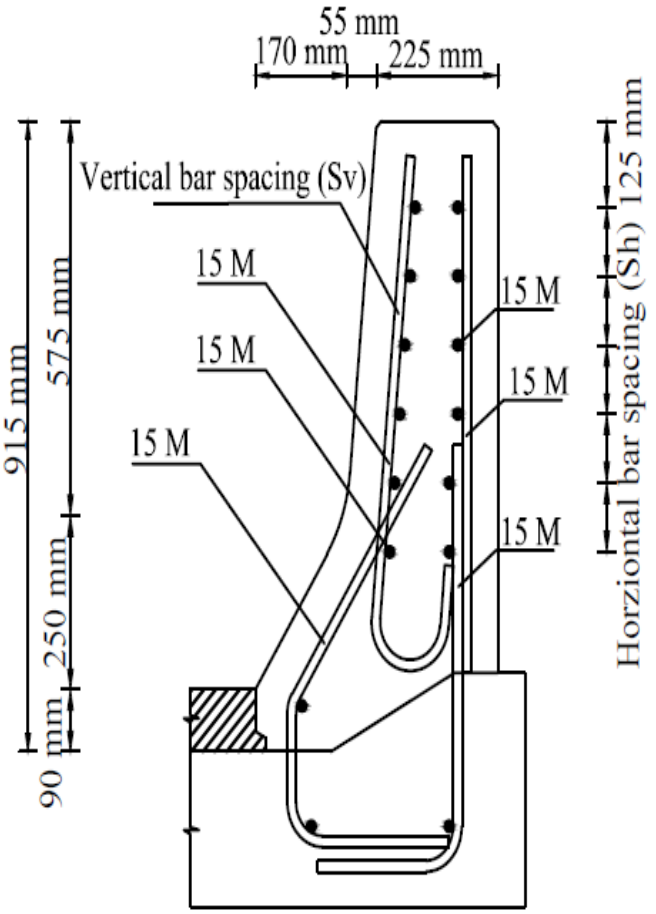

(b) Standard PL-2 barrier

Figure 6. 26 View of CHBDC standard PL-3 and PL-2 traffic barriers

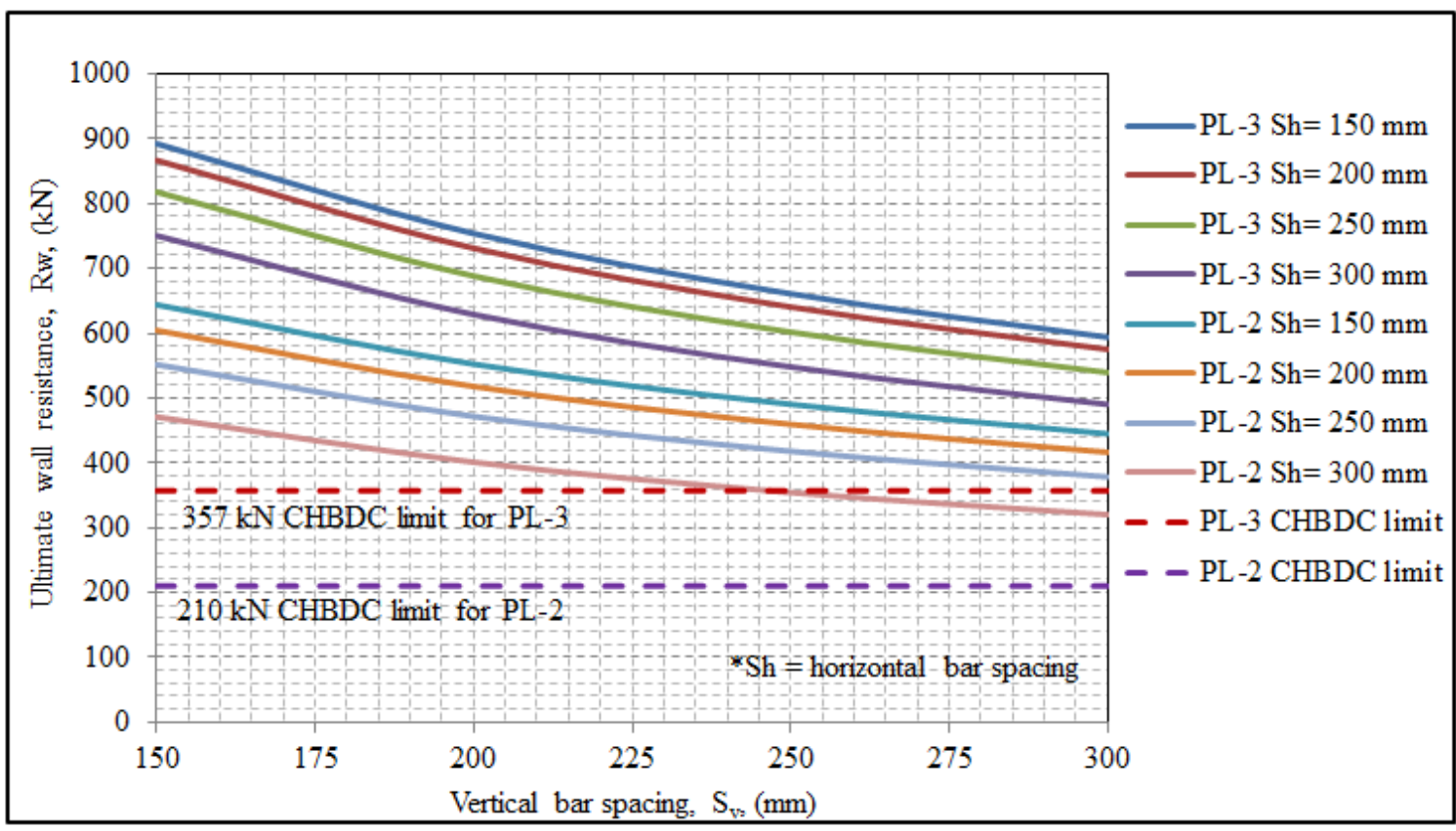

Figure 6. 27 Graphs of critical wall lateral resistance, $R_{w}$, as a function of bar vertical and horizontal spacing in PL-3 and PL-2 barriers at interior location 


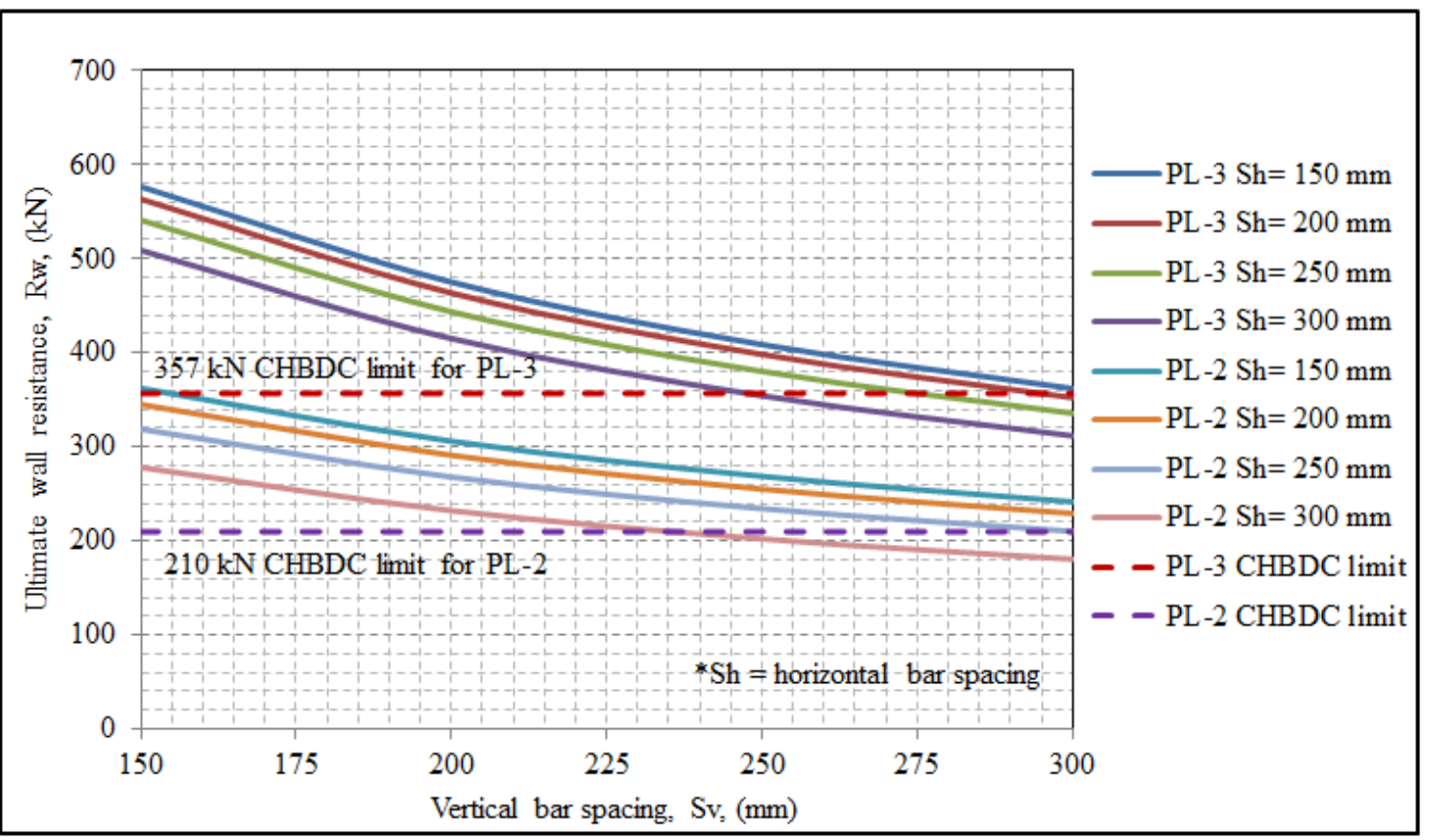

Figure 6. 28 Graphs of critical wall lateral resistance, $R_{w}$, as a function of bar vertical and horizontal spacing in PL-3 and PL-2 barriers at exterior locations

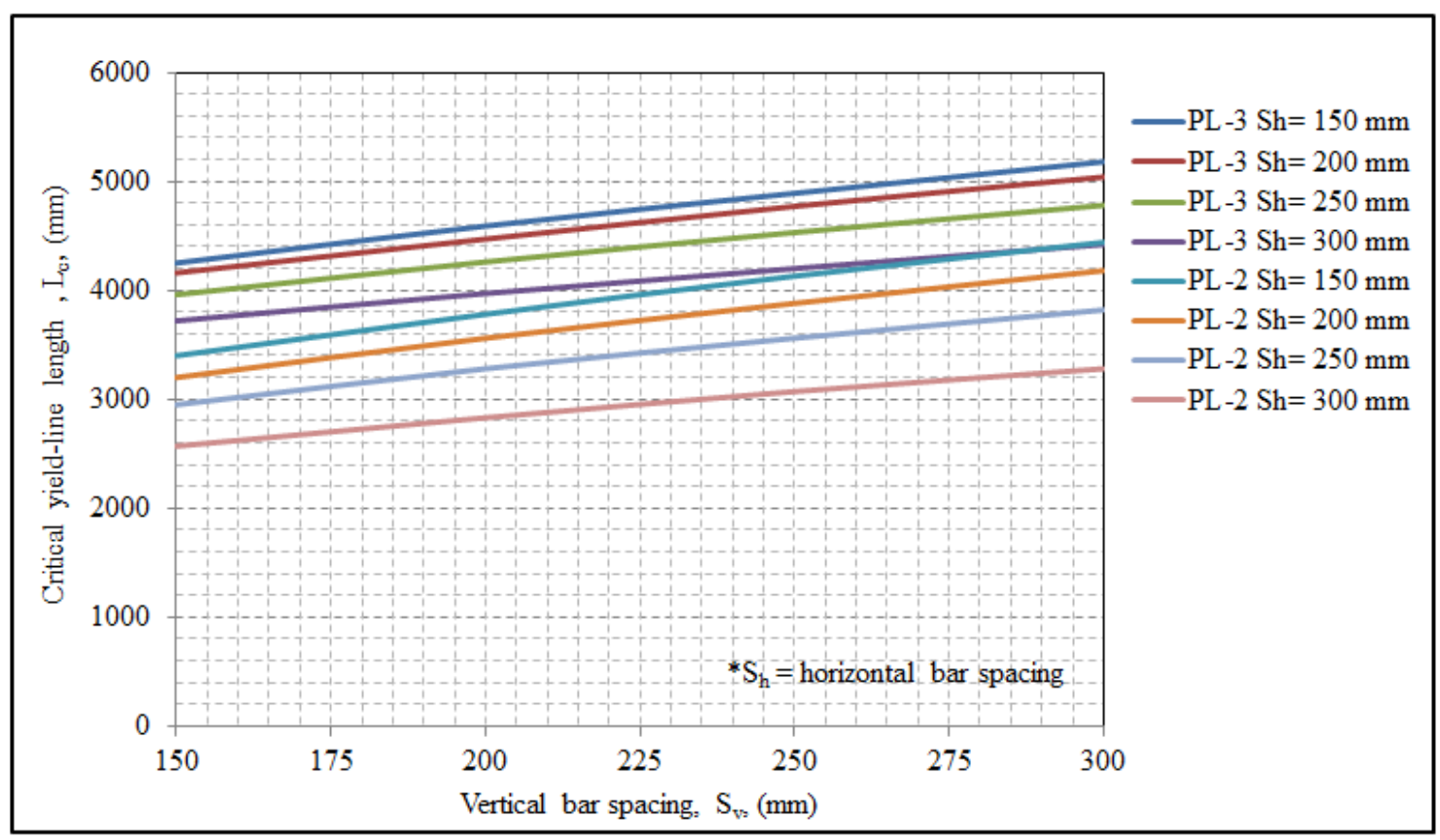

Figure 6. 29 Graphs of critical yield line length, $\mathrm{L}_{\mathrm{c}}$, as a function of bar vertical and horizontal spacing in PL-3 and PL-2 barriers at interior locations 


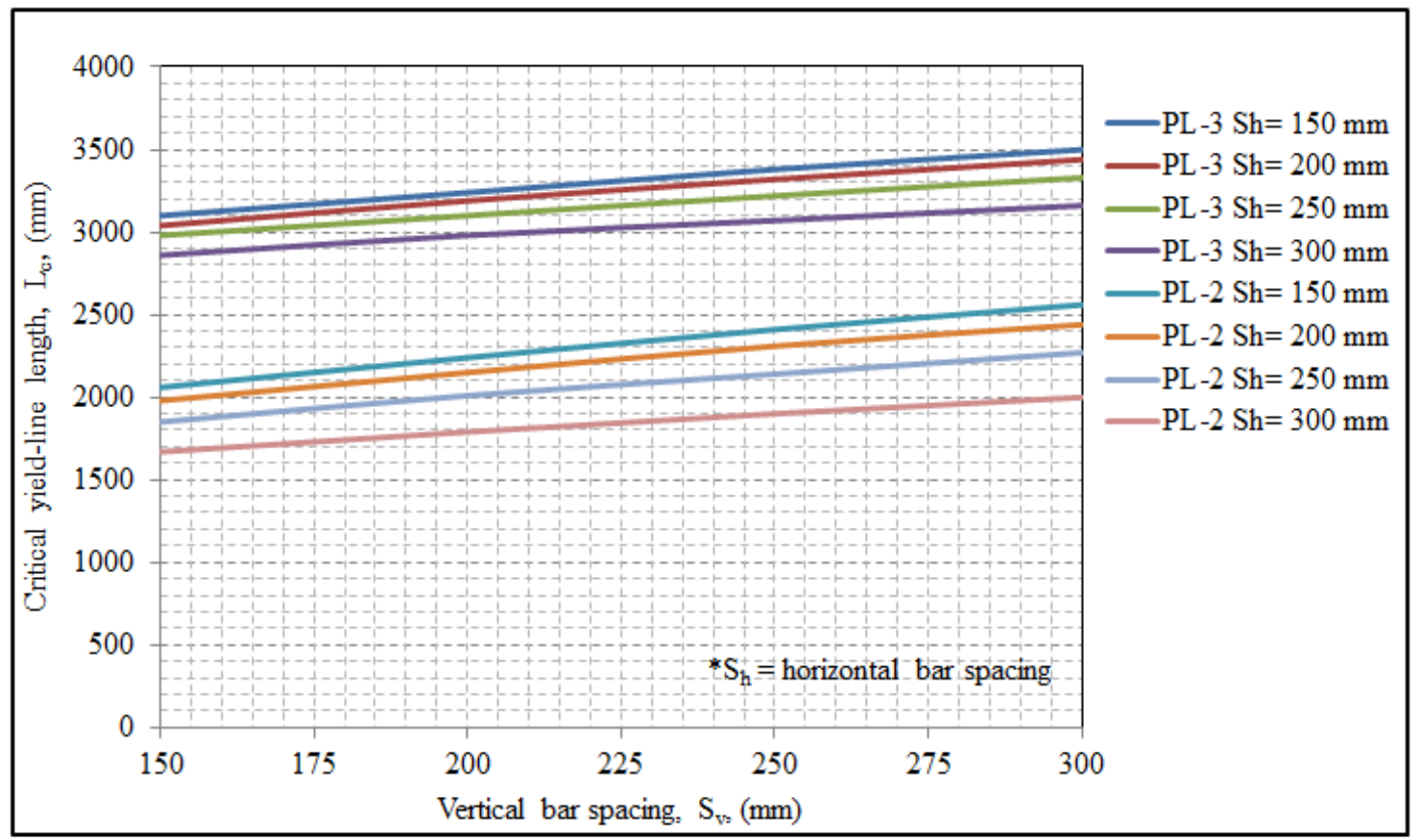

Figure 6. 30 Graphs of critical yield line length, $\mathrm{L}_{\mathrm{c}}$, as a function of bar vertical and horizontal spacing in PL-3 and PL-2 barriers at exterior locations

Thus, the current study was extended to find the minimum longitudinal length required so that the one-way action failure of the barrier wall is prevented. In accordance with CHBDC requirements, static test of bridge barrier wall is performed with a line load over a length of 2400-mm and 1050-mm in PL-3 and PL-2 barriers, respectively. The load is applied transversely at the top of the wall, $900-\mathrm{mm}$ or $700-\mathrm{mm}$ above the asphalt layer in PL-3 and PL-2, respectively. For simplicity, the transverse line load is converted to an equivalent point load at the top of the wall. The wall resistance load and critical length can be derived by assuming $\mathrm{L}_{\mathrm{t}}$ equal to zero in Eq.s 2.35 to 2.38. If assuming there is no cap-beam in the wall system, the wall resistance load and critical yield-line lengths due to two-way actions at interior and exterior locations as well as one-way action of barrier wall can be derived as follows;

- Wall resistance load and critical length due to a point load at interior location; two-way action:

$\mathrm{P}_{2 \text {-int. }}=\frac{8 M_{W} \cdot H}{L_{C}}+\frac{M_{C} \cdot L_{C}}{H}$

(Eq. 6.44) 
$\mathrm{L}_{\mathrm{c}, 2 \text {-int. }}=\sqrt{\frac{8 M_{w} H^{2}}{M_{c}}}$

Substituting $\mathrm{L}_{\mathrm{c}}$ from Eq. 6.45 into Eq. 6.44, the wall resistance load can be rearranged as:

$\mathrm{P}_{2 \text {-int. }}=4 \cdot \sqrt{2 M_{w} \cdot M_{c}}$

- Wall resistance load and critical length due to a point load at exterior location; two-way action:

$\mathrm{P}_{2 \text {-ext. }}=\frac{M_{W} \cdot H}{L_{C}}+\frac{M_{C} \cdot L_{C}}{H}$

$\mathrm{L}_{\mathrm{c}, 2 \text {-ext. }}=\sqrt{\frac{M_{w} H^{2}}{M_{c}}}$

Substituting Eq. 6.48 into Eq. 6.47 yields the following wall resistance load:

$\mathrm{P}_{2 \text {-ext. }}=2 \cdot \sqrt{M_{w} \cdot M_{c}}$

- Wall resistance load due to a point load; one-way action:

$\mathrm{P}_{1}=\frac{M_{C} \cdot L}{H}$

(Eq. 6.50)

Where $\mathrm{M}_{\mathrm{w}}, \mathrm{M}_{\mathrm{c}}, \mathrm{L}_{\mathrm{c}}$ and $\mathrm{H}$ are introduced similarly in Eq.s 2.35 - 2.38. $\mathrm{P}_{2 \text {-int. }}$ and $\mathrm{P}_{\text {2-ext. }}$ are the wall resistance loads due to two-way action at interior and exterior locations, respectively., $\mathrm{L}_{\mathrm{c}, \text {, } 2 \text {-int. and }}$ $\mathrm{L}_{\mathrm{c}}$, 2-ext. are the critical yield-line length due to two-way action at interior or exterior locations, respectively and $\mathrm{P}_{1}$ is the wall resistance load due to one-way action of barrier wall. For a given height in PL-2 or PL-3 barrier, the one-way action failure depends relatively to the longitudinal length of the wall section. For a short barrier wall, the one-way action failure does not represent the ultimate resistance of the wall section due to the fact that the maximum strength associated 
with a given section may not attain. The minimum barrier longitudinal length to avoid failure by one-way action can be obtained by equating Eq.s 6.46 and 6.49 to Eq. 6.50 and assuming that $\mathrm{M}_{\mathrm{c}}$ $\cong\left(\mathrm{M}_{\mathrm{w}} / \mathrm{H}\right)$ providing that;

$\mathrm{L}_{\text {int. }} \geq 4 \mathrm{H}^{2} \cdot \sqrt{\frac{2}{H}} \quad$ (at interior location, and $\mathrm{H}$ in $\mathrm{m}$ )

$\mathrm{L}_{\text {ext. }} \geq 2 \mathrm{H}^{2} \cdot \sqrt{\frac{1}{H}} \quad$ (at exterior location, and $\mathrm{H}$ in $\mathrm{m}$ )

In other words, if the constructed barrier length satisfies the conditions given above, failure of wall section will be accompanied by two-way actions by formation of the yield-line patterns. For instance, for a PL-3 barrier wall with height of $(\mathrm{H}=1.14 \mathrm{~m})$, when $\mathrm{L}$ is greater than $6.9 \mathrm{~m}$ at interior location or $2.43 \mathrm{~m}$ at exterior location, two-way action failure of barrier followed by diagonal yield-lines will occur.

\subsection{Bending and Twisting Moments Along or Normal to the Yield-Lines}

Concrete bridge barriers are generally reinforced in vertical and horizontal directions. A barrier wall is said to be orthotropically reinforced if its ultimate strengths are different in two perpendicular directions. In such cases, yield-line occurs across these orthogonal directions. Figure 6.31 shows a typical barrier wall at exterior location by trapezoidal failure pattern with the development of bending moment strength, $\mathbf{M}_{\alpha}$, along the diagonal yield line. As mentioned earlier, the horizontal reinforcement develops bending moment resistance about vertical axis, $\mathrm{M}_{\mathrm{w}}$, and the vertical reinforcement develops resistance moment about the horizontal axis, $\mathbf{M}_{\mathrm{c}}$. The bending and twisting moment resistances across a diagonal yield line as well as the moment capacities in any other direction, $\alpha$, are shown in Figure 6.32 . It can be noted $\mathrm{M}_{\alpha}$ as the ultimate resisting moment per length along the diagonal yield-line and $\mathrm{M}_{t}$ as the ultimate torsional resisting moment normal to the direction of the diagonal yield-line. By writing the equilibrium in vector notation, the following can be assumed: 


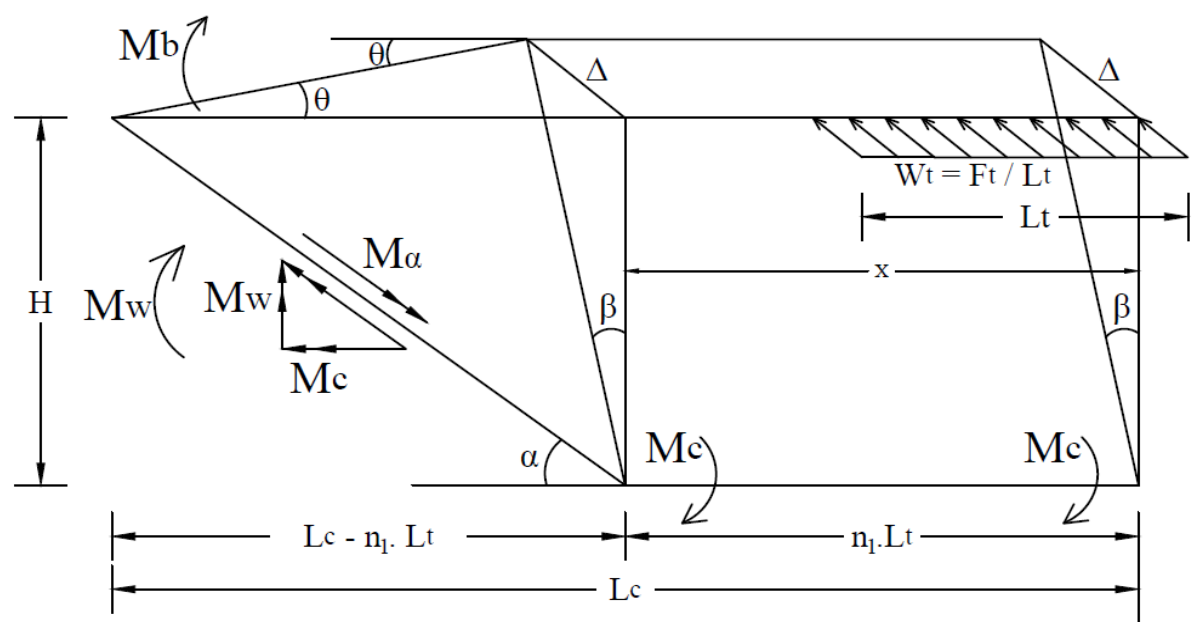

Figure 6. 31 Resisting bending moments of barrier wall along the diagonal yield-line at exterior location

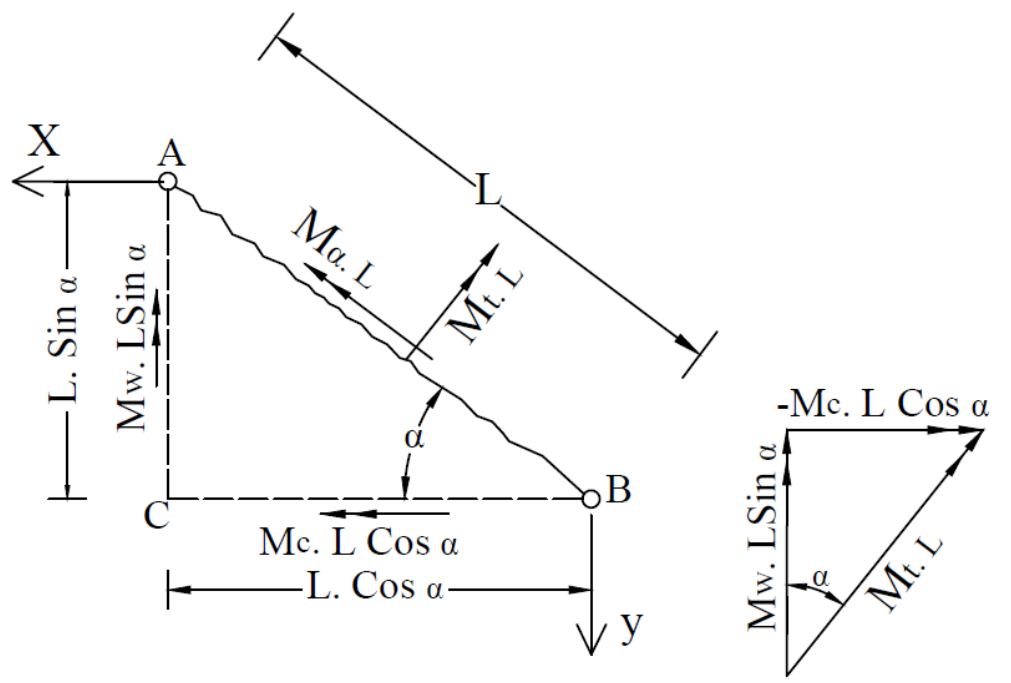

Figure 6. 32 Resisting bending and twisting moments across a diagonal yield-line

$M_{w} \cdot(A C)=M_{w} \cdot$ L.Sin $\alpha$

$M_{c} \cdot(B C)=M_{c} \cdot L \cdot \operatorname{Cos} \alpha$

$M_{\alpha} \cdot(A B)=M_{\alpha} . L$

$M_{t} \cdot(A B)=M_{t} \cdot L$

(Eq. 6.56) 
From Figure 6.32, the bending moment resistance, $M_{\alpha}$, and the twisting moment resistance, $M_{t}$ can be rearranged in the following forms:

$M_{\alpha} \cdot L=M_{w} . L \cdot \operatorname{Sin}^{2} \alpha+M_{c} \cdot L \cdot \operatorname{Cos}^{2} \alpha$

$M_{t} \cdot L=M_{w} . L \cdot \operatorname{Sin} \alpha \cdot \operatorname{Cos} \alpha-M_{c} . L \cdot \operatorname{Cos} \alpha \cdot \operatorname{Sin} \alpha$

Thus, the ultimate bending moment resistance along the diagonal yield-line, $\mathrm{M}_{\alpha}$, and the ultimate twisting moment resistance normal to the plane of the yield-line, $\mathbf{M}_{t}$, can be written as:

$M_{\alpha}=M_{w} \cdot \operatorname{Sin}^{2} \alpha+M_{c} \cdot \operatorname{Cos}^{2} \alpha$

$M_{t}=(1 / 2) \cdot\left(M_{w}-M_{c}\right) \cdot \operatorname{Sin} 2 \alpha$

Where, the inclination angle of the diagonal yield-line can be determined as follow:

$\operatorname{Tan} \alpha=\frac{\mathrm{H}}{\mathrm{L}_{\mathrm{c}}-\mathrm{n}_{2} \cdot \mathrm{L}_{\mathrm{t}}} \quad$ (for exterior location)

$\operatorname{Tan} \alpha=\frac{2 \mathrm{H}}{\mathrm{L}_{\mathrm{c}}-\mathrm{n}_{2} \cdot \mathrm{L}_{\mathrm{t}}} \quad$ (for interior location)

(Eq. 6.62)

In Eqs. 6.61 and 6.62, the critical yield-line length, $\mathrm{L}_{\mathrm{c}}$ can be determined from Eq. 6.21 for interior location and 6.42 for exterior location. The reduction factor $\left(\mathrm{n}_{2}\right)$ can be minimized for the least value of the wall resistance, $\mathrm{R}_{\mathrm{w}}$, obtained from Eq. 6.22 and 6.43 for interior and exterior locations, respectively.

It is worth to mention if moment resistances about vertical and horizontal axis are equal $\left(\mathrm{M}_{\mathrm{w}}=\right.$ $\mathrm{M}_{\mathrm{c}}$ ), the ultimate bending moment resistance, $\mathrm{M}_{\alpha}$, along the diagonal yield-line has the same resistance as the moment resistance of the horizontal reinforcement about the vertical axis (i.e . $\mathrm{M}_{\alpha}=\mathrm{M}_{\mathrm{w}}$ ). Thus, it is assumed that diagonal yield-line cracking occurs at an angle of $45^{\circ}$. In such 
a case, it can also be assumed that no twisting moment will be developed normal to the direction of the diagonal yield- line (i.e $\mathrm{M}_{\mathrm{t}}=0$ ).

\subsection{Analytical Investigation of Punching Shear Strength in Steel-Reinforced Barriers}

A number of design code standards provide punching shear design equations, typically for concrete deck slabs reinforced with steel bars. Accordingly, an attempt was made to modify the current punching shear equations to be used safely in punching shear calculations of bridge barrier walls reinforced with steel. The punching shear resistance of steel-reinforced concrete slabs is provided by shear resistance of concrete, $V_{c}$. The shear resistance acts over critical perimeter area which is equal to critical perimeter, $b_{0}$, multiplied by effective depth of the concrete section, $\mathrm{d}$. The critical perimeter varies from $0.5 \mathrm{~d}$ to $2 \mathrm{~d}$ offset from perimeter area of the patch loading depending on different code provisions. Punching shear models from various codes are provided in section 2.21 in Chapter 2. The selected models were used to predict punching shear capacities of the PL-3 and PL-2 steel barrier walls, which were then compared to the actual test ultimate capacities.

Punching shear capacities of the tested PL-2 and PL-3 steel barriers have been determined according to the specified code provisions in Chapter 2. Table 6.5 provides the predicted punching shear capacities of the PL-2 and PL-3 steel barriers at interior or exterior locations. Table 6.5 also provides the experimental tests-to-predicted punching shear capacities $\left(\mathrm{V}_{\mathrm{c}}\right.$, test $/$ $\mathrm{V}_{\mathrm{c}}$, of the tested barrier walls. By comparing the results it was observed that CSA-A23.3 (2004) yielded the best prediction model. CSA-A23.3 (2004) showed the best yet conservative prediction at interior location in both PL-3 and PL-2 barriers. However, the ratio of experimental-to-predicted punching shear strength at exterior location was relatively close to unity in both PL-2 and PL-3 barriers. This indicates that CSA-A23.3 (2004) perfectly predict the punching shear capacity at exterior locations. ACI 318 (2005) and BS 8110 (1997) were also showed good prediction capacities at interior locations of PL-3 and PL-2 steel barriers. However, at exterior locations both code provisions provided un-conservativeness in capacity predictions which is deemed to be unsafe. JSCE (2007), Enrocode 2 (2004) and MC90 (1990) code provisions provided unsafe prediction capacities at both interior and exterior locations of PL-3 and PL-2 steel barrier walls. It should also be mentioned that all prediction models considered 
steel reinforcement ratio in punching shear equations except the CSA-A23.3 (2004) and the ACI318 (2005). ACI318 (2005) specifies the assumption on the basis that punching shear resistance of the concrete slabs is provided by shear resistance of compressive concrete. In other words, the ACI equations are a function of the concrete strength and surface area of an approximated shear failure plane. Since the depth to neutral axis of steel-reinforced concrete sections remain unchanged after cracking, reinforcement ratio has not been involved in punching shear resistant of concrete slabs. From tests-to-predicted capacity ratios, it can be observed that CSA-A23.3 (2004) and ACI318 (2005) provided most agreement with the experimental ultimate test results when compared to other code provisions considering reinforcement ratio of steel bars.

Table 6. 5 Punching shear capacities from various codes for PL-3 and PL-2 steel bars

\begin{tabular}{|c|c|c|c|c|c|c|c|c|}
\hline \multirow{3}{*}{$\begin{array}{c}\text { Code } \\
\text { designation }\end{array}$} & \multicolumn{4}{|c|}{ PL-3 steel barrier $(\mathrm{kN})$} & \multicolumn{4}{|c|}{ PL-2 steel barrier $(\mathrm{kN})$} \\
\hline & \multicolumn{2}{|c|}{$\begin{array}{c}\text { Int. location } \\
\left(\mathrm{V}_{\mathrm{c}, \text { test }}=885.9 \mathrm{kN}\right)\end{array}$} & \multicolumn{2}{|c|}{$\begin{array}{c}\text { Ext. location } \\
\left(\mathrm{V}_{\mathrm{c} \text {,test }}=627.13 \mathrm{kN}\right)\end{array}$} & \multicolumn{2}{|c|}{$\begin{array}{c}\text { Int. location } \\
\left(\mathrm{V}_{\mathrm{c}, \text { test }}=421.9 \mathrm{kN}\right)\end{array}$} & \multicolumn{2}{|c|}{$\begin{array}{c}\text { Ext. location } \\
\left(\mathrm{V}_{\mathrm{c}, \text { test }}=243.66 \mathrm{kN}\right)\end{array}$} \\
\hline & $\mathrm{V}_{\mathrm{c}}$ & $\mathrm{V}_{\mathrm{c}, \text { test }} / \mathrm{V}_{\mathrm{c}}$ & $\mathrm{V}_{\mathrm{c}}$ & $\mathrm{V}_{\mathrm{c}, \text { test }} / \mathrm{V}_{\mathrm{c}}$ & $\mathrm{V}_{\mathrm{c}}$ & $\mathrm{V}_{\mathrm{c}, \text { test }} / \mathrm{V}_{\mathrm{c}}$ & $\mathrm{V}_{\mathrm{c}}$ & $\mathrm{V}_{\mathrm{c}, \text { test }} / \mathrm{V}_{\mathrm{c}}$ \\
\hline A23.3-04 & 690.03 & 1.28 & 595.03 & 1.05 & 319.4 & 1.32 & 251.8 & 0.97 \\
\hline ACI $318-05$ & 803.9 & 1.10 & 693.17 & 0.90 & 372.2 & 1.13 & 293.45 & 0.83 \\
\hline JSCE-07 & 1250.1 & 0.71 & 1259.8 & 0.50 & 492.3 & 0.86 & 420.7 & 0.58 \\
\hline $\begin{array}{l}\text { EURO- } \\
2004\end{array}$ & 965.9 & 0.92 & 819.3 & 0.76 & 403.08 & 1.05 & 312 & 0.78 \\
\hline BS-8110 & 781.1 & 1.13 & 777.6 & 0.81 & 343.6 & 1.23 & 312.8 & 0.78 \\
\hline MC-1990 & 962.5 & 0.92 & 926.3 & 0.68 & 430.95 & 0.98 & 379.87 & 0.64 \\
\hline
\end{tabular}

\subsubsection{Proposed Punching Shear Prediction Models for PL-3 and PL-2 Steel-Reinforced Bridger Barriers}

The punching shear capacity models specified in the Section 2.21 in Chapter 2 have been empirically derived specifically for two-way slab sections having steel reinforcement. However, 
none is known for punching shear capacity of PL-3 and PL-2 steel-reinforced bridge barriers. For steel-reinforced concrete slabs, the dominant factor determining the concrete shear resistance is the area of concrete in compression zone after cracking. Due to relatively high modulus of elasticity of steel bar, the depth of compression zone remains practically unchanged after the cracking. CSA-A23.3 (2004) and ACI318 (2005) provisions specify that in two-way reinforced concrete slabs the punching shear resistance is provided by the shear resistance of concrete, $V_{c}$ and the presence of tensile steel reinforcement is less effective. Based on experimental test results and the predicted punching shear equations, it was found that the CSA-A23.3 (2004) provided the most agreement with the experimental results. From experimental test observations, the critical perimeter for punching shear was considered as the average punching shear cracks at front and back faces of the barrier wall which was equal to $1.5 \mathrm{~d}$ away from the patch loading area (see Figure 6.33). Therefore, the CSA-A23.3 (2004) equation was modified to account for critical perimeter of $1.5 \mathrm{~d}$ from loading area. The modification was made by taking the average value of the ratio $\left(0.19 . b_{o}, 0.5 \mathrm{~d}\right) /\left(b_{o}, 1.5 \mathrm{~d}\right)$ from all experimental test results for tested PL-3 and PL2 barriers at interior and exterior locations. Thus, the following punching shear equations were adopted for PL-3 and PL-2 steel-reinforced traffic barriers:

$$
\begin{array}{lll}
\mathrm{V}_{\mathrm{c} \text {, prop. }}=\left(1+2 / \beta_{\mathrm{c}}\right) \cdot 0 \cdot 161 \cdot \lambda \cdot \varphi_{\mathrm{c}} \cdot V_{\mathrm{f}_{\mathrm{c}}^{\prime}} \cdot \mathrm{b}_{\mathrm{o}, 1.5 \mathrm{~d} \cdot \mathrm{d}} & \text { (For PL-3 Steel barriers) } & \text { (Eq. 6.63) } \\
\mathrm{V}_{\mathrm{c} \text {, prop. }}=\left(1+2 / \beta_{\mathrm{c}}\right) \cdot 0.146 \cdot \lambda \cdot \varphi_{\mathrm{c}} \cdot{ }_{\mathrm{f}^{\prime}} \cdot \mathrm{b}_{\mathrm{c}, 1.5 \mathrm{~d} \cdot \mathrm{d}} & \text { (For PL-2 Steel barriers) } & \text { (Eq. 6.64) }
\end{array}
$$

Where $\beta_{\mathrm{c}}$ is the ratio of long side-to- short side of loading patch $\left(\beta_{\mathrm{c}}=\mathrm{L}_{\mathrm{t}} / \mathrm{W}\right)$. CHDBC specifies the length of load application $\left(\mathrm{L}_{\mathrm{t}}\right)$ of $2400-\mathrm{mm}$ for PL-3 and 105-mm for PL-2 bridge barrier walls. For width of loading patch (W) of 250-mm, $\beta_{\mathrm{c}}$ can be assumed as 9.6 for PL-3 and 4.2 for PL-2 steel barrier walls. 


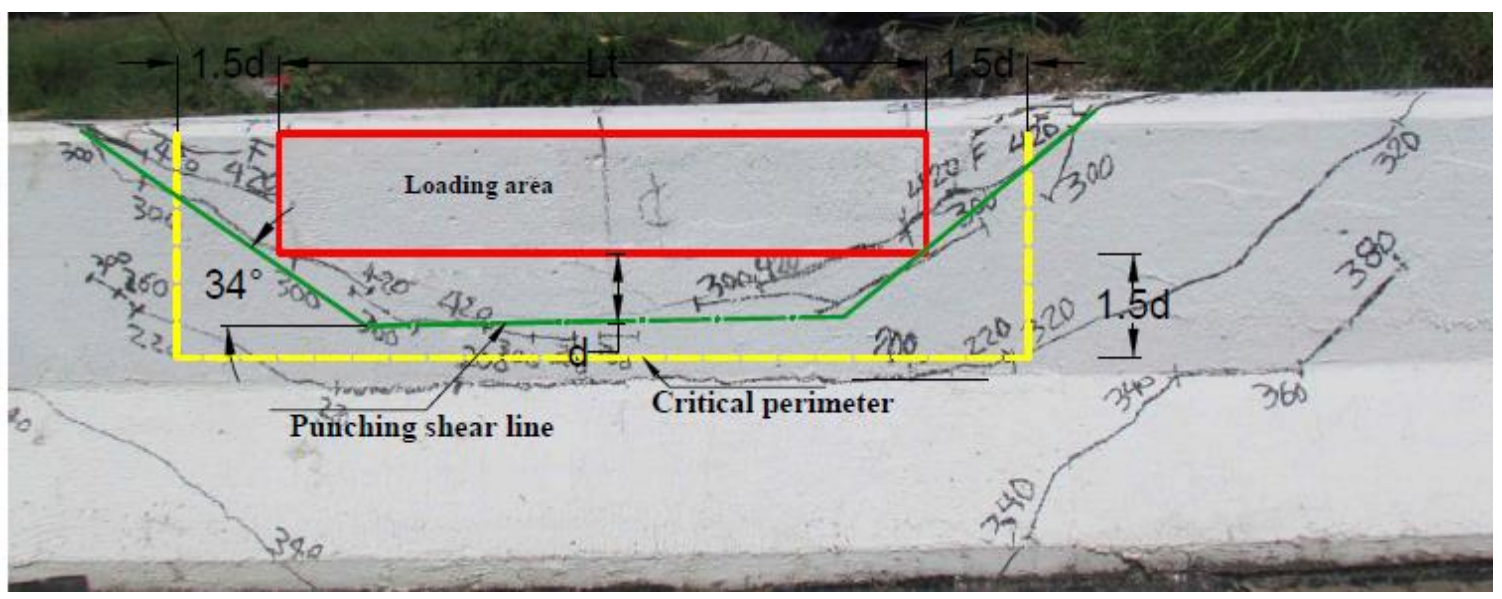

(a) Punching shear zone at barrier front face

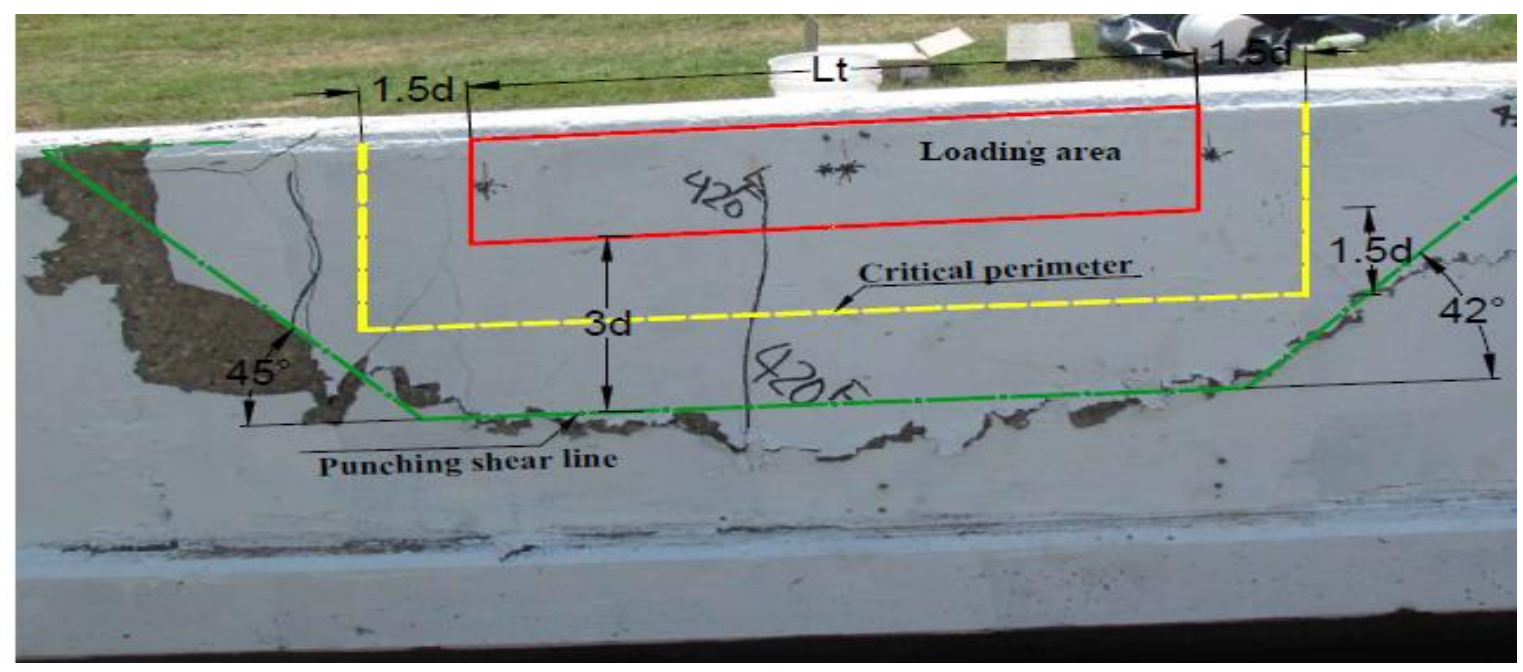

(b) Punching shear zone at barrier back face

Figure 6. 33 Critical perimeter of punching shear zone in steel-reinforced barriers

For the tested PL-3 and PL-2 barriers, the proposed punching shear capacities and the corresponding punching shear ratios at each of the interior or exterior location has been calculated and provided in Table 6.6. The proposed punching shear model has shown reasonably good agreement with experimental test results while still maintaining some level of conservativeness. In both PL-3 and PL-2 barriers, the proposed punching shear equations maintain same level of conservativeness as CSA A23.3 (2004) in predicting the punching shear capacities at interior locations. However, at exterior locations, the proposed equations yielded punching shear ratios of 1.09 and 1.06 in PL-3 and PL-2 barriers, respectively indicating good agreement with the tested barriers. The proposed punching shear capacities were also compared 
with CHBDC limits. CHBDC (2006) specifies a minimum factored horizontal load of $357 \mathrm{kN}$ that should be applied over 2400-mm length of PL-3 barrier walls. It also specifies a minimum factored horizontal load of $170 \mathrm{kN}$ that can be applied over 1050-mm of PL-2 bridge barrier walls. The ratio of the Proposed-to-CHBDC capacities is also provided in Table 6.6. It can be observed that the proposed models safely predict the punching shear capacity of the barriers when it compared to CHBDC recommendations with a minimum factor of safety equal to 1.35 at exterior location of PL-2 barrier.

Although the ratio between the experimental and the design values for punching shear strength should be at least 1 for a safe design, it may be recommended to consider a durability factor for environmental effects that may lead to degradation of steel reinforcing bars. CSA-A23.3 (2004) specifies steel resistance factor of 0.85 for design of reinforced concrete structures. Therefore, the ratio between the proposed and the design values for punching shear strength of bridge barrier walls should be greater than 1.18. Table 6.6 shows the minimum ratio of the proposed-toCHBDC design capacity ratio of 1.35 for PL-2 barrier at exterior location. Thus, the proposed equations for the prediction of punching shear resistance of the PL-3 and PL-2 barriers meets both strength and durability requirements.

Table 6. 6 Experimental and proposed punching shear capacities of the tested barriers

\begin{tabular}{|c|c|c|c|c|c|}
\hline \multicolumn{2}{|c|}{ Load location } & $\mathrm{V}_{\mathrm{c}, \text { test }}(\mathrm{kN})$ & $\begin{array}{c}\mathrm{V}_{\mathrm{c} \text {, proposed }} \\
(\mathrm{kN})\end{array}$ & $\begin{array}{c}\mathrm{V}_{\mathrm{c}, \text { test }} / \mathrm{V}_{\mathrm{c} \text {,proposed }} \\
\text { ratio }\end{array}$ & $\begin{array}{c}\mathrm{V}_{\mathrm{c} \text {,proposed }} / \mathrm{V}_{\mathrm{CHBDC} *} \\
\text { ratio }\end{array}$ \\
\hline \multirow{2}{*}{$\begin{array}{c}\text { PL-3 } \\
\text { Barrier }\end{array}$} & Interior location & 885.9 & 730.6 & 1.21 & 2.05 \\
\cline { 2 - 6 } & Exterior location & 627.13 & 576.96 & 1.09 & 1.62 \\
\hline PL-2 & Interior location & 421.9 & 318.2 & 1.32 & 1.87 \\
\cline { 2 - 6 } Barrier & Exterior location & 243.66 & 229.9 & 1.06 & 1.35 \\
\hline
\end{tabular}

$* \mathrm{~V}_{\mathrm{CHBDC}}=357 \mathrm{kN}$ for PL-3 barriers and $170 \mathrm{kN}$ for PL-2 barriers

\subsection{Summary of Findings}

From the experimental test observation on GFRP-reinforced bridge barriers, a trapezoidal crack pattern was observed, which was dissimilar to the triangular failure pattern specified in the AASHTO-LRFD specifications for steel-reinforced bridge barriers. Therefore, two full-scale steel-reinforced PL-3 and PL-2 bridge barriers constructed at Texas Transportation Institution 
(TTI) site were further investigated under monotonic static load testing to-complete-collapse simulating the equivalent vehicle impact force specified in the CHBDC. From the experimental and theoretical investigations, the following conclusions have been made: (i) The experimental ultimate wall resistance was found to be far beyond the minimum transverse wall resistances specified in the CHBDC for both PL-3 and PL-2 traffic barriers, (ii) Comparison has been made for the failure mode of the tested barriers. The shape of yield-line pattern observed in the test differed from those stipulated in AAHSTO-LRFD specifications. Similar to the GFRP-reinforced barriers, a trapezoidal failure shape was observed, (iii) Based on the failure pattern of the tested barriers by trapezoidal shape, new equations were developed on the basis of yield-line theory to provide the least value of the nominal wall resistance against vehicle impact, (iv) On the basis of trapezoidal failure pattern observed, the test results were analyzed to verify the developed equations for the ultimate strength of barriers in terms of the yield-line theory, (v) The experimental observations and the theoretical equations confirmed the failure pattern of the barrier wall by trapezoidal failure shape with the presence of a horizontal yield-line at the base of the wall. The length of the horizontal yield-line was found to be 0.5 to 1 times the loaded length, $\mathrm{L}_{\mathrm{t}}$, and (vi) The failure mode of the barrier by punching shear was also investigated. The CSAA23.3 (2004) punching shear equation was modified for PL-3 and PL-2 barriers to account for the cantilever actions of the barrier and the critical punching shear perimeter area identified using punching shear plane located at distance $1.5 \mathrm{~d}$ from the patch loading boundaries. The proposed models yielded good results at exterior location and good yet conservative results at interior location of the barriers. 


\section{Chapter VII}

\section{Finite-Element Modeling of PL-3 Traffic Barriers Reinforced with GFRP Bars}

\subsection{Introduction}

With developments in modern computer programs, finite-element method has extensively being used as powerful tools in engineering practice and design. The development of structural design codes, equations or revising them require a wide range of experimental programs, which are deemed very costly, time consuming and uneconomical. Although the experimental programs are compulsory for a research to progress, the problems can be simplified with advances in modern computers using finite-lement software. ABAQUS (Hibbitt et al. 2011) is regarded as sophisticated and general purpose software that can be utilized to model the behavior of structural members under externally applied load.

In this chapter, a finite-element model, describing the non-linear behavior of GFRP-reinforced bridge barriers under static load testing was developed. The non-linear finite element package "ABAQUS" was utilized for this purpose. Results of the experimental program performed on sand-coated GFRP-reinforced bridge barrier at interior and exterior locations have been simulated by finite-element method. Numerical simulations on the structural response of statically loaded bridge barriers and the associated failure modes have been performed herein by the ABAQUS/ Explicit, which is suitable for static test events and strong discontinuous geometrical or material response (Hibbitt et al. 2011). The concrete barrier was reinforced with conventional steel reinforcement in the deck slab, while the barrier wall was reinforced with high-modulus (HM) GFRP bars. As such, the concrete damaged plasticity (CDP) model and elastic-perfectly plastic with isotropic hardening material models have been used to define the static behavior of concrete and reinforcing steel, respectively. The linear elastic model was used to model GFRP bars. 
In this chapter, a brief explanation regarding basics of the selected material models for concrete, steel and GFRP bars including their implementations is presented. The chapter is intended to present general concept of non-linear behavior of concrete; thus, the detailed description of material models and their background theory will not be presented. For material models of concrete and steel, both linear elastic and plastic properties are assigned to express the non-linear behavior of concrete and steel. The numerical analysis is conducted by performing the following tasks:

1. Details of concrete barrier models;

2. Constitutive models for concrete and reinforcement;

3. Material properties assignments to concrete, steel and GFRP reinforcing bars;

4. Defining contact interface between reinforcing bars and concrete;

5. Defining boundary conditions and loads;

6. Mesh assignment; and

7. Results and discussions.

\subsection{Details of Concrete Barriers}

The FE modeling was carried out on the selected 1-m length barrier model 1 as well as the 27.6$\mathrm{m}$ length barrier tested at TTI. The short length barrier represents the case for one-way action behavior of barriers under static load testing so that only horizontal flexural cracks are expected in the wall portion. However, the long barrier represents structural behavior of tested barriers by two-way actions, in which the failure of the wall expected to include horizontal flexural cracks as well as the diagonal shear cracks. Figure 7.1 shows views of the selected barriers with reinforcing steel and GFRP bars placed in the formwork. Barrier Model 1 was modeled in smallscale domain to validate the numerical modeling with the experimental test results so that the results can be implemented in the actual FE modeling of the long barriers. The FE modeling was conducted on Barrier Model 1 (short length) stated in Chapter 4 with High- Modulus (HM) bars and headed-end bars as connecting reinforcement of the wall to the deck portion. This model was analyzed first to study the numerical behavior of the tested short length barriers. Comparison was made between the experimental test results and numerical analysis in plain concrete, reinforced concrete as well as by manual calculations. Results of this study were used in the actual modeling of the long barrier tested at TTI at interior and exterior locations. In all barrier models, 
steel reinforcement was used as reinforcing bars in the deck slab, with GFRP high modulus bars as reinforcement in the wall portion. In the deck portion, M25 steel bars were used at tension face, while M15 steel bars used at compression face of the deck slab similar to the experimental program. However, in the barrier wall, M15 bars were used to reinforce the barrier wall everywhere, except M12 bars were used as vertical bars at back face of the wall.

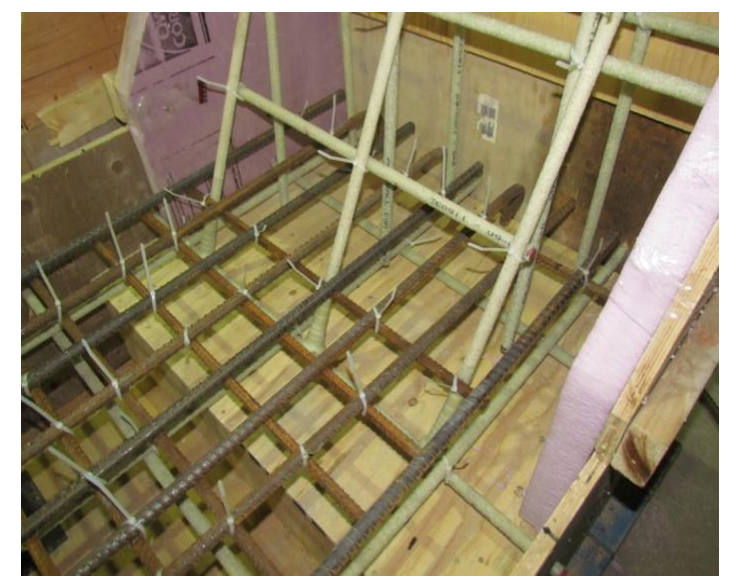

(a) Barrier Model 1 with $1 \mathrm{~m}$ length

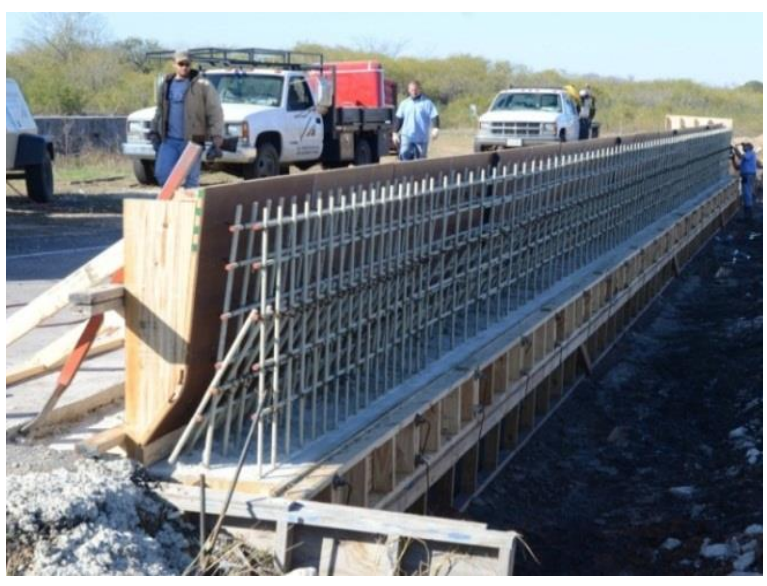

(b) TTI barrier with $27.6 \mathrm{~m}$ length

Figure 7. 1 Selected barrier models for numerical analysis

\subsection{Constitutive Models}

\subsubsection{Concrete Damaged Plasticity (CDP) Model}

Concrete damaged plasticity model in ABAQUS/Explicit is capable of modeling the behavior of plain and reinforced concrete structures or other quasi-brittle materials subjected to static, cyclic or dynamic loading. The model proposed by Lubliner et al. (1989) for static loading and further modified by Lee and Fenves (1998) for cyclic or dynamic loading. The CDP model utilizes concepts of isotropic damaged elasticity in combination with isotropic tensile and compressive plasticity to represent the inelastic behavior of the concrete such as tensile cracking or concrete crushing. In this model, the stiffness degradation of materials has been considered both in tension and compression. Generally, the CDP model is regarded as a continuum, plasticity-based, damage model for concrete structures. Therefore, it assumes that the main two failure mechanism is concrete crushing or concrete tensile cracking of the materials. As such, the evolution of yield or failure surface is categorized by the tensile and compressive equivalent 
plastic strains $\left(\widetilde{\mathcal{E}}^{\mathrm{pl}}{ }_{\mathrm{t}}\right.$ and $\left.\widetilde{\mathcal{E}}^{\mathrm{pl}}{ }_{\mathrm{c}}\right)$ linked to the failure mechanism under tension and compression loading, respectively.

It should also be noted that concrete material in ABAQUS can also be defined by Concrete Smeared Cracking (CSC) model. The CSC model significantly reduces properties of the concrete material in the region that has exceeded tensile yield stress. The model also does not track the individual cracks rather distributes the effect of the cracks. In addition, the smeared cracking model does not consider the compression damage; rather the ultimate compression yield stress may be specified in the elastic properties. This method is efficient for use with concrete shell elements in which reinforcement is defined in layers. As such, this model has not been used in the current study.

In FE analysis, there exists two different approaches to model the cracking namely as; the discrete crack approach and the smeared crack approach. The smeared crack approach models cracking as the solid cracks continuum, while the discrete crack approach models cracking as separation of elements (Panakaj, 2010). The concrete damaged plasticity model is regarded as a smeared crack approach. This represents that the CDP model does not track the individual cracks, but the cracking zone coincide with the dimension of the elements (similar to the CSC model).

\section{Uniaxial Behavior}

In ABAQUS, the uniaxial tension and compression response of concrete is typically characterized by damage plasticity as shown in ABAQUS user manual 6.10 volume 3 (Refer to Figure 20.6.3-1). From Figure 20.6.3-1a (ABAQUS user manual 6.10 vol.3), the stress-strain response under uniaxial tension is linear until it reaches the failure stress, $\sigma_{t 0}$. The failure stress represents the onset of micro-cracks in concrete. After the failure stress, formation of microcracks follows by a softening stress-strain response that induces strain localization in the concrete structure. Under the uniaxial compression (Refer to ABAQUS user manual 6.10 vol. 3 Figure 20.6.3-1b), the stress-strain response is linear until it reaches the value of initial yield, $\sigma_{\mathrm{c} 0}$. The response after this value is inelastic by formation of stress hardening, which is followed by strain softening after the ultimate stress of $\sigma_{\mathrm{cu}}$. 
Also shown in Figure 20.6.3-1 (ABAQUS user manual 6.10 vol.3), upon unloading of concrete specimen at any point on the strain-softening branch of the stress-strain curve, the unloading response is weakened, therefore, the elastic stiffness of the concrete material is degraded. The stiffness degradation of the concrete material can be represented by tensile damage, $\mathrm{d}_{\mathrm{t}}$, and compressive damage, $\mathrm{d}_{\mathrm{c}}$, which can be taken zero representing undamaged material to one, which represents fully damaged material.

\section{Defining Tensile Behavior}

The tensile behavior of concrete after failure is modeled in ABAQUS with tension stiffening. The tension stiffening allows defining the strain-softening branch of concrete after failure due to bond interaction between concrete and the reinforcement. The tension stiffening can be specified in ABAQUS by means of post-failure stress-strain response or by defining fracture energy cracking criterion, $G_{F}$. The former method is further investigated in the current study.

In ABAQUS, the uniaxial behavior of concrete in tension after failure (post-failure behavior) must be defined as a function of cracking strain, $\varepsilon_{t}^{c k}$, such as stress-cracking strain response. The cracking strain can be determined as the total strain $\left(\varepsilon_{t}\right)$ minus the elastic strain of the undamaged materials $\left(\varepsilon_{0 t}^{e l}\right)$ providing that;

$\varepsilon_{t}^{c k}=\varepsilon_{\mathrm{t}}-\varepsilon_{0 t}^{e l}$

Where, the elastic strain is equal to $\varepsilon_{0 t}^{e l}=\sigma_{\mathrm{t}} / \mathrm{E}_{0}$ (Refer to Figure 20.6.3.1a in ABAQUS user manual 6.10 vol.3). ABAQUS specifies a lower limit on the post-failure stress equal to $1 / 100$ of the initial failure stress $\left(\sigma_{\mathrm{t}} \geq \sigma_{\mathrm{t} 0} / 100\right)$. When the parameter of unloading (i.e. cracking strain, $\varepsilon_{t}^{c k}$, and tensile damage, $\mathrm{d}_{\mathrm{t}}$ ) are available, ABAQUS automatically converts the inelastic cracking strain values to plastic strain values using the following relationship;

$\varepsilon_{t}^{p l}=\varepsilon_{t}^{c k}-\frac{d_{t}}{\left(1-d_{t}\right)} \cdot \frac{\sigma_{t}}{E_{0}}$ 
It should be noted the FE modeling conducted herein did only consider testing of the barrier walls by static load rather than dynamic or cyclic loadings. As such, the tensile damage parameter, $d_{t}$, has not been considered and the tensile plastic strains from Eq. 7.2 can be obtained equal to inelastic cracking strains.

\section{Defining Compressive Behavior}

The stress-strain response of plain concrete can be defined outside of elastic range in uniaxial compression. The compressive stress in stress-strain response can be defined as a function of inelastic strain or crushing strain, $\varepsilon_{c}^{i n}$. Although the compressive strains are in negative sign, the positive (absolute) values of stress and strains should be used in ABAQUS. Thus, the stressstrain curve can be assigned in ABAQUS after the peak stress, into the strain-softening branch. Hardening strains are provided in terms of inelastic strains, $\varepsilon_{c}^{i n}$. The inelastic compressive strain is defined as total compressive strain $\left(\varepsilon_{\mathrm{c}}\right)$ minus the elastic strain of undamaged material $\left(\varepsilon_{0 c}^{e l}\right)$ as follow;

$\varepsilon_{c}^{i n}=\varepsilon_{\mathrm{c}}-\varepsilon_{0 c}^{e l}$

Where, the elastic strain is defined as compressive stress divided by initial (undamaged) modulus of the materials, $\varepsilon_{0 c}^{e l}=\sigma_{c} / \mathrm{E}_{0}$ (Refer to Figure 20.6.3.1b in ABAQUS user manual 6.10 vol.3). If the parameters of unloading are available (i.e. inelastic compressive strain, $\varepsilon_{c}^{i n}$, and compressive damage, $d_{c}$ ), ABAQUS automatically converts the inelastic compressive strain values to plastic strain values using the following relationship.

$\varepsilon_{c}^{p l}=\varepsilon_{c}^{i n}-\frac{d_{c}}{\left(1-d_{c}\right)} \cdot \frac{\sigma_{c}}{E_{0}}$

It should also be noted that the current numerical analysis focuses on static load testing of concrete barriers rather than cyclic or dynamic effects. As such, the compressive damage parameter, $d_{c}$, was disregarded and the plastic strains in Eq. 7.4 was assumed equal to inelastic strains. 


\section{Yield Surface Function}

A Drucker-Prager yield criterion is implemented in concrete damaged plasticity model. The model originally uses the yield criterion of Lubliner et al. (1989), which was then modified by Lee and Fenves (1998) to account variation of strength evolution in tension and compression. The model known as a pressure dependent criterion dependent upon the two stress invariants of the effective stress tensor namely as; the Hydrostatic pressure, $\bar{p}$, and the Mises equivalent stress, $\bar{q}$. The evolution of yield surface is controlled by the equivalent plastic strains in tension and compression $\left(\tilde{\varepsilon}_{t}^{p l}\right.$ and $\tilde{\varepsilon}_{c}^{p l}$ ). The following equation represents the implemented yield surface in terms of effective stress;

$\mathrm{F}=\frac{1}{1-\alpha}\left(\bar{q}-3 \alpha \bar{p}+\beta\left(\tilde{\varepsilon}^{p l}\right)\left\langle\bar{\sigma}_{\max }\right\rangle-\gamma\left\langle-\bar{\sigma}_{\max }\right\rangle\right)-\bar{\sigma}_{c}\left(\tilde{\varepsilon}_{c}^{p l}\right)=0$

Where,

$\alpha=\frac{\left(\frac{\sigma_{b 0}}{\sigma_{c 0}}\right)-1}{2\left(\frac{\sigma_{b 0}}{\sigma_{c 0}}\right)-1} \quad$ For $0 \leq \alpha \leq 0.50$

$\beta=\frac{\bar{\sigma}_{c}\left(\tilde{\varepsilon}_{c}^{p l}\right)}{\bar{\sigma}_{t}\left(\tilde{\varepsilon}_{t}^{p l}\right)}(1-\alpha)-(1+\alpha)$

$\gamma=\frac{3\left(1-K_{C}\right)}{2 K_{C}-1}$

In which, $\bar{\sigma}_{\text {max }}$ is the maximum principal effective stress, $\frac{\sigma_{b 0}}{\sigma_{c 0}}$ is the used defined ratio of the initial biaxial compressive yield stress to the initial uniaxial compressive yield stress with a default value of $1.16 . \mathrm{K}_{\mathrm{c}}$ is the user defined parameter depending on the stress invariants. It is equal to the ratio of the second stress invariant on the tensile meridian to the compressive meridian for any value of the pressure invariant $\mathrm{p}$ at initial yield such that the maximum principal 
stress is negative $\left(\bar{\sigma}_{\max }<0\right)$. $\mathrm{K}_{\mathrm{c}}$ must be defined to satisfy the condition that $0.50<\mathrm{K}_{\mathrm{c}} \leq 1.0$ with a default value given as $2 / 3$.

\section{Plastic Flow}

The concrete damaged plasticity model assumed the Drucker-Prager hyperbolic potential plastic flow function that is illustrated in Figure 7.2. The potential flow used in the model in DruckerPrager function can be obtained as;

$\mathrm{G}=\sqrt{\left(\varepsilon \sigma_{t 0} \tan \psi\right)^{2}+\overline{q^{2}}}-\bar{p} \tan \psi$

Where, $\sigma_{t 0}$ is the uniaxial tensile stress at failure that can be obtained from user defined tension stiffening data.

$\psi$ is the dilation angle measured in p-q plane that can be defined as the inclination of the plastic flow potential in high confining pressure. The dilation angle is the angle of internal shearing resistance that is equal to the friction angle in low stresses. The dilation angle decreases in high level of confining pressure and plastic strain. It also controls the amount of plastic volumetric strains developed during plastic shearing, which is deemed constant during plastic yielding. ABAQUS takes a minimum value of dilation angle equal to $0^{\circ}$ to a maximum angle of $56.3^{\circ}$. In literatures, dilation angles varied between $20^{\circ}$ to $53^{\circ}$. If assumed $\psi=0^{\circ}$, the inelastic deformation is incompressible, while for $\psi>0^{\circ}$ the material dilatancy occurs. In general, upper values of dilation angle represent a more ductile behavior, while lower values show a more brittle behavior.

$\varepsilon$ is the eccentricity parameter, which defines a small positive number showing the range that plastic potential function approaches the asymptote (the flow potential tends to a straight line as the eccentricity tends to zero) as depicted in Figure 7.2. ABAQUS specifies a default eccentricity value of 0.1 indicating that the material has almost the same dilation angle over a wide range of confining pressure values. In reduced confining pressure with higher eccentricity values, the 
dilation angle rapidly increases due to more curvature to the flow potential. However, for very small values of eccentricity compared to the default value may cause convergence problems if the material is subjected to low confining pressure due to the locally tight curvature of the flow potential where intersecting the p-axis.

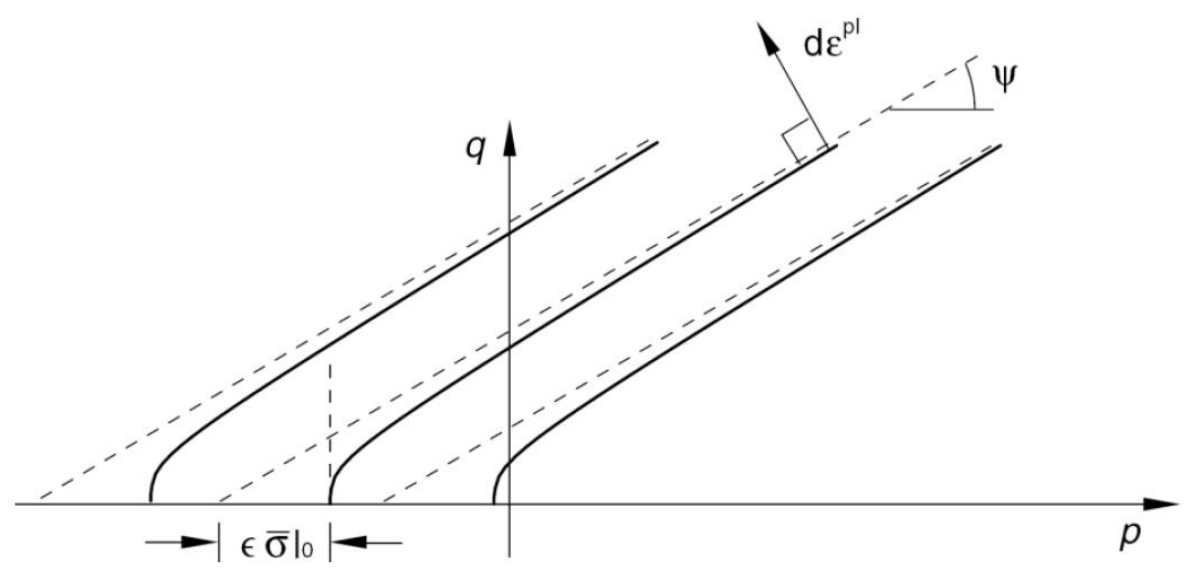

Figure 7. 2 The Drucker-Prager hyperbolic plastic flow function (Adopted; Hibbitt et al. 2011)

The hydrostatic pressure stress, $\bar{p}$, can be obtained as follow;

$\bar{p}=-\left(\frac{1}{3}\right) \operatorname{trace}(\bar{\sigma})$

Where, the effective stress is defined as $\bar{\sigma}=D_{0}^{e l}:\left(\varepsilon-\varepsilon^{p l}\right)$. And, the Mises equivalent effective stress, $\bar{q}$, is defined as;

$\bar{q}=\sqrt{\frac{2}{3}(\bar{S}: \bar{S})}$

Where, $\bar{S}$ is the effective stress deviator obtained as $\bar{S}=\bar{\sigma}+\bar{p}$.I

The concrete damaged plasticity model requires assigning the viscosity parameter, $\mu$. The viscosity parameter does not affect the analysis in ABAQUS/Explicit, but it contributes to convergence analysis in ABAQUS/Standard. As such, a viscosity parameter of $\mu=0$ was 
considered in the current study due to the fact that Dynamic Explicit analysis has been utilized. A value of $\mu=10^{-7}$ is recommended by Malm (2009) since it should be small in compression with characteristic time increment.

\subsubsection{Reinforcement Modeling}

\subsubsection{Steel Reinforcing bars}

Steel reinforcing bars are modeled as a linear-elastic material up to the point of yielding. After yielding, a yield plateau occurs followed by either a linear or non-linear strain hardening phase until rupture. The overall trend of stress-strain relationship of ductile steel reinforcement is shown in VecTor 2 user manual by Wong et al. 2013 (Refer to Figure 60). The elastic-plastic or bilinear stress-strain curves are generated by tri-linear strain hardening option (Refer to VecTor 2 Figure 60a). The stress in reinforcement in tension or compression can be determined as follow:

$f_{s}=E_{s} \varepsilon_{s} \quad$ for $\varepsilon_{s} \leq \varepsilon_{y}$

$f_{s}=f_{y} \quad$ for $\varepsilon_{y}<\varepsilon_{s}<\varepsilon_{s h}$

$f_{s}=f_{u}+\left(f_{y}-f_{u}\right) \cdot\left(\frac{\varepsilon_{u}-\varepsilon_{s}}{\varepsilon_{u}-\varepsilon_{s h}}\right)^{\mathrm{P}} \quad$ for $\varepsilon_{s h}<\varepsilon_{s}<\varepsilon_{u}$

$f_{s}=0 \quad$ for $\varepsilon_{s}>\varepsilon_{u}$

Where, $\varepsilon_{s}$ is strain in reinforcement, $\varepsilon_{y}$ is yield strain of the reinforcement, $\varepsilon_{s h}$ is the strain at strain hardening, and $\varepsilon_{u}$ is the ultimate strain. $f_{y}$ is the yield strength of reinforcement, and $f_{u}$ is the ultimate strength. $\mathrm{E}_{\mathrm{s}}$ is the modulus of elasticity of reinforcement, and $\mathrm{P}$ is the strain hardening parameter taken as 1 for linear strain hardening and 4 for non-linear strain hardening.

In ABAQUS, reinforcement in concrete is typically provided by means of one dimensional rebars, which can be defined singly or embedded in oriented surfaces. The behavior of rebar material is typically defined by metal plasticity model. Using this modeling approach, the concrete behaves independently from the rebar, however, the effects associated with rebar such as bond-slip and dowel action can be modeled by introducing interface elements between rebar 
and concrete elements or approximately by using some tension stiffening behavior of concrete. Generally, there are several ways to model reinforcement in concrete in ABAQUS including smeared reinforcement in concrete, cohesive element method, discrete truss or beam elements embedded in concrete and modeling full rebar geometry by solid elements. In membrane, shell and surface elements, rebar is defined as uniaxial smeared reinforcement, thus, one or multiple layers of reinforcement can be defined. For each layer, rebar name, cross-sectional area and the rebar spacing should be defined. In current study, reinforcement is defined as the embedded discrete truss elements tied to the concrete elements. Truss element is a common way of reinforcement modeling that only requires defining the cross-sectional area of bars. The truss bar elements are two-nodded with a uniform cross-sectional area as shown in Figure 7.3. The element is defined with two nodes that can be displaced in $\mathrm{x}$ and $\mathrm{y}$ directions at each node, thus the element have four degrees of freedom. Since failure of the experimentally tested barriers followed by diagonal tension cracks in barrier model 1 and punching shear cracks in TTI long barrier, the anchorage or bond failure was not observed during testing. As such, a fully bonded interaction between reinforcement and concrete elements was assumed. Beam element modeling was also being used that takes into account the dowel action effects, in addition, it slightly increases the load bearing capacity of structures. However, due to required large number of input parameters and computational effort, its use was not recommended (Eriksson and Gasch. 2010, Hibbitt et al. 2011 and Malm, 2006).

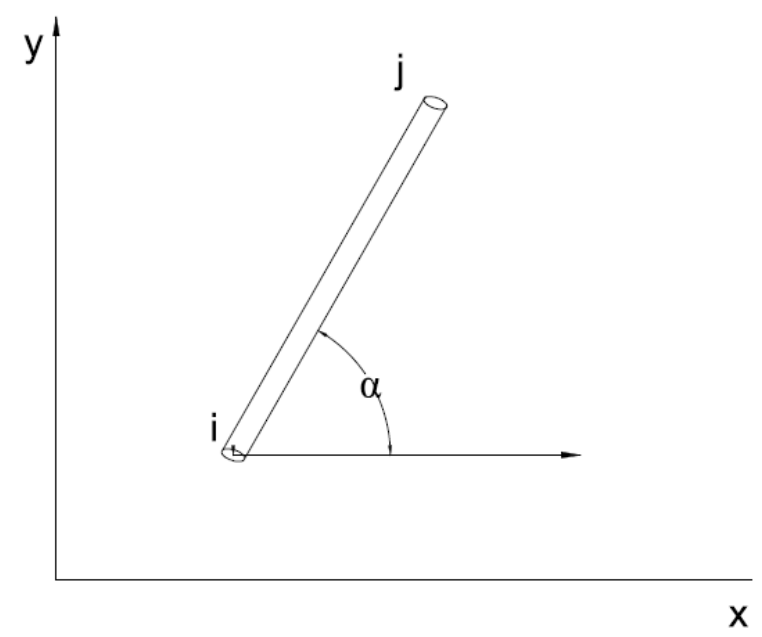

Figure 7. 3 Truss bar element 


\section{Classical Metal Plasticity Model}

The material property definition of steel bars requires to define density, elastic and plastic behavior. The elastic behavior of steel reinforcing bars is defined by introducing Young's modulus of elasticity $\left(E_{s}\right)$ and Poisson's ratio $(v)$, which can be defined as $200 \mathrm{GPa}$ and 0.3 , respectively. The plastic behavior is defined in a tabular form or as a linear piecewise plastic strain versus true stress curve. The input values of stress and strain at each point for an isotropic material can be obtained by converting the nominal stress-strain curve to true stress-plastic strain curve using the following equations;

$\sigma_{\text {true }}=\sigma_{\text {nominal }} \cdot\left(1+\varepsilon_{\text {nominal }}\right)$

$\varepsilon^{\mathrm{pl}}=\ln \left(1+\varepsilon_{\text {nominal }}\right)-\left(\sigma_{\text {true }} / \mathrm{E}\right)$

It is also assumed that the behavior of steel reinforcement is identical in tension and compression.

\subsubsection{GFRP Reinforcing bars}

The material property definition for GFRP bars requires only to define density and elastic behavior of GFRP bars due to the fact that GFRP bars do not experience plastic behavior. The elastic behavior is defined by specifying the Young modulus and the Poisson's ratio which are provided in Table 7.1 for currently used GFRP bars of different diameters.

Table 7. 1 Elastic material properties of GFRP reinforcing bars

\begin{tabular}{|c|c|c|c|}
\hline Bar Size & Modulus of elasticity (GPa) & Poisson's ratio & $\begin{array}{c}\text { Cross-secional area } \\
\left(\mathrm{mm}^{2}\right)\end{array}$ \\
\hline M12 (\#4) & 65.6 & 0.2 & 126.7 \\
\hline M15 (\#5) & 62.5 & 0.2 & 197.9 \\
\hline M19 (\#6) & 64.7 & 0.2 & 285 \\
\hline
\end{tabular}




\subsubsection{Dynamic Explicit Analysis versus Implicit/Standard Analysis}

In ABAQUS there are two analytical procedures to model the structural elements namely as Explicit and Implicit/Standard analysis. There are few differences between the two analysis procedures.

An Explicit analysis depends on the time increment and at the end of each increment updates the stiffness matrix based on the changes in the geometry of structure or material changes. Thus, a new stiffness matrix is constructed and the next increment of load or displacement is applied to the structure. If the time increment is small enough, results will be more accurate. The method also does not enforce the equilibrium between internal structural forces and the externally applied loads. In addition, ABAQUS/Explicit determines the solution to a non-linear problem without iterating by explicitly advancing the kinematic state from the previous increment. Also, ABAQUS/Explicit requires much less disk space and memory compared with ABQUS/Standard. However, the method requires many small increments for good accuracy, which might be time consuming. If a large number of increments are defined the results may not yield a correct solution.

An implicit analysis is similar to explicit but the method utilizes the Newton-Raphson iterations to enforce equilibrium of internal structural forces and externally applied load after each increment. The equilibrium can be adjusted by some user specified tolerance. The Implicit analysis tends to be more accurate than explicit analysis and a larger increment step can be defined. However, one drawback of this method is that the stiffness matrix must be updated and reconstructed for each iteration during the Newton-Raphson iterations. Also, the implicit analysis method may have convergence difficulty because of contact, material and geometry complexities, resulting in a large number of iterations. Such method of analysis may be costly due to the fact that each iteration requires solving a larger set of linear equations.

In current study, the dynamic explicit analysis has been used based on the central difference integration rule that is appropriate for non-linear geometry and material response. One of the main advantage of using explicit analysis over implicit is the absence of a global tangent stiffness matrix and convergence problem (Hibbitt et al. 2011). As mentioned earlier, the explicit 
analysis requires very small time increment steps to satisfy the stability limit. If the time steps defined is not small enough, the central difference integration rule implemented in the dynamic explicit may reveal meaningless results. The stability limit of an un-damped system is given in terms of the highest frequency of the system (Chopra, 2007) providing that;

$\Delta \mathrm{t} \leq 2 /\left(\omega_{\max }\right)$

However, in case of high non-linearity, ABAQUS/Explicit uses an automatic estimation of stable time increment. The automatic estimation is based on the shortest time interval necessary for dilatational waves to pass through the mesh elements (Hibbitt et al. 2011). The estimation is presented as follow;

$\Delta \mathrm{t} \leq \min \left(\mathrm{L}^{\mathrm{e}} / \mathrm{C}_{\mathrm{d}}\right)$

Where, $L^{e}$ is the length of the element and $C_{d}$ is the propagation velocity of dilatational waves. Propagation velocity (P-wave) for a linear elastic material with zero Poisson's ratio can be determined as follow;

$C_{d}=\sqrt{\frac{E}{\rho}}$

Where, $\mathrm{E}$ is the modulus of elasticity and $\rho$ is the density of the material.

The automatic estimation of time increment should be decreased when a more accurate representation of the higher mode response is required, or problem arises with large deformations and/ or non-linear material response.

\subsubsection{Convergence Difficulties}

During modeling and analyzing reinforced concrete structures, there might be several convergence problems relative to mesh assignment, boundary condition, material properties and applied loads. 
At some points, ABAQUS may not be able to analysis a problem due to any of the aforementioned conditions so it is required to define time increment into smaller steps. In such a case, the minimum time step should be defined lower than the default values so that the maximum number of increments increases. This in turn results in more accurate results. However, the computational capacity may increase, which is time consuming. Malm (2006) suggested the most efficient way to overcome convergence problem is to increase the tolerance and the number of iterations.

The convergence problems may also occur where reinforcement and concrete nodes coincide. This can be due to distortion of elements with less stiff material because of high stress developed in reinforcement. As such, the coincidence of reinforcement and concrete element nodes is not recommended. In some instances also due to local instabilities such as material instability or local buckling convergence difficulties may arise at above mentioned zone. In such a case, it is recommended to specify automatic stabilization which can be defined in time step.

In concrete damaged plasticity model, the viscosity parameter may cause convergence problem if it is taken non-zero value.

Concrete damaged plasticity model is recommended in ABAQUS/Explicit in static problems if there are convergence difficulties. Due to the fact that ABAQUS/Explicit is a dynamic solver, to eliminate the dynamic effects of loading, the load should be applied as velocity with very low speed. Thus, the kinetic energy of the whole model after analysis must be very small compared to the strain energy.

\subsection{Material Properties Assignments}

\subsubsection{Material Properties of Concrete}

Concrete behave differently in tension and compression. It is very strong in compression compared with its tension behavior. The tensile strength of concrete is relatively low (about $8 \%$ to $15 \%$ of the compressive strength). Figure 7.4 illustrates typical stress-strain curve of concrete behavior in tension and in compression. In tension, concrete is loaded until it reaches the tensile cracking strength, $f_{t}^{\prime}$, after which the stress-strain curve follows by some tension stiffening 
branch if reinforcement presents. In compression, concrete is loaded until it reaches the peak compressive strength, $f_{c}^{\prime}$, followed by crushing of concrete with increase in compressive straining. Two types of material properties were defined to represent non-linear properties of concrete material namely as elastic and plastic properties. Table 7.2 presents the concrete compressive strength obtained from experimental testing of the barriers, which are used for the numerical modeling.

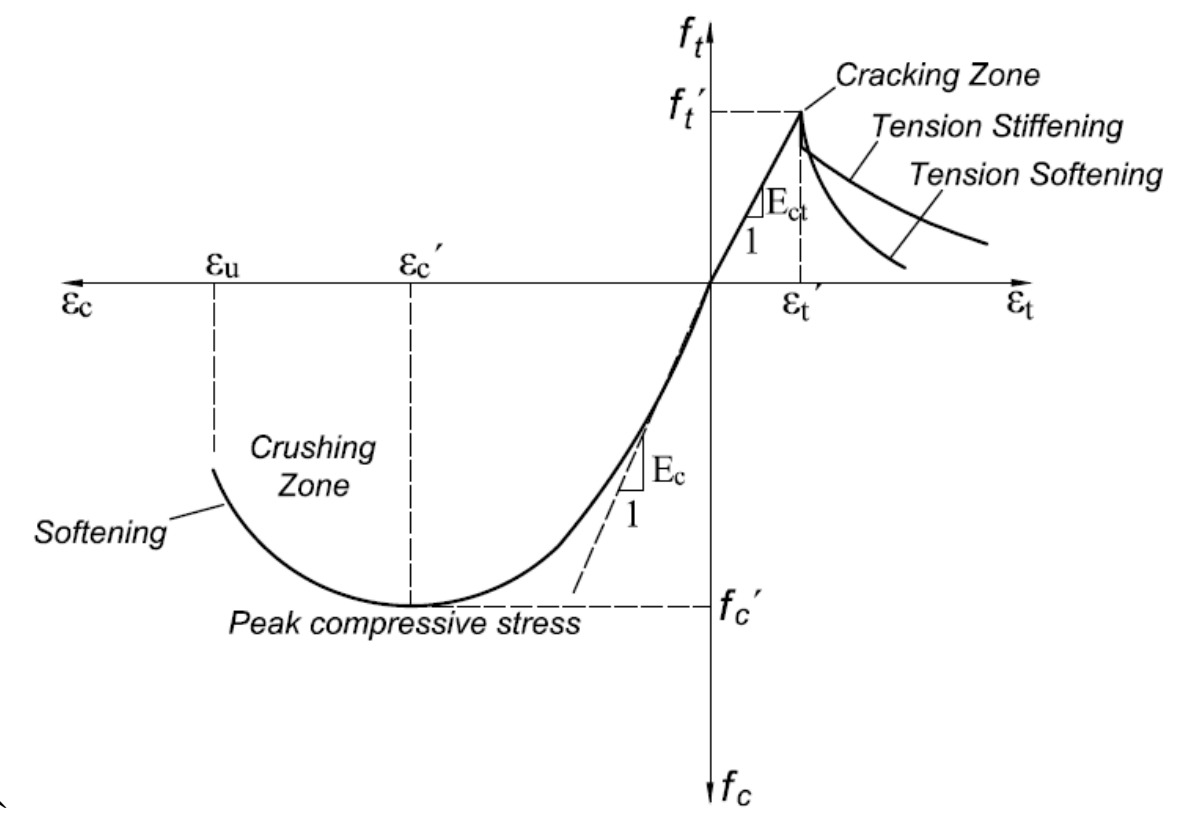

Figure 7. 4 Typical stress-strain curve of concrete in tension and compression

Table 7. 2 Experimental concrete compressive strengths

\begin{tabular}{|c|c|c|}
\hline Barrier model & $\begin{array}{c}\text { Concrete compressive strength } \\
(\mathrm{MPa})\end{array}$ & $\begin{array}{c}\text { Elastic modulus } \\
(\mathrm{MPa})\end{array}$ \\
\hline Short barrier (Model 1) & 25.4 & 22,680 \\
\hline Long TTI barrier & 30.9 & 25,015 \\
\hline
\end{tabular}

\subsubsection{Elastic Properties}

In FE modeling, evolution of the yield criterion is based on the uniaxial elastic behavior of material models; thus, the definition of material parameters and uniaxial material behavior is 
more important. CSA A23.3 specifies approximate elastic modulus of normal density concrete with a density of about $2300 \mathrm{~kg} / \mathrm{m}^{3}$ as follow;

$\mathrm{E}_{\mathrm{ct}}=4500 \sqrt{f^{\prime}} \quad(\mathrm{MPa}) \quad$ (in tension)

(Eq. 7.21a)

$\mathrm{E}_{\mathrm{c}}=2 \frac{f^{\prime}{ }_{c}}{{\varepsilon^{\prime}}_{c}} \cong 4500 \sqrt{f^{\prime}{ }_{c}} \quad(\mathrm{MPa}) \quad$ (in compression)

Values of the elastic modulus of numerically tested barriers are calculated using Eq. 7.21 and provided in Table 7.2. For concrete in tension before cracking, it is necessary to determine the uniaxial tensile cracking strength, $f_{t}^{\prime}$, and the corresponding cracking strain of concrete, $\varepsilon_{c r}$ as follow;

$f_{\mathrm{t}}=0.33 \sqrt{f^{\prime}} \quad(\mathrm{MPa})$

$\varepsilon_{c r}=\varepsilon_{t}^{\prime}=\frac{f_{t}^{\prime}}{E_{c t}}$

Where, $\mathrm{E}_{\mathrm{ct}}$ is the initial tangent stiffness of concrete, and ${f^{\prime}}_{c}$ is concrete compressive strength estimated from experimental concrete test cylinders that are provided in Table 7.2. It should be noted that the uniaxial tensile cracking strength (Eq. 7.22) varies in the codes from 0.3-0.4 times the square roots of the compressive strength. Due to the fact that, strain gauges have not been used in the current experimental programs, a range of concrete cracking strength have been examined in the numerical programs and the results were compared with the experimental results. Before cracking, concrete behaves linear-elastic in tension providing that:

$f_{\mathrm{t} 1}=\mathrm{E}_{\mathrm{ct}} \cdot \varepsilon_{\mathrm{t} 1} \quad$ for $0<\varepsilon_{\mathrm{t} 1} \leq \varepsilon_{\mathrm{t}}^{\prime}$

It is generally supposed that a range of concrete elastically is $0.3 f^{\prime}{ }_{\mathrm{c}}$ in compression and $0.7 f_{\mathrm{t}}^{\prime}$ in tension. 


\subsubsection{Plastic Properties}

\section{Tensile Behavior:}

After concrete cracking, tensile stresses may still exist in reinforced concrete members between cracks due to bond interaction between steel reinforcement and the concrete. Due to such bond, stresses can be transferred and concrete can carry tensile stresses. Thus, it is assumed that the stiffness of cracked reinforced concrete to be greater than the bare steel, and this phenomenon is called, tension stiffening. In cracked reinforced concrete structures, the concrete tensile stresses gradually reduce to zero at the free surface of cracks, however, due to bond interaction between concrete and the surrounding reinforcement, the average tensile stresses in concrete (which is deemed less than the concrete cracking strength) continue to exist in concrete between cracks and in the vicinity of the reinforcement. Upon increasing the tensile straining in concrete, cracks widen resulting in degradation of bond action, thus, the tensile stresses gradually diminish to zero. This phenomenon can be attributed to the mechanical interlocking of concrete materials so that concrete is not perfectly brittle.

In FE modeling, effects associated with concrete-bar interface such as bond-slip action can be modeled approximately by introducing some tension stiffening into concrete modeling to simulate load-transfer mechanism across cracks through the bar. Tension stiffening is important to model the post-failure behavior by direct straining, which allows to define the strain-softening behavior of cracked concrete. The effects also simulate the bond interaction between concrete and reinforcement in a simple manner. If tension stiffening is neglected in the modeling, concrete tensile stresses reduce immediately to zero after concrete cracking and the tensile stresses must be redistributed entirely to reinforcement, which may cause an unrealistic deviation in the loaddeformation response.

In ABAQUS, tension stiffening is required in concrete damaged plasticity model. Tension stiffening in the current study was specified by means of post-failure tensile stress-strain relationship stated earlier. To model the tension stiffening, the modified Vecchio and Collins (1982) model (Collins and Mitchell, 1987) was used. The model by Collins and Mitchel (1987) results in more rapidly diminishing tension stiffening effect compared to the Vecchio and Collins 
(1982) model, which is more suitable for large scale elements and structures. The average tensile stress-strain response by Collins and Mitchell (1987) can be determined as follow;

$f_{t}=\frac{f_{c r}}{1+\sqrt{500 \varepsilon_{t}}} \quad$ for $0<\varepsilon_{\mathrm{cr}}<\varepsilon_{\mathrm{t}}$

Where, $f_{c r}$, is the cracking strength, $\varepsilon_{\mathrm{cr}}$ is the cracking strain and $\varepsilon_{\mathrm{t}}$ is the tensile strain greater than the cracking strain. Since ABAQUS requires specification of post-failure stress as a function of plastic strain, $\varepsilon_{t}^{p l}$, the strain, $\varepsilon_{t}$, was replaced by cracking strain using Eq. (7.2).

Thus, based on the material properties provided in Table 7.2, stress-cracking strain curves for concrete in tension can be obtained, which are shown in Figure 7.5.

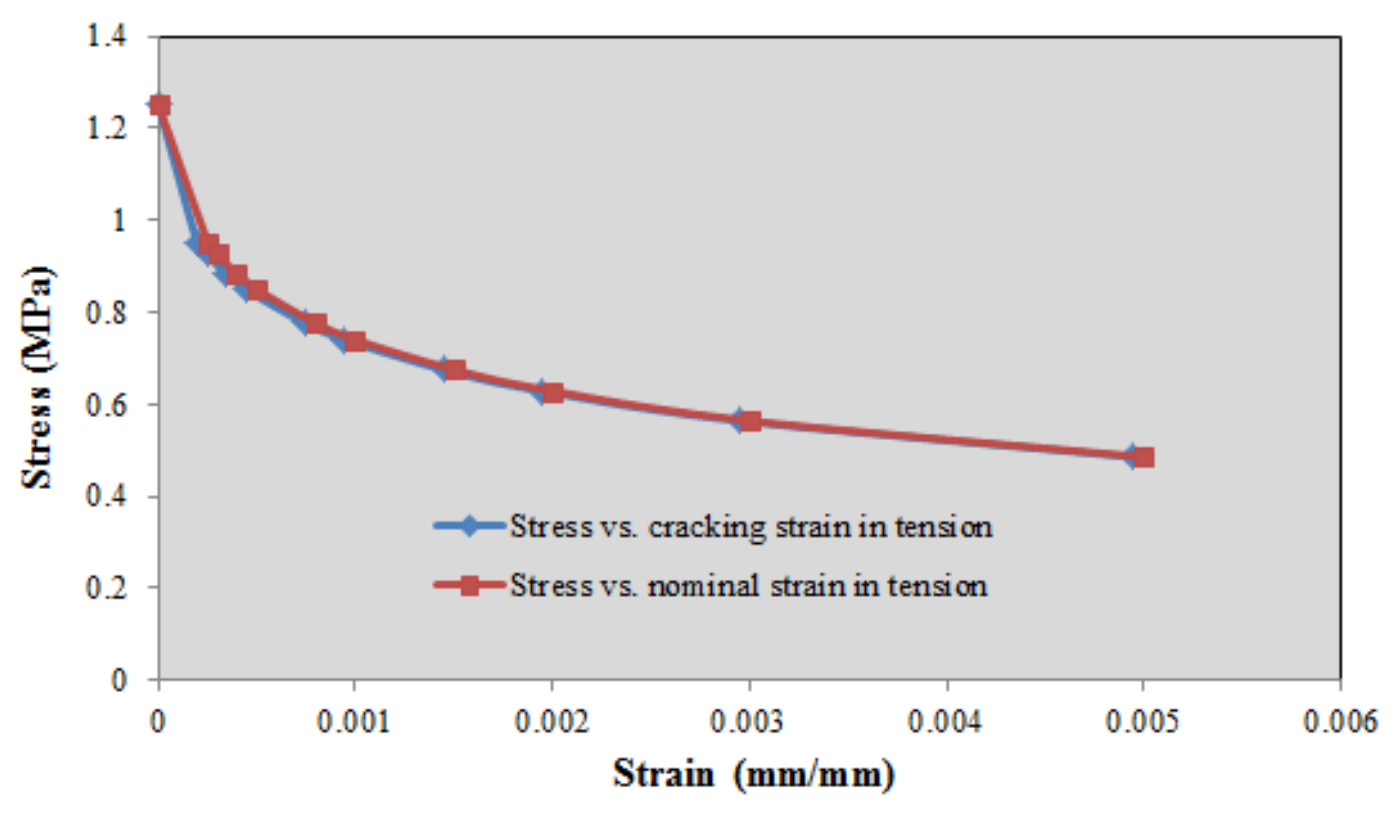

(a) For 1-m long barrier Model 1 


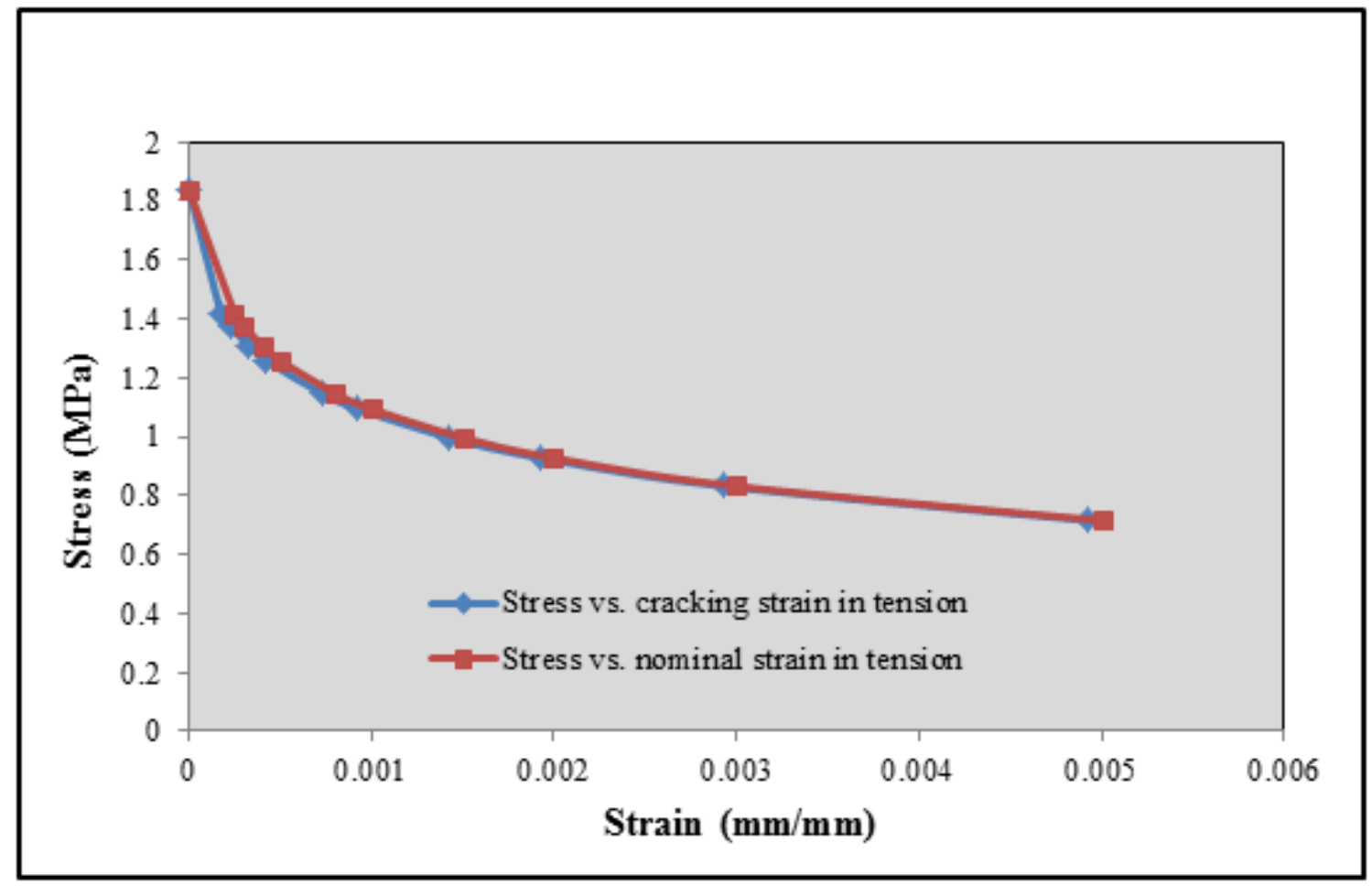

(b) For the 27.6-m long TTI barrier

Figure 7. 5 Graphs of tension stiffening response of concrete

\section{Compressive Behavior:}

This section describes the constitutive model used for compressive behavior of concrete. The stress-strain response of concrete in compression will be introduced. At each load step, from stresses and strains calculated from the constitutive model, the stiffness of the structure is determined. It is presumed that stress-strain response of concrete in uniaxial compression is nonlinear beyond low compressive stresses. The Hognestad parabola shown in Figure 7.6 was used to define the concrete pre-peak and post-peak behavior in compression. It is a simple compression response that is appropriate for normal strength concrete less than $40 \mathrm{MPa}\left(f_{c}^{\prime}<40\right.$ $\mathrm{MPa}$ ). Since normal strength concrete was used in the constructions of the tested barriers, the Hognestad parabola model has been selected. The model describes the stress-strain curve using the following relationship;

$f_{c i}=-f_{p}\left\{2\left(\frac{\varepsilon_{c i}}{\varepsilon_{p}}\right)-\left(\frac{\varepsilon_{c i}}{\varepsilon_{p}}\right)^{2}\right\}<0 \quad$ for $\varepsilon_{c i}<0$ 
Where, $f_{p}$ is the peak compressive stress, $\varepsilon_{p}$ is the strain corresponding to the peak compressive stress. The model assumes a symmetric stress-strain relationship about $\varepsilon_{p}$ diminishing to zero strain at $2 \varepsilon_{p}$.

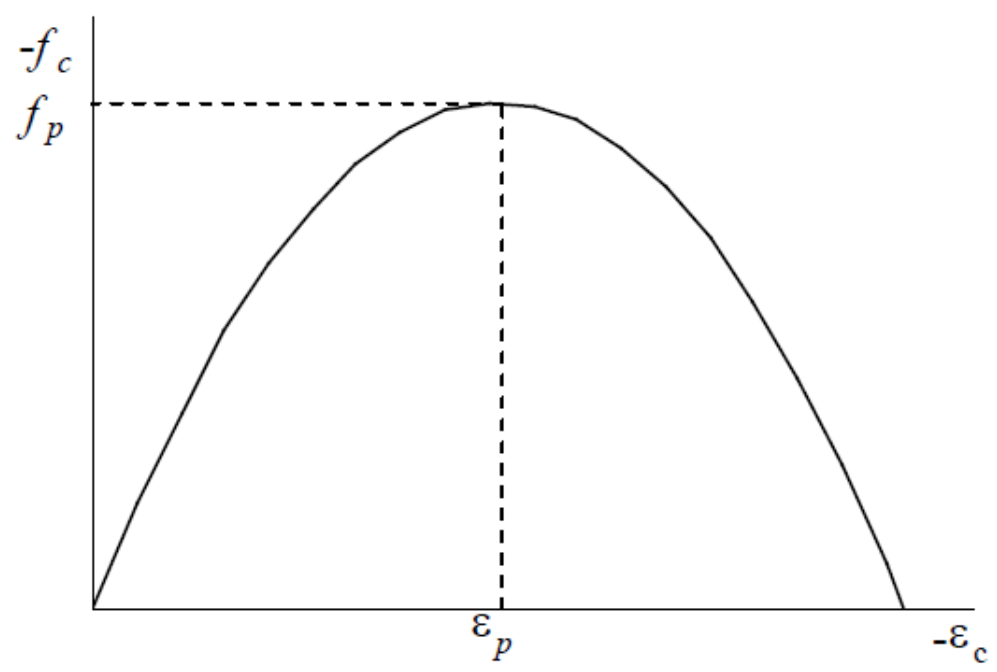

Figure 7. 6 Hognestad parabolic pre- and post-peak concrete compression response (Adopted: VecTor 2 Manual, Wong et al. 2013)

In ABAQUS, the uniaxial behavior of concrete in compression must be defined as stress versus inelastic strain. For given normal strains, the inelastic strains have been calculated using Eq. 7.3. The graphs of stress-inelastic strains in compression for barrier Model 1 and the TTI long barrier are provided in Figure 7.7.

\subsubsection{Material Properties of Reinforcement}

Reinforcement is defined as embedded truss bar elements tied to concrete elements. Linear elastic properties were assigned only to GFRP bars as the bars did not experience plastic behavior. In case of steel reinforcement, elasto-plastic material behavior was assigned to the rebars. ABAQUS requires defining stress-strain curve of steel reinforcement as true stress versus plastic strain values according to Eqs. 7.16 and 7.17. Figure 7.8 illustrate the true stress-plastic strain of steel reinforcing bars that were used for both barrier Model 1 and the TTI long barrier. 


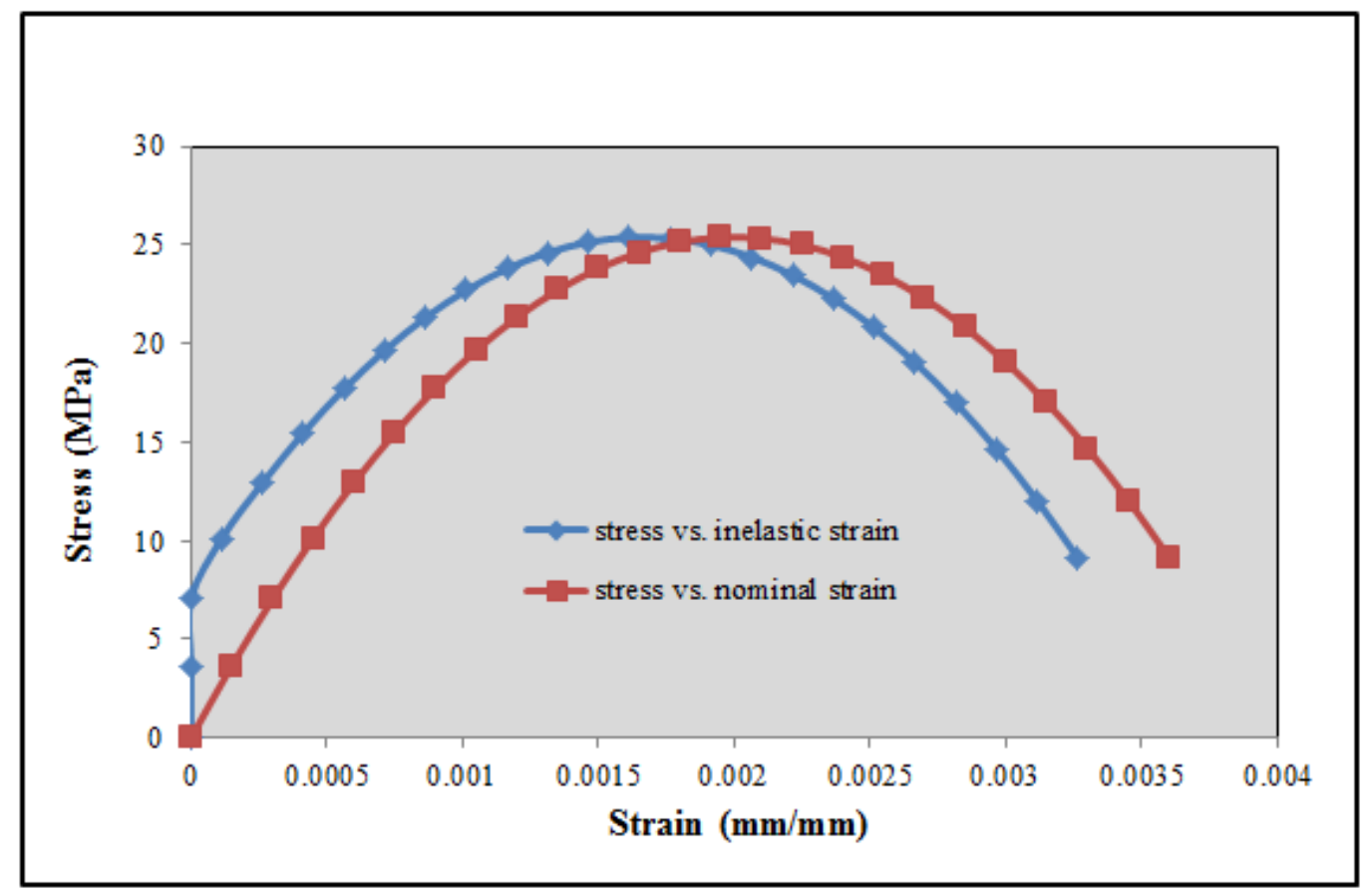

(a) For 1-m long barrier Model 1

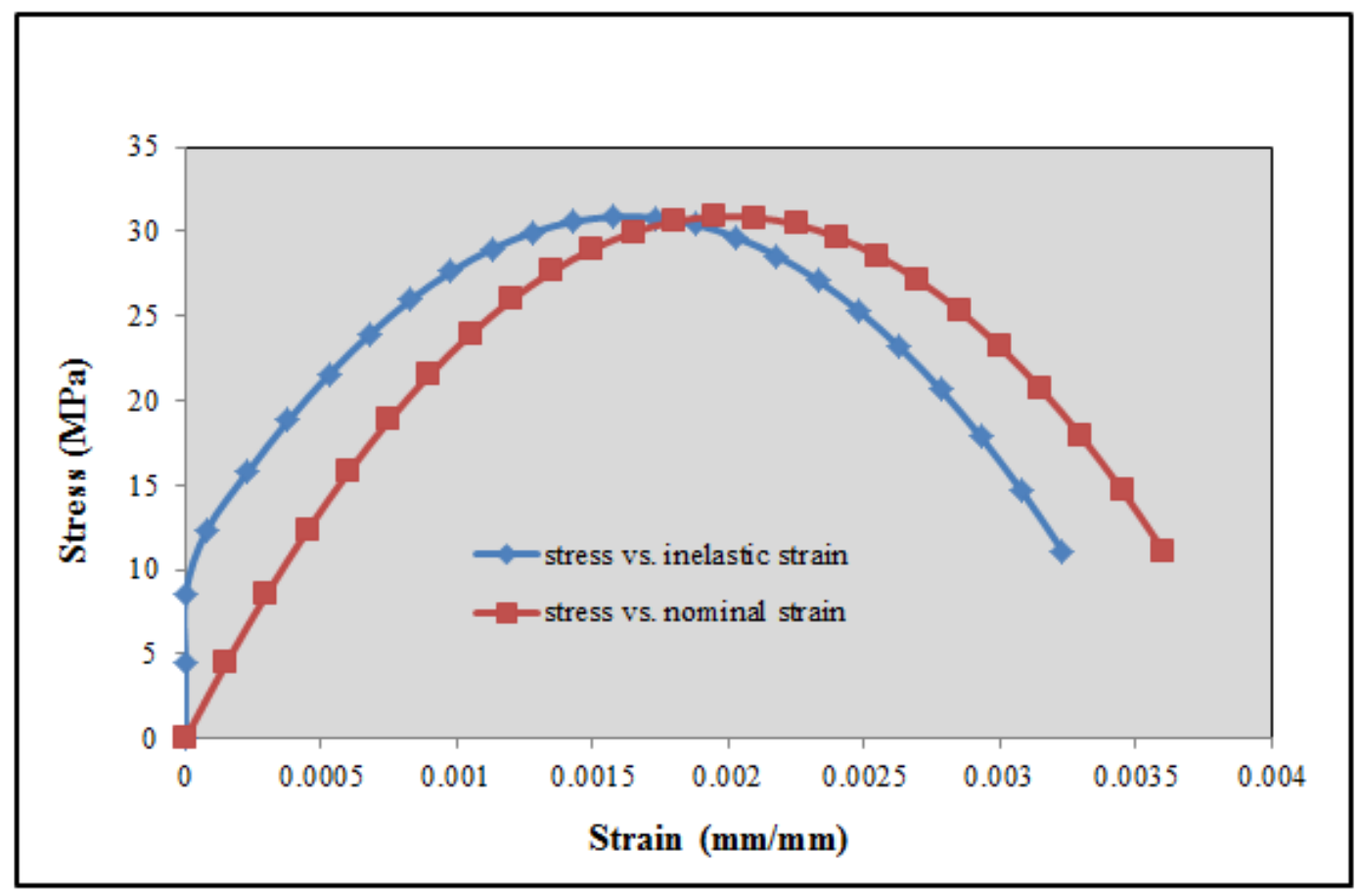

(a) For the 27.6-m long TTI barrier

Figure 7. 7 Graphs of concrete response in compression 


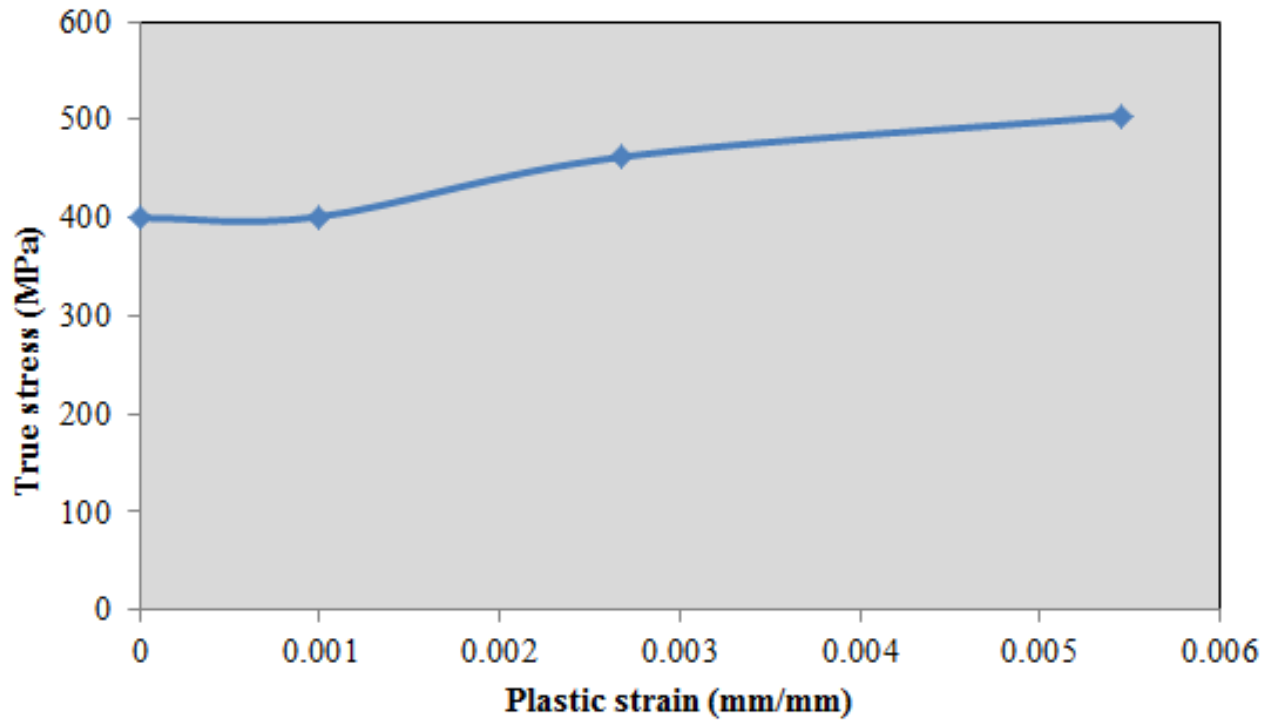

Figure 7. 8 Graph of true stress vs. plastic strain for steel reinforcement

\subsection{Defining contact interface between reinforcing bars and concrete}

It was observed that the experimentally tested barriers did not fail by bond interaction or anchorage failure of the reinforcing bars. Thus, the embedded element has been used to define the contact interface between reinforcing bars and the concrete. The embedded element assumes a fully bond interaction between bars and the concrete.

The embedded element method can be used to model reinforcing bars. It can be used to specify that an element or groups of elements are embedded into a group of host elements. When a node of embedded element lies within a host element, the node becomes an embedded node by constraining the translational degrees of freedom at the node. However, the rotational degrees of freedom of an embedded element are allowed, but these rotations are not constrained by the embedding. The embedded element can be used in geometrically linear or non-linear analysis. In addition, it can be used to model a set of reinforcing bar membrane, shell or surface elements that are embedded in a set of solid (continuum) elements; a set of truss or beam elements embedded in a set of solid elements and a set of solid elements embedded in another set of solid elements. 
ABAQUS also allows users to define how far an embedded node can lie outside the region of the host elements by using the geometric tolerance. The default value assumes that the embedded nodes must lie within a distance determined by multiplying the average size of all non-embedded elements in the model by 0.05 . However, this default value can be changed using either a fraction of the average size of all non-embedded elements in the model or an absolute distance in the length units specified for the model. If both geometric tolerances are defines, ABAQUS uses the tighter value of the two as the exterior tolerance of an embedded element.

\subsection{Defining boundary conditions and loads}

Boundary conditions were applied to both barrier models to restrain the deck portion as fixed support so that the failure is emphasized in the barrier portion similar to experimental testing. In barrier Model 1, only the deck slab was made fixed, while barrier wall's translation and rotation in all directions were kept free. The experimental failure load obtained from testing of Barrier Model 1 was applied as pressure load at a height $990 \mathrm{~mm}$ above the deck slab similar to experimental testing. The load was applied uniformly over an area of 1000x200 mm at the top of the barrier wall similar to the experiments. Figure 7.9 shows view of barrier Model 1 modeled in ABAQUS with boundary conditions and applied transverse pressure load.

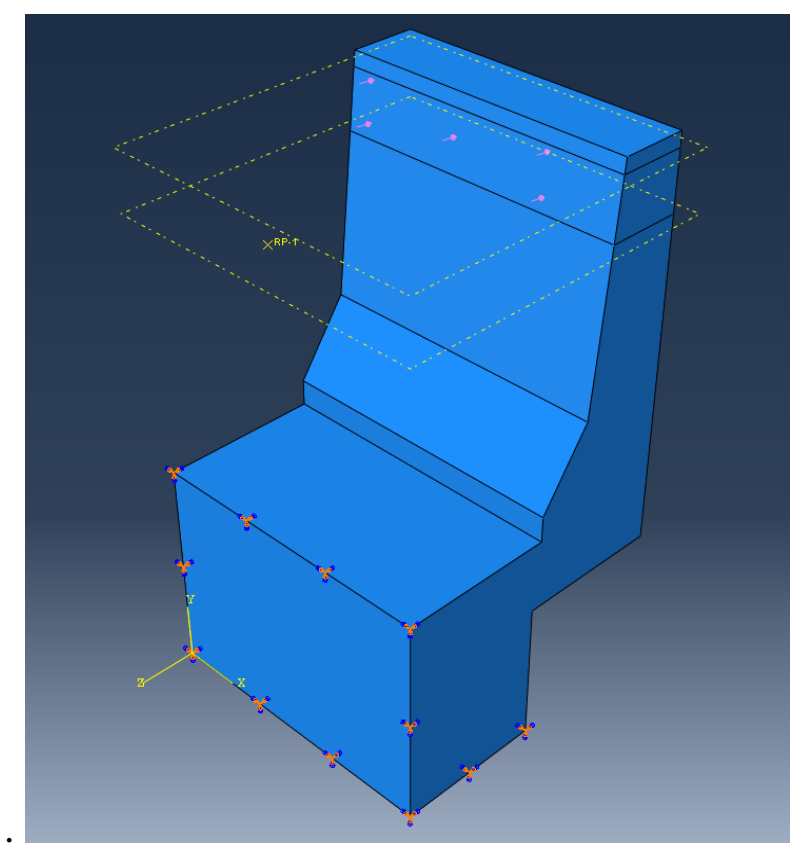

Figure 7.9 Barrier Model 1 showing boundary conditions and the applied pressure load 
The TTI barrier was modeled both at interior and exterior locations. Due to symmetry of loading, barrier geometry and boundary conditions, the barrier at interior location was modeled using the principle of symmetry. Since the critical barrier length affected by static testing at interior location was $7.2 \mathrm{~m}$, it is assumed that the longitudinal length of barrier outside this region will not affect the modeling. However, to ensure precision of barrier modeling, this critical length was increased to $12 \mathrm{~m}$, so that by principle of symmetry only half of the length $(6 \mathrm{~m})$ was modeled at interior location. Figure 7.10 shows view of the TTI barrier FE model at interior location with a length considered as $6 \mathrm{~m}$. The boundary conditions were applied to fix the deck slab portion as well as the right side of the barrier assuming that the length beyond this region will not affect the modeling. Thus, the displacements and rotations at right-end of the barrier were assumed zero. This is meant a good assumption as LVDT's attached to the barrier wall showed almost symmetrical lateral deformation of the wall $(2.55 \mathrm{~mm})$ at the edge of the loading area. On the left side of the barrier, due to symmetry, only the barrier longitudinal displacement was restrained; however, lateral and vertical displacements and the rotations of the barrier were kept free. In addition, due to principle of symmetry, only half of the experimental failure load was applied as a pressure load over an area of 1200x200 mm with a centroid of $990 \mathrm{~mm}$ above the deck slab as per CHBDC code and experimental testing. The time increment was adjusted in ABAQUS so that the load was applied in 40 increments.

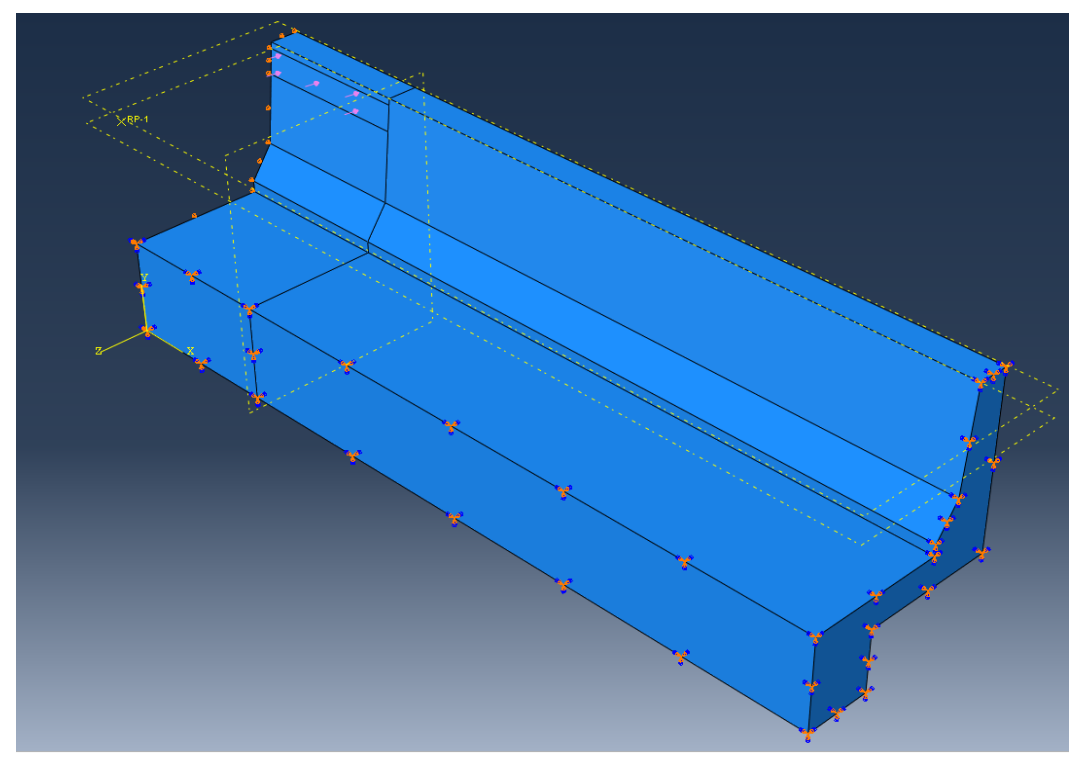

Figure 7. 10 View of TTI barrier model at interior location showing boundary conditions and transverse applied pressure load 
At exterior location, the entire experimental failure load at the end-region was applied to the model. Since the load is applied over an area of $2400 \times 200 \mathrm{~mm}$, it was decided to increase the longitudinal length of the barrier to $12 \mathrm{~m}$ so that the FE results are not affected by the barrier longitudinal length. It should be mentioned that the barrier at exterior location was first modeled with $6 \mathrm{~m}$ longitudinal length similar to the interior location. However, the FE results showed a considerable barrier lateral deflection $(0.78 \mathrm{~mm})$ at the right-end (far end from the unloaded end) indicating a larger barrier length is required. As such, the length was increased to $12 \mathrm{~m}$ showing the barrier lateral deformation of $0.0053 \mathrm{~mm}$ at the right-end of the barrier wall which was deemed equal to zero. As such, due to such a small barrier lateral deflection, the right-end of the wall was made as fixed. The deck slab was also restrained in all directions (rotations and displacements), while no restraint was applied at the exterior end portion of the wall as shown in Figure 7.11. Similar to interior location, the applied pressure load was applied at a height of 990 $\mathrm{mm}$ above the deck slab and in a 40 increments.

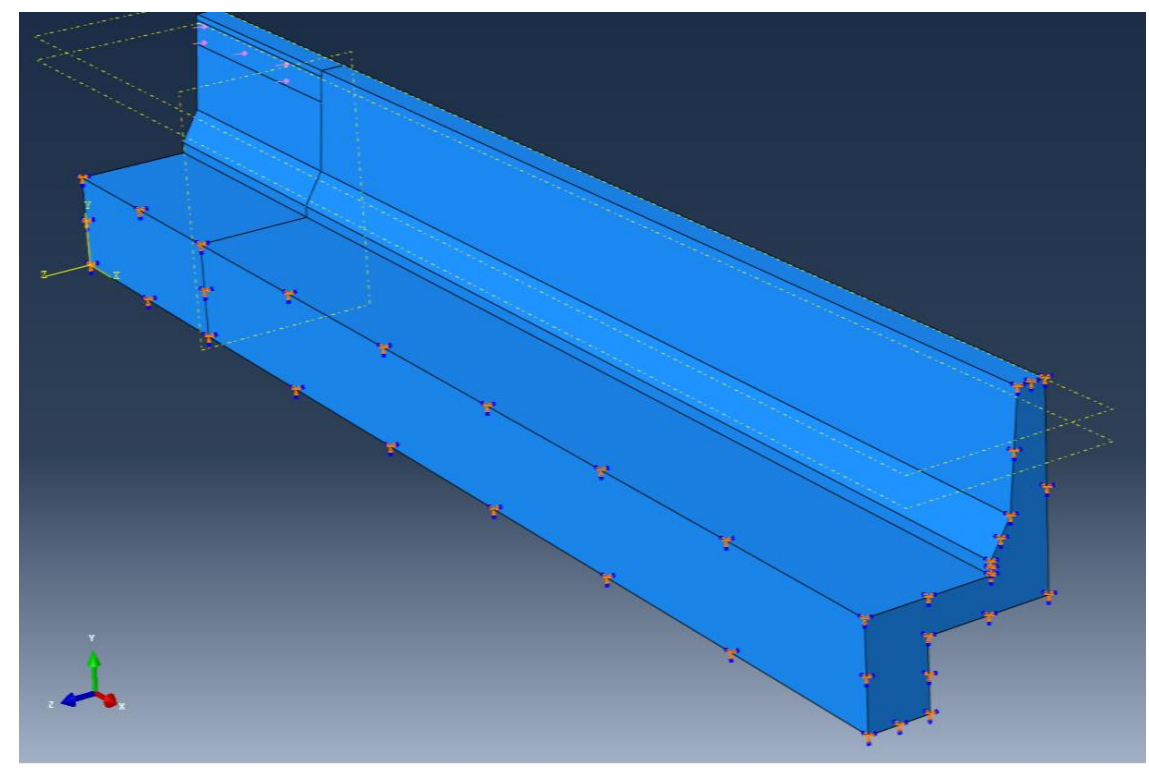

Figure 7. 11 View of TTI barrier model at exterior location showing boundary conditions and transverse applied pressure load

\subsection{FE Mesh assignment}

After the load and boundary conditions are assigned, FE mesh was developed for each barrier model. ABAQUS provides a wide variety of mesh tools to control mesh assignment. When mesh elements are selected, seeds along the edges of the model specify the mesh density indicating 
where the corner nodes of the elements should be located. Mesh element shapes in ABAQUS include; hexahedral, hexahedral-dominated, tetrahedral and wedge. Each mesh element shape can be defined by specific meshing technique such as chosen-free, structured and sweep where applicable. Each mesh element shape is defined by element type to assign the mesh by selecting element family (i.e. 3D stress, acoustic, $\ldots$ etc), geometric order (linear or quadratic) and shape along with specific element controls. In current study, the hexahedron element shape with sweep technique was selected to mesh the models. For the dynamic explicit analysis, the element type was selected as a linear 3D stress with reduced integration at each point. Figure 7.12 shows views of the meshed barrier models.

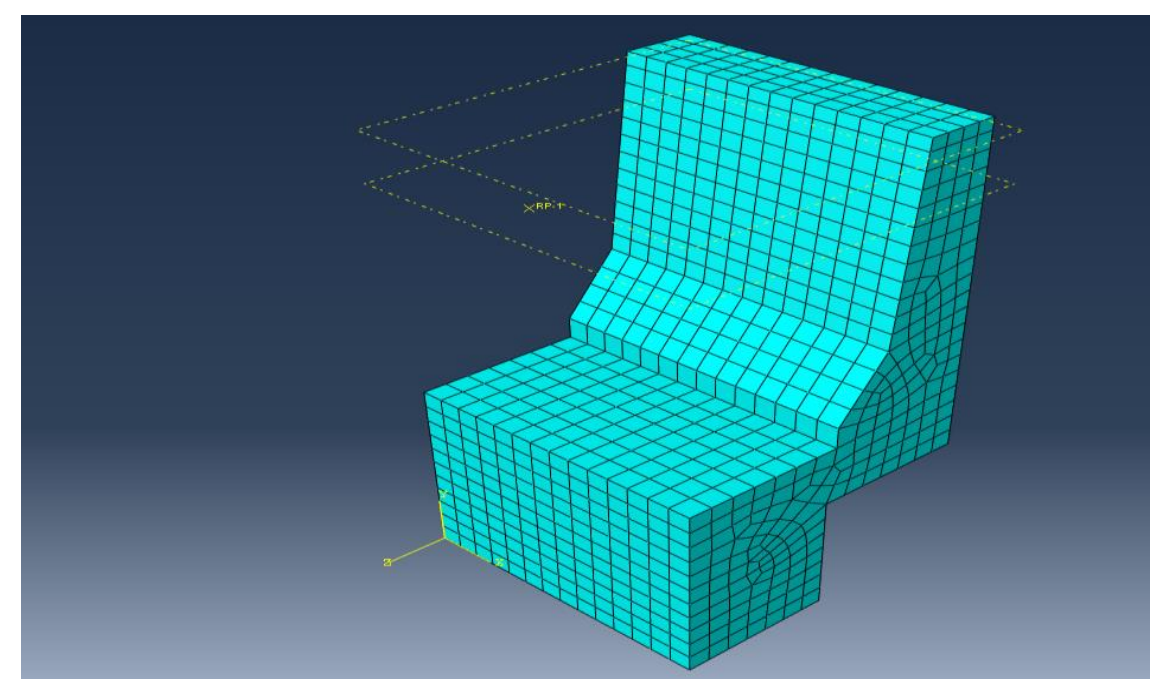

(a) Barrier model 1

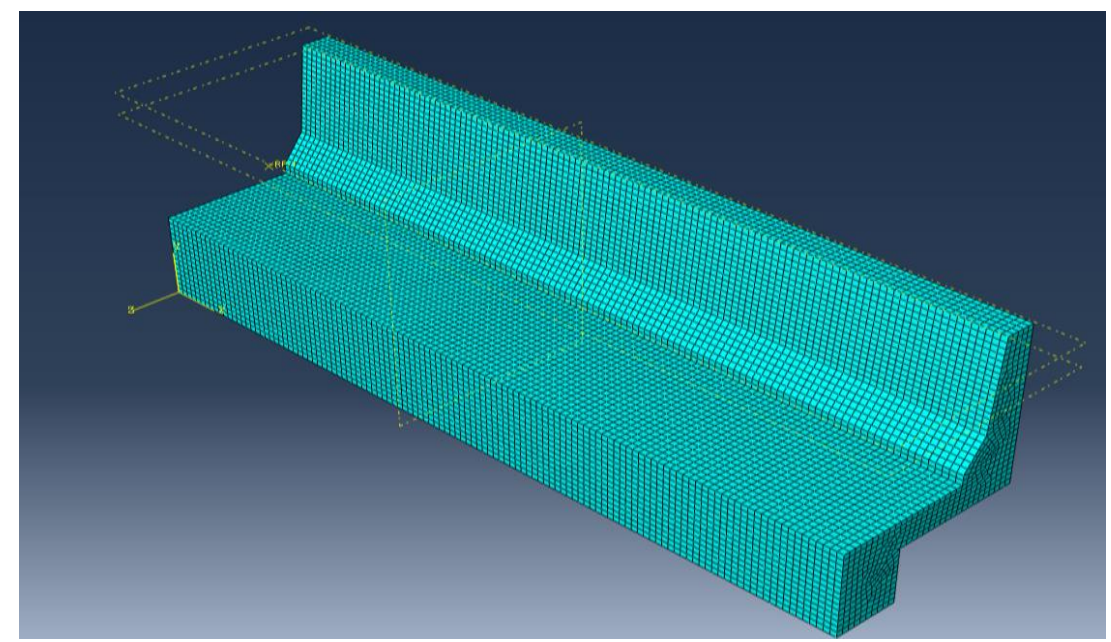

(b) TTI barrier - interior location 


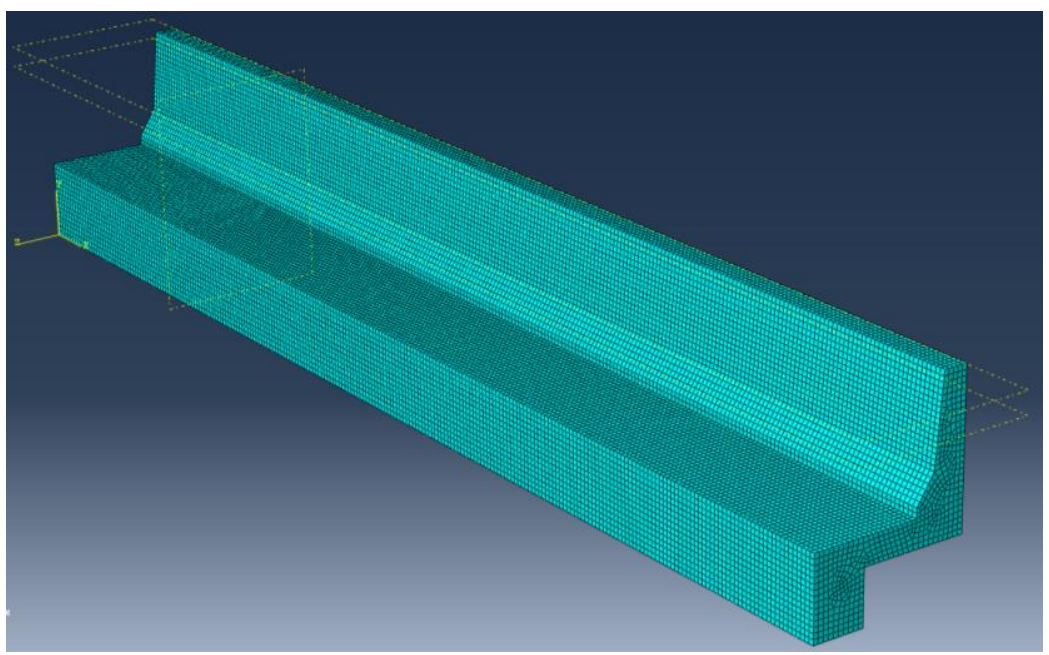

(c) TTI barrier - exterior location

Figure 7. 12 Barrier models with finite-element meshing

Solid 3D elements with 8 nodes linear brick and reduced integration with hourglass control (C3D8R), were used to mesh the concrete barrier wall. Also, the 3D stress-linear displacement truss elements with 2 nodes (T3D2) were used to model the reinforcing bars.

The C3D8R is a brick element with 8 nodes at its corners. The element is called linear or firstorder element, which uses linear interpolation in each direction. It has only three degrees of freedom at each node with stress/displacement elements.

On the other hand, the T3D2 element is a 3D truss element with two degrees of freedom at each node. Truss elements are generally used to model the slender, line-like structures in 2D or 3D that develop loading along the axis of the element. This means that no moment or forces normal to the axis of the truss elements can be developed. The T3D2 also uses a linear displacement interpolation with a constant stress. The cross-sectional area of the truss element is defined as a part of section definition.

The element models selected are stress-displacement elements that can be used to model both linear and complex non-linear mechanical problems. The stress-displacement elements are commonly used for static or quasi-static analysis. The hexahedral elements with good meshing approach yield relatively reasonable prediction results and accuracy at low cost. In general, the 
hexahedral (C3D8) and quadrilateral elements give a better convergence rate and sensitivity to mesh orientation compared with triangle and tetrahedral elements. However, the triangle and tetrahedral elements are less sensitive to initial element shape.

\subsection{Results and Discussions}

In this section, the ability of ABAQUS/Explicit to model the behavior of traffic barrier walls under static load testing has been investigated. The FE model has been calibrated according to the experimentally tested barriers for verification. The ABAQUS/Explicit version 6.13 was used to model the barriers. 3D FE models were generated based on the geometry and load conditions of the tested barrier Model 1 and the TTI long barrier reinforced with GFRP-HM bars. Figure 7.13 shows the geometry of the barrier models, and arrangement of transverse and longitudinal reinforcement in the wall and deck slab portion.

The numerical simulation is meaningful when the results are similar to those of the actual model. To validate FE model accuracy, geometry, shape and material properties should be imported from actual model to the FE model. The output results in terms of load-displacement, strains and stresses should yield relatively similar values. Therefore, numerical models with the same properties as the experimentally tested barriers were analyzed to verify their accuracies. For each model, the load-displacement curve, the barrier wall lateral displacement and crack patterns were compared to the experimental testing. The FE modeling was first carried out on small scale barrier (barrier Model 1) to examine the accuracy of the FE modeling. When the accuracy of the model was confirmed with the small scale experiments, the material property definition was taken similarly to model the large scale barrier (the TTI barrier) at interior and exterior locations. The following subsections discuss the FE results of each barrier model in more detail.

\subsubsection{Finite-Element Results of Barrier Model (1)}

In order to evaluate the reliability of the FE model and calibrate some unknown parameters with high uncertainty, the results of the FE models were compared with the experimental loaddisplacement responses as well as the obtained crack patterns from the tests. Prior to conducting non-linear analysis of barrier Model 1, the barrier with plain and reinforced concretes were modelled first with linear elastic analysis and the load-displacement responses were compared 
with the experimental results and manual calculations. It should be noted that the loaddisplacement response by manual calculation was performed using Eqs. 4.20 to 4.26 considering a gross-moment of inertia in lieu of the cracked moment of inertia (prior to cracking). Also, an average wall thickness along the height of the barrier was considered for the calculations. In linear analysis, it is assumed that the barrier is subjected to the experimentally failure load of $95.5 \mathrm{kN}$ which is applied $990 \mathrm{~mm}$ above the deck slab. The linear response of the barrier was compared with the experiment. In the experimental testing of the barrier Model 1, the first crack was observed at a load of $20 \mathrm{kN}$ at barrier-deck interface.

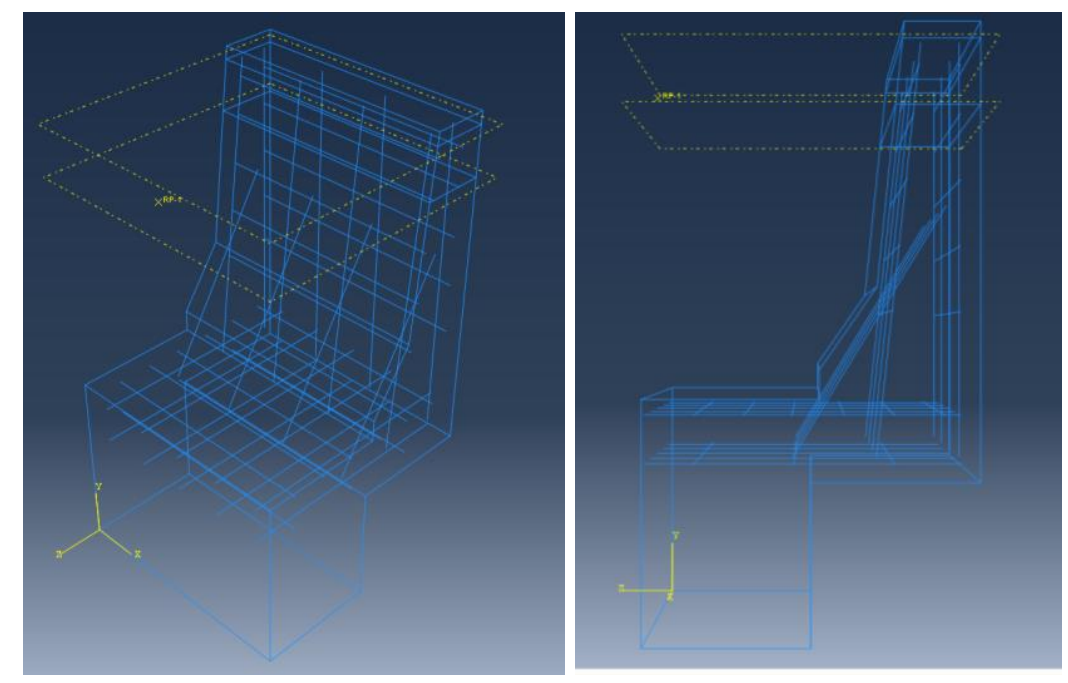

(a) Barrier Model 1 with front and side views
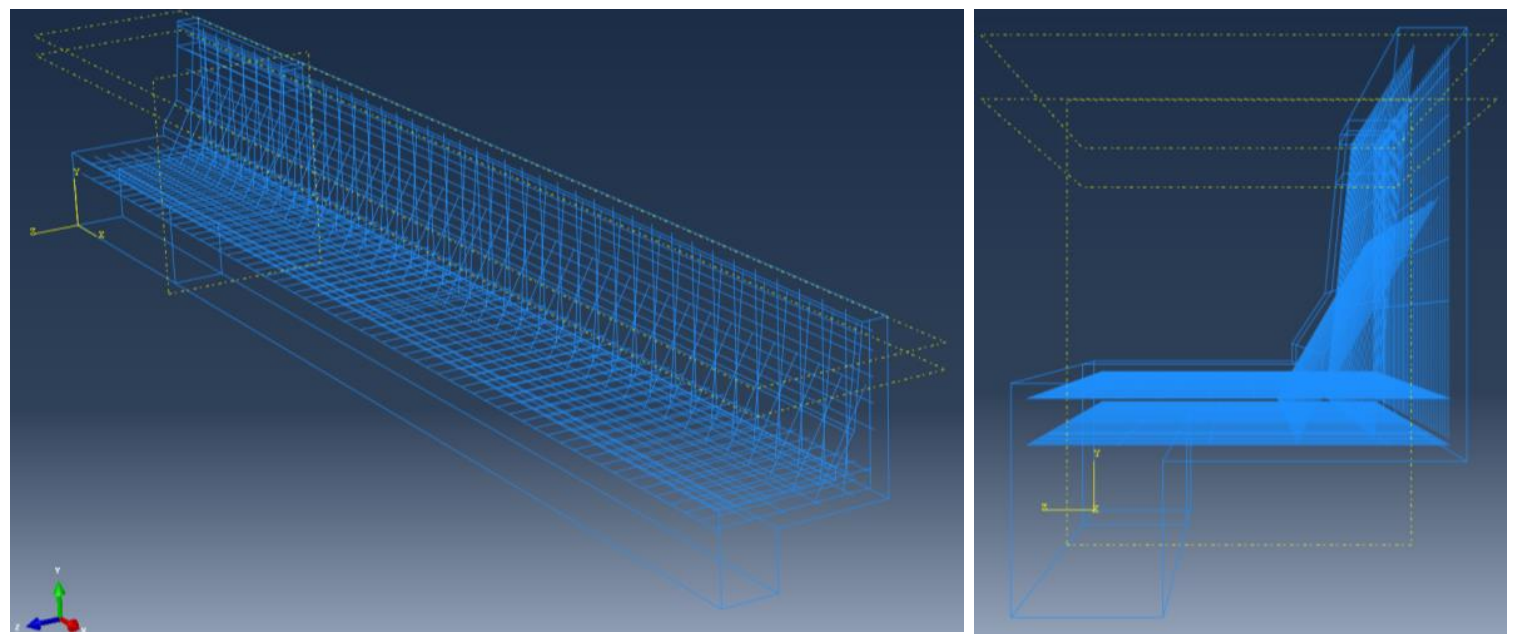

(a) TTI barrier with front and side views

Figure 7.13 Geometry of modelled barriers with bar arrangements in the deck and the wall 
Therefore, it is assumed that the linear part of load-displacement curve of the barrier Model 1 is up to the load of $20 \mathrm{kN}$. Figure 7.14 illustrates graphs of load-displacement response of the barrier Model 1 with plain and reinforced concrete material by linear elastic analysis that is compared to experiment test results and the manual calculations. Within the elastic range, good correlation between the FE modeling and the experimental results was observed. Therefore, it can be concluded that the material behavior in ABAQUS has precisely defined within the elastic range.

Once the elastic range of the load-displacement response is verified, the FE modeling was further investigated in barrier Model 1 by conducting non-linear analysis using the principles stated earlier to define the non-linear parameters of concrete and reinforcing steel. It should be noted that to simplify the modeling and better comparison with the experimental results, the response of the barrier model is only valid up to the point of experimentally tested failure load. Thus, the barrier model was subjected to transverse pressure load equal to the failure load of $95.5 \mathrm{kN}$ for tested barrier Model 1. The load was spread over an area of 1000x200 mm as shown in Figure 7.9. For this reason, the load-displacement response and the crack patterns are only presented up to the peak failure loads. Since the tested barrier was reinforced with headed-end bars as connecting bars at barrier-deck interface, the following subsections explain the influences of concrete tensile cracking strength, headed-end geometry and dilation angle on the behavior of the barrier model followed by crack patterns and mesh refinement of the barrier model.

\subsubsection{Influence of Concrete Tensile Cracking Strength}

It should be mentioned that strain gauges have not been used to measure strains in the reinforcing bars, also, concrete tensile or compressive cracking strains during experimental testing of the barrier Model 1. Thus, the tensile cracking strain of concrete has been calibrated to best fit with the experimental results. For the barrier Model 1 with concrete compressive strength of 25.4 $\mathrm{MPa}$, graphs of stress versus plastic strains (plastic strains are equal to cracking strains for static load testing) were plotted and implemented in the ABAQUS. Figure 7.15 shows loaddisplacement curves of the barrier model in terms of variation in the tensile cracking strain, which are compared to the experimental test results. It can be noticed that as the concrete tensile 
cracking strain increases, the graph of load-displacement curve approaches the experimental test results, but, the displacement corresponding to the peak load decreases.

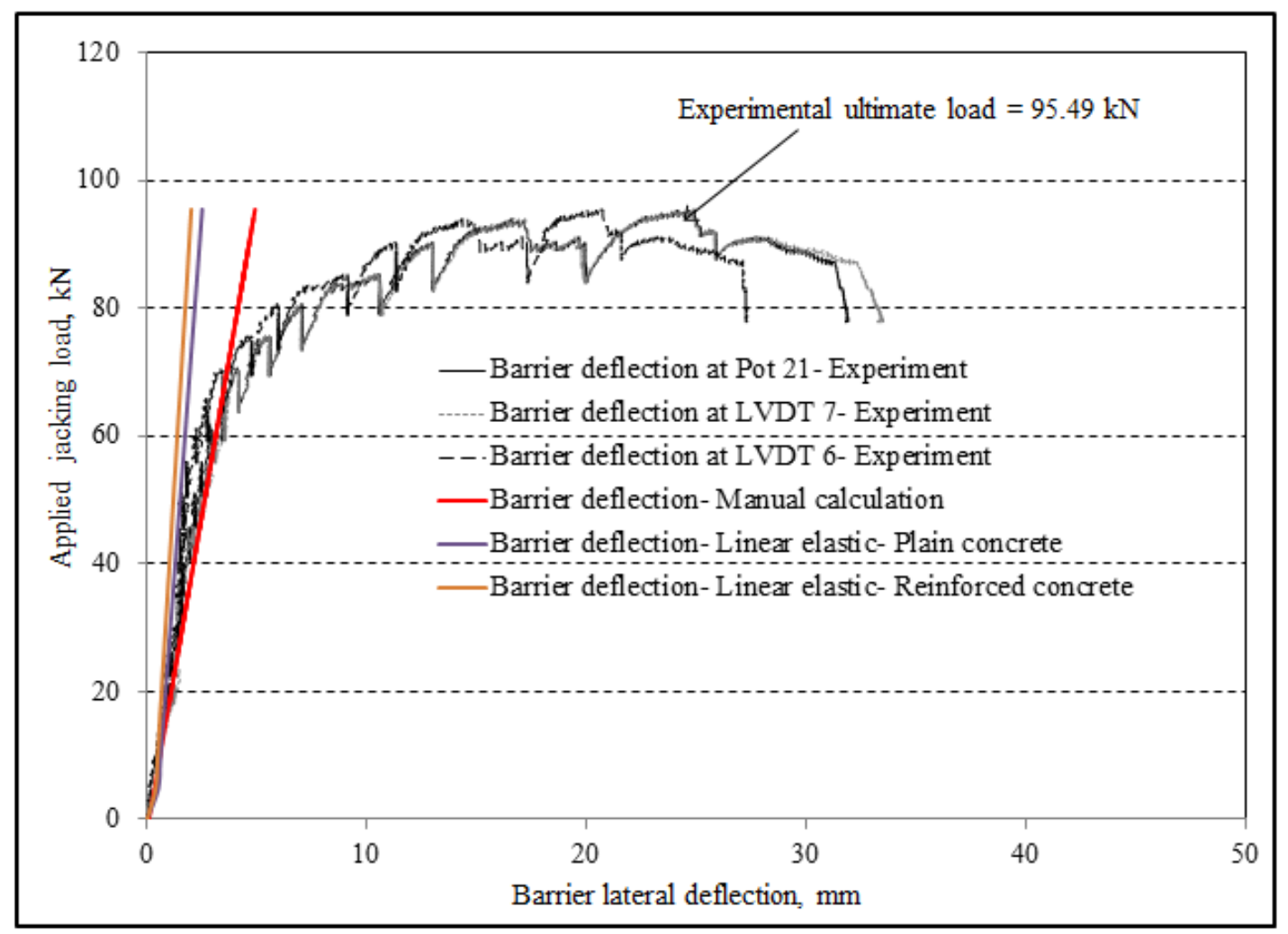

Figure 7. 14 FE modeling of load-deformation response of barrier Model 1 by linear analysis and comparison with experimental results and manual calculations

For a concrete tensile cracking stress of $1.66 \mathrm{MPa}$ (approximately $0.33 \sqrt{ } f^{\prime} \mathrm{c}$ ), the loaddisplacement curve provides the best fit with the experimental graphs, while the displacement at peak load was $15.3 \mathrm{~mm}$, which was comparably smaller than the experimental barrier displacement of $24.5 \mathrm{~mm}$. However, for a tensile concrete cracking of $1.25 \mathrm{MPa}$, the barrier model yielded a displacement at peak load of $26.6 \mathrm{~mm}$ close to the experimental results, which can be regarded as a reasonable assumption. It can also be noticed that the FE model correlate well with the experimental results at almost $50 \%$ of the failure load. However, as the barrier experience to crack and cracks get widened, the plastic deformation of the FE model behaves stiffer than the experiment if lower values of concrete tensile cracking are assumed. 


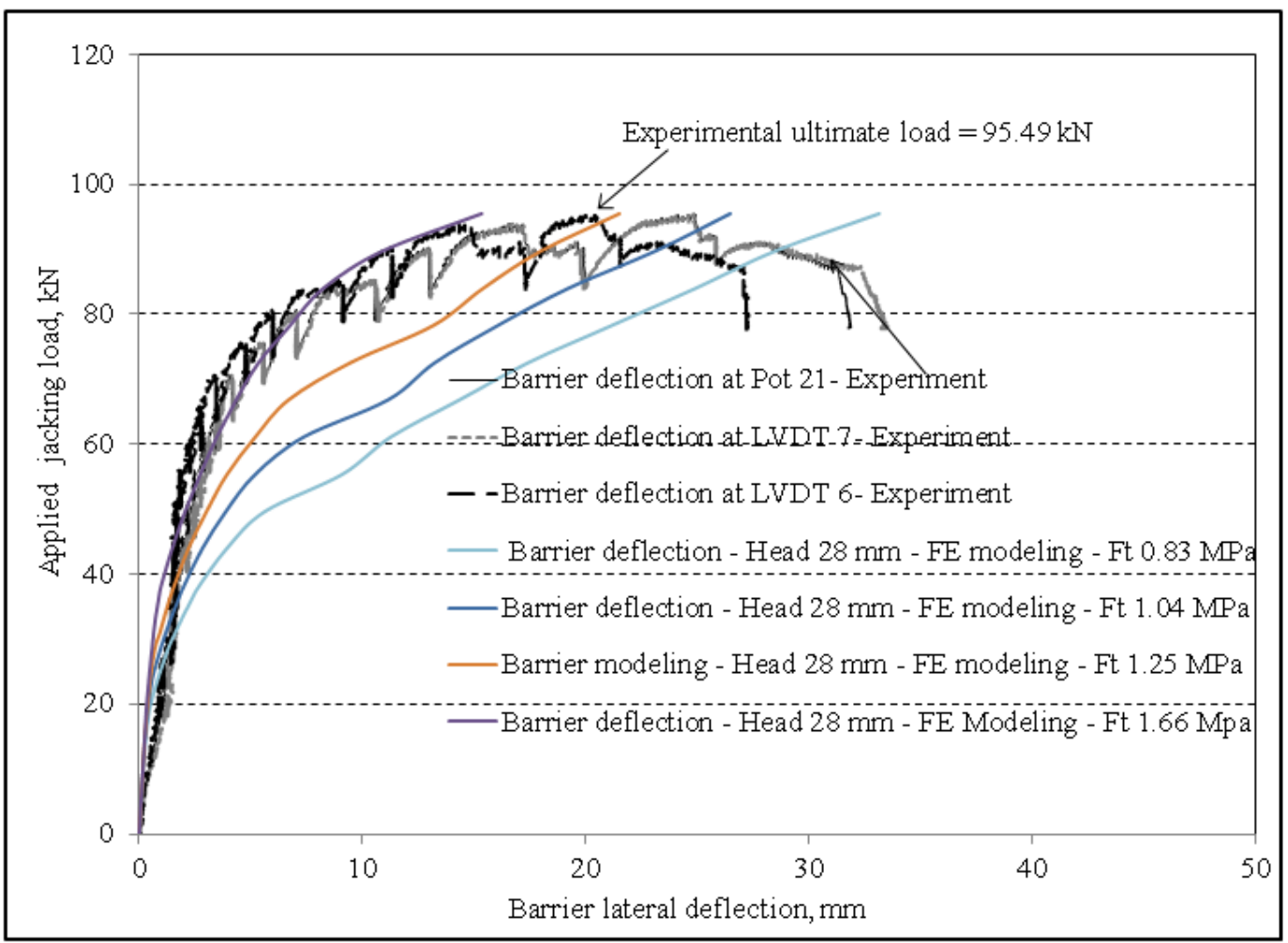

Figure 7. 15 Load-displacement response of the barrier model with variable concrete tensile cracking strength

\subsubsection{Influence of Headed-End GFRP Bars}

As pointed out in Chapter 4, barrier Model 1 was constructed using high-modulus GFRP bars with headed-end bars as the connecting bars at deck-wall interface. The headed-end anchor placed at the end of the GFRP bars has a length of $100 \mathrm{~mm}$, which is tapered in five steps toward the inner portion of the bar. The head has a wide disc shape with the diameter equal to 2.5 times the bar diameter (almost $40 \mathrm{~mm}$ for $16 \mathrm{~mm}$ bar) that proportionally decreases along each tapered portion to the last step equal to the bar diameter as shown in Figure 7.16. The implementation of such geometric non-linearity in ABAQUS is tedious and may end with convergence difficulties. Thus, the influence of headed-end anchors was investigated by assuming such geometric nonlinearity as a uniform diameter along the length of the headed anchor. Therefore, the head anchor diameters of $16,22,28,32,36$ and $40 \mathrm{~mm}$ were assumed and simulated as the diameter of the headed portion in ABAQUS. The $28 \mathrm{~mm}$ diameter was taken as the marginal value. The graphs of load-displacement response of the barrier model in terms of variation in head anchor diameters are plotted in Figure 7.17. It can be noticed from the load-displacement graphs that 
variation in head anchor diameter did not influence the $\mathrm{FE}$ results as the load-displacement graphs for all headed anchor diameters coincided on each other. This indicates that anchorage failure did not occur and stresses and strains developed in the headed-end anchors were significantly below the ultimate values. The finding was confirmed by observing the stresses and strains of the reinforcing bars in the FE modeling.

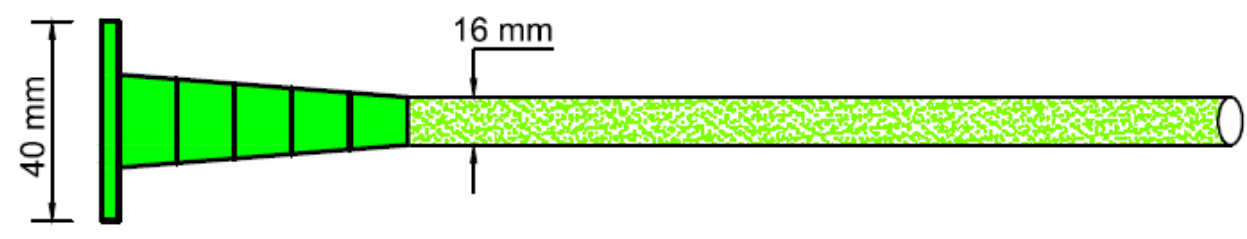

Figure 7. 16 Geometric variation of the headed-end anchor

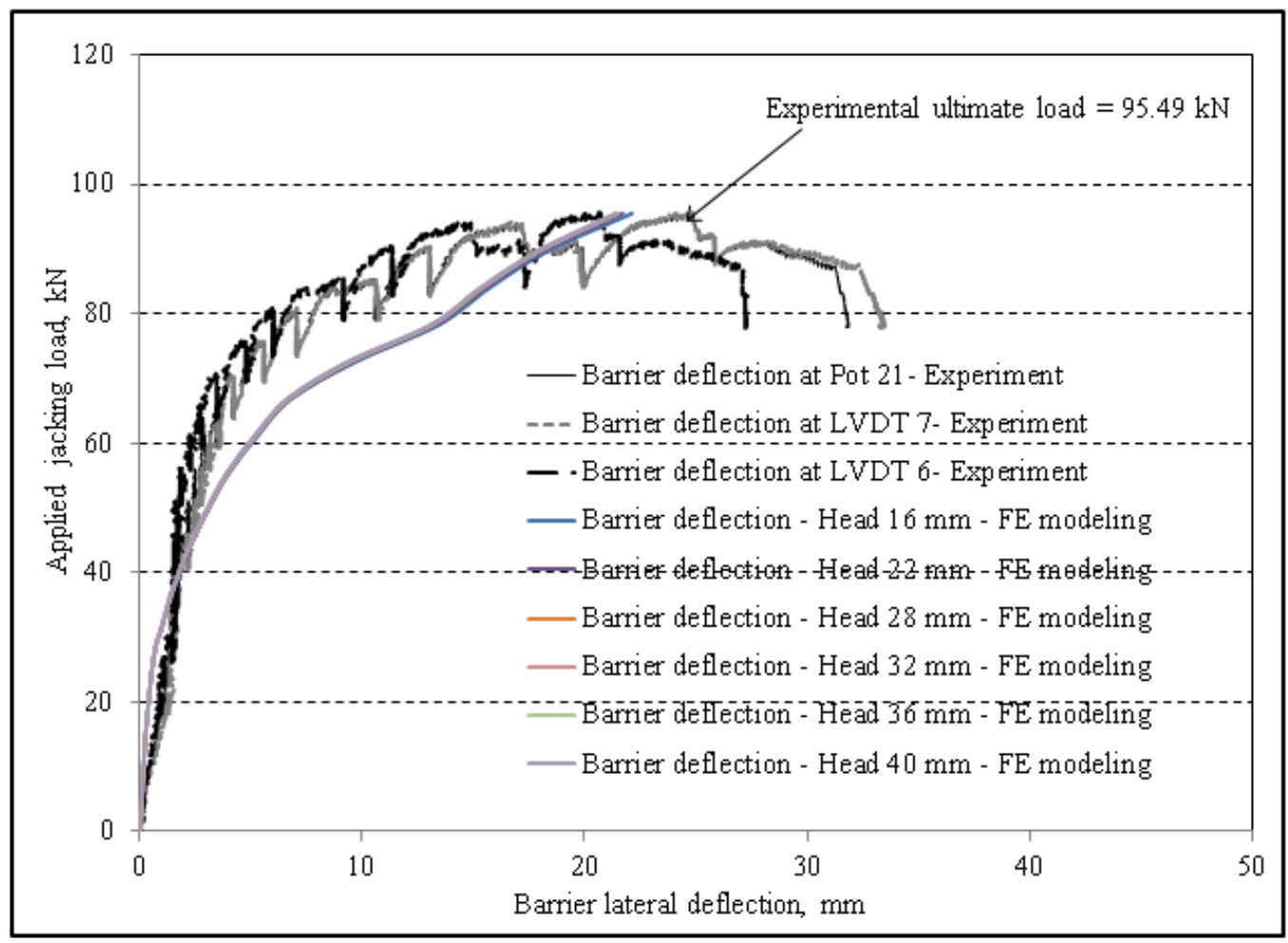

Figure 7. 17 Variation of head anchor diameter on FE modeling results

The M15-GFRP bars in the barrier wall have an ultimate tensile strength of $1184 \mathrm{MPa}$ and strain at rupture of $18.9 \times 10^{-3}$. Also, the steel reinforcement in the deck slab has a yield strength of 
$400 \mathrm{MPa}$ and yield strain of 0.002 . Figure 7.18 shows that the reinforcing bars developed a maximum stress of $327 \mathrm{MPa}$ in the deck slab with the corresponding strain of 0.0012 . In addition, the diagonal GFRP bars at deck-wall interface developed a maximum stress of 109 $\mathrm{MPa}$ and strain of $3.61 \times 10^{-3}$ which are comparably less than the ultimate strength and strain values, respectively. This finding was confirmed with experimental crack pattern as the failure due to bond or head anchors have not been observed during testing. Based on these investigations, an average head anchor diameter of $28 \mathrm{~mm}$ was selected to simulate the head portion of diagonal GFRP bars in the TTI actual barrier for the rest of the study.

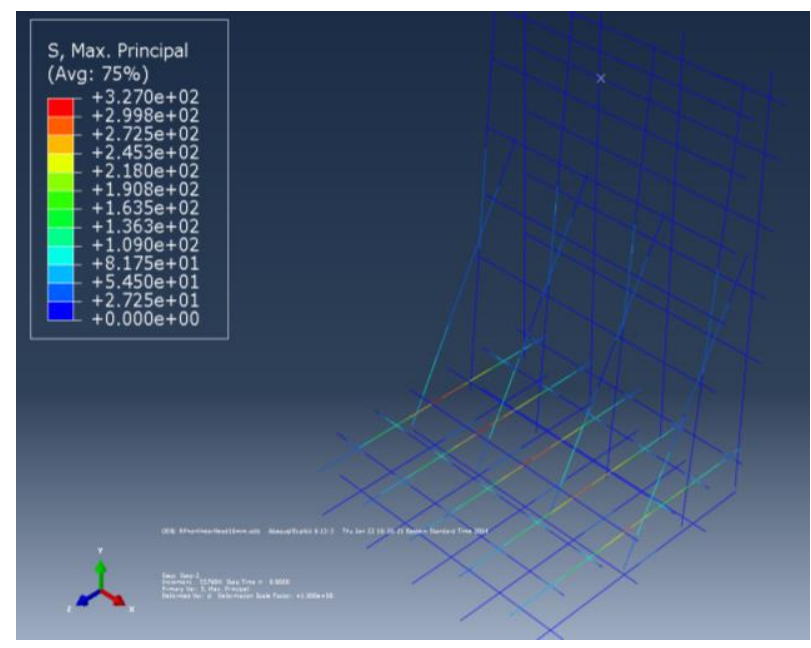

(a) Stresses in the bars

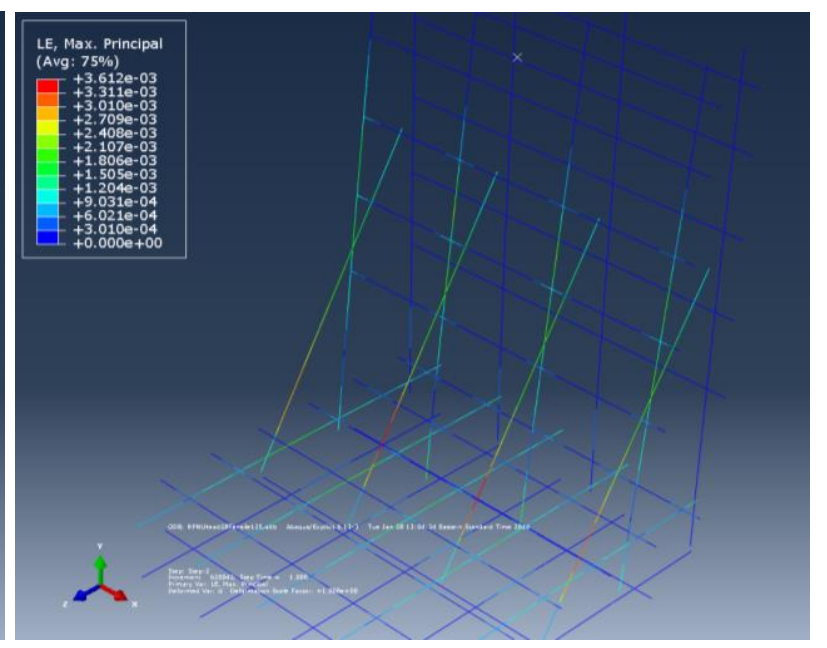

(b) Strains in the bars

Figure 7. 18 Stresses and strains developed in the reinforcing bars in barrier Model 1

\subsubsection{Influence of Dilation Angle}

In the process of calibration, the effect of dilation angle on the behavior of barrier model was investigated. Generally, dilation angle refers to the angle of internal shear resistance or concrete internal friction angle at low stresses. Figure 7.19 shows the effect of different values of dilation angle on load-displacement response of the tested barrier model. It can be noticed from the graphs that as the dilation angle increases the non-linear portion of stress-strain curves approaches the experimental results. This indicates that the increase in the frictional angle of the concrete components leads to a more ductile failure so that the load-displacement response shows a stiffer plastic deformation similar to the experimental results. However, increasing the dilation angle decreases the overall displacement of the structure due to increase in the angle of 
internal shear resistance. The FE results in this model showed that to achieve a good agreement with the experimental test results, the dilation angle should be between $25^{\circ}$ and $35^{\circ}$. The dilation angle less than $25^{\circ}$ leads to a softer response, while the dilation angle greater than $35^{\circ}$ shows stiffer load-displacement response. The graphs also show that by increasing the dilation angle, the failure response changes from brittle failure mode to more ductile failure mode. From these investigations, a dilation angle of $30^{\circ}$ was calibrated for this barrier model. For such dilation angle, a maximum wall lateral deflection of $21.5 \mathrm{~mm}$ was obtained, which is within the $12.2 \%$ tolerance of the experimental tested barrier. This difference between FE modeling and experimental test results is deemed acceptable.

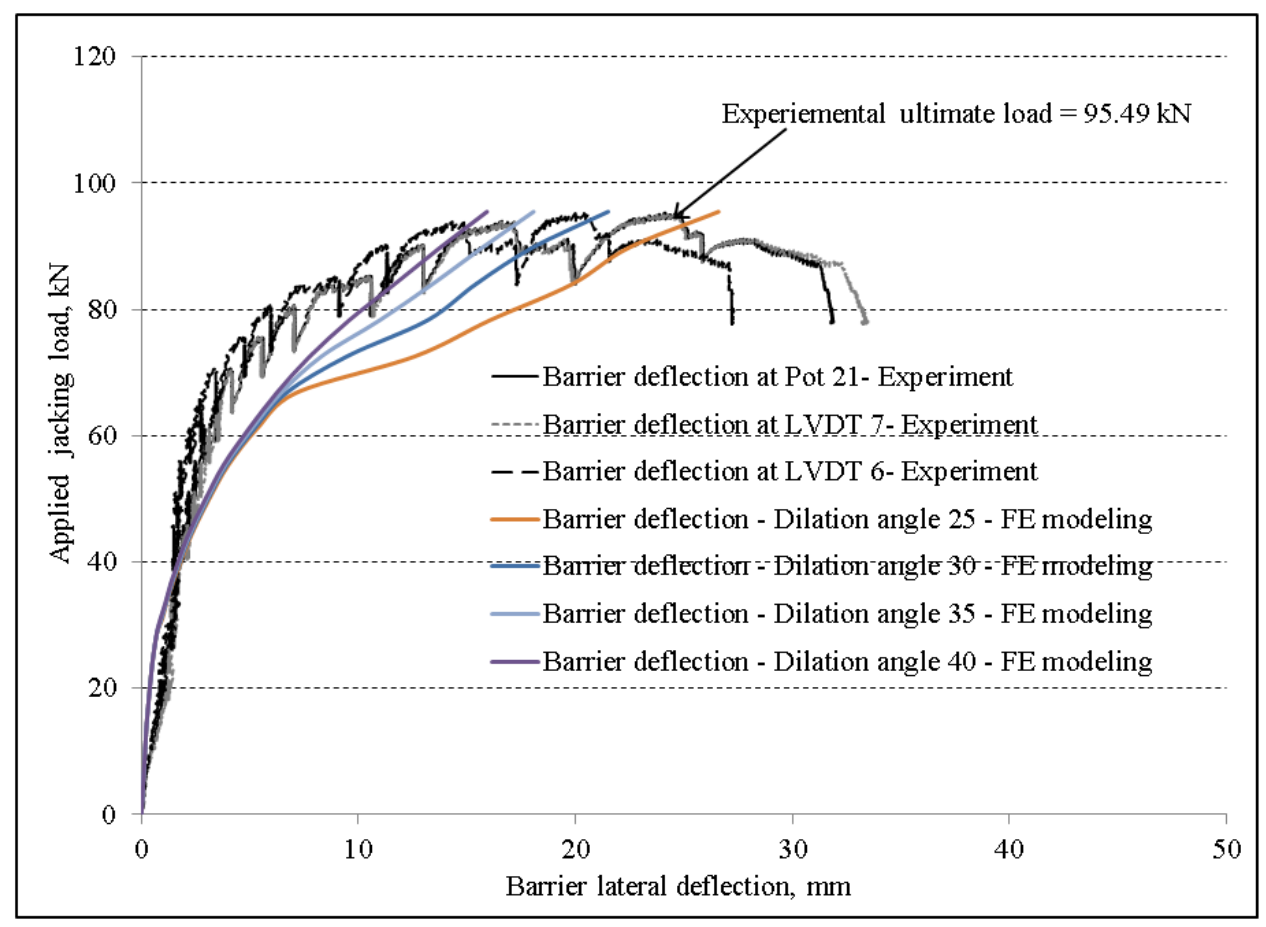

Figure 7. 19 Influence of dilation angle on the load-displacement response of tested barrier Model 1 and comparison with the experimental results

\subsubsection{Crack Patterns}

The crack patterns of the tested barrier model have been investigated and compared with the experimental findings. ABAQUS shows crack pattern as smeared crack approach for the cracked elements by solid crack continuum. Cracks in ABAQUS can be presented by strains at cracking strain or stresses by the limiting tensile cracking stress. Figure 7.20 compares the experimental 
results with FE modeling in terms of crack pattern. For the calibrated concrete tensile cracking strength of $1.25 \mathrm{MPa}$, the cracking strain limit was determined as $4.2 \times 10^{-5}$. In the barrier model, cracks in elements were observed at deck-wall interface as well as at the tapered portion in red contour with strains greater than the cracking strain limit (Figure 7.20c). Similar to experimental observations, cracks were first developed at deck-wall interface under the low load in the initial load steps. By increasing the load, cracks were also developed at high stress/strain concentration locations namely at the tapered wall portion. In the deck slab, cracks were propagated in the deck at the strain limit due to the combined effects of tension and flexure in the deck slab (Figure 7.20d). In FE modeling, it was observed that cracks propagated only in the deck slab within the cantilever portion and did not expend into the slab. This may be attributed to the large slab thickness that the entire slab has been defined as fixed base in ABAQUS. However, in the experimental test results, crack were observed in the slab on the top surface due to the fact that the slab was tied down to the rigid floor so the connection was not assumed fully fixed leading to the deck slab uplift at this point. In addition, due to the applied load, diagonal tension cracks were observed in the FE modeling in a similar trend as the experiment as shown in Figure 7.20b. The diagonal crack was mapped at lower portion of the deck slab and propagated toward the corner joint of the deck-wall interface. By comparison of the FE modeling and the experimental test observations, it can be noticed that the FE model cannot represent the crack pattern perfectly. However, it can show a reasonable representation of the induced damage pattern and the failure mode. The compressive strains at back face of the wall illustrated in Figure 7.20e show a maximum compressive strain of -0.001168 that is comparably less than the concrete crushing strain (strain at failure of -0.002) indicating that the barrier did not fail in compression. Although the codes allow a maximum crushing strain of -0.0035 , the value of -0.002 was selected to correspond to the peak failure stress of concrete under uniaxial compressive test. This finding agreed with the experimental test results as the concrete crushing at back face of the wall was not observed.

It is also possible to define the cracked surface range (tensile cracking and compressive crushing) in ABAQUS. For the barrier Model 1, the cracking strain limit is defined as 0.000042 in tension as tensile cracking and -0.002 in compression as crushing strain at peak failure stress. For this range, Figure 7.21 shows the cracked surface areas in grayed color. The area outside of this 
region is deemed not to crack at failure. Figure 7.21 depicts the cracked surface extended into the corner joint at the deck-wall interface, also through the wall thickness as the tapered portion of the wall. This observation agreed with the experimental test results.

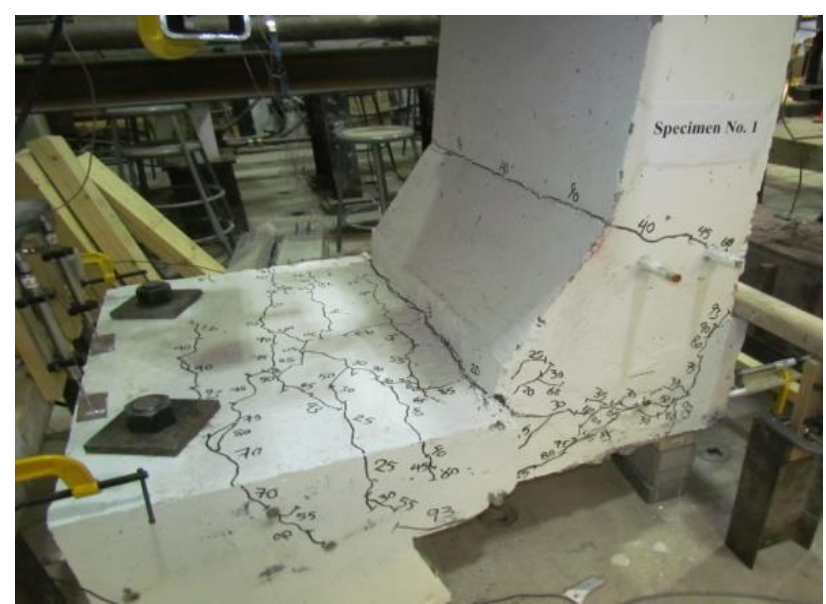

(a) experimental cracks propagation

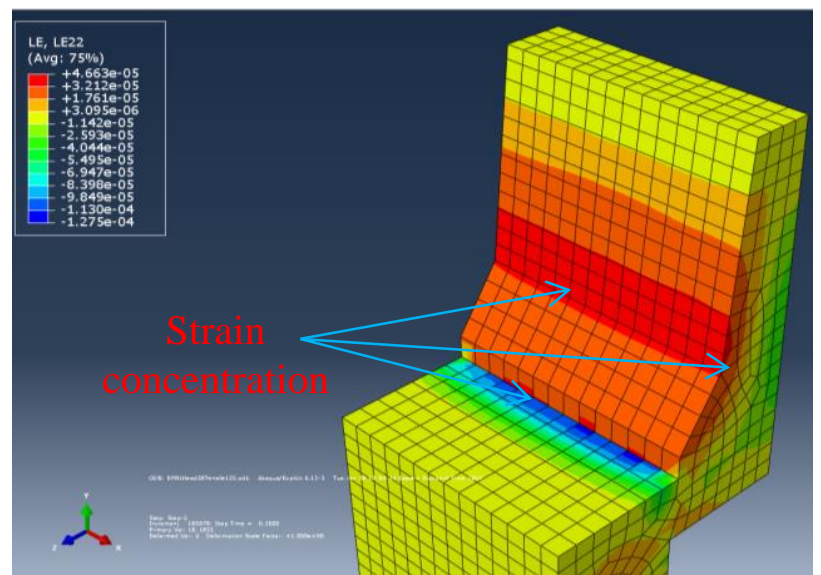

(c) Cracks in wall portion

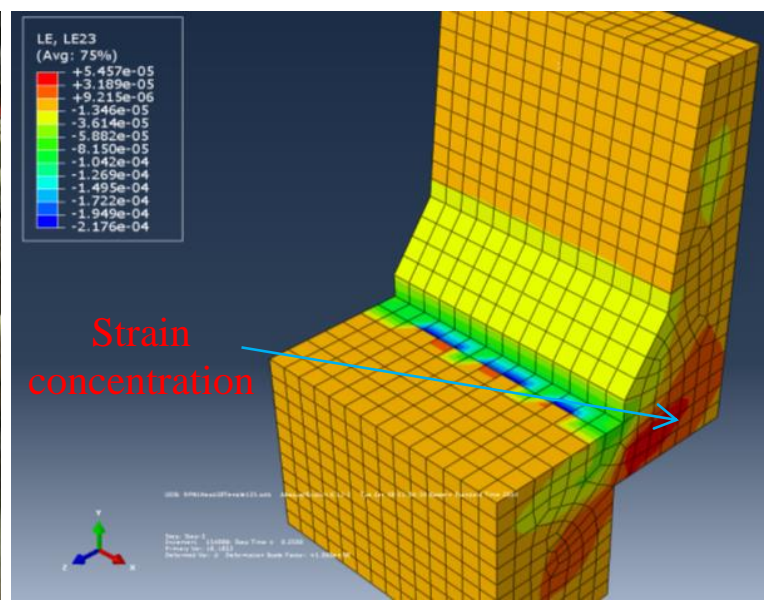

(b) Diagonal corner cracks

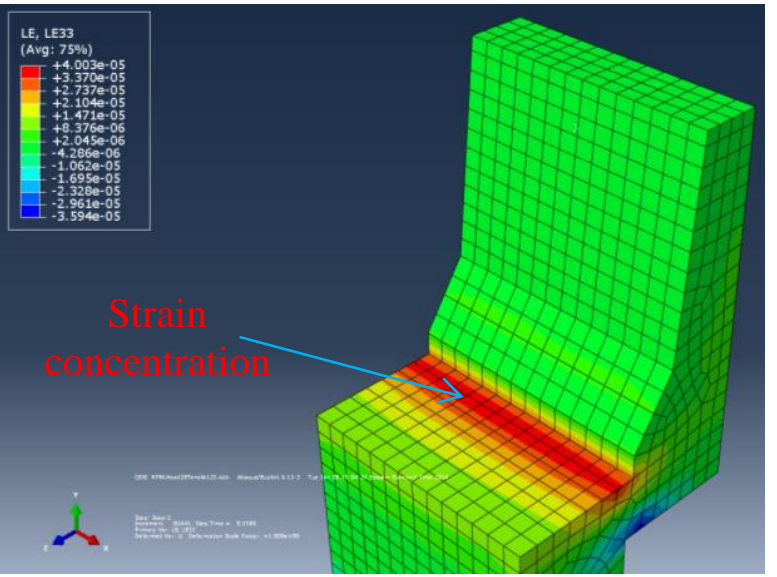

(d) Cracks in the deck slab 


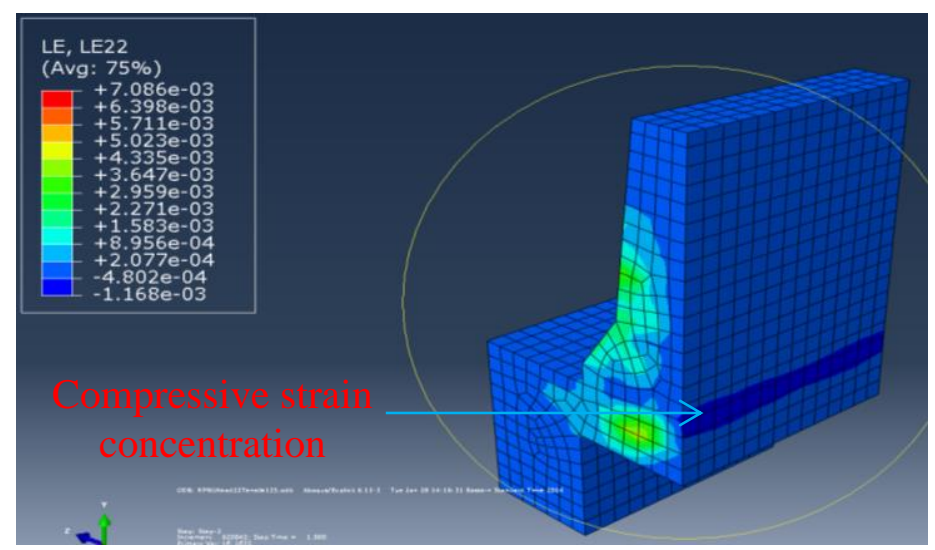

(e) Compressive strain concentration at back face of the wall

Figure 7. 20 Induced crack patterns in the modeling compared with experimental cracks

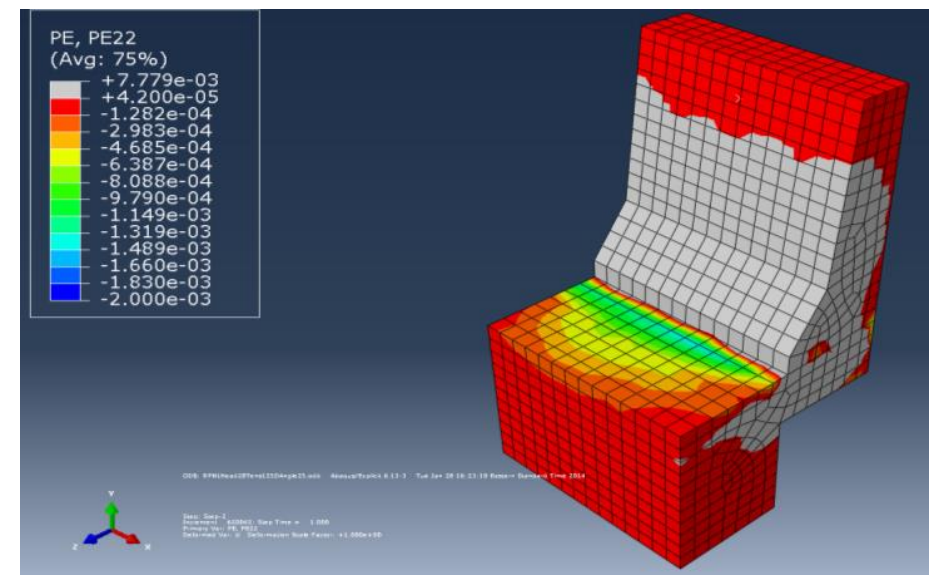

(a) Cracked surface area in the wall portion

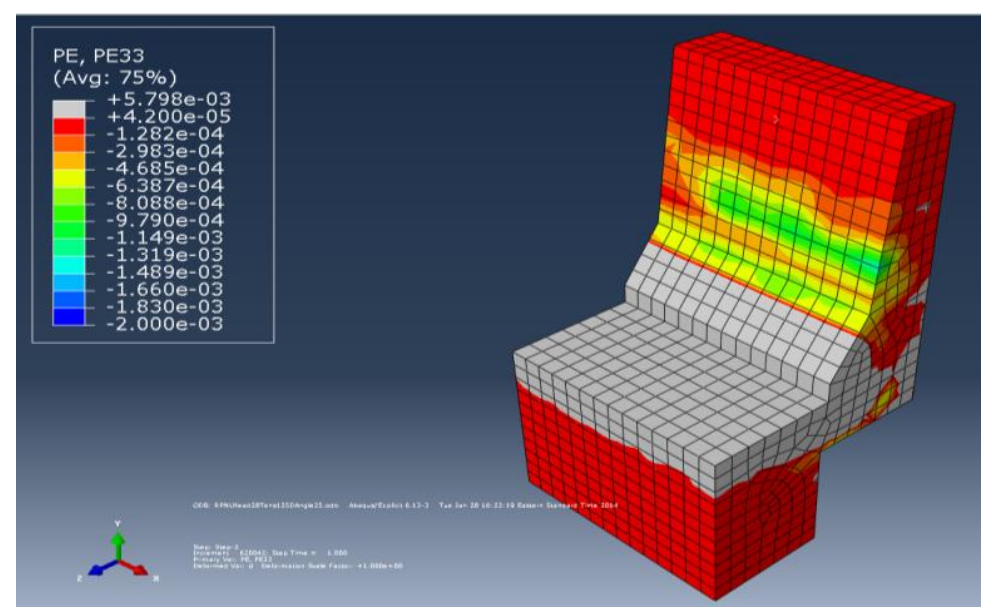

(b) Cracked surface area in the deck slab

Figure 7. 21 Cracking surface range in the wall and deck portions of the barrier model 


\subsubsection{FE Mesh Refinement}

In order to reduce the size of the initial finite-element mesh, mesh refinement has been carried out on the barrier model. The accuracy of the solution is linked effectively to the mesh size. As mesh size decreases toward zero leading to a model of infinite size, the accuracy of the model moves toward the exact solution for solving the equations. However, since the finite computational resources and time are limited during modeling of a structure, an approximation of the real solution is meant acceptable. The purpose of mesh refinement, therefore, is to minimize the difference or error between the exact and the approximated solutions to ensure that the difference is within the acceptable tolerance level, which in most finite-element models is up to $20 \%$ in the literatures.

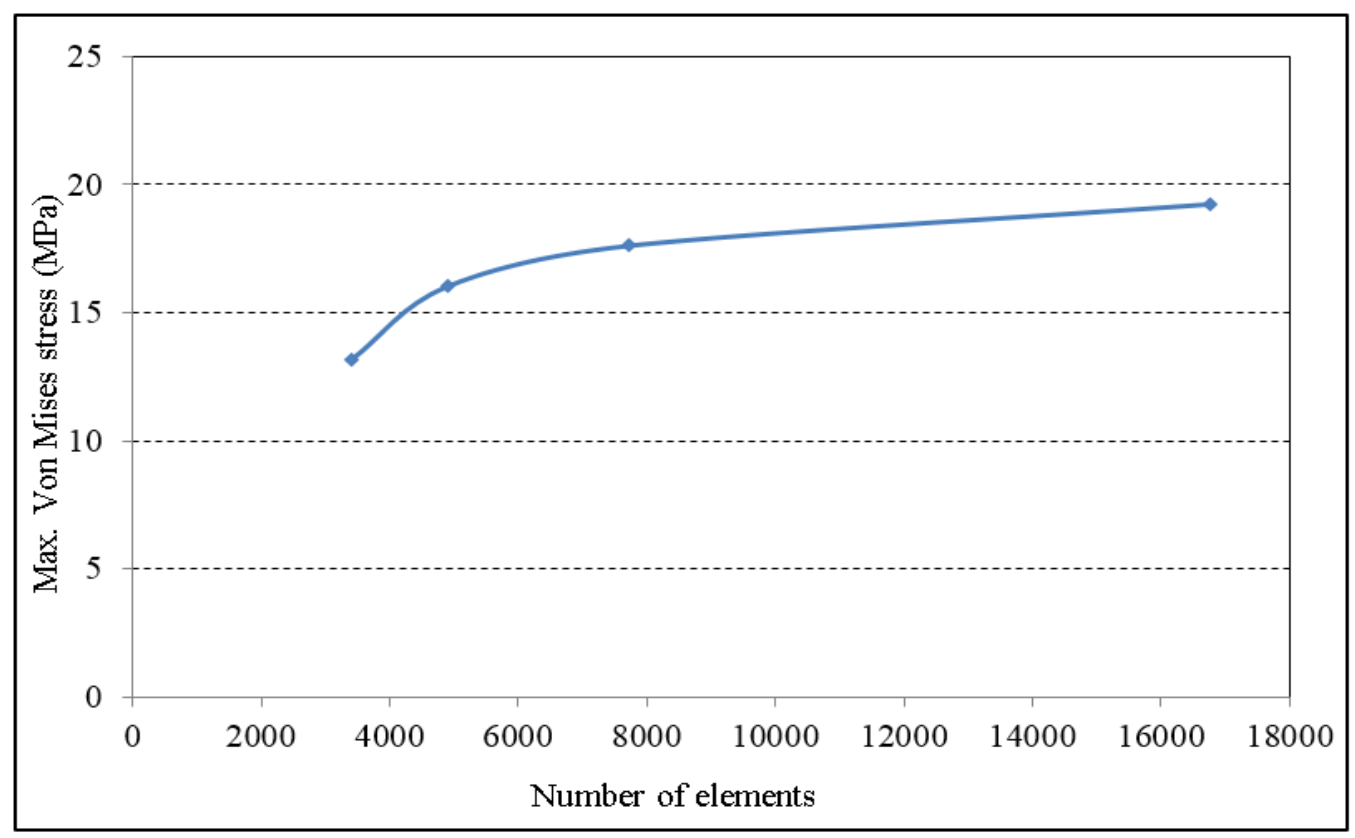

Figure 7. 22 Mesh refinement study on the barrier Model 1

For the constructed barrier model, mesh element sizes of 40, 50, 60 and $70 \mathrm{~mm}$ have been selected and implemented in ABAQUS. For each mesh element size, the number of elements and the corresponding maximum Von-Mises stress have been identified. The comparison was made with Von-Mises stresses due to the fact that this failure stress was experimentally verified in which failure occurs within the failure surface of the proposed theory. Plot of stress as a function 
of number of elements is shown in Figure 7.22. It can be observed that as the number of element increases or the mesh size decreases, the graph shows relatively flat line indicating that the VonMises stress tends to yield similar values with a small difference. As the graph became flat line, the finite-element solution approaches the exact solution.

\subsubsection{Finite-Element Results of TTI Barrier at Interior Location}

The finite-element model has been calibrated based on the results of the barrier Model 1. In order to verify the accuracy of FE modeling for the actual long barrier tested at TTI, the calibrated FE models in terms of bar arrangement by head anchors, linear and non-linear material definitions and the initial dilation angle were implemented in ABAQUS software to simulate the TTI barrier at interior and exterior locations.

As pointed out earlier, due to symmetry of barrier geometry, boundary conditions and loading of the TTI barrier at interior location, this barrier was modeled using the principle of symmetry. A barrier length of $6 \mathrm{~m}$ was selected for modeling since the response beyond this length at interior location was found to be negligible. The barrier boundary conditions at support, line of symmetry and the right-side end of the barrier model was shown in Figure 7.10. Similar to barrier Model 1, the FE modeling for this barrier studied the influences of concrete tensile cracking strength and dilation angle on the barrier overall response. In addition, comparison was made to examine the crack patterns and mesh refinement with the experimental test results. The following subsections explain these effects in more details. It should also be noted that an average head anchor diameter of $28 \mathrm{~mm}$ was used to model the headed-end bars in the barrier based on the FE results of the barrier Model 1.

\subsubsection{Influence of Concrete Tensile Cracking Strength}

Similar to the tested barrier Model 1, strain gauges were not used to measure strains in reinforcing bars, as well as the concrete tensile cracking or concrete compressive strains. Thus, an attempt was made to define various concrete tensile cracking strains, which the response would be then compared to the load-displacement response of the experimental test results for the initiation of cracks. The best curve fit has been selected as the concrete tensile cracking strength of the tested TTI barrier. It should be noted that the experimental test results did not 
show failure of the TTI barrier by concrete crushing, bond or anchorage failure modes. Therefore, it was assumed that strains in the reinforcing bars were below the yielding point for the steel bars in the deck and below the rupture strain limit for the GFRP bars in the barrier wall. In addition, the concrete compressive strain did not reach the strain limit of -0.002 at peak failure stress. These assumptions were then compared with the FE modeling and will be discussed later. For the TTI barrier with concrete compressive strength of $30.9 \mathrm{MPa}$, plots of stress versus cracking strains were developed and defined in ABAQUS software. Figure 7.23 shows loaddisplacement responses obtained from FE modeling which are compared with the experimental results. Similar to the barrier model 1, it was observed that as the concrete tensile cracking strength increases, the load-displacement response develops more ductile behavior approaching the experimental test response. However, the lateral deflection of the barrier decreases as the concrete tensile cracking strength increases. Since the tested barrier at interior location experienced a maximum lateral deformation of $17.81 \mathrm{~mm}$ at the centroidal point of the patch loading, it can be noticed the FE model with concrete tensile cracking strength of $1.84 \mathrm{MPa}$ develops similar deformation response although there exists some differences for the inelastic deformation. For the FE model with concrete tensile cracking of $1.93 \mathrm{MPa}$, a barrier lateral deflection of $16.62 \mathrm{~mm}$ was observed with a difference of $6.7 \%$ to the experimental results. For the concrete tensile cracking strength beyond $1.93 \mathrm{MPa}$, the barrier lateral deformation comparably reduced although the inelastic responses were similar to the experimental findings.

Therefore, the concrete tensile cracking strength of 1.84 was selected as the calibrated value for the TTI model. It was also observed that at initial stage of the load-displacement curves, the FE model revealed a good agreement with the experimental results. However, for non-linear part, the FE model with 1.84 MPa concrete tensile cracking strength showed an average difference of 9.74\% with the experimental results which is deemed acceptable 


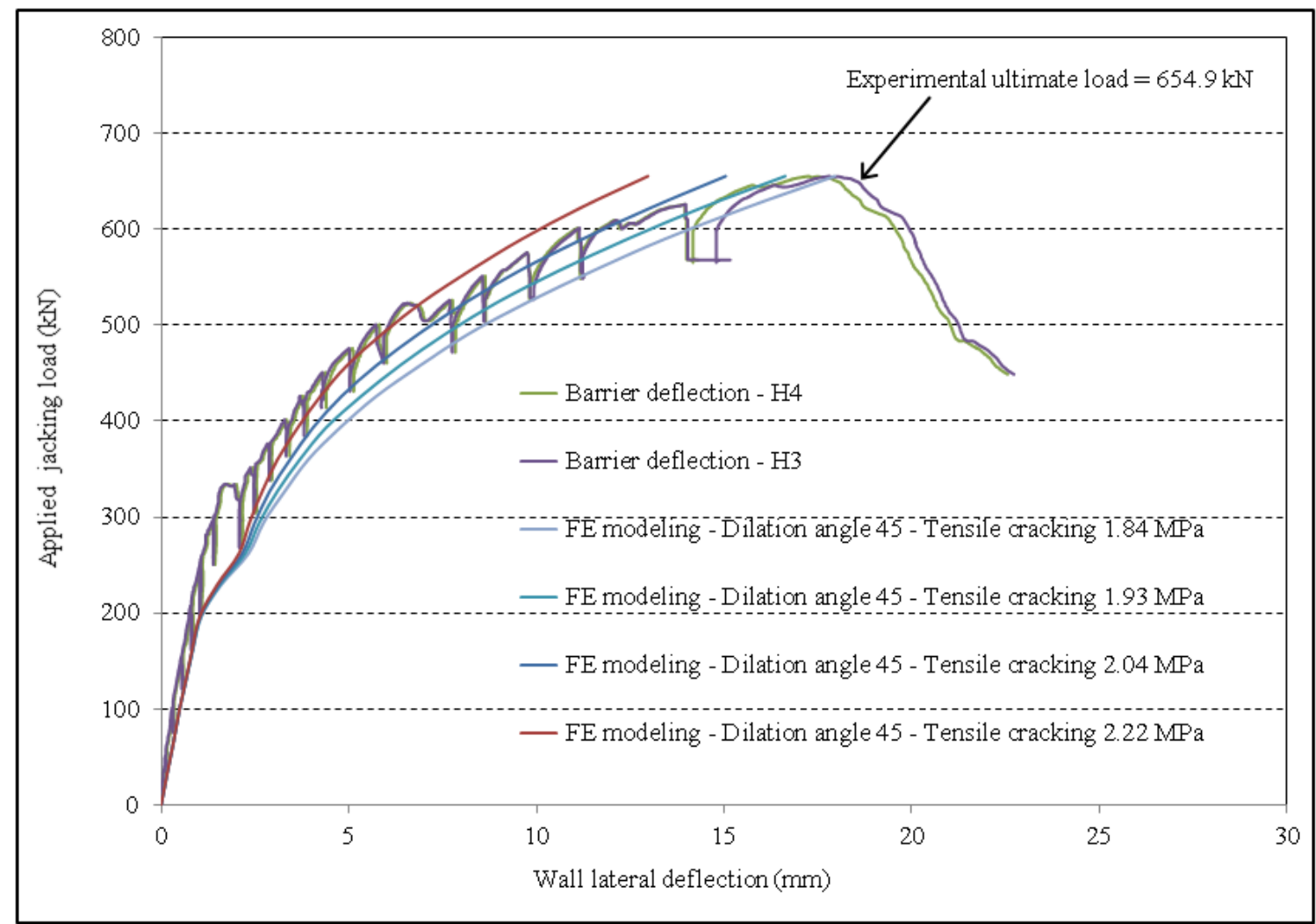

Figure 7. 23 Influence of concrete tensile cracking on the barrier response

\subsubsection{Influence of Dilation Angle}

The effect of change in dilation angle on post-cracking behavior of the TTI barrier model at interior location was investigated. Dilation angles of $25^{\circ}, 30^{\circ}, 35^{\circ}, 40^{\circ}, 45^{\circ}$ and $50^{\circ}$ were selected and defined in the concrete damaged plasticity model in ABAQUS. Based on the values of dilation angle, load-displacement response of the barrier model was obtained and compared with the experimental results. Figure 7.24 shows the influence of dilation angle change on loaddisplacement response of the barrier model. It can be noticed from the graphs that as the dilation angle increases, the post-cracking response of the barrier shows a ductile behavior similar to the experimental test results. However, excessive increase of the dilation angle results in a stiffer response and the overall deformation of the barrier model decreases. Based on the values of dilation angles generated, an angle of 45 degree represented the best response of the barrier model compared to the experiment results. It can also be noted that prior to cracking, dilation angle does not change the barrier response due to the intact material response of concrete. However, upon cracking of concrete, the increase in dilation angle changes the material response 
due to the increase in concrete frictional resistance, thus, a stiffer response of the barrier is developed.

Once the barrier model is calibrated in terms of concrete tensile cracking strength and dilation angle, the FE results were compared with the experimental observations. In order to verify the accuracy of the model, the experimental failure load was applied transversely to the barrier as a pressure load and over an area of 1200x200 mm. It should be mentioned that due to symmetry of the model, only half of the experimental failure load was applied to the barrier. Figure 7.25 shows view of the barrier lateral deformation under the applied pressure load. It can be noticed a maximum barrier deformation of $21.39 \mathrm{~mm}$ at the corner tip of the barrier wall. This deformation occurred at the top of the barrier wall. However, at location of the applied pressure load, within the centroid of the loading area, lateral deflection of wall was $17.94 \mathrm{~mm}$ which is very close to the experimental observation.

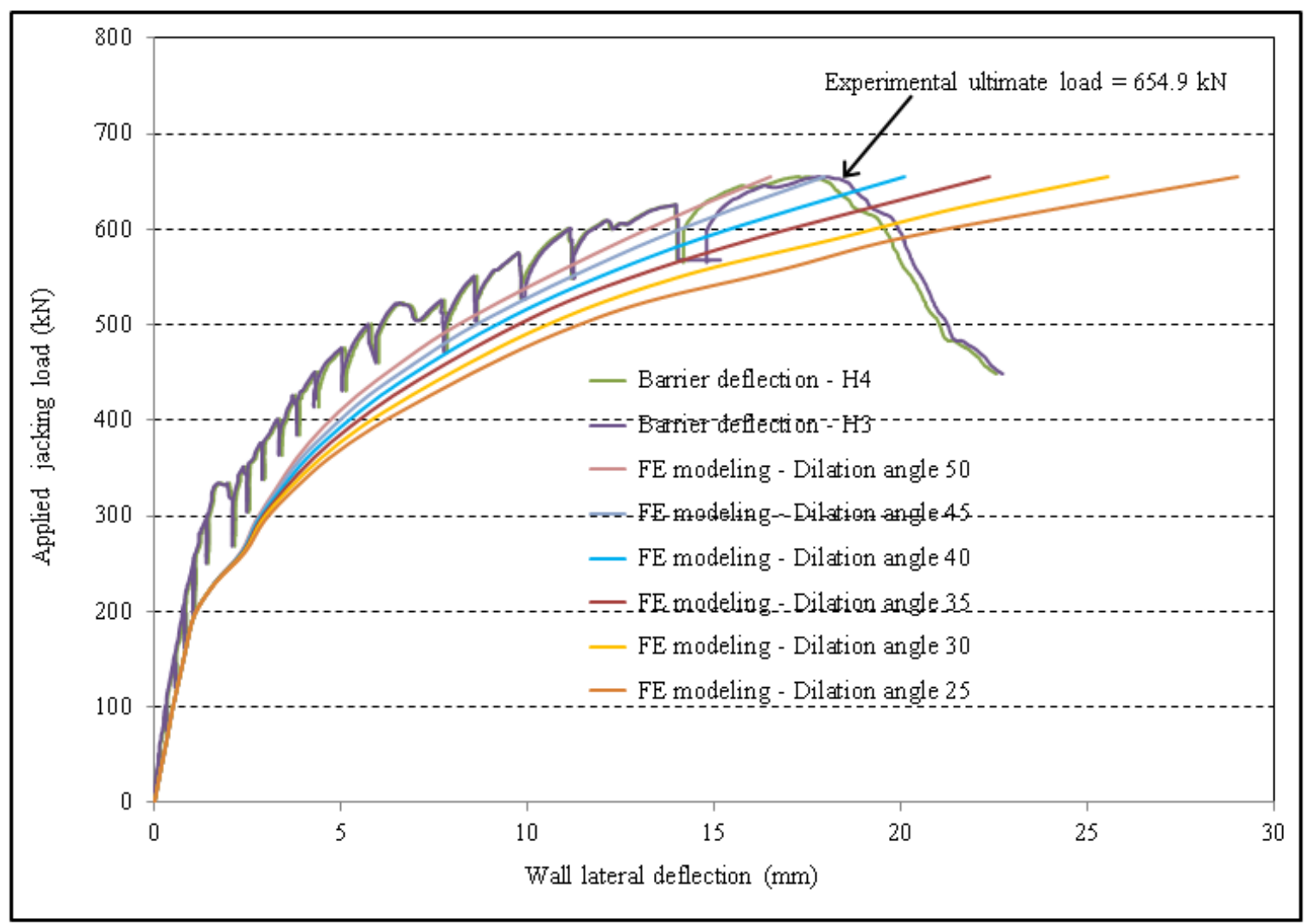

Figure 7. 24 Influence of dilation angle on the barrier response at TTI interior location 


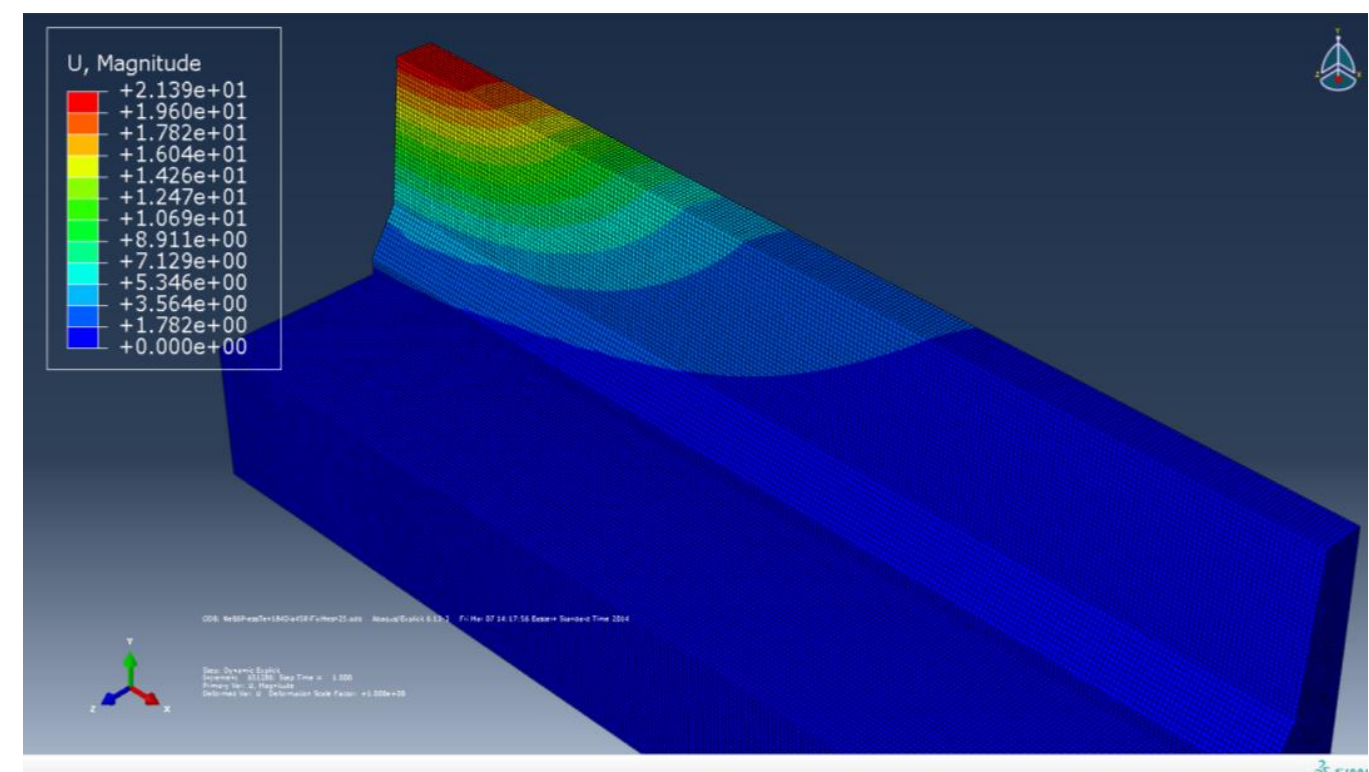

Figure 7. 25 Lateral deformation of the TTI barrier model at interior location (half barrier length is shown)

It can also be observed that the barrier model experienced lateral deformation within approximately $2.5 \mathrm{~m}$ of the wall from the loading area, but the deformation at right-end of the wall is zero meaning that the barrier longitudinal length greater than this length (6 m modeled) will not affect the results. As such, as shown in Figure 7.10, the wall at right-end was assumed as fixed.

The strains in reinforcing steel bars in the deck slab as well as the GFRP bars in the barrier wall were examined to ensure that they were less than the yielding strain of 0.002 and rupture strain of 0.0189 , respectively. Figure 7.26 shows strain values of the reinforcing bars in the barrier model at interior location. The FE model shows a maximum strain of 0.001428 in the deck slab, which is less than the yielding strain of the reinforcing steel bars. As such, the steel bars in the deck slab did not yield. Also, the reinforcing GFRP bars in the barrier wall experienced a maximum strain of 0.00428 , which is significantly less than the rupture strain of 0.0189 . Therefore, it can be concluded that the barrier wall did not fail by bond and the assumption of full bond interaction between reinforcing bars and the concrete was correct. This assumption was also confirmed in the experimental observations as no bond or anchorage failures occurred during the testing. The barrier model was also checked against concrete crushing failure at back 
face of the wall. Due to the applied transverse load, maximum compressive strains were obtained from the model that is shown in Figure 7.27. It can be observed that the barrier model experienced a maximum compressive strain of -0.00006267 at lower back face of the wall. This compressive strain was found to be significantly less than the concrete compressive strain of 0.002 at peak failure stress. As such, the barrier model did not fail by concrete crushing, which was also observed similarly in the actual experimental testing of the barrier at interior location.

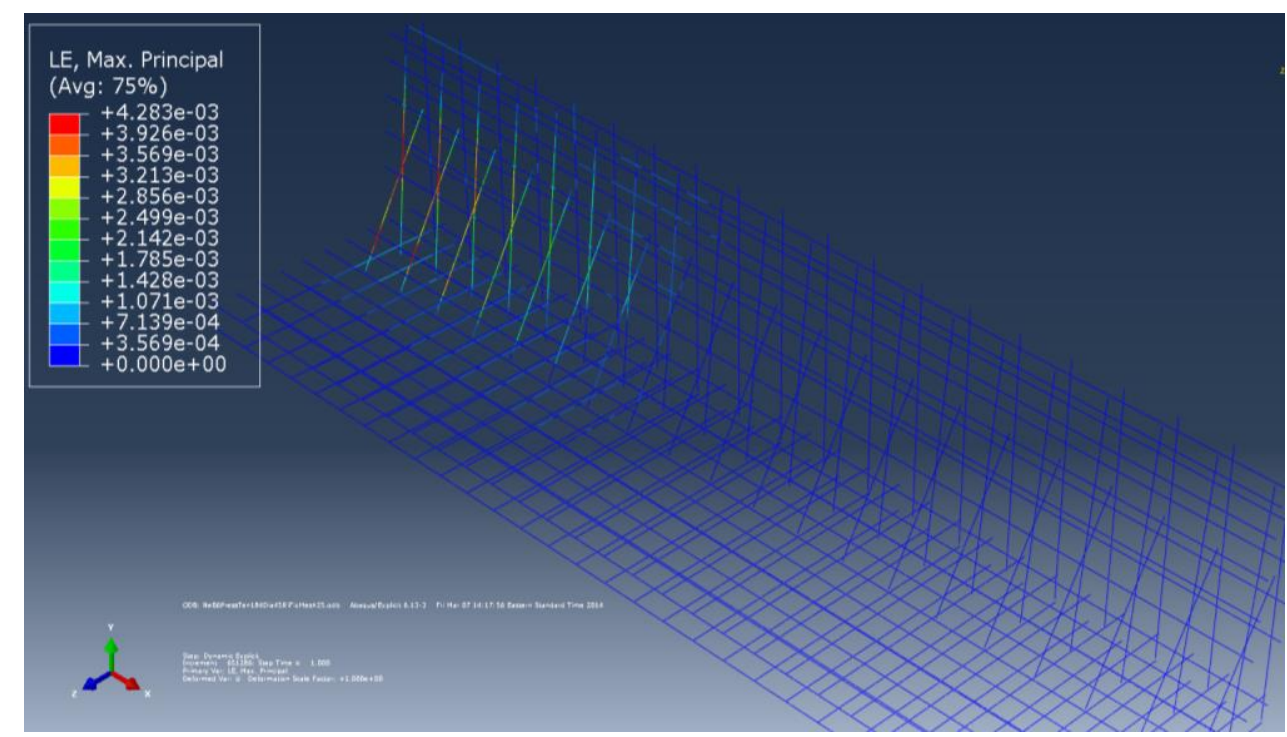

Figure 7. 26 Maximum principal strains in reinforcing bars at interior location (half barrier legth is shown)

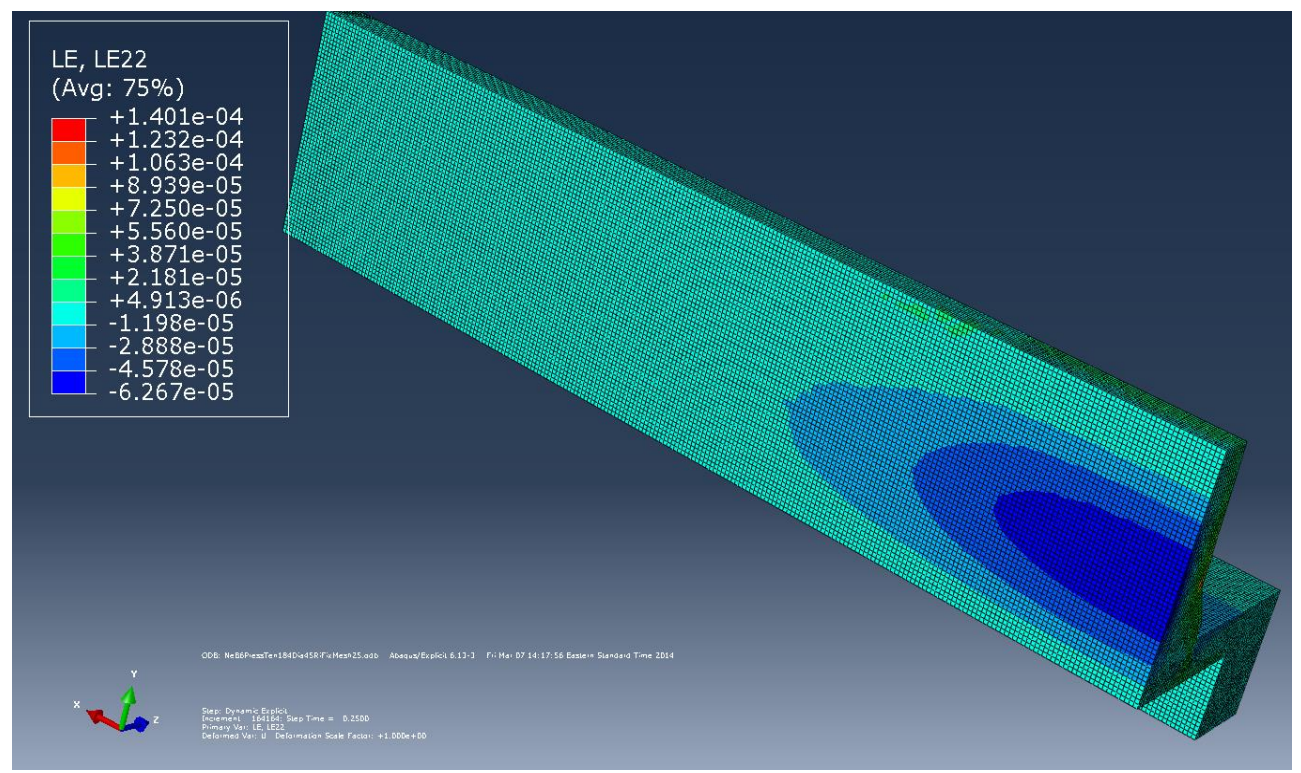

Figure 7.27 Concrete compressive strains at back of the barrier model at interior location 


\subsubsection{Crack Patterns}

The barrier model at interior location was compared with the experimental tested barrier in terms of crack propagations. Figure 7.28 compares the overall failure of the barrier model by VonMises failure criterion that is compared to the experimental results. The FE model shows only half of the barrier model due to symmetry of the barrier. Similar trend of failure in both the FE model and the experiment was observed. The experimental test results showed development of horizontal flexural cracks followed by diagonal shear cracks at barrier front face, which are extended to the top of the wall and through the wall thickness by punching shear cracks (Figure 7.28a). In the barrier model, the horizontal flexural cracks, diagonal shear cracks and the punching shear cracks are shown in Figure 7.29 in terms of cracking strains and stresses. It should be noted that for the TTI barrier with calibrated tensile cracking strength of $1.84 \mathrm{MPa}$, a cracking strain limit of 0.0000736 was obtained. The crack patterns of the barrier model were compared to these limiting values as the initiation of cracks in the barrier wall. From FE modeling, it can be observed that the barrier model experienced horizontal flexural crack mapping within the loaded length of the barrier at barrier front face similar to the experimental observations. These cracks appeared at deck-wall interface as well as above the tapered portion of the wall (Figure 7.29a). The FE model represented a good indication of induced cracks at the barrier front face due to flexure. As the load continued to increase, diagonal shear cracks appeared in the wall as shown in Figure 7.29b. The diagonal shear crack mapping cannot be clearly shown due to the fact the diagonal shear of elements on which the maximum shearing stresses act lies in the direction of the larger principal stress. By further load increase, similar to the experimental testing, punching shear cracks appeared on the top of the wall and through the wall thickness, which can be seen in Figure 7.29c.

The punching shear crack at failure load further developed at back face of the wall tending to punch out the barrier under the applied load. Figure 7.30 compares failure pattern at back face of the barrier wall with the FE modeling. It can be observed a high stress concentration causing shear failure of the model as was expected in the experimental test results. 


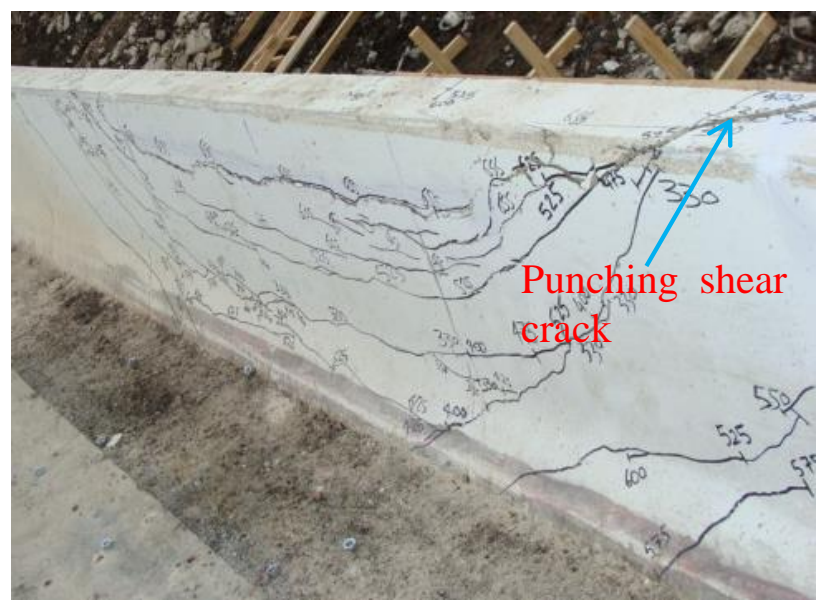

(a) experimental failure pattern

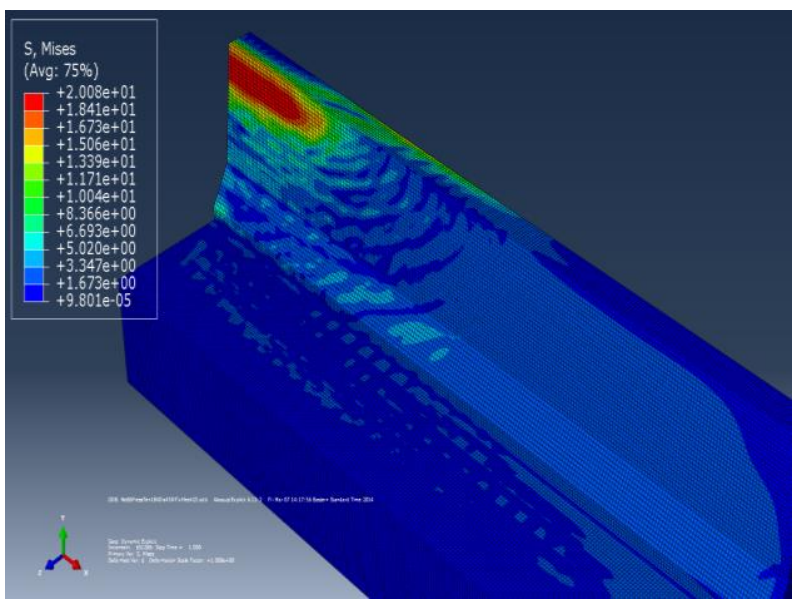

(b) FE failure pattern (half barrier length)

Figure 7. 28 Barrier overall failure criterion compared with the experiment at interior location
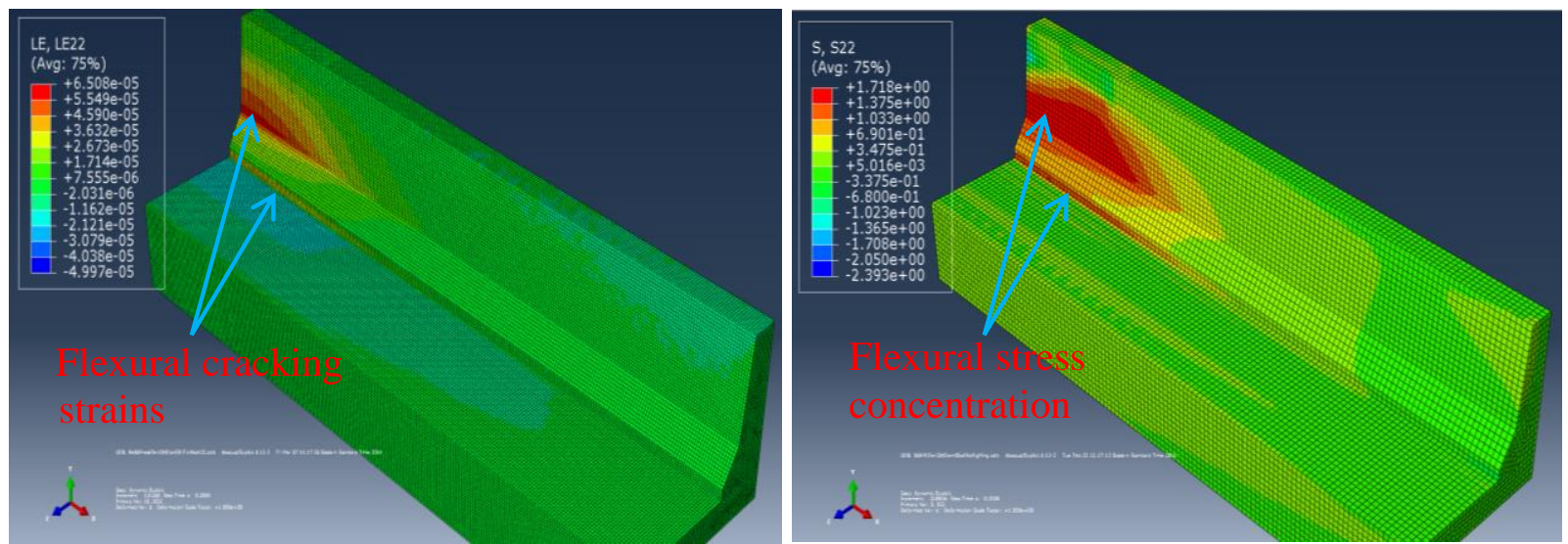

(a) Flexural crack mapping in the wall
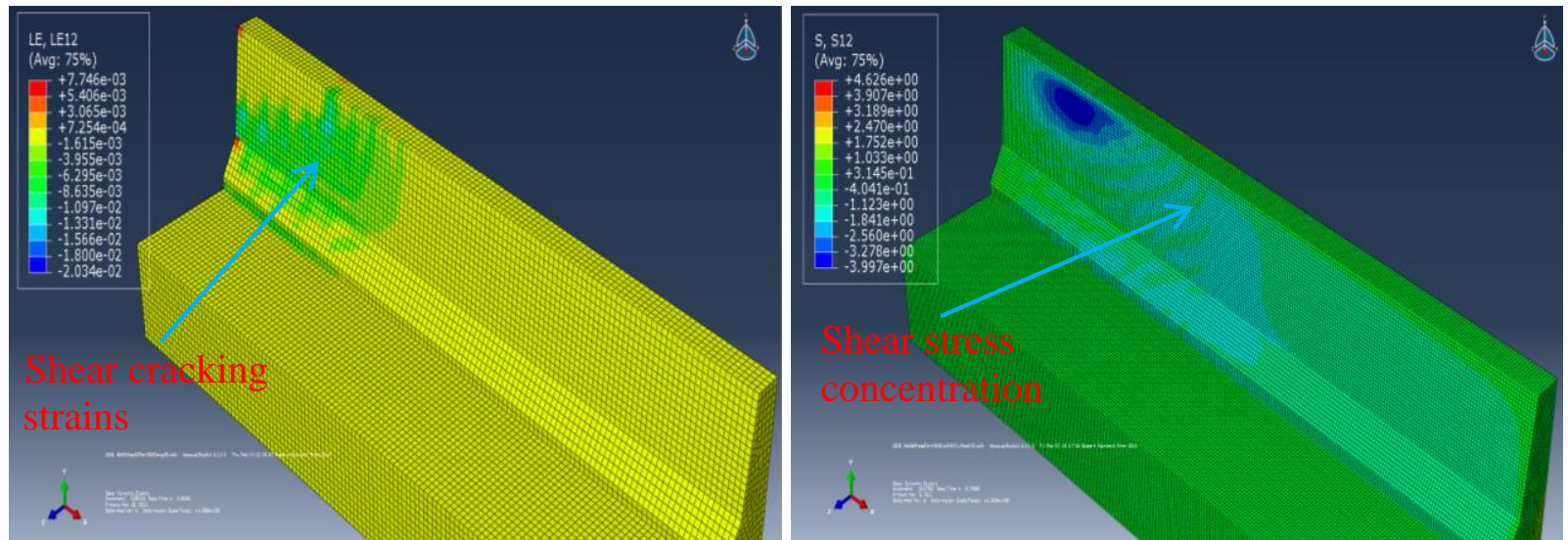

(b) Diagonal shear cracks in the wall 

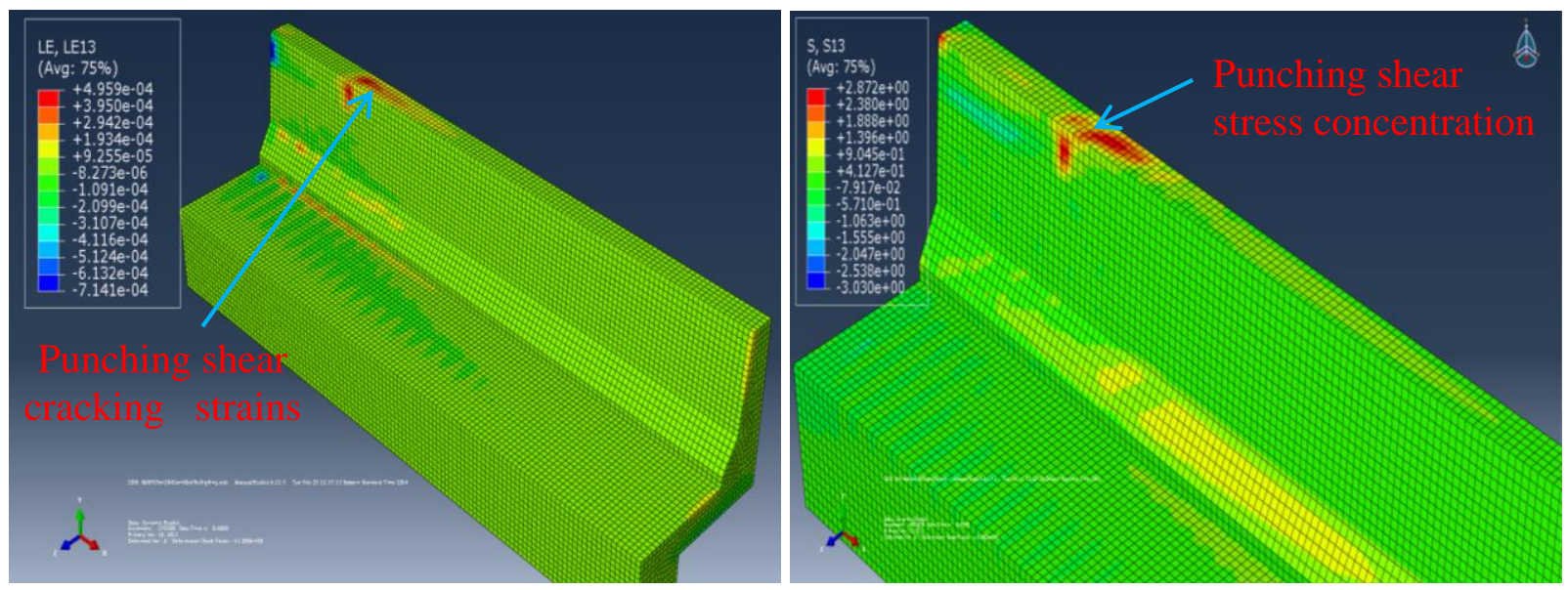

(c) Punching shear crack through the wall thickness

Figure 7. 29 Flexural, diagonal and punching shear crack mappings of the barrier model at interior location (half barrier length is shown)

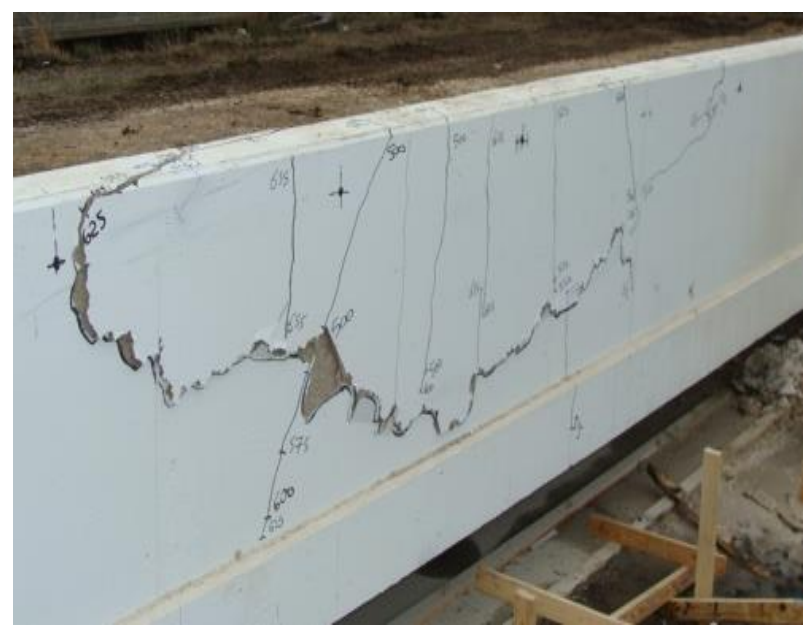

(a) experimental crack pattern

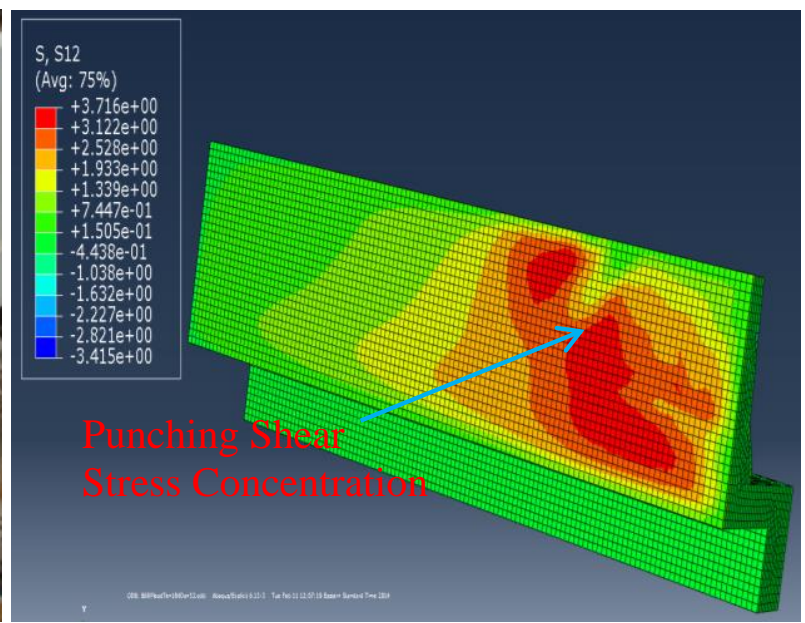

(b) shear stress contours (half barrier length)

Figure 7. 30 Punching shear failure pattern of the barrier wall at back face

From ABAQUS software, the concrete damage surface was obtained by defining the tensile cracking and compressive crushing strain ranges. Figure 7.31 illustrates views of the induced cracked surfaces on the front and back faces of the barrier model. The grayed surface shown in the model defines the cracked surface area of the barrier model. The area outside this range is deemed not to crack under the applied transverse patch load. 


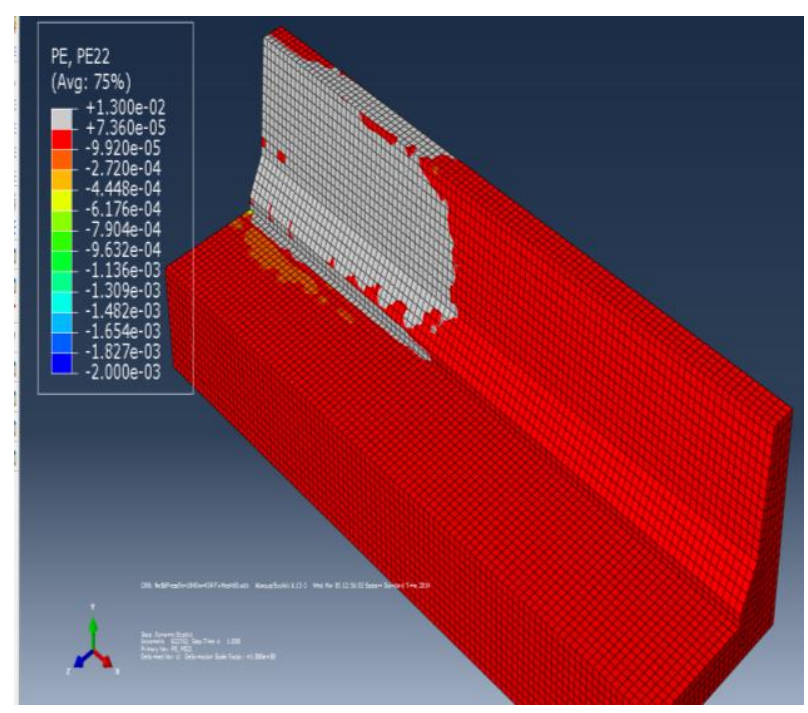

(a) Flexural cracked surface in the wall

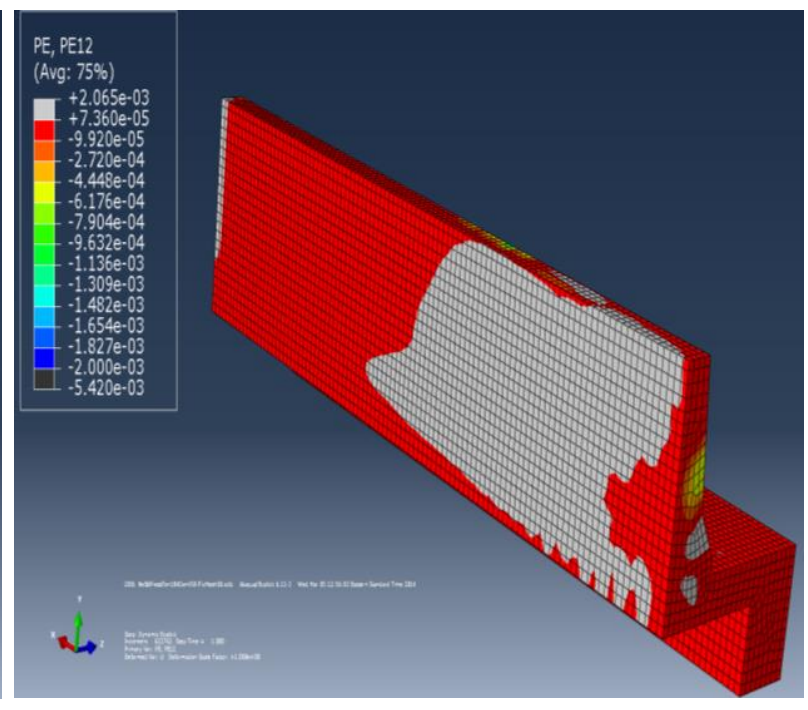

(b) Shear cracked surface at face of the wall

Figure 7. 31 Induced cracked surface in the barrier model at interior location

\subsubsection{FE Mesh Refinement}

Mesh refinement was also carried out on the TTI barrier model at interior location to examine the accuracy of the model with actual barrier testing. For the barrier model, mesh element sizes of 25, 40, 50, 60 and $70 \mathrm{~mm}$ were used in ABAQUS. The number of elements and the maximum Von-Mises stresses were determined for each mesh element size. Figure 7.32 shows plot of stress versus the number of elements for the barrier model at interior location. Comparing the mesh element sizes showes that as the mesh size reduces or the number of element increases, the maximum Von-Mises stresses becomes flat line indicating the accuracy of the model with the actual solutions. For each mesh element size, the graph of load-displacement response of the barrier model was obtained, which is compared to the experimental test results as shown in Figure 7.33. The graphs clearly show that as the mesh size reduces the finite-element loaddisplacement response approaches the experimental curves. 


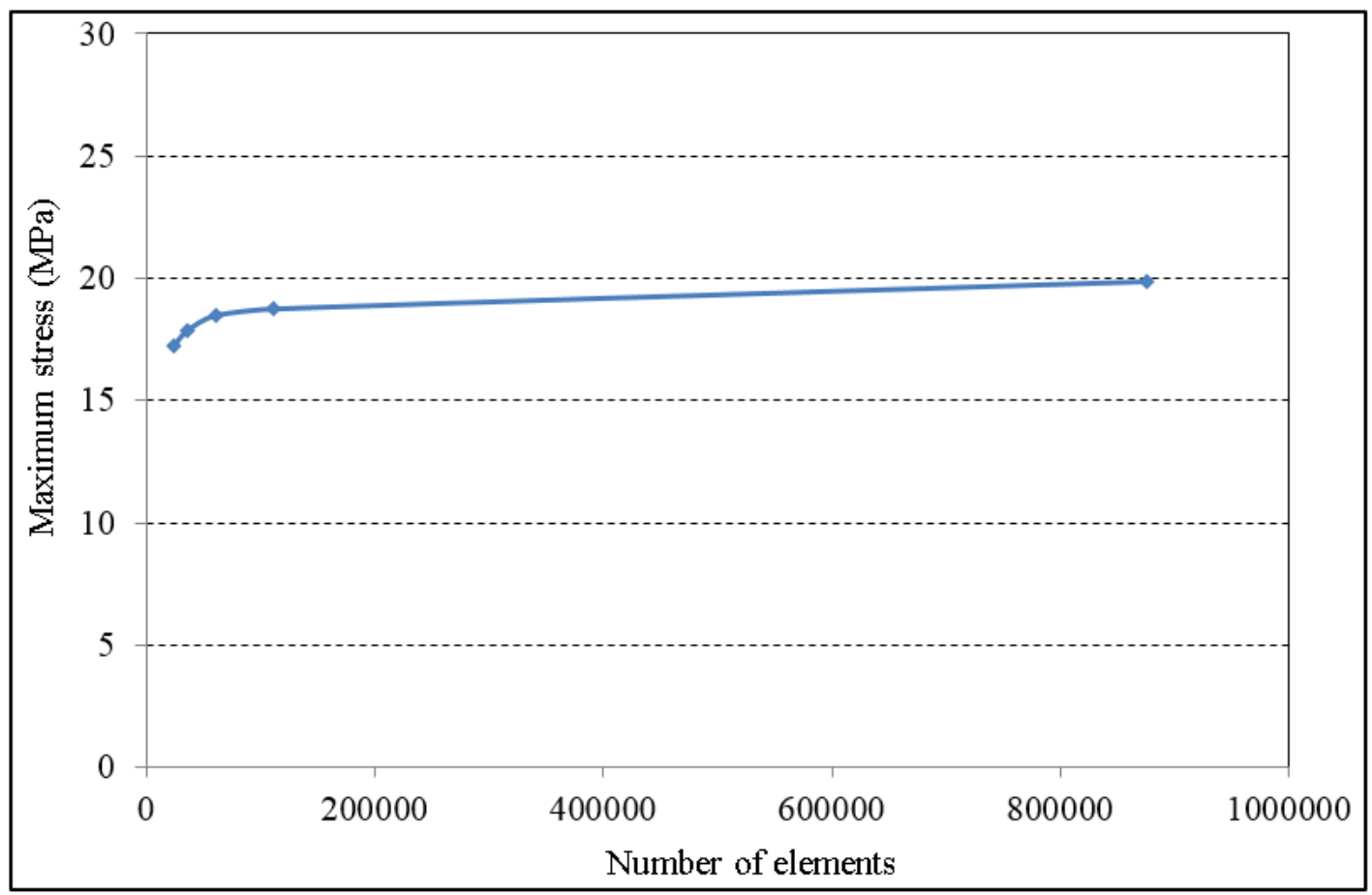

Figure 7. 32 Mesh refinement study on the TTI barrier at interior location

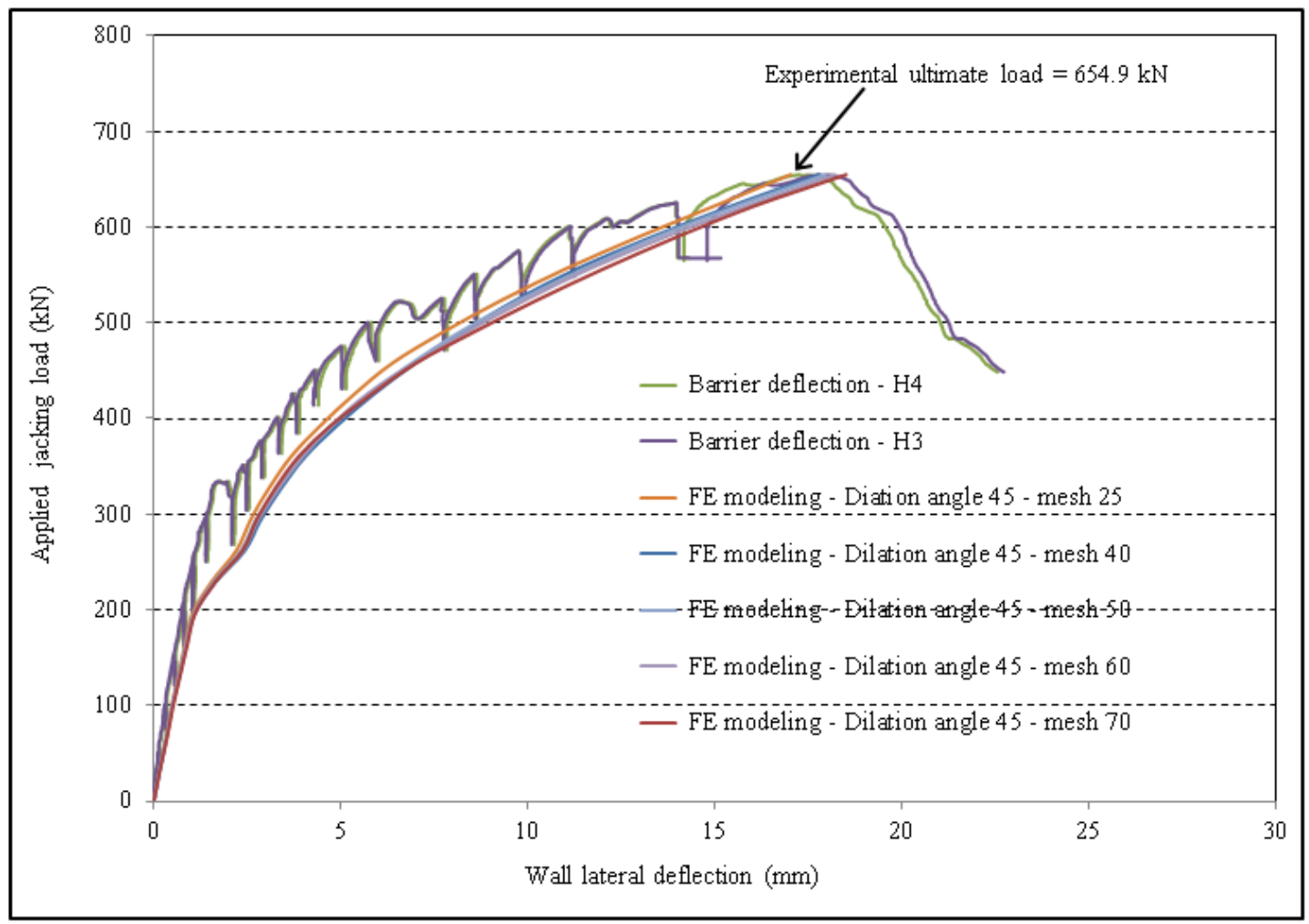

Figure 7. 33 Influence of mesh element size on the barrier response at interior location 


\subsubsection{Finite-Element Results of TTI Barrier at Exterior Location}

The accuracy of the finite-element modeling has also been verified at exterior location of the TTI barrier. The results from barrier Model 1 and TTI barrier at interior location were used and implemented in ABAQUS for this model. Similar to interior location, the barrier at exterior location was also examined with variable concrete tensile cracking strength and dilation angle for consistency with the barrier model at interior location and results are discussed below. In addition, crack patterns and mesh refinement were performed and verified with the experimental test results. As mentioned earlier, FE model at exterior location was first performed on a $6 \mathrm{~m}$ long barrier and a transverse pressure load equal to the experimental failure load was applied over $2400 \times 200 \mathrm{~mm}$ to the barrier. However, the results showed that the entire length of the barrier is affected by the applied transverse pressure load developing small amount of barrier deformation and stress distributions along the longitudinal length of the barrier. Therefore, the length of the barrier was increased to $12 \mathrm{~m}$, where the effects associated with lateral deformation and stress distribution became zero. Beyond this length, the barrier wall was not affect by the applied load, so the barrier was made fixed a right-end of the wall as was shown in Figure 7.11.

\subsubsection{Influence of Concrete Tensile Cracking Strength}

The influence of concrete tensile cracking strength at exterior location was examined and compared with the experimental results, to ensure consistency of the result with barrier at interior location. For the TTI barrier with concrete compressive strength of $30.9 \mathrm{MPa}$, the stress-cracking strains were measured and defined in ABAQUS. Similar to the interior location, tensile cracking strengths of 1.84, 1.93, 2.04 and 2.22 MPa were considered and plots of load-displacement responses of the models were compared to the experimental results as shown in Figure 7.34. Similar to the previously discussed barriers, the concrete cracking strength affected the postcracking behavior of barrier model. As the tensile cracking strength increased, a more ductile barrier response was observed, but the deformation response of the barrier model was reduced. Similar to barrier at interior location, the barrier with concrete tensile cracking strength of 1.84 MPa revealed similar deformation response as the experimental results but the inelastic response of the barrier showed an average difference of $8.95 \%$ which is deemed acceptable. Other concrete tensile cracking strengths showed smaller deformation response compared to the experimental results, while the differences in inelastic load-deformation response became less. 
The barrier with tensile cracking strength of $2.22 \mathrm{MPa}$ showed very stiff behavior compared to the experimental results, thus the results were disregarded.

\subsubsection{Influence of Dilation Angle}

The effect of dilation angle on non-linear behavior of the barrier at exterior location was investigated and compared with the experimental results. Dilation angles of $30^{\circ}, 35^{\circ}, 40^{\circ}, 43^{\circ}$, $45^{\circ}$ and $50^{\circ}$ were considered. For each dilation angle defined, the barrier load-displacement response were plotted and compared with the experiment results. Figure 7.35 illustrates the influence of dilation angle on the barrier overall response at exterior location. For a dilation angle of $30^{\circ}$, the barrier showed a very soft load-displacement response with increased deformation response compared to the experiment. As the dilation angle increased, the response became stiffer and the barrier deformation reduced. The dilation angles between $40^{\circ}$ and $50^{\circ}$ showed good approximation with the experimental results. As such, a dilation angle of $45^{\circ}$ was selected similar to the barrier at interior location.

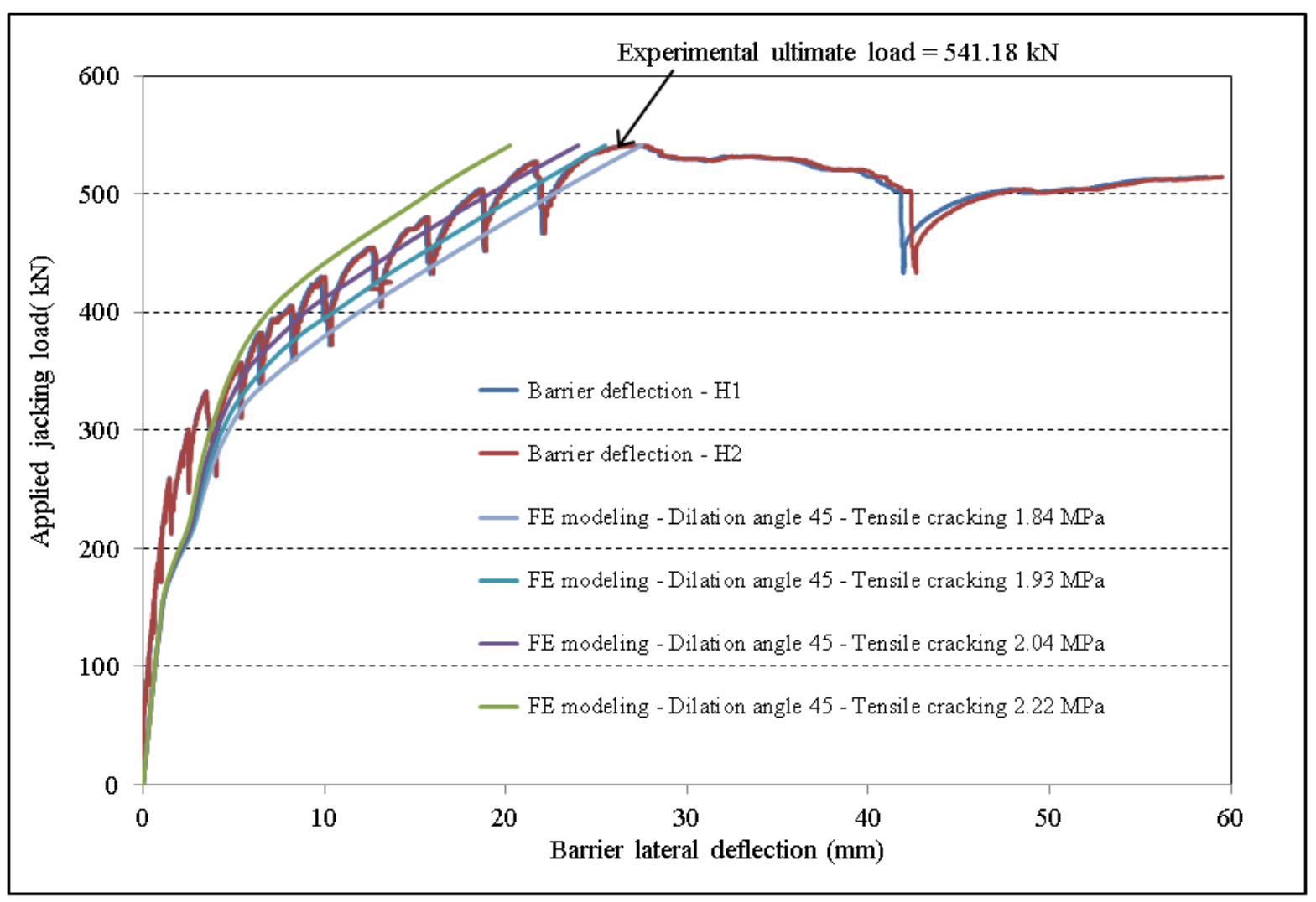

Figure 7. 34 Influence concrete cracking strength on the barrier model at exterior location 


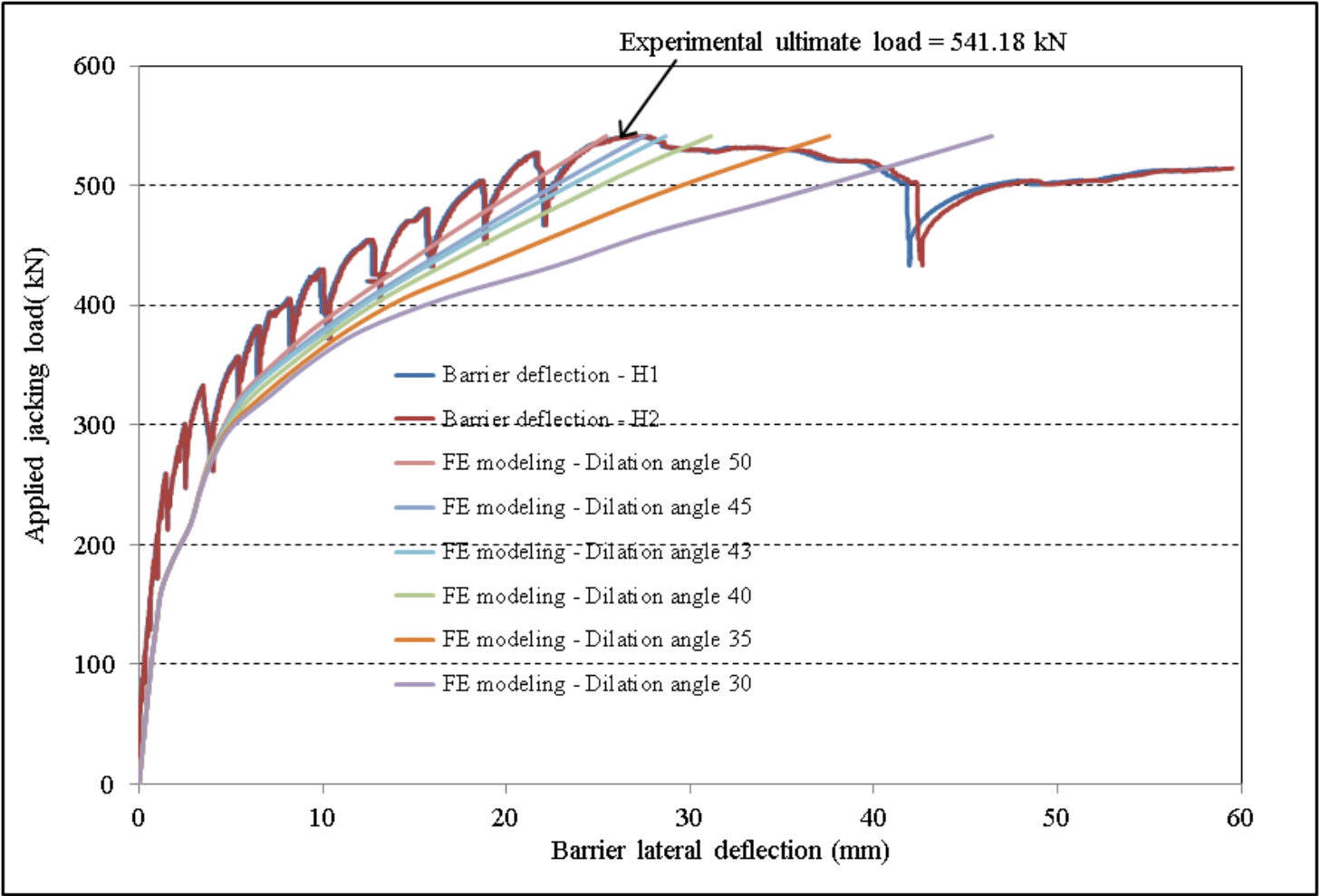

Figure 7. 35 Influence of dilation angle on the barrier response at exterior location

Once the barrier model was calibrated in terms of tensile cracking strength and dilation angle, it was compared to the experimental observation for the maximum wall lateral deflection and crack patterns. From experimental test results on TTI barrier at exterior location, a maximum wall lateral deflection of $26.67 \mathrm{~mm}$ was observed at a height of $990 \mathrm{~mm}$ above the deck slab that was discussed in Chapter 5. Figure 7.36 shows wall lateral deformation of the barrier model at exterior location. It can be observed that the wall experienced a maximum deflection at the tip of cantilever barrier equal to $32.32 \mathrm{~mm}$. This deformation magnitude represents the wall deformation at a height of $1140 \mathrm{~mm}$ above the deck slab. However, at a height of $990 \mathrm{~mm}$, the barrier model showed a maximum deflection of $28.32 \mathrm{~mm}$ which is very close to the experimental observation. 


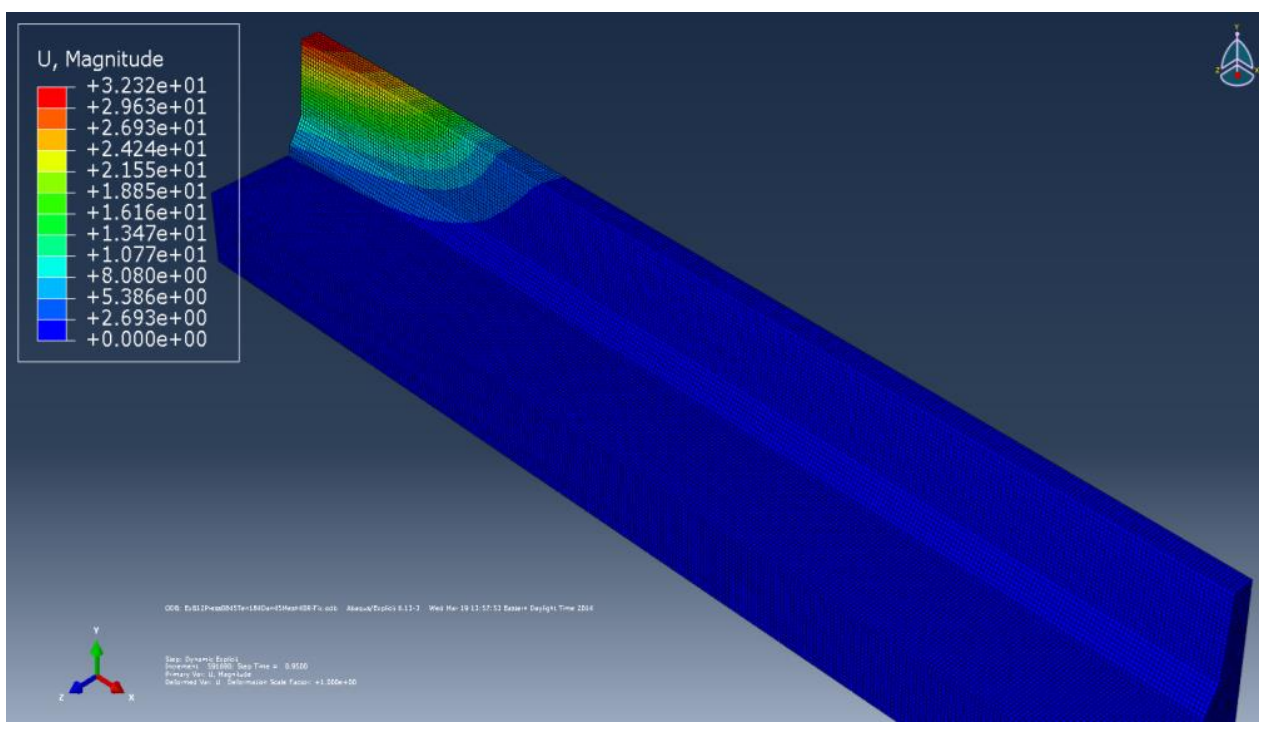

Figure 7. 36 Lateral deformation of barrier model at exterior location

The stresses and strains of the reinforcing bars in the deck slab and barrier wall were also examined to ensure the yielding of steel reinforcement or rupturing of the GFRP bars have not occurred. Figure 7.37 shows views of stresses and strains in the reinforcing bars of the barrier model at exterior location. it can be noticed that a maximum stress of $360.7 \mathrm{MPa}$ in the reinforcement that is below the ultimate tensile of strength of GFRP bars (1140 MPa) and the yield strength of steel reinforcement (400 MPa). Also, a maximum strain of 0.005762 was observed in the diagonal GFRP bars, which is significantly less than the rupturing strain of M15GFRP bars (0.0189). The maximum strain in deck reinforcement was observed equal to 0.00144 which was also less than the yield strain 0.002 for steel reinforcement. Thus, it can be assumed that the bond and anchorage failure did not occur in the barrier model at exterior location as was observed in the experimental test results.

At back face of the barrier wall at exterior location, the concrete compressive strains were also checked to ensure that the barrier did not fail by concrete crushing. Figure 7.38 shows view of concrete compressive strains at back face of the barrier wall. It can be observed a maximum compressive strain of -0.0000728 , which is significantly less than the strain corresponds to failure stress of -0.002 indicating that the concrete crushing did not occur. The finding was confirmed with experimental results that the barrier did not experiment concrete crushing failure. 


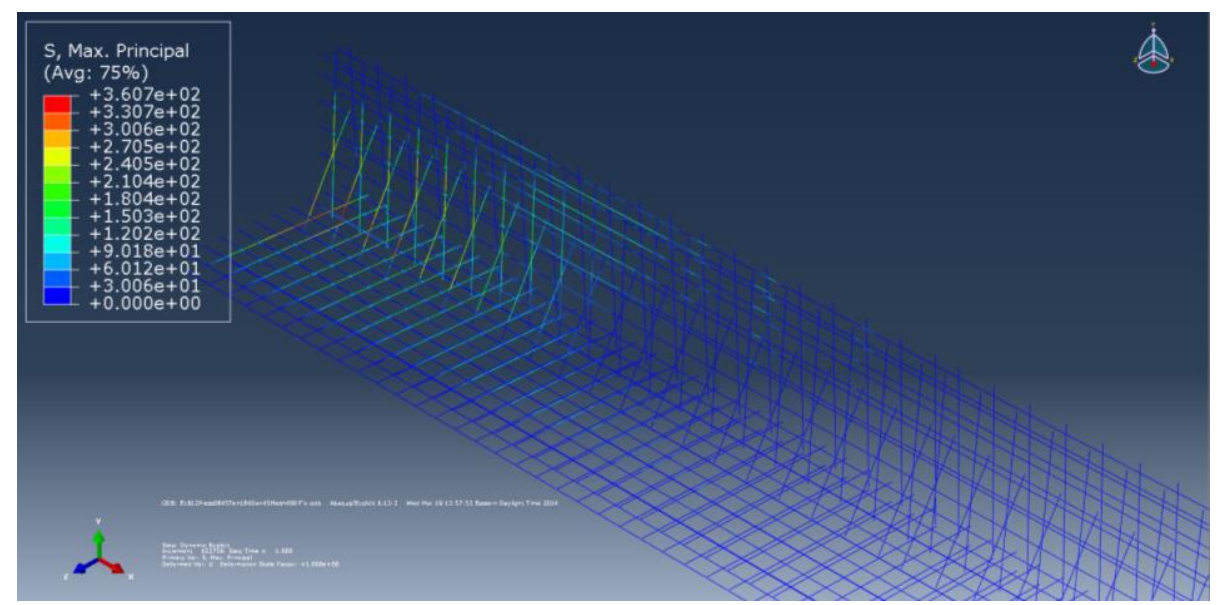

(a) Stress in reinforcing bars

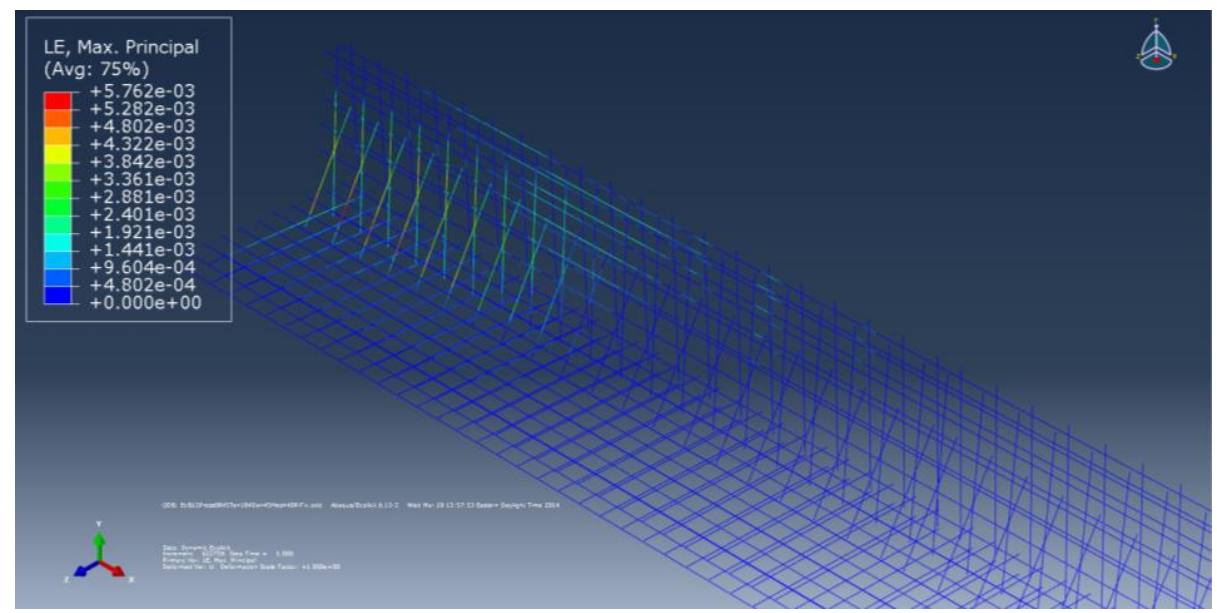

(b) Strain in reinforcing bars

Figure 7. 37 Stresses and strains in the reinforcement at exterior location of the barrier model

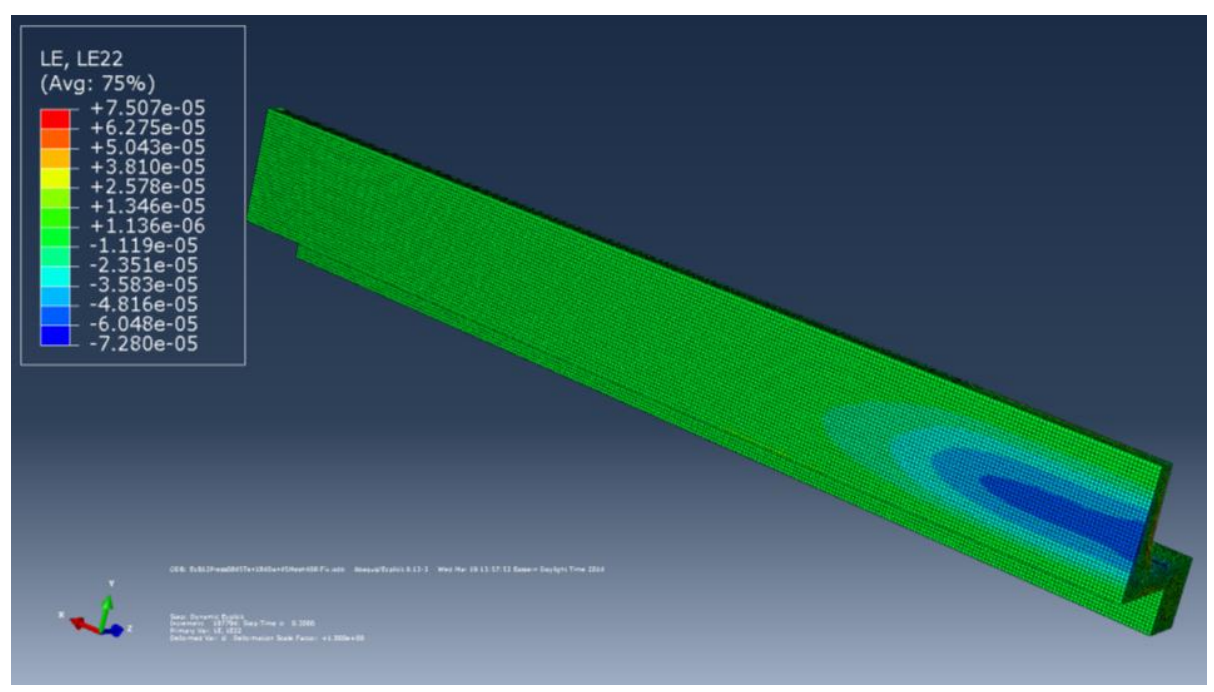

Figure 7. 38 Concrete compressive strains at back of the barrier model at exterior location 


\section{8.3.3 Crack Patterns}

The barrier model at exterior location was compared to the experimental test results in terms of crack patterns. Figure 7.39 shows view of the overall failure pattern of the barrier model by VonMises failure criterion which is compared to the experimental results. The overall failure patterns were the same showing horizontal and shear crack mapping similar to those observed in the experiment testing. Experimental test results at exterior location showed that the barrier developed horizontal flexural cracks within the loaded length of the wall followed by the diagonal shear cracks outside the loaded length toward the interior region of the barrier. With increase in the applied load, punching shear crack observed on the top of the wall and through the wall thickness (see Figure 7.39a). Figure 7.40 shows crack mapping of the barrier wall by developing the stress and strain concentrations at the damaged locations. In the barrier model at front face, the wall experienced horizontal flexural cracks within the loaded region at deck-wall interface as well as above the tapered portion of the wall. These flexural cracks are shown in Figure 7.40a by stress or strain crack mappings. The FE model showed a good indication of induced cracks due to the barrier flexural behavior. Similar to the barrier at interior location, it is presumed that the induced cracks appear at cracking strength of $1.84 \mathrm{MPa}$ corresponding to the cracking strain limit of 0.0000736 . In addition, diagonal shear cracks were observed in the barrier model as the load steps continued to increase (Figre 7.40b). Similar to experimental observation, these diagonal shear cracks appeared outside the loaded region of the barrier wall and extended diagonally to the top of the barrier wall. As load increased nearly to the failure load, punching shear crack was observed at the top of the wall through the barrier wall thickness as shown in Figure 7.40c.

At failure load, the punching shear crack extended to back face of the barrier wall by developing stress concentration shown in Figure 7.41 due to the applied transverse pressure load. The stress concentration indicates the region of the barrier affected by the punching shear failure. However, the experimental test results at exterior location developed torsional-shear cracks at back face of the wall, which are not shown in the FE modeling. At barrier exterior corner, the experimental test results showed that crack extended into the corner joint at deck-wall interface as well as through the wall thickness at tapered portion of the barrier wall as shown in Figure 7.42. The FE model at exterior location also showed stress concentrations at these locations indicating 
progress of shear and flexural cracks at the corner joints. Based on numerical model generated herein on the selected barrier models, it can be clearly concluded that the FE modeling can approximately predict the damage location by formation of crack mapping in terms of stress and strain concentrations. Therefore, the finite-element method can be employed to identify damage location and overall failure pattern of the barrier model. In addition, the overall structural performance such as load-deformation curves can be obtained from the finite-element analysis by defining proper material behavior and mesh element size.

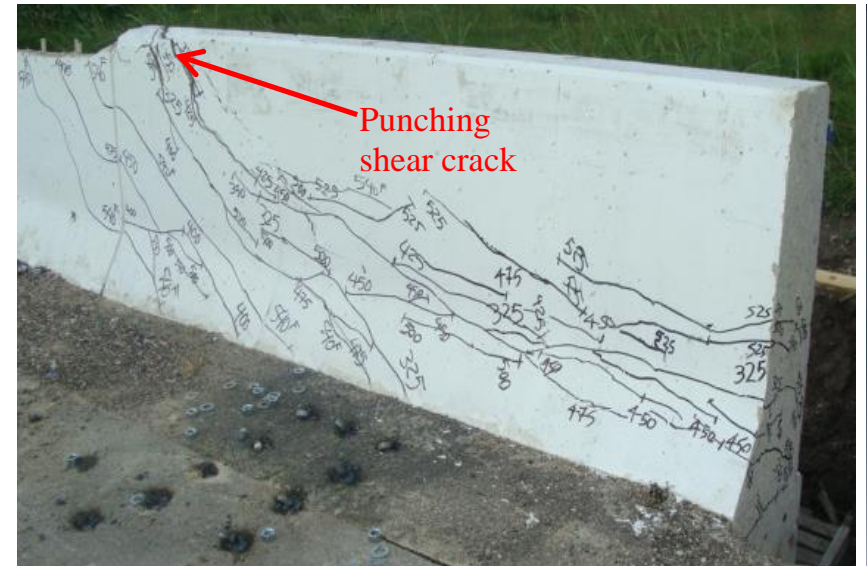

(a) experimental failure pattern

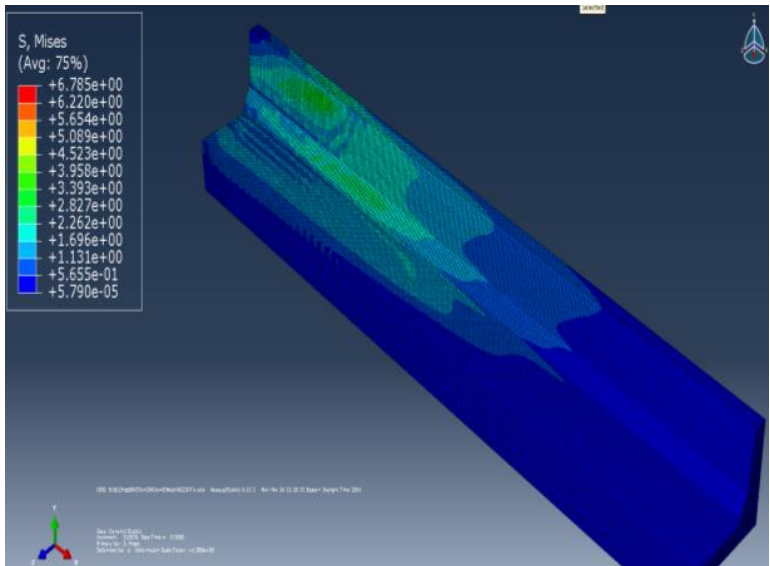

(b) FE failure pattern

Figure 7.39 FE barrier overall failure mode compared with the experiment at exterior location
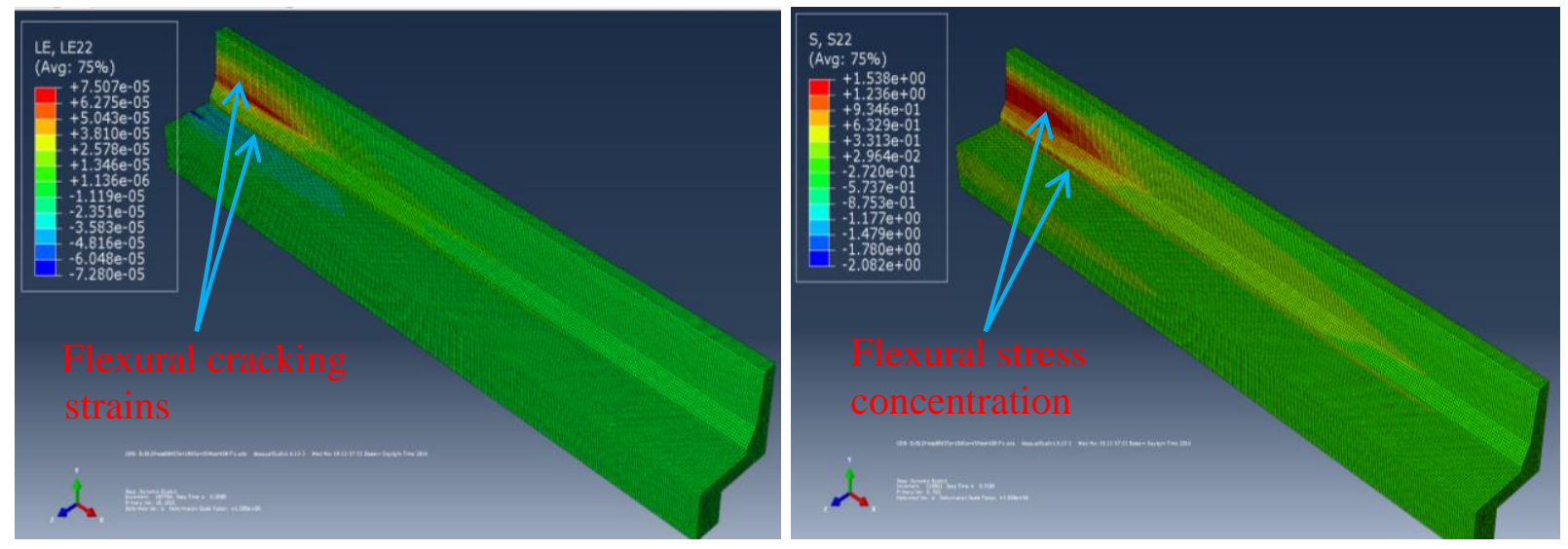

(a) Flexural crack mapping in the wall 


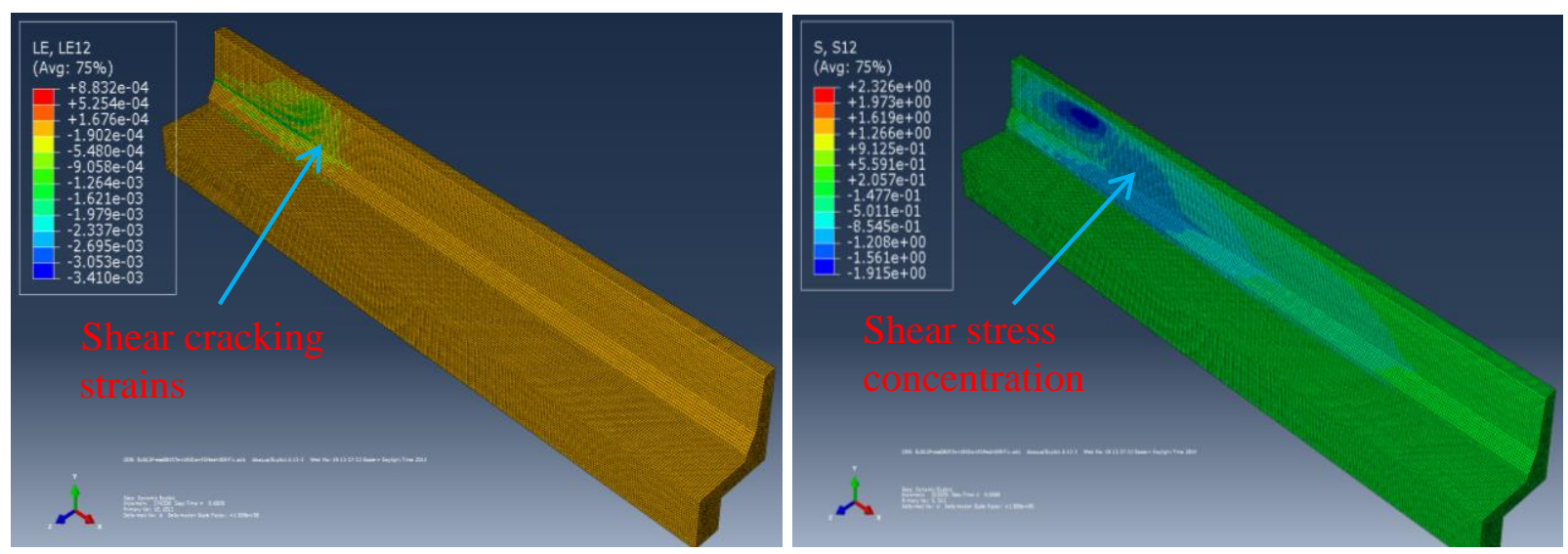

(b) Diagonal shear cracks in the wall
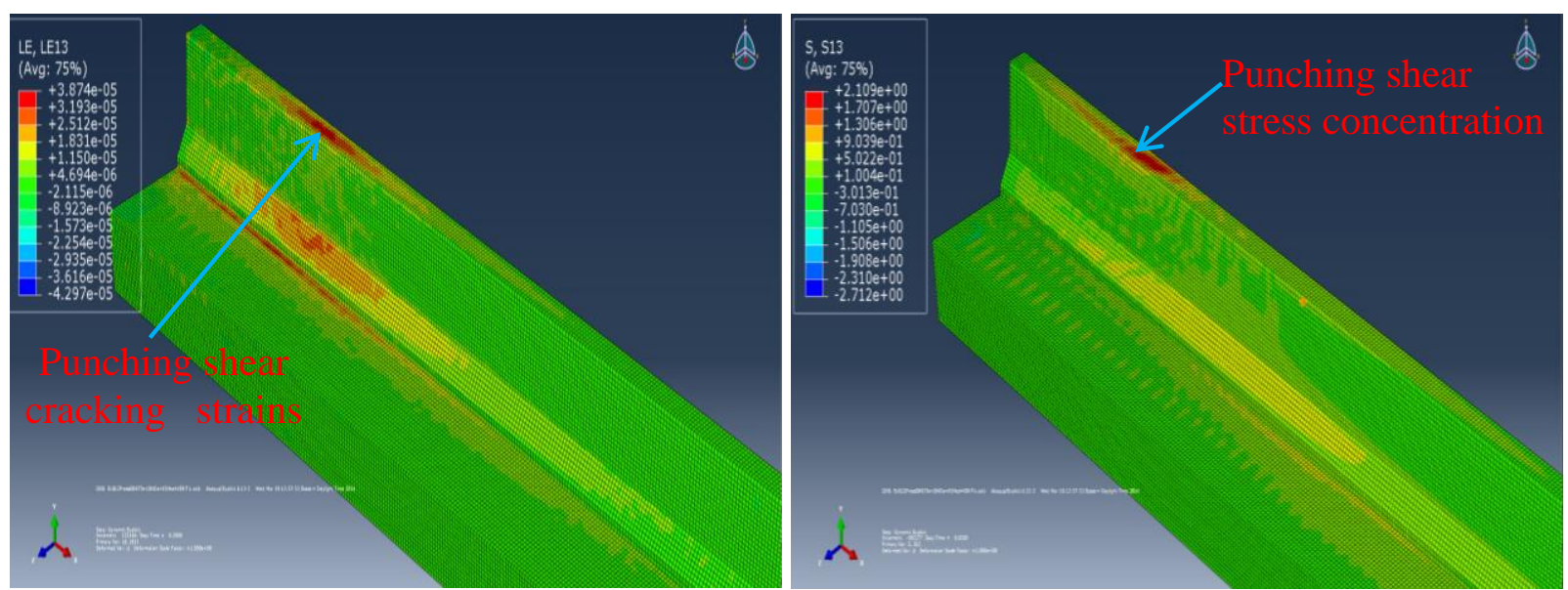

(c) Punching shear crack through the wall thickness

Figure 7. 40 Flexural, diagonal and punching shear crack mappings of the barrier model at exterior location
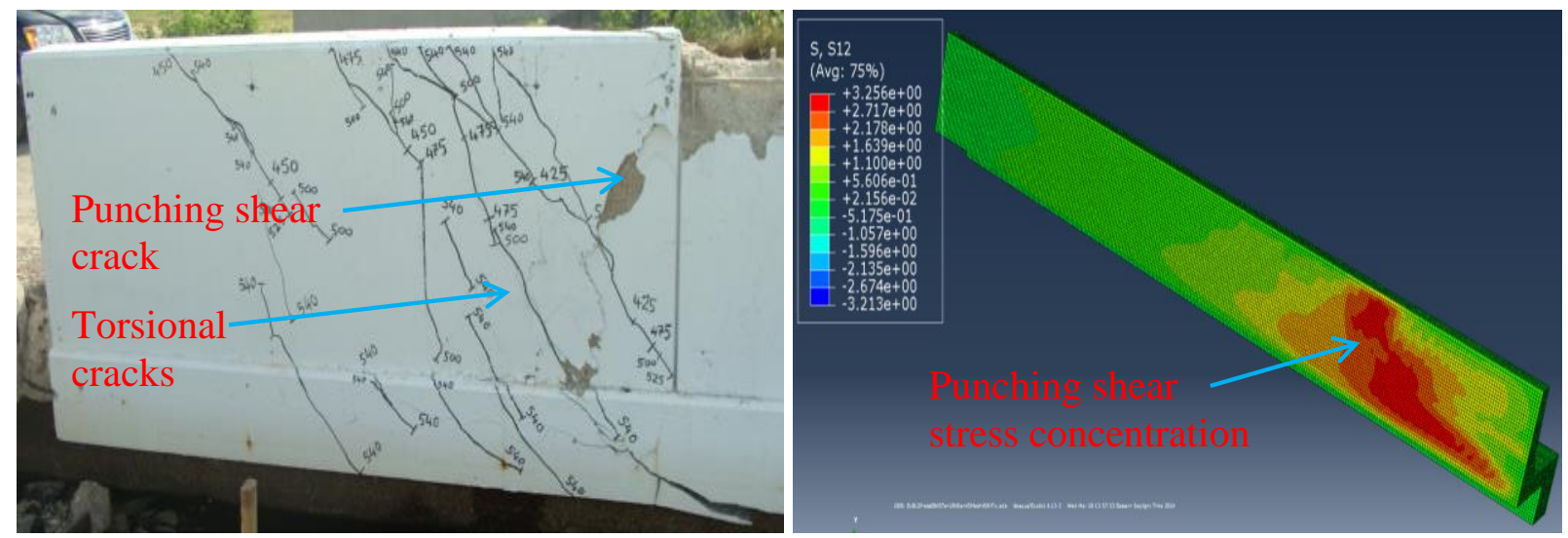

Figure 7. 41 Punching shear failure pattern of the barrier at back face 

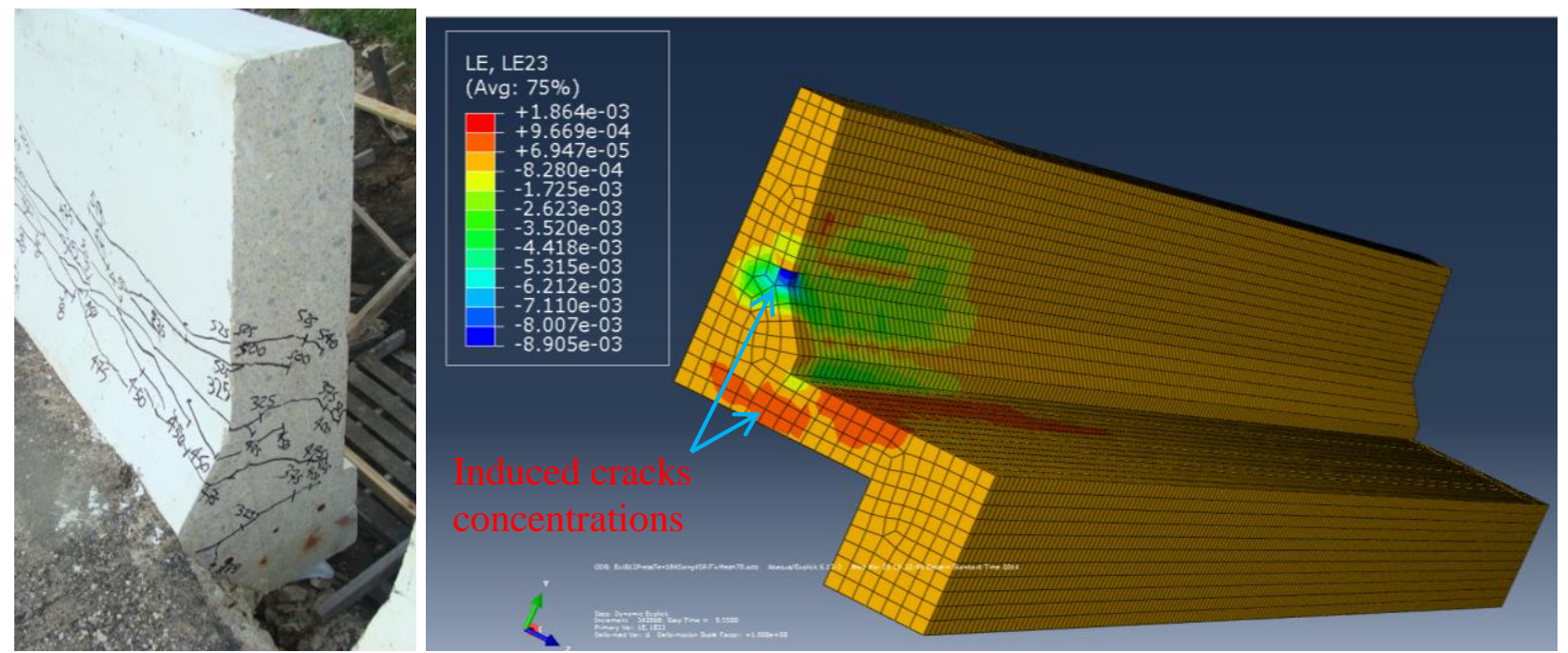

Figure 7. 42 Crack pattern at corner joint of the exterior location of the barrier model

\subsubsection{FE Mesh Refinement}

Mesh refinement was performed on the TTI barrier model at exterior location. Mesh element sizes of 40, 50, 60, 70 and $80 \mathrm{~mm}$ were selected and defined in ABAQUS. For each mesh size, the maximum number of elements and Von-Mises stresses was obtained from ABAQUS. Figure 7.43 shows a graph of stress as a function of number of elements. For large mesh size or small number of elements, there is a large difference between the FE modeling and exact solutions. However, as the number of elements increase, the trend become close to flat line indicating the accuracy of the FE modeling. In addition, for each mesh size, the plot of load-displacement was obtained from ABAQUS and compared with the experimental test results. Figure 7.44 shows the influence of mesh element size on the load-displacement response of the barrier wall at exterior location. It can be clearly observed that as the mesh size decreases the load-displacement response approaches the experimental test results and the accuracy of the FE modeling increases. 


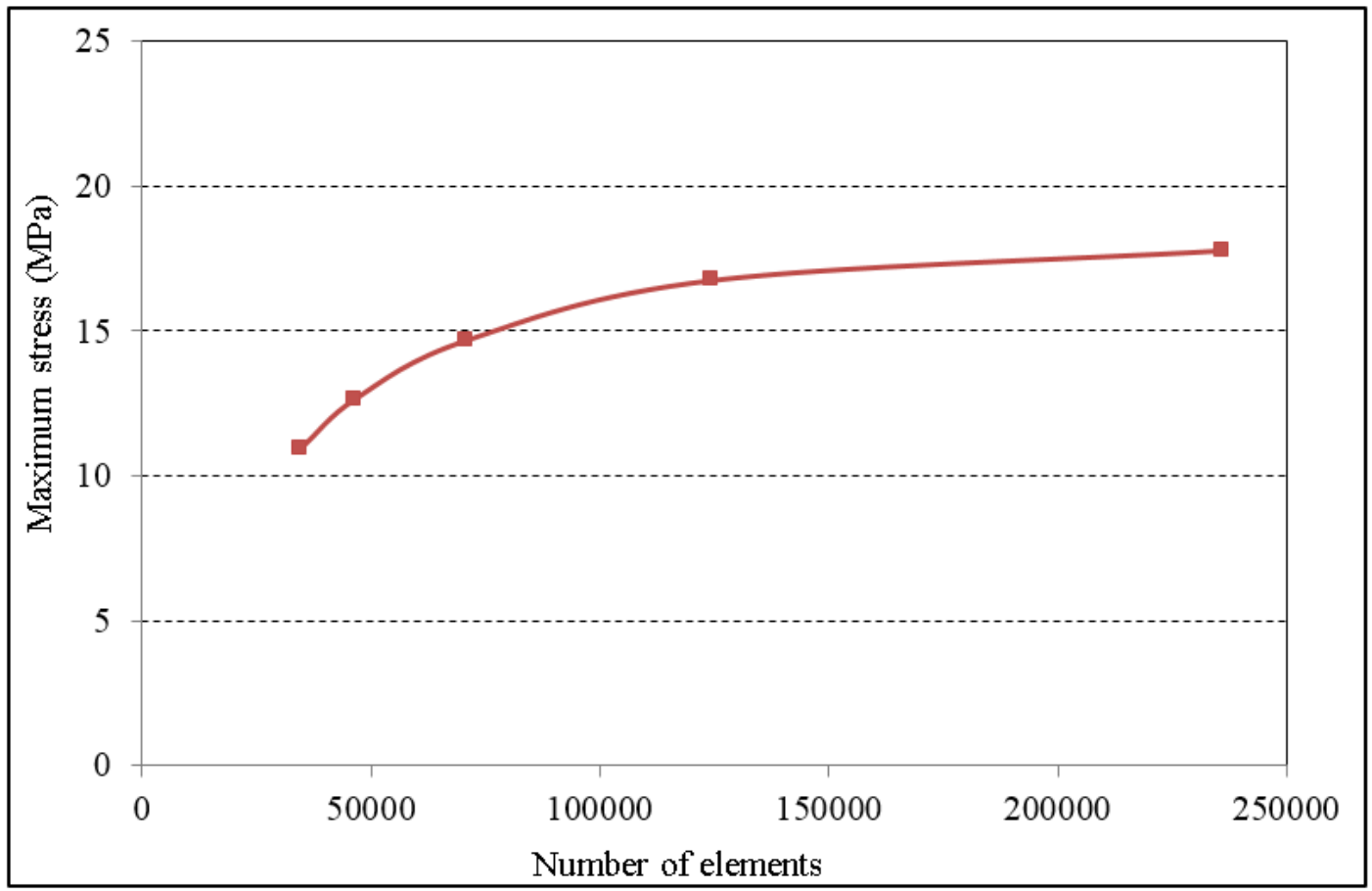

Figure 7. 43 Mesh refinement study on the TTI barrier at exterior location

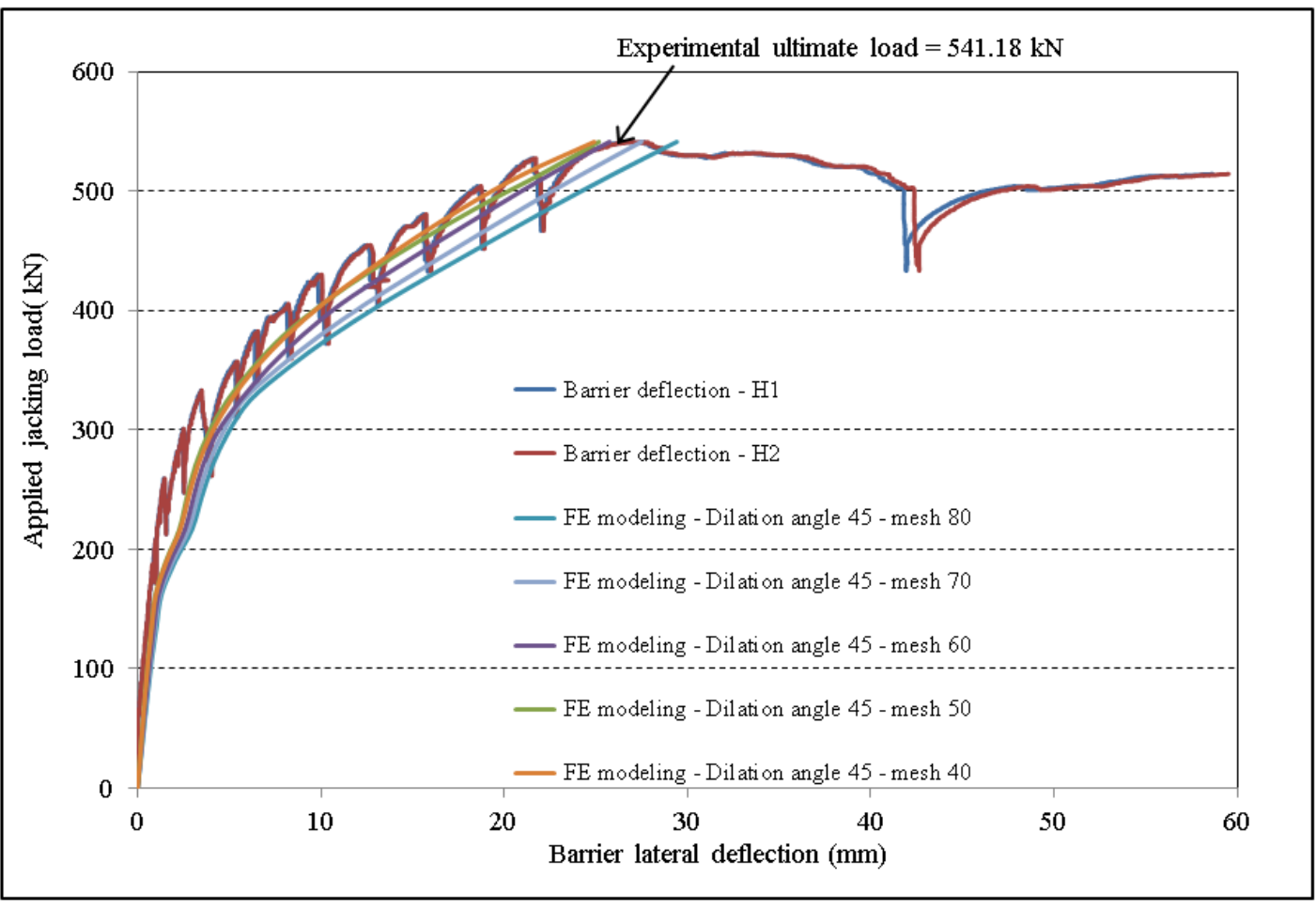

Figure 7. 44 Influence of mesh element size on the barrier response at exterior location 
Similar to the interior location, the cracked surface range was obtained from ABAQUS for the barrier model at wall front and back faces. The front face surface cracks represent cracks due to flexural behavior of the barrier model under the applied load. At back face of the wall, cracks are presented due to shearing stresses developed at the back face of the wall. Figure 7.45 shows views of the damaged surfaces with grayed color as the cracked surface ranges.

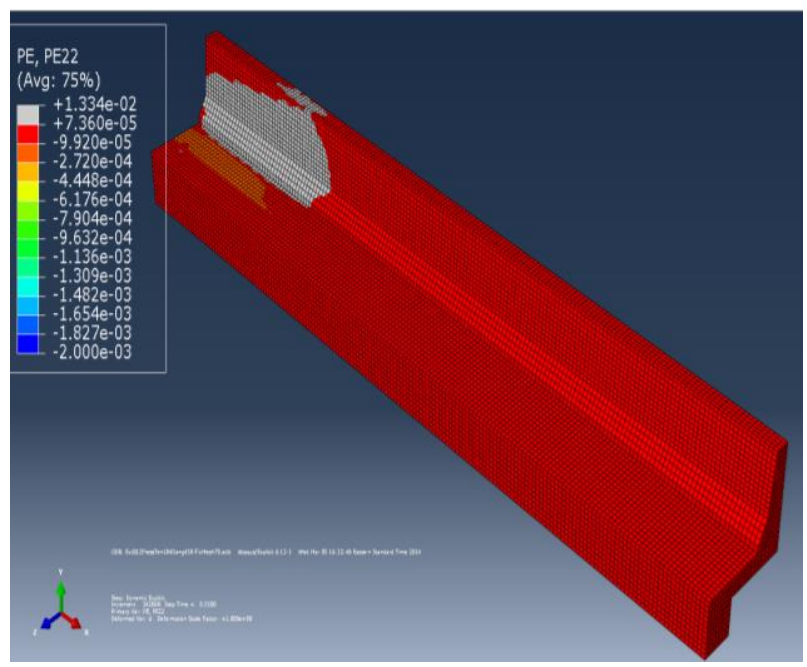

(a) Flexural cracked surface in the wall

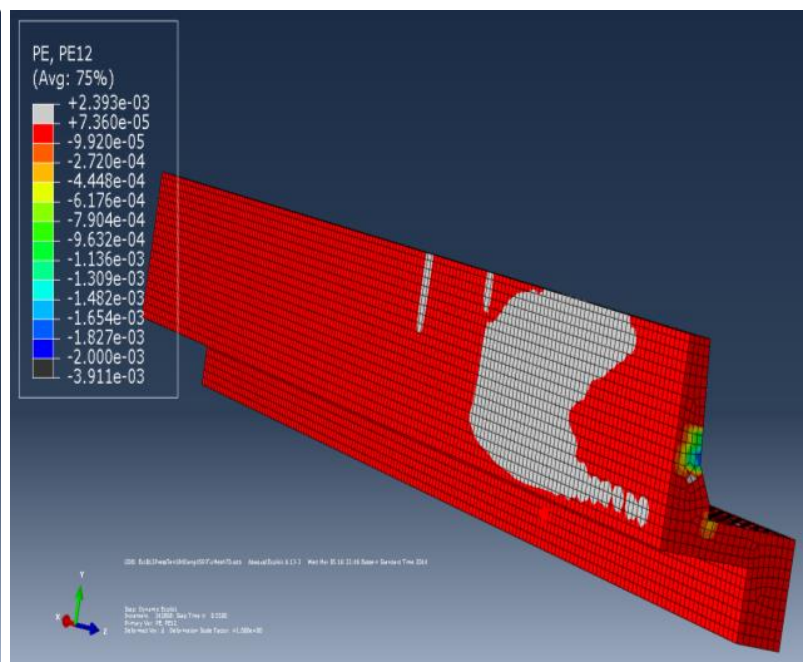

(b) Shear cracked surface at face of the wall

Figure 7. 45 Induced cracked surface in the barrier model at exterior location

\subsection{Summary of Findings}

Non-linear finite-element using dynamic explicit analysis has been conducted on the 1-m long barrier model 1 with headed-end anchors as well as the full-scale GFRP-reinforced bridge barrier at interior and exterior locations. In the FE modeling, the results from the 1-m long barrier model 1 was obtained and verified with the experiment findings. The results were then used to model the full-scale GFRP-reinforced bridge barriers. Based on numerical models generated herein, the following conclusions have been made: (i) The FE modeling can approximately predict the damage location by formation of crack mapping in terms of stress and strain concentrations. Therefore, the finite-element method can be employed to identify damage location and overall failure pattern of the barrier model, (ii) In 1-m long barrier model, flexure and tension-flexure cracks were observed in the wall and deck slab, respectively, similar to those observed in the experimental testing, (iii) In full-scale barrier, the FE model clearly showed the induced crack patterns due to flexure. The shear cracks were also shown by shear stress 
distributions along the elements in the barrier wall or at the barrier-deck corner joint, (iv) The punching shear cracks were developed in the barrier model at the top of the wall, extending to the back face of the wall by formation of shear stress concentrations, and (v) The overall structural performance in the form of load-deformation curves can be obtained from the finiteelement analysis by defining proper material behavior and mesh element size. For the selected barrier models, good agreements were found between the load-displacement responses of the barrier models and the experimental test results. 


\section{Chapter VIII}

\section{Conclusions and Recommendations for Future Study}

\subsection{Summary}

In civil engineering structures, steel bars have been commonly used worldwide and served as suitable civil engineering materials. Steel bars with their cost-effective, strength and ductility applications have been successfully contributed to economic health and prosperity of the developed word. However, such steel reinforcement if subjected to harsh environment and adverse weathering conditions such as de-icing salt will normally suffer by corrosion of the bars. In bridge structures built in Canada with severe weather conditions, corrosion of steel reinforcement leads to the reduced structural performance and degradation of the materials. This may not economically benefit the bridge owners owing to the fact that the cost of repair, maintenance and rehabilitation is increased. As such, to preclude such deteriorations in civil engineering structures, researches have been conducted on new materials to extend the service life of the structures; however, efforts have been made to maintain the design requirements and durability of the structures. Glass Fiber Reinforced Polymer (GFRP) bars known as lightweight, non-conductive and non-corrosive, high tensile and alkaline resistances are considered an alternative to conventional steel reinforcement in bridge structures especially when they are exposed to harsh environment. The use of GFRP bars in bridge construction has been rapidly increasing due to their non-corrosive nature. Traffic barriers, that are one of the major concerns affected by corrosion of steel bars, are the main objective of the current research for the use of GFRP bars as reinforcement in the barrier wall. Due to corrosion resistance and high tensile strength of GFRP bars, the current study investigated the use of high-modulus (HM) and standard-modulus (SM) GFRP bars in bridge barrier construction. These advantages have also been utilized in the development of connection at deck-wall interface where GFRP bars were used as the connecting reinforcement. However, due to the fact that mechanical properties of GFRP bars significantly differ from those of conventional steel reinforcement, the bond behavior and anchorage capacity of the GFRP bars were first investigated. Then, the use of GFRP bars in 
PL-3 traffic barriers was investigated. Therefore, the current research emphasized on the development of a prototype design procedure for GFRP-reinforced PL-3 traffic barriers, in addition, to revising the proposed design procedure of steel-reinforced bridge barriers by the yield-line theory of analysis. As such, the first objective of this research included experimental investigation on mechanical properties of GFRP bars in concrete slabs and concrete cubes under direct pullout loads. Specifically, this research was intended to investigate the bond behavior and the required development length of GFRP bars in concrete. The anchorage length of bar into the deck slab was meant to sustain the pullout load resulting from vehicle crashes into bridge barriers. GFRP bars with variable end-geometry, diameter, and fiber content have been investigated, the second objective of this research was to conduct laboratory testing on PL-3 traffic barrier segments reinforced with SM and HM-GFRP bars to investigate their ultimate load-carrying capacities at deck-barrier joint. The results have been compared with the CHBDC limits, the third objective of this research was to perform experimental program on full-scale PL3 traffic barriers reinforced with HM-GFRP bars and compared the results with CHBDC design limits. The experimental results have also examined crack and failure patterns compared with AASHTO-LRFD specifications. The research was further carried out on the selected PL-2 and PL-3 traffic barriers reinforced with steel bars. The experimental results have been compared with the AASHTO-LRFD design specifications by yield-line theory. Linear elastic analysis has also been performed on PL-2 and PL-3 as well as TL-4 and TL-5 traffic barriers investigating the effects of geometrical variations on the factored transverse moments and tensile forces developed in the deck slab. The last objective of this research was to develop non-linear finite-element model at exterior and interior locations of the barrier wall and correlate the FE results with experimental findings for future computer modeling. In this study, the load-deformation responses as well as the crack pattern have been compared with the experimental test results. The following section summarizes the experimental findings and recommendations for future research.

\subsection{Pullout of GFRP Bars in Concrete Cubes and Concrete Slabs}

To examine ultimate pullout strength and the required development length of GFRP bars in concrete, a total of 114 concrete cubes were cast and tested under monotonic increasing loading. The experimental program comprises several test variables, namely: fiber content (i.e. HM 
versus SM bars), bar end anchorage condition and bar diameter. Generally, the experimental test results were consistent with the literatures for pullout testing of FRP bars in concrete in terms of factors affecting bond strength such as: embedment length, bar diameter and concrete compressive strength. Comparison of test results showed the following main findings:

1. Increasing bar diameter lowered the bond strength.

2. The bar approached its ultimate tensile strength with increase in the embedment depth.

3. The increase in embedment depth also led to reduction in bond strength between concrete and GFRP bars and increase in the required applied load to pull the bar out of concrete.

4. GFRP bars with head anchors provided the most promising candidate in developing bond behavior between concrete and the bars.

5. New equations for basic development lengths of GFRP bars in tension with straight-ends, headed-ends and $180^{\circ}$-hook bars were proposed. It was found that the CSA-S806 (2012) and CSA-S6 (2006) overestimated the basic development lengths of straight bars with a factor of safety of minimum 2 that could be reduced accordingly.

Pullout tests were also carried out on GFRP bars embedded in concrete slabs with the same variables as concrete cubes except that the concrete slabs of 30.6 and $36.17 \mathrm{MPa}$ were cast. Based on experimental and analytical studies conducted on the GFRP bars, the following conclusions have been made:

1. Similar to concrete cube specimens, increasing bar size lowers the bond strength of GFRP bars in concrete.

2. From the test results obtained in both 30.6 and $36.17 \mathrm{MPa}$ concretes, it was observed that the value of average bond strength is slightly increased in the 36.17-MPa concrete. However, the increase in bond strength was not very significant in all types of GFRP bars with a difference of $3 \%$ to maximum of $8 \%$. The reason is that for both concrete compressive strengths, the bond failure occurred at the surface of the GFRP bars; consequently, the bond strength of GFRP bars in this study does not depend much on the value of concrete compressive strength.

3. An increase in embedment depth for the same load decreased the average value of bond strength. This might be due to non-linear distribution of the stresses along the length of the bars in case of larger embedment depth. 
4. The larger bar diameter required larger embedment depth to develop the same bond strength, while for bars with the same diameter, increasing the embedment depth reduces the bond strength of the GFRP bars.

5. Bars with different end anchorages have been investigated in this study, namely: straightend, headed-end and $180^{\circ}$-hook. From the test results, it was observed that GFRP bars with headed-ends developed the most promising bond strength characteristics possessing the highest value of the average bond strength. The hooked bars also developed relatively high values of bond strength than those of straight-end. However, the maximum bond strength followed by rupturing the bars at bend portion. The least bond strength development was attributed to GFRP bars with straight ends as expected.

6. The existing equations in the code for the required development length of FRP bars in concrete overestimated the results by a minimum safety factor of 2 for straight-end bars and 1.92 for hook bars. In case of hook bars, the experimental test results showed failure of all bars by rupturing at the bend portion. Thus, a maximum of $50 \%$ reduction to the ACI 440.1R (2006) or CSA-S806 (2012) equations is recommended. In case of headedend bars, the failure of the bars in concrete was governed by concrete breakout capacity given in CSA-A23.3 (2004) provision. Based on such failure mode, a new equation was proposed for the development length of headed-end bars in concrete on the basis of concrete breakout capacity.

\subsection{Development of Deck-Wall Joint Detail Using GFRP Bars}

Experimental programs have been carried out on (i) four PL-3 barriers, of 1-m length, reinforced with high-modulus (HM) and standard-modulus (SM) GFRP bars and (ii) one steel-reinforced barrier as reference. Three new GFRP bar arrangements were proposed in PL-3 traffic barriers. The connection detail at deck-wall interface using the new proposals was investigated incorporating the use of GFRP headed-end, bend and hook anchor bars as connecting reinforcement. Based on the data generated from the experimental study, the following conclusions are drawn:

1. GFRP bars with head anchors, GFRP bend and $180^{\circ}$ hook bars can be safely used in bridge barrier walls to resist the applied vehicle impact load specified in the Canadian Highway Bridge Design Code (CHBDC) at the barrier wall-deck slab interface. 
Comparable to steel reinforced barrier wall, GFRP bars developed ultimate load carrying capacity well beyond the design limits prescribed by CHBDC at both interior and exterior locations.

2. Ultimate flexural capacity of reinforcing bars in tension face of the barrier wall at deckwall interface can be safely examined by both cross-sectional analysis and strut and tie models. The results of flexural capacity of the barrier models by cross-sectional analysis were far beyond the limits prescribed in the CHBDC at interior location $(83 \mathrm{kN} \cdot \mathrm{m} / \mathrm{m})$ and exterior location $(102 \mathrm{kN} . \mathrm{m} / \mathrm{m})$ indicating that sufficient amount of GFRP tension reinforcement are provided. Similar results have been achieved by strut and tie model by calculating design strength of tension tie reinforcement.

3. Failure of deck-barrier wall joint may be due to several reasons, namely: (i) flexure or tension-flexure failure governed by GFRP tension reinforcement, (ii) concrete crushing at the weakest connection in the deck-wall joint, (iii) insufficient anchorage of the barrier wall or development length of the deck reinforcement or (iv) diagonal tension crack in the slab at the corner joint. Flexural capacities of the barrier wall and deck slab were examined by conventional cross-sectional analysis indicating additional capacities of the barrier wall and deck slab segments. However, due to the fact that failure of barrier models occurred due to diagonal tension cracks at corner joint, new equations were developed to investigate the effect of diagonal tension failure of the barriers. Accordingly, minimum reinforcement ratio equations were also developed for both the wall and thedeck sections so that diagonal tension failure will be prevented. The results of current study were compared to the work conducted by Matta et al. (2008) presenting similar agreements. Thus, as general considerations, the design of barriers per meter length may be governed by diagonal tension crack failure rather than flexural failure in the wall or deck slab portion.

4. In addition, analytical modeling was performed to study load-deformation response of barrier wall under the applied transverse load. The structural response developed herein 
provided relatively good agreements with the experimental investigations and can be incorporated in the design principles of GFRP reinforced concrete structures.

5. Linear-elastic finite-element analysis was performed on the PL-3 and PL-2 traffic barriers to study the effect of geometrical variations on moment and tensile force intensity factors developed in the deck. From the parametric studies, the following fundamental results were achieved:

a. CHBDC overestimated the moment and tensile force intensity factors for barrier length greater than 8-m, cantilever deck length greater than 1.5-m and deck thickness less than 200-mm. However, it underestimated the moment and tensile force intensity factors for barrier lengths less than 6-m, deck cantilever length less than $1-\mathrm{m}$ and deck thickness more than 250 - $\mathrm{mm}$ by average of $8.1 \%$ to $51.3 \%$;

b. The barriers with fixed base representing the case of rigidly base barriers exhibited significantly greater moment and tensile force intensity factors compared to the CHBDC design limits;

c. Based on the linear elastic analysis results, new empirical equation were developed to account for geometrical variations in barrier length or deck cantilever length and thickness. The empirical equations are meant to determine moments and tensile force intensities at interior and exterior locations of traffic barriers; and

d. The experimental load carrying capacities were found to be in good agreement with the developed equations.

\subsection{Static Tests on Full-Scale GFRP-Reinforced Bridge Barriers}

Based on experimental test results obtained from the 1-m long bridge barriers, proposal No.1 with HM-GFRP bars and headed-end anchors has been further investigated on a full-scale traffic barrier at interior and exterior locations. The cost-efficiency of the proposed GFRP bar detailing was introduced through (i) the use of high-modulus headed-end bars in lieu of bend bars to connect the barrier to the deck slab; (ii) the use of M12 bars as vertical reinforcement at back face of the barrier, which are always in compression under impact loading; (iii) the use of vertical reinforcement at maximum spacing of 300-mm specified in the CHBDC; (iv) eliminating 
splices between barrier vertical reinforcement and the projecting dowels from the deck slab; and (v) eliminating the bars with $180^{\circ}$ hooks and bends. Full-scale PL-3 barrier wall reinforced with high-modulus GFRP bars was tested under static loading to-collapse to study its structural behavior, crack pattern and ultimate load carrying capacity. Based on experimental and theoretical investigations, the following conclusions were drawn:

1. In contrast to AASHTO-LRFD yield-line failure pattern specified for steel-reinforced barriers, the developed GFRP-reinforced barrier wall failed due to punching shear around the patch loading location.

2. The developed GFRP-reinforced barrier exhibited ultimate load carrying capacity far greater than the CHBDC design load with factors of safety of 1.83 and 1.52 for interior and exterior load locations, respectively.

3. Based on the test data, an empirical equation was developed for the prediction of punching shear resistance of the developed GFRP-reinforced barrier wall to meet both strength and durability requirements. The equation leads to the factor of safety of 1.54 and 1.36 for interior and exterior load locations, respectively. The equation assumes the punching shear plane located at distance $1.5 \mathrm{~d}$ from the loading patch boundaries where $\mathrm{d}$ is the effective depth of the section.

4. As GFRP-reinforced barriers cannot develop plastic moment at failure, the design procedure of the traffic barrier reinforced with GFRP bars were developed based on ultimate and serviceability limit states as follows: (i) punching shear strength of GFRPreinforced barriers should be determined based on the developed equations and compared with the CHBDC design limits at interior and exterior locations, (ii) flexural strength of the traffic barriers should be determined at deck-wall interface based on the conventional cross-sectional analysis and compared with the CHBDC design limits, (iii) Due to lower modulus of elasticity of GFRR bars compared to steel reinforcement, the wall deformation per meter length of the barrier should be limited. As such, the barrier should be checked for deformability factor in accordance with the CHBDC (2006) clause 16.8.2.1 and for crack width control in accordance with the CHBDC (2006) clause 16.8.2.3. Based on the experimental and analytical investigations, the proposed barrier satisfied both ultimate and serviceability limit state requirements. 


\subsection{Static Tests on Full-Scale Steel-Reinforced Bridge Barriers}

From the experimental test observation on GFRP-reinforced bridge barriers, a trapezoidal crack pattern was observed, which was dissimilar to the triangular failure pattern specified in the AASHTO-LRFD specifications for steel-reinforced bridge barriers. Therefore, two full-scale steel-reinforced PL-3 and PL-2 bridge barriers constructed at Texas Transportation Institution (TTI) site were further investigated under monotonic static load testing to-complete-collapse simulating the equivalent vehicle impact force specified in the CHBDC. The test levels and corresponding loading patterns for static load testing were adopted from the CHBDC. From the experimental and theoretical investigations, the following conclusions have been made:

1. The experimental ultimate wall resistance was found to be far beyond the minimum transverse wall resistances specified in the CHBDC for both PL-3 and PL-2 traffic barriers.

2. Comparison has been made for the failure mode of the tested barriers. The shape of yieldline pattern observed in the test differed from those stipulated in AAHSTO-LRFD specifications. Similar to the GFRP-reinforced barriers, a trapezoidal failure shape was observed.

3. Based on the failure pattern of the tested barriers by trapezoidal shape, new equations were developed on the basis of yield-line theory to provide the least value of the nominal wall resistance against vehicle impact.

4. On the basis of trapezoidal failure pattern observed, the test results were analyzed to verify the developed equations for the ultimate strength of barriers in terms of the yieldline theory.

5. The experimental observations and the theoretical equations confirmed the failure pattern of the barrier wall by trapezoidal failure shape with the presence of a horizontal yield-line at the base of the wall. The length of the horizontal yield-line was found to be 0.5 to 1 times the loaded length, $\mathrm{L}_{\mathrm{t}}$.

6. The failure mode of the barrier by punching shear was also investigated. The CSA-A23.3 (2004) punching shear equation was modified for PL-3 and PL-2 barriers to account for the cantilever actions of the barrier and the critical punching shear perimeter area identified using punching shear plane located at distance $1.5 \mathrm{~d}$ from the patch loading 
boundaries. The proposed models yielded good results at exterior location and good yet conservative results at interior location of the barriers.

\subsection{Finite-Element Modeling of GFRP-Reinforced Bridge Barriers}

Non-linear finite-element using dynamic explicit analysis has been conducted on the 1-m long barrier model 1 with headed-end anchors as well as the full-scale GFRP-reinforced bridge barrier at interior and exterior locations. The FE modeling was conducted for the aim of validation with experimental test results. In the FE modeling, the results from the 1-m long barrier model 1 was obtained and verified with the experiment findings. The results were then used to model the fullscale GFRP-reinforced bridge barriers. Based on numerical models generated herein, the following conclusions have been made:

1. The FE modeling can approximately predict the damage location by formation of crack mapping in terms of stress and strain concentrations. Therefore, the finite-element method can be employed to identify damage location and overall failure pattern of the barrier model.

2. In 1-m long barrier model, flexure and tension-flexure cracks were observed in the wall and deck slab, respectively, similar to those observed in the experimental testing.

3. In full-scale barrier, the FE model clearly showed the induced crack patterns due to flexure. The shear cracks were also shown by shear stress distributions along the elements in the barrier wall or at the barrier-deck corner joint.

4. The punching shear cracks were developed in the barrier model at the top of the wall, extending to the back face of the wall by formation of shear stress concentrations.

5. In addition, the overall structural performance in the form of load-deformation curves can be obtained from the finite-element analysis by defining proper material behavior and mesh element size. For the selected barrier models, good agreements were found between the load-displacement responses of the barrier models and the experimental test results.

\subsection{Recommendations for Future Research}

Based on the experimental and numerical research programs conducted herein, it is recommended the following considerations to be directed for future research; 
1. Since bridge construction are subjected to repeated freeze and thaw effects, it is recommended that pullout specimens to be carried out considering these effects for more realistic bond behavior of GFRP bars in concrete.

2. In bridge barriers, due to cantilever action of the reinforcing bars by vehicle impact, the connecting bars and surrounding concrete are subjected to tensile stresses. Therefore, the bond behavior of GFRP bars by beam tests may represent more realistic result.

3. It might be beneficial to perform bond behavior of GFRP bars in high-strength and ultrahigh strength concrete to investigate the effect of concrete strength on bond properties.

4. In barrier proposals No. 2 and No. 3 with GFRP standard-modulus (SM) bars, it may be more economically to use M19@300 mm spacing as tension reinforcing bars in the wall rather than M15@200 mm. The new proposed barrier should be experimentally examined.

5. Due to the fact that the load carrying capacities of proposals No. 2 and 3 barriers were comparably greater than the CHBDC limits, it is recommended that those proposals to be experimentally tested in a full-scale barrier at interior and exterior locations since GFRP manufacturers claim that SM bars are less expensive than HM bars.

6. Punching shear equation developed in the current study is meant for PL-3 traffic barriers reinforced with GFRP bars. It is therefore recommended that the proposed equation be validated for PL-2 traffic barriers reinforced with GFRP bars. Also, the proposed punching shear equation is only valid for GFRP bars.

7. To precisely model the experimentally tested barriers in a finite-element software, it is recommended that strain gauges being installed at concrete tension and compression faces as well as the tension reinforcing bars to measure tensile strains till failure.

8. It is recommended to carry out parametric studies using non-linear finite element to evaluate the factored ultimate resistance of the barriers considering variable concrete and GFRP material properties and detaling.

9. Develop FE modeling of the studied PL-2 and PL-3 steel-reinforced barriers to simulate the load history, crack pattern and failure mode for future optimization of barrier geometry and bar detailing. 
10. Develop fiber reinforced concrete (FRC) bridge barriers (with chopped fibers mixed with concerete) to reduce concrete material content, reduce bar amount and enhance energy absorption of the wall due to vehicle impact. 
Appendix A

Experimental Results of Pullout of GFRP bars in Concrete 
Table A.1 Experimental results for single GFRP bars in slab model 1 with $\mathrm{f}_{\text {c. avg. }}=30.6 \mathrm{MPa}$

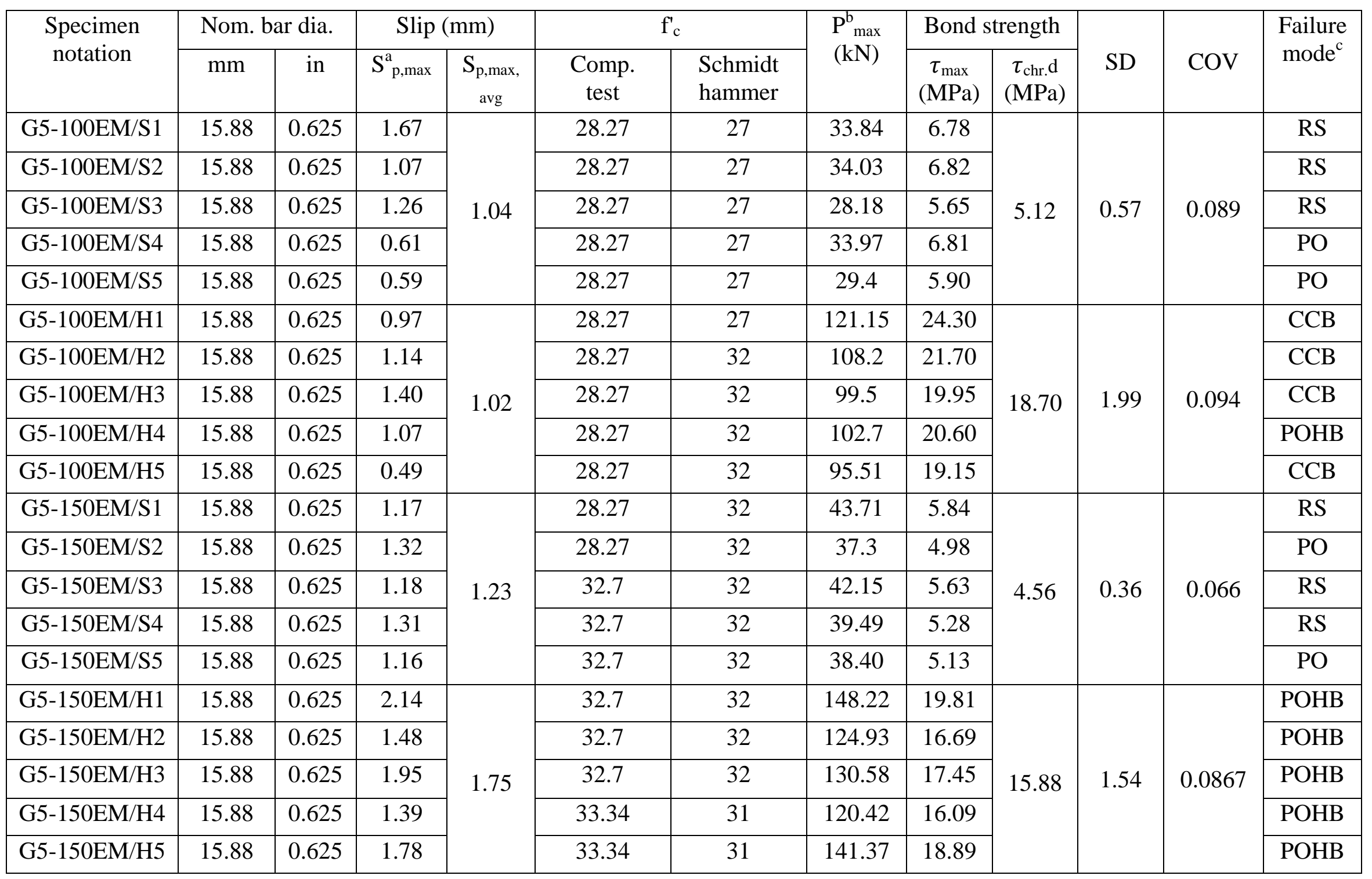


Table A.1 Experimental result for single GFRP bars in slab model 1 with $\mathrm{f}_{\mathrm{c} \text {, avg. }}=30.6 \mathrm{MPa}$ (cont'd)

\begin{tabular}{|c|c|c|c|c|c|c|c|c|c|c|c|c|}
\hline \multirow{3}{*}{$\begin{array}{l}\text { Specimen } \\
\text { notation }\end{array}$} & \multicolumn{2}{|c|}{ Nom. bar dia. } & \multicolumn{2}{|c|}{ Slip (mm) } & \multicolumn{2}{|c|}{$\mathrm{f}_{\mathrm{c}}^{\prime}$} & \multirow{3}{*}{$\begin{array}{l}\mathrm{P}_{\text {max }}^{\mathrm{b}} \\
(\mathrm{kN})\end{array}$} & \multicolumn{2}{|c|}{ Bond strength } & \multirow{3}{*}{ SD } & \multirow{3}{*}{$\mathrm{COV}$} & \multirow{3}{*}{$\begin{array}{l}\text { Failure } \\
\text { mode }^{\mathrm{c}}\end{array}$} \\
\hline & & & & & \multirow{2}{*}{$\begin{array}{c}\text { Comp. } \\
\text { test }\end{array}$} & \multirow{2}{*}{$\begin{array}{l}\text { Schmidt } \\
\text { hammer }\end{array}$} & & \multirow{2}{*}{$\begin{array}{c}\tau_{\max } \\
(\mathrm{MPa})\end{array}$} & \multirow{2}{*}{$\begin{array}{c}\tau_{\text {chr.d }} \\
(\mathrm{MPa})\end{array}$} & & & \\
\hline & $\mathrm{mm}$ & in & $\mathrm{S}_{\mathrm{p}, \max }^{\mathrm{a}}$ & $\begin{array}{c}\mathrm{S}_{\mathrm{p}, \max }, \\
\text { avg }\end{array}$ & & & & & & & & \\
\hline G5-200EM/S1 & 15.88 & 0.625 & 1.61 & \multirow{5}{*}{1.51} & 33.34 & 31 & 54.31 & 5.44 & \multirow{5}{*}{4.25} & \multirow{5}{*}{0.40} & \multirow{5}{*}{0.077} & $\mathrm{PO}$ \\
\hline G5-200EM/S2 & 15.88 & 0.625 & 1.49 & & 33.34 & 31 & 47.23 & 4.73 & & & & $\mathrm{PO}$ \\
\hline G5-200EM/S3 & 15.88 & 0.625 & 1.54 & & 33.34 & 31 & 56.70 & 5.683 & & & & $\mathrm{PO}$ \\
\hline G5-200EM/S4 & 15.88 & 0.625 & 1.51 & & 33.34 & 31 & 48.28 & 4.838 & & & & $\mathrm{PO}$ \\
\hline G5-200EM/S5 & 15.88 & 0.625 & 1.38 & & 27.84 & 29 & 50.84 & 5.10 & & & & $\mathrm{PO}$ \\
\hline G5-200EM/H1 & 15.88 & 0.625 & 2.11 & \multirow{5}{*}{2.08} & 27.84 & 29 & 156.75 & 15.71 & \multirow{5}{*}{13.46} & \multirow{5}{*}{0.33} & \multirow{5}{*}{0.021} & $\mathrm{POHB}$ \\
\hline G5-200EM/H2 & 15.88 & 0.625 & 1.96 & & 27.84 & 29 & 160.5 & 16.08 & & & & POHB \\
\hline G5-200EM/H3 & 15.88 & 0.625 & 2.43 & & 27.84 & 29 & 153.5 & 15.38 & & & & POHB \\
\hline G5-200EM/H4 & 15.88 & 0.625 & - & & 27.84 & 29 & - & - & & & & - \\
\hline G5-200EM/H5 & 15.88 & 0.625 & 1.85 & & 27.84 & 29 & 153.75 & 15.41 & & & & POHB \\
\hline G5-150EM/HO1 & 15.88 & 0.625 & 1.61 & \multirow{5}{*}{1.93} & 28.31 & 30 & 102.56 & 13.71 & \multirow{5}{*}{12.55} & \multirow{5}{*}{1.16} & \multirow{5}{*}{0.082} & RR \\
\hline G5-150EM/HO2 & 15.88 & 0.625 & 1.67 & & 28.31 & 30 & 93.31 & 12.47 & & & & RR \\
\hline G5-150EM/HO3 & 15.88 & 0.625 & 1.79 & & 28.31 & 30 & 106.62 & 14.25 & & & & $\mathrm{PO}$ \\
\hline G5-150EM/HO4 & 15.88 & 0.625 & 2.24 & & 28.31 & 30 & 116.38 & 15.56 & & & & $\mathrm{PO}$ \\
\hline G5-150EM/HO5 & 15.88 & 0.625 & 2.31 & & 28.31 & 30 & 110.35 & 14.75 & & & & RR \\
\hline
\end{tabular}

(a) Maximum net loaded-end slip at peak load

(b) Maximum peak load

(c) $\mathrm{PO}=$ pull-out; $\mathrm{RR}=$ rebar rupture; $\mathrm{RS}=$ rebar slippage; $\mathrm{POHB}=$ pull-out and head broken, $\mathrm{CCB}=$ concrete cone breakout

(d) $\tau_{\text {chr }}$ is the characteristic bond strength obtained from 5 identical samples 
Table A.1 Experimental result for single GFRP bars in slab model 1 with $\mathrm{f}_{\mathrm{c} \text {, avg. }}=30.6 \mathrm{MPa}$ (cont'd)

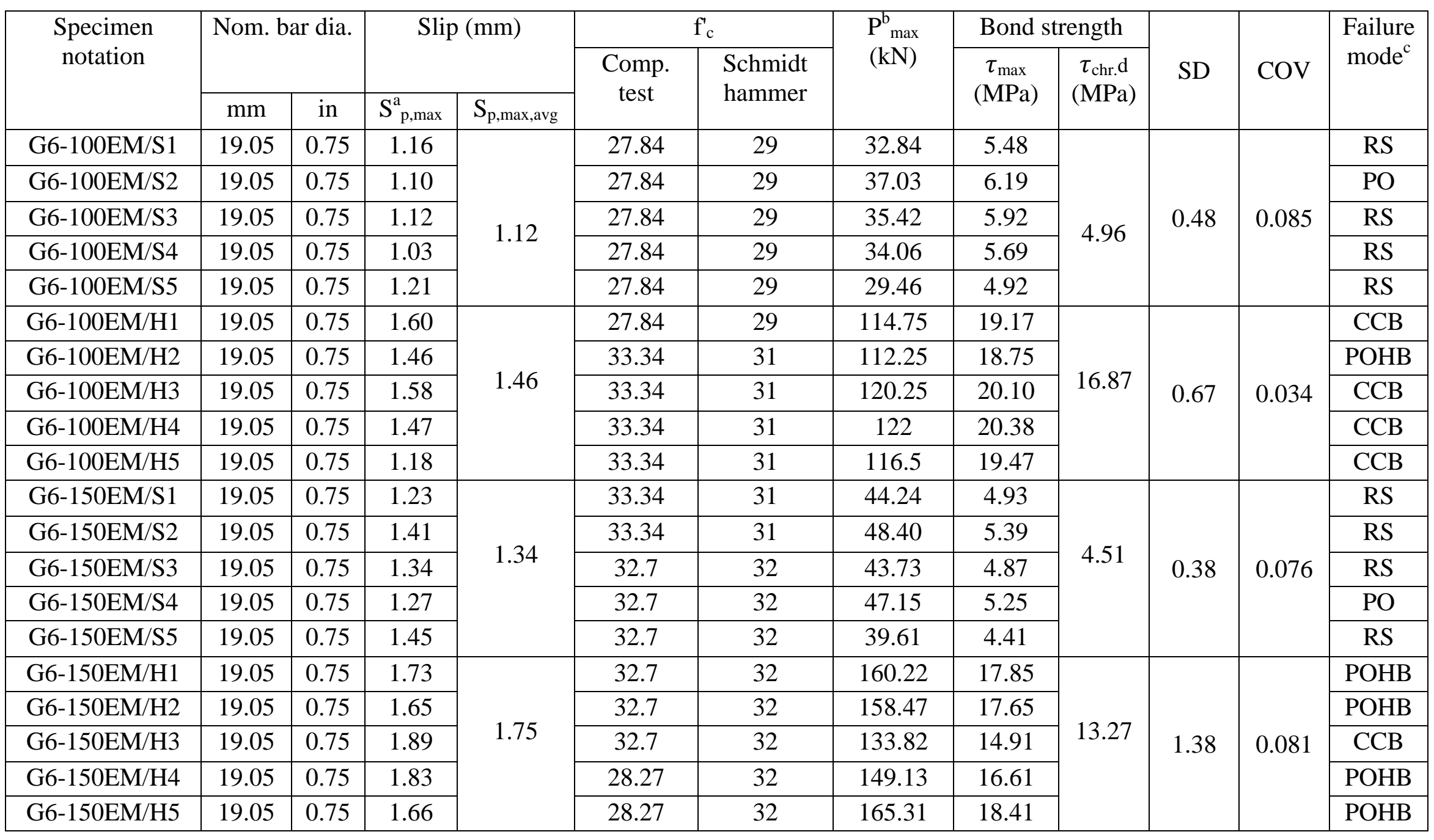


Table A.1 Experimental result for single GFRP bars in slab model 1 with $\mathrm{f}_{\mathrm{c} \text {, avg. }}=30.6 \mathrm{MPa}$ (cont'd)

\begin{tabular}{|c|c|c|c|c|c|c|c|c|c|c|c|c|}
\hline \multirow{3}{*}{$\begin{array}{c}\text { Specimen } \\
\text { notation }\end{array}$} & \multicolumn{2}{|c|}{ Nom. bar dia. } & \multicolumn{2}{|c|}{ Slip (mm) } & \multicolumn{2}{|c|}{$\mathrm{f}_{\mathrm{c}}^{\prime}$} & \multirow{3}{*}{$\begin{array}{l}\mathrm{P}_{\text {max }}^{\mathrm{b}} \\
(\mathrm{kN})\end{array}$} & \multicolumn{2}{|c|}{ Bond strength } & \multirow{3}{*}{ SD } & \multirow{3}{*}{$\mathrm{COV}$} & \multirow{3}{*}{$\begin{array}{l}\text { Failure } \\
\text { mode }^{\mathrm{c}}\end{array}$} \\
\hline & & & & & \multirow{2}{*}{$\begin{array}{c}\text { Comp. } \\
\text { test }\end{array}$} & \multirow{2}{*}{$\begin{array}{l}\text { Schmidt } \\
\text { hammer }\end{array}$} & & \multirow{2}{*}{$\begin{array}{c}\tau_{\max } \\
(\mathrm{MPa})\end{array}$} & \multirow{2}{*}{$\begin{array}{c}\tau_{\text {chr.d }} \\
(\mathrm{MPa})\end{array}$} & & & \\
\hline & $\mathrm{mm}$ & in & $\mathrm{S}_{\mathrm{p}, \max }^{\mathrm{a}}$ & $S_{p, \text { max,avg }}$ & & & & & & & & \\
\hline G6-200EM/S1 & 19.05 & 0.75 & 1.59 & \multirow{5}{*}{1.57} & 28.27 & 32 & 53.04 & 4.43 & \multirow{5}{*}{4.14} & \multirow{5}{*}{0.27} & \multirow{5}{*}{0.057} & PO \\
\hline G6-200EM/S2 & 19.05 & 0.75 & 1.65 & & 28.27 & 32 & 58.70 & 4.904 & & & & $\mathrm{PO}$ \\
\hline G6-200EM/S3 & 19.05 & 0.75 & 1.57 & & 28.27 & 32 & 54.62 & 4.563 & & & & PO \\
\hline G6-200EM/S4 & 19.05 & 0.75 & 1.47 & & 28.27 & 32 & 57.34 & 4.79 & & & & $\mathrm{RS}$ \\
\hline G6-200EM/S5 & 19.05 & 0.75 & 1.56 & & 28.27 & 27 & 61.15 & 5.11 & & & & PO \\
\hline G6-200EM/H1 & 19.05 & 0.75 & 2.21 & \multirow{5}{*}{2.05} & 28.27 & 27 & 184.75 & 15.43 & \multirow{5}{*}{11.17} & \multirow{5}{*}{0.68} & \multirow{5}{*}{0.045} & POHB \\
\hline G6-200EM/H2 & 19.05 & 0.75 & 1.93 & & 28.27 & 27 & 191 & 15.96 & & & & POHB \\
\hline G6-200EM/H3 & 19.05 & 0.75 & 1.97 & & 28.27 & 27 & 191.25 & 15.98 & & & & POHB \\
\hline G6-200EM/H4 & 19.05 & 0.75 & 2.11 & & 28.27 & 27 & 172.75 & 14.43 & & & & POHB \\
\hline G6-200EM/H5 & 19.05 & 0.75 & 2.03 & & 28.27 & 27 & 177.5 & 14.83 & & & & POHB \\
\hline G5-200EM/HO1 & 15.88 & 0.625 & 1.87 & \multirow{5}{*}{2.30} & 28.31 & 30 & 114.93 & 11.52 & \multirow{5}{*}{10.71} & \multirow{5}{*}{0.79} & \multirow{5}{*}{0.064} & $\mathrm{RR}$ \\
\hline G5-200EM/HO2 & 15.88 & 0.625 & 1.98 & & 28.31 & 30 & 117.45 & 11.77 & & & & $\mathrm{RR}$ \\
\hline G5-200EM/HO3 & 15.88 & 0.625 & 2.78 & & 28.31 & 30 & 129.70 & 13.00 & & & & RR \\
\hline G5-200EM/HO4 & 15.88 & 0.625 & 2.32 & & 28.31 & 30 & 126.38 & 12.67 & & & & $\mathrm{RR}$ \\
\hline G5-200EM/HO5 & 15.88 & 0.625 & 2.55 & & 28.31 & 30 & 133.11 & 13.34 & & & & RR \\
\hline
\end{tabular}

(a) Maximum net loaded-end slip at peak load

(b) Maximum peak load

(c) $\mathrm{PO}=$ pull-out; $\mathrm{RR}=$ rebar rupture; $\mathrm{RS}=$ rebar slippage; $\mathrm{POHB}=$ pull-out and head broken, $\mathrm{CCB}=$ concrete cone breakout

(d) $\tau_{\text {chr }}$ is the characteristic bond strength obtained from 5 identical samples 
Table A.2 Experimental results for single GFRP bars in slab model 2 with $\mathrm{f}_{\mathrm{c}}$, avg. $=36.17 \mathrm{MPa}$

\begin{tabular}{|c|c|c|c|c|c|c|c|c|c|c|c|c|}
\hline \multirow{3}{*}{$\begin{array}{l}\text { Specimen } \\
\text { notation }\end{array}$} & \multicolumn{2}{|c|}{ Nom. bar dia. } & \multicolumn{2}{|c|}{ Slip (mm) } & \multicolumn{2}{|c|}{$\mathrm{f}_{\mathrm{c}}^{\prime}$} & \multirow{3}{*}{$\begin{array}{l}\mathrm{P}_{\text {max }}^{\mathrm{b}} \\
(\mathrm{KN})\end{array}$} & \multicolumn{2}{|c|}{ Bond strength } & \multirow{3}{*}{ SD } & \multirow{3}{*}{$\mathrm{COV}$} & \multirow{3}{*}{$\begin{array}{l}\text { Failure } \\
\text { mode }^{c}\end{array}$} \\
\hline & & & & & \multirow{2}{*}{$\begin{array}{c}\text { Comp. } \\
\text { test }\end{array}$} & \multirow{2}{*}{$\begin{array}{l}\text { Schmidt } \\
\text { hammer }\end{array}$} & & \multirow{2}{*}{$\begin{array}{c}\tau_{\max } \\
(\mathrm{MPa})\end{array}$} & \multirow{2}{*}{$\begin{array}{c}\tau_{\text {chr. }} \text { d } \\
(\mathrm{MPa})\end{array}$} & & & \\
\hline & $\mathrm{mm}$ & in & $\mathrm{S}_{\mathrm{p}, \max }^{\mathrm{a}}$ & $\mathrm{S}_{\mathrm{p}, \mathrm{max}, \mathrm{avg}}$ & & & & & & & & \\
\hline G5-100EM/S1 & 15.88 & 0.625 & 0.98 & \multirow{5}{*}{0.91} & 36.63 & 29 & 33.29 & 6.67 & \multirow{5}{*}{5.14} & \multirow{5}{*}{0.88} & \multirow{5}{*}{0.132} & $\mathrm{PO}$ \\
\hline G5-100EM/S2 & 15.88 & 0.625 & 1.07 & & 36.63 & 29 & 40.8 & 8.18 & & & & $\mathrm{RS}$ \\
\hline G5-100EM/S3 & 15.88 & 0.625 & 1.11 & & 36.63 & 29 & 30.68 & 6.15 & & & & $\mathrm{RS}$ \\
\hline G5-100EM/S4 & 15.88 & 0.625 & 0.82 & & 36.63 & 29 & 29.56 & 5.93 & & & & $\mathrm{RS}$ \\
\hline G5-100EM/S5 & 15.88 & 0.625 & 0.57 & & 36.63 & 29 & 32.41 & 6.49 & & & & $\mathrm{PO}$ \\
\hline G5-100EM/H1 & 15.88 & 0.625 & 1.18 & \multirow{5}{*}{1.166} & 36.63 & 29 & 119.75 & 24.02 & \multirow{5}{*}{17.10} & \multirow{5}{*}{2.14} & \multirow{5}{*}{0.103} & POHB \\
\hline G5-100EM/H2 & 15.88 & 0.625 & 1.30 & & 36.63 & 28 & 107.28 & 21.51 & & & & CCB \\
\hline G5-100EM/H3 & 15.88 & 0.625 & 0.98 & & 36.63 & 28 & 103.08 & 20.67 & & & & $\mathrm{CCB}$ \\
\hline G5-100EM/H4 & 15.88 & 0.625 & 0.89 & & 36.63 & 28 & 98.31 & 19.71 & & & & POHB \\
\hline G5-100EM/H5 & 15.88 & 0.625 & 1.48 & & 36.63 & 28 & 91.18 & 18.28 & & & & $\mathrm{CCB}$ \\
\hline G5-150EM/S1 & 15.88 & 0.625 & 1.43 & \multirow{5}{*}{1.35} & 36.63 & 28 & 46.39 & 6.57 & \multirow{5}{*}{4.85} & \multirow{5}{*}{0.55} & \multirow{5}{*}{0.092} & $\mathrm{RS}$ \\
\hline G5-150EM/S2 & 15.88 & 0.625 & 1.33 & & 36.63 & 28 & 37.44 & 5.20 & & & & $\mathrm{RS}$ \\
\hline G5-150EM/S3 & 15.88 & 0.625 & 1.43 & & 34.23 & 34 & 46.28 & 6.38 & & & & $\mathrm{RS}$ \\
\hline G5-150EM/S4 & 15.88 & 0.625 & 1.46 & & 34.23 & 34 & 39.16 & 5.73 & & & & $\mathrm{PO}$ \\
\hline G5-150EM/S5 & 15.88 & 0.625 & 1.13 & & 34.23 & 34 & 42.63 & 5.82 & & & & $\mathrm{PO}$ \\
\hline G5-150EM/H1 & 15.88 & 0.625 & 1.48 & \multirow{5}{*}{1.54} & 34.23 & 34 & 136.03 & 18.187 & \multirow{5}{*}{15.31} & \multirow{5}{*}{1.05} & \multirow{5}{*}{0.057} & POHB \\
\hline G5-150EM/H2 & 15.88 & 0.625 & 1.68 & & 34.23 & 34 & 127.21 & 17.008 & & & & CCB \\
\hline G5-150EM/H3 & 15.88 & 0.625 & 1.49 & & 34.23 & 34 & 134.41 & 17.97 & & & & POHB \\
\hline G5-150EM/H4 & 15.88 & 0.625 & 1.46 & & 38.87 & 32 & 147.07 & 19.664 & & & & POHB \\
\hline G5-150EM/H5 & 15.88 & 0.625 & 1.58 & & 38.87 & 32 & 141.44 & 18.910 & & & & CCB \\
\hline
\end{tabular}


Table A.2 Experimental result for single GFRP bars in slab model 2 with $\mathrm{f}_{\mathrm{c} \text {, avg. }}=36.17 \mathrm{MPa}$ (cont'd)

\begin{tabular}{|c|c|c|c|c|c|c|c|c|c|c|c|c|}
\hline \multirow{3}{*}{$\begin{array}{l}\text { Specimen } \\
\text { notation }\end{array}$} & \multicolumn{2}{|c|}{ Nom. bar dia. } & \multicolumn{2}{|c|}{ Slip (mm) } & \multicolumn{2}{|c|}{$\mathrm{f}_{\mathrm{c}}^{\prime}$} & \multirow{3}{*}{$\begin{array}{l}\mathrm{P}_{\text {max }}^{\mathrm{b}} \\
(\mathrm{KN})\end{array}$} & \multicolumn{2}{|c|}{ Bond strength } & \multirow{3}{*}{ SD } & \multirow{3}{*}{$\mathrm{COV}$} & \multirow{3}{*}{$\begin{array}{l}\text { Failure } \\
\text { mode }^{c}\end{array}$} \\
\hline & & & & & \multirow{2}{*}{$\begin{array}{c}\text { Comp. } \\
\text { Test }\end{array}$} & \multirow{2}{*}{$\begin{array}{l}\text { Schmidt } \\
\text { hammer }\end{array}$} & & \multirow{2}{*}{$\begin{array}{c}\tau_{\max } \\
(\mathrm{MPa})\end{array}$} & \multirow{2}{*}{$\begin{array}{c}\tau_{\text {chr. }} \text { d } \\
(\mathrm{MPa})\end{array}$} & & & \\
\hline & $\mathrm{mm}$ & in & $\mathrm{S}_{\mathrm{p}, \max }^{\mathrm{a}}$ & $\mathrm{S}_{\mathrm{p}, \text { max,avg }}$ & & & & & & & & \\
\hline G5-200EM/S1 & 15.88 & 0.625 & 1.84 & \multirow{5}{*}{1.878} & 38.87 & 32 & 55.51 & 5.563 & \multirow{5}{*}{4.25} & \multirow{5}{*}{0.27} & \multirow{5}{*}{0.049} & $\mathrm{PO}$ \\
\hline G5-200EM/S2 & 15.88 & 0.625 & 2.14 & & 38.87 & 32 & 55.83 & 5.595 & & & & PO \\
\hline G5-200EM/S3 & 15.88 & 0.625 & 2.12 & & 38.87 & 32 & 57.57 & 5.770 & & & & $\mathrm{PO}$ \\
\hline G5-200EM/S4 & 15.88 & 0.625 & 1.88 & & 38.87 & 32 & 53.96 & 5.408 & & & & $\mathrm{PO}$ \\
\hline G5-200EM/S5 & 15.88 & 0.625 & 1.41 & & 39.58 & 34 & 50.41 & 5.052 & & & & $\mathrm{PO}$ \\
\hline G5-200EM/H1 & 15.88 & 0.625 & 1.72 & \multirow{5}{*}{1.28} & 39.58 & 34 & 158.5 & 15.88 & \multirow{5}{*}{13.95} & \multirow{5}{*}{0.37} & \multirow{5}{*}{0.023} & POHB \\
\hline G5-200EM/H2 & 15.88 & 0.625 & 1.15 & & 39.58 & 34 & 159.75 & 16.01 & & & & POHB \\
\hline G5-200EM/H3 & 15.88 & 0.625 & 1.50 & & 39.58 & 34 & 160.32 & 16.07 & & & & POHB \\
\hline G5-200EM/H4 & 15.88 & 0.625 & 1.17 & & 39.58 & 34 & 167.75 & 16.81 & & & & POHB \\
\hline G5-200EM/H5 & 15.88 & 0.625 & 0.88 & & 39.58 & 34 & 163.5 & 16.38 & & & & POHB \\
\hline G5-150EM/HO1 & 15.88 & 0.625 & 1.45 & \multirow{5}{*}{1.82} & 34.67 & 34 & 121.46 & 16.23 & \multirow{5}{*}{13.71} & \multirow{5}{*}{0.82} & \multirow{5}{*}{0.053} & RR \\
\hline G5-150EM/HO2 & 15.88 & 0.625 & 2.15 & & 34.67 & 34 & 118.34 & 15.81 & & & & RR \\
\hline G5-150EM/HO3 & 15.88 & 0.625 & 3.25 & & 34.67 & 34 & 113.1 & 15.11 & & & & RR \\
\hline G5-150EM/HO4 & 15.88 & 0.625 & 1.55 & & 34.67 & 34 & 122.66 & 16.39 & & & & $\mathrm{RR}$ \\
\hline G5-150EM/HO5 & 15.88 & 0.625 & 0.70 & & 34.67 & 34 & 107.92 & 14.42 & & & & RR \\
\hline
\end{tabular}

(a) Maximum net loaded-end slip at peak load

(b) Maximum peak load

(c) $\mathrm{PO}=$ pull-out; $\mathrm{RR}=$ rebar rupture; $\mathrm{RS}=$ rebar slippage; $\mathrm{POHB}=$ pull-out and head broken, $\mathrm{CCB}=$ concrete cone breakout

(d) $\tau_{\text {chr }}$ is the characteristic bond strength obtained from 5 identical samples 
Table A.2 Experimental result for single GFRP bars in slab model 2 with $\mathrm{f}_{c \text {, avg. }}^{\prime}=36.17 \mathrm{MPa}$ (cont'd)

\begin{tabular}{|c|c|c|c|c|c|c|c|c|c|c|c|c|}
\hline \multirow{3}{*}{$\begin{array}{c}\text { Specimen } \\
\text { notation }\end{array}$} & \multicolumn{2}{|c|}{ Nom. bar dia. } & \multicolumn{2}{|c|}{ Slip (mm) } & \multicolumn{2}{|c|}{$\mathrm{f}_{\mathrm{c}}^{\prime}$} & \multirow{3}{*}{$\begin{array}{l}\mathrm{P}_{\text {max }}^{\mathrm{b}} \\
(\mathrm{KN})\end{array}$} & \multicolumn{2}{|c|}{ Bond strength } & \multirow{3}{*}{ SD } & \multirow{3}{*}{$\mathrm{COV}$} & \multirow{3}{*}{$\begin{array}{l}\text { Failure } \\
\text { mode }^{\mathrm{c}}\end{array}$} \\
\hline & & & & & \multirow{2}{*}{$\begin{array}{c}\text { Comp. } \\
\text { test }\end{array}$} & \multirow{2}{*}{$\begin{array}{l}\text { Schmidt } \\
\text { hammer }\end{array}$} & & \multirow{2}{*}{$\begin{array}{c}\tau_{\max } \\
(\mathrm{MPa})\end{array}$} & \multirow{2}{*}{$\begin{array}{c}\tau_{\text {chr.d }} \\
(\mathrm{MPa})\end{array}$} & & & \\
\hline & $\mathrm{mm}$ & in & $\mathrm{S}_{\mathrm{p}, \max }^{\mathrm{a}}$ & $\mathrm{S}_{\mathrm{p}, \text { max,avg }}$ & & & & & & & & \\
\hline G6-100EM/S1 & 19.05 & 0.75 & - & \multirow{5}{*}{0.557} & 39.58 & 34 & 39.43 & 6.56 & \multirow{5}{*}{4.97} & \multirow{5}{*}{0.55} & \multirow{5}{*}{0.088} & RS \\
\hline G6-100EM/S2 & 19.05 & 0.75 & 0.57 & & 39.58 & 34 & 32.75 & 5.47 & & & & $\mathrm{PO}$ \\
\hline G6-100EM/S3 & 19.05 & 0.75 & 0.62 & & 39.58 & 34 & 41.16 & 6.88 & & & & RS \\
\hline G6-100EM/S4 & 19.05 & 0.75 & 0.62 & & 39.58 & 34 & 36.84 & 6.16 & & & & $\mathrm{RS}$ \\
\hline G6-100EM/S5 & 19.05 & 0.75 & 0.42 & & 39.58 & 34 & 35.41 & 5.92 & & & & $\mathrm{PO}$ \\
\hline G6-100EM/H1 & 19.05 & 0.75 & 1.21 & \multirow{5}{*}{1.13} & 39.58 & 34 & 113.24 & 18.92 & \multirow{5}{*}{16.41} & \multirow{5}{*}{1.09} & \multirow{5}{*}{0.057} & $\mathrm{CCB}$ \\
\hline G6-100EM/H2 & 19.05 & 0.75 & 1.25 & & 38.87 & 31 & 108.75 & 18.17 & & & & $\mathrm{CCB}$ \\
\hline G6-100EM/H3 & 19.05 & 0.75 & 1.4 & & 38.87 & 31 & 121.5 & 20.30 & & & & POHB \\
\hline G6-100EM/H4 & 19.05 & 0.75 & 1.08 & & 38.87 & 31 & 116.5 & 19.46 & & & & POHB \\
\hline G6-100EM/H5 & 19.05 & 0.75 & 0.72 & & 38.87 & 31 & 104.75 & 17.50 & & & & POHB \\
\hline G6-150EM/S1 & 19.05 & 0.75 & 1.52 & \multirow{5}{*}{1.448} & 38.87 & 31 & 51.51 & 5.438 & \multirow{5}{*}{4.43} & \multirow{5}{*}{0.42} & \multirow{5}{*}{0.078} & $\mathrm{RS}$ \\
\hline G6-150EM/S2 & 19.05 & 0.75 & 1.43 & & 38.87 & 31 & 48.4 & 4.892 & & & & $\mathrm{RS}$ \\
\hline G6-150EM/S3 & 19.05 & 0.75 & 1.65 & & 34.23 & 32 & 51.86 & 5.176 & & & & $\mathrm{RS}$ \\
\hline G6-150EM/S4 & 19.05 & 0.75 & 1.15 & & 34.23 & 32 & 53.7 & 5.282 & & & & $\mathrm{PO}$ \\
\hline G6-150EM/S5 & 19.05 & 0.75 & 1.49 & & 34.23 & 32 & 53.97 & 6.012 & & & & $\mathrm{RS}$ \\
\hline G6-150EM/H1 & 19.05 & 0.75 & 1.98 & \multirow{5}{*}{1.81} & 34.23 & 32 & 153.27 & 17.07 & \multirow{5}{*}{14.67} & \multirow{5}{*}{0.63} & \multirow{5}{*}{0.036} & POHB \\
\hline G6-150EM/H2 & 19.05 & 0.75 & 1.6 & & 34.23 & 32 & 152.69 & 17.008 & & & & POHB \\
\hline G6-150EM/H3 & 19.05 & 0.75 & 1.58 & & 34.23 & 32 & 158.16 & 17.618 & & & & $\mathrm{CCB}$ \\
\hline G6-150EM/H4 & 19.05 & 0.75 & 1.24 & & 36.63 & 29 & 166.53 & 18.55 & & & & POHB \\
\hline G6-150EM/H5 & 19.05 & 0.75 & 2.65 & & 36.63 & 29 & 159.76 & 17.80 & & & & $\mathrm{CCB}$ \\
\hline
\end{tabular}


Table A.2 Experimental result for single GFRP bars in slab model 2 with $\mathrm{f}_{\mathrm{c} \text {, avg. }}=36.17 \mathrm{MPa}$ (cont'd)

\begin{tabular}{|c|c|c|c|c|c|c|c|c|c|c|c|c|}
\hline \multirow{3}{*}{$\begin{array}{l}\text { Specimen } \\
\text { notation }\end{array}$} & \multicolumn{2}{|c|}{ Nom. bar dia. } & \multicolumn{2}{|c|}{ Slip (mm) } & \multicolumn{2}{|c|}{$\mathrm{f}_{\mathrm{c}}^{\prime}$} & \multirow{3}{*}{$\begin{array}{l}\mathrm{P}^{\mathrm{b}}{ }_{\max } \\
(\mathrm{KN})\end{array}$} & \multicolumn{2}{|c|}{ Bond strength } & \multirow{3}{*}{ SD } & \multirow{3}{*}{$\mathrm{COV}$} & \multirow{3}{*}{$\begin{array}{l}\text { Failure } \\
\text { mode }^{c}\end{array}$} \\
\hline & & & & & \multirow{2}{*}{$\begin{array}{c}\text { Comp. } \\
\text { test }\end{array}$} & \multirow{2}{*}{$\begin{array}{l}\text { Schmidt } \\
\text { hammer }\end{array}$} & & \multirow{2}{*}{$\begin{array}{c}\tau_{\max } \\
(\mathrm{MPa})\end{array}$} & \multirow{2}{*}{$\begin{array}{c}\tau_{\text {chr. }} \text { d } \\
(\mathrm{MPa})\end{array}$} & & & \\
\hline & $\mathrm{mm}$ & in & $\mathrm{S}_{\mathrm{p}, \max }^{\mathrm{a}}$ & $\mathrm{S}_{\mathrm{p}, \text { max,avg }}$ & & & & & & & & \\
\hline G6-200EM/S1 & 19.05 & 0.75 & 1.78 & \multirow{5}{*}{1.42} & 36.63 & 29 & 61.20 & 5.11 & \multirow{5}{*}{3.94} & \multirow{5}{*}{0.46} & \multirow{5}{*}{0.092} & $\mathrm{RS}$ \\
\hline G6-200EM/S2 & 19.05 & 0.75 & 0.97 & & 36.63 & 29 & 58.25 & 4.87 & & & & $\mathrm{PO}$ \\
\hline G6-200EM/S3 & 19.05 & 0.75 & 1.31 & & 36.63 & 29 & 51.13 & 4.27 & & & & PO \\
\hline G6-200EM/S4 & 19.05 & 0.75 & 1.81 & & 36.63 & 29 & 59.25 & 4.94 & & & & $\mathrm{PO}$ \\
\hline G6-200EM/S5 & 19.05 & 0.75 & 1.25 & & 36.63 & 30 & 66.25 & 5.53 & & & & PO \\
\hline G6-200EM/H1 & 19.05 & 0.75 & 1.07 & \multirow{5}{*}{1.81} & 36.63 & 30 & 183.25 & 15.31 & \multirow{5}{*}{12.78} & \multirow{5}{*}{0.52} & \multirow{5}{*}{0.033} & POHB \\
\hline G6-200EM/H2 & 19.05 & 0.75 & 1.88 & & 36.63 & 30 & 192.75 & 16.10 & & & & POHB \\
\hline G6-200EM/H3 & 19.05 & 0.75 & 1.31 & & 36.63 & 30 & 197.75 & 16.52 & & & & RR \\
\hline G6-200EM/H4 & 19.05 & 0.75 & 1.86 & & 36.63 & 30 & 184.25 & 15.39 & & & & POHB \\
\hline G6-200EM/H5 & 19.05 & 0.75 & 2.98 & & 36.63 & 30 & 186.5 & 15.58 & & & & POHB \\
\hline G5-200EM/HO1 & 15.88 & 0.625 & 1.57 & \multirow{5}{*}{1.71} & 34.67 & 34 & 128.13 & 12.84 & \multirow{5}{*}{12.31} & \multirow{5}{*}{0.54} & \multirow{5}{*}{0.039} & RR \\
\hline G5-200EM/HO2 & 15.88 & 0.625 & 0.64 & & 34.67 & 34 & 134.68 & 13.50 & & & & RR \\
\hline G5-200EM/HO3 & 15.88 & 0.625 & 1.68 & & 34.67 & 34 & 139.25 & 13.95 & & & & RR \\
\hline G5-200EM/HO4 & 15.88 & 0.625 & 3.63 & & 34.67 & 34 & 131.51 & 13.18 & & & & $\mathrm{RR}$ \\
\hline G5-200EM/HO5 & 15.88 & 0.625 & 1.04 & & 34.67 & 34 & 141.2 & 14.15 & & & & RR \\
\hline
\end{tabular}

(a) Maximum net loaded-end slip at peak load

(b) Maximum peak load

(c) $\mathrm{PO}=$ pull-out; $\mathrm{RR}=$ rebar rupture; $\mathrm{RS}=$ rebar slippage; $\mathrm{POHB}=$ pull-out and head broken, $\mathrm{CCB}=$ concrete cone breakout

(d) $\tau_{\text {chr }}$ is the characteristic bond strength obtained from 5 identical samples 
Table A.3 Experimental pullout cube results for single GFRP bars $\mathrm{f}_{\mathrm{c}}=34.9 \mathrm{MPa}$

\begin{tabular}{|c|c|c|c|c|c|c|c|c|c|c|c|}
\hline \multirow{3}{*}{ Specimen notation } & \multirow{2}{*}{\multicolumn{2}{|c|}{$\begin{array}{l}\text { Bar propetry } \\
\text { Nom. bar dia. }\end{array}$}} & \multirow{2}{*}{\multicolumn{2}{|c|}{ Slip (mm) }} & \multirow{3}{*}{$\begin{array}{c}\mathrm{f}_{\mathrm{c}}^{\prime} \\
(\mathrm{MPa})\end{array}$} & \multirow{3}{*}{$\begin{array}{l}\mathrm{P}_{\text {max }}^{\mathrm{a}} \\
(\mathrm{KN})\end{array}$} & \multicolumn{2}{|c|}{ Bond strength } & \multirow{3}{*}{ SD } & \multirow{3}{*}{$\mathrm{COV}$} & \multirow{3}{*}{$\begin{array}{l}\text { Failure } \\
\text { mode }^{c}\end{array}$} \\
\hline & & & & & & & \multirow{2}{*}{$\begin{array}{c}\tau_{\max } \\
(\mathrm{MPa})\end{array}$} & \multirow{2}{*}{$\begin{array}{l}\tau_{\text {chr.d }} \\
(\mathrm{MPa})\end{array}$} & & & \\
\hline & $\mathrm{mm}$ & in & $\mathrm{S}_{\mathrm{fe}}{ }^{\mathrm{b}}$ & $\mathrm{S}_{\mathrm{le}} \mathrm{b}$ & & & & & & & \\
\hline G5-150x150x100/S2 & 15.88 & 0.625 & 0.01 & 13.08 & 34.90 & 65.71 & 13.17 & 11.2 & 1.86 & 0.17 & CS \\
\hline G5-150x150x150/S2 & 15.88 & 0.625 & 0.15 & 22.77 & 34.90 & 89.33 & 11.93 & \multirow[t]{2}{*}{10.7} & \multirow[t]{2}{*}{1.20} & \multirow[t]{2}{*}{0.11} & PO \\
\hline G5-150x150x150/S3 & 15.88 & 0.625 & 0.26 & 24.96 & 34.90 & 71.3 & 9.53 & & & & $\mathrm{PO}$ \\
\hline G5-150x150x200/S1 & 15.88 & 0.625 & 0.01 & 24.4 & 34.90 & 84.81 & 8.5 & 9.17 & 0.603 & 0.066 & $\mathrm{PO}$ \\
\hline G5-150x150x250/S2 & 15.88 & 0.625 & 0.05 & 21.9 & 34.90 & 111.3 & 8.9 & \multirow[t]{2}{*}{9.06} & \multirow[t]{2}{*}{0.21} & \multirow[t]{2}{*}{0.023} & $\mathrm{PO}$ \\
\hline G5-150x150x250/S3 & 15.88 & 0.625 & 0.02 & 18.05 & 34.90 & 112.18 & 9 & & & & $\mathrm{CS}$ \\
\hline G5-150x150x100/H1 & 15.88 & 0.625 & 0.01 & 12.98 & 34.90 & 62.03 & 12.43 & \multirow{3}{*}{14.2} & \multirow{3}{*}{1.67} & \multirow{3}{*}{0.12} & $\mathrm{CS}$ \\
\hline G5-150x150x100/H2 & 15.88 & 0.625 & 0.01 & 12.46 & 34.90 & 78.6 & 15.75 & & & & $\mathrm{CS}$ \\
\hline G5-150x150x100/H3 & 15.88 & 0.625 & 0.01 & 13.32 & 34.90 & 71.92 & 14.42 & & & & $\mathrm{CS}$ \\
\hline G5-150x150x150/H1 & 15.88 & 0.625 & 0.14 & 31.9 & 34.90 & 107.8 & 14.4 & \multirow[b]{2}{*}{12.8} & \multirow[b]{2}{*}{1.43} & \multirow[b]{2}{*}{0.11} & CS-POHB \\
\hline G5-150x150x150/H2 & 15.88 & 0.625 & 0.57 & 30.6 & 34.90 & 93.6 & 12.5 & & & & CS-POHB \\
\hline
\end{tabular}


Table A.3 Experimental pullout cube result for single GFRP bars $\mathrm{f}_{\mathrm{c}}=34.9 \mathrm{MPa}$ (cont'd)

\begin{tabular}{|c|c|c|c|c|c|c|c|c|c|c|c|}
\hline \multirow{3}{*}{ Specimen notation } & \multirow{2}{*}{\multicolumn{2}{|c|}{$\begin{array}{l}\text { Bar property } \\
\text { Nom. bar dia. }\end{array}$}} & \multirow{2}{*}{\multicolumn{2}{|c|}{ Slip (mm) }} & \multirow{3}{*}{$\begin{array}{c}\mathrm{f}_{\mathrm{c}} \\
(\mathrm{MPa})\end{array}$} & \multirow{3}{*}{$\begin{array}{l}\mathrm{P}_{\text {max }}^{\mathrm{a}} \\
(\mathrm{KN})\end{array}$} & \multicolumn{2}{|c|}{ Bond strength } & \multirow{3}{*}{ SD } & \multirow{3}{*}{$\mathrm{COV}$} & \multirow{3}{*}{$\begin{array}{l}\text { Failure } \\
\text { mode }^{c}\end{array}$} \\
\hline & & & & & & & \multirow{2}{*}{$\begin{array}{c}\tau_{\max } \\
(\mathrm{MPa})\end{array}$} & \multirow{2}{*}{$\begin{array}{l}\tau_{\text {chr. }} \text { d } \\
(\mathrm{MPa})\end{array}$} & & & \\
\hline & $\mathrm{mm}$ & in & $\mathrm{S}_{\mathrm{fe}}{ }^{\mathrm{b}}$ & $\mathrm{S}_{\mathrm{le}}^{\mathrm{b}}$ & & & & & & & \\
\hline G5-150x150x200/H1 & 15.88 & 0.625 & 0.01 & 30.07 & 34.90 & 138.6 & 13.9 & \multirow{3}{*}{11.85} & \multirow{3}{*}{1.69} & \multirow{3}{*}{0.14} & CS-POHB \\
\hline G5-150x150x200/H2 & 15.88 & 0.625 & 0.01 & 26.5 & 34.90 & 101.2 & 10.14 & & & & CS-POHB \\
\hline G5-150x150x200/H3 & 15.88 & 0.625 & 0.02 & 26.8 & 34.90 & 106.4 & 10.6 & & & & CS-POHB \\
\hline G5-150x150x250/H1 & 15.88 & 0.625 & 0.07 & 30.15 & 34.90 & 127.59 & 10.2 & \multirow{3}{*}{9.97} & \multirow{3}{*}{0.68} & \multirow{3}{*}{0.068} & CS-POHB \\
\hline G5-150x150x250/H2 & 15.88 & 0.625 & 0.2 & 27.1 & 34.90 & 131.96 & 10.5 & & & & CS-POHB \\
\hline G5-150x150x250/H3 & 15.88 & 0.625 & 0.27 & 24.45 & 34.90 & 114.63 & 9.2 & & & & CS-POHB \\
\hline G6-150x150x100/S1 & 19.05 & 0.75 & 0.02 & 25.03 & 34.90 & 57.3 & 9.57 & \multirow{3}{*}{10.5} & \multirow{3}{*}{1.03} & \multirow{3}{*}{0.098} & $\mathrm{CS}$ \\
\hline G6-150x150x100/S2 & 19.05 & 0.75 & 0.09 & 23.98 & 34.90 & 61.42 & 10.3 & & & & $\mathrm{PO}$ \\
\hline G6-150x150x100/S3 & 19.05 & 0.75 & 0.01 & 22.38 & 34.90 & 69.39 & 11.6 & & & & $\mathrm{CS}$ \\
\hline G6-150x150x150/S1 & 19.05 & 0.75 & 0.03 & 24.9 & 34.90 & 85.96 & 9.57 & \multirow{3}{*}{10.03} & \multirow{3}{*}{0.51} & \multirow{3}{*}{0.050} & $\mathrm{PO}$ \\
\hline G6-150x150x150/S2 & 19.05 & 0.75 & 0.01 & 22.69 & 34.90 & 94.93 & 10.57 & & & & $\mathrm{CS}$ \\
\hline G6-150x150x150/S3 & 19.05 & 0.75 & 0.03 & 25.95 & 34.90 & 89.23 & 9.94 & & & & $\mathrm{CS}$ \\
\hline G6-150x150x200/S1 & 19.05 & 0.75 & 0.16 & 25.52 & 34.90 & 118.47 & 9.8 & \multirow{3}{*}{9.57} & \multirow{3}{*}{1.16} & & $\mathrm{PO}$ \\
\hline G6-150x150x200/S2 & 19.05 & 0.75 & 0.01 & 27.47 & 34.90 & 127.29 & 10.6 & & & & $\mathrm{CS}$ \\
\hline G6-150x150x200/S3 & 19.05 & 0.75 & 0.11 & 24.38 & 34.90 & 99.53 & 8.31 & & & & $\mathrm{PO}$ \\
\hline G6-150x150x250/S1 & 19.05 & 0.75 & 0.01 & 23.81 & 34.90 & 101.75 & 6.8 & \multirow{3}{*}{8.44} & \multirow{3}{*}{0.12} & & $\mathrm{CS}$ \\
\hline G6-150x150x250/S2 & 19.05 & 0.75 & 0.08 & 24.96 & 34.90 & 135.68 & 9.07 & & & & $\mathrm{PO}$ \\
\hline G6-150x150x250/S3 & 19.05 & 0.75 & 0.11 & 22.36 & 34.90 & 141.63 & 9.46 & & & & $\mathrm{PO}$ \\
\hline
\end{tabular}


Table A.3 Experimental pullout cube results for single GFRP bars $\mathrm{f}_{\mathrm{c}}=34.9 \mathrm{MPa}$

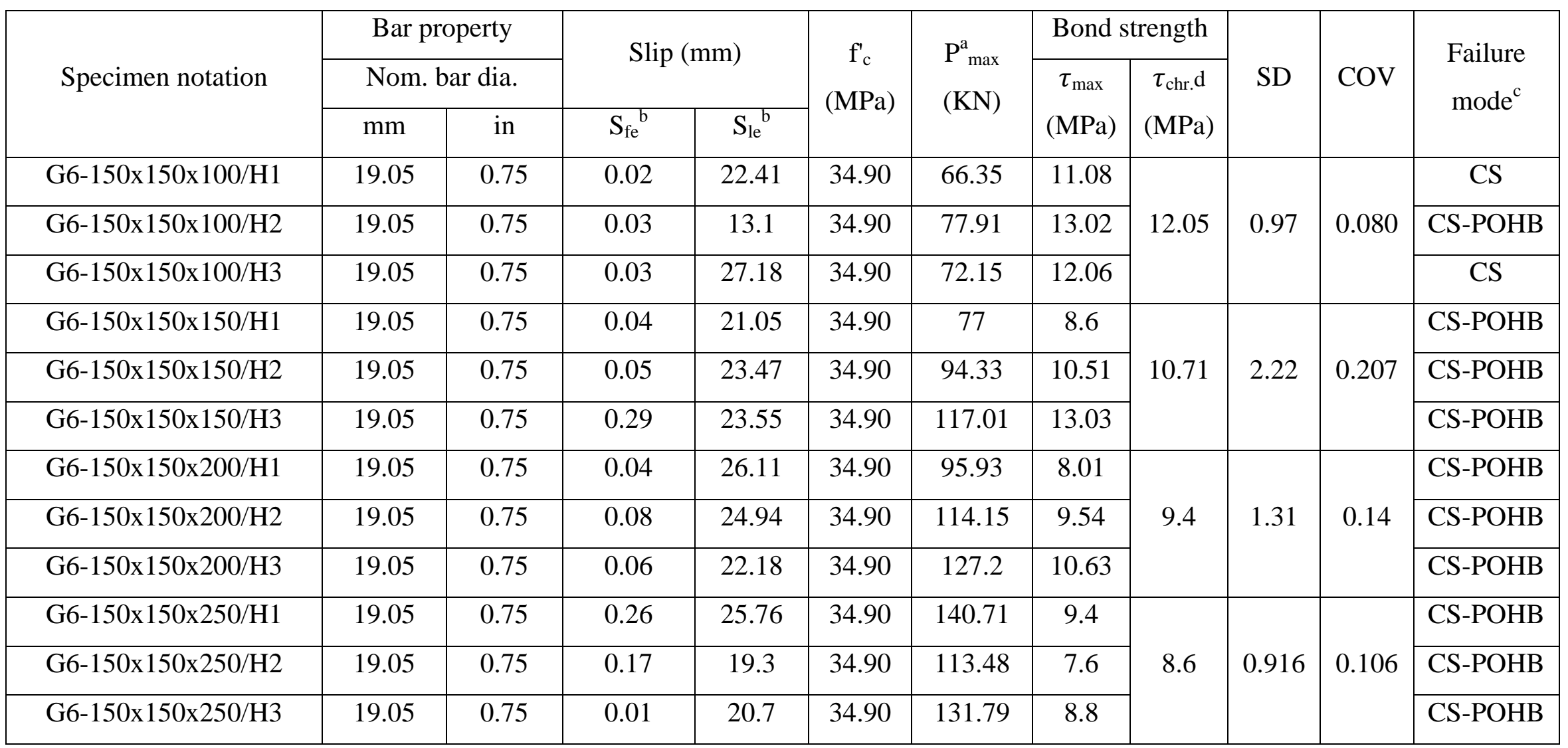

(a) Maximum peak load

(b) Maximum slip at peak load

(c) $\mathrm{PO}=$ pull-out; $\mathrm{RR}=$ rebar rupture; $\mathrm{CS}=$ concrete splitting; $\mathrm{CS}-\mathrm{POHB}=$ concrete splitting with bar pulled-out from head broken; $\mathrm{POHB}=$ bar pulled-out from broken head

(d) $\tau_{\text {chr }}$ is the characteristic bond strength obtained from 3 identical samples 
Table A.3 Experimental pullout cube results for single GFRP bars $\mathrm{f}_{\mathrm{c}}=34.9 \mathrm{MPa}$

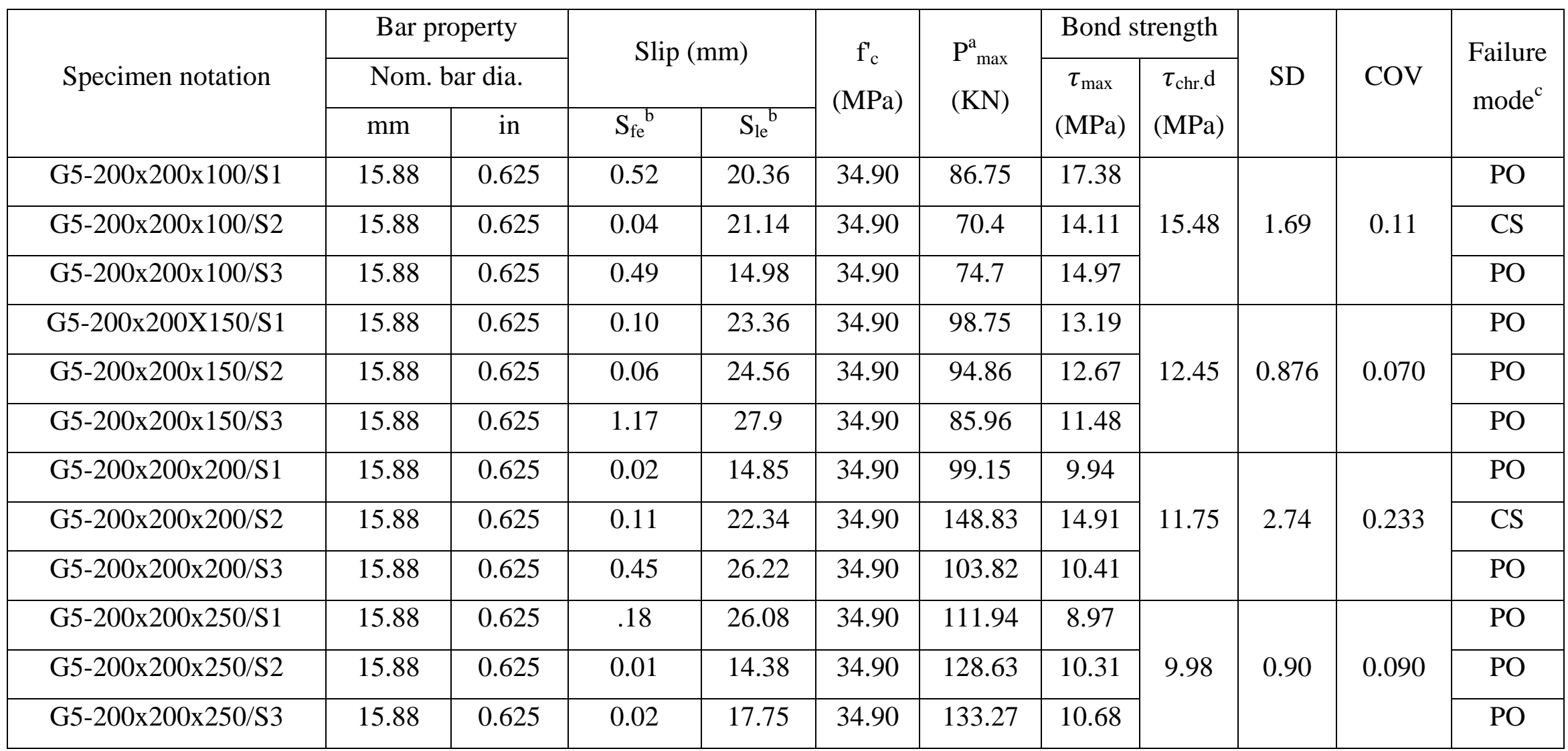

(e) Maximum peak load

(f) Maximum slip at peak load

(g) $\mathrm{PO}=$ pull-out; $\mathrm{RR}=$ rebar rupture; $\mathrm{CS}=$ concrete splitting; $\mathrm{CS}-\mathrm{POHB}=$ concrete splitting with bar pulled-out from head broken; POHB = bar pulled-out from broken head

(h) $\tau_{\text {chr }}$ is the characteristic bond strength obtained from 3 identical samples 
Table A.3 Experimental pullout cube results for single GFRP bars $\mathrm{f}_{\mathrm{c}}=34.9 \mathrm{MPa}$

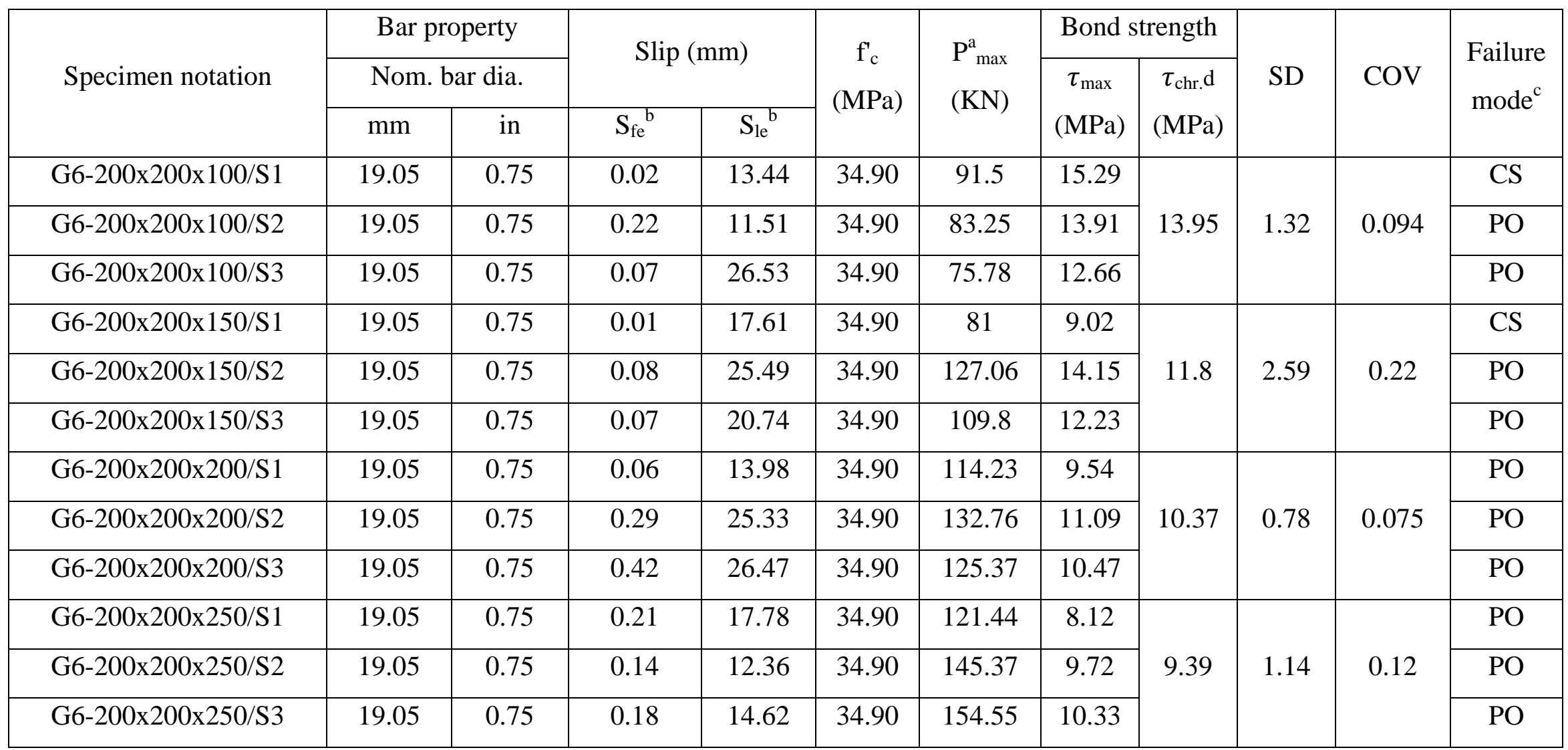

(a) Maximum peak load

(b) Maximum slip at peak load

(c) $\mathrm{PO}=$ pull-out; $\mathrm{RR}=$ rebar rupture; $\mathrm{CS}=$ concrete splitting; $\mathrm{CS}-\mathrm{POHB}=$ concrete splitting with bar pulled-out from head broken; POHB = bar pulled-out from broken head

(d) $\tau_{\text {chr }}$ is the characteristic bond strength obtained from 3 identical samples 
Table A.3 Experimental pullout cube results for single GFRP bars $\mathrm{f}_{\mathrm{c}}=34.9 \mathrm{MPa}$

\begin{tabular}{|c|c|c|c|c|c|c|c|c|c|c|c|}
\hline \multirow{3}{*}{ Specimen notation } & \multirow{2}{*}{\multicolumn{2}{|c|}{$\begin{array}{l}\text { Bar property } \\
\text { Nom. bar dia. }\end{array}$}} & \multirow{2}{*}{\multicolumn{2}{|c|}{ Slip (mm) }} & \multirow{3}{*}{$\begin{array}{c}\mathrm{f}_{\mathrm{c}}^{\prime} \\
(\mathrm{MPa})\end{array}$} & \multirow{3}{*}{$\begin{array}{l}\mathrm{P}_{\text {max }}^{\mathrm{a}} \\
(\mathrm{KN})\end{array}$} & \multicolumn{2}{|c|}{ Bond strength } & \multirow{3}{*}{ SD } & \multirow{3}{*}{$\mathrm{COV}$} & \multirow{3}{*}{$\begin{array}{l}\text { Failure } \\
\text { mode }^{c}\end{array}$} \\
\hline & & & & & & & \multirow{2}{*}{$\begin{array}{c}\tau_{\max } \\
(\mathrm{MPa})\end{array}$} & \multirow{2}{*}{$\begin{array}{c}\tau_{\text {chr. }} \text { d } \\
(\mathrm{MPa})\end{array}$} & & & \\
\hline & $\mathrm{mm}$ & in & $\mathrm{S}_{\mathrm{fe}}{ }^{\mathrm{b}}$ & $\mathrm{S}_{\mathrm{le}}^{\mathrm{b}}$ & & & & & & & \\
\hline G5-300x300x100/H1 & 15.88 & 0.625 & 0.18 & 9.6 & 34.90 & 121.15 & 24.28 & \multirow[b]{2}{*}{24.16} & \multirow[b]{2}{*}{3.70} & \multirow[b]{2}{*}{0.153} & CS-POHB \\
\hline G5-300x300x100/H2 & 15.88 & 0.625 & 0.16 & 9.28 & 34.90 & 138.71 & 27.8 & & & & CS-POHB \\
\hline G5-300x300x150/H2 & 15.88 & 0.625 & 0.12 & 17.74 & 34.90 & 133.65 & 17.86 & \multirow[t]{2}{*}{17.82} & \multirow[t]{2}{*}{0.94} & \multirow[t]{2}{*}{0.052} & CS-POHB \\
\hline G5-300x300x150/H3 & 15.88 & 0.625 & 0.14 & 21.88 & 34.90 & 140.23 & 18.74 & & & & CS-POHB \\
\hline G5-300x300x200/H1 & 15.88 & 0.625 & 0.07 & 22.62 & 34.90 & 132.27 & 13.26 & 14.88 & 1.67 & 0.11 & POHB \\
\hline G5-300x300x250/H2 & 15.88 & 0.625 & 0.03 & 26.44 & 34.90 & 169.61 & 13.6 & \multirow[t]{2}{*}{12.6} & \multirow[t]{2}{*}{0.91} & \multirow[t]{2}{*}{0.072} & POHB \\
\hline G5-300x300x250/H3 & 15.88 & 0.625 & 0.16 & 16.84 & 34.90 & 153.85 & 12.34 & & & & POHB \\
\hline
\end{tabular}

(a) Maximum peak load

(b) Maximum slip at peak load

(c) $\mathrm{PO}=$ pull-out; $\mathrm{RR}=$ rebar rupture; $\mathrm{CS}=$ concrete splitting; $\mathrm{CS}-\mathrm{POHB}=$ concrete splitting with bar pulled-out from head broken; $\mathrm{POHB}=$ bar pulled-out from broken head

(d) $\tau_{\text {chr }}$ is the characteristic bond strength obtained from 3 identical samples 
Table A.3 Experimental pullout cube results for single GFRP bars $\mathrm{f}_{\mathrm{c}}=34.9 \mathrm{MPa}$

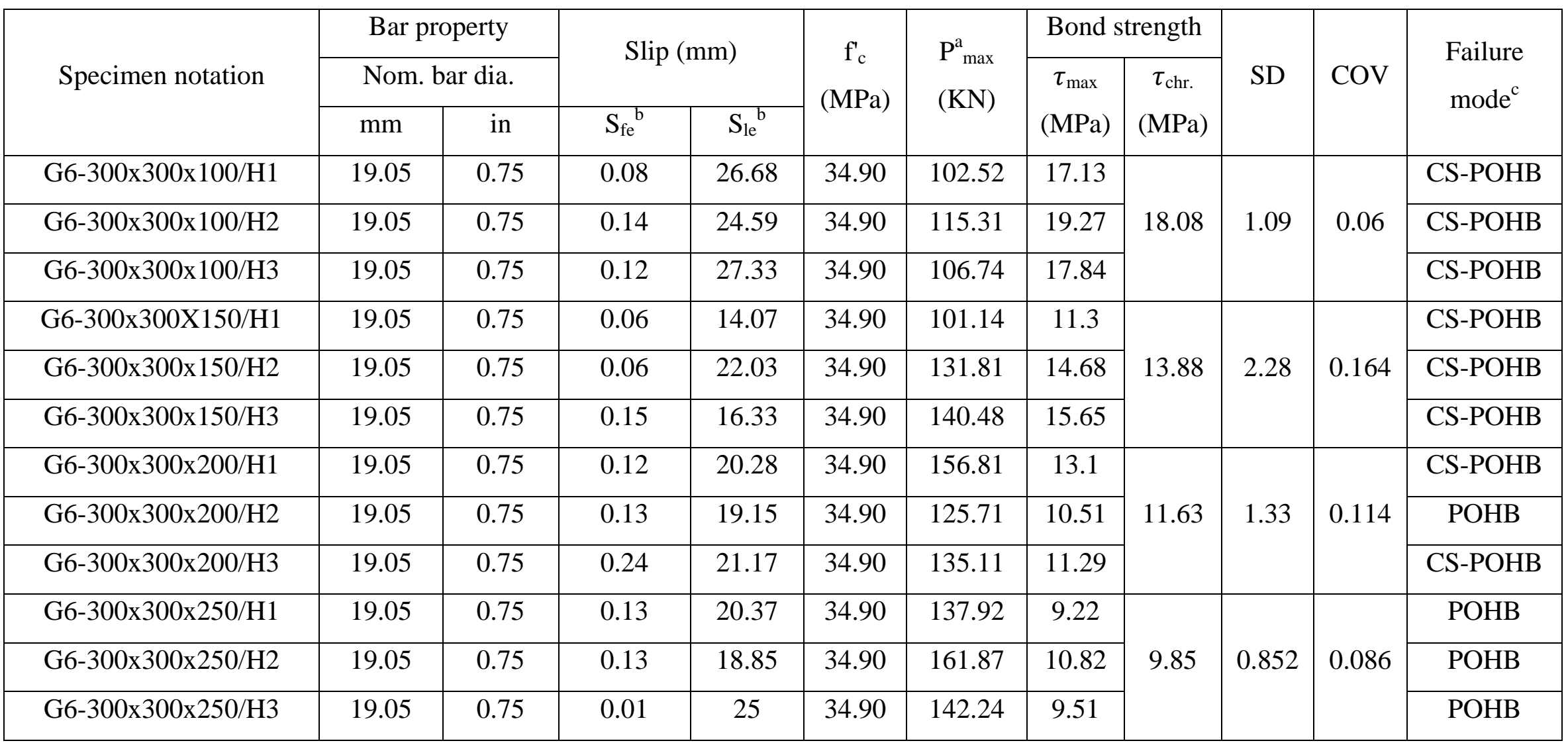

\footnotetext{
(a) Maximum peak load

(b) Maximum slip at peak load

(c) $\mathrm{PO}=$ pull-out; $\mathrm{RR}=$ rebar rupture; $\mathrm{CS}=$ concrete splitting; $\mathrm{CS}-\mathrm{POHB}=$ concrete splitting with bar pulled-out from head broken; $\mathrm{POHB}=$ bar pulled-out from broken head

(d) $\tau_{\text {chr }}$ is the characteristic bond strength obtained from 3 identical samples
} 
Table A.3 Experimental pullout cube results for single GFRP bars $\mathrm{f}_{\mathrm{c}}=34.9 \mathrm{MPa}$

\begin{tabular}{|c|c|c|c|c|c|c|c|c|c|c|c|}
\hline \multirow{3}{*}{ Specimen notation } & \multirow{2}{*}{\multicolumn{2}{|c|}{$\begin{array}{l}\text { Bar property } \\
\text { Nom. bar dia. }\end{array}$}} & \multirow{2}{*}{\multicolumn{2}{|c|}{ Slip (mm) }} & \multirow{3}{*}{$\begin{array}{c}\mathrm{f}_{\mathrm{c}} \\
(\mathrm{MPa})\end{array}$} & \multirow{3}{*}{$\begin{array}{l}\mathrm{P}_{\max }^{\mathrm{a}} \\
(\mathrm{KN})\end{array}$} & \multicolumn{2}{|c|}{ Bond strength } & \multirow{3}{*}{ SD } & \multirow{3}{*}{$\mathrm{COV}$} & \multirow{3}{*}{$\begin{array}{l}\text { Failure } \\
\text { mode }^{c}\end{array}$} \\
\hline & & & & & & & \multirow{2}{*}{$\begin{array}{c}\tau_{\max } \\
(\mathrm{MPa})\end{array}$} & \multirow{2}{*}{$\begin{array}{c}\tau_{\mathrm{chr}} \\
(\mathrm{MPa})\end{array}$} & & & \\
\hline & $\mathrm{mm}$ & in & $\mathrm{S}_{\mathrm{fe}}{ }^{\mathrm{b}}$ & $\mathrm{S}_{\mathrm{le}}{ }^{\mathrm{b}}$ & & & & & & & \\
\hline G5-300x500x150/HO1 & 15.88 & 0.625 & 0.22 & 18.66 & 34.90 & 111.87 & 14.95 & 14.03 & 2.34 & 0.167 & $\mathrm{CS}$ \\
\hline G5-300x500x200/HO1 & 15.88 & 0.625 & 0.36 & 30.14 & 34.90 & 121.35 & 12.16 & \multirow[t]{2}{*}{12.3} & \multirow[t]{2}{*}{1.43} & \multirow[t]{2}{*}{0.117} & RR \\
\hline G5-300x500x200/HO1 & 15.88 & 0.625 & 0.23 & 30.31 & 34.90 & 109.18 & 10.94 & & & & RR \\
\hline G5-300x500x250/HO1 & 15.88 & 0.625 & 0.12 & 30.96 & 34.90 & 149.83 & 12.01 & 11.58 & 1.24 & 0.107 & RR \\
\hline G6-300x500x150/HO1 & 19.05 & 0.75 & 0.01 & 17.77 & 34.90 & 94.35 & 10.51 & \multirow[t]{2}{*}{13.33} & \multirow[t]{2}{*}{2.68} & \multirow[t]{2}{*}{0.201} & $\mathrm{CS}$ \\
\hline G6-300x500x150/HO1 & 19.05 & 0.75 & 0.01 & 27.81 & 34.90 & 142.32 & 15.85 & & & & $\mathrm{RR}$ \\
\hline G6-300x500x200/HO1 & 19.05 & 0.75 & 0.10 & 21.86 & 34.90 & 126.37 & 10.56 & \multirow{3}{*}{11.77} & \multirow{3}{*}{1.14} & \multirow{3}{*}{0.096} & $\mathrm{RR}$ \\
\hline G6-300x500x200/HO1 & 19.05 & 0.75 & 0.15 & 28.37 & 34.90 & 143.08 & 11.95 & & & & RR \\
\hline G6-300x500x200/HO1 & 19.05 & 0.75 & 0.06 & 34.62 & 34.90 & 153.4 & 12.81 & & & & $\mathrm{RR}$ \\
\hline G6-300x500x250/HO1 & 19.05 & 0.75 & 0.13 & 25.59 & 34.90 & 176.59 & 11.8 & \multirow{3}{*}{11.03} & \multirow{3}{*}{0.97} & \multirow{3}{*}{0.088} & RR \\
\hline G6-300x500x250/HO1 & 19.05 & 0.75 & 0.04 & 25.66 & 34.90 & 148.76 & 9.94 & & & & $\mathrm{RR}$ \\
\hline G6-300x500x250/HO1 & 19.05 & 0.75 & 0.06 & 27.52 & 34.90 & 169.61 & 11.34 & & & & RR \\
\hline
\end{tabular}




\section{Appendix B}

\section{Results from Concrete Core Sampling}


Table B.1 Concrete core sample detailing of the tested barrier walls

\begin{tabular}{|c|c|c|c|c|c|c|c|c|c|c|}
\hline \multirow{2}{*}{$\begin{array}{c}\text { Sample } \\
\text { No. }\end{array}$} & \multirow{2}{*}{$\begin{array}{c}\text { Ultimate } \\
\text { load } \\
(\mathrm{kN})\end{array}$} & \multirow{2}{*}{$\begin{array}{c}\mathrm{f}_{\text {core }} \\
(\mathrm{MPa})\end{array}$} & \multirow{2}{*}{$\begin{array}{c}\text { No. of } \\
\text { bars inside }\end{array}$} & \multirow{2}{*}{$\begin{array}{l}\text { Remarks } \\
\text { (type of } \\
\text { bars) }\end{array}$} & \multicolumn{5}{|c|}{ Correction factors $* *$} & \multirow{2}{*}{$\mathrm{f}_{\mathrm{eq}} *$} \\
\hline & & & & & $\mathrm{F}_{1 / \mathrm{d}}$ & $\mathrm{F}_{\mathrm{dia}}$ & $\mathrm{F}_{\mathrm{r}}$ & $\mathrm{F}_{\mathrm{mc}}$ & $F_{d}$ & \\
\hline 1 & 263.86 & 33.6 & - & No bars & 0.87 & 1 & 1 & 1.08 & 1 & 31.57 \\
\hline 2 & 189.28 & 24.1 & - & No bars & 0.87 & 1 & 1 & 1.08 & 1 & 22.64 \\
\hline 3 & 248.74 & 31.67 & - & No bars & 0.87 & 1 & 1 & 1.08 & 1 & 29.76 \\
\hline 4 & 212.51 & 27.05 & - & No bars & 0.87 & 1 & 1 & 1.08 & 1 & 25.41 \\
\hline 5 & 229.73 & 29.25 & - & No bars & 0.87 & 1 & 1 & 1.08 & 1 & 27.48 \\
\hline 6 & 209.71 & 26.7 & - & No bars & 0.87 & 1 & 1 & 1.08 & 1 & 25.09 \\
\hline 7 & 282.12 & 35.92 & - & No bars & 0.87 & 1 & 1 & 1.08 & 1 & 33.75 \\
\hline 8 & 304.39 & 38.75 & - & No bars & 0.87 & 1 & 1 & 1.08 & 1 & 36.41 \\
\hline 9 & 212.45 & 27.05 & 2 & Steel bars & 0.87 & 1 & 1.13 & 1.08 & 1 & 28.72 \\
\hline 10 & 180.95 & 23.4 & 1 & Steel bars & 0.87 & 1 & 1.08 & 1.08 & 1 & 23.74 \\
\hline 11 & 222.27 & 28.3 & 1 & Steel bars & 0.87 & 1 & 1.08 & 1.08 & 1 & 28.72 \\
\hline 12 & 186.55 & 23.75 & 1 & Steel bars & 0.87 & 1 & 1.08 & 1.08 & 1 & 24.10 \\
\hline 13 & 230.12 & 29.3 & 1 & Steel bars & 0.87 & 1 & 1.08 & 1.08 & 1 & 29.73 \\
\hline 14 & 212.47 & 27.05 & 1 & FRP bars & 0.87 & 1 & 1.08 & 1.08 & 1 & 27.45 \\
\hline 15 & 221.6 & 28.2 & 1 & FRP bars & 0.87 & 1 & 1.08 & 1.08 & 1 & 28.62 \\
\hline 16 & 208.2 & 26.51 & 1 & FRP bars & 0.87 & 1 & 1.08 & 1.08 & 1 & 26.90 \\
\hline 17 & 236.94 & 30.17 & 2 & FRP bars & 0.87 & 1 & 1.13 & 1.08 & 1 & 32.03 \\
\hline 18 & 240.39 & 30.6 & 2 & FRP bars & 0.87 & 1 & 1.13 & 1.08 & 1 & 32.48 \\
\hline 19 & 229.44 & 29.2 & 1 & FRP bars & 0.87 & 1 & 1.08 & 1.08 & 1 & 29.63 \\
\hline 20 & 303.39 & 38.63 & 2 & FRP bars & 0.87 & 1 & 1.13 & 1.08 & 1 & 41.02 \\
\hline 21 & 339.14 & 43.18 & 2 & FRP bars & 0.87 & 1 & 1.13 & 1.08 & 1 & 45.84 \\
\hline 22 & 233.02 & 29.67 & 2 & FRP bars & 0.87 & 1 & 1.13 & 1.08 & 1 & 31.50 \\
\hline 23 & 218.27 & 27.79 & 1 & FRP bars & 0.87 & 1 & 1.08 & 1.08 & 1 & 28.20 \\
\hline 24 & 300.58 & 38.2 & 1 & FRP bars & 0.87 & 1 & 1.08 & 1.08 & 1 & 38.76 \\
\hline 25 & 231.7 & 29.5 & 1 & FRP bars & 0.87 & 1 & 1.08 & 1.08 & 1 & 29.94 \\
\hline
\end{tabular}

* $\mathrm{f}_{\mathrm{eq}}=\mathrm{f}_{\text {core }}\left(\mathrm{F}_{\mathrm{l} / \mathrm{d}} \cdot \mathrm{F}_{\mathrm{dia}} \cdot \mathrm{F}_{\mathrm{r}} \cdot \mathrm{F}_{\mathrm{mc}} . \mathrm{F}_{\mathrm{d}}\right)=$ equivalent compressive strength of tested core sample as influenced by strength correction factors (MacGregor and Bartlett, 2000)

$* * \mathrm{~F}_{1 / \mathrm{d}}=$ Correction factor for length/diameter ratio

$\mathrm{F}_{\mathrm{dia}}=$ Correction factor for diameter of core

$\mathrm{F}_{\mathrm{r}}=$ Correction factor for the presence of reinforcement

$\mathrm{F}_{\mathrm{mc}}=$ Correction factor to account for the effect of moisture content

$\mathrm{F}_{\mathrm{d}}=$ Correction factor for the effect of the damage of the core surface during drilling

$\mathrm{f}_{\text {core }}=$ Compressive strength of tested core sample 
Table B.2 Calculated characteristic compressive strength of the barrier walls

\begin{tabular}{|c|c|c|c|c|c|c|}
\hline & $\mathrm{n}$ & $\mathrm{K}_{\mathrm{c}}$ & $\begin{array}{c}\overline{\mathrm{f}}_{\mathrm{eq}} \\
(\mathrm{MPa})\end{array}$ & $\begin{array}{c}\text { Standard } \\
\text { deviation }(\mathrm{SD})\end{array}$ & $\begin{array}{c}\text { Coefficient of } \\
\text { variation }(\mathrm{V})\end{array}$ & $\begin{array}{c}\mathrm{f}_{\mathrm{c}}{ }^{* * * *} \\
(\mathrm{MPa})\end{array}$ \\
\hline All samples included & 25 & 1.02 & 30.38 & 5.575 & 0.1881 & 25.43 \\
\hline
\end{tabular}

$* * * \mathrm{f}_{\mathrm{c}}^{\prime}=0.9 \overline{\mathrm{f}}_{\mathrm{eq}}\left\{1-1.28 \sqrt{\frac{(K c . V)^{2}}{n}+0.0015}\right\}=$ characteristic strength as affected by the number of samples tested and the change of the strength value of each sample as compared to the average value (CSA, 2006b).

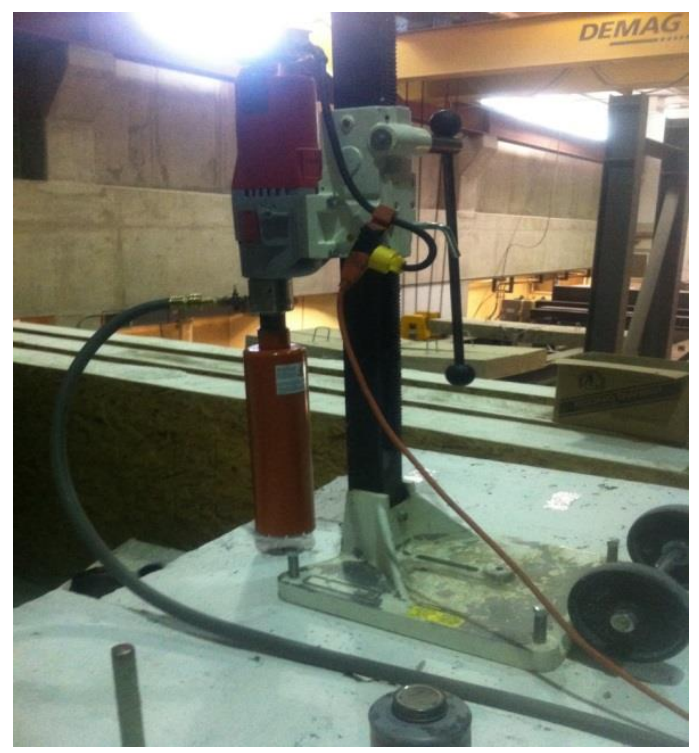

Figure B.1 Photo of core sampling machine

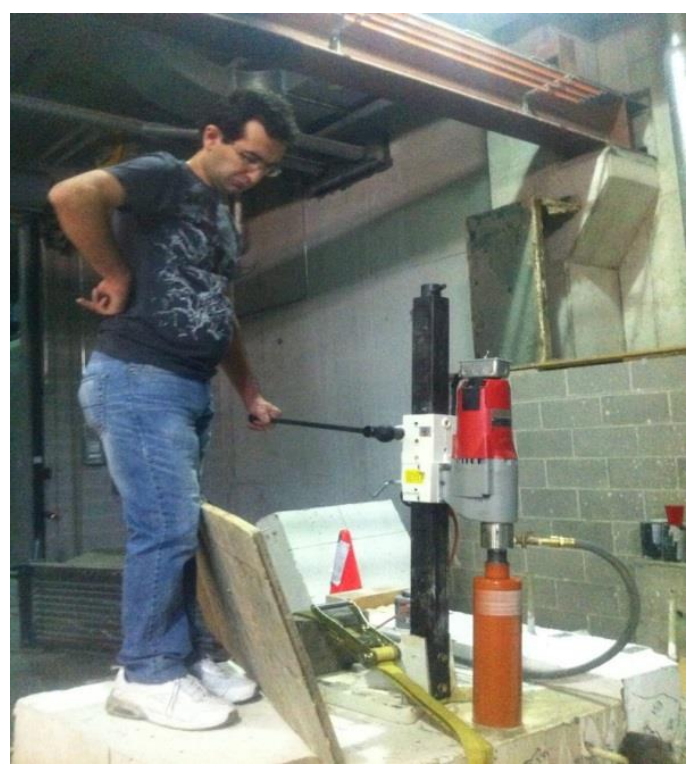

Figure B.2 Core sampling of the tested barrier wall 


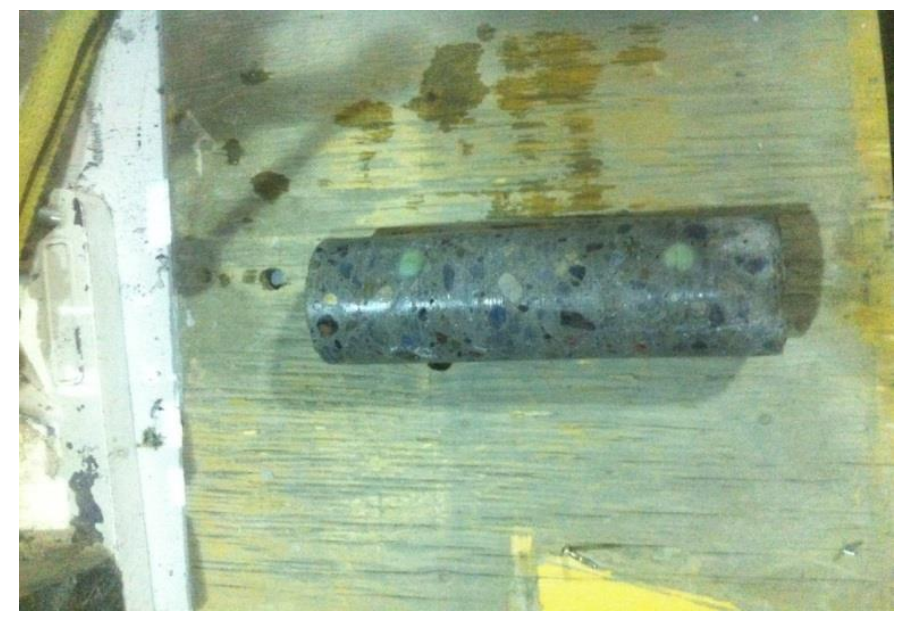

Figure B.3 Image of a core sample taken from the barriers

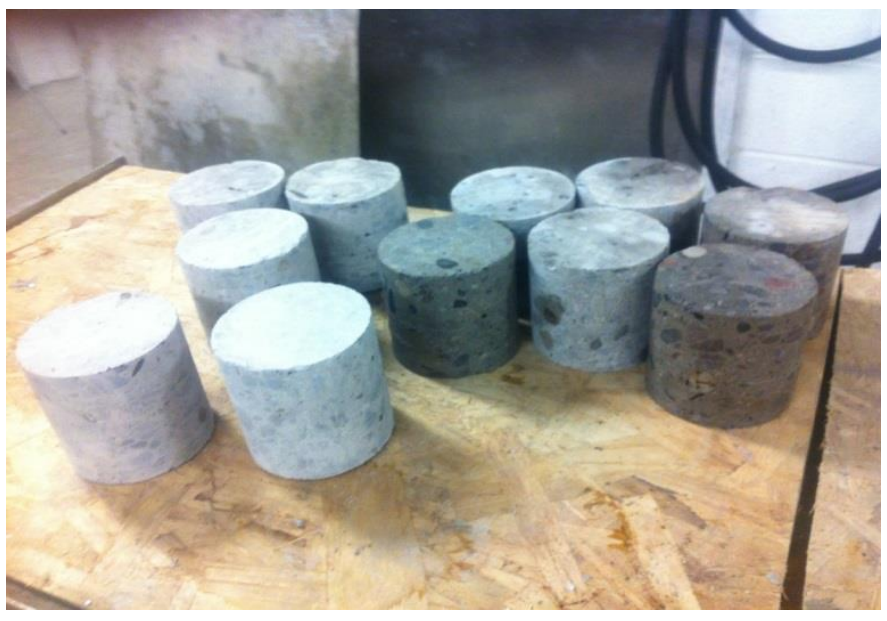

Figure B.4 Image of core samples after cutting and grinding

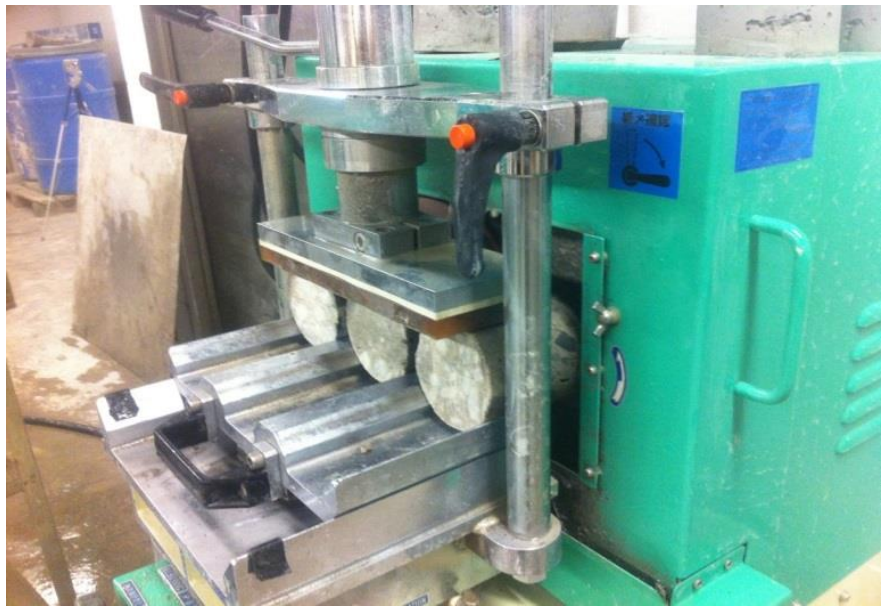

Figure B.5 Concrete cap grinding machine 


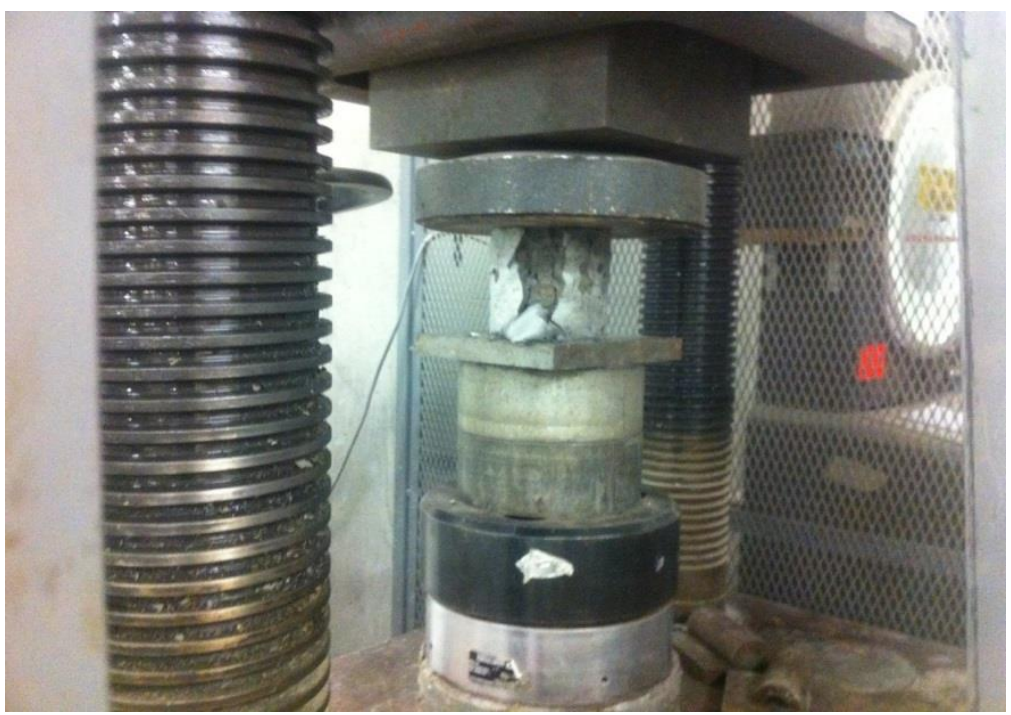

Figure B.6 Concrete compressive strength testing machine during testing

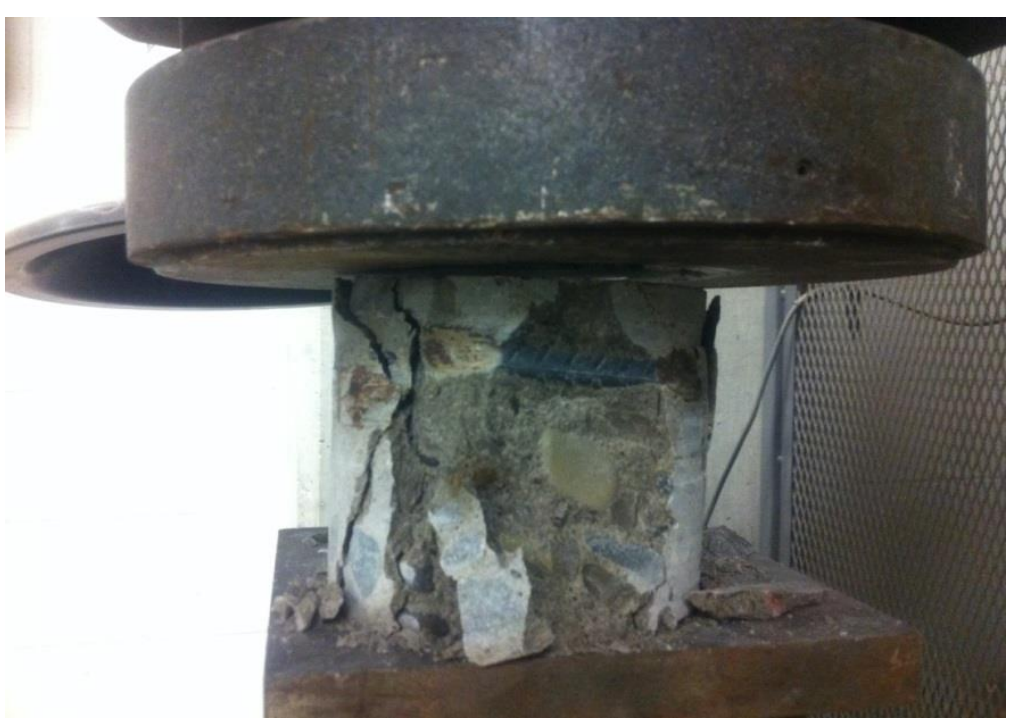

Figure B.7 Close-up view of tested concrete core showing presence of steel bar in the core sample 


\section{Appendix C}

Results of Strut and Tie Model in Barrier Models 1 to 5 
Table C-S1 Applied load to design strength of Struts in Barrier Model 1 (GS1- HM)-CSA A23.3

\begin{tabular}{|c|c|c|c|c|c|c|c|}
\hline $\begin{array}{c}\text { Strut } \\
\text { No. }\end{array}$ & $\begin{array}{c}\text { Load in strut } \\
\mathrm{F},(\mathrm{kN})\end{array}$ & $\beta_{\mathrm{s}}$ & $\varphi_{\mathrm{c}}$ & $\begin{array}{c}\varphi_{\mathrm{c}} \alpha_{1} \beta_{\mathrm{s}} f_{\mathrm{c}} \\
(\mathrm{MPa})\end{array}$ & $\begin{array}{c}\text { Width of strut } \\
\mathrm{W}_{\mathrm{s}},(\mathrm{mm})\end{array}$ & $\begin{array}{c}\varphi_{\mathrm{c}} \mathrm{F}_{\mathrm{ns}} \\
(\mathrm{kN})\end{array}$ & $\mathrm{F} /\left(\varphi_{\mathrm{c}} \mathrm{F}_{\mathrm{ns}}\right)$ \\
\hline $\mathrm{S} 1$ & 106.1 & 1.00 & 0.65 & 14.03 & 100 & 1403 & 0.076 \\
\hline $\mathrm{S} 2$ & 290.8 & 0.31 & 0.65 & 4.14 & 105 & 414 & 0.702 \\
\hline $\mathrm{S} 3$ & 0 & 0.31 & 0.65 & 4.14 & 100 & 414 & 0 \\
\hline S4 & 0 & 1.00 & 0.65 & 14.03 & 100 & 1403 & 0 \\
\hline S5 & 735.6 & 0.285 & 0.65 & 3.82 & 100 & 382 & 1.920 \\
\hline S6 & 871.9 & 0.21 & 0.65 & 2.81 & 105 & 295 & 2.960 \\
\hline
\end{tabular}

$f_{\mathrm{c}}^{\prime}=25.4 \mathrm{MPa}, \quad a_{1}=0.85-0.0015 * 25.4=0.81$

$\mathrm{F}_{\mathrm{ns}}=f_{\mathrm{ce}} \mathrm{A}_{\mathrm{cs}}=\alpha_{1} \beta_{\mathrm{s}} f_{\mathrm{c}}$. $\mathrm{A}_{\mathrm{cs}}$

$\mathrm{A}_{\mathrm{cs}}=\mathrm{W}_{\mathrm{s}} \cdot \mathrm{b}(\mathrm{b}=1000 \mathrm{~mm})$

Table C-S2 Applied load to design strength of Struts in Barrier Model 2 (GS2- ST) - CSA A23.3

\begin{tabular}{|c|c|c|c|c|c|c|c|}
\hline $\begin{array}{c}\text { Strut } \\
\text { No. }\end{array}$ & $\begin{array}{c}\text { Load in strut } \\
\mathrm{F},(\mathrm{kN})\end{array}$ & $\beta_{\mathrm{s}}$ & $\varphi_{\mathrm{c}}$ & $\begin{array}{c}\varphi_{\mathrm{c}} \alpha_{1} \beta_{\mathrm{s}} f_{\mathrm{c}} \\
(\mathrm{MPa})\end{array}$ & $\begin{array}{c}\text { Width of strut } \\
\mathrm{W}_{\mathrm{s}},(\mathrm{mm})\end{array}$ & $\begin{array}{c}\varphi_{\mathrm{c}} \mathrm{F}_{\mathrm{ns}} \\
(\mathrm{kN})\end{array}$ & $\mathrm{F} /\left(\varphi_{\mathrm{c}} \mathrm{F}_{\mathrm{ns}}\right)$ \\
\hline $\mathrm{S} 1$ & 116.3 & 1.00 & 0.65 & 13.37 & 100 & 1337 & 0.087 \\
\hline $\mathrm{S} 2$ & 318.8 & 0.492 & 0.65 & 6.6 & 105 & 693 & 0.46 \\
\hline $\mathrm{S} 3$ & 0 & 0.494 & 0.65 & 6.6 & 100 & 660 & 0 \\
\hline S4 & 0 & 1.00 & 0.65 & 13.37 & 100 & 1337 & 0 \\
\hline S5 & 806.4 & 0.46 & 0.65 & 6.15 & 100 & 615 & 1.310 \\
\hline S6 & 922.65 & 0.34 & 0.65 & 4.55 & 105 & 478 & 1.930 \\
\hline
\end{tabular}

Table C-S3 Applied load to design strength of Struts in Barrier Model 3 (GS3- ST) - CSA A23.3

\begin{tabular}{|c|c|c|c|c|c|c|c|}
\hline $\begin{array}{c}\text { Strut } \\
\text { No. }\end{array}$ & $\begin{array}{c}\text { Load in strut } \\
\mathrm{F},(\mathrm{kN})\end{array}$ & $\beta_{\mathrm{s}}$ & $\varphi_{\mathrm{c}}$ & $\begin{array}{c}\varphi_{\mathrm{c}} \alpha_{1} \beta_{\mathrm{s}} f_{\mathrm{c}} \\
(\mathrm{MPa})\end{array}$ & $\begin{array}{c}\text { Width of strut } \\
\mathrm{W}_{\mathrm{s}},(\mathrm{mm})\end{array}$ & $\begin{array}{c}\varphi_{\mathrm{c}} \mathrm{F}_{\mathrm{ns}} \\
(\mathrm{KN})\end{array}$ & $\mathrm{F} /\left(\varphi_{\mathrm{c}} \mathrm{F}_{\mathrm{ns}}\right)$ \\
\hline S1 & 107.2 & 1.00 & 0.65 & 13.37 & 100 & 1337 & 0.080 \\
\hline S2 & 293.86 & 0.492 & 0.65 & 6.6 & 105 & 693 & 0.43 \\
\hline S3 & 0 & 0.494 & 0.65 & 6.6 & 100 & 660 & 0 \\
\hline S4 & 0 & 1.00 & 0.65 & 13.37 & 100 & 1337 & 0 \\
\hline S5 & 743.3 & 0.46 & 0.65 & 6.15 & 100 & 615 & 1.210 \\
\hline S6 & 880.9 & 0.34 & 0.65 & 4.55 & 105 & 478 & 1.840 \\
\hline
\end{tabular}


Table C-S4 Applied load to design strength of Struts in Barrier Model 4 (GS4- HM)- CSA A23.3

\begin{tabular}{|c|c|c|c|c|c|c|c|}
\hline $\begin{array}{c}\text { Strut } \\
\text { No. }\end{array}$ & $\begin{array}{c}\text { Load in strut } \\
\mathrm{F},(\mathrm{kN})\end{array}$ & $\beta_{\mathrm{s}}$ & $\varphi_{\mathrm{c}}$ & $\begin{array}{c}\varphi_{\mathrm{c}} \alpha_{1} \beta_{\mathrm{s}} f_{\mathrm{c}} \\
(\mathrm{MPa})\end{array}$ & $\begin{array}{c}\text { Width of strut } \\
\mathrm{W}_{\mathrm{s}},(\mathrm{mm})\end{array}$ & $\begin{array}{c}\varphi_{\mathrm{c}} \mathrm{F}_{\mathrm{ns}} \\
(\mathrm{kN})\end{array}$ & $\mathrm{F} /\left(\varphi_{\mathrm{c}} \mathrm{F}_{\mathrm{ns}}\right)$ \\
\hline $\mathrm{S} 1$ & 170.3 & 1.00 & 0.65 & 14.03 & 100 & 1403 & 0.12 \\
\hline $\mathrm{S} 2$ & 486.3 & 0.31 & 0.65 & 4.14 & 105 & 414 & 1.17 \\
\hline S3 & 0 & 0.31 & 0.65 & 4.14 & 100 & 414 & 0 \\
\hline S4 & 0 & 1.00 & 0.65 & 14.03 & 100 & 1403 & 0 \\
\hline S5 & 1180.7 & 0.285 & 0.65 & 3.82 & 100 & 382 & 3.10 \\
\hline S6 & 1399.5 & 0.21 & 0.65 & 2.81 & 105 & 295 & 4.74 \\
\hline
\end{tabular}

Table C-S5 Applied load to design strength of Struts in Barrier Model 5 (SS5- CS) - CSA A23.3

\begin{tabular}{|c|c|c|c|c|c|c|c|}
\hline $\begin{array}{c}\text { Strut } \\
\text { No. }\end{array}$ & $\begin{array}{c}\text { Load in strut } \\
\mathrm{F},(\mathrm{kN})\end{array}$ & $\beta_{\mathrm{s}}$ & $\varphi_{\mathrm{c}}$ & $\begin{array}{c}\varphi_{\mathrm{c}} \alpha_{1} \beta_{\mathrm{s}} f_{\mathrm{c}} \\
(\mathrm{MPa})\end{array}$ & $\begin{array}{c}\text { Width of strut } \\
\mathrm{W}_{\mathrm{s}},(\mathrm{mm})\end{array}$ & $\begin{array}{c}\varphi_{\mathrm{c}} \mathrm{F}_{\mathrm{ns}} \\
(\mathrm{kN})\end{array}$ & $\mathrm{F} /\left(\varphi_{\mathrm{c}} \mathrm{F}_{\mathrm{ns}}\right)$ \\
\hline $\mathrm{S} 1$ & 128.9 & 1.00 & 0.65 & 13.37 & 100 & 1337 & 0.096 \\
\hline $\mathrm{S} 2$ & 353.3 & 0.586 & 0.65 & 7.84 & 105 & 823 & 0.430 \\
\hline S3 & 0 & 1.00 & 0.65 & 13.37 & 100 & 1337 & 0 \\
\hline S4 & 0 & 1.00 & 0.65 & 13.37 & 100 & 1337 & 0 \\
\hline S5 & 893.7 & 1.00 & 0.65 & 13.37 & 100 & 1337 & 0.670 \\
\hline S6 & 1059.3 & 0.823 & 0.65 & 11 & 105 & 1155 & 0.920 \\
\hline
\end{tabular}

Table C-S6 Applied load to design strength of Struts in Barrier Model 1 (GS1- HM) - ACI-318

\begin{tabular}{|c|c|c|c|c|c|c|c|}
\hline $\begin{array}{c}\text { Strut } \\
\text { No. }\end{array}$ & $\begin{array}{c}\text { Load in strut } \\
\mathrm{F},(\mathrm{kN})\end{array}$ & $\beta_{\mathrm{s}}$ & $\varphi_{\mathrm{c}}$ & $\begin{array}{c}\varphi_{\mathrm{c}} 0.85 \beta_{\mathrm{s}} f_{\mathrm{c}} \\
(\mathrm{MPa})\end{array}$ & $\begin{array}{c}\text { Width of strut } \\
\mathrm{W}_{\mathrm{s}},(\mathrm{mm})\end{array}$ & $\begin{array}{c}\varphi_{\mathrm{c}} \mathrm{F}_{\mathrm{ns}} \\
(\mathrm{kN})\end{array}$ & $\mathrm{F} /\left(\varphi_{\mathrm{c}} \mathrm{F}_{\mathrm{ns}}\right)$ \\
\hline $\mathrm{S} 1$ & 106.1 & 1.0 & 0.75 & 16.2 & 100 & 1620 & 0.065 \\
\hline S2 & 290.8 & 0.6 & 0.75 & 9.72 & 105 & 1020.6 & 0.290 \\
\hline S3 & 0 & 0.6 & 0.75 & 9.72 & 100 & 972 & 0 \\
\hline S4 & 0 & 1.0 & 0.75 & 16.2 & 100 & 1620 & 0 \\
\hline S5 & 735.6 & 0.6 & 0.75 & 9.72 & 100 & 972 & 0.760 \\
\hline S6 & 871.9 & 0.6 & 0.75 & 9.72 & 105 & 1020.6 & 0.850 \\
\hline
\end{tabular}

$f_{\mathrm{c}}^{\prime}=25.4 \mathrm{MPa}$

$\mathrm{F}_{\mathrm{ns}}=f_{\mathrm{ce}} \mathrm{A}_{\mathrm{cs}}=0.85 \beta_{\mathrm{s}} f_{\mathrm{c}} . \mathrm{A}_{\mathrm{cs}}$

$\mathrm{A}_{\mathrm{cs}}=\mathrm{W}_{\mathrm{s}} \cdot \mathrm{b} \quad(\mathrm{b}=1000 \mathrm{~mm})$ 
Table C-S7 Applied load to design strength of Struts in Barrier Model 2 (GS2- ST) - ACI-318

\begin{tabular}{|c|c|c|c|c|c|c|c|}
\hline $\begin{array}{c}\text { Strut } \\
\text { No. }\end{array}$ & $\begin{array}{c}\text { Load in strut } \\
\mathrm{F},(\mathrm{kN})\end{array}$ & $\beta_{\mathrm{s}}$ & $\varphi_{\mathrm{c}}$ & $\begin{array}{c}\varphi_{\mathrm{c}} 0.85 \beta_{\mathrm{s}} f_{\mathrm{c}} \\
(\mathrm{MPa})\end{array}$ & $\begin{array}{c}\text { Width of strut } \\
\mathrm{W}_{\mathrm{s}},(\mathrm{mm})\end{array}$ & $\begin{array}{c}\varphi_{\mathrm{c}} \mathrm{F}_{\mathrm{ns}} \\
(\mathrm{kN})\end{array}$ & $\mathrm{F} /\left(\varphi_{\mathrm{c}} \mathrm{F}_{\mathrm{ns}}\right)$ \\
\hline $\mathrm{S} 1$ & 116.3 & 1.0 & 0.75 & 16.2 & 100 & 1620 & 0.072 \\
\hline $\mathrm{S} 2$ & 318.8 & 0.6 & 0.75 & 9.72 & 105 & 1020.6 & 0.320 \\
\hline $\mathrm{S} 3$ & 0 & 0.6 & 0.75 & 9.72 & 100 & 972 & 0 \\
\hline S4 & 0 & 1.0 & 0.75 & 16.2 & 100 & 1620 & 0 \\
\hline S5 & 806.4 & 0.6 & 0.75 & 9.72 & 100 & 972 & 0.830 \\
\hline S6 & 922.65 & 0.6 & 0.75 & 9.72 & 105 & 1020.6 & 0.910 \\
\hline
\end{tabular}

Table C-S8 Applied load to design strength of Struts in Barrier Model 3 (GS3- ST) - ACI-318

\begin{tabular}{|c|c|c|c|c|c|c|c|}
\hline $\begin{array}{c}\text { Strut } \\
\text { No. }\end{array}$ & $\begin{array}{c}\text { Load in strut } \\
\mathrm{F},(\mathrm{kN})\end{array}$ & $\beta_{\mathrm{s}}$ & $\varphi_{\mathrm{c}}$ & $\begin{array}{c}\varphi_{\mathrm{c}} 0.85 \beta_{\mathrm{s}} f_{\mathrm{c}} \\
(\mathrm{MPa})\end{array}$ & $\begin{array}{c}\text { Width of strut } \\
\mathrm{W}_{\mathrm{s}},(\mathrm{mm})\end{array}$ & $\begin{array}{c}\varphi_{\mathrm{c}} \mathrm{F}_{\mathrm{ns}} \\
(\mathrm{kN})\end{array}$ & $\mathrm{F} /\left(\varphi_{\mathrm{c}} \mathrm{F}_{\mathrm{ns}}\right)$ \\
\hline S1 & 107.2 & 1.0 & 0.75 & 16.2 & 100 & 1620 & 0.066 \\
\hline S2 & 293.86 & 0.6 & 0.75 & 9.72 & 105 & 1020.6 & 0.290 \\
\hline S3 & 0 & 0.6 & 0.75 & 9.72 & 100 & 972 & 0 \\
\hline S4 & 0 & 1.0 & 0.75 & 16.2 & 100 & 1620 & 0 \\
\hline S5 & 743.3 & 0.6 & 0.75 & 9.72 & 100 & 972 & 0.760 \\
\hline S6 & 880.9 & 0.6 & 0.75 & 9.72 & 105 & 1020.6 & 0.860 \\
\hline
\end{tabular}

Table C-S9 Applied load and design strength of Struts in Barrier Model 4 (GS4- HM) - ACI-318

\begin{tabular}{|c|c|c|c|c|c|c|c|}
\hline $\begin{array}{c}\text { Strut } \\
\text { No. }\end{array}$ & $\begin{array}{c}\text { Load in strut } \\
\mathrm{F},(\mathrm{kN})\end{array}$ & $\beta_{\mathrm{s}}$ & $\varphi_{\mathrm{c}}$ & $\begin{array}{c}\varphi_{\mathrm{c}} 0.85 \beta_{\mathrm{s}} f_{\mathrm{c}} \\
(\mathrm{MPa})\end{array}$ & $\begin{array}{c}\text { Width of strut } \\
\mathrm{W}_{\mathrm{s}},(\mathrm{mm})\end{array}$ & $\begin{array}{c}\varphi_{\mathrm{c}} \mathrm{F}_{\mathrm{ns}} \\
(\mathrm{kN})\end{array}$ & $\mathrm{F} /\left(\varphi_{\mathrm{c}} \mathrm{F}_{\mathrm{ns})}\right.$ \\
\hline S1 & 170.3 & 1.0 & 0.75 & 16.2 & 100 & 1620 & 0.11 \\
\hline S2 & 486.3 & 0.6 & 0.75 & 9.72 & 105 & 1020.6 & 0.48 \\
\hline S3 & 0 & 0.6 & 0.75 & 9.72 & 100 & 972 & 0 \\
\hline S4 & 0 & 1.0 & 0.75 & 16.2 & 100 & 1620 & 0 \\
\hline S5 & 1180.7 & 0.6 & 0.75 & 9.72 & 100 & 972 & 1.21 \\
\hline S6 & 1399.5 & 0.6 & 0.75 & 9.72 & 105 & 1020.6 & 1.37 \\
\hline
\end{tabular}


Table C-S10 Applied load to design strength of Struts in Barrier Model 5 (SS5- CS) - ACI-318

\begin{tabular}{|c|c|c|c|c|c|c|c|}
\hline $\begin{array}{c}\text { Strut } \\
\text { No. }\end{array}$ & $\begin{array}{c}\text { Load in strut } \\
\mathrm{F},(\mathrm{kN})\end{array}$ & $\beta_{\mathrm{s}}$ & $\varphi_{\mathrm{c}}$ & $\begin{array}{c}\varphi_{\mathrm{c}} 0.85 \beta_{\mathrm{s}} f_{\mathrm{c}} \\
(\mathrm{MPa})\end{array}$ & $\begin{array}{c}\text { Width of strut } \\
\mathrm{W}_{\mathrm{s}},(\mathrm{mm})\end{array}$ & $\begin{array}{c}\varphi_{\mathrm{c}} \mathrm{F}_{\mathrm{ns}} \\
(\mathrm{kN})\end{array}$ & $\mathrm{F} /\left(\varphi_{\mathrm{c}} \mathrm{F}_{\mathrm{ns}}\right)$ \\
\hline $\mathrm{S} 1$ & 128.9 & 1.0 & 0.75 & 16.2 & 100 & 1620 & 0.08 \\
\hline $\mathrm{S} 2$ & 353.3 & 0.6 & 0.75 & 9.72 & 105 & 1020.6 & 0.35 \\
\hline $\mathrm{S} 3$ & 0 & 0.6 & 0.75 & 9.72 & 100 & 972 & 0 \\
\hline S4 & 0 & 1.0 & 0.75 & 16.2 & 100 & 1620 & 0 \\
\hline S5 & 893.7 & 0.6 & 0.75 & 9.72 & 100 & 972 & 0.92 \\
\hline S6 & 1059.3 & 0.6 & 0.75 & 9.72 & 105 & 1020.6 & 1.04 \\
\hline
\end{tabular}

Table C-S11 Applied load to design strength of Struts in Barrier Model 1 (GS1- HM)- AS- 3600

\begin{tabular}{|c|c|c|c|c|c|c|c|}
\hline $\begin{array}{c}\text { Strut } \\
\text { No. }\end{array}$ & $\begin{array}{c}\text { Load in strut } \\
\mathrm{F},(\mathrm{kN})\end{array}$ & $\beta_{\mathrm{s}}$ & $\varphi_{\mathrm{st}}$ & $\begin{array}{c}0.9 \varphi_{\mathrm{st}} \beta_{\mathrm{s}} f_{\mathrm{c}} \\
(\mathrm{MPa})\end{array}$ & $\begin{array}{c}\text { Width of strut } \\
\mathrm{W}_{\mathrm{s}},(\mathrm{mm})\end{array}$ & $\begin{array}{c}\varphi_{\mathrm{st}} \mathrm{F}_{\mathrm{ns}} \\
(\mathrm{kN})\end{array}$ & $\mathrm{F} /\left(\varphi_{\mathrm{st}} \mathrm{F}_{\mathrm{ns})}\right.$ \\
\hline S1 & 106.1 & 1.00 & 0.6 & 13.72 & 100 & 1372 & 0.077 \\
\hline $\mathrm{S} 2$ & 290.8 & 0.34 & 0.6 & 4.66 & 105 & 489 & 0.590 \\
\hline S3 & 0 & 1.00 & 0.6 & 13.72 & 100 & 1372 & 0 \\
\hline S4 & 0 & 1.00 & 0.6 & 13.72 & 100 & 1372 & 0 \\
\hline S5 & 735.6 & 0.94 & 0.6 & 12.9 & 100 & 1290 & 0.570 \\
\hline S6 & 871.9 & 0.74 & 0.6 & 10.15 & 105 & 1066 & 0.820 \\
\hline
\end{tabular}

$f_{\mathrm{c}}^{\prime}=25.4 \mathrm{MPa}$

$\varphi_{\mathrm{st}} \mathrm{F}_{\mathrm{ns}}=\varphi_{\mathrm{st}} f_{\mathrm{ce}} \mathrm{A}_{\mathrm{cs}}=0.9 \varphi_{\mathrm{st}} \beta_{\mathrm{s}} f_{\mathrm{cc}} . \mathrm{A}_{\mathrm{cs}}, \mathrm{A}_{\mathrm{cs}}=\mathrm{W}_{\mathrm{s} \cdot} \cdot \mathrm{b} \quad(\mathrm{b}=1000 \mathrm{~mm})$

Table C-S12 Applied load to design strength of Struts in Barrier Model 2 (GS2- ST) - AS- 3600

\begin{tabular}{|c|c|c|c|c|c|c|c|}
\hline $\begin{array}{c}\text { Strut } \\
\text { No. }\end{array}$ & $\begin{array}{c}\text { Load in strut } \\
\mathrm{F},(\mathrm{kN})\end{array}$ & $\beta_{\mathrm{s}}$ & $\varphi_{\mathrm{st}}$ & $\begin{array}{c}0.9 \varphi_{\mathrm{st}} \beta_{\mathrm{s}} f_{{ } \mathrm{c}} \\
(\mathrm{MPa})\end{array}$ & $\begin{array}{c}\text { Width of strut } \\
\mathrm{W}_{\mathrm{s}},(\mathrm{mm})\end{array}$ & $\begin{array}{c}\varphi_{\mathrm{st}} \mathrm{F}_{\mathrm{ns}} \\
(\mathrm{N})\end{array}$ & $\mathrm{F} /\left(\varphi_{\mathrm{st}} \mathrm{F}_{\mathrm{ns})}\right.$ \\
\hline S1 & 116.3 & 1.00 & 0.6 & 13.72 & 100 & 1372 & 0.085 \\
\hline S2 & 318.8 & 0.34 & 0.6 & 4.66 & 105 & 489 & 0.650 \\
\hline S3 & 0 & 1.00 & 0.6 & 13.72 & 100 & 1372 & 0 \\
\hline S4 & 0 & 1.00 & 0.6 & 13.72 & 100 & 1372 & 0 \\
\hline S5 & 806.4 & 0.94 & 0.6 & 12.9 & 100 & 1290 & 0.630 \\
\hline S6 & 922.65 & 0.74 & 0.6 & 10.15 & 105 & 1066 & 0.86 \\
\hline
\end{tabular}


Table C-S13 Applied load to design strength of Struts in Barrier Model 3 (GS3- ST) - AS- 3600

\begin{tabular}{|c|c|c|c|c|c|c|c|}
\hline $\begin{array}{c}\text { Strut } \\
\text { No. }\end{array}$ & $\begin{array}{c}\text { Load in strut } \\
\mathrm{F},(\mathrm{kN})\end{array}$ & $\beta_{\mathrm{s}}$ & $\varphi_{\mathrm{st}}$ & $\begin{array}{c}0.9 \varphi_{\mathrm{st}} \beta_{\mathrm{s}} f_{\mathrm{c}} \\
(\mathrm{MPa})\end{array}$ & $\begin{array}{c}\text { Width of strut } \\
\mathrm{W}_{\mathrm{s}},(\mathrm{mm})\end{array}$ & $\begin{array}{c}\varphi_{\mathrm{st}} \mathrm{F}_{\mathrm{ns}} \\
(\mathrm{kN})\end{array}$ & $\mathrm{F} /\left(\varphi_{\mathrm{st}} \mathrm{F}_{\mathrm{ns}}\right)$ \\
\hline $\mathrm{S} 1$ & 107.2 & 1.00 & 0.6 & 13.72 & 100 & 1372 & 0.078 \\
\hline S2 & 293.86 & 0.34 & 0.6 & 4.66 & 105 & 489 & 0.600 \\
\hline S3 & 0 & 1.00 & 0.6 & 13.72 & 100 & 1372 & 0 \\
\hline S4 & 0 & 1.00 & 0.6 & 13.72 & 100 & 1372 & 0 \\
\hline S5 & 743.3 & 0.94 & 0.6 & 12.9 & 100 & 1290 & 0.570 \\
\hline S6 & 880.9 & 0.74 & 0.6 & 10.15 & 105 & 1066 & 0.830 \\
\hline
\end{tabular}

Table C-S14 Applied load and design strength of Struts in Barrier Model 4 GS4- HM- AS- 3600

\begin{tabular}{|c|c|c|c|c|c|c|c|}
\hline $\begin{array}{c}\text { Strut } \\
\text { No. }\end{array}$ & $\begin{array}{c}\text { Load in Strut } \\
\mathrm{F},(\mathrm{kN})\end{array}$ & $\beta_{\mathrm{s}}$ & $\varphi_{\mathrm{st}}$ & $\begin{array}{c}0.9 \varphi_{\mathrm{st}} \beta_{\mathrm{s}} f_{\mathrm{c}} \\
(\mathrm{MPa})\end{array}$ & $\begin{array}{c}\text { Width of Strut } \\
\mathrm{W}_{\mathrm{s}},(\mathrm{mm})\end{array}$ & $\begin{array}{c}\varphi_{\mathrm{st}} \mathrm{F}_{\mathrm{ns}} \\
(\mathrm{kN})\end{array}$ & $\mathrm{F} /\left(\varphi_{\mathrm{st}} \mathrm{F}_{\mathrm{ns}}\right)$ \\
\hline $\mathrm{S} 1$ & 170.3 & 1.00 & 0.6 & 13.72 & 100 & 1372 & 0.12 \\
\hline $\mathrm{S} 2$ & 486.3 & 0.34 & 0.6 & 4.66 & 105 & 489 & 0.99 \\
\hline S3 & 0 & 1.00 & 0.6 & 13.72 & 100 & 1372 & 0 \\
\hline S4 & 0 & 1.00 & 0.6 & 13.72 & 100 & 1372 & 0 \\
\hline S5 & 1180.7 & 0.94 & 0.6 & 12.9 & 100 & 1290 & 0.92 \\
\hline S6 & 1399.5 & 0.74 & 0.6 & 10.15 & 105 & 1066 & 1.31 \\
\hline
\end{tabular}

Table C-S15 Applied load and design strength of Struts in Barrier Model 5 (SS5- CS)- AS- 3600

\begin{tabular}{|c|c|c|c|c|c|c|c|}
\hline $\begin{array}{c}\text { Strut } \\
\text { No. }\end{array}$ & $\begin{array}{c}\text { Load in strut } \\
\mathrm{F},(\mathrm{kN})\end{array}$ & $\beta_{\mathrm{s}}$ & $\varphi_{\mathrm{st}}$ & $\begin{array}{c}0.9 \varphi_{\mathrm{st}} \beta_{\mathrm{s}} f_{\mathrm{c}} \\
(\mathrm{MPa})\end{array}$ & $\begin{array}{c}\text { Width of strut } \\
\mathrm{W}_{\mathrm{s}},(\mathrm{mm})\end{array}$ & $\begin{array}{c}\varphi_{\mathrm{st}} \mathrm{F}_{\mathrm{ns}} \\
(\mathrm{kN})\end{array}$ & $\mathrm{F} /\left(\varphi_{\mathrm{st}} \mathrm{F}_{\mathrm{ns}}\right)$ \\
\hline $\mathrm{S} 1$ & 128.9 & 1.00 & 0.6 & 13.72 & 100 & 1372 & 0.094 \\
\hline $\mathrm{S} 2$ & 353.3 & 0.34 & 0.6 & 4.66 & 105 & 489 & 0.720 \\
\hline $\mathrm{S} 3$ & 0 & 1.00 & 0.6 & 13.72 & 100 & 1372 & 0 \\
\hline S4 & 0 & 1.00 & 0.6 & 13.72 & 100 & 1372 & 0 \\
\hline S5 & 893.7 & 0.94 & 0.6 & 12.9 & 100 & 1290 & 0.690 \\
\hline S6 & 1059.3 & 0.74 & 0.6 & 10.15 & 105 & 1066 & 0.994 \\
\hline
\end{tabular}


Table C-S16 Applied load to design strength of Struts in Barrier 1 (GS1- HM) - JSCE- 2007

\begin{tabular}{|c|c|c|c|c|c|c|c|}
\hline $\begin{array}{c}\text { Strut } \\
\text { No. }\end{array}$ & $\begin{array}{c}\text { Load in strut } \\
\mathrm{F},(\mathrm{kN})\end{array}$ & $v_{1}$ & $v_{2}$ & $\begin{array}{c}v_{1} v_{2} f^{\prime}{ }^{\prime} / \gamma_{\mathrm{b}} \\
(\mathrm{MPa})\end{array}$ & $\begin{array}{c}\text { Width of strut } \\
\mathrm{W}_{\mathrm{s}},(\mathrm{mm})\end{array}$ & $\begin{array}{c}\mathrm{F}_{\mathrm{Rcd}} \\
(\mathrm{kN})\end{array}$ & $\mathrm{F} /\left(\mathrm{F}_{\mathrm{Rcd}}\right)$ \\
\hline S1 & 106.1 & 0.85 & 1.0 & 16.61 & 100 & 1661 & 0.064 \\
\hline S2 & 290.8 & 0.85 & 0.8 & 13.3 & 105 & 1397 & 0.210 \\
\hline S3 & 0 & 0.85 & 0.8 & 13.3 & 100 & 1330 & 0 \\
\hline S4 & 0 & 0.85 & 0.8 & 13.3 & 100 & 1330 & 0 \\
\hline S5 & 735.6 & 0.85 & 0.8 & 13.3 & 100 & 1330 & 0.550 \\
\hline S6 & 871.9 & 0.85 & 0.6 & 9.96 & 105 & 1046 & 0.830 \\
\hline
\end{tabular}

$f^{\prime}{ }_{c d}=25.4 \mathrm{MPa}, \mathrm{F}_{\mathrm{Rcd}}=f_{\text {'cd.eff }} \mathrm{A}_{\mathrm{cs}} / \gamma_{\mathrm{b}}=\left(v_{1} v_{2} f_{c d}^{\prime}\right) . \mathrm{A}_{\mathrm{cs}} / \gamma_{\mathrm{b}}$ where; $\gamma_{\mathrm{b}}=1.3$

$\mathrm{A}_{\mathrm{cs}}=\mathrm{W}_{\mathrm{s}} \cdot \mathrm{b}(\mathrm{b}=1000 \mathrm{~mm}), v=0.85 . \beta_{\mathrm{s}}$ and $\beta_{\mathrm{s}}=\left(v_{1} v_{2}\right) / 0.85=v_{2}$

Table C-S17 Applied load to design strength of Struts in Barrier 2 (GS2- ST) - JSCE- 2007

\begin{tabular}{|c|c|c|c|c|c|c|c|}
\hline $\begin{array}{c}\text { Strut } \\
\text { No. }\end{array}$ & $\begin{array}{c}\text { Load in strut } \\
\mathrm{F},(\mathrm{kN})\end{array}$ & $v_{1}$ & $v_{2}$ & $\begin{array}{c}v_{1} v_{2 f^{\prime} c} / \gamma_{\mathrm{b}} \\
(\mathrm{MPa})\end{array}$ & $\begin{array}{c}\text { Width of strut } \\
\mathrm{W}_{\mathrm{s}},(\mathrm{mm})\end{array}$ & $\begin{array}{c}\mathrm{F}_{\text {Rcd }} \\
(\mathrm{kN})\end{array}$ & $\mathrm{F} /\left(\varphi_{c} \mathrm{~F}_{\mathrm{ns})}\right.$ \\
\hline S1 & 116.3 & 0.85 & 1.0 & 16.61 & 100 & 1661 & 0.07 \\
\hline S2 & 318.8 & 0.85 & 0.8 & 13.3 & 105 & 1397 & 0.23 \\
\hline S3 & 0 & 0.85 & 0.8 & 13.3 & 100 & 1330 & 0 \\
\hline S4 & 0 & 0.85 & 0.8 & 13.3 & 100 & 1330 & 0 \\
\hline S5 & 806.4 & 0.85 & 0.8 & 13.3 & 100 & 1330 & 0.61 \\
\hline S6 & 922.65 & 0.85 & 0.6 & 9.96 & 105 & 1046 & 0.88 \\
\hline
\end{tabular}

Table C-S18 Applied load to design strength of Struts in Barrier 3 (GS3- ST) - JSCE- 2007

\begin{tabular}{|c|c|c|c|c|c|c|c|}
\hline $\begin{array}{c}\text { Strut } \\
\text { No. }\end{array}$ & $\begin{array}{c}\text { Load in strut } \\
\mathrm{F},(\mathrm{kN})\end{array}$ & $v_{1}$ & $v_{2}$ & $\begin{array}{c}v_{1} v_{2} f^{\prime} c d \\
(\mathrm{MPa})\end{array}$ & $\begin{array}{c}\text { Width of strut } \\
\mathrm{W}_{\mathrm{s}},(\mathrm{mm})\end{array}$ & $\begin{array}{c}\mathrm{F}_{\mathrm{Rcd}} \\
(\mathrm{kN})\end{array}$ & $\mathrm{F} /\left(\varphi_{\mathrm{c}} \mathrm{F}_{\mathrm{ns}}\right)$ \\
\hline $\mathrm{S} 1$ & 107.2 & 0.85 & 1.0 & 16.61 & 100 & 1661 & 0.065 \\
\hline S2 & 293.86 & 0.85 & 0.8 & 13.3 & 105 & 1397 & 0.210 \\
\hline S3 & 0 & 0.85 & 0.8 & 13.3 & 100 & 1330 & 0 \\
\hline S4 & 0 & 0.85 & 0.8 & 13.3 & 100 & 1330 & 0 \\
\hline S5 & 743.3 & 0.85 & 0.8 & 13.3 & 100 & 1330 & 0.56 \\
\hline S6 & 880.9 & 0.85 & 0.6 & 9.96 & 105 & 1046 & 0.84 \\
\hline
\end{tabular}


Table C-S19 Applied load to design strength of Struts in Barrier 4 (GS4- HM) - JSCE- 2007

\begin{tabular}{|c|c|c|c|c|c|c|c|}
\hline $\begin{array}{c}\text { Strut } \\
\text { No. }\end{array}$ & $\begin{array}{c}\text { Load in strut } \\
\mathrm{F},(\mathrm{kN})\end{array}$ & $v_{1}$ & $v_{2}$ & $\begin{array}{c}v_{1} v_{2 f} f^{\prime} / \gamma_{\mathrm{b}} \\
(\mathrm{MPa})\end{array}$ & $\begin{array}{c}\text { Width of strut } \\
\mathrm{W}_{\mathrm{s}},(\mathrm{mm})\end{array}$ & $\begin{array}{c}\mathrm{F}_{\mathrm{Rcd}} \\
(\mathrm{kN})\end{array}$ & $\mathrm{F} /\left(\varphi_{\mathrm{c}} \mathrm{F}_{\mathrm{ns})}\right.$ \\
\hline S1 & 170.3 & 0.85 & 1.0 & 16.61 & 100 & 1661 & 0.102 \\
\hline S2 & 486.3 & 0.85 & 0.8 & 13.3 & 105 & 1397 & 0.350 \\
\hline S3 & 0 & 0.85 & 0.8 & 13.3 & 100 & 1330 & 0 \\
\hline S4 & 0 & 0.85 & 0.8 & 13.3 & 100 & 1330 & 0 \\
\hline S5 & 1180.7 & 0.85 & 0.8 & 13.3 & 100 & 1330 & 0.890 \\
\hline S6 & 1399.5 & 0.85 & 0.6 & 9.96 & 105 & 1046 & 1.340 \\
\hline
\end{tabular}

Table C-S20 Applied load to design strength of Struts in Barrier 5 (SS5- CS) - JSCE- 2007

\begin{tabular}{|c|c|c|c|c|c|c|c|}
\hline $\begin{array}{c}\text { Strut } \\
\text { No. }\end{array}$ & $\begin{array}{c}\text { Load in strut } \\
\mathrm{F},(\mathrm{kN})\end{array}$ & $v_{1}$ & $v_{2}$ & $\begin{array}{c}v_{1} v_{2 f} f^{\prime} d \gamma_{\mathrm{b}} \\
(\mathrm{MPa})\end{array}$ & $\begin{array}{c}\text { Width of strut } \\
\mathrm{W}_{\mathrm{s}},(\mathrm{mm})\end{array}$ & $\begin{array}{c}\mathrm{F}_{\mathrm{Rcd}} \\
(\mathrm{kN})\end{array}$ & $\mathrm{F} /\left(\varphi_{\mathrm{c}} \mathrm{F}_{\mathrm{ns})}\right.$ \\
\hline S1 & 128.9 & 0.85 & 1.0 & 16.61 & 100 & 1661 & 0.077 \\
\hline S2 & 353.3 & 0.85 & 0.8 & 13.3 & 105 & 1397 & 0.250 \\
\hline S3 & 0 & 0.85 & 0.8 & 13.3 & 100 & 1330 & 0 \\
\hline S4 & 0 & 0.85 & 0.8 & 13.3 & 100 & 1330 & 0 \\
\hline S5 & 893.7 & 0.85 & 0.8 & 13.3 & 100 & 1330 & 0.670 \\
\hline S6 & 1059.3 & 0.85 & 0.6 & 9.96 & 105 & 1046 & 1.010 \\
\hline
\end{tabular}

Table C-T1 Applied load to design strength in tension tie (T1) in the deck-wall joint- CSA A23.3

\begin{tabular}{|c|c|c|c|c|c|c|}
\hline $\begin{array}{c}\text { Specimen } \\
\text { ID }\end{array}$ & $\begin{array}{c}\text { Load in tie 1 } \\
\mathrm{T} 1,(\mathrm{kN})\end{array}$ & $\Phi_{\text {frp }}$ & $\mathrm{A}_{\mathrm{st}}$ & $\begin{array}{c}\text { Ultimate tensile } \\
\text { strength, } f_{f \mathrm{u}},(\mathrm{MPa})\end{array}$ & $\begin{array}{c}\varphi_{\text {frp }} \mathrm{F}_{\mathrm{nt}} \\
(\mathrm{kN})\end{array}$ & $\mathrm{T} 1 /\left(\varphi_{\mathrm{c}} \mathrm{F}_{\mathrm{nt}}\right)$ \\
\hline GS1- HM & 302.8 & 0.50 & 1583.2 & 1184 & 937.3 & 0.32 \\
\hline GS2- ST & 331.9 & 0.50 & 1979 & 500 & 494.7 & 0.67 \\
\hline GS3- ST & 306 & 0.50 & 1979 & 500 & 494.7 & 0.62 \\
\hline GS4- HM & 486.06 & 0.50 & 2770.6 & 1184 & 1640.2 & 0.30 \\
\hline SS5- CS & 367.9 & $0.85^{*}$ & 1000 & $400^{* *}$ & 340 & 1.08 \\
\hline
\end{tabular}

\footnotetext{
$\Phi_{\text {frp }} \mathrm{F}_{\mathrm{nt}}=0.5 f_{f \mathrm{u}} \mathrm{A}_{\mathrm{st}}$

$* \varphi_{\mathrm{s}}=0.85$ resistance factor for steel reinforcement

$* * \mathrm{~F}_{\mathrm{y}}=400$ yield strength of reinforcing steel bars
} 
Table C-T2 Applied load to design strength in tension tie (T1) in the deck-wall joint - ACI-318

\begin{tabular}{|c|c|c|c|c|c|c|c|}
\hline $\begin{array}{c}\text { Specimen } \\
\text { ID }\end{array}$ & $\begin{array}{c}\text { Load in tie 1 } \\
\text { T1, (kN) }\end{array}$ & $\Phi_{\text {frp }}$ & $\mathrm{A}_{\mathrm{st}}$ & $\begin{array}{c}\text { Guaranteed } \\
\text { tensile } \\
\text { strength } \\
, f_{f \mathrm{u}^{*}},(\mathrm{MPa})\end{array}$ & $\begin{array}{c}\text { Ultimate } \\
\text { tensile strength } \\
, f_{f \mathrm{u}},(\mathrm{MPa})\end{array}$ & $\begin{array}{c}\varphi_{\text {frp }} \mathrm{F}_{\mathrm{nt}} \\
(\mathrm{kN})\end{array}$ & $\mathrm{T1} /\left(\varphi_{\mathrm{c}} \mathrm{F}_{\mathrm{nt}}\right)$ \\
\hline GS1- HM & 302.8 & 0.50 & 1583.2 & 1184 & 828.8 & 656 & 0.46 \\
\hline GS2- ST & 331.9 & 0.50 & 1979.0 & 500 & 350 & 346.3 & 0.96 \\
\hline GS3- ST & 306 & 0.50 & 1979.0 & 500 & 350 & 346.3 & 0.88 \\
\hline GS4- HM & 486.06 & 0.50 & 2770.6 & 1184 & 828.8 & 1148 & 0.42 \\
\hline SS5- CS & 367.9 & $0.90^{*}$ & 1000.0 & $400^{* *}$ & $400^{* *}$ & 360 & 1.02 \\
\hline
\end{tabular}

$\Phi_{\mathrm{frp}} \mathrm{F}_{\mathrm{nt}}=0.5 f_{f \mathrm{u}} \mathrm{A}_{\mathrm{st}}$

$* \varphi_{\mathrm{s}}=0.90$ resistance factor for steel reinforcement in ACI

$* * \mathrm{~F}_{\mathrm{y}}=400$ yield strength of reinforcing steel bars

$f_{f \mathrm{u}}=\mathrm{C}_{\mathrm{E}} \cdot f_{f \mathrm{u}^{*}}=0.7 \cdot f_{f_{\mathrm{u}^{*}}}$

Table C-T3 Applied load to design strength in tension tie (T1) in the deck-wall joint- AS- 3600

\begin{tabular}{|c|c|c|c|c|c|c|}
\hline $\begin{array}{c}\text { Specimen } \\
\text { ID }\end{array}$ & $\begin{array}{c}\text { Load in tie 1 } \\
\text { T1, }(\mathrm{kN})\end{array}$ & $\Phi_{\text {frp }}$ & $\mathrm{A}_{\mathrm{st}}$ & $\begin{array}{c}\text { Ultimate tensile } \\
\text { strength, } f_{\text {fu }},(\mathrm{MPa})\end{array}$ & $\begin{array}{c}\varphi_{\mathrm{fr}} \mathrm{F}_{\mathrm{nt}} \\
(\mathrm{kN})\end{array}$ & $\mathrm{T} 1 /\left(\varphi_{\mathrm{c}} \mathrm{F}_{\mathrm{nt})}\right.$ \\
\hline GS1- HM & 302.8 & 0.50 & 1583.2 & 1184 & 937.3 & 0.32 \\
\hline GS2- ST & 331.9 & 0.50 & 1979 & 500 & 494.7 & 0.67 \\
\hline GS3- ST & 306 & 0.50 & 1979 & 500 & 494.7 & 0.62 \\
\hline GS4- HM & 486.06 & 0.50 & 2770.6 & 1184 & 1640.2 & 0.30 \\
\hline SS5- CS & 367.9 & $0.80^{*}$ & 1000 & $400^{* *}$ & 320 & 1.15 \\
\hline
\end{tabular}

$\Phi_{\mathrm{frp}} \mathrm{F}_{\mathrm{nt}}=0.5 f_{f \mathrm{u}} \mathrm{A}_{\mathrm{st}}$

$* \varphi_{\mathrm{s}}=0.80$ resistance factor for steel reinforcement in AS3600-2009

$* * \mathrm{~F}_{\mathrm{y}}=400$ yield strength of reinforcing steel bars

Table C-T4 Applied load to design strength in tension tie (T1) in deck-wall joint- JSCE - 2007

\begin{tabular}{|c|c|c|c|c|c|c|}
\hline $\begin{array}{c}\text { Specimen } \\
\text { ID }\end{array}$ & $\begin{array}{c}\text { Load in tie 1 } \\
\mathrm{T} 1,(\mathrm{kN})\end{array}$ & $\Phi_{\mathrm{frp}}$ & $\mathrm{A}_{\mathrm{st}}$ & $\begin{array}{c}\text { Ultimate tensile } \\
\text { strength, } f_{\text {fu }},(\mathrm{MPa})\end{array}$ & $\begin{array}{c}\varphi_{\mathrm{frp}} \mathrm{F}_{\mathrm{nt}} \\
(\mathrm{kN})\end{array}$ & $\mathrm{T} 1 /\left(\varphi_{\mathrm{c}} \mathrm{F}_{\mathrm{nt}}\right.$ \\
\hline GS1- HM & 302.8 & 0.77 & 1583.2 & 1184 & 1443.4 & 0.210 \\
\hline GS2- ST & 331.9 & 0.77 & 1979.0 & 500 & 762 & 0.435 \\
\hline GS3- ST & 306 & 0.77 & 1979.0 & 500 & 762 & 0.401 \\
\hline GS4- HM & 486.06 & 0.77 & 2770.6 & 1184 & 2525.9 & 0.190 \\
\hline SS5- CS & 367.9 & $0.95^{*}$ & 1000.0 & $400^{* *}$ & 380 & 0.970 \\
\hline
\end{tabular}

$\Phi_{\mathrm{frp}} \mathrm{F}_{\mathrm{nt}}=0.77 f_{\mathrm{fu}} \mathrm{A}_{\mathrm{st}}$

* $\varphi_{\mathrm{s}}=0.95$ resistance factor for steel reinforcement in JSCE 2007

$* * \mathrm{~F}_{\mathrm{y}}=400$ yield strength of reinforcing steel bars 
Table C-N1 Applied load to design strength of Nodes in GS1- HM- CSA A23.3

\begin{tabular}{|c|c|c|c|c|c|c|c|c|}
\hline $\begin{array}{c}\text { Node } \\
\text { No. }\end{array}$ & $\begin{array}{c}\text { Node } \\
\text { face }\end{array}$ & $\begin{array}{c}\mathrm{F} \\
(\mathrm{kN})\end{array}$ & $\beta_{\mathrm{n}}$ & $\varphi_{\mathrm{c}}$ & $\begin{array}{c}\varphi_{\mathrm{c}} \alpha_{1} \beta_{\mathrm{n}} f_{\mathrm{c}} \\
(\mathrm{MPa})\end{array}$ & $\begin{array}{c}\mathrm{W}_{\mathrm{s}} \\
(\mathrm{mm})\end{array}$ & $\begin{array}{c}\varphi_{\mathrm{c}} \mathrm{F}_{\mathrm{nn}} \\
(\mathrm{kN})\end{array}$ & $\mathrm{F} /\left(\varphi_{\mathrm{c}} \mathrm{F}_{\mathrm{nn}}\right)$ \\
\hline P1 & $\mathrm{S} 1$ & 106.1 & 0.867 & 0.65 & 11.6 & 100 & 1160 & 0.091 \\
\hline \multirow{2}{*}{ P2 } & $\mathrm{S} 1$ & 106.1 & 0.765 & 0.65 & 10.23 & 150 & 1535 & 0.070 \\
\cline { 2 - 9 } & $\mathrm{T} 1$ & 302.8 & 0.765 & 0.65 & 10.23 & 100 & 1023 & 0.296 \\
\cline { 2 - 9 } & $\mathrm{S} 2$ & 290.8 & 0.765 & 0.65 & 10.23 & 105 & 1074 & 0.271 \\
\hline \multirow{3}{*}{ P3 } & $\mathrm{S} 2$ & 290.8 & 0.765 & 0.65 & 10.23 & 110 & 1125 & 0.260 \\
\cline { 2 - 9 } & $\mathrm{T} 2$ & 841.7 & 0.765 & 0.65 & 10.23 & 100 & 1023 & 0.823 \\
\cline { 2 - 9 } & $\mathrm{S} 3$ & 0 & 0.765 & 0.65 & 10.23 & 110 & 1125 & 0 \\
\cline { 2 - 9 } & $\mathrm{S} 6$ & 871.9 & 0.765 & 0.65 & 10.23 & 110 & 1125 & 0.78 \\
\hline \multirow{3}{*}{ P4 } & $\mathrm{S} 3$ & 0 & 0.867 & 0.65 & 11.6 & 140 & 1624 & 0 \\
\cline { 2 - 9 } & $\mathrm{S} 4$ & 0 & 0.867 & 0.65 & 11.6 & 140 & 1624 & 0 \\
\hline \multirow{4}{*}{ 55 } & $\mathrm{S} 4$ & 0 & 0.765 & 0.65 & 10.23 & 105 & 1074 & 0 \\
\cline { 2 - 9 } & $\mathrm{S} 6$ & 871.9 & 0.765 & 0.65 & 10.23 & 105 & 1074 & 0.810 \\
\cline { 2 - 9 } & $\mathrm{T} 1$ & 302.8 & 0.765 & 0.65 & 10.23 & 115 & 1176 & 0.260 \\
\cline { 2 - 8 } & $\mathrm{S} 5$ & 735.6 & 0.765 & 0.65 & 10.23 & 100 & 1023 & 0.720 \\
\hline P8 & $\mathrm{S} 5$ & 735.6 & 0.867 & 0.65 & 11.6 & 100 & 1160 & 0.640 \\
\hline
\end{tabular}

$\varphi_{\mathrm{c}} \mathrm{F}_{\mathrm{nn}}=\varphi_{\mathrm{c}} f_{\mathrm{ce}} \mathrm{A}_{\mathrm{n}}=\varphi_{\mathrm{c}} \alpha_{1} \beta_{\mathrm{n}} f_{\mathrm{c}} . \mathrm{A}_{\mathrm{n}}$

$\mathrm{A}_{\mathrm{n}}=\mathrm{W}_{\mathrm{s}} \cdot \mathrm{b} \quad(\mathrm{b}=1000 \mathrm{~mm})$

$f_{\mathrm{c}}^{\prime}=25.4 \mathrm{MPa}, \quad a_{1}=0.85-0.0015 * 25.4=0.81$

Table C-N2 Applied load to design strength of Nodes in GS2- ST - CSA A23.3

\begin{tabular}{|c|c|c|c|c|c|c|c|c|}
\hline $\begin{array}{c}\text { Node } \\
\text { No. }\end{array}$ & $\begin{array}{c}\text { Node } \\
\text { face }\end{array}$ & $\begin{array}{c}\mathrm{F} \\
(\mathrm{kN})\end{array}$ & $\beta_{\mathrm{n}}$ & $\varphi_{\mathrm{c}}$ & $\begin{array}{c}\varphi_{\mathrm{c}} \alpha_{1} \beta_{\mathrm{n}} f_{\mathrm{c}} \\
(\mathrm{MPa})\end{array}$ & $\begin{array}{c}\mathrm{W}_{\mathrm{s}} \\
(\mathrm{mm})\end{array}$ & $\begin{array}{c}\varphi_{\mathrm{c}} \mathrm{F}_{\mathrm{nn}} \\
(\mathrm{kN})\end{array}$ & $\mathrm{F} /\left(\varphi_{\mathrm{c}} \mathrm{F}_{\mathrm{nn}}\right)$ \\
\hline P1 & $\mathrm{S} 1$ & 116.3 & 0.867 & 0.65 & 11.6 & 100 & 1160 & 0.100 \\
\hline \multirow{2}{*}{ P2 } & $\mathrm{S} 1$ & 116.3 & 0.765 & 0.65 & 10.23 & 150 & 1535 & 0.076 \\
\cline { 2 - 9 } & $\mathrm{T} 1$ & 331.9 & 0.765 & 0.65 & 10.23 & 100 & 1023 & 0.324 \\
\cline { 2 - 9 } & $\mathrm{S} 2$ & 318.8 & 0.765 & 0.65 & 10.23 & 105 & 1074 & 0.297 \\
\hline \multirow{3}{*}{ P3 } & $\mathrm{S} 2$ & 318.8 & 0.765 & 0.65 & 10.23 & 110 & 1125 & 0.283 \\
\cline { 2 - 9 } & $\mathrm{T} 2$ & 922.7 & 0.765 & 0.65 & 10.23 & 100 & 1023 & 0.900 \\
\cline { 2 - 9 } & $\mathrm{S} 3$ & 0 & 0.765 & 0.65 & 10.23 & 110 & 1125 & 0 \\
\cline { 2 - 9 } & $\mathrm{S} 6$ & 955.7 & 0.765 & 0.65 & 10.23 & 110 & 1125 & 0.85 \\
\hline \multirow{3}{*}{ P4 } & $\mathrm{S} 3$ & 0 & 0.867 & 0.65 & 11.6 & 140 & 1624 & 0 \\
\cline { 2 - 9 } & $\mathrm{S} 4$ & 0 & 0.867 & 0.65 & 11.6 & 140 & 1624 & 0 \\
\hline \multirow{3}{*}{ P5 } & $\mathrm{S} 4$ & 0 & 0.765 & 0.65 & 10.23 & 105 & 1074 & 0 \\
\cline { 2 - 8 } & $\mathrm{S} 6$ & 955.7 & 0.765 & 0.65 & 10.23 & 105 & 1074 & 0.890 \\
\cline { 2 - 9 } & $\mathrm{T} 1$ & 331.9 & 0.765 & 0.65 & 10.23 & 115 & 1176 & 0.280 \\
\cline { 2 - 8 } & $\mathrm{S} 5$ & 806.4 & 0.765 & 0.65 & 10.23 & 100 & 1023 & 0.790 \\
\hline P8 & $\mathrm{S} 5$ & 806.4 & 0.867 & 0.65 & 11.6 & 100 & 1160 & 0.695 \\
\hline
\end{tabular}


Table C-N3 Applied load to design strength of Nodes in GS3- ST - CSA A23.3

\begin{tabular}{|c|c|c|c|c|c|c|c|c|}
\hline $\begin{array}{c}\text { Node } \\
\text { No. }\end{array}$ & $\begin{array}{c}\text { Node } \\
\text { face }\end{array}$ & $\begin{array}{c}\mathrm{F} \\
(\mathrm{kN})\end{array}$ & $\beta_{\mathrm{n}}$ & $\varphi_{\mathrm{c}}$ & $\begin{array}{c}\varphi_{\mathrm{c}} \alpha_{1} \beta_{\mathrm{n}} f_{\mathrm{c}} \\
(\mathrm{MPa})\end{array}$ & $\begin{array}{c}\mathrm{W}_{\mathrm{s}} \\
(\mathrm{mm})\end{array}$ & $\begin{array}{c}\varphi_{\mathrm{c}} \mathrm{F}_{\mathrm{nn}} \\
(\mathrm{kN})\end{array}$ & $\mathrm{F} /\left(\varphi_{\mathrm{c}} \mathrm{F}_{\mathrm{nn}}\right)$ \\
\hline P1 & $\mathrm{S} 1$ & 107.2 & 0.867 & 0.65 & 11.6 & 100 & 1160 & 0.092 \\
\hline \multirow{3}{*}{ P2 } & $\mathrm{S} 1$ & 107.2 & 0.765 & 0.65 & 10.23 & 150 & 1535 & 0.070 \\
\cline { 2 - 9 } & $\mathrm{T} 1$ & 306 & 0.765 & 0.65 & 10.23 & 100 & 1023 & 0.300 \\
\cline { 2 - 9 } & $\mathrm{S} 2$ & 294 & 0.765 & 0.65 & 10.23 & 105 & 1074 & 0.274 \\
\hline \multirow{4}{*}{ P3 } & $\mathrm{S} 2$ & 294 & 0.765 & 0.65 & 10.23 & 110 & 1125 & 0.261 \\
\cline { 2 - 9 } & $\mathrm{T} 2$ & 805.5 & 0.765 & 0.65 & 10.23 & 100 & 1023 & 0.790 \\
\cline { 2 - 9 } & $\mathrm{S} 3$ & 0 & 0.765 & 0.65 & 10.23 & 110 & 1125 & 0 \\
\cline { 2 - 9 } & $\mathrm{S} 6$ & 881 & 0.765 & 0.65 & 10.23 & 110 & 1125 & 0.783 \\
\hline \multirow{3}{*}{ P4 } & $\mathrm{S} 3$ & 0 & 0.867 & 0.65 & 11.6 & 140 & 1624 & 0 \\
\cline { 2 - 9 } & $\mathrm{S} 4$ & 0 & 0.867 & 0.65 & 11.6 & 140 & 1624 & 0 \\
\hline & $\mathrm{S} 4$ & 0 & 0.765 & 0.65 & 10.23 & 105 & 1074 & 0 \\
\cline { 2 - 9 } & $\mathrm{S} 6$ & 881 & 0.765 & 0.65 & 10.23 & 105 & 1074 & 0.820 \\
\cline { 2 - 9 } & $\mathrm{T} 1$ & 306 & 0.765 & 0.65 & 10.23 & 115 & 1176 & 0.260 \\
\cline { 2 - 8 } & $\mathrm{S} 5$ & 743.3 & 0.765 & 0.65 & 10.23 & 100 & 1023 & 0.730 \\
\hline P8 & $\mathrm{S} 5$ & 743.3 & 0.867 & 0.65 & 11.6 & 100 & 1160 & 0.640 \\
\hline
\end{tabular}

Table C-N4 Applied load to design strength of Nodes in GS4- HM - CSA A23.3

\begin{tabular}{|c|c|c|c|c|c|c|c|c|}
\hline $\begin{array}{c}\text { Node } \\
\text { No. }\end{array}$ & $\begin{array}{c}\text { Node } \\
\text { face }\end{array}$ & $\begin{array}{c}\mathrm{F} \\
(\mathrm{kN})\end{array}$ & $\beta_{\mathrm{n}}$ & $\varphi_{\mathrm{c}}$ & $\begin{array}{c}\varphi_{\mathrm{c}} \alpha_{1} \beta_{\mathrm{n}} f_{\mathrm{c}} \\
(\mathrm{MPa})\end{array}$ & $\begin{array}{c}\mathrm{W}_{\mathrm{s}} \\
(\mathrm{mm})\end{array}$ & $\begin{array}{c}\varphi_{\mathrm{c}} \mathrm{F}_{\mathrm{nn}} \\
(\mathrm{kN})\end{array}$ & $\mathrm{F} /\left(\varphi_{\mathrm{c}} \mathrm{F}_{\mathrm{nn}}\right)$ \\
\hline P1 & $\mathrm{S} 1$ & 170.3 & 0.867 & 0.65 & 11.6 & 100 & 1160 & 0.150 \\
\hline \multirow{2}{*}{ P2 } & $\mathrm{S} 1$ & 170.3 & 0.765 & 0.65 & 10.23 & 150 & 1535 & 0.110 \\
\cline { 2 - 9 } & $\mathrm{T} 1$ & 486.06 & 0.765 & 0.65 & 10.23 & 100 & 1023 & 0.475 \\
\cline { 2 - 9 } & $\mathrm{S} 2$ & 486.3 & 0.765 & 0.65 & 10.23 & 105 & 1074 & 0.453 \\
\hline \multirow{3}{*}{ P3 } & $\mathrm{S} 2$ & 486.3 & 0.765 & 0.65 & 10.23 & 110 & 1125 & 0.432 \\
\cline { 2 - 9 } & $\mathrm{T} 2$ & 1351.05 & 0.765 & 0.65 & 10.23 & 100 & 1023 & 1.320 \\
\cline { 2 - 9 } & $\mathrm{S} 3$ & 0 & 0.765 & 0.65 & 10.23 & 110 & 1125 & 0 \\
\cline { 2 - 9 } & $\mathrm{S} 6$ & 1399.5 & 0.765 & 0.65 & 10.23 & 110 & 1125 & 1.240 \\
\hline \multirow{3}{*}{ P4 } & $\mathrm{S} 3$ & 0 & 0.867 & 0.65 & 11.6 & 140 & 1624 & 0 \\
\cline { 2 - 9 } & $\mathrm{S} 4$ & 0 & 0.867 & 0.65 & 11.6 & 140 & 1624 & 0 \\
\hline \multirow{3}{*}{ P5 } & $\mathrm{S} 4$ & 0 & 0.765 & 0.65 & 10.23 & 105 & 1074 & 0 \\
\cline { 2 - 8 } & $\mathrm{S} 6$ & 1399.5 & 0.765 & 0.65 & 10.23 & 105 & 1074 & 1.300 \\
\cline { 2 - 8 } & $\mathrm{T} 1$ & 486.06 & 0.765 & 0.65 & 10.23 & 115 & 1176 & 0.413 \\
\cline { 2 - 8 } & $\mathrm{S} 5$ & 1180.7 & 0.765 & 0.65 & 10.23 & 100 & 1023 & 1.150 \\
\hline P8 & $\mathrm{S} 5$ & 1180.7 & 0.867 & 0.65 & 11.6 & 100 & 1160 & 1.020 \\
\hline
\end{tabular}


Table C-N5 Applied load to design strength of Nodes in SS5- CS - CSA A23.3

\begin{tabular}{|c|c|c|c|c|c|c|c|c|}
\hline $\begin{array}{c}\text { Node } \\
\text { No. }\end{array}$ & $\begin{array}{c}\text { Node } \\
\text { face }\end{array}$ & $\begin{array}{c}\mathrm{F} \\
(\mathrm{kN})\end{array}$ & $\beta_{\mathrm{n}}$ & $\varphi_{\mathrm{c}}$ & $\begin{array}{c}\varphi_{\mathrm{c}} \alpha_{1} \beta_{\mathrm{n}} f_{\mathrm{c}} \\
(\mathrm{MPa})\end{array}$ & $\begin{array}{c}\mathrm{W}_{\mathrm{s}} \\
(\mathrm{mm})\end{array}$ & $\begin{array}{c}\varphi_{\mathrm{c}} \mathrm{F}_{\mathrm{nn}} \\
(\mathrm{kN})\end{array}$ & $\mathrm{F} /\left(\varphi_{\mathrm{c}} \mathrm{F}_{\mathrm{nn}}\right)$ \\
\hline P1 & $\mathrm{S} 1$ & 128.9 & 0.867 & 0.65 & 11.6 & 100 & 1160 & 0.110 \\
\hline \multirow{2}{*}{ P2 } & $\mathrm{S} 1$ & 128.9 & 0.765 & 0.65 & 10.23 & 150 & 1535 & 0.084 \\
\cline { 2 - 9 } & $\mathrm{T} 1$ & 367.9 & 0.765 & 0.65 & 10.23 & 100 & 1023 & 0.360 \\
\cline { 2 - 9 } & $\mathrm{S} 2$ & 353.3 & 0.765 & 0.65 & 10.23 & 105 & 1074 & 0.330 \\
\hline \multirow{4}{*}{ 33 } & $\mathrm{S} 2$ & 353.3 & 0.765 & 0.65 & 10.23 & 110 & 1125 & 0.310 \\
\cline { 2 - 9 } & $\mathrm{T} 2$ & 1022.6 & 0.765 & 0.65 & 10.23 & 100 & 1023 & 1.00 \\
\cline { 2 - 9 } & $\mathrm{S} 3$ & 0 & 0.765 & 0.65 & 10.23 & 110 & 1125 & 0 \\
\cline { 2 - 9 } & $\mathrm{S} 6$ & 1059.3 & 0.765 & 0.65 & 10.23 & 110 & 1125 & 0.94 \\
\hline \multirow{3}{*}{ P4 } & $\mathrm{S} 3$ & 0 & 0.867 & 0.65 & 11.6 & 140 & 1624 & 0 \\
\cline { 2 - 9 } & $\mathrm{S} 4$ & 0 & 0.867 & 0.65 & 11.6 & 140 & 1624 & 0 \\
\hline \multirow{4}{*}{ 55 } & $\mathrm{S} 4$ & 0 & 0.765 & 0.65 & 10.23 & 105 & 1074 & 0 \\
\cline { 2 - 8 } & $\mathrm{S} 6$ & 1059.3 & 0.765 & 0.65 & 10.23 & 105 & 1074 & 0.986 \\
\cline { 2 - 8 } & $\mathrm{T} 1$ & 367.9 & 0.765 & 0.65 & 10.23 & 115 & 1176 & 0.310 \\
\cline { 2 - 8 } & $\mathrm{S} 5$ & 893.7 & 0.765 & 0.65 & 10.23 & 100 & 1023 & 0.870 \\
\hline P8 & $\mathrm{S} 5$ & 893.7 & 0.867 & 0.65 & 11.6 & 100 & 1160 & 0.770 \\
\hline
\end{tabular}

Table C-N6 Applied load to design strength of Nodes in GS1- HM - ACI-318

\begin{tabular}{|c|c|c|c|c|c|c|c|c|}
\hline $\begin{array}{c}\text { Node } \\
\text { No. }\end{array}$ & $\begin{array}{c}\text { Node } \\
\text { face }\end{array}$ & $\begin{array}{c}\mathrm{F} \\
(\mathrm{kN})\end{array}$ & $\beta_{\mathrm{n}}$ & $\varphi_{\mathrm{c}}$ & $\begin{array}{c}\varphi_{\mathrm{c}} 0.85 \beta_{\mathrm{n}} f_{\mathrm{c}} \\
(\mathrm{MPa})\end{array}$ & $\begin{array}{c}\mathrm{W}_{\mathrm{s}} \\
(\mathrm{mm})\end{array}$ & $\begin{array}{c}\varphi_{\mathrm{c}} \mathrm{F}_{\mathrm{nn}} \\
(\mathrm{kN})\end{array}$ & $\mathrm{F} /\left(\varphi_{\mathrm{c}} \mathrm{F}_{\mathrm{nn}}\right)$ \\
\hline P1 & $\mathrm{S} 1$ & 106.1 & 1 & 0.75 & 16.2 & 100 & 1620 & 0.065 \\
\hline \multirow{3}{*}{ P2 } & $\mathrm{S} 1$ & 106.1 & 0.8 & 0.75 & 12.95 & 150 & 1942.5 & 0.055 \\
\cline { 2 - 9 } & $\mathrm{T} 1$ & 302.8 & 0.8 & 0.75 & 12.95 & 100 & 1295 & 0.234 \\
\cline { 2 - 9 } & $\mathrm{S} 2$ & 290.8 & 0.8 & 0.75 & 12.95 & 105 & 1360 & 0.220 \\
\hline \multirow{3}{*}{ P3 } & $\mathrm{S} 2$ & 290.8 & 0.8 & 0.75 & 12.95 & 110 & 1425 & 0.204 \\
\cline { 2 - 9 } & $\mathrm{T} 2$ & 841.7 & 0.8 & 0.75 & 12.95 & 100 & 1295 & 0.650 \\
\cline { 2 - 9 } & $\mathrm{S} 3$ & 0 & 0.8 & 0.75 & 12.95 & 110 & 1425 & 0 \\
\cline { 2 - 9 } & $\mathrm{S} 6$ & 871.9 & 0.8 & 0.75 & 12.95 & 110 & 1425 & 0.610 \\
\hline \multirow{3}{*}{ P4 } & $\mathrm{S} 3$ & 0 & 1 & 0.75 & 16.2 & 140 & 2268 & 0 \\
\cline { 2 - 9 } & $\mathrm{S} 4$ & 0 & 1 & 0.75 & 16.2 & 140 & 2268 & 0 \\
\hline \multirow{3}{*}{ P5 } & $\mathrm{S} 4$ & 0 & 0.8 & 0.75 & 12.95 & 105 & 1360 & 0 \\
\cline { 2 - 9 } & $\mathrm{S} 6$ & 871.9 & 0.8 & 0.75 & 12.95 & 105 & 1360 & 0.640 \\
\cline { 2 - 9 } & $\mathrm{T} 1$ & 302.8 & 0.8 & 0.75 & 12.95 & 115 & 1490 & 0.203 \\
\cline { 2 - 9 } & $\mathrm{S} 5$ & 735.6 & 0.8 & 0.75 & 12.95 & 100 & 1295 & 0.570 \\
\hline P8 & $\mathrm{S} 5$ & 735.6 & 1 & 0.75 & 16.2 & 100 & 1620 & 0.450 \\
\hline
\end{tabular}

$\varphi_{\mathrm{c}} \mathrm{F}_{\mathrm{nn}}=\varphi_{\mathrm{c}} f_{\mathrm{cu}} \mathrm{A}_{\mathrm{n}}=\varphi_{\mathrm{c}} 0.85 \beta_{\mathrm{n}} f_{\mathrm{c}} . \mathrm{A}_{\mathrm{n}}$

$\mathrm{A}_{\mathrm{n}}=\mathrm{W}_{\mathrm{s}} \cdot \mathrm{b} \quad(\mathrm{b}=1000 \mathrm{~mm})$ 
Table C-N7 Applied load to design strength of Nodes in GS2- ST - ACI-318

\begin{tabular}{|c|c|c|c|c|c|c|c|c|}
\hline $\begin{array}{c}\text { Node } \\
\text { No. }\end{array}$ & $\begin{array}{c}\text { Node } \\
\text { face }\end{array}$ & $\begin{array}{c}\mathrm{F} \\
(\mathrm{kN})\end{array}$ & $\beta_{\mathrm{n}}$ & $\varphi_{\mathrm{c}}$ & $\begin{array}{c}\varphi_{\mathrm{c}} 0.85 \beta_{\mathrm{n}} f_{\mathrm{c}} \\
(\mathrm{MPa})\end{array}$ & $\begin{array}{c}\mathrm{W}_{\mathrm{s}} \\
(\mathrm{mm})\end{array}$ & $\begin{array}{c}\varphi_{\mathrm{c}} \mathrm{F}_{\mathrm{nn}} \\
(\mathrm{kN})\end{array}$ & $\mathrm{F} /\left(\varphi_{\mathrm{c}} \mathrm{F}_{\mathrm{nn}}\right)$ \\
\hline P1 & $\mathrm{S} 1$ & 116.3 & 1 & 0.75 & 16.2 & 100 & 1620 & 0.072 \\
\hline \multirow{3}{*}{ P2 } & $\mathrm{S} 1$ & 116.3 & 0.8 & 0.75 & 12.95 & 150 & 1942.5 & 0.060 \\
\cline { 2 - 9 } & $\mathrm{T} 1$ & 331.9 & 0.8 & 0.75 & 12.95 & 100 & 1295 & 0.260 \\
\cline { 2 - 9 } & $\mathrm{S} 2$ & 318.8 & 0.8 & 0.75 & 12.95 & 105 & 1360 & 0.240 \\
\hline \multirow{3}{*}{ P3 } & $\mathrm{S} 2$ & 318.8 & 0.8 & 0.75 & 12.95 & 110 & 1425 & 0.223 \\
\cline { 2 - 9 } & $\mathrm{T} 2$ & 922.7 & 0.8 & 0.75 & 12.95 & 100 & 1295 & 0.710 \\
\cline { 2 - 9 } & $\mathrm{S} 3$ & 0 & 0.8 & 0.75 & 12.95 & 110 & 1425 & 0 \\
\cline { 2 - 9 } & $\mathrm{S} 6$ & 955.7 & 0.8 & 0.75 & 12.95 & 110 & 1425 & 0.670 \\
\hline \multirow{3}{*}{ P4 } & $\mathrm{S} 3$ & 0 & 1 & 0.75 & 16.2 & 140 & 2268 & 0 \\
\cline { 2 - 9 } & $\mathrm{S} 4$ & 0 & 1 & 0.75 & 16.2 & 140 & 2268 & 0 \\
\hline \multirow{3}{*}{ P5 } & $\mathrm{S} 4$ & 0 & 0.8 & 0.75 & 12.95 & 105 & 1360 & 0 \\
\cline { 2 - 9 } & $\mathrm{S} 6$ & 955.7 & 0.8 & 0.75 & 12.95 & 105 & 1360 & 0.700 \\
\cline { 2 - 9 } & $\mathrm{T} 1$ & 331.9 & 0.8 & 0.75 & 12.95 & 115 & 1490 & 0.223 \\
\cline { 2 - 8 } & $\mathrm{S} 5$ & 806.4 & 0.8 & 0.75 & 12.95 & 100 & 1295 & 0.620 \\
\hline P8 & $\mathrm{S} 5$ & 806.4 & 1 & 0.75 & 16.2 & 100 & 1620 & 0.490 \\
\hline
\end{tabular}

Table C-N8 Applied load to design strength of Nodes in GS3- ST - ACI-318

\begin{tabular}{|c|c|c|c|c|c|c|c|c|}
\hline $\begin{array}{c}\text { Node } \\
\text { No. }\end{array}$ & $\begin{array}{c}\text { Node } \\
\text { face }\end{array}$ & $\begin{array}{c}\mathrm{F} \\
(\mathrm{kN})\end{array}$ & $\beta_{\mathrm{n}}$ & $\varphi_{\mathrm{c}}$ & $\begin{array}{c}\varphi_{\mathrm{c}} 0.85 \beta_{\mathrm{n}} f_{\mathrm{c}} \\
(\mathrm{MPa})\end{array}$ & $\begin{array}{c}\mathrm{W}_{\mathrm{s}} \\
(\mathrm{mm})\end{array}$ & $\begin{array}{c}\varphi_{\mathrm{c}} \mathrm{F}_{\mathrm{nn}} \\
(\mathrm{kN})\end{array}$ & $\mathrm{F} /\left(\varphi_{\mathrm{c}} \mathrm{F}_{\mathrm{nn}}\right)$ \\
\hline P1 & $\mathrm{S} 1$ & 107.2 & 1 & 0.75 & 16.2 & 100 & 1620 & 0.066 \\
\hline \multirow{3}{*}{ P2 } & $\mathrm{S} 1$ & 107.2 & 0.8 & 0.75 & 12.95 & 150 & 1942.5 & 0.055 \\
\cline { 2 - 9 } & $\mathrm{T} 1$ & 306 & 0.8 & 0.75 & 12.95 & 100 & 1295 & 0.240 \\
\cline { 2 - 9 } & $\mathrm{S} 2$ & 294 & 0.8 & 0.75 & 12.95 & 105 & 1360 & 0.220 \\
\hline \multirow{4}{*}{ P3 } & $\mathrm{S} 2$ & 294 & 0.8 & 0.75 & 12.95 & 110 & 1425 & 0.210 \\
\cline { 2 - 9 } & $\mathrm{T} 2$ & 805.5 & 0.8 & 0.75 & 12.95 & 100 & 1295 & 0.620 \\
\cline { 2 - 9 } & $\mathrm{S} 3$ & 0 & 0.8 & 0.75 & 12.95 & 110 & 1425 & 0 \\
\cline { 2 - 9 } & $\mathrm{S} 6$ & 881 & 0.8 & 0.75 & 12.95 & 110 & 1425 & 0.620 \\
\hline \multirow{3}{*}{ P4 } & $\mathrm{S} 3$ & 0 & 1.0 & 0.75 & 16.2 & 140 & 2268 & 0 \\
\cline { 2 - 9 } & $\mathrm{S} 4$ & 0 & 1.0 & 0.75 & 16.2 & 140 & 2268 & 0 \\
\hline \multirow{4}{*}{ P5 } & $\mathrm{S} 4$ & 0 & 0.8 & 0.75 & 12.95 & 105 & 1360 & 0 \\
\cline { 2 - 9 } & $\mathrm{S} 6$ & 881 & 0.8 & 0.75 & 12.95 & 105 & 1360 & 0.650 \\
\cline { 2 - 9 } & $\mathrm{T} 1$ & 306 & 0.8 & 0.75 & 12.95 & 115 & 1490 & 0.210 \\
\cline { 2 - 9 } & $\mathrm{S} 5$ & 743.3 & 0.8 & 0.75 & 12.95 & 100 & 1295 & 0.570 \\
\hline P8 & $\mathrm{S} 5$ & 743.3 & 1.0 & 0.75 & 16.2 & 100 & 1620 & 0.460 \\
\hline
\end{tabular}


Table C- N9 Applied load to design strength of Nodes in GS4- HM - ACI-318

\begin{tabular}{|c|c|c|c|c|c|c|c|c|}
\hline $\begin{array}{c}\text { Node } \\
\text { No. }\end{array}$ & $\begin{array}{c}\text { Node } \\
\text { face }\end{array}$ & $\begin{array}{c}\mathrm{F} \\
(\mathrm{kN})\end{array}$ & $\beta_{\mathrm{n}}$ & $\varphi_{\mathrm{c}}$ & $\begin{array}{c}\varphi_{\mathrm{c}} 0.85 \beta_{\mathrm{n}} f_{\mathrm{c}} \\
(\mathrm{MPa})\end{array}$ & $\begin{array}{c}\mathrm{W}_{\mathrm{s}} \\
(\mathrm{mm})\end{array}$ & $\begin{array}{c}\varphi_{\mathrm{c}} \mathrm{F}_{\mathrm{nn}} \\
(\mathrm{kN})\end{array}$ & $\mathrm{F} /\left(\varphi_{\mathrm{c}} \mathrm{F}_{\mathrm{nn}}\right)$ \\
\hline P1 & $\mathrm{S} 1$ & 170.3 & 1.0 & 0.75 & 16.2 & 100 & 1620 & 0.110 \\
\hline \multirow{2}{*}{$\mathrm{P} 2$} & $\mathrm{~S} 1$ & 170.3 & 0.8 & 0.75 & 12.95 & 150 & 1942.5 & 0.088 \\
\cline { 2 - 9 } & $\mathrm{T} 1$ & 486.06 & 0.8 & 0.75 & 12.95 & 100 & 1295 & 0.375 \\
\cline { 2 - 9 } & $\mathrm{S} 2$ & 486.3 & 0.8 & 0.75 & 12.95 & 105 & 1360 & 0.360 \\
\hline \multirow{3}{*}{ P3 } & $\mathrm{S} 2$ & 486.3 & 0.8 & 0.75 & 12.95 & 110 & 1425 & 0.340 \\
\cline { 2 - 9 } & $\mathrm{T} 2$ & 1351.05 & 0.8 & 0.75 & 12.95 & 100 & 1295 & 1.040 \\
\cline { 2 - 9 } & $\mathrm{S} 3$ & 0 & 0.8 & 0.75 & 12.95 & 110 & 1425 & 0 \\
\cline { 2 - 9 } & $\mathrm{S} 6$ & 1399.5 & 0.8 & 0.75 & 12.95 & 110 & 1425 & 0.980 \\
\hline \multirow{3}{*}{ P4 } & $\mathrm{S} 3$ & 0 & 1.0 & 0.75 & 16.2 & 140 & 2268 & 0 \\
\cline { 2 - 9 } & $\mathrm{S} 4$ & 0 & 1.0 & 0.75 & 16.2 & 140 & 2268 & 0 \\
\hline \multirow{3}{*}{ P5 } & $\mathrm{S} 4$ & 0 & 0.8 & 0.75 & 12.95 & 105 & 1360 & 0 \\
\cline { 2 - 9 } & $\mathrm{S} 6$ & 1399.5 & 0.8 & 0.75 & 12.95 & 105 & 1360 & 1.030 \\
\cline { 2 - 9 } & $\mathrm{T} 1$ & 486.06 & 0.8 & 0.75 & 12.95 & 115 & 1490 & 0.330 \\
\cline { 2 - 8 } & $\mathrm{S} 5$ & 1180.7 & 0.8 & 0.75 & 12.95 & 100 & 1295 & 0.910 \\
\hline P8 & $\mathrm{S} 5$ & 1180.7 & 1.0 & 0.75 & 16.2 & 100 & 1620 & 0.730 \\
\hline
\end{tabular}

Table C-N10 Applied load to design strength of Nodes in SS5- C - ACI-318

\begin{tabular}{|c|c|c|c|c|c|c|c|c|}
\hline $\begin{array}{c}\text { Node } \\
\text { No. }\end{array}$ & $\begin{array}{c}\text { Node } \\
\text { face }\end{array}$ & $\begin{array}{c}\mathrm{F} \\
(\mathrm{kN})\end{array}$ & $\beta_{\mathrm{n}}$ & $\varphi_{\mathrm{c}}$ & $\begin{array}{c}\varphi_{\mathrm{c}} 0.85 \beta_{\mathrm{n}} f_{\mathrm{c}} \\
(\mathrm{MPa})\end{array}$ & $\begin{array}{c}\mathrm{W}_{\mathrm{s}} \\
(\mathrm{mm})\end{array}$ & $\begin{array}{c}\varphi_{\mathrm{c}} \mathrm{F}_{\mathrm{nn}} \\
(\mathrm{kN})\end{array}$ & $\mathrm{F} /\left(\varphi_{\mathrm{c}} \mathrm{F}_{\mathrm{nn}}\right)$ \\
\hline P1 & $\mathrm{S} 1$ & 128.9 & 1.0 & 0.75 & 16.2 & 100 & 1620 & 0.080 \\
\hline \multirow{3}{*}{ P2 } & $\mathrm{S} 1$ & 128.9 & 0.8 & 0.75 & 12.95 & 150 & 1942.5 & 0.066 \\
\cline { 2 - 9 } & $\mathrm{T} 1$ & 367.9 & 0.8 & 0.75 & 12.95 & 100 & 1295 & 0.284 \\
\cline { 2 - 9 } & $\mathrm{S} 2$ & 353.3 & 0.8 & 0.75 & 12.95 & 105 & 1360 & 0.260 \\
\hline \multirow{4}{*}{ P3 } & $\mathrm{S} 2$ & 353.3 & 0.8 & 0.75 & 12.95 & 110 & 1425 & 0.250 \\
\cline { 2 - 9 } & $\mathrm{T} 2$ & 1022.6 & 0.8 & 0.75 & 12.95 & 100 & 1295 & 0.790 \\
\cline { 2 - 9 } & $\mathrm{S} 3$ & 0 & 0.8 & 0.75 & 12.95 & 110 & 1425 & 0 \\
\cline { 2 - 9 } & $\mathrm{S} 6$ & 1059.3 & 0.8 & 0.75 & 12.95 & 110 & 1425 & 0.740 \\
\hline \multirow{3}{*}{ P4 } & $\mathrm{S} 3$ & 0 & 1.0 & 0.75 & 16.2 & 140 & 2268 & 0 \\
\cline { 2 - 9 } & $\mathrm{S} 4$ & 0 & 1.0 & 0.75 & 16.2 & 140 & 2268 & 0 \\
\hline \multirow{4}{*}{ P5 } & $\mathrm{S} 4$ & 0 & 0.8 & 0.75 & 12.95 & 105 & 1360 & 0 \\
\cline { 2 - 9 } & $\mathrm{S} 6$ & 1059.3 & 0.8 & 0.75 & 12.95 & 105 & 1360 & 0.780 \\
\cline { 2 - 9 } & $\mathrm{T} 1$ & 367.9 & 0.8 & 0.75 & 12.95 & 115 & 1490 & 0.250 \\
\cline { 2 - 9 } & $\mathrm{S} 5$ & 893.7 & 0.8 & 0.75 & 12.95 & 100 & 1295 & 0.690 \\
\hline P8 & $\mathrm{S} 5$ & 893.7 & 1.0 & 0.75 & 16.2 & 100 & 1620 & 0.550 \\
\hline
\end{tabular}


Table C-N11 Applied load to design strength of Nodes in GS1- HM - AS- 3600

\begin{tabular}{|c|c|c|c|c|c|c|c|c|}
\hline $\begin{array}{c}\text { Node } \\
\text { No. }\end{array}$ & $\begin{array}{c}\text { Node } \\
\text { face }\end{array}$ & $\begin{array}{c}\mathrm{F} \\
(\mathrm{kN})\end{array}$ & $\beta_{\mathrm{n}}$ & $\varphi_{\mathrm{st}}$ & $\begin{array}{c}\varphi_{\mathrm{ss}} 0.90 \beta_{\mathrm{n}} f_{\mathrm{c}} \\
(\mathrm{MPa})\end{array}$ & $\begin{array}{c}\mathrm{W}_{\mathrm{s}} \\
(\mathrm{mm})\end{array}$ & $\begin{array}{c}\varphi_{\mathrm{st}} \mathrm{F}_{\mathrm{nn}} \\
(\mathrm{kN})\end{array}$ & $\mathrm{F} /\left(\varphi_{\mathrm{st}} \mathrm{F}_{\mathrm{nn}}\right)$ \\
\hline $\mathrm{P} 1$ & $\mathrm{~S} 1$ & 106.1 & 1.0 & 0.6 & 13.72 & 100 & 1372 & 0.077 \\
\hline \multirow{2}{*}{ P2 } & $\mathrm{S} 1$ & 106.1 & 0.8 & 0.6 & 10.97 & 150 & 1646 & 0.064 \\
\cline { 2 - 9 } & $\mathrm{T} 1$ & 302.8 & 0.8 & 0.6 & 10.97 & 100 & 1097 & 0.277 \\
\cline { 2 - 9 } & $\mathrm{S} 2$ & 290.8 & 0.8 & 0.6 & 10.97 & 105 & 1152 & 0.252 \\
\hline \multirow{3}{*}{ P3 } & $\mathrm{S} 2$ & 290.8 & 0.8 & 0.6 & 10.97 & 110 & 1207 & 0.241 \\
\cline { 2 - 9 } & $\mathrm{T} 2$ & 841.7 & 0.8 & 0.6 & 10.97 & 100 & 1097 & 0.770 \\
\cline { 2 - 9 } & $\mathrm{S} 3$ & 0 & 0.8 & 0.6 & 10.97 & 110 & 1207 & 0 \\
\cline { 2 - 9 } & $\mathrm{S} 6$ & 871.9 & 0.8 & 0.6 & 10.97 & 110 & 1207 & 0.720 \\
\hline \multirow{3}{*}{ P4 } & $\mathrm{S} 3$ & 0 & 1.0 & 0.6 & 13.72 & 140 & 1921 & 0 \\
\cline { 2 - 9 } & $\mathrm{S} 4$ & 0 & 1.0 & 0.6 & 13.72 & 140 & 1921 & 0 \\
\hline \multirow{3}{*}{ P5 } & $\mathrm{S} 4$ & 0 & 0.8 & 0.6 & 10.97 & 105 & 1152 & 0 \\
\cline { 2 - 9 } & $\mathrm{S} 6$ & 871.9 & 0.8 & 0.6 & 10.97 & 105 & 1152 & 0.760 \\
\cline { 2 - 9 } & $\mathrm{T} 1$ & 302.8 & 0.8 & 0.6 & 10.97 & 115 & 1262 & 0.240 \\
\cline { 2 - 9 } & $\mathrm{S} 5$ & 735.6 & 0.8 & 0.6 & 10.97 & 100 & 1097 & 0.670 \\
\hline P8 & $\mathrm{S} 5$ & 735.6 & 1.0 & 0.6 & 13.72 & 100 & 1372 & 0.540 \\
\hline
\end{tabular}

$\varphi_{\mathrm{st}} \mathrm{F}_{\mathrm{nn}}=\varphi_{\mathrm{st}} f_{\mathrm{cu}} \mathrm{A}_{\mathrm{n}}=\varphi_{\mathrm{st}} 0.90 \beta_{\mathrm{n}} f_{\text {'c }} . \mathrm{A}_{\mathrm{n}}$

$A_{n}=W_{s} \cdot b \quad(b=1000 \mathrm{~mm})$

Table C-N12 Applied load to design strength of Nodes in GS2- ST - AS- 3600

\begin{tabular}{|c|c|c|c|c|c|c|c|c|}
\hline $\begin{array}{c}\text { Node } \\
\text { No. }\end{array}$ & $\begin{array}{c}\text { Node } \\
\text { face }\end{array}$ & $\begin{array}{c}\mathrm{F} \\
(\mathrm{kN})\end{array}$ & $\beta_{\mathrm{n}}$ & $\varphi_{\mathrm{st}}$ & $\begin{array}{c}\varphi_{\mathrm{s}}\left(0.90 \beta_{\mathrm{n}} f^{\prime} \mathrm{c}\right. \\
(\mathrm{MPa})\end{array}$ & $\begin{array}{c}\mathrm{W}_{\mathrm{s}} \\
(\mathrm{mm})\end{array}$ & $\begin{array}{c}\varphi_{\mathrm{st}} \mathrm{F}_{\mathrm{nn}} \\
(\mathrm{kN})\end{array}$ & $\mathrm{F} /\left(\varphi_{\mathrm{st}} \mathrm{F}_{\mathrm{nn}}\right)$ \\
\hline $\mathrm{P} 1$ & $\mathrm{~S} 1$ & 116.3 & 1.0 & 0.6 & 13.72 & 100 & 1372 & 0.085 \\
\hline \multirow{3}{*}{$\mathrm{P} 2$} & $\mathrm{~S} 1$ & 116.3 & 0.8 & 0.6 & 10.97 & 150 & 1646 & 0.071 \\
\cline { 2 - 9 } & $\mathrm{T} 1$ & 331.9 & 0.8 & 0.6 & 10.97 & 100 & 1097 & 0.302 \\
\cline { 2 - 9 } & $\mathrm{S} 2$ & 318.8 & 0.8 & 0.6 & 10.97 & 105 & 1152 & 0.277 \\
\hline \multirow{3}{*}{ P3 } & $\mathrm{S} 2$ & 318.8 & 0.8 & 0.6 & 10.97 & 110 & 1207 & 0.264 \\
\cline { 2 - 9 } & $\mathrm{T} 2$ & 922.7 & 0.8 & 0.6 & 10.97 & 100 & 1097 & 0.840 \\
\cline { 2 - 9 } & $\mathrm{S} 3$ & 0 & 0.8 & 0.6 & 10.97 & 110 & 1207 & 0 \\
\cline { 2 - 9 } & $\mathrm{S} 6$ & 955.7 & 0.8 & 0.6 & 10.97 & 110 & 1207 & 0.790 \\
\hline \multirow{3}{*}{ P4 } & $\mathrm{S} 3$ & 0 & 1.0 & 0.6 & 13.72 & 140 & 1921 & 0 \\
\cline { 2 - 9 } & $\mathrm{S} 4$ & 0 & 1.0 & 0.6 & 13.72 & 140 & 1921 & 0 \\
\hline \multirow{3}{*}{ P5 } & $\mathrm{S} 4$ & 0 & 0.8 & 0.6 & 10.97 & 105 & 1152 & 0 \\
\cline { 2 - 9 } & $\mathrm{S} 6$ & 955.7 & 0.8 & 0.6 & 10.97 & 105 & 1152 & 0.830 \\
\cline { 2 - 8 } & $\mathrm{T} 1$ & 331.9 & 0.8 & 0.6 & 10.97 & 115 & 1262 & 0.263 \\
\cline { 2 - 8 } & $\mathrm{S} 5$ & 806.4 & 0.8 & 0.6 & 10.97 & 100 & 1097 & 0.740 \\
\hline P8 & $\mathrm{S} 5$ & 806.4 & 1.0 & 0.6 & 13.72 & 100 & 1372 & 0.590 \\
\hline
\end{tabular}


Table C-N13 Applied load to design strength of Nodes in GS3- ST - AS- 3600

\begin{tabular}{|c|c|c|c|c|c|c|c|c|}
\hline $\begin{array}{c}\text { Node } \\
\text { No. }\end{array}$ & $\begin{array}{c}\text { Node } \\
\text { face }\end{array}$ & $\begin{array}{c}\mathrm{F} \\
(\mathrm{kN})\end{array}$ & $\beta_{\mathrm{n}}$ & $\varphi_{\mathrm{st}}$ & $\begin{array}{c}\varphi_{\mathrm{st}} 0.90 \beta_{\mathrm{n}} f_{\mathrm{c}} \\
(\mathrm{MPa})\end{array}$ & $\begin{array}{c}\mathrm{W}_{\mathrm{s}} \\
(\mathrm{mm})\end{array}$ & $\begin{array}{c}\varphi_{\mathrm{s}} \mathrm{F}_{\mathrm{nn}} \\
(\mathrm{kN})\end{array}$ & $\mathrm{F} /\left(\varphi_{\mathrm{st}} \mathrm{F}_{\mathrm{nn}}\right)$ \\
\hline P1 & $\mathrm{S} 1$ & 107.2 & 1.0 & 0.6 & 13.72 & 100 & 1372 & 0.078 \\
\hline \multirow{2}{*}{ P2 } & $\mathrm{S} 1$ & 107.2 & 0.8 & 0.6 & 10.97 & 150 & 1646 & 0.065 \\
\cline { 2 - 9 } & $\mathrm{T} 1$ & 306 & 0.8 & 0.6 & 10.97 & 100 & 1097 & 0.28 \\
\cline { 2 - 9 } & $\mathrm{S} 2$ & 294 & 0.8 & 0.6 & 10.97 & 105 & 1152 & 0.255 \\
\hline \multirow{3}{*}{ P3 } & $\mathrm{S} 2$ & 294 & 0.8 & 0.6 & 10.97 & 110 & 1207 & 0.243 \\
\cline { 2 - 9 } & $\mathrm{T} 2$ & 805.5 & 0.8 & 0.6 & 10.97 & 100 & 1097 & 0.730 \\
\cline { 2 - 9 } & $\mathrm{S} 3$ & 0 & 0.8 & 0.6 & 10.97 & 110 & 1207 & 0 \\
\cline { 2 - 9 } & $\mathrm{S} 6$ & 881 & 0.8 & 0.6 & 10.97 & 110 & 1207 & 0.730 \\
\hline \multirow{3}{*}{ P4 } & $\mathrm{S} 3$ & 0 & 1.0 & 0.6 & 13.72 & 140 & 1921 & 0 \\
\cline { 2 - 9 } & $\mathrm{S} 4$ & 0 & 1.0 & 0.6 & 13.72 & 140 & 1921 & 0 \\
\hline \multirow{3}{*}{ P5 } & $\mathrm{S} 4$ & 0 & 0.8 & 0.6 & 10.97 & 105 & 1152 & 0 \\
\cline { 2 - 9 } & $\mathrm{S} 6$ & 881 & 0.8 & 0.6 & 10.97 & 105 & 1152 & 0.760 \\
\cline { 2 - 9 } & $\mathrm{T} 1$ & 306 & 0.8 & 0.6 & 10.97 & 115 & 1262 & 0.240 \\
\cline { 2 - 9 } & $\mathrm{S} 5$ & 743.3 & 0.8 & 0.6 & 10.97 & 100 & 1097 & 0.680 \\
\hline P8 & $\mathrm{S} 5$ & 743.3 & 1.0 & 0.6 & 13.72 & 100 & 1372 & 0.540 \\
\hline
\end{tabular}

Table C-N14 Applied load to design strength of Nodes in GS4- HM - AS- 3600

\begin{tabular}{|c|c|c|c|c|c|c|c|c|}
\hline $\begin{array}{c}\text { Node } \\
\text { No. }\end{array}$ & $\begin{array}{c}\text { Node } \\
\text { face }\end{array}$ & $\begin{array}{c}\mathrm{F} \\
(\mathrm{kN})\end{array}$ & $\beta_{\mathrm{n}}$ & $\varphi_{\mathrm{st}}$ & $\begin{array}{c}\varphi_{\mathrm{st}} 0.90 \beta_{\mathrm{n}} f_{\mathrm{c}} \\
(\mathrm{MPa})\end{array}$ & $\begin{array}{c}\mathrm{W}_{\mathrm{s}} \\
(\mathrm{mm})\end{array}$ & $\begin{array}{c}\varphi_{\mathrm{st}} \mathrm{F}_{\mathrm{nn}} \\
(\mathrm{kN})\end{array}$ & $\mathrm{F} /\left(\varphi_{\mathrm{st}} \mathrm{F}_{\mathrm{nn}}\right)$ \\
\hline P1 & $\mathrm{S} 1$ & 170.3 & 1.0 & 0.6 & 13.72 & 100 & 1372 & 0.124 \\
\hline \multirow{3}{*}{ P2 } & $\mathrm{S} 1$ & 170.3 & 0.8 & 0.6 & 10.97 & 150 & 1646 & 0.103 \\
\cline { 2 - 9 } & $\mathrm{T} 1$ & 486.06 & 0.8 & 0.6 & 10.97 & 100 & 1097 & 0.440 \\
\cline { 2 - 9 } & $\mathrm{S} 2$ & 486.3 & 0.8 & 0.6 & 10.97 & 105 & 1152 & 0.42 \\
\hline \multirow{3}{*}{ P3 } & $\mathrm{S} 2$ & 486.3 & 0.8 & 0.6 & 10.97 & 110 & 1207 & 0.402 \\
\cline { 2 - 9 } & $\mathrm{T} 2$ & 1351.05 & 0.8 & 0.6 & 10.97 & 100 & 1097 & 1.230 \\
\cline { 2 - 9 } & $\mathrm{S} 3$ & 0 & 0.8 & 0.6 & 10.97 & 110 & 1207 & 0 \\
\cline { 2 - 9 } & $\mathrm{S} 6$ & 1399.5 & 0.8 & 0.6 & 10.97 & 110 & 1207 & 1.160 \\
\hline \multirow{3}{*}{ P4 } & $\mathrm{S} 3$ & 0 & 1.0 & 0.6 & 13.72 & 140 & 1921 & 0 \\
\cline { 2 - 9 } & $\mathrm{S} 4$ & 0 & 1.0 & 0.6 & 13.72 & 140 & 1921 & 0 \\
\hline \multirow{3}{*}{ P5 } & $\mathrm{S} 4$ & 0 & 0.8 & 0.6 & 10.97 & 105 & 1152 & 0 \\
\cline { 2 - 8 } & $\mathrm{S} 6$ & 1399.5 & 0.8 & 0.6 & 10.97 & 105 & 1152 & 1.210 \\
\cline { 2 - 8 } & $\mathrm{T} 1$ & 486.06 & 0.8 & 0.6 & 10.97 & 115 & 1262 & 0.385 \\
\cline { 2 - 8 } & $\mathrm{S} 5$ & 1180.7 & 0.8 & 0.6 & 10.97 & 100 & 1097 & 1.070 \\
\hline P8 & $\mathrm{S} 5$ & 1180.7 & 1.0 & 0.6 & 13.72 & 100 & 1372 & 0.860 \\
\hline
\end{tabular}


Table C-N15 Applied load to design strength of Nodes in SS5- CS - AS- 3600

\begin{tabular}{|c|c|c|c|c|c|c|c|c|}
\hline $\begin{array}{c}\text { Node } \\
\text { No. }\end{array}$ & $\begin{array}{c}\text { Node } \\
\text { face }\end{array}$ & $\begin{array}{c}\mathrm{F} \\
(\mathrm{kN})\end{array}$ & $\beta_{\mathrm{n}}$ & $\varphi_{\mathrm{st}}$ & $\begin{array}{c}\varphi_{\mathrm{st}} 0.90 \beta_{\mathrm{n}} f_{{ }_{\mathrm{c}}} \\
(\mathrm{MPa})\end{array}$ & $\begin{array}{c}\mathrm{W}_{\mathrm{s}} \\
(\mathrm{mm})\end{array}$ & $\begin{array}{c}\varphi_{\mathrm{st}} \mathrm{F}_{\mathrm{nn}} \\
(\mathrm{kN})\end{array}$ & $\mathrm{F} /\left(\varphi_{\mathrm{st}} \mathrm{F}_{\mathrm{nn}}\right)$ \\
\hline $\mathrm{P} 1$ & $\mathrm{~S} 1$ & 128.9 & 1.0 & 0.6 & 13.72 & 100 & 1372 & 0.094 \\
\hline \multirow{2}{*}{ P2 } & $\mathrm{S} 1$ & 128.9 & 0.8 & 0.6 & 10.97 & 150 & 1646 & 0.078 \\
\cline { 2 - 9 } & $\mathrm{T} 1$ & 367.9 & 0.8 & 0.6 & 10.97 & 100 & 1097 & 0.340 \\
\cline { 2 - 9 } & $\mathrm{S} 2$ & 353.3 & 0.8 & 0.6 & 10.97 & 105 & 1152 & 0.310 \\
\hline \multirow{3}{*}{ P3 } & $\mathrm{S} 2$ & 353.3 & 0.8 & 0.6 & 10.97 & 110 & 1207 & 0.293 \\
\cline { 2 - 9 } & $\mathrm{T} 2$ & 1022.6 & 0.8 & 0.6 & 10.97 & 100 & 1097 & 0.930 \\
\cline { 2 - 9 } & $\mathrm{S} 3$ & 0 & 0.8 & 0.6 & 10.97 & 110 & 1207 & 0 \\
\cline { 2 - 9 } & $\mathrm{S} 6$ & 1059.3 & 0.8 & 0.6 & 10.97 & 110 & 1207 & 0.880 \\
\hline \multirow{3}{*}{ P4 } & $\mathrm{S} 3$ & 0 & 1.0 & 0.6 & 13.72 & 140 & 1921 & 0 \\
\cline { 2 - 9 } & $\mathrm{S} 4$ & 0 & 1.0 & 0.6 & 13.72 & 140 & 1921 & 0 \\
\hline \multirow{3}{*}{ P5 } & $\mathrm{S} 4$ & 0 & 0.8 & 0.6 & 10.97 & 105 & 1152 & 0 \\
\cline { 2 - 9 } & $\mathrm{S} 6$ & 1059.3 & 0.8 & 0.6 & 10.97 & 105 & 1152 & 0.920 \\
\cline { 2 - 9 } & $\mathrm{T} 1$ & 367.9 & 0.8 & 0.6 & 10.97 & 115 & 1262 & 0.290 \\
\cline { 2 - 9 } & $\mathrm{S} 5$ & 893.7 & 0.8 & 0.6 & 10.97 & 100 & 1097 & 0.810 \\
\hline P8 & $\mathrm{S} 5$ & 893.7 & 1.0 & 0.6 & 13.72 & 100 & 1372 & 0.650 \\
\hline
\end{tabular}

$\varphi_{\mathrm{st}} \mathrm{F}_{\mathrm{nn}}=\varphi_{\mathrm{st}} f_{\mathrm{cu}} \mathrm{A}_{\mathrm{n}}=\varphi_{\mathrm{st}} 0.90 \beta_{\mathrm{n}} f_{{ }_{\mathrm{c}}} . \mathrm{A}_{\mathrm{n}}$

$A_{n}=W_{s} \cdot b \quad(b=1000 \mathrm{~mm})$ 


\section{Appendix D}

Moment and Tensile Force Intensity Factors in Traffic Barriers 


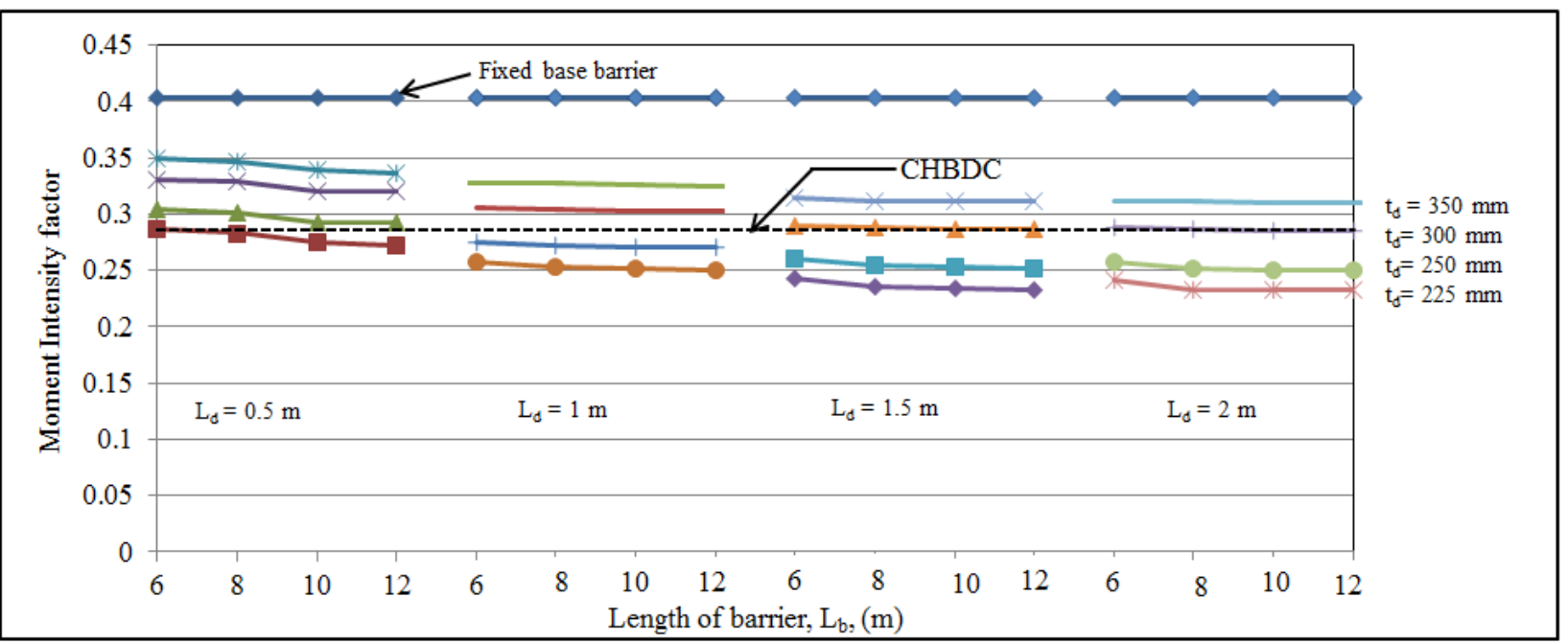

Figure D.1 Moment intensity in the deck of the PL-3 barrier wall versus barrier length as a function of cantilever deck slab length and deck slab thickness at exterior location

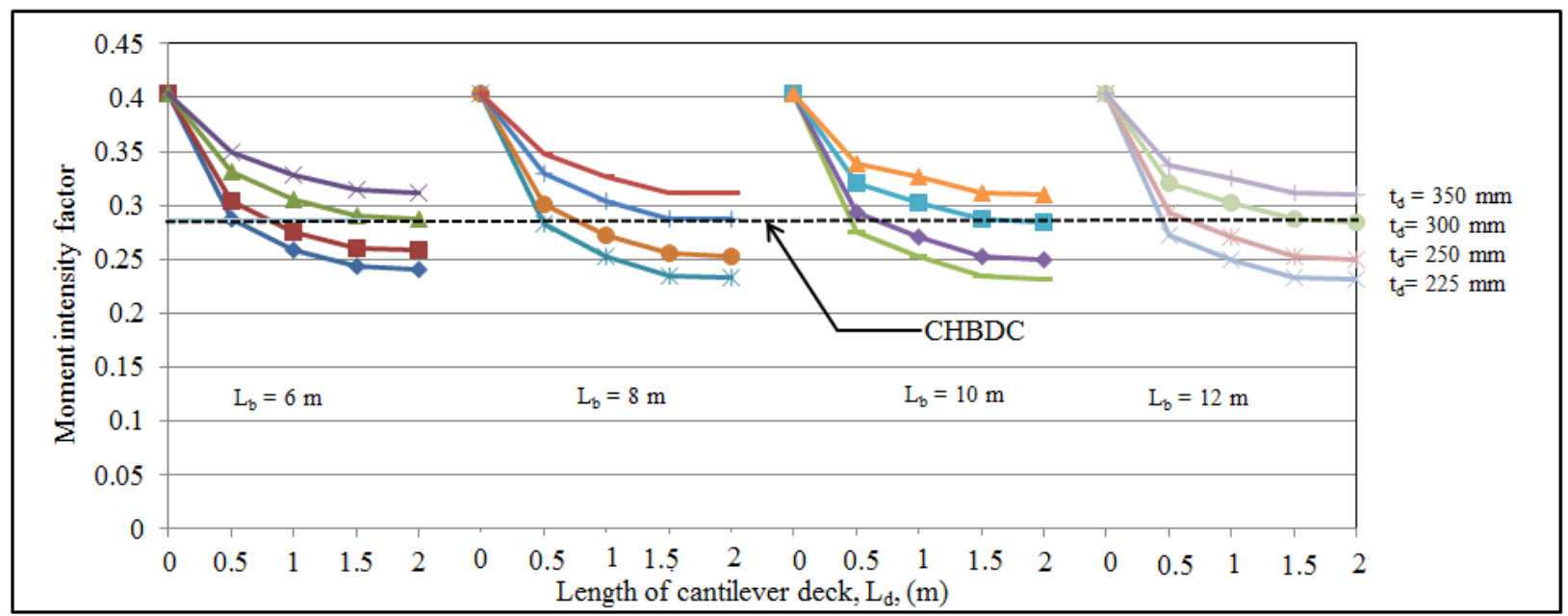

Figure D2 Moment intensity in the deck of the PL-3 barrier wall versus cantilever deck length as a function of barrier length and deck slab thickness at exterior location 


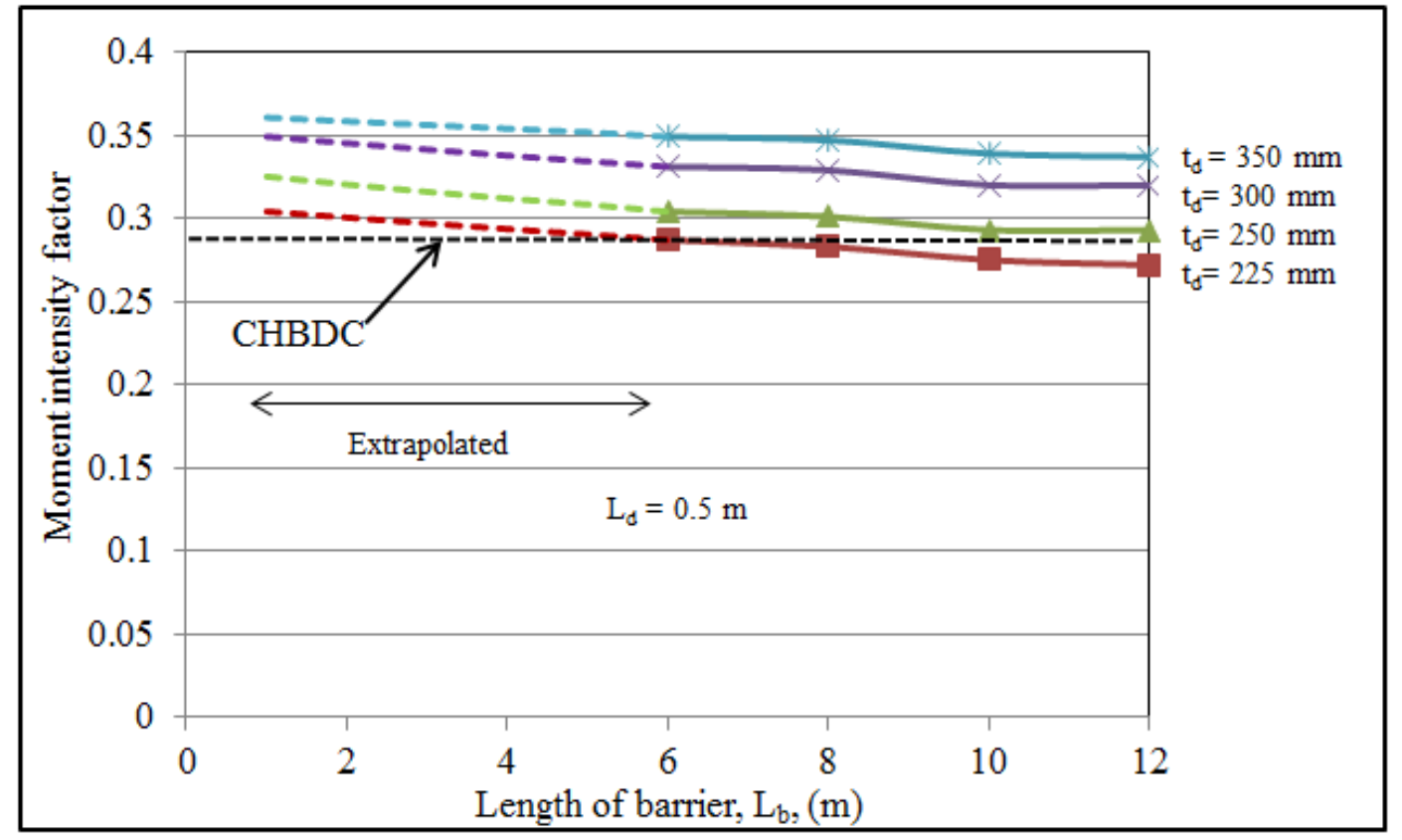

Figure D3 Extrapolation of moment intensity versus barrier longitudinal length for PL-3 barrier at exterior location

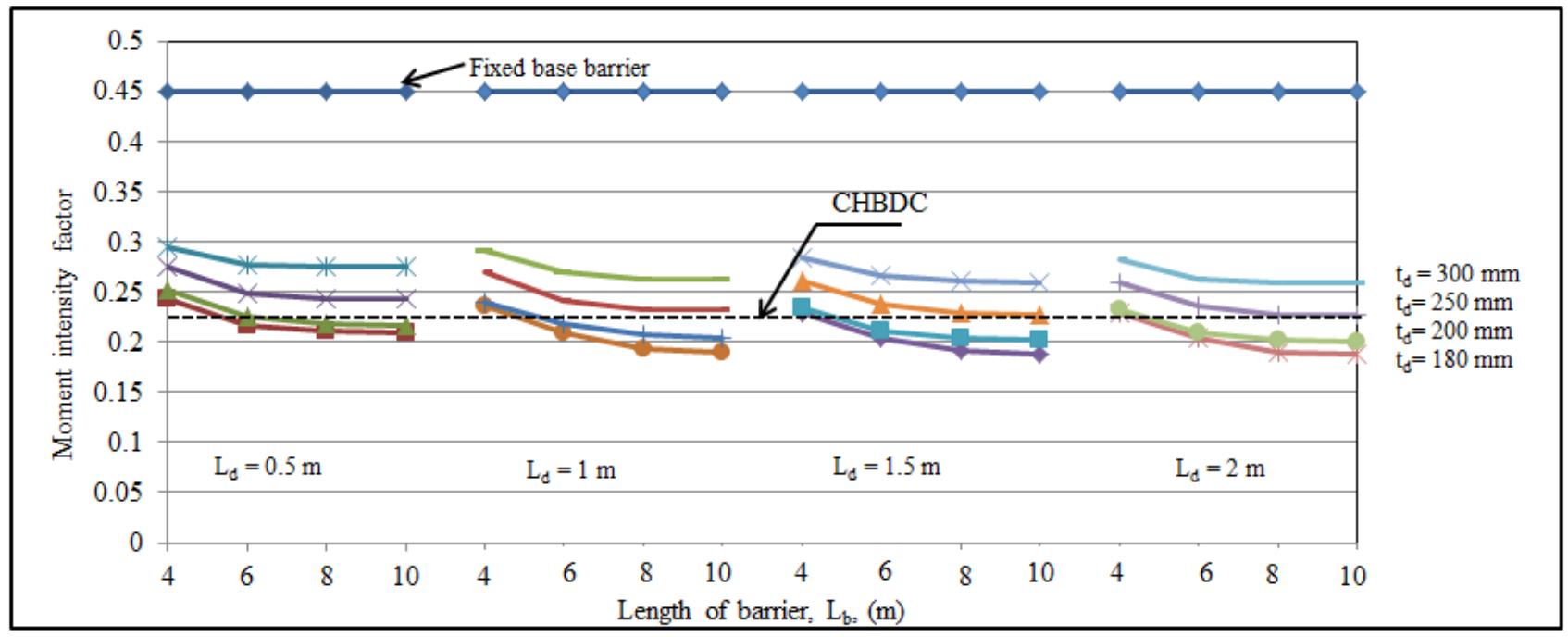

Figure D4 Moment intensity in the deck of the PL-2 barrier wall versus barrier length as a function of cantilever deck slab length and deck slab thickness at interior location 


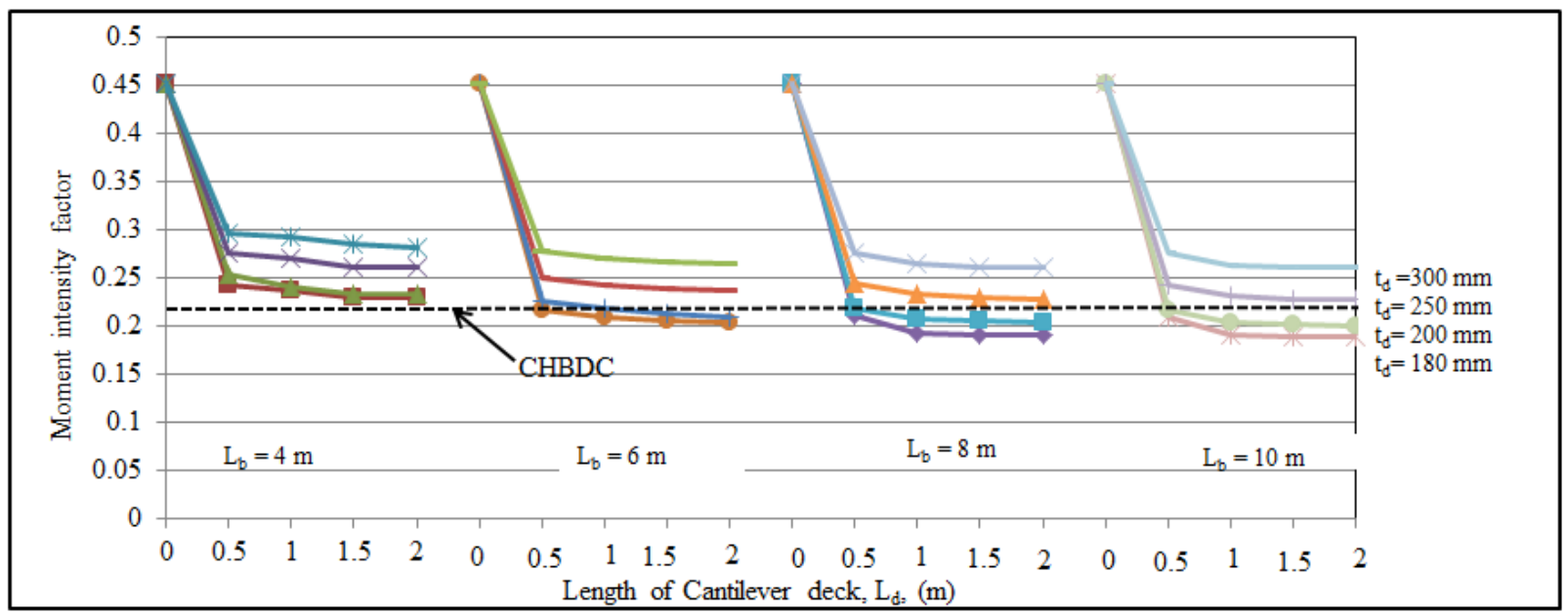

Figure D5 Moment intensity in the deck of the PL-2 barrier wall versus cantilever deck length as a function of barrier length and deck slab thickness at interior location

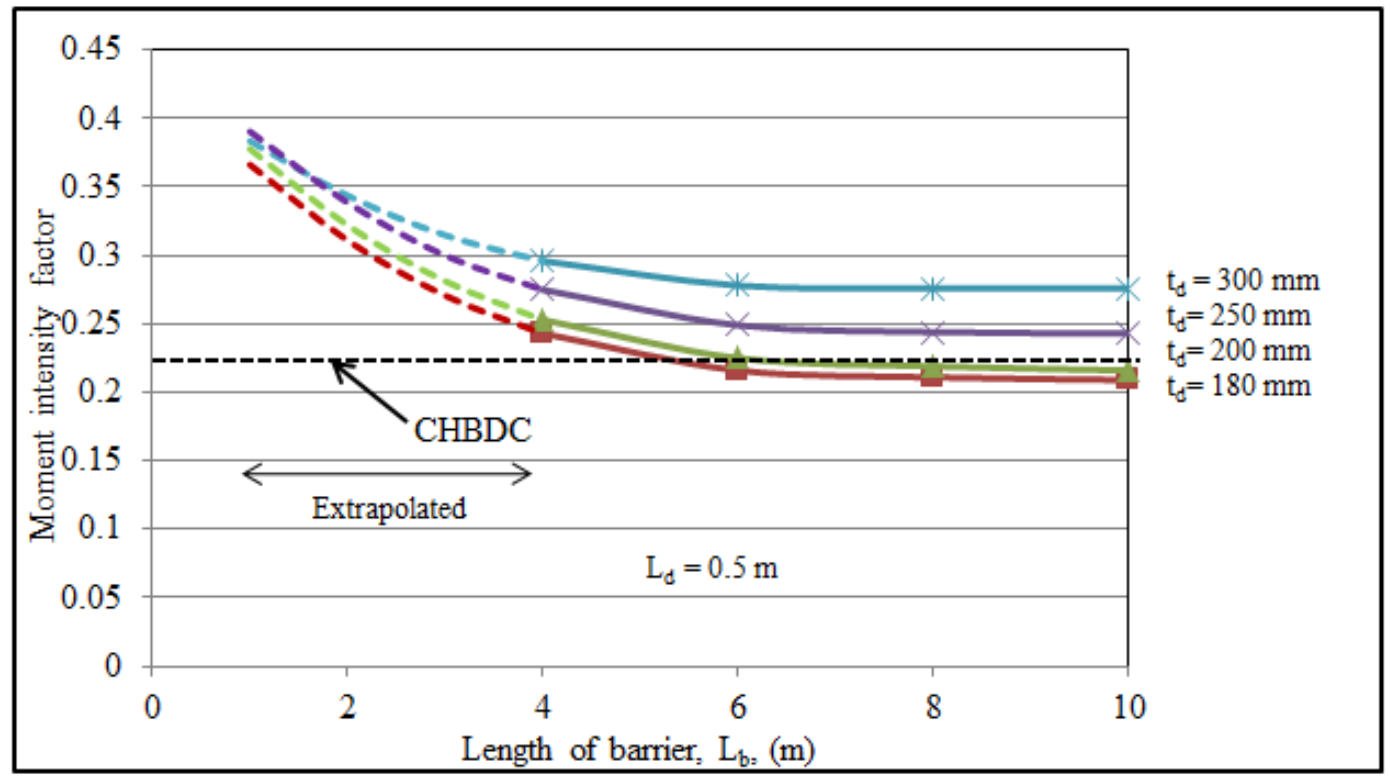

Figure D6 Extrapolation of moment intensity versus barrier longitudinal length for PL-2 barrier at interior location 


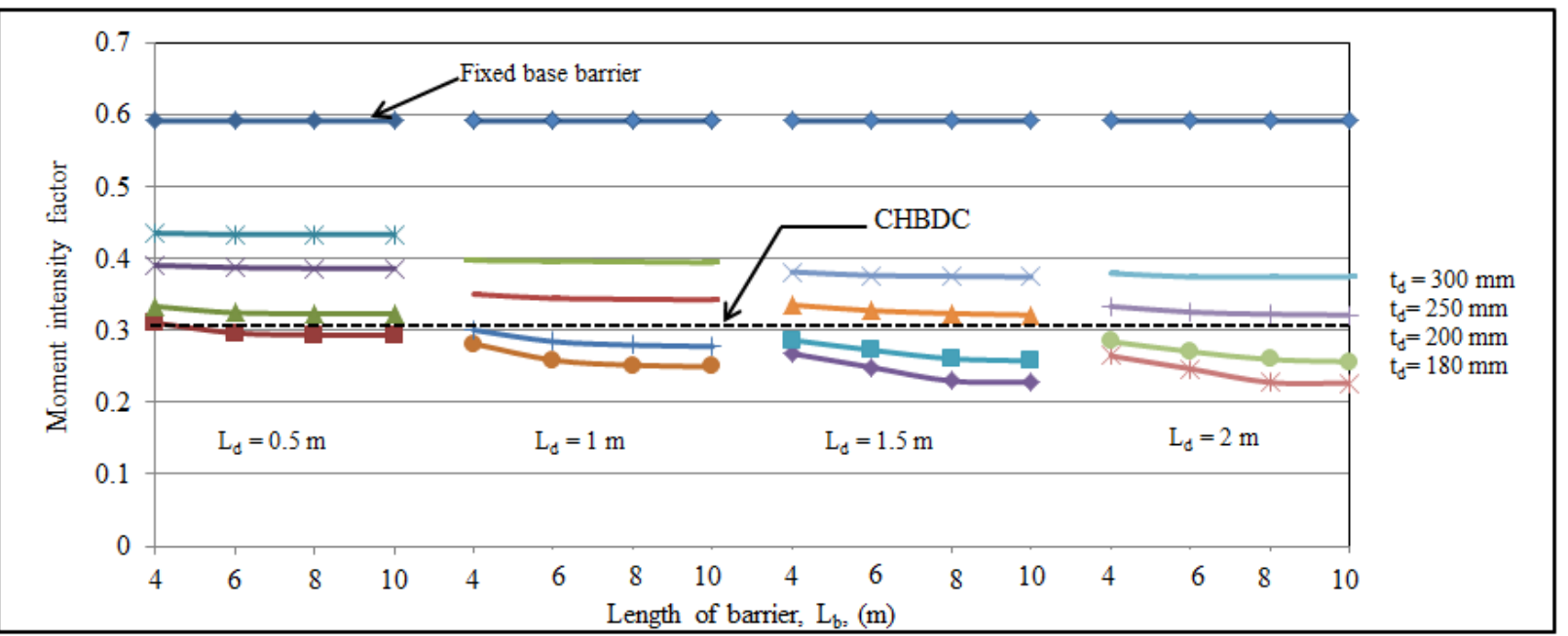

Figure D7 Moment intensity in the deck of the PL-2 barrier wall versus barrier length as a function of cantilever deck slab length and deck slab thickness at exterior location

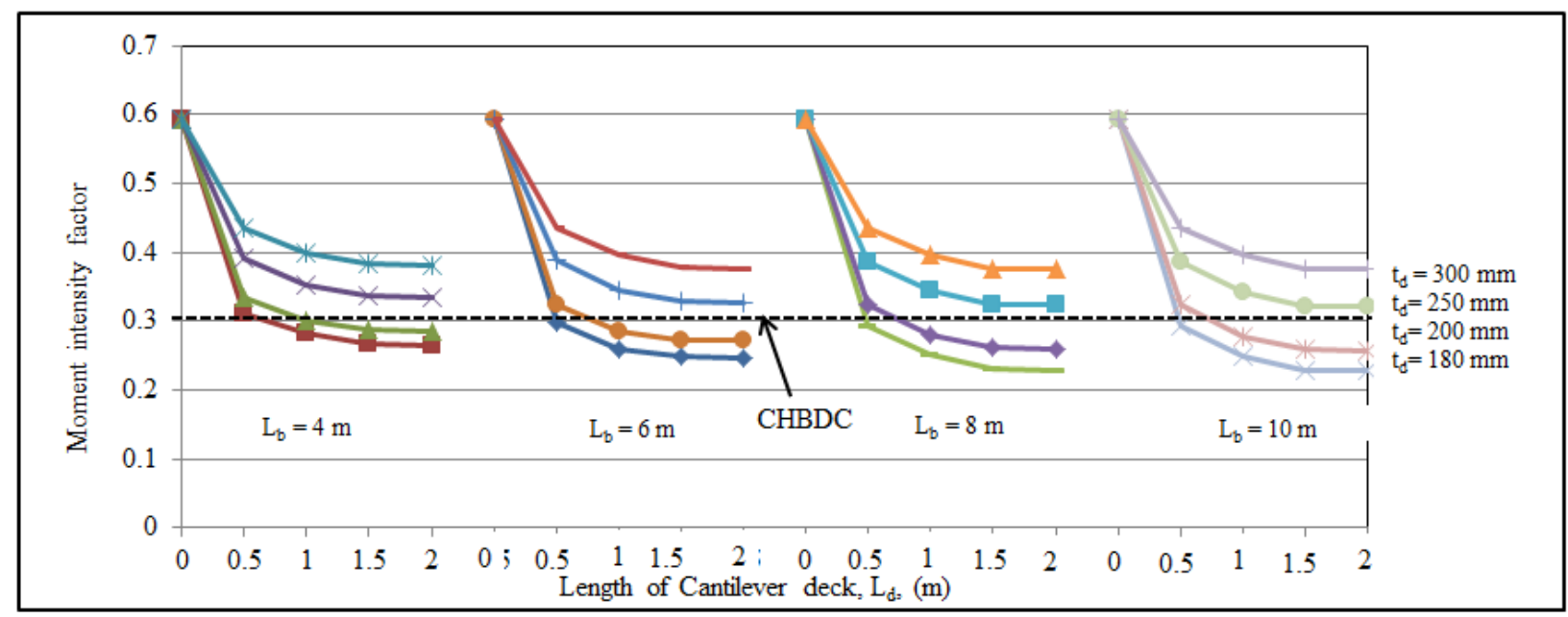

Figure D8 Moment intensity in the deck of the PL-2 barrier wall versus cantilever deck length as a function of barrier length and deck slab thickness at exterior location 


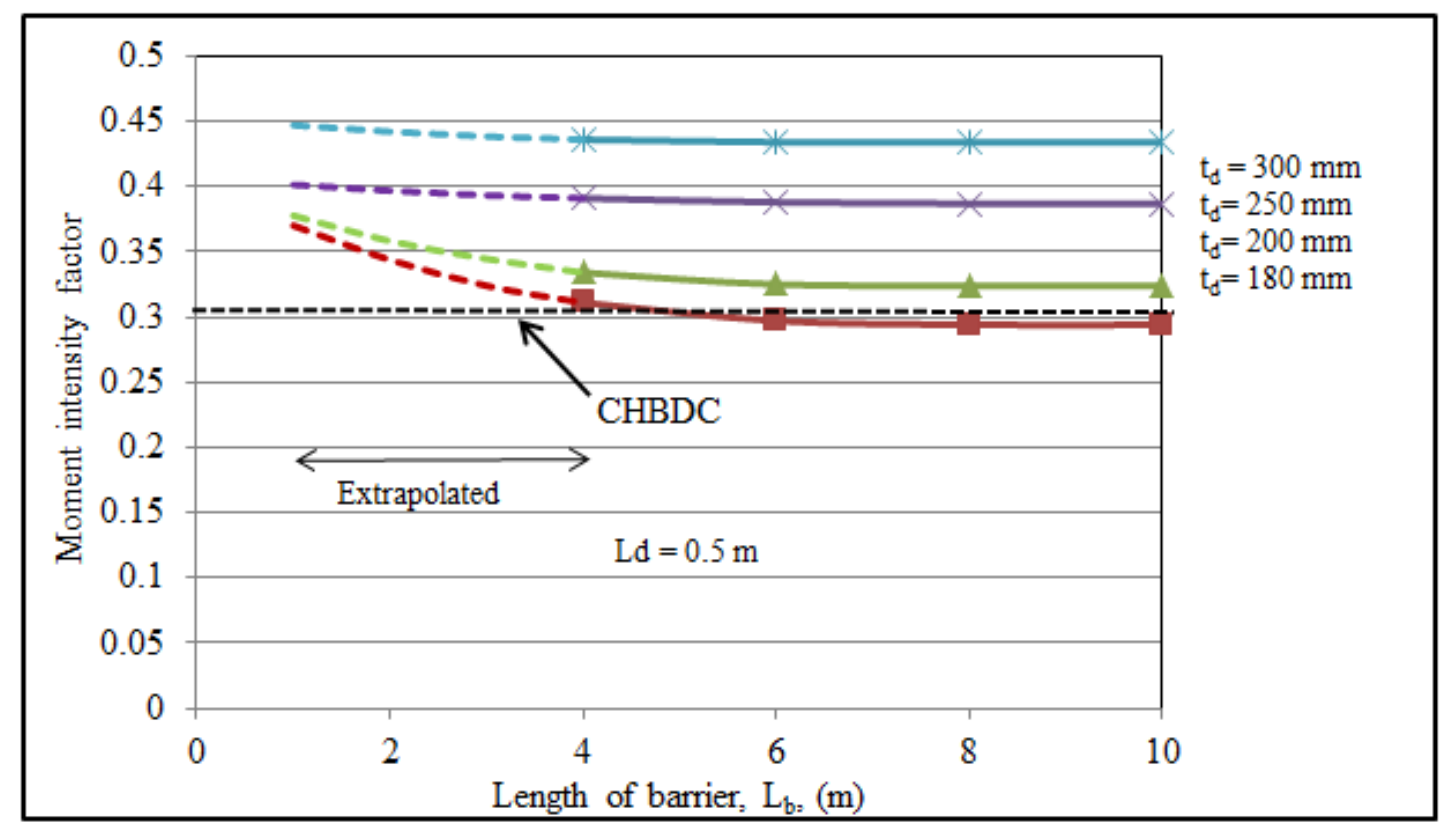

Figure D9 Extrapolation of moment intensity versus barrier longitudinal length for PL-2 barrier at exterior location

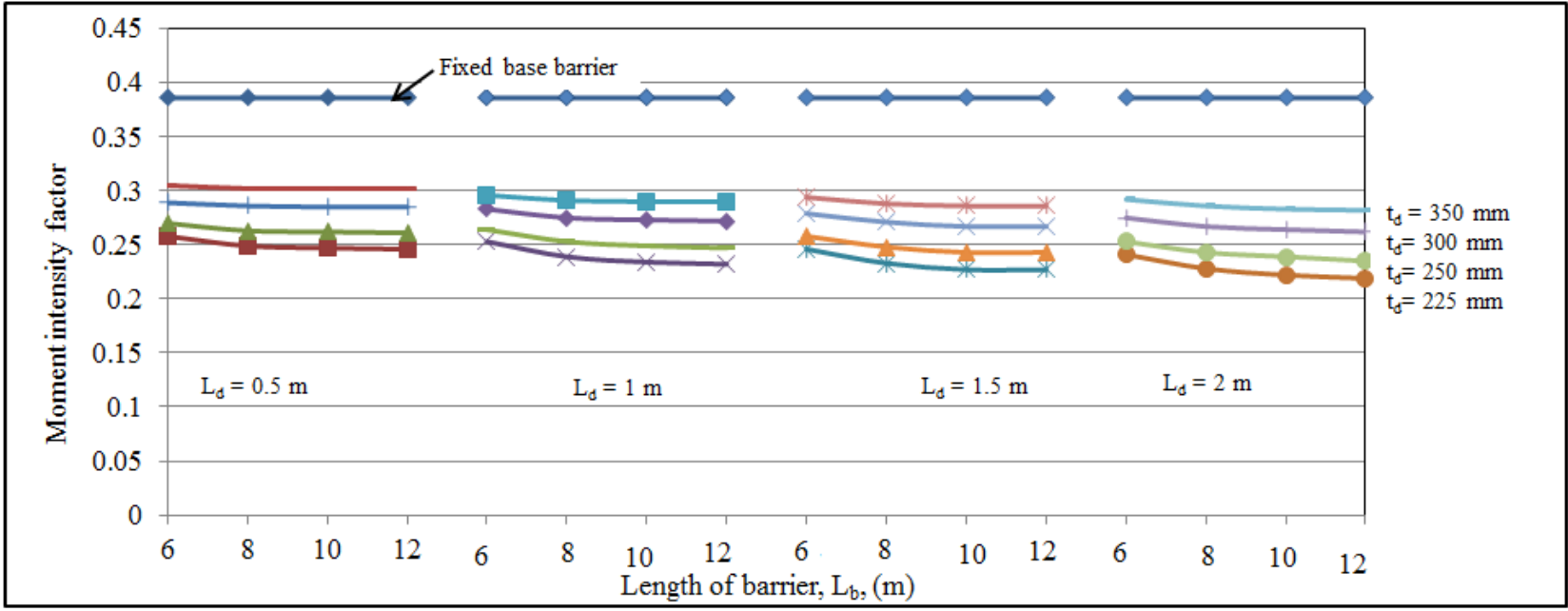

Figure D10 Moment intensity in the deck of the TL-5 barrier wall versus barrier length as a function of cantilever deck slab length and deck slab thickness at interior location 


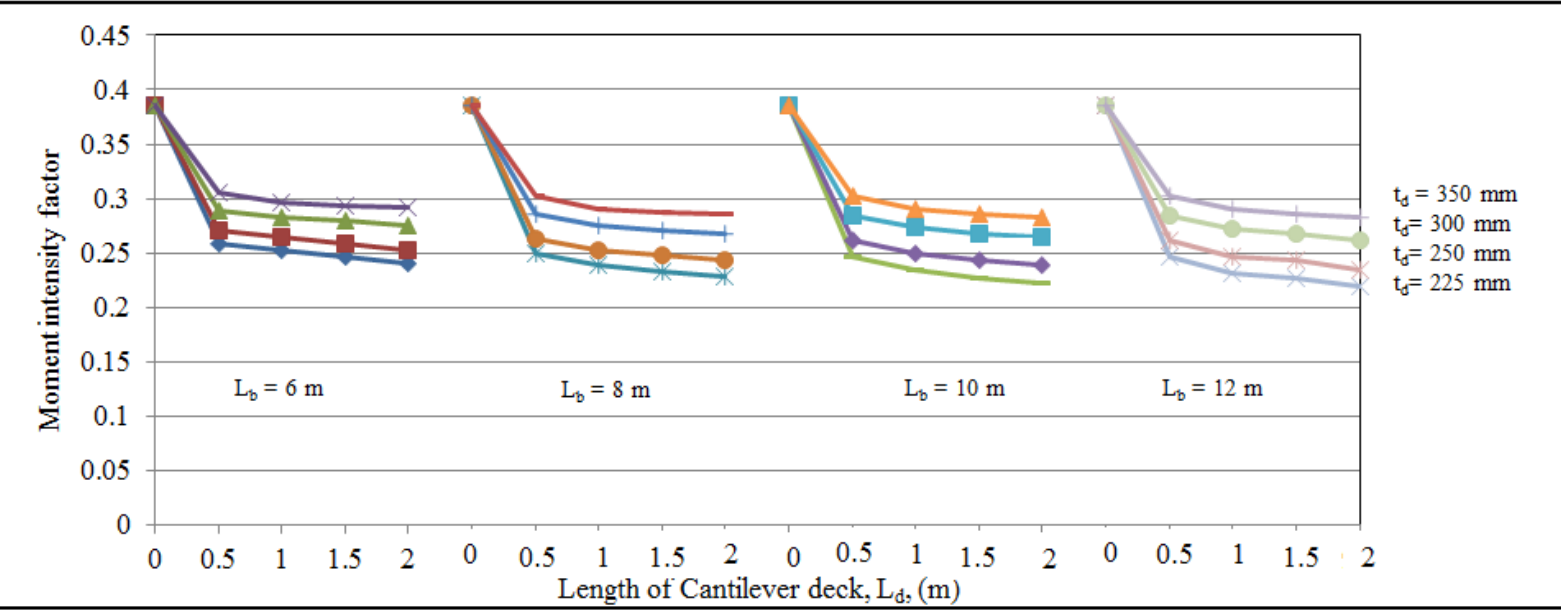

Figure D11 Moment intensity in the deck of the TL-5 barrier wall versus cantilever deck length as a function of barrier length and deck slab thickness at interior location

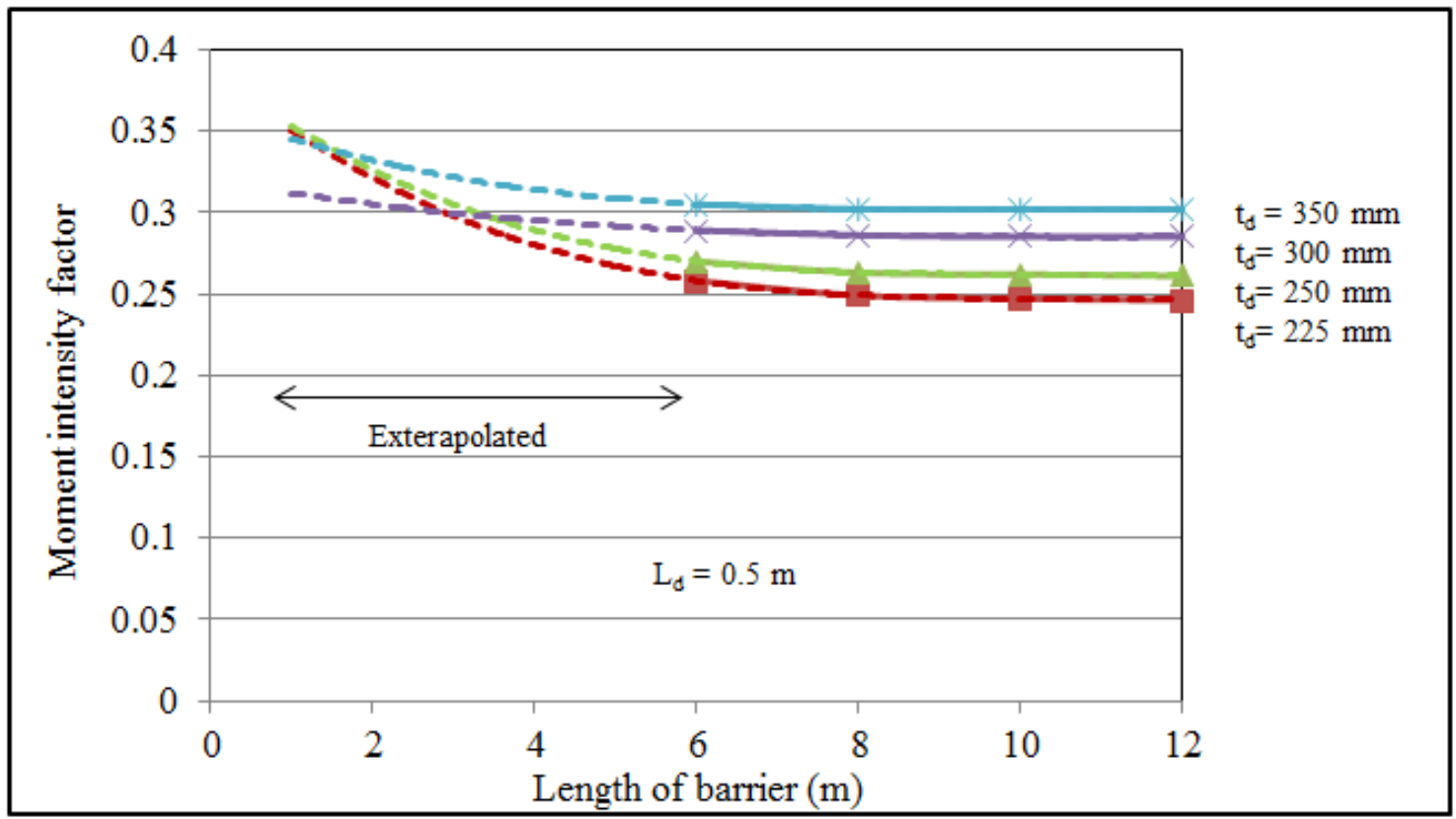

Figure D12 Extrapolation of moment intensity versus barrier longitudinal length for TL-5 barrier at interior location 


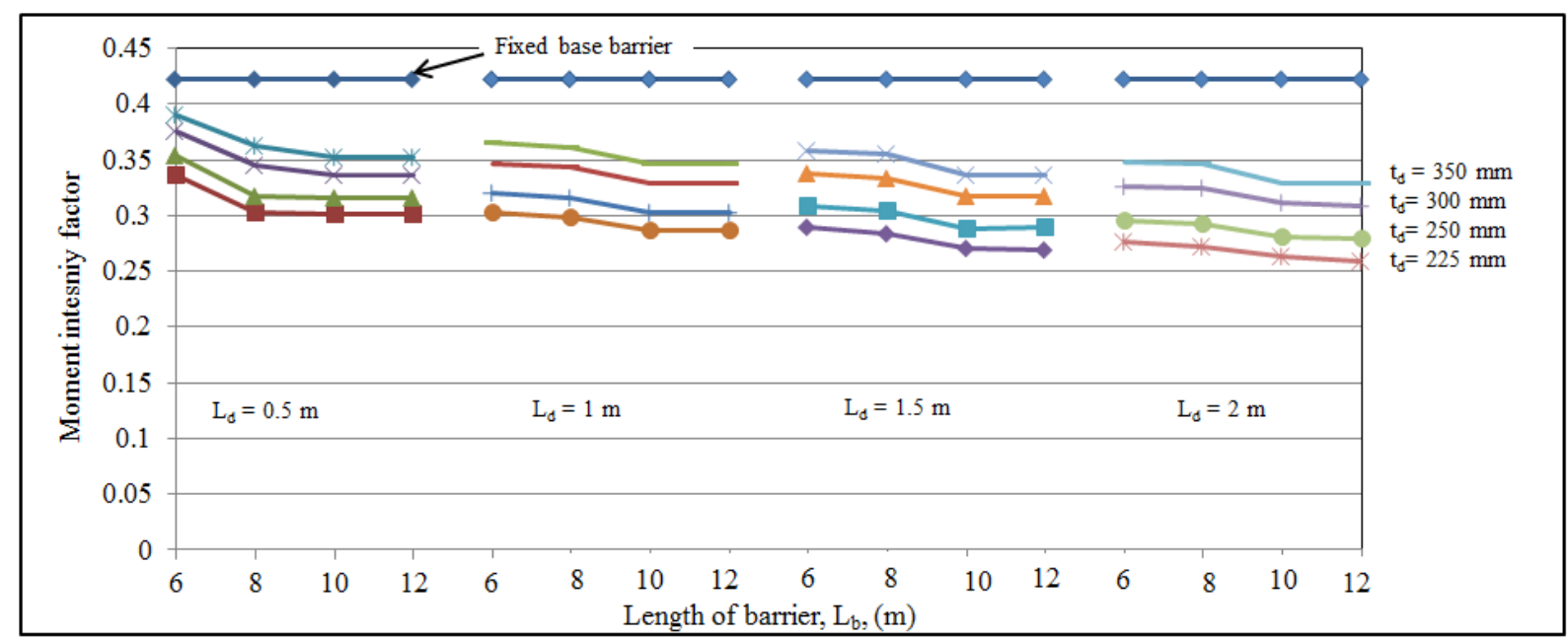

Figure D13 Moment intensity in the deck of the TL-5 barrier wall versus barrier length as a function of cantilever deck slab length and deck slab thickness at exterior location

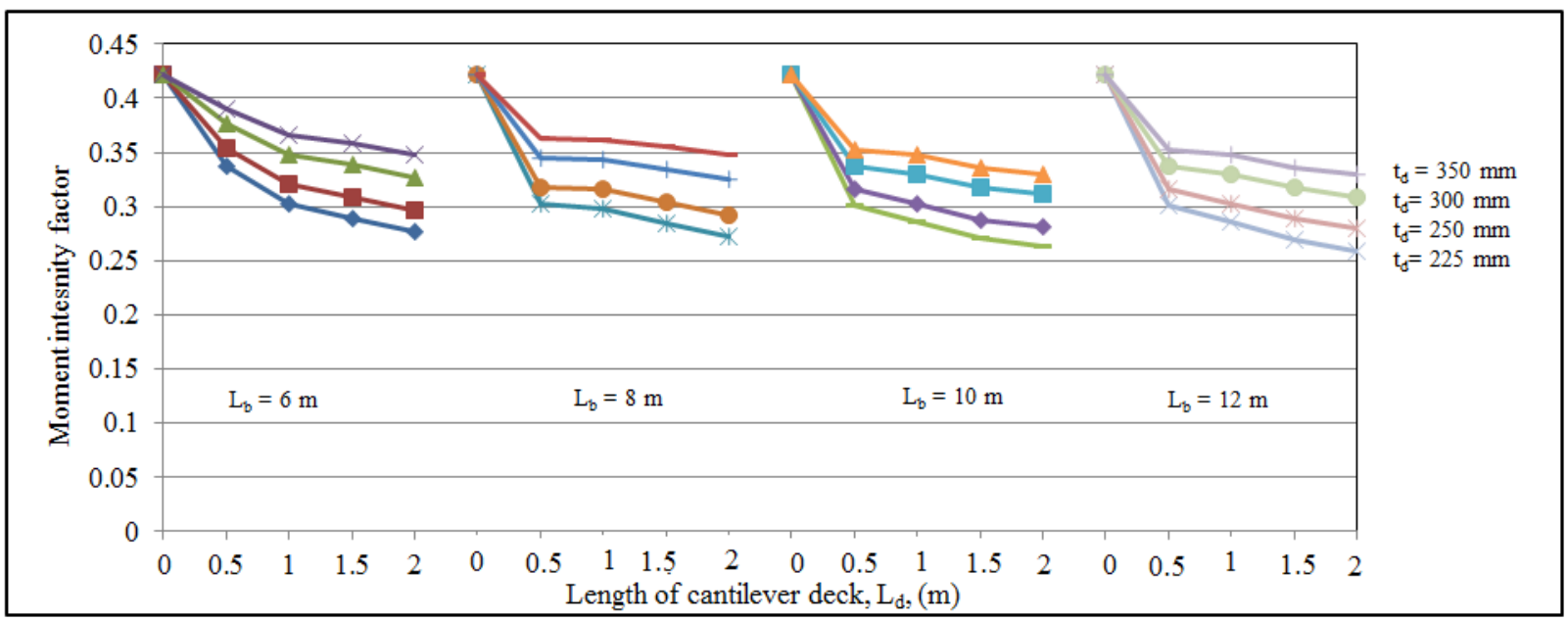

Figure D14 Moment intensity in the deck of the TL-5 barrier wall versus cantilever deck length as a function of barrier length and deck slab thickness at exterior location 


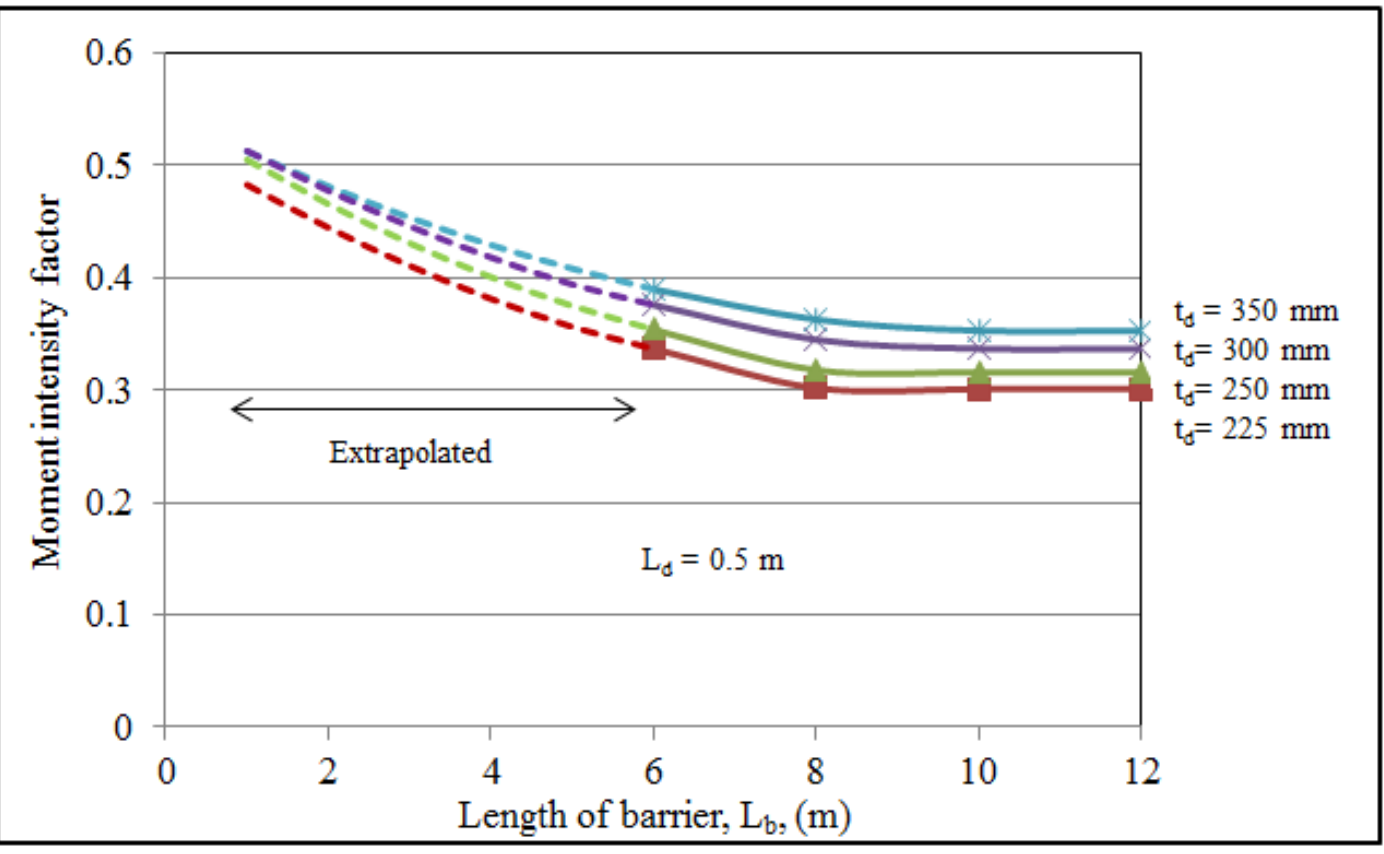

Figure D15 Extrapolation of moment intensity versus barrier longitudinal length for TL-5 barrier at exterior location

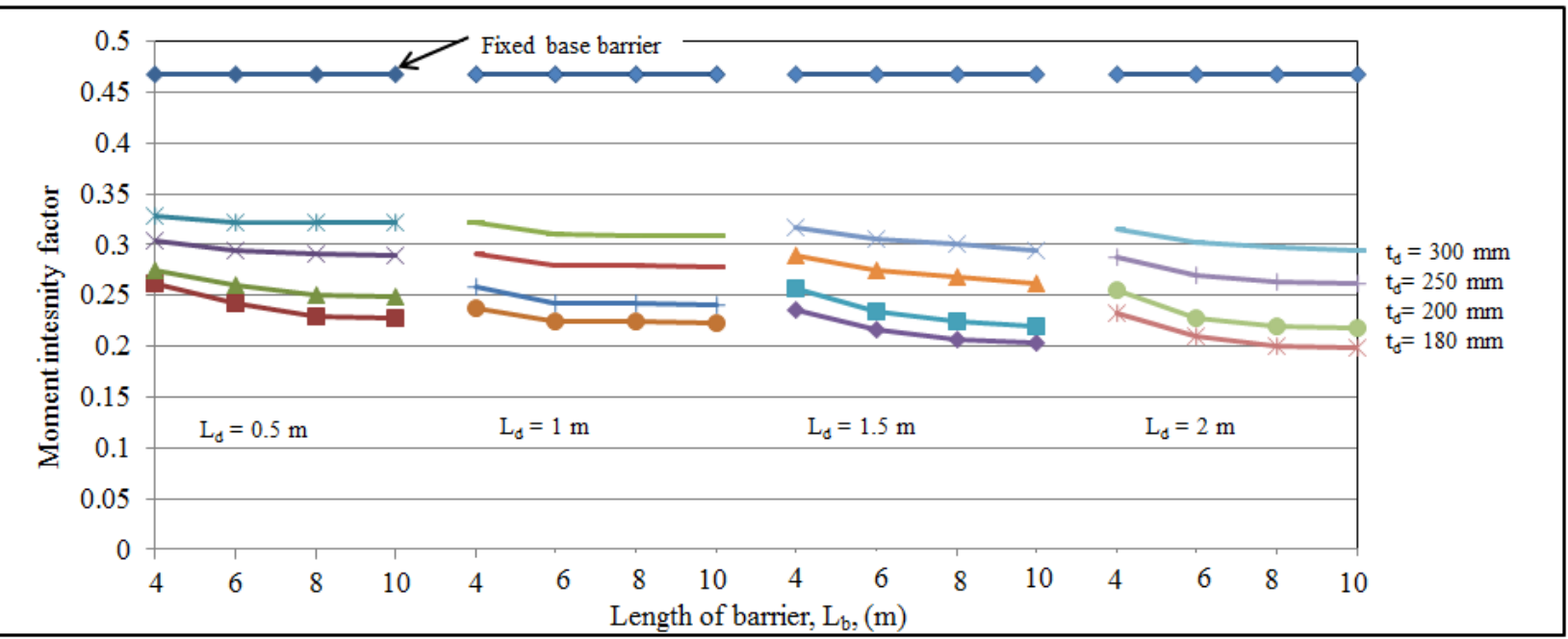

Figure D16 Moment intensity in the deck of the TL-4 barrier wall versus barrier length as a function of cantilever deck slab length and deck slab thickness at interior location 


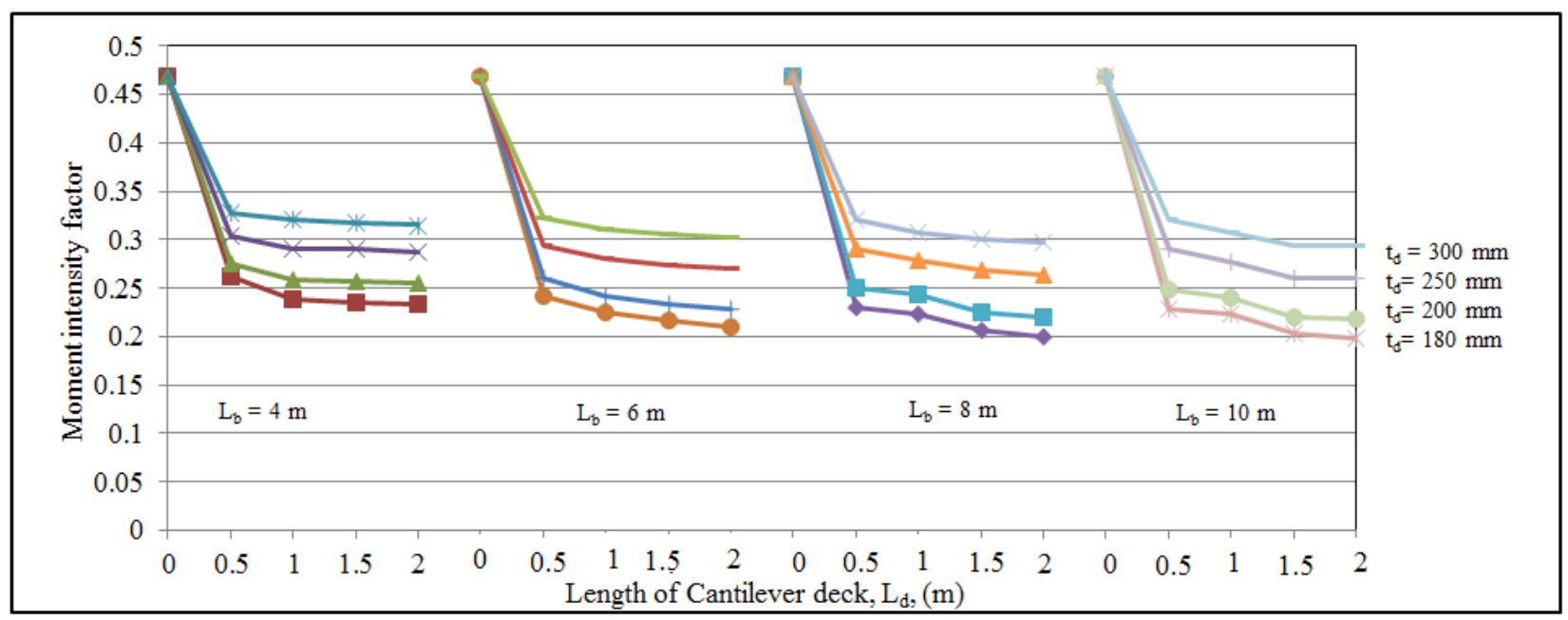

Figure D17 Moment intensity in the deck of the TL-4 barrier wall versus cantilever deck length as a function of barrier length and deck slab thickness at interior location

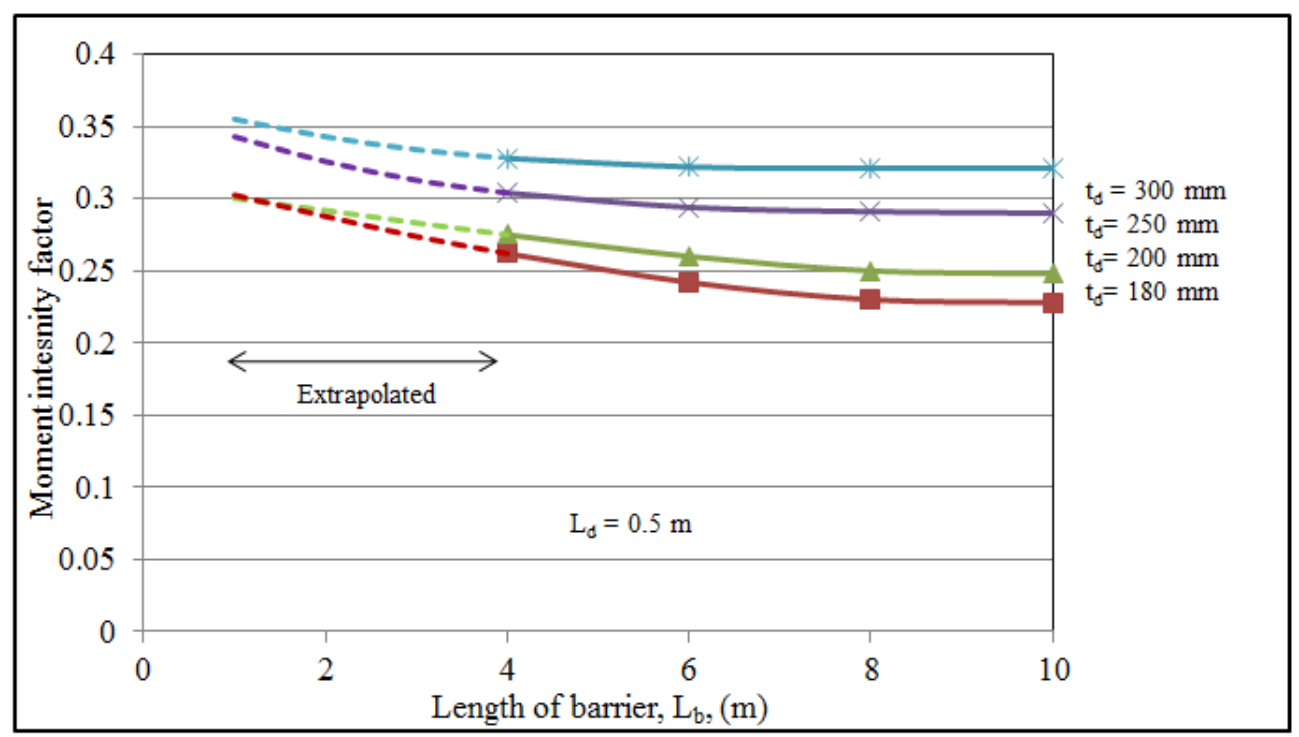

Figure D18 Extrapolation of moment intensity versus barrier longitudinal length for TL-4 barrier at interior location 


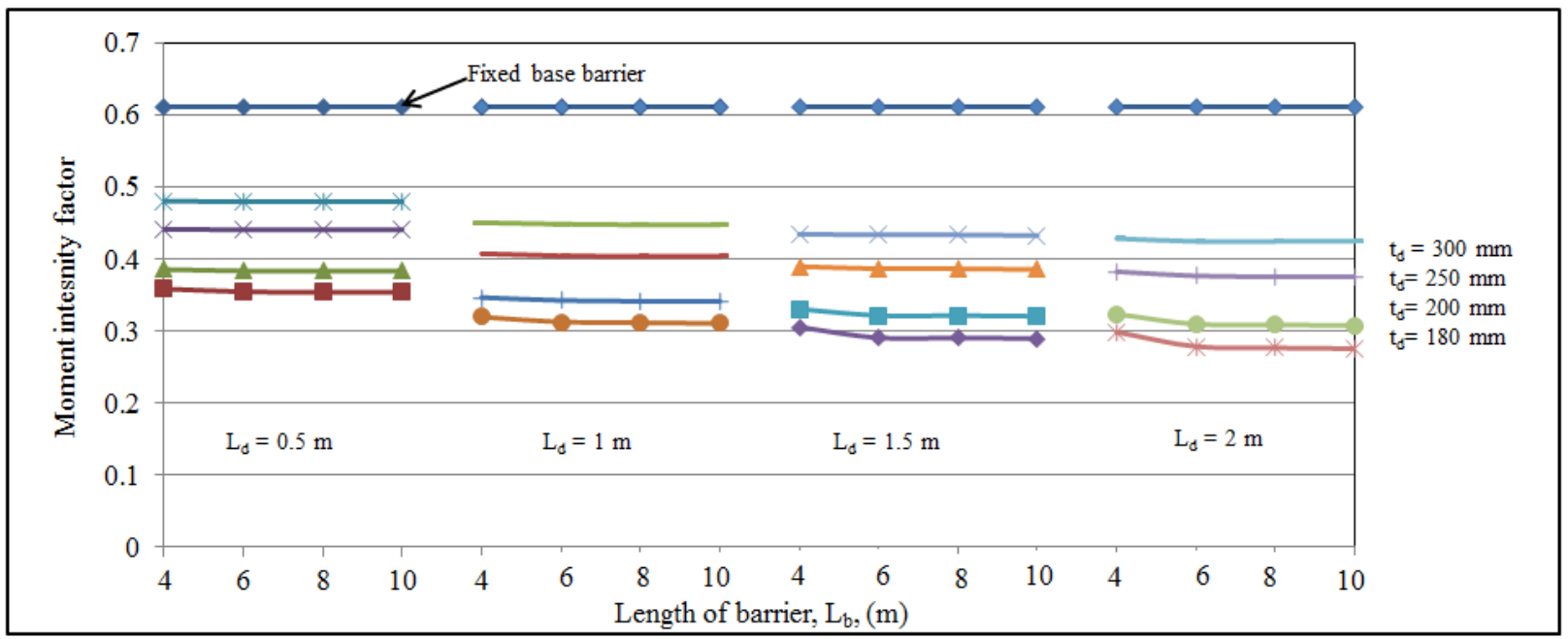

Figure D19 Moment intensity in the deck of the TL-4 barrier wall versus barrier length as a function of cantilever deck slab length and deck slab thickness at exterior location

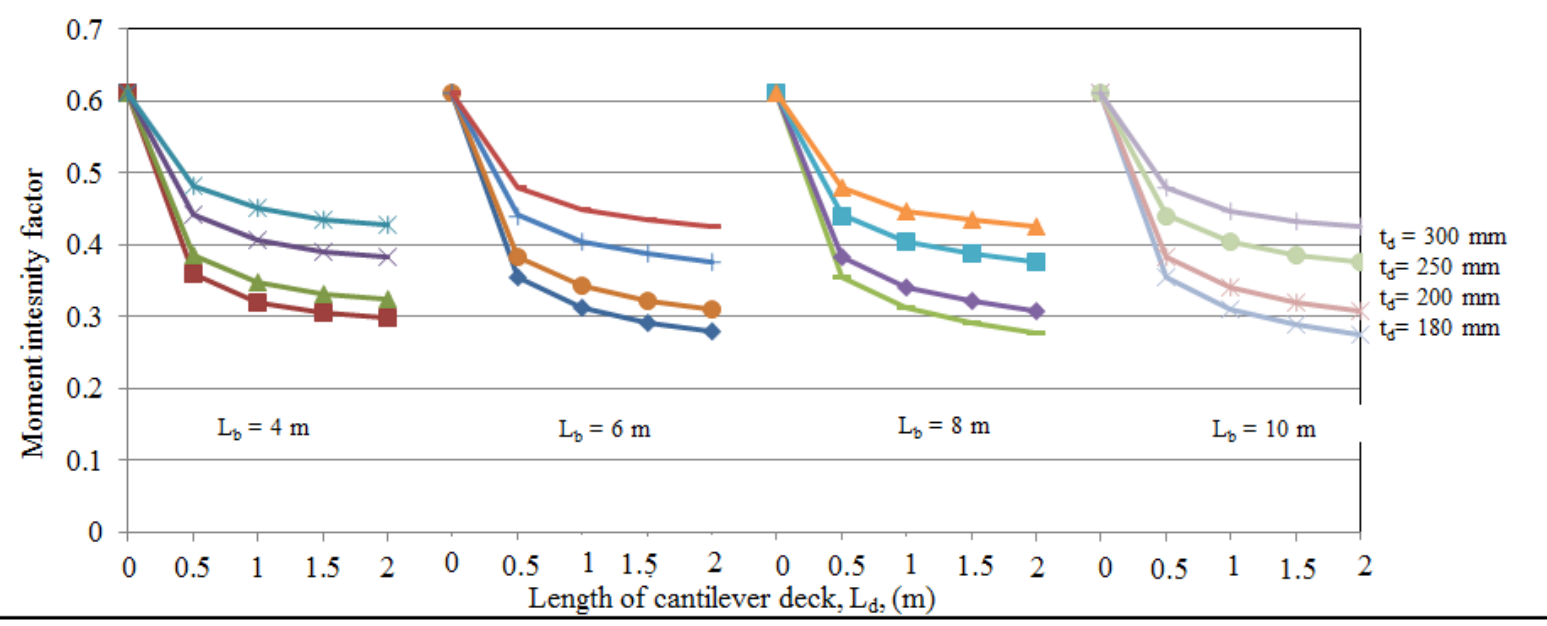

Figure D20 Moment intensity in the deck of the TL-4 barrier wall versus cantilever deck length as a function of barrier length and deck slab thickness at exterior location 


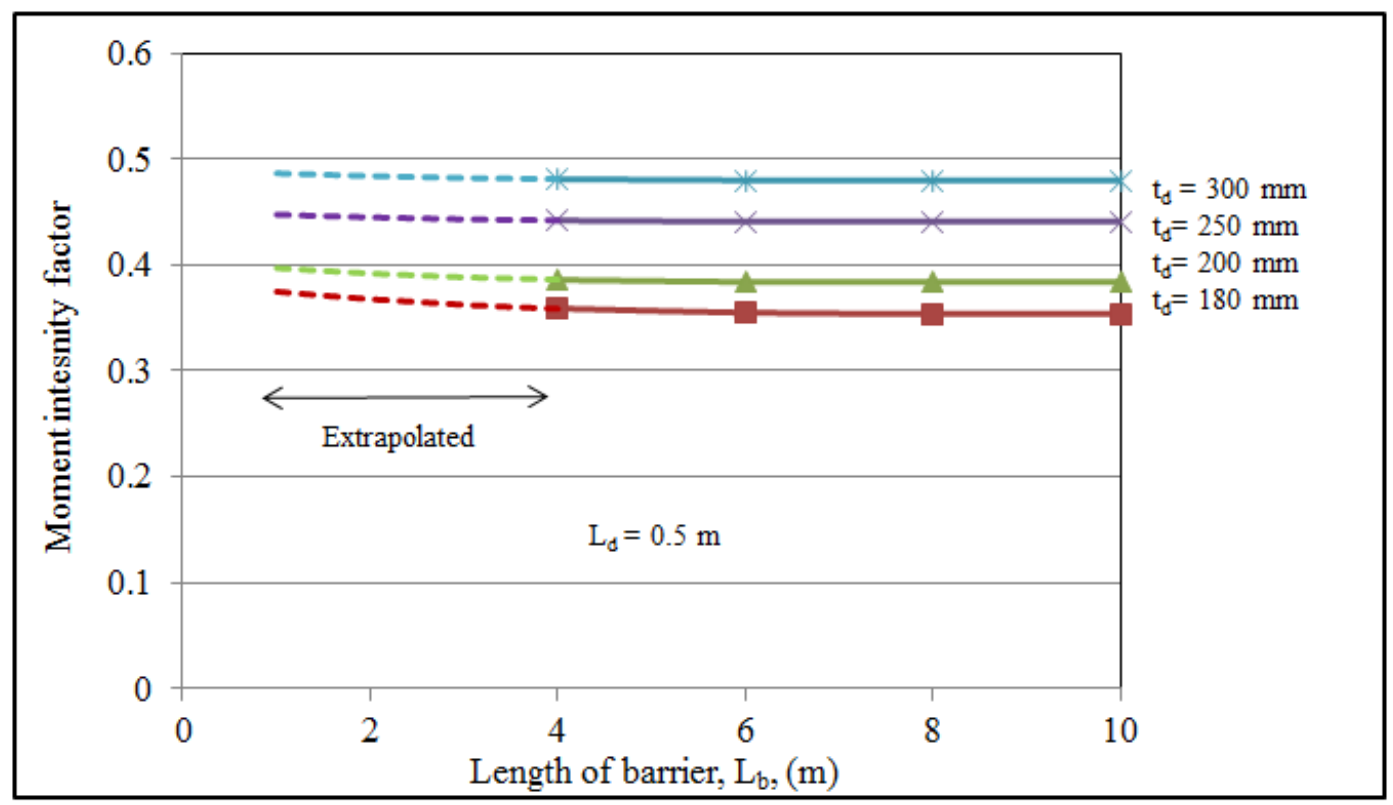

Figure D21 Extrapolation of moment intensity versus barrier longitudinal length for TL-4 barrier at exterior location

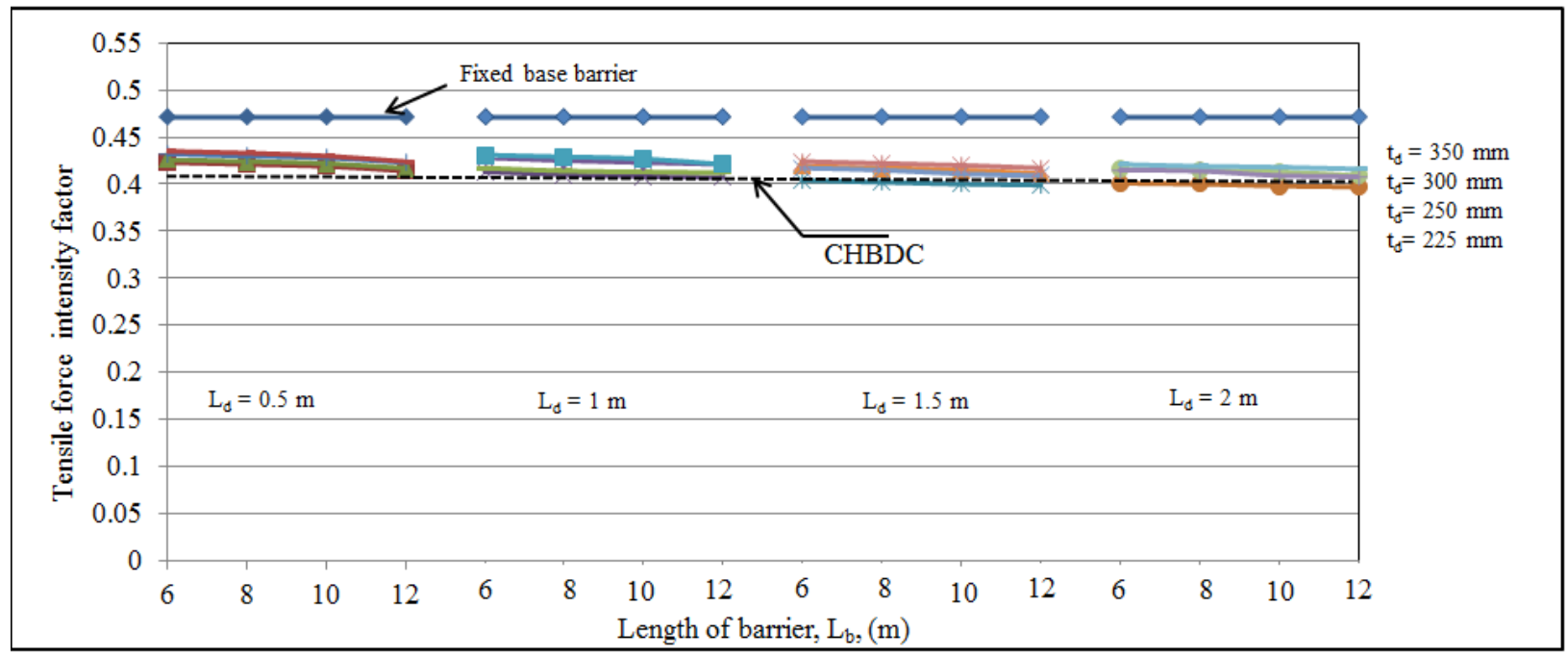

Figure D22 Tensile force intensity in the deck slab versus longitudinal length of PL-3 barrier as a function of cantilever deck slab length and deck slab thickness at interior location 


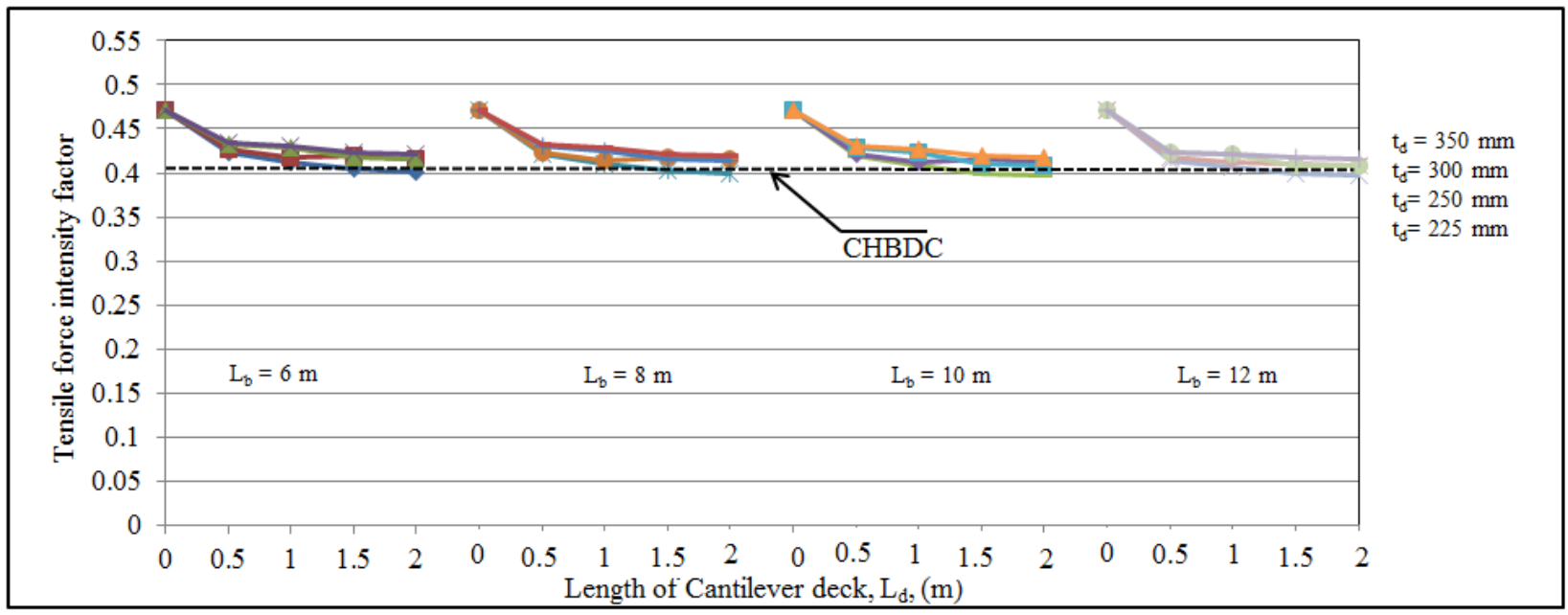

Figure D23 Tensile force intensity in the deck slab versus cantilever deck slab length as a function of PL-3 barrier length and deck slab thickness at interior location

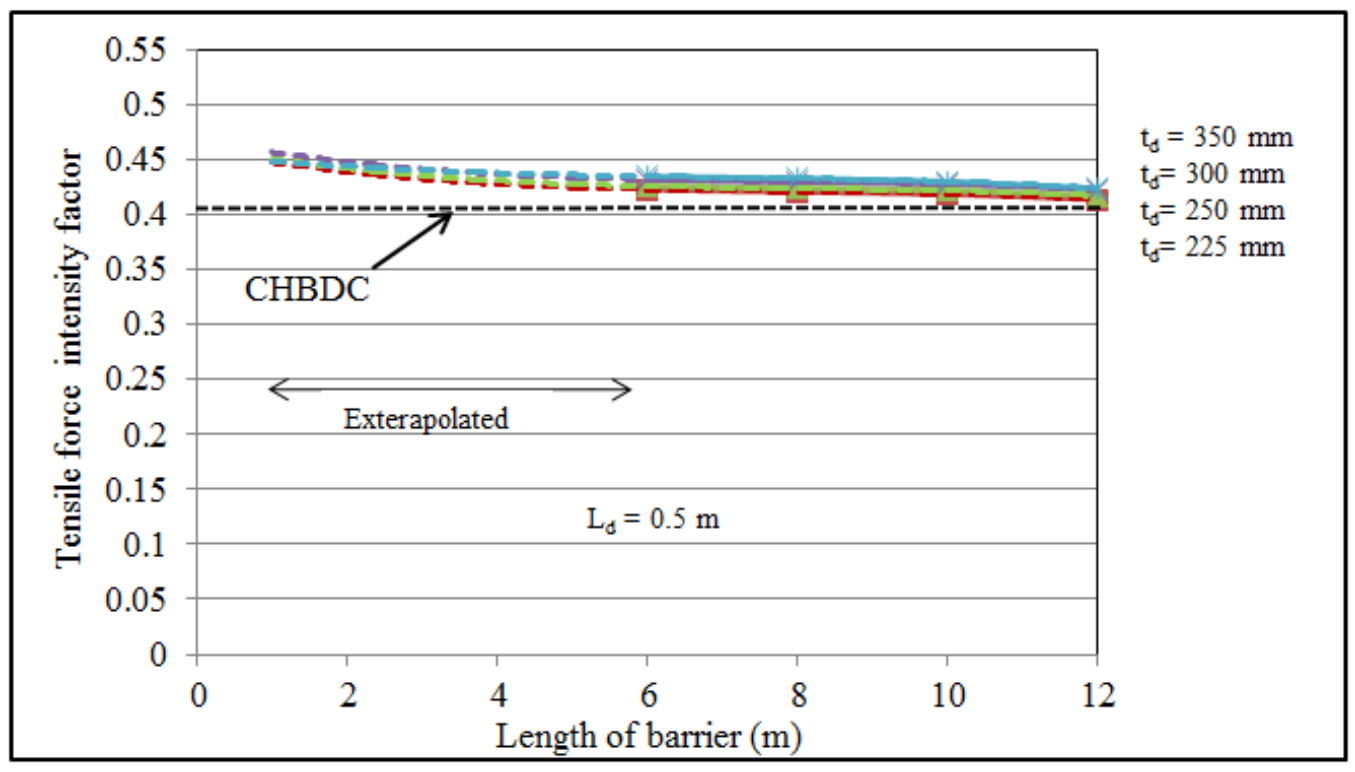

Figure D24 Extrapolation of tensile force intensity versus barrier longitudinal length for PL-3 barrier at interior location 


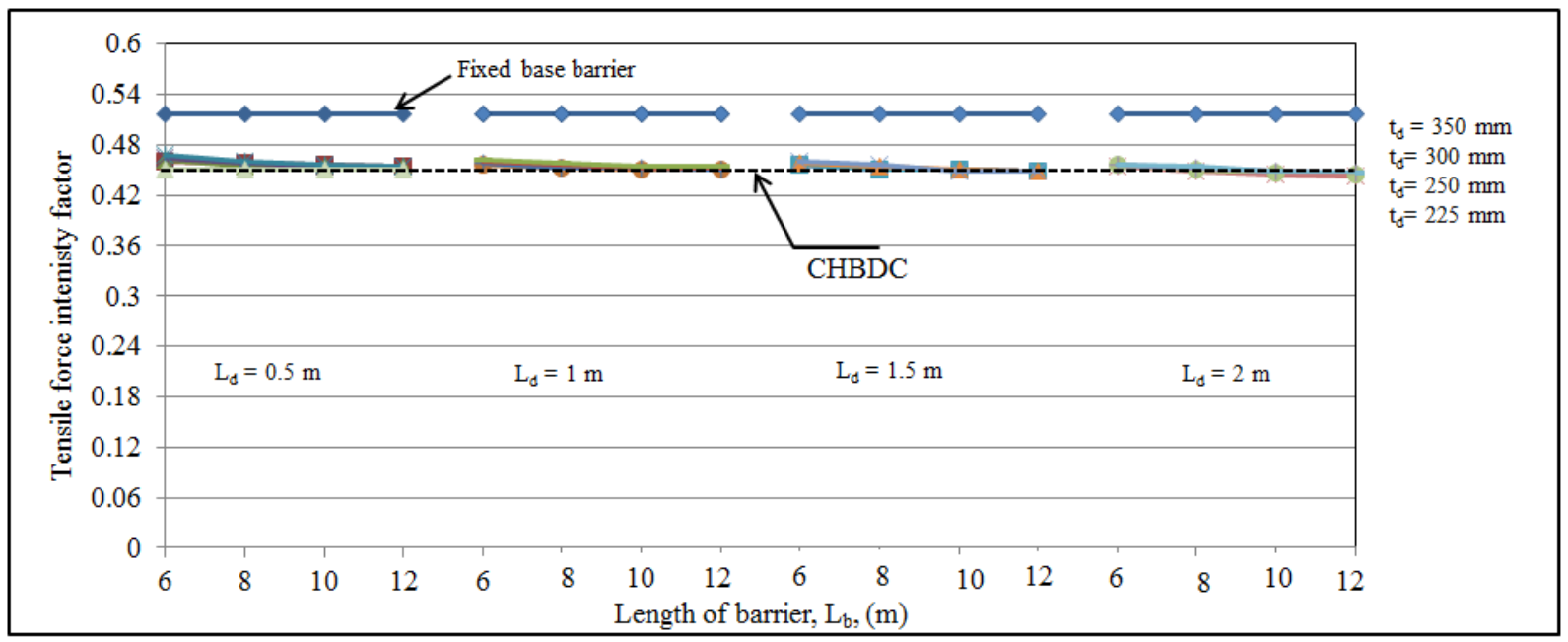

Figure D25 Tensile force intensity in the deck slab versus longitudinal length of PL-3 barrier as a function of cantilever deck slab length and deck slab thickness at exterior location

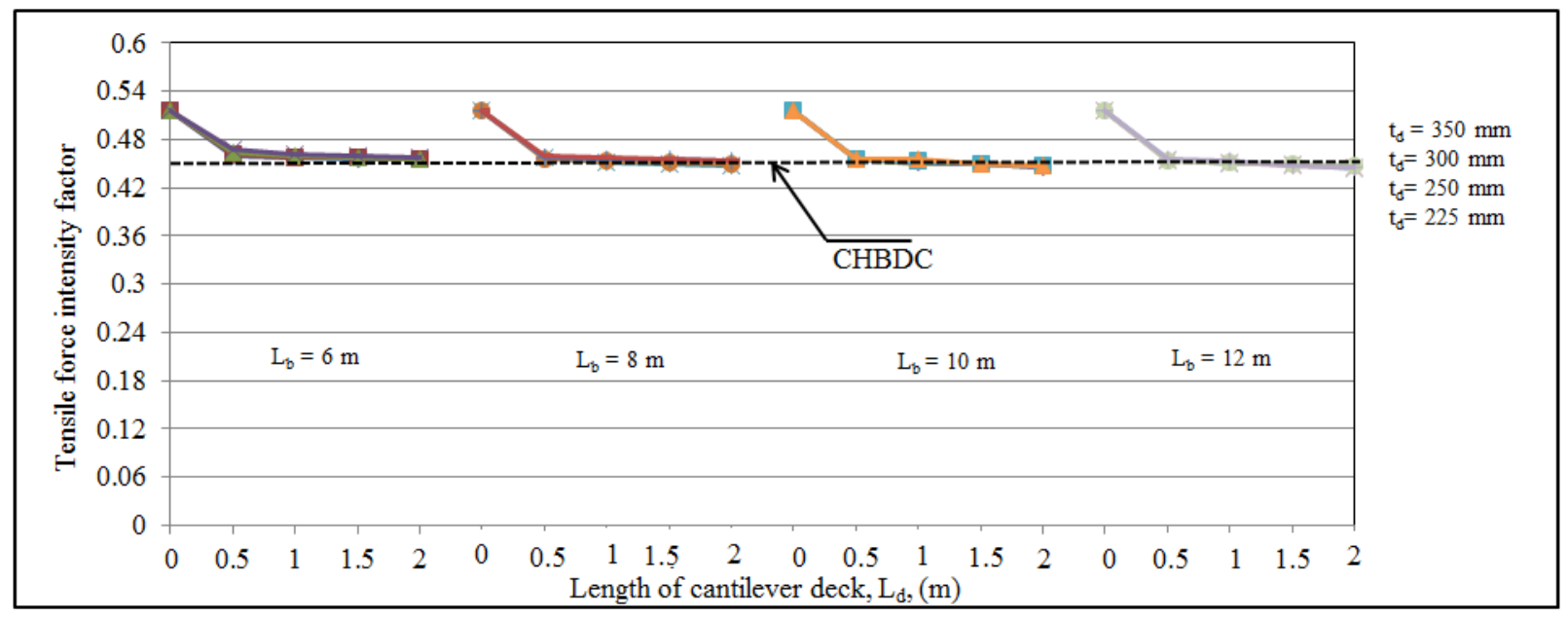

Figure D26 Tensile force intensity in the deck slab versus cantilever deck slab length as a function of PL-3 barrier length and deck slab thickness at exterior location 


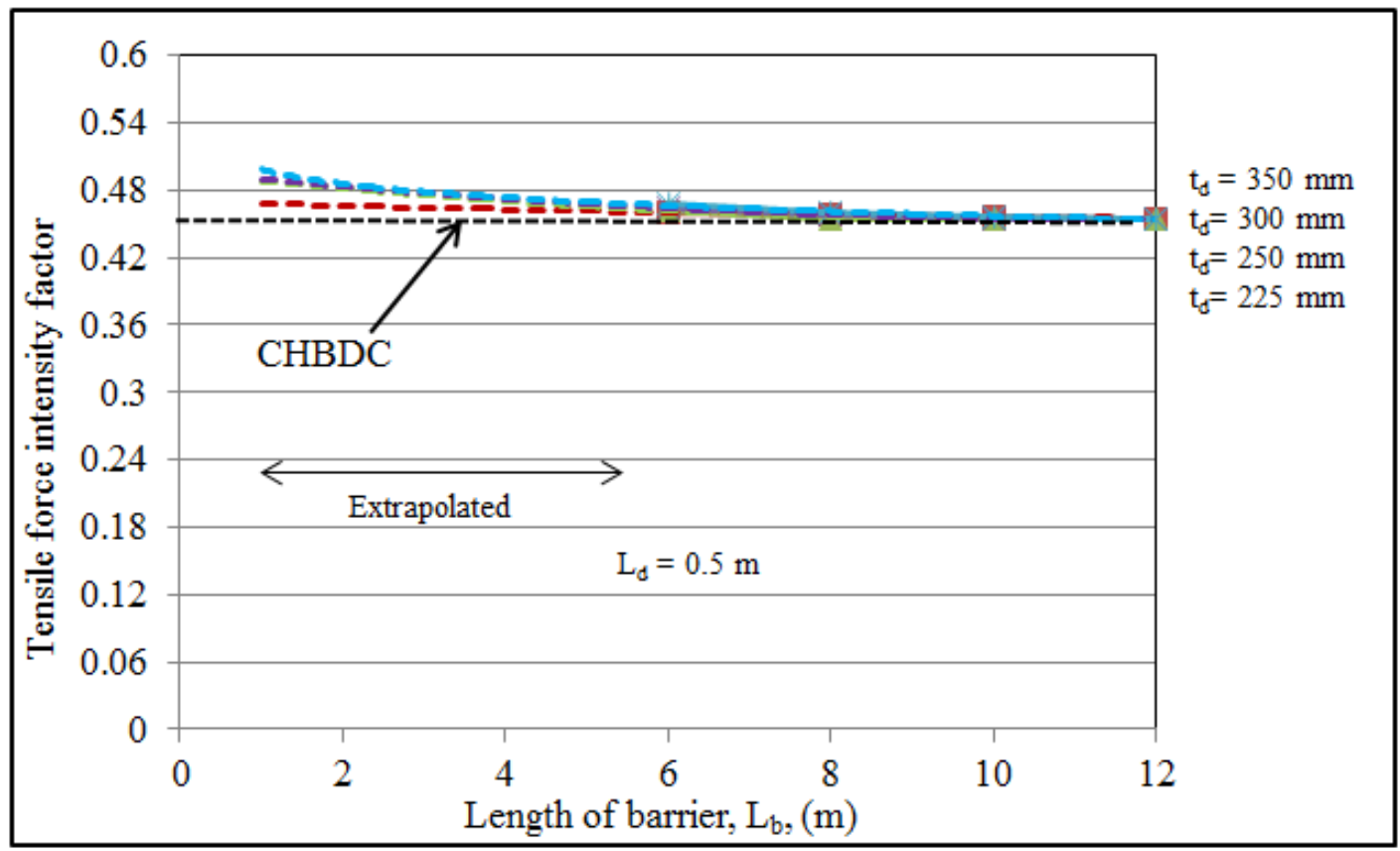

Figure D27 Extrapolation of tensile force intensity versus barrier longitudinal length for PL-3 barrier at exterior location

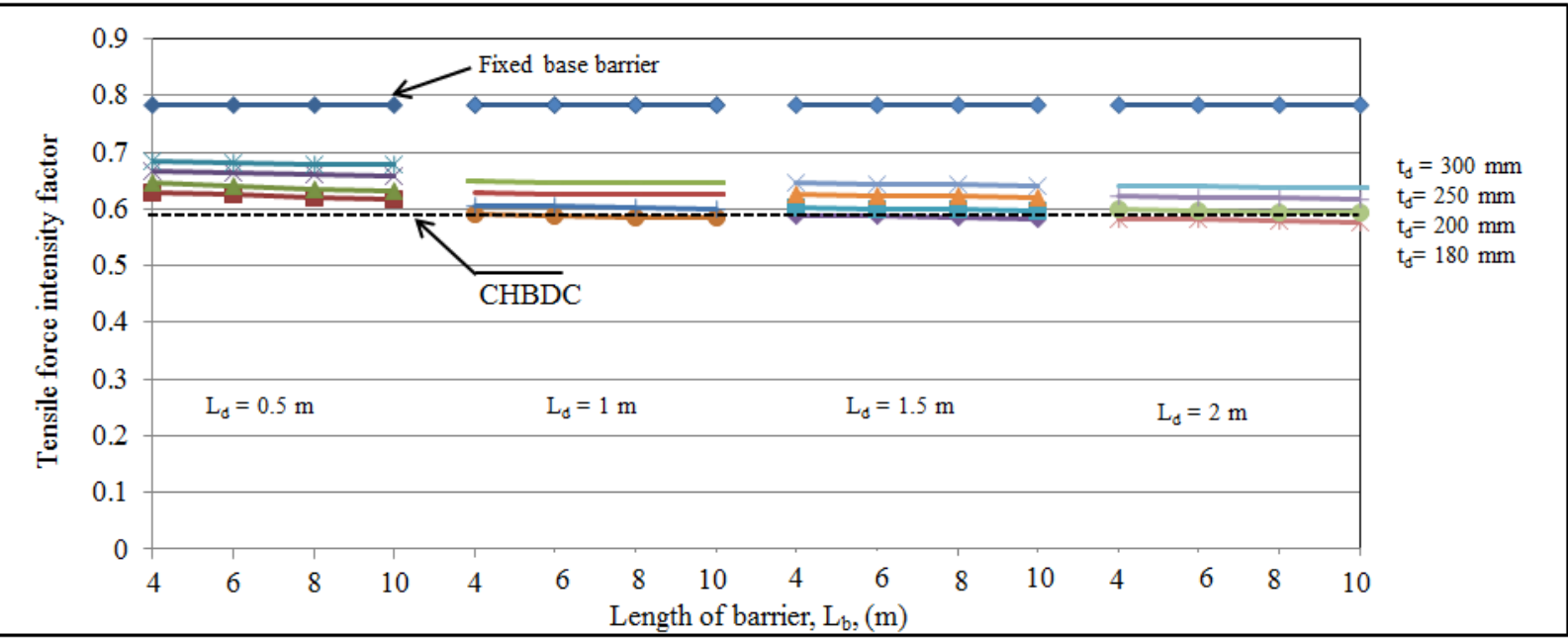

Figure D28 Tensile force intensity in the deck slab versus longitudinal length of PL-2 barrier as a function of cantilever deck slab length and deck slab thickness at interior location 


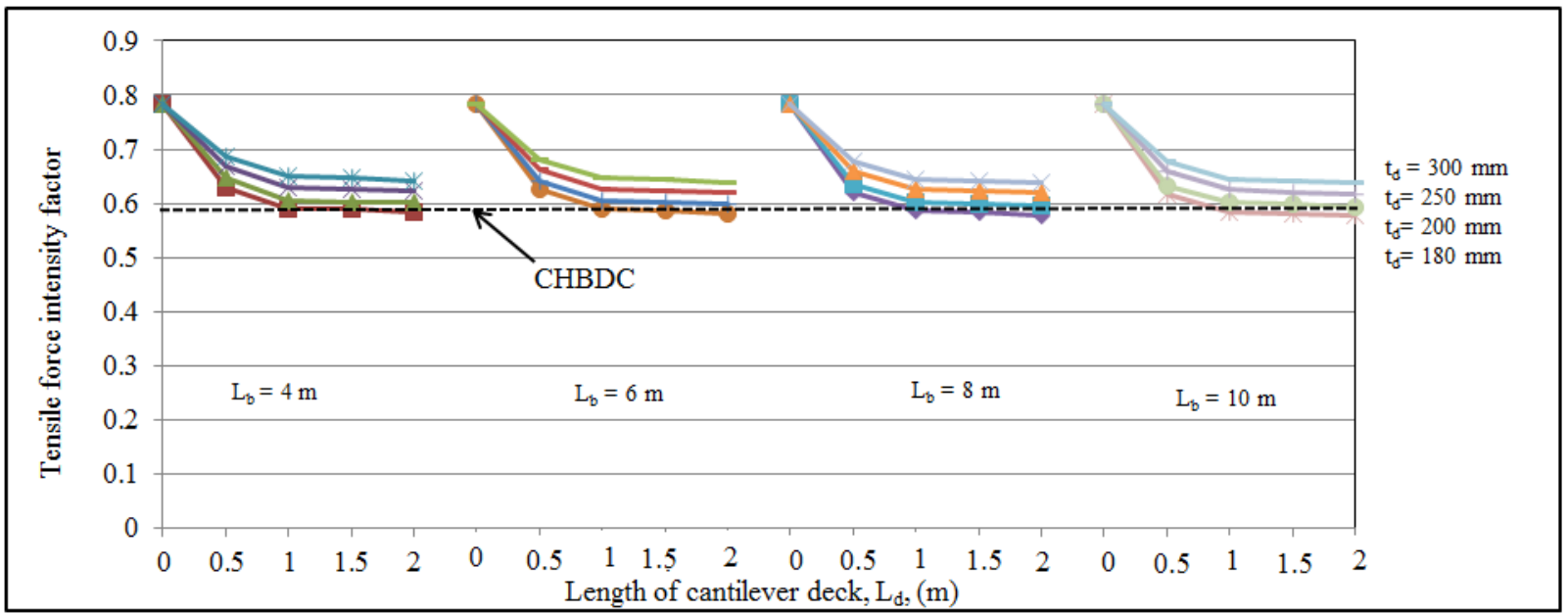

Figure D29 Tensile force intensity in the deck slab versus cantilever deck slab length as a function of PL-2 barrier length and deck slab thickness at interior location

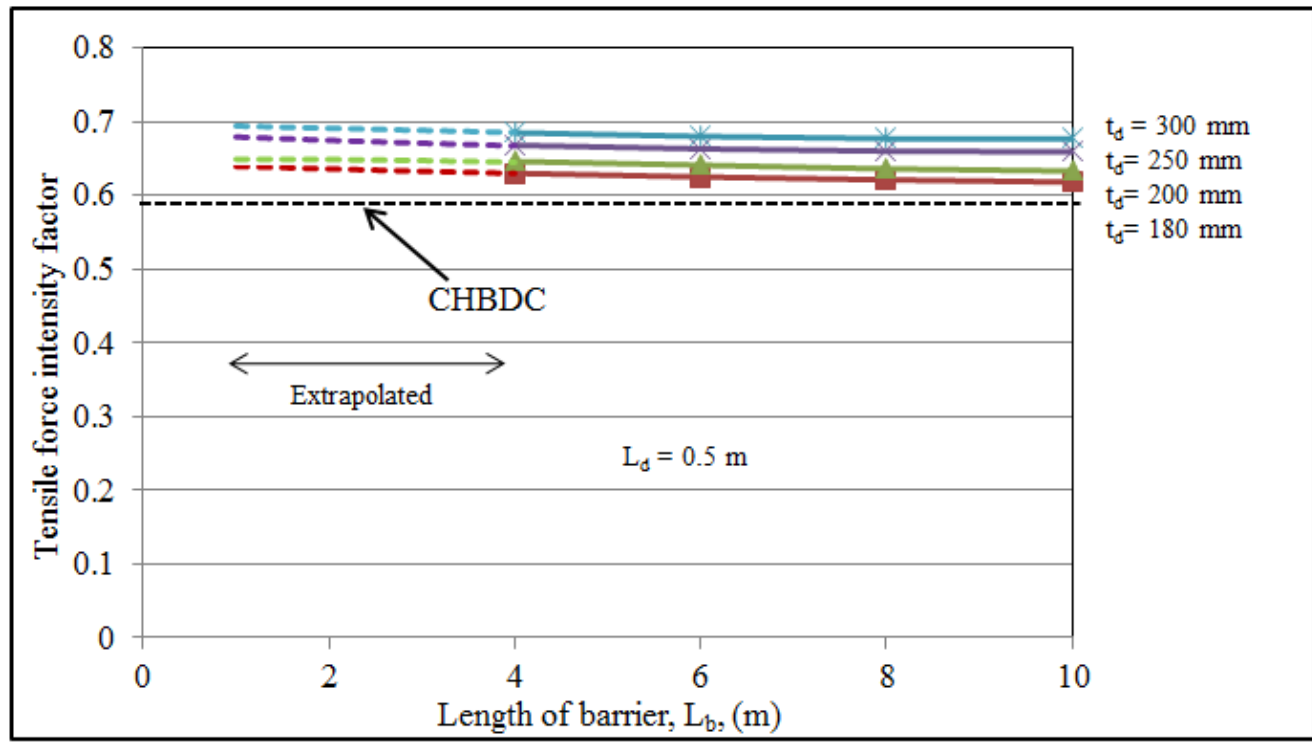

Figure D30 Extrapolation of tensile force intensity versus barrier longitudinal length for PL-2 barrier at interior location 


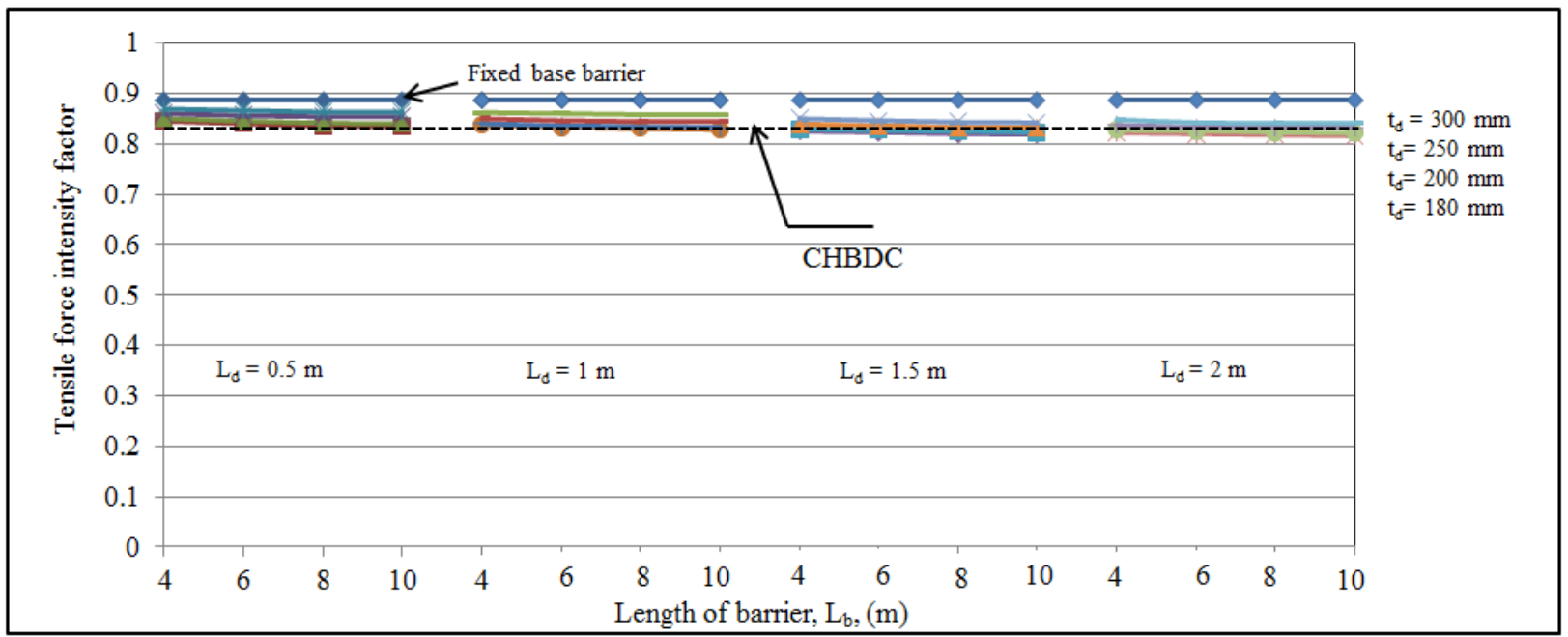

Figure D31 Tensile force intensity in the deck slab versus longitudinal length of PL-2 barrier as a function of cantilever deck slab length and deck slab thickness at exterior location

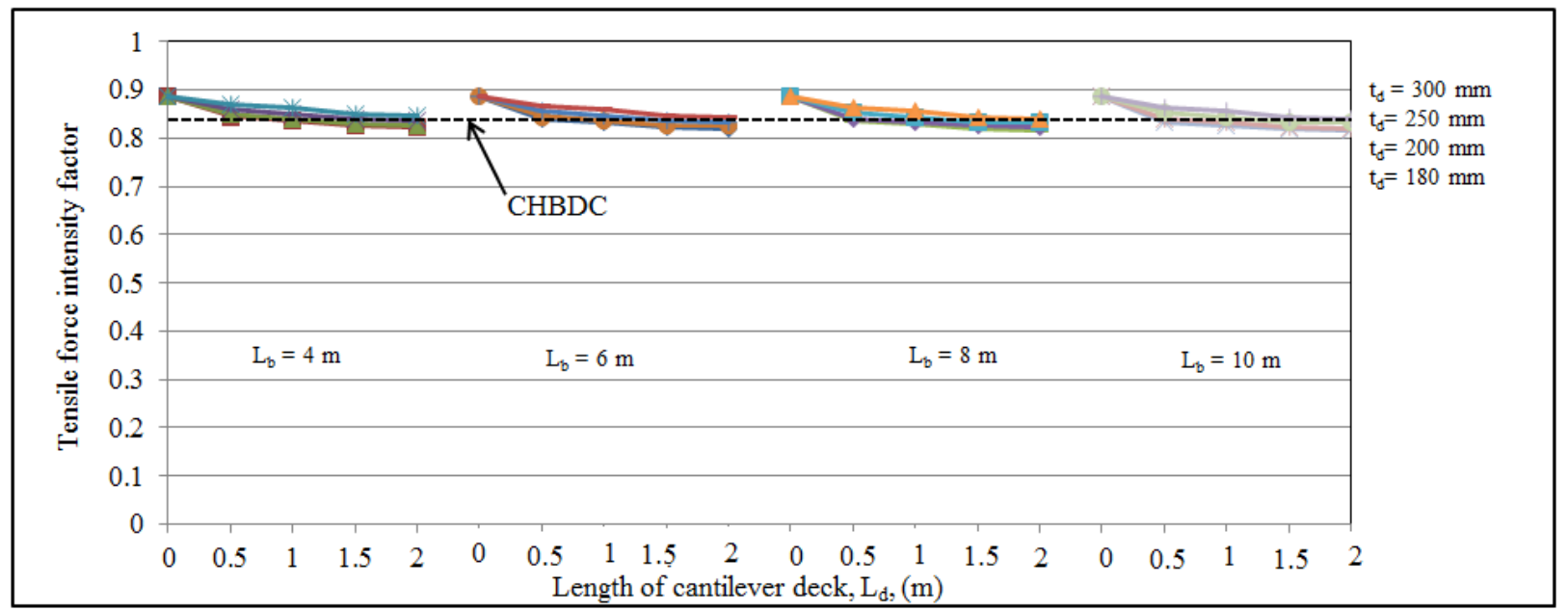

Figure D32 Tensile force intensity in the deck slab versus cantilever deck slab length as a function of PL-2 barrier length and deck slab thickness at exterior location 


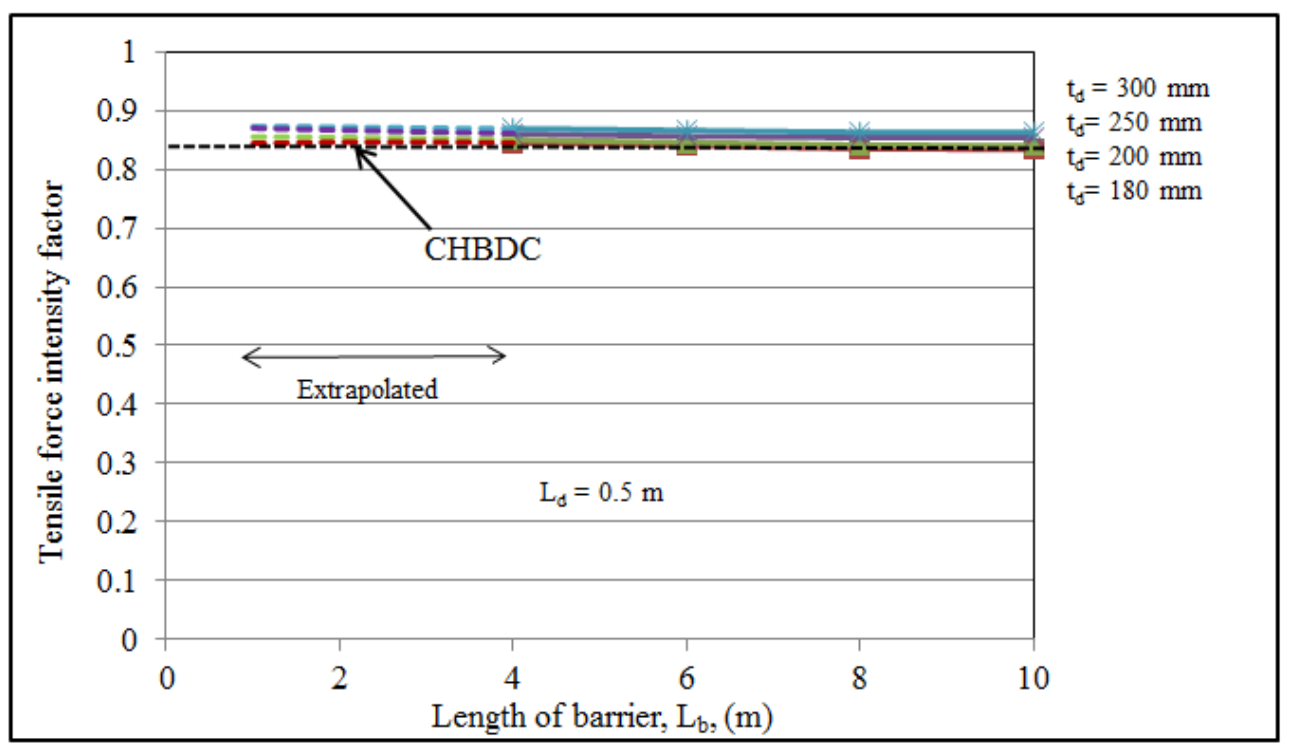

Figure D33 Extrapolation of tensile force intensity versus barrier longitudinal length for PL-2 barrier at exterior location

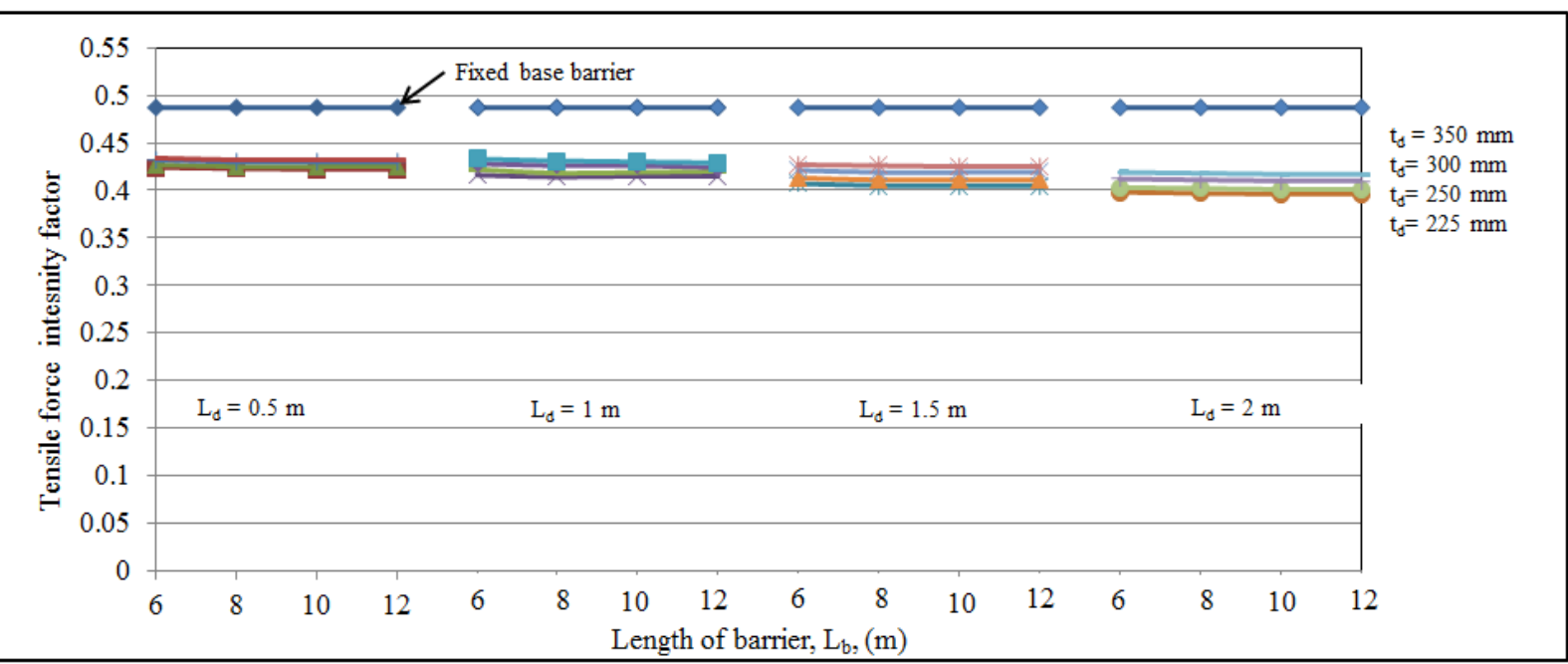

Figure D34 Tensile force intensity in the deck slab versus longitudinal length of TL-5 barrier as a function of cantilever deck slab length and deck slab thickness at interior location 


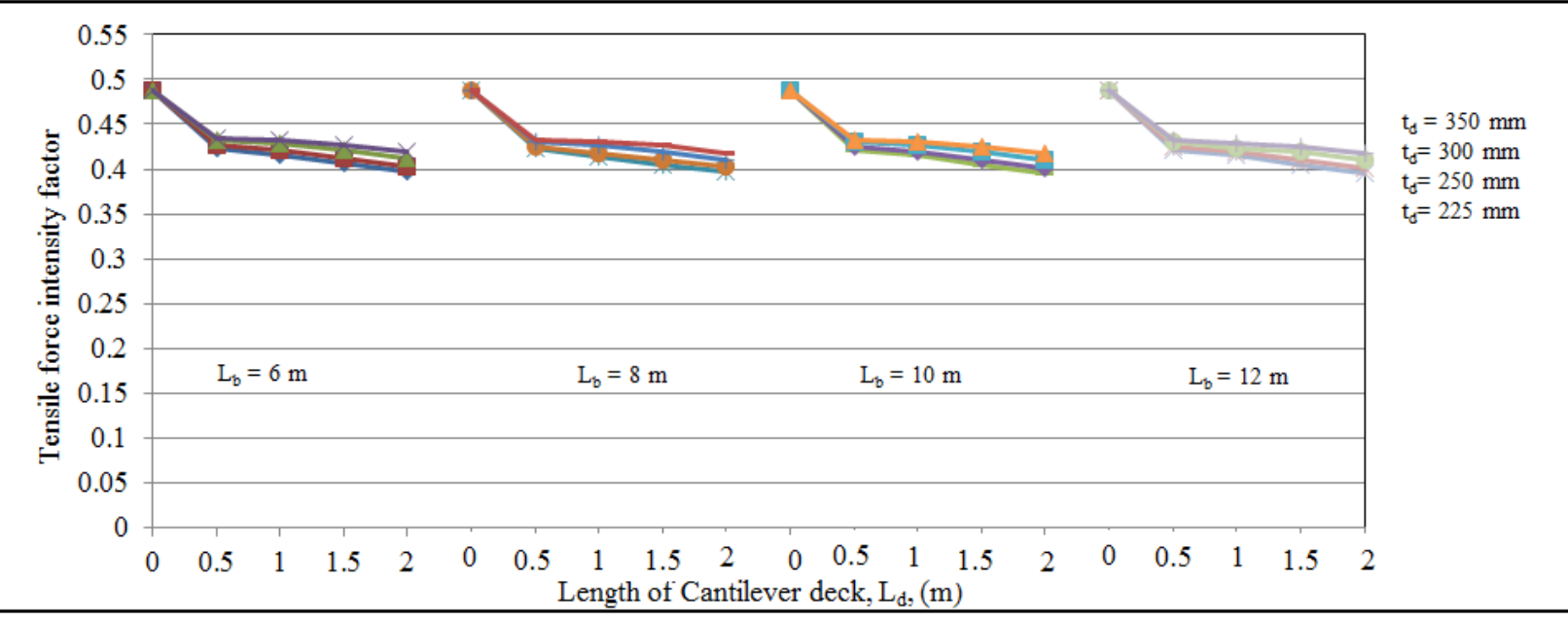

Figure D35 Tensile force intensity in the deck slab versus cantilever deck slab length as a function of TL-5 barrier length and deck slab thickness at interior location

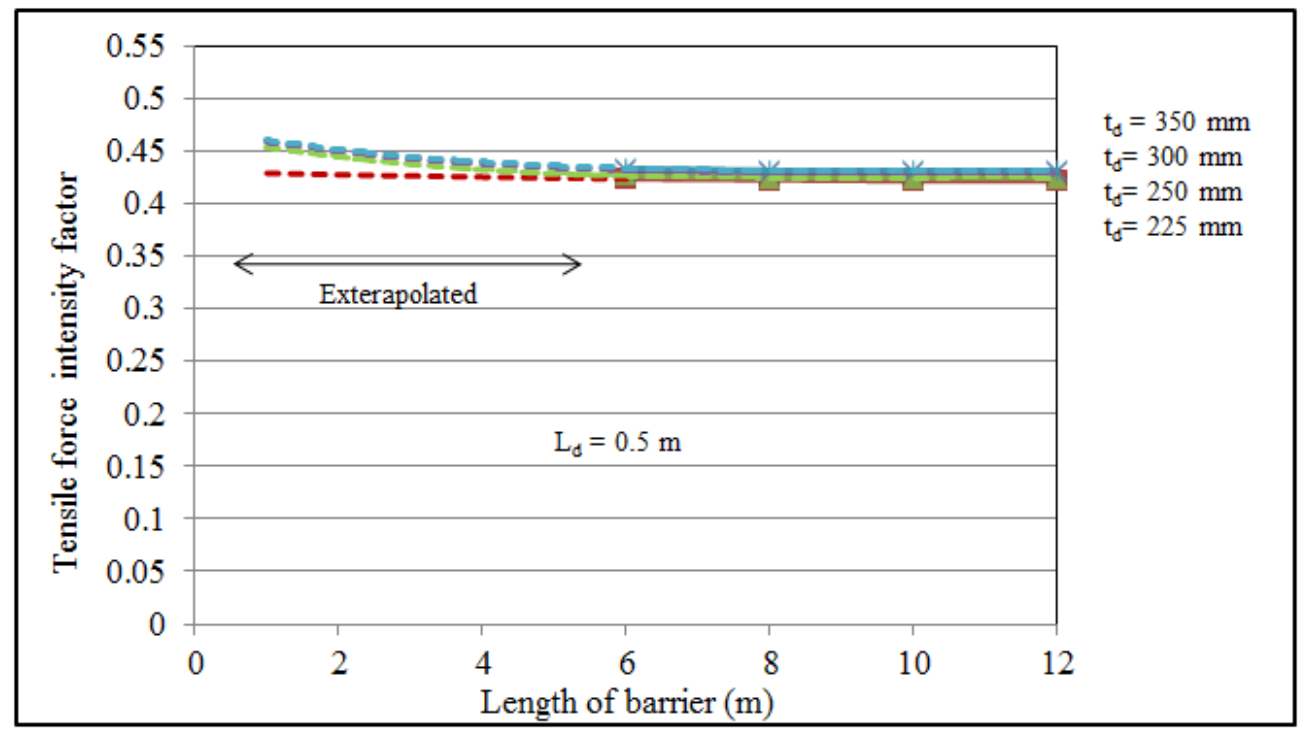

Figure D36 Extrapolation of tensile force intensity versus barrier longitudinal length for TL-5 barrier at interior location 


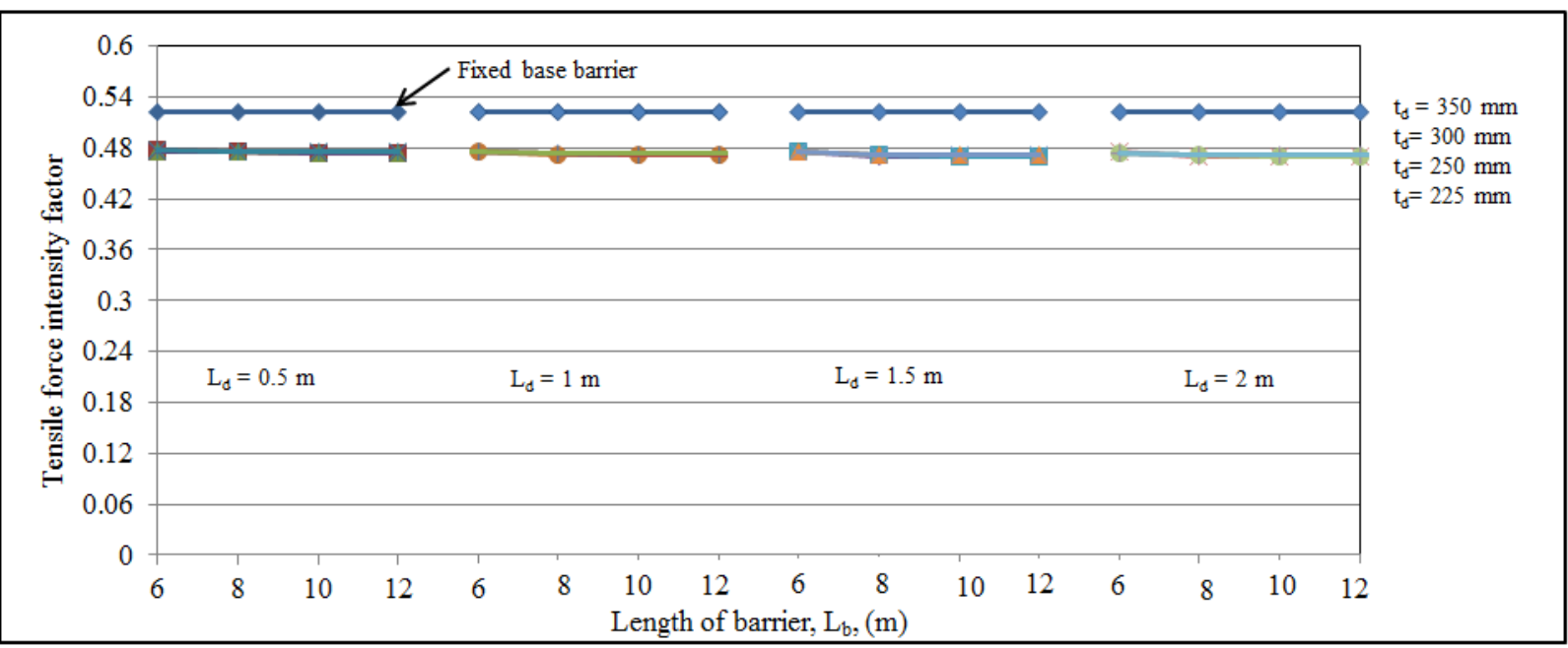

Figure D37 Tensile force intensity in the deck slab versus longitudinal length of TL-5 barrier as a function of cantilever deck slab length and deck slab thickness at exterior location

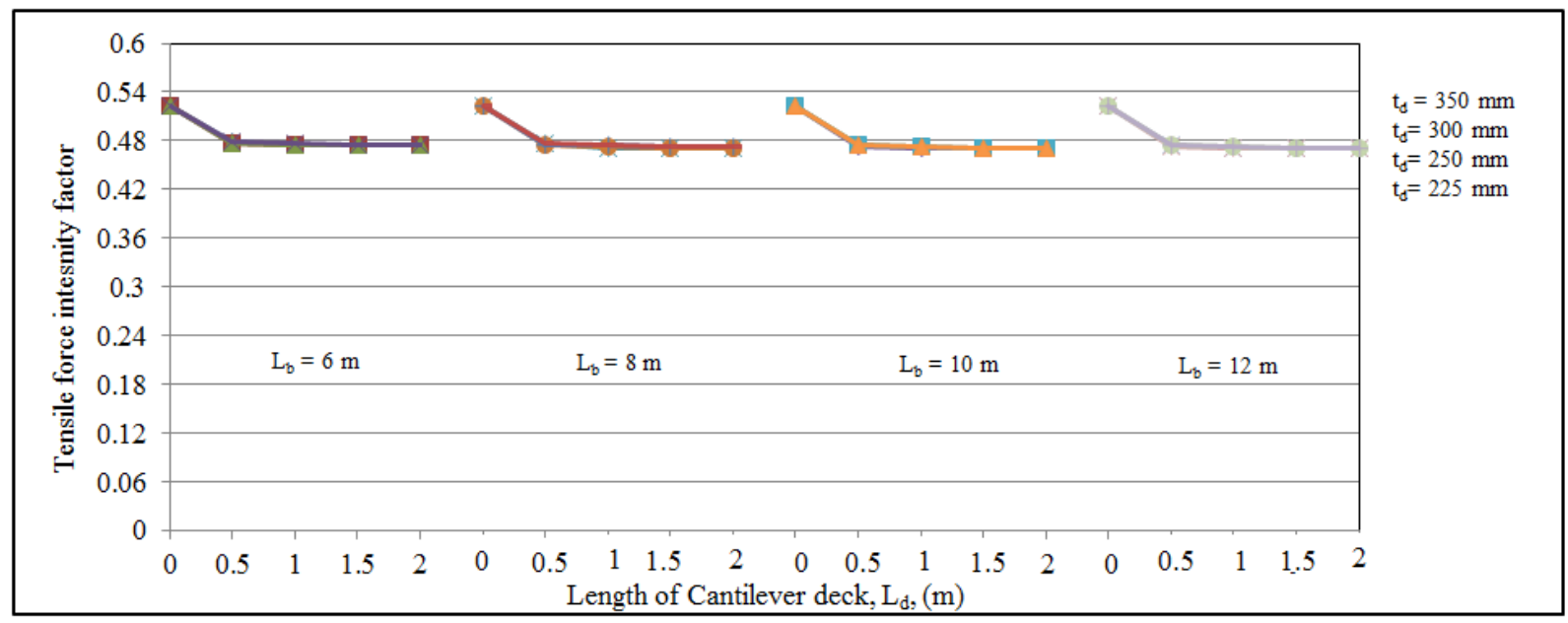

Figure D38 Tensile force intensity in the deck slab versus cantilever deck slab length as a function of TL-5 barrier length and deck slab thickness at exterior location 


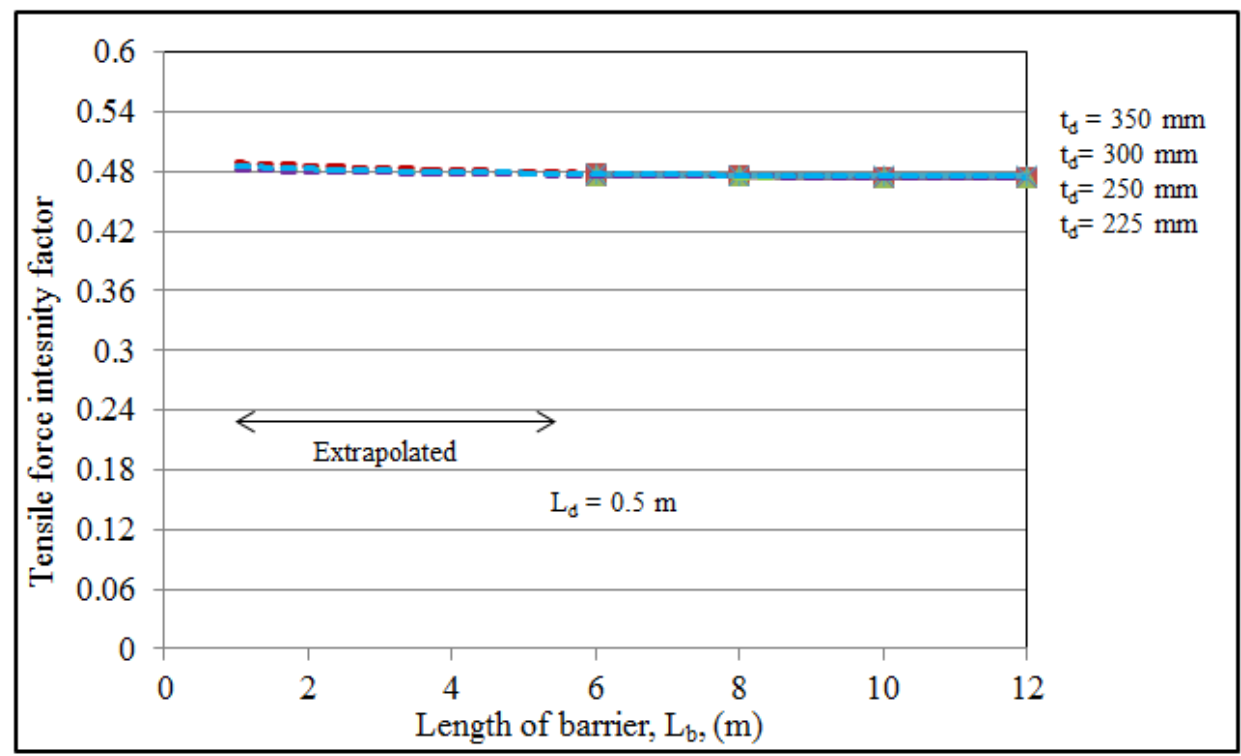

Figure D39 Extrapolation of tensile force intensity versus barrier longitudinal length for TL-5 barrier at exterior location

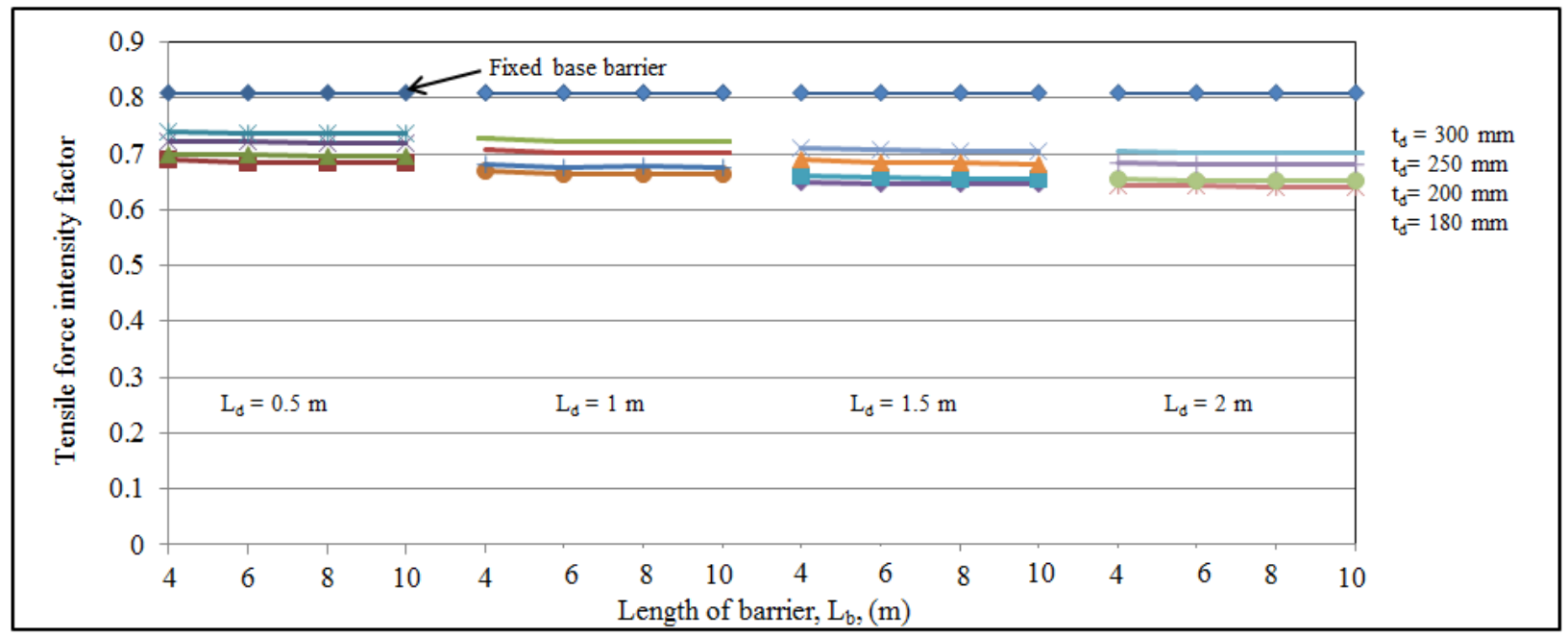

Figure D40 Tensile force intensity in the deck slab versus longitudinal length of TL-4 barrier as a function of cantilever deck slab length and deck slab thickness at interior location 


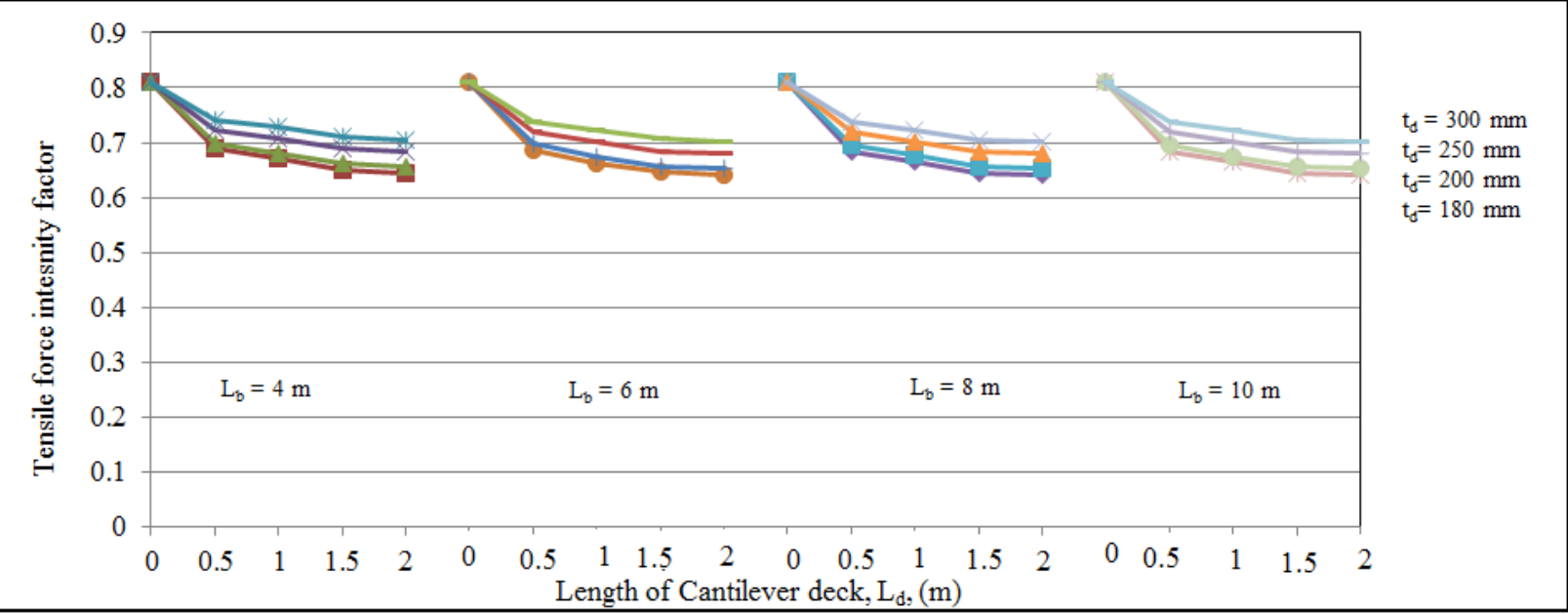

Figure D41 Tensile force intensity in the deck slab versus cantilever deck slab length as a function of TL-4 barrier length and deck slab thickness at interior location

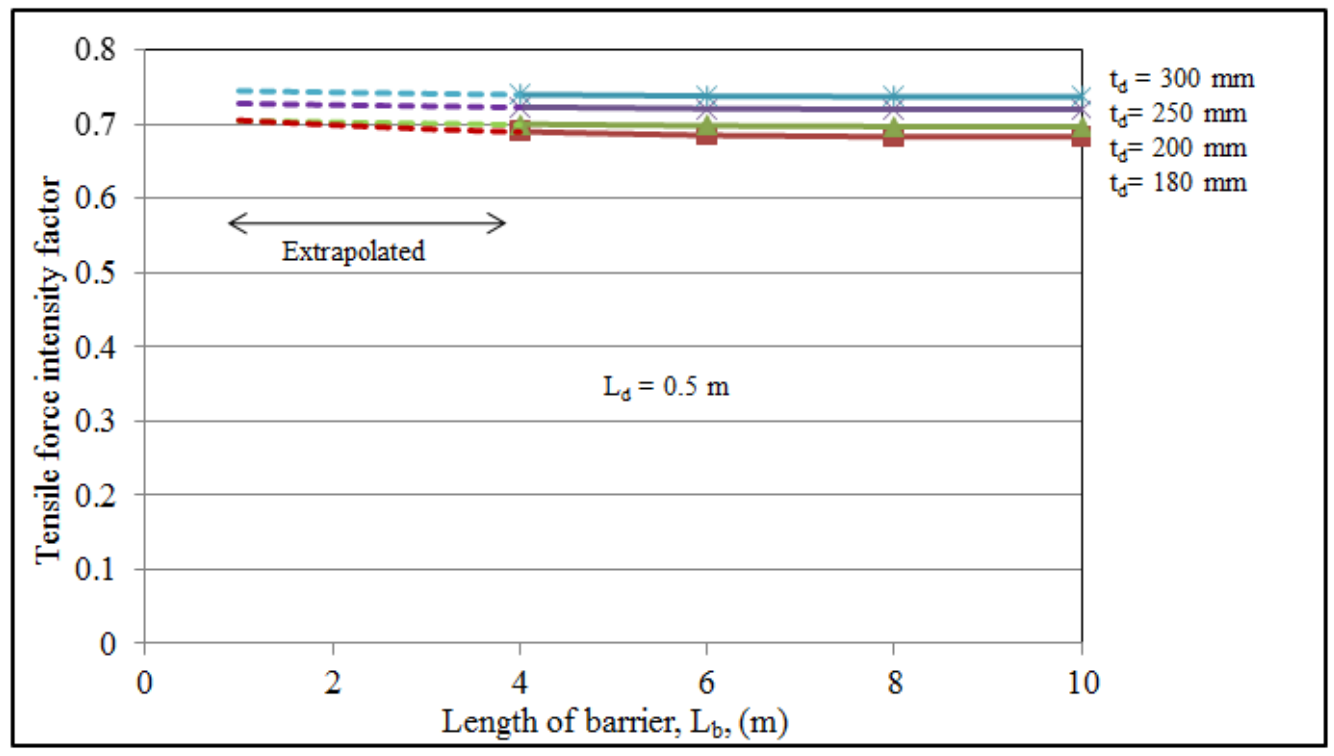

Figure D42 Extrapolation of tensile force intensity versus barrier longitudinal length for TL-4 barrier at interior location 


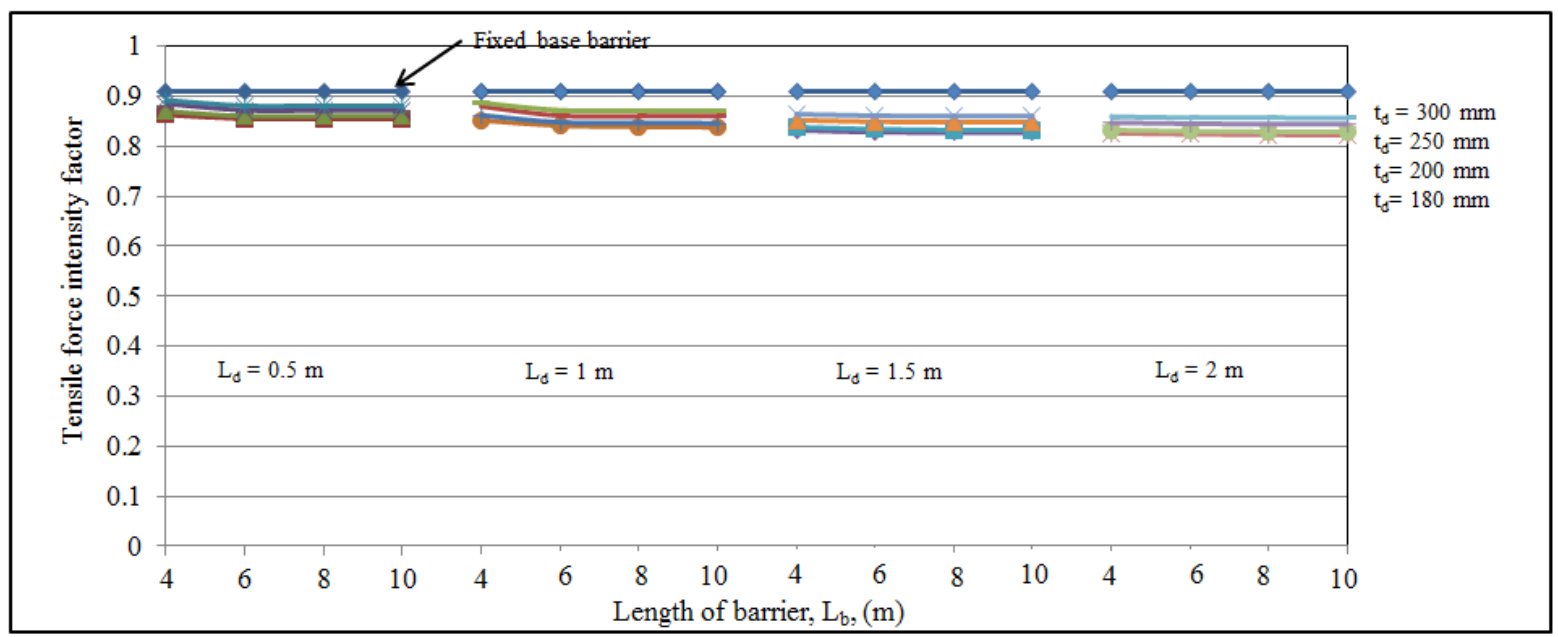

Figure D43 Tensile force intensity in the deck slab versus longitudinal length of TL-4 barrier as a function of cantilever deck slab length and deck slab thickness at exterior location

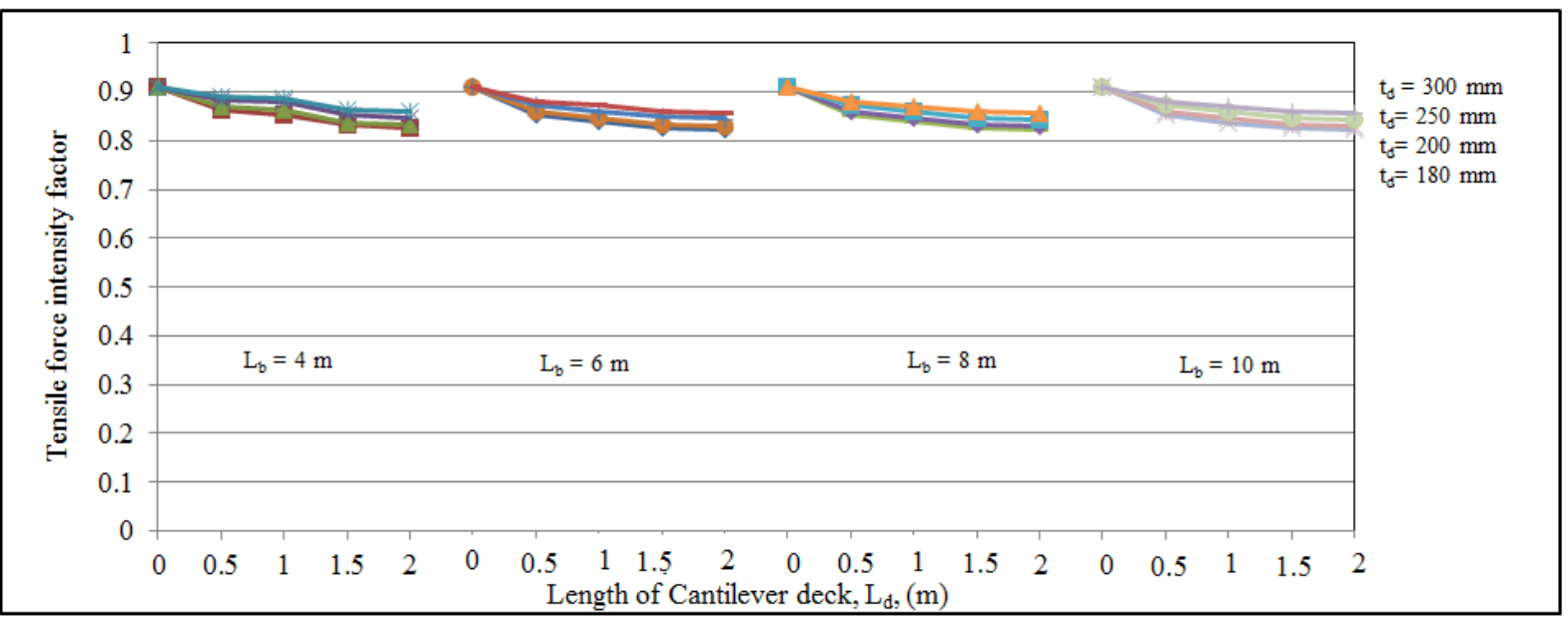

Figure D44 Tensile force intensity in the deck slab versus cantilever deck slab length as a function of TL-4 barrier length and deck slab thickness at exterior location 


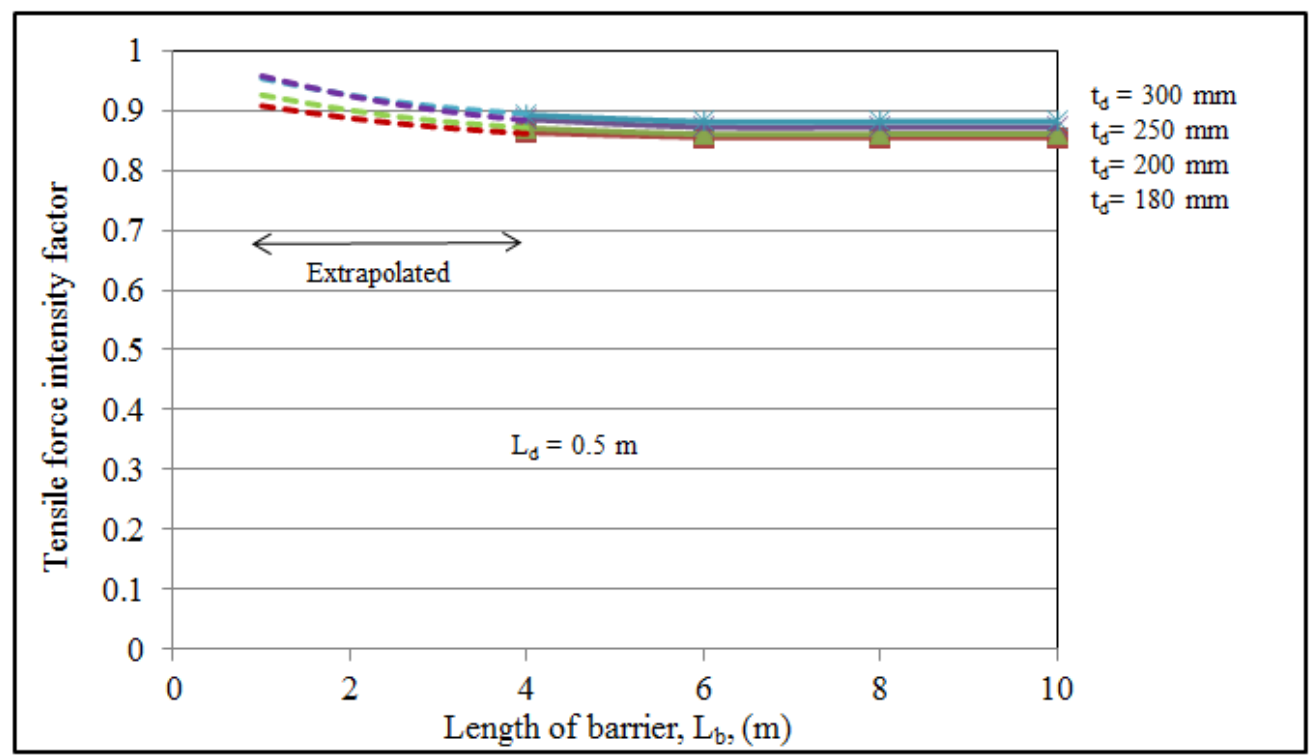

Figure D45 Extrapolation of tensile force intensity versus barrier longitudinal length for TL-4 barrier at exterior location 


\section{Appendix E}

Punching Shear Resistance of GFRP-Reinforced PL-3 Barriers 
Table E.1 Punching shear resistance $(\mathrm{kN})$ of PL-3 GFRP-reinforced concrete barriers with $\mathrm{f}^{\prime} \mathrm{c}=25 \mathrm{MPa}$ (HM bars)-Interior location

\begin{tabular}{|c|c|c|c|c|c|c|c|c|c|c|c|c|c|c|c|c|c|}
\hline & \multicolumn{17}{|c|}{ Vertical bar spacing, $S_{\mathrm{y}}(\mathrm{mm})$} \\
\hline \multirow{17}{*}{ 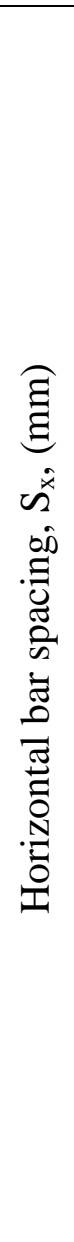 } & & & \multicolumn{3}{|c|}{100} & \multicolumn{3}{|c|}{150} & \multicolumn{3}{|c|}{200} & \multicolumn{3}{|c|}{250} & \multicolumn{3}{|c|}{300} \\
\hline & & & \#6 & $\# 5$ & $\# 4$ & \#6 & $\# 5$ & \#4 & \#6 & $\# 5$ & $\# 4$ & \#6 & $\# 5$ & $\# 4$ & $\# 6$ & $\# 5$ & $\# 4$ \\
\hline & \multirow{3}{*}{100} & \#6 & 750.1 & 716.3 & 688.3 & 705.8 & 682.6 & 662.9 & 681.5 & 664.6 & 649.4 & 666 & 653.2 & 641 & 655.2 & 645.5 & 635.3 \\
\hline & & $\# 5$ & 708.4 & 667.5 & 634.3 & 657.8 & 628.1 & 603.8 & 629.2 & 606.5 & 587.3 & 610.8 & 592.7 & 576.9 & 597.8 & 583.1 & 569.8 \\
\hline & & \#4 & 673.7 & 627.6 & 590.6 & 618.5 & 583.6 & 555.7 & 586.7 & 558.9 & 536.6 & 565.8 & 543 & 524.4 & 551 & 531.8 & 515.9 \\
\hline & \multirow{3}{*}{150} & \#6 & 705.8 & 664.9 & 631.8 & 655.2 & 625.5 & 601.3 & 626.7 & 603.9 & 584.8 & 608.3 & 590.1 & 574.4 & 593.3 & 580.5 & 567.3 \\
\hline & & $\# 5$ & 675.3 & 628.1 & 589.8 & 618.8 & 583.1 & 554.1 & 586.3 & 557.7 & 534.3 & 564.9 & 541.3 & 521.8 & 549.7 & 529.8 & 513 \\
\hline & & $\# 4$ & 648.9 & 597.4 & 555.7 & 588.6 & 548.2 & 515.9 & 553.2 & 520 & 493.5 & 529.5 & 501.4 & 478.9 & 512.5 & 488.3 & 468.7 \\
\hline & \multirow{3}{*}{200} & \#6 & 681.5 & 636 & 599.3 & 626.7 & 592.6 & 565.1 & 593.3 & 568.3 & 546.3 & 574.8 & 552.7 & 534.4 & 560.2 & 541.8 & 526.1 \\
\hline & & $\# 5$ & 657.5 & 606.5 & 564.9 & 597.4 & 557.7 & 525.5 & 562.3 & 529.8 & 503.4 & 538.9 & 511.5 & 489.2 & 522.1 & 498.5 & 479.2 \\
\hline & & \#4 & 635.7 & $\overline{581.1}$ & 536.6 & 572.4 & 528.7 & 493.5 & 537.8 & 498.1 & 468.7 & 509.3 & 477.8 & 452.6 & 490.9 & 463.2 & 441.1 \\
\hline & \multirow{3}{*}{250} & \#6 & 666 & 617.4 & 578 & 608.3 & 571 & 541 & 574.8 & 544.7 & 520.3 & 552.7 & 527.6 & 507.1 & 536.8 & 515.6 & 499 \\
\hline & & $\# 5$ & 646.3 & 592.7 & 548.8 & 583.8 & 541.3 & 506.8 & 546.8 & 511.5 & 482.9 & 522 & 491.8 & 467.3 & 504 & 477.8 & 456.4 \\
\hline & & \#4 & 627.5 & 570.8 & 524.4 & 562.3 & 516.2 & 478.9 & 523.1 & 484 & 452.6 & 496.4 & 462.4 & 435.1 & 476.9 & 446.8 & 422.7 \\
\hline & \multirow{3}{*}{300} & \#6 & 655.2 & 604.3 & 562.9 & 593.3 & 555.6 & 523.6 & 560.2 & 527.7 & 501.5 & 536.8 & 509.4 & 487.2 & 520.1 & 496.5 & 477.2 \\
\hline & & $\# 5$ & 638.6 & 583.1 & 537.5 & 574.3 & 529.8 & 493.5 & 536 & 498.5 & 468.2 & 510.1 & 477.8 & 451.6 & 491.2 & 462.8 & 439.8 \\
\hline & & $\# 4$ & 621.9 & 563.8 & 515.9 & 555.3 & 507.6 & 468.7 & 515 & 474.1 & 441.1 & 487.4 & 451.5 & 422.7 & 467.2 & 435.1 & 409.5 \\
\hline
\end{tabular}


Table E.2 Punching shear resistance $(\mathrm{kN})$ of PL-3 GFRP-reinforced concrete barriers with $\mathrm{f}^{\prime} \mathrm{c}=30 \mathrm{MPa}$ (HM bars)-Interior location

\begin{tabular}{|c|c|c|c|c|c|c|c|c|c|c|c|c|c|c|c|c|c|}
\hline & \multicolumn{17}{|c|}{ Vertical bar spacing, $S_{\mathrm{y}},(\mathrm{mm})$} \\
\hline \multirow{17}{*}{ 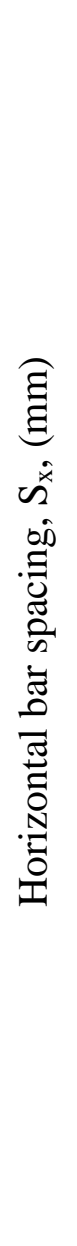 } & & & \multicolumn{3}{|c|}{100} & \multicolumn{3}{|c|}{150} & \multicolumn{3}{|c|}{200} & \multicolumn{3}{|c|}{250} & \multicolumn{3}{|c|}{300} \\
\hline & & & $\# 6$ & $\# 5$ & $\# 4$ & $\# 6$ & $\# 5$ & $\# 4$ & \#6 & $\# 5$ & \#4 & \#6 & $\# 5$ & \#4 & $\# 6$ & $\# 5$ & \#4 \\
\hline & \multirow{3}{*}{100} & \#6 & 797.1 & 760.9 & 731.4 & 750.1 & 725.4 & 704.4 & 724.2 & 706.2 & 690.1 & 707.7 & 694.2 & 681.2 & 696.3 & 685.9 & 675.2 \\
\hline & & $\# 5$ & 752.8 & 709.3 & 674 & 699 & 667.5 & 641.6 & 668.6 & 644.5 & 624.1 & 649.1 & 629.8 & 613.1 & 635.3 & 619.6 & 605.5 \\
\hline & & $\# 4$ & 716 & 666.9 & 627.6 & 657.2 & 620.9 & 590.6 & 623.4 & 594 & 570.2 & 601.3 & 577 & 557.2 & 585.5 & 565.2 & 548.2 \\
\hline & \multirow{3}{*}{150} & \#6 & 750.1 & 706.5 & 671.4 & 696.3 & 664.7 & 639 & 666 & 641.7 & 621.4 & 646.4 & 627.1 & 610.4 & 632.6 & 616.9 & 602.8 \\
\hline & & $\# 5$ & 717.6 & 667.5 & 626.8 & 657.6 & 619.6 & 588.8 & 623.1 & 592.7 & 567.8 & 600.3 & 575.2 & 554.5 & 584.1 & 563 & 545.2 \\
\hline & & $\# 4$ & 689.5 & 634.8 & 590.6 & 625.5 & 582.6 & 548.2 & 587.8 & 552.6 & 524.4 & 562.7 & 532.9 & 508.9 & 544.6 & 518.9 & 498.1 \\
\hline & \multirow{3}{*}{200} & \#6 & 724.2 & 675.9 & 636.9 & 666 & 629.8 & 600.5 & 632.6 & 604 & 580.5 & 610.8 & 587.3 & 567.9 & 595.3 & 575.7 & 559.1 \\
\hline & & $\# 5$ & 689.6 & 644.5 & 600.3 & 634.8 & 592.7 & 558.5 & 597.5 & 563 & 535 & 572.6 & 543.6 & 519.8 & 554.8 & 529.8 & 509.2 \\
\hline & & $\# 4$ & 675.5 & 617.5 & 570.2 & 608.3 & 561.8 & 524.4 & 568.3 & 529.3 & 498.1 & 541.3 & 507.7 & 480.9 & 521.6 & 492.3 & 468.7 \\
\hline & \multirow{3}{*}{250} & \#6 & 707.7 & 656.1 & 614.2 & 646.4 & 606.8 & 574.8 & 610.8 & 578.8 & 552.9 & 587.3 & 560.7 & 538.9 & 570.5 & 547.9 & 529.2 \\
\hline & & $\# 5$ & 686.7 & 629.8 & 583.2 & 620.4 & 575.2 & 538.5 & 581.1 & 543.6 & 513.2 & 554.7 & 522.6 & 496.6 & 535.6 & 507.7 & 485 \\
\hline & & $\# 4$ & 666.8 & 606.6 & 557.2 & 597.5 & 548.6 & 508.9 & 555.9 & 514.3 & 480.9 & 527.5 & 491.4 & 462.4 & 506.8 & 474.8 & 449.2 \\
\hline & \multirow{3}{*}{300} & \#6 & 696.3 & 642.1 & 598.2 & 632.6 & 590.4 & 556.4 & 595.3 & 560.8 & 532.9 & 570.5 & 541.4 & 517.8 & 552.6 & 527.6 & 507.1 \\
\hline & & $\# 5$ & 678.6 & 619.6 & 571.2 & 610.3 & 563 & 524.4 & 569.6 & 529.8 & 497.5 & 542 & 507.7 & 479.9 & 522 & 491.8 & 467.3 \\
\hline & & \#4 & 660.9 & 599.1 & 548.2 & 590.1 & 539.4 & 498.1 & 547.3 & 503.8 & 468.7 & 518 & 479.8 & 449.2 & 496.4 & 462.4 & 435.1 \\
\hline
\end{tabular}


Table E.3 Punching shear resistance $(\mathrm{kN})$ of PL-3 GFRP-reinforced concrete barriers with $\mathrm{f}^{\prime} \mathrm{c}=35 \mathrm{MPa}$ (HM bars)-Interior location

\begin{tabular}{|c|c|c|c|c|c|c|c|c|c|c|c|c|c|c|c|c|c|}
\hline & \multicolumn{17}{|c|}{ Vertical bar spacing, $S_{\mathrm{y}},(\mathrm{mm})$} \\
\hline \multirow{17}{*}{ 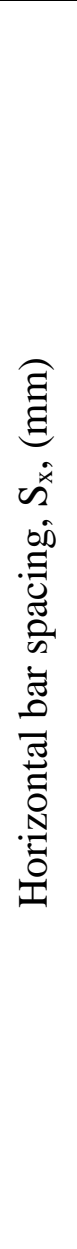 } & & & \multicolumn{3}{|c|}{100} & \multicolumn{3}{|c|}{150} & \multicolumn{3}{|c|}{200} & \multicolumn{3}{|c|}{250} & \multicolumn{3}{|c|}{300} \\
\hline & & & \#6 & $\# 5$ & $\# 4$ & \#6 & $\# 5$ & \#4 & \#6 & $\# 5$ & \#4 & \#6 & $\# 5$ & \#4 & $\# 6$ & \#5 & \#4 \\
\hline & \multirow{3}{*}{100} & \#6 & 839.1 & 801.1 & 770 & 789.6 & 763.6 & 741.6 & 762.3 & 743.4 & 726.5 & 745.1 & 730.8 & 717.1 & 733 & 722.1 & 710.7 \\
\hline & & $\# 5$ & 792.5 & 746.7 & 709.6 & 735.8 & 702.7 & 675.4 & 703.9 & 678.4 & 657 & 683.3 & 663 & 645.4 & 668.8 & 652.3 & 637.4 \\
\hline & & $\# 4$ & 753.7 & 702.1 & 660.7 & 691.9 & 652.9 & 621.7 & 656.3 & 625.3 & 600.3 & 633 & 607.4 & 586.6 & 616.4 & 595 & 577.2 \\
\hline & \multirow{3}{*}{150} & \#6 & 789.6 & 743.8 & 706.8 & 733 & 699.8 & 672.6 & 701.1 & 675.6 & 654.2 & 680.5 & 660.1 & 642.6 & 666 & 649.4 & 634.6 \\
\hline & & $\# 5$ & 755.5 & 702.7 & 659.9 & 692.3 & 652.3 & 619.9 & 655.9 & 623.9 & 597.8 & 632 & 605.6 & 583.7 & 614.9 & 592.7 & 573.9 \\
\hline & & $\# 4$ & 725.9 & 668.3 & 621.7 & 658.4 & 613.3 & 577.2 & 618.8 & 581.7 & 552 & 592.4 & 561 & 535.8 & 573.3 & 546.2 & 524.4 \\
\hline & \multirow{3}{*}{200} & \#6 & 762.3 & 711.5 & 670.5 & 701.1 & 663 & 632.2 & 666 & 635.8 & 611.2 & 643 & 618.3 & 597.8 & 626.7 & 606.1 & 588.6 \\
\hline & & $\# 5$ & 735.5 & 678.4 & 631.2 & 668.3 & 623.9 & 587.9 & 629 & 592.7 & 563.2 & 602.8 & 572.2 & 547.2 & 584.1 & 557.7 & 536.1 \\
\hline & & $\# 4$ & 711.1 & 650 & 600.3 & 640.4 & 591.5 & 552 & 598.2 & 557.2 & 524.4 & 569.8 & 534.5 & 506.3 & 549.1 & 518.2 & 493.5 \\
\hline & \multirow{3}{*}{250} & \#6 & 745.1 & 690.6 & 646.6 & 680.5 & 638.8 & 605.2 & 643 & 609.3 & 582.1 & 618.3 & 590.2 & 567.3 & 600.6 & 576.8 & 557.1 \\
\hline & & $\# 5$ & 722.9 & 663 & 613.9 & 653.1 & 605.6 & 566.9 & 611.7 & 572.2 & 540.2 & 583.9 & 550.2 & 522.8 & 563.8 & 534.5 & 510.5 \\
\hline & & $\# 4$ & 702 & 638.6 & 586.6 & 629 & 577.5 & 535.8 & 585.2 & 541.5 & 506.3 & 555.4 & 517.3 & 486.8 & 533.5 & 499.8 & 472.9 \\
\hline & \multirow{3}{*}{300} & \#6 & 733 & 676 & 629.7 & 666 & 621.6 & 585.7 & 626.7 & 590.3 & 561 & 600.6 & 569.9 & 545.1 & 581.8 & 555.4 & 534 \\
\hline & & $\# 5$ & 714.3 & 652.3 & 601.3 & 642.5 & 592.7 & 552.1 & 599.6 & 557.7 & 523.7 & 570.6 & 534.5 & 505.2 & 549.5 & 517.7 & 492 \\
\hline & & \#4 & 695.7 & 630.7 & 577.2 & 621.2 & 567.8 & 524.4 & 576.1 & 530.4 & 493.5 & 545.3 & 505.1 & 472.9 & 522.6 & 486.8 & 458.1 \\
\hline
\end{tabular}


Table E.4 Punching shear resistance $(\mathrm{kN})$ of PL-3 GFRP-reinforced concrete barriers with $\mathrm{f}^{\prime} \mathrm{c}=25 \mathrm{MPa}$ (HM bars)-Exterior location

\begin{tabular}{|c|c|c|c|c|c|c|c|c|c|c|c|c|c|c|c|c|c|}
\hline & \multicolumn{17}{|c|}{ Vertical bar spacing, $\mathrm{S}_{\mathrm{y}},(\mathrm{mm})$} \\
\hline \multirow{17}{*}{ 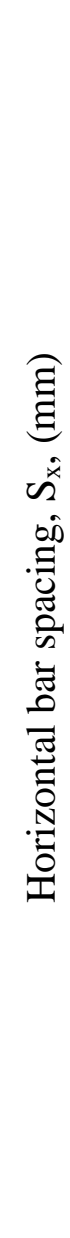 } & & & \multicolumn{3}{|c|}{100} & \multicolumn{3}{|c|}{150} & \multicolumn{3}{|c|}{200} & \multicolumn{3}{|c|}{250} & \multicolumn{3}{|c|}{300} \\
\hline & & & \#6 & \#5 & \#4 & \#6 & $\# 5$ & $\# 4$ & \#6 & \#5 & \#4 & \#6 & \#5 & $\# 4$ & \#6 & $\# 5$ & $\# 4$ \\
\hline & \multirow{3}{*}{100} & \#6 & 595.9 & 567.9 & 545 & 560.7 & 541.4 & 524.9 & 541.4 & 527.1 & 514.2 & 529.1 & 518.1 & 507.6 & 520.5 & 511.9 & 503.1 \\
\hline & & \#5 & 562.8 & 529.4 & 502.2 & 522.5 & 498.2 & 478.1 & 499.8 & 481 & 465 & 485.2 & 470.1 & 456.8 & 474.9 & 462.5 & 451.2 \\
\hline & & \#4 & 535.2 & 497.7 & 467.6 & 491.3 & 463 & 440.1 & 466.1 & 443.3 & 424.9 & 449.5 & 430.7 & 415.2 & 437.7 & 421.8 & 408.5 \\
\hline & \multirow{3}{*}{150} & \#6 & 560.7 & 527.3 & 500.3 & 520.5 & 496.1 & 476.1 & 497.9 & 478.9 & 463.1 & 483.2 & 468 & 454.8 & 472.9 & 460.4 & 449.2 \\
\hline & & \#5 & 536.5 & 498.2 & 467.1 & 491.6 & 462.5 & 438.7 & 465.8 & 442.3 & 423.1 & 448.8 & 429.3 & 413.1 & 436.7 & 420.2 & 406.2 \\
\hline & & $\# 4$ & 515.5 & 473.8 & 440.1 & 467.6 & 434.8 & 408.5 & 439.4 & 412.4 & 390.7 & 420.7 & 397.7 & 379.2 & 407.1 & 387.3 & 371.2 \\
\hline & \multirow{3}{*}{200} & \#6 & 541.4 & 504.4 & 474.6 & 497.9 & 470 & 447.5 & 472.9 & 450.8 & 432.6 & 456.6 & 438.4 & 423.1 & 445 & 429.7 & 416.6 \\
\hline & & $\# 5$ & 522.3 & 481 & 447.3 & 474.6 & 442.3 & 416.1 & 446.7 & 420.2 & 398.6 & 428.1 & 405.7 & 387.3 & 414.7 & 395.4 & 379.4 \\
\hline & & \#4 & 505 & 460.8 & 424.9 & 454.7 & 419.3 & 390.7 & 424.8 & 395.1 & 371.2 & 404.6 & 378.9 & 358.4 & 390 & 367.4 & 349.3 \\
\hline & \multirow{3}{*}{250} & \#6 & 529.1 & 489.6 & 457.7 & 483.2 & 452.9 & 428.3 & 456.6 & 432 & 412 & 439 & 418.5 & 401.6 & 426.5 & 408.9 & 394.3 \\
\hline & & \#5 & 513.4 & 470.1 & 434.6 & 463.8 & 429.3 & 401.3 & 434.4 & 405.7 & 382.4 & 414.6 & 390.1 & 370.1 & 400.4 & 378.9 & 361.4 \\
\hline & & \#4 & 498.5 & 452.7 & 415.2 & 446.7 & 409.4 & 379.2 & 415.5 & 383.9 & 358.4 & 393.3 & 366.7 & 344.6 & 378.9 & 354.4 & 334.7 \\
\hline & \multirow{3}{*}{300} & \#6 & 520.5 & 479.3 & 445.7 & 472.9 & 440.7 & 414.6 & 445 & 418.5 & 397.1 & 426.5 & 404 & 385.5 & 413.1 & 393.8 & 377.9 \\
\hline & & \#5 & 507.3 & 462.5 & 425.6 & 456.3 & 420.2 & 390.7 & 425.8 & 395.4 & 370.7 & 405.2 & 378.9 & 357.6 & 390.2 & 367.1 & 348.2 \\
\hline & & $\# 4$ & 494.1 & 447.1 & 408.5 & 441.2 & 402.6 & 371.2 & 409.1 & 376 & 349.3 & 387.2 & 358.1 & 334.7 & 371.1 & 345.1 & 324.2 \\
\hline
\end{tabular}


Table E.5 Punching shear resistance $(\mathrm{kN})$ of PL-3 GFRP-reinforced concrete barriers with $\mathrm{f}^{\prime} \mathrm{c}=30 \mathrm{MPa}$ (HM bars)-Exterior location

\begin{tabular}{|c|c|c|c|c|c|c|c|c|c|c|c|c|c|c|c|c|c|}
\hline & \multicolumn{17}{|c|}{ Vertical bar spacing, $S_{\mathrm{y}}(\mathrm{mm})$} \\
\hline \multirow{17}{*}{ 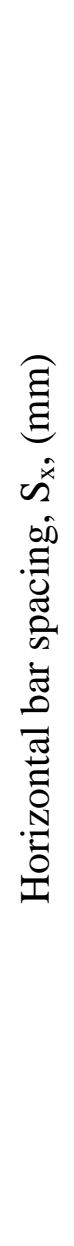 } & & & \multicolumn{3}{|c|}{100} & \multicolumn{3}{|c|}{150} & \multicolumn{3}{|c|}{200} & \multicolumn{3}{|c|}{250} & \multicolumn{3}{|c|}{300} \\
\hline & & & \#6 & $\# 5$ & $\# 4$ & $\# 6$ & \#5 & $\# 4$ & \#6 & $\# 5$ & $\# 4$ & \#6 & $\# 5$ & $\# 4$ & \#6 & \#5 & $\# 4$ \\
\hline & \multirow{3}{*}{100} & \#6 & 633.2 & 603.5 & 579.2 & 595.9 & 575.3 & 557.8 & 575.3 & 560.1 & 546.4 & 562.2 & 550.6 & 539.4 & 553.1 & 544 & 534.6 \\
\hline & & $\# 5$ & 598 & 562.6 & 533.7 & 555.3 & 529.4 & 508 & 531.2 & 511.1 & 494.2 & 515.6 & 499.5 & 485.4 & 504.7 & 491.4 & 479.4 \\
\hline & & $\# 4$ & 568.8 & 528.9 & 496.9 & 522.1 & 491.9 & 467.6 & 495.3 & 471.1 & 451.5 & 477.6 & 457.6 & 441.2 & 465.1 & 448.2 & 434.1 \\
\hline & \multirow{3}{*}{150} & \#6 & 595.9 & 560.4 & 531.6 & 553.1 & 527.2 & 506 & 529.1 & 509 & 492.1 & 513.5 & 497.3 & 483.3 & 502.6 & 489.3 & 477.4 \\
\hline & & $\# 5$ & 570.1 & 529.4 & 496.3 & 522.4 & 491.4 & 466.2 & 495 & 470.1 & 449.6 & 476.9 & 456.2 & 439 & 464 & 446.5 & 431.7 \\
\hline & & $\# 4$ & 547.8 & 503.5 & 467.6 & 496.9 & 462.1 & 434.1 & 467.9 & 438.2 & 415.2 & 447 & 422.6 & 403 & 432.6 & 411.5 & 394.4 \\
\hline & \multirow{3}{*}{200} & \#6 & 575.3 & 536 & 504.3 & 529.1 & 499.5 & 475.5 & 502.6 & 479 & 459.7 & 485.2 & 465.8 & 449.6 & 472.9 & 456.6 & 442.7 \\
\hline & & $\# 5$ & 555 & 511.1 & 475.3 & 504.3 & 470.1 & 442.2 & 474.7 & 446.5 & 423.6 & 454.9 & 431.1 & 411.6 & 440.7 & 420.2 & 403.2 \\
\hline & & $\# 4$ & 536.6 & 489.7 & 451.5 & 483.2 & 445.6 & 415.2 & 451.4 & 419.8 & 394.4 & 430 & 402.7 & 380.8 & 414.4 & 390.4 & 371.2 \\
\hline & \multirow{3}{*}{250} & $\# 6$ & 562.2 & 520.3 & 486.4 & 513.5 & 481.2 & 455.2 & 485.2 & 459.1 & 437.8 & 466.5 & 444.7 & 426.7 & 453.2 & 434.5 & 419 \\
\hline & & $\# 5$ & 545.6 & 499.5 & 461.8 & 492.8 & 456.2 & 426.4 & 461.6 & 431.1 & 406.3 & 440.6 & 414.5 & 393.2 & 425.5 & 402.7 & 384 \\
\hline & & $\# 4$ & 529.7 & 481.1 & 441.2 & 474.7 & 435.1 & 403 & 441.6 & 407.9 & 380.8 & 419.1 & 389.7 & 366.1 & 402.6 & 376.6 & 355.7 \\
\hline & \multirow{3}{*}{300} & $\# 6$ & 553.1 & 509.3 & 473.6 & 502.6 & 468.3 & 440.6 & 472.9 & 444.8 & 422 & 453.2 & 429.4 & 410 & 439 & 418.5 & 401.6 \\
\hline & & $\# 5$ & 539.1 & 491.4 & 452.3 & 484.8 & 446.5 & 415.2 & 452.5 & 420.2 & 393.4 & 430.6 & 402.7 & 380 & 414.6 & 390.1 & 370.1 \\
\hline & & $\# 4$ & 525 & 475.2 & 434.1 & 468.8 & 427.8 & 394.4 & 434.8 & 399.6 & 371.2 & 411.5 & 380.6 & 355.7 & 394.3 & 366.7 & 344.6 \\
\hline
\end{tabular}


Table E.6 Punching shear resistance $(\mathrm{kN})$ of PL-3 GFRP-reinforced concrete barriers with $\mathrm{f}^{\prime} \mathrm{c}=35 \mathrm{MPa}$ (HM bars)-Exterior location

\begin{tabular}{|c|c|c|c|c|c|c|c|c|c|c|c|c|c|c|c|c|c|}
\hline & \multicolumn{17}{|c|}{ Vertical bar spacing, $S_{\mathrm{y}}(\mathrm{mm})$} \\
\hline \multirow{17}{*}{ 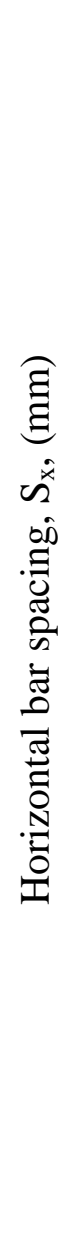 } & & & \multicolumn{3}{|c|}{100} & \multicolumn{3}{|c|}{150} & \multicolumn{3}{|c|}{200} & \multicolumn{3}{|c|}{250} & \multicolumn{3}{|c|}{300} \\
\hline & & & \#6 & $\# 5$ & $\# 4$ & $\# 6$ & \#5 & $\# 4$ & \#6 & $\# 5$ & $\# 4$ & \#6 & $\# 5$ & $\# 4$ & \#6 & \#5 & $\# 4$ \\
\hline & \multirow{3}{*}{100} & \#6 & 666.6 & 635.3 & 609.7 & 627.3 & 605.6 & 587.2 & 605.6 & 589.6 & 575.2 & 591.9 & 579.6 & 567.8 & 582.3 & 572.7 & 562.8 \\
\hline & & $\# 5$ & 629.6 & 592.2 & 561.8 & 584.6 & 557.3 & 534.8 & 559.2 & 538.1 & 520.2 & 542.8 & 525.8 & 511 & 531.3 & 517.4 & 504.7 \\
\hline & & $\# 4$ & 598.8 & 556.8 & 523.1 & 549.6 & 517.8 & 492.3 & 521.4 & 495.9 & 475.3 & 502.8 & 481.8 & 464.5 & 489.7 & 471.9 & 457 \\
\hline & \multirow{3}{*}{150} & \#6 & 627.3 & 589.9 & 559.7 & 582.3 & 555 & 532.6 & 557 & 535.8 & 518 & 540.6 & 523.6 & 508.8 & 529.1 & 515.1 & 502.5 \\
\hline & & $\# 5$ & 600.1 & 557.3 & 522.5 & 550 & 517.4 & 490.8 & 521.1 & 494.8 & 473.3 & 502 & 480.3 & 462.2 & 488.5 & 470.1 & 454.4 \\
\hline & & $\# 4$ & 576.7 & 530 & 492.3 & 523.1 & 486.4 & 457 & 491.6 & 461.4 & 437.1 & 470.6 & 444.9 & 424.2 & 455.5 & 433.2 & 415.2 \\
\hline & \multirow{3}{*}{200} & \#6 & 605.6 & 564.3 & 530.9 & 557 & 525.8 & 500.6 & 529.1 & 504.3 & 483.9 & 510.8 & 490.4 & 473.4 & 497.9 & 480.7 & 466.1 \\
\hline & & $\# 5$ & 584.3 & 538.1 & 500.4 & 530.9 & 494.8 & 465.5 & 499.7 & 470.1 & 445.9 & 478.9 & 453.8 & 433.3 & 464 & 442.3 & 424.5 \\
\hline & & $\# 4$ & 564.9 & 515.5 & 475.3 & 508.6 & 469.1 & 437.1 & 475.2 & 441.9 & 415.2 & 452.6 & 423.9 & 400.9 & 436.2 & 411 & 390.7 \\
\hline & \multirow{3}{*}{250} & $\# 6$ & 591.8 & 547.7 & 512 & 540.6 & 506.6 & 479.2 & 510.8 & 483.3 & 460.9 & 491.1 & 468.1 & 449.2 & 477.1 & 457.4 & 441.1 \\
\hline & & $\# 5$ & 574.3 & 525.8 & 486.1 & 518.8 & 480.3 & 448.9 & 485.9 & 453.8 & 427.7 & 463.9 & 436.6 & 414 & 447.9 & 423.9 & 361.4 \\
\hline & & $\# 4$ & 557.7 & 506.5 & 464.5 & 499.7 & 458 & 424.2 & 464.9 & 429.4 & 400.9 & 441.2 & 410.3 & 385.5 & 423.8 & 396.4 & 374.4 \\
\hline & \multirow{3}{*}{300} & $\# 6$ & 582.3 & 536.1 & 498.6 & 529.1 & 493 & 463.8 & 497.9 & 468.2 & 444.2 & 477.1 & 452 & 431.6 & 462.2 & 440.5 & 422.7 \\
\hline & & $\# 5$ & 567.5 & 517.4 & 476.1 & 510.4 & 470.1 & 437.1 & 476.3 & 442.3 & 414.7 & 453.3 & 423.9 & 400 & 436.5 & 410.6 & 389.6 \\
\hline & & \#4 & 552.7 & 500.2 & 457 & 493.5 & 450.3 & 415.2 & 457.7 & 420.7 & 390.7 & 433.2 & 400.6 & 374.4 & 415.2 & 386.1 & 362.7 \\
\hline
\end{tabular}


Table E.7 Punching shear resistance $(\mathrm{kN})$ of PL-3 GFRP-reinforced concrete barriers with $\mathrm{f}^{\prime} \mathrm{c}=25 \mathrm{MPa}(\mathrm{SM}$ bars$)$-Interior location

\begin{tabular}{|c|c|c|c|c|c|c|c|c|c|c|c|c|c|c|c|c|c|}
\hline & \multicolumn{17}{|c|}{ Vertical bar spacing, $S_{\mathrm{y}},(\mathrm{mm})$} \\
\hline \multirow{17}{*}{ 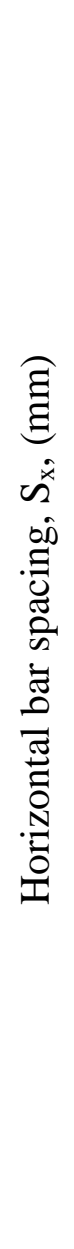 } & & & \multicolumn{3}{|c|}{100} & \multicolumn{3}{|c|}{150} & \multicolumn{3}{|c|}{200} & \multicolumn{3}{|c|}{250} & \multicolumn{3}{|c|}{300} \\
\hline & & & \#6 & $\# 5$ & $\# 4$ & $\# 6$ & \#5 & $\# 4$ & \#6 & $\# 5$ & $\# 4$ & \#6 & $\# 5$ & $\# 4$ & \#6 & \#5 & $\# 4$ \\
\hline & \multirow{3}{*}{100} & \#6 & 721.1 & 688.1 & 659.6 & 678.6 & 656.1 & 638.1 & 655.2 & 638.9 & 626.7 & 640.3 & 628.1 & 619.7 & 629.9 & 620.6 & 614.9 \\
\hline & & $\# 5$ & 680.8 & 640.8 & 604.4 & 631.9 & 603.1 & 578.1 & 604.4 & 582.2 & 564 & 586.6 & 569 & 555.2 & 574.1 & 559.8 & 549.2 \\
\hline & & $\# 4$ & 645.7 & 598 & 552.1 & 589.7 & 553.2 & 519.6 & 557.1 & 527.8 & 501.6 & 535.7 & 511.3 & 490.2 & 520.3 & 499.6 & 482.3 \\
\hline & \multirow{3}{*}{150} & \#6 & 678.6 & 638.7 & 602.4 & 629.9 & 601.1 & 576.2 & 602.5 & 580.4 & 562.2 & 584.8 & 567.2 & 553.5 & 572.3 & 558.1 & 547.5 \\
\hline & & $\# 5$ & 649.1 & 603.1 & 559.1 & 594.7 & 559.8 & 528 & 563.3 & 535.5 & 511 & 542.7 & 519.7 & 500.2 & 528 & 508.6 & 492.7 \\
\hline & & $\# 4$ & 624.6 & 572 & 519.6 & 564.1 & 522.4 & 482.3 & 528.2 & 493.6 & 461.3 & 504.1 & 474.6 & 447.7 & 486.7 & 461.1 & 438.2 \\
\hline & \multirow{3}{*}{200} & \#6 & 655.2 & 610.9 & 569.2 & 602.5 & 569.4 & 539.6 & 572.3 & 546.2 & 523.5 & 552.6 & 531.1 & 513.4 & 538.6 & 520.8 & 506.4 \\
\hline & & $\# 5$ & 632 & 582.2 & 533.4 & 574.2 & 535.5 & 498.9 & 540.3 & 508.6 & 479.7 & 517.8 & 491.1 & 467.4 & 501.6 & 478.6 & 458.9 \\
\hline & & $\# 4$ & 613.5 & 558.1 & 501.6 & 550.3 & 505.6 & 461.3 & 512.5 & 474.7 & 438.2 & 486.8 & 454 & 423.1 & 468.1 & 439.1 & 412.4 \\
\hline & \multirow{3}{*}{250} & $\# 6$ & 640.3 & 592.9 & 547.2 & 584.8 & 548.5 & 515 & 552.6 & 523.4 & 497.3 & 531.3 & 507 & 486 & 516.1 & 495.5 & 478.2 \\
\hline & & $\# 5$ & 621.4 & 569 & 516.7 & 561.2 & 519.7 & 479.7 & 525.5 & 491.1 & 458.8 & 501.6 & 472.2 & 445.3 & 484.3 & 458.7 & 435.9 \\
\hline & & $\# 4$ & 606.6 & 549.4 & 490.2 & 541.8 & 494.9 & 447.7 & 502.6 & 462.5 & 423.1 & 475.7 & 440.6 & 406.8 & 456 & 424.8 & 395.2 \\
\hline & \multirow{3}{*}{300} & $\# 6$ & 629.9 & 580.3 & 531.6 & 572.3 & 533.7 & 497.2 & 538.6 & 507 & 478.1 & 516.1 & 489.5 & 465.9 & 500 & 477.1 & 457.4 \\
\hline & & $\# 5$ & 614 & 559.8 & 505 & 552.1 & 508.6 & 466 & 515.2 & 478.6 & 443.7 & 490.2 & 458.7 & 429.3 & 472 & 444.3 & 419.1 \\
\hline & & \#4 & 601.9 & 543.4 & 482.3 & 535.9 & 487.5 & 438.2 & 495.7 & 454 & 412.4 & 468.1 & 431.3 & 395.2 & 447.7 & 414.6 & 382.8 \\
\hline
\end{tabular}


Table E.8 Punching shear resistance $(\mathrm{kN})$ of PL-3 GFRP-reinforced concrete barriers with $\mathrm{f}^{\prime} \mathrm{c}=30 \mathrm{MPa}(\mathrm{SM}$ bars$)$-Interior location

\begin{tabular}{|c|c|c|c|c|c|c|c|c|c|c|c|c|c|c|c|c|c|}
\hline & \multicolumn{17}{|c|}{ Vertical bar spacing, $\mathrm{S}_{\mathrm{y}}(\mathrm{mm})$} \\
\hline \multirow{17}{*}{ 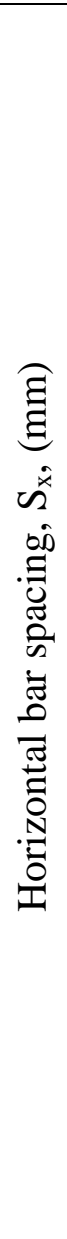 } & & & \multicolumn{3}{|c|}{100} & \multicolumn{3}{|c|}{150} & \multicolumn{3}{|c|}{200} & \multicolumn{3}{|c|}{250} & \multicolumn{3}{|c|}{300} \\
\hline & & & \#6 & $\# 5$ & \#4 & \#6 & $\# 5$ & $\# 4$ & \#6 & $\# 5$ & $\# 4$ & \#6 & $\# 5$ & $\# 4$ & \#6 & $\# 5$ & $\# 4$ \\
\hline & \multirow{3}{*}{100} & \#6 & 766.3 & 731.2 & 701 & 721.1 & 697.2 & 678 & 696.2 & 678.9 & 666 & 680.4 & 667.4 & 658.5 & 669.4 & 659.5 & 653.5 \\
\hline & & $\# 5$ & 723.4 & 681 & 642.3 & 671.5 & 640.8 & 614.4 & 642.3 & 618.7 & 599.4 & 623.3 & 604.7 & 590 & 610.1 & 594.9 & 583.6 \\
\hline & & $\# 4$ & 686.1 & 635.5 & 586.7 & 626.6 & 587.9 & 552.1 & 592.1 & 560.8 & 533.1 & 569.2 & 543.3 & 520.9 & 552.9 & 530.9 & 512.5 \\
\hline & \multirow{3}{*}{150} & \#6 & 721.1 & 678.8 & 640.1 & 669.4 & 638.8 & 612.3 & 640.3 & 616.8 & 597.5 & 621.4 & 602.8 & 588.2 & 608.2 & 593.1 & 581.8 \\
\hline & & $\# 5$ & 689.8 & 640.8 & 594.1 & 632 & 594.9 & 561.1 & 598.6 & 569 & 543 & 576.7 & 552.3 & 531.5 & 561.1 & 540.5 & 523.6 \\
\hline & & $\# 4$ & 663.7 & 607.8 & 552.1 & 599.4 & 555.2 & 512.5 & 561.3 & 524.6 & 490.2 & 535.7 & 504.4 & 475.8 & 517.2 & 489.9 & 465.7 \\
\hline & \multirow{3}{*}{200} & \#6 & 696.2 & 649.2 & 604.8 & 640.3 & 605.1 & 573.4 & 608.2 & 580.4 & 556.4 & 587.2 & 564.5 & 545.6 & 572.3 & 553.4 & 538.2 \\
\hline & & $\# 5$ & 671.6 & 618.7 & 566.8 & 610.2 & 569 & 530.2 & 574.2 & 540.5 & 509.8 & 550.2 & 521.8 & 496.7 & 533 & 508.6 & 487.6 \\
\hline & & $\# 4$ & 651.9 & 593 & 533.1 & 584.8 & 537.3 & 490.2 & 544.6 & 504.4 & 465.7 & 517.3 & 482.4 & 449.6 & 497.3 & 466.6 & 438.2 \\
\hline & \multirow{3}{*}{250} & $\# 6$ & 680.4 & 630.1 & 581.5 & 621.4 & 582.9 & 547.3 & 587.2 & 556.2 & 528.4 & 564.6 & 538.8 & 516.5 & 548.5 & 526.5 & 508.2 \\
\hline & & $\# 5$ & 660.3 & 604.7 & 549.1 & 596.3 & 552.3 & 509.7 & 558.5 & 521.8 & 487.6 & 533 & 501.8 & 473.2 & 514.6 & 487.4 & 463.2 \\
\hline & & $\# 4$ & 644.6 & 583.8 & 520.9 & 575.7 & 525.9 & 475.8 & 534.1 & 491.5 & 449.6 & 505.6 & 468.2 & 432.3 & 484.6 & 451.4 & 419.9 \\
\hline & \multirow{3}{*}{300} & $\# 6$ & 669.4 & 616.6 & 564.9 & 608.2 & 567.1 & 528.4 & 572.3 & 538.7 & 508.1 & 548.5 & 520.2 & 495.1 & 531.3 & 507 & 486 \\
\hline & & $\# 5$ & 652.5 & 594.9 & 536.6 & 586.7 & 540.5 & 495.2 & 547.5 & 508.6 & 471.6 & 520.9 & 487.4 & 456.2 & 501.6 & 472.2 & 445.3 \\
\hline & & $\# 4$ & 639.7 & 577.5 & 512.5 & 569.5 & 518.1 & 465.7 & 526.8 & 482.5 & 438.2 & 497.4 & 458.3 & 419.9 & 475.7 & 440.6 & 406.8 \\
\hline
\end{tabular}


Table E.9 Punching shear resistance $(\mathrm{kN})$ of PL-3 GFRP-reinforced concrete barriers with $\mathrm{f}^{\prime} \mathrm{c}=35 \mathrm{MPa}(-\mathrm{SM}$ bars$)$-Interior location

\begin{tabular}{|c|c|c|c|c|c|c|c|c|c|c|c|c|c|c|c|c|c|}
\hline & \multicolumn{17}{|c|}{ Vertical bar spacing, $S_{y},(\mathrm{~mm})$} \\
\hline \multirow{17}{*}{ 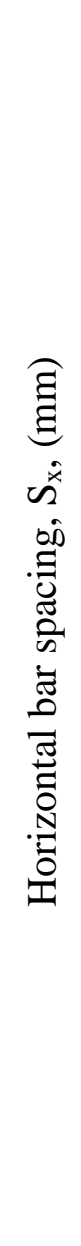 } & & & \multicolumn{3}{|c|}{100} & \multicolumn{3}{|c|}{150} & \multicolumn{3}{|c|}{200} & \multicolumn{3}{|c|}{250} & \multicolumn{3}{|c|}{300} \\
\hline & & & $\# 6$ & $\# 5$ & $\# 4$ & \#6 & $\# 5$ & $\# 4$ & \#6 & $\# 5$ & \#4 & \#6 & $\# 5$ & $\# 4$ & \#6 & $\# 5$ & $\# 4$ \\
\hline & \multirow{3}{*}{100} & \#6 & 806.7 & 769.8 & 737.9 & 759.1 & 734 & 713.8 & 732.9 & 714.7 & 701.1 & 716.3 & 702.6 & 693.3 & 704.7 & 694.3 & 687.9 \\
\hline & & $\# 5$ & 761.2 & 716.9 & 676.2 & 706.9 & 674.6 & 646.7 & 676.1 & 651.4 & 631 & 656.2 & 636.5 & 621.1 & 642.2 & 626.3 & 614.4 \\
\hline & & $\# 4$ & 722.3 & 669 & 617.6 & 659.6 & 618.9 & 581.2 & 623.3 & 590.4 & 561.2 & 599.2 & 571.9 & 548.4 & 582.1 & 558.9 & 539.6 \\
\hline & \multirow{3}{*}{150} & \#6 & 759.1 & 714.6 & 673.9 & 704.7 & 672.5 & 644.6 & 674 & 649.3 & 629 & 654.2 & 634.6 & 619.2 & 640.3 & 624.3 & 612.5 \\
\hline & & $\# 5$ & 726.2 & 674.6 & 625.5 & 665.3 & 626.3 & 590.7 & 630.2 & 599 & 571.6 & 607.1 & 581.4 & 559.6 & 590.7 & 569 & 551.2 \\
\hline & & $\# 4$ & 698.7 & 639.9 & 581.2 & 631 & 584.4 & 539.6 & 590.9 & 552.2 & 516.1 & 564 & 531 & 500.9 & 544.5 & 515.8 & 490.2 \\
\hline & \multirow{3}{*}{200} & \#6 & 732.9 & 683.4 & 636.7 & 674 & 637 & 603.7 & 640.3 & 611 & 585.7 & 618.2 & 594.3 & 574.3 & 602.5 & 582.6 & 566.5 \\
\hline & & $\# 5$ & 707.1 & 651.4 & 596.7 & 642.4 & 599 & 558.1 & 604.5 & 569 & 536.7 & 579.2 & 549.4 & 522.9 & 561.1 & 535.5 & 513.3 \\
\hline & & $\# 4$ & 686.3 & 624.3 & 561.2 & 615.7 & 565.6 & 516.1 & 573.3 & 531 & 490.2 & 544.6 & 507.9 & 473.3 & 523.6 & 491.2 & 461.3 \\
\hline & \multirow{3}{*}{250} & \#6 & 716.3 & 663.3 & 612.2 & 654.2 & 613.6 & 576.1 & 618.2 & 585.5 & 556.3 & 594.4 & 567.2 & 543.7 & 577.4 & 554.3 & 535 \\
\hline & & \#5 & 695.1 & 636.5 & 578.1 & 627.8 & 581.4 & 536.6 & 587.9 & 549.4 & 513.3 & 561.1 & 528.2 & 498.2 & 541.8 & 513.1 & 487.6 \\
\hline & & $\# 4$ & 678.6 & 614.6 & 548.4 & 606.1 & 553.6 & 500.9 & 562.2 & 517.4 & 473.3 & 532.2 & 492.9 & 455.1 & 510.2 & 475.2 & 442.1 \\
\hline & \multirow{3}{*}{300} & \#6 & 704.7 & 649.2 & 594.6 & 640.3 & 597 & 556.2 & 602.5 & 567.2 & 534.9 & 577.4 & 547.6 & 521.2 & 559.3 & 533.7 & 511.6 \\
\hline & & $\# 5$ & 686.9 & 626.3 & 564.9 & 617.7 & 569 & 521.3 & 576.3 & 535.5 & 496.4 & 548.4 & 513.1 & 480.2 & 528.1 & 497.1 & 468.8 \\
\hline & & \#4 & 673.4 & 607.9 & 539.6 & 599.5 & 545.4 & 490.2 & 554.6 & 507.9 & 461.3 & 523.7 & 482.4 & 442.1 & 500.8 & 463.9 & 428.3 \\
\hline
\end{tabular}


Table E.10 Punching shear resistance $(\mathrm{kN})$ of PL-3 GFRP-reinforced concrete barriers with $\mathrm{f}^{\prime} \mathrm{c}=25 \mathrm{MPa}(\mathrm{SM}$ bars$)$-Exterior location

\begin{tabular}{|c|c|c|c|c|c|c|c|c|c|c|c|c|c|c|c|c|c|}
\hline & \multicolumn{17}{|c|}{ Vertical bar spacing, $S_{\mathrm{y}}(\mathrm{mm})$} \\
\hline \multirow{17}{*}{ 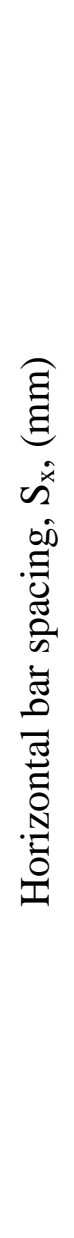 } & & & \multicolumn{3}{|c|}{100} & \multicolumn{3}{|c|}{150} & \multicolumn{3}{|c|}{200} & \multicolumn{3}{|c|}{250} & \multicolumn{3}{|c|}{300} \\
\hline & & & \#6 & $\# 5$ & $\# 4$ & $\# 6$ & \#5 & $\# 4$ & \#6 & $\# 5$ & $\# 4$ & \#6 & $\# 5$ & $\# 4$ & \#6 & \#5 & $\# 4$ \\
\hline & & \#6 & 572.8 & 545.7 & 522.3 & 539.1 & 520.4 & 505.2 & 520.5 & 506.7 & 496.2 & 508.6 & 498.1 & 490.7 & 500.4 & 492.2 & 486.2 \\
\hline & 100 & $\# 5$ & 540.8 & 508.3 & 478.6 & 502 & 478.3 & 457.8 & 480.1 & 461.8 & 446.2 & 466 & 451.3 & 439.6 & 456.1 & 444 & 434.9 \\
\hline & & \#4 & 512.9 & 474.3 & 437.2 & 468.4 & 438.7 & 411.4 & 442.6 & 418.6 & 397.2 & 425.5 & 405.5 & 388.2 & 413.3 & 396.3 & 381.9 \\
\hline & & \#6 & 539.1 & 506.6 & 477 & 500.4 & 476.8 & 456.3 & 478.6 & 460.3 & 445.2 & 464.6 & 449.9 & 438.3 & 454.7 & 442.6 & 433.5 \\
\hline & 150 & $\# 5$ & 515.7 & 478.3 & 442.7 & 472.4 & 444 & 418.1 & 447.5 & 424.7 & 404.6 & 431.1 & 412.2 & 396.1 & 419.4 & 403.4 & 390.2 \\
\hline & & $\# 4$ & 496.2 & 453.7 & 411.4 & 448.1 & 414.3 & 381.9 & 419.6 & 391.5 & 365.3 & 400.5 & 376.4 & 354.5 & 386.6 & 365.7 & 347 \\
\hline & & \#6 & 520.5 & 484.5 & 450.7 & 478.6 & 451.6 & 427.3 & 454.7 & 433.2 & 414.6 & 439 & 421.3 & 406.5 & 427.9 & 413 & 401 \\
\hline & 200 & $\# 5$ & 502.1 & 461.8 & 422.4 & 456.2 & 424.7 & 395.1 & 429.2 & 403.4 & 379.8 & 411.3 & 389.5 & 370.1 & 398.4 & 379.6 & 363.3 \\
\hline & & \#4 & 487.3 & 442.6 & 397.2 & 437.2 & 401 & 365.3 & 407.1 & 376.5 & 347 & 386.7 & 360.1 & 335 & 371.8 & 348.2 & 326.5 \\
\hline & & \#6 & 508.6 & 470.2 & 433.3 & 464.6 & 435 & 407.8 & 439 & 415.1 & 393.8 & 422.1 & 402.1 & 384.8 & 410 & 393 & 378.7 \\
\hline & 250 & $\# 5$ & 493.6 & 451.3 & 409.2 & 445.8 & 412.2 & 379.8 & 417.5 & 389.5 & 363.3 & 398.5 & 374.5 & 352.6 & 384.7 & 363.8 & 345.1 \\
\hline & & $\# 4$ & 481.9 & 435.7 & 388.2 & 430.4 & 392.5 & 354.5 & 399.2 & 366.8 & 335 & 377.9 & 349.5 & 322.1 & 362.3 & 336.9 & 312.9 \\
\hline & & $\# 6$ & 500.4 & 460.2 & 420.9 & 454.7 & 423.3 & 393.7 & 427.9 & 402.1 & 378.6 & 410 & 388.2 & 368.9 & 397.2 & 378.4 & 362.2 \\
\hline & 300 & $\# 5$ & 487.8 & 444 & 399.8 & 438.6 & 403.4 & 369 & 409.3 & 379.6 & 351.4 & 389.4 & 363.8 & 339.9 & 375 & 352.4 & 331.8 \\
\hline & & $\# 4$ & 478.2 & 431 & 381.9 & 425.7 & 386.7 & 347 & 393.8 & 360.1 & 326.5 & 371.9 & 342 & 312.9 & 355.6 & 328.9 & 303.1 \\
\hline
\end{tabular}


Table E.11 Punching shear resistance $(\mathrm{kN})$ of PL-3 GFRP-reinforced concrete barriers with $\mathrm{f}^{\prime} \mathrm{c}=30 \mathrm{MPa}(\mathrm{SM}$ bars$)$-Exterior location

\begin{tabular}{|c|c|c|c|c|c|c|c|c|c|c|c|c|c|c|c|c|c|}
\hline & \multicolumn{17}{|c|}{ Vertical bar spacing, $\mathrm{S}_{\mathrm{y}},(\mathrm{mm})$} \\
\hline \multirow{17}{*}{ 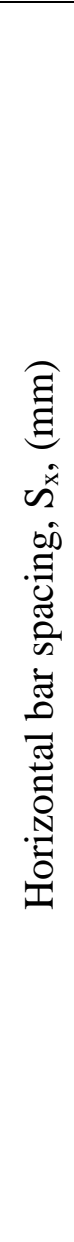 } & & & \multicolumn{3}{|c|}{100} & \multicolumn{3}{|c|}{150} & \multicolumn{3}{|c|}{200} & \multicolumn{3}{|c|}{250} & \multicolumn{3}{|c|}{300} \\
\hline & & & \#6 & $\# 5$ & \#4 & \#6 & $\# 5$ & $\# 4$ & \#6 & $\# 5$ & \#4 & \#6 & $\# 5$ & $\# 4$ & \#6 & $\# 5$ & \#4 \\
\hline & \multirow{3}{*}{100} & \#6 & 608.7 & 580 & 555 & 572.8 & 553 & 536.9 & 553.1 & 538.4 & 527.3 & 540.5 & 529.3 & 521.4 & 531.8 & 523.1 & 517.4 \\
\hline & & \#5 & 574.7 & 540.1 & 508.6 & 533.5 & 508.3 & 486.5 & 510.2 & 490.7 & 474.6 & 495.2 & 479.6 & 467.2 & 484.6 & 471.8 & 462.1 \\
\hline & & \#4 & 545.1 & 504 & 464.6 & 497.8 & 466.2 & 437.2 & 470.3 & 444.8 & 422.1 & 452.2 & 430.9 & 412.5 & 439.2 & 421.1 & 405.8 \\
\hline & \multirow{3}{*}{150} & \#6 & 572.8 & 538.3 & 506.9 & 531.8 & 506.6 & 484.9 & 508.6 & 489.2 & 473.1 & 493.7 & 478.1 & 465.7 & 483.2 & 470.4 & 460.7 \\
\hline & & $\# 5$ & 548 & 508.3 & 470.5 & 502 & 471.8 & 444.3 & 475.5 & 451.3 & 430 & 458.1 & 438 & 420.9 & 445.7 & 428.7 & 414.6 \\
\hline & & $\# 4$ & 527.3 & 482.1 & 437.2 & 476.2 & 440.3 & 405.8 & 445.9 & 416 & 388.2 & 425.6 & 400 & 376.7 & 410.9 & 388.6 & 368.7 \\
\hline & \multirow{3}{*}{200} & $\# 6$ & 553.1 & 514.9 & 478.9 & 508.6 & 479.9 & 454.1 & 483.2 & 460.3 & 440.5 & 466.5 & 447.7 & 432 & 454.7 & 438.9 & 426.1 \\
\hline & & $\# 5$ & 533.6 & 490.7 & 448.8 & 484.7 & 451.3 & 419.8 & 456.1 & 428.7 & 403.7 & 437.1 & 413.9 & 393.3 & 423.4 & 403.4 & 386.1 \\
\hline & & $\# 4$ & 517.9 & 470.4 & 422.1 & 464.6 & 426.1 & 388.2 & 432.6 & 400 & 368.7 & 410.9 & 382.6 & 356 & 395.1 & 370.1 & 347 \\
\hline & \multirow{3}{*}{250} & \#6 & 540.5 & 499.7 & 460.5 & 493.7 & 462.3 & 433.4 & 466.5 & 441.1 & 418.4 & 448.5 & 427.3 & 409 & 435.7 & 417.6 & 402.4 \\
\hline & & $\# 5$ & 524.5 & 479.6 & 434.8 & 473.7 & 438 & 403.6 & 443.7 & 413.9 & 386.1 & 423.4 & 398 & 374.7 & 408.8 & 386.6 & 366.7 \\
\hline & & \#4 & 512.1 & 463 & 412.5 & 457.4 & 417.1 & 376.7 & 424.3 & 389.8 & 356 & 401.6 & 371.4 & 342.3 & 385 & 358 & 332.5 \\
\hline & \multirow{3}{*}{300} & \#6 & 531.8 & 489.1 & 447.3 & 483.2 & 449.8 & 418.4 & 454.7 & 427.3 & 402.3 & 435.7 & 412.6 & 392 & 422.1 & 402.1 & 384.4 \\
\hline & & $\# 5$ & 518.3 & 471.8 & 424.9 & 466.1 & 428.7 & 392.1 & 434.9 & 403.4 & 373.4 & 413.8 & 386.6 & 361.2 & 398.5 & 374.5 & 352.6 \\
\hline & & \#4 & 508.2 & 458 & 405.8 & 452.4 & 410.9 & 368.7 & 418.5 & 382.6 & 347 & 395.2 & 363.5 & 332.5 & 377.9 & 349.5 & 322.1 \\
\hline
\end{tabular}


Table E.12 Punching shear resistance $(\mathrm{kN})$ of PL-3 GFRP-reinforced concrete barriers with $\mathrm{f}^{\prime} \mathrm{c}=35 \mathrm{MPa}$ (SM bars)-Exterior location

\begin{tabular}{|c|c|c|c|c|c|c|c|c|c|c|c|c|c|c|c|c|c|}
\hline & \multicolumn{17}{|c|}{ Vertical bar spacing, $S_{\mathrm{y}}(\mathrm{mm})$} \\
\hline \multirow{17}{*}{ 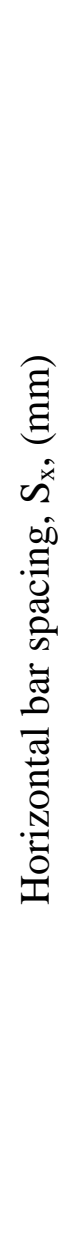 } & & & \multicolumn{3}{|c|}{100} & \multicolumn{3}{|c|}{150} & \multicolumn{3}{|c|}{200} & \multicolumn{3}{|c|}{250} & \multicolumn{3}{|c|}{300} \\
\hline & & & \#6 & $\# 5$ & $\# 4$ & $\# 6$ & \#5 & $\# 4$ & \#6 & $\# 5$ & $\# 4$ & \#6 & $\# 5$ & $\# 4$ & \#6 & \#5 & $\# 4$ \\
\hline & \multirow{3}{*}{100} & \#6 & 640.8 & 610.5 & 584.3 & 603.1 & 582.1 & 565.2 & 582.2 & 566.8 & 555.1 & 569 & 557.2 & 548.9 & 559.8 & 550.7 & 544.7 \\
\hline & & $\# 5$ & 605 & 568.6 & 535.4 & 561.6 & 535.1 & 512.1 & 537.1 & 516.6 & 499.6 & 521.3 & 504.8 & 491.8 & 510.2 & 496.7 & 486.5 \\
\hline & & $\# 4$ & 573.8 & 530.6 & 489.1 & 524 & 490.8 & 460.2 & 495.1 & 468.3 & 444.3 & 476 & 453.6 & 434.2 & 462.4 & 443.3 & 427.2 \\
\hline & \multirow{3}{*}{150} & \#6 & 603.1 & 566.7 & 533.6 & 559.8 & 533.4 & 510.4 & 535.5 & 515 & 498 & 519.7 & 503.3 & 490.3 & 508.6 & 495.2 & 485 \\
\hline & & $\# 5$ & 576.9 & 535.1 & 495.3 & 528.5 & 496.7 & 467.7 & 500.6 & 475.1 & 452.6 & 482.3 & 461.1 & 443.1 & 469.2 & 451.3 & 436.5 \\
\hline & & $\# 4$ & 555.1 & 507.5 & 460.2 & 501.3 & 463.5 & 427.2 & 469.4 & 438 & 408.6 & 448 & 421.1 & 396.6 & 432.5 & 409.1 & 388.2 \\
\hline & \multirow{3}{*}{200} & \#6 & 582.2 & 542 & 504.2 & 535.5 & 505.2 & 478 & 508.6 & 484.6 & 463.8 & 491.1 & 471.3 & 454.8 & 478.6 & 462 & 448.6 \\
\hline & & $\# 5$ & 561.7 & 516.6 & 472.5 & 510.3 & 475.1 & 441.9 & 480.2 & 451.3 & 424.9 & 460.1 & 435.7 & 414.1 & 445.7 & 424.7 & 406.5 \\
\hline & & $\# 4$ & 545.2 & 495.2 & 444.3 & 489.1 & 448.6 & 408.6 & 455.4 & 421.1 & 388.2 & 432.6 & 402.8 & 374.8 & 415.9 & 389.6 & 365.3 \\
\hline & \multirow{3}{*}{250} & $\# 6$ & 569 & 526.1 & 484.7 & 519.7 & 486.7 & 456.2 & 491.1 & 464.3 & 440.5 & 472.2 & 449.8 & 430.5 & 458.7 & 439.6 & 423.6 \\
\hline & & $\# 5$ & 552.2 & 504.8 & 457.7 & 498.7 & 461.1 & 424.9 & 467 & 435.7 & 406.4 & 445.8 & 418.9 & 394.5 & 430.4 & 407 & 386.1 \\
\hline & & $\# 4$ & 539.1 & 487.4 & 434.2 & 481.5 & 439.1 & 396.6 & 446.6 & 410.3 & 374.8 & 422.8 & 390.9 & 360.3 & 405.3 & 376.9 & 350 \\
\hline & \multirow{3}{*}{300} & $\# 6$ & 559.8 & 514.8 & 470.9 & 508.6 & 473.5 & 440.4 & 478.6 & 449.8 & 423.5 & 458.7 & 434.3 & 412.7 & 444.3 & 423.3 & 405.1 \\
\hline & & $\# 5$ & 545.7 & 496.7 & 447.3 & 490.7 & 451.3 & 412.8 & 457.9 & 424.7 & 393.1 & 435.6 & 407 & 380.3 & 419.5 & 394.2 & 372.1 \\
\hline & & \#4 & 534.9 & 482.1 & 427.2 & 476.3 & 432.6 & 388.2 & 440.6 & 402.8 & 365.3 & 416 & 382.6 & 350 & 397.9 & 367.9 & 339.1 \\
\hline
\end{tabular}




\section{Appendix F}

Calculations of Critical Wall Resistance, $\mathbf{R}_{w}$, and Critical Yield-Line Length, $L_{c}$, for Standard CHBDC PL-3 and PL-2 Barriers 
Table F.1 Ultimate transverse load resistance, $R_{w}(\mathrm{kN})$ for PL-3 and PL-2 steel-reinforced concrete barriers with various spacing of horizontal and vertical bars at interior locations

\begin{tabular}{|c|c|c|c|c|c|c|c|c|c|c|}
\hline & \multicolumn{8}{|c|}{ c/c spacing between horizontal bars $(\mathrm{mm})$} \\
\hline & & & \multicolumn{4}{|c|}{ PL-3 Steel barrier } & \multicolumn{4}{|c|}{ PL-2 Steel barrier } \\
\hline & & & 150 & 200 & 250 & 300 & 150 & 200 & 250 & 300 \\
\hline \multirow{8}{*}{ 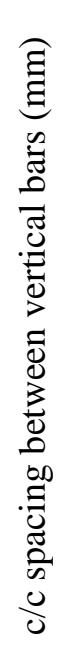 } & \multirow{4}{*}{ 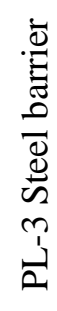 } & 150 & 892.3 & 866.7 & 817.9 & 750.5 & & & & \\
\hline & & 200 & 753.8 & 731.2 & 688.3 & 628.9 & & & & \\
\hline & & 250 & 660.9 & 640.5 & 601.7 & 548.1 & & & & \\
\hline & & 300 & 593.9 & 575.2 & 539.5 & 490.2 & & & & \\
\hline & \multirow{4}{*}{ 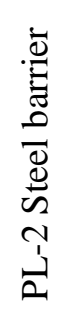 } & 150 & & & & & 644 & 604.5 & 551.7 & 470.9 \\
\hline & & 200 & & & & & 552.4 & 517.9 & 471.7 & 401.1 \\
\hline & & 250 & & & & & 490.5 & 459.5 & 417.9 & 354.4 \\
\hline & & 300 & & & & & 444.9 & 416.5 & 378.4 & 320.2 \\
\hline
\end{tabular}

Table F.2 Critical Length, $L_{c}(\mathrm{~mm})$ for PL-3 and PL-2 steel-reinforced concrete barriers with various spacing of horizontal and vertical bars at interior locations

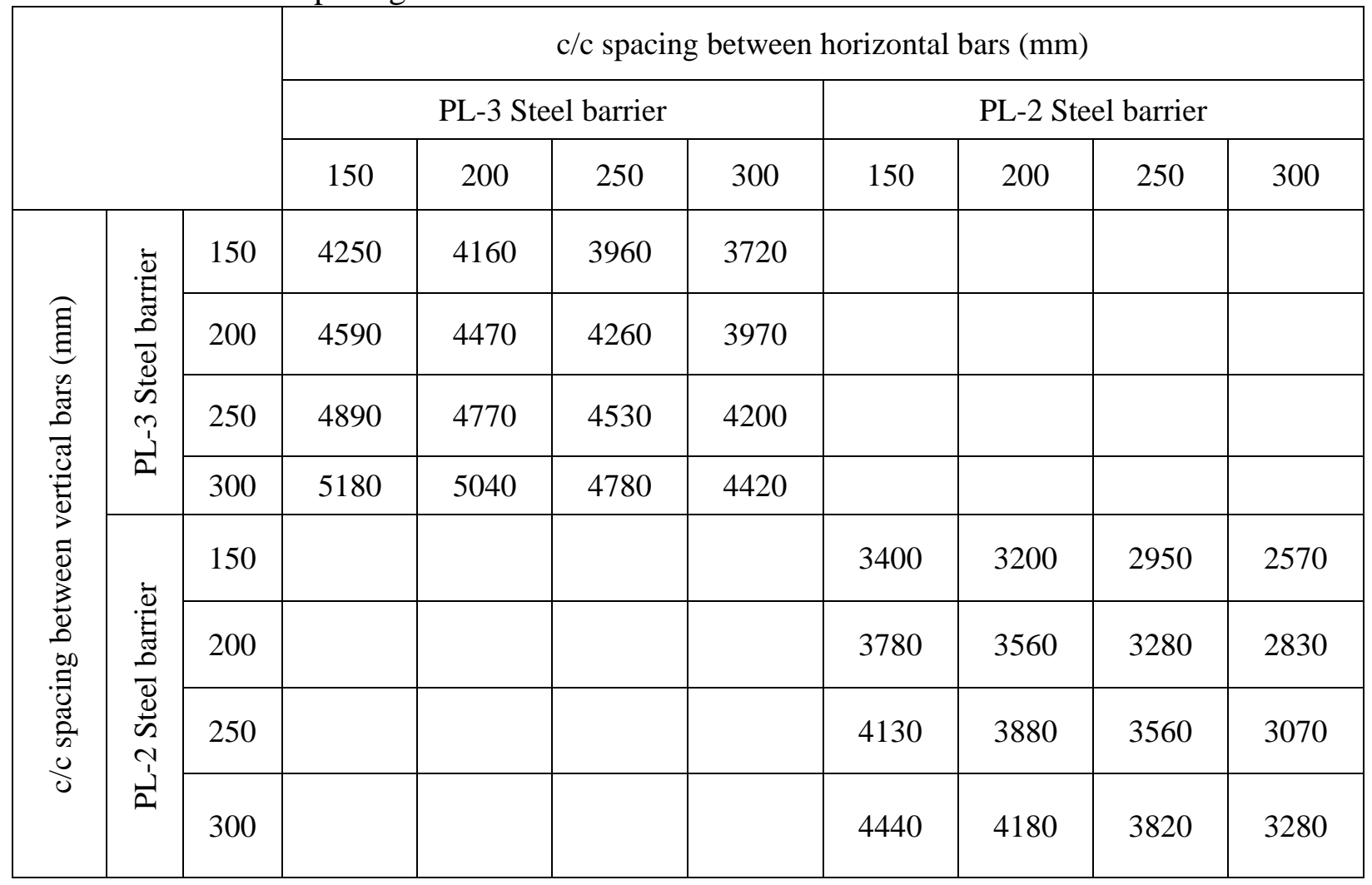


Table F.3 Ultimate transverse load resistance, $R_{w}(\mathrm{kN})$ for PL-3 and PL-2 steel-reinforced concrete barriers with various spacing of horizontal and vertical bars at exterior locations

\begin{tabular}{|c|c|c|c|c|c|c|c|c|c|c|}
\hline & \multicolumn{8}{|c|}{$\mathrm{c} / \mathrm{c}$ spacing between horizontal bars $(\mathrm{mm})$} \\
\hline & & & \multicolumn{4}{|c|}{ PL-3 Steel barrier } & \multicolumn{4}{|c|}{ PL-2 Steel barrier } \\
\hline & & & 150 & 200 & 250 & 300 & 150 & 200 & 250 & 300 \\
\hline \multirow{8}{*}{ 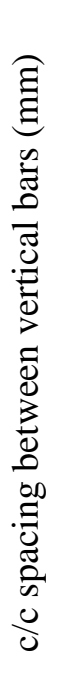 } & \multirow{4}{*}{ 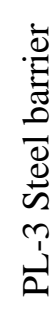 } & 150 & 576.6 & 563.5 & 541.1 & 508.9 & & & & \\
\hline & & 200 & 475.2 & 463.6 & 443.7 & 415.2 & & & & \\
\hline & & 250 & 408.9 & 398.4 & 380.4 & 354.5 & & & & \\
\hline & & 300 & 362.1 & 352.4 & 335.8 & 311.8 & & & & \\
\hline & \multirow{4}{*}{ 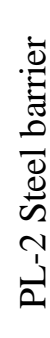 } & 150 & & & & & 362.4 & 345.2 & 318.9 & 278.2 \\
\hline & & 200 & & & & & 306.1 & 291.1 & 268.1 & 232.3 \\
\hline & & 250 & & & & & 268.8 & 255.3 & 234.5 & 202.3 \\
\hline & & 300 & & & & & 241.8 & 229.3 & 210.3 & 180.7 \\
\hline
\end{tabular}

Table F.4 Critical Length, $L_{c}(\mathrm{~mm})$ for PL-3 and PL-2 steel-reinforced concrete barriers with various spacing of horizontal and vertical bars at exterior locations

\begin{tabular}{|c|c|c|c|c|c|c|c|c|c|c|}
\hline & \multicolumn{8}{|c|}{ c/c spacing between horizontal bars $(\mathrm{mm})$} \\
\hline & & & \multicolumn{4}{|c|}{ PL-3 Steel Barrier } & \multicolumn{4}{|c|}{ PL-2 Steel Barrier } \\
\hline & & & 150 & 200 & 250 & 300 & 150 & 200 & 250 & 300 \\
\hline \multirow{8}{*}{ 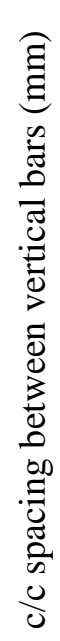 } & \multirow{4}{*}{ 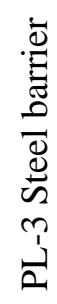 } & 150 & 3100 & 3040 & 2980 & 2860 & & & & \\
\hline & & 200 & 3240 & 3190 & 3100 & 2980 & & & & \\
\hline & & 250 & 3380 & 3320 & 3220 & 3070 & & & & \\
\hline & & 300 & 3500 & 3440 & 3330 & 3160 & & & & \\
\hline & \multirow{4}{*}{ 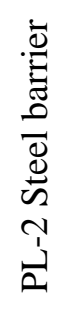 } & 150 & & & & & 2060 & 1980 & 1850 & 1670 \\
\hline & & 200 & & & & & 2240 & 2150 & 2010 & 1790 \\
\hline & & 250 & & & & & 2410 & 2310 & 2140 & 1900 \\
\hline & & 300 & & & & & 2560 & 2440 & 2270 & 2000 \\
\hline
\end{tabular}




\section{References}

AASHTO. 1977. AASHTO Guide for Selecting, Locating, and Designing Traffic Barriers. American Association of State Highway and Transportation Officials, Washington D.C, 322 pages.

AASHTO. 1989. AASHTO Guide Specifications for Bridge Railings. American Association of State Highway and Transportation Officials, Washington D.C, 210 pages.

AASHTO. 2004. AASHTO-LRFD Bridge Design Specifications. Fifth Edition, American Association of State Highway and Transportation Officials, Washington, DC, 941 pages.

AASHTO. 2012. AASHTO-LRFD Bridge Design Specifications. Third Edition, American Association of State Highway and Transportation Officials, Washington, DC, 1661 pages.

ABAQUS 6.10. 2010. ABQUS User's Manual. Volume III. Materials. Dassault Systemes Simulia Corp., Providence, RI, USA.

ABAQUS 6.10. 2010. ABQUS User's Manual. Volume IV. Elements. Dassault Systemes Simulia Corp., Providence, RI, USA.

Achillides, Z. 1998. Bond Behaviour of FRP Bars in Concrete. PhD Thesis, University of Sheffield, Centre for Cement and Concrete, Dept. of Civil and Structural Engineering, Sheffield, UK, 355 pages.

Achillides, Z., and Pilakoutas, K. 2004. Bond Behavior of Fibre Reinforced Polymer Bars under

Direct Pullout Conditions. Journal of Composites for Construction, 8 (2), pp. 173-181.

Al-Dulaijan, S. U., Nanni, A., Al-Zahrani, M. M., and Bakis, C. E., 1996. Bond Evaluation of Environmentally Conditioned GFRP/Concrete System. Proceedings of the Second International Conference on Advanced Composite Materials in Bridges and Structures (ACMBS-2), M. M. El- Badry, ed., Canadian Society for Civil Engineering, Montreal, Quebec, pp. 845-852.

ACI 318. 2005. Building Code Requirements for Structural Concrete (ACI 318-05), and Commentary (ACI 318R-05). American Concrete Institute, Farmington Hills MI, USA, 432 pages.

ACI-349-01. 2001. Code Requirements for Nuclear Safety Related Concrete Structures. American Concrete Institute, Farmington Hills, Michigan, USA, 134 pages. 
ACI Committee 408. 1992: State-of-the-Art Report on Bond Under Cyclic Loads. Reported by ACI Committee 408. ACI 408.2R-92, ACI, Michigan, 26 pages.

ACI Committee 408. 2003. Bond and Development of Straight Reinforcing Bars in Tension (ACI 408R-03). Farmington Hills, MI: American Concrete Institute, 49 pages.

ACI 440R-96. State of the Art Report on Fiber Reinforced Plastic (FRP) Reinforcement for Concrete Structures. Reported by ACI Committee 440. Reapproved 2002, 68 pages.

ACI 440.1R-03. 2003. Guide for the Design and Construction of Concrete Reinforced with FRP Bars.. Reported by ACI Committee 440, 42 pages.

ACI 440.1R-06. 2006. Guide for the design and construction of structural concrete reinforced with FRP bars. American Concrete Institute, Farmington Hills MI, USA, 44 pages.

Ahmed, E., El-Salakawy, E., and Benmokrane, B. 2008. Tensile Capacity of GFRP PostInstalled Adhesive Anchors in Concrete. Journal of Composites for Construction, 12(6): pp. 596-607.

Alberson, D., Williams, W., Boyd, C., and Bloschock, M. 2005. Analysis and Testing of the Florida Jersey Safety Shaped Bridge Rail. TRB 2005 Annual Meeting, Transportation Research Board, pp. 1-24.

Alberson, D., Zimmer, R. and Menges, W. 1997. NCHRP Report 350 Compliance Test 5-12 of the $1.07 \mathrm{~m}$ Vertical wall Bridge Railing, Report to Federal Highway Administration, Texas Transportation Institute, January, 57 pages.

Alberson, D., Williams, W., Boyd, C., and Bloschock, M. 2005. Analysis and Design of Concrete Traffic Railings. Transportation Research Board, pp. 1-12.

Alberson, D., Williams, W., Boyd, C., and Bloschock, M. 2011. Analysis and Design of concrete Traffic Railings, Transportation Research Board, pp. 1-12.

Alunno Rossetti, V., Galeota, V., and Giammatteo, M. M. 1995. Local Bond Stress-Slip Relationships of Glass Fibre Reinforced Plastic Bars Embedded in Concrete . Materials and Structures , 28 (6), pp. 340-344.

Aly, R., Benmokrane, B., and Ebead, U. 2005. Bond Splitting Strength of Lap Splicing of GFRP Bars in Concrete. Proc., 33rd Annual General Conference of the Canadian Society for Civil Engineering, Toronto, pp. 1-10. 
Aminmansour, A. 2004. Performance Characteristics of Precast and Reinforced Concrete Bridge Barrier Subjected to Static and Impact Loads. Ph.D. Thesis, The Pennsylvania State University, 307 pages.

AS-3600. 2009. Concrete Structures. Australian Standard. Fourth Edition. Sydney Australia. GPO Box 476, Sydney, NSW 2001, Australia ISBN 073379347 9, 221 pages.

ASTM. 1996. Standard Test Methods for Strength of Anchors and Masonry Elements. E-488-98, ASTM Int., West Conshohocken, Pa., pp. 65-72.

Baena, M., Torres, L., Turon, A., and Barris, C. 2009. Experimental Study of Bond Behaviour between Concrete and FRP Bars using a Pullout Test. Composites: Part B , 40 (8), pp. 784797.

Bakis, C. E., Al-Dulaijan, S. U., Nanni, A., Boothby, T. E. and Al-Zahrani, M. M., 1998. Effect of Cyclic Loading on Bond Behavior of GFRP Rods Embedded in Concrete Beams. Journal of Composites Technology and Research, V. 20, No. 1, pp. 29-37.

Bank, L. C., Puterman, M., and Katz, A., 1998. The Effect of Material Degradation on Bond Properties of FRP Reinforcing Bars in Concrete. ACI Materials Journal, V. 95, No. 3, MayJune, pp. 232-243.

Beason, W., and Hirsch. T. 1989. Measurement of Heavy Vehicle Impact Forces and Inertia Properties. Research Report. Texas Transportation Institute, College Station, TX., 239 pages. Benmokrane, B., and Masmoudi, R. 1996. FRP C-bar as Reinforcing Rod for Concrete Structures. Proceedings of the $2^{\text {nd }}$ International Conference on Advanced Composite Materials in Bridges and Structures (ACMBS II). Montreal: Canadian Society of Civil Engineering, pp. 181-188

Benmokrane, B., Tighiouart, B., and Chaallal, O., 1996. Bond Strength and Load Distribution of Composite GFRP Reinforcing Bars in Concrete. ACI Materials Journal, V. 93, No. 3, MayJune, pp. 246-253.

Brzev, S., Pao, J. 2006. Reinforced Concrete Design. A Practical Approach. Pearson Education Canada, Inc, 768 pages.

BS 8110. 1997. Structural Use of Concrete. Part 1; Code of Practice for Design and Construction. Technical Committee B/525, Building and Civil Engineering Structures, 238 pages. 
Buth, C., and Campise, W. 1982. Full-Scale Crash Tests of High-Performance Median Barrier, Federal Highway Administration, U. S. Department of Transportation, Washington D.C., Prepared by the Texas Transportation Institute, College Station, TX, 42 pages.

Buth, C., Hirsh, T. and Menges, W. 1993a. Testing of New Bridge Rail and Transition DesignVolume XI: Appendix J: 42 in (1.07 m) F-Shape Bridge Railing. Report No. FHWA-RD-93068, Pooled Funds Bridge Rail Study, Federal Highway Administration, Washington, D.C., September, 64 pages.

Buth, C., Hirsh, T. and Menges, T. 1993b. Testing of New Bridge Rail and Transition DesignVolume X: Appendix I: 42 in (1.07 m) Concrete Parapet Bridge Railing. Report No. FHWARD-93-067, Pooled Funds Bridge Rail Study, Federal Highway Administration, Washington, D.C., September, 42 pages.

Buth, C., William, W., Bligh, R., Menges, W., and Haug, R. 2003. Performance of the TxDOT T202 (MOD) bridge rail reinforced with reinforced polymer bars.” Report No. FHWA/TX03/0-4138-3, Texas Transportation Institute, College Station, Texas, 98 pages.

Campise, W., and Buth, E. 1986. Performance Limits of Longitudinal Barrier Systems, Volume III-Appendix B: Details of Full-Scale Crash Tests on Longitudinal Barriers. Performed for the Federal Highway Administration, Performed by the Texas Transportation Institute, Texas A\&M University System, College Station, Texas, February, 108 pages.

Caprani, C. 2006. Analysis and Design of Slabs. Civil Engineering Design (1) lecutre.

Chaallal, O., and Benmokrane, B. 1993. Pullout and Bond of Glass Fibre Rods Embedded in Concrete and Cement Grout. Materials and Structures, 26(3): pp. 167-175.

Chaallal, O., Lachemi, M. 2010. Reinforced Concrete Structures. Design According to CSA A23.3 - 04. University of Quebec, 446 pages.

Chopra, A. K., 2007. Dynamics of Structures, Theory and application to earthquake engineering. 3rd Edition. Pearson Education, Inc.794 pages.

CEB-FIP Model Code 1990. 1993. Design of Concrete Structures. Comite' Eruo-International du Beton, Thomas Telford Services Ltd., London, 1993, 438 pages.

Collins, M.P. and Mitchell, D. 1987. Prestressed Concrete Basics . Canadian Prestressed Concrete Institute, 743 pages.

Collins, M. P., Mitchell, D. 1991. Prestressed Concrete Structures. Prentice Hall, Englewood Cliffs, New Jersey, 760 pp. 
Collins, M.P., and Mitchell, D. 1997. Prestressed Concrete Structures, Response Publications, Canada, 766 pp.

Computers and Structures Inc. 2010. Integrated structural analysis and design software. SAP2000, 574 Berkeley, CA.

Cosenza, E., Manfredi, G., and Realfonzo, R. 1995. Analytical Modelling of Bond Between FRP Reinforcing Bars and Concrete. Proc., 2nd Int.RILEM Symp, pp. 164-171.

Cosenza, E., Manfredi, G., and Realfonzo, R. 1996. Bond Characteristics and Anchorage Length of FRP Rebars. Proc., 2nd Int. Conf. on Advanced Compos. Mat. in Bridge Structures. Montreal: The Canadian Society of Civil Engineering, pp. 909-916.

Cosenza, E., Manfredi, G., and Realfonzo, R. 1997. Behaviour and Modelling of Bond of FRP Rebars to Concrete. Journal of Composites for Construction, 1 (2), pp. 40-51.

Cosenza, E., Manfredi, G., Pecce, M., \& Realfonzo, R. 1999. Bond between GFRP Rebars and Concrete: An Experimental Analysis. Proc., 4th Int. Symp. on Fiber Reinforced Polymerfor Reinforced Concrete Struct., American Concrete Institute, Detroit, pp. 347-358.

Cosenza, E., Manfredi, G., and Realfonzo, R. 2002. Development Length of FRP Straight Rebars. CompositesbPart B: Engineering , 33 (7), pp. 493-504.

CSA. 2004. Design of Concrete Structures, CSA-A23.3-04. Canadian Standards Associations. Mississauga, Ontario, Canada, 240 pages.

CSA. 2006a. Canadian Highway Bridge Design Code. CAN/CSA-S6-06. Canadian Standard Association, Toronto, Ontario, Canada, 800 pages.

CSA. 2006b. Commentaries on CAN/CSA-S6-06, Canadian Highway Bridge Design Code. Canadian Standard Association, Toronto, Ontario, Canada, 828 pages.

CSA S807-10. 2010. Specifications for Fiber-Reinforced Polymers. Canadian Standard Associations, Mississauga, Ontario, Canada, 44 pages.

CSA S806-02. 2002. Design and Constructions of Building Structures with Fiber - Reinforced Polymers. Canadian Standard Associations, Mississauga, Ontario, Canada, 206 pages.

CSA S806-12. 2012. Design and Constructions of Building Structures with Fiber - Reinforced Polymers. Canadian Standard Associations, Mississauga, Ontario, Canada, 206 pages. CAN/CSA-S6-88. 1988. Design of Highway Bridges. Withdrawn. Canadian Standard Associations, 356 pages. 
Darwin, D., and Graham, E. 1993. Effect of Deformation Height and Spacing on Bond Strength of Reinforcing Steel Bars. SL Report, University of Kansas Centre for Research, Lawrence, Kansas, 68 pages.

Darwin, D., Tholen, M. L., Idun, E. K., and Zuo, J. 1996. Splice Strength of High Relative Rib Area Reinforcing Bars. ACI Structural Journal,, 93 (1), pp. 95-107.

Ehsani, M. R., 1993. Glass-Fiber Reinforcing Bars. Alternative Materials for the Reinforcement and Prestressing of Concrete, J. L. Clarke, Blackie Academic \& Professional, London, England, pp. 35-54.

Ehsani, M. R., Saadatmanesh, H., and Tao, S. 1995. Bond of Hooked Glass Fibre Reinforced Plastic (GFRP) Reinforcing Bars to Concrete. ACI Materials Journal , 92 (4), pp. 391-400.

Ehsani, M. R., Saadatmanesh, H., and Tao, S. 1996. Bond Behavior and Design Recommendations for Fiber-Glass Reinforcing Bars. Proceedings of the First International Conference on Composites in Infrastructure, Tucson, Ariz, pp. 466-476.

Ehsani, M. R., Saadatmanesh, H., and Tao, S. (1996a). Design Recommendation for Bond of GFRP Rebars to Concrete. Journal of Structural Engineering, V. 122, No. 3, pp. 247-257.

Ehsani, M., Saadatmanesh, H., and Tao, S. 1997. Bond Behaviour of Deformed GFRP. Journal of Composite Materials, 1997 31(14), pp. 1413-1430.

El-Gamal, S., El-Salakawy, E., and Benmokrane, B. 2005. A New Punching Shear Equation for Two-Way Concrete Slabs Reinforced with FRP Bars. ACI Special Publication, SP-230-50, pp. 877-894.

El-Gamal, S., Tobbi, H., El-Sayed, A., and Benmokrane, B. 2007. Impact Testing of Concrete Bridge Barriers Reinforced with New GFRP Bars (Types 201 and 301). Technical Report submitted to Ministry of Transportation of Quebec, October.

El-Ghandour, A., Pilakoutas, K., and Waldron, P. 1999. New Approach for Punching Shear Capacity Prediction of Fiber Reinforced Polymer Reinforced Concrete Flat Slabs. ACI journal, SP 188-13, pp. 135-144.

El-Ghandour, A., Pilakoutas, K., and Waldron, P. 2000. Punching shear behavior and design of FRP RC flat slabs. Proceedings of the international workshop on punching shear capacity of RC slab, Stockholm: TRITA-BKN Bulletin 57, pp. 359- 66.

Eligehausen, R. 1979. Bond in Tensile Lapped Splices of Ribbed Bars with Straight Anchorages. German Institute for Reinforced Concrete. Berlin: Publication 301, 118 pages. 
Eligehausen, R., Popov, E. P., and Bertero, V. V. 1983. Local Bond Stress-Slip Relationships of Deformed Bars Under Generalized Excitations. Earthquake Engineering Research Center, University of California, Berkeley, 169 pages.

Eriksson, D., Gasch, T., 2010. FEM-modeling of reinforced concrete and verification of the concrete material models available in ABAQUS. Royal Institute of Technology, Stockholm, SWEDEN.

El-Salakawy, E., Benmokrane, B., Masmoudi, R., Brière, F., and Breaumier, È. 2003. Concrete Bridge Barriers Reinforced with Glass Fiber-Reinforced Polymer Composite Bars. ACI Structural Journal, 100(6): pp. 815-824.

El-Salakawy, E., Masmoudi, R., Benmokrane, B., Brière, F., and Desgagne, G. 2005. Pendulum Impacts on Concrete Bridge Barriers Reinforced with Glass Fiber-Reinforced Polymer Composite Bars. Canadian Journal of Civil Engineering, 31: pp. 539-552.

El- Salakawy, E., Islam, M. R. 2012. Behavior of Full- Scale GFRP- Reinforced Concrete Bridge Barriers. pp. 1-6.

Eurocode 2. 2004. Design of Concrete Structures. European Standard. BS-EN 1992-1-1. General Rules and Rules for Buildings, 99 pages.

Faoro, M. 1992. Bearing and Deformation Behaviour of Structural Components with Reinforcements Comprising Resin Bounded Glass Fibre Bars and Conventional Ribbed Steel Bars. Proc., Int. Conf. on Bond in Concrete.

Faza, S. S., and GangaRao, H. V. S. 1993b. Glass FRP Reinforcing Bars for Concrete, FiberReinforced-Plastic (FRP) Reinforcement for Concrete Structures: Properties and Applications, Developments in Civil Engineering, V. 42, A. Nanni, ed., Elsevier, Amsterdam, pp. 167-188.

Focacci, F., Nanni, A., Bakis, C.E. 2000. Local Bond-Slip Relationship for FRP Reinforcement in Concrete. Journal of Composites for Construction. Vol. 4, No.1, pp. 24 - 31.

Fuchs, W., Eligehausen, R., and Breen, J. 1995. Concrete Capacity Design (CCD) Approach for Fastening to Concrete. ACI Structural Journal, 92(1): pp. 73-94.

Freimanis, A. J., Bakis, C. E., Nanni, A., and Gremel, D., 1998. A Comparison of Pullout and Tensile Behaviors of FRP Reinforcement for Concrete. Proceedings of theSecond International Conference on Composites in Infrastructure (ICCI-98), Tucson, Ariz., V. 2, pp. 52-65. 
Gao, D., Benmokrane, B., and Tighiouart, B. 1998b. Bond Properties of FRP Rebars to Concrete. Technical Report, Department of Civil Engineering, University of Sherbrooke, Sherbrooke, Quebec, Canada, 27 pp.

Ghosh, A. 2004. Modeling the Bond Stress at Steel-Concrete Interface for Uncorroded and Corroded Reinforcing Steel. Master Thesis Ryerson University, Toronto, Canada, 135 pages.

Harajili, M. H., Hamad, B. S., and Rteil, A. A. 2004. Effect of Confinement on Bond Strength between Steel Bars and Concrete. ACI Structural Journal, 101(5), pp. 595-603.

Hao, Q., Wang, Y., and Ou, J. 2008. Design Recommendations for Bond between GFRP/Steel Wire Composite Rebars and Concrete. Engineering Structures, 30(11), pp. 3239-3246.

Hao, Q., Wang, Y., He, Z., and Ou, J. 2009. Bond Strength of Glass Fiber Reinforced Polymer Ribbed Rebars in Normal Strength Concrete. Construction and Building Materials , 23 (2), pp. 865-871.

Hibbitt, Karlsson, Sorensen. 2011. ABAQUS User's Manual, Pawtucket, 6th Edition.

Hirsch, T. J. 1978. Analytical Evaluation of Texas Bridge Rails to Contain Buses and Trucks. Research report 20-2, Texas Transportation Institute, Texas A\&M University, 105 pages.

Hirsch, T. and Arnold. A. 1981. Bridge Rail to Restrain and Redirect 80,000 lb Trucks. Report No. FHWA/TX-81/16+230-4F, Performed for the Texas State Department of Highways and Public Transportation, Performed by the Texas Transportation Institute, Texas A\&M University System, College Station, Texas, November, 37 pages.

Hirsch, T., and Fairbanks, W. 1984a. Bridge Rail to Contain and Redirect 80,000 lb Tank Trucks. Report No. FHWA/TX-84-911-1F, Performed for the Texas State Department of Highways and Public Transportation, Performed by the Texas Transportation Institute, Texas A\&M University System, College Station, Texas, February, 42 pages.

Hirsch, T., and Fairbanks, W. 1984b. Bridge Rail to Contain and Redirect 80,000 lb Tank Trucks. Report No. FHWA/TX-84-911-1F, Performed for the Texas State Department of Highways and Public Transportation, Performed by the Texas Transportation Institute, Texas A\&M University System, College Station, Texas, February, 42 pages.

Hirsch, T., Fairbanks, W., and Buth, C. 1986. Concrete Safety Shape with Metal Rail on Top to Redirect 80,000 lb Trucks. Texas Transportation Institute, Transportation Research Record No. 1065 , pp. 79-87. 
ISIS Manual 3. 2007. Reinforcing Concrete Structures with Fiber Reinforced Polymers. ISIS Canada, Intelligent Sensing for Innovative Structures, University of Manitoba, Winnipeg, Manitoba, Canada, 151 pages.

ISIS Canada Module 2, 2006. An Introduction to FRP Composites for Construction. Prepared by ISIS Canada, Department of Civil Engineering, Queen's University, 27 pages.

ISIS Canada Module 3, 2006. An Introduction to FRP Composites for Construction. Prepared by ISIS Canada, Department of Civil Engineering, Queen's University, 36 pages.

ISIS Canada Module 4, 2006. An Introduction to FRP Strengthening of Concrete Structures. Prepared by ISIS Canada, Department of Civil Engineering, Queen's University, 42 pages.

ISIS Canada Module 6, 2006. An Introduction to FRP Strengthening of Concrete Structures.

Prepared by ISIS Canada, Department of Civil Engineering, Queen's University, 28 pages.

Jacobson, D., Bank, L., Oliva, M., Russell, J. 2005. Punching Shear Capacity of Double Layer FRP Grid Reinforced Slabs. ACI Special Publication, SP- 230-49, pp. 857-875.

Jaeger, L.G., Tadros, G., and Mufti, A.A. 1995. Balanced Section, Ductility and Deformability in Concrete with FRP Reinforcement, Research Report No. 2-1995, The Nova Scotia CADCAM Centre, 29 pages.

Jeon, S. J., Choi, M. S., Kim, Y. J. 2008. Ultimate Strength of Concrete Barrier by the Yield Line Theory. Internal Journal of Concrete Structures and Materials. Vol. 2, No. 1, pp. 57-62.

Johansen, K. W. Brudlinieteorier. Jul. Gjellerups Forlag, Copenhagen,1943. Yield Line theory, Translated by Cement and Concrete Association, London, 1962. 181 pages.

Johansen, K. W. Pladeformler. Polyteknisk Forlag, Copenhagen, 1968. Yield line formulae for slabs, Translated by Cement and Concrete Association, London, 1972. Ref 12.044. 106 pages.

Japan Society of Civil Engineers (JSCE). 1997. Recommendation for Design and Construction of Concrete Structures Using Continuous Fiber Reinforcing Materials. Concrete Engineering Series No. 23, 325 pages.

Japanese Society of Civil Engineering, JSCE, 2007. Standard Specifications for Concrete Structures. JSCE Concrete Committee, 503 pages.

Kachlakev, D. I., and Lundy, J. R., 1998. Bond Strength Study of Hollow Composite Rebars with Different Micro Structure. Proceedings of the Second International Conference on Composites in Infrastructure (ICCI-98), Tucson, Ariz., pp. 1-14. 
Kadam, S. 2006. Analytical Investigation of Bond-Slop Relationship Parameters between Fiber Reinforced Polymers (FRP) Bars and Concrete. Master's thesis, University of Missouri, Kansas City.

Kennedy, G., Goodchild, C.H. 2004. Practical Yield Line Design. Published by; The Concrete Centre. Price Group L. September 2004, 175 pages.

Khederzadeh, H.R., Sennah, K. 2014. Development of Cost-Effective Concrete Bridge Barrier Reinforced with GFRP Bars. Static Load Test, Canadian Journal of Civil Engineering,41(4) pp. 368-379.

Kobayashi, K., Okuda, M., Ishikawa, N., and Ohta, T. 1996. Impact Model Test and Impact Response Analysis of the Precast Concrete Guardfense Buried into the Soil. Japan Society for Civil Engineers J. Structural and Earthquake Engineering, 549(I-37), pp.175-189.

Larralde, J., and Silva-Rodriguez, R. 1993. Bond and Slip of FRP Reinforcing Bars in Concrete. Journal of Materials in Civil Engineering, 5 (1), pp. 30-40.

Lechtenberg, K., Bielenberh, R., Rosenbaugh, S., Faller, R., Sicking, D. 2009. High-Performance Aesthetic Bridge Rail and Median Barrier. Transportation Research Record: Journal of the Transportation Research Board, No. 2120, Washington, D.C., pp. 60-73.

Lee, J., Fenves, G., 1998. Plastic-Damage Model for Cyclic Loading of Concrete Structure, Engineering Mechanics, Vol. 124, No. 8, pp. 892-900.

Lublinear, J., Oliver, J., Oller, S., Onate, E., 1989. A Plastic-Damage Model for Concrete, Solids and Structures, Vol. 25, No. 3, pp. 299-326.

MacGregor, J.G. 1997. Reinforced Concrete, Mechanics and Design. Third Edition. Prentice Hall, New Jersey, 939 pages.

Maheu, J. and Bakht, B. 1994. A New Connnection Between Concrete Barrier Walls and Bridge Decks. Proceedings of the CSCE Annual Conference, Winnipeg, Manitoba, pp.224-229.

Makitani, E., Irisawa, I., and Nishiura, N. 1993. Investigation of Bond in Concrete Member with Fibre Reinforced Plastic Bars. Fibre-Reinforced-Plastic Reinforcement for Concrete Structures-Int. Symp, ACI SP138-20, pp. 315-331.

Mallick, P. K., 1988. Fiber Reinforced Composites, Materials, Manufacturing, and Design. Marcell Dekker, Inc., New York, N.Y., 469 pages. 
Malm, R., 2006. Shear Cracks in Concrete Structures Subjected to In-Plane Stresses. Licentiate thesis, Royal Institute of Technology, Division of Structural Design and Bridges, Stockholm, Sweden, 148 pages.

Malm, R., 2009. Predicting Shear Type Cracks Initiation and Growth in Concrete with Nonlinear Finite Elements Methods, PhD thesis, Royal Institute of Technology, Division of Structural Design and Bridges, Stockholm, Sweden, 64 pages.

Malvar, L. J. 1994. Bond Stress-Slip Characteristics of FRP Rebars. Report TR- 2013-SHR, Naval facilities Engineering Service Center, Port Hueneme, 50 pages.

Malvar, L. J. 1995. Tensile and Bond Properties of GFRP Reinforcing Bars. ACI Materials Journal, 92(M30), pp. 276-285.

Malvar, L. J., Cox, J. V., and Cochran, K. B. 2003. Bond between Carbon Fiber Reinforced Polymer Bars and Concrete. I: Experimental study. Journal of Composites for Construction, 7(2), pp. 154-163.

Marti, P. 1999. How to Treat Shear in Structural Concrete. ACI Structural Journal. Vol. 96, No. 3, pp. 408-414.

Martin, H. 1982. Bond Performance of Ribbed Bars (Pullout Tests)-Influence of Concrete Composition and Consistency. International Conference-Bond in Concrete, Paisley, Scotland, pp. 289-299.

MASH. 2009. Manual for Assessing Safety Hardware, MASH. American Association of State Highway and Transportation Officials, Washington. D.C., 276 pages.

Matta, F. 2008. Crashworthy Design of Concrete Highway Bridge Railing Reinforced with Advanced Composite Bars. Advanced Composite Materials in Bridge and Structures. Winnipeg, Manitoba, Canada, Sptember 22-24, 12 pages.

Matta, F., and Nanni, A. 2009. Connection of Concrete Railing Post and Bridge Deck with Internal FRP Reinforcement. ASCE Journal of Bridge Engineering, 14(1): pp. 66-76.

Matthys, S., and Taerwe, L. 2000. Concrete Slabs Reinforced with FRP Grids, Part II: Punching Resistance. ASCE Journal of Composites for Constructions, 4(3): pp. 154-161.

Michaluk, C., Rizkalla, S., Tadros, G., and Benmokrane, B. 1998. Flexural Behavior of OneWay Concrete Slabs Reinforced by Fiber Reinforced Plastic Reinforcement. ACI Structural Journal, 95(3): pp. 353-364. 
Mirza, S. M., and Houde, J. 1978. Study of Bond Stress-Slip Relationships in Reinforced Concrete. ACI Journal, Vol. 76, No. 1, pp. 47-71.

Mosley, C. P., Tureyen, A. K., and Frosch, R. J. 2008. Bond Strength of Nonmetallic Reinforcing Bars. ACI Structural Journal, 105(5), pp. 634-642.

Murray, Y.D., Abu-deh, A., Bligh, R. 2007. Analysis of Safety-Shaped Barrier. Texas Transportation Institution (TTI). Report No. FHWA-HRT-05-063, 209 pages.

Nagasaka, T. Fukuyama, H. and Tanigaki, M. 1993. Shear Performance of Concrete Beams Reinforced with FRP Stirrups. Fiber-Reinforced-Plastic Reinforcement for Concrete Structures International Symposium, SP-138, A, pp. 789-812.

Nanni, A., Al-Zahrani, M., Al-Dulaijan, S., Bakis, C. E., and Boothby, T. E., 1995. Bond of FRP Reinforcement to Concrete Experimental Results. Proceedings of the Second International RILEM Symposium on Non-Metallic (FRP) Reinforcement for Concrete Structures (FRPRCS-2), Ghent, Belgium, pp. 135-145.

Nanni, A., Bakis, C. E., and Boothby, T. E., 1995. Test Methods for FRP-Concrete Systems Subjected to Mechanical Loads. State of the Art Review," Journal of Reinforced Plastics and Composites, V. 14, pp. 524-588.

Nanni, A., Nenninger, J., Ash, K., and Liu, J., 1997. Experimental Bond Behavior of Hybrid Rods for Concrete Reinforcement. Structural Engineering and Mechanics, V. 5, No. 4, pp. 339-354.

Nanni, A., Rizkalla, S., Bakis, C. E., Conrad, J. O., and Abdelrahman, A. A. 1998. Characterization of GFRP Ribbed Rod Used for Reinforced Concrete Construction. Proceedings of the International Composites Exhibition (ICE-98), Nashville, Tenn., pp. 16A/1-6.

Newhook, J., Svecova, D. 2006. Reinforcing Concrete Structures with Fibre-Reinforced Polymers. Winnipeg: ISIS Canada Corporation, 151 pages.

Ngan, C. L. 2008. Experimental Investigations of Anchorage Capacity of Precast Concrete Bridge Barrier for Performance Level 2. Master's Thesis, University of British Columbia, 93 pages.

Nilsson, I. H. E., and Losberg, A. 1976. Reinforced concrete corners and joints subjected to bending moment. J. Struct. Div., 102 (6), pp. 1229-1254. 
Orangun, C. O., Jirsa, J. O., and Breen, J. E. 1977. Reevaluation of Test Data on Development Length and Splices. ACI Proceedings, 74 (3), pp. 114-122.

Ospina, C., Alexander, S., and Cheng, R. 2003. Punching of Two-Way Concrete Slabs with Fiber-Reinforced Polymer Reinforcing Bars or Grids. ACI structural Journal, 100(5), pp. 589-598.

Pankaj, P. 2010. Real Structural Behavior and Its Analysis - Material Nonlinearity, Lecture Note(Accessed 2010.11.22). URL www.see.ed.ac.uk/pankaj/real structural behaviour/.

Pecce, M., Manfredi, G., Realfonzo, R., and Cosenza, E. 2001. Experimental and Analytical Evaluation of Bond Properties of GFRP Bars. Journal of Materials in Civil Engineering,13(4), ISSN 0899-1561/01/0004-0282-0290, pp. 282-290.

Pefeifer, B. and Sickling, D. 1997. Development of a Metal-Cutting Guardrail Terminal. Transportation Research Record 1258, pp.1-10.

Phillips, L.N. 1989. Design with Advanced Composite Materials, Springer- Verlag. OSTI ID: 6765914, 204 pages.

Plaxico, C., Ray, M., and Hiranmayee, K. 2000. Comparison of the Impact Performance of the G4(1W) and G4(2W) Guardrail Systems under NCHRP Report 350 Test 3-11 Conditions. TRB Annual Meeting, pp.1-32.

Polivka, K., Faller, R., Holloway, J., Rohde, J., and Sicking, D. 2005. Development, Testing, and Evaluation of NDor's TL-5 Aesthetic Open Concrete Bridge Rail. Nebraska Department of Road. MwRSF Research Report No. TRP-03-148-05, 164 pages.

Pultrall. 2011. GFRP manufacturer data sheet. Pultrall Inc., Quebce, Canada.

RCCAO. 2007. Ontario's Bridges Bridging the Gap. Report Prepared by MMM Group for Residential and Construction Alliance of Ontario, RCCAO, 56 pages.

Reid, J., Rohde, J., and Sicking, D. 2001. Box-beam Bursting Energy Absorbing Terminal. Journal of Transportation Engineering, 128 (1): pp. 287-294.

Ritter, W. 1899. The Hennebique Design Method (Die Bauweise Henebique). Schweizersche Bauzeitung (Zurich), 33(7), pp. 59-61.

Rosenbaugh, S., Siking, D., and Faller, R. 2007. Development of a TL-5 Vertical Faced Concrete Median Barrier Incorporating Head Ejection Criteria. MwRSF Report No. TRP-03-194-07, University of Nebraska-Lincoln, Lincoln, Nebraska, 368 pages. 
Ross, H., Sicking, D., Zimmer, and Michie, J. 1993. Recommended Procedures for Safety Performance Evaluation of Highway Feature. National Cooperative Research Program (NCHRP) Report No. 350, Transportation Research Board, Washington, D.C., 74 pages.

Rossetti, V. A., Galeota, D., \& Giammatteo, M. M. 1995. Local Bond Stress-Slip Relationships of Glass Fibre Reinforced Plastic Bars Embedded in Concrete. Materials and Structures,28, doi: 0025-5432/95, pp. 340-344.

Schlaich, L., Schafer, K., Mattias, J. 1987. Toward a Consistent design of Structural Concrete. Journal of Prestressed Concrete Insitutie, Vol 32, No.3, pp. 74.150.

Sennah, K., Tropynina, E., Goremykin, S., Lam, M., and Lucic, S. 2010. Concrete Bridge Barriers Reinforced with GFRP Bars with Headed Ends. Proceedings of the $8^{\text {th }}$ International Conference on Short and Medium Span Bridges, Niagara Falls, pp.1-10.

Sennah, K., Juette, B., Weber, a., Witt, C. 2011. Vehicle crash testing of a GFRP reinforced PL3concrete bridge barrier. 2011 Anuual Confrence of the Transportation Association of Canada Edmonton, Alberta, pp.1-10.

Sennah, K., and Kederzadeh, H. 2012. Vehicle Crash Testing of a PL-3 Concrete Bridge Barrier Reinforced with GFRP Bars with Sand-Coated Surface and Headed Ends. Technical Report submitted to Pultrall Inc. and Ontario Ministry of Transportation, 86 pages.

Sennah, K, and, Khederzadeh, H.R. 2014. Development of Cost-Effective Concrete Bridge Barrier Reinforced with GFRP Bars. Vehicle Crash Test, Canadian Journal of Civil Engineering, 41(4) pp. 357-367.

Sheikh, N., Bligh, R., Holt, J. 2012. Minimum Rail Height and Design Impact Load for MASH TL-4 Longitudinal Barriers. TRB Annual Meeting, pp. 1-16.

Shield, C. K., French, C. W., and Retika, A. 1997. Thermal and Mechanical Fatigue Effects on GFRP Rebar-Concrete Bond. Proc., Third Int. Symp. on Non-Metallic Reinforcement for Concrete Structures, (pp. 381-388). Sapporo, Japan.

Sonobe, Y., et al. 1997. Design Guidelines of FRP Reinforced Concrete Building Structures. Journal of Composites for Constructions, 1(3), pp. 90-115.

Tepfers, R. 1973. A Theory of Bond Applied to Overlapping Tensile Reinforcement Splices for Deformed Bars. Thesis Submitted to Chalmers University of Technology, Division of Concrete Structures, Goteborg, 328 pages. 
Tighiouart, B., Benmokrane, B., and Gao, D. 1998. Investigation of Bond in Concrete Member with Fibre Reinforced Polymer (FRP) Bars. Construction and Building Materials, 12, pp. 453-462.

Tighiouart, B., Benmokrane, B., and Mukhopadhyaya, P. 1999. Bond Strength of Glass FRP Rebar Splices in Beams under Static Loading. Construction and Building Materials, 13 (7), pp. 383-392.

Tureyen, A. , and Frosch, R. 2002. Shear Tests of FRP Reinforced Concrete Beams without Stirrups. ACI Structural Journal, 99(4) pp. 427-434.

Tureyen, A., and Frosch, R. 2003. Concrete Shear Strength: Another Perspective. ACI Structural Journal, 100(5), pp. 609-615.

Vecchio, F.J. and Collins, M.P., 1982. Response of Reinforced Concrete to In-Plane Shear and Normal Stresses, Publication No. 82-03, Department of Civil Engineering, University of Toronto, 332 pages.

Vecchio, F.J. and Collins, M.P., 1986. The Modified Compression Field Theory for Reinforced Concrete Elements Subject to Shear, ACI Journal, Vol. 83, No. 2, pp. 219-231.

Vecchio, F.J. and Collins, M.P., 1993. Compression Response of Cracked Reinforced Concrete, ASCE Journal of Structural Engineering, Vol. 119, No. 12, pp. 3590-3610.

Wambeke, B. W., and Shield, C. K. 2006. Development Length of Glass Fibre Reinforced Polymer Bars in Concrete. ACI Structural Journal, 103 (1), pp. 11-17.

Wang, Z., Goto, Y., and Joh, O. 1999. Bond Strength of Various Types of Fiber Reinforced Plastic Rods. ACI SP-188, American Concrete Institute (ACI) Special Publications, Fiber Reinforced Polymer Reinforcement for Reinforced Concrete Structures, Farmington Hills, Michigan, pp. 1117-1130.

Wong, P.S., Vecchio, F. J., Trommels, H. 2013. VecTor 2 \& FormWork User's Manual. Second Edition, 347 pages.

Wu, W. P., 1990. Thermomechanical Properties of Fiber Reinforced Plastic (FRP) Bars. PhD dissertation, West Virginia University, Morgantown, W.Va., 292 pp.

Zhao, W., Maruyama, K., and Suzuki, H. 1995. Shear Behavior of Concrete Beams Reinforced by FRP Rods as Longitudinal and Shear Reinforcement. Proceedings of the Second International RILEM Symposium on Non-Metallic (FRP) Reinforcement for Concrete Structures (FRPRCS-2), Ghent, Belgium, pp. 352-359. 